\title{
QUALITY OF RIVERS OF THE UNITED STATES, 1975 WATER YEAR-BASED ON THE NATIONAL STREAM QUALITY ACCOUNTING NETWORK (NASQAN)
}

\section{U.S. GEOLOGICAL SURVEY}

Open-File Report $\quad \mathbf{7 8 - 2 0 0}$

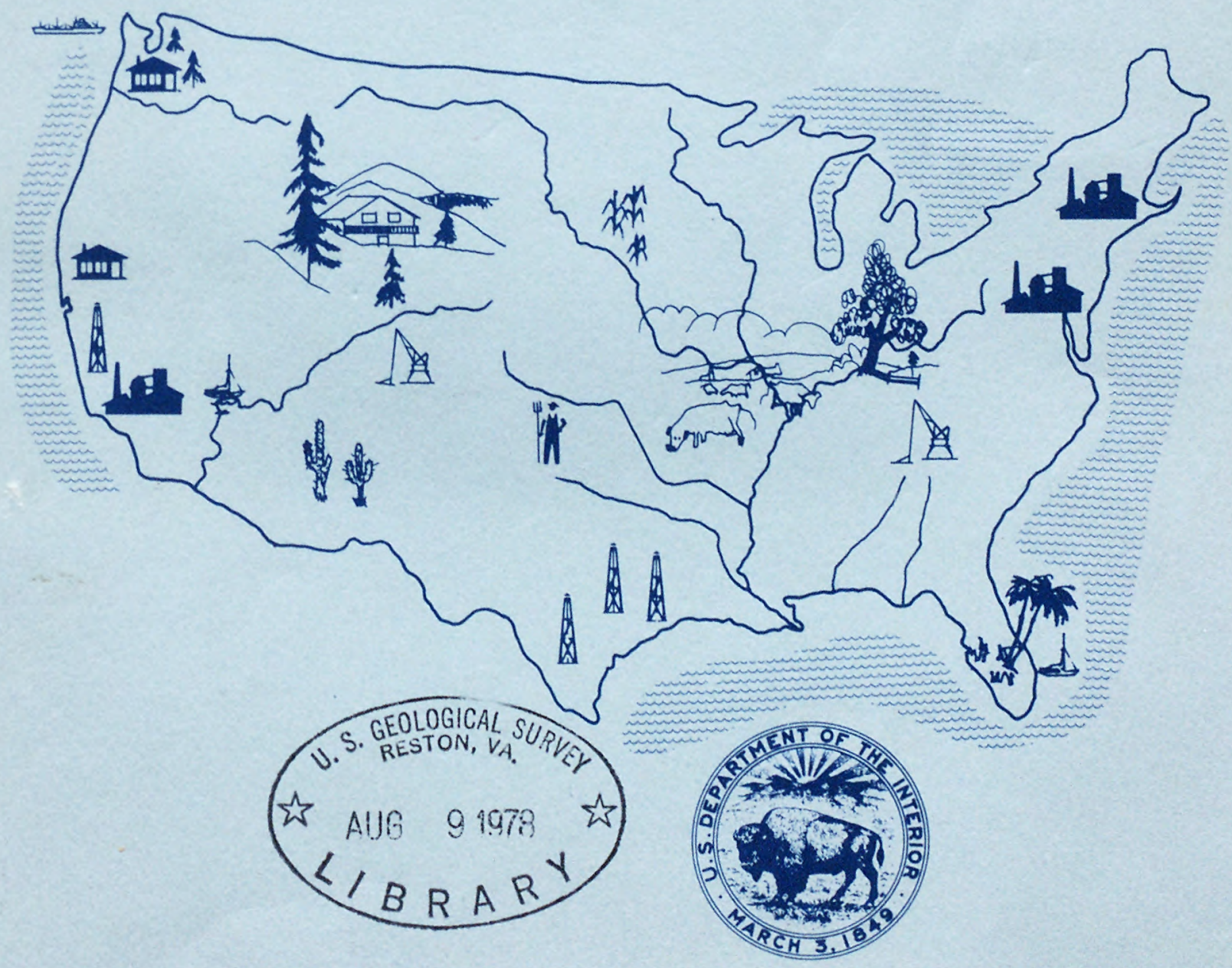





$$
\begin{aligned}
& (200) \\
& R^{290} \\
& n 0.78-200
\end{aligned}
$$

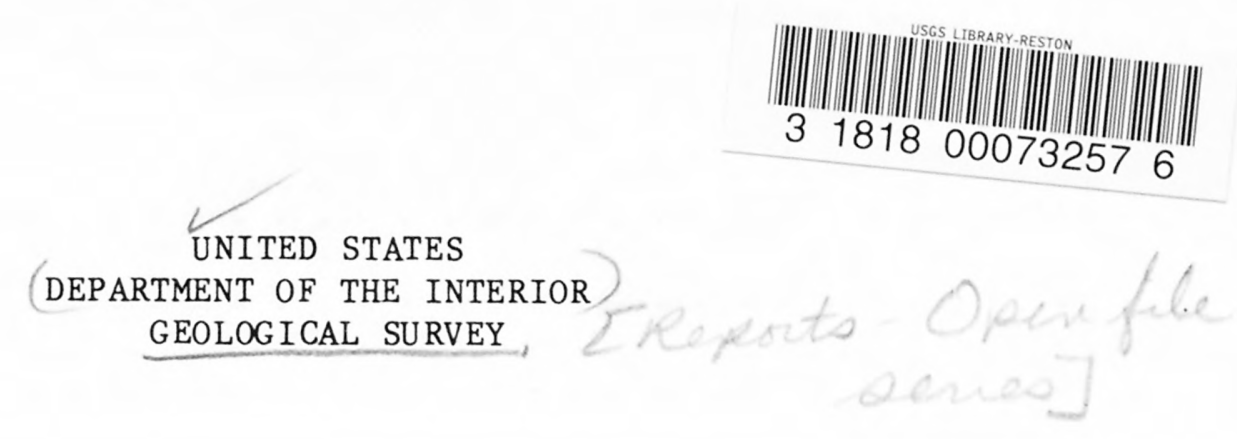

QUALITY OF RIVERS OF THE UNITED STATES, 1975 WATER YEAR--BASED ON THE NATIONAL STREAM QUALITY ACCOUNTING NETWORK (NASQAN) by John C. Briggs and John F. Fickle $<_{c}$

Open-File Report 78-200

$28986 ?$

Teston, Virginia

May 1977 
UNITED STATES DEPARTMENT OF THE INTERIOR

CECIL D. ANDRUS, Secretary

GEOLOGICAL SURVEY

H. William Menard, Director 
Metric conversion table . . . . . . . . . . . . . vii

Abstract ......................... . . . 1

Introduction . . . . . . . . . . . . . . . . 3

Purpose and scope of this report . . . . . . . . . 5

Acknowledgments . . . . . . . . . . . . . 5

A description of NASQAN . . . . . . . . . . . . . 6

Descriptions of river quality . . . . . . . . . . . . 17

Stream temperature . . . . . . . . . . . . . . 17

Major inorganic chemicals . . . . . . . . . . . 21

Specific conductance . . . . . . . . . . . . . 32

Major nutrients, nitrogen and phosphorus . . . . . . . 33

Suspended sediment . . . . . . . . . . . . 38

Bacteria . . . . . . . . . . . . . 40

Phytoplankton . . . . . . . . . . . . . 45

Periphyton . . . . . . . . . . . . . . 47

Minor elements . . . . . . . . . . . . . 49

Total organic carbon . . . . . . . . . . . . . 58

Pesticides . . . . . . . . . . . . . . 59

Radioactive substances . . . . . . . . . . . . 60

Variations within the Mississippi River basin

above Memphis, Tennessee . . . . . . . . . . . . 65

Dissolved solids . . . . . . . . . . . . . 65

Nitrogen, phosphorus, and phytoplankton . . . . . . 68

Zinc ....................... 74

Regional summaries . . . . . . . . . . . . . 78 
References . . . . . . . . . . . . . . . . .

Tables 13 and 14 . . . . . . . . . . . . . .

\section{ILLUSTRATIONS}

Figure 1. Map showing locations of NASQAN stations . . . • . 6

2. Map outlining Water Resources Regions . . . . . . 18

3. Maps showing stream tempertures, means, and amplitudes. - 20

4-13. Map and histogram showing mean concentrations:

4. Dissolved solids ............ 23

5. Hardness ................ 25

6. Dissolved chloride . . . . . . . . . 26

7. Dissolved sulfate . . . . . . . . . 28

8. Alkalinity .............. 30

9. Dissolved fluoride . . . . . . . . . 31

10. Total nitrite plus nitrate . . . . . . . 35

11. Total kjeldahl nitrogen . . . . . . . . 37

12. Total phosphorus . . . . . . . . . 39

13. Suspended sediment . . . . . . . . . 41

14. Map and histogram showing maximum concentrations of suspended sediment . . . . . . . . . . .

15-16. Map and histogram showing mean numbers:

15. Fecal coliform bacteria . . . . . . . . 44

16. Phytoplankton ............... 46

17-18. Map and histogram showing mean concentrations:

17. Dissolved arsenic . . . . . . . . . 54

18. Dissolved zinc . . . . . . . . . 57 
Figure 19-25. Diagram showing mean values for Mississippi

River above Memphis, Tennessee:

19. Concentration of dissolved solids . . . . . 67

20. Tons per day of dissolved solids . . . . . 69

21. Concentration of total nitrite plus nitrate . . 70

22. Concentration of total phosphorus . . . . . 72

23. Concentration of phytoplankton . . . . . . 73

24. Concentration of total zinc . . . . . . 76

25. Concentration of dissolved zinc . . . . . . 77 
Table 1. National Stream Quality Accounting Network stations operated during 1975 water year (sorted by state) . . . 8

2. Characteristics measured at NASQAN stations . . . . . . 16

3. Ranges of periphyton biomass and chlorophyl1 measured at NASQAN stations during the 1975 water year, summarized by Water Resources Regions . . . . . . . . . .

4. Standards and criteria for maximum concentration of minor elements in water . . . . . . . . . 50

5. Ranges of total concentrations of minor elements measured at NASQAN stations during the 1975 water year, summarized by Water Resources Regions . . . . . . . . . .

6. Ranges of concentrations of dissolved minor elements measured at NASQAN stations during the 1975 water year, summarized by Water Resources Regions . . . . . . .

7. Ranges of concentrations of total organic carbon measured at NASQAN stations during the 1975 water year, summarized by Water Resources Regions . . . . . . . . . .

8 Maximum concentrations of pesticides residues in a watersediment sample at which pesticide was detected at NASQAN stations during the 1975 water year, summarized by Water Resources Regions . . . . . . . . . . . . .

9 Maximum concentrations of pesticides in bottom materials at which pesticide was detected at NASQAN stations during the 1975 water year, summarized by Water Resources Regions . . . . . . . . . . . . . . . .

10 Ranges of concentrations of radioactive substances measured at NASQAN stations during the 1975 water year, summarized by Water Resources Regions . . . . . . . . . 64

11 NASQAN stations shown in figures 19-25 . . . . . . 66

12 Comparison of abundance of phytoplankton with the presence of total phosphorus and total nitrite plus nitrate . . 74

13 National Stream Quality Accounting Network stations operated during 1975 water year (sorted by station no.) . . . 84

14 Summary of measurements at each station . . . . . . . 91 
METRIC CONVERSION TABLE

Multiply U.S. Customary units

inch (in)

square mile $\left(\mathrm{mi}^{2}\right)$

ton (short)
$\underline{B Y}$

25.4

2.590

.9072
To obtain metric unit

millimeter (mm)

square kilometer $\left(\mathrm{km}^{2}\right)$

metric ton $(t)$ 
viii 
BASED ON THE NATIONAL STREAM QUALITY ACCOUNTING NETWORK (NASQAN)

by

John C. Briggs and John F. Ficke

\begin{abstract}
The National Stream Quality Accounting Network (NASQAN) was established by the U.S. Geological Survey to provide a nationally uniform basis for continuously assessing the quality of U.S. rivers. Stations generally are at the downstream end of hydrologic accounting units in order to measure the quantity and quality of water flowing from the units. The 1975 water year was the first year of operation of the network that represents essentially all of the accounting units and thereby describes the waterquality of the entire country. Data are available on a large number of water-quality constituents measured at 345 stations during the 1975 water year.
\end{abstract}

Temperature data (usually continuous or daily measurements) from NASQAN stations were fitted to a first order harmonic equation and the parameters for the harmonic function are reported for each station. Mean temperatures generally range from $5^{\circ}-10^{\circ} \mathrm{C}$ in the North to more than $20^{\circ} \mathrm{C}$ along the southern border of the continental United States and in Hawaii and Puerto Rico; means were less than $10^{\circ} \mathrm{C}$ at 63 stations and greater than $25^{\circ} \mathrm{C}$ at only 7 stations. Amplitudes of the temperature curves are greatest (greater than $12^{\circ} \mathrm{C}$ ) for the streams at midlatitudes and in the Great and Central Plains, and they are smallest for the subtropical and cold-climate streams.

Considering chemical and biological characteristics of U.S. streams as described by NASQAN data, water quality is best (by many standards) in the Northeast, Southeast, and Northwest. Waters there generally are low in dissolved solids and major and minor chemical constituents, generally are soft (except in Florida), and carry relatively small amounts of sediment. These conditions mainly reflect the geology of the regions and the relatively large amounts of precipitation. However, many of these waters show the effects of pollution and carry moderate or high levels of major nutrients and have correspondingly high populations of attached and floating plants. High counts of indicator bacteria also show signs of local pollution, particularly in regions of the country with large human and animal populations. In the Northeast, some heavy metals are at moderate levels, but not above most water-quality criteria. 
Rivers of most of the Mid-Continent and Southwest reflect the arid or semi-arid climate, erodible soils, and agricultural activities. They are characterized by moderate to high levels of dissolved major and minor constituents, sediment, major nutrients, and biota (floating and attached aquatic plants and indicator bacteria). In addition, the most incidences of pesticides in stream and bottom sediments were found in these regions.

A special analysis was made to study the patterns of dissolved solids, major nutrients, phytoplankton, and zinc in the Mississippi River above Memphis, Tennessee. It was found that flow volume is an important factor in influencing river quality, and that stations with low concentration of major nutrients generally had low phytoplankton populations as well. 


\section{INTRODUCTION}

Water quality has been a topic of concern for nearly as many years as people have been using water. Tales in ancient and recent history recall instances where waters were defiled and unfit for human use, and schemes for separating fresh, clean water for human use from polluted waste waters date back several millennia.

Early means of judging water quality were imprecise. People could see or taste obvious pollution, and they knew that using some waters would make them sick, even though the actions of chemical toxins or pathogens were not yet understood.

As analytical chemistry, pathology, toxicology, and related sciences advanced, it became possible to describe criteria for water quality in quantitative terms. It also became obvious that waters suitable for some specific uses were not fit for other uses. During the twentieth century these developments evolved into complex sets of standards of water quality. Today we have water-quality standards and criteria, most of which pertain to particular uses, such as drinking, recreational bathing, propagation of fish and shellfish, and industrial processing. There also are many programs to monitor water quality in order to measure whether or not it is suitable for different uses.

Most programs for monitoring the quality of waters have been developed at local levels. They have considered the local needs for judging suitability for specific uses and for enforcing standards for controlling pollution.

There have, on the other hand, been demands for information on water quality that have not been satisfied by the data collected in connection with many local programs. During the 1960's and 1970's, there have been many Federal programs to regulate and improve water quality. In order to evaluate the effectiveness of these programs, it is necessary to be able to uniformly appraise the characteristics of the Nation's waters and assess whether they are getting better or worse. Work by Wolman (1971), Enviro Control (1972), and the National Commission on Water Quality (NCWQ) (1975) found that so far, available data are inadequate for such an assessment. The NCWQ Staff Report summarized:

"We also find that there is still a major lack of adequate information. We simply do not know enough. There are not sufficient data to tell us how bad the water was and how much better it is getting. The measuring and analytical techniques are not good enough in many instances to tell us the value of incremental water quality improvements. If billions of dollars are to be invested wisely, we must have more and better data." 
NASUAN.--To aid in remedying the shortage of information on national water quality, the U.S. Geological Survey developed the National Stream Quality Accounting Network (NASQAN). NASQAN provides a uniform, continuing measure of the characteristics of the rivers of the United States on national and regional bases. The design of the network is described in Geological Survey Circular 719 (Ficke and Hawkinson, 1975) and other papers such as the one by Pickering and Ficke (1976), and is summarized in a later section of this report (pages 6-16). 


\section{Purpose and Scope of this Report}

This report summarizes the quality of the rivers of the United States during the 1975 water year (October 1974 through September 1975) as represented by the data from the 345 stations of the National Stream Quality Accounting Network (NASQAN). Data are presented in a manner to (1) show areal patterns of stream quality, and (2) account for the quality and quantity of water flowing from the accounting units represented by the NASQAN stations.

It is important to realize that NASQAN is a fixed-station accounting network. Data from the network stations represent the quality of water leaving the respective accounting units; but in fact water quality within an accounting unit may vary greatly from that measured at the unit's downstream NASQAN station. If some of the upstream tributaries of a river are polluted but others are not, the NASQAN values for that accounting unit depend very much upon the relative flow in the tributaries and the distance of the sampling point from the upstream sources of pollution.

This is the second annual report on national stream quality as represented by NASQAN, and the first report that includes data representing all accounting units. A report showing data from 100 NASQAN stations for the 1974 water year was published as Geological Survey Open-File Report 77-151 (Hawkinson and others, 1977).

Comments from readers of this report and from potential users of NASQAN data are welcome.

\section{Acknowledgments}

NASQAN is a large program, with stations operated by Geological Survey employees in over 100 field offices, samples analyzed in three central laboratories, and data processed and reviewed in 46 district offices and USGS National Headquarters. We thank all of the involved personnel for the role they played in providing the data that are the basis for this report. In addition, special thanks is given to Karen Judy and Cecile Fumagali who prepared several of the illustrations and to Janis Printz who prepared all of the final illustrations. The data-processing programs used in preparing tables and histograms were developed by Jurate Maciunas Landwehr and Kay Rahrer of CACI, Inc. Automated mapping programs used to prepare colored U.S. maps were developed under a contract supported by the President's Council on Environmental Quality.

Although NASQAN is a U.S. Geological Survey water-quality data network, some of the data used to fulfill network data requirements are provided by or obtained from programs operated by numerous state and local organizations, and other Federal agencies such as the Tennessee Valley Authority, U.S. Army Corps of Engineers, Environmental Protection Agency, and International Boundary and Water Commission. The cooperation of these agencies is acknowledged for helping the U.S. Geological Survey achieve the goals of NASQAN. 


\section{A DESCRIPTION OF NASQAN}

Objectives of the National Stream Quality Accounting Network (NASQAN) are (1) to account for the quantity and quality of water moving within and from the United States, (2) to depict areal variability, (3) to detect changes in stream quality, and (4) to lay the groundwork for future assessments of changes in stream quality. It is an "accounting network"; that is, it measures the quantity and quality of water flowing from one hydrologic accounting unit to the other or to the oceans. The basis for the design of the network is the system of hydrologic regions, subregions, and accounting units developed by the U.S. Water Resources Council and the Geological Survey (Water Resources Council, 1970) and modified in 1974 by the Geological Survey. Outlines of accounting units are shown in this report on the several maps (fig. 4-18) describing various components of water quality.

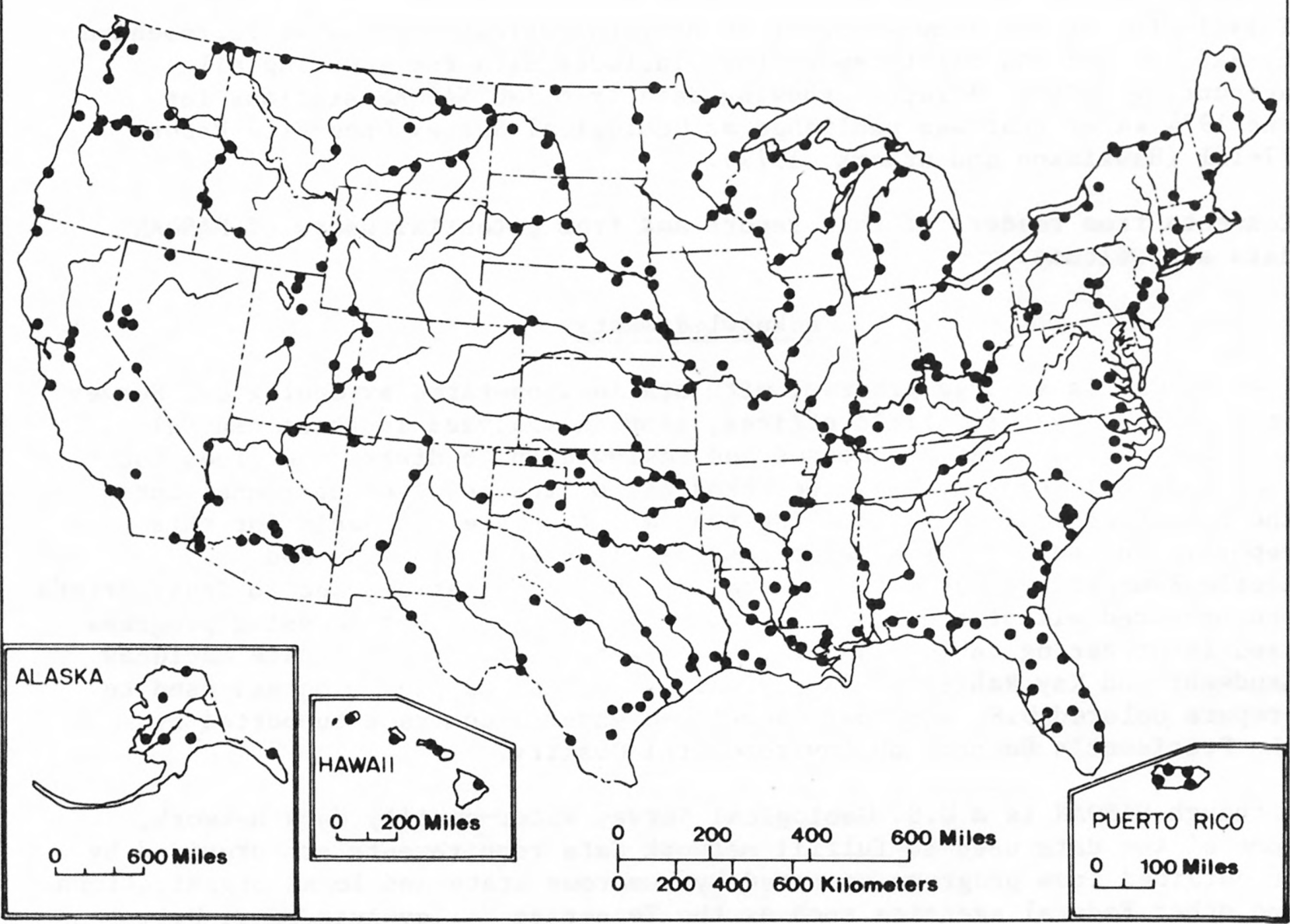

Figure 1.--Locations of stations in the National Stream Quality Accounting Network in operation as of January 1, 1975. 
A hydrologic accounting unit with a regular, integrated stream pattern can be represented by a single station near the downstream end of the unit. Coastal accounting units and others with patterns of parallel or interrupted drainage, however, may need more than one NASQAN station in order to adequately describe the amount and quality of flow from the unit. In order to define national and regional water quality, NASQAN was designed to ultimately include 525 measuring and sampling stations.

NASQAN was started with 50 stations in January 1973, and 295 more stations were added during 1974 (Ficke and Hawkinson, 1975, fig. 4). During the 1975 water year (October 1974 through September 1975), 345 stations were operational in the network. Locations of these stations are shown on figure 1 and are listed, by state, in table 1 .

NASQAN is considered to be a uniform national network because an identical suite of water-quality characteristics is measured at each station using the same set of rules concerning collecting techniques, frequency of sampling, and analytical methods. Table 2 is a list of constituents measured at each station and the frequency of measurement. As indicated by the footnotes of table 2, frequency of measurements of some constituents vary from station to station depending upon the availability of long-term records.

NASQAN stations are sampled at relatively uniform time intevals, without concern for the hydrologic patterns of high or low flow. Most of the samples, consequently, are collected during periods of relatively low flow. The samples provide a fairly good representation of what one would expect to find in the stream on any given day. They do not, however, necessarily provide good information on the total load of sediment or chemical constituents carried during a year, or on the complete range of concentrations because the samples usually are not collected during the periods of highest flows or extremes in concentrations. 
TABLE 1:

USGS

STAT.NO.
NATIONAL STREAM QUALITY ACCOUNTING NETWORK STATIONS OPERATED DURING 1975 WATER YEAR (SORTED BY STATE)

STATION NAME

02420000 ALABAMA RIVER NEAR MONTGOMERY

02429500 ALABAMA RIVER AT CLAIBORNE

02449000 TOMBIGBEE RIVER AT GAINESVILLE

02469762 TOMBIGBEE R. AT COFFEEVILLE L\&D NR. CFVL

15024800 STIKINE RIVER NEAR WRANGELL

15294350 SUSITNA RIVER AT SUSITNA STATION

15304000 KUSKOKWIM RIVER AT CROOKED CREEK

15565447 YUKON RIVER AT PILOT STATION

15744500 KOBUK RIVER NEAR KIANA

15896000 KUPARUK RIVER NEAR DEADHORSE

09380000 COLORADO RIVER AT LEES FERRY

09401200 LITTLE COLORADO RIVER AT CAMERON

09421500 COLORADO RIVER BELOW HOOVER DAM

09426600 BILL WILLIAMS R NEAR PLANET

09429490

09466500

09473500

09474000

09489000

09502000

09510000

09518000

09520700

09522000

COLORADO RIVER ABOVE IMPERIAL DAM

GILA RIVER AT CALVA

SAN PEDRO RIVER AT WINKELMAN

GILA RIVER AT KELVIN

SANTA CRUŻ RIVER NEAR LAVEEN

SALT RIVER BELOW STEWART MT DAM

VERDE RIVER BELOW BARTLETT DAM

GILA RIVER ABOVE DIV AT GILLESPIE DAM

GILA RIVER NEAR MOUTH NEAR YUMA

COLORADO R AT N INT BDRY AB MORELOS DAM

07032000

07047800

07047900

07077800

07250550

07263620

07265450

07362000

MISSISSIPPI RIVER AT MEMPHIS

ST FRANCIS RIVER AT PARKIN

ST FRANCIS BAY AT RIVERFRONT

WHITE RIVER AT CLARENDON

ARKANSAS RIVER AT DAM 13 NEAR VAN BUREN

ARKANSAS RIVER AT L AND D 6 LIT ROCK

MISSISSIPPI RIVER NEAR ARKANSAS CITY

(TN)

OUACHITA RIVER AT CAMDEN

09424190

10254970

10261500

10277400

11074000

11103010

11152500

11250000

11303500

11325500

11447650

11467000

11530500
COLORADO RIVER AQUED. NR SAN JACINTO

NEW RIVER AT INT. BDRY. NR. CALEXICO

MOJAVE R. AT LOW NARROWS NR VICTORVILLE

OWENS RIVER BLW TINEMAHA D. NR BIG PINE

SANTA ANA RIVER BELOW PRADO DAM

LOS ANGELES R.AT WIL.ST.BRDG.AT LONG BCH

SALINAS RIVER NEAR SPRECKELS

FRIANT-KERN CANAL. AT FRIANT

SAN JOAQUIN RIVER NEAR VERNALIS

MOKELUMNE RIVER AT WOODBRIDGE

SACRAMENTO RIVER AT FREEPORT

RUSSIAN RIVER NEAR GUERNEVILLE

KLAMATH RIVER NEAR KLAMATH

\section{ST LATI - LONGI - \\ TUDE TUDE \\ DEG/ DEG/ \\ MIN MIN}

AL $\begin{array}{lll}3225 & 08624\end{array}$

AL $3133 \quad 08731$

$A L \quad 3249 \quad 08809$

AL $3146 \quad 08808$

AK $5642 \quad 13208$

AK $6133 \quad 15031$

AK $6152 \quad 15807$

$A K \quad 6156 \quad 16253$

AK $6659 \quad 16007$

AK $7017 \quad 14858$

AZ $3652 \quad 11135$

AZ $3553 \quad 11125$

$A Z 3601 \quad 11444$

$A Z 3416 \quad 11402$

$A Z 3253 \quad 11428$

AZ 3311 11013

$A Z 3259 \quad 11046$

$A Z 3306 \quad 11059$

AZ $3314 \quad 11210$

AZ $3334 \quad 11132$

AZ $3349 \quad 11138$

AZ $3314 \quad 11246$

$A Z \quad 3243 \quad 11433$

AZ $3243 \quad 11443$

AR $3508 \quad 09004$

AR $3516 \quad 09034$

$A R \quad 3516 \quad 09041$

AR 344109119

AR $3521 \quad 09418$

$A R \quad 3440 \quad 09209$

AR $3334 \quad 09115$

AR $3336 \quad 09249$

CA $3349 \quad 11658$

CA $3240 \quad 11530$

CA $3434 \quad 11719$

CA 370311813

CA $3353 \quad 11739$

CA $3348 \quad 11812$

CA $3638 \quad 12140$

CA $3700 \quad 11942$

CA $3741 \quad 12116$

CA $3810 \quad 12118$

$\begin{array}{lll}C A & 3827 & 12130\end{array}$

CA $3830 \quad 12256$

C. 4 4131 12358 
06764000 SOUTH PLATTE RIVER AT JULESBURG

08251500 RIO GRANDE NEAR LOBATOS

09152500 GUNNISON RIVER NEAR GRAND JUNCTION

09163530 COLORADO RIVER BLW. COLO-UTAH STATE LINE

09251000 YAMPA RIVER NEAR MAYBELL

09260000 LITTLE SNAKE RIVER NEAR LILY

01184000 CONNECTICUT RIVER AT THOMPSONVILLE

OI205500 HOUSATONIC RIVER AT STEVENSON

02231000 ST MARYS RIVER NEAR MACCLENNY

02244450 ST JOHNS RIVER AT PALATKA

02248000 SPRUCE CREEK NEAR SAMSÜLA

02253000 MAIN CANAL AT VERO BEACH

02273000

02279000

02288600

02292480

02296750

02303000

02313000

02320500

02329000

02358000

02359000

02366500

02368000

02375500

02202500

02226000

02228000

16031000

16213000

16229300

16400000

$166180 \cap 0$

16704000

12318500

13154500

13213000

13213100

13290450

13317000

05446500

05543500

05586100

05594100

05599500

03276500

03374100

03378500
KISSIMMEE RIVER AT S65E NEAR OKEECHOBEE

WEST PALM BEACH CANAL AT WEST PALM BEACH

MIAMI CANAL AT NW 36TH STREET, MIAMI

CALOOSAHATCHEE CNL AT ORTONA L.NR LABELLEFL 2647

PEACE RIVER AT ARCADIA

HILLSBOROUGH RIVER NEAR ZEPHYRHILLS

WITHLACOOCHEE RIVER NEAR HOLDER

SUWANNEE RIVER AT BRANFORD

OCHLOCKONEE RIVER NEAR HAVANA

APALACHICOLA RIVER AT CHATTAHOOCHEE

CHIPOLA RIVER NEAR ALTHA

CHOCTAWHATCHEE RIVER NEAR BRUCE

YELLOW RIVER AT MILLIGAN

ESCAMBIA RIVER NEAR CENTURY

OGEECHEE RIVER NEAR EDEN

ALTAMAHA RIVER AT DOCTORTOWN

SATILLA RIVER AT ATKINSON

WAIMEA RIVER AT WAIMEA

WAIKELE STREAM AT WAIPAHU

KALIHI STREAM AT KALIHI

HALAWA STREAM NEAR HALAWA

KAHAKUL OA STREAM NEAR HONOKOHAU

WAILUKU RIVER AT PIIHONUA

KOOTENAI RIVER NEAR COPELAND

SNAKE RIVER AT KING HILL

BOISE RIVER NEAR PARMA

SNAKE RIVER AT NYSSA

SNAKE RIVER AT HELLS CANYON DAM

SALMON RIVER AT WHITE BIRD

ROCK RIVER NEAR JOSLIN

ILLINOIS RIVER AT VALLEY CITY

KASKASKIA RIVER NEAR VENEDY STATION

BIG MUDDY RIVER AT MURPHYSBORO

WHITEWATER RIVER AT BROOKVILLE

WHITE RIVER AT HAZELTON

WABASH RIVER AT NEW HARMONY
ILLINOIS RIVER AT MARSEILLES
CO 4059

CO 3705

CO 3859

CO 3905

CO 4030

CO 4033

CT 4159

CT 4123

$F L \quad 3022$

FL 2939

FL 2903

FL 2739

FL 2714

FL 2639

FL 2647

FL 2713

FL 2809

FL 2859

FL 2957

FL 3033

FL 3042

FL 3032

FL 3027

FL 3045

FL 3057

GA 3211

GA 3139

GA 3113

HI 2159

HI 2123

HI 2120

HI 2110

HI 2059

HI 1943

ID 4855

ID 4300

ID 4347

(OR) ID 4353

(OR) ID 4515

ID 4545

IL 4134

IL 4120

IL 3942

IL 3827

IL 3745

IN 3924

IN 3829

IN 3808
10215

10545

10827

10906

10802

10825

07236

07310

08205

08138

08103

08024

08058

08004

08016

08118

08153

08214

08221

08256

08423

08452

08510

08554

08638

08714

08125

08150

08152

15940

15801

15753

15646

15633

15509

11625

11512

11658

11659

11642

11619

09011

08843

09039

08938

08921

08501

08733

08756 
05420500 MISSISSIPPI RIVER AT CLINTON

05474500 MISSISSIPPI RIVER AT KEOKUK

06486000 MISSOURI RIVER AT SIOUX CITY

06807000 MISSOURI RIVER AT NEBRASKA CITY

$\begin{array}{rll}\text { IA } & 4147 & 09015 \\ \text { IA } 4024 & 09122 \\ \text { IA } 4229 & 09625 \\ \text { (NB) IA } 4041 & 09551\end{array}$

06856600 REPUBLICAN RIVER AT CLAY CENTER

KS 392109708

06877600 SMOKY HILL RIVER AT ENTERPRISE

KS $3854 \quad 09707$

06887000 BIG BLUE RIVER NEAR MANHATTAN

06892350 KANSAS RIVER AT DESOTO

07137500 ARKANSAS RIVER NR COOLIDGE

07139500 ARKANSAS RIVER AT DODGE CITY

07146500 ARKANSAS RIVER AT ARKANSAS CITY

KS $3914 \quad 09634$

KS 385909458

KS $3802 \quad 10201$

KS $3745 \quad 10001$

KS $3703 \quad 09704$

03215000 BIG SANDY RIVER AT LOUISA

03216600 OHIO RIVER AT GREENUP DAM

03254000 LICKING RIVER AT BUTLER

03277200 OHIO R. AT MARKLAND DAM NEAR WARSAW

03290500 KENTUCKY RIVER AT LOCK 2 AT LOCKPORT

KY $3810 \quad 08238$

KY 383908252

KY $3847 \quad 08421$

KY $3846 \quad 08458$

KY $3826 \quad 08458$

03301630 ROLLING FORK NEAR LEBANON JUNCTION

KY 374908545

03303280 OHIO RIVER AT CANNELTON DAM

03321230 GREEN RIVER NEAR BEECH GROVE

KY $3754 \quad 08642$

03438220 CUMBERLAND RIVER NEAR GRANO RIVERS

KY 3735

08724

03609750

TENNESSEE RIVER AT HWY 60 NEAR PADUCAH

KY 3701

08813

03612500

08832

02489500 PEARL RIVER NEAR BOGALUSA

02492000 BOGUE CHITTO NEAR BUSH

07344410 RED RIVER ABOVE SHREVEPORT

07355500 RED RIVER AT ALEXANDRIA

07367640 OUACHITA RIVER AT COLUMBIA

07369500 TENSAS RIVER AT TENDAL

07373420 MISSISSIPPI RIVER NEAR ST FRANCISVILLE

07374508 MISSISSIPPI RIVER AT NEW ORLEAÑS

07378510 AMITE RIVER AT 4-H CAMP NR DENHAM SPGS

07381490 ATCHAFALAYA RIVER AT SIMMESPORT

07385700 BAYOU TECHE AT KEYST L NR ST MARTINSVL

08015900 CALCASIEU RIVER NEAR LAKE CHARLES

01017100 AROOSTOOK RIVER AT CARIBOU

01021050 ST. CROIX RIVER AT MILLTOWN

01034500 PENOBSCOT RIVER AT WEST ENFIELD

01046500 KENNEBEC RIVER AT BINGHAM

01059000 ANDROSCOGGIN RIVER NEAR AUBURN

01066000 SACO RIVER AT CORNISH

01491000 CHOPTANK RIVER NEAR GREENSBORO

01645500 POTOMAC RIVER AT GREAT FALLS

LA $3048 \quad 08949$

LA $3038 \quad 08954$

LA $3233 \quad 09346$

LA 311909227

LA $3206 \quad 09204$

LA $3226 \quad 09122$

LA $3046 \quad 09124$

LA $2957 \quad 09008$

LA $3026 \quad 09058$

LA 305909148

LA $3004 \quad 09150$

LA $3018 \quad 09311$

ME 4651 06800

ME $4510 \quad 06718$

ME 451406839

ME 450306953

ME $4404 \quad 07013$

ME $4348 \quad 07047$

MD $3900 \quad 07547$

MD $3900 \quad 07715$

01096550 MERRIMACK RIVER ABOVE LOWELL

01103500 CHARLES RIVER AT CHARLES RIVER VILLAGE

MA $4238 \quad 07122$

MA $4215 \quad 07116$

04040000 ONTONAGON RIVER NEAR ROCKLAND

04045500 TAHQUAMENON R. NR TAHQUAMENON PARADISE

04045580 ST MARYS RIVER AROVE SAULT STE MARIE

04057005 MANISTIQUE RIVER AT MANISTIQUE

MI $4643 \quad 08912$

MI $4634 \quad 08516$

MI 462908425

MI $4557 \quad 08615$ 
04059000 ESCANABA RIVER AT CORNELL

04059500 FORD RIVER NEAR HYDE

04108690 KALAMAZOO RIVER AT SAUGATUCK

04122030 MUSKEGON RIVER NEAR BRIDGETON

04126520 MANISTEE RIVER AT MANISTEE

04132052 CHEBOYGAN RIVER AT CHEBOYGAN

04142000 RIFLE RIVER NEAR STERLING

04157000 SAGINAW RIVER AT SAGINAW

04165500 CLINTON RIVER AT MT. CLEMENS

04165700 DETROIT RIVER AT DETROIT

04014500 BAPTISM RIVER NEAR BEAVER BAY

04024000 ST LOUIS RIVER AT SCANLON

05112000 ROSEAU RIVER NEAR CARIBOU

05131500 LITTLE FORK RIVER AT LITTLEFORK

05132000 BIG FORK RIVER AT BIG FALLS

05267000 MISSISSIPPI RIVER NEAR ROYALTON

05330000 MINNESOTA RIVER NEAR JORDAN

05331000 MISSISSIPPI RIVER AT ST PAUL

05378500 MISSISSIPPI RIVER AT WINONA

02479020 PASCAGOULA RIVER NEAR BENNDALE

07287120 YAZOO R AT SHELL BLUFF NR MORGAN CITY

07289000 MISSISSIPPI RIVER AT VICKSBURG

07290000 BIG BLACK RIVER NEAR BOVINA

07292500 HOMOCHITTO RIVER AT ROSETTA

05490600 DES MOINES RIVER AT ST FRANCISVILLE

05587550 MISSISSIPPI RIVER BELOW ALTON

06818000 MISSOURI RIVER AT ST JOSEPH

06902000 GRAND RIVER NEAR SUMNER

06926510 OSAGE RIVER BELOW ST. THOMAS

06934500 MISSOURI RIVER AT HERMANN

07022000 MISSISSIPPI RIVER AT THEBES

06054500 MISSOURI RIVER AT TOSTON

06109500 MISSOURI RIVER AT VIRGELLE

06130500 MUSSELSHELL RIVER AT MOSBY

06132000 MISSOURI RIVER BELOW FT PECK DAM

06174500 MILK RIVER AT NASHUA

06185500 MISSOURI RIVER NEAR CULBERTSON

06214500 YELLOWSTONE RIVER AT BILLINGS

06294700 BIGHORN RIVER AT BIGHORN

06308500 TONGUE RIVER AT MILES CITY

06326500 POWDER RIVER NEAR LOCATE

06329500 YELLOWSTONE RIVER NEAR SIDNEY

12355000 FLATHEAD RIVER AT FLATHEAD, B.C.

06465500 NIOBRARA RIVER NEAR VERDEL

06686000 NORTH PLATTE RIVER AT LISCO

06792499 LOUP R POWER CANAL AT DIV NR GENOA

06796000 PLATTE RIVER AT NORTH BEND

06805500 PLATTE RIVER NEAR LOUISVILLE

MI 4555

MI 4545

MI 4239

MI 4319

MI 4415

MI 4539

MI 4404

MI 4325

MI 4236

MI 4221

MN 4720

MN 4642

MN 4859

MN 4824

MN 4812

MN 4552

MN 4442

MN 4457

MN 4403

MS 3053

MS 3324

MS 3219

MS 3221

MS 3119

MO 4028

(IL) MO 3852

MO 3948

MO 3938

MO 3820

MO 3843

(IL) MO 3713

08713

08712

08612

08602

08619

08428

08401

08358

08255

08258

09112

09225

09628

09334

09348

09422

09338

09305

09138

08846

09018

09054

09042

09106

09134

09008

09453

09316

09214

09126

08928

MT 4609

11125

MT 4800

11015

MT 4700

10753

MT 4803

10621

MT 4808

MT 4807

MT 4548

MT 4609

MT 4622

MT 4627

MT 4741

MT 4900

10622

10428

10828

10728

10548

10519

10409

NB $4244 \quad 09813$

NB $4130 \quad 10238$

NB $4124 \quad 09749$

NB $4127 \quad 09646$

NB 410109609 
10249900 CHIATOVICH CREEK NEAR DYER 10301500 WALKER RIVER NEAR WABUSKA 10312000 CARSON RIVER NEAR FORT CHURCHILL

10335000

10346000

10351700

10352500

01155050

01404100 01408500 01463500

07227140 08313000 08358300 08407500 08481500 09368000

01304500 01358000 04219640 04232006 04249000 04260500 04264331 04269000 04295000

02081000 02083500 02089500 02105769 02129000

05054020 05083500

05124000 06337000 06338490 06340500 06354000

03150000 03234500 03245500 03274600 04193500 04208000

07157950 07161000 07164400 07178620 07193500
HUMBOLDT RIVER NEAR RYE PATCH

TRUCKEE RIVER AT FARAD

TRUCKEE RIVER NEAR NIXON

MC DERMITT CREEK NEAR MC DERMITT

CONNECTICUT RIVER AT WALPOLE

RARITAN RIVER NEAR SOUTH BOUND BROOK

TOMS RIVER NEAR TOMS RIVER

DELAWARE RIVER AT TRENTON

CANADIAN RIVER ABOVE NM-TEX STATE LINE

RIO GRANDE AT OTOWI BRDG NR S.ILDEFONSO

RIO GRANDE CNV CH AT SAN MARCIAL

PECOS RIVER AT RED BLUFF

RIO TULAROSA NEAR BENT

SAN JUAN RIVER AT SHIPROCK

PECONIC RIVER AT RIVERHEAD

HUOSON RIVER AT GREEN ISLAND

NIAGARA RIVER AT FORT NIAGARA

GENESEE R AT CHARLOTTE DOCKS AT ROCHESTER

OSWEGO RIVER AT LOCK 7, OSWEGO

BLACK RIVER AT WATERTOWN

ST LAWRENCE R AT CORNWALL ONT NR MASSENA

ST REGIS RIVER AT BRASHER CENTER

RICHELIEU RIVER AT ROUSES POINT

ROANOKE RIVER NEAR SCOTLANO NECK

TAR RIVER AT TARBORO

NEUSE RIVER AT KINSTON

CAPE FEAR RIVER AT LOCK I NEAR KELLY

PEE DEE RIVER NEAR ROCKINGHAM

RED RIVER OF THE NORTH BELOW FARGO

RED RIVER OF THE NORTH AT OSLO

SOURIS (MOUSE) RIVER NEAR WESTHOPE

LITTLE MISSOURI RIVER NEAR WATFORD CITY

MISSOURI RIVER AT GARRISON DAM

KNIFE RIVER AT HAZEN

CANNONBALL RIVER AT BREIEN

MUSKINGUM RIVER AT MCCONNELSVILLE

SCIOTO RIVER AT HIGBY

LITTLE MIAMI RIVER AT MILFORD

GREAT MIAMI RIVER AT NEW BALTIMORE

MAUMEE RIVER AT WATERVILLE

CUYAHOGA RIVER AT INDEPENDENCE

CIMARRON RIVER NEAR BUFFALO

CIMARRON RIVER AT PERKINS

ARKANSAS RIVER AT SAND SPRINGS NR TULSA

NEWT GRAHAM LSD (VERDIGRIS R) NEAR INOLA

NEOSHO R BL FT GIBSON LAKE NR FT GIBSON
NV 3750

NV 3909

NV 3918

NV 4028

(CA) NV 3926

NV 3947

NV 4158

NH 4305

NJ 4031

NJ 3959

NJ 4013

NM 3523

NM 3552

NM 3341

NM 3204

NM 3309

NM 3648

NY 4100

NY 4243

NY 4316

NYY 4313

NY 4327

NY 4359

NY 4500

NY 4452

NY 4500

11812

11906

11919

11818

12002

11920

11750

07226

07432

07413

07447

10303

10608

10700

10402

10554

10844

07241

07341

07904

07737

07630

07556

07448

07447

07322

NC $3612 \quad 07723$

NC $3554 \quad 07732$

NC $3515 \quad 07735$

NC $3424 \quad 07818$

NC $3457 \quad 07952$

ND $4656 \quad 09647$

(MN) ND $4812 \quad 09708$

ND $4900 \quad 10057$

ND $4735 \quad 10315$

ND $4730 \quad 10126$

ND $4717 \quad 10137$

ND $4623 \quad 10056$

$\mathrm{OH} 3939$

$\mathrm{OH} 3913$

$\mathrm{OH} 3910$

$\mathrm{OH} 3916$

$\mathrm{OH} 4130$

$\mathrm{OH} 4124$

08151

08252

08418

08440

08343

08138

OK 3655

OK 3558

09924

09702

09607

09532

09514 
07231500 07232500 07234000 07237500 07245000 07305000 07331000

10396000 14048000 14103000 14128910 14207500 14211720 14301000 14321000 14372300

01474500 SCHUYLKILL RIVER AT PHILADELPHIA 01540500 SUSQUEHANNA RIVER AT DANVILLE 01553500 W.BR. SUSQUEHANNA RIVER AT LEWISBURG 01570500 SUSQUEHANNA RIVER AT HARRISBURG 03049625 ALLEGHENY RIVER AT NEW KENSINGTON 03085000 MONONGAHELA RIVER AT BRADDOCK

50038100 RIO GRANDE DE MANATI AT HWY 2 NR MANATI 50046000 RIO DE LA PLATA AT TOA ALTA 50092000 RIO GRANDE DE PATILLAS NEAR PATILLAS 50144000 RIO GRANDE DE ANASCO NEAR SAN SEBASTIAN

02132000 LYNCHES RIVER AT EFFINGHAM

02136000 BLACK RIVER AT KINGSTREE

02170500 LAKE MARION MOULTRIE CANAL NR PINEVILLE

02171500 SANTEE RIVER NEAR PINEVILLE

02175000 EDISTO RIVER NEAR GIVHANS

02176500 COOSAWHATCHIE RIVER NEAR HAMPTON

02198500 SAVANNAH RIVER NEAR CLYO

06357800 GRAND RIVER AT LITTLE EAGLE

06438000 BELLE FOURCHE RIVER NEAR ELM SPRINGS

06439300

06440000

06452000

06453000

06478500

06485500

CHEYENNE RIVER AT CHERRY CREEK

MISSOURI RIVER AT PIERRE

WHITE RIVER NEAR OACOMA

MISSOURI RIVER BELOW FT RANDALL DAM

JAMES RIVER NEAR SCOTLAND

BIG SIOUX RIVER AT AKRON

03425000 CUMBERLAND RIVER AT CARTHAGE

03470500 FRENCH BROAD RIVER NEAR KNOXVILLE

03543005 TENNESSEE R. AT WATTS BAR DAM (TAILWATER)

03571850 TENNESSEE RIVER AT SOUTH PITTSBURG

03593005

07026000
TENNESSEE R. AT PICKWICK LAND. D. (L.LOCK) OBION RIVER AT OBION
OK $3459 \quad 09614$

OK 3643

OK 3649

OK 3626

OK 3516

OK 3438

OK 3414

OR 4247

OR 4535

OR 4537

OR 4537

OR 4521

OR 4531

OR 4542

OR 4335

OR 4235

PA 4000

PA 4057

PA 4058

PA 4015

PA 4034

PA 4024

PR 1826

ṔR 1824

PR 1802

$\begin{array}{ll}\text { PR } & 1817\end{array}$

SC 3403

SC 3340

SC 3323

SC 3327

SC 3302

SC 3250

(GA) SC 3232

10130

10031

09917

09514

09906

09659

11852

12024

12054

12202

12240

12240

12345

12333

12404

07512

07637

07653

07653

07946

07953

06632

06615

06602

06703

07945

07950

08008

08009

08024

08108

08116

SD 4530

10049

SD 4422

SD 4436

SD 4422

SD 4345

SD 4304

SD 4311

(IA) SD 4250

10234

10129

10022

09933

09833

09738

09634

TN 3615

IN 3558

08557

08346

08447

08542

08815

08912 
07228000 CANADIAN RIVER NEAR CANADIAN 07297910

07300000

07308500

07331600

08030500

08041000

08065350

08066500

08068000

08082000

08082500

08098290

08116650

08123800

08136700

08158000

08162000

08164500

08176500

08188500

08210000

08212400

08370500

08377200

08447410

08459000

08475000

09180500

09234500

09315000

09379500

10059500

10126000

10141000

10171000

10224000

10237000

04296500

01673000

02035000

02049500

12031000 CHEHALIS RIVER AT PORTER

12045500 ELWHA R AT MCDONALD BRIDGE NR PT ANGELES

12200500

12398600

12400520

12433000

12510500

13353200

14113000
PDTF RED RIVER NEAR WAYSIDE TEXAS

SALT FORK RED RIVER NEAR WELLINGTON

RED RIVER NEAR BURKBURNETT

RED RIVER AT DENISON DAM NEAR DENISON

SABINE RIVER NEAR RULIFF

NECHES RIVER AT EVADALE

TRINITY RIVER NEAR CROCKETT

TRINITY RIVER AT ROMAYOR

WEST FORK SAN JACINTO RIVER NEAR CONROE

SALT FORK BRAZOS RIVER NEAR ASPERMONT

BRAZOS RIVER AT SEYMOUR

BRAZOS RIVER NEAR HIGHBANK

BRAZOS RIVER AT ROSHARON

BEALS CREEK NEAR WESTBROOK

COLORADO RIVER NEAR STACY

COLORADO RIVER AT AUSTIN

COLORADO RIVER AT WHARTON

NAVIDAD RIVER NEAR GANADO

GUADALUPE RIVER AT VICTORIA

SAN ANTONIO RIVER AT GOLIAD

NUECES RIVER NEAR THREE RIVERS

LOS OLMOS CREEK NEAR FALFURRIAS

RIO GRANDE AT FT QUITMAN

RIO GRANDE AT FOSTER RANCH NR LANGTRY

PECOS RIVER NEAR LANGTRY

RIO GRANDE AT LAREDO

RIO GRANDE NEAR BROWNSVILLE

COLORADO RIVER NEAR CISCO

GREEN RIVER NEAR GREENDALE

GREEN RIVER AT GREEN RIVER

SAN JUAN RIVER NEAR BLUFF

BEAR LAKE OUTLET CANAL NEAR PARIS

BEAR RIVER NEAR CORINNE

WEBER RIVER NEAR PLAIN CITY

JORDAN RIVER AT SÁLT LAKE CITY

SEVIER RIVER NEAR LYNNDYL

BEAVER RIVER AT ADAMSVILLE

CLYDE RIVER AT NEWPORT

PAMUNKEY RIVER NEAR HANOVER

JAMES RIVER AT CARTERSVILLE

BLACKWATER RIVER NEAR FRANKLIN
$T \times 3556$

$T X 3450$

$T \times 3457$

TX 3406

$T \times 3349$

$T \times 3018$

$T \times 3021$

$T X 3120$

TX 3026

$T \times 3015$

$T \times 3320$

ix 3335

TX 3108

Tx 292!

Tx 3212

$T \times 3130$

$T \times 3015$

TX 2919

TX 2902

TX 2848

TX 2839

TX 2826

TX 2716

TX 3105

TX 2947

TX 2948

ix 2730

TX 2553

UT 3849

UT 4054

UT 3859

UT 3709

(ID)

UT 4213

UT 4135

UT 4117

UT 4044

UT 3929

UT 3815

VT 4456

VA 3746

VA 3740

VA 3646

WA 4656

WA 4803

WA 4831

SKAGIT RIVER NEAR MT VERNON

PEND OREILLE R AT INTERNATIONAL BOUNDARY

COLUMBIA RIVER AT NORTHPORT

SPOKANE RIVER AT LONG LAKE

YAKIMA RIVER AT KIONA

SNAKE RIVER AT BURBANK

KLICKITAT RIVER NEAR PITT
10022

10125

10013

09832

09634

09345

09406

09539

09451

09527

10014

09916

09649

09535

10101

09934

09742

09606

09633

09701

09723

09811

09808

10536

10145

10127

09930

09727

10918

10925

11009

10952

11121

11206

11205

11155

11224

11246

07211

07720

07805

07654

12319

12335

12220

11721

11747

11751

11929

11901

12113 


$\begin{array}{llll}03201300 & \text { KANAWHA RIVER AT WINFIELD } & \text { WV } 3832 & 08155 \\ 03204500 & \text { MUD RIVER NEAR MILTON } & \text { WV } 3823 & 08207 \\ 04027000 & \text { BAD RIVER NEAR ODANAH } & \text { WI } 4629 & 09042 \\ 04085000 & \text { FOX RIVER AT WRIGHTSTOWN } & \text { WI } 4420 & 08810 \\ 04087000 & \text { MILWAUKEE RIVER AT MILWAUKEE } & \text { WI } 4306 & 08755 \\ 05340500 & \text { ST CROIX RIVER AT ST CROIX FALLS } & \text { WI } 4524 & 09239 \\ 05369500 & \text { CHIPPEWA RIVER AT DURAND } & \text { WI } 4438 & 09158 \\ 05407000 & \text { WISCONSIN RIVER AT MUSCODA } & \text { WI } 4312 & 09026 \\ & & & \end{array}$


Table 2.--Characteristics measured at NASQAN stations

(Frequencies: C, continuous; D, daily; M, monthly; Q, quarterly)

Field determination:

Water temperature-

Specific conductance--

pH--

Discharge--

Coliform, fecal-_-

Streptococci, feca1---

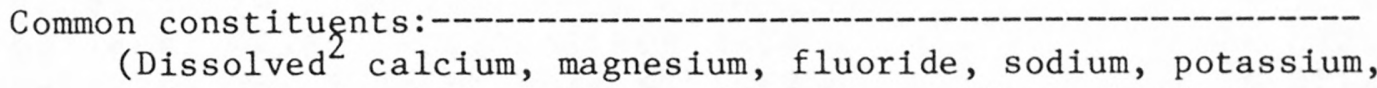

(Dissolved ${ }^{2}$ calcium, magnesium, fluoride, sodium, potass
dissolved solids, silica, chloride, sulfate, hardness, and noncarbonate hardness; total ${ }^{4}$ bicarbonate and carbonate; and turbidity).

Major nutrients:

Phosphorus, total as P--

Nitrite plus nitrate, total as $\mathrm{N}-$

Nitrogen, total Kjeldahl as $\mathrm{N}-$

Trace elements (total and dissolved):-

(Arsenic, cadmium, chromium, cobalt, copper, iron, lead, manganese, mercury, selenium, and zinc).

Organics and biological:

Organic carbon, total

Phytoplankton, total, cells/mL-

Phytoplankton, identification of 3 co-dominants-----

Phytoplankton, 3 co-dominants, percent

of total-

Periphyton, biomass, dry weight $\mathrm{g} / \mathrm{m}^{2}$

Periphyton, biomass, ash weight $\mathrm{g} / \mathrm{m}^{2}-\mathrm{C}_{-}$

Periphyton, chlorophyll a-co Q

Periphyton, chlorophyl1 b-_-

Suspended sediment:

Suspended sediment concentration--

Percent finer than $0.062-\mathrm{mm}$ sieve diameter

${ }^{1}$ Continuous or daily depending upon whether the station is equipped with a monitor or whether daily observations are made. Monthly

measurements made at stations where a long-term record is made.

${ }^{2}$ Dissolved constituents in water are those remaining after filtering samples through 0.45 -micrometer membrane filters.

3 Quarterly or monthly, depending upon whether relationships have been established between conductance and concentrations of various common constituents.

${ }^{4}$ Total concentrations are those determined by analyses of unfiltered samples. They include both dissolved and suspended materials. 
There is no clear, simple, quantitative way to describe the term "water quality." In practice, the quality of water in rivers is represented by measurements of a large suite of physical, chemical, and biological characteristics. Results of the many different measurements usually are compared with water-quality standards or criteria in order to judge the suitability of the water. There are several different sets of criteria, depending upon the intended use of the water; water that meets the criteria for one particular use will not necessarily meet the criteria for other uses.

Discussions in the subsections that follow deal with the results of measurements of selected water-quality characteristics, and relate the results to some of the criteria for selected water uses. Among the commonly cited standards and criteria are Water Quality Criteria 1972 of the National Academy of Sciences and National Academy of Engineering (1972), Quality Criteria for Water of the U.S. Environmental Protection Agency (1976a), National Interim Primary and Secondary Drinking Water Regulations (U.S. Environmental Protection Agency, 1975, 1976b, 1977), standards and criteria set by individual states, and recommended criteria proposed in miscellaneous articles and reports.

The Water Resources Regions, as shown in figure 2, are referred to in the discussion of areal variability of the various water-quality constituents in order to provide consistency throughout the text.

\section{Stream Temperature}

Measurement of stream temperature at NASQAN stations varies in frequency (continuous, once daily, or once a month) depending on several factors. The design of the network specifies that a period (generally about three years) of either continuous or daily temperature measurements be available for analysis.

The statistical technique of Steele (1974) was used for analysis of the temperature data to fit a harmonic (sinusoidal) equation to daily stream temperature records. Steele's procedure is similar to that previously used by Ward (1963) and Collings (1969). The harmonic expression used to represent annual temperature has the form:

$$
\mathrm{T}_{\mathrm{d}}^{\prime}=M+A \sin [(\mathrm{b}) \mathrm{x}(\mathrm{d})+\mathrm{C}]
$$




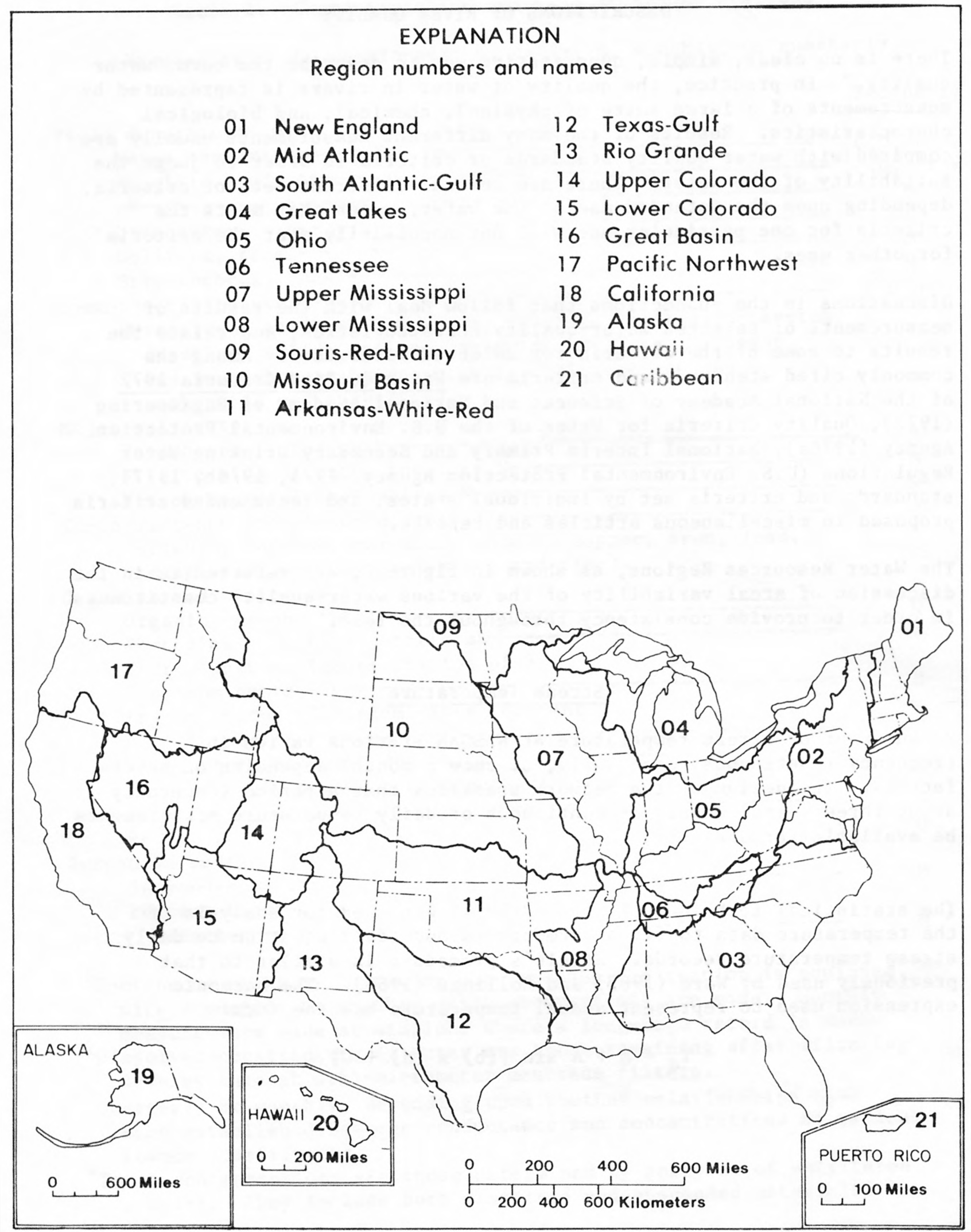

Figure 2.--Water Resources Regions of the United States, as designated by the U.S. Water Resouces Council. 
where

$\mathrm{T}_{\mathrm{d}}^{\prime}$ represents estimated temperature on the $\mathrm{d}^{\mathrm{th}}$ day, in ${ }^{\circ} \mathrm{C}$,

d represents a day of year (in this case 0ctober 1, the beginning of the water year, is represented by integer 1 ),

b a constant equal to 0.0172 , i.e. $2 \pi \div 365$ or 366 ,

A represents the harmonic amplitude of the stream temperature curve, in ${ }^{\circ} \mathrm{C}$,

$M$ represents the mean annual water temperature, in ${ }^{\circ} \mathrm{C}$, and

C represents the phase angle, in radians.

The annual harmonic analyses of 1975 stream temperature records for each station, where available, are summarized near the middle of each page of table 14. Each summary in table 14 shows the harmonic coefficients ( $M, A$, and $C$ ), the standard error of estimate of a daily temperature value in ${ }^{\circ} \mathrm{C}$, and the percentage of the variation in daily temperature values that is accounted for by the harmonic function. These latter two values, standard error of estimate and percentage variation explained by the harmonic function, will be used in the future to decide whether or not the sampling frequency can be reduced to monthly.

A summary of mean temperatures measured at NASQAN stations is presented on the map at the top of figure 3. As would be expected, mean temperatures were lowest in the North and highest in the subtropical regions along the southern border of the continental United States and in Hawaii and Puerto Rico. Of the 345 stations for which stream temperture data are shown on table 3 , mean temperatures of less than $10^{\circ} \mathrm{C}$ were found at 63 (18 percent). All but five of these were at latitudes greater than $43^{\circ} \mathrm{N}$. Some, such as the Colorado River at Lees Ferry, Arizona (at lat $36^{\circ} 51^{\prime \prime} \mathrm{N}_{\text {.) }}$ were influenced by outflow from large, stratified reservoirs. Mean temperatures were in the range of $20^{\circ}-25^{\circ} \mathrm{C}$ at 42 stations, all located south of latitude $35^{\circ} \mathrm{N}$. Seven of the means exceeded $25^{\circ} \mathrm{C}$, and three of those were for stations in Puerto Rico. 


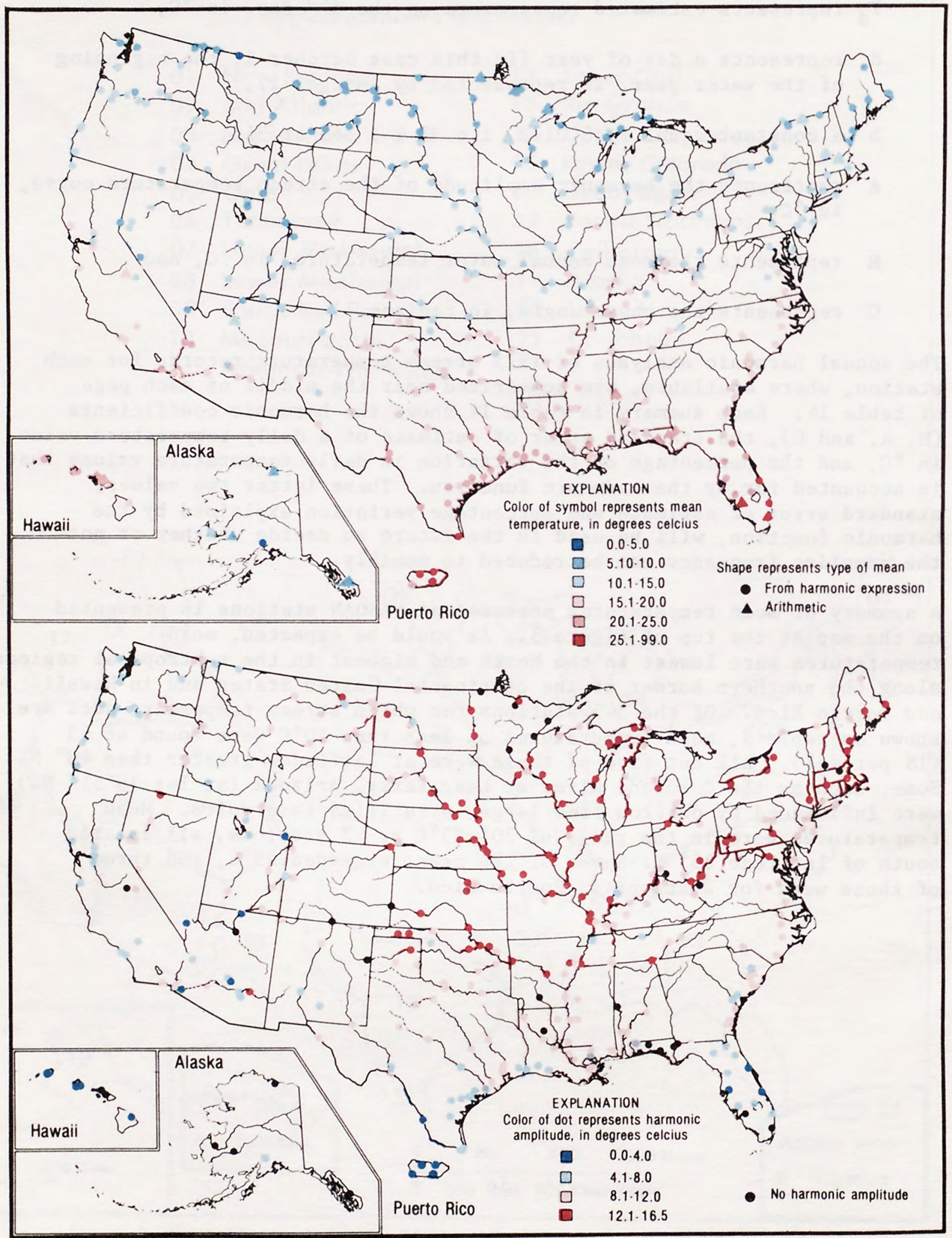

Figure 3.--Mean (top) and harmonic amplitude (bottom) of temperature at NASQAN stations during 1975 water year. 
The map at the bottom of figure 3 shows the values of harmonic amplitude of the stream temperature curves. Amplitudes were greatest, (above $12^{\circ} \mathrm{C}$ ) for the streams at midlatitudes $\left(36^{\circ} \mathrm{N}\right.$. to $\left.45^{\circ} \mathrm{N}.\right)$ and in the Great Plains. Streams in these regions generally range from freezing in the winter to relatively high temperatures in the summer. Amplitudes were smallest for the subtropical streams, which are consistently warm, and for the cold-climate streams, which even in the summer do not get more than a few degrees above freezing. The temperature-damping influences of reservoirs were observed at some northern stations. Amplitudes in the range of 1 to $2^{\circ} \mathrm{C}$ were found at four stations, and an amplitude of less than $1^{\circ} \mathrm{C}$ was found for Waikele Stream at Waipahu, Oahu, Hawaii.

Standard errors of estimate of stream temperature provided by the harmonic equation were $2^{\circ} \mathrm{C}$ or less at about 60 percent of the stations and were $3^{\circ} \mathrm{C}$ or less at about 80 percent of the stations.

\section{Major Inorganic Chemicals}

The major inorganic chemicals often are called "common constituents" as indicated in table 2 of this report. These substances generally dominate the total mass of dissolved material in water and have been the subject of most chemical analyses performed by the Geological Survey in the past. Earlier reports describing national patterns of water quality in terms of major inorganic chemicals include the maps by Rainwater (1962), an analysis of data from 88 NASQAN stations by Steele and others (1974), and the 1974 water year NASQAN report by Hawkinson and others (1977).

A summary of data on major inorganic chemicals measured at each NASQAN station during the 1975 water year is given in the top portions of each page of table 14 of this report. The second through sixth columns in the table for each station list the number of measurements, mean concentration (arithmetic average), standard deviation of measurements, and range of values for each constituent during the 1975 water year.

In this subsection, histograms and maps are used to show frequencies, ranges, and distribution of common constituents in the streams of the United States during the 1975 water year. Histograms for the common constituents were constructed using the mean concentration from each of the 345 NASQAN stations that operated during the water year. Areal patterns showing concentrations of common constituents, based on NASQAN data, are displayed on U.S. maps. Outlines of the accounting units are depicted on the maps, and the units are colored to show the mean concentrations of constituents measured at the NASQAN station(s) monitoring drainage from the respective accounting units. The use of a particular color does not imply that all streams within the accounting unit have the same or even similar mean concentrations for a constituent. 
Dissolved solids.--The amount of dissolved minerals in water is represented by the concentration of dissolved solids and data on dissolved solids are widely used as general indicators of inorganic water quality. Waters with dissolved-solids concentrations of less than 500 milligrams per liter (mg/L) usually are considered by most standards and criteria to be suitable for drinking, assuming that other factors also are acceptable. Waters with higher concentrations of dissolved solids, however, can be and are used for domestic purposes, provided that certain critical substances are within suitable concentration ranges. Irrigation water usually is expected to contain less than $2,000 \mathrm{mg} / \mathrm{L}$ of dissolved solids (National Academy of Sciences and National Academy of Engineering, 1972, p. 335), but again, higher concentrations can be tolerated in some soil situations, depending upon the concentrations of certain ions. The Geological Survey (Krieger and others, 1957, p. 5) classifies water with 1,000 to $3,000 \mathrm{mg} / \mathrm{L}$ of dissolved solids as slightly saline, water with 3,000 to $10,000 \mathrm{mg} / \mathrm{L}$ as moderately saline, and water with 10,000 to $35,000 \mathrm{mg} / \mathrm{L}$ as very saline.

Frequency distributions of mean concentration of dissolved solids at 341 stations are shown on the histogram at the top of figure 4. Mean concentrations were less than $300 \mathrm{mg} / \mathrm{L}$ at about 60 percent of the stations, and were less than $500 \mathrm{mg} / \mathrm{L}$ at 76 percent of the stations. Mean concentrations were greater than $4,000 \mathrm{mg} / \mathrm{L}$ at eight stations; five were in the range of $4,000-8,000 \mathrm{mg} / \mathrm{L}$, and two were in the range of $8,000-10,000$ $\mathrm{mg} / \mathrm{L}$. The highest mean value was $26,000 \mathrm{mg} / \mathrm{L}$. The eight highest values are lumped in the last bar of the histogram in order to maintain the expanded scale shown.

Areal patterns in dissolved-solids concentrations are shown by the U.S. map at the bottom of figure 4. The outlines of accounting units are shown on the map. Units are colored to show the mean concentrations of dissolved solids at the NASQAN station(s) monitoring drainage from the respective accounting units.

Lowest concentrations of dissolved solids were found in the New England, Mid Atlantic, Tennessee, Alaska, Hawaii, and Caribbean Water Resources Regions (fig. 2), and in sizeable parts of the South Atlantic-Gulf, Lower Mississippi, Pacific Northwest, and California Regions. Most of these are areas with relatively large amounts of precipitation.

Highest concentrations occurred in the Missouri, Arkansas-White-Red, Rio Grande, and in the southernmost part of the California Region. Most of these are regions with annual precipitation rates considerably below the national average and with significant amounts of irrigated agriculture. The highest mean concentration of dissolved solids, 26,000 $\mathrm{mg} / \mathrm{L}$, was at the station on the Salt Fork of the Brazos River near Aspermont, Texas. Mean concentrations greater than $4,000 \mathrm{mg} / \mathrm{L}$ were found at eight NASQAN stations-five in Texas, and one each in Oklahoma, New Mexico, and California. 


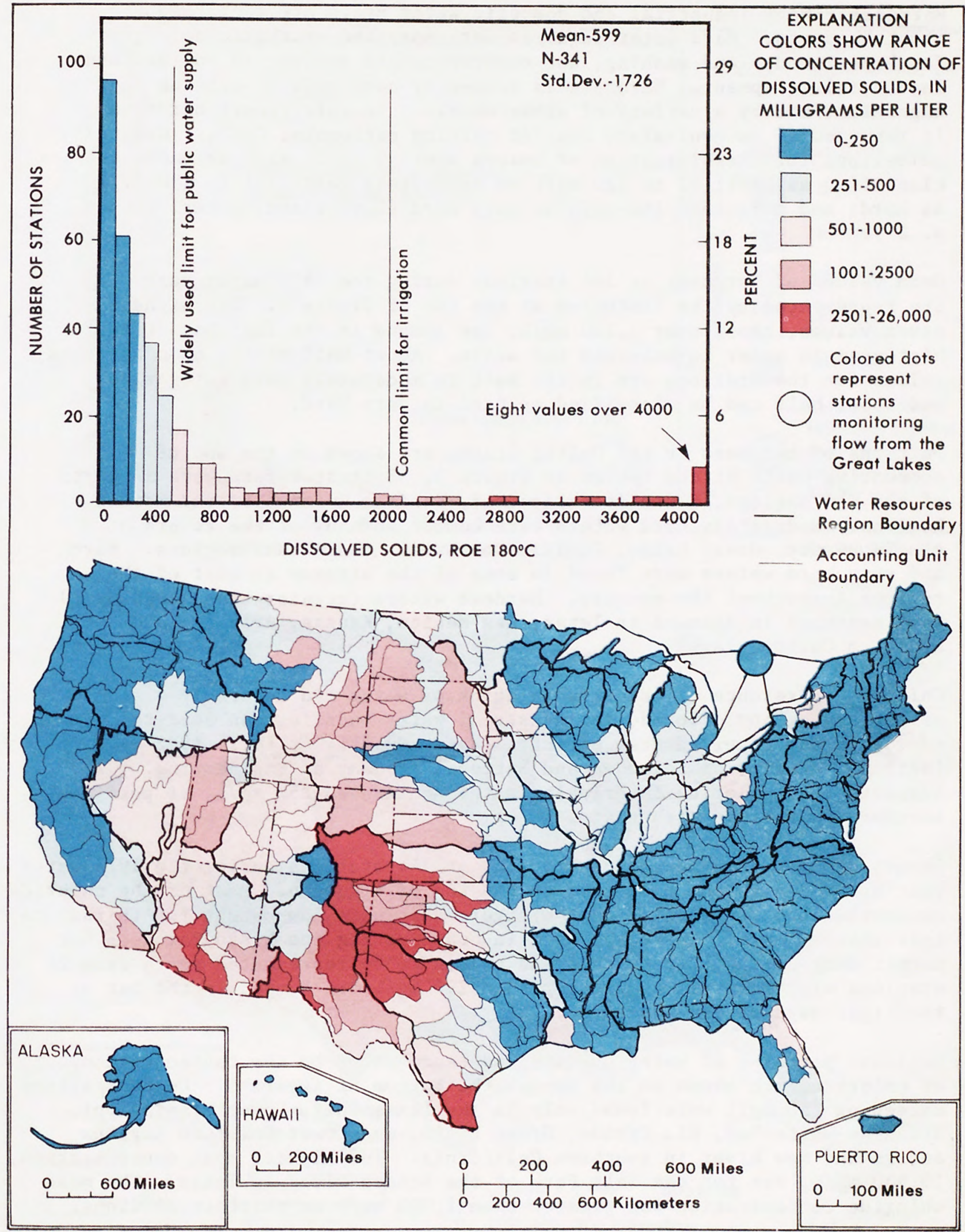

Figure 4.--Mean concentration of dissolved solids measured as residue on evaporation (ROE) at $180^{\circ} \mathrm{C}$ at NASQAN stations during 1975 water year. Map at the bottom is colored to show station data representing flow from the accounting unit. 
Hardness.--Many industrial and domestic water users are concerned about hardness. Hard water requires more soap and synthetic detergents for home laundry and washing, and contributes to scaling in boilers and industrial equipment. Hardness is caused by compounds of calcium and magnesium, and by a variety of other metals. In this report hardness is reported as an equivalent mass of calcium carbonate, $\mathrm{CaCO}_{3} \cdot$ General guidelines for classification of waters are: 0 to $60 \mathrm{mg} / \mathrm{L}$ as $\mathrm{CaCO}_{3}$ is classified as soft; 61 to $120 \mathrm{mg} / \mathrm{L}$ as moderately hard; 121 to $180 \mathrm{mg} / \mathrm{L}$ as hard; and more than $180 \mathrm{mg} / \mathrm{L}$ as very hard (Durfor and Becker, 1964, p. 27).

Mean values of hardness at 344 stations during the 1975 water year are represented by the histogram at the top of figure 5. The highest seven values, those over $1,120 \mathrm{mg} / \mathrm{L}$, are lumped in the last bar of the histogram in order to maintain the scale. About half of the mean hardness values for the stations are in the soft to moderately hard categories, and about half can be classified as hard to very hard.

Patterns of hardness in the United States are shown on the map of accounting units at the bottom of figure 5. Softest waters were in parts of the New England, South Atlantic-Gulf, Pacific Northwest, and Hawaii Regions. Moderately hard waters were common in many of the rivers of the Tennessee, Great Lakes, Pacific Northwest, and Alaska regions. Hard and very hard waters were found in some of the streams in most of the regions throughout the country. Hardest waters (greater than $1,000 \mathrm{mg} / \mathrm{L}$ ) were measured in streams in Texas, New Mexico, Kansas, Arizona, and southern California.

Chloride.--Presence of chloride in drinking water can adversely affect taste, and chloride in industrial water supplies can lead to corrosion and other adverse effects. Water Quality Criteria 1972 (National Academy of Sciences and National Academy of Engineering, 1972) suggests that chloride in drinking water not exceed $250 \mathrm{mg} / \mathrm{L}$, if possible, because of problems with taste.

Ranges of mean chloride concentrations at 344 stations during the 1975 water year are shown in the histogram at the top of figure 6. Most of the chloride concentrations represented in the figure are quite low--about two-thirds are less than $30 \mathrm{mg} / \mathrm{L}$. The scale used in constructing the histogram does not permit many of the highest chloride values to be represented--data from 26 stations with mean values greater than $290 \mathrm{mg} / \mathrm{L}$ are lumped in the bar at the right edge of the histogram.

National patterns of water quality, as represented by the concentration of chloride, are shown on the map at the bottom of figure 6. Concentrations exceeding $250 \mathrm{mg} / \mathrm{L}$ were found only in the Texas-Gulf, Lower Mississippi, Arkansas-White-Red, Rio Grande, Great Basin, and Lower Colorado Regions and in the New River in southern California. The highest mean concentration, $12,900 \mathrm{mg} / \mathrm{L}$, was for the Salt Fork of the Brazos River in Texas. The mean chloride concentration was greater than $1,000 \mathrm{mg} / \mathrm{L}$ at thirteen stations. 


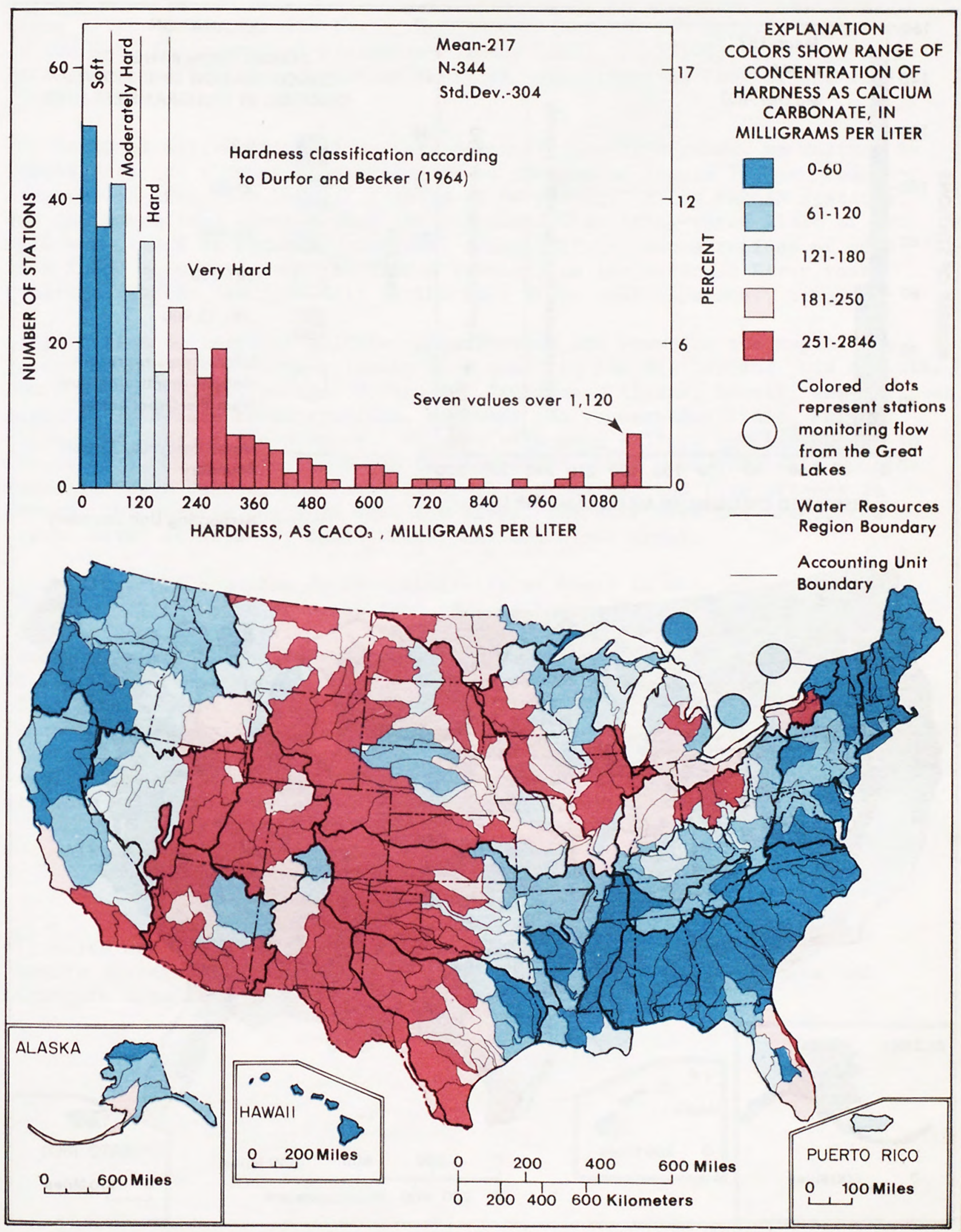

Figure 5.--Mean hardness as calcium carbonate at NASQAN stations during 1975 water year. Map at bottom is colored to show station data representing flow from the accounting unit. 


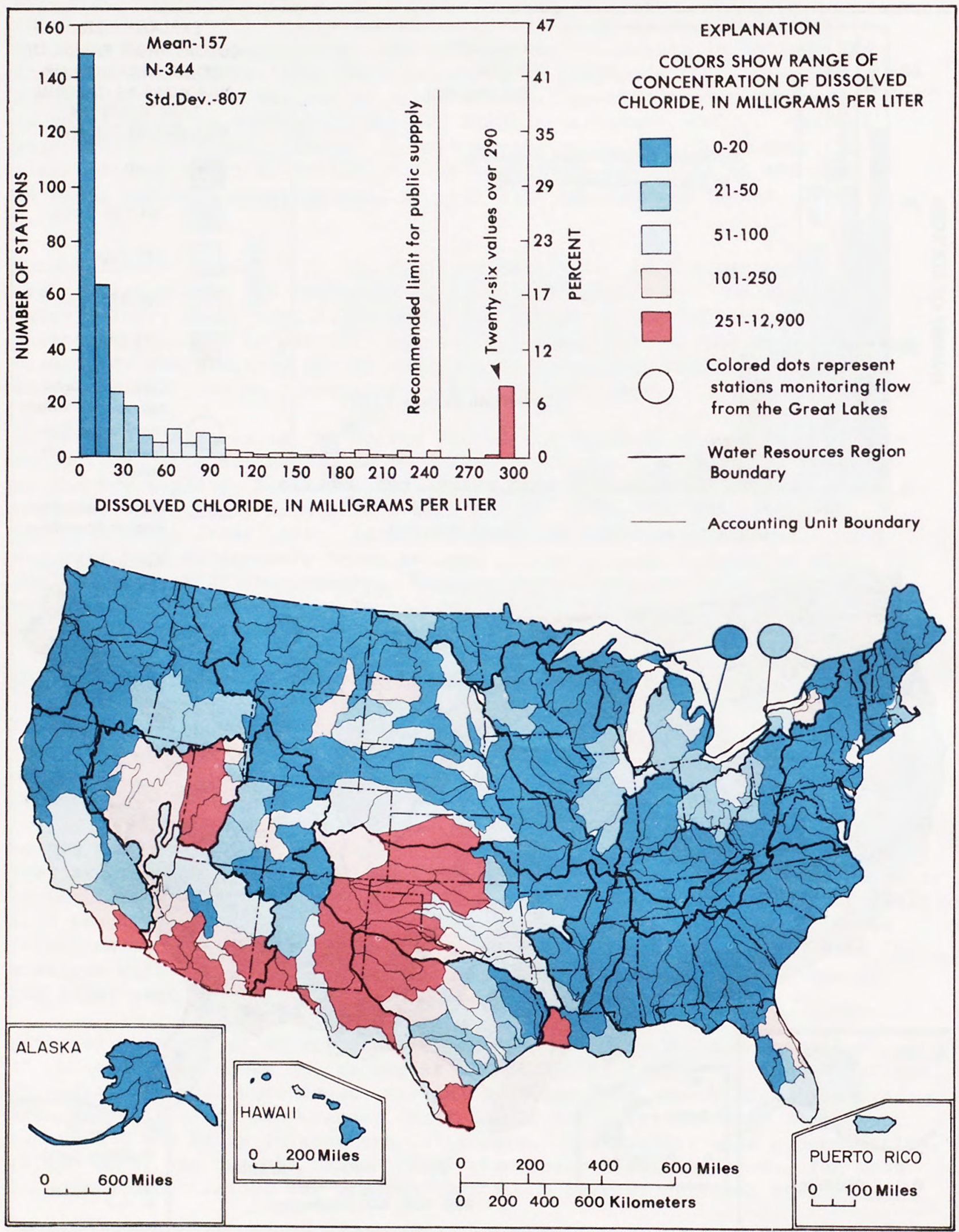

Figure 6.--Mean concentration of dissolved chloride at NASQAN stations during 1975 water year. Map at bottom is colored to show station data representing flow from the accounting unit. 
Sulfate.--Large amounts of sulfate in drinking water are undesirable because of the laxative effects. A recommended limit of $250 \mathrm{mg} / \mathrm{L}$ is suggested by the U.S. Environmental Protection Agency (1977, p. 17146), although some water supplies contain considerably higher concentrations (Durfor and Becker, 1964, p. 78).

The national distribution of sulfate concentration in streams, as defined by NASQAN data, is shown in the histogram at the top of figure 7 . Mean concentrations of less than $50 \mathrm{mg} / \mathrm{L}$ existed at 60 percent of the NASQAN stations, and concentrations greater than the recommended drinking-water limit of 250 $\mathrm{mg} / \mathrm{L}$ were found at about 50 stations. Mean sulfate concentrations of more than $2,100 \mathrm{mg} / \mathrm{L}$ were found at NASQAN stations on the Arkansas River near Coolidge, Kansas, and the Salt Fork Brazos River near Aspermont, Texas.

Distribution patterns of sulfate concentration are shown on the map at the bottom of figure 7. Lowest levels were found in the New England, Mid Atlantic, South Atlantic-Gulf, Pacific Northwest, Tennessee, Alaska, Hawaii, and Caribbean Regions. Moderate concentrations, not over the recommended limit, existed throughout most of the Midwest. Streams with mean sulfate concentrations in excess of $1,000 \mathrm{mg} / \mathrm{L}$ included the two mentioned above plus the Belle Fourche River in South Dakota, the Pecos River in New Mexico, and five streams in Texas: the Prairie Dog Town Fork Red River, the Salt Fork Red River, the Brazos River at Seymour, Beals Creek, and Los Olmos Creek.

Alkalinity.--Information on the alkalinity of water is more of an indicator of the type of water than it is a means of judging suitability for most uses. Alkalinity is the sum total of components in the water that tend to elevate the $\mathrm{pH}$ of the water above a value of about 4.5 ; therefore, it is a measure of the buffering capacity of water--that is, the ability of water to resist change in $\mathrm{pH}$ due to addition of acids. Alkalinity is influenced mainly by the amount of bicarbonate and carbonate, but also by phosphate, hydroxides, and other substances to a lesser degree. It usually is measured directly, but it also can be estimated from concentrations of bicarbonate and carbonate by the relation:

$$
\begin{aligned}
\text { Alkalinity as } \mathrm{CaCO}_{3}=50.04 \times & {[(\text { bicarbonate } \mathrm{x} .01639)+} \\
& (\text { carbonate } \mathrm{x} .03323)]
\end{aligned}
$$

All units are in milligrams per liter. This equation can be used to compute average alkalinity for NASQAN stations using the bicarbonate and carbonate data given in table 14. 


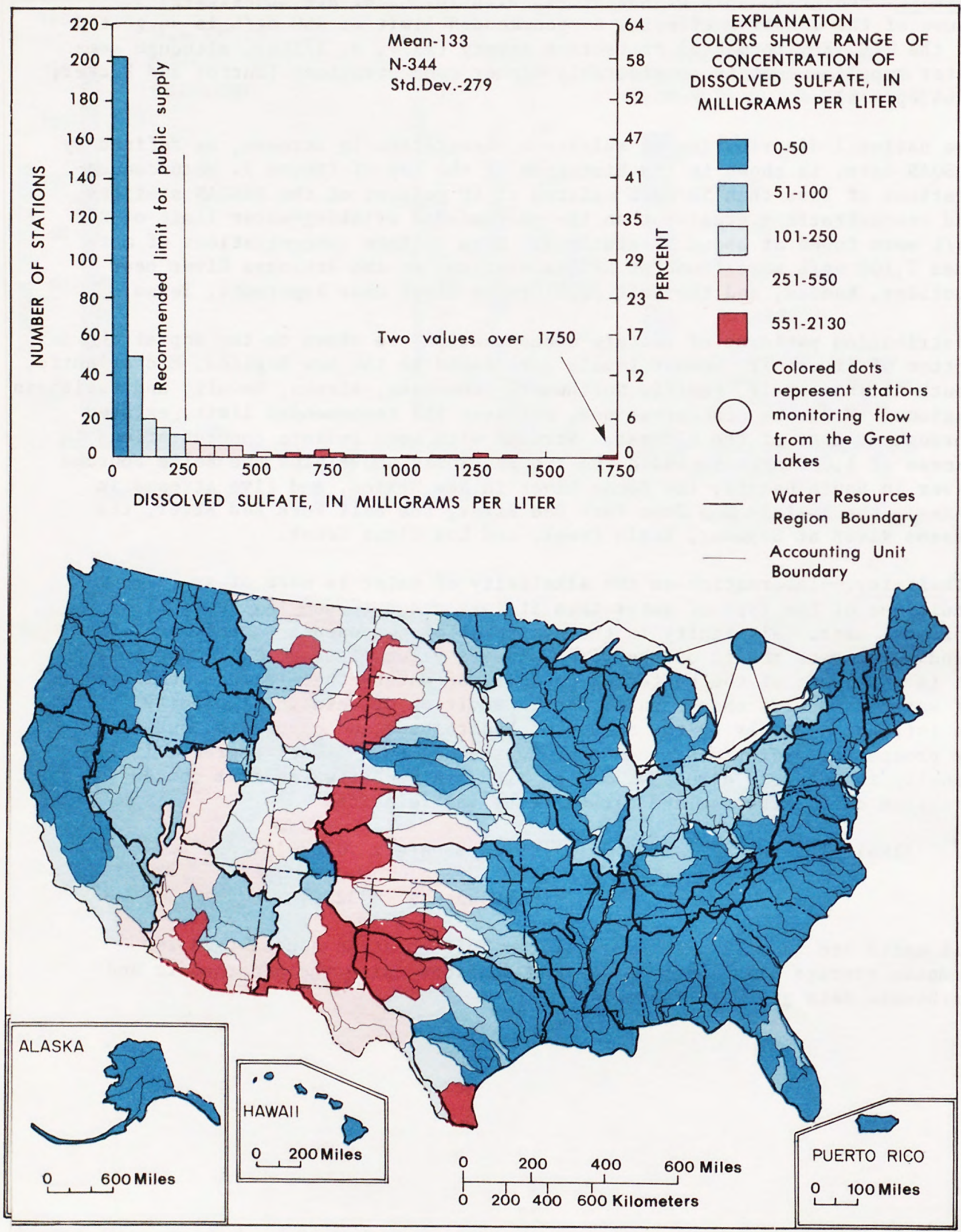

Figure 7.--Mean concentration of dissolved sulfate at NASQAN stations during 1975 water year. Map at bottom is colored to show station data representing flow from the accounting unit. 
A moderate amount of alkalinity is desirable in streams to prevent fluctuation of $\mathrm{pH}$ from biological processes. Also, water with high alkalinity will more effectively resist alteration by addition of acid mine drainage or acid pollution than will waters with low alkalinity. Bicarbonate, which usually is the principal component in stream alkalinity, can limit a water's utility for irrigation through induction of iron chlorosis in some plants at concentrations of $610 \mathrm{mg} / \mathrm{L}$ (National Academy of Sciences and National Academy of Engineering, 1972). Large amounts of carbonate and bicarbonate also can harm boilers and water heaters, and can be detrimental to a number of industrial processes. For example, Quality Criteria for Water (U.S. Environmental Protection Agency, 1976a) lists alkalinity maxima ranging from 50 to $500 \mathrm{mg} / \mathrm{L}$ for several industrial uses. It also lists a minimum alkalinity of $20 \mathrm{mg} / \mathrm{L}$ for protection of freshwater aquatic life.

Variations in alkalinity at NASQAN stations are shown by the histogram at the top of figure 8 . The histogram is quite uniform, with about 97 percent of the NASQAN stations having concentrations less than $300 \mathrm{mg} / \mathrm{L}$. The seven highest values are lumped in the bar at the right edge of the histogram. The greatest mean alkalinity was slightly more than $500 \mathrm{mg} / \mathrm{L}$ and the median was about $120 \mathrm{mg} / \mathrm{L}$.

National patterns in alkalinity are shown on the map at the bottom of figure 8 . Lowest alkalinities (poor buffering capacity) were found in some of the rivers in the New England, Mid Atlantic, South Atlantic-Gulf, Pacific Northwest, and Hawaii regions; the same waters that contained small concentrations of dissolved solids. Moderate or high alkalinities are found in rivers of all the other Water Resource Regions.

Fluoride.--Small amounts of fluoride in drinking water, at concentrations up to about $1 \mathrm{mg} / \mathrm{L}$, are considered to have a beneficial health effect through the reduction in the incidence of tooth decay. However, large amounts of fluoride in the diet produce dental fluorosis--mottling and chipping of tooth enamel. Amounts of fluoride ingested through drinking water vary with the amount of water consumed, and the amounts consumed generally vary with the climate--people drink more where it is hot. Therefore, standards for the recommended maximum amount of fluoride in drinking water consider the annual average of maximum daily air temperature (National Academy of Sciences and National Academy of Engineering, 1972, p. 66).

The histogram at the top of figure 9 summarizes the mean concentration of fluoride measured at NASQAN stations, and also summarizes the recommended maximum concentrations for drinking water as a function of air temperature. A recommended maximum level for livestock of $2.0 \mathrm{mg} / \mathrm{L}$ also is noted on the illustration. Data plotted on the histogram demonstrate the general low level of fluoride in rivers, with three-fourths of the streams having mean fluoride concentrations of less than $0.5 \mathrm{mg} / \mathrm{L}$, and with only six streams having concentrations greater than $1.4 \mathrm{mg} / \mathrm{L}$. 


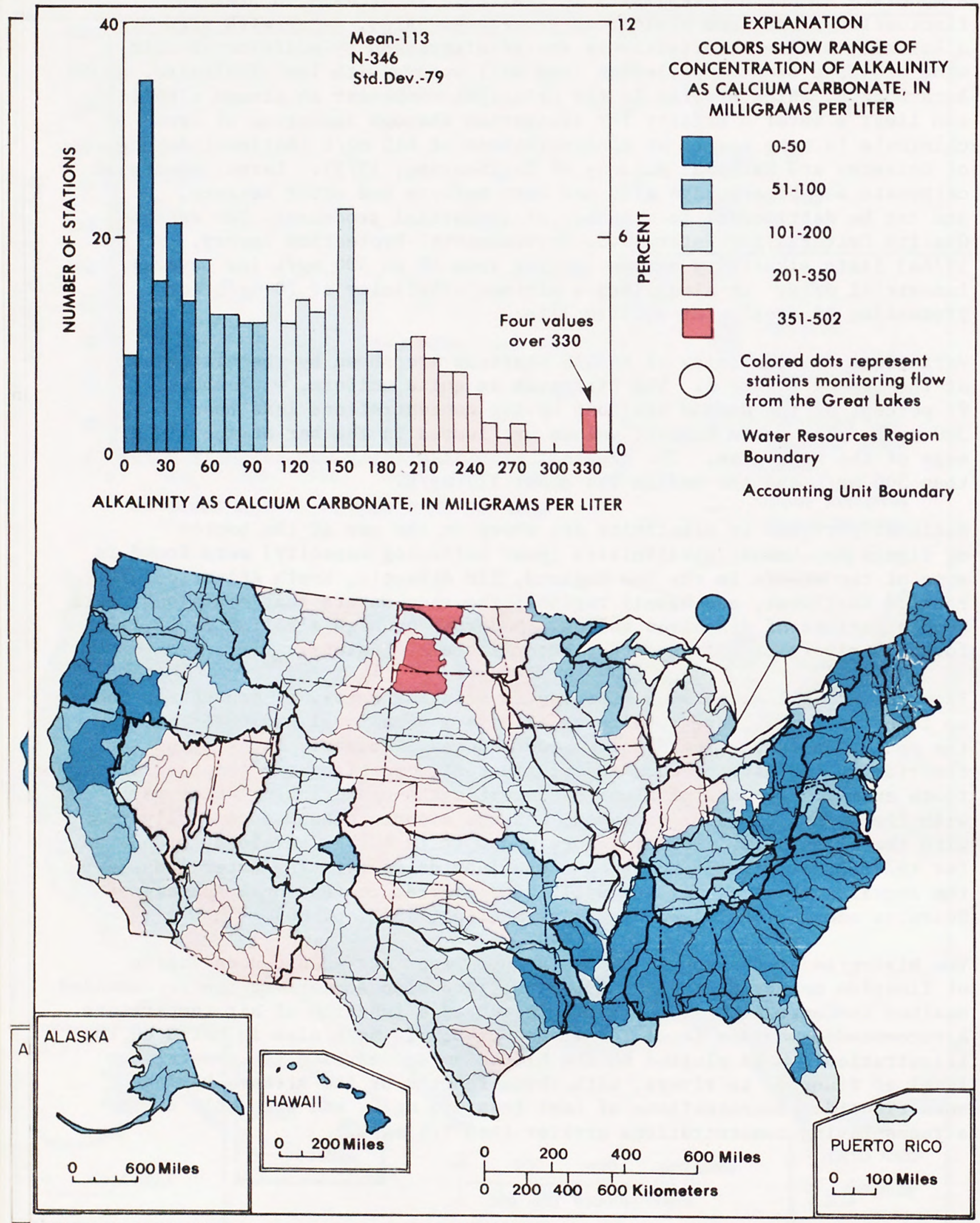

Fi is colored to show station data representing flow from the accounting unit. 


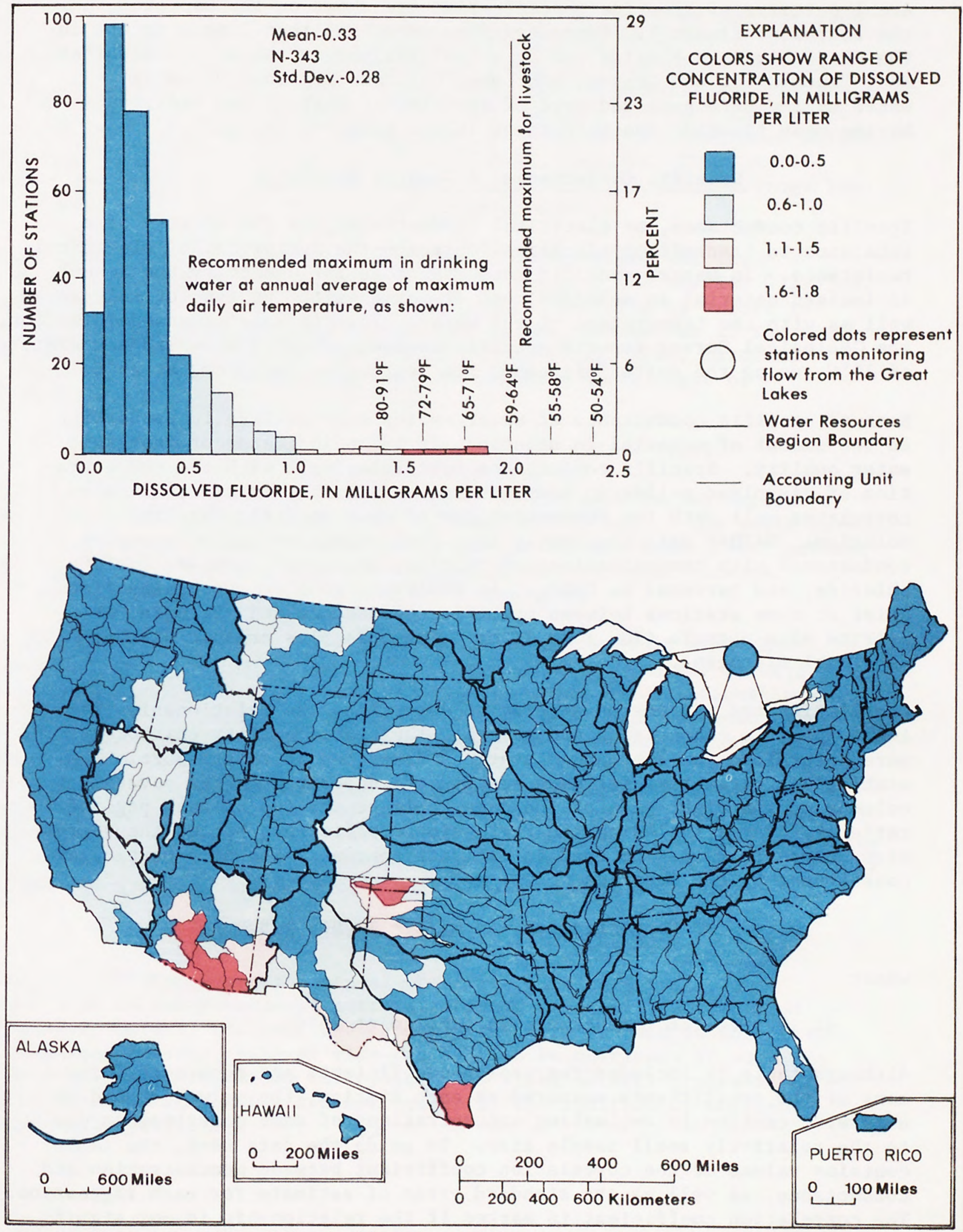

Figure 9.--Mean concentration of dissolved fluoride at NASQAN stations during 1975 water year. Map at bottom is colored to show station data representing flow from the accounting unit. Recommended maxima shown on the histogram are from the National Academy of Sciences (1972). 
Areal patterns of fluoride concentration are shown on the map at the bottom of figure 9. Concentrations were less than $1 \mathrm{mg} / \mathrm{L}$ except in the Peace River in Florida and at a few stations in the Arkansas-WhiteRed, Texas-Gulf, Rio Grande, and Lower Colorado Regions. Drinking water maxima were exceeded part of the time at most of the stations having mean fluoride concentrations in the range of $1-2 \mathrm{mg} / \mathrm{L}$.

\section{Specific Conductance, A General Indicator}

Specific conductance, or electrical conductivity, is the ability of a substance to transmit an electrical current--the reciprocal of electrical resistance. In water, specific conductance is influenced by the amount of ionized material in solution, and it varies with the type of solutes as well as with the temperature of the water. For the sake of standardization, the Geological Survey reports specific conductance at a standard temperature of $25^{\circ} \mathrm{C}$, using the units "micromhos per centimeter $\left(\mu \mathrm{mho} / \mathrm{cm}\right.$ ) at $25^{\circ} \mathrm{C} . "$

Because specific conductance of water varies more or less in proportion to the amount of material in solution, it is an indicator of inorganic water quality. Specific conductance correlates well with the concentration of dissolved solids in many waters, and in many instances it also correlates well with the concentrations of many specific ions in solution. NASQAN data frequently show good relationships of specific conductance with concentrations of calcium, magnesium, sodium, sulfate, chloride, and hardness as $\mathrm{CaCO}_{3}$. In addition, good relationships also exist at some stations between specific conductance and nitrogen, as nitrite plus nitrate $\left(\mathrm{NO}_{2}+\mathrm{NO}_{3}\right)$, or as ammonia plus organic nitrogen (kjeldahl nitrogen).

Correlation and regression statistics describing the relationships between specific conductance and several other water-quality characteristics were determined for the NASQAN stations described in this report. The statistical parameters for each station are described in the several columns on the right side of the data table at the top of each page of table 14. Terms including the regression coefficient, $\underline{R}$, and the regression constant, $\underline{B}$, can be used to estimate concentration of a particular constituent by the equation

$$
\text { Concentration, in } \mathrm{mg} / \mathrm{L}=\mathrm{R}(\mathrm{SC})+\mathrm{B} \text {, }
$$

where

$\mathrm{SC}$ is specific conductance in $\mu \mathrm{mho} / \mathrm{cm}$ at $25^{\circ} \mathrm{C}$.

Although table 14 includes regression coefficients and constants for many of the constituents measured at each station, the values should be used with caution in estimating concentrations of some constituents due to the relatively small sample size. To guide the data user, the table contains values of the correlation coefficient between concentration and conductance, as well as the standard error of estimate for each regression. The correlation coefficient is marked if the relationship is not significant at the 95 percent confidence level (Weatherburn, 1952, p. 193). 
Duration tables of continuous or daily specific conductance are included in table 14 for most NASQAN stations. These tables show the values of conductance that were exceeded during specific percentages of the year. They describe the annual variation as determined from daily observations or from continuous records of conductance. Data in the duration tables provide more detail than is provided by the summary of conductance values measured at the time of the periodic chemical sampling. They provide more information on the extremes, and generally have a greater range than is shown by the twelve or so periodic measurements.

As an example of the application of the duration tables and the regression equations, consider the data in table 14 for station 03290500 , the Kentucky River at Lock 2 at Lockport, Ky. As shown by values in the duration table, specific conductance at the station was in the range of 185 to 309 micromhos for 80 percent of the year. Also, hardness correlates with conductance having a correlation coefficient of 0.974 , and the regression equation is

$$
\text { Hardness, in } \mathrm{mg} / \mathrm{L} \text { as } \mathrm{CaCO}_{3}=0.379(\mathrm{SC})+19.35 \text {. }
$$

Therefore, hardness values ranged from 89 to $136 \mathrm{mg} / \mathrm{L}$ for 80 percent of the time, with a standard error of estimate of $4.5 \mathrm{mg} / \mathrm{L}$. The table further shows that specific conductance exceeded 395 micromhos for 1 percent of the time, from which it can be estimated that hardness exceeded $169 \mathrm{mg} / \mathrm{L}$ as $\mathrm{CaCO}_{3}$ for about 1 percent of the time.

As mentioned previously, users of table 14 should keep in mind that limited data can create false impressions regarding both the first and second statistical moments (mean and variance) and the relationships between concentrations of dissolved materials and specific conductance. There may be situations where generally good relationships should exist, but where it is not evident from the 8 to 12 samples collectd; and vice versa, 8 to 12 samples over a limited range may indicate a good relationship which has no physical meaning and which could be discredited with the collection of additional data. It always is risky to extrapolate any of the functional relationships between conductance and concentrations beyond the range of the data used to establish the relationships.

\section{Major Nutrients, Nitrogen and Phosphorus}

Nitrogen and phosphorus in natural water are nutrients that play a major role in the process of eutrophication. Generally, eutrophication is a slow, natural process, and commonly the term is used in connection with lakes; however, streams also can be rich in nutrients in much the same manner that lakes are eutrophic. The slow, natural processes of eutrophication frequently are speeded up by the addition of nutrients from human activities. 
Nitrogen.--Several forms of nitrogen are found in natural waters. Most common are the nitrate $\left(\mathrm{NO}_{3}\right)$, nitrite $\left(\mathrm{NO}_{2}\right)$, and ammonia $\left(\mathrm{NH}_{4}\right)$ ions and several forms of organic nitrogen. Samples of unfiltered water from NASQAN stations are analyzed for the sum of nitrite plus nitrate $\left(\mathrm{NO}_{2}+\mathrm{NO}_{3}\right)$, and for the sum of ammonia plus organic nitrogen, frequently called kjeldahl nitrogen (KN).

There frequently is confusion in the reporting of concentrations of the various forms of nitrogen because some investigators report the concentrations of the ions $\left(\mathrm{NO}_{3}\right.$ or $\left.\mathrm{NO}_{2}\right)$ in mass per unit volume, and other investigators report only the mass of nitrogen (N). Results can be considerably different. For example, $1.0 \mathrm{mg} / \mathrm{L}$ of "nitrate nitrogen as $\mathrm{N}^{\prime \prime}\left(\mathrm{NO}_{3}-\mathrm{N}\right)$ is equivalent to $4.4 \mathrm{mg} / \mathrm{L}$ of nitrate $\left(\mathrm{NO}_{3}\right)$; and 1.0 $\mathrm{mg} / \mathrm{L}$ of "nitrite nitrogen as $\mathrm{N}^{\prime}\left(\mathrm{NO}_{2}-\mathrm{N}\right)$ is equivalent to $3.3 \mathrm{mg} / \mathrm{L}$ of nitrite $\left(\mathrm{NO}_{2}\right)$.

There are many sets of standards and criteria for the concentrations of the various forms of nitrogen in natural waters. The U.S. Environmental Protection Agency (EPA) (1975) specifies a maximum allowable concentration of $\mathrm{NO}_{3}--\mathrm{N}$ of $10 \mathrm{mg} / \mathrm{L}$ for public water supplies. On the other hand, in the 1975 Annual Report of the U.S. Council on Environmental Quality (CEQ) (1975, p. 353), CEQ used a maximum $\mathrm{NO}_{3}^{--\mathrm{N}}$ concentation of $0.6 \mathrm{mg} / \mathrm{L}$ as a "benchmark" level for "aquatic life protection," suggesting that higher levels are indicative of undesirable eutrophication.

Many state water-quality standards specify a maximum of $45 \mathrm{mg} / \mathrm{L} \mathrm{NO}_{3}$

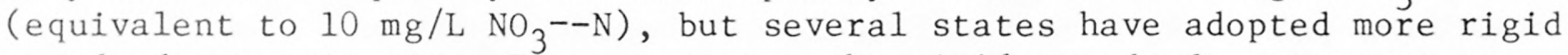
standards or criteria. In most cases, the rigid standards represent an interest in controlling rates of eutrophication. According to a summary by the U.S. Environmental Protection Agency (EPA) (1971b), general criteria for California list maximum values of total $\mathrm{N}$ ranging from 1.0 to 3.0 $\mathrm{mg} / \mathrm{L}$, depending on the region within the State. Criteria for Lake Tahoe are more rigid, giving a maximum for the average value of total $\mathrm{N}$ of $24 \mathrm{\mu g} / \mathrm{L}$ (equal to $0.024 \mathrm{mg} / \mathrm{L}$ ). Several classes of waters in Hawaii have criteria for maximum levels of total $\mathrm{N}$ in the ranges of 0.10 to $0.20 \mathrm{mg} / \mathrm{L}$. Criteria for Lake Michigan set by Illinois and Indiana state that total $\mathrm{N}$ should not exceed $0.4 \mathrm{mg} / \mathrm{L}$. Established criteria for total $\mathrm{NO}_{3}$ concentrations in various waters within Nevada range from $0.5 \mathrm{mg} / \mathrm{L}$ to 2 or $3 \mathrm{mg} / \mathrm{L}$ of $\mathrm{NO}_{3} \cdot$

Data representing annual mean concentrations of nitrite plus nitrate, as nitrogen $\left(\mathrm{NO}_{2}+\mathrm{NO}_{3}--\mathrm{N}\right)$ at 100 NASQAN stations during the 1975 water year are shown on the histogram at the top of figure 10. Mean concentrations were less than $0.5 \mathrm{mg} / \mathrm{L}$ at 65 percent of the stations, and were less than $1.0 \mathrm{mg} / \mathrm{L}$ at about 85 percent of the stations. The widely used standard for drinking water, $10 \mathrm{mg} / \mathrm{L} \mathrm{NO}_{3}--\mathrm{N}$, possibly was exeeded at the station on the Gila River above the diversion at Gillespie Dam, Arizona, where the average $\mathrm{NO}_{2}+\mathrm{NO}_{3}--\mathrm{N}$ was $9.5 \mathrm{mg} / \mathrm{L}$ and where a maximum concentration of $13 \mathrm{mg} / \mathrm{L}$ was measured during the year. Assuming that the amount of nitrite was small, as it frequently is in large streams, it is estimated that the CEQ criterion of $0.6 \mathrm{mg} / \mathrm{L}$ maximum $\mathrm{NO}_{3}{ }^{-\mathrm{N}}$ for aquatic life protection was exceeded by the annual mean concentration at about one-fourth of the rivers represented. 


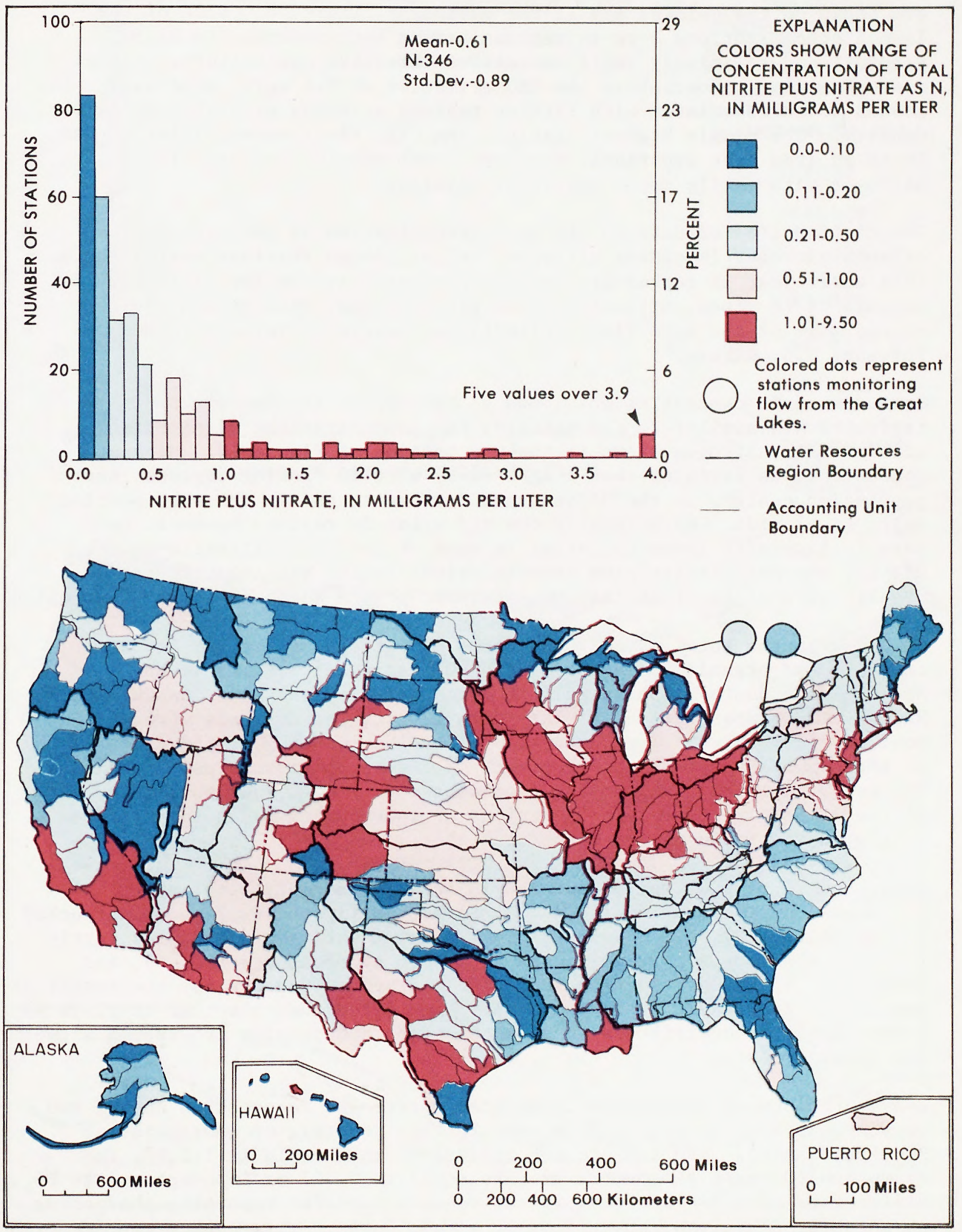

Figure 10.--Mean concentration of total nitrite plus nitrate as N at NASQAN stations during 1975 water year. Map at bottom is colored to show station data representing flow from the accounting unit. 
Patterns of national distribution of nitrite plus nitrate nitrogen are shown on the colored map at the bottom of figure 10 . Some of the lowest concentrations were in regions having both moderate to high rainfall and relatively small amounts of intensive agriculture. Higher concentrations, those above the CEQ criterion of $0.6 \mathrm{mg} / \mathrm{L}$, generally seemed to be associated with farming regions or areas of high population density. The single highest station, the Gila River above Gillespie Dam, is in an area that apparently received local runoff that was high in nitrogen with little opportunity for dilution.

The distribution of data on the mean concentration of ammonia plus organic nitrogen (kjeldahl nitrogen, KN) at NASQAN stations during the 1975 water year is represented on the histogram at the top of figure 11. Amounts of $\mathrm{KN}$ alone, without nitrite plus nitrate, were enough to exceed some of the more rigid criteria for levels of total nitrogen set for some U.S. waters.

Patterns of $\mathrm{KN}$ concentrations shown on the map at the bottom of figure 11 are similar to the patterns for concentrations of nitrite plus nitrate nitrogen shown in the map portion of figure 10. Highest concentrations (greater than $1 \mathrm{mg} / \mathrm{L}$ as $\mathrm{N}$ ) were in farming regions, near population centers in the Midwest and Southwest, and in three accounting units in Florida. KN values in the Mid Atlantic region, however, were more in line with lower KN values in most of the South Atlantic-Gulf Region, whereas nitrite plus nitrate values in the Mid Atlantic region usually were higher than they were in most of the South Atlantic-Gulf region.

Considering the total of all four forms of nitrogen (nitrite, nitrate, ammonia, and organic N) measured at NASQAN stations, rivers in the New England, South Atlantic-Gulf, Lower Mississippi, Alaska, and Hawaii Regions had concentrations of less than $1 \mathrm{mg} / \mathrm{L}$, and probably were within most of the more stringent criteria for limitation of eutrophication. On the other hand, most of the rivers in the Upper Mississippi region had mean values of total nitrogen greater than $2 \mathrm{mg} / \mathrm{L}$, and more than half of the rivers in the remaining regions of the country had total nitrogen levels in the range of $1-2 \mathrm{mg} / \mathrm{L}$, or higher.

Phosphorus.--Most of the phosphorus in streams is contributed by (1) breakdown and erosion of mineral forms (mostly phosphate-bearing rocks) in the soils, (2) animal wastes, (3) synthetic detergents, and (4) fertilizers. Phosphorus usually occurs as a form of phosphate $\left(\mathrm{PO}_{4}{ }^{-3}\right)$, and frequently is associated with suspended sediments. Concern for the levels of phosphorus in streams or lakes usually stems from the role that it plays as a nutrient that contributes to eutrophication and problem growths of algae and rooted plants.

Concentrations of phosphorus in natural waters are reported in one of two ways, phosphorus as $\mathrm{P}$ (the form used in this report), or phosphorus as $\mathrm{PO}_{4}$ (phosphate). The two are not equivalent--the ratio is $1: 3.07$, for example $0.100 \mathrm{mg} / \mathrm{L}$ phosphorus as $\mathrm{P}$ is equal to $0.307 \mathrm{mg} / \mathrm{L}$ phosphorus as $\mathrm{PO}_{4}$. Differences also may be found in the schemes used for reporting phosphorus as soluble, dissolved, suspended, or total. Data in this report represent "total" phosphorus and therefore include the portions that are in solution (dissolved) plus phosphorus that is associated with suspended sediments. 


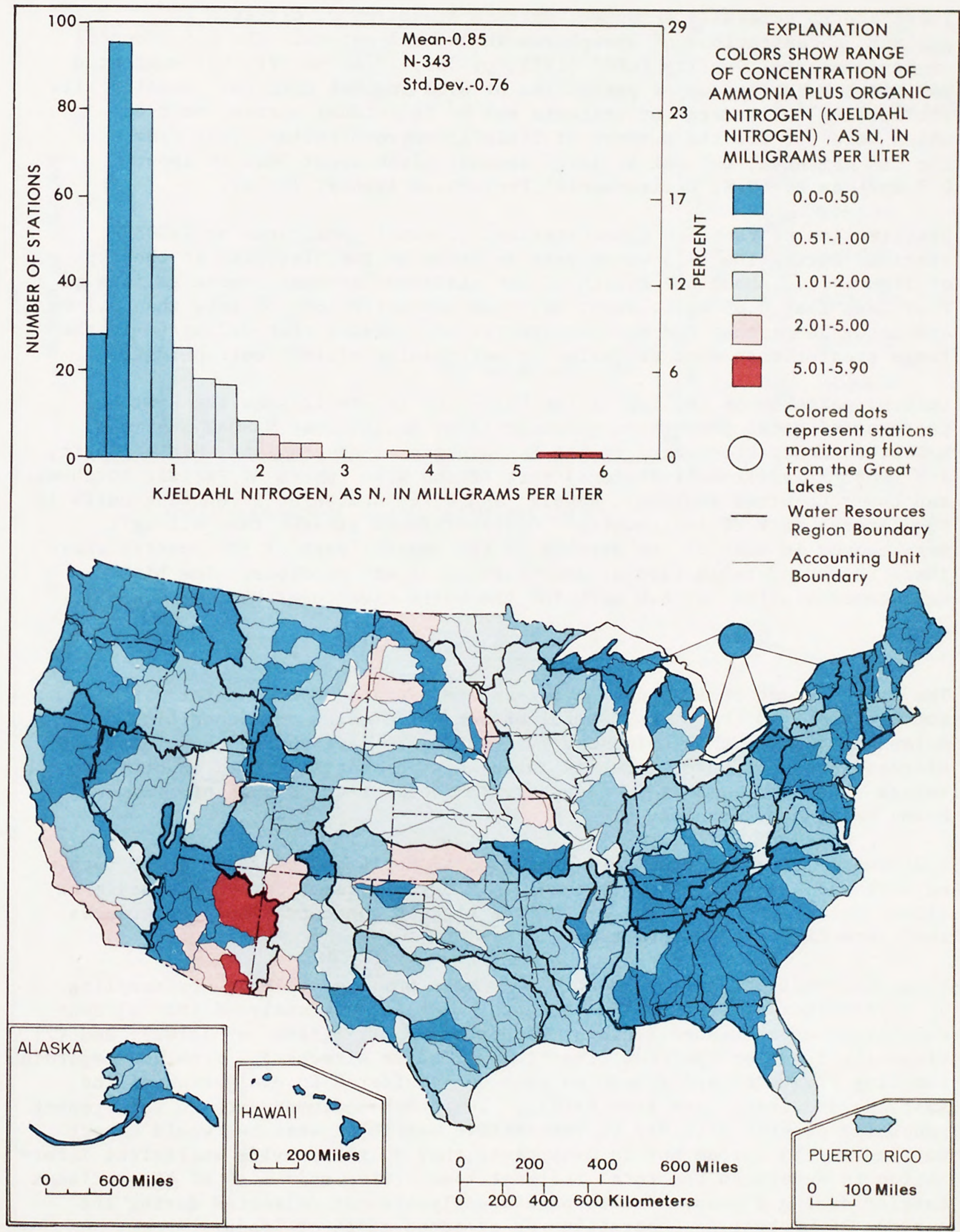

Figure 11.--Mean concentration of ammonia plus organic nitrogen (Kjeldahl nitrogen), as N, at NASQAN stations during 1975 water year. Map at bottom is colored to show station data representing flow from the accounting unit. 
There are no generally accepted, uniform standards or criteria for maximum concentrations of phosphorus in natural waters. The U.S. Council on Environmental Quality (CEQ) (1975, p. 353; 1976, p. 271) has suggested maximum concentrations of phosphorus of 0.03 and $0.1 \mathrm{mg} / \mathrm{L}$ for "aquatic life protection." Standards or criteria set by individual states, most of which were set for the purpose of limiting eutrophication, vary from the CEQ criteria, but not by large amounts (from about 0.01 to about $0.3 \mathrm{mg} / \mathrm{L}$ as P) (U.S. Environmental Protection Agency, 1971a).

Distribution of the mean concentrations of total phosphorus at NASQAN stations during the 1975 water year is shown on the histogram at the top of figure 12. About one fourth of the stations had mean concentrations of $\mathrm{P}$ of less than $0.05 \mathrm{mg} / \mathrm{L}$, about half had concentrations of less than $0.1 \mathrm{mg} / \mathrm{L}$, and about 30 percent had mean concentrations greater than $0.2 \mathrm{mg} / \mathrm{L}--$ in the range greater than most criteria for maintaining minimal eutrophication.

Colored patterns on the map at the bottom of figure 12 show the national patterns of total phosphorus concentrations measured at NASQAN stations. Lowest concentrations were in the East (parts of New England, Mid Atlantic, and South Atlantic-Gulf Regions) part of the West (parts of Pacific Northwest and Lower Colorado Regions), Hawaii, and a few scattered accounting units in the central part of the country. Concentrations greater than $0.1 \mathrm{mg} / \mathrm{L}$ were common in most of the streams of the central part of the country where there is considerable farming and where soils are erodible. The highest mean concentration was $6.0 \mathrm{mg} / \mathrm{L}$ for the White River near Oacoma, S. Dak.

\section{Suspended Sediment}

The great amount of interest in stream sedimentation stems mainly from concerns for (1) the often harmful effects of erosion and deposition of material, and (2) the influences that sediments have on the usefulness and attractiveness of water, such as influences on aquatic life. In order to assess these problems it is necessary to document the amount of sediment being carried by streams.

Sediment in streams results from erosion of soils and by scouring of both natural and man-made stream channels. Flowing streams carry some sediment almost all of the time, but by far the highest concentrations and greatest loads are carried by storm runoff.

Suspended-sediment data at most NASQAN stations are collected by sampling at a frequency of about once per month. Samples are analyzed for (1) concentration of suspended sediment (reported in milligrams per liter), and (2) clay-silt fraction (percent finer than $0.062 \mathrm{~mm}$ diameter). Problems regarding sampling frequency and schedules must be considered in evaluation of the suspended-sediment data from NASQAN. Suspended-sediment data in this report generally provide a fairly representative sample of what one would expect to find in the stream but in many cases they do not provide sufficient information to determine the total sediment load or the mean size of the sediment carried during a year. The samples usually are not collected during the periods of highest concentrations or greatest sediment loads. 


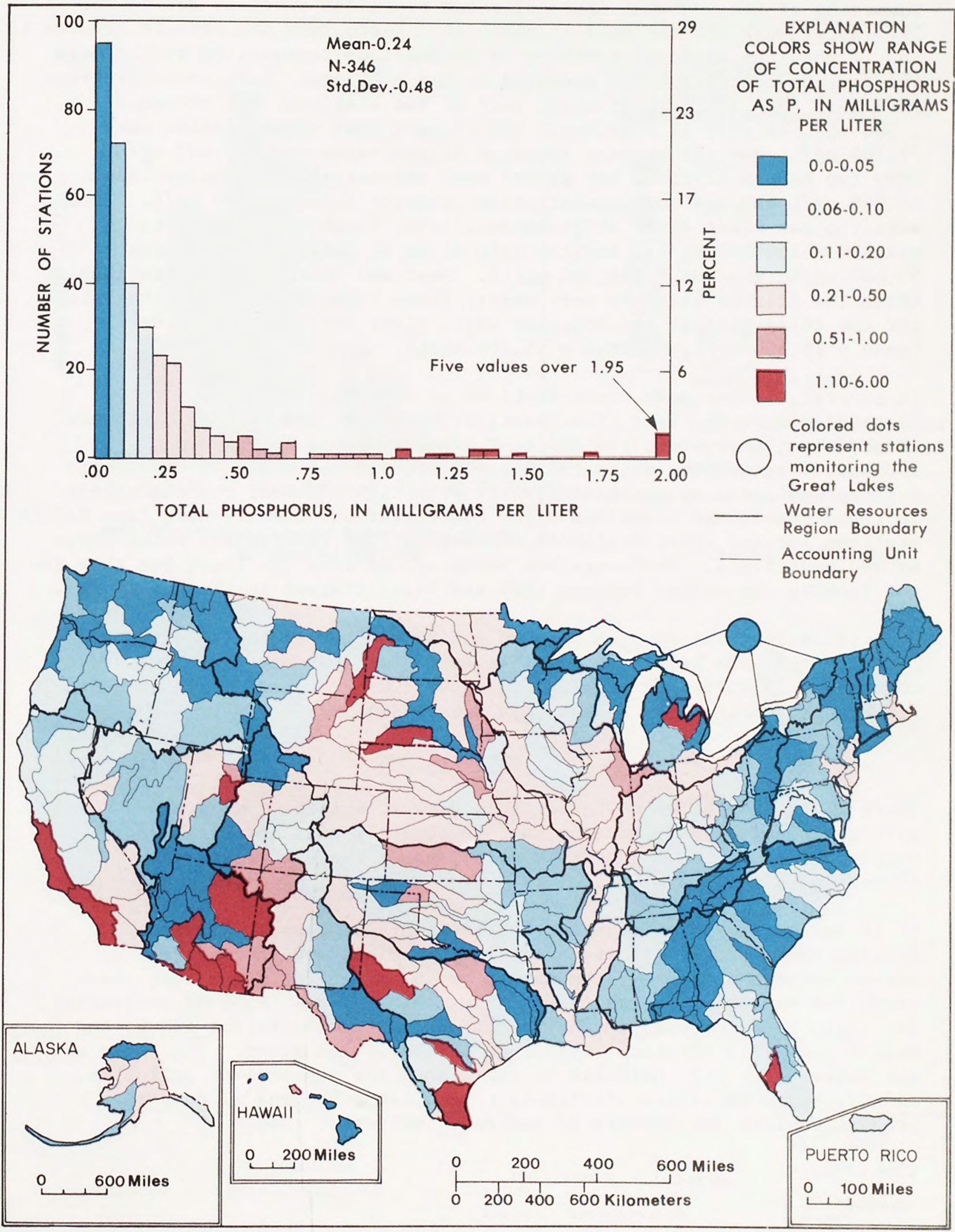

Figure 12.--Mean concentrations of total phosphorus as $P$ at NASQAN stations during 1975 water year. Map at bottom is colored to show station data representing flow from the accounting unit. 
Summaries of the sediment data collected at NASQAN stations during the 1975 water year are included in table 14. Histograms and maps in figures 13 and 14 show the national patterns of sediment as represented by the mean and maximum concentrations measured at the stations. Mean concentrations were less than $100 \mathrm{mg} / \mathrm{L}$ at about half of the stations, and exceeded $1,000 \mathrm{mg} / \mathrm{L}$ at only 19 stations. The largest mean concentration was $77,100 \mathrm{mg} / \mathrm{L}$, and the highest reported single value was $150,000 \mathrm{mg} / \mathrm{L}$. Only two NASQAN stations had annual mean concentrations greater than $50,000 \mathrm{mg} / \mathrm{L}$ and maximum concentrations greater than $100,000 \mathrm{mg} / \mathrm{L}$. These were the San Pedro River at Winkelman, Ariz. (mean $=77,100 \mathrm{mg} / \mathrm{L}$; maximum $=150,000 \mathrm{mg} / \mathrm{L})$, and the Gila River at Kelvin, Ariz. (mean = $50,600 \mathrm{mg} / \mathrm{L}$; maximum $=136,000 \mathrm{mg} / \mathrm{L})$. Mean and maximum concentrations at these two Arizona stations were nearly three times as great as the values for the third-highest station, the White River near Oacoma, S. Dak. (mean $=18,300 \mathrm{mg} / \mathrm{L} ;$ maximum $=55,100 \mathrm{mg} / \mathrm{L})$.

In general, lowest mean concentrations of suspended sediment were associated with the East, Southeast, Great Lakes, and Pacific Northwest. In addition, there were low sediment concentrations for several individual accounting units that are located in the midst of hydrologic regions dominated by accounting units with high sediment concentrations. In these cases, the anomalously low concentrations usually were from NASQAN stations located short distances downstream from reservoirs, which serve as sediment traps. Sediments are being eroded from the land, but they are not leaving the basins because they are being trapped in the reservoirs.

Highest concentrations of suspended sediment occurred in the streams draining the more heavily farmed, semiarid, or sparsely vegetated areas of the Mid Atlantic, Mississippi, Missouri, Ohio, Colorado, Texas-Gulf, Rio Grande, California, Alaska, and Hawaii Regions.

\section{Bacteria}

There are many species of bacteria in natural waters; some are pathogenic, or disease causing, but fortunately most are harmless. People, of course, are concerned mainly about those that present threats of disease.

It is impossible to monitor for all forms of pathogens. Instead, knowing that certain disease-producing organisms move from person to person through the water, the waters are examined for signs that these organisms may be present. Classically, this has been done by monitoring for indicator organisms in the so-called coliform bacterial group, and more recently in the fecal streptococcai bacterial group. The logic of the scheme is: (1) indicator bacteria show the presence of pollution, and (2) polluted waters are likely to contain pathogens in numbers proportional to the numbers of indicator bacteria. 


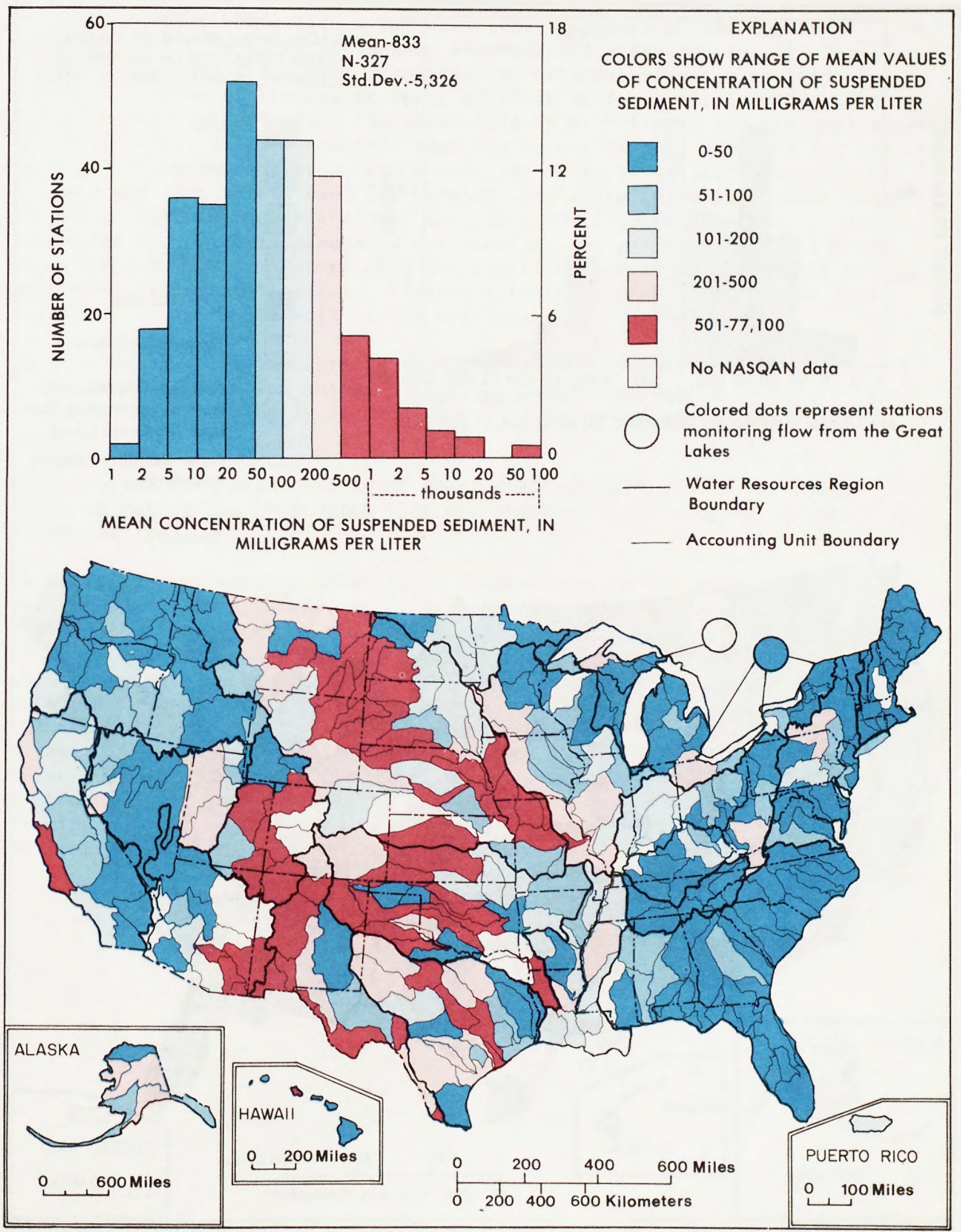

Figure 13.--Mean concentration of suspended sediment at NASQAN stations during 1975 water year. Map at bottom is colored to show station data representing flow from the accounting unit. 


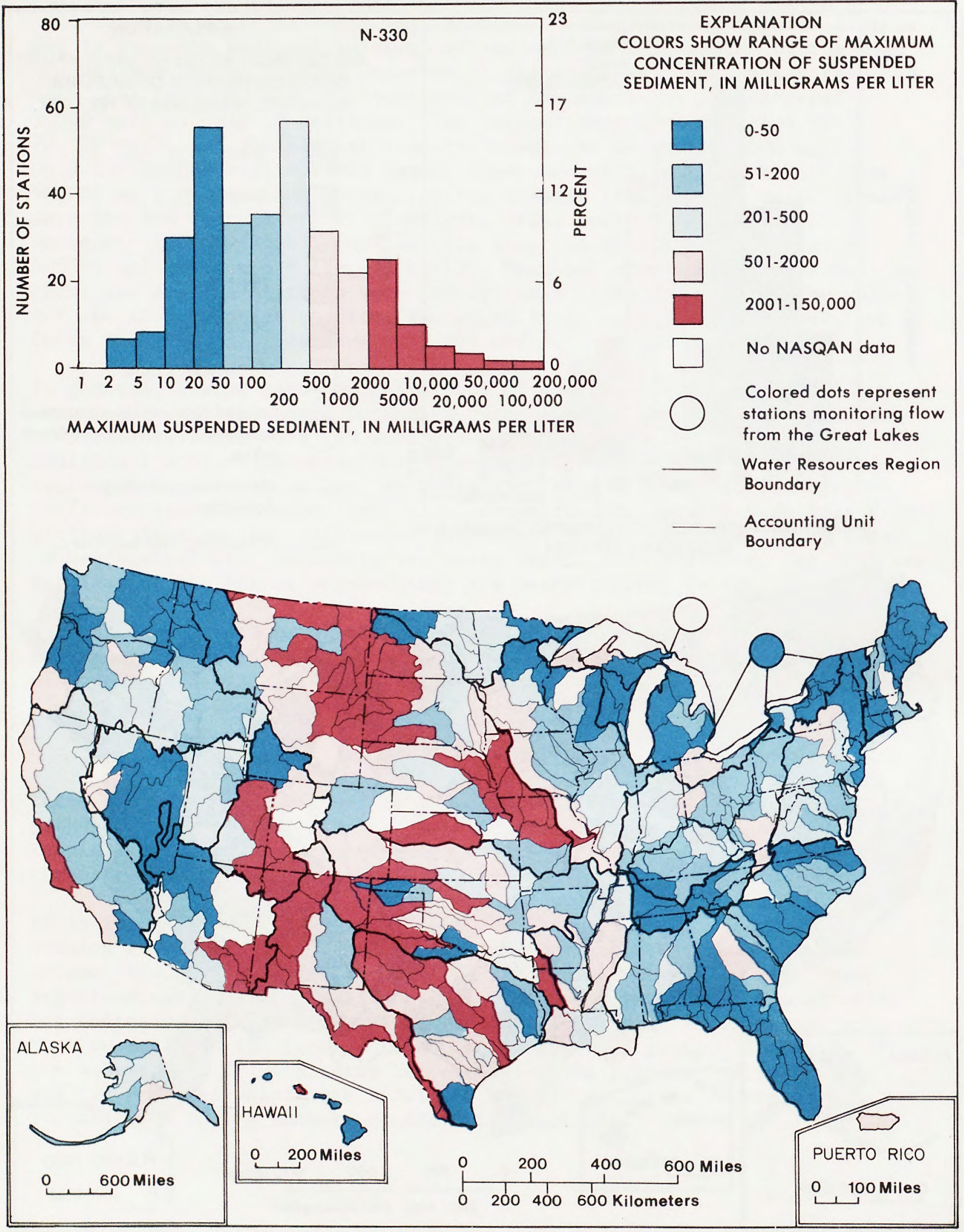

Figure 14.--Maximum concentration of suspended sediment at NASQAN stations during 1975 water year. Map at bottom is colored to show station data representing flow from the accounting unit. 
At NASQAN stations, data are collected at monthly intervals on numbers of (1) fecal coliform bacteria (those members of the coliform group found in the feces of various warm-blooded animals), and (2) fecal streptococci bacteria. Most standards and criteria of water quality are written in terms of numbers of total coliform or fecal coliform bacteria. Water Quality Criteria 1972 (National Academy of Sciences and National Academy of Engineering, 1972) recommends that raw waters used as a source for public supply contain not more than 2,000 colonies of fecal coliform bacteria per $100 \mathrm{~mL}$, and that waters used for bathing have a $\log$ (geometric) mean count of fecal coliform bacteria of not more than 200 colonies per $100 \mathrm{~mL}$. State standards and criteria generally are similar, but may differ over a broad range in some cases. Waters used for shellfish harvesting generally have much more stringent standards. Treated drinking waters usually have limits for total coliform bacteria of not more than 1 colony per $100 \mathrm{~mL}$.

Data on fecal coliform bacteria are used in hydrological studies as indicators of human and animal pollution. Rivers with high counts of fecal coliform bacteria usually are influenced by untreated sewage or by animal wastes.

Data representing mean numbers of fecal coliform bacteria at 342 NASQAN stations during the 1975 water year are shown on the histogram and map on figure 15.

The life span of enteric bacteria is limited outside the body of a warm-blooded animal, so bacterial data from water monitoring stations may reflect the influences of the reach immediately upstream from the sampling site. For this reason, maps with entire accounting units colored according to measurements at stations near the downstream end of the units are not so effective a form of presentation as were maps of chemical data. Nevertheless, the map of figure 15 does show regions affected by animal or human wastes. Lowest mean colony counts generally occurred in the South Atlantic-Gulf, Tennessee, Upper Missouri, Upper Colorado, Great Basin, Pacific Northwest, California, and Alaska Regions. Highest colony counts are in streams flowing through heavily populated areas in several parts of the country or from areas with large populations of livestock. 


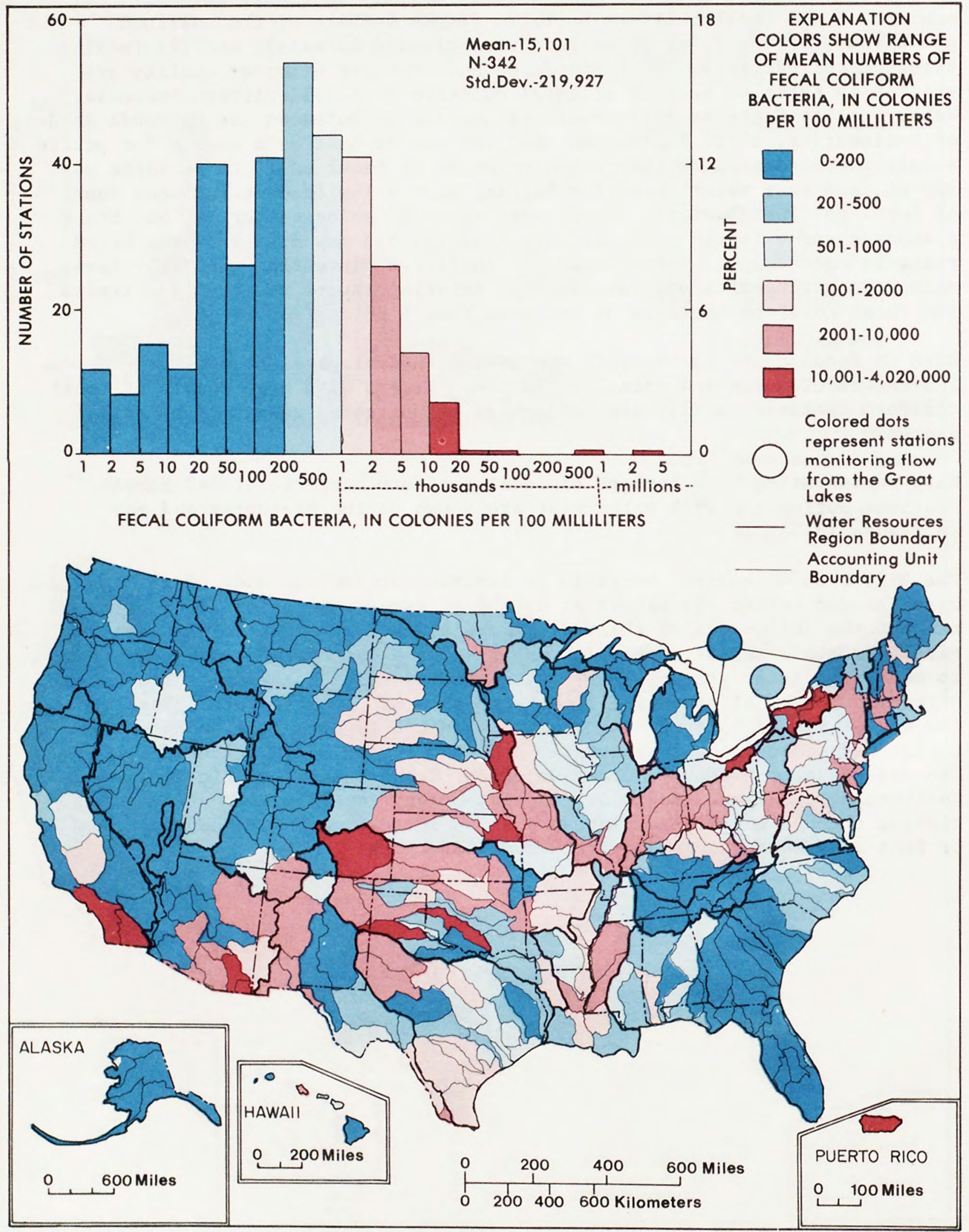

Figure 15.--Mean numbers of fecal coliform bacteria sampled at NASQAN stations during 1975 water year. Map at bottom is colored to show station data representing flow from the accounting unit. 
Information on fecal streptococci bacteria often is collected as part of hydrologic studies to provide information about the probable sources of bacterial pollution. While fecal streptococci bacteria are found in the gut of all warm-blooded animals, there are many more fecal streptococci bacteria then fecal coliform bacteria in animals. Humans have more fecal coliform bacteria than fecal streptococci bacteria. Commonly used guidelines in interperating bacteria data are: (1) a ratio of fecal coliform/fecal streptococci bacteria of greater than 4 indicates predominantly human sources, and (2) a ratio of fecal coliform/fecal streptococci bacteria of less than 1 indicates predominantly animal sources. Ratios in the range of 1 to 4 are common and indicate a combination of human and animal sources. Data interpretation generally must be on a sample-by-sample basis and cannot be made from the data summaries and ranges given in table 14 of this report. Readers are directed to the USGS individual state reports of Water Resources Data for the specific information needed for interpretation. $\overline{\text { Also, }} \overline{\text { the ratio }}$ can not be used if the bacteria entered the stream more than 24 hours prior to the sampling.

\section{Phytoplankton}

Phytoplankton are suspended or free-floating plants that drift with water currents. A majority of the phytoplankton populations are made up of microscopic single-celled, colonial, or multi-celled algae. They serve as food for higher forms of aquatic life, and in large numbers they form nuisance "blooms" and can cause filter clogging, objectionably tastes and odors, and other problems in water-treatment plants.

Data on the sizes and types of phytoplankton populations are widely used in water-quality studies as indicators of pollution and nutrient enrichment. In general, large populations indicate nutrient enrichment, and small populations indicate oligotrophic conditions (low nutrients and low productivity).

Samples for phytoplankton analyses are collected at NASQAN stations at approximately monthly intervals. They are analyzed for numbers of cells, and the predominant forms are identified. Summaries of the numbers of phytoplankton at NASQAN stations are given on the data sheets of table 14, and national summaries are represented on the map and histogram of figure 16. These data allow the interpretation of a national pattern, but it is not possible to cite any references of what really represents "good" or "bad" water as related to phytoplankton populations. There is, however, a similarity between the color patterns on figure 16 and the patterns for the principal nutrients, nitrogen and phosphorus, on figures 10,11 , and 12 . Smallest populations were associated with regions of low human and livestock populations and low nutrient concentrations. Highest populations occurred in the nutrient rich waters in the areas of large human and livestock population, intensive agriculture, and erodible soils. 


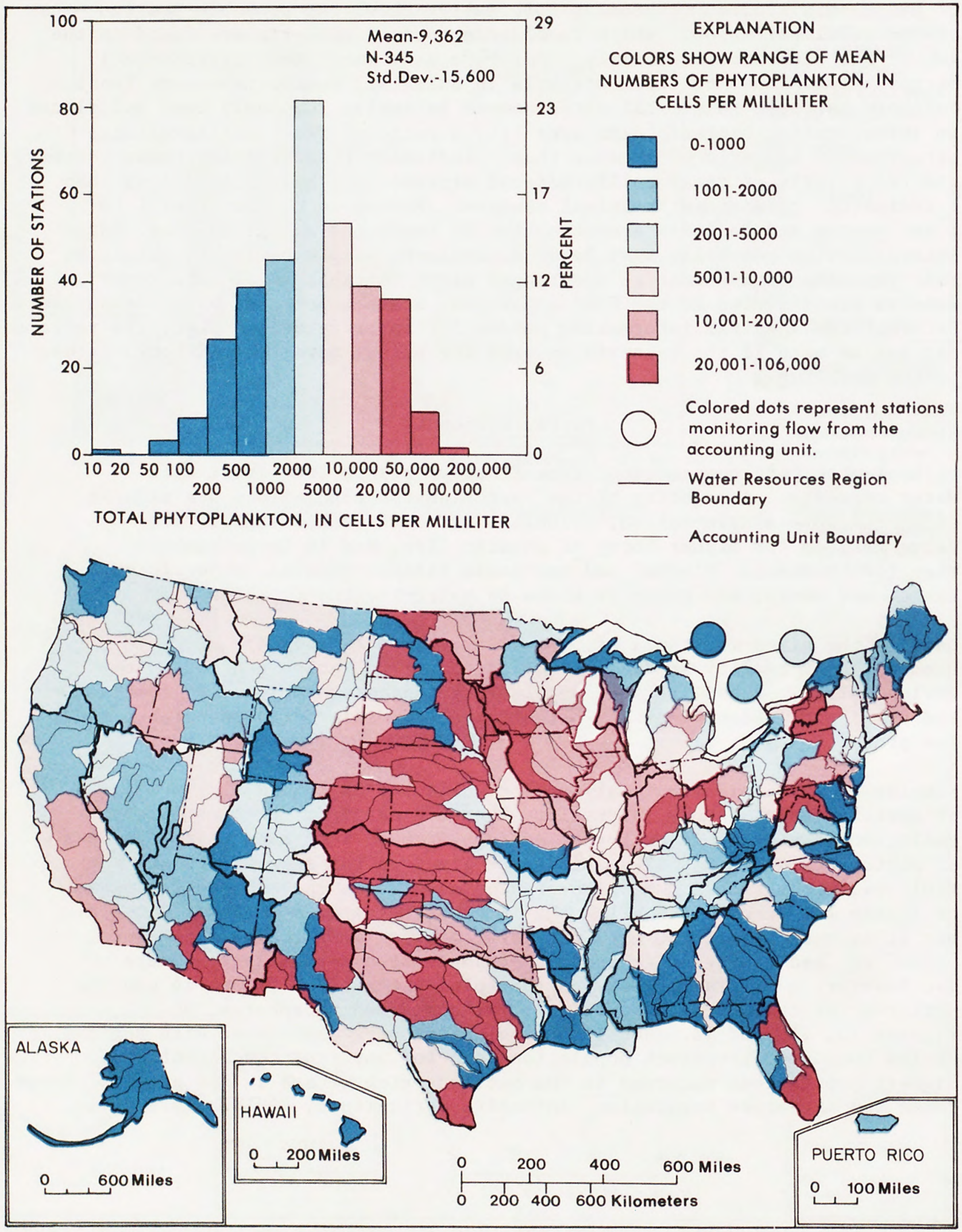

Figure 16.--Mean numbers of phytoplankton sampled at NASQAN stations during 1975 water year. Map at bottom is colored to show station data representing flow from the accounting unit. 
The term periphyton is applied to the community of microorganisms that are attached to or live upon submerged surfaces. They include algae that grow attached to stream bottoms, piers, rooted plants, floating debris, and other similar objects. They are studied in hydrologic investigations for much the same reasons that phytoplankton are studied-they serve as integrators and indicators of overall stream quality. Large growths of periphyton usually occur in waters rich in plant nutrients.

There are several ways to sample and measure periphyton. A common method is to scrape a sample from rocks or other objects, but such techniques do not provide the uniform results desired from a widely scattered network such as NASQAN. Consequently, data at NASQAN stations were collected using artificial (plastic strip) substrates placed in the streams for exposure periods of from two to four weeks each. An attempt is made to collect periphyton samples four times per year (once each calendar quarter), but because of vandalism and other disturbances, recovery rate has been poor.

When periphyton substrate strips are recovered from streams at NASQAN stations, they are preserved and shipped to laboratories for analyses of biomass and chlorophyll content. Biomass analyses of "dry weight" determine the amount of plant growth per unit area. Measurements of sample "ash weight" provide information on the amount of inorganic (mineral) content of the plants. Amounts of chlorophyll $a$ and $b$ in the periphyton serve to indicate the biological productivity of the plant community.

Data summarizing the biomass and the chlorophyll content of periphyton samples collected at NASQAN stations during the 1975 water year are shown in the tables in the lower portion of each page of table 14. Numbers of samples are small--too small to compute mean values and construct histograms and maps, as was done with major inorganic chemicals, bacteria, and phytoplankton.

Table 3 has been constructed in order to facilitate interpretation of the periphyton data from the NASQAN stations. Data are summarized according to the twenty-one Water Resources Regions designated by the U.S. Water Resources Council. Outlines of these regions are shown on the map in figure 2 .

Because of the small amount of data and the variability at each station and in each region, it is difficult to interpret the periphyton data, even on a regional basis. The biomass and chlorophyll data in table 3 suggest that periphyton growths tended to be least in Alaska and the Caribbean Regions, but data from those two regions were so scarce that valid comparisons with other regions probably cannot be made. The New England, Mid Atlantic, and Souris-Red-Rainy Regions also seemed to have moderately small growths of periphyton. Relatively high periphyton growths were indicated in the Lower Mississippi, Missouri, Rio Grande, Great Basin, Pacific Northwest, and California Regions. 
Table 3.--Ranges of periphyton biomass and chlorophyl1 measured at NASQAN stations during the 1975 water year, summarized by Water Resources Regions

\begin{tabular}{|c|c|c|c|c|c|c|}
\hline & $\begin{array}{c}\text { Region } \\
\text { Number and Name }\end{array}$ & $\begin{array}{c}\text { Number } \\
\text { of } \\
\text { stations } \\
\end{array}$ & $\begin{array}{l}\text { Biomass } \\
\text { dry } w t \\
\left(\mathrm{gm} / \mathrm{m}^{2}\right)\end{array}$ & $\begin{array}{l}\text { Biomass } \\
\text { ash wt. } \\
\left(\mathrm{g} / \mathrm{m}^{2}\right)\end{array}$ & $\begin{array}{c}\text { Ch1orophy11 } \\
\left(\mathrm{mg} / \mathrm{m}^{2}\right)\end{array}$ & $\begin{array}{c}\text { Chlorophy11 } \\
\left(\mathrm{mg} / \mathrm{m}^{2}\right)\end{array}$ \\
\hline $\begin{array}{l}06 \\
07 \\
08 \\
09 \\
10\end{array}$ & $\begin{array}{l}\text { Tennessee } \\
\text { Upper Mississippi } \\
\text { Lower Mississippi } \\
\text { Souris-Red-Rainy } \\
\text { Missouri Basin }\end{array}$ & $\begin{array}{r}3 \\
12 \\
11 \\
6 \\
34\end{array}$ & $\begin{array}{l}0.0-140 \\
0.1-6300 \\
0.6-1000 \\
0.29-29 \\
0.2-340\end{array}$ & $\begin{array}{l}0.5-91 \\
0.1-170 \\
0.5-970 \\
0.0-55 \\
0.1-290\end{array}$ & $\begin{array}{l}0.3-150 \\
0.0-90 \\
0.0-98 \\
0.0-15 \\
0.0-200\end{array}$ & $\begin{array}{l}0.1-14 \\
0.0-16 \\
0.0-12 \\
0.0-16 \\
0.0-37\end{array}$ \\
\hline $\begin{array}{l}11 \\
12 \\
13 \\
14 \\
15\end{array}$ & $\begin{array}{l}\text { Arkansas-White-Red } \\
\text { Texas-Gulf } \\
\text { Rio Grande } \\
\text { Upper Colorado } \\
\text { Lower Colorado }\end{array}$ & $\begin{array}{r}10 \\
15 \\
8 \\
7 \\
11\end{array}$ & $\begin{array}{l}0.8-91 \\
0.2-330 \\
0.1-1200 \\
0.1-71 \\
0.3-74\end{array}$ & $\begin{array}{l}0.4-65 \\
0.1-330 \\
0.0-1100 \\
0.1-39 \\
0.0-64\end{array}$ & $\begin{array}{l}0.0-87 \\
0.0-130 \\
0.0-77 \\
0.0-64 \\
0.0-83\end{array}$ & $\begin{array}{l}0.0-16 \\
0.0-29 \\
0.0-5.5 \\
0.0-11 \\
0.0-19\end{array}$ \\
\hline $\begin{array}{l}16 \\
17 \\
18 \\
19 \\
20 \\
21\end{array}$ & $\begin{array}{l}\text { Great Basin } \\
\text { Pacific Northwest } \\
\text { California } \\
\text { Alaska } \\
\text { Hawaii } \\
\text { Caribbean }\end{array}$ & $\begin{array}{r}12 \\
25 \\
11 \\
2 \\
6 \\
2\end{array}$ & $\begin{array}{l}1.7-540 \\
0.2-220 \\
1.9-300 \\
0.2-1.8 \\
0.8-18 \\
0.2-0.6\end{array}$ & $\begin{array}{l}0.8-170 \\
0.1-530 \\
1.1-280 \\
0.2-1.3 \\
0.5-14 \\
0.2-0.5\end{array}$ & $\begin{array}{l}0.2-160 \\
0.0-140 \\
0.1-86 \\
0.2 \\
0.0-100 \\
0.1-0.8\end{array}$ & $\begin{array}{c}0.0-28 \\
0.0-26 \\
0.0-31 \\
0.0 \\
0.0-39 \\
0.0-0.2\end{array}$ \\
\hline
\end{tabular}




\section{Minor Elements}

So-called minor elements are those that commonly occur in relatively small amounts in natural water. They also frequently are called trace metals. Many are of concern because, even in trace quantities, they may be toxic to people, to aquatic plants and animals, or to crops when present in irrigation water.

Eleven minor elements are measured regularly at NASQAN stations-arsenic, cadmium, chromium, cobalt, copper, iron, lead, manganese, mercury, selenium, and zinc. Analyses are performed on unfiltered samples (water sediment mixtures) and on samples that have been filtered through 0.45 micrometer pore-size membrane filters. Concentrations of constituents measured in unfiltered samples are reported as "total" concentrations, and those measured in filtered samples are reported as "dissolved." In a few instances, dissolved values reported for a particular sample exceed reported total values because of the different precisions in the two determinations or non-representative sample-splitting for the analyses.

Data on dissolved constituents approximate what may be in water after it has passed through public-supply treatment plants which use only sedimentation, filtration, and chlorination. Water passing through plants with more extensive treatment where for example it may be softened or filtered through charcoal, may have part of the dissolved substances removed or other substances substituted for the original constituents. Data on total concentrations approximate amounts that may be consumed by livestock, may be in water used for irrigation, or may be taken up by aquatic plants or animals. Under some conditions, such as change of $\mathrm{pH}$ or total ionic balance of the sample, some of the metals present in the undissolved portion of the total concentrations may be converted to the dissolved state.

There are many different sets of standards and criteria for evaluating the suitability of water based upon the concentrations of minor elements. Some of these are summarized in table 4, including: (1) the criteria contained in the 1975 Annual Report of the U.S. Council on Environmental Quality (1975), (2) Water Quality Criteria of the National Academy of Sciences and National Academy of Engineering (1972), (3) criteria recently summarized by the U.S. Environmental Protection Agency (1976a), (4) "National Interim Primary Drinking Water Standards" (U.S. Environmental Protection Agency, 1975), and (5) a summary of criteria for fish and aquatic life based on a literature survey by Wentz (1974). The several criteria for public water supply generally are in close agreement, but the published criteria for aquatic life differ considerably among themselves and from the public-supply criteria. 
Table 4.--Standards and criteria for maximum concentration of minor elements in water

(Concentration in micrograms per liter)

\begin{tabular}{|c|c|c|c|c|c|c|c|c|c|c|c|}
\hline Source & $\begin{array}{l}\text { Ar- } \\
\text { senic } \\
\text { (As) }\end{array}$ & $\begin{array}{l}\text { Cad- } \\
\text { mium } \\
(\mathrm{Cd})\end{array}$ & $\begin{array}{l}\text { Chro- } \\
\text { mium } \\
(\mathrm{Cr})\end{array}$ & $\begin{array}{l}\text { Cobalt } \\
(\mathrm{Co})\end{array}$ & $\begin{array}{l}\text { Copper } \\
(\mathrm{Cu})\end{array}$ & $\begin{array}{l}\text { Iron } \\
(\mathrm{Fe})\end{array}$ & $\begin{array}{l}\text { Lead } \\
(\mathrm{Pb})\end{array}$ & $\begin{array}{c}\text { Man- } \\
\text { ganese } \\
(M n)\end{array}$ & $\begin{array}{l}\text { Mer- } \\
\text { cury } \\
(\mathrm{Hg})\end{array}$ & $\begin{array}{l}\text { Sele- } \\
\text { nium } \\
(\mathrm{Se})\end{array}$ & $\begin{array}{l}\text { Zinc } \\
(Z n)\end{array}$ \\
\hline \multicolumn{12}{|l|}{$\begin{array}{l}\text { U.S. Council on Environmental } \\
\text { Quality (1975) }\end{array}$} \\
\hline Aquatic life & 50 & 4 & - & - & 10 & 300 & 30 & 100 & - & - & 1000 \\
\hline Public water supply & 50 & 10 & - & - & 1000 & 300 & 50 & 50 & - & - & 5000 \\
\hline \multicolumn{12}{|c|}{ Water Quality Criteria 1972 (National } \\
\hline \multicolumn{12}{|c|}{ Academy of Sciences and National } \\
\hline Public water supply sources & $100 \mathrm{a} /$ & 10 & 50 a/ & - & 1000 & 300 b/ & 50 & $50 \mathrm{~b} /$ & 2 a/ & 10 & 5000 \\
\hline Freshwater aquatic life & - & 30 & $50^{-}$ & - & c $/$ & - & 30 & $-{ }^{-}$ & $0.2^{-}$ & - & f/ \\
\hline Marine aquatic life & $\mathrm{d} /$ & cl & $\underline{\mathrm{e}} /$ & - & $\overline{\mathrm{d}} /$ & 300 & 10 & 100 & 0.1 & 10 & $1 \overline{0} 0$ \\
\hline Agriculture, livestock & $2 \overline{0} 0$ & $\overline{50}$ & $10 \overline{0} 0$ & 1000 & $5 \overline{00}$ & $g /$ & 50 & $\mathrm{~g} /$ & 10 & 50 & 25000 \\
\hline Agriculture, irrigation h/ & $100-$ & $10-50$ & $100-$ & $\begin{array}{l}50- \\
5000\end{array}$ & $200-$ & $5000-$ & $\begin{array}{l}5000- \\
10000\end{array}$ & $200-$ & - & 20 & $\begin{array}{l}2000- \\
10000\end{array}$ \\
\hline \multicolumn{12}{|c|}{$\begin{array}{l}\text { U.S. Environmental Protection Agency } \\
\text { (1976a) }\end{array}$} \\
\hline Domestic water supply & 50 & 10 & 50 & - & 1000 & 300 & 50 & 50 & 2 & 10 & 5000 \\
\hline Irrigation & 100 & - & - & - & - & - & - & - & - & - & - \\
\hline Aquatic life & - & $0.4-12$ & 300 & - & $\underline{c} /$ & 1000 & el & 100 & $0.05-0.1$ & ef & e/ \\
\hline \multicolumn{12}{|c|}{$\begin{array}{l}\text { National Interim Primary Drinking Water } \\
\text { Standards (U.S. Environmental }\end{array}$} \\
\hline Protection Agency, 1975) & 50 & 10 & 50 & - & - & - & 50 & - & 2 & 10 & - \\
\hline $\begin{array}{l}\text { Wentz }(1974, \mathrm{p} \cdot 27) \\
\quad \text { Fish and other aquatic life }\end{array}$ & 1000 & 10 & 50 & 500 & $10-20$ & - & $5-10$ & 1050 & 1 & 1000 & $30-70$ \\
\hline
\end{tabular}

a/ Criterion specified for total form.

e/ 0.01 times 96-hr. LC50.

b/ Criterion specified for soluble form.

c/ 0.1 times the median lethal concentration with

a 96-hour test period (96-hr. LC50).

f/ 0.005 times 96-hr. LC50.

g/ No limit needed.

d/ 0.05 times $96-\mathrm{hr}$. LC50.

h/ Range given; specific criteria depend on soil texture and $\mathrm{pH}$. 
Samples for analysis of minor elements are collected about four times per year at most NASQAN stations. Summaries of measured ranges at stations are shown in the bottom part of each summary page in table 14 . For most constituents not enough data were available to compute mean values or construct maps and histograms as was done for major inorganics. Maps and histograms have been constructed only for dissolved arsenic and dissolved zinc.

Tables 5 and 6 summarize ranges of concentrations of total and dissolved minor elements by Water Resources Regions (see fig. 2). In some cases table 6 shows higher ranges for dissolved concentrations of some elements than table 5 shows for total concentrations of that same element in the same particular region. There are two possible explanations for this: (1) analytical and subsampling errors of the types mentioned in a previous paragraph; and (2) samples collected at different times, so that equivalent pairs of data are not presented.

The following paragraphs briefly summarize some of the more obvious patterns in the minor elements data and compare the measured concentrations with some of the common standards and criteria of water quality.

Arsenic.--Average values of dissolved arsenic at NASQAN stations are shown on the map and histogram in figure 17. Average concentrations did not exceed the drinking water standard of $50 \mu \mathrm{g} / \mathrm{L}$ at any of the stations, and indeed, exceeded $5 \mu \mathrm{g} / \mathrm{L}$ at only about 10 percent of the stations. The highest single measured concentration of dissolved arsenic was $65 \mu \mathrm{g} / \mathrm{L}$ in a sample from the Belle Fourche River, S. Dak. As shown on the map in figure 17, the highest concentrations of dissolved arsenic generally were in the Missouri, Great Basin, and Lower Colorado Regions.

Total arsenic concentrations were considerably higher than concentrations of dissolved arsenic in about half of the Water Resources Regions. Samples exceeded the drinking water standard of $50 \mu \mathrm{g} / \mathrm{L}$ in seven regions, mostly in the central and western parts of the country. The highest observed concentration of total arsenic was in the Belle Fourche River, the same stream that had highest dissolved arsenic.

Cadmium.--Measured concentrations of dissolved cadmium exceeded public supply standards and criteria of $10 \mu \mathrm{g} / \mathrm{L}$ at NASQAN stations in the Ohio and Lower Mississippi Regions. A maximum concentration of $23 \mu \mathrm{g} / \mathrm{L}$ was measured in the Kanawha River, W. Va. High values also were observed at two stations on the Mississippi River in January 1975: $190 \mu \mathrm{g} / \mathrm{L}$ in the Mississippi River at Memphis, Tenn., and $14 \mu \mathrm{g} / \mathrm{L}$ in the Mississippi River near Arkansas City, Ark. The highest measured value of total cadmium of $840 \mu \mathrm{g} / \mathrm{L}$ also was found at the Memphis station in January 1975. The identical timing of the high values at the two Mississippi River stations suggests that the river was polluted by a chemical spill. Relatively high values of total cadmium (exceeding some, but not all criteria and standards) also were measured at stations in about half of the Water Resources Regions. 


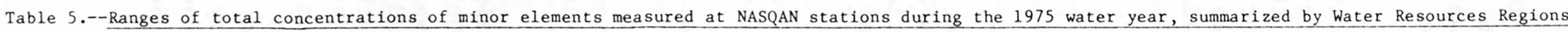
Range of Concentrations (micrograms per liter)

\begin{tabular}{|c|c|c|c|c|c|c|c|c|c|c|c|}
\hline $\begin{array}{c}\text { Region } \\
\text { Number and Name }\end{array}$ & $\begin{array}{l}\text { Arsenic } \\
\text { (As) }\end{array}$ & $\begin{array}{l}\text { Cadmium } \\
\text { (Cd) }\end{array}$ & $\begin{array}{l}\text { Chromium } \\
\quad(\mathrm{Cr})\end{array}$ & $\begin{array}{l}\text { Cobalt } \\
(\mathrm{Co})\end{array}$ & $\begin{array}{l}\text { Copper } \\
(\mathrm{Cu})\end{array}$ & $\begin{array}{l}\text { Iron } \\
(\mathrm{Fe})\end{array}$ & $\begin{array}{l}\text { Lead } \\
(\mathrm{Pb})\end{array}$ & $\begin{array}{l}\text { Manganese } \\
\text { (Mn) }\end{array}$ & $\begin{array}{l}\text { Mercury } \\
(\mathrm{Hg})\end{array}$ & $\begin{array}{l}\text { Selenium } \\
(\mathrm{Se})\end{array}$ & $\begin{array}{l}\text { Zinc } \\
(Z n)\end{array}$ \\
\hline 01 New England & $0.0-2$ & $0.0-18$ & $0.0-70$ & $0.0-2$ & $0.0-30$ & $110-920$ & $0.0-100$ & $10-130$ & $0.0-1.1$ & $0.0-2$ & $0.0-150$ \\
\hline 02 Mid-Atlantic & $.0-9$ & $.0-1$ & $.0-70$ & $.0-8$ & $.0-30$ & $60-19000$ & $.0-57$ & $10-880$ & $.1-1.3$ & $.0-1$ & $.0-190$ \\
\hline 03 South Atlantic-Gulf & $.0-50$ & $.0-50$ & $.0-50$ & $.0-100$ & $.0-40$ & $60-5500$ & $.0-100$ & $.0-370$ & $.0-2.2$ & $.0-3$ & $.0-440$ \\
\hline 04 Great Lakes & $.0-11$ & $.0-20$ & $.0-20$ & $.0-50$ & $.0-170$ & $20-10000$ & $.0-100$ & $.0-530$ & $.0-1.1$ & $.0-3$ & $4-320$ \\
\hline 05 Ohio & $.0-6$ & $.0-22$ & $.0-20$ & $.0-20$ & $.0-110$ & $70-7900$ & $.0-250$ & $20-12000$ & $.0-1.2$ & $.0-3$ & $.0-600$ \\
\hline 06 Tennessee & $.0-5$ & $.0-13$ & $.0-10$ & $.0-10$ & $3-40$ & $60-1300$ & $2-130$ & $10-130$ & $.0-0.9$ & $.0-2$ & $10-80$ \\
\hline 07 Upper Mississippi & $.0-31$ & $.0-20$ & $.0-40$ & $.0-100$ & $.0-460$ & $260-15000$ & $1-200$ & $10-1900$ & $.0-2.1$ & $.0-3$ & $10-380$ \\
\hline 08 Lower Mississippi & $.0-14$ & $.0-840$ & $.0-160$ & $.0-50$ & $.0-120$ & $620-20000$ & $.0-200$ & $40-610$ & $.0-0.5$ & $.0-4$ & $.0-230$ \\
\hline 09 Souris-Red-Rainy & $.0-10$ & $<10-20$ & $.0-20$ & $.0-50$ & $<10-60$ & $140-4800$ & $<100-200$ & $.0-420$ & $.0-0.6$ & $.0-2$ & $6-110$ \\
\hline 10 Missouri Basin & $.0-2300$ & $.0-40$ & $.0-250$ & $.0-300$ & $.0-610$ & $.0-410000$ & $1-600$ & $.0-11000$ & $.0-11$ & $.0-5$ & $.0-1900$ \\
\hline 11 Arkansas-White-Red & $.0-240$ & $.0-40$ & $.0-290$ & $.0-350$ & $2-550$ & $20-180000$ & $.0-400$ & $.0-3000$ & $.0-1$ & $.0-34$ & $.0-870$ \\
\hline 12 Texas Gulf & $.0-200$ & $<10-50$ & $.0-120$ & $50-450$ & $<10-180$ & $.0-78000$ & $<100-200$ & $.0-6100$ & $.0-1.2$ & $.0-8$ & $.0-710$ \\
\hline 13 Rio Grande & $.0-140$ & $.0-30$ & $.0-150$ & $.0-300$ & $<10-210$ & $.0-200000$ & $<100-500$ & $20-5600$ & $.0-1.7$ & $.0-7$ & $.0-920$ \\
\hline 14 Upper Colorado & $.0-56$ & $<10-20$ & $.0-140$ & $.0-100$ & $<10-1400$ & $50-130000$ & $<100-200$ & $.0-3600$ & $.0-0.6$ & $.0-21$ & $20-690$ \\
\hline 15 Lower Colorado & $1-110$ & $<10-20$ & $.0-90$ & $.0-100$ & $<10-480$ & $.0-88000$ & $<100-300$ & $.0-5000$ & $.0-0.8$ & $.0-14$ & $.0-470$ \\
\hline 16 Great Basin & $.0-50$ & $.0-40$ & $.0-20$ & $.0-50$ & $.0-270$ & $10-44000$ & $<100-300$ & $.0-2000$ & $.0-2.6$ & $.0-4$ & $.0-580$ \\
\hline 17 Pacific Northwest & $.0-20$ & $.0-20$ & $.0-10$ & $.0-50$ & $.0-2300$ & $.0-11000$ & $<100$ & $.0-1600$ & $.0-1.5$ & $.0-4$ & $.0-360$ \\
\hline 18 California & $.0-220$ & $.0-30$ & $.0-1100$ & $.0-450$ & $.0-4500$ & $80-20000$ & $<100-300$ & $.0-1100$ & $.0-1.1$ & $.0-4$ & $.0-1600$ \\
\hline 19 Alaska & $.0-11$ & $<10$ & $.0-20$ & $<50$ & $10-140$ & $.0-16000$ & $<100$ & $.0-320$ & $.0-2.2$ & $.0-1$ & $10-90$ \\
\hline 20 Hawaii & $.0-10$ & $<10$ & $.0-60$ & $.0-100$ & $.0-1000$ & $60-8600$ & $<100-200$ & $.0-210$ & $.0-0.9$ & $.0-2$ & $10-110$ \\
\hline 21 Caribbean & $.0-2$ & $.0-20$ & $<10$ & $.0-7$ & $.0-29$ & $50-8500$ & $.0-15$ & $.0-500$ & $.0-0.3$ & .0 & $.0-170$ \\
\hline
\end{tabular}


Table 6.--Ranges of concentrations of dissolved minor elements measured at NASQAN stations during the 1975 water year, summarized by Water Resources $\underline{\text { Regions }}$

Range of Concentrations (micrograms per liter)

\begin{tabular}{|c|c|c|c|c|c|c|c|c|c|c|c|c|}
\hline Numb & $\begin{array}{l}\text { Region } \\
\text { aber and Name }\end{array}$ & $\begin{array}{l}\text { Arsenic } \\
\text { (As) }\end{array}$ & $\begin{array}{l}\text { Cadmium } \\
\text { (Cd) }\end{array}$ & $\begin{array}{l}\text { Chromium } \\
\text { (Cr) }\end{array}$ & $\begin{array}{l}\text { Cobalt } \\
(\mathrm{Co})\end{array}$ & $\begin{array}{c}\text { Copper } \\
(\mathrm{Cu})\end{array}$ & $\begin{array}{l}\text { Iron } \\
(\mathrm{Fe})\end{array}$ & $\begin{array}{l}\text { Lead } \\
(\mathrm{Pb})\end{array}$ & $\begin{array}{l}\text { Manganese } \\
\text { (Mn) }\end{array}$ & $\begin{array}{l}\text { Mercury } \\
(\mathrm{Hg})\end{array}$ & $\begin{array}{l}\text { Selenium } \\
\quad(\mathrm{Se})\end{array}$ & $\begin{array}{l}\text { Zinc } \\
(Z n)\end{array}$ \\
\hline $01 \mathrm{~s}$ & New England & $0.0-3$ & $0.0-10$ & $0.0-20$ & $0.0-2$ & $0.0-20$ & $20-380$ & $0.0-45$ & $0.0-160$ & 0.5 & $0.0-1$ & $0.0-40$ \\
\hline $02 \mathrm{r}$ & Mid Atlantic & $.0-3$ & $.0-5$ & $.0-70$ & $.0-5$ & $.0-30$ & $.0-1200$ & $.0-42$ & $.0-390$ & $.0-1.3$ & $.0-2$ & $.0-130$ \\
\hline 03 & South Atlantic-Gulf & $.0-3$ & $.0-7$ & $.0-11$ & $.0-9$ & $.0-18$ & $.0-1600$ & $.0-73$ & $.0-210$ & $.0-2.0$ & $.0-1$ & $.0-100$ \\
\hline 04 & Great Lakes & $.0-5$ & $.0-5$ & $.0-20$ & $.0-5$ & $.0-24$ & $.0-1100$ & $.0-35$ & $.0-150$ & $.0-1.1$ & $.0-3$ & $.0-80$ \\
\hline 05 & Ohio & $.0-5$ & $.0-23$ & $.0-10$ & $.0-8$ & $.0-100$ & $.0-1600$ & $.0-34$ & $.0-580$ & $.0-0.5$ & $.0-2$ & $.0-260$ \\
\hline 06 & Tennessee & $.0-2$ & $.0-2$ & $.0-1$ & $.0-5$ & $1-8$ & $.0-110$ & $.0-9$ & $.0-50$ & $.0-0.3$ & .0 & $.0-40$ \\
\hline 07 & Upper Mississippi & $.0-5$ & $.0-5$ & $.0-10$ & $.0-7$ & $.0-20$ & $.0-2200$ & $.0-38$ & $.0-1200$ & $.0-1.2$ & $.0-3$ & $.0-190$ \\
\hline 08 & Lower Mississippi & $.0-4$ & $.0-190$ & $.0-10$ & $.0-3$ & $.0-25$ & $.0-870$ & $.0-10$ & $.0-450$ & $.0-0.5$ & $.0-2$ & $.0-90$ \\
\hline 09 & Souris-Red-Rainy & $.0-7$ & $.0-2$ & $.0-10$ & $.0-4$ & $.0-13$ & $10-480$ & $.0-6$ & $.0-420$ & $.0-0.2$ & $.0-2$ & $.0-30$ \\
\hline 10 & Missouri Basin & $.0-65$ & $.0-8$ & $.0-40$ & $.0-10$ & $.0-320$ & $.0-7800$ & $.0-16$ & $.0-1500$ & $.0-9.0$ & $.0-6$ & $.0-360$ \\
\hline 11 & Arkansas-White-Red & $.0-10$ & $.0-8$ & $.0-20$ & $.0-3$ & $.0-80$ & $.0-6700$ & $.0-50$ & $.0-810$ & $.0-8 \cdot 2$ & $.0-25$ & $.0-460$ \\
\hline 12 & Texas-Gulf & $.0-17$ & $.0-1$ & $.0-30$ & $.0-4$ & $.0-8$ & $.0-1100$ & $.0-34$ & $.0-770$ & $.0-0.3$ & $.0-7$ & $.0-210$ \\
\hline 13 & Rio Grande & $.0-13$ & $.0-1$ & $.0-20$ & $.0-3$ & $.0-12$ & $.0-3400$ & $.0-20$ & $.0-730$ & $.0-1.0$ & $.0-2$ & $.0-60$ \\
\hline 14 & Upper Colorado & $.0-18$ & $.0-2$ & $.0-40$ & $.0-20$ & $1-46$ & $.0-3700$ & $.0-23$ & $.0-150$ & $.0-0.6$ & $.0-16$ & $.0-70$ \\
\hline 15 & Lower Colorado & $.0-20$ & $.0-3$ & $.0-20$ & $.0-4$ & $.0-35$ & $.0-220$ & $.0-12$ & $.0-1100$ & $.0-0.4$ & $.0-13$ & $.0-70$ \\
\hline 16 & Great Basin & $.0-48$ & $.0-1$ & $.0-20$ & $.0-4$ & $.0-11$ & $10-590$ & $.0-6$ & $.0-290$ & $.0-1.8$ & $.0-4$ & $.0-40$ \\
\hline 17 & Pacific Northwest & $.0-11$ & $.0-10$ & $.0-40$ & $.0-3$ & $.0-30$ & $.0-620$ & $.0-43$ & $.0-60$ & $.0-0.3$ & $.0-1$ & $.0-300$ \\
\hline 18 & California & $.0-32$ & $.0-3$ & $.0-40$ & $.0-3$ & $.0-80$ & $.0-1100$ & $.0-48$ & $.0-280$ & $.0-1.6$ & $.0-4$ & $.0-150$ \\
\hline 19 & Alaska & $.0-4$ & $.0-1$ & $.0-30$ & $.0-2$ & $1-10$ & $.0-1200$ & $.0-10$ & $.0-80$ & $.0-1.8$ & $.0-1$ & $.0-80$ \\
\hline 20 & Hawaii & $.0-8$ & $.0-1$ & $.0-10$ & $.0-4$ & $.0-5$ & $.0-260$ & $.0-11$ & $.0-70$ & $.0-0.2$ & $.0-1$ & $.0-20$ \\
\hline 21 & Caribbean & $.0-1$ & $.0-5$ & $.0-1$ & $.0-4$ & $.0-34$ & $.0-2400$ & $.0-17$ & $.0-360$ & $.0-0.3$ & .0 & $.0-40$ \\
\hline
\end{tabular}




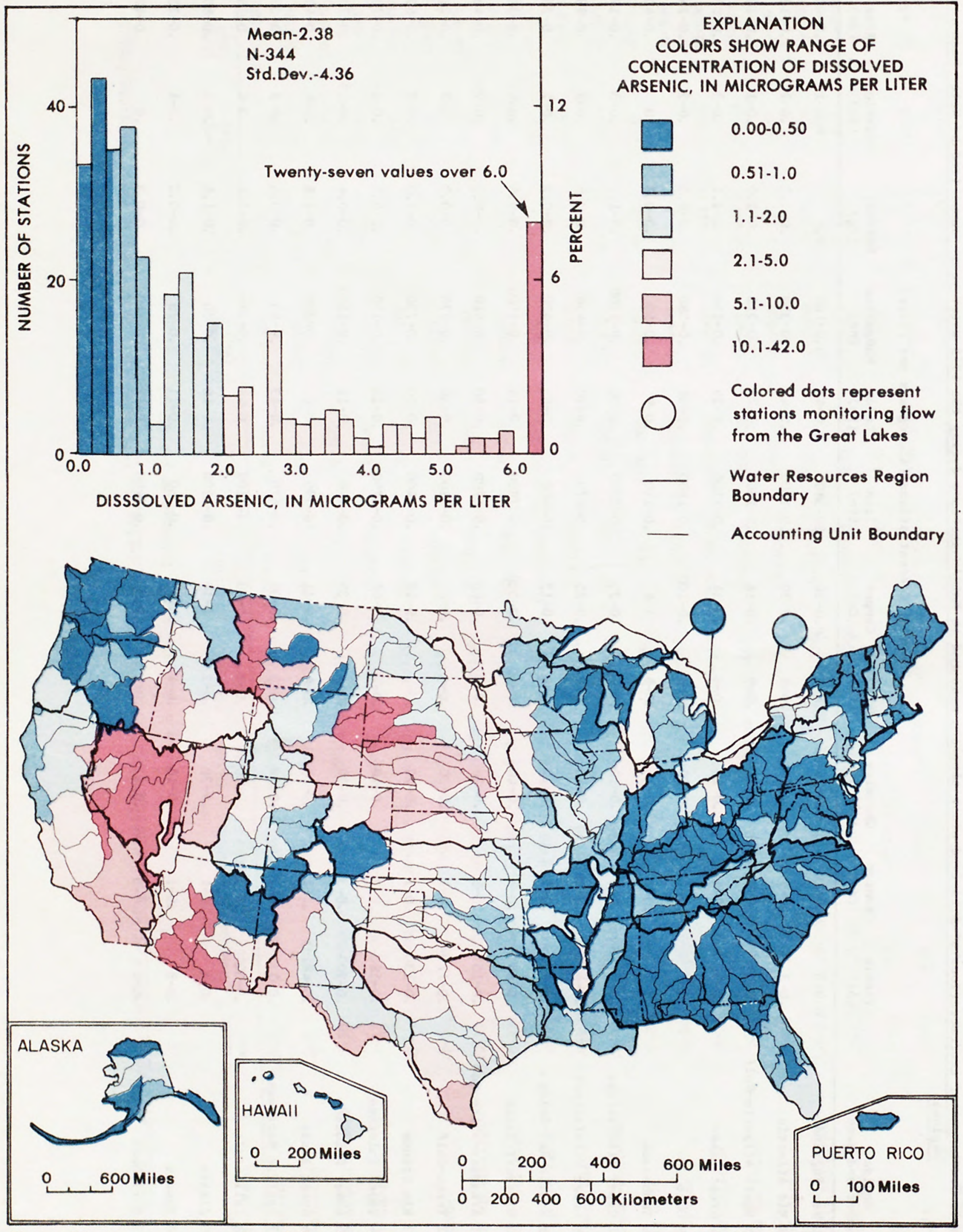

Figure 17.--Mean concentration of dissolved arsenic at NASQAN stations during 1975 water year. Map at bottom is colored to show station data representing flow from the accounting unit. 
Chromium.--The common public water supply and aquatic life standards of $50 \mu \mathrm{g} / \mathrm{L}$ for chromium were exceeded by the concentration of dissolved chromium in only one sample, which was from the Delaware River at Trenton, N. J. Dissolved and total concentrations of that sample were $70 \mu \mathrm{g} / \mathrm{L}$, and the one time occurrence suggests that it may have resulted from a chemical spill which persisted for only a short time. Concentrations of total chromium, however, were above the $50 \mu \mathrm{g} / \mathrm{L}$ standard at stations in 12 of the 21 Water Resources Regions.

Cobalt.--Data on cobalt showed concentrations below most established standards and criteria at most NASQAN stations. Even the maximum measured values of total cobalt of $450 \mu \mathrm{g} / \mathrm{L}$ were below standards and criteria for livestock and aquatic life shown in table 4. The most stringent criterion of $50 \mu \mathrm{g} / \mathrm{L}$ for irrigation, as suggested by the National Academy of Sciences and National Academy of Engineering (1972), was exceeded by concentrations of total cobalt in 10 Water Resources Regions.

Copper.--The criterion for copper in public water supplies $(1,000 \mu \mathrm{g} / \mathrm{L})$ is high compared with the amounts found in most waters and was not exceeded by measured dissolved concentrations at any NASQAN station. Total copper, on the other hand, exceeded the $1,000 \mu \mathrm{g} / \mathrm{L}$ criterion in four Water Resources Regions. Some authors have suggested much more stringent criteria (10 to $20 \mu \mathrm{g} / \mathrm{L}$ ) for aquatic life, however. These more stringent criteria were exceeded by measured values of dissolved copper in about half of the Water Resources Regions, and by some measured total concentrations in all of the Regions.

Iron.--Concentrations of iron measured at NASQAN stations frequently exceed water-quality criteria. The common criterion for public supply of $300 \mu \mathrm{g} / \mathrm{L}$ was exceeded by dissolved iron levels in all except three of the Water Resources Regions, Tennessee, Lower Colorado, and Hawaii, and by measured total concentrations in all of them. The highest measured values of both dissolved and total iron were in the Missouri Region.

Lead.--Standards and criteria for lead in public water supplies of $\overline{50 \mu} \mathrm{g} / \mathrm{L}$ were exceeded by the dissolved concentration at stations in the South Atlantic-Gulf and the Arkansas-White-Red Regions. Total concentration exceeded $50 \mu \mathrm{g} / \mathrm{L}$ in all of the regions except the Caribbean. The more stringent criteria for aquatic life of $30 \mu \mathrm{g} / \mathrm{L}$ was exceeded by the dissolved concentration in 10 of the 21 regions.

There is a problem in interpreting some of the data on total lead because of interferences in the analytical methods. It is necessary, therefore, to report some values as "less than 100." The true value is not known and it is impossible to interpret if the standards in the range of 5 to $50 \mu \mathrm{g} / \mathrm{L}$ were exceeded. 
Manganese.--Criteria for manganese in public supplies (usually $50 \mu \mathrm{g} / \mathrm{L}$ ) are set to avoid consumer complaints about the brownish staining of laundry and the objectionable tastes in beverages associated with higher concentrations. Criteria were equaled or exceeded by dissolved and total levels in all of the Water Resources Regions. Criteria for aquatic life are much more lenient (from 100 to $1,000 \mu \mathrm{g} / \mathrm{L}$ ), but even these higher values were exceeded by concentrations of dissolved and total manganese in the Upper Mississippi, Missouri, and Lower Colorado Regions, and by total concentrations in the Ohio, Arkansas-White-Red, Texas-Gulf, Rio Grande, Upper Colorado, Great Basin, Pacific Northwest, and California Regions. In general, lowest concentrations of manganese are in the Tennessee, Alaska, and Hawaii Regions.

Mercury.--Ten of the NASQAN samples analyzed for dissolved and total $\overline{\text { mercury }}$ exceeded the common public water supply standard of $2 \mu \mathrm{g} / \mathrm{L}$, but only four of the ten were more than $2.6 \mu \mathrm{g} / \mathrm{L}$. Total mercury of $11 \mu \mathrm{g} / \mathrm{L}$ and dissolved mercury of $9 \mu \mathrm{g} / \mathrm{L}$ were measured in samples taken from the Milk River in Montana. A maximum dissolved mercury concentration of 4.6 $\mu \mathrm{g} / \mathrm{L}$ was determined in the Yellowstone River in Montana, and a maximum dissolved mercury of $8.2 \mu \mathrm{g} / \mathrm{L}$ was found in the Arkansas River in Oklahoma. The high samples from these three rivers, however, appear to be anomalous-other samples during the year from the same streams were less than $1 \mu \mathrm{g} / \mathrm{L}$. Criteria for mercury for the protection of aquatic life are highly variable--some authors suggest criteria as 1 ow as 0.05 to $0.2 \mu \mathrm{g} / \mathrm{L}$. These stringent criteria were exceeded by measured mercury levels at NASQAN stations in most regions of the United States.

Selenium.--NASQAN stations in the Arkansas-White-Red and Upper and Lower Colorado Regions reported dissolved and total selenium values greater than the common public supply and aquatic life standard of $10 \mu \mathrm{g} / \mathrm{L}$; values in the other regions were less than $10 \mu \mathrm{g} / \mathrm{L}$. In evaluating the selenium data, however, it should be noted that Wentz (1974), based on a literature survey, proposed an aquatic life criterion of $1,000 \mu \mathrm{g} / \mathrm{L}$, a value higher than those measured at any of the NASQAN stations. The highest reported concentration at any NASQAN station was $34 \mu \mathrm{g} / \mathrm{L}$ total selenium for the Arkansas River at Dodge City, Kans.

Zinc.--In addition to the data on maximum and minimum concentrations of zinc given in tables 5 and 6 , a summary of mean concentrations is shown on the histogram and map that make up figure 18. As illustrated by the data summarized in tables 5 and 6 and on figure 18, the common standard for zinc in public water supply of 5,000 $\mu \mathrm{g} / \mathrm{L}$ was not exceeded by any measured values of total or dissolved concentrations at NASQAN stations. On the other hand, the much more stringent criteria for aquatic life of 30-70 or $100 \mu \mathrm{g} / \mathrm{L}$ were exceeded by dissolved concentrations in all but two of the Water Resources Regions, and by some values of total concentrations in all of the 21 regions. Mean values of dissolved zinc at NASQAN stations were not quite so high, however; the histogram on figure 18 shows about 80 percent of the mean values as less than $30 \mu \mathrm{g} / \mathrm{L}$. Generally, zinc concentrations in streams were higher in the western half of the country than in the East, and were highest in the Missouri Basin and Arkansas-White-Red Regions. 


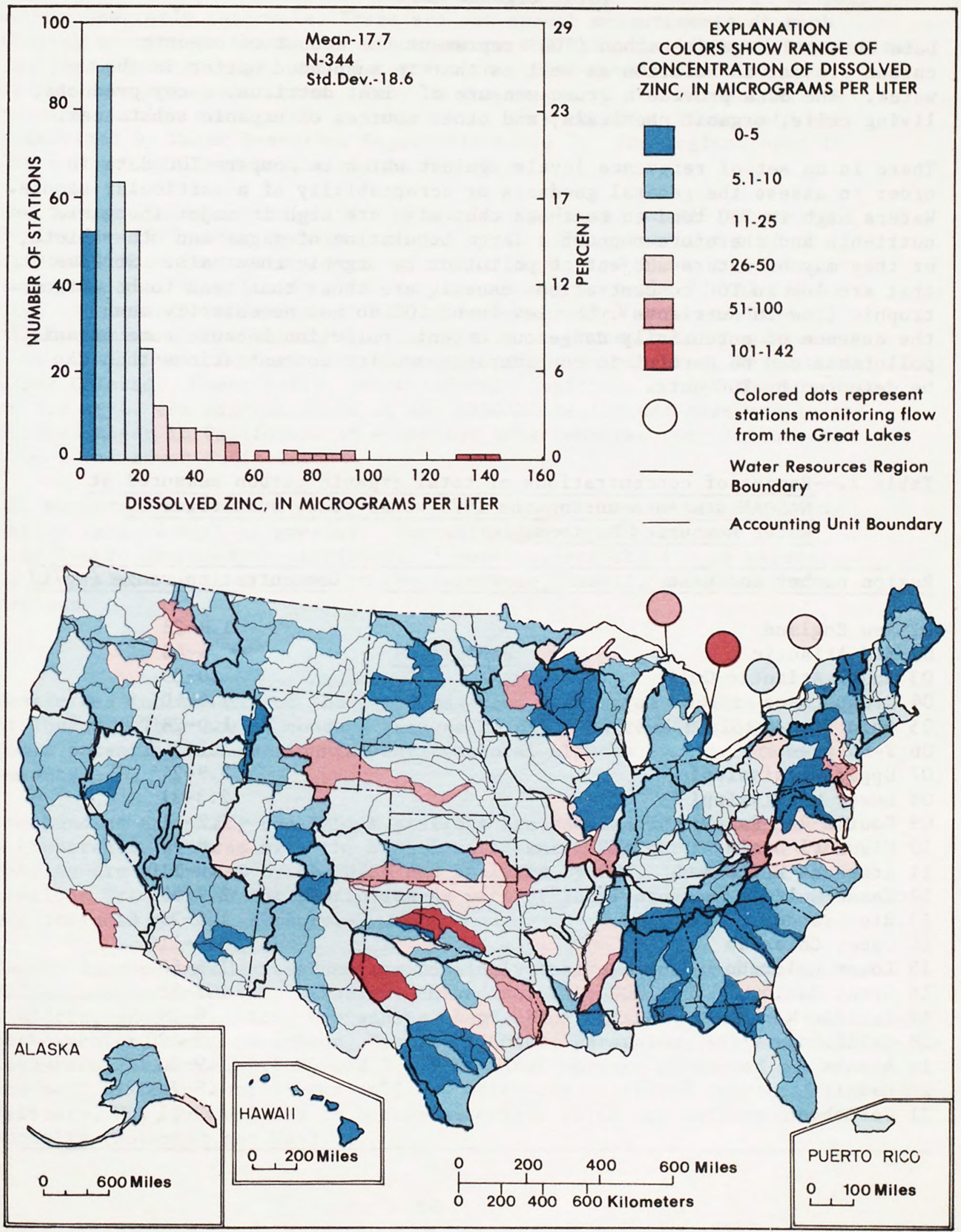

Figure 18.--Mean concentration of dissolved zinc at NASQAN stations during 1975 water year. Map at bottom is colored to show station data representing flow from the accounting unit. 


\section{Total Organic Carbon}

Data on total organic carbon (TOC) represent the amount of organic carbon present in solution as well as that in suspended matter in the water. The data provide a gross measure of plant detritus, decay products, living cells, organic chemicals, and other sources of organic substances.

There is no set of reference levels against which to compare TOC data in order to assess the general goodness or acceptability of a particular sample. Waters high in TOC tend to be those that also are high in major inorganic nutrients and therefore support a large population of algae and other biota, or they may be waters subject to pollution by organic chemicals. Streams that are low in TOC concentrations usually are those that tend to be oligotrophic (low in nutrients). Low levels of TOC do not necessarily mean the absence of potentially dangerous organic pollution because some organic pollutants can be harmful in considerably smaller concentrations than can be detected by TOC data.

Table 7.--Ranges of concentrations of total organic carbon measured at NASQAN stations during the 1975 water year, summarized by Water Resources Regions

Region number and name Concentration range (mg/L)

01 New England

02 Mid Atlantic

03 South Atlantic-Gulf

04 Great Lakes

05 Ohio

06 Tennessee

07 Upper Mississippi

08 Lower Mississippi

09 Souris-Red-Rainy

10 Missouri Basin

11 Arkansas-White-Red

$1.8-28$

$.4-48$

$.0-35$

$1.6-40$

$1.0-28$

$1.2-5.7$

$3.9-24$

$2.3-31$

$1.2-41$

$.8-78$

$.6-110$

12 Texas-Gulf

$2.7-59$

13 Rio Grande

$1.6-25$

14 Upper Colorado

3.0-110

15 Lower Colorado

$1.5-50$

16 Great Basin

$1.1-55$

17 Pacific Northwest

$.0-28$

18 California

$1.3-320$

19 Alaska

$.9-30$

20 Hawaii

$.8-7.1$

21 Caribbean

$.9-11$ 
Samples for analyses of TOC at NASQAN stations were collected at approximately quarterly intervals. There are not enough measurements at each station to compute meaningful annual means and make the kinds of statistical analyses, summary maps, and histograms that were constructed for many of the inorganic substances. Data on the ranges of TOC concentrations at each station are listed in table 14 of this report. These data are summarized by Water Resources Regions in table 7. The regions used in table 7 are outlined on the map in figure 2 .

The median concentration of TOC in samples collected at NASQAN stations during the 1975 water year was about $6 \mathrm{mg} / \mathrm{L}$. About one-fourth of the samples had concentrations greater than $11 \mathrm{mg} / \mathrm{L}$, and about one-fourth were less than $4 \mathrm{mg} / \mathrm{L}$. As shown in the summary in table 7 , relatively high concentrations (values in the highest quartile) were measured in all but three of the Water Resources Regions. Concentrations greater than $50 \mathrm{mg} / \mathrm{L}$ were found in the Missouri, Arkansas-White-Red, Texas-Gulf, Upper Colorado, Great Basin, and California Regions. A high concentration of $320 \mathrm{mg} / \mathrm{L}$, the highest found at any NASQAN station was measured in the Salinas River in California at a station that measures some influences from local sewer outfalls.

All measured concentrations of TOC at stations in the Souris-Red-Rainy Region were $12 \mathrm{mg} / \mathrm{L}$ or greater. Concentrations of TOC of less than $1 \mathrm{mg} / \mathrm{L}$ were measured at stations in 7 regions, and the lowest values, in general, were at stations in the Tennessee, Hawaii, and Caribbean Regions.

\section{Pesticides}

Pesticides include all of the compounds used to control insects, weeds, or fungus. They are of concern because of their extreme toxicity and their potential for detrimental environmental effects even in trace amounts.

One hundred and fifty-one NASQAN stations are sampled for pesticides in a cooperative program with the U.S. Environmental Protection Agency (EPA). Samples are collected by the USGS and analyzed by EPA. Additional NASQAN stations are sampled for pesticides as part of local programs. These results are included in this summary.

Twenty-four pesticide residues are routinely analyzed for at the selected NASQAN stations--aldrin, atrazine, chlordane, DDD, DDE, DDT, Diazinon, dieldrin, endrin, ethion, heptachlor, heptachlor epoxide, lindane, malathion, methoxychlor, methy parathion, Methyl Trithion, parathion, silvex, simazine, toxaphene, Trithion, 2,4-D, and 2,4,5-T. Analyses are performed on watersediment mixtures (unfiltered samples) which are collected quarterly (November, February, May, August) and on bottom materials which are collected semiannually (November and May). 
Table 8 summarizes the pesticide residues which were found in samples of water-sediment mixtures during the 1975 water year. The number of NASQAN stations within a region in which a particular pesticide was found and the maximum concentration of that pesticide are listed by Water Resources Region (fig. 2). Recommended or mandatory limits which have been set for some of the pesticides are listed at the bottom of the table.

The Lower Mississippi, Arkansas-White-Red, Texas-Gulf, and California Regions have higher incidents of pesticide occurrence and higher maximum concentrations than the rest of the United States. The highest concentration of any pesticide in a water-sediment sample was $0.50 \mu \mathrm{g} / \mathrm{L}$ of $2,4-\mathrm{D}$ in the Red River above Shreveport, La. This value is still below the maximum allowed for domestic water supplies. No sample collected contained pesticides in concentrations exceeding the mandatory limits for domestic water supplies. Recommended limits for aquatic-life protection were exceeded for chlordane, DDT, dieldrin, endrin, heptachlor epoxide, and lindane.

Table 9 summarizes the maximum concentrations of pesticides detected in bottom materials. Since pesticides may be associated with silt, clay, and organic matter, samples of bottom materials of a stream of ten contain higher concentrations of a pesticide than a sample of water-sediment mixture collected from the flowing stream at the same time. Most pesticide values shown in table 9 are considerably higher than the values for the water-sediment mixtures. Pesticides were found in bottom materials but not in water sediment mixtures in the New England, Great Lakes, SourisRed-Rainy, Rio Grande, Upper Colorado, Pacific Northwest, and Caribbean Regions.

Highest values occurred in bottom materials in the Pacific Northwest in the Snake River at Nyssa, Oreg. No pesticides were found in the water-sediment mixture collected at the same time as the bottom-material sample. A bottom-material sample for the same station collected six months later still had pesticides present but in much smaller concentrations (for dieldrin, $0.1 \mu \mathrm{g} / \mathrm{L}$ compared to $1,890 \mu \mathrm{g} / \mathrm{L}$ ).

\section{Radioactive Substances}

Radioactive substances are of concern because the effects of radioactivity, from any source, are generally considered to be harmful to health. Even though people are constantly exposed to natural radioactivity, they should avoid additional exposure to radioactive substances. Radioactive substances may occur naturally or be man-made. Naturally occurring isotopes include the uranium isotopes, radium-226, radium-228, radon, potassium-40, tritium, and carbon-14. Artificial or man-made isotopes include strontium-90, cesium-137, plutonium-239, and some of the isotopes which also occur natura11y. 
Table 8.--Maximum concentrations of pesticides in a water-sediment sample at which pesticide was detected at NASQAN stations during the 1975 water year, summarized by Water Resources Regions

Number of stations in region at which pesticide was detected / maximum concentrations in micrograms per liter

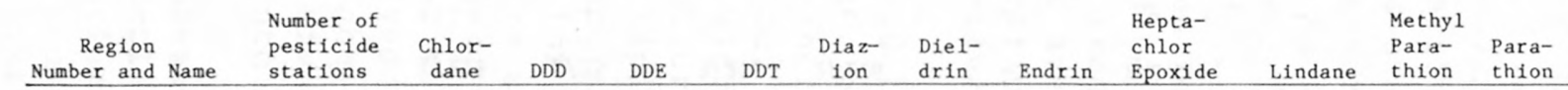

01 New England

stations

02 Mid Atlantic

03 South Atlantic-Gulf 18

04 Great Lakes

05 Ohio

06 Tennessee

07 Upper Mississippi

08 Lower Mississippi

09 Souris-Red-Rainy

10 Missouri Basin 20

Arkansas-White-Red

12 Texas Gulf

13 Rio Grande

14 Upper Colorado

15 Lower Colorado

16 Great Basin

17 Pacific Northwest

18 California

19 Alaska

20 Hawaii

21 Caribbean

Recommended maximum

concentration for

aquatic life protection a/

Maximum allowable

oncentration for

domestic water supply b/

a/ U.S. Environmental Protection Agency (1976a).

b/ U.S. Environmental Protection Agency (1975) maximum allowable for domestic water supply.

f Value for Heptachlor. 
Table 9.--Maximum concentrations of pesticides in bottom materials at which pesticide was detected at NASQAN stations during the 1975 water year, summarized by Water Resources Regions

Number of Stations in region at which pesticide was detected / maximum concentrations in micrograms per kilogram

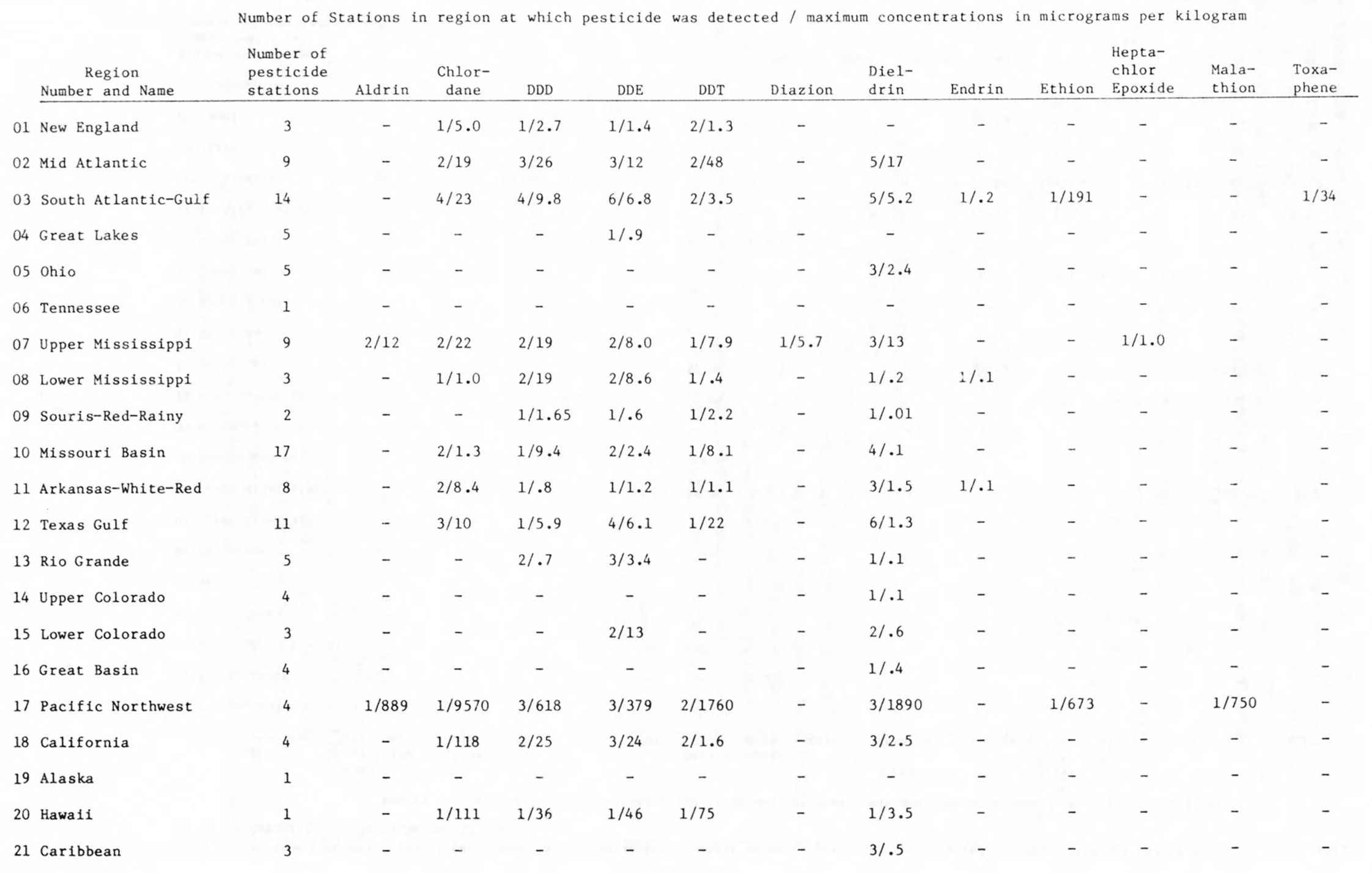


Measurements of gross alpha-radioactivity (reported as natural uranium), gross beta-radioactivity (reported as cesium-137 and also as strontium90/yttrium-90 equilibrium mixture), uranium, and radium-226 have been

made at fifty NASQAN sations. Samples are collected twice a year, once during high flow, the other during low flow, and analyses are made on both the dissolved and suspended material.

Under provisions of the Safe Drinking Water Act, the U.S. Environmental Protection Agency (1976) has set maximum contaminant levels for radium-226, radium-228, and gross alpha-radioactivity; and for beta- and photonradioactivity from man-made radionuclides in community water systems. Water from a system is assumed to be in compliance for alpha-radioactivity if the measured gross alpha-radioactivity does not exceed 5 picocuries per liter $(\mathrm{pCi} / \mathrm{L})$. If the $5 \mathrm{pCi} / \mathrm{L}$ limit is exceeded, the water should be analyzed for radium-226. If radium-226 exceeds $3 \mathrm{pCi} / \mathrm{L}$, the sample should be analyzed for radium-228 and the total radioactivity of radium226 and radium-228 should not exceed 5 pCi/L. Gross alpha-radioactivity excluding radon and all isotopes of uranium should not exceed $15 \mathrm{pCi} / \mathrm{L}$. Water from a system is assumed to be in compliance for beta-radioactivity if the average annual gross beta-radioactivity is less than $50 \mathrm{pCi} / \mathrm{L}$ and tritium and strontium-90 do not exceed $20,000 \mathrm{pCi} / \mathrm{L}$ and $8 \mathrm{pCi} / \mathrm{L}$ respectively.

Table 10 lists the ranges in radiochemical measurements made on samples from the 50 NASQAN sites in the 1975 water year. Radioactive substances were generally higher west of the Mississippi River with the Missouri, Arkansas, Rio Grande, and Colorado Regions having the highest values. Gross alpha-radioactivity is reported as micrograms per liter of natural uranium. To convert this value to picocuries per liter it may be multiplied by $0.68 \mathrm{pCi} / \mu \mathrm{g}$ if the isotopic composition is assumed to be the same as natural uranium. In order to be within the maximum limit of 5 pCi/L for gross alpha radiation in the dissolved phase, the weight-equivalent activity should not exceed $7.4 \mu \mathrm{g} / \mathrm{L}$. Of the 18 regions having radiochemical analyses, 9 had dissolved gross alpha-radiation values above $7.4 \mu \mathrm{g} / \mathrm{L}$. The highest value, $150 \mu \mathrm{g} / \mathrm{L}$, was in the South Platte River near Julesburg, Colo. Dissolved radium-226, however, did not exceed $3 \mathrm{pCi} / \mathrm{L}$ at any site. In fact, the highest value for radium-226 was $0.71 \mu \mathrm{g} / \mathrm{L}$ at the Cumberland River near Grand Rivers, Ky. The highest natural uranium value, $53 \mu \mathrm{g} / \mathrm{L}$, was also from the South Platte River at Julesburg, Colo.

Gross beta-radioactivity is reported two ways; the first using a cesium-137 calibration standard, the other using a standard of strontium-90/ yttrium-90 equalbrium mixture. The screening method in the EPA standards specifies the cesium-137 calibration standard. No NASQAN station exceeded the dissolved phase limit of $50 \mathrm{pCi} / \mathrm{L}$. The highest value measured was $42 \mathrm{pCi} / \mathrm{L}$ at the South Platte River near Julesburg, Colo. No analyses were made for tritium and strontium-90. 


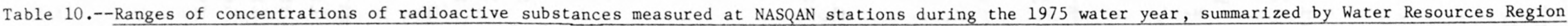

\begin{tabular}{|c|c|c|c|c|c|c|c|c|c|c|}
\hline & $\begin{array}{c}\text { Region } \\
\text { Number and Name }\end{array}$ & $\begin{array}{l}\text { Number } \\
\text { of } \\
\text { Stations }\end{array}$ & $\begin{array}{c}\text { Alpha, gross } \\
\text { dissolved as } \\
\text { U Natural } \\
\mu \mathrm{g} / \mathrm{L}\end{array}$ & $\begin{array}{c}\text { Alpha, gross } \\
\text { suspended as } \\
\text { U Natural } \\
\mu g / L\end{array}$ & $\begin{array}{l}\text { Radium-266 } \\
\text { dissolved } \\
\text { radon method } \\
\text { pCi/L }\end{array}$ & $\begin{array}{c}\text { Natural } \\
\text { Uranium } \\
\text { dissolved } \\
\mu \mathrm{g} / \mathrm{L}\end{array}$ & $\begin{array}{l}\text { Beta, gross } \\
\text { dissolved as } \\
\text { CS-137 pCi/L }\end{array}$ & $\begin{array}{r}\text { Beta, gross } \\
\text { suspended a } \\
\mathrm{CS}-137 \mathrm{pCi} / \mathrm{L}\end{array}$ & $\begin{array}{l}\text { Beta, gross } \\
\text { dissolved as } \\
\text { yttrium-90 } \\
\mathrm{pCi} / \mathrm{L}\end{array}$ & $\begin{array}{l}\text { Beta, gross } \\
\text { suspended as } \\
\text { strontium/ } \\
\text { yttrium-90 } \\
\mathrm{pCi} / \mathrm{L}\end{array}$ \\
\hline & New England & 3 & $<0.4-3.8$ & $<0.4-2.6$ & $0.02-.04$ & $0.02-.09$ & $2.2-3.5$ & $<0.4-512$ & $1.8-3.3$ & $<0.4-4.6$ \\
\hline 02 & Mid Atlantic & 5 & $.8-2.4$ & $<.4-220$ & $<.01-.12$ & $<.01-.32$ & $2.0-11$ & $<.4-69$ & $1.6-9.1$ & $<.4-65$ \\
\hline 03 & South Atlantic-Gulf & 8 & $<.4-7.9$ & $<.4-9.3$ & $<.01-.32$ & $<.01-.14$ & $2.8-18$ & $<.4-5.4$ & $2.2-14$ & $<.4-4.3$ \\
\hline 04 & Great Lakes & 2 & $<.4-2.2$ & $<.4-.4$ & $.03-.04$ & $.03-.40$ & $2.0-4.4$ & $<.4-.4$ & $1.6-3.6$ & $<.4-.4$ \\
\hline 05 & Ohio & 4 & $.8-5.9$ & $<.4-9.8$ & $.02-.71$ & $.04-.13$ & $1.6-4.9$ & $<.4-4.4$ & $1.2-3.8$ & $<.4-3.8$ \\
\hline 06 & Tennessee & 2 & $<.5-1.9$ & $<.4-3.7$ & $<.01-.04$ & $.02-.21$ & $2.4-3.4$ & $.5-3.2$ & $1.9-2.7$ & $<.4-2.6$ \\
\hline 07 & Upper Mississippi & 2 & $3.7-15$ & $1.4-4.5$ & $.07-.08$ & $1.8-2.7$ & $6.8-10$ & $1.7-5.0$ & $5.5-8.2$ & $1.4-4.0$ \\
\hline 08 & Lower Mississippi & 2 & $<.5-8.0$ & $1.2-6.8$ & $.02-.17$ & $.03-1.5$ & $3 \cdot 2-11$ & $.7-5.9$ & $2.5-8.7$ & $.6-5.0$ \\
\hline 09 & Souris-Red-Rainy & 2 & $1.2-4.2$ & $1.0-7.9$ & $.06-.10$ & $.5-3.2$ & $4 \cdot 7-13$ & $1.6-9.0$ & $3.8-11$ & $1.4-7.8$ \\
\hline 10 & Missouri Basin & 4 & $1.6-150$ & $<.4-32$ & $.03-.08$ & $.23-53$ & $3.1-42$ & $<.4-19$ & $2.5-33$ & $<.4-17$ \\
\hline 11 & Arkansas-White-Red & 3 & $1.6-38$ & $1.1-140$ & $.04-.13$ & $.4-3.2$ & $4 \cdot 1-13$ & $1.2-91$ & $3 \cdot 3-10$ & $1.1-74$ \\
\hline 12 & Texas-Gulf & 1 & $4 \cdot 1-4 \cdot 1$ & $4.8-4.8$ & $.07-.07$ & $1.0-1.0$ & $6.3-6.3$ & $4.1-4.1$ & $5.1-5.1$ & $3.5-3.5$ \\
\hline 13 & Rio Grande & 3 & $2 \cdot 6-17$ & $<.4-73$ & $<.01-.07$ & $.8-4.7$ & $4 \cdot 3-6 \cdot 3$ & $.9-43$ & $3.4-5.1$ & $.8-36$ \\
\hline 14 & Upper Colorado & 2 & $8 \cdot 3-13$ & $5 \cdot 1-120$ & $.06-.09$ & $2 \cdot 3-14$ & $4.9-6.5$ & $4 \cdot 2-50$ & $4 \cdot 2-5 \cdot 2$ & $3.3-43$ \\
\hline 15 & Lower Colorado & 1 & $12-13$ & $<.4-1.4$ & $.12-.12$ & $4.1-4.7$ & $9.7-11$ & $1.1-1.9$ & $7.8-8.5$ & $1.0-1.5$ \\
\hline 16 & Great Basin & 0 & - & - & - & - & - & - & - & - \\
\hline 17 & Pacific Northwest & 3 & $<.4-8.1$ & $<.4-6.5$ & $<.01-.13$ & $<.01-9.5$ & $.9-5.2$ & $<.4-2.8$ & $0.7-4.2$ & $<.4-2.2$ \\
\hline 18 & California & 2 & $<.1-1.1$ & $<.4-5.5$ & $<.01-.02$ & $.02-.16$ & $1.5-4.2$ & $<.4-2.1$ & $1.2-3.4$ & $<.4-1.7$ \\
\hline 19 & Alaska & 2 & $.7-2.4$ & $<.4-28$ & $.03-.17$ & $.09-.6$ & $1.6-14$ & $<.4-11$ & $1.3-11$ & $<.4-9.7$ \\
\hline 20 & Hawaii & 0 & - & - & - & - & - & - & - & - \\
\hline 21 & Caribbean & 0 & - & - & - & - & - & - & - & - \\
\hline
\end{tabular}


The Mississippi River above Memphis, Tenn. and its major tributaries, the Ohio, Tennessee, and Missouri Rivers, drain the mid-section of the United States. This area is agriculturally diverse, ranging from areas of forest and rangeland to areas of intensive farming which produce much of the country's corn and soy bean crops. Precipitation varies widely from areas in the Tennessee Basin receiving over 48 inches $(1,200 \mathrm{~mm})$ of rain per year to areas in the western part of the Missouri Basin with less than 16 inches $(410 \mathrm{~mm})$ of rain a year.

The report to this point examined the general national pattern of water quality constituents in the NASQAN program. The following pages show in more detail the Mississippi drainage system and the occurrence of selected water quality constituents. Table 11 lists NASQAN stations in the Mississippi Basin above Memphis; map numbers in table 11 refer to numbers used to designate stations in figures 19-25.

\section{Dissolved Solids}

Figure 19 is a schematic diagram of the Mississippi River and its tributaries above Memphis, Tenn. with each triangle representing a NASQAN station. The size of the triangle represents discharge at the station. The distance from the lower point of each triangle to the top of the vertical line through it represents the drainage area above the station. A horizontal line indicates that a tributary with a NASQAN station enters the river. The length of the horizontal line has no significance. Total drainage area at the Missouri River below Fort Peck Dam, Mont. (49), for example, is represented by the distance from the tip of the triangle (49) to the top of the vertical line above (47) plus the length of the line from the tip of triangle (50) representing a tributary, the Musselshell River at Mosby, Mont. Because triangle size is related to discharge, several sites with small drainage areas have no visible vertical lines since the lines do not extend beyond the bounds of the triangle.

Figure 19, mean concentration of dissolved solids, shows expected general trends--lower dissolved solids in the east, higher in the west. The Tennessee River had less than $100 \mathrm{mg} / \mathrm{L}$ dissolved solids even at its mouth near Paducah, Ky. (27). In the Ohio drainage, only one site, the Muskingum River (3) had an average value above the proposed EPA secondary standard limit of $500 \mathrm{mg} / \mathrm{L}$, but all of the streams entering the Ohio from the northern side of the river $(3,5,8,9,11,16,17)$ were above $250 \mathrm{mg} / \mathrm{L}$. This area of Ohio, Indiana, and Illinois is intensively cultivated and produces large quantities of corn and other grain crops. Streams entering the Ohio River from Kentucky and West Virginia, which flow through areas having more forests and less intensive agriculture, were all below $250 \mathrm{mg} / \mathrm{L}$ of dissolved solids. The Minnesota River (30), draining a major agricultural area and receiving less rainfall than other upper Mississippi tributaries, was the only upper Mississippi tributary to have mean dissolved solids greater than $500 \mathrm{mg} / \mathrm{L}$. 
Map Station

Number Number

03049625

03085000

03150000

03201300

03234500

03204500

03215000

03274600

03276500

03216600

03245500

03277200

03254000

03290500

03321230

03378500

03374100

03425000

03438220

03303280

03301630

03612500

03470500

03543005

03571850

03593005

03609750

05267000

05331000

05330000

05340500

05378500

05369500

05420500

05407000

05474500

05446500

05490600

05587550

05543500

05543500

05586100

05599500

07022000
Station Name

Allegheny $R$ at New Kensington, PA Monongahela River at Braddock, PA Muskingum $\mathrm{R}$ at McConnelsville, $\mathrm{OH}$ Kanawha at Winfield

Scioto $\mathrm{R}$ at Higby, OH

Mud River near Milton, WV

Big Sandy $R$ at Louisa, KY

G Miami $\mathrm{R}$ at New Baltimore, $\mathrm{OH}$

Whitewater River at Brookville, IN

Ohio $\mathrm{R}$ at Greenup Dam $\mathrm{nr}$ Greenup, KY

Miami $\mathrm{R}$ at Milford, $\mathrm{OH}$

Ohio $R$ at Markland Dam nr Warsaw, KY

Licking River at Butler, KY

Kentucky River at Lock 2, at Lockport, KY

Green River $\mathrm{n}^{-}$Beech Grove, KY

Wabash River at New Harmony, IN

White River at Hazleton, IN

Cumberland River at Carthage, TN

Cumberland River near Grand Rivers, KY

Ohio $\mathrm{R}$ at Cannelton Dam, KY

Rolling Fork nr Lebanon Junction, KY

Ohio R at Lock and Dam $53 \mathrm{nr}$ Grand Chain, IL

French Broad River near Knoxville, TN

Tennessee River at Watts Bar Dam (Tailwater), TN

Tennessee River at South Pittsburg, TN

Tennessee River at Pickwick Landing Dam (LL), TN

Tennessee River at Highway 60 , near Paducah, KY

Mississippi River near Royalton, MN

Mississippi River at St. Paul, MN

Minnesota River near Jordan, MN

St. Croix River at St. Croix Falls, WI

Mississippi River at Winona, MN

Chippewa River at Durand, WI

Mississippi River at Clinton, IA

Wisconsin River at Muscoda, WI

Mississippi River at Keokuk, IA

Rock River near Joslin, IL

Des Moines River at St. Francisville, MO

Mississippi River below Alton, IL

Illinois River at Marseilles, IL

Illinois River at Valley City, IL

Big Muddy River at Murphysboro, IL

Mississippi River at Thebes, IL $\begin{array}{cl}\text { Map } & \text { Station } \\ \text { Number } & \text { Number }\end{array}$

44

45

46

47

48
49

50

51

52

54

54

55

56

58

58

05594100

07032000

07026000

06214500

06308500

06326500

06337000

06439300

06440000

06354000

06257300

06453000

06478500

06764000

06796000

06805500

06892350

06887000

06926510

06934500

06934500

\section{Station Name}

06054500

06109500

06132000

06130500

06174500

06185500

06294700

06329500

06338490

06438000

06452000

06465500

0648600 w

06485500

06807000

06818000

06856600

06877600

06792499

Obion River at Obion, TN Milk River at Nashua, MT Knife River at Hazen, ND piatte $R$ at Louisville, NE Kansas $R$ at Desoto, KS
Kaskaskia River near Venedy Station, IL issippi River at Memphis, TN

Missouri River at Toston, MT

Missouri River at Virgelle, MT

Missouri River below Fort Peck Dam, MT Musselshell River at Mosby, MT

Missouri River near Culbertson, MT Yellowstone River at Billings, MT Bighorn River at Bighorn, MT

Tongue River at Miles City, MT

Powder River near Locate, MT

Yellowstone River near Signey, MT Missouri River at Garrison Dam, ND Little Missouri River nr Watford City, ND Cheyenne River at Cherry Creek, SD Belle Fourche $\mathrm{R}$ nr Elm Springs, SD Missouri River at Pierre, SD

Cannonball River at Breinen, ND Grand River at Little Eagle, SD Missouri River at Fort Randall Dam, SD White River near Oacoma, SD

Niobrara River nr Verdel, NB

James River near Scotlands, SD Missouri River at Sioux City, IA Big Sioux River at Akron, IA North Platte River at Lisco, NB South Platte River at Julesburg, CO Platte River at North Bend, NB Missouri River at Nebraska City, NB Missouri River at St. Joseph, MO Republican R at Clay Center, KS Smoky Hill R at Enterprise, KS

Big Blue R nr Manhattan, KS Grand River near Sumner, MO Osage River below St. Thomas, Mo Missour1 River at Hermann, MO

Loup R Power Ca at Div nr Genoa, NB 


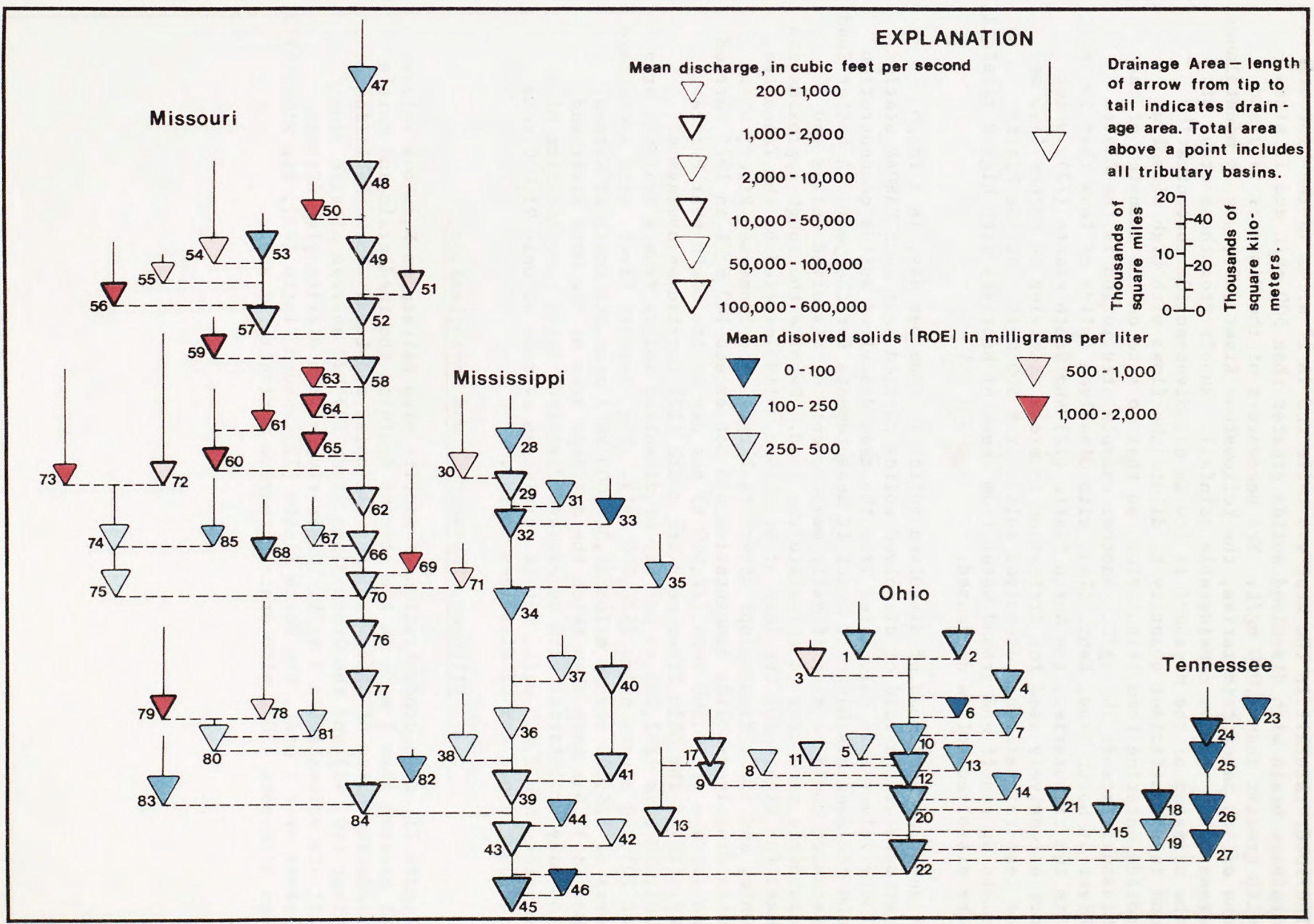

Figure 19.--Mean concentration of dissolved solids measured as residue on evaporation (ROE) at $180^{\circ} \mathrm{C}$ for the Mississippi River basin above Memphis, Tenn. during the 1975 water year. 
The lower rainfall in the west was reflected in 17 sites in the Missouri drainage basin with dissolved solids greater than $500 \mathrm{mg} / \mathrm{L}$ and 11 sites with greater than $1,000 \mathrm{mg} / \mathrm{L}$. The headwaters of the Missouri (47) and one of its major tributaries, the Yellowstone River (53), are in mountainous areas which receive considerable rainfall. Runoff from these areas of the mainstem of the Missouri is low in dissolved-solids concentration and is of sufficient quantity to dilute the flows with high dissolved solids entering from tributaries, so that no site on the mainstem of the Missouri exceeds $500 \mathrm{mg} / \mathrm{L}$. Another example of dilution is the Platte River at North Bend, Nebr. (74), with dissolved solids of less than $500 \mathrm{mg} / \mathrm{L}$. Its two tributaries, the North Platte (72) and South Platte (73), which are extensively used for irrigation in areas receiving 16 inches (406 mm) or less rainfall, had dissolved solids over $500 \mathrm{mg} / \mathrm{L}$. As the Platte picks up runoff and ground water from areas of Nebraska with higher rainfall, the dissolved solids decreased.

Figure 20, mean load of dissolved solids in tons per day, is a rough estimate of the load of dissolved solids carried past each NASQAN station. These values were calculated from the mean dissolved solids concentration and the mean discharge of about 12 measurements for the year. A better load estimate could be made if daily measurements of dissolved solids and discharge were used to calculate the load. Despite the rough approximation used for figure 20, the load of dissolved solids carried by the Tennessee, Ohio, and upper Mississippi Rivers is large. The Tennessee River, whose mean dissolved-solids concentation did not exceed $100 \mathrm{mg} / \mathrm{L}$ in 1975 carried an average of 19,300 tons $(17,500$ t) per day at its mouth near Paducah, Ky. (27). The Ohio River near its mouth (22) carried an average of 201,000 tons $(182,000$ t) per day of dissolved solids from a drainage area of 203,000 square miles $\left(526,000 \mathrm{~km}^{2}\right)$. The Missouri River, with a drainage area of 528,000 square miles $\left(1,368,000 \mathrm{~km}^{2}\right)$ near its mouth at Herman, Mo. (84), has more than twice the drainage area of the Ohio River and has many tributaries with an average dissolved solid concentration of greater than $1,000 \mathrm{mg} / \mathrm{L}$, but it carried an average of only 91,000 tons $(83,000$ t) per day of dissolved solids.

\section{Nitrogen, Phosphorus, and Phytoplankton}

Figure 21, mean concentration of nitrite plus nitrate as $\mathrm{N}$, shows values of greater than $1 \mathrm{mg} / \mathrm{L}$ in the streams draining the feed grain and cattle producing areas of Ohio, Indiana, Illinois, and Iowa. Both the Illinois River $(40,41)$ and the Great Miami River (8) had average nitrite plus nitrate values above $3 \mathrm{mg} / \mathrm{L}$. Other rivers with nitrite plus nitrate values over $1 \mathrm{mg} / \mathrm{L}$, the North Platte (72), South Platte (73), Big Sioux (71), and Minnesota (30), also drain intensive agricultural areas. 


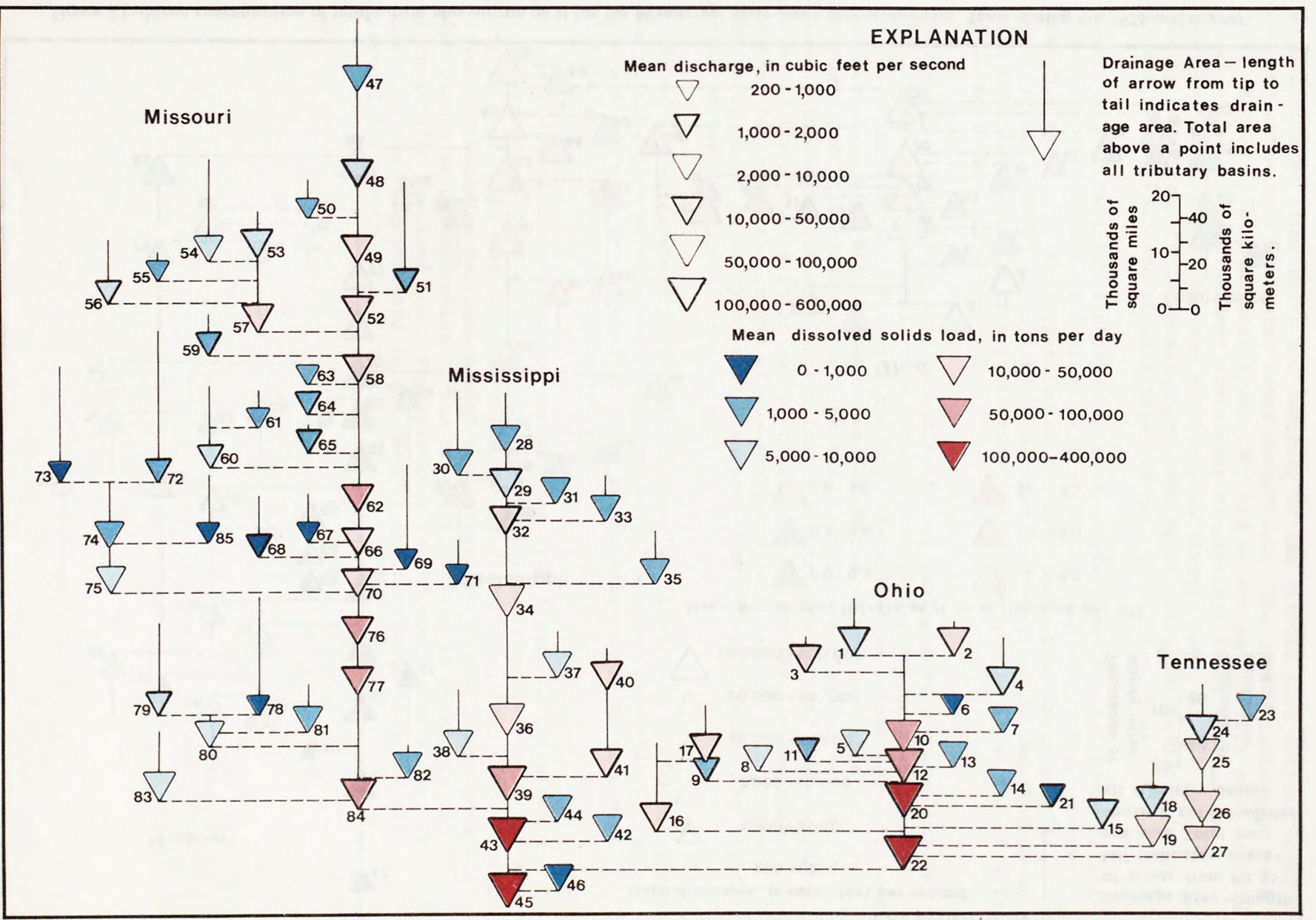

Figure 20.--Mean dissolved solids load in tons per day for the Mississippi River basin above Memphis, Tenn. during the 1975 water year. 


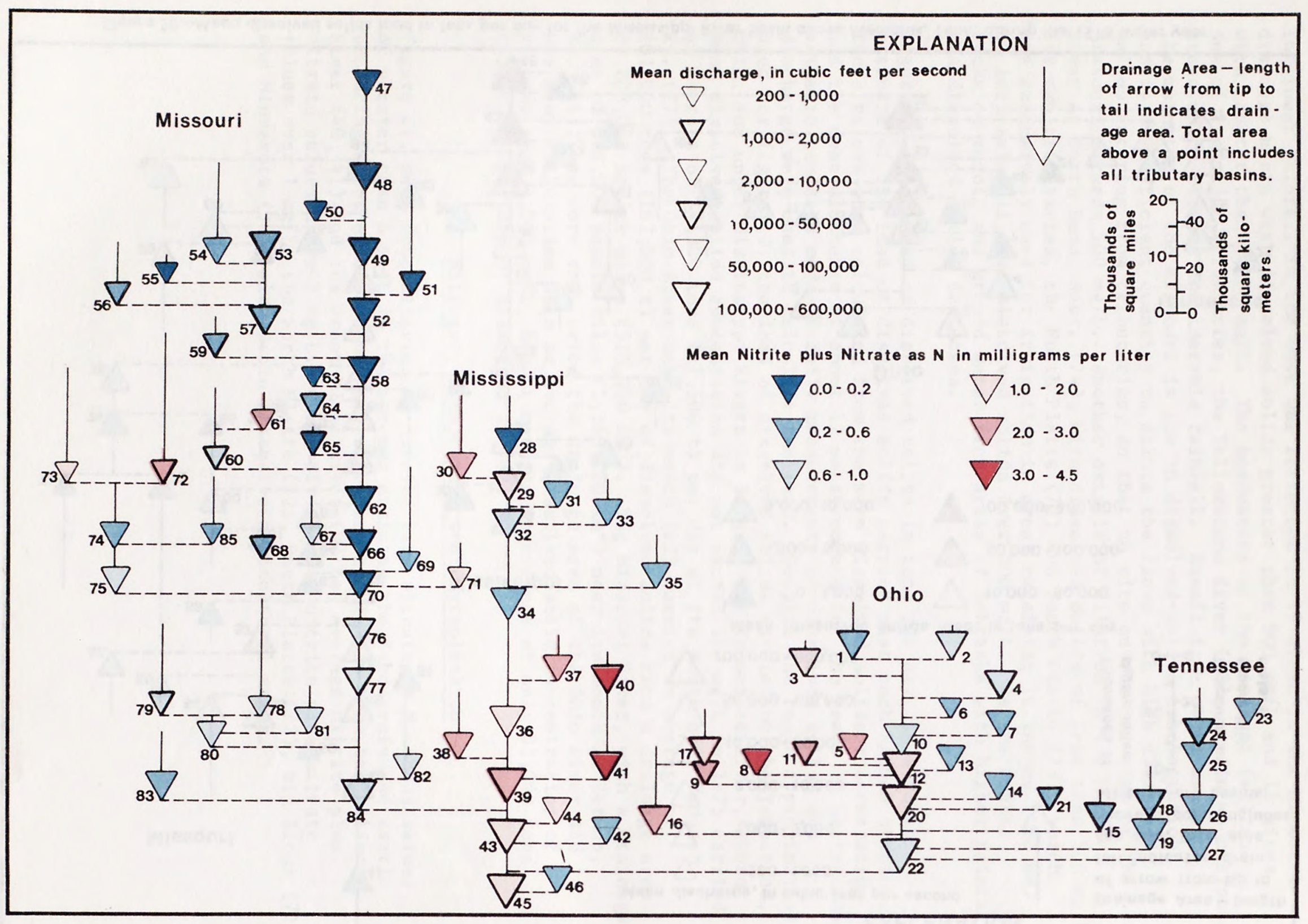

Figure 21.--Mean concentration of total nitrite plus nitrate as $\mathrm{N}$ for the Mississippi River basin above Memphis, Tenn. during the 1975 water year. 
Figure 21 also illustrates the lowering of the nitrite plus nitrate level in many streams as the water moves downstream. The upper Mississippi is a good example. The Minnesota River (30) had an average nitrite plus nitrate level of $2.8 \mathrm{mg} / \mathrm{L}$. The next downstream Mississippi River station, at St. Paul (29), had an average nitrite plus nitrate level of $1.1 \mathrm{mg} / \mathrm{L}$. Moving downstream on the Mississippi, the level decreased to $0.7 \mathrm{mg} / \mathrm{L}$ at Winona, Minn. (32) and to less than $0.6 \mathrm{mg} / \mathrm{L}$ at Clinton, Iowa (34).

Figure 22, average total phosphorus as $P$, again shows the influence of the intensive agriculture of Indiana, Illinois, and Iowa with values greater than $0.1 \mathrm{mg} / \mathrm{L}$. If the suggestion of the U.S. Council on Environmental Quality (CEQ) (1975, p. 353) for a maximum concentration of phosphorous of $0.03 \mathrm{mg} / \mathrm{L}$ for "aquatic life protection" is followed, only 11 of the 84 sites shown meet this criterion.

Figure 23, illustrating mean concentration of phytoplankton shows that in the intensive agricultural areas streams generally averaged over 10,000 cells per milliliter. However, the high phytoplankton values generally did not correlate with high nitrogen and phosphorus values, as table 12 shows. Nitrogen and phosphorus may be high and phytoplankton low for several reasons including the possibility that the nutrients entered the stream close to the sampling point and phytoplankton had no time to use thein. Another factor is the amount of suspended sediment carried by a stream. The water could be carrying enough suspended material to reduce the light which phytoplankton must have to grow.

At 31 of the sites where phytoplankton were low (less than $10,000 \mathrm{cells} / \mathrm{mL}$ ), the nitrite plus nitrate and phosphorus were low also (less than $1.0 \mathrm{mg} / \mathrm{L}$ $\mathrm{mg} / \mathrm{L}$ and $0.2 \mathrm{mg} / \mathrm{L}$ respectively). Only at six sites where nitrite plus nitrate were low was phytoplankton high.

On the Missouri River mainstem, one can see from figure 23 the effects of the series of 5 major reservoirs located between the Missouri River at Virgil, Mont. (48) and the Missouri River at Sioux City, Iowa (70). Despite various tributaries delivering high concentrations of plant nutrients and high counts of phytoplankton to the Missouri, values of nutrients and phytoplankton remained low. Phytoplankton in the reservoirs appear to remain in the reservoir and to use many of the nutrients entering the Missouri for growth. 


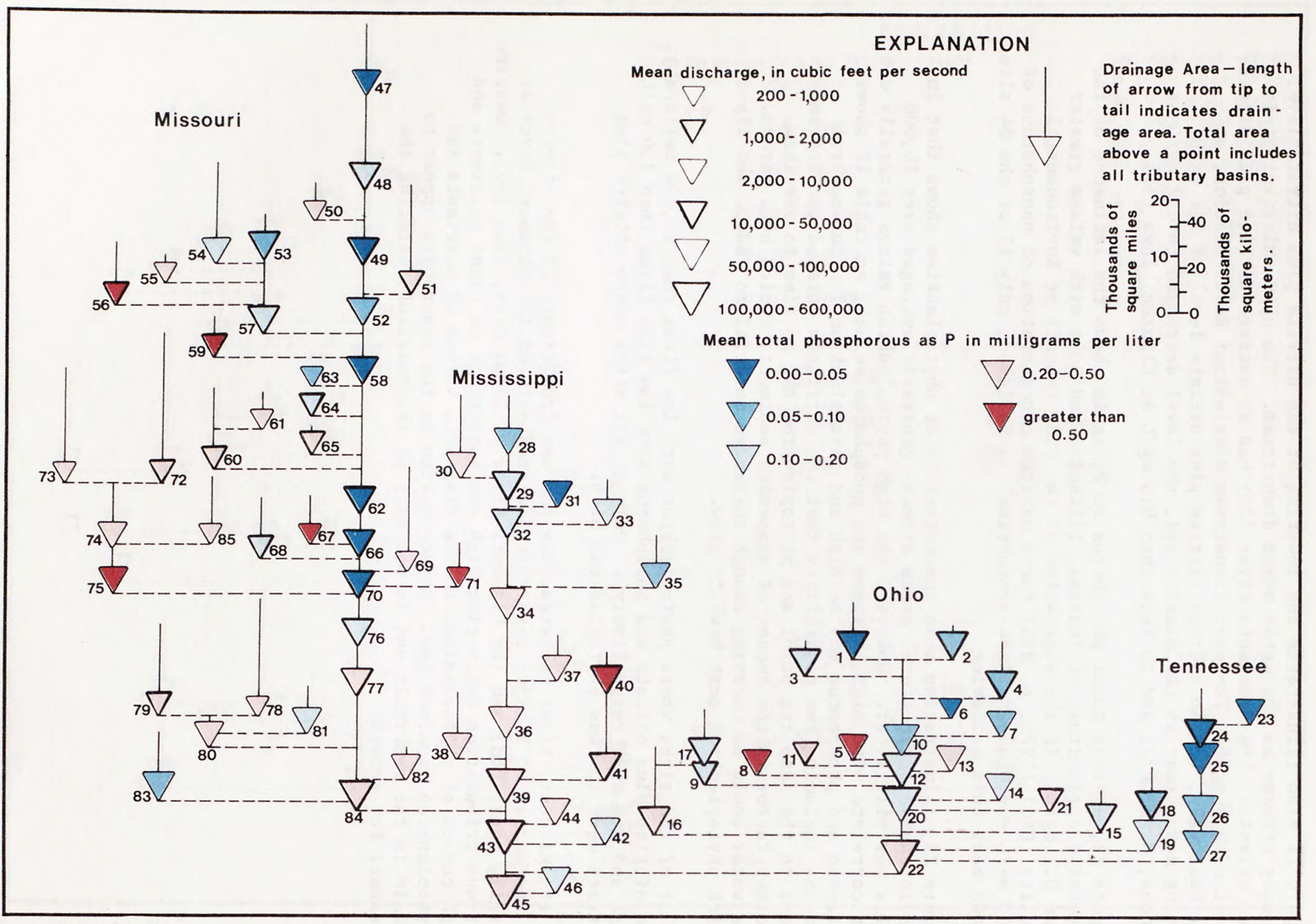

Figure 22.--Mean concentration of total phosphorus as $P$ for the Mississippi River basin above Memphis, Tenn. during the 1975 water year. 


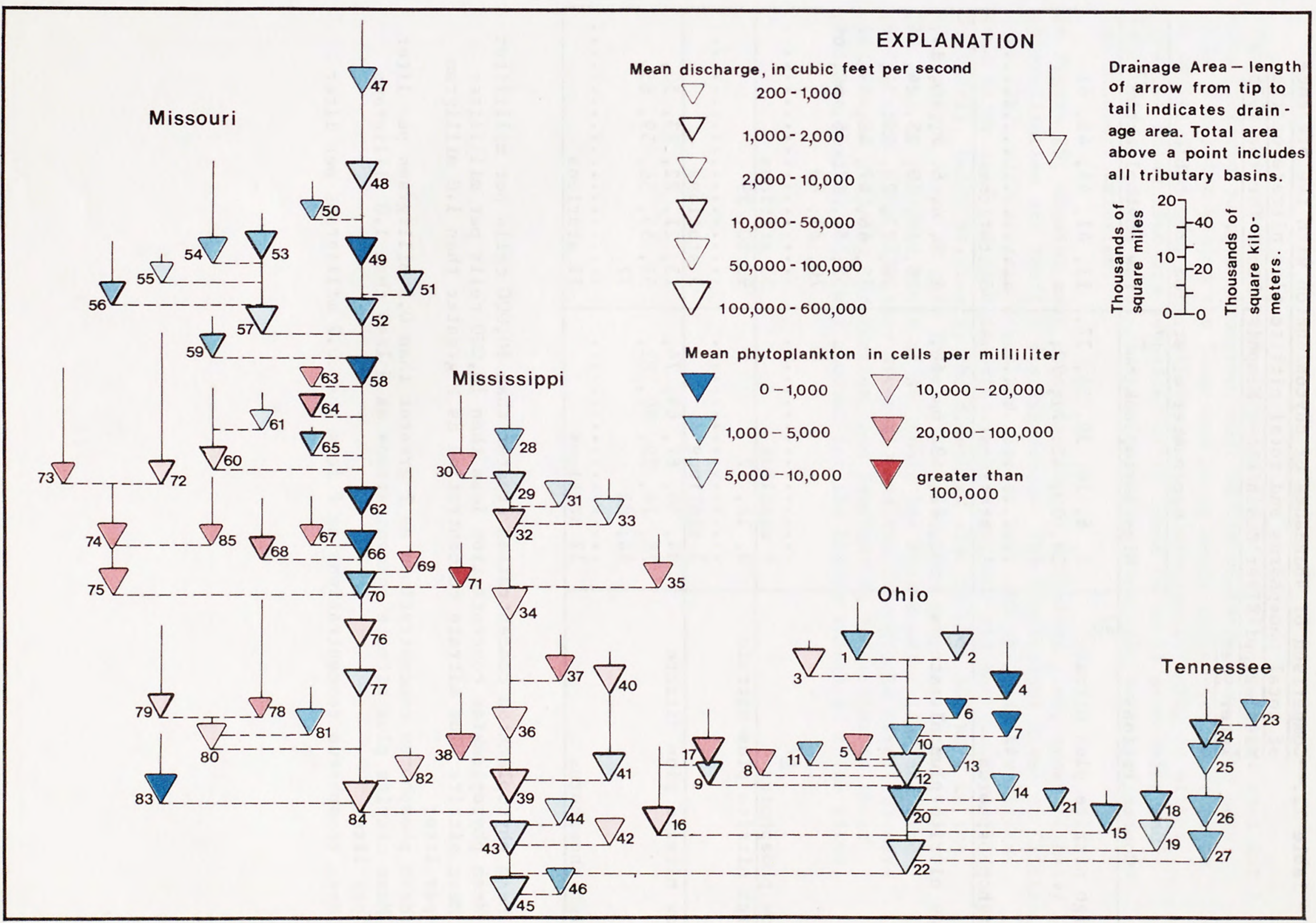

Figure 23.--Mean concentration of phytoplankton for the Mississippi River basin above Memphis, Tenn. during the 1975 water year. 
Table 12.--Comparison of abundance of phytoplankton with the presence of total phosphorus and total nitrite plus nitrate of the Mississippi River Basin above Memphis, Tenn. for the 1975 water year

\begin{tabular}{|c|c|c|}
\hline Concentrations & $\frac{\text { Map number of sta }}{\text { High phytoplankton }}$ & Lon from table 11 \\
\hline $\begin{array}{l}\text { High nitrite plus nitrate } e^{\underline{3 /}} \\
\text { High phosphorus }\end{array}$ & $\begin{array}{l}5,8,16,30,36,37 \\
38,39,40,71,72 \\
73 \\
\text { i2 stations }\end{array}$ & $\begin{array}{l}11,41,44,45,61 \\
\ldots \ldots \ldots \ldots \ldots \ldots \ldots \ldots \\
5 \text { stations }\end{array}$ \\
\hline $\begin{array}{l}\text { Low nitrite plus nitrate } \underline{5 /} \\
\text { Low phosphorus }\end{array}$ & $\begin{array}{l}32,42,63,64,68, \\
76\end{array}$ & $\begin{array}{l}1,2,4,6,7,10,14, \\
15,18,19,23,24,25, \\
26,27,28,29,31,33, \\
35,46,47,48,49,52, \\
53,54,57,58,62,66, \\
70,81,83 \\
\ldots \ldots \ldots \ldots . \ldots . \ldots . . . . . . . . .\end{array}$ \\
\hline High nitrite plus nitrate & $\begin{array}{l}3,12,17 \\
\ldots \ldots \ldots \ldots \ldots \ldots \\
3 \text { stations }\end{array}$ & 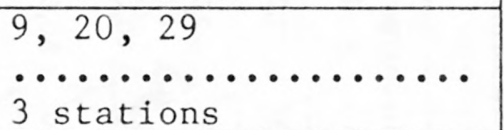 \\
\hline Low nitrite plus nit & $\begin{array}{l}34,60,67,69,74, \\
75,78,79,80,82, \\
84,85 \\
\ldots \ldots \ldots \ldots \ldots \ldots \\
12 \text { stations }\end{array}$ & $\begin{array}{l}13,21,22,43,50, \\
51,55,56,59,65, \\
77 \\
\ldots \ldots \ldots \ldots \ldots \ldots \ldots \ldots \ldots \\
11 \text { stations }\end{array}$ \\
\hline
\end{tabular}

1/ Mean phytoplankton concentration greater than 10,000 cells per milliliter

$\underline{2} /$ Mean phytoplankton concentration less than 10,000 cells per milliliter

$\underline{3} /$ Mean nitrite plus nitrate concentration as $N$ greater than 1.0 milligram per liter

4/ Mean phosphorus concentrations as $\mathrm{P}$ greater than 0.2 milligrams per liter

$\underline{5} /$ Mean nitrite plus nitrate concentrations as $N$ less than 1.0 milligrams per liter

6/ Mean phosphorus concentrations as $\mathrm{P}$ less than 0.2 milligrams per liter 
Figure 24 , representing mean concentration of total zinc, shows that total zinc exceeded $30 \mathrm{\mu g} / \mathrm{L}$ throughout most of the drainage area. The only major exception was on the Tennessee River where three sites were below $30 \mu \mathrm{g} / \mathrm{L}$. Total zinc does not appear to relate specifically to either areas of known zinc ore deposites or to areas of metal processing and fabrication. Also, total zinc was not affected by the series of dams on the Missouri mainstem.

In Figure 25, showing mean concentration of dissolved zinc, areas of heavy mineralization are readily distinguished. The Mississippi River at Clinton, Iowa (34), with average dissolved zinc of over $100 \mu \mathrm{g} / \mathrm{L}$, is downstream from major lead and zinc deposits in eastern Iowa and northwestern Illinois. Similarly, below St. Louis, the dissolved zinc is over $100 \mu \mathrm{g} / \mathrm{L}$ in the Mississippi River at both Thebes, Ill. (43), and Memphis, Tenn. (45). The area of Missouri south of St. Louis has been a major lead and zinc mining area. The Allegheny River (1) and the Monongohela River (2) have large metal refining, production, and fabricating industries in their drainage basins, which may account for the higher values at those sites. 


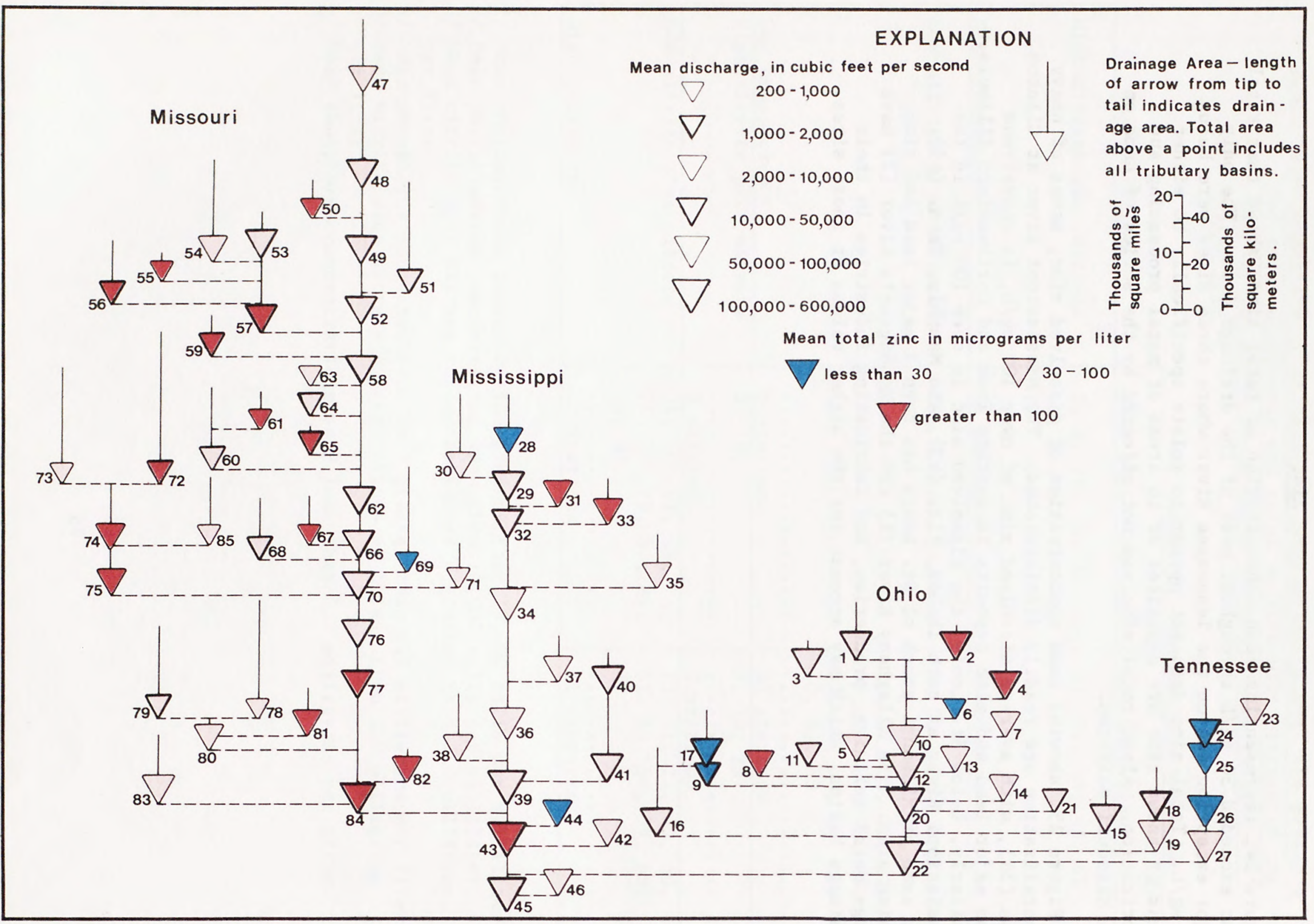

Figure 24.--Mean concentration of total zinc for the Mississippi River basin above Memphis, Tenn. during the 1975 water year. 


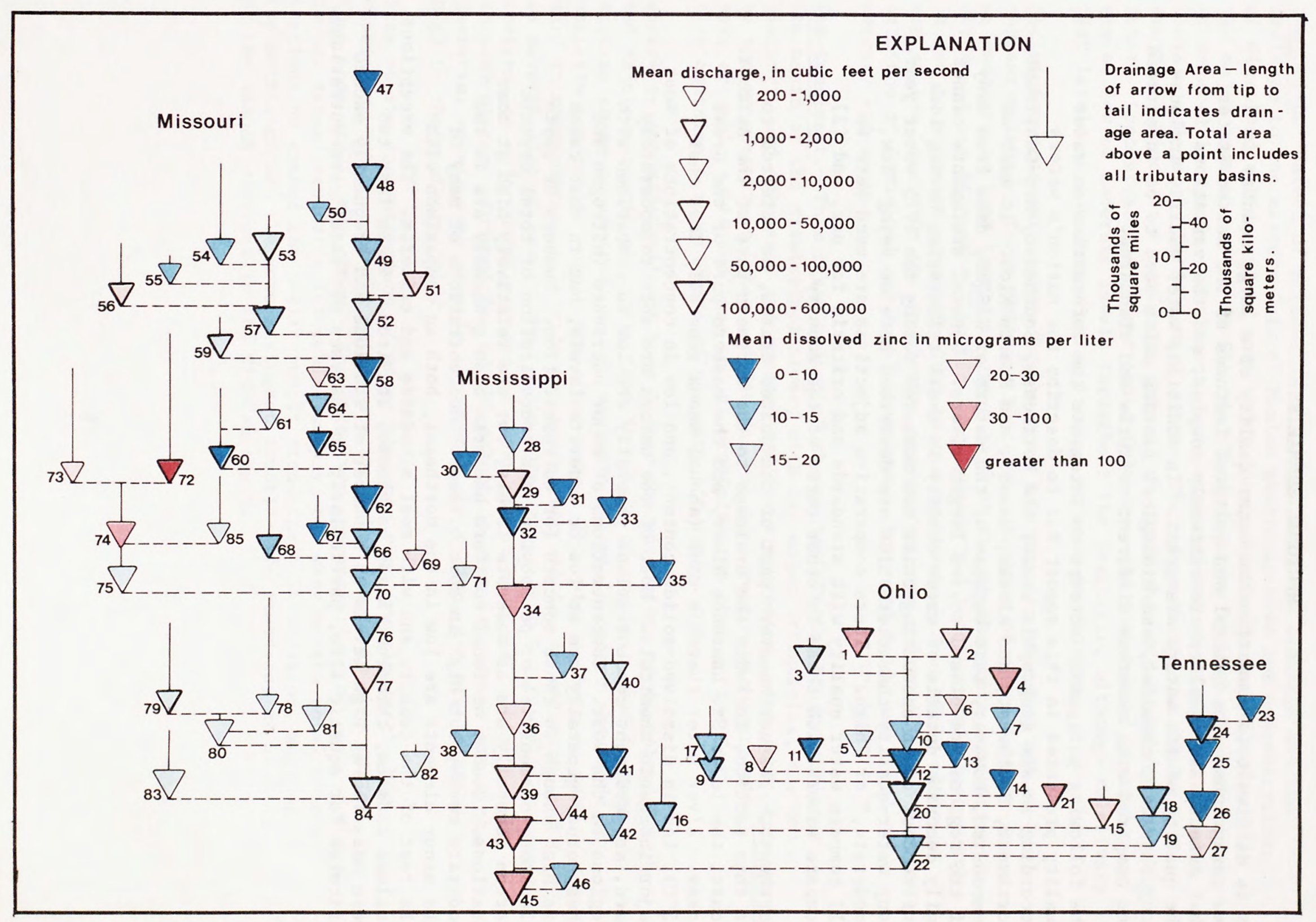

Figure 25.--Mean concentration of dissolved zinc for the Mississippi River basin above Memphis, Tenn. during the 1975 water year. 


\section{REGIONAL SUMMARIES}

It is difficult to summarize the water quality of a large country in a few paragraphs. The natural and cultural features of the United States that affect water quality are extremely complex, and the variations in the quality of its waters are great. In addition, water quality includes many physical, chemical, and biological factors which need to be integrated and compared with numerous different criteria and standards.

The following paragraphs attempt to integrate the information on water quality presented in this report and to describe the nation's waters according to six geographic areas; the Northeast, Southeast, Mid-Continent, Northwest, Southwest, and Alaska, Hawaii, and Puerto Rico. It must be remembered, however, that because of the nature of NASQAN, data from many of the regions are biased toward larger rivers. General statements cannot fully describe details of water quality in small tributaries having local influences, or in accounting units not measured during the 1975 water year. Many water-quality characteristics are described here as being "low," "moderate," or "high." These comparative adjectives are used here to (1) compare water quality with standards and criteria for use, and (2) compare waters with those in other parts of the country.

Northeast.--The northeastern part of the United States, as referred to in this section, includes the drainage to the northern part of the Atlantic coast, the lower St. Lawrence River, and the eastern part of the Great Lakes. River water there is cool (annual means generally less that $15^{\circ} \mathrm{C}$ ), low in dissolved-solids content, and low in concentrations of most major inorganic chemicals. Most of the waters are soft to moderately hard, and sediment concentrations generally are low in comparison with regions to the west. Concentrations of major nutrients (nitrogen and phosphorus) generally are at low or moderate levels, but in most cases are high enough to cause concern for eutrophication. Numbers of phytoplankton, communities of periphyton, and concentration of total organic carbon generally are at moderate levels, but are relatively high at some stations. Counts of fecal coliform bacteria also generally are in the moderate range, but high in some streams. Concentrations of many of the minor elements are low in the Northeast, both in comparison with the rest of the country and with most standards and criteria. The exceptions include cadmium, chromium, lead, manganese, and iron. These last two were measured at high levels at a number of stations and frequently exceed criteria for aquatic life, particularly in analyses of "total" concentrations. 
Southeast.--Waters of streams in the south Atlantic drainage and the drainage to the eastern Gulf of Mexico generally have low concentrations of dissolved solids and of most major inorganic chemicals and are soft. The major exceptions are in Florida where moderate to high concentrations of several inorganic constituents were measured and where several streams contain moderately hard or hard water. The concentration of fluoride in the Peace River of Florida was greater at times than standards for drinking water. Concentrations of nutrients (nitrogen and phosphorus) generally are at low or moderate levels throughout the Southeast, although relatively high levels of phosphorus exist in some streams in Florida.

Sediment concentrations are low in most southeastern streams, and so are concentrations of fecal coliform bacteria. Numbers of phytoplankton are at moderate to high levels in about half of the Southeastern accounting units and are highest in Florida. Periphyton and total organic carbon are at low to moderate concentrations in the Southeast. Most minor elements are at low levels in the Southeast, except for some moderately high concentrations of dissolved and total manganese, iron, and lead, and total mercury and zinc.

Mid-Continent.--This large region of the central United States includes the basin of the Mississippi River, with its major tributaries, the Ohio, Missouri, and Arkansas, and several smaller tributaries, plus some drainage to the western Great Lakes and Canada. It is a region with generally more erodible soils and less annual precipitation than in the East. It also contains a major share of the Nation's agriculture.

Waters in the Mid-Continent have higher concentrations of dissolved solids and major inorganic chemicals than do waters of the East, and in some streams these concentrations of inorganic materials exceed standards or criteria for public supply and other uses. The water is hard or very hard in many places. Fluoride concentrations are low to moderate, and in several streams are in the nearly ideal range of $0.5-1.0 \mathrm{mg} / \mathrm{L}$. Concentrations of major nutrients and sediment are at moderate to high levels at many places. Communities of phytoplankton also frequently are high. Bacterial counts vary greatly throughout the region, and are relatively high in the southern half.

Data on the concentrations of minor elements vary greatly in the MidContinent, but most of the metals are at higher levels in this region than they are in any other. The dissolved concentrations of most of these do not exceed standards for public supply, but many of the total concentrations do exceed the public-supply standards. In addition, many of the metals exceed the more stringent aquatic-life standards at several of the NASQAN stations in the Mid-Continent. 
Northwest.--Rivers of the relatively humid Northwest are somewhat like the rivers of the East. Their levels of dissolved solids and concentrations of major chemicals are low, and they generally are soft to moderately hard. Concentrations of major nutrients range from low to high levels, while sediment concentrations, phytoplankton numbers, and periphyton values range from low to moderately high. Counts of fecal coliform bacteria are low, and concentrations of total organic carbon are in the low to moderate range. Dissolved minor elements generally are at low or moderate levels; high concentrations were found for total concentrations of copper, iron, lead, and manganese.

Southwest.--Many of the highest concentrations of dissolved solids and major chemicals are found in the rivers of the Southwest, and concentrations commonly exceed water-quality standards or criteria. Waters in most rivers of this region are hard or very hard, and most carry large amounts of sediment and moderate to high concentrations of nutrients. Communities of phytoplankton and periphyton also are moderately high. Fluoride is at nearly ideal concentrations in several of the rivers, but exceeds the drinking water standards at one site in each of the lower Colorado and Rio Grande basins. Bacterial counts range widely and are moderately high in some streams, and total organic carbon varies over a large range. Concentrations of minor elements usually are at low levels in dissolved forms and are at moderate levels in total forms.

Alaska, Hawaii, and Puerto Rico.--Waters at NASQAN stations in Alaska, Hawaii, and Puerto Rico are low in dissolved solids and major constituents. The Hawaii water is soft, but water in several of the Alaska and Puerto Rico streams is hard. Nutrient concentrations generally are in the moderate range, but they vary considerably in Alaska and Hawaii. Phytoplankton communities are low and periphyton communities are at low-to moderate levels compared with the rest of the United States. Concentrations of sediment are at moderate levels and numbers of fecal coliform bacteria are low in Alaska, moderately high in Hawaii, and high in Puerto Rico. Minor elements are generally at low levels, except for total concentrations of copper, manganese, iron, lead, and zinc which are moderately high in some samples. 


\section{REFERENCES}

Collings, M. R., 1969, Temperature analysis of a stream: U.S. Geological Survey Professional Paper 650-B, p. B174-B179.

Durfor, C. N., and Becker, Edith, 1964, Public water supplies of the 100 largest cities in the United States, 1962: U.S. Geological Survey Water-Supply Paper 1812, p. 23-27.

Enviro Control, 1972, National assessment of trends in water quality: U.S. Department of Commerce, National Technical Information Service, $\mathrm{PB}-210669,52 \mathrm{p}$.

Ficke, J. F., and Hawkinson, R. 0., 1975, The National Stream Quality Accounting Network (NASQAN)--some questions and answers; U.S. Geological Survey Circular 719,23 p.

Hawkinson, R. O., Ficke, J. F., and Saindon, L. G., 1977, Quality of rivers of the United States, 1974 water year--based on the National Stream Quality Accounting Network (NASQAN): U.S. Geological Survey Open-File Report 77-151, 158 p.

Krieger, R. A., Hatchett, J. L., and Poole, J. L., 1957, Preliminary survey of the saline-water resources of the United States: U.S. Geological Survey Water-Supply Paper 1374 , p. 5 .

National Academy of Sciences and National Academy of Engineering, 1972 [1974], Water quality criteria 1972: Washington, D.C., U.S. Government Printing Office, Ecological Research Series, EPA-R3-73-033-March 1973, 594 p.

Pickering, R. J., and Ficke, J.F., 1976, Design of nationwide water-qualitymonitoring networks: American Water Works Association Journal, v. 68 , no. 2 , Feb. 1976, p. 82-85.

Rainwater, F. H., 1962, Stream composition of the conterminous United States: U.S. Geological Survey Hydrologic Inventory Atlas HA-61, 3 plates.

Steele, T. D., 1974, Harmonic analysis of stream temperatures: U.S. Geological Survey Computer Center Contribution, Program No. B260, PB-239 016/AS, $48 \mathrm{p}$.

Steele, T. D., Gilroy, E. J., and Hawkinson, R. 0., 1974, An assessment of areal and temporal variations in streamflow quality using selected data from the National Stream Quality Accounting Network: U.S. Geological Survey Open-File Report 74-217, 210 p. 
U.S. Council on Environmental Quality, 1975, Environmental quality, 1975-Sixth annual report of the Council on Environmental Quality:

Washington, D.C., U.S. Government Printing Office, 763 p.

U.S. Council on Environmental Quality, 1976, Environmental quality, 1976-Seventh annual report of the Council on Environmental Quality:

Washington, D.C., U.S. Government Printing Office, 378 p.

U.S. Environmental Protection Agency, 1971a, Phosphate criteria: U.S. Environmental Protection Agency, Water Programs Office, Water Quality Standards Division, June 1971, 21 p.

1971b, Nitrates: U.S. Environmental Protection Agency, Water Programs Office, Water Quality Standards Division, Nov. 1971, 40 p.

1975, National interim primary drinking water regulations: Federal Register, v. 40, no. 248, Dec. 24, 1975, p. 59566-59588.

1976a, Quality criteria for water: U.S. Environmental Protection Agency report EPA-44019-76-023, 501 p.

1976b, Drinking water regulations, radionuclides: Federal Register, v. 41, no. 133, July 9, 1976, p. 28402-28409.

1977, National secondary drinking water regulations: Federal Register, v. 42, no. 62, March 31, 1977 , p. 17143-17147.

U.S. National Commission on Water Quality, 1975, Staff draft report: Washington, D.C., U.S. National Commission on Water Quality, Nov. 1975,865 p.

U.S. Water Resources Council, 1970, Water resources regions and subregions for the national assessment of water and related land resources: Washington, D.C., U.S. Water Resources Council, 188 p., 6 plates.

Ward, J. C., 1963, Annual variation of stream water temperature: American Society Civil Engineers Proceeding Journal Sanitary Engineering Division, v. 89 , no. SA6, p. 1-16.

Weatherburn, C. E., 1952, A first course in mathematical statistics: Cambridge, The University Press, 273 p.

Wentz, D. A., 1974, Effect of mine drainage on the quality of streams in Colorado, 1971-72: Denver, Colorado Water Conservation Board, Colorado Water-Resources Circular 21, 117 p., 3 plates.

Wolman, M. G., 1971, The Nation's rivers: Science, v. 174, no. 4012, p. 905-918. 
(a) Table 13--a listing of NASQAN stations in numerical order by station number, supplementing the alphabetical listing in table 1.

(b) Table 14--a station-by-station summary of measurements of water-quality characteristics.

Table 14 includes one page per station, arranged in numerical order by USGS station number--the same order given in table 13. Identification information, including the station number and name, latitude and longitude, and drainage area are given at the top of each page.

The upper part of each page of table 14 contains a statistical summary of water-quality characteristics measured at approximately monthly intervals. Statistics include the number of measurements, their arithmetic mean, standard deviation, and range. A regression summary shows the results of a regression analysis performed with specific conductance as the independent variable. Use of the regression coefficient, $\underline{R}$, the constant, $\underline{B}$, and the standard error of estimate are explained in the subsection of this report on specific conductance (pages 32-33).

A duration table of daily measurements of specific conductance is included in table 14 for each station for which more than 100 daily measurements are available. Application of values in the duration table are explained in the subsection on specific conductance.

A summary of the harmonic analysis of data on stream temperature is included in table 14 for each station having more than 50 measurements during the year. The subsection of this report on stream temperature record (pages 17-21) explains the use of the temperature statistics.

Data on minor elements, periphyton, and organic carbon are collected only 4 times per year at most NASQAN stations. Consequently, the summary at the bottom of each page of table 14 is included to show only maximum and minimum measured values.

Details on all the individual measurements summarized in table 14 are published as USGS reports in the series "Water Resources Data for (State Name), Water Year 1975." These data reports are published annually on a state-by-state basis and copies are available from district offices of the USGS, Water Resources Division, or from the National Technical Information Service, Springfield, VA 22151. Most state data reports prior to 1975 are published in two volumes, with water-quality data usually included in volume 2 . 
TABLE 13: NATIONAL STREAM QUALITY ACCOUNTING NETWORK STATIONS OPERATED DURING 1975 WATER YEAR (SORTED BY STATION NO.)

USGS

STAT.NO.

01017100 01021050

01034500

01046500

01059000

01066000

01096550

01103500

01155050

01184000

01205500

01304500

01358000

01404100

01408500

01463500

01474500

01491000

01540500

01553500

01570500

01645500

01673000

02035000

02049500

02081000

02083500

02089500

02105769

02129000

02132000

02136000

02170500

02171500

02175000

02176500

02198500

02202500

02226000

02228000

02231000

02244450

02248000

02253000

02273000

02279000

02288600
AROOSTOOK RIVER AT CARIBOU

ST. CROIX RIVER AT MILLTOWN

PENOBSCOT RIVER AT WEST ENFIELO

KENNEBEC RIVER AT BINGHAM

ANDROSCOGGIN RIVER NEAR AUBURN

SACO RIVER AT CORNISH

MERRIMACK RIVER ABOVE LOWELL

CHARLES RIVER AT CHARLES RIVER VILLAGE

CONNECTICUT RIVER AT WALPOLE

CONNECTICUT RIVER AT THOMPSONVILLE

HOUSATONIC RIVER AT STEVENSON

PECONIC RIVER AT RIVERHEAD

HUDSON RIVER AT GREEN ISLAND

RARITAN RIVER NEAR SOUTH BOUND BROOK

TOMS RIVER NEAR TOMS RIVVER

DELAWARE RIVER AT TRENTON

SCHUYLKILL RIVER AT PHILADELPHIA

CHOPTANK RIVER NEAR GREENSBORO

SUSQUEHANNA RIVEO AT DANVILLE

W.BR. SUSQUEHANNA RIVER AT LEWISBURG

SUSQUEHANNA RIVER AT HARRISBURG

POTOMAC RIVER AT GREAT FALLS

PAMUNKEY RIVER NEAR HANOVER

JAMES RIVER AT CARTERSVILLE

BLACKWATER RIVER NEAR FRANKLIN

ROANOKE RIVER NEAR SCOTLAND NECK

TAR RIVER AT TARBORO

NEUSE RIVER AT KINSTON

CAPE FEAR RIVER AT LOCK I NEAR KELLY

PEE DEE RIVER NEAR ROCK INGHAM

LYNCHES RIVER AT EFFINGHAM

BLACK RIVER AT KINGSTREE

LAKE MARION MOULTRIE CANAL NR PINEVILLE

SANTEE RIVER NEAR PINEVILLE

EDISTO RIVER NEAR GIVHANS

COOSAWHATCHIE RIVER NEAR HAMPTON

SAVANNAH RIVER NEAR CLYO

OGEECHEE RIVER NEAR EDEN

ALTAMAHA RIVER AT DOCTORTOWN

SATILLA RIVER AT ATKINSON

ST MARYS RIVER NEAR MACCLENNY

ST JOHNS RIVER AT PALATKA

SPRUCE CREEK NEAR SAMSULA

MAIN CANAL AT VERO BEACH

KISSIMMEE RIVER AT S65E NEAR OKEECHOBEE

WEST PALM BEACH CANAL AT WEST PALM BEACH MIAMI CANAL AT NW 36TH STREET, MIAMI
ST LATI - LONGI -

TUDE TUDE

DEG/ DEG/

MIN MIN

ME 4651 06800

ME $4510 \quad 06718$

ME 451406839

ME $4503 \quad 06953$

ME 440407013

ME $4348 \quad 07047$

MA $4238 \quad 07122$

MA 4215 07116

NH $4305 \quad 07226$

CT $4159 \quad 07236$

CT $4123 \quad 07310$

NY $4100 \quad 07241$

NY 424307341

NJ 4031 07432

NJ 395907413

NJ $4013 \quad 07447$

PA $4000 \quad 07512$

MD $3900 \quad 07547$

PA 405707637

PA 405807653

PA 401507653

MD $3900 \quad 07715$

VA $3746 \quad 07720$

VA $3740 \quad 07805$

VA $3646 \quad 07654$

NC $3612 \quad 07723$

NC $3554 \quad 07732$

NC $3515 \quad 07735$

NC $3424 \quad 07818$

NC $3457 \quad 07952$

SC $3403 \quad 07945$

SC $3340 \quad 07950$

SC 332308008

SC $3327 \quad 08009$

SC $3302 \quad 08024$

SC $3250 \quad 08108$

(GA) SC $3232 \quad 08116$

GA 321108125

GA 313908150

GA 311308152

FL 302208205

FL 293908138

FL $2903 \quad 08103$

FL $2739 \quad 08024$

FL $2714 \quad 08058$

FL 263908004

FL $2548 \quad 08016$ 
02292480 02296750 02303000 02313000 02320500 02329000 02358000 02359000 02366500 02368000 02375500 02420000 02429500 02449000 02469762 02479020 02489500 02492000 03049625 03085000 03150000 03201300 03204500 03215000 03216600 03234500 03245500 03254000 03274600 03276500 03277200 03290500 03301630 03303280 03321230 03374100 03378500 03425000 03438220 03470500 03543005 03571850 03593005 03609750 03612500 04014500 04024000 04027000 04040000 04045500 04045580 04057005 04059000 04059500 04085000
CALOOSAHATCHEE CNL AT ORTONA L.NR LABELLEFL 2647

PEACE OIVER AT ARCADIA

HILLSBOROUGH RIVER NEAR ZEPHYRHILLS

WITHLACOOCHEE RIVER NEAR HOLDER

SUWANNEE RIVER AT BRANFORD

OCHLOCKONEE RIVER NEAR HAVANA

APALACHICOLA RIVER AT CHATTAHOOCHEE

CHIPOLA RIVER NEAR ALTHA

CHOCTAWHATCHEE RIVER NEAR BRUCE

YELLOW RIVER AT MILLIGAN

ESCAMBIA RIVER NEAR CENTURY

ALABAMA RIVER NEAR MONTGOMERY

ALABAMA RIVER AT CLAIBORNE

TOMBIGBEE RIVER AT GAINESVILLE

TOMBIGBEE R. AT COFFEEVILLE L\&D NR.

PASCAGOULA RIVER NEAR BENNDALE

PEARL RIVER NEAR BOGALUSA

BOGUE CHITTO NEAR BUSH

ALLEGHENY RIVER AT NEW KENSINGTON

MONONGAHELA RIVER AT BRADDOCK

MUSKINGUM RIVER AT MCCONNELSVILLE

KANAWHA RIVER AT WINF IELD

MUD RIVER NEAR MILTON

BIG SANDY RIVER AT LOUISA

OHIO RIVER AT GREENUP DAM

SCIOTO RIVER AT HIGBY

LITTLE MIAMI RIVER AT MILFORD

LICKING RIVER AT BUTLER

GREAT MIAMI RIVER AT NEW BALTIMORE

WHITEWATER RIVER AT BROOKVILLE

OHIO R. AT MARKLAND DAM NEAR WARSAW

KENTUCKY RIVER AT LOCK 2 AT LOCKPORT

ROLLING FORK NEAR LEBANON JUNCTION

OHIO RIVER AT CANNELTON DAM

GREEN RIVER NEAR BEECH GROVE

WHITE RIVER AT HAZELTON

WABASH RIVER AT NEW HARMONY

CUMBERLAND RIVER AT CARTHAGE

CUMBERLAND RIVER NEAR GRAND RIVERS

FRENCH BROAD RIVER NEAR KNOXVILLE

TENNESSEE R. AT WATTS BAR DAM (TAILWATER) TN 3537

TENNESSEE RIVER AT SOUTH PITTSBURG

TN 3501

TENNESSEE R. AT PICKWICK LAND. D. (L.LOCK) TN 3504

TENNESSEE RIVER AT HWY 60 NEAR PADUCAH

KY 3702

OHIO RIVER AT LSD 53 NEAR GRAND CHAIN(IL)KY 3712

BAPTISM RIVER NEAR BEAVER BAY

ST LOUIS RIVER AT SCANLON

BAD RIVER NEAR ODANAH

ONTONAFON RIVER NEAR ROCKLAND

TAHQUAMENON R. NR TAHQUAMENON PARADISE

ST MARYS RIVER AROVE SAULT STE MARIE

MANISTIQUE RIVER AT MANISTIQUE

ESCANABA RIVER AT CORNELL

FORD RIVER NEAR HYDE

FOX RIVER AT WRIGHTSTOWN
08118

08153

08214

08221

08256

08423

08452

08510

08554

$0 \overline{8} 638$

08714

08624

08731

08809

08808

08846

08949

08954

07946

07953

08151

08155

08207

08238

08252

08252

08418

08421

08440

08501

08458

08458

08545

08642

08724

08733

08756

08557

08813

08346

08447

08542

08815

08832

08902

09112

09225

09042

08912

08516

08425

08615

08713

08712

08810 
04087000 MILWAUKEE RIVER AT MILWAUKEE

04108690 KALAMAZOO RIVER AT SAUGATUCK

04122030 MUSKEGON RIVER NEAR BRIDGETON

04126520 MANISTEE RIVER AT MANISTEE

04132052 CHEBOYGAN RIVER AT CHEBOYGAN

04142000 RIFLE RIVER NEAR STERLING

04157000 SAGINAW RIVER AT SAGINAW

04165500 CLINTON RIVER AT MT - CLEMENS

04165700 DETROIT RIVER AT DETROIT

04193500 MAUMEE RIVER AT WATERVILLE

04208000 CUYAHOGA RIVER AT INDEPENDENCE

04219640 NIAGARA RIVER AT FORT NIAGARA

04232006

04249000

04260500

04264331

04269000

04295000

04296500

05054020

05083500

05112000

05124000

GENESEE R AT CHARLOTTE DOCKS A

OSWEGO RIVER AT LOCK 7, OSWEGO

BLACK RIVER AT WATERTOWN

WI 4306

08755

MI 4239

08612

MI 4319

08602

MI 4415

08619

MI 4539

08428

MI 4404

08401

MI 4325

08358

MI 4236

08255

MI 4221

08258

$\mathrm{OH} 4130$

08343

$\mathrm{OH} 4124$

08138

NY 4316

07904

07737

07630

07556

ST LAWRENCE R AT CORNWALL ONT NR MASSENA NY $4500 \quad 07448$

ST REGIS RIVER AT BRASHER CENTER

RICHELIEU RIVER AT ROUSES POINT

CLYDE RIVER AT NEWPORT

RED RIVER OF THE NORTH BELOW FARGO

RED RIVER OF THE NORTH AT OSLO

ROSEAU RIVER NEAR CARIBOU

05131500

05132000

05267000

05330000

05331000

05340500

05369500

05378500

SOURIS (MOUSE) RIVER NEAR WESTHOPE

LITTLE FORK RIVER AT LITTLEFORK

BIG FORK RIVER AT BIG FALLS

MISSISSIPPI RIVER NEAR ROYALTON

MINNESOTA RIVER NEAR JORDAN

MISSISSIPPI RIVER AT ST PAUL

ST. CROIX RIVER AT ST. CROIX FALLS

CHIPPEWA RIVER AT DURAND

MISSISSIPPI RIVER AT WINONA

05407000

05420500

05446500

05474500

05490600

05543500

05586100

05587550

05594100

WISCONSIN RIVER AT MUSCODA

MISSISSIPPI RIVER AT CLINTON

ROCK RIVER NEAR JOSLIN

MISSISSIPPI RIVER AT KEOKUK

DES MOINES RIVER AT ST FRANCISVILLE

ILLINOIS RIVER AT MARSEILLES

ILLINOIS RIVER AT VALLEY CITY

MISSISSIPPI RIVER BELOW ALTON

KASKASKIA RIVER NEAR VENEDY STATION

(MN)

07447

07322

07211

09647

09708

09628

10057

09334

09348

09422

09338

09305

09239

09158

09138

09026

09015

09011

09122

09134

08843

09039

(IL)

IL 4120

IL 3942

09008

05599500 BIG MUDOY RIVER AT MURPHYSBORO

MO 3852

IL 3827

IL 3745

08938

06054500 MISSOURI RIVER AT TOSTON

06109500 MISSOURI RIVER AT VIRGELLE

06130500 MUSSELSHELL RIVER AT MOSBY

06132000 MISSOURI RIVER BELOW FT PECK DAM

06174500 MILK RIVER AT NASHUA

06185500

MISSOURI RIVER NEAR CULBERTSON

06214500

YELLOWSTONE RIVER AT BILLINGS

06294700

BIGHORN RIVER AT BIGHORN

06308500

06326500

TONGUE RIVER AT MILES CITY

06329500

POWDER RIVER NEAR LOCATE

MT 4609

08921

MT 4800

11125

MT 4700

11015

MT 4803

10753

MT 4808

10621

MT 4807

10622

MT 4548

MT 4609

MT 4622

MT 4627

MT 4741

10428

10828

10728

YELLOWSTONE RIVER NEAR SIDNEY

06337000 LITTLE MISSOURI RIVER NEAR WATFORD CITY

06338490

MISSOURI RIVER AT GARRISON DAM

ND 4735

10548

10519

10409

ND 4730

10315

06340500 KNIFE RIVER AT HAZEN

ND 4717

10126

10137 
06354000 CANNONBALL RIVER AT BREIEN

06357800 GRAND RIVER AT LITTLE EAGLE

06438000 BELLE FOURCHE RIVER NEAR ELM SPRINGS

06439300 CHEYENNE RIVER AT CHERRY CREEK

06440000 MISSOURI RIVER AT PIERRE

06452000 WHITE RIVER NEAR OACOMA

06453000 MISSOURI RIVER BELOW FT RANDALL DAM

06465500 NIOBRARA RIVER NEAR VERDEL

06478500 JAMES RIVER NEAR SCOTLAND

06485500 BIG SIOUX RIVER AT AKRON

06486000 MISSOURI RIVER AT SIOUX CITY

06686000 NORTH PLATTE RIVER AT LISCO

06764000 SOUTH PLATTE RIVER AT JULESBURG

06792499 LOUP R POWER CANAL AT DIV NR GENOA

06796000 PLATTE RIVER AT NORTH BEND

06805500 PLATTE RIVER NEAR LOUISVILLE

06807000 MISSOURI RIVER AT NEBRASKA CITY

06818000 MISSOURI RIVER AT ST JOSEPH

06856600 REPUBLICAN RIVER AT CLAY CENTER

06877600 SMOKY HILL RIVER AT ENTERPRISE

06887000 BIG BLUE RIVER NEAR MANHATTAN

06892350 KANSAS RIVER AT DESOTO

06902000 GRAND RIVER NEAR SUMNER

06926510 OSAGE RIVER BELOW ST. THOMAS

06934500 MISSOURI RIVER AT HERMANN

07022000 MISSISSIPPI RIVER AT THEBES

07026000 OBION RIVER AT OBION

07032000 MISSISSIPPI RIVER AT MEMPHIS

07047800 ST FRANCIS RIVER AT PARKIN

07047900 ST FRANCIS BAY AT RIVERFRONT

07077800 WHITE RIVER AT CLARENDON

07137500 ARKANSAS RIVER NR COOLIDGE

07139500 ARKANSAS RIVER AT DODGE CITY

07146500 ARKANSAS RIVER AT ARKANSAS CITY

07157950

07161000

07164400

CIMARRON RIVER NEAR BUFFALO

ND 4623

10056

SD $4530 \quad 10049$

SD $4422 \quad 10234$

SD $4436 \quad 10129$

SD $4422 \quad 10022$

SD $4345 \quad 09933$

SD $4304 \quad 09833$

NB 424409813

SD $4311 \quad 09738$

(IA) SD $4250 \quad 09634$

IA 422909625

NB $4130 \quad 10238$

CO $4059 \quad 10215$

NB 4124

NB 4127

NB 4101

(NB) IA 4041

MO 3948

KS 3921

KS 3854

KS 3914

KS 3859

MO 3938

MO 3820

MO 3843

(IL) MO 3713

TN 3615

(TN) AR 3508

AR 3516

09749

09646

09609

09551

09453

09708

09707

09634

09458

09316

09214

09126

08928

08912

09004

09034

AR $3516 \quad 09041$

AR 3441

KS 3802

09119

KS 3745

KS 3703

OK 3655

OK 3558

ARKANSAS RIVER AT SAND SPRINGS NR TULSA OK 3607

07178620

07193500

07227140

07228000

07231500

07232500

07234000

07237500

07245000

07250550

07263620

07265450

NEWT GRAHAM L\&D (VERDIGRIS R) NEAR INOLA

NEOSHO R BL FT GIBSON LAKE NR FT GIBSON

CANADIAN RIVER ABOVE NM-TEX STATE LINE

CANADIAN RIVER NEAR CANADIAN

CANADIAN RIVER AT CALVIN

BEAVER RIVER NEAR GUYMON

BEAVER RIVER AT BEAVER

NORTH CANADIAN RIVER AT WOODWARO

OK 3603

OK 3551

NM 3523

TX 3556

OK 3459

OK 3643

OK 3649

OK 3626

OK 3516

AR 3521

10201

10001

09704

09924

09702

09607

09532

09514

10303

10022

09614

10130

10031

09917

09514

ARKANSAS RIVER AT DAM 13 NEAR VAN BUREN

ARKANSAS RIVER AT L AND D 6 LIT ROCK

07287120

MISSISSIPPI RIVER NEAR ARKANSAS CITY

AR 3440

09418

AR 3334

09209

MS 3324

MS 3219

MS 3221

MS 3119

09115

07289000 MISSISSIPPI RIVER AT VICKSBURG

07290000 BIG BLACK RIVER NEAR BOVINA

07292500 HOMOCHITTO RIVER AT ROSETTA

07297910

PDTF RED RIVER NEAR WAYSIDE TEXAS

07300000

SALT FORK RED RIVER NEAR WELLINGTON

TX 3450

09018

09054

09042

09106

TX $3457 \quad 10013$ 
07305000 NF RED RIVER NEAR HEADRICK

07308500 RED RIVER NEAR BURKBURNETT

OK 3438

TX 3406

09906

07331000 WASHITA RIVER NEAR DURWOOD

OK 3414

09832

07331600

RED RIVER AT DENISON DAM NEAR DENISON

$T \times 3349$

09659

07344410

RED RIVER ABOVE SHREVEPORT

LA 3233

09634

07355500

RED RIVER AT ALEXANDRIA

07362000 OUACHITA RIVER AT CAMDEN

07367640 OUACHITA RIVER AT COLUMBIA

07369500

TENSAS RIVER ATT TENDAL

07373420

MISSISSIPPI RIVER NEAR ST FRANCISVILLE

07374508

MISSISSIPPI RIVER AT NEW ORLEANS

07378510

AMITE RIVER AT 4-H CAMP NR DENHAM SPGS

07381490

ATCHAFALAYA RIVER AT SIMMESPORT

07385700

08015900

BAYOU TECHE AT KEYST L NR ST MARTINSVL

LA 3119

09346

AR 3336

09227

LA 3206

09249

LA 3226

09204

LA 3046

09122

LA 2957

09124

09008

LA 3026

09058

LA 305909148

CALCASIEU RIVER NEAR LAKE CHARLES

08030500

SABINE RIVER NEAR RULIFF

08041000 NECHES RIVER AT EVADALE

08065350

08066500

TRINITY RIVER NEAR CROCKETT

TRINITY RIVER AT ROMAYOR

08068000

WEST FORK SAN JACINTO RIVER NEAR CONROE

08082500

SALT FORK BRAZOS RIVER NEAR ASPERMONT

LA 3004

LA 3018

09150

TX 3018

09311

$T X 3021$

$T X 3120$

09345

09406

$T \times 3026$

09539

$T \times 3015$

09451

09527

$T \times 3320 \quad 10014$

08098290

BRAZOS RIVER AT SEYMOUR

$T \times 3335$

09916

BRAZOS RIVER NEAR HIGHBANK

TX 3108

BRAZOS RIVER AT ROSHARON

08123800

BEALS CREEK NEAR WESTBROOK

08136700 COLORADO RIVER NEAR STACY

08158000

COLORADO RIVER AT AUSTIN

08162000

COLORADO RIVER AT WHARTON

08164500

NAVIDAD RIVER NEAR GANADO

08176500

GUADALUPE RIVER AT VICTORIA

08188500

SAN ANTONIO RIVER AT GOLIAD

08210000

NUECES RIVER NEAR THREE RIVERS

08212400 LOS OLMOS CREEK NEAR FALFURRIAS

08251500 RIO GRANDE NEAR LOBATOS

08313000 RIO GRANDE AT OTOWI BRDG NR S.ILDEFONSO

08358300

RIO GRANDE CNV CH AT SAN MARCIAL

08370500

RIO GRANDE AT FT QUITMAN

08377200

RIO GRANDE AT FOSTER RANCH NR LANGTRY

$T \times 2921$

09649

TX 3212

09535

TX 3130

$T \times 3015$

TX 2919

$T \times 2902$

TX 2848

TX 2839

TX 2826

TX 2716

CO 3705

10101

09934

09742

09606

09633

09701

09723

09811

09808

10545

NM 3552

10608

NM 3341

10700

TX 3105

10536

$T \times 2947 \quad 10145$

08407500 PECOS RIVER AT RED BLUFF

NM 3204

10402

PECOS RIVER NEAR LANGTRY

TX 2948

10127

08459000 RIO GRANDE AT LAREDO

08475000 RIO GRANDE NEAR BROWNSVILLE

08481500 RIO TULAROSA NEAR BENT

09152500

GUNNISON RIVER NEAR GRAND JUNCTION

$T \times 2730$

$T \times 2553$

09930

NM 3309

09727

09163530

COLORADO RIVER BLW. COLO-UTAH STAT

CO 3859

10554

10827

09180500

COLORADO RIVER NEAR CISCO

CO 3905

10906

09234500 GREEN RIVER NEAR GREENDALE

09251000 YAMPA RIVER NEAR MAYBELL

UT 3849

10918

UT 4054

10925

09260000 LITTLE SNAKE RIVER NEAR LILY

CO 4030

10802

09315000 GREEN RIVER AT GREEN RIVER

09368000 SAN JUAN RIVER AT SHIPROCK

09379500 SAN JUAN RIVER NEAR BLUFF

09380000 COLORADO RIVER AT LEES FERRY

09401200 LITTLE COLORADO RIVER AT CAMERON

09421500 COLORADO RIVER BELOW HOOVER DAM

CO 4033

10825

UT $3859 \quad 11009$

NM $3648 \quad 10844$

UT $3709 \quad 10952$

AZ $3652 \quad 11135$

AZ $3553 \quad 11125$

AZ $3601 \quad 11444$ 
09424190 09426600 09429490 09466500 09473500 09474000 09489000 09502000 09510000 09518000 09520700 09522000 10059500 10126000 10141000 10171000 10224000 10237000 10249900 10254970 10261500 10277400 10301500 10312000 10335000 10346000 10351700 10352500 10396000 11074000 11103010 11152500 11250000 11303500 11325500 11447650 11467000 11530500 12031000 12045500 12200500 12318500 12355000 12398600 12400520 12433000 12510500 13022500 13154500 13213000 13213100 13290450 13317000 13353200 14048000
COLORADO RIVER AQUED. NR SAN JACINTO

BILL WILLIAMS R NEAR PLANET

COLORADO RIVER ABOVE IMPERIAL DAM

GILA RIVER AT CALVA

SAN PEDRO RIVER AT WINKELMAN

GILA RIVER AT KELVIN

SANTA CRUZ RIVER NEAR LAVEEN

SALT RIVER BELOW STEWART MT DAM

VERDE RIVER BELOW BARTLETT DAM

GILA RIVER ABOVE DIV AT GILLESPIE DAM

GILA RIVER NEAR MOUTH NEAR YUMA

COLORADO R AT N INT BDRY AB MORELOS DAM

BEaR Lake outLet canal near páis

BEAR RIVER NEAR CORINNE

WEBER RIVER NEAR PLAIN CITY

JORDAN RIVER AT SALT LAKE CITY

SEVIER RIVER NEAR LYNNDYL

BEAVER RIVER AT ADAMSVILLE

CHIATOVICH CREEK NEAR DYER

NEW RIVER AT INT. BDRY. NR. CALEXICO

MOJAVE R. AT LOW NARROWS NR VICTORVILLE

OWENS RIVER BLW TINEMAHA D. NR BIG PINE

WALKER RIVER NEAR WABUSKA

CARSON RIVER NEAR FORT CHURCHILL

HUMBOLDT RIVER NEAR RYE PATCH

TRUCKEE RIVER AT FARAD

TRUCKEE RIVER NEAR NIXON

MC DERMITT CREEK NEAR MC DERMITT

DONNER UND BLITZEN R. NEAR FRENCHGLEN

SANTA ANA RIVER BELOW PRADO DAM

LOS ANGELES R.AT WIL.ST.BRDG.AT LONG BCH

SALINAS RIVER NEAR SPRECKELS

FRIANT-KERN CANAL AT FRIANT

SAN JOAQUIN RIVER NEAR VERNALIS

MOKELUMNE RIVER AT WOODBRIDGE

SACRAMENTO RIVER AT FREEPORT

RUSSIAN RIVER NEAR GUERNEVILLE

KLAMATH RIVER NEAR KLAMATH

CHEHALIS RIVER AT PORTER

ELWHA R AT MCDONALD BRIDGE NR PT ANGELES

SKAGIT RIVER NEAR MT VERNON

KOOTENAI RIVER NEAR COPELAND

FLATHEAD RIVER aT FLATHEAD, B.C.

PEND OREILLE $R$ AT INTERNATIONAL BOUNDARY

COLUMBIA RIVER AT NORTHPORT

SPOKANF RIVER AT LONG LAKE

YAKIMA RIVER AT KIONA

SNAKE RIVER ABOVE RESERVOIR NEAR ALPINE

SNAKE RIVER AT KING HILL

BOISE RIVER NEAR PARMA

SNAKE RIVER AT NYSSA

SNAKE RIVER AT HELLS CANYON DAM

SALMON RIVER AT WHITE BIRD

SNAKE RIVER AT BURBANK

JOHN DAY RIVER AT MCDONALD FERRY
CA 3349

AZ 3416

AZ 3253

AZ 3311

AZ 3259

AZ 3306

AZ 3314

AZ 3334

AZ 3349

AZ 3314

AZ 3243

AZ 3243

UT 4213

UT 4135

UT 4117

UT 4044

UT 3929

UT 3815

NV 3750

CA 3240

CA 3434

CA 3703

NV 3909

NV 3918

NV 4028

(CA) NV 3926

NV 3947

NV 4158

OR 4247

CA 3353

CA 3348

CA 3638

CA 3700

CA 3741

CA 3810

CA 3827

CA 3830

CA 4131

WA 4656

WA 4803

WA 4831

ID 4855

MT 4900

WA 4900

WA 4855

WA 4750

WA 4615

WY 4318

ID 4300

ID 4347

(OR) ID 4353

(OR) ID 4515

ID 4545

WA 4613

OR 4535
11658

11402

11428

11013

11046

11059

11210

11132

11138

11246

11433

11443

11121

11206

11205

11155

11224

11246

11812

11530

11719

11813

11906

11919

11818

12002

11920

11750

11852

11739

11812

12140

11942

12116

12118

12130

12256

12358

12319

12335

12220

11625

11428

11721

11747

11751

11929

11047

11512

11658

11659

11642

11619

11901

12024 
14103000 DESCHUTES RIVER AT MOODY NEAR BIGGS

14113000 KLICKITAT RIVER NEAR PITT

14128910 COLUMBIA RIVER AT WARRENDALE

14207500 TUALATIN RIVER AT WEST LINN

14211720 WILLAMETTE RIVER AT PORTLAND

14301000 NEHALEM RIVER NEAR FOSS

14321000 UMPQUA RIVER NEAR ELKTON

14372300 ROGUE RIVER NEAR AGNESS

15024800 STIKINE RIVER NEAR WRANGELL

15294350 SUSITNA RIVER AT SUSITNA STATION

15304000 KUSKOKWIM RIVER AT CROOKED CREEK

15565447 YUKON RIVER AT PILOT STATION

15744500 KOBUK RIVER NEAR KIANA

15896000 KUPARUK RIVER NEAR DEADHORSE

16031000 WAIMEA RIVER AT WAIMEA

16213000 WAIKELE STREAM AT WAIPAHU

16229300 KALIHI STREAM AT KALIHI

16400000 HALAWA STREAM NEAR HALAWA

16618000 KAHAKULOA STREAM NEAR HONOKOHAU

16704000 WAILUKU RIVER AT PIIHONUA

50038100 RIO GRANDE DE MANATI AT HWY 2 NR MANATI

50046000

RIO DE LA PLATA AT TOA ALTA

50092000 RIO GRANDE DE PATILLAS NEAR PATILLAS

50144000 RIO GRANDE DE ANASCO NEAR SAN SEBASTIAN

$\begin{array}{lll}\text { OR } & 4537 & 12054 \\ W A & 4545 & 12113 \\ \text { OR } & 4537 & 12202 \\ \text { OR } & 4521 & 12240 \\ \text { OR } & 4531 & 12240 \\ \text { OR } & 4542 & 12345 \\ \text { OR } & 4335 & 12333 \\ \text { OR } & 4235 & 12404 \\ A K & 5642 & 13208 \\ A K & 6133 & 15031 \\ A K & 6152 & 15807 \\ A K & 6156 & 16253 \\ A K & 6659 & 16007 \\ A K & 7017 & 14858 \\ H I & 2159 & 15940 \\ H I & 2123 & 15801 \\ H I & 2120 & 15753 \\ H I & 2110 & 15646 \\ H I & 2059 & 15633 \\ H I & 1943 & 15509 \\ P R & 1826 & 06632 \\ P R & 1824 & 06615 \\ P R & 1802 & 06602 \\ P R & 1817 & 06703\end{array}$ 
Table 14.--Summary of measurements at each station

LAT 46D5OM57S LONG 068D00MI2S

DRAINAGE AREA: 0 SQ MI

PERIOD OF RECORD: $10 / 01 / 74-09 / 30 / 75$ S

STATISTICAL SUMMARY OF SELECTED DISSOLVED CHEMICAL CONSTITUENTS AND

REGRESSION RELATIONSHIPS OF CONSTITUENT CONCENTRATIONS TO SPECIFIC CONDUCTANCE

CONSILIUENI

\section{CONSILIUENI_IHG/L OR UNII SHOWN \\ SAMPLE \\ STANDARD \\ MEAN DEVIALION}

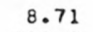

103.9

2051.5

7.17

7.17
0.077

0.077
0.257

0.257
0.408

0.408
3361.9

3361.9
5.4

94.9

135.9

156.3

3.50

13.22

2.25
2.80
1.20

1.20

42.8

0.0
7.75

2.95

2.95
55.0
83.5
42.0

83.5
42.0
8.0
2.8

8.0
2.8

0.20

9.62
21.7
2587.5
0.64
0.047
0.199
0.115
5561.0
3.5
8.3
181.8
278.1
1.65
2.79
0.66
0.99
0.91
13.8
0.0
2.34
1.28
11.3
13.8
9.6
7.1
1.0
0.08

0.0 REGRESSION
COEFICIENT

BEGRESSION SUMMARY

SAMPLE COEFICIENT, CONSTANT,

CORRELATION COEEISIENI

STANDARD SIZE.

- B - B - B -

$\begin{array}{rrrr}0.0 & 23.0 & & \\ 72 & 128 & & \\ 321 & 9580 & 12 & -53.127 \\ 6.5 & 8.5 & 12 & 0.0089 \\ 0.04 & 0.19 & 12 & 0.00074 \\ 0.04 & 0.61 & 12 & -0.00069 \\ 0.27 & 0.61 & 12 & 0.00117 \\ 41 & 19000 & 12 & 60.048\end{array}$

7572.324
6.2389
0.00081
0.32805
0.28631
-2878.068

$-0.445 *$

$0.302^{*}$

0.341 .

-0.075 .

0.222.

$0.234^{*}$

ESIIMAIE

0.00117
60.048

$-2878.068$

0.0218
0.0704
0.0172
0.0299
0.0223
0.338
0.000
0.0505
0.0383
0.416
0.504
0.252
0.002
0.001
-0.0028

0.340 *

0.649

0.671 *

0.781

0.033 .

0.629 .

$0.000^{\circ}$

0.556

0.770

0.943 .

0.939 *

$0.074^{*}$

$0.007^{\circ}$

$0.007^{*}$

$0.024^{*}$
2430.7

0.64

0.046

0.209

0.117
5670.6

*Not significant at the 95 percent confidence level.

SUMMARY OF HARMONIC ANALYSIS OF STREAM TEMPERATURE EORM OF EQUAIUN: I. $(D)=M+A+S I N G .0172+D \pm C)$

\begin{tabular}{|c|c|c|c|c|c|}
\hline & & & & & STANDARD \\
\hline & HARMONIC & AMPLI TUDE & PHASE & VAR IATION & ERROR OF \\
\hline $\begin{array}{l}\text { SAMPLE } \\
\text { SIZE. }\end{array}$ & $\begin{array}{l}\text { MEAN - M } \\
\text { SDEG CI }\end{array}$ & ${ }_{10 E}^{-A}(1)$ & $\begin{array}{l}\text { ANGLE - C } \\
\text { (RADIANSI }\end{array}$ & $\begin{array}{c}\text { EXPLAINED } \\
(g)\end{array}$ & $\begin{array}{l}\text { ESTIMATE } \\
\text { IDEG_CI }\end{array}$ \\
\hline 31 & 7.80 & 11.70 & 2.67 & 85 & 2.67 \\
\hline
\end{tabular}

SUMMARY OF MAXIMUM AND MINIMUM CONCENTRATIONS OF CONSTITUENTS SAMPLED AT A FREQUENCY OF QUARTERLY 11975 WY

01017100 -- AROOSTOOK RIVER AT CARIBOU ME

\begin{tabular}{|c|c|c|c|c|c|c|}
\hline \multirow{2}{*}{ CONSTITUENT } & \multicolumn{3}{|c|}{ TOTAL } & \multicolumn{3}{|c|}{ DISSOLVED } \\
\hline & $\begin{array}{l}\text { NO. } \\
\text { SAMPLES }\end{array}$ & $\begin{array}{l}\text { MINIMUM } \\
\text { CONC. }\end{array}$ & $\begin{array}{l}\text { MAXIMUM } \\
\text { CONC. }\end{array}$ & $\begin{array}{l}\text { NO. } \\
\text { SAMPLES }\end{array}$ & $\begin{array}{c}\text { MINIMUM } \\
\text { CONC. }\end{array}$ & $\begin{array}{l}\text { MAXIMUM } \\
\text { CONC. }\end{array}$ \\
\hline \multicolumn{7}{|l|}{ MINOR ELEMENTS: } \\
\hline ARSENIC (AS), UG/L & 4 & 0 & 1 & 4 & 0 & 2 \\
\hline CADMIUM $(C D), U G / L$ & 4 & 0 & 0 & 4 & 0 & 1 \\
\hline CHROMIUM (CR), UG/L & 4 & $<10$ & 10 & 4 & 0 & 20 \\
\hline COBALT $(C O), U G / L$ & 4 & 0 & 2 & 4 & 0 & 1 \\
\hline COPPER (CU), UG/L & 4 & 0 & 10 & 4 & 0 & 10 \\
\hline IRON (FE), UG/L & 4 & 180 & 410 & 4 & 20 & 110 \\
\hline $\operatorname{LEAD}(P B), U G / L$ & 4 & 13 & 69 & 4 & 2 & 8 \\
\hline MANGANESE (MN), UG/L & 4 & 30 & 40 & 4 & 10 & 40 \\
\hline MERCURY (HG), UGIL & 4 & $<0.5$ & $<0.5$ & 4 & $<0.5$ & $<0.5$ \\
\hline \multicolumn{7}{|l|}{ PERIPHYTON : } \\
\hline GIOMASS, DRY WT., G/SO M & 2 & .00 & 1.79 & & & \\
\hline BIOMASS, ASH WT., G/SQ M & 2 & .50 & 1.29 & & & \\
\hline CHLOROPHYLL A, MG/SO M & 2 & .5 & 1.5 & & & \\
\hline CHLOROPHYLL B, MG/SQ M & 2 & .0 & $\cdot 0$ & & & \\
\hline ORGANIC CARBON, MG/L & 3 & 6.0 & 11.0 & & & \\
\hline
\end{tabular}


Table 14.--Summary of measurements at each station--Continued

LAT 4501OM11S LONG $067017 M 50 S$

DRAINAGE AREA: 1460 SQ MI ( 3781 SQ KM)

PERIOD OF RECORD: $10 / 01 / 74$ - 09/30/75

STATISTICAL SUMMARY OF SELECTED DISSOLVED CHEMICAL CONSTITUENTS AND

REGRESSION RELATIONSHIPS OF CONSTITUENT CONCENTRATIONS TO SPECIFIC CONDUCTANCE

CONSIITUENI

GONSIUUENT IMG/L OR UNII SHOWNI

\begin{tabular}{c} 
CONSIUU \\
SAMPLE \\
SIZE \\
\hline 23 \\
23 \\
23 \\
23 \\
23 \\
9 \\
9 \\
9 \\
9 \\
9 \\
9 \\
22 \\
21 \\
3 \\
4 \\
4 \\
3 \\
3 \\
4 \\
4 \\
4 \\
4 \\
3 \\
3 \\
4 \\
4 \\
23 \\
3
\end{tabular}

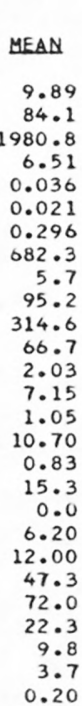

STANDARD

REYIAIION

9.37
21.0
1495.7
0.11
0.009
0.021
0.087
822.4
2.6
5.8
507.8
127.6
0.51
2.19
0.06
3.01
0.21
5.6
0.0
1.05
1.41
4.5
4.4
7.8
9.4
1.9
0.10

21.0

495.7

0.009

.021

2.6

507.8

127.6

2.19

0.06

3.01

5.6

1.41

4.5
4.4

7.8
9.4

0.10
TEMPERATURE, WATER (DEG C) SPECIFIC CONDUCTANCE (MICROMHOS) STREAMFLOW (CUBIC FT/SEC) PH (STANDARD UNITS

NITRITE + NITRATE, TOTAL NITROGEN, KJELDAHL, TOTAL PHYTOPLANKTON, TOTAL (CELLS/ML) SEDIMENT, SUSPENDED

SEDIMENT, CLAY-SILT (PERCENT) STREPTOCOCCI, FECAL $(\mathrm{COL} / 100 \mathrm{ML}$ SILICA, DISSOLVED

MAGNESIUM, DISSOLVED

SODIUM, DISSOLVED

POTASSIUM, DISSOLVED

BICARBONATE, ION

CARBONATE, ION

SULFATE, DISSOLVED

CHLURIDE, DISSOLVED

DISSOLVED SOLIDS, SUM OF CONST

DISSOLVED SOLIDS,
HARDNESS, TOTAL

HARDNESS, NONCARBONATE

FLOURIDE, DISSOLVED
BANGE

BEGRESS $10 N$ SUMMARY

REGRESSION

SAMPLE

SIZE COEFICIENT,

CONSTANT, CORRELAIION
COEEICIENI

0.0
43
793
6.3
0.02
0.00
0.12
40
1
85
5
1
1.6
5.0
0.5
8.1
0.6
10
0
5.2
10.0
43
67
16
1
1
0.1

*Not significant at the 95 percent confidence level

DAILY SPECIFIC CONOUCTANCE IN
MICROMHOS AT 25 DEG C, THAT WAS
EQUALLED OR EXCEEDE FOR THE
INOICATED PERCENTAGE OF TIME

SUMMARY OF HARMONIC ANALYSIS OF STREAM TEMPERATURE

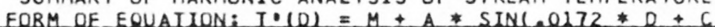

\begin{tabular}{|c|c|c|c|c|c|}
\hline & & & & & STANDARD \\
\hline & HARMONIC & AMPLITUDE & PHASE & VARIATION & ERROR OF \\
\hline SAMPLE & MEAN - M & $-A$ & ANGLE - C & EXPLA INED & ESTIMATE \\
\hline 142 & 8.86 & 14.02 & 2.75 & 91 & 2.11 \\
\hline
\end{tabular}

SUMMARY OF MAXIMUM AND MINIMUM CONCENTRATIONS OF CONSTITUENTS SAMPLED AT A FREOUENCY OF QUARTERLY (1975 WY)

01021050 -- ST. CROIX RIVER AT MILLTOWN, MAINE

\begin{tabular}{|c|c|c|c|c|c|c|}
\hline \multirow{2}{*}{ CONSTITUENT } & \multicolumn{3}{|c|}{ TOTAL } & \multicolumn{3}{|c|}{ DISSOLVED } \\
\hline & $\begin{array}{c}\text { NO. } \\
\text { SAMPLES }\end{array}$ & $\begin{array}{l}\text { MIN IMUM } \\
\text { CONC. }\end{array}$ & $\begin{array}{l}\text { MAXIMUM } \\
\text { CONC. }\end{array}$ & $\begin{array}{l}\text { NO. } \\
\text { SAMPLES }\end{array}$ & $\begin{array}{l}\text { MINIMUM } \\
\text { CONC. }\end{array}$ & $\begin{array}{c}\text { MAXIMUM } \\
\text { CONC. }\end{array}$ \\
\hline \multicolumn{7}{|l|}{ MINOR ELEMENTS: } \\
\hline ARSENIC (AS), UG/L & 3 & 0 & 1 & 3 & 0 & 1 \\
\hline CADMIUM $(C D), U G / L$ & 3 & 0 & 0 & 5 & 0 & $<7$ \\
\hline CHROMIUM (CR), UG & 3 & 0 & 10 & 5 & 0 & $<10$ \\
\hline COBALT $(C O), U G / L$ & 3 & 0 & 0 & 5 & 0 & 0 \\
\hline COPPER $(C U), U G / L$ & 3 & 0 & 20 & 5 & 0 & 2 \\
\hline IRON $(F E), U G / L$ & 3 & 220 & 330 & 5 & 170 & 360 \\
\hline LEAD $(P B), U G / L$ & 3 & 9 & 37 & 5 & 6 & 45 \\
\hline MANGANESE (MN), UG/L & 3 & 60 & 100 & 5 & 60 & 160 \\
\hline MERCURY $(H G), U G / L$ & 4 & $<0.5$ & 1.1 & 3 & $<0.5$ & $<0.5$ \\
\hline SELENIUM (SE), UG/L & 3 & 0 & 0 & 3 & 0 & 0 \\
\hline ZINC $(Z N), U G / L$ & 3 & 0 & 10 & 5 & 0 & 10 \\
\hline \multicolumn{7}{|l|}{ PERIPHYTON: } \\
\hline BIOMASS, ORY WT., G/SQ M & 2 & .79 & 1.79 & & & \\
\hline BIOMASS, ASH WT., G/SQ M & 2 & .59 & 4.39 & & & \\
\hline CHLOROPHYLL A, MG/SQ M & 2 & .8 & 3.0 & & & \\
\hline CHLOROPHYLL B, MG/SQ M & 2 & .3 & .3 & & & \\
\hline ORGANIC CARBON, MG/L & 16 & 3.3 & 16.0 & & & \\
\hline
\end{tabular}


IT 45014M15S LONG 068039M1OS

(AINAGE AREA: 6670 SQ MI $1 \quad 17275$ SQ KM)

RIOD OF RECORD: 10/01/74 - 09/30/75

STATISTICAL SUMMARY OF SELECTED DISSOLVED CHEMICAL CONSIITUENTS AND

REGRESSION RELATIONSHIPS OF CONSTITUENT CONCENTRATIONS TO SPECIFIC CONDUCTANCE

CONSIIIUENI

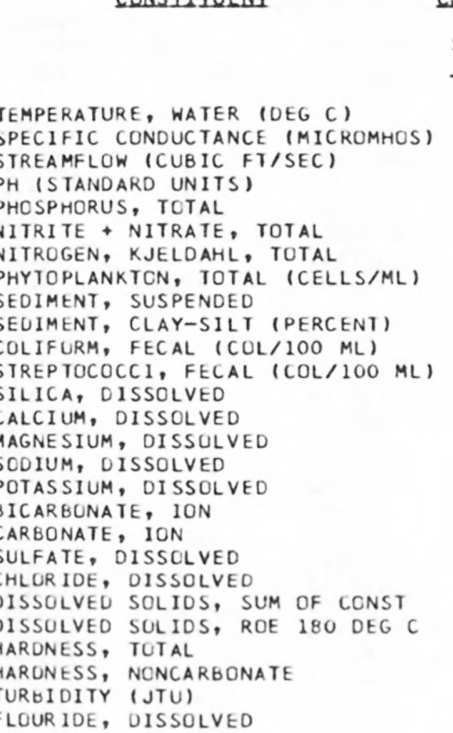

\begin{tabular}{|c|c|c|}
\hline $\begin{array}{l}\text { SAMPLE } \\
\text { SIZE }\end{array}$ & MEAN & $\begin{array}{l}\text { STANDARD } \\
\text { DEY } I A \amalg U N\end{array}$ \\
\hline 12 & 9.29 & 9.35 \\
\hline 12 & 58.5 & 7.8 \\
\hline 12 & 9696.7 & 7241.1 \\
\hline 12 & 6.58 & 0.13 \\
\hline 11 & 0.024 & 0.008 \\
\hline 11 & 0.045 & 0.050 \\
\hline 11 & 0.312 & 0.143 \\
\hline 12 & 641.8 & 1225.2 \\
\hline 12 & 5.0 & 2.3 \\
\hline 12 & 90.4 & 18.0 \\
\hline 12 & $138 \cdot 3$ & 83.4 \\
\hline 12 & 92.1 & 76.3 \\
\hline 4 & 3.20 & 0.36 \\
\hline 4 & 6.57 & 1.04 \\
\hline 4 & 1.35 & 0.39 \\
\hline 4 & 3.07 & 0.75 \\
\hline 4 & 0.57 & 0.33 \\
\hline 4 & 14.3 & 2.5 \\
\hline 4 & 0.0 & 0.0 \\
\hline 4 & 8.55 & 1.59 \\
\hline 4 & 2.97 & 0.22 \\
\hline 4 & 33.8 & 5.0 \\
\hline 4 & 47.5 & 9.7 \\
\hline 4 & 22.3 & 4.2 \\
\hline 4 & 10.5 & 4.1 \\
\hline 4 & 3.0 & 1.2 \\
\hline 4 & 0.17 & 0.05 \\
\hline
\end{tabular}

BEGRESSION SUMMABY

REGRESSION

SAMPLE COEFICIENT, CONSTANT, CORRELATION ERTANDARD SIZE - B - - B COEEICIENI_ ESIIMAIE

$\begin{array}{rr}\text { BANGE } & \\ 0.0 & 23.0 \\ 48 & 72 \\ 4630 & 30200 \\ 6.4 & 6.8 \\ 0.01 & 0.04 \\ 0.00 & 0.14 \\ 0.14 & 0.69 \\ 70 & 4500 \\ 1 & 9 \\ 43 & 100 \\ 50 & 350 \\ 38 & 290 \\ 2.9 & 3.6 \\ 5.1 & 7.5 \\ 0.8 & 1.7 \\ 2.2 & 4.0 \\ 0.2 & 1.0 \\ 11 & 17 \\ 0 & 0 \\ 6.2 & 9.6 \\ 2.7 & 3.2 \\ 27 & 38 \\ 34 & 55 \\ 16 & 25 \\ 5 & 15 \\ 2 & 4 \\ 0.1 & 0.2 \\ & \end{array}$

$12-222.209$

12

11

11

12

$-0.0003$

$-0.00084$

0.00437

0.00532

$-44.468$

22695.875

6.6010

0.07362

$-0.21351$

$-0.00325$

3243.141

$-0.238^{*}$

$-0.018$

$-0.795$

0.666

0.283 *
-0.281 .

7376.5

0.13

0.005

0.039

0.145
1233.1

4
4
4
4
4
4
4
4
4
4
4
4
4
4
4

1.3445
3.0132
0.9254
-1.4302
0.4099
-3.913
0.000
4.1936
1.7092
9.769
25.327
10.692
14.746
-4.234
0.1986

0.686 *

0.452 *

$0.144^{\circ}$

$0.795^{*}$

0.066 *

0.956 :
$0.000^{*}$

$0.361^{*}$

$0.751^{*}$

0.632 .

0.301 *

0.363 *

$-0.135^{*}$

0.824 *
-0.062 *
0.32

1.13

0.47

0.55
0.40

0.9

0.0

1.81

0.18

11.3

4.8

4.8

5.0
0.8
0.06

*Not significant at the 95 percent confidence level.

DURAIUON IABLE OF DAILY SPECIEIC CONOUCIANCE

DAILY SPECIFIC CONDUCTANCE IN

MICKOMHOS AT 25 DEG C. THAT WAS

EQUALLED OR EXCEEDED FOR THE

$\begin{array}{rrrrrr}-18 & 5 z & 10 z & 20 z & 30 z & 50 z \\ 124 & 94 & 81 & 71 & 67 & 61\end{array}$

INDICATED PERCENTAGE OF TIME

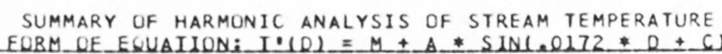

\begin{tabular}{|c|c|c|c|c|c|}
\hline & & & & & STAND ARD \\
\hline & HARMONIC & AMPLITUDE & PHASE & VARIATION & ERROR OF \\
\hline SAMPLE & MEAN - M & $-A$ & ANGLE - C & EXPLAINED & $\begin{array}{l}\text { ESTIMATE } \\
\text { IDEG }\end{array}$ \\
\hline SIZE_ & $10 E G \quad C 1$ & (DEG $C)$ & $(B A D I A N S)$ & $-(z)$ & 1DEG 61 \\
\hline
\end{tabular}

$\begin{array}{llllll}338 & 9.12 & 12.98 & 2.66 & 93 & 2.43\end{array}$

SUMMARY OF MAXIMUM AND MINIMUM CONCENTRATIONS OF CONSTITUENTS SAMPLED AT A FREQUENCY OF QUARTERLY (1975 WY)

01034500 -- PENOBSCOT RIVER AT WEST ENFIELD, MAINE

\begin{tabular}{|c|c|c|c|c|c|c|}
\hline \multirow{2}{*}{ CONSTI TUENT } & \multicolumn{3}{|c|}{ TOTAL } & \multicolumn{3}{|c|}{ DISSOLVED } \\
\hline & $\begin{array}{l}\text { NO. } \\
\text { SAMPLES }\end{array}$ & $\begin{array}{l}\text { MINIMUM } \\
\text { CONC. }\end{array}$ & $\begin{array}{l}\text { MAXIMUM } \\
\text { CONC. }\end{array}$ & $\begin{array}{l}\text { NO. } \\
\text { SAMPLES }\end{array}$ & $\begin{array}{l}\text { MINIMUM } \\
\text { CONC. }\end{array}$ & $\begin{array}{l}\text { MAXIMUM } \\
\text { CONC. }\end{array}$ \\
\hline \multicolumn{7}{|l|}{ MINOR ELEMENTS: } \\
\hline ARSENIC (AS), UG/L & 4 & 0 & 1 & 4 & 0 & 0 \\
\hline CADMIUM $(C D), U G / L$ & 4 & 0 & 1 & 4 & 0 & 0 \\
\hline CHROMIUM (CR), UG & 4 & 0 & 10 & 4 & 0 & 20 \\
\hline COBALT $(C O), U G / L$ & 4 & 0 & 2 & 4 & 0 & 1 \\
\hline COPPER (CU), UG/L & 4 & 0 & 10 & 4 & 0 & 10 \\
\hline IRON $(F E), U G / L$ & 4 & 220 & 300 & 4 & 80 & 120 \\
\hline LEAD $(P B), U G / L$ & 4 & 10 & 49 & 4 & 1 & 8 \\
\hline MANGANESE $(M N), U G / L$ & 4 & 40 & 60 & 4 & 30 & 60 \\
\hline MERCURY $(H G), U G / L$ & 4 & $<0.5$ & $\infty .5$ & 4 & $<0.5$ & $<0.5$ \\
\hline SELENIUM (SE), UG/L & 4 & 0 & 1 & 4 & 0 & 0 \\
\hline ZINC $(Z N), U G / L$ & 4 & 0 & 10 & 4 & 10 & 10 \\
\hline \multicolumn{7}{|l|}{ PERIPHYTON : } \\
\hline BIOMASS, DRY WT., G/SQ M & 3 & 3.29 & 11.00 & & & \\
\hline BIOMASS, ASH WT., G/SQ M & 3 & 2.29 & 4.79 & & & \\
\hline CHLOROPHYLL A, MG/SO M & 3 & .7 & $8 \cdot 2$ & & & \\
\hline CHLOROPHYLL B, MG/SQ M & 3 & .0 & $2 \cdot 0$ & & & \\
\hline ORGANIC CARBON, MG/L & 3 & 6.1 & 9.5 & & & \\
\hline
\end{tabular}


Table 14.--Summary of measurements at each station--Continued

LAT 45003MO5S LONG $069053 M 15 S$

DRAINAGE AREA: 2720 SQ MI $1 \quad 7045$ SO KM)

PERIOD OF RECORD: $10 / 01 / 74-09 / 30 / 75$

STATISTICAL SUMMARY OF SELECTED DISSOLVED CHEMICAL CONSTITUENTS AND

REGRESSION RELATIONSHIPS OF CONSTITUENT CONCENTRATIONS TO SPECIFIC CONDUCTANCE

CONSIIIUENI

CONSIUUUENI IMG LL QB UNII SHOWNI

SIZE MEAN

STANDARD

REYLALION

8.38

36.5

5370.0

6.59
0.012

0.012

0.112
0.222

0.222
383.5

2.3

100.5

1.7

2.7

3.52

4.27

0.92

4.92
1.15

0.40

9.8
0.0
4.40

1.52

21.5

28.5

14.5

14.5
6.5

6.5
1.3

0.15

7.94
3.7

2265.8

0.006

0.098

HARDNESS, NCNCARBONATE

TURBIDITY I JTUI

FLOURIDE, DISSOLVEN
0.09

0.043

304.6

1.3
3.2
1.4

3.8

0.39

0.61

0.61

0.22

0.41

1.5

0.0

0.63

0.59

2.4

6.0

2.4

2.1

BEGRESS LON SUMMABY

REGRESSION

SAMPLE COEFICIENT, CONSTANT,

BANGE

SIZE

$\begin{array}{rr}0.5 & 21.5 \\ 32 & 41\end{array}$

$1580 \quad 8760$

$6.4 \quad 6.7$

0.01
0.06
0.06
24

1

96

0
3.2

3.2

0.6

0.7

0.3

8
0
3.8

3.8
0.8

0.8
18
20

20

11
4

0.1

0.10

- B

CORRELATION

STANDARD

ERROR CF

ESIUHAIE

SUMMARY OF HARMONIC ANALYSIS OF STREAM TEMPERATURE EORM OF EQUAIION: I.1OI $=M+A *$ SINC.0172* $+C$

\begin{tabular}{|c|c|c|c|c|c|}
\hline & & & & & $\overline{\text { STANDARD }}$ \\
\hline & HARMONIC & AMPLITUDE & PHASE & VARIATION & ERROR OF \\
\hline SAMPLE & MEAN - M & & ANGLE - C & EXPLAINED & ESTIMATE \\
\hline SIZE & DEEG 61 & - $D E G(1$ & (BADIANS) & - (z) & LDEG CL \\
\hline 42 & 8.59 & 11.28 & 2.46 & 96 & 1.21 \\
\hline
\end{tabular}

SUMMARY OF MAXIMUM AND MINIMUM CONCENTRATIONS OF CONSTITUENTS SAMPLED AT A FREQUENCY OF QUARTERLY (1975 WY)

01046500 -- KENNEBEC RIVER AT BINGHAM, ME.

\begin{tabular}{|c|c|c|c|c|c|c|}
\hline \multirow{2}{*}{ CONSTITUENT } & \multicolumn{3}{|c|}{ TOTAL } & \multicolumn{3}{|c|}{ DISSOLVED } \\
\hline & $\begin{array}{l}\text { NO. } \\
\text { SAMPLES }\end{array}$ & $\begin{array}{l}\text { MIN IMUM } \\
\text { CONC. }\end{array}$ & $\begin{array}{l}\text { MAXIMUM } \\
\text { CONC. }\end{array}$ & $\begin{array}{l}\text { NO. } \\
\text { SAMPLES }\end{array}$ & $\begin{array}{l}\text { MINIMUM } \\
\text { CONC. }\end{array}$ & $\begin{array}{l}\text { MAXIMUM } \\
\text { CONC. }\end{array}$ \\
\hline \multicolumn{7}{|l|}{ MINOR ELEMENTS: } \\
\hline ARSENIC (AS), UG/L & 4 & 0 & 0 & 4 & 0 & 0 \\
\hline CADMIUM $(C D), U G / L$ & 4 & 0 & 0 & 4 & 0 & 0 \\
\hline CHROMIUM (CR), UG/L & 4 & 0 & $<10$ & 4 & 0 & $<10$ \\
\hline COBALT $(C O), U G / L$ & 4 & 0 & 1 & 4 & 0 & 1 \\
\hline COPPER (CU), UG/L & 4 & 0 & 20 & 4 & 0 & 10 \\
\hline IRON (FE), UG/L & 4 & 110 & 260 & 4 & 30 & 110 \\
\hline LEAD $(P B), U G / L$ & 4 & 2 & 100 & 4 & 2 & 7 \\
\hline MANG ANESE $(M N), U G / L$ & 4 & 10 & 40 & 4 & 10 & 20 \\
\hline MERCURY $(H G), U G / L$ & 4 & $<0.5$ & $<0.5$ & 4 & $<0.5$ & $<0.5$ \\
\hline SELENIUM (SE), UG/L & 4 & 0 & 1 & 4 & 0 & 1 \\
\hline$Z I N C \quad(Z N), U G / L$ & 4 & 0 & 20 & 4 & 0 & 10 \\
\hline \multicolumn{7}{|l|}{ PERIPHYTON: } \\
\hline BIOMASS, DRY WT., G/SO M & 2 & 2.29 & 5.79 & & & \\
\hline BIOMASS, ASH WT., G/SQ M & 2 & .79 & 5.69 & & & \\
\hline CHLOROPHYLL A, MG/SQ M & 2 & .3 & .5 & & & \\
\hline CHLOROPHYLL $B$, MG/SO M & 2 & .1 & .5 & & & \\
\hline ORGANIC CARBON, MG/L & 4 & 5.8 & 7.1 & & & \\
\hline
\end{tabular}


Tab1e 14.--Summary of measurements at each station---Continued

LAT $44004 M 2 O S$ LONG OTOD12M31S

DRAINAGE AREA: 3257 SQ MI $(18436$ SQ KM)

PERIOD OF RECORD: $10 / 01 / 74-09 / 30 / 75$

STATISTICAL SUMMARY OF SELECTED DISSOLVED CHEMICAL CONSTITUENTS AND

REGRESSION RELATIONSHIPS OF CONSTITUENT CONCENTRATIONS TO SPECIFIC CONDUCTANCE

CONSILIUENI

TEMPERATURE, WATER (DEG C)
SPECIFIC CONDUCTANCE (MICROMHOS)
STREAMFLOW (CUBIC FT/SEC)
PH (STANDARD UNITS)
PHCSPHORUS, TCTAL
NITRITE, NITRATE, TOTAL
NITROGEN, KJELDAHL, TOTAL
PHYTOPLANKTON, TOTAL (CELLS/ML)
SEDIMENT, SUSPENDED
SEDIMENT, CLAY SILT (PERCENT)
COLIFORM, FECAL (COL/IOO ML)
STREPTOCOCCI, FECAL (COL/IOO ML)
SILICA, DISSOLVED
CALCIUM, DISSOLVE
MAGNESIUM, OISSULVEO
SODIUM, DISSOLVED
POTASSIUM, DISSOLVED
BICARBONATE, ION
CARBONATE, ION
SULFATE, DISSOLVED
CHLURIOE, DISSOLVED
DISSOLVED SOLIDS, SUM CF CONST
OISSOLVED SOLIDS, ROE IBO DEG C
HARDNESS, TOTAL
HARDNESS, NONCAREONATE
TURBIDITY IJTU)
FLOURIDE, DISSOLVED

SAMPL
SIZE
12
12
12
12
9
9
9
9
9
9
12
12
4
4
4
4
4
4
4
4
4
4
3
4
4
3
4

UENI IMG/

IZE

12
12
12
12
9
9
9
9
9
9
12
12
4
4
4
4
4
4
4
4
4
4
3
4
4
3
4

10.00

108.3

5805.0

6.66

0.041

0.187

0.577

1820.0

5.3
98.4

98.4

1888.3

720.3

5.02

7.10
0.97

13.85

1.10

20.0

0.0

12.37

15.60

66.5
87.0

87.0
21.8

21.8
3.3

3.3

MEAN STANDARD

STANDARD

LALION

9.57

41.6
3808.5

3868.5
0.10

0.013

0.071

0.245

1820.3

3.5

3.3
3101.2

1250.2

1.01

1.43

0.22

0.44
0.24

0.24
5.3

5.3
0.0

3.14
8.70

8.70
22.5

24.1

2.4
1.3

2.3

2.3
0.00
BANGE

0.0
50

50
2020
6.5

6.5
0.02

0.02
0.10

0.25

130

90

100

83

4.1
5.8
0.7

0.7
8.3
0.8

15

9.6

8.4

49
62

17
4
2

0.2
BEG

REGRESSION

SAMPLE COEFICIENT, SIZE. - B

CONSTANT, CORRELATION
- COEEICIENI STANDARD
ERROR OF 24.0
200 13900 6.8
0.06 0.28 0.94 6100

$12 \quad-55.387$ 0.0014 0.00012 $-0.00004$ 0.00469 6.5069 0.02724 0.19152 0.05603 1259.344

$-0.596$ 0.584. $-0.029^{\circ}$ 0.896 $0.130^{*}$

$$
1259.344
$$

$$
\text { . } 130+
$$$$
11000
$$$$
4600
$$$$
\begin{array}{llllll}
6.0 & 4 & 0.0098 & 3.7170 & 0.468^{*} & 1.10
\end{array}
$$$$
8.7
$$$$
22.2
$$$$
22.0
$$$$
\begin{array}{r}
1.4 \\
27 \\
0
\end{array}
$$$$
\begin{array}{r}
27 \\
16.0 \\
28.0 \\
97
\end{array}
$$$$
\begin{array}{r}
97 \\
110 \\
20 \\
7
\end{array}
$$

*Not significant at the 95 percent confidence level. SUMMARY GF HARMONIC ANALYSIS OF STREAM TEMPERATURE

\begin{tabular}{|c|c|c|c|c|c|}
\hline & & & & & STANDARD \\
\hline & HARMONIC & AMPLITUDE & PHASE & VARIATION & ERROR OF \\
\hline SAMPLE & MEAN - M & $-A$ & $A N G L E-C$ & EXPLAINED & ESTIMATE \\
\hline SLZE_ & IDEG C) & $-10 E 6(1$ & IBADLANSI & $-(q)$ & $10 E G_{2}(1$ \\
\hline 12 & 9.76 & 12.56 & 2.74 & 94 & 2.54 \\
\hline
\end{tabular}
EOBM DE EQUALION: I. $\left.101 \equiv M \pm A * S I N C .0172 * D_{ \pm} \pm C\right)$

SUMMARY OF MAXIMUM AND MINIMUM CONCENTRATIONS OF CONSTITUENTS SAMPLED AT A FREQUENCY OF QUARTERLY $(1975$ WY)

\begin{tabular}{|c|c|c|c|c|c|c|}
\hline \multirow{2}{*}{ CONSTITUENT } & \multicolumn{3}{|c|}{ TOTAL } & \multicolumn{3}{|c|}{ DISSOLVED } \\
\hline & $\begin{array}{l}\text { NO. } \\
\text { SAMPLES }\end{array}$ & $\begin{array}{l}\text { MINIMUM } \\
\text { CONC. }\end{array}$ & $\begin{array}{l}\text { MAXIMUM } \\
\text { CONC. }\end{array}$ & $\begin{array}{l}\text { NO. } \\
\text { SAMPLES }\end{array}$ & $\begin{array}{l}\text { MINIMUM } \\
\text { CONC. }\end{array}$ & $\begin{array}{l}\text { MAXIMUM } \\
\text { CONC. }\end{array}$ \\
\hline \multicolumn{7}{|l|}{ MINOR ELEMENTS: } \\
\hline ARSENIC (AS), UG/L & 3 & 0 & 0 & 3 & 0 & 0 \\
\hline CADMIUM $(C D), U G / L$ & 3 & 0 & 0 & 3 & 0 & 0 \\
\hline CHROMIUM (CR), UG/L & 3 & 10 & 70 & 3 & $<10$ & 20 \\
\hline COBALT $(C O), U G / L$ & 3 & 0 & 0 & 3 & 0 & 0 \\
\hline COPPER $(C U), U G / L$ & 3 & 0 & 10 & 3 & 0 & 10 \\
\hline IRON $(F E), U G / L$ & 3 & 460 & 600 & 3 & 170 & 380 \\
\hline LEAD $(P B)$, UG/L & 3 & 2 & 23 & 3 & 2 & 6 \\
\hline MANGANESE $(M N), U G / L$ & 3 & 50 & 70 & 3 & 40 & 70 \\
\hline MERCURY $(H G), U G / L$ & 3 & $<0.5$ & $<0.5$ & 3 & $<0.5$ & $<0.5$ \\
\hline SELENIUM (SE), UG/L & 3 & 0 & 0 & 3 & 0 & 0 \\
\hline ZINC $(Z N), U G / L$ & 3 & 10 & 10 & 3 & 0 & 10 \\
\hline \multicolumn{7}{|l|}{ PERIPHYTON: } \\
\hline BIOMASS, DRY WT., G/SO M & 2 & 4.50 & 13.00 & & & \\
\hline BIOMASS, ASH WT., G/SO M & 2 & 3.69 & 10.00 & & & \\
\hline CHLOROPHYLL A, MG/SO M & 2 & .3 & 4.5 & & & \\
\hline CHLOROPHYLL B, MG/SO M & 2 & .0 & 1.0 & & & \\
\hline ORGANIC CARBON, MG/L & 3 & 5.3 & 11.0 & & & \\
\hline
\end{tabular}

$01059000--$ ANDRUSCOGGIN RIVER NEAR AUBURN, ME. 
LAT $43048 M 30 S$ LONG $070046 M 555$

DRAINAGE AREA: 1298 SO MI ( 3362 SO KM)

PERICD OF RECORD: $10 / 01 / 74-09 / 30 / 75$

STATISTICAL SUMMARY OF SELECTED DISSOLVED CHEMICAL CONSTITUENTS AND

REGRESSION RELATIONSHIPS OF CONSTITUENT CONCENTRATIONS TO SPECIFIC CONDUCTANCE

CONSIIUENI

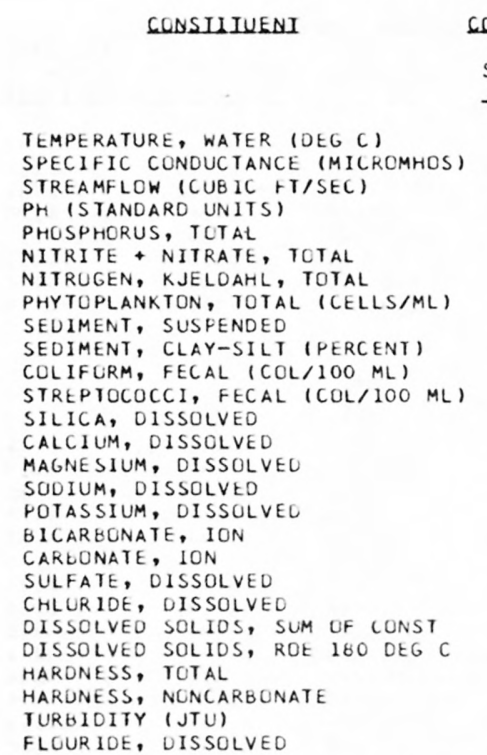

CONSIUUENT IMG/LOR UNII SHOWNU

SAMP
S12
12
12
12
12
12
12
12
12
12
12
12
12
4

STANDARD

DEYIAIION

9.70 $39 \cdot 3$
2717.1

2717.1

6.58
0.014

0.014

0.099
0.181

397.5

4.3

34.3

34.3
73.5

73.5
0.37

0.37
3.10

0.42

2.92
0.55

0.55
7.8

0.0

3.67

3.95

25.3

31.8

$9 \cdot 3$

1.3

0.37
9.61

2571.8

0.15

0.008
0.012

0.012

0.120
350.7

4.1
8.0

52.2

198.4

198.4
0.94

0.94

0.71

0.76
0.59

0.26

1.0

0.0

0.89
1.00

1.00
3.8

3.8
5.7

2.6

2.6

0.15

BANGE
0.0
34
519
6.4
0.01
0.08
0.10
120
1
77
1
1
5.3
2.4
0.2
2.3
0.3
7
0
2.6
3.2
21
25
7
1
1
0.3

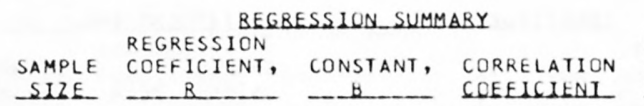

BEGRESSION_SUMMARY

SIZE

R

$-1$

COEEICIENI

ERROR OF

ESILMAIE

* Not significant at the 95 Dercent confidence level. SUMMARY OF HARMONIC ANALYSIS OF STREAM TEMPERATURE

\begin{tabular}{|c|c|c|c|c|c|}
\hline & & & & & STANDARD \\
\hline & HARMONIC & AMPLITUDE & PHASE & VARIATION & ERROR OF \\
\hline SAMPLE & MEAN - M & $-A$ & ANGLE - C & EXPLAINED & ESTIMATE \\
\hline$S 12 E_{-}$ & NUEG_L & $-1 D E G(1)$ & (BADIANSI) & $-(x)$ & $10 E G_{2} C_{1}$ \\
\hline 92 & 9.82 & 14.32 & 2.86 & 92 & 1.78 \\
\hline
\end{tabular}

$$
\begin{array}{r}
-311.457 \\
0.0020 \\
-0.00058 \\
0.00126 \\
-0.00478 \\
-27.021 \\
\\
\\
0.1750 \\
0.1667 \\
0.0583 \\
0.1194 \\
0.0278 \\
0.139 \\
0.000 \\
0.1583 \\
-0.0056 \\
0.750 \\
1.528 \\
0.583 \\
0.583 \\
0.028 \\
0.0250
\end{array}
$$

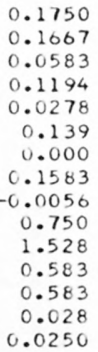$$
\begin{array}{r}
941.750 \\
6.5052
\end{array}
$$$$
6.5052
$$$$
0.04962
$$$$
0.04962
$$$$
1458.085
$$

-0.485 *

$-0.485 *$
$0.052 *$

-0.294 *

0.407 *

$-0.159$.

-0.308 *

2359.2

0.16

0.008

0.012

0.124

349.8
0.043.

$0.816 *$

0.768 .

0.707 *

0.364 *

0.503 *

0.000 *

$0.617 *$

$-0.019^{*}$

$0.088^{*}$

0.922 .

0.922.

0.768 *

$0.768^{*}$

\begin{tabular}{|c|c|c|c|c|c|c|}
\hline \multirow{2}{*}{ CONSTI TUENT } & \multicolumn{3}{|c|}{ TOTAL } & \multicolumn{3}{|c|}{ DISSOLVED } \\
\hline & $\begin{array}{l}\text { NO. } \\
\text { SAMPLES }\end{array}$ & $\begin{array}{l}\text { MINIMUM } \\
\text { CONC. }\end{array}$ & $\begin{array}{l}\text { MAXIMUM } \\
\text { CONC. }\end{array}$ & $\begin{array}{l}\text { NO. } \\
\text { SAMPLES }\end{array}$ & $\begin{array}{l}\text { MINIMUM } \\
\text { CONC. }\end{array}$ & $\begin{array}{l}\text { MAXIMUM } \\
\text { CONC. }\end{array}$ \\
\hline \multicolumn{7}{|l|}{ MINOR ELEMENTS: } \\
\hline AKSENIC (AS), UG/L & 4 & 0 & 0 & 4 & 0 & 0 \\
\hline CAOMIUM $(C D), U G / L$ & 4 & 0 & 0 & 4 & 0 & 0 \\
\hline CHROMIUM (CR), UG $/ L$ & 4 & 0 & 10 & 4 & 0 & 10 \\
\hline COBALT $(C O), U G / L$ & 4 & 0 & 0 & 4 & 0 & 0 \\
\hline COPPER (CU), UG/L & 4 & 0 & 10 & 4 & 0 & 0 \\
\hline IRON $(F E), U G / L$ & 4 & 180 & 270 & 4 & 90 & 110 \\
\hline LEAD $(P B), U G / L$ & 4 & 14 & 37 & 4 & 2 & 9 \\
\hline MANG ANESE $(M N), U G / L$ & 4 & 10 & 30 & 4 & 10 & 20 \\
\hline MERCURY (HG), UG/L & 4 & $<0.5$ & $<0.5$ & 4 & $<0.5$ & $\infty .5$ \\
\hline SELENIUM (SE), UG/L & 4 & 0 & 1 & 4 & 0 & 0 \\
\hline$Z I N C(Z N), U G / L$ & 4 & 0 & 40 & 4 & 0 & 10 \\
\hline \multicolumn{7}{|l|}{ PERIPHYTON: } \\
\hline BIOMASS, URY WT., G/SU M & 3 & 1.50 & 4.79 & & & \\
\hline GIOMASS, ASH WT., G/SO M & 3 & .79 & 3.69 & & & \\
\hline CHLOROPHYLL A, MG/SQ M & 3 & .0 & 1.3 & & & \\
\hline CHLOROPHYLL B, MG/SO M & 3 & .1 & .3 & & & \\
\hline ORGANIC CARBON, MG/L & 3 & 3.3 & 4.2 & & & \\
\hline
\end{tabular}

0.192 *

0.577 *

SUMMARY OF MAXIMUM AND MINIMUM CONCENTRATIONS OF CONSTITUENTS SAMPLED AT A FREQUENCY OF QUARTERLY (1975 WY)

01066000 -- SACO RIVER AT CORNISH, MAINE 
Table 14.--Summary of measurements at each station--Continued

STATION NUMBER: 01096550 NAME: MERRIMACK RIVER ABOVE LOWELL, MASS.

LAT 42D38M2OS LONG 071D22M17S

DRAINAGE AREA: 0 SO MI

PERIOD OF RECORD: $10 / 01 / 74-09 / 30 / 75$

0 SO KM)

STATISTICAL SUMMARY OF SELECTED DISSOLVED CHEMICAL CONSTITUENTS AND

REGRESSION RELATIONSHIPS OF CONSTITUENT CONCENTRATIONS TO SPECIFIC CONDUCTANCE

GONSIIIUENI

S)

CONSILIUENI IMG $\angle L O R$ UNII SHOWNI

SAMPLE

TEMPERATURE, WATER (DEG C)

SPECIFIC CONDUCTANCE (MICROMHOS)

STREAMFLOW (CUBIC FT/SEC)

PH (STANDARD UNITS)

PHOSPHORUS, TOTAL

NITRITE + NITRATE, TOTAL

PHYTOPLANKTON, TOTAL (CELLS/ML)

SEDIMENT, SUSPENDED

SEDIMENT, CLAY-SILT (PERCENT)

COLIFURM, FECAL (COL/200 ML)

STREP TOCOCCI, FECAL (COL/100 ML)

SILICA, DISSOLVED

CALCIUM, DISSOL VED

MAGNESIUM, DISSOLVED

SODIUM, DISSOLVED

POTASSIUM, DISSOLVED

BICARBONATE, ION

CARBONATE, ION

SULFATE, DISSCLVED

CHLORIDE, DISSOLVED

DISSOLVED SOLIDS, SUM OF CONST

OISSOLVED SOLIDS, ROE 180 DEG

HARDNESS, TOTAL

HARDNESS, NONCARBONATE

TURBIDITY (JTU)

FLOURIDE, DISSOLVED
STANDARD

MEAN DEYIAIION

$11.45 \quad 10.73$

$93.6 \quad 19.2$

$8780.0 \quad 7587$.

$6.73 \quad 0.37$

0.141

0.301

0.908

14765.6

0.075

0.176

0.36

$4317.8 \quad 4591.1$

$\begin{array}{rr}4317.8 & 4591.1 \\ 317.0 & 312.7\end{array}$

4.27

5.13

0.90

6.37

0.97

9.5

0.0
7.55

7.55
10.90

10.90
39.3

$39 \cdot 3$
50.3

16.3

10.0

4.5
0.20

312.7
2.61

1.63

0.10

1.74
0.25

0.25

3.7

0.95

0.95
2.62

7.4
9.8

9.8
4.0

6.1

6.1
2.7
0.10

0.20
*Not significant at the 95 percent confidence level

\section{BEGRESSION SUMMARY}

REGRESSION

SAMPLE COEFICIENT,

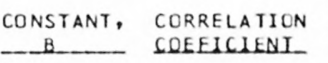

STANDARD ERROR OF BANGE

SIZE $0.0 \quad 28.0$ $\begin{array}{rr}56 & 115 \\ 1450 & 22100\end{array}$

6.3

0.05

$0.12 \quad 0.30$

0.53

690

1.60

$\begin{array}{rr}10 & -318.494 \\ 9 & 0.0020\end{array}$

0.0020

0.00157

-0.00082
0.00813

517.475
38591.047
6.5450
$-0.00601$
0.37757
0.14706

$0.109^{*}$
$0.400^{*}$

$-0.089^{*}$

$0.424^{*}$

$0.403^{*}$

ESIIMAIE

SUMMARY OF MAXIMUM ANO MINIMUM CONCENTRATIONS OF CONSTITUENTS

SAMPLED AT A FREQUENCY OF QUARTERLY (1975 WY)

01096550 -- MERRIMACK RIVER ABOVE LOWELL, MASS.

\begin{tabular}{|c|c|c|c|c|c|c|}
\hline \multirow{2}{*}{ CONSTITUENT } & \multicolumn{3}{|c|}{ TOTAL } & \multicolumn{3}{|c|}{ DISSOLVED } \\
\hline & $\begin{array}{l}\text { NO. } \\
\text { SAMPLES }\end{array}$ & $\begin{array}{l}\text { MINIMUM } \\
\text { CONC. }\end{array}$ & $\begin{array}{l}\text { MAXIMUM } \\
\text { CONC: }\end{array}$ & $\begin{array}{l}\text { NO. } \\
\text { SAMPLES }\end{array}$ & $\begin{array}{l}\text { MINIMUM } \\
\text { CONC. }\end{array}$ & $\begin{array}{l}\text { MAXIMUM } \\
\text { CONC. }\end{array}$ \\
\hline \multicolumn{4}{|l|}{$\begin{array}{l}\text { MINOR ELEMENTS: } \\
\text { ARSENIC (AS): UG }\end{array}$} & 3 & 0 & 3 \\
\hline CADMIUM (CD), UG/L & 4 & 0 & $<18$ & 3 & 0 & 1 \\
\hline CHROMIUM (CR), UG/L & 4 & 3 & 30 & 3 & $<10$ & 10 \\
\hline COBALT $(C O), U G / L$ & 4 & 0 & $<2$ & 3 & 0 & 1 \\
\hline COPPER $(C U), U G / L$ & 4 & 3 & 10 & 3 & 0 & 10 \\
\hline IRON (FE), UG/L & 4 & 340 & 920 & 3 & 80 & 310 \\
\hline LEAD $(P B), U G / L$ & 4 & 4 & 10 & 3 & 1 & 5 \\
\hline MANG ANESE $(M N), U G / L$ & 4 & 27 & 100 & 3 & 20 & 90 \\
\hline MERCURY (HG), UG/L & 3 & $<0.5$ & $<0.5$ & 3 & $<0.5$ & $<0.5$ \\
\hline SELENIUM (SE), UG/L & 3 & 0 & 0 & 3 & 0 & 0 \\
\hline ZINC $(Z N), U G / L$ & 4 & 10 & $<80$ & 3 & 10 & 20 \\
\hline \multicolumn{7}{|l|}{ PERIPHYTON: } \\
\hline BIOMASS, DRY WT., G/SQ M & 0 & & & & & \\
\hline BIOMASS, ASH WT., G/SQ M & 0 & & & & & \\
\hline CHLOROPHYLL A, MG/SQ M & 0 & & & & & \\
\hline CHLOROPHYLL $8, M G / S Q M$ & 0 & & & & & \\
\hline ORGANIC CARBON, MG/L & 2 & 2.5 & 6.0 & & & \\
\hline
\end{tabular}


LAT 42D15M22S LONG 071015M38S DRAINAGE AREA: 184 SQ MI PERIOD OF RECORD: $10 / 01 / 74-09 / 30 / 777$ SQ KM)

STATISTICAL SUMMARY OF SELECTED DISSOLVED CHEMICAL CONSTITUENTS AND REGRESSION RELATIONSHIPS OF CONSTITUENT CONCENTRATIONS TO SPECIFIC CONDUCTANCE

\section{GONSILIUENI}

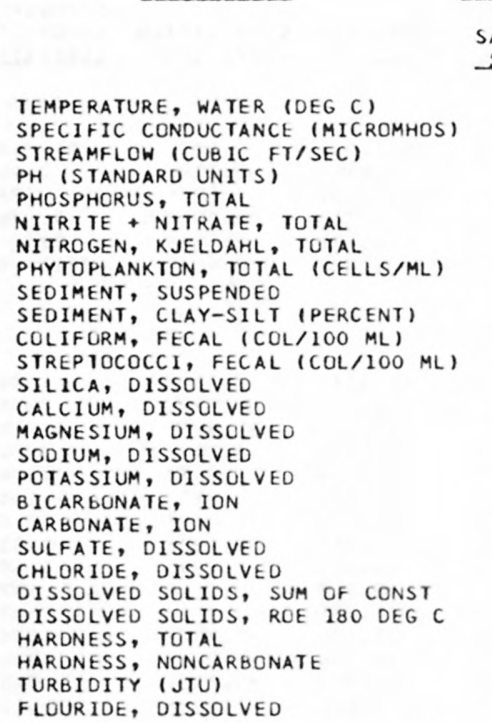

\section{CONSIUTUENI IMG LL OR UNII SHOHNU}

SAM
SI
1
1
1
1
1
1
1
1
1

STANDARD

DEXIAILON

11.00
188.8
299.9
6.82
0.232
0.367
0.696
4590.0
39.0
218.4
90.2
3.92
13.20
2.72
19.40
1.92
23.2
0.0
15.00
33.60
101.8
116.2
44.2
25.2
3.4
0.24
4

453.5

100.7

3.10

3.27

0.47

1.82
0.54

0.54
5.2

0.0

2.92

2.41
12.2

12.2
18.6

8.3

7.8

1.1
0.09
BANGE

9.14
28.2
254.8
0.24
0.122
0.261
0.326
8925.7
18.5

$\begin{array}{rr}0.0 & 25.0 \\ 148 & 238 \\ 36 & 786 \\ 6.6 & 7.3 \\ 0.06 & 0.42 \\ 0.00 & 0.72 \\ 0.34 & 1.50\end{array}$

$400 \quad 1.50$

22

\section{BEGRESSION SUMMABY} REGRESSION
SAMPLE COEFICIENT, CONSTANT, SAMPLE $B$ B CONSTANT

CORRELATION COEEICLENI

*Not significant at the 95 percent confidence level.

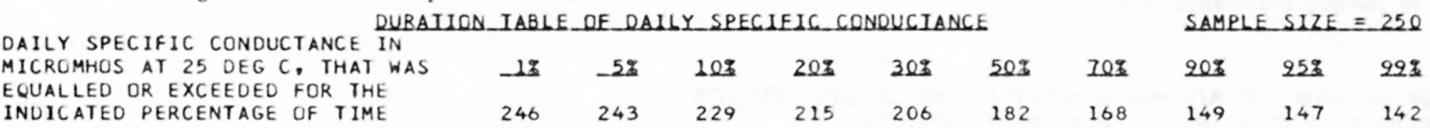

SUMMARY OF MARMONIC ANALYSIS OF STREAM TEMPERATURE

\begin{tabular}{|c|c|c|c|c|c|}
\hline & & & & & STANDARD \\
\hline & HARMONIC & AMPLITUDE & PHASE & VARIATION & ERROR OF \\
\hline SAMPLE & MEAN - M & $-A$ & ANGLE - C & EXPLAINED & ESTIMATE \\
\hline SIZE & LEEG C) & $10 E 6(1)$ & (RADIANS) & -181 & $10 E G(1)$ \\
\hline 225 & 11.93 & 12.82 & 2.79 & 97 & 1.68 \\
\hline
\end{tabular}

SUMMARY OF MAXIMUM AND MINIMUM CONCENTRATIONS OF CONSTITUENTS SAMPLED AT A FREQUENCY OF QUARTERLY (1975 WY)

01103500 -- CHARLES RIVER AT CHARLES RIVER VILLAGE, MASS.

\begin{tabular}{|c|c|c|c|c|c|c|}
\hline \multirow{2}{*}{ CONSTITUENT } & \multicolumn{3}{|c|}{ TOTAL } & \multicolumn{3}{|c|}{ DISSOLVED } \\
\hline & $\begin{array}{l}\text { NO. } \\
\text { SAMPLES }\end{array}$ & $\begin{array}{l}\text { MINIMUM } \\
\text { CONC. }\end{array}$ & $\begin{array}{l}\text { MAXIMUM } \\
\text { CONC. }\end{array}$ & $\begin{array}{l}\text { NO. } \\
\text { SAMPLES }\end{array}$ & $\begin{array}{l}\text { MINIMUM } \\
\text { CONC. }\end{array}$ & $\begin{array}{l}\text { MAXIMUM } \\
\text { CONC. }\end{array}$ \\
\hline \multicolumn{7}{|l|}{ MINOR ELEMENTS: } \\
\hline ARSENIC (AS), UG/L & 5 & 0 & 2 & 5 & 0 & 1 \\
\hline CAUMIUM $(C D), U G / L$ & 5 & 0 & 1 & 5 & 0 & 1 \\
\hline CHROMIUM (CR), UG/L & 5 & 0 & 10 & 5 & 0 & 0 \\
\hline COBALT $(C O), U G / L$ & 5 & 0 & 0 & 5 & 0 & 2 \\
\hline COPPER $(C U), U G / L$ & 5 & 0 & 10 & 5 & 0 & 10 \\
\hline IRON $(F E), U G / L$ & 5 & 300 & 630 & 5 & 180 & 340 \\
\hline LEAD $(P B), U G / L$ & 5 & 2 & 14 & 5 & 2 & 7 \\
\hline MANG ANESE $(M N), U G / L$ & 5 & 50 & 130 & 5 & 30 & 70 \\
\hline MERCURY (HG), UG/L & 5 & $<0.5$ & 0.7 & 5 & $<0.5$ & $<0.5$ \\
\hline SELENIUM (SE), UG/L & 5 & 0 & 1 & 5 & 0 & 1 \\
\hline$Z I N C(Z N), U G / L$ & 5 & 10 & 30 & 5 & 10 & 40 \\
\hline \multicolumn{7}{|l|}{ PERIPHYTON: } \\
\hline BIOMASS, DRY WT., G/SO M & 2 & 7.09 & 350.00 & & & \\
\hline BIOMASS, ASH WT., G/SQ M & 2 & 3.59 & 170.00 & & & \\
\hline $\begin{array}{l}\text { CHLOROPHYLL A, MG/SO M } \\
\text { CHLOROPHYL }\end{array}$ & $\begin{array}{l}1 \\
1\end{array}$ & $\begin{array}{r}8.3 \\
.5\end{array}$ & & & & \\
\hline CHLOROPHYLL B, MG/SO M & 1 & .5 & & & & \\
\hline ORGANIC CARBON, MG/L & 4 & 6.0 & 28.0 & & & \\
\hline
\end{tabular}


Table 14.--Sumary of measurements at each station--Continued

STATION NUMBER: 01155050 NAME: CONNECTICUT RIVER AT WALPOLE, N.H.

LAT 43D05MO4S LONG 072026M04S

DRAINAGE AREA: 0 SQ MI 1

PERIOD OF RECORD: $10 / 01 / 74-09 / 30 / 75$

SQ KMI

STATISTICAL SUMMARY OF SELECTED DISSOLVED CHEMICAL CONSTITUENTS AND

REGRESSION RELATIONSHIPS OF CONSTITUENT CONCENTRATIONS TO SPECIFIC CONDUCTANCE

CONSIIIUENI

TEMPERATURE, WATER (DEG C)
SPECIFIC CONDUCTANCE (MICROMHCS)
STREAMFLOW (CUBIC FI/SEC)
PH (STANDARD UNITS)
PHOSPHORUS, TOTAL
NITRITE + NITRATE, TOTAL
NITROGEN, KJELDAHL, TOTAL
PHYTOPLANKTON, TOTAL (CELLS/ML)
SEDIMENT, SUSPENDED
SEDIMENT, CLAY-SILT (PERCENT)
COLIFORM, FECAL (COL/IOO ML)
STREPTOCOCCI, FECAL (COL/IOO ML)
SILICA, DISSOLVED
CALCIUM, DISSOLVE
MAGNESIUM, DISSOLVED
SODIUM, DISSOLVED
PCTASSIUM, DISSOLVED
BICARBONATE, ION
CARBONATE, ION
SULFATE, DISSOLVED
CHLORIDE, DISSOLVED
DISSOLVED SOLIDS, SUM OF CONST
DISSOLVED SOLIDS, ROE IBO DEG C
HARDNESS, TOTAL
HARONESS, NONCAREONATE
TURGIUITY (JTU)
FLOURIDE, DISSOLVED

\begin{tabular}{r} 
CONSI \\
SAMPL \\
SIZ \\
\hline \\
7 \\
7 \\
6 \\
7 \\
7 \\
7 \\
7 \\
7 \\
3 \\
1 \\
6 \\
7 \\
2 \\
2 \\
2 \\
2 \\
2 \\
2 \\
2 \\
2 \\
2 \\
2 \\
2 \\
2 \\
2 \\
2 \\
2
\end{tabular}

SIZE

14.86

6156.7

7.19

0.026

0.314

0.470

1725.7

1725.7
26.7

26.7
100.0

102.5

63.4

4.10

16.00

2.00

5.80

1.30

49.0

0.0

9.55

9.20

72.0

76.5

48.5

8.0

1.5
0.10
STANDARD

9.05

22.9
4986.8

4986.8
0.49

0.011

0.221

0.304

2003.5

35.1

0.0

84.3

42.5
0.57

0.57

1.41

1.41

0.28

4.2

0.0

0.64
0.99

0.99
5.7

13.4

6.4
2.8

2.8
0.7

0.00

*Not significant at the 95 percent confidence level.

SUMMARY OF MAXIMUM AND MINIMUM CONCENTRATIONS OF CONSTITUENTS

SAMPLED AT A FREQUENCY OF QUARTERLY (1975 WY)

01155050 -- CONNECTICUT RIVER AT WALPOLE, N.H.

\begin{tabular}{|c|c|c|c|c|c|c|}
\hline \multirow{2}{*}{ CONSTITUENT } & \multicolumn{3}{|c|}{ TOTAL } & \multicolumn{3}{|c|}{ DISSOLVED } \\
\hline & $\begin{array}{l}\text { NO. } \\
\text { SAMPLES }\end{array}$ & $\begin{array}{l}\text { MINIMUM } \\
\text { CONC. }\end{array}$ & $\begin{array}{l}\text { MAXIMUM } \\
\text { CONC. }\end{array}$ & $\begin{array}{l}\text { NO. } \\
\text { SAMPLES }\end{array}$ & $\begin{array}{l}\text { MINIMUM } \\
\text { CONC. }\end{array}$ & $\begin{array}{l}\text { MAXIMUM } \\
\text { CONC. }\end{array}$ \\
\hline \multicolumn{7}{|l|}{ MINOR ELEMENTS: } \\
\hline ARSENIC (AS), UG/L & 2 & 0 & 0 & 2 & 0 & 0 \\
\hline CADMIUM $(C D), U G / L$ & 2 & 0 & 4 & 2 & 0 & 0 \\
\hline CHROMIUM (CR), UG $/ L$ & 2 & $<10$ & 20 & 2 & 0 & 20 \\
\hline COBALT $(C O), U G / L$ & 2 & 0 & 0 & 2 & 0 & 0 \\
\hline COPPER (CU), UG/L & 2 & 0 & 0 & 2 & 0 & 0 \\
\hline IRON (FE), UG/L & 2 & 170 & 310 & 2 & 30 & 100 \\
\hline LEAD (PE), UG/L & 2 & 3 & 4 & 2 & 1 & 7 \\
\hline MANG ANESE (MN), UG/L & 2 & 30 & 50 & 2 & 0 & 10 \\
\hline MERCURY $(H G), U G / L$ & 2 & $<0.5$ & $<0.5$ & 2 & $<0.5$ & $<0.5$ \\
\hline SELENIUM (SE), UG/L & 2 & 0 & 1 & 2 & 0 & 1 \\
\hline$Z I N C(Z N), U G / L$ & 2 & 10 & 20 & 2 & 10 & 20 \\
\hline \multicolumn{7}{|l|}{ PERIPHYTON: } \\
\hline BIOMASS, DRY WT., G/SO M & 1 & 6.29 & & & & \\
\hline BIOMASS, ASH WT., G/SQ M & 1 & 4.79 & & & & \\
\hline CHLOROPHYLL A, MG/SO M & 1 & 3.7 & & & & \\
\hline CHLOROPHYLL B, MG/SO M & 1 & .5 & & & & \\
\hline ORGANIC CARBON, MG/L & 1 & 4.2 & & & & \\
\hline
\end{tabular}


Table 14.--Summary of measurements at each station--Continued

LAT $41059 M 14 S$ LONG 072D36M21S DRAINAGE AREA: 9661 SQ MI 125022 SQ KM)

PERIOD OF RECORD: $10 / 01 / 74-09 / 30 / 75$

STATISTICAL SUMMARY OF SELECTED DISSOLVED CHEMICAL CONSTITUENTS AND

REGRESSION RELATIONSHIPS OF CONSTITUENT CONCENTRATIONS TO SPECIFIC CONDUCTANCE

CONSIIIUENI

\begin{tabular}{|c|c|c|}
\hline $\begin{array}{l}\text { SAMPLE } \\
\text { SIZE }\end{array}$ & MEAN & $\begin{array}{l}\text { STANDARD } \\
\text { DEXIAIUON }\end{array}$ \\
\hline 12 & 11.63 & 9.72 \\
\hline 12 & 110.7 & 25.8 \\
\hline 12 & 14424.2 & 8456.8 \\
\hline 12 & 7.00 & 0.13 \\
\hline 12 & 0.077 & 0.027 \\
\hline 12 & 0.336 & 0.117 \\
\hline 12 & 0.532 & 0.238 \\
\hline 12 & 8926.7 & 14500.8 \\
\hline 12 & 17.8 & 11.4 \\
\hline 11 & 86.2 & 9.7 \\
\hline 12 & 4939.2 & 4199.2 \\
\hline 12 & 680.8 & 495.4 \\
\hline 12 & 5.06 & 1.09 \\
\hline 12 & 10.21 & 2.00 \\
\hline 12 & 1.70 & 0.35 \\
\hline 12 & 6.75 & 1.50 \\
\hline 12 & 1.22 & 0.38 \\
\hline 12 & 25.6 & 6.4 \\
\hline 12 & 0.0 & 0.0 \\
\hline 12 & 10.84 & 1.59 \\
\hline 12 & 10.52 & 3.12 \\
\hline 12 & 59.3 & 8.4 \\
\hline 12 & 70.1 & 11.0 \\
\hline 12 & 32.3 & 5.2 \\
\hline 12 & 11.3 & 1.4 \\
\hline 12 & 3.8 & 1.2 \\
\hline 12 & 0.10 & 0.07 \\
\hline
\end{tabular}

\section{BEGRESS ION SUMMABY}

$\begin{array}{lll}\text { REGRESSION } & \text { STANDARD } \\ \text { SAMPLE COEFICIENT, CONSTANT, CORRELATION ERROR OF } \\ \text { SIZE }\end{array}$

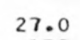

$\begin{array}{rr}0.0 & 27 \\ 79 & 17 \\ 2200 & 2730 \\ 6.8 & 7 \\ 0.04 & 0 . \\ 0.15 & 0.5 \\ 0.17 & 0.8 \\ 290 & 480 \\ 4 & \\ 67 & 1 \\ 970 & 150 \\ 130 & 140 \\ 2.6 & 6 \\ 7.3 & 14 \\ 1.0 & 2 \\ 4.2 & 8 \\ 0.8 & 2 \\ 16 & \\ 0 & \\ 8.5 & 13 \\ 4.5 & 16 \\ 41 & \\ 50 & \\ 24 & \\ 8 & \\ 1 & \\ 0.0 & 0\end{array}$

175
7300
7.3
0.14
0.51
0.88
8000
41
100
5000
1400
6.2
14.0
2.3
8.5
2.1
33
0
13.0
16.0
68
82
39
13
5
0.2

$\begin{array}{rr}12 & -254.761 \\ 12 & -0.0006 \\ 12 & 0.00039 \\ 12 & -0.00139 \\ 12 & 0.00608 \\ 11 & 285.290\end{array}$
42617.707
7.0681
7.0681
0.03325
0.48928
$-0.14094$
$-22379.324$

$-0.778$

$-0.118$

$-0.306 *$

0.659
$0.504 *$

5574.7

0.14

0.026

0.117

0.188

$11 \quad 285.290$

0.504

13640.7

$\begin{array}{rrrrr}12 & -0.0203 & 7.3053 & -0.482^{*} & 1.00 \\ 12 & 0.0588 & 3.7031 & 0.758 & 1.37 \\ 12 & 0.0014 & 1.5491 & 0.100 * & 0.37 \\ 12 & 0.0391 & 2.4203 & 0.674 & 1.16 \\ 12 & 0.0023 & 0.9654 & 0.161 * & 0.39 \\ 12 & 0.197 & 3.800 & 0.794 * & 4.1 \\ 12 & 0.000 & 0.000 & 0.000^{*} & 0.0 \\ 12 & 0.0038 & 10.4258 & 0.061 * & 1.67 \\ 12 & 0.0324 & 6.9377 & 0.268 * & 3.16 \\ 12 & 0.212 & 35.782 & 0.649 & 6.7 \\ 12 & 0.120 & 56.812 & 0.282 * & 11.1 \\ 12 & 0.152 & 15.470 & 0.760 & 3.5 \\ 12 & -0.002 & 11.600 & -0.043 * & 1.5 \\ 12 & -0.007 & 4.505 & -0.145 * & 1.3 \\ 12 & 0.0010 & -0.0102 & 0.348 * & 0.07\end{array}$

TEMPERATURE, WATER (DEG C) SPECIFIC CONDUCTANCE (MICROMHOS) STREAMFLOW (CUBIC FT/SEC)

PH (STANDARD UNITS)

PHOSPHORUS, TOTAL

NITRITE + NITRATE, TOTAL

NITROGEN, KJELDAHL, TOTAL

PHYTOPLANKTON, TOTAL

SEDIMENT, CLAY-SILT (PERCENT)

COLIFURM, FECAL (COL/1OO ML)

STREPTOCOCCI, FEC

SILICA, DISSOLVED

MAGNESIUM, DISSOLVED

SODIUM, DISSOLVED

POTASSIUM, DISSOLVED

BICARBONATE, ION

CARBONATE, ION
SULFATE, DISSOLVED

CHLORIDE, DISSOLVED

OISSOLVED SOLIDS, SUM OF CONST

DISSOLVED SOLIDS,

HARDNESS, TUTAL
HARDNESS, NONCARBONATE

TURBIDITY (JTU)

FLOURIDE, DISSOLVED

*Not significant at the 95 percent confidence level.

DURAIION IABLE_OF_DALY SPECIEIC CONDUCIANCE

DAILY SPECIFIC CONDUCTANCE IN

MICROMHOS AT 25 DEG C, THAT WAS

EQUALLED OR EXCEEDED FOR THE

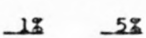

$134 \quad 123$

117

114

100

SUMMARY OF HARMONIC ANALYSIS OF STREAM TEMPERATURE

EORM OF EQUAION: I. (D) $=M+A *$ SINC.0272*D+C)

\begin{tabular}{|c|c|c|c|c|c|}
\hline & & & & & STANDARD \\
\hline & HARMONIC & AMPLITUDE & PHASE & VARIATION & ERROR OF \\
\hline SAMPLE & MEAN - M & $-A$ & ANGLE - C & EXPLAINED & ESTIMATE \\
\hline SIZE_ & $10 E G C 1$ & IDEG $C 1$ & $(B A D I A N S)$ & $-(z)$ & DEEG CL \\
\hline 346 & 11.86 & 12.48 & 2.69 & 95 & 2.11 \\
\hline
\end{tabular}

SUMMARY OF MAXIMUM AND MINIMUM CONCENTRATIONS OF CONSTITUENTS SAMPLED AT A FREQUENCY OF QUARTERLY (1975 WY)

$01184000-$ CONNECTICUT R AT THOMPSONVILLE, CT

\begin{tabular}{|c|c|c|c|c|c|c|}
\hline \multirow{2}{*}{ CONSTITUENT } & \multicolumn{3}{|c|}{ TOTAL } & \multicolumn{3}{|c|}{ DISSOLVED } \\
\hline & $\begin{array}{c}\text { NO. } \\
\text { SAMPLES }\end{array}$ & $\begin{array}{l}\text { MINIMUM } \\
\text { CONC. }\end{array}$ & $\begin{array}{c}\text { MAXIMUM } \\
\text { CONC. }\end{array}$ & $\begin{array}{c}\text { NO. } \\
\text { SAMPLES }\end{array}$ & $\begin{array}{l}\text { MINIMUM } \\
\text { CONC. }\end{array}$ & $\begin{array}{l}\text { MAXIMUM } \\
\text { CONC. }\end{array}$ \\
\hline \multicolumn{7}{|l|}{ MINOR ELEMENTS: } \\
\hline ARSENIC (AS), UG/L & 4 & 0 & 2 & 4 & 0 & 2 \\
\hline CADMIUM $(C D), U G / L$ & 4 & 1 & 10 & 4 & 1 & $<10$ \\
\hline CHROMIUM (CR), UG/L & 4 & 0 & 20 & 4 & 0 & $<10$ \\
\hline COBALT $(C O), U G / L$ & 4 & 0 & 2 & 4 & 0 & 2 \\
\hline COPPER $(C U), U G / L$ & 4 & 0 & 30 & 12 & 0 & 20 \\
\hline IRON (FE), UG/L & 4 & 260 & 760 & 12 & 40 & 220 \\
\hline LEAD $(P B), U G / L$ & 4 & 2 & 6 & 4 & 0 & 3 \\
\hline MANG ANESE (MN), UG/L & 4 & 60 & 130 & 12 & 0 & 70 \\
\hline MERCURY (HG), UG/L & 4 & $\infty .5$ & $<0.5$ & 4 & $<0.5$ & $<0.5$ \\
\hline $\begin{array}{l}\text { SELENIUM ISE), UG/L } \\
\text { ZINC }(Z N), U G / L\end{array}$ & $\begin{array}{l}4 \\
4\end{array}$ & $\begin{array}{l}0 \\
0\end{array}$ & $\begin{array}{r}1 \\
150\end{array}$ & $\begin{array}{r}4 \\
12\end{array}$ & $\begin{array}{l}0 \\
0\end{array}$ & 1 \\
\hline \multicolumn{7}{|l|}{ PERIPHYTON: } \\
\hline BIOMASS, DRY WT., G/SO M & 3 & 3.79 & 51.00 & & & \\
\hline BIOMASS, ASH WT., G/SO M & 3 & 2.09 & 39.00 & & & \\
\hline CHLOROPHYLL A, MG/SQ M & 3 & 1.7 & 6.1 & & & \\
\hline CHLOROPHYLL B, MG/SO M & 3 & .0 & 1.8 & & & \\
\hline ORGANIC CARBON, MG/L & 12 & 3.5 & 7.7 & & & \\
\hline
\end{tabular}


Table 14.--Summary of measurements at each station--Continued

LAT 41023MO2S LONG 073010MOSS DRAINAGE AREA: 1541 SQ MI ( 3991 SQ KM) PERIOD OF RECORD: $10 / 01 / 74$ - 09/30/75

STATISTICAL SUMMARY OF SELECTED DISSOLVED CHEMICAL CONSTITUENTS AND

REGRESSION RELATIONSHIPS OF CONSTITUENT CONCENTRATIONS TO SPECIFIC CONDUCTANCE

CONSIIIUENI

\section{CONSIUIUE \\ SAMPLE
SIZE}

TEMPERATURE, WATER (DEG C) SPECIFIC CONDUCTANCE (MICROMHCS) STREAMFLOW (CUBIC FT/SEC) PH (STANDARD UNITS I PHOSPHORUS, TOTAL

NITRITE + NITRATE, TOTAL

NITROGEN, KJELDAHL, TOTAL

PHYTOPLANKTON, TOTAL (CELLS/ML)

SEDIMENT, SUSPENDED

SEDIMENT, CLAY-SILT (PERCENT)

COLIFORM, FECAL (COL/1OO ML)

STREPTOCOCCI, FECAL (COL/100 ML)

SILICA, DISSOLVED

CALCIUM, DISSOLVED

MAGNESIUM, DISSOLVED

SODIUM, DISSOLVED

POTASSIUM, DISSOLVED

BICARBONATE, ION

CARBONATE, ION

SULFATE, DISSOLVEU

CHLOR IDE, DISSOLVED

DISSOLVED SOLIDS, SUM OF CONST

UISSOLVED SOLIDS, ROE 180 DEG

HARDNESS, TOTAL

HARDNESS, NONCARBONATE

TURBIDITY (JTU)

FLOURIDE, DISSOLVED

$\begin{array}{rrr}12 & 10.96 & 8.51 \\ 12 & 188.3 & 16.9 \\ 12 & 5295.4 & 1905.0 \\ 12 & 7.57 & 0.25 \\ 12 & 0.052 & 0.010 \\ 11 & 0.391 & 0.113 \\ 11 & 0.362 & 0.143 \\ 12 & 4762.5 & 9301.1 \\ 13 & 6.8 & 5.4 \\ 11 & 93.8 & 11.4 \\ 12 & 37.1 & 67.3 \\ 12 & 119.3 & 318.8 \\ 12 & 4.12 & 0.82 \\ 12 & 21.92 & 3.63 \\ 12 & 7.98 & 1.32 \\ 11 & 6.89 & 0.97 \\ 11 & 1.65 & 0.54 \\ 12 & 86.8 & 14.4 \\ 12 & 0.0 & 0.0 \\ 12 & 12.52 & 2.58 \\ 12 & 10.30 & 1.13 \\ 11 & 110.1 & 13.0 \\ 12 & 124.0 & 15.6 \\ 12 & 86.9 & 13.2 \\ 12 & 16.3 & 5.1 \\ 12 & 2.3 & 1.4 \\ 11 & 0.15 & 0.07\end{array}$

STANDARD

YIAIION

8.51

905.0

0.25

0.010

0.143

301.1
5.4

11.4

18.8

0.82

3.63

1.32

0.54

14.4
0.0

2.58

13.0

15.6

13.2

0.07
REGRESSION

BEGRESSION SUMMABY

COEFICIENT, CONSTANT,

SAMPLE

BANGE

$1.0 \quad 23.0$

$\begin{array}{rr}165 & 210 \\ 95 & 8600\end{array}$

$\begin{array}{rrr}95 & 8600 & 12\end{array}$

7.2

0.04

0.26

0.12

560
1

64
1

2.6

2.6
17.0

6.0

6.0
5.7

5.7
1.3

69
0

9.3
8.2

8.2

103

67

1
0.1

0.0
0.55
0
34
1
1
1
1
12
1

0.07

0.55
0.54

34000

$12 \quad 0.0052$

$-0.00035$

$-0.00206$

0.00299

223.820

-

CORRELATION

STANDARD

ERROR OF

ESIIMAIE

*Not significant at the 95 percent confidence level.

DAILY SPECIFIC CONDUCTANCE IN

MICROMHOS AT 25 DEG C, THAT WAS

URAIION IABLE OF DAILY SPECIEIC CONDUCIANCE

EQUALLED OR EXCEEDED FOR THE

$\begin{array}{llllll}18 & -58 & 108 & 208 & 30 \% & 508 \\ 309 & 279 & 255 & 215 & 205 & 194\end{array}$

$50 \% \quad 70 \%$

$20 \% \quad 25 \% \quad 298$

INDICATED PERCENTAGE OF TIME

SUMMARY OF HARMONIC ANALYSIS OF STREAM TEMPERATUR

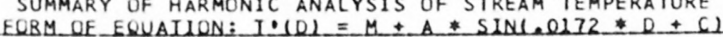

\begin{tabular}{|c|c|c|c|c|c|}
\hline & & & & & STANDARD \\
\hline & HARMONIC & AMPLITUDE & PHASE & VARIATION & ERROR OF \\
\hline $\begin{array}{l}\text { SAMPLE } \\
\text { SIZE }\end{array}$ & $\begin{array}{l}\text { MEAN - M } \\
\text { IDEG CI }\end{array}$ & $\begin{array}{c}-A \\
-10 E G(1)\end{array}$ & $\begin{array}{l}\text { ANGLE - C } \\
\text { (BADIANS) }\end{array}$ & $\begin{array}{l}\text { EXPLAINED } \\
(Z)\end{array}$ & $\begin{array}{l}\text { ESTIMATE } \\
\text { LDEG GI }\end{array}$ \\
\hline
\end{tabular}

$\begin{array}{llllll}189 & 10.98 & 11.96 & 2.66 & 97 & 1.34\end{array}$

SUMMARY OF MAXIMUM AND MINIMUM CONCENTRATIONS OF CONSTITUENTS

SAMPLED AT A FREQUENCY OF QUARTERLY (1975 WY)

01205500 -- HOUSATONIC R AT STEVENSON, CT

\begin{tabular}{|c|c|c|c|c|c|c|}
\hline \multirow{2}{*}{ CONSTITUENT } & \multicolumn{3}{|c|}{ TOTAL } & \multicolumn{3}{|c|}{ DISSOLVED } \\
\hline & $\begin{array}{l}\text { NO. } \\
\text { SAMPLES }\end{array}$ & $\begin{array}{l}\text { MINIMUM } \\
\text { CONC. }\end{array}$ & $\begin{array}{l}\text { MAXIMUM } \\
\text { CONC. }\end{array}$ & $\begin{array}{l}\text { NO. } \\
\text { SAMPLES }\end{array}$ & $\begin{array}{l}\text { MINIMUM } \\
\text { CONC. }\end{array}$ & $\begin{array}{l}\text { MAXIMUM } \\
\text { CONC. }\end{array}$ \\
\hline \multicolumn{7}{|l|}{ MINOR ELEMENTS: } \\
\hline ARSENIC (AS), UG/L & 4 & 0 & 2 & 4 & 0 & 2 \\
\hline CADMIUM $(C D), U G / L$ & 4 & 0 & 1 & 4 & 0 & 1 \\
\hline CHROMIUM (CR), UG/L & 4 & 0 & 10 & 4 & 0 & $<10$ \\
\hline COBALT $(C O), U G / L$ & 4 & 0 & 1 & 4 & 0 & 1 \\
\hline COPPER (CU), UG/L & 4 & 0 & 20 & 12 & 0 & 10 \\
\hline IRON (FE), UG/L & 4 & 140 & 200 & 12 & 20 & 90 \\
\hline LEAD $(P B), U G / L$ & 4 & 2 & 5 & 4 & 0 & 5 \\
\hline MANG ANESE (MN), UG/L & 4 & 30 & 120 & 12 & 0 & 90 \\
\hline MERCURY $(H G), U G / L$ & 4 & $<0.5$ & $<.5$ & 4 & $<0.5$ & $<0.5$ \\
\hline SELENIUM (SE), UG/L & 4 & 0 & 2 & 4 & 0 & 0 \\
\hline ZINC $(Z N), U G / !$ & 4 & $<10$ & 10 & 12 & 0 & 20 \\
\hline \multicolumn{7}{|l|}{ PERIPHYTON : } \\
\hline BIOMASS, DRY WT., G/SO M & 1 & 1.59 & & & & \\
\hline BIOMASS, ASH WT., G/SO M & 1 & 1.29 & & & & \\
\hline CHLOROPHYLL A, MG/SQ M & 1 & 6.5 & & & & \\
\hline CHLOROPHYLL B, MG/SO M & 1 & .5 & & & & \\
\hline ORGANIC CARBON, MG/L & 12 & 1.7 & 10.0 & & & \\
\hline
\end{tabular}


Table 14.--Summary of measurements at each station--Continued

LAT 40054M49S LONG $072041 M 14 S$

DRAINAGE AREA: 75 SQ MI 1194 SQ KM

PERIOD OF RECORD: $10 / 01 / 74-09 / 30 / 75$

STATISTICAL SUMMARY OF SELECTED DISSOLVED CHEMICAL CONSTITUENTS AND

REGRESSION RELATIONSHIPS OF CONSTITUENT CONCENTRATIONS TO SPECIFIC CONDUCTANCE

CONSILIUENI

\begin{tabular}{|c|}
\hline $\begin{array}{l}\text { TEMPERATURE, WATER (DEG C) } \\
\text { SPECIFIC CONDUCTANCE (MICROMHOS) } \\
\text { STREAMFLOW (CUBIC FT/SEC) } \\
\text { PH (STANDARD UNIIS) } \\
\text { PHOSPHORUS, TOTAL } \\
\text { NITRITE + NITRATE, TOTAL } \\
\text { NITROGEN, KJELDAHL, TOTAL } \\
\text { PHYTOPLANKTON, TOTAL (CELLS/ML) } \\
\text { SEDIMENT, SUSPENDED } \\
\text { SEDIMENT, CLAY-SILT (PERCENT) } \\
\text { COLIFORM, FECAL (COL IOO ML) } \\
\text { STREPTOCOCCI, FECAL (COL/IOO ML) } \\
\text { SILICA, DISSOLVED } \\
\text { CALCIUM, DISSOLVED } \\
\text { MAGNESIUM, DISSOLVED } \\
\text { SODIUM, DISSOLVED } \\
\text { POTASSIUM, OISSOLVED } \\
\text { BICARBONATE, ION } \\
\text { CARBONATE, ION } \\
\text { SULFATE, DISSOLVED } \\
\text { CHLORIDE, DISSOLVED } \\
\text { DISSOLVED SOLIDS, SUM OF CONST } \\
\text { DISSOLVED SOLIDS, ROE I8O DEG C } \\
\text { HARONESS, TOTAL } \\
\text { HARDNESS, NONCARBONATE } \\
\text { TURBIDITY (JTU) } \\
\text { FLOURIDE, DISSOLVED }\end{array}$ \\
\hline
\end{tabular}

\begin{tabular}{c} 
GONSII \\
SAMPL \\
SIZE \\
\hline 15 \\
15 \\
15 \\
15 \\
15 \\
15 \\
15 \\
15 \\
10 \\
10 \\
10 \\
9 \\
9 \\
15 \\
15 \\
15 \\
15 \\
15 \\
15 \\
15 \\
15 \\
15 \\
15 \\
10 \\
15 \\
15 \\
10 \\
15
\end{tabular}

*Not significant at the 95 percent confidence level.

$\begin{array}{ll}\text { STEAN } & \text { SENDARD } \\ \text { DEYIALION }\end{array}$

11.27

11.27
92.1

44.0

6.44

0.090

0.218

0.478

337.0

53.4

71.2
173.2

173.2
97.6

5.34

6.49

2.01

6.29

1.43

14.9
0.0

10.69

9.45

49.5

56.9

24.5

12 .

1.9

8.36

14.1
11.0

0.32

0.047

0.093

0.158

4136.5

133.2

14.1
188.0

188.0
107.5

1.05

1.16

0.25

0.37

0.50

3.2
0.0

1.84

1.00

4.4
9.6

3.8
2.9

0.6
0.07

2.0
76
22
5.7
0.03
0.04
0.24
360
2
55
1
1
3.7
4.3
1.6
5.6
1.0
11
0
7.3
7.8
41
42
18
8
1
0.0

BANGE

$2.0 \quad 23.0$

$\begin{array}{ll}76 & 128\end{array}$

$\begin{array}{rr}22 & 60 \\ 5.7 & 6.9\end{array}$

$0.03 \quad 0.19$

0.24

$\begin{array}{rr}0.73 & 15 \\ 14000 & 10\end{array}$

97

500
320

320
6.7

9.0
2.5

2.5
7.0

3.1
21

$\begin{array}{rr}11 & 21 \\ 0 & 0\end{array}$

$\begin{array}{ll}7.3 & 13.0 \\ 7.8 & 11.0\end{array}$

42
18
8

0.2

15
15
15
15
15
15
15
15
15
15
10
15
15
10
15

SUMMARY OF HARMONIC ANALYSIS OF STREAM TEMPERATURE EORM OE EQUAILN: I. $101=M+A *$ SINC.0172*D+C

\begin{tabular}{|c|c|c|c|c|c|}
\hline & & & & & STANDARD \\
\hline & HARMONIC & AMPLITUDE & PHASE & VAR IATION & ERROR OF \\
\hline SAMPLE & MEAN - M & $-A$ & ANGLE - C & EXPLAINED & ESTIMATE \\
\hline SLZE- & $10 E G_{2}()_{-}$ & $1 D E G(1$ & (BADIANS) & (8) & (DEG_Cl \\
\hline 134 & 12.29 & 11.54 & 2.80 & 88 & 1.74 \\
\hline
\end{tabular}

SUMMARY OF MAXIMUM AND MINIMUM CONCENTRATIONS OF CONSTITUENTS

SAMPLED AT A FREQUENCY OF QUARTERLY (1975 WY)

01304500 -- PECONIC RIVER AT RIVERHEAD NY

\begin{tabular}{|c|c|c|c|c|c|c|}
\hline \multirow{2}{*}{ CONSTITUENT } & \multicolumn{3}{|c|}{ TOTAL } & \multicolumn{3}{|c|}{ DISSOLVED } \\
\hline & $\begin{array}{l}\text { NO. } \\
\text { SAMPLES }\end{array}$ & $\begin{array}{l}\text { MINIMUM } \\
\text { CONC. }\end{array}$ & $\begin{array}{l}\text { MAXIMUM } \\
\text { CONC. }\end{array}$ & $\begin{array}{l}\text { NO. } \\
\text { SAMPLES }\end{array}$ & $\begin{array}{l}\text { MINIMUM } \\
\text { CONC. }\end{array}$ & $\begin{array}{l}\text { MAXIMUM } \\
\text { CONC. }\end{array}$ \\
\hline \multicolumn{7}{|l|}{ MINOR ELEMENTS: } \\
\hline ARSENIC (AS), UG/L & 2 & 0 & 1 & 3 & 0 & 1 \\
\hline CADMIUM $(C D), U G / L$ & 3 & 0 & 0 & 3 & 0 & 0 \\
\hline CHROMIUM (CR), UG/L & 3 & 0 & $<10$ & 3 & 0 & $<10$ \\
\hline COBALT $(C O), U G / L$ & 3 & 0 & 0 & 3 & 0 & 1 \\
\hline COPPER (CU), UG/L & 3 & 0 & 0 & 3 & 0 & 10 \\
\hline IRON (FE), UG/L & 8 & 450 & 2200 & 3 & 90 & 1200 \\
\hline LEAD $(P B), U G / L$ & 3 & 0 & 5 & 3 & 0 & 2 \\
\hline MANG ANESE (MN), UG/L & 8 & 50 & 120 & 3 & 40 & 70 \\
\hline MERCURY (HG), UG/L & 3 & $<0.5$ & $<0.5$ & 3 & $<0.5$ & $<0.5$ \\
\hline SELENIUM (SE), UG/L & 3 & 0 & 1 & 3 & 0 & 1 \\
\hline ZINC $(2 N), U G / L$ & 3 & 0 & 20 & 3 & 0 & 10 \\
\hline \multicolumn{7}{|l|}{ PERIPHYTON: } \\
\hline BIOMASS, DRY WT., G/SO M & 3 & .79 & 5.79 & & & \\
\hline BIOMASS, ASH WT., G/SO M & 3 & .00 & 2.69 & & & \\
\hline CHLOROPHYLL A, MG/SO M & 3 & .1 & 2.0 & & & \\
\hline CHLOROPHYLL $B$, MG/SO M & 3 & .0 & .5 & & & \\
\hline ORGANIC CARBON, MG/L & 3 & 4.2 & 6.5 & & & \\
\hline
\end{tabular}


LAT 41D43M18S LONG 073D56M28S DRAINAGE AREA: 11700 SQ MI ( 30303 SQ KM) PRAINAGE AREA: 11700 OF RECORD: $10 / 01 / 74-09 / 30 / 75$

STATISTICAL SUMMARY OF SELECTED DISSOLVED CHEMICAL CONSTITUENTS AND REGRESSION RELATIONSHIPS OF CONSTITUENT CONCENTRATIONS TO SPECIFIC CONDUCTANCE

CONSIIIUENI

CONSIUIUENT IHE/L OR UNII SHOWN

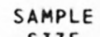

SIZE

STANDARD

MEAN REXIALION

TEMPERATURE, WATER (DEG C)

SPECIFIC CONDUCTANCE (MICROMHOS)

STREAMFLOW (CUBIC FT/SEC)

PH (STANDARD UNITS)

PHOSPHORUS, TOTAL

NITRITE + NITRATE, TOTAL

NITROGEN, KJELDAHL, TOTAL

PHYTOPLANKTON, TOTAL (CELLS/ML)

SEDIMENT, SUSPENDED

SEDIMENT, CLAY-SILT (PERCENT)

COLIFORM, FECAL (COL/100 ML)

STREPTOCOCCI, FECAL (COL/100 ML)

SILICA, DISSOLVED

CALCIUM, DISSOLVED

MAGNESIUM, DI SSOL VED

SODIUM, DISSOLVED

POTASSIUM, DISSOLVED

BICARBONATE, ION

CARBONATE, ION

SULFATE, DISSOLVED

CHLORIDE, DISSOLVED

DISSOLVED SOLIDS, SUM OF CONST

DISSOLVED SOLIDS, ROE 180 DEG

HARDNESS, TOTAL

HARDNESS, NONCARBONATE

TURBIDITY (JTU)

FLOUR IDE, DISSOLVED

$\begin{array}{rr}15.48 & 7.59 \\ 178.3 & 29.8 \\ 7.40 & 0.18 \\ 0.070 & 0.021 \\ 0.669 & 0.129 \\ 0.417 & 0.086 \\ 3612.0 & 5040.3 \\ 13.0 & 7.1 \\ 89.0 & 2.8 \\ 402.0 & 331.7 \\ 66.7 & 54.5 \\ 1.43 & 2.22 \\ 18.07 & 2.52 \\ 3.23 & 0.71 \\ 5.57 & 1.30 \\ 0.93 & 0.15 \\ 65.5 & 11.2 \\ 0.0 & 0.0 \\ 18.00 & 2.93 \\ 10.06 & 2.33 \\ 82.3 & 11.1 \\ 100.0 & 9.2 \\ 60.0 & 8.2 \\ 12.7 & 2.1 \\ 15.0 & 12.3 \\ 0.13 & 0.06\end{array}$

*Not significant at the 95 percent confidence level.

SUMMARY OF HARMONIC ANALYSIS OF STREAM TEMPERATURE

\begin{tabular}{|c|c|c|c|c|c|}
\hline & & & & & STANDARD \\
\hline & HARMONIC & AMPLITUDE & PHASE & VARIATION & ERROR OF \\
\hline SAMPLE & MEAN - M & $-A$ & $A N G L E-C$ & EXPLAINED & ESTIMATE \\
\hline SIZE & 10EG 61 & DEE $(1)$ & (BADLANS) & -181 & $10 E G_{C}(1)$ \\
\hline 311 & 11.96 & 12.69 & 2.63 & 98 & 1.29 \\
\hline
\end{tabular}

BEGRESSION SUMMABY

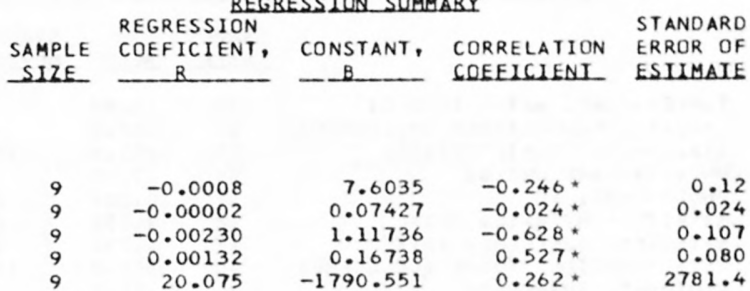

$\begin{array}{rrrr}0.186 & 30.066 & 0.638^{*} & 8.4 \\ 0.000 & 0.000 & 0.000^{*} & 0.0 \\ 0.0786 & 2.6748 & 0.946 & 1.02 \\ 0.0478 & 0.9668 & 0.740 & 1.03\end{array}$

$0.0624 .396 \quad 0.166 *$

13.8

SUMMARY OF MAXIMUM AND MINIMUM CONCENTRATIONS OF CONSTITUENTS SAMPLED AT A FREQUENCY OF QUARTERLY (1975 WY)

01372043 - HUDSON RIVER NEAR POUGHKEEPSIE, NY

\begin{tabular}{|c|c|c|c|c|c|c|}
\hline \multirow{2}{*}{ CONSTITUENT } & \multicolumn{3}{|c|}{ TOTAL } & \multicolumn{3}{|c|}{ DISSOLVED } \\
\hline & $\begin{array}{l}\text { NO. } \\
\text { SAMPLES }\end{array}$ & $\begin{array}{l}\text { MINIMUIH } \\
\text { CONC. }\end{array}$ & $\begin{array}{l}\text { MAXIMUM } \\
\text { CONC. }\end{array}$ & $\begin{array}{l}\text { NC. } \\
\text { SAMPLES }\end{array}$ & $\begin{array}{l}\text { MINIMUM } \\
\text { CONC. }\end{array}$ & $\begin{array}{l}\text { MAXIMUM } \\
\text { CONC. }\end{array}$ \\
\hline \multicolumn{7}{|l|}{ MINOR ELEMENTS: } \\
\hline ARSENIC (AS), UG/L & 4 & 0 & 1 & 3 & 0 & 1 \\
\hline CADMIUM $(C D)$, UG/L & 3 & 0 & 1 & 3 & 0 & 1 \\
\hline CHROMIUM (CR), UG/L & 3 & $<10$ & 20 & 3 & $<10$ & 20 \\
\hline COBALT $(C O), U G / L$ & 3 & 0 & 0 & 3 & 0 & 0 \\
\hline COPPER $(C U), U G / L$ & 4 & 10 & 20 & 3 & 0 & 10 \\
\hline IRON $(F E), U G / L$ & 11 & 470 & 1800 & 3 & 10 & 80 \\
\hline LEAD $(P B), U G / L$ & 4 & 5 & 8 & 3 & 1 & 2 \\
\hline MANGANESE (MN), UG/L & 11 & 40 & 80 & 3 & 0 & 10 \\
\hline MERCURY (HG), UG/L & 4 & $<0.5$ & 0.5 & 3 & $<0.5$ & $<0.5$ \\
\hline SELENIUM (SE), UG/L & 3 & 0 & 0 & 3 & 0 & 0 \\
\hline ZINC $(Z N), U G / L$ & 3 & 10 & 30 & 3 & 0 & 10 \\
\hline \multicolumn{7}{|l|}{ PERIPHYTON: } \\
\hline BIOMASS, DRY WT., G/SQ M & 2 & 7.39 & 8.89 & & & \\
\hline BIOMASS, ASH WT., G/SO M & 2 & 3.09 & 5.79 & & & \\
\hline CHLOROPHYLL A, MG/SQ M & 2 & 24.0 & $42 \cdot 0$ & & & \\
\hline CHLOROPHYLL $B$, MG/SQ M & 2 & 4.5 & $14 \cdot 0$ & & & \\
\hline ORGANIC CARBON, MG/L & 11 & 1.8 & 14.0 & & & \\
\hline
\end{tabular}


-AT $40030 M 47 S$ LONG 074032M24S

$\begin{array}{lll}\text { JRAINAGE AREA: } & 862 \text { SQ MI } 12233 \text { SQ KMI } \\ \text { PERIOD OF RECORD: } & 10 / 01 / 74-09 / 30 / 75\end{array}$

STATISTICAL SUMMARY OF SELECTED DISSOLVED CHEMICAL CONSTITUENTS AND

REGRESSION RELATIONSHIPS OF CONSTITUENT CONCENTRATIONS TO SPECIFIC CONDUCTANCE

CONSIIIUENI

CONSIUIUENI IMGLL OR UNII SHOWNI

SAMPLE

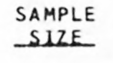

TEMPERATURE, WATER (DEG C) SPECIFIC CONDUCTANCE (MICROMHOS) STREAMFLOW ICUBIC FT/SEC)

PH (STANDARD UNITS)

PHOSPHORUS, TOTAL

NITRITE + NITRATE, TOTAL NITROGEN, KJELDAHL, TOTAL PHYTOPLANKTON, TOTAL (CELLS/ML) SEDIMENT, SUSPENDED

SEDIMENT, CLAY-SILT (PERCENT)

COLIFORM, FECAL (COL/100 ML)

STREP TOCOCCI, FECAL (COL/100 ML)

SILICA, DISSOLVED

CALCIUM, DISSOLVED

MAGNESIUM, DISSOLVED

SODIUM, DISSOLVED

POTASSIUM, DISSOLVED

BICARBONATE, ION

CARBONATE, ION

SULFATE, DISSOLVED

CHLORIDE, DISSOLVED

DISSOLVED SOLIDS, SUM OF CONST

DISSOLVED SOLIDS, ROE 180 DEG

HARDNESS, TOTAL

HARDNESS, NONCARBONATE

TURBIDITY (JTU)

FLOURIDE, DISSOLVED
STANDARD

DEVIAIION

8.62
97.6
1206.0
0.47
0.098
0.487
1.171
1268.4
15.8
6.7
2958.2
3213.8
1.81
6.40
1.29
10.19
1.19
10.0
0.0
16.93
13.01
50.1
48.6
21.2
16.8
6.0
0.07

0.07
BANGE

\begin{abstract}
13.95
\end{abstract}
13.95
288.3

1343.8

1343.8
7.45

0.209

1.550

1.746

2801.0

17.3
94.9

94.9
1101.8

1126.5

9.52
20.75

20.75

6.43

20.25

2.93

45.8

0.0
47.58

47.58
27.58

157.8

176.5

78.6

40.8
8.3

0.17

0.11
1.10

1.10
0.57

0.57
810

4.6

8.5

1.3
29

23.0
11.0
BEGRESSION SUMMARY

REGRESSION

SAMPLE COEFICIENT,

CONSTANT,
-8

CORRELATION

STANDARO SIZE

$\begin{array}{rr}2.3 & 24 . \\ 149 & 54 \\ 306 & 470 \\ 6.5 & 8 .\end{array}$

24.5
543
4700
8.1

$\begin{array}{rr}8.1 & 13 \\ 0.49 & 12\end{array}$

$2.90 \quad 12$

5.00

4700

47
1.00

1.00
10000

10000
10800

10800
12.0

$\begin{array}{rr}6.8 & 12.0 \\ 13.0 & 37.0\end{array}$

8.5

$46.0 \quad 12$

$46.5 \quad 12$

62
0

83.0

62.0

280
294

294
130
77

77
20

0.3

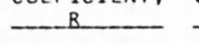

$-B$

CDEEICIENI

ERROR OF

ESIIMAIF

13
13
12
12
12
10



12
12
12
12
12
12
10
12
12
12
12
12
12
12
12

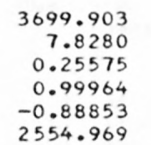

-0.662
$-0.276^{*}$
$-0.166^{*}$
$0.396^{*}$
0.787
$0.051^{*}$

944.6

$-0.0013$

$-0.00016$

0.00190

0.919

2554.969

$-0.0040$

0.0564

0.0100

0.0080

0.066

0.000

0.1573

0.1254

0.483

0.464

0.188

0.129

$-0.038$

$-0.0001$

4.3570
3.5247

$-7.5196$

0.6000

26.478

0.000

1.8954

$-8.8470$

17.521

41.775

24.090

3.239
19.245

0.1977 $-0.222^{\star}$

0.897

0.790

0.954

0.688
0.673

$0.000 *$

0.945

0.980

0.980

0.971

0.783

$-0.633$

-0.167 .

DURALION IABLE OE DALYY SPECIEIC CONOUCIANCE

DAILY SPECIFIC CONDUCTANCE IN

MICROMHOS AT 25 DEG C, THAT WAS

EQUALLED OR EXCEEDED FOR THE

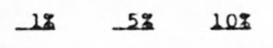

202

$30 \% \quad 50 \%$

SAMPLE SIZE $=291$

INDICATED PERCENTAGE OF TIME

541

455

387

295

253

213

703

$203 \quad 258$

292

SUMMARY OF HARMONIC ANALYSIS OF STREAM TEMPERATURE

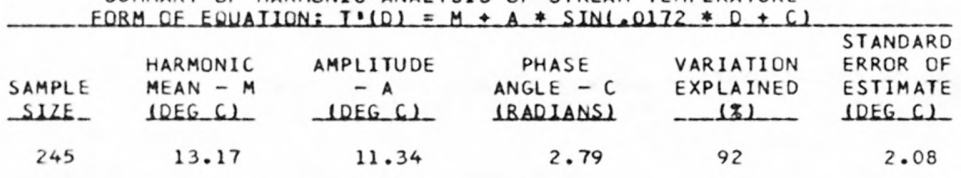

SUMMARY OF MAXIMUM AND MINIMUM CONCENTRATIONS OF CONSTITUENTS SAMPLED AT A FREQUENCY OF QUARTERLY (1975 WY)

01404100 -- RARITAN R NR SOUTH BOUND BROOK NJ

\begin{tabular}{|c|c|c|c|c|c|c|}
\hline \multirow{2}{*}{ CONSTITUENT } & \multicolumn{3}{|c|}{ TOTAL } & \multicolumn{3}{|c|}{ DISSOLVED } \\
\hline & $\begin{array}{l}\text { NO. } \\
\text { SAMPLES }\end{array}$ & $\begin{array}{l}\text { MIN IMUM } \\
\text { CONC. }\end{array}$ & $\begin{array}{l}\text { MAXIMUM } \\
\text { CONC. }\end{array}$ & $\begin{array}{l}\text { NO. } \\
\text { SAMPLES }\end{array}$ & $\begin{array}{l}\text { MINIMUM } \\
\text { CONC. }\end{array}$ & $\begin{array}{l}\text { MAXIMUM } \\
\text { CONC. }\end{array}$ \\
\hline \multicolumn{7}{|l|}{ MINOR ELEMENTS: } \\
\hline ARSENIC (AS), UG/L & 4 & 1 & 3 & 4 & 0 & 2 \\
\hline CADMIUM $(C D), U G / L$ & 4 & 0 & 0 & 4 & 0 & 0 \\
\hline CHROMIUM (CRI, UG/L & 4 & $<10$ & 20 & 4 & 0 & 10 \\
\hline COBALT $(C O), U G / L$ & 4 & 0 & 2 & 4 & 0 & 0 \\
\hline COPPER (CU), UG/L & 4 & 10 & 20 & 4 & 0 & 10 \\
\hline IRON $(F E), U G / L$ & 4 & 370 & 660 & 4 & 60 & 180 \\
\hline LEAD (PB), UG/L & 4 & 2 & 11 & 4 & 1 & 7 \\
\hline MANGANESE $(M N), U G / L$ & 4 & 70 & 220 & 4 & 60 & 190 \\
\hline MERCURY (HG), UG $/ L$ & 4 & $\infty .5$ & 0.7 & 4 & $<0.5$ & $<0.5$ \\
\hline SELENIUM (SE), UG/L & 4 & 0 & 1 & 4 & 0 & 1 \\
\hline ZINC $(Z N), U G / L$ & 4 & 20 & 20 & 4 & 10 & 20 \\
\hline \multicolumn{7}{|l|}{ PERIPHYTON: } \\
\hline BIOMASS, DRY WT., G/SO M & 3 & .59 & 7.79 & & & \\
\hline BIOMASS, ASH WT., G/SO M & 3 & .59 & 7.79 & & & \\
\hline CHLOROPHYLL A, MG/SO M & 3 & .0 & 6.5 & & & \\
\hline CHLOROPHYLL B, MG/SO M & 3 & .0 & 1.2 & & & \\
\hline ORGANIC CARBON, MG/L & 12 & 3.5 & 16.0 & & & \\
\hline
\end{tabular}


Table 14.--Summary of measurements at each station--Continued

STATION NUMBER: 01408500

NAME: TOMS R NR TOMS RIVER NJ

LAT 39D59M1OS LONG 074D13M29S

$\begin{array}{llll}\text { DRAINAGE AREA: } & 124 \text { SQ MI } 11321 \text { SQ KM) } \\ \text { PERIOD OF RECORD: } & 10 / 01 / 74-09 / 30 / 75 & \end{array}$

STATISTICAL SUMMARY OF SELECTED DISSOLVED CHEMICAL CONSTITUENTS ANC

REGRESSION RELATIONSHIPS OF CONSTITUENT CONCENTRATIONS TO SPECIFIC CONDUCTANCE

CONSIUIUENI

CONSIUUENI IMG/L_OR UNII SHOWNI)

SAMPLE

SIZE

TEMPERATURE, WATER (DEG C) SPECIFIC CONDUCTANCE (MICROMHOS)

STREAMFLOW (CUBIC FT/SEC)

PH (STANDARD UNITS)

PHOSPHORUS, TOTAL

NITRITE + NITRATE, TOTAL

NITROGEN, KJELDAHL, TOTAL

PHYTOPLANKTON, TOTAL ICELLS/ML)

SEDIMENT, SUSPENDED

SEDIMENT, CLAY-SILT (PERCENT)

COLIFORM, FECAL (COL/100 ML)

STREP TOCOCCI, FECAL (COL/100 ML)

SILICA, DISSOLVED

CALCIUM, DISSOLVED

MAGNESIUM, DISSOLVED

SODIUM, DISSOLVED

POTASSIUM, DISSOLVED

BICARBONATE, ION

CARBONATE, ION

SULFATE, DISSOLVED

CHLORIDE, DISSOLVED

DISSOLVED SOLIDS, SUM CF CONST

DISSOLVED SOLIDS, ROE 180 DEG C

HARDNESS, TOTAL

HARDNESS, NONCARBONATE

TURBIDITY (JTU)

FLOURIDE, DISSOLVED

\section{STANDARD}

DEVIATUON

11
11
13
12
12
12
12
12
12
12
12
9
11
12
12
12
12
10
12
12
12
10
12
12
10
12
11
$12.48 \quad 7.55$

$66.1 \quad 4.7$

$\begin{array}{ll}4.81 & 0.69 \\ 0.043 & 0.025\end{array}$

$0.304 \quad 0.120$

$0.373 \quad 0.198$

298.0

8.8
90.6

90.6
94.2

94.2
348.7

4.11

3.26

3.26
1.07

1.07
4.37

4.37
1.05

0.2
0.0

0.0
10.81

6.75

33.5

45.1

12.7

13.1

2.6
$4.81 \quad 87.3$
0.198
279.2

279.2
9.8

16.5

197.8

321.9

1.29

1.61

0.27

0.65
0.20

0.20
0.4

0.0

4.78

1.59
5.3

14.0

4.4
4.5
1.1

0.09

*Not significant at the 95 percent confidence level

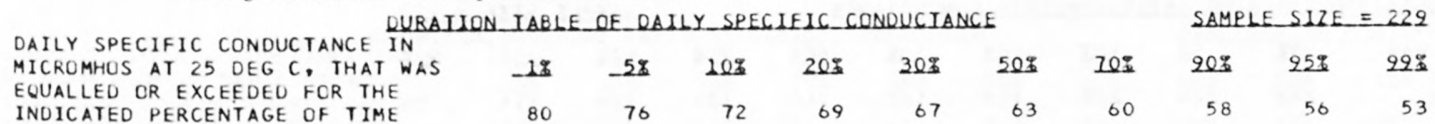

EOUALLED OR EXCEEDEU FOR THE

80

BEGRESSION SUMMARY SAMPLE COEFICIENT,
SIZE

CONSTANT,

STANDARD

1.2
57
110
3.9
0.02
0.12

23.2
72
435

$11 \quad 1.379$

0.0612
-0.00272

$-0.00070$

$-0.01655$

14.761

$-661.367$

63
0
10
1.4
2.3
0.5
3.5
0.8
0
0
5.7
3.4
27
17
8
10
1
0.0

38
100
700

700
784

$5.8 \quad 10$

$\begin{array}{lll}7.8 & 11 & 0.0535\end{array}$

0.1155

$-4.3056$

$-0.0077$

$-0.0103$

0.0015

0.000

0.5798

$-0.1247$

0.630

$-0.639$

0.241

0.232

$-0.0057$
CORRELATION

47.669
0.7028

0.7028

0.22161

0.33462

1.44664

0.424.
-0.511.

$-0.030^{\circ}$

$-0.405$

$0.244^{\circ}$

0.65

0.023

0.118

293.3

0.3632

0.191 *

0.328 *

1.5349

4.9980

1.1471

0.000

$-0.075$

$-0.034$.

$-0.417$.

0.417.

0.549

$-27.5289$

14.9874
-8.713

85.962

$-3.221$

$-2.312$

$-4.347$

-0.355 .

0.520

$-0.220$

$0.250^{\circ}$

0.225 *

0.438 *

-0.312 *

ROR CF

ESILIMAIE

0.4981

SUMMARY OF HARMONIC ANALYSIS OF STREAM TEMPERATURE FORM OF EUUAION. I T SING.0172*0+C)

\begin{tabular}{|c|c|c|c|c|c|}
\hline & & & & & STANDARD \\
\hline $\begin{array}{l}\text { SAMPLE } \\
\text { SHZE. }\end{array}$ & $\begin{array}{l}\text { HARMONIC } \\
\text { MEAN - M } \\
\text { (OEG C) }\end{array}$ & $\begin{array}{c}\text { AMPLI TUDE } \\
-A \\
(D E G \text { (I) }\end{array}$ & $\begin{array}{c}\text { PHASE } \\
\text { ANGLE - C } \\
\text { IRAD LANSI }\end{array}$ & $\begin{array}{l}\text { VAR IATION } \\
\text { EXPLA INED } \\
-(X)\end{array}$ & $\begin{array}{l}\text { ERROR OF } \\
\text { ESTIMATE } \\
\text { LOEG_CI }\end{array}$ \\
\hline 225 & 12.35 & 9.89 & 2.76 & 95 & 1.51 \\
\hline
\end{tabular}

SUMMARY OF MAXIMUM ANO MINIMUM CONCENTRATIONS OF CONSTITUENTS SAMPLED AT A FREQUENCY OF QUARTERLY (1975 WY)

01408500 -- TOMS R NR TOMS RIVER NJ

\begin{tabular}{|c|c|c|c|c|c|c|}
\hline \multirow{2}{*}{ CONSTITUENT } & \multicolumn{3}{|c|}{ TOTAL } & \multicolumn{3}{|c|}{ DISSOLVED } \\
\hline & $\begin{array}{l}\text { NO. } \\
\text { SAMPLES }\end{array}$ & $\begin{array}{l}\text { MIN IMUM } \\
\text { CONC. }\end{array}$ & $\begin{array}{l}\text { MAXIMUM } \\
\text { CONC. }\end{array}$ & $\begin{array}{c}\text { NO. } \\
\text { SAMPLES }\end{array}$ & $\begin{array}{l}\text { MINIMUM } \\
\text { CONC. }\end{array}$ & $\begin{array}{l}\text { MAXIMUM } \\
\text { CONC. }\end{array}$ \\
\hline \multicolumn{7}{|l|}{ MINOR ELEMENTS: } \\
\hline ARSENIC (AS), UG/L & 4 & 0 & 1 & 4 & 0 & 1 \\
\hline CADMIUM $(C D), U G / L$ & 4 & 0 & 1 & 4 & 0 & 1 \\
\hline CHROMIUM (CR), UGIL & 4 & 0 & 40 & 4 & 0 & 40 \\
\hline COBALT $(C O), U G / L$ & 4 & 0 & 1 & 4 & 0 & 1 \\
\hline COPPER (CU), UGIL & 4 & 0 & 20 & 4 & 0 & 20 \\
\hline IRON (FE), UG/L & 4 & 400 & 1500 & 4 & 340 & 1200 \\
\hline$L E A D(P B), U G / L$ & 4 & 4 & 13 & 4 & 3 & 13 \\
\hline MANGANESE (MN), UG/L & 4 & 30 & 60 & 4 & 20 & 60 \\
\hline MERCURY $(H G), U G / L$ & 4 & $<0.5$ & 0.6 & 4 & $<0.5$ & 0.6 \\
\hline SELENIUM $(S E), U G / L$ & 4 & 0 & 1 & 4 & 0 & 0 \\
\hline ZINC $(Z N), U G / L$ & 4 & 20 & 110 & 4 & 20 & 110 \\
\hline \multicolumn{7}{|l|}{ PERIPHYTON: } \\
\hline BIOMASS, DRY WT., G/SQ M & 2 & 1.79 & 4.39 & & & \\
\hline BIOMASS, ASH WT., G/SO M & 2 & .89 & 2.50 & & & \\
\hline CHLOROPHYLL A, MG/SQ M & 3 & .0 & 2.1 & & & \\
\hline CHLOROPHYLL B, MG/SQ M & 3 & .0 & $\cdot 3$ & & & \\
\hline ORGANIC CARBON, MG/L & 12 & 4.6 & 19.0 & & & \\
\hline
\end{tabular}


Table 14.--Summary of measurements at each station--Continued

LAT 40D13M18S LONG 074046M42S

DRAINAGE AREA: 6780 SQ MI ( 17560 SQ KM)

PERIOD OF RECORD: $10 / 01 / 74$ - 09/30/75

STATISTICAL SUMMARY OF SELECTED DISSOLVED CHEMICAL CONSTITUENTS AND

REGRESSION RELATIONSHIPS OF CONSTITUENT CONCENTRATIONS TO SPECIFIC CONDUCTANCE

CONSILIUENI

CONSIIIUENI_LG L OR_UNII_SHOWN)

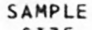

SIZE

STANDARD

MEAN DEXIALION BANGE

TEMPERATURE, WATER (DEG C) SPECIFIC CONDUCTANCE (MICROMHOS) STREAMFLOW (CUBIC FT/SEC)

PH (STANDARD UNITS)

PHOSPHORUS, TOTAL

NITRITE + NITRATE, TOTAL

NITROGEN, KJELDAHL, TOTAL

PHYTOPLANKTON, TOTAL (CELLS/ML)

SEDIMENT, SUSPENDED

SEDIMENT, CLAY-SILT (PERCENT)

COLIFORM, FECAL ( COL/100 ML)

STREPTOCOCCI, FECAL ( COL/100 ML)

SILICA, DISSOLVED

CALCIUM, DISSOLVED

MAGNESIUM, DISSOLVED

SODIUM, DISSOLVED

POTASSIUM, DISSOLVED

BICAR BONATE, ION

CARBONATE, ION

SULFATE, DISSOLVED

CHLOR IDE, DISSOLVED

CHLOR IDE, DISSOLVED
DISSOLVED SOLIDS, SUM OF CONST

OISSOLVED SOLIDS, ROE 180 DEG

DISSOLVED SOLID
HARONESS, TOTAL

HARONESS, TOTAL
HARDNESS, NONCARBONATE

TURBIUITY (JTU)

FLOUR IDE, DISSOLVED
11.73

160.8

17892.0

7892.0
7.95

0.085

0.860

0.430

4649.1

64.5

$96 \cdot 5$

96.5
805.1

334.0

3.63

15.00

6.01
6.20

6.20
1.49

44.8

0.0

22.75

8.84

86.6
102.6

102.6
62.3

62.3
25.5

5.4

0.15
8.61

38.0
16799.2

6799.2
0.49

0.49
0.029

0.159

0.177

100.3

5.0
100

1570.6

724.0

1.00

4.05

4.16

1.13

0.40

14.1

7.51

1.91

21.7

23.2

26.1

16.5

4.8
0.08

\begin{tabular}{lll}
\multicolumn{2}{c}{ REGRESSION SUMMABY } & \\
SAMPLE & SEGESSION & STANDARO \\
SOEFICIENT, CONSTANT, CORRELATION ERROR OF
\end{tabular}

BEGRESS ION SUMMABY

SIZE

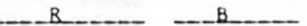

COEEICJENI.

ESIUMAIE

$2.1 \quad 25.6$

$\begin{array}{rrr}110 & 226 \\ 4580 & 72900 & 12\end{array}$

$0.58 \quad 1.10 \quad 12$

0.20

500

304

100

4026
2250

$\begin{array}{rr}2250 & \\ 5.1 & 11 \\ 22.0 & 12\end{array}$

$\begin{array}{rr}1.2 & 5.1 \\ 7.0 & 22.0 \\ 2.1 & 18.0\end{array}$

4.7

0.8

21
0

14.0

5.9

49
75

26
9

2
0.0

43.0

12.0
125

147

130
73

20
0.3 $\begin{array}{rrr}7.1 & 8.6 & 12 \\ 0.05 & 0.14 & 12\end{array}$
$-141.580$

0.0007

0.00025

0.00371

0.00118

$-13.213$

35235.75

7.8435

0.04514

0.26273

0.24004

6818.496

-0.0050
0.1017
0.0885
0.0231
0.0061
0.344
0.000
0.0888
0.0171
0.491
0.526
0.620
0.334
-0.020
-0.0003

4.4314
-1.3494
-8.2174
2.4900
0.5121
-10.479
0.000
8.4747
6.0964
7.232
17.995
-37.393
-28.163
8.674
0.2015

0.954

0.808

0.774

0.580

0.926

0.000 *

$0.449 *$

0.896

0.896

0.903

.770

-0.161 *

-0.168 *
4304.0

0.52

0.029

0.077

6558.4

confidence level.

DAILY SPECIFIC CONDUCTANCE IN

INDICATED PERCENTAGE OF TIME

$\begin{array}{llllll}-18 & -58 & 108 & 208 & 308 & 508 \\ 242 & 224 & 208 & 189 & 161 & 146\end{array}$

503

\section{8}

SAMPLE SIZE $=227$

207252928

$120 \quad 114 \quad 94$

SUMMARY OF HARMONIC ANALYSIS OF STREAM TEMPERATURE

\begin{tabular}{|c|c|c|c|c|c|}
\hline & & & & & STANDARD \\
\hline & HARMONIC & AMPLITUDE & PHASE & VAR IATION & ERROR OF \\
\hline $\begin{array}{l}\text { SAMPLE } \\
\text { SIZE. }\end{array}$ & $\begin{array}{l}\text { MEAN - M } \\
\text { LOEG CI }\end{array}$ & $\begin{array}{l}-A \\
\text { (DEG }\end{array}$ & $\begin{array}{l}\text { ANGLE }-C \\
\text { (RADIANSI) }\end{array}$ & $\begin{array}{c}\text { EXPLAINED } \\
(\bar{l})\end{array}$ & $\begin{array}{l}\text { ESTIMATE } \\
\text { (DEG_C) }\end{array}$ \\
\hline 257 & 13.28 & 11.72 & 2.76 & 94 & 1.95 \\
\hline
\end{tabular}

SUMMARY OF MAXIMUM AND MINIMUM CONCENTRATIONS OF CONSTITUENTS

SAMPLED AT A FREQUENCY OF QUARTERLY (1975 WY)

01463500 -- DELAWARE R AT TRENTON NJ

\begin{tabular}{|c|c|c|c|c|c|c|}
\hline \multirow{2}{*}{ CONSTITUENT } & \multicolumn{3}{|c|}{ TOTAL } & \multicolumn{3}{|c|}{ DISSOLVED } \\
\hline & $\begin{array}{l}\text { NO. } \\
\text { SAMPLES }\end{array}$ & $\begin{array}{l}\text { MIN IMUM } \\
\text { CONC. }\end{array}$ & $\begin{array}{l}\text { MAXIMUM } \\
\text { CONC. }\end{array}$ & $\begin{array}{l}\text { NO. } \\
\text { SAMPLES }\end{array}$ & $\begin{array}{l}\text { MINIMUM } \\
\text { CONC. }\end{array}$ & $\begin{array}{l}\text { MAXIMUM } \\
\text { CONC. }\end{array}$ \\
\hline \multicolumn{7}{|l|}{ MINOR ELEMENTS: } \\
\hline ARSENIC (AS), UG/L & 4 & 0 & 2 & 4 & 0 & 2 \\
\hline CADM IUM $(C D), U G / L$ & 4 & 0 & 1 & 4 & 0 & 1 \\
\hline CHROMIUM (CR), UG/L & 4 & 10 & 70 & 4 & 0 & 70 \\
\hline COBALT $(C O), U G / L$ & 4 & 0 & 1 & 4 & 0 & 1 \\
\hline COPPER (CU), UG/L & 4 & 10 & 30 & 4 & 10 & 30 \\
\hline IRON $(F E), U G / L$ & 4 & 170 & 1800 & 4 & 20 & 80 \\
\hline LEAD $(P B), U G / L$ & 4 & 5 & 15 & 4 & 4 & 12 \\
\hline MANG ANESE $(M N), U G / L$ & 4 & 10 & 150 & 4 & 10 & 70 \\
\hline MERCURY (HG), UG/L & 4 & $<0.5$ & 1.3 & 4 & $<0.5$ & 1.3 \\
\hline SELENIUM (SE), UG/L & 4 & 0 & 1 & 4 & 0 & 0 \\
\hline$Z I N C(Z N), U G / L$ & 4 & 30 & 80 & 4 & 20 & 60 \\
\hline \multicolumn{7}{|l|}{ PERIPHYTON: } \\
\hline BIOMASS, DRY WT., G/SQ M & 4 & 3.59 & 15.00 & & & \\
\hline BIOMASS, ASH WT., G/SO M & 4 & 2.09 & 14.00 & & & \\
\hline CHLOROPHYLL A, MG/SQ M & 4 & 2.1 & 15.0 & & & \\
\hline CHLOROPHYLL $B, M G / S O M$ & 4 & .2 & 4.1 & & & \\
\hline ORGANIC CARBON, MG/L & 12 & .5 & 8.0 & & & \\
\hline
\end{tabular}


LAT 39059M42S LONG $075011 M 40 S$

$\begin{array}{llll}\text { DRAINAGE AREA: } & 1893 \mathrm{SQ} \mathrm{MI}(1 / 4903 & \text { SQ KM) } \\ \text { PERIOD OF RECORD: } & 10 / 01 / 74-09 / 30 / 75 & \end{array}$

STATISTICAL SUMMARY OF SELECTED DISSOLVED CHEMICAL CONSTITUENTS AND REGRESSION RELATIONSHIPS OF CONSTITUENT CONCENTRATIONS TO SPECIFIC CONDUCTANCE

CONSIUIUENI

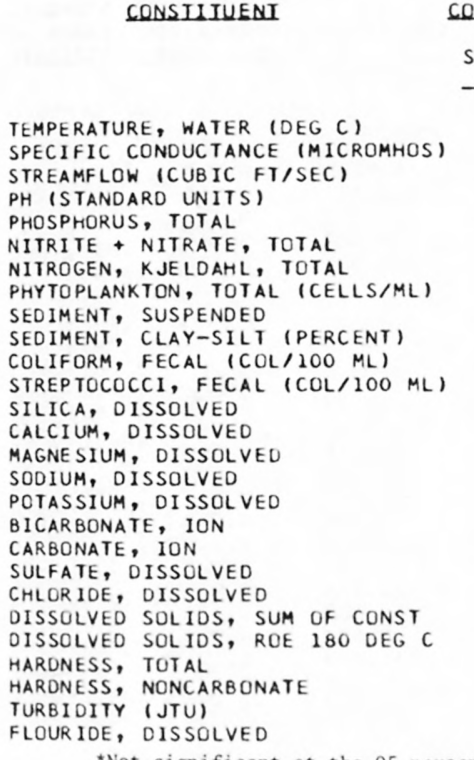

CONSIUTUENI IMG L OR UNII SHOWNI

SAM

STANDARD

DEVIAILON

20.00

341.4

5177.1

7.47

0.246

2.300
0.964

0.964
16251.4

53.4

90.0
716.7

1366.7

1366.16
8.167

29.57

10.26

12.66

2.94

71.0
0.0

0.0
54.29

18.14

171.3

201.6

116.4

116.4
57.9

22.3

0.19
8.37
80.6

4567.0

467.0
0.48

0.48
0.070

0.432

0.579

14741.2

28.7
10.5

3074.0

1228.9

0.42

8.00

2.85

4.23
0.66

20.1

0.0

17.55

4.91

46.4
63.5

30.5

17.0

22.5
0.09
BANGE

7.5
240
1080
7.0
0.16
1.40
0.49

0.49

360

13
73
2200

180
784

7.4

18.0

6.6
7.5
2.0

45

31.0
11.0

11.0

116
134

72
35

3
0.1

QURAIION IABLE_OF_DAILY SPECIEIC CONOUCIANCE

DAILY SPECIFIC CONDUCTANCE IN

MICROMHOS AT 25 DEG C, THAT WAS

19

EQUALLED OR EXCEEDED FOR THE

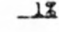

$-5 \%$

$10 \%$

208

302

$50 \%$

527

$501 \quad 480$

437

412

363 $\begin{array}{ll} & \text { REGRESSION } \\ \text { SAMPLE } & \text { COEFICIENT, } \\ \text { SIZE_ }\end{array}$ GRESSION_SUMMABY 27.0
440 $\begin{array}{lll}13900 & 7 & -34.506\end{array}$ $8.4 \quad 7 \quad-34.500$ 0.38 2.70 2.70 37000 0.00057 0.00425 0.00283 $-10.844$ CONSTANT, CORRELATION CORRELATION ERROR DF COEEICIENI ESIIMAIE

3700

91
100
9200

9200

3400

$8.6 \quad 7$

40.0

14.0

18.0

3.7
103

78.0
24.0

24.0
229

308

150
84

84

0.3

SUMMARY OF HARMONIC ANALYSIS OF STREAM TEMPERATURE EORM OE EOUALUON: I. $(0) \equiv M+A * S I N(.0172 * 0+C)$

\begin{tabular}{|c|c|c|c|c|c|}
\hline & & & & & STANDARD \\
\hline & HARMONIC & AMPLITUDE & PHASE & VAR IATION & ERROR OF \\
\hline SAMPLE & MEAN - M & $-A$ & $A N G L E-C$ & EXPLAINED & ESTIMATE \\
\hline SIZE- & 1DEG C) & IDEG 61 & (BADLANS) & $-(3)$ & $10 E G_{2}(1)$ \\
\hline 305 & 14.48 & 11.19 & 2.75 & 93 & 2.21 \\
\hline
\end{tabular}

SUMMARY OF MAXIMUM AND MINIMUM CONCENTRATIONS OF CONSTITUENTS SAMPLED AT A FREQUENCY OF OUARTERLY (1975 WY)

01474500 - SCHUYLKILL RIVER AT PHILADELPHIA, PA.

\begin{tabular}{|c|c|c|c|c|c|c|}
\hline CONSTI TUENT & $\begin{array}{l}\text { NO. } \\
\text { SAMPLES }\end{array}$ & $\begin{array}{l}\text { MIN IMUM } \\
\text { CONC. }\end{array}$ & $\begin{array}{l}\text { MAXIMUM } \\
\text { CONC. }\end{array}$ & $\begin{array}{l}\text { NO. } \\
\text { SAMPLES }\end{array}$ & $\begin{array}{l}\text { MINIMUM } \\
\text { CONC. }\end{array}$ & $\begin{array}{l}\text { MAXIMUM } \\
\text { CONC. }\end{array}$ \\
\hline \multicolumn{7}{|l|}{ MINOR ELEMENTS: } \\
\hline ARSENIC (AS), UG/L & 2 & 2 & 2 & 2 & 1 & 2 \\
\hline CADMIUM $(C D)$, UG/L & 2 & 0 & 0 & 2 & 0 & 0 \\
\hline CHROMIUM (CR), UG/L & 2 & $<10$ & 10 & 2 & $<10$ & 10 \\
\hline COBALT $(C O)$, UG/L & 2 & 1 & 3 & 2 & 1 & 2 \\
\hline COPPER (CU), UG/L & 2 & 0 & 10 & 2 & 10 & 10 \\
\hline IRON $(F E), U G / L$ & 2 & 270 & 530 & 2 & 30 & 50 \\
\hline LEAD $(P B), U G / L$ & 2 & 5 & 6 & 2 & 3 & 3 \\
\hline MANG ANESE (MN), UG/L & 2 & 130 & 230 & 2 & 40 & 230 \\
\hline MERCURY (HG), UG/L & 2 & $<0.5$ & 0.5 & 2 & $<0.5$ & 0.5 \\
\hline SELENIUM (SE), UG/L & 2 & 0 & 1 & 2 & 0 & 1 \\
\hline ZINC $(Z N), U G / L$ & 2 & 40 & 190 & 2 & 40 & 130 \\
\hline \multicolumn{7}{|l|}{ PERIPHYTON: } \\
\hline BIOMASS, DRY WT., G/SO M & 2 & 4.89 & 14.00 & & & \\
\hline BIOMASS, ASH WT., G/SQ M & 2 & 3.89 & 12.00 & & & \\
\hline CHLOROPHYLL A, MG/SQ M & 2 & 5.5 & 9.5 & & & \\
\hline CHLOROPHYLL $B$, MG/SQ M & 2 & 1.0 & 2.5 & & & \\
\hline ORGANIC CARBON, MG/L & 2 & 2.5 & 3.6 & & & \\
\hline
\end{tabular}


Table 14.--Summary of measurements at each station--Continued

LAT 38D59M5OS LONG 075D47M1OS $\begin{array}{lll}\text { DRAINAGE AREA: } & 113 \text { SQ MI } 12 & 293 \text { SQ KM) } \\ \text { PERIOD OF RECORO: } & 10 / 01 / 74-09 / 30 / 75\end{array}$

STATISTICAL SUMMARY OF SELECTED DISSOLVED CHEMICAL CONSTITUENTS AND REGRESSION RELATIONSHIPS OF CONSTITUENT CONCENTRATIONS TO SPECIFIC CONDUCTANCE

CONSUUUENI

\section{CONSIUIUENI IMG $\angle L$ OB UNII SHOHNI}

SAMPLE

SIZE

TEMPERATURE, WATER (DEG C) SPECIFIC CONDUCTANCE (MICROMHOS) STREAMFLOW (CUBIC FT/SEC)

PH (STANDARD UNITS)

PHOSPHORUS, TOTAL

NITRITE + NITRATE, TOTAL

NITROGEN, KJELDAHL, TOTAL

PHYTOPLANKTON, TOTAL (CELLS/ML)

SEDIMENT, SUSPENDED

SEDIMENT, CLAY-SILT (PERCENT)

COLIFORM, FECAL (COL/100 ML)

STREPTOCOCCI, FECAL (COL/100 ML)

SILICA, DISSOLVED

CALCIUM, DISSOLVED

MAGNESIUM, DISSOLVED

SODIUM, DISSOLVED

POTASSIUM, DISSOLVED

BICAR BONATE, ION

CARBONATE, ION

SULFATE, DISSOLVED

CHLOR IDE, DISSOLVED

DISSOLVED SOLIDS, SUM OF CONST

DISSOLVED SOLIDS, ROE 180 DEG C

HARDNESS, TOTAL

HARDNESS, NONCARBONATE

TURBIDITY (JTU)

FLOURIDE, DISSOLVED

$\begin{array}{rrrr}12 & 13.54 & 7.24 & 2.0 \\ 12 & 114.2 & 27.2 & 75 \\ 12 & 199.2 & 206.1 & 25 \\ 11 & 6.66 & 0.53 & 5.6 \\ 10 & 0.082 & 0.054 & 0.03 \\ 10 & 0.885 & 0.336 & 0.33 \\ 10 & 0.472 & 0.247 & 0.20 \\ 11 & 704.8 & 920.5 & 73 \\ 11 & 15.1 & 20.3 & 1 \\ 11 & 96.6 & 4.0 & 90 \\ 10 & 451.0 & 665.3 & 28 \\ 10 & 465.0 & 759.2 & 39 \\ 11 & 14.57 & 2.92 & 9.3 \\ 11 & 9.07 & 2.55 & 6.3 \\ 11 & 2.46 & 0.62 & 1.2 \\ 11 & 5.88 & 1.49 & 3.8 \\ 11 & 2.13 & 0.30 & 1.6 \\ 11 & 17.5 & 9.7 & 7 \\ 9 & 0.0 & 0.0 & 0 \\ 11 & 15.45 & 2.21 & 12.0 \\ 11 & 9.71 & 2.52 & 6.0 \\ 11 & 68.3 & 13.6 & 50 \\ 11 & 90.0 & 12.8 & 71 \\ 11 & 32.9 & 8.3 & 24 \\ 11 & 18.4 & 3.1 & 14 \\ 11 & 18.6 & 22.7 & 3 \\ 11 & 0.21 & 0.09 & 0.0\end{array}$

STANDARD

STANDARD
EYIALION

0.09
BE

SAMPLE SIZE

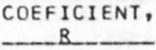

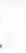

CONSTANT, MUABY

24.0
159
764
7.3
0.20
1.40
0.99
3400
71
100
2000
2500
18.0
14.0
3.4
8.4
2.7
35
0
19.0
13.0
89
114
49
23
75
0.3

*Not significant at the 95 percent confidence level.

\section{DURAIION IABLE OE DAUY SPECIEIC CONOUCIANCE}

DAILY SPECIFIC CONDUCTANCE IN

MICROMHOS AT 25 DEG C, THAT WAS

EQUALLED OR EXCEEDED FOR THE

$\begin{array}{llllll}-12 & -5 z & 10 z & 20 z & 30 z & 50 z \\ 164 & 160 & 154 & 138 & 130 & 113\end{array}$

SUMMARY OF HARMONIC ANALYSIS OF STREAM TEMPERATURE

FORM OF EOUALION: I. $(0)=M+A * \operatorname{SIN}(.0172 * 0+C)$

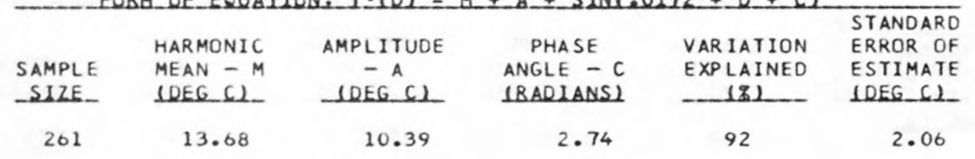

SUMMARY OF MAXIMUM AND MINIMUM CONCENTRATIONS OF CONSTITUENTS SAMPLED AT A FREQUENCY OF QUARTERLY (1975 WY)

01491000 -- CHOPTANK RIVER NEAR GREENSBORO, MD.

\begin{tabular}{|c|c|c|c|c|c|c|}
\hline \multirow{2}{*}{ CONSTITUENT } & \multicolumn{3}{|c|}{ TOTAL } & \multicolumn{3}{|c|}{ DISSOLVED } \\
\hline & $\begin{array}{l}\text { ND. } \\
\text { SAMPLES }\end{array}$ & $\begin{array}{l}\text { MINIMUM } \\
\text { CONC. }\end{array}$ & $\begin{array}{l}\text { MAXIMUM } \\
\text { CONC. }\end{array}$ & $\begin{array}{l}\text { NO. } \\
\text { SAMPLES }\end{array}$ & $\begin{array}{l}\text { MINIMUM } \\
\text { CONC. }\end{array}$ & $\begin{array}{l}\text { MAXIMUM } \\
\text { CONC. }\end{array}$ \\
\hline \multicolumn{7}{|l|}{ MINOR ELEMENTS: } \\
\hline ARSENIC (AS), UG/L & 3 & 0 & 2 & 3 & 0 & 1 \\
\hline CADMIUM $(C D), U G / L$ & 3 & 0 & 0 & 3 & 0 & 1 \\
\hline CHROMIUM (CR), UG/L & 3 & 0 & $<10$ & 3 & 0 & $<10$ \\
\hline COBALT $(C O), U G / L$ & 3 & 0 & 2 & 3 & 0 & 1 \\
\hline COPPER $(C U), U G / L$ & 3 & 0 & 10 & 3 & 0 & 10 \\
\hline IRON (FE), UG/L & 3 & 910 & 2500 & 3 & 300 & 440 \\
\hline LEAD $(P B), U G / L$ & 3 & 0 & 5 & 3 & 1 & 3 \\
\hline MANG ANESE (MN), UG/L & 3 & 50 & 70 & 3 & 40 & 50 \\
\hline MERC URY $(H G), U G / L$ & 3 & $<0.5$ & $<0.5$ & 3 & $<0.5$ & $<0.5$ \\
\hline SELENIUM $(S E), U G / L$ & 3 & 0 & 1 & 3 & 0 & 1 \\
\hline ZINC $(Z N), U G / L$ & 3 & 20 & 30 & 3 & 10 & 20 \\
\hline \multicolumn{7}{|l|}{ PERIPHYTON: } \\
\hline BIOMASS, DRY WT., G/SQ M & 3 & 1.59 & 12.00 & & & \\
\hline BIOMASS, ASH WT., G/SQ M & 3 & .50 & 2.50 & & & \\
\hline CHLOROPHYLL A, MG/SO M & 3 & .0 & 20.0 & & & \\
\hline CHLOROPHYLL B, MG/SO M & 3 & .0 & 1.7 & & & \\
\hline ORGANIC CARBON, MG/L & 3 & 3.8 & 11.0 & & & \\
\hline
\end{tabular}


LAT 40D57M29S LONG 076037M10S DRAINAGE AREA: 11220 SQ MI ( 29060 SQ KM) PERIOD OF RECORD: $10 / 01 / 74-09 / 30 / 75$

STATISTICAL SUMMARY OF SELECTED DISSOLVED CHEMICAL CONSTITUENTS AND REGRESSION RELATIONSHIPS OF CONSTITUENT CONCENTRATIONS TO SPECIFIC CONDUCTANCE

CONSIUIUENI

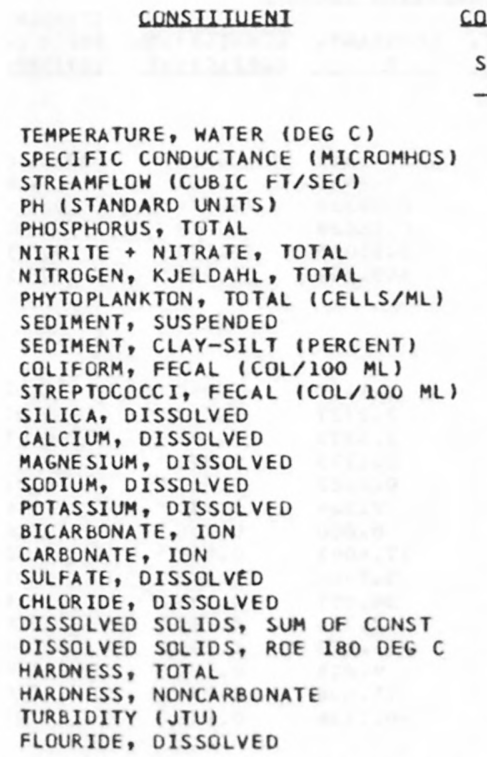

CONSIUUENI IMGLL OR UNII_SHOWN)

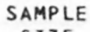

\begin{tabular}{l} 
SAMPLE \\
SIZE \\
\hline
\end{tabular}

STANDARD

DEYIAIUON
12.59

254.4

33620.7

7.23
0.086

0.086

0.579

0.514

208.6

92.1

92.1
689.7

689.7
1857.7

2.73

23.67

6.97
7.20

1.50

47.3

0.0

45.25

9.62

122.7

164.2

88.3

49.0

15.5
0.07
8.78

81.6

47050.3

0.67
0.070

0.298

0.271

27516.3

267.2

4.8

4929.5

4929.5
1.40

1.40
8.08

3.05

2.60

0.30

11.9

0.0
15.17

1.92

40.1

69.7
33.1

33.1
21.1

39.4

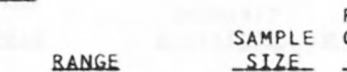

1.0

110
2810

6.3
0.03

0.00

0.09

160

8
82
20

$\begin{array}{r}20 \\ 47 \\ \hline\end{array}$

47
1.6
15.0

15.0
3.9

4.6
1.2

1.2
32

0
28.0
7.3

81
58
54

54
27

3
0.0

26.5
420

762

100
3400

3400
15000

10.0

9.8
1.8

1.8
61

0
64.0

12.0
161
356

356
120

120
69
200

200
0.1

3
3
3
4
4
4
4
3
24
3
3
24
3

*Not significant at the 95 percent confidence level.

DURAILON IABLE OF DAUY SPECIFIC CONDUCIANCE

DAILY SPECIFIC CONDUCTANCE IN

MICROMHOS AT 25 DEG C, THAT WAS

EQUALLED OR EXCEEDED FOR THE

INOICATED PERCENTAGE OF TIME

$\begin{array}{llll}18 & 58 & 208 & 208 \\ 372 & 352 & 342 & 307\end{array}$

302

279

\begin{tabular}{|c|c|c|c|c|c|}
\hline 000 & & & & & \\
\hline 000 & 24 & -241.637 & 81174.625 & -0.600 & 26897.5 \\
\hline 8.7 & 24 & 0.0051 & 5.9222 & 0.626 & 0.5 \\
\hline 0.31 & 24 & -0.00023 & 0.14513 & $-0.270^{*}$ & 0.069 \\
\hline 1.10 & 24 & -0.00173 & 1.02012 & -0.475 & 0.268 \\
\hline 1.20 & 24 & 0.00100 & 0.26096 & $0.300^{*}$ & 0.264 \\
\hline 84000 & 9 & 222.013 & -28972.133 & 0.799 & 17688.1 \\
\hline
\end{tabular}

REGRESSION SUMMABY

REGRESSION STANDARD COEFICIENT, CONSTANT,

15000

$\begin{array}{rrr}4.3 & 3 & -0.0175 \\ 31.0 & 3 & 0.1035\end{array}$

0.1035
0.0393

0.0335

0.0039

0.184

0.000

0.235

0.0296

0.517

0.779
0.426

0.271

$-0.184$

$-0.0006$

6.9050
-0.9931
-2.4113
-0.7929
0.5777
4.263
0.000
-9.8354
2.7161
-0.467
-33.848
-13.248
-15.657
62.408
0.2187

$-0.968^{*}$

0.992 *

1.000 *

$1.000^{*}$

$1.000^{*}$

$0.988^{*}$

$0.000 *$

$0.993^{*}$

0.984 *

$0.984 *$

0.911

0.911

0.999

$0.998^{*}$

$-0.382 *$

-0.857 .

0.50

1.42

0.04

0.07

0.01

2.2

2.17

0.42

3.0

29.3

2.4

37.2

0.04

SAMPLE SIZE $=351$

$50 \times \quad 70 \% \quad 208 \quad 25 \% \quad 298$

$227 \quad 188$

$147-135-108$

SUMMARY OF HARMONIC ANALYSIS OF STREAM TEMPERATURE

\begin{tabular}{|c|c|c|c|c|c|}
\hline $\begin{array}{l}\text { SAMPLE } \\
\text { S12E_- }\end{array}$ & $\begin{array}{l}\text { HARMONIC } \\
\text { MEAN - M } \\
\text { LOEG_Ll }\end{array}$ & $\begin{array}{c}\text { AMPLITUDE } \\
-A \\
\text { IDEG } \\
\text { LEL }\end{array}$ & $\begin{array}{c}\text { PHASE } \\
\text { ANGLE - C } \\
\text { IBADIANSI }\end{array}$ & $\begin{array}{l}\text { VARIATION } \\
\text { EXPLAINED } \\
(z) \\
\end{array}$ & $\begin{array}{l}\text { STANDARD } \\
\text { ERROR OF } \\
\text { ESTIMATE } \\
\text { IDEG CL }\end{array}$ \\
\hline 225 & .11 .69 & 11.04 & 2.65 & 91 & 1.75 \\
\hline
\end{tabular}

SUMMARY OF MAXIMUM AND MINIMUM CONCENTRATIONS OF CONSTITUENTS SAMPLED AT A FREQUENCY OF QUARTERLY (1975 WY)

01540500 -- SUSQUEHANNA RIVER AT DANVILLE, PA.

\begin{tabular}{|c|c|c|c|c|c|c|}
\hline \multirow{2}{*}{ CONSTITUENT } & \multicolumn{3}{|c|}{ TOTAL } & \multicolumn{3}{|c|}{ DISSOLVED } \\
\hline & $\begin{array}{l}\text { NO. } \\
\text { SAMPLES }\end{array}$ & $\begin{array}{l}\text { MINIMUM } \\
\text { CONC. }\end{array}$ & $\begin{array}{l}\text { MAXIMUM } \\
\text { CONC. }\end{array}$ & $\begin{array}{l}\text { NO. } \\
\text { SAMPLES }\end{array}$ & $\begin{array}{l}\text { MINIMUM } \\
\text { CONC. }\end{array}$ & $\begin{array}{l}\text { MAXIMUM } \\
\text { CONC. }\end{array}$ \\
\hline \multicolumn{7}{|l|}{ MINOR ELEMENTS: } \\
\hline $\begin{array}{l}\text { ARSENIC (AS), UG/L } \\
\text { CADMIUM (CD), UG }\end{array}$ & 24 & 0 & $\begin{array}{l}9 \\
1\end{array}$ & $\begin{array}{l}4 \\
3\end{array}$ & $\begin{array}{l}0 \\
0\end{array}$ & $\begin{array}{l}3 \\
0\end{array}$ \\
\hline $\begin{array}{l}\text { CADM IUM (CD), UG/L } \\
\text { CHROMIUM (CR), UG/L }\end{array}$ & $\begin{array}{l}24 \\
24\end{array}$ & $\begin{array}{l}0 \\
0\end{array}$ & $\begin{array}{r}1 \\
30\end{array}$ & 3 & 0 & 10 \\
\hline COBALT $(C O), U G / L$ & 3 & 2 & 7 & 3 & 0 & 1 \\
\hline COPPER (CU), UG/L & 24 & 0 & 20 & 3 & 0 & 0 \\
\hline IRON $(F E), U G / L$ & 24 & 800 & 19000 & 3 & 20 & 240 \\
\hline LEAD $(P B), U G / L$ & 24 & 0 & 50 & 3 & 2 & 3 \\
\hline MANG ANESE (MN), UG/L & 24 & 130 & 760 & 3 & 90 & 150 \\
\hline MERCURY (HG), UG/L & 3 & $<0.5$ & 0.5 & 3 & $<0.5$ & $<0.5$ \\
\hline SELENIUM (SE), UG/L & 3 & 0 & 0 & 3 & 0 & 0 \\
\hline ZINC $(Z N), U G / L$ & 24 & 10 & 80 & 3 & 0 & 10 \\
\hline \multicolumn{7}{|l|}{ PERIPHYTON : } \\
\hline BIOMASS, DRY WT., G/SQ M & 1 & 6.50 & & & & \\
\hline BIOMASS, ASH WT., G/SO M & 1 & 5.00 & & & & \\
\hline $\begin{array}{l}\text { CHLOROPHYLL A, MG/SQ M } \\
\text { CHLOROPHYL }\end{array}$ & 1 & 12.0 & & & & \\
\hline CHLOROPHYLL B, MG/SQ M & 1 & 2.6 & & & & \\
\hline ORGANIC CARBON, MG/L & 24 & 1.8 & 15.0 & & & \\
\hline
\end{tabular}


Table 14.--Summary of measurements at each station--Continued

LAT $40058 M 02 S$ LONG $076052 M 45 S$

DRAINAGE AREA: 6847 SQ MI 117734 SQ KM)

PERIOD OF RECORD: $10 / 01 / 74-09 / 30 / 75$

STATISTICAL SUMMARY OF SELECTED DISSOLVED CHEMICAL CONSTITUENTS AND REGRESSION RELATIONSHIPS OF CONSTITUENT CONCENTRATIONS TO SPECIFIC CONDUCTANCE

CONSIIIUENI

CONSIIIUENI
TEMPERATURE, WATER (DEG C)
SPECIFIC CONDUCTANCE (MICROMHOS)
STREAMFLOW (CUBIC FT/SEC)
PH (STANDARD UNITS)
PHOSPHORUS, TOTAL
NITRITE, NITRATE, TOTAL
NITROGEN, KJELDAHL, TOTAL
PHYTOPLANKTON, TOTAL (CELLS/ML)
SEDIMENT, SUSPENDED
SEDIMENT, CLAYSILT (PERCENT)
COLIFORM, FECAL (COL/IOO ML)
STREPTOCOCCI, FECAL (COL/IOO ML)
SILICA, DISSOLVED
CALCIUM, DISSOLVED
MAGNESIUM, DISSOLVED
SODIUM, DISSOLVED
POTASSIUM, DISSOLVED
BICARBONATE, ION
CARBONATE, ION
SULFATE, DISSOLVED
CHLORIDE, DISSOLVED
DISSOLVED SOLIDS, SUM OF CONST
DISSOLVED SOLIOS, ROE I8O DEG C
HARDNESS, TOTAL
HARDNESS, NONCARBONATE
TURBIDITY (JTU)
FLOURIDE, DISSOLVED
FLOLO

CONSIUIUENI IMGLL OR UNII SHOWNI

\begin{tabular}{r} 
SAMPLE \\
SIZE \\
\hline 10 \\
9 \\
9 \\
10 \\
10 \\
9 \\
9 \\
9 \\
10 \\
9 \\
9 \\
10 \\
10 \\
3 \\
3 \\
3 \\
3 \\
3 \\
3 \\
3 \\
3 \\
3 \\
3 \\
3 \\
3 \\
3 \\
3 \\
3
\end{tabular}

\section{STANDARD \\ DEYIALION BANG}

\author{
9.11
}

$$
64.2
$$

33035.0

3035.0
0.40

0.024

0.155

0.119

866.8

39.1
7.0

1066.0

89.9

1885.0

1890.6

4.23
13.67

13.67
4.87

2.83

1.17

12.3

0.0
42.33

42.33

4.00
79.7

79.7
95.7

95.7

54.0

44.0
5.7

5.7
0.10
2967.0

3201.9

0.90

4.62

1.42
1.10

1.10
0.25

4.2

0.0

10.21

0.10

18.5

35.9

17.3

13.9

0.10
N) $2.0 \quad 27.0$ $110 \quad 300$
$2020 \quad 112000$

$\begin{array}{rr}2020 & 112000 \\ 6.4 & 7.6\end{array}$

$\begin{array}{rr}6.4 & 7.6 \\ 0.01 & 0.09\end{array}$

$0.28 \quad 0.77$

$0.02 \quad 0.37$

$130 \quad 2600$

2600
119
100

100

10000

10000
4.8

4.8
19.0
6.5

4.1
1.4

1.4
17

54.0

4.1

137

74

60
10

10
0.2

*Not significant at the 95 percent confidence level.

DAILY SPECIFIC CONDUCTANCE IN

UBAIION IABLE OF DAILY SPECIEIC CONDUCIANCE

MICROMHOS AT 25 DEG C, THAT WAS

EQUALLED OR EXCEEDED FOR THE

$-304.147$

0.0055

0.00010

0.00184

0.00032
3.850

\subsection{5} 5.8443 0.16629 0.15015 449.569

0.851
$-0.274 *$

$-0.274$

0.763

0.174 *
0.283 *

$0.283^{\circ}$

$$
\begin{array}{r}
-0.0141 \\
0.0727 \\
0.0223 \\
0.0173 \\
0.0032 \\
0.064 \\
0.000 \\
0.1591 \\
0.0014 \\
0.291 \\
0.564 \\
0.273 \\
0.218 \\
-0.064 \\
0.0014
\end{array}
$$

6.4409

2.2727

1.3773

0.1273

0.6682
2.364

2.364
0.000

17.4091

3.7864

\begin{tabular}{|c|c|c|c|c|c|}
\hline & & & & & STANDARD \\
\hline & HARMONIC & AMPLITUDE & PHASE & VAR IATION & ERROR OF \\
\hline SAMPLE & MEAN - M & $-A$ & ANGLE - C & EXPLAINED & ESTIMATE \\
\hline SIZE. & (DEG C $)$ & DEEG $(2)$ & (BADLANS) & $(8)$ & WEEG Cl \\
\hline 333 & 11.32 & 11.65 & 2.73 & 94 & 1.95 \\
\hline
\end{tabular}

34.091
7.364

11.273

11.273

9.818

\begin{tabular}{|c|c|c|c|c|c|c|}
\hline \multirow{2}{*}{ CONSTI IUENT } & \multicolumn{3}{|c|}{ TOTAL } & \multicolumn{3}{|c|}{ DISSOLVED } \\
\hline & $\begin{array}{l}\text { NO. } \\
\text { SAMPLES }\end{array}$ & $\begin{array}{l}\text { MIN IMUM } \\
\text { CONC. }\end{array}$ & $\begin{array}{l}\text { MAXIMUM } \\
\text { CONC. }\end{array}$ & $\begin{array}{l}\text { NO. } \\
\text { SAMPLES }\end{array}$ & $\begin{array}{l}\text { MINIMUM } \\
\text { CONC. }\end{array}$ & $\begin{array}{l}\text { MAXIMUM } \\
\text { CONC. }\end{array}$ \\
\hline \multicolumn{7}{|l|}{ MINOR ELEMENTS: } \\
\hline ARSENIC (AS), UG/L & 3 & 0 & 3 & 3 & 0 & 2 \\
\hline CADMIUM $(C D), U G / L$ & 3 & 0 & 1 & 3 & 0 & 1 \\
\hline CHROMIUM $(C R), U G / L$ & 3 & $<10$ & 30 & 3 & $<10$ & 20 \\
\hline COBALT $(C D), U G / L$ & 3 & 0 & 7 & 3 & 0 & 5 \\
\hline COPPER $(C U), U G / L$ & 3 & 10 & 10 & 3 & 0 & 10 \\
\hline IRON (FE), UG/L & 3 & 70 & 700 & 3 & 10 & 60 \\
\hline LEAD $(P B), U G / L$ & 3 & 2 & 12 & 3 & 1. & 4 \\
\hline MANGANESE (MN), UG/L & 3 & 10 & 380 & 3 & 230 & 380 \\
\hline MERC URY (HG), UG/L & 3 & $<0.5$ & $<0.5$ & 3 & $<0.5$ & $<0.5$ \\
\hline SELENIUM (SE), UG/L & 3 & 0 & 1 & 3 & 0 & 1 \\
\hline$Z I N C(Z N), U G / L$ & 3 & 20 & 50 & 3 & 10 & 20 \\
\hline \multicolumn{7}{|l|}{ PERIPHYTON: } \\
\hline BIOMASS, DRY WT., G/SQ M & 2 & 3.59 & 6.00 & & & \\
\hline BIOMASS, ASH WT, , G/SQ M & 2 & 3.19 & 7.19 & & & \\
\hline CHLOROPHYLL A, MG/SO M & 2 & 5.2 & 5.7 & & & \\
\hline CHLOROPHYLL B, MG/SQ M & 2 & .8 & 1.2 & & & \\
\hline ORGANIC CARBON, MG/L & 3 & .3 & 9.5 & & & \\
\hline
\end{tabular}

15.636
-0.1136
STANDARD STANDARD
ERROR OF ESIUMAIF
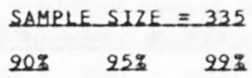

$115 \quad 108 \quad 103$

SUMMARY OF HARMONIC ANALYSIS OF STREAM TEMPERATURE EORM OE EOUAION: I. $(O)=M+A+S I N(.0172+D+C)$

SUMMARY OF MAXIMUM AND MINIMUM CONCENTRATIONS OF CONSTITUENTS SAMPLED AT A FREQUENCY OF QUARTERLY (1975 HY)

01553500 -- WEST BRANCH SUSQUEHANNA RIVER AT LEWISBURG, PA. 
LAT 40D15M27S LONG 076053M12S

DRAINAGE AREA: 24100 SQ MI 102419 SQ KMI

PERIOD OF RECORD: $10 / 01 / 74-09 / 30 / 75$

STATISTICAL SUMMARY OF SELECTED DISSOLVED CHEMICAL CONSTITUENTS AND

REGRESSION RELATIONSHIPS OF CONSTITUENT CONCENTRATIONS TO SPECIFIC CONDUCTANCE

CONSIITUENI

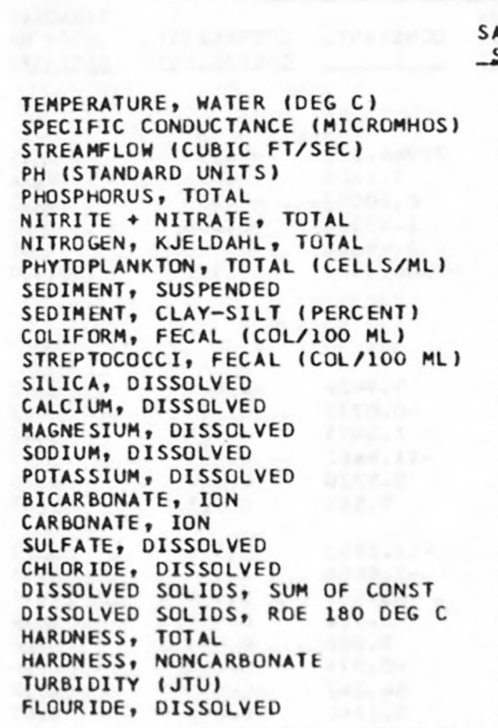

STANDARD

DEYIAIION

SIZE

50

50
50
51
42
50
42
50
12
32
32
42
30
22
22
22
22
22
22
22
22
22
22
42
22
22
42
22
207.6 1107.6 7.56
0.080 0.080 0.921 0.402 2479.2 120.5 90.8 866.1 678.0 4.59 4.59
20.23 5.52 5.14 1.51 1.51
45.4 0.0 34.73 7.77 102.3 137.1 73.4 35.9 13.8
CONSIUIUENI IMG/L OR UNII SHOWN
BANGE

8.52

149533.4

533.4
0.59

0.051

0.517

$6961 \cdot 3$

166.2
9.6

$1255 \cdot 5$

821.4

1.14

7.91

1.78
2.27

0.61

27.8

0.0
12.88

3.22

28.9

52.6
25.8

13.1

17.1

0.10

0.06

0.06
0.12

0.12
280

2
57

$\begin{array}{r}36 \\ 23 \\ \hline\end{array}$

1.5
11.0

3.1

2.2

0.9
14

14
19.0

19.0
3.5

3.5
65

65
40
40

19

0.0
REGRESSION $\begin{array}{rr}2.0 & 30.0 \\ 91 & 380 \\ 6900 & 525999 \\ 6.7 & 9.0\end{array}$ $\begin{array}{ll}6.7 & 9.0 \\ 0.02 & 0.33\end{array}$
335

$1.10 \quad 50$
$61000 \quad 12$

500
100

100
5100

3700

7.2
38.0

9.6

11.0

3.6

113
0

66.0
17.0

17.0
160

160
278

130
63

63
100

0.5
$2.90 \quad 42$

$-1295.765$

0.0068

$-0.00003$

0.00091

.00066
BES

COEFICIENT,

CONSTANT,

374904.688 0.0320

0.08610

0.71629

$745 \cdot 168$ COEEICIENI

ST ANDARD ERROR OF ESIUMAIE *Not significant at the 95 percent confidence level.

DURAIION IABLE OE DAILY SPECIEIC CONOUCIANCE

DAILY SPECIFIC CONDUCTANCE IN MICROMHOS AT 25 DEG C, THAT WAS EQUALLED OR EXCEEDED FOR THE INDICATED PERCENTAGE OF IIME

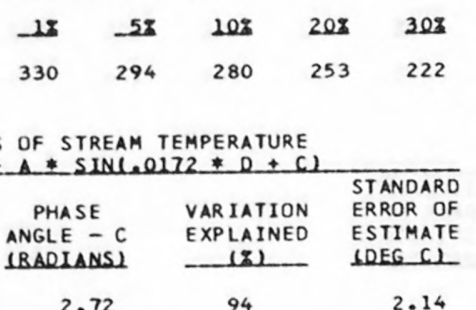

SUMMARY OF HARMONIC ANALYSIS OF STREAM TEMPERATURE

\begin{tabular}{|c|c|c|c|c|c|}
\hline $\begin{array}{l}\text { SAMPLE } \\
\text { SIZE_ }\end{array}$ & $\begin{array}{l}\text { HARMONIC } \\
\text { MEAN - M } \\
\text { IDEG CI }\end{array}$ & $\begin{array}{c}\text { AMPLITUDE } \\
-A \\
\text { DEEG }\end{array}$ & $\begin{array}{l}\text { PHASE } \\
\text { ANGLE - C } \\
\text { (BADLANS) }\end{array}$ & $\begin{array}{l}\text { VAR IATION } \\
\text { EXPLAINED } \\
(\Omega) \\
\end{array}$ & $\begin{array}{l}\text { STANDARD } \\
\text { ERROR OF } \\
\text { ESTIMATE } \\
\text { LDEG C) }\end{array}$ \\
\hline 302 & 13.28 & 12.31 & 2.72 & 94 & 2.14 \\
\hline
\end{tabular}

SUMMARY OF MAXIMUM AND MINIMUM CONCENTRATIONS OF CONSTITUENTS

SAMPLED AT A FREQUENCY OF QUARTERLY (1975 WY)

01570500 -- SUSQUEHANNA RIVER AT HARRISBURG, PA.

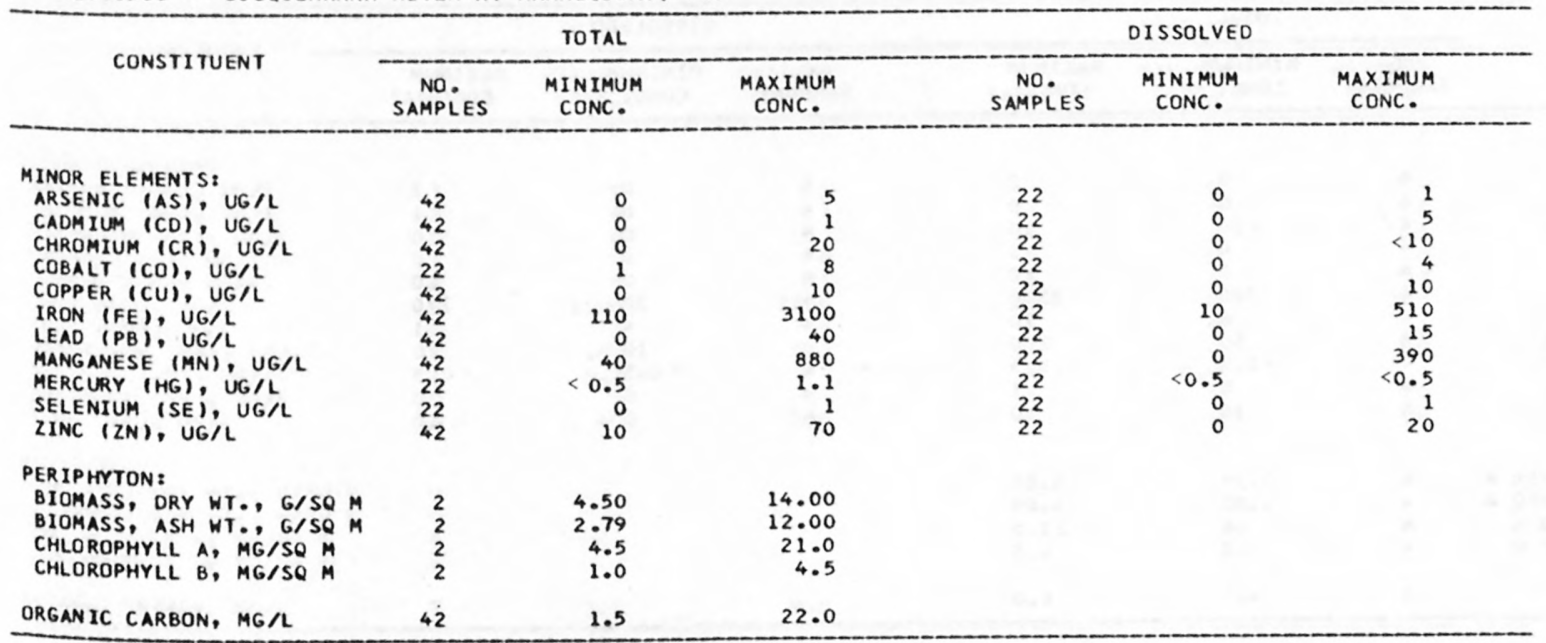


LAT 39D0OM03S LONG 077014M56S

DRAINAGE AREA:

0 SQ MI

PERIOD OF RECORD: $10 / 01 / 74-09 / 30 / 75$

O SQ KM)

STATISTICAL SUMMARY OF SELECTED DISSOLVED CHEMICAL CONSTITUENTS AND

REGRESSION RELATIONSHIPS OF CONSTITUENT CONCENTRATIONS TO SPECIFIC CONDUCTANCE

SONSIITUENI

GONSIUUUENI IMG/L OR UNII SHOWN

TEMPERATURE, WATER (DEG C)
SPECIFIC CONDUCTANCE (MICROMHOS)
STREAMFLOW (CUBIC FT/SEC)
PH (STANDARD UNITS)
PHOSPHORUS, TOTAL
NITRITE, NITRATE, TOTAL
NITROGEN, KJELDAHL, TOTAL
PHYTOPLANKTON, TOTAL (CELLS/ML)
SEDIMENT, SUSPENDED
SEDIMENT, CLAY-SILT (PERCENT)
COLIFORM, FECAL (COL/IOO ML)
STREPTOCOCCI, FECAL (COL/IOO ML)
SILICA, DISSOLVED
CALCIUM, DISSOLVED
MAGNESIUM, DISSOLVED
SODIUM, DISSOLVED
POTASSIUM, DISSOLVED
BICARBONATE, ION
CARBONATE, ION
SULFATE, DISSOLVED
CHLOR IDE, DISSOLVED
DISSOLVED SOLIDS, SUM OF CONST
DISSOLVED SOLIDS, ROE I8O DEG C
HARDNESS, TOTAL
HARDNESS, NONCARBONATE
TURBIDITY (JTU)
FLOURIDE, DISSOLVED

STANDARD

MEAN DEVIAIION

14.38

14.38
281.8

1860.8

8.19

0.109

0.857

0.584

28118.3

8118.3
43.5

98.5

1962.6

3806 .

4.12

33.33
7.72

7.72
10.00

10.00
2.44

2.44
102.3

36.50

36.50
11.41

11.41
156.1

178.8

115.4

31.1

19.1

0.16

9.90

78.6
9633.7

033.7
0.44

0.078

0.355

0.250

25526.4

54.6

2.2

5734.4

10588.1

2.38

9.52

2.01

6.35

0.75

28.9

14.89

4.53

47.9

50.4

32.1
10.7

21.1

21.1
0.07
REGRESSION

SAMPLE

BANGE SIZE

$\begin{array}{rr}0.5 & 27 \\ 195 & 45 \\ 2850 & 3320 \\ 7.6 & 8 .\end{array}$

27.5
455
3200
8.8

$\begin{array}{ll}0.02 & 0.32 \\ 0.39 & 1.40\end{array}$

0.20

0.20
820

1.40

1.10

75000
208

208
100

$\begin{array}{rr}93 & 100 \\ 9 & 20000\end{array}$

$\begin{array}{rr}9 & 20000 \\ 87 & 37000 \\ 0.1 & 6.5\end{array}$

$\begin{array}{rr}0.1 & 6.5 \\ 23.0 & 52.0\end{array}$

5.0

5.0

1.5

11.0

23.0

3.8
150

150

23.0
7.2

7.2
108

66.0
22.0

22.0
249
273

273
180
56

56
80

0.2

CEFICIENT,

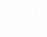

12
12
12
12
12
12


12
12
12
12
12
12
12
12
12
12
12
12
12
12

-91.831
0.0036
-0.00032
-0.00275
0.00031
227.864


-0.0206
0.1186
0.0226
0.0768
0.0068
0.336
0.1735
0.0542
0.596
0.610
0.399
0.112
-0.132
0.0001

* Not significant at the 95 percent confidence level.

DURAIION IABLE OF DAILY SPECIEIC CONDUCIANCE

DAILY SPECIFIC CONDUCTANCE IN

MICROMHOS AT 25 DEG C, THAT WAS

EQUALLED OR EXCEEDED FOR THE

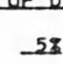

108

202

$30 z$

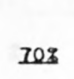

CONSTANT,

CORRELATION

STANDARD
ERROR OF
37944.273
7.1808
1.63236
1.63236
$-36082.434$

-0.719
0.638
$-0.325 *$
-0.608
$0.098{ }^{\star}$
0.702

7306.4

0.077

0.296

0.261

19078.0

INDICATED PERCENTAGE OF TIME

460

409

$388 \quad 311$

278

226

204

SAMPLE S1ZE $=348$

$20225292 \%$

$\begin{array}{lll}176 & 164 & 150\end{array}$

SUMMARY OF HARMONIC ANALYSIS OF STREAM TEMPERATURE

\begin{tabular}{|c|c|c|c|c|c|}
\hline & & & & & STANDARD \\
\hline & $\begin{array}{l}\text { HARMONIC } \\
\text { MEAN - M }\end{array}$ & AMPLITUDE & $\begin{array}{l}\text { PHASE } \\
\text { ANGLE - C }\end{array}$ & $\begin{array}{l}\text { VARIATION } \\
\text { EXPLAINED }\end{array}$ & $\begin{array}{l}\text { ERROR OF } \\
\text { ESTIMATE }\end{array}$ \\
\hline SIZE. & LEE CI & (DEG $(1)$ & IRADLANSI & $(\pi)$ & $10 E G(\mathrm{Cl}$ \\
\hline 334 & 14.99 & 12.09 & 2.72 & 94 & 2.01 \\
\hline
\end{tabular}

SUMMARY OF MAXIMUM AND MINIMUM CONCENTRATIONS OF CONSTITUENTS SAMPLEO AT A FREQUENCY OF QUARTERLY (1975 WY)

01645500 -- POTOMAC RIVER AT GREAT FALLS MD

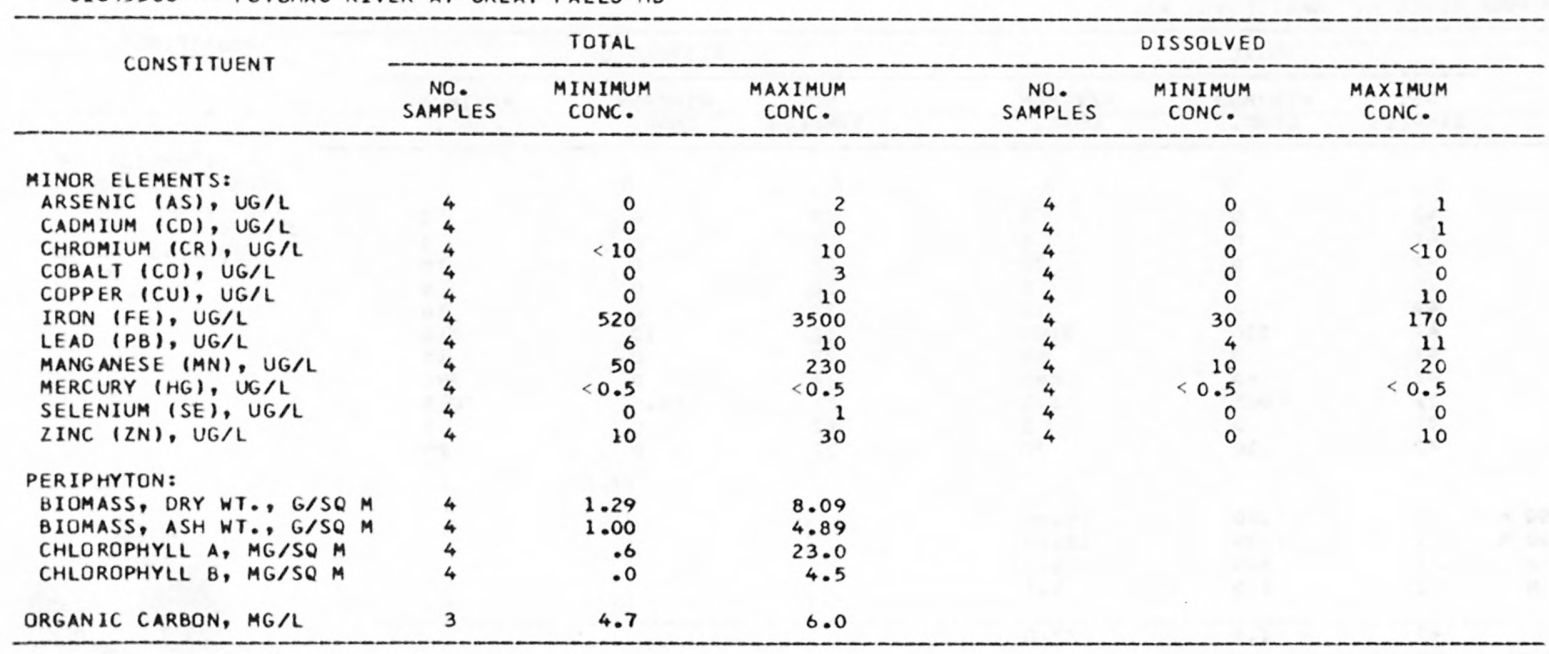


LAT 37046M03S LONG 077D19M57S

DRAINAGE AREA: 1081 SQ MI 1 2800 SQ KM )

PERIOD OF RECORD: $10 / 01 / 74-09 / 30 / 75$

STATISTICAL SUMMARY OF SELECTED DISSOLVED CHEMICAL CONSTITUENTS AND REGRESSION RELATIONSHIPS OF CONSTITUENT CONCENTRATIONS TO SPECIFIC CONDUCTANCE

CONSIUIUENI

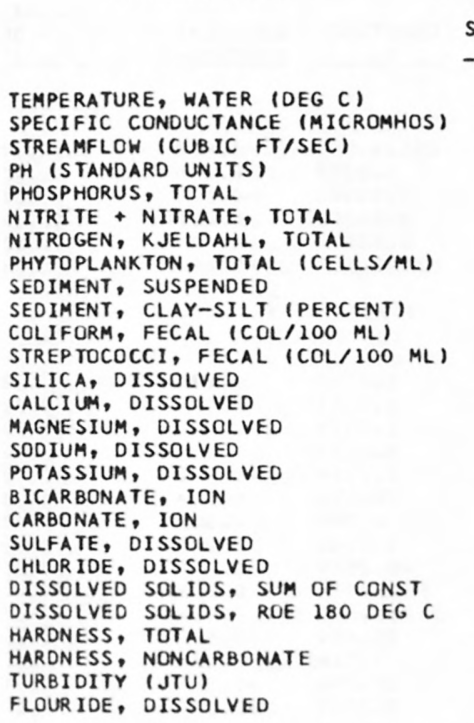

CONSIUIUENT IMG/L OR UNII SHOWNU

SAMPLE
SIVE

MEAN DEVIALION BANGE

$37 \quad 14.69$

$37 \quad 62.3$

$11 \quad 1723.3$

6.73

0.048

0.169

1645.6

18.3

18.3
97.2

439.5

1305.5

10.46
5.50

5.50
2.12

3.99

3.99
2.27

2.27
23.7

0.0

6.69
3.75

3.75
48.4

48.4
55.8

22.5

3.3

0.17

LIAIUNON

8.11
17.2

17.2
1232.6
0.70

0.70
0.033

0.073

0.320

1327.3

20.9

5.2

702.1
4006.9

4006.9
1.74

1.74
0.97

0.45

0.67

0.66

5.6
0.0
1.17
0.99

0.99

5.4
9.3

3.4
3.2

13.0

0.16

2.0
25

$25 \quad 28.0$

304
6.0

0.01

0.04

0.24
410

3

86
15

$\begin{array}{rr}7.4 & 14000\end{array}$

3.5

1.4

2.9

16

0
4.7

2.3

40
36

17
0

2
0.0

*Not significant at the 95 percent confidence level.

$$
\begin{array}{r}
28.0 \\
130 \\
4000 \\
8.2 \\
0.12
\end{array}
$$

0.29
42000

BEGRESSION SUMMARY

REGRESSION

SAMPLE COEFICIENT,

CONSTANT, CORRELATION

STANDARD SIZE $B$ COANT, COEEICIENI

12

$1.40 \quad 12$

$\begin{array}{rr}-0.266 & 1742.014 \\ 0.0043 & 6.14308 \\ -0.00001 & 0.14902 \\ -0.00042 & 0.19859 \\ 0.00172 & 0.48134 \\ -27.425 & 3321.540\end{array}$

$-0.000^{*}$

$0.155 *$

-0.008 *

-0.146 *

$0.134 *$

$-0.315 *$

1299.2

0.73
0.034

0.075

0.333

1346.7

DURATON TABLE OF DAUY SPEC

DAILY SPECIFIC CONDUCTANCE IN DURAIION IABLE.OF

MICROMHOS AT 25 DEG C. THAT HAS

$18 \quad 58 \quad 202$

$208 \quad 302$

502

$\begin{array}{rr}29 \\ 8.1 & 29\end{array}$

$3.1 \quad 29$

$\begin{array}{ll}5.3 & 29 \\ 5.0 & 29\end{array}$

$35 \quad 29$

$\begin{array}{rr}3.7 & 29 \\ 8 & 29\end{array}$

$\begin{array}{rr}7.3 & 29 \\ 61 & 29\end{array}$

$\begin{array}{ll}61 & 29 \\ 73 & 29 \\ 31 & 29\end{array}$

$\begin{array}{rr}31 & 29 \\ 9 & 29\end{array}$

$\begin{array}{rr}30 & 4 \\ 0.9 & 29\end{array}$

INDICATED PERCENTAGE OF TIME

$83 \quad 80 \quad 75$

65

62

$55-50$

0.0105

0.0032

0.0033

11.5932

4.8520

1.9227
3.7870

1.4109

0.0137

21.192

$-0.176 *$

0.181 *

$0.119 *$

$0.083^{*}$

0.348 *

$0.121 *$

0.0102

0.0120

6.0583

0.048

3.0058

0.146 *
0.203 *

0.203 *
0.149 *

0.025 *

0.014
0.037

0.008

$-0.015$

54.972

20.189

2.788

12.487

0.182 *

0.044 *

-0.035 *

1.74

0.97

0.45

0.68

0.63

1.18

0.99

9.5

3.5

3.2

15.9
0.17

\begin{tabular}{|c|c|c|c|c|c|}
\hline & & & & & ST ANDARD \\
\hline $\begin{array}{l}\text { SAMPLE } \\
\text { SLZE }\end{array}$ & $\begin{array}{l}\text { HARMONIC } \\
\text { MEAN - M } \\
\text { LOEG CI }\end{array}$ & $\begin{array}{l}\text { AMPL I TUDE } \\
-\bar{A} \\
\text { (DEG }\end{array}$ & $\begin{array}{l}\text { PHASE } \\
\text { ANGLE - C } \\
\text { IBADLANSI }\end{array}$ & $\begin{array}{l}\text { VAR IATION } \\
\text { EXPLA INED } \\
(\boldsymbol{Z}) \\
\end{array}$ & $\begin{array}{l}\text { ERROR OF } \\
\text { ESTIMATE } \\
\text { LDEG CI }\end{array}$ \\
\hline 365 & 15.28 & 11.62 & 2.72 & 95 & 1.90 \\
\hline
\end{tabular}

SUMMARY OF HARMONIC ANALYSIS OF STREAM TEMPERATURE

SUMMARY OF MAXIMUM AND MINIMUM CONCENTRATIONS OF CONSTITUENTS SAMPLED AT A FREQUENCY OF QUARTERLY (1975 WY)

\begin{tabular}{|c|c|c|c|c|c|c|}
\hline \multirow{2}{*}{ CONSTITUENT } & \multicolumn{3}{|c|}{ TOTAL } & \multicolumn{3}{|c|}{ DISSOLVED } \\
\hline & $\begin{array}{l}\text { NO. } \\
\text { SAMPLES }\end{array}$ & $\begin{array}{l}\text { MINIMUM } \\
\text { CONC. }\end{array}$ & $\begin{array}{l}\text { MAXIMUM } \\
\text { CONC. }\end{array}$ & $\begin{array}{l}\text { NO. } \\
\text { SAMPLES }\end{array}$ & $\begin{array}{l}\text { MINIMUM } \\
\text { CONC. }\end{array}$ & $\begin{array}{l}\text { MAXIMUM } \\
\text { CONC. }\end{array}$ \\
\hline \multicolumn{7}{|l|}{ MINOR ELEMENTS: } \\
\hline ARSENIC (AS), UG/L & 1 & 0 & & 4 & 0 & 0 \\
\hline CADMIUM $(C D), U G / L$ & 3 & 0 & 1 & 4 & 0 & 2 \\
\hline CHROMIUM (CR), UG/L & 3 & 0 & 10 & 4 & 0 & 1 \\
\hline COBALT $(C O), U G / L$ & 3 & 0 & 8 & 4 & 0 & 0 \\
\hline COPPER $(C U), U G / L$ & 3 & 9 & 11 & 4 & 6 & 17 \\
\hline IRON (FE), UG/L & 3 & 1900 & 3000 & 29 & 0 & 270 \\
\hline LEAD $(P B), U G / L$ & 3 & 2 & 8 & 4 & 0 & 2 \\
\hline MANG ANESE (MN), UG/L & 3 & 180 & 380 & 4 & 0 & 60 \\
\hline MERCURY (HG), UG/L & 1 & 0.2 & & 4 & 0.0 & 0.4 \\
\hline SELENIUM (SE), UG/L & 0 & & & 4 & 0 & 0 \\
\hline ZINC $(Z N), U G / L$ & 3 & 40 & 100 & 4 & 0 & 70 \\
\hline \multicolumn{7}{|l|}{ PERIPHYTON: } \\
\hline BIOMASS, DRY WT., G/SO M & 0 & & & & & \\
\hline BIOMASS, ASH WT.., G/SO M & 0 & & & & & \\
\hline CHLOROPHYLL A, MG/SO M & 0 & & & & & \\
\hline CHLOROPHYLL B, MG/SQ M & 0 & & & & & \\
\hline ORGANIC CARBON, MG/L & 7 & 2.5 & 9.0 & & & \\
\hline
\end{tabular}

01673000 -- PAMUNKEY RIVER NR HANOVER VA 
LAT 37D4OM15S LONG 078D05MIOS

DRAINAGE AREA: 6257 SQ MI ( 16206 SQ KM)

PERIOD OF RECORD: $10 / 01 / 74-09 / 30 / 75$

STATISTICAL SUMMARY OF SELECTED DISSOLVED CHEMICAL CONSTITUENTS AND

REGRESSION RELATIONSHIPS OF CONSTITUENT CONCENTRATIONS TO SPECIFIC CONDUCTANCE

CONSIUIUENI

\section{CONSIUUVENI IMG/L OR UNII SHOHNI}

SAMPLE

SIZE

TEMPERATURE, WATER (DEG C) SPECIFIC CONDUCTANCE (MICROMHOS) STREAMFLOW (CUBIC FT/SEC)

PH (STANDARD UNITS)

PHOSPHORUS, TOTAL

NITRITE + NITRATE, TOTAL

NITROGEN, KJELDAHL, TOTAL

PHYTOPLANKTON, TOTAL (CELLS/ML)

SEDIMENT, SUSPENDED

SEDIMENT, CLAY-SILT (PERCENT)

COLIFORM, FECAL (COL/100 ML)

STREPTOCOCCI, FECAL (COL/100 ML)

SILICA, DISSOLVED

CALCIUM, DISSOLVED

MAGNESIUM, DISSOLVED

SODIUM, DISSOLVED

POTASSIUM, DISSOLVED

BICARBONATE, ION

CARBONATE, ION

SULFATE, DISSOLVED

CHLORIDE, DISSOLVED

DISSOLVED SOLIDS, SUM OF CONST
DISSOLVED SOLIDS, ROE 180 DEG

HARDNESS, TOTAL

HARDNESS, NONCARBCNATE

TURBIDITY (JTU)

FLOURIDE, DISSOLVED

$\begin{array}{rrr}61 & 15.25 & 7.87 \\ 61 & 119.0 & 41.3 \\ 30 & 9840.2 & 7876.8 \\ 37 & 7.03 & 0.40 \\ 35 & 0.091 & 0.074 \\ 35 & 0.333 & 0.112 \\ 35 & 0.524 & 0.282 \\ 10 & 2358.0 & 2476.0 \\ 38 & 61.6 & 85.5 \\ 11 & 95.7 & 5.7 \\ 35 & 553.2 & 770.4 \\ 10 & 287.9 & 419.3 \\ 28 & 9.32 & 2.14 \\ 28 & 14.14 & 3.43 \\ 28 & 3.37 & 0.91 \\ 28 & 5.52 & 2.34 \\ 28 & 1.76 & 0.41 \\ 31 & 52.1 & 14.2 \\ 5 & 0.0 & 0.0 \\ 31 & 10.09 & 2.22 \\ 31 & 6.38 & 3.65 \\ 28 & 77.2 & 22.8 \\ 48 & 82.6 & 26.4 \\ 28 & 49.3 & 12.2 \\ 28 & 6.4 & 5.0 \\ 28 & 16.2 & 18.5 \\ 27 & 0.18 & 0.18\end{array}$

${ }^{*}$ Not significant at the 95 percent confidence level.

DURAIION IABLE OE DAUY SPECIEIC CONDUCIANCE

DAILY SPECIFIC CONDUCTANCE IN

MICROMHOS AT 25 DEG C, THAT WAS

EQUALLED OR EXCEEDED FOR THE

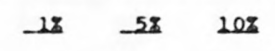

208

308

BANGE

REGRESSION

EEGRESSION SUMMARY

INDICATED PERCENTAGE OF TIME

$168 \quad 150$

132

$\begin{array}{rr}3.0 & 28 \\ 55 & 2 \\ 120 & 238 \\ 6.3 & 7\end{array}$

SAMPLE COEFICIENT

CONSTANT,

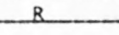

28.0
240
23800
7.9
0.30
0.64
1.20
7800
381
100
3168
1100
12.0
21.0
5.3
11.0
2.4
76
0
16.0
17.0
116
189
73
14
60
1.0

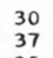

30
37
35

35
35

0.01

0.10

330

1
87

2
10
0.5

0.5
6.4

1.7

2.4

1.2
20

6.8
1.5

4
40

23
0

2

$\begin{array}{rr}-87.650 & 20536.355 \\ 0.0015 & 6.8395 \\ -0.00052 & 0.15756 \\ -0.00012 & 0.34860 \\ -0.00240 & 0.82979 \\ -3.242 & 2740.543\end{array}$

-0.479
$0.176 *$

-0.335 *

-0.051 *

$-0.403$

-0.060 *

2740.543

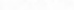

$\begin{array}{rr}28 & 0.0224 \\ 28 & 0.0719 \\ 28 & 0.0130 \\ 28 & 0.0448 \\ 28 & 0.0042 \\ 31 & 0.294 \\ 5 & 0.000 \\ 31 & 0.0252 \\ 31 & 0.0599 \\ 28 & 0.439 \\ 48 & 0.299 \\ 28 & 0.233 \\ 28 & -0.006 \\ 27 & -0.150 \\ 27 & -0.0005\end{array}$

6.8599
6.2281
1.9413
0.6033
1.2966
19.486
0.000
7.2946
-0.2549
28.941
47.450
23.639
7.116
35.090
0.2337

0.275 *

0.554 .

0.505

$0.266^{\circ}$

0.523

0.523

0.000.

0.288

0.416

0.509

0.424

0.503

-0.033 *

-0.342 .

-0.069 .

CORRELATION

STANDARD - B COEEICIENI ERROR OF ESILIMAIE

SUMMARY OF HARMONIC ANALYSIS OF STREAM TEMPERATURE

\begin{tabular}{|c|c|c|c|c|c|}
\hline & & & & & STANDARD \\
\hline $\begin{array}{l}\text { SAMPLE } \\
\text { SIZE - }\end{array}$ & $\begin{array}{l}\text { HARMONIC } \\
\text { MEAN - M } \\
\text { LEEG Cl }\end{array}$ & $\begin{array}{c}\text { AMPLITUDE } \\
-{ }^{A} \\
\text { SDEG C) }\end{array}$ & $\begin{array}{l}\text { PHASE } \\
\text { ANGLE - C } \\
\text { (RADLANS) }\end{array}$ & $\begin{array}{l}\text { VAR IATION } \\
\text { EXPLAINED } \\
\text { (z) }\end{array}$ & $\begin{array}{l}\text { ERROR OF } \\
\text { ESTIMATE } \\
\text { LEEG_C) }\end{array}$ \\
\hline 344 & 14.68 & 11.14 & 2.79 & 94 & 2.03 \\
\hline
\end{tabular}

SUMMARY OF MAXIMUM AND MINIMUM CONCENTRATIONS OF CONSTITUENTS

SAMPLED AT A FREQUENCY OF QUARTERLY (1975 WY)

02035000 -- JAMES RIVER AT CARTERSVILLE, VA

\begin{tabular}{|c|c|c|c|c|c|c|}
\hline \multirow{2}{*}{ CONSTITUENT } & \multicolumn{3}{|c|}{ TOTAL } & \multicolumn{3}{|c|}{ DISSOLVED } \\
\hline & $\begin{array}{l}\text { NO. } \\
\text { SAMPLES }\end{array}$ & $\begin{array}{l}\text { MIN IMUM } \\
\text { CONC. }\end{array}$ & $\begin{array}{l}\text { MAXIMUM } \\
\text { CONC. }\end{array}$ & $\begin{array}{l}\text { NO. } \\
\text { SAMPLES }\end{array}$ & $\begin{array}{l}\text { MINIMUM } \\
\text { CONC. }\end{array}$ & $\begin{array}{l}\text { MAXIMUM } \\
\text { CONC. }\end{array}$ \\
\hline \multicolumn{7}{|l|}{ MINOR ELEMENTS: } \\
\hline ARSENIC (AS), UG/L & 3 & 1 & 2 & 4 & 0 & 2 \\
\hline CADMIUM $(C D), U G / L$ & 2 & 0 & 1 & 4 & 0 & 1 \\
\hline CHROMIUM (CR), UG/L & 2 & $<10$ & $<10$ & 4 & 0 & 5 \\
\hline COBALT $(C O), U G / L$ & 2 & 0 & 3 & 4 & 0 & 0 \\
\hline COPPER $(C U), U G / L$ & 2 & 9 & 12 & 4 & 4 & 8 \\
\hline IRON (FE), UG/L & 2 & 2600 & 8000 & 28 & 0 & 290 \\
\hline LEAD $(P B), U G / L$ & 2 & 9 & 13 & 4 & 0 & 10 \\
\hline MANG ANESE (MN), UG/L & 2 & 40 & 210 & 4 & 0 & 30 \\
\hline MERCURY (HG), UG/L & 4 & 0.1 & 0.6 & 4 & 0.0 & 0.2 \\
\hline SELENIUM (SE), UG/L & 2 & 0 & 0 & 4 & 0 & 0 \\
\hline ZINC $(Z N), U G / L$ & 2 & 70 & 90 & 4 & 0 & 70 \\
\hline \multicolumn{7}{|l|}{ PERIPHYTON: } \\
\hline BIOMASS, DRY WT, G/SQ & $M$ & 20.00 & & & & \\
\hline $\begin{array}{l}\text { BIOMASS, ASH WT. }, G / S Q \\
\text { CHLOROPHYLL A, MG/SQ M }\end{array}$ & $\begin{array}{l}1 \\
0\end{array}$ & 20.00 & & & & \\
\hline CHLOROPHYLL B, MG/SQ M & 0 & & & & & \\
\hline ORGANIC CARBON, MG/L & 31 & 1.1 & 20.0 & & & \\
\hline
\end{tabular}


Table 14.--Sumnary of measurements at each station--Continued

LAT 36045M45S LONG 076053M55S

DRAINAGE AREA: 617 SQ MI 11598 SQ KMI

PERIOD OF RECORD: $10 / 01 / 74-09 / 30 / 75$

STATISTICAL SUMMARY OF SELECTED DISSOLVED CHEMICAL CONSTITUENTS AND REGRESSION RELATIONSHIPS OF CONSTITUENT CONCENTRATIONS TO SPECIFIC CONDUCTANCE

CONSIIIUENI

$$
\text { CONSIUUENI IMG/L OR UNII SHOWN }
$$

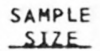

TEMPERATURE, WATER (DEG C)

SPECIFIC CONDUCTANCE (MICROMHOS)

STREAMFLOW (CUBIC FT/SEC)

PH (STANDARD UNITS )

PHOSPHORUS, TOTAL

NITRITE + NITRATE, TOTAL

NITROGEN, KJELDAHL, TOTAL

PHYTOPLANKTON, TOTAL (CELLS/ML)

SEDIMENT, SUSPENDED

SEDIMENT, CLAY-SILT (PERCENT)

COLIFORM, FECAL (COL/100 ML)

STREPTOCOCCI, FECAL (COL/100 ML)

SILICA, DISSOLVED

CALCIUM, DISSOLVED

MAGNESIUM, DISSOL VED

SODIUM, DISSOLVED

POTASSIUM, DISSOLVED

BICARBONATE, ION

CARBONATE, ION

SULFATE, DISSOLVED

CHLOR IDE, DISSOLVED

DISSOLVED SOLIDS, SUM OF CONST

DISSOLVED SOLIDS, ROE 180 DEG

HARONESS, TOTAL

HARDNESS, NONCARBONATE

TURBIDITY (JTU)

FLOURIDE, DISSOLYED

$S$

\section{STANDARD}

MEAN REYIAIION

$\begin{array}{lll}14 & 15.04 & 7.62\end{array}$

$14 \quad 92.7 \quad 24.6$

782.0

6.77

0.039

0.251

0.670

598.8

10.1

93.1

174.3

478.2

8.67
11.36

11.36
1.70

4.00

2.76

28.0

0.0

9.20

9.36
64.3

64.3
75.5

35.2

12.4

9.3

747.2

0.76
0.014

0.140

0.190

1253.6

6.7

20.7

270.9

966.9

2.00

4.17

0.56

1.32

0.71

13.4

0.0

.98

3.35

16.2
17.9

12.6

7.8

0.07

*Not significant at the 95 percent confidence level.

NAME: BLACKWATER R NR FRANKLIN, VA

SUMMARY OF HARMONIC ANALYSIS OF STREAM TEMPERATURE

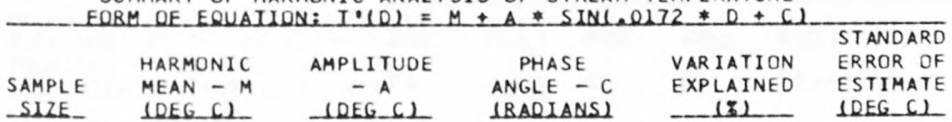
14
15.09
10.56
2.71
98
1.11

SUMMARY OF MAXIMUM AND MINIMUM CONCENTRATIONS OF CONSTITUENTS SAMPLED AT A FREQUENCY OF OUARTERLY (1975 WY)

02049500 - BLACKWATER R NR FRANKLIN, VA

\begin{tabular}{|c|c|c|c|c|c|c|}
\hline \multirow{2}{*}{ CONSTITUENT } & \multicolumn{3}{|c|}{ TOTAL } & \multicolumn{3}{|c|}{ DISSOLVED } \\
\hline & $\begin{array}{l}\text { NO. } \\
\text { SAMPLES }\end{array}$ & $\begin{array}{l}\text { MINIMUM } \\
\text { CONC. }\end{array}$ & $\begin{array}{l}\text { MAXIMUM } \\
\text { CONC. }\end{array}$ & $\begin{array}{l}\text { NO. } \\
\text { SAMPLES }\end{array}$ & $\begin{array}{l}\text { MINIMUM } \\
\text { CONC. }\end{array}$ & $\begin{array}{l}\text { MAXIMUM } \\
\text { CONC. }\end{array}$ \\
\hline \multicolumn{7}{|l|}{ MINOR ELEMENTS: } \\
\hline ARSENIC (AS), UG/L & 2 & 0 & 1 & 4 & 0 & 1 \\
\hline CADMIUM $(C D)$, UG/L & 3 & 1 & 1 & 3 & 1 & 1 \\
\hline CHROMIUM (CR), UG/L & 3 & 0 & $<10$ & 4 & 0 & 2 \\
\hline COBALT $(C O), U G / L$ & 3 & 0 & 3 & 4 & 0 & 1 \\
\hline COPPER (CU), UGIL & 3 & 8 & 9 & 4 & 6 & 8 \\
\hline IRON $(F E), U G / L$ & 3 & 680 & 1900 & 5 & 40 & 1300 \\
\hline LEAD $(P B), U G / L$ & 3 & 6 & 16 & 4 & 0 & 9 \\
\hline MANGANESE (MN), UG/L & 3 & 20 & 130 & 4 & 0 & 130 \\
\hline MERCURY (HG), UG/L & 2 & 0.1 & 0.3 & 4 & 0.1 & 0.3 \\
\hline SELENIUM (SE), UG/L & 1 & 0 & & 4 & 0 & 0 \\
\hline ZINC $(Z N), U G / L$ & 3 & 50 & 440 & 4 & 10 & 70 \\
\hline \multicolumn{7}{|l|}{ PERIPHYTON: } \\
\hline BIOMASS, DRY WT., G/SQ M & 1 & 17.00 & & & & \\
\hline $\begin{array}{l}\text { BIOMASS, ASH WT, G/SO M } \\
\text { CHLOROPHYLL A, MG/SQ M }\end{array}$ & 1 & 16.00 & & & & \\
\hline CHLOROPHYLL B, MG/SQ M & 0 & & & & & \\
\hline ORGANIC CARBON, MG/L & 7 & 8.8 & 17.0 & & & \\
\hline
\end{tabular}


LAT 36D12M33S LONG 077D23M02S DRAINAGE AREA: 8700 SQ MI 122533 SQ KM) PERIOD OF RECORD: $10 / 01 / 74$ - 09/30/75

STATISTICAL SUMMARY OF SELECTED DISSOLVED CHEMICAL CONSTITUENTS AND REGRESSION RELATIONSHIPS OF CONSTITUENT CONCENTRATIONS TO SPECIFIC CONDUCTANCE

CONSIIIUENI

\begin{tabular}{|c|}
\hline $\begin{array}{l}\text { TEMPERATURE, WATER (DEG C) } \\
\text { SPECIFIC CONDUCTANCE (MICROMHOS) } \\
\text { STREAMFLOH (CUBIC FT/SEC) } \\
\text { PH (STANDARD UNITS) } \\
\text { PHOSPHORUS, TOTAL } \\
\text { NITRITE + NITRATE, TOTAL } \\
\text { NITROGEN, KJELDAHL, TOTAL } \\
\text { PHYTOPLANKTON, TOTAL (CELLS/ML) } \\
\text { SEDIMENT, SUSPENDED } \\
\text { SEDIMENT, CLAY-SILT (PERCENT) } \\
\text { COLIFORM, FECAL (COL/IOO ML) } \\
\text { STREPTOCOCCI, FECAL (COL/1OO ML) } \\
\text { SILICA, DISSOLVED } \\
\text { CALCIUM, DISSOLVED } \\
\text { MAGNESIUM, DISSOLVED } \\
\text { SODIUM, DISSOLVED } \\
\text { POTASSIUM, DISSOLVED } \\
\text { BICARBONATE, ION } \\
\text { CARBONATE, ION } \\
\text { SULFATE, DISSOLVED } \\
\text { CHLORIDE, DISSOLVED } \\
\text { DISSOLVED SOLIDS, SUM OF CONST } \\
\text { DISSOLVED SOLIDS, ROE I8O DEG C } \\
\text { HARONESS, TOTAL } \\
\text { HARDNESS, NONCARBONATE } \\
\text { TURBIDITY (JTU) } \\
\text { FLOURIDE, DISSOLVED }\end{array}$ \\
\hline
\end{tabular}

CONSILIUENI IMG/L OR UNII_SHOHNU

SAMPLE STANDARD

SIZE MEAN DEXIAILON BANGE

DEYIATION

BANGE
15.64 76.5

14618.5 6.79 0.79
0.045 0.045
0.160 0.160
0.403 0.403
9196.4 9196.4
19.2 19.2
93.3 695.8 330.5

330.5
9.28

9.28
6.88

6.88
2.39

2.39
6.56

6.56
2.08

2.08
32.8

32.8
0.0

8.15

4.93

56.8

61.1

27.0
1.6

1.6
14.9
0.17
7.21

10429.1

0.25

0.25
0.013

0.051

0.089

6110.1

6.5
5.9

5.9
997.1

259.7

1.59

1.52

0.26

2.25
0.36

5.8

0.0

1.81

0.97

9.6
10.5

4.4

2.3

8.8
0.15

$\begin{array}{rrr}6.0 & 27.0 & \\ 55 & 160 & \\ 1300 & 33000 & 24 \\ 6.3 & 7.3 & 24 \\ 0.03 & 0.07 & 12 \\ 0.09 & 0.24 & 12 \\ 0.28 & 0.64 & 12 \\ 460 & 22000 & 11\end{array}$

460
10
80

10

$4.0 \quad 10.0$

2.0

2.0
1.8
26

26

5.9
3.8

5.9
3.8
42
49

18

0.0

*Not significant at the 95 percent confidence level.

DURAIION IABLE OF DALY SPECIEIC CONDUCIANCE

DAILY SPECIFIC CONDUCTANCE IN

MICROMHOS AT 25 DEG C, THAT WAS

EOUALLED OR EXCEEDED FOR THE

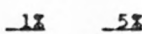

102

208

302

508

$134 \quad 121$

105

100

$97 \quad 85$

\begin{tabular}{ll}
\multicolumn{2}{c}{ REGBESSION SUMMA } \\
REGRESSION \\
SAMPLE COEFICIENT, CONSTANT, \\
SIZE
\end{tabular}
CORRELATION
$-B$ COEEICIENI

STANDARD ESIUMAIE

SUMMARY OF HARMONIC ANALYSIS OF STREAM TEMPERATURE

\begin{tabular}{|c|c|c|c|c|c|}
\hline & & & & & STANDARD \\
\hline & HARMONIC & AMPLITUDE & PHASE & VARIATION & ERROR OF \\
\hline SAMPLE & MEAN - $M$ & $-A$ & ANGLE - C & EXPLAINED & ESTIMATE \\
\hline SIZE & $10 E G \quad C)$ & DOEG $C)$ & (BADIANS) & $(3)$ & (DEG () \\
\hline 365 & 16.19 & 9.72 & 2.57 & 95 & 1.49 \\
\hline
\end{tabular}

SUMMARY OF MAXIMUM AND MINIMUM CONCENTRATIONS OF CONSTITUENTS SAMPLED AT A FREQUENCY OF QUARTERLY (1975 WY)

02081000 -- ROANOKE RIVER NEAR SCOTLAND NECK NC

\begin{tabular}{|c|c|c|c|c|c|c|}
\hline \multirow{2}{*}{ CONSTITUENT } & \multicolumn{3}{|c|}{ TOTAL } & \multicolumn{3}{|c|}{ DISSOLVED } \\
\hline & $\begin{array}{c}\text { NO. } \\
\text { SAMPLES }\end{array}$ & $\begin{array}{l}\text { MIN IMUM } \\
\text { CONC. }\end{array}$ & $\begin{array}{l}\text { MAXIMUM } \\
\text { CONC. }\end{array}$ & $\begin{array}{l}\text { NO. } \\
\text { SAMPLES }\end{array}$ & $\begin{array}{l}\text { MINIMUM } \\
\text { CONC. }\end{array}$ & $\begin{array}{l}\text { MAXIMUM } \\
\text { CONC. }\end{array}$ \\
\hline \multicolumn{7}{|l|}{ MINOR ELEMENTS: } \\
\hline ARSENIC (AS), UG/L & 7 & 0 & 30 & 6 & 0 & 1 \\
\hline CADM IUM $(C D), U G / L$ & 7 & 0 & 0 & 6 & 0 & 2 \\
\hline CHROMIUM (CR), UG/L & 7 & 410 & $<50$ & 6 & 0 & 1 \\
\hline COBALT $(C O), U G / L$ & 6 & 0 & 2 & 6 & 0 & 0 \\
\hline COPPER $(C U), U G / L$ & 7 & 2 & $<40$ & 6 & 2 & 7 \\
\hline IRDN (FE), UG/L & 7 & 480 & 1400 & 6 & 50 & 220 \\
\hline LEAD $(P B), U G / L$ & 7 & 4 & $<100$ & 6 & 0 & 34 \\
\hline MANG ANESE (MN), UG/L & 7 & 70 & 170 & 6 & 10 & 60 \\
\hline MERC URY $(H G), U G / L$ & 6 & 0.0 & 0.3 & 6 & 0.0 & 0.1 \\
\hline SELENIUM (SE), UG/L & 6 & 0 & 0 & 6 & 0 & 0 \\
\hline ZINC $(Z N), U G / L$ & 7 & 0 & $<50$ & 6 & 10 & 90 \\
\hline \multicolumn{7}{|l|}{ PERIPHYTON: } \\
\hline $\begin{array}{l}\text { BIOMASS, DRY WT., G/SO M } \\
\text { BIOMASS, ASH WT., G/SQ M }\end{array}$ & $\begin{array}{l}2 \\
2\end{array}$ & $\begin{array}{l}.50 \\
.50\end{array}$ & $\begin{array}{l}1.79 \\
1.50\end{array}$ & & & \\
\hline CHLOROPHYLL A, MG/SQ M & 2 & .0 & .1 & & & \\
\hline CHLOROPHYLL $B, M G / S Q M$ & 2 & .0 & .0 & & & \\
\hline ORGANIC CARBON, MG/L & 7 & 4.2 & 16.0 & & & \\
\hline
\end{tabular}


LAT 35D53M38S LONG 077032 MOOS

DRAINAGE AREA: 2140 SQ MI

PERIOD OF RECORD: $10 / 01 / 74-09 / 30 / 7543$ SQ KMI

STATISTICAL SUMMARY OF SELECTED DISSOLVED CHEMICAL CONSTITUENTS AND

REGRESSION RELATIONSHIPS OF CONSTITUENT CONCENTRATIONS TO SPECIFIC CONDUCTANCE

GONSIUIUENI

TEMPERATURE, WATER (DEG C)
SPECIFIC CONDUCTANCE (MICROMHOS)
STREAMFLOW (CUBIC FT/SEC)
PH (STANDARD UNITS)
PHOSPHORUS, TOTAL
NITRITE NITRATE, TOTAL
NITROGEN, KJELDAHL, TOTAL
PHYTOPLANKTON, TOTAL (CELLS/ML)
SEDIMENT, SUSPENDED
SEDIMENT, CLAY-SILT (PERCENT)
COLIFORM, FECAL (COL/IOO ML)
STREPTOCOCCI, FECAL (COL/IOO ML)
SILICA, DISSOLVED
CALCIUM, DISSOLVED
MAGNESIUM, DISSOLVED
SODIUM, DISSOLVED
POTASSIUM, DISSOLVED
BICARBONATE, ION
CARBONATE, ION
SULFATE, DISSOLVED
CHLORIDE, DISSOLVED
DISSOLVED SOLIDS, SUM OF CONST
DISSOLVED SOLIDS, ROE I8O DEG C
HARDNESS, TOTAL
HARDNESS, NONCARBONATE
TURBIDITY (JTU)
FLOURIDE, DISSOLVED

CONSIUUENI IMGLL OB UNII SHOWN

SAMPL

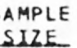

$\begin{array}{rr}42 & \\ 38 & \\ 44 & 38 \\ 41 & \\ 12 & \\ 12 & \\ 12 & 0 \\ 11 & 1325 \\ 12 & \\ 11 & \\ 43 & \\ 11 & \\ 11 & \\ 11 & \\ 11 & \\ 11 & \\ 11 & \\ 11 & \\ 5 & \\ 11 & \\ 11 & \\ 11 & \\ 11 & \\ 11 & \\ 11 & \\ 16 & \\ 11 & \end{array}$

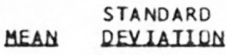

68.6

3850.9

6.58

0.142

0.562

3251.8

27.8
90.9

90.9
480.7

902.7

11.56

6.14

1.96

6.84
2.21

24.5

0.0
7.65

7.65
6.69

55.9

63.9

23.4

4.4

22.5

0.24
25.1

0.89
0.053

0.053

0.093

0.148

29162.0

16.4
10.8

10.8
086.5

1086.5
950.5

950.5
3.53

1.57

0.42

2.99

0.45

11.6

0.0
1.69

2.42

16.6

11.4
5.5

6.0

18.7

0.14
*Not significant at the 95 percent confidence 1 evel.

$$
5.97
$$

5.0
30
332
1.6

DURAIION IABLE OF DAILY SPECIEIC CONDUCIANCE

DAILY SPECIFIC CONDUCTANCE IN

MICROHOS AT 25 DEG C, THAT WAS

$\begin{array}{lll}18 & -58 & 108 \\ 133 & 116 & 112\end{array}$

208

$30 \%$

508

INDICATED PERCENTAGE OF TIME

SUMMARY OF HARMONIC ANALYSIS OF STREAM TEMPERATURE

\begin{tabular}{|c|c|c|c|c|c|}
\hline & & & & & STANDARD \\
\hline & HARMONIC & AMPLITUDE & PHASE & VAR IATION & ERROR OF \\
\hline SAMPLE & MEAN - $M$ & $-A$ & ANGLE - C & EXPLA INED & ESTIMATE \\
\hline SIZE & $10 E G(1)$ & DOEG $(1)$ & (BADIANSI & 181 & IDEG CI \\
\hline 365 & 16.84 & 10.87 & 2.86 & 92 & 2.20 \\
\hline
\end{tabular}

BANGE

BEGRESSION SUMMARY SAMPLE COEFICIENT, CONSTANT, CO SIZE

CORRELATION STANDARD ESIUMAIE

0.11

160
6

66
10

60
6.5

$3.6 \quad 16.0$

1.3

3.0

10
10

6.0
3.1

3.1
36

48

0

0.0

27.0

$19400 \quad 38 \quad-116.040$

0.0107

0.00151

0.00171

0.00359

227.231

12333.945

5.9573

0.02036

0.14435

0.27716

$-4513.543$

$-0.551$

4472.7
0.27

0.721

$0.480^{*}$

$0.596 * 20.0013$

$0.200 * \quad 30117.7$

57

100
7100

7100

16.0
8.0

2.6
12.0

$\begin{array}{rl}1 & 1 \\ 1 & 1 \\ 1 & 1 \\ 11 \\ 11 \\ 11 \\ 5 \\ 11 \\ 11 \\ 11 \\ 11 \\ 11 \\ 1 & 1 \\ 1 & 5 \\ 11\end{array}$

0.1142

0.0466

0.0098

0.1143

0.0119

0.418
0.000

0.0275

0.0858

0.633

0.384

0.159

$-0.145$

$-0.484$

0.0028
2.6340
2.4913
1.1989
.0998
1.2806
-8.130
0.000
5.5008
$-0.0153$
6.412
33.864
10.895
15.723
59.531
0.0202

0.830
0.762
0.598
0.981
0.670
0.923
0.000
0.420
0.910
0.976
0.864
0.749
-0.618
-0.616
0.521

2.08
1.07

0.36

0.62

0.36

4.7

4.07
1.61
1.06

3.8

6.1

SUMMARY OF MAXIMUM AND MINIMUM CONCENTRATIONS OF CONSTITUENTS

SAMPLED AT A FREQUENCY OF QUARTERLY (1975 WY)

02083500 - TAR RIVER AT TARBORO, N. C.

\begin{tabular}{|c|c|c|c|c|c|c|}
\hline \multirow{2}{*}{ CONSTI TUENT } & \multicolumn{3}{|c|}{ TOTAL } & \multicolumn{3}{|c|}{ DISSOLVED } \\
\hline & $\begin{array}{l}\text { NO. } \\
\text { SAMPLES }\end{array}$ & $\begin{array}{l}\text { MINIMUM } \\
\text { CONC. }\end{array}$ & $\begin{array}{l}\text { MAXIMUM } \\
\text { CONC. }\end{array}$ & $\begin{array}{l}\text { NO. } \\
\text { SAMPLES }\end{array}$ & $\begin{array}{l}\text { MINIMUM } \\
\text { CONC. }\end{array}$ & $\begin{array}{l}\text { MAXIMUM } \\
\text { CONC. }\end{array}$ \\
\hline \multicolumn{7}{|l|}{ MINOR ELEMENTS: } \\
\hline ARSENIC (AS), UG/L & 7 & 0 & 30 & 6 & 0 & 1 \\
\hline CADMIUM (CD), UG/L & 7 & 0 & $<50$ & 6 & 0 & 1 \\
\hline CHROMIUM (CR), UGII & 8 & $<10$ & $<50$ & 7 & 0 & 1 \\
\hline COBALT $(C O), U G / L$ & 6 & 0 & 2 & 6 & 0 & 1 \\
\hline COPPER (CU), UG/L & 8 & 1 & $<40$ & 7 & 2 & 7 \\
\hline IRON (FE), UG/L & 8 & 1300 & 1800 & 7 & 310 & 850 \\
\hline LEAD (PB), UG/L & 8 & 1 & $<100$ & 7 & 0 & 8 \\
\hline MANG ANESE (MN), UG/L & 7 & 50 & 190 & 6 & 16 & 100 \\
\hline MERCURY (HG), UG/L & 6 & 0.0 & 0.3 & 6 & 0.0 & 0.3 \\
\hline SELENIUM (SE), UG/L & 6 & 0 & 0 & 6 & 0 & 0 \\
\hline ZINC $(Z N), U G / L$ & 8 & 0 & $<50$ & 7 & 0 & 20 \\
\hline \multicolumn{7}{|l|}{ PERIPHYTON: } \\
\hline BIOMASS, DRY WT., G/SQ M & 1 & 19.00 & & & & \\
\hline BIOMASS, ASH WT., G/SQ M & 1 & 14.00 & & & & \\
\hline CHLOROPHYLL A, MG/SO M & 1 & 18.0 & & & & \\
\hline CHLOROPHYLL B, MG/SO M & 1 & 3.1 & & & & \\
\hline ORGANIC CARBON, MG/L & 7 & 5.0 & 22.0 & & & \\
\hline
\end{tabular}


LAT 35D15M29S LONG 077035M09S

DRAINAGE AREA: 2690 SQ MI 10667 SQ KM

PERIOD OF RECORD: $10 / 01 / 74-09 / 30 / 75$

STATISTICAL SUMMARY OF SELECTED DISSOLVED CHEMICAL CONSTITUENTS AND

REGRESSION RELATIONSHIPS OF CONSTITUENT CONCENTRATIONS TO SPECIFIC CONDUCTANCE

CONSIIIUENI

\section{CONSIUIUES \\ SIZE}

TEMPERATURE, WATER (DEG C) SPECIFIC CONDUCTANCE (MICROMHOS) STREAMFLOW (CUBIC FT/SEC) PH (STANDARO UNITS) PHOSPHORUS, TOTAL

NITRITE + NITRATE, TOTAL NITROGEN, KJELDAHL, TOTAL PHYTOPLANKTON, TOTAL (CELLS/ML) SEDIMENT, SUSPENDED

SEDIMENT, CLAY-SILT (PERCENT) COLIFORM, FECAL ( COL/IOO ML) STREPTOCOCCI, FECAL (COL/100 ML) SILICA, DISSOLVED

CALCIUM, DISSOL VED MAGNESIUM, DISSOL VED SODIUM, DISSOLVED

POTASSIUM, DISSOLVED

BICARBONATE, ION

CARBONATE, ION

SULFATE, DISSOLVED

CHLORIDE, DISSOLVED

DISSOLVED SOLIDS, SUM OF CONST

DISSOLVED SOLIDS, ROE 180 DEG C

HARDNESS, TOTAL

HARDNESS, NONCARBONATE

TURBIDITY (JTU)

FLOURIDE, DISSOLVED

$\begin{array}{rrr}43 & 19.12 & 7.04 \\ 42 & 93.8 & 32.3 \\ 44 & 3749.2 & 4284.3 \\ 16 & 6.69 & 0.42 \\ 15 & 0.204 & 0.082 \\ 15 & 0.491 & 0.292 \\ 15 & 0.682 & 0.224 \\ 13 & 27606.2 & 46374.2 \\ 14 & 29.8 & 18.2 \\ 13 & 91.0 & 10.6 \\ 42 & 702.3 & 1719.4 \\ 12 & 636.7 & 784.0 \\ 13 & 10.00 & 2.40 \\ 13 & 5.49 & 1.42 \\ 13 & 1.80 & 0.40 \\ 13 & 7.72 & 3.30 \\ 13 & 2.46 & 0.47 \\ 13 & 20.4 & 8.1 \\ 6 & 0.0 & 0.0 \\ 13 & 9.25 & 1.34 \\ 13 & 8.37 & 3.40 \\ 13 & 55.8 & 14.9 \\ 13 & 64.2 & 16.5 \\ 13 & 21.2 & 4.9 \\ 13 & 4.8 & 2.7 \\ 13 & 13.9 & 6.7 \\ 13 & 0.21 & 0.14\end{array}$

*Not significant at the 95 percent confidence level.

0.14

\section{BEGRESS ION SUMMABY}

$\begin{array}{ll} & \text { REGRESSION } \\ \text { SAMPLE COEFICIENT, CONSTANT, }\end{array}$ SIZE $-{ }_{B}$ - B

CORRELATION

BANGE

$\begin{array}{rr}5.0 & 28.5 \\ 48 & 185\end{array}$

$\begin{array}{rr}48 & 185 \\ 484 & 10000\end{array}$

6.1

0.08

7.4

7.4
0.33

0.33
1.10

1.10
1.10

0.44

170000

$42 \quad-78.982$

0.0136
0.00265

$0: 00222$

0.00524

722.422

5.4572

0.30602

0.24435

$-34188.715$

$-0.587$

0.801

0.793

0.187

0.575

0.392 .

100

11000

2400

$14.0 \quad 13$

14.0
7.8
2.5

2.5

2.5
15.0

13

$\begin{array}{rr}3.1 & 13 \\ 36 & 13\end{array}$

$\begin{array}{rr}13.0 & 6 \\ 15.0 & 13\end{array}$

15.0

$93 \quad 13$

$29 \quad 13$

913
$21 \quad 13$
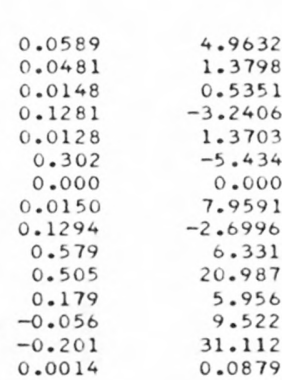

0.017

0.853

0.930

0.977

0.678
0.938

0.938
$0.000 *$

0.282 *

0.957

0.978

0.770

0.917

$-0.521$

-0.755
0.245

DAILY SPECIFIC CONDUCTANCE IN MICROMHOS AT 25 DEG C. THAT WAS

EQUALLED OR EXCEEDED FOR THE

INDICATED PERCENTAGE OF TIME

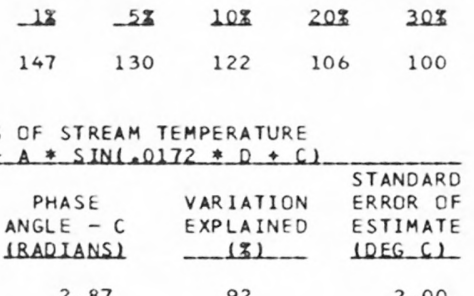

SUMMARY OF HARMONIC ANALYSIS OF STREAM TEMPERATURE

\begin{tabular}{|c|c|c|c|c|c|}
\hline & & & & & STANDARD \\
\hline & HARMONIC & AMPLITUDE & PHASE & VARIATION & ERROR OF \\
\hline SAMPLE & MEAN - $M$ & $-A$ & ANGLE - C & EXPLAINED & ESTIMATE \\
\hline SIZE_- & $10 E G(C)$ & $-10 E G_{2}(1)$ & (BADIANS) & $-(3)$ & $10 E G(1)$ \\
\hline 365 & 16.93 & 10.05 & 2.87 & 92 & 0 \\
\hline
\end{tabular}

SUMMARY OF MAXIMUM AND MINIMUM CONCENTRATIONS OF CONSTITUENTS SAMPLED AT A FREQUENCY OF QUARTERLY (1975 WY)

02089500 - NEUSE RIVER AT KINSTON, N.'C.

\begin{tabular}{|c|c|c|c|c|c|c|}
\hline \multirow{2}{*}{ CONSTI TUENT } & \multicolumn{3}{|c|}{ TOTAL } & \multicolumn{3}{|c|}{ DISSOLVED } \\
\hline & $\begin{array}{l}\text { NO. } \\
\text { SAMPLES }\end{array}$ & $\begin{array}{l}\text { MIN IMUM } \\
\text { CONC. }\end{array}$ & $\begin{array}{l}\text { MAXIMUM } \\
\text { CONC. }\end{array}$ & $\begin{array}{l}\text { NO. } \\
\text { SAMPLES }\end{array}$ & $\begin{array}{l}\text { MINIMUM } \\
\text { CONC. }\end{array}$ & $\begin{array}{l}\text { MAXIMUM } \\
\text { CONC. }\end{array}$ \\
\hline \multicolumn{7}{|l|}{ MINOR ELEMENTS: } \\
\hline ARSENIC (AS), UG/L & 8 & 1 & 50 & 6 & 0 & 1 \\
\hline CADMIUM $(C D), U G / L$ & 8 & 0 & $<50$ & 6 & 0 & 1 \\
\hline CHROMIUM (CR), UG/L & 9 & $<10$ & $<50$ & 7 & 0 & 2 \\
\hline COBALT $(C O), U G / L$ & 8 & 0 & $<100$ & 6 & 0 & 0 \\
\hline COPPER (CU), UG/L & 9 & 3 & $<40$ & 7 & 2 & 7 \\
\hline IRON (FE), UG/L & 9 & 920 & 1600 & 7 & 210 & 480 \\
\hline LEAD $(P B), U G / L$ & 9 & 3 & $<100$ & 7 & 0 & 5 \\
\hline MANGANESE $(M N), U G / L$ & 8 & 59 & 250 & 6 & 10 & 50 \\
\hline MERCURY (HG), UG/L & 8 & 0.0 & 2.2 & 6 & 0.0 & 0.1 \\
\hline SELENIUM (SE), UG/L & 6 & 0 & 0 & 6 & 0 & 0 \\
\hline$Z I N C(Z N), U G / L$ & 9 & 4 & $<50$ & 7 & 0 & 20 \\
\hline \multicolumn{7}{|l|}{ PERIPHYTON: } \\
\hline BIOMASS, DRY WT., G/SO M & 1 & 13.00 & & & & \\
\hline BIOMASS, ASH WT., G/SO M & 1 & 10.00 & & & & \\
\hline CHLOROPHYLL A, MG/SO M & 1 & 4.5 & & & & \\
\hline CHLOROPHYLL $B$, MG/SO M & 1 & 1.8 & & & & \\
\hline ORGANIC CARBON, MG/L & 7 & 5.0 & 15.0 & & & \\
\hline
\end{tabular}


Table 14.--Summary of measurements at each station--Continued

AT 34D24M15S LONG 078D17M38S

JRAINAGE AREA: 5220 SQ MI 113520 SQ KM)

PERIOD OF RECORD: $10 / 01 / 74-09 / 30 / 75$

STATISTICAL SUMMARY OF SELECTED DISSOLVED CHEMICAL CONSTITUENTS AND

REGRESSION RELATIONSHIPS OF CONSTITUENT CONCENTRATIONS TO SPECIFIC CONDUCTANCE

GONSIIIUENI

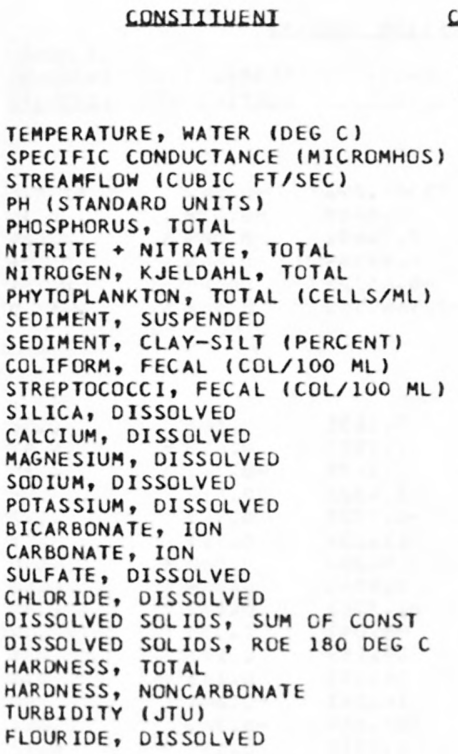

\section{CONSIUUUENI_MGGLL OR UNII SHOHNU}

46
44
47
45
13
13
13
12
12
12
45
12
12
12
12
12
12
12
6
12
12
12
12
12
12
12
12

STANDARD

DEYIALION

18.46

18.46
65.6

65.6
8477.9

877.9
6.59

6.59
0.171

0.450

0.588

1360.8

50.2

96.5

266.3

279.2

7.71

4.04

1.68
6.92

6.92
1.87

16.3

0.0

8.59

6.37

46.3

54.0

17.0

4.3
26.8

0.16
6.84

26.3

10191.6

0.41
0.072

0.072

0.101

0.126

1917.4

50.2

6.3
30.9

430.9

349.0

1.24
0.97

0.97
0.26

3.73

0.48

6.9
0.0

2.02

2.91

13.2

11.6

3.0

3.3
31.4

0.11
BEGRESS ION SUMMABY

REGRESSION

SAMPLE COEFICIENT, CONSTANT,

SIZE

$\mathrm{B}$

B.

CORRELATION

STANDARD

ERROR OF

BANGE

5.0
10
1170
5.3

31.0

$\begin{array}{lll}46600 & 44 & -205.364\end{array}$

0.00019

0.00219

0.00333
0.00087

$-4.937$

22293.195

6.5953

0.01533

0.21318

0.52551

1703.864

$-0.517$

0.006 *

0.602

0.659

0.138

$-0.051$

9045.1

0.42

0.060

0.079

0.130
2008.3

$\begin{array}{lll}28 & 5700 & 12 \\ 14 & 186\end{array}$

100

2100

1100

$\begin{array}{lll}9.3 & 12 & -0.0158\end{array}$

-0.0158
0.0165

0.0165
0.0040

0.1832

0.0102

0.304
0.000

0.0864

0.1431

0.619

0.337

0.062

0.002
-0.109

-0.109
-0.722

$-0.0018$
8.8053
2.8939
1.4073
-5.8097
1.1591
-4.873
0.000
2.5865
-3.5815
3.203
30.601
12.069
11.825
76.979
0.2829

$-0.254$

0.341 *

.

$0.421 *$

0.875

0.000

0.855

0.981

0.938

0.937

0.577
0.421.

0.421

-0.652
-0.459

$-0.350$
1.26

0.95

0.26

0.77

0.46

3.5

1.10

0.60

4.8

10.0

2.8

2.6

29.3
0.11

*Not significant at the 95 percent confidence level.

DAILY SPECIFIC CONDUCTANCE IN

IABLE OF DAIIY SPECIEIC CONDUCIANCE

SAMPLE SIZE $=365$

MICROMHOS AT 25 DEG C, THAT WAS

$\begin{array}{rrrrrr}18 & -58 & 108 & 208 & 308 & 508 \\ 121 & 111 & 106 & 91 & 79 & 70\end{array}$

2702

$20 \% 25 \% 29 \%$

EQUALLED OR EXCEEDED FOR THE

$121 \quad 111$

SUMMARY OF HARMONIC ANALYSIS OF STREAM TEMPERATURE

EORM OF EVUALION: I. $(0)=M+A *$ SINL.0172*D+C

\begin{tabular}{|c|c|c|c|c|c|}
\hline & & & & & \\
\hline SAMPLE & $\begin{array}{l}\text { HARMONIC } \\
\text { MEAN - M }\end{array}$ & AMPL I TUDE & $\begin{array}{l}\text { PHASE } \\
\text { ANGLE - C }\end{array}$ & $\begin{array}{l}\text { VAR IATION } \\
\text { EXPLAINED }\end{array}$ & ESTIM \\
\hline
\end{tabular}

365

16.77

10.87

2.80

93

1.94

SUMMARY OF MAXIMUM AND MINIMUM CONCENTRATIONS OF CONSTITUENTS SAMPLED AT A FREQUENCY OF OUARTERLY (1975 WY)

02105769 -- CAPE FEAR R AT LOCK \# I NR KELLY, NC

\begin{tabular}{|c|c|c|c|c|c|c|}
\hline \multirow{2}{*}{ CONSTI TUENT } & \multicolumn{3}{|c|}{ TOTAL } & \multicolumn{3}{|c|}{ DISSOLVED } \\
\hline & $\begin{array}{l}\text { NO. } \\
\text { SAMPLES }\end{array}$ & $\begin{array}{l}\text { MINIMUM } \\
\text { CONC. }\end{array}$ & $\begin{array}{l}\text { MAXIMUM } \\
\text { CONC. }\end{array}$ & $\begin{array}{l}\text { NO. } \\
\text { SAMPLES }\end{array}$ & $\begin{array}{l}\text { MINIMUM } \\
\text { CONC. }\end{array}$ & $\begin{array}{l}\text { MAXIMUM } \\
\text { CONC. }\end{array}$ \\
\hline \multicolumn{7}{|l|}{ MINOR ELEMENTS: } \\
\hline ARSENIC (AS), UG/L & 7 & 1 & 30 & 6 & 0 & 1 \\
\hline CADMIUM $(C D), U G / L$ & 7 & 0 & $<50$ & 0 & 0 & 2 \\
\hline CHROMIUM (CR), UG/L & 7 & $<10$ & $<50$ & 6 & 0 & 3 \\
\hline COBALT $(C O), U G / L$ & 7 & 0 & $<100$ & 6 & 0 & 2 \\
\hline COPPER (CU), UG/L & 7 & 3 & $<40$ & 6 & 2 & 5 \\
\hline IRON (FE), UG/L & 7 & 790 & 5300 & 6 & 250 & 660 \\
\hline LEAD (PB), UG/L & 7 & 2 & $<100$ & 6 & 1 & 10 \\
\hline MANG ANESE (MN), UG/L & 7 & 70 & 200 & 6 & 40 & 110 \\
\hline MERCURY (HG), UG/L & 7 & 0.0 & 1.0 & 6 & 0.0 & 0.2 \\
\hline SELENIUM (SE), UG/L & 6 & 0 & 0 & 6 & 0 & 0 \\
\hline ZINC $(Z N), U G / L$ & 7 & 8 & 60 & 6 & 0 & 20 \\
\hline \multicolumn{7}{|l|}{ PERIPHYTON : } \\
\hline BIOMASS, DRY WT.. G/SQ M & 3 & 3.09 & 31.00 & & & \\
\hline BIOMASS, ASH WT., G/SQ M & 3 & 2.29 & 24.00 & & & \\
\hline CHLOROPHYLL A, MG/SO M & 3 & .0 & $44 \cdot 0$ & & & \\
\hline CHLOROPHYLL B, MG/SO M & 3 & $\cdot 1$ & 9.6 & & & \\
\hline ORGANIC CARBON, MG/L & 6 & 7.0 & 14.0 & & & \\
\hline
\end{tabular}


AT $34056 M 46 S$ LONG 079052M11S

JRAINAGE AREA: 6870 SQ MI ( 17793 SQ KM

'ERIOD OF RECORD: $10 / 01 / 74-09 / 30 / 75$

STATISTICAL SUMMARY OF SELECTED DISSOLVED CHEMICAL CONSTITUENTS AND

REGRESSION RELATIONSHIPS OF CONSTITUENT CONCENTRATIONS TO SPECIFIC CONDUCTANCE

CONSIIUUENI

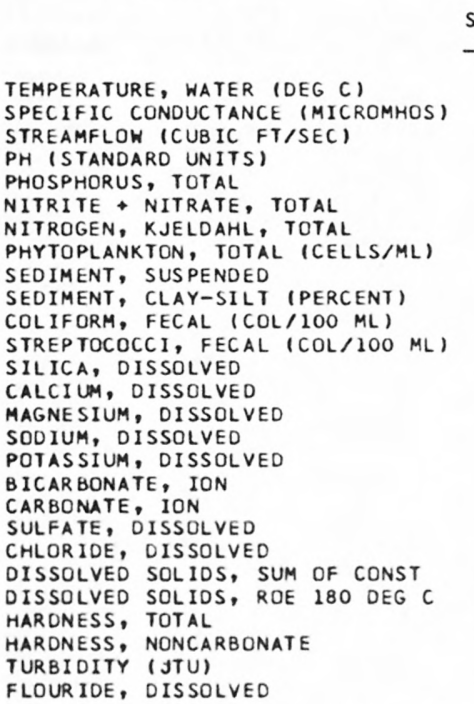

CONSIUIUENT IMG $\angle L$ OR_UNII SHOHNI

SAM

STANDARD

SIZE

19.75

19.75
62.3

12000.6

6.78

0.416

0.440

0.440
1531.2

531.2
39.8

99.2
312.3

$312 \cdot 3$
142.3

142.3
10.82

4.30

1.94

5.54
2.07

21.9

21.9
0.0

6.24
4.99

4.99
47.3

47.3
57.3

18.6

2.3

39.6
STANDARD

6.90

20.8
9710.0

9710.0
0.36

0.062

0.108

0.166

2790.0

19.9

1.1
1292.4

168.3

0.98

0.84

0.20

1.57

5.1

5.1
0.0
0.58

0.58
1.16

1.16
7.3

8.4
2.5

2.5
2.5

23.6

*Not significant at the 95 percent confidence level.

BEGRESSION SUMMARY

REGRESSION

SAMPLE COEFICIENT,

CONSTANT, CORRELATION COEEICIENI

STANDARD SIZE -

$\begin{array}{rrr}7.0 & 30.0 & \\ 20 & 120 & \\ 914 & 57600 & 40 \\ 6.2 & 7.8 & 40 \\ 0.06 & 0.29 & 12 \\ 0.25 & 0.53 & 12 \\ 0.30 & 0.88 & 11 \\ 25 & 8900 & 12 \\ 10 & 76 & \\ 97 & 100 & \\ 8 & 8000 & \\ 20 & 600 & \\ 8.6 & 12.0 & 12 \\ 3.3 & 6.2 & 11 \\ 1.5 & 2.2 & 11 \\ 3.3 & 7.7 & 11 \\ 1.6 & 2.6 & 11 \\ 15 & 32 & 12 \\ 0 & 0 & 6 \\ 5.3 & 7.2 & 12 \\ 3.2 & 7.9 & 12 \\ 36 & 60 & 11 \\ 45 & 66 & 12 \\ 15 & 24 & 11 \\ 0 & 7 & 11 \\ 10 & 85 & 12 \\ 0.1 & 0.5 & 12\end{array}$

$\begin{array}{lr}40 & -170.274 \\ 40 & -0.0014\end{array}$ $-0.0014$ $-0.00690$ 0.00704

196.385 6.8619 0.14401

0.89743

12166

$-12166.703$

$-0.362$

-0.078 *

$-0.069 *$

$-0.498 *$

$0.546 *$

0.064

0.098

0.164

2451.2

DAILY SPECIFIC CONDUCTANCE IN

CE IN MICROMHOS AT 25 DEG C, THAT WAS

EQUALLED OR EXCEEDED FOR THE

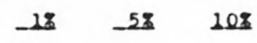

$208 \quad 30 \% \quad 508$

$105 \quad 92 \quad 87$

80

76

0.0819
0.0430
-0.0087
0.1570
0.0364
0.475
0.000
0.0411
0.0971
0.720
0.317
0.059
-0.197
-2.312
0.0024
5.1035
1.2973
2.5479
-5.4383
-0.4708
$-11.234$
0.000
3.3740
$-1.7781$
-3.047
35.159
35.159
14.537
16.037
200.859

0.0315

0.648

$0.415 *$
-0.362 *

0.814

0.757

0.727

0.000 *

0.554
0.652

0.652

0.795
0.291 *

0.193 *

$-0.641$

-0.760
0.155

SUMMARY OF HARMONIC ANALYSIS OF STREAM TEMPERATURE

\begin{tabular}{|c|c|c|c|c|c|}
\hline & & & & & STANDARD \\
\hline & HARMONIC & AMPLITUDE & PHASE & VARIATION & ERROR OF \\
\hline SAMPLE & MEAN - M & $-A$ & ANGLE - C & EXPLAINED & ESTIMATE \\
\hline SIZE_ & IDEG C & IDEG C & (RADIANSI) & -181 & (DEG $C)$ \\
\hline 365 & 18.05 & 10.50 & 2.70 & 95 & 1.71 \\
\hline
\end{tabular}

SUMMARY OF MAXIMUM AND MINIMUM CONCENTRATIONS OF CONSTITUENTS SAMPLED AT A FREQUENCY OF QUARTERLY (1975 WY)

02129000 - PEE DEE R NR ROCKINGHAM, NC

\begin{tabular}{|c|c|c|c|c|c|c|}
\hline \multirow{2}{*}{ CONSTI TUENT } & \multicolumn{3}{|c|}{ TOTAL } & \multicolumn{3}{|c|}{ DISSOLVED } \\
\hline & $\begin{array}{c}\text { NO. } \\
\text { SAMPLES }\end{array}$ & $\begin{array}{l}\text { MIN IMUM } \\
\text { CONC. }\end{array}$ & $\begin{array}{l}\text { MAXIMUM } \\
\text { CONC. }\end{array}$ & $\begin{array}{c}\text { NO. } \\
\text { SAMPLES }\end{array}$ & $\begin{array}{l}\text { MINIMUM } \\
\text { CONC. }\end{array}$ & $\begin{array}{l}\text { MAXIMUM } \\
\text { CONC. }\end{array}$ \\
\hline \multicolumn{7}{|l|}{ MINOR ELEMENTS: } \\
\hline ARSENIC (AS), UG/L & 6 & 1 & 7 & 6 & 0 & 1 \\
\hline CADM IUM $(C D), U G / L$ & 6 & 0 & 1 & 6 & 0 & 0 \\
\hline CHROMIUM (CR), UG/L & 6 & 0 & 25 & 6 & 0 & 1 \\
\hline COBALT $(C O), U G / L$ & 6 & 0 & 5 & 6 & 0 & 6 \\
\hline COPPER (CU), UG/L & 6 & 1 & 13 & 6 & 2 & 4 \\
\hline IRON (FE), UG/L & 6 & 720 & 3900 & 6 & 0 & 140 \\
\hline LEAD $(P B), U G / L$ & 6 & 4 & 8 & 6 & 0 & 7 \\
\hline MANG ANESE $(M N), U G / L$ & 6 & 94 & 370 & 6 & 0 & 140 \\
\hline MERC URY (HG), UG/L & 6 & 0.0 & 0.3 & 6 & 0.0 & 0.2 \\
\hline SELENIUM (SE), UG/L & 6 & 0 & 0 & 6 & 0 & 0 \\
\hline ZINC $(Z N), U G / L$ & 6 & 8 & 60 & 6 & 0 & 20 \\
\hline \multicolumn{7}{|l|}{ PERIPHYTON: } \\
\hline BIOMASS, DRY WT., G/SQ M & 1 & 27.00 & & & & \\
\hline BIOMASS, ASH WT., G/SO M & 1 & 24.00 & & & & \\
\hline CHLOROPHYLL A, MG/SO M & 1 & 8.0 & & & & \\
\hline CHLOROPHYLL B, MG/SQ M & 1 & 3.0 & & & & \\
\hline ORGANIC CARBON, MG/L & 7 & 4.0 & 15.0 & & & \\
\hline
\end{tabular}


LAT 34003M05S LONG 079045M15S

DRAINAGE AREA: 1030 SQ MI ( 2668 SQ KM)

PERIOD OF RECORD: $10 / 01 / 74-09 / 30 / 75$

STATISTICAL SUMMARY OF SELECTED DISSOLVED CHEMICAL CONSTITUENTS AND REGRESSION RELATIONSHIPS OF CONSTITUENT CONCENTRATIONS TO SPECIFIC CONDUCTANCE

CONSIIIUENI

CONSIIIUENI
TEMPERATURE, WATER (DEG C)
SPECIFIC CONDUCTANCE (MICROMHOS)
STREAMFLOW (CUBIC FT/SEC)
PH (STANDARD UNITS)
PHOSPHORUS, TOTAL
NITRITE, NITRATE, TOTAL
NITROGEN, KJELDAHL, TOTAL
PHYTOPLANKTON, TOTAL (CELLS/ML)
SEDIMENT, SUSPENDED
SEDIMENT, CLAY-SILT (PERCENT)
COLIFORM, FECAL (COL/IOO ML)
STREPTOCOCCI, FECAL (COL/IOO ML)
SILICA, DISSOLVED
CALCIUM, DISSOLVED
MAGNESIUM, DISSOLVED
SODIUM, DISSOLVED
POTASSIUM, DISSOLVED
BICARBONATE, ION
CARBONATE, ION
SULFATE, DISSOLVED
CHLORIDE, DISSOLVED
DISSOLVED SOLIDS, SUM OF CONST
DISSOLVED SOLIDS, ROE I8O DEG C
HARDNESS, TOTAL
HARDNESS, NONCARBONATE
TURBIDITY (JTU)
FLOURIDE, DISSOLVED

CONSIUUUENI MG/L OR UNII SHOHNL

SAMPLE

SIZE

MEAN REYIALLON
16.23

56.4

1301.0

6.68

0.040

0.188

0.351

223.0

10.5

10.5
100.0

100.0
339.6

339.6
180.0

6.68

3.26

1.08

6.39

1.24

14.2

0.0

5.03

6.98
38.1

38.1
47.8

12.6
2.7

2.7
5.0

5.0
0.17

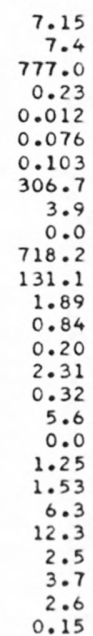

BANGE

5.0
50

*Not significant at the 95 percent confidence level.

DURAIION IABLE OF DALY SPECIEIC CONOUCIANCE DAILY SPECIFIC CONDUCTANCE IN MICROMHOS AT MICROMHOS AT 25 DEG C, THAT WAS EQUALLED OR EXCEEDED FOR THE
INDICATED PERCENTAGE OF TIME

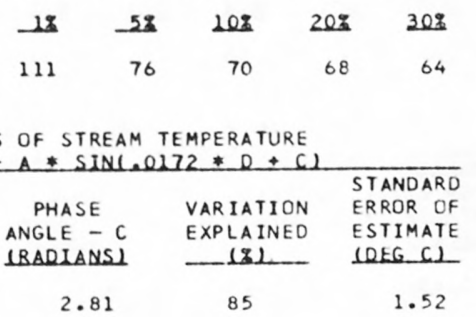

SUMMARY OF HARMONIC ANALYSIS OF STREAM TEMPERATURE

\begin{tabular}{|c|c|c|c|c|c|}
\hline & & & & & $\overline{\text { STANDARD }}$ \\
\hline & HARMONIC & AMPLITUDE & PHASE & VARIATION & ERROR OF \\
\hline $\begin{array}{l}\text { SAMPLE } \\
\text { SLZE. }\end{array}$ & $\begin{array}{l}\text { MEAN - M } \\
\text { (DEG C) }\end{array}$ & $\begin{array}{l}-A \\
\text { (DEG }\end{array}$ & $\begin{array}{l}\text { ANGLE - C } \\
\text { (RADIANS) }\end{array}$ & $\begin{array}{l}\text { EXPLA INED } \\
(\boldsymbol{X})\end{array}$ & $\begin{array}{l}\text { ESTIMATE } \\
\text { (DEG C) }\end{array}$ \\
\hline 124 & 17.83 & 7.79 & 2.81 & 85 & 1.52 \\
\hline
\end{tabular}

SUMMARY OF MAXIMUM AND MINIMUM CONCENTRATIONS OF CONSTITUENTS SAMPLED AT A FREQUENCY OF QUARTERLY (1975 WY)

02132000 -- LYNCHES RIVER AT EFFINGHAM S. C.

\begin{tabular}{|c|c|c|c|c|c|c|}
\hline \multirow{2}{*}{ CONSTITUENT } & \multicolumn{3}{|c|}{ TOTAL } & \multicolumn{3}{|c|}{ DISSOLVED } \\
\hline & $\begin{array}{l}\text { NO. } \\
\text { SAMPLES }\end{array}$ & $\begin{array}{l}\text { MINIMUM } \\
\text { CONC. }\end{array}$ & $\begin{array}{l}\text { MAXIMUM } \\
\text { CONC. }\end{array}$ & $\begin{array}{l}\text { NO. } \\
\text { SAMPLES }\end{array}$ & $\begin{array}{l}\text { MINIMUM } \\
\text { CONC. }\end{array}$ & $\begin{array}{l}\text { MAXIMUM } \\
\text { CONC. }\end{array}$ \\
\hline \multicolumn{7}{|l|}{ MINOR ELEMENTS: } \\
\hline ARSENIC (AS), UG/L & 4 & 0 & 1 & 4 & 0 & 1 \\
\hline CADMIUM $(C D), U G / L$ & 4 & 0 & 2 & 4 & 0 & 2 \\
\hline CHROMIUM (CR), UG $/ L$ & 4 & 1 & $<10$ & 4 & 0 & 1 \\
\hline COBALT $(C O), U G / L$ & 4 & 0 & 1 & 4 & 0 & 1 \\
\hline COPPER (CU), UG/L & 4 & 1 & 10 & 4 & 1 & 4 \\
\hline IRON (FE), UG/L & 4 & 500 & 1500 & 4 & 260 & 730 \\
\hline$L E A D(P B), U G / L$ & 4 & 3 & 19 & 4 & 0 & 7 \\
\hline MANG ANESE (MN), UG/L & 4 & 40 & 90 & 4 & 30 & 60 \\
\hline MERCURY (HG), UG/L & 3 & 0.1 & 0.2 & 4 & 0.0 & 0.1 \\
\hline SELENIUM (SE), UG/L & 3 & 0 & 1 & 4 & 0 & 1 \\
\hline ZINC $(Z N), U G / L$ & 4 & 8 & 40 & 4 & 3 & 20 \\
\hline \multicolumn{7}{|l|}{ PERIPHYTON: } \\
\hline BIOMASS, DRY WT., G/SQ & M & 9.09 & & & & \\
\hline BIOMASS, ASH WT., G/SQ & M & 6.50 & & & & \\
\hline CHLOROPHYLL A, MG/SQ M & 1 & 32.0 & & & & \\
\hline CHLOROPHYLL B, MG/SO M & 1 & 6.5 & & & & \\
\hline ORGANIC CARBON, MG/L & 4 & 6.7 & 9.1 & & & \\
\hline
\end{tabular}


Table 14.--Summary of measurements at each station--Continued

STATION NUMBER: 02136000 NAME: BLACK RIVER AT KINGSTREE S. C.

LAT 33D39M4OS LONG 079D5OMIOS

DRAINAGE AREA: 1260 SO MI ( 3263 SQ KM)

PERIOD OF RECORD: $10 / 01 / 74-09 / 30 / 75$

STATISTICAL SUMMARY OF SELECTED DISSOLVED CHEMICAL CONSTITUENTS AND

REGRESSION RELATIONSHIPS OF CONSTITUENT CONCENTRATIONS TO SPECIFIC CONDUCTANCE

CONSIIIUENI

CONSILUENI IMG $\angle L$ OR UNII SHOWNL

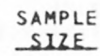

TEMPERATURE, WATER (DEG C) SPECIFIC CONDUC TANCE (MICROMHOS)

STREAMFLOW (CUBIC FT/SEC)

PH (STANDARD UNITS)

PHOSPHORUS, TOTAL

NITRITE + NITRATE, TOTAL

NITROGEN, KJELDAHL, TOTAL

PHYTOPLANKTON, TOTAL (CELLS/ML)

SEDIMENT, SUSPENDED

SEUIMENT, CLAY-SILT (PERCENT)

COL IFORM, FECAL (COL/1OO ML)

STREP TOCOCCI, FECAL (COL/100 ML)

SILICA, DISSOLVED

CALCIUM, DISSOLVED

MAGNESIUM, DISSOLVED

SODIUM, DISSOLVED

POTASSIUM, DISSOLVED

BICARBONATE, ION

CARBONATE, ION

SULFATE, DISSOLVED

CHLORIDE, DISSOLVED

DISSOLVED SOLIDS, SUM OF CONST

DISSOLVED SOLIDS, ROE I80 DEG

HARDNESS, TOTAL

HARDNESS, NONCARBONATE

TURBIDITY (JTU)

FLOURIDE, DISSOLVED
MEAN

STANDARD

DEYIALION

17.63

65.3

1239.1

6.63
0.104

0.104
0.077

0.077

0.592
258.4

6.6

100.0

107.3

259.3

259.3
6.96

6.96
3.76

1.09

7.42

1.68

15.2

0.0

6.55

8.46

43.7

61.3

13.9

2.8
2.9

0.21

6.22
19.2

19.2
1053.8

0.17

0.060

0.049

0.283

3.8

0.0

79.1

141.4

3.54
0.92

0.34

3.47

0.62

0.0

2.26

13.7

13.7

17.3

2.9

2.1

0.09

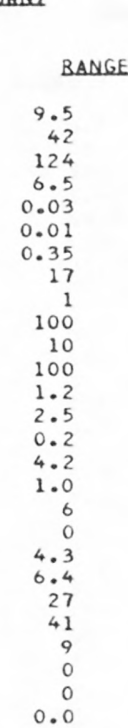

BEGRESS ION SUMMARY REGRESSION

SAMPLE COEFICIENT, CONSTANT, CORRELATION ERROR OF SIZE

$-1$ COEFICIENI ESILUAIE

25.5

110
$3010 \quad 12$

$7.0 \quad 12$

$0.21 \quad 12$

0.16

$1.40 \quad 12$

$1200 \quad 12$

100

280

370

$11.0 \quad 12$

$\begin{array}{ll}5.3 & 12 \\ 1.4 & 12\end{array}$

16.012

2.6

0
1.0

$\begin{array}{ll}11.0 & 12 \\ 11.0 & 12\end{array}$

74

100

$\begin{array}{ll}19 & 12 \\ 11 & 12\end{array}$

$\begin{array}{rr}7 & 12 \\ 0.3 & 12\end{array}$

$\begin{array}{rr}-35.768 & 3572.917 \\ 0.0066 & 6.2027 \\ 0.00217 & -0.03737 \\ 0.00073 & 0.02997 \\ -0.00164 & 0.69894 \\ 1.477 & 162.046\end{array}$

$-0.652$

0.736

0.692

0.287 *

$-0.111 *$
0.080 *

0.12

0.046

0.049

0.295
372.9

$$
\begin{array}{r}
0.1408 \\
0.0344 \\
-0.0005 \\
0.1786 \\
0.0284 \\
0.324 \\
0.000 \\
0.0787 \\
0.0724 \\
0.691 \\
0.821 \\
0.084 \\
-0.045 \\
0.030 \\
0.0007
\end{array}
$$

-2.2263
1.5161
1.1218
-4.2279
-0.1672
-5.990
0.000
1.4164
3.7318
-1.395
7.755
8.449
5.798
0.968
0.1621

0.764

0.720

-0.026 *

0.989

0.880

0.768

0.669
0.883

0.971

0.914

0.554 *

\begin{tabular}{|c|c|c|c|c|c|}
\hline & & & & & STANDARD \\
\hline & HARMONIC & AMPLITUDE & PHASE & VARIATION & ERROR OF \\
\hline SAMPLE & MEAN - $M$ & $-A$ & ANGLE - C & EXPLAINED & ESTIMATE \\
\hline SIZE_- & $10 E G \mathrm{CL}$ & $10 E 6(1)$ & (BADIANS) & $\ldots(2)$ & (NEG_C) \\
\hline 125 & 18.49 & 7.17 & 2.61 & 79 & 1.65 \\
\hline
\end{tabular}

-0.240 *

0.278 *

0.151 *

SAMPLE SIZE $\equiv 114$

\begin{tabular}{|c|c|c|c|c|c|c|}
\hline \multirow{2}{*}{ CONSTITUENT } & \multicolumn{3}{|c|}{ TOTAL } & \multicolumn{3}{|c|}{ DISSOLVED } \\
\hline & $\begin{array}{l}\text { NO. } \\
\text { SAMPLES }\end{array}$ & $\begin{array}{l}\text { MIN IMUM } \\
\text { CONC. }\end{array}$ & $\begin{array}{l}\text { MAXIMUM } \\
\text { CONC. }\end{array}$ & $\begin{array}{l}\text { NO. } \\
\text { SAMPLES }\end{array}$ & $\begin{array}{l}\text { MINIMUM } \\
\text { CONC. }\end{array}$ & $\begin{array}{l}\text { MAXIMUM } \\
\text { CONC. }\end{array}$ \\
\hline \multicolumn{7}{|l|}{ MINOR ELEMENTS: } \\
\hline ARSENIC (AS), UG/L & 4 & 0 & 1 & 4 & 0 & 0 \\
\hline CADMIUM $(C D), U G / L$ & 4 & 0 & 2 & 4 & 0 & 2 \\
\hline CHROMIUM (CR), UG $/ L$ & 4 & 1 & 10 & 4 & 0 & 1 \\
\hline COBALT $(C O), U G / L$ & 4 & 0 & 1 & 4 & 0 & 1 \\
\hline COPPER (CU), UG/L & 4 & 0 & 14 & 4 & 0 & 6 \\
\hline IRON $(F E), U G / L$ & 4 & 290 & 1400 & 4 & 200 & 610 \\
\hline LEAD $(P B), U G / L$ & 3 & 4 & 25 & 4 & 1 & 48 \\
\hline MANGANESE (MN), UG/L & 4 & 10 & 40 & 4 & 10 & 40 \\
\hline MERCURY $(H G)$, UG/L & 3 & 0.1 & 0.2 & 4 & 0.0 & 0.1 \\
\hline SELENIUM (SE), UG/L & 3 & 0 & 0 & 4 & 0 & 0 \\
\hline$Z I N C(Z N), U G / L$ & 4 & 10 & 80 & 4 & 0 & 10 \\
\hline \multicolumn{7}{|l|}{ PERIPHYTON: } \\
\hline BIOMASS, DRY WT., G/SO M & 0 & & & & & \\
\hline BIOMASS, ASH WT, G G/SO M & 0 & & & & & \\
\hline CHLOROPHYLL A, MG/SQ M & 0 & & & & & \\
\hline CHLOROPHYLL B, MG/SQ M & 0 & & & & & \\
\hline ORGANIC CARBON, MG/L & 4 & 2.7 & 19.0 & & & \\
\hline
\end{tabular}

DAILY SPECIFIC CONDUCTANCE IN

MICROMHOS AT 25 DEG C. THAT WAS

EQUALLED OR EXCEEDED FOR THE

$\begin{array}{lllllll}18 & 5 \% & 10 \% & 20 \% & 30 \% & 50 \%\end{array}$

503

702

$20 \% \quad 258 \quad 298$

54

SUMMARY OF HARMONIC ANALYSIS OF STREAM TEMPERATURE

SUMMARY OF MAXIMUM AND MINIMUM CONCENTRATIONS OF CONSTITUENTS SAMPLED AT A FREQUENCY OF QUARTERLY (1975 WY)

02136000 -- BLACK RIVER AT KINGSTREE S. C. 
LAT 33D23M15S LONG 080D08M25S

DRAINAGE AREA: 0 SQ MI 1

PERIOD OF RECORD: $10 / 01 / 74-09 / 30 / 75$

So $K M$ )

STATISTICAL SUMMARY OF SELECTED DISSOLVED CHEMICAL CONSTITUENTS AND REGRESSION RELATIONSHIPS OF CONSTITUENT CONCENTRATIONS TO SPECIFIC CONDUCTANCE

CONSIIIUENI

CONSIIIUENI
TEMPERATURE, WATER (DEG C)
SPECIFIC CONDUCTANCE (MICROMHOS)
STREAMFLOW (CUBIC FT/SEC)
PH (STANDARD UNITS)
PHOSPHORUS, TOTAL
NITRITE, NITRATE, TOTAL
NITROGEN, KJELDAHL, TOTAL
PHYTOPLANKTON, TOTAL (CELLS/ML)
SEDIMENT, SUSPENDED
SEDIMENT, CLAY-SILT (PERCENT)
COLIFORM, FECAL (COL/IOO ML)
STREPTOCOCCI, FECAL (COL/IOO ML)
SILICA, DISSOLVED
CALCIUM, DISSOLVED
MAGNESIUM, DISSOLVED
SODIUM, DISSOLVED
POTASSIUM, DISSOLVED
BICARBONATE, ION
CARBONATE, ION
SULFATE, DISSOLVED
CHLORIDE, DISSOLVED
DISSOLVED SOLIDS, SUM OF CONST
DISSOLVED SOLIDS, RUE I8O DEG C
HARDNESS, TOTAL
HARDNESS, NONCARBONATE
TURBIOITY (JTU)
FLOURIDE, DISSOLVED

CONSILIUENI IMGLL OR UNII SHOHNI

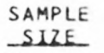

SAMPLE
SIZE

MEAN DEYIAILON
18.83

70.8

18758.3

7.21

0.030

0.302

8383.3

8383.3
11.8

11.8
100.0

100.0
2.3

2.3
60.3

9.54

4.91

1.71

6.51

22.5
0.0

6.53

5.84

48.0

52.1

19.3

1.9

8.0
7.44
10.5
5575.3
0.22

0.015

0.052

10024.3

$$
\begin{array}{r}
5.5 \\
0.0
\end{array}
$$

0.0

1.7
62.8

1.34

1.20

0.21

1.80
0.20

2.6

0.0

1.23
1.87

1.87

6.7
7.9

3.7

2.7
7.4
0.09

0.09
*Not significant at the 95 percent confidence level.

\section{BEGRESSION_SUMMABY}

REGRESSION

SAMPLE COEFICIENT.

\begin{tabular}{l} 
CONSTANT, CORRELATION \\
\hline
\end{tabular}

STANDARD ERROR OF ESIUMAIE

$\begin{array}{rrr}10.0 & 28.0 & \\ 57 & 85 & \\ 10900 & 28700 & 12 \\ 7.0 & 7.5 & 12 \\ 0.01 & 0.05 & 12 \\ 0.01 & 0.35 & 12 \\ 0.23 & 0.38 & 12 \\ 1200 & 31000 & 12 \\ 6 & 25 & \\ 100 & 100 & \\ 0 & 5 & \\ 4 & 128 & \\ 6.2 & 11.0 & 12 \\ 3.8 & 7.7 & 12 \\ 1.4 & 2.1 & 12 \\ 4.7 & 9.7 & 12 \\ 1.4 & 2.1 & 12 \\ 17 & 27 & 12 \\ 0 & 0 & 12 \\ 4.8 & 8.4 & 12 \\ 3.7 & 9.2 & 12 \\ 40 & 59 & 12 \\ 40 & 68 & 12 \\ 16 & 28 & 12 \\ 0 & 8 & 12 \\ 1 & 25 & 12 \\ 0.0 & 0.3 & 12\end{array}$

DURAILN IABLE_OF_DAILY_SPECIEIC CONOUCIANCE DAILY SPECIFIC CONDUCTANCE IN MICROMHOS AT 25 DEG C, THAT WAS
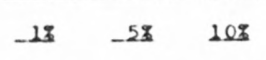

$\begin{array}{rrr}20 \pi & 308 & 503 \\ 87 & 83 & 70\end{array}$
EQUALLED OR EXCEEDED FOR THE INDICATED PERCENTAGE OF TIME

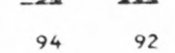

87

SUMMARY OF HARMONIC ANALYSIS OF STREAM TEMPERATURE

\begin{tabular}{|c|c|c|c|c|c|}
\hline & & & & & STANDARD \\
\hline & HARMONIC & AMPLITUDE & PHASE & VARIATION & ERROR OF \\
\hline SAMPLE & MEAN - M & $-A$ & ANGLE - C & EXPLAINED & ESTIMATE \\
\hline SIZE. & IDEG C) & WDEG (1) & (RADLANSI) & $-(8)$ & LEG_CL \\
\hline 349 & 19.51 & 9.83 & 2.80 & 96 & 1.44 \\
\hline
\end{tabular}

SUMMARY OF MAXIMUM AND MINIMUM CONCENTRATIONS OF CONSTITUENTS SAMPLED AT A FREQUENCY OF QUARTERLY (1975 WY)

02170500 -- LAKES M-M DIV CANAL NR PINEVILLE S. C.

\begin{tabular}{|c|c|c|c|c|c|c|}
\hline \multirow{2}{*}{ CONSTITUENT } & \multicolumn{3}{|c|}{ TOTAL } & \multicolumn{3}{|c|}{ DISSOLVED } \\
\hline & $\begin{array}{l}\text { NO. } \\
\text { SAMPLES }\end{array}$ & $\begin{array}{l}\text { MINIMUM } \\
\text { CONC. }\end{array}$ & $\begin{array}{l}\text { MAXIMUM } \\
\text { CONC. }\end{array}$ & $\begin{array}{l}\text { NO. } \\
\text { SAMPLES }\end{array}$ & $\begin{array}{l}\text { MINIMUM } \\
\text { CONC. }\end{array}$ & $\begin{array}{l}\text { MAXIMUM } \\
\text { CONC. }\end{array}$ \\
\hline \multicolumn{7}{|l|}{ MINOR ELEMENTS: } \\
\hline ARSENIC (AS), UG/L & 4 & 0 & 1 & 4 & 0 & 1 \\
\hline CADMIUM $(C D)$, UG/L & 4 & 0 & 0 & 4 & 0 & 0 \\
\hline CHROMIUM (CR), UG/L & 4 & 0 & 10 & 4 & 0 & 0 \\
\hline COBALT $(C O)$, UG/L & 4 & 0 & 1 & 4 & 0 & 0 \\
\hline COPPER (CU), UG/L & 4 & 0 & 9 & 4 & 0 & 4 \\
\hline IRON (FE), UG/L & 4 & 160 & 1000 & 4 & 10 & 170 \\
\hline LEAD $(P B), U G / L$ & 4 & 8 & 10 & 4 & 2 & 10 \\
\hline MANGANESE (MN), UG/L & 4 & 13 & 50 & 4 & 0 & 20 \\
\hline MERCURY $(H G), U G / L$ & 3 & 0.2 & 0.2 & 4 & 0.0 & 0.1 \\
\hline SELENIUM (SE), UG/L & 3 & 0 & 1 & 4 & 0 & 0 \\
\hline ZINC $(Z N), U G / L$ & 4 & 0 & 60 & 4 & 0 & 7 \\
\hline \multicolumn{7}{|l|}{ PERIPHYTON: } \\
\hline BIOMASS, DRY WT., G/SO M & 1 & 1.50 & & & & \\
\hline BIOMASS, ASH WT., G/SQ M & 2 & 1.19 & 1.50 & & & \\
\hline CHLOROPHYLL A, MG/SQ M & $i$ & 5.1 & & & & \\
\hline CHLOROPHYLL B, MG/SO M & 1 & .5 & & & & \\
\hline ORGANIC CARBON, MG/L & 4 & 2.0 & 15.0 & & & \\
\hline
\end{tabular}


LAT 33D27M15S LONG 080D09M25S DRAINAGE AREA: 14700 SQ MI 138073 SO KM

PERIOD OF RECORD: 10/01/74 - 09/30/75

STATISTICAL SUMMARY OF SELECTED DISSOLVED CHEMICAL CONSTITUENTS AND

REGRESSION RELATIONSHIPS OF CONSTITUENT CONCENTRATIONS TO SPECIFIC CONDUCTANCE

CONSIIIUENI

\section{CONSIUI \\ SAMPLE}

TEMPERATURE, WATER (DEG C) SPECIFIC CONDUCTANCE (MICROMHOS) STREAMFLOW (CUBIC FT/SEC)

PH (STANDARD UNITS)

PHOSPHORUS, TOTAL

NITRITE + NITRATE, TOTAL

NITROGEN, KJELDAHL, TOTAL

PHYTOPLANKTON, TOTAL (CELLS/ML)

SEDIMENT, SUSPENDED

SEDIMENT, CLAY-SILT IPERCENT)

COLIFORM, FECAL (COL/100 ML)

STREPTOCOCCI, FECAL (COL/100 ML)

SILICA, DISSOLVED

CALCIUM, DISSOLVED

MAGNESIUM, DISSOLVED

SOOIUM, DISSOLVED

POTAS SIUM, DISSOLVED

BICARBONATE, ION

CARGONATE, ION

SULFATE, DISSOLVED

CHLORIDE, DISSOLVED

DISSOLVED SOLIDS, SUM OF CONST

DISSOLVED SOLIDS, ROE 180 DEG C

HARDNESS, TOTAL

HARDNESS, NONCARBONATE

TURBIDITY (JTU)

FLOURIDE, DISSOLVED

*Not significant at the 95 percent confidence level.

SUMMARY OF HARMONIC ANALYSIS OF STREAM TEMPERATURE

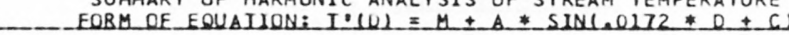

\section{SAMPLE MARMONIC \\ SIZF \\ (DEG C)}

20

19.65
PHASE

ANGLE - C

VARIATION

$-13)$

2.72

96

9.33

5.9

0.0
39.5

0.0

0.92
0.78

0.19

1.82

0.16
1.9

0.0

1.39
1.50

5.6

$8 \cdot 2$

1.4

8.1
BEGRESSION SUMMABY

REGRESSION STANDARD SAMPLE COEFICIENT, CONSTANT, CORRELATION ERROR OF SIZE -B B - B - COEEICIENI ESIUMAIE

\section{BANGE}

29.0

$\begin{array}{rr}11.0 & 29.0 \\ 52 & 90\end{array}$

$391 \quad 8010$

6.7

7.6
0.08

0.08
0.28

0.28
0.52

14000

0.20

1500

4
100

0

8.8

4.3

1.7

5.8

1.6
20

0

5.8
5.4

46
50

18

1
1
0.1

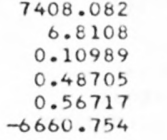

-0.302 *

0.129.

$-0.575$

$-0.503$

$-0.383$

0.363 *

$-6660.754$

0.0198
0.0607
0.0184
0.1393
0.0169
0.099
-0.0248
0.1122
0.381
-0.720
0.198
0.124
-0.797
-0.0124

8.1973
0.4078
0.3838
-4.0580
0.4698
13.489
9.0507
-2.4288
19.814
114.297
4.977
-6.757
68.810
1.1757

0.165 *

0.598 *

0.745 *

0.587

0.797 *

-0.137 .

0.575 *

0.527

$-0.676$

0.604 *

0.675 .

$-0.874$

-0.675 .

2444.4

0.25

0.014

0.080

0.071

4210.5

SUMMARY OF MAXIMUM AND MINIMUM CONCENTRATIONS OF CONSTITUENTS

SAMPLED AT A FREQUENCY OF OUARTERLY (1975 WY)

02171500 -- SANTEE RIVER NR. PINEVILLE S. C.

\begin{tabular}{|c|c|c|c|c|c|c|}
\hline \multirow{2}{*}{ CONSTITUENT } & \multicolumn{3}{|c|}{ TOTAL } & \multicolumn{3}{|c|}{ DISSOLVED } \\
\hline & $\begin{array}{l}\text { NO. } \\
\text { SAMPLES }\end{array}$ & $\begin{array}{l}\text { MIN IMUM } \\
\text { CONC. }\end{array}$ & $\begin{array}{l}\text { MAXIMUM } \\
\text { CONC. }\end{array}$ & $\begin{array}{l}\text { NO. } \\
\text { SAMPLES }\end{array}$ & $\begin{array}{l}\text { MINIMUM } \\
\text { CONC. }\end{array}$ & $\begin{array}{l}\text { MAXIMUM } \\
\text { CONC. }\end{array}$ \\
\hline \multicolumn{7}{|l|}{ MINOR ELEMENTS: } \\
\hline ARSENIC (AS), UG/L & 3 & 0 & 1 & 3 & 0 & 0 \\
\hline CAOMIUM $(C D), U G / L$ & 4 & 0 & 4 & 4 & 0 & 1 \\
\hline CHROMIUM (CR), UG $/ L$ & 4 & 0 & 20 & 4 & 0 & 0 \\
\hline COBALT $(C O), U G / L$ & 4 & 0 & 0 & 4 & 0 & 0 \\
\hline COPPER (CU), UG/L & 4 & 0 & 12 & 4 & 0 & 3 \\
\hline IRON (FE), UG/L & 4 & 190 & 920 & 4 & 10 & 180 \\
\hline LEAD $(P B), U G / L$ & 4 & 2 & 45 & 4 & 0 & 25 \\
\hline MANG ANESE $(M N), U G / L$ & 4 & 25 & 73 & 4 & 0 & 20 \\
\hline MERCURY (HG), UG $/ L$ & 3 & 0.2 & 0.3 & 3 & 0.0 & 0.1 \\
\hline SELENIUM (SE), UG/L & 3 & 0 & 0 & 3 & 0 & 0 \\
\hline ZINC $(Z N), U G / L$ & 4 & 0 & 100 & 4 & 0 & 10 \\
\hline \multicolumn{7}{|l|}{ PER I PHYTON : } \\
\hline BIOMASS, DRY WT., G/SO M & 3 & .29 & 13.00 & & & \\
\hline BIOMASS, ASH WT,, G/SQ M & 4 & .19 & 8.79 & & & \\
\hline CHLOROPHYLL A, MG/SQ M & 4 & .5 & 26.0 & & & \\
\hline CHLOROPHYLL $B, M G / S Q M$ & 4 & .0 & 12.0 & & & \\
\hline ORGANIC CARBON, MG/L & 4 & 3.5 & 13.0 & & & \\
\hline
\end{tabular}


Table 14.--Summary of measurements at each station--Continued

LAT 33001M4OS LONG 080D23M3OS DRAINAGE AREA: 2730 SO MI 1 7071 SQ KM) PERIOD OF RECORD: $10 / 01 / 74-09 / 30 / 75$

STATISTICAL SUMMARY OF SELECTED DISSOLVED CHEMICAL CONSTITUENTS AND REGRESSION RELATIONSHIPS OF CONSTITUENT CONCENTRATIONS TO SPECIFIC CONDUCTANCE

CONSILIUENI

TEMPERATURE, WATER (DEG C)

SPECIFIC CONDUCTANCE (MICROMHOS)

STREAMFLOW (CUBIC FT/SEC)

PH (STANDARD UNITS)

PHOSPHORUS, TOTAL

NITRITE + NITRATE, TOTAL

NITROGEN, KJELDAHL, TOTAL

SEDIMENT, SUSPENDED

SEDIMENT, CLAY-SILT (PERCENT)

COLIFORM, FECAL ( $C O L / 100 \mathrm{ML})$

STREPTOCOCCI, FECAL (COL/100 ML)

SILICA, DISSOLVED

CALCIUM, DISSOLVED

MAGNESIUM, DISSOLVED

SODIUM, DISSOLVED

POTASSIUM, DISSOLVED

BICARBONATE, ION

CARBONATE, ION

SULFATE, DISSOLVED

CHLOR IDE, DISSOLVED

DISSOLVED SOLIDS, SUM OF CONST

DISSOLVED SOLIDS, ROE 180 DEG

HARDNESS, TOTAL

HARDNESS, NONCARBONATE

TURBIDITY (JTU)

FLOURIDE, DISSOLVED
PHYTOPLANKTON, TOTAL (CELLS/ML)
CONSIUIUENI_IMG/L OR UNII_SHOHNU

SAMP

STANDARD

DEYIAIION

18.46

51.3

3044.8

3044.8
6.73

0.052

0.104

0.370
66.1

66.1
6.4

100.0

58.8

170.0

7.70

4.05

1.10

4.57
1.10

1.10
17.5

0.0

5.42

4.97
38.5

38.5
50.8

14.8

3.5

2.3
0.35

7.09
5.4
1579.5

0.16

0.020

0.046

0.141

73.2

3.7

0.0
47.9

28.3

1.33

0.24

0.35

0.45

0.34
10.0

0.0

1.82

0.49

7.4

1.0

2.9

0.44
*Not significant at the 95 percent confidence level.

9.5

9.5
44
964

6.5
0.02

0.02
0.04

0.04
0.01

4

100

1
150

150
6.5

6.5
3.8

0.8

4.2

0.9
10

0
3.8
4.5

4.5
34

34
43

14

1
0.1

SUMMARY OF HARMONIC ANALYSIS OF STREAM TEMPERATURE

\begin{tabular}{|c|c|c|c|c|c|}
\hline & & & & & STANDARD \\
\hline & HARMONIC & AMPLITUDE & PHASE & VARIATION & ERROR OF \\
\hline SAMPLE & MEAN - M & $-A$ & ANGLE - C & EXPLAINED & ESTIMATE \\
\hline SIZE_ & (DEG $(1)$ & DEE $\mathrm{Cl}$ & (RADIANS) & (8) & DEE $C)$ \\
\hline 12 & 18.69 & 9.03 & 2.80 & 91 & 2.42 \\
\hline
\end{tabular}

BEGRESSION SUMMABY REGRESSION SAMPLE COEFICIENT, CONSTANT, CORRELATION STANDARD COEEICIENI. ESIUMAIE

$\begin{array}{rr}29.5 & \\ 60 & \\ 5920 & 12 \\ 7.0 & 12 \\ 0.08 & 12 \\ 0.19 & 12 \\ 0.51 & 12 \\ 250 & 12 \\ 17 & \\ 100 & \\ 170 & \\ 190 & \\ 9.6 & 4 \\ 4.3 & 4 \\ 1.6 & 4 \\ 5.2 & 4 \\ 1.6 & 4 \\ 32 & 4 \\ 0 & 4 \\ 7.1 & 4 \\ 5.6 & 4 \\ 43 & 4 \\ 58 & 4 \\ 16 & 4 \\ 7 & 4 \\ 4 & 4 \\ 1.0 & 4\end{array}$

$0.400 *$

-0.122 *

$-0.367 *$

-0.374 *

$-0.374$

0.036
-0.090 .
$-0.479$

128.432

$-0.0325$

0.0358

0.0243

0.0241
1.071

1.071
0.000

0.0371

$-0.0393$

0.684

0.353

0.053

$-0.303$

0.115

0.0420
1518.7

0.16

0.020

0.045

0.114
76.5

SUMMARY OF MAXIMUM AND MINIMUM CONCENTRATIONS OF CONSTITUENTS SAMPLED AT A FREQUENCY OF QUARTERLY (1975 WY)

02175000 -- EDISTO RIVER NR GIVHANS S.C.

\begin{tabular}{|c|c|c|c|c|c|c|}
\hline \multirow{2}{*}{ CONSTI TUENT } & \multicolumn{3}{|c|}{ TOTAL } & \multicolumn{3}{|c|}{ DISSOLVED } \\
\hline & $\begin{array}{l}\text { NO. } \\
\text { SAMPLES }\end{array}$ & $\begin{array}{l}\text { MINIMUM } \\
\text { CONC. }\end{array}$ & $\begin{array}{l}\text { MAXIMUM } \\
\text { CONC. }\end{array}$ & $\begin{array}{l}\text { NO. } \\
\text { SAMPLES }\end{array}$ & $\begin{array}{l}\text { MINIMUM } \\
\text { CONC. }\end{array}$ & $\begin{array}{l}\text { MAXIMUM } \\
\text { CONC. }\end{array}$ \\
\hline \multicolumn{7}{|l|}{ MINOR ELEMENTS: } \\
\hline ARSENIC (AS), UG/L & 4 & 0 & 2 & 4 & 0 & 0 \\
\hline CADMIUM $(C D), U G / L$ & 4 & 0 & 2 & 4 & 0 & 2 \\
\hline CHROMIUM (CR), UG/L & 4 & 1 & $<10$ & 4 & 0 & 2 \\
\hline COBALT $(C O), U G / L$ & 4 & 0 & 1 & 4 & 0 & 0 \\
\hline COPPER (CU), UG/L & 4 & 0 & 11 & 4 & 0 & 3 \\
\hline IRON (FE), UG/L & 4 & 410 & 1100 & 4 & 160 & 580 \\
\hline LEAD $(P B), U G / L$ & 4 & 0 & 68 & 4 & 0 & 68 \\
\hline MANG ANESE (MN), UG/L & 4 & 0 & 50 & 4 & 0 & 30 \\
\hline MERCURY (HG), UG/L & 3 & 0.0 & 0.2 & 4 & 0.0 & 0.1 \\
\hline SELENIUM (SE), UG/L & 3 & 0 & 3 & 4 & 0 & 0 \\
\hline ZINC $(Z N), U G / L$ & 4 & 4 & 20 & 3 & 1 & 10 \\
\hline \multicolumn{7}{|l|}{ PERIPHYTON: } \\
\hline BIOMASS, DRY WT., G/SQ M & 1 & 1.89 & & & & \\
\hline BIOMASS, ASH WT., G/SO M & 1 & 1.50 & & & & \\
\hline CHLOROPHYLL A, MG/SO M & 1 & .3 & & & & \\
\hline CHLOROPHYLL $B, H G / S O M$ & 1 & $\cdot 1$ & & & & \\
\hline ORGANIC CARBON, MG/L & 4 & 8.1 & 19.0 & & & \\
\hline
\end{tabular}


LAT 32D5OMIOS LONG $081007 M 55 S$

$\begin{array}{lll}\text { DRAINAGE AREA: } & 203 \mathrm{SQMI} \text { MI } & 526 \text { SO KM) } \\ \text { PERIOD OF RECORD: } & 10 / 01 / 74-09 / 30 / 75\end{array}$

STATISTICAL SUMMARY OF SELECTED DISSOLVED CHEMICAL CONSTITUENTS AND

REGRESSION RELATIONSHIPS OF CONSTITUENT CONCENTRATIONS TO SPECIFIC CONDUCTANCE

BEGBESSION SUMMABY

REGRESSION SAMPLE COEFICIENT, CONSTANT, CORRELATION \begin{tabular}{l} 
SAMPLE COEFICIENT, CONSTANT, CORRELATION ERROR OF \\
SIZE \\
\hline
\end{tabular}

TEMPERATURE, WATER (DEG C) SPECIFIC CONDUCTANCE (MICROMHOS STREAMFLOW (CUBIC FT/SEC) PH (STANDARD UNITS)

PHOSPHORUS, TOTAL TITAL

NITROGEN, KJELDAHL, TOTAL

PHYTOPLANKTON, TOTAL (CELLS/ML)

SEDIMENT, SUSPENDED

SEDIMENT, CLAY-SILT IPERCENT

COLIFORM, FECAL (COL/100 ML)

STREP YOCOCCI, FECAL ICOL/100 ML)

SIL ICA, DISSOLVED

CALCIUM, DISSOLVED

MAGNESIUM, DISSOLVEO

SODIUM, DISSOLVED

POTASSIUM, DISSOLVEO

BICARBONATE, ION

CARBONATE, ION

SULFATE, DISSOLVED

CHLORIDE, DISSOLVED

DISSOLVED SOLIDS, SUM OF CONST

DISSOLVED SOLIDS, RCE 180 DEG C

HARDNESS, TOTAL

HARDNESS, NONCARBONATE

TURBIDITY (JTU)

FLOUR IDE, DISSOLVED

CONSIIIUENI

\begin{tabular}{r} 
CONSI \\
SAMP \\
SIZ \\
\hline 12 \\
12 \\
12 \\
12 \\
12 \\
12 \\
12 \\
12 \\
10 \\
10 \\
12 \\
3 \\
12 \\
12 \\
12 \\
12 \\
12 \\
12 \\
12 \\
12 \\
12 \\
12 \\
12 \\
12 \\
12 \\
12 \\
12 \\
12
\end{tabular}

STANDARD

15.92

69.3

495.6

6.60

0.083

0.081

0.565

222.1

100.0

100.0

182.3
391.0

391.0
8.26

8.02

1.47

3.96

1.31

19.8

19.8
0.0

7.68

7.27

48.1

67.1

26.0
10.2

3.6
0.25

6.74
29.1
543.6
0.18
0.033
0.065
0.127
244.6
3.5
0.0
266.1
176.8
3.45
3.98
0.61
1.23
0.47
10.1
0.0
8.74
1.89
18.7
21.4
12.1
12.6
1.3
0.19

MEAN REYLALION

BANGE

*Not significant at the 95 percent confidence level.

5.0
40
11
6.3
0.04
0.00
0.33
29
1
100
37
220
2.7
4.5
0.6
2.1
0.8
9
0
3.6
4.8
31
47
16
0
1
0.0

24.0

142

$1860 \quad 12$

$7.0 \quad 12$

$0.14 \quad 12$

$0.79 \quad 12$

$920 \quad 12$

-10.826
-0.0000

$-0.00038$

$-0.00150$

$-3.010$

6.5993

0.10962

0.18455

0.75261

430.742

$-0.579$

0.002 *

$-0.669$

$-0.621$

-0.358 .

2.2053

$-1.0259$

0.1163

0.2978

12.156

$-8.5414$

-8.5414
3.4268

4.276

26.283

$-1.92$

$-11.267$

3.810

0.3283

$-0.003$

$-0.0011$
464.9

0.18

0.033

0.104

239.6

DURAIJON IABLE OF DALLY SPECIEIC CONDUCIANGE

DAILY SPECIFIC CONDUCTANCE IN

MICROMHOS AT 25 DEG C, THAT WAS

EQUALLED OR EXCEEDED FOR THE

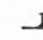

19.5

$20 z$

$303 \quad 502$

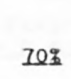

SAMPLE SIZE $=116$

142

81

79

70

66

61

56

$20 \% \quad 258 \quad 998$

$44 \quad 42$

39

SUMMARY OF HARMONIC ANALYSIS OF STREAM TEMPERATURE

\begin{tabular}{|c|c|c|c|c|c|}
\hline & & & & & STANDARD \\
\hline & HARMONIC & AMPLITUDE & PHASE & VARIATION & ERROR OF \\
\hline SAMPLE & $M E A N-M$ & $-A$ & ANGLE - C & EXPLAINED & ESTIMATE \\
\hline SIZE - & WEECL & $-(D E G(C)$ & (BADLANS) & $-(8)$ & $10 E G(C)$ \\
\hline 118 & 17.46 & 7.02 & 2.74 & 78 & 1.75 \\
\hline
\end{tabular}

SUMMARY OF MAXIMUM AND MINIMUM CONCENTRATIONS OF CONSTITUENTS

SAMPLED AT A FREQUENCY OF QUARTERLY (1975 WY)

02176500 -- COOSAWHATCHIE RIVER NR HAMPTON S.C.

\begin{tabular}{l} 
CONSTITUENT \\
\cline { 2 - 3 }
\end{tabular}


Table 14.--Summary of measurements at each station--Continued

STATION NUMBER: 02198500 NAME: SAVANNAH RIVER NR CLYO GA.

LAT 32D31M3OS LONG $081015 M 45 S$

DRAINAGE AREA: 9850 SQ MI 125512 SQ KMI

DRAINAGE AREA: 9850 PQR OF RECORD: $10 / 01 / 74-09 / 30 / 75$

STATISTICAL SUMMARY OF SELECTED DISSOLVED CHEMICAL CONSTITUENTS AND

REGRESSION RELATIONSHIPS OF CONSTITUENT CONCENTRATIONS TO SPECIFIC CONDUCTANCE

CONSIITUENI

CONSIUTUENI IMG/L OR UNII SHOHNU

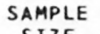

SIZE

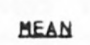

STANDARD

DEYIAIION

TEMPERATURE, WATER (DEG C) SPECIFIC CONDUCTANCE (MICROMHOS) STREAMFLOW (CUBIC FT/SEC)

PH (STANDARD UNITS)

PHOSPHORUS, TOTAL

NITRITE + NITRATE, TOTAL

NITROGEN, KJELDAHL, TOTAL

PHYTOPLANKTON, TOTAL (CELLS/ML)

SEDIMENT, SUSPENDED

SEDIMENT, CLAY-SILT (PERCENT)

COLIFORM, FECAL (COL/100 ML)

STREPTOCOCCI, FECAL (COL/100 ML)

SILICA, DISSOLVED

CALCIUM, DISSOLVED

MAGNE SIUM, DISSOLVED

SODIUM, DISSOLVED

POTASSIUM, DISSOLVED

BICAR BONATE, ION

CARBONATE, ION

SULFATE, DISSOLVED

CHLORIDE, DISSOLVED

DISSOLVED SOLIDS, SUM OF CONSI

DISSOLVED SOLIDS, ROE 180 DEG C

HARDNESS, TOTAL

HARDNESS, NONCARBONATE

TURBIDITY (JTU)

FLOURIDE, DISSOLVED

*Not significant at the 95 percent confidence level.

DURAIION IABLE OF DAILY SPECIEIC CONOUCIANCE

DAILY SPECIFIC CONDUCTANCE IN

EQUALLED OR EXCEEDED FOR THE

INDICATED PERCENTAGE OF TIME

6.41
6.7

6.7
8604.5

8604.5
0.21

0.21
0.032

0.094

0.075

253.9

19.7

0.0

79.1

21.9
1.79

1.79
0.88

0.13

0.92

0.10

3.5
0.0

0.48

0.84

5.3

5.4

2.3
0.5

7.7

0.19
BANGE

9.0
52
7500

7500
6.7

6.7
0.03

0.08

0.21

8

100

43
49

49
6.2

4.0
1.1

1.1
4.5

4.5
1.3
22

4.2

3.7
37

44

14
0

7
0.2
15.8
BE REGRESSION

SAMPLE

OEFICIENT,

CONSTANT,

27.0
71

$39200 \quad 16$

1066.375

0.0140
0.00215

0.00215

$-0.00731$

-0.00731
-15.787

6.1470

$-0.05505$

$-0.24254$

284.186

0.453

0.447

0.542

$-0.588$

$880 \quad 12$

81
100

320

80
10.0
6.1

6.1
1.4

1.4
6.6

1.5

30
0

5.3

5.6

48
57

21
1
25

25
0.6

$\begin{array}{rrrrrrr}18 & -58 & 108 & 208 & 308 & 508 & 708 \\ 76 & 73 & 71 & 70 & 68 & 65 & 58\end{array}$

SAMPLE SIZE $=365$
$20 \%$ 25\% $29 \%$

SUMMARY OF HARMONIC ANALYSIS OF STREAM TEMPERATURE FORY OF EOUAION* ION =

\begin{tabular}{|c|c|c|c|c|c|}
\hline & & & & & STANDARD \\
\hline & HARMONIC & AMPLITUDE & PHASE & VARIATION & ERROR OF \\
\hline SAMPLE & MEAN - M & $-A$ & ANGLE - C & EXPLAINED & ESTIMATE \\
\hline SIZE_ & DEE $C 1$ & (DEG () & (BADLANS) & $(x)$ & LEG_C) \\
\hline 336 & 16.82 & 7.43 & 2.71 & 91 & 1.58 \\
\hline
\end{tabular}

SUMMARY OF MAXIMUM AND MINIMUM CONCENTRATIONS OF CONSTITUENTS SAMPLED AT A FREQUENCY OF QUARTERLY (1975 WY)

02198500 -- SAVANNAH RIVER NR CLYO GA.

\begin{tabular}{|c|c|c|c|c|c|c|}
\hline \multirow{2}{*}{ CONSTI TUENT } & \multicolumn{3}{|c|}{ TOTAL } & \multicolumn{3}{|c|}{ DISSOLVED } \\
\hline & $\begin{array}{l}\text { NO. } \\
\text { SAMPLES }\end{array}$ & $\begin{array}{l}\text { MIN IMUM } \\
\text { CONC. }\end{array}$ & $\begin{array}{l}\text { MAXIMUM } \\
\text { CONC. }\end{array}$ & $\begin{array}{l}\text { NO. } \\
\text { SAMPLES }\end{array}$ & $\begin{array}{l}\text { MINIMUM } \\
\text { CONC. }\end{array}$ & $\begin{array}{l}\text { MAXIMUM } \\
\text { CONC. }\end{array}$ \\
\hline \multicolumn{7}{|l|}{ MINOR ELEMENTS: } \\
\hline ARSENIC (AS), UG/L & 4 & 0 & 1 & 4 & 0 & 1 \\
\hline CAOMIUM $(C D), U G / L$ & 4 & 0 & 1 & 4 & 0 & 0 \\
\hline CHROMIUM (CR), UG/L & 4 & 5 & $<10$ & 4 & 0 & 5 \\
\hline COBALT $(C O), U G / L$ & 4 & 0 & 1 & 4 & 0 & 1 \\
\hline COPPER (CU), UGIL & 4 & 0 & 5 & 4 & 0 & 4 \\
\hline IRON (FE), UG/L & 4 & 700 & 2000 & 4 & 110 & 400 \\
\hline LEAD $(P B), U G / L$ & 4 & 0 & 20 & 4 & 0 & 32 \\
\hline MANGANESE (MN), UG/L & 4 & 40 & 100 & 4 & 20 & 30 \\
\hline MERCURY (HG), UG/L & 3 & 0.1 & 0.2 & 4 & 0.0 & 0.1 \\
\hline SELENIUM $(S E), U G / L$ & 4 & 0 & 0 & 4 & 0 & 0 \\
\hline ZINC $(Z N), U G / L$ & 4 & 0 & 30 & 4 & 0 & 10 \\
\hline \multicolumn{7}{|l|}{ PER IPHYTON : } \\
\hline BIOMASS, DRY WT., G/SQ M & 1 & .89 & & & & \\
\hline BIOMASS, ASH WT., G/SO M & 3 & .50 & 23.00 & & & \\
\hline CHLOROPHYLL A, MG/SO M & 2 & 4.2 & 6.0 & & & \\
\hline CHLOROPHYLL B, MG/SO M & 2 & .5 & 1.3 & & & \\
\hline ORGANIC CARBON, MG/L & 8 & 3.7 & 11.0 & & & \\
\hline
\end{tabular}


Table 14.--Summary of measurements at each station--Continued

LAT 32D11M29S LONG $081024 M 58 \mathrm{~S}$

DRAINAGE AREA: $\begin{gathered}2650 \mathrm{SQ} M I \\ 10 / 01 / 74-09 / 30 / 75\end{gathered}$

STATISTICAL SUMMARY OF SELECTED DISSOLVED CHEMICAL CONSTITUENTS AND

REGRESSION RELATIONSHIPS OF CONSTITUENT CONCENTRATIONS TO SPECIFIC CONDUCTANCE

CONSIUTUENI

CONSIUUENT MG/L OR UNIT SHOHNL

SAMPLE

SIZE MEAN

STANDARD

SEYIALUN

18.26
53.7
3538.5
6.93
0.039
0.074
0.484
164.
13.9

TEMPERATURE, WATER (DEG C) SPECIFIC CONDUCTANCE (MICROMHOS) STREAMFLOW (CUBIC FT/SEC)

PH (STANDARD UNITS)

PHOSPHORUS, TOTAL

NITRITE + NITRATE, TOTAL

NITROGEN, KJELDAHL, TOTAL

PHYTOPLANKTON, TOTAL (CELLSIML)

SEDIMENT, SUSPENDED

SEDIMENT, CLAY-SILT (PERCENT)

COL IFORM, FECAL (COL/100 ML)

STREPTOCOCCI, FECAL (COL/100 ML)

SILICA, DISSOLVED

CALCIUM, DISSOLVED

MAGNESIUM, DISSOL VED

SODIUM, DISSOLVED

POTASSIUM, DISSOLVED

BICARBONATE, ION

CARBONATE, ION

SULFATE, DISSOLVED

CHLOR IDE, DISSOLVED

DISSOLVED SOLIDS, SUM OF CONST

DISSOLVED SOLIDS, ROE 180 DEG C

HARDNESS, TOTAL

HARDNESS, NONCARBONATE

TURBIDITY (JTU)

FLCUR IDE, DISSOLVED

$\begin{array}{rrr}17 & 18.26 & 6.65 \\ 11 & 53.7 & 19.5 \\ 22 & 3538.5 & 3610.8 \\ 9 & 6.93 & 1.22 \\ 10 & 0.039 & 0.015 \\ 10 & 0.074 & 0.080 \\ 10 & 0.484 & 0.328 \\ 11 & 164.8 & 377.8 \\ 18 & 13.9 & 13.6 \\ 0 & & \\ 8 & 95.3 & 191.0 \\ 9 & 261.7 & 260.9 \\ 8 & 10.96 & 1.97 \\ 8 & 6.82 & 2.20 \\ 8 & 1.00 & 0.22 \\ 8 & 3.89 & 0.73 \\ 8 & 0.99 & 0.11 \\ 8 & 23.0 & 10.7 \\ 4 & 0.0 & 0.0 \\ 8 & 4.71 & 0.97 \\ 8 & 5.19 & 1.01 \\ 8 & 45.3 & 9.2 \\ 8 & 55.5 & 19.4 \\ 8 & 21.3 & 6.0 \\ 8 & 2.9 & 2.8 \\ 8 & 6.4 & 2.8 \\ 8 & 0.25 & 0.12\end{array}$

REGRESSION COEFICIENT,

EGRESS LON SUMYABY

7.5
27
402
5.6
0.01
0.00
0.22
7

28.0
83
1600
8.9
0.06
0.23
1.30
1300

$11 \quad-93.508$

0.0032

0.00022

0.00320

0.00236

1300
50

$-5.543$

566
900

900
13.0

10.0

1.3

5.0

1.2
36

0.3

7.3

58

86
30
8

8
10

0.5
CONSTANT, CORRELATION

COEEICIENI ESIUMAIE

SUMMARY OF HARMONIC ANALYSIS OF STREAM TEMPERATURE

\begin{tabular}{|c|c|c|c|c|c|}
\hline & & & & & STANDARD \\
\hline $\begin{array}{l}\text { SAMPLE } \\
\text { SUZE_- }\end{array}$ & $\begin{array}{l}\text { HARMONIC } \\
\text { MEAN - M } \\
\text { IDEG C) }\end{array}$ & $\begin{array}{c}\text { AMPLI TUDE } \\
-A \\
(D E G C)\end{array}$ & $\begin{array}{c}\text { PHASE } \\
\text { ANGLE - C } \\
\text { (BADLANS) }\end{array}$ & $\begin{array}{l}\text { VARIATION } \\
\text { EXPLAINED } \\
\text { (I) }\end{array}$ & $\begin{array}{l}\text { ERROR OF } \\
\text { ESTIMATE } \\
\text { LDEG CI }\end{array}$ \\
\hline
\end{tabular}

17

17.17

9.10

2.79

95

1.55

SUMMARY OF MAXIMUM AND MINIMUM CONCENTRATIONS OF CONSTITUENTS SAMPLED AT A FREQUENCY OF QUARTERLY (1975 WY)

02202500 -- OGEECHEE RIVER NEAR EDEN, GA.

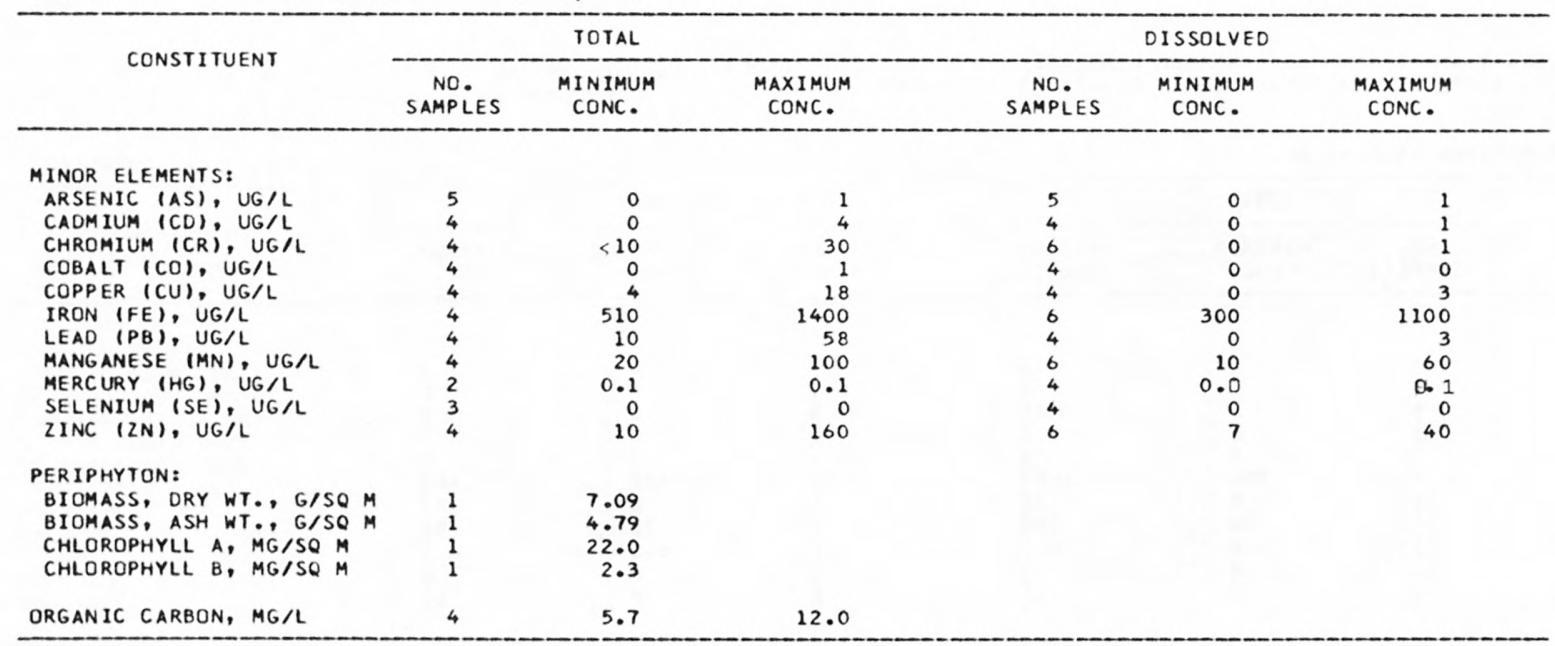


LAT $31039 M 16 S$ LONG $081049 M 41 S$

DRAINAGE AREA: 13600 SO MI 135224 SQ KMI

PERIOD OF RECORD: $10 / 01 / 74$ - 09/30/75

STATISTICAL SUMMARY OF SELECTED DISSOLVED CHEMICAL CONSTITUENTS AND

REGRESSION RELATIONSHIPS OF CONSTITUENT CONCENTRATIONS TO SPECIFIC CONDUCTANCE

CONSIIUENI

CONSIUIUENT (MG/L_OR UNII SHOKN)

SAMPLE

SAMPLE STANDARD

12

\section{MEAN DEYIAIION}

TEMPERATURE, WATER (DEG C) SPECIFIC CONDUCTANCE (MICROMHOS) STREAMFLOW (CUBIC FT/SECI

PH (STANDARD UNITS)

PHOSPHORUS, TOTAL

NITRITE + NITRATE, TOTAL

NITROGEN, KJELDAHL, TOTAL

PHYTOPLANKTON, TOTAL (CELLS/ML)

SEDIMENT, SUSPENDED

SEDIMENT, CLAY-SILT (PERCENT)

COLIFORM, FECAL (COL/100 ML)

STREPTOCOCCI, FECAL (COL/100 ML)

SILICA, DISSOLVED

CALCIUM, DISSOLVED

MAGNESIUM, DISSOLVED

SODIUM, DISSOLVED

POTASSIUM, DISSOLVED

BICARBONATE, ION

CARBONATE, ION

SULFATE, DISSOLVED

CHLORIDE, DISSOLVED

DISSOLVED SOLIDS, SUM OF CONST

DISSOLVED SOLIDS, ROE 180 DEG HARDNESS, TOTAL

HARONESS, NONCARBONATE

TURBIDITY (JTU)

FLOURIDE, DISSOLVED

$\begin{array}{rr}18.11 & 6.31 \\ 66.4 & 15.8 \\ 9298.0 & 27313.0 \\ 6.88 & 1.16 \\ 0.063 & 0.020 \\ 0.211 & 0.094 \\ 0.393 & 0.310 \\ 241.8 & 182.7 \\ 77.5 & 118.5 \\ & \\ 123.4 & 111.0 \\ 228.0 & 153.8 \\ 11.47 & 1.62 \\ 6.54 & 2.40 \\ 1.30 & 0.32 \\ 6.74 & 2.41 \\ 1.75 & 0.39 \\ 26.5 & 11.2 \\ 0.0 & 0.0 \\ 7.31 & 2.08 \\ 5.72 & 1.70 \\ 54.3 & 14.5 \\ 66.8 & 16.8 \\ 21.9 & 6.7 \\ 1.4 & 1.7 \\ 20.0 & 6.0 \\ 0.22 & 0.10\end{array}$

$0.22 \quad 0.10$ REGRESSION

BEGRESSION SUMMABY

COEFICIENT, CONSTANT,

CORRELATION SAMPLE
SIZE C B COEEICIENI

STANDARD ERROR OF ESIUMAIE

\section{5}

$42 \quad 89$

$\begin{array}{rrr}3110 & 103000 & 11 \\ 5.5 & 8.7 & 9\end{array}$

0.04

0.04

0.07
0.03

0.03
16

16

0.11

0.11
0.36

$0.36 \quad 10$

1.20
470

470
512

11
9
10
10
10
11

-980.325
0.0276
0.00031
0.00490
-0.00330
-0.011

87722.438 5.0402 0.04210

$-0.12297$

-0.12297
0.61791

242.567

$-0.799$

0.415

0.803

$-0.164$

$-0.164$

12316.2

1.13

0.021
0.059
0.324

192.6

\section{6 \\ 330}

100

9.3

4.3

590
14.0

11.0

1.8

1.8
11.0

4.8
1.3
14

0

4.6
4.0

39

44

16

10

0.1

46
0

10.0
9.0

80
92

34
4

30

*Not significant at the 95 percent confidence level.

SUMMARY OF HARMONIC ANALYSIS OF STREAM TEMPERATURE

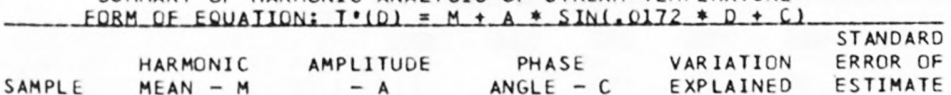

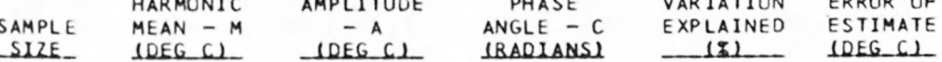

$\begin{array}{llllll}15 & 18.15 & 8.37 & 2.75 & 93 & 1.79\end{array}$

SUMMARY OF MAXIMUM AND MINIMUM CONCENTRATIONS OF CONSTITUENTS SAMPLED AT A FREQUENCY OF QUARTERLY (1975 WY)

02220000 -- ALTAMAHA RIVER AT DOCTORTOWN, GA.

\begin{tabular}{|c|c|c|c|c|c|c|}
\hline \multirow{2}{*}{ CONSTITUENT } & \multicolumn{3}{|c|}{ TOTAL } & \multicolumn{3}{|c|}{ DISSOLVED } \\
\hline & $\begin{array}{l}\text { NO. } \\
\text { SAMPLES }\end{array}$ & $\begin{array}{l}\text { MINIMUM } \\
\text { CONC. }\end{array}$ & $\begin{array}{l}\text { MAXIMUM } \\
\text { CONC. }\end{array}$ & $\begin{array}{l}\text { NO. } \\
\text { SAMPLES }\end{array}$ & $\begin{array}{l}\text { MINIMUM } \\
\text { CONC. }\end{array}$ & $\begin{array}{l}\text { MAXIMUM } \\
\text { CONC. }\end{array}$ \\
\hline \multicolumn{7}{|l|}{ MINOR ELEMENTS: } \\
\hline ARSENIC (AS), UG/L & 5 & 0 & 1 & 5 & 0 & 1 \\
\hline CADMIUM $(C D), U G / L$ & 4 & 1 & 2 & 4 & 0 & 1 \\
\hline CHROMIUM (CR), UG/L & 4 & $<10$ & 30 & 6 & 0 & 1 \\
\hline COBALT $(C O), U G / L$ & 4 & 0 & 3 & 4 & 0 & 3 \\
\hline COPPER (CU), UG/L & 4 & 6 & 18 & 4 & 1 & 5 \\
\hline IRON $(F E), U G / L$ & 4 & 680 & 1700 & 6 & 170 & 770 \\
\hline LEAD $(P B), U G / L$ & 4 & 9 & 38 & 4 & 1 & 6 \\
\hline MANGANESE (MN), UG/L & 4 & 40 & 110 & 6 & 19 & 40 \\
\hline MERCURY $(H G), U G / L$ & 2 & 0.1 & 0.1 & 4 & 0.0 & 0.1 \\
\hline SELENIUM (SE), UG/L & 3 & 0 & 0 & 4 & 0 & 0 \\
\hline$Z I N C(Z N), U G / L$ & 4 & 30 & 70 & 6 & 0 & 40 \\
\hline \multicolumn{7}{|l|}{ PERIPHYTON: } \\
\hline BIOMASS, DRY WT., G/SQ M & 2 & .09 & 8.09 & & & \\
\hline BIOMASS, ASH WT., G/SO M & 3 & .09 & 4.19 & & & \\
\hline CHLOROPHYLL A, MG/SO M & 3 & .1 & 3.7 & & & \\
\hline CHLOROPHYLL B, MG/SQ M & 3 & .0 & .5 & & & \\
\hline ORGANIC CARBON, MG/L & 4 & 3.5 & 23.0 & & & \\
\hline
\end{tabular}


LAT 31D13M16S LONG $081052 M 03 S$ DRAINAGE AREA: 2790 SQ MI ( 7226 SO KM)

PERIOD OF RECORD: $10 / 01 / 74-09 / 30 / 75$

STATISTICAL SUMMARY OF SELECTED DISSOLVED CHEMICAL CONSTITUENTS AND

REGRESSION RELATIONSHIPS OF CONSTITUENT CONCENTRATIONS TO SPECIFIC CONDUCTANCE

CONSIUIUENI

CONS

CONSTITUENI IMG/L OR UNII SHOWN

STANDARD
SIZE MEAN DEVIAIION

19.25

44.9

2614.4

6.04

0.699
520.6

520.6
26.1
0.072

0.105

6.69
8.8
3596.9
1.49
0.046
0.096
0.274
806.9
31.0
204.5
495.7
2.08
1.22
0.29
1.63
0.33
3.6
0.0
0.80
1.88
8.7
11.0
4.4
3.8
1.3
0.08

6.69
8.8
596.9
1.49
0.046
0.096
0.274
806.9
31.0
204.5
495.7
2.08
1.22
0.29
1.63
0.33
3.6
0.0
0.80
1.88
8.7
11.0
4.4
3.8
1.3
0.08

BANGE

144.5

516.8

8.20

2.66

1.02

4.60

1.27

3.9

0.0

6.50

7.75

34.3

11.4

4.7
0.19
7.5

28
134

$134 \quad 16800$

4.6
0.01

0.01
0.00

0.00
0.34

0.34
6

5

20
50

$\begin{array}{rr}50 & 1600 \\ 6.1 & 11.0\end{array}$

$\begin{array}{rr}6.1 & 11.0 \\ 1.3 & 4.9\end{array}$

0.8

3.0

1.0

0

4.8
5.7

5.7
26

42

7
3
2

1.5
7.5

7.5
2.0

11
0

7.4
11.0

11.0
74

74
20
13

13
7
0.3

*Not significant at the 95 percent confidence level.

QURAILON IABLE OF OAILY SPECIEIC CONDUCIANCE

DAILY SPECIFIC CONDUCTANCE IN

MICROMHOS AT 25 DEG C, THAT WAS

EQUALLED OR EXCEEDED FOR THE

$\begin{array}{rrr}-18 & -58 & 107 \\ 58 & 48 & 44\end{array}$

$20 \Omega$

42

302
\begin{tabular}{ll}
\multicolumn{2}{c}{ BEGBESSION SUMMABY } \\
REGRESSION \\
SAMPLE COEFICIENT, CONSTANT, \\
SIZE
\end{tabular} CORRELATION STANDARD COEFICIENT, CONSTANT, CORRELATION ERROR OF

INDICATED PERCENTAGE OF TIME

SUMMARY OF HARMONIC ANALYSIS OF STREAM TEMPERATURE

\begin{tabular}{|c|c|c|c|c|c|}
\hline & & & & & $\overline{\text { STANDARD }}$ \\
\hline & HARMONIC & AMPLITUDE & PHASE & VARIATION & ERROR OF \\
\hline SAMPLE & MEAN - M & $-A$ & ANGLE - C & EXPLAINED & ESTIMATE \\
\hline SIZE & LEEG C1 & DEE ( ) & (BADIANSI) & $-(x)$ & DEG C) \\
\hline 335 & 19.98 & 8.22 & 2.83 & 92 & 1.80 \\
\hline
\end{tabular}

SUMMARY OF MAXIMUM AND MINIMUM CONCENTRATIONS OF CONSTITUENTS SAMPLED AT A FREQUENCY OF QUARTERLY (1975 WY)

02228000 -- SATILLA RIVER AT ATKINSON, GA.

CONSTITUENT
SAMPLES


Table 14.--Sumnary of measurements at each station--Continued

LAT 30D21M31S LONG 082004M54S

DRAINAGE AREA: $700 \mathrm{SQ}$ MI ( 1813 SQ KM)

PERIOD OF RECORD: $10 / 01 / 74-09 / 30 / 75$

STATISTICAL SUMMARY OF SELECTED DISSOLVED CHEMICAL CONSTITUENTS AND

REGRESSION RELATIONSHIPS OF CONSTITUENT CONCENTRATIONS TO SPECIFIC CONDUCTANCE

BEGBESSION_SUMMABY

CONSIUIUENI

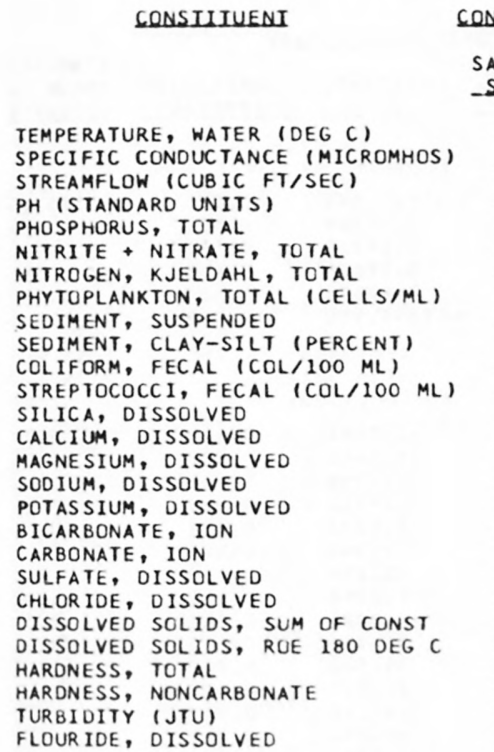

\begin{tabular}{c} 
CONSIU \\
SAMPLE \\
S1ZE \\
\hline 13 \\
13 \\
12 \\
13 \\
13 \\
12 \\
12 \\
13 \\
13 \\
0 \\
12 \\
10 \\
13 \\
13 \\
13 \\
13 \\
13 \\
13 \\
6 \\
13 \\
13 \\
13 \\
13 \\
13 \\
13 \\
13 \\
13
\end{tabular}

ENI IMG $\angle \perp$ OB UNII SHOWNI

STANDARD

MEAN

20.08

47.1
546.3

546.3

5.06

0.045

0.062

0.657
887.8

887.8
4.7

65.4

34.5
4.91

4.91
3.33

1.20

3.42

0.37

7.5

5.92

5.92
6.61

30.1

60.8

13.4
7.3

3.9

0.26

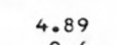

9.6
565.5

565.5
0.99

0.021

0.038

0.140

739.3

63.1

34.6
1.45

1.45
1.32

1.32

0.83

0.17

9.8
0.0

1.61

1.28

9.1
8.2

8.2
5.8

3.3

2.4
0.17
REGRESSION

SAMPLE COEFICIENT,

BANGE

\begin{tabular}{rr}
36 & \\
80 & 1850 \\
3.8 & 6.8 \\
0.02 & 0.10 \\
0.02 & 0.14 \\
0.35 & 0.89 \\
4 & 10000 \\
\hline
\end{tabular}

SIZE

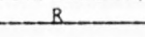

64
850
6.8
.10
.14
.89
000
15

$\begin{array}{lll}650 & 12 & -18.870\end{array}$

$\begin{array}{ll}13 & 0.0702 \\ 13 & 0.00186\end{array}$

0.00186

$-0.00812$

153.841

$\begin{array}{rrr}10 & 180 & \\ 5 & 100 & \\ 3.2 & 7.8 & 13 \\ 1.5 & 6.0 & 13 \\ 0.5 & 2.2 & 13 \\ 2.5 & 5.0 & 13 \\ 0.2 & 0.7 & 13 \\ 0 & 30 & 13 \\ 0 & 0 & 6 \\ 2.4 & 8.2 & 13 \\ 4.8 & 9.3 & 13 \\ 21 & 48 & 13 \\ 49 & 75 & 13 \\ 6 & 24 & 13 \\ 0 & 12 & 13 \\ 1 & 9 & 13 \\ 0.1 & 0.7 & 13\end{array}$

$$
\begin{array}{r}
0.1293 \\
0.1090 \\
0.0444 \\
0.0686 \\
0.0145 \\
0.800 \\
0.000 \\
-0.1023 \\
0.1038 \\
0.769 \\
0.175 \\
0.463 \\
-0.184 \\
0.001 \\
-0.0059
\end{array}
$$

$10.5 \quad 28$.

CONSTANT,

CORRELATION COEEICIENI.

STANOARD ERROR OF ESIIMAIE

*Not significant at the 95 percent confidence level.

\section{DURAJION IABLE OF DAILY SPECIEIC CONOUCIANCE}

DAILY SPECIFIC CONDUCTANCE IN

MICROMHOS AT 25 DEG C, THAT WAS

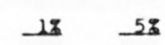

108

$20 z$

$30 \% \quad 50 \%$

$69 \quad 66$

62

50

47

42

1417.479
1.7587
-0.04291
0.00254
1.03255

$-0.315 *$

0.681

0.834 .

0.321 *

$-0.547$.

562.9

0.76
0.012

0.038

0.123

2407.4

0.859

0.795

0.704

$-0.8891$

0.1949

$-0.3143$

$-30.111$

0.7379

10.7379
1.7220

$-6.109$

52.538

$-8.423$

15.966
3.877

0.5396

0.845

\begin{tabular}{|c|c|c|c|c|c|}
\hline & & & & & $\begin{array}{l}\text { STANDARD } \\
\text { ERROR }\end{array}$ \\
\hline SAMPLE & $\begin{array}{l}\text { HARMONIC } \\
\text { MEAN - M }\end{array}$ & $\begin{array}{c}\text { AMPLI I UUDE } \\
-\end{array}$ & $\begin{array}{c}\text { PHASE } \\
\text { ANGLE - C }\end{array}$ & $\begin{array}{l}\text { VARIATION } \\
\text { EXPLAINED }\end{array}$ & $\begin{array}{l}\text { ERROR OF } \\
\text { ESTIMATE }\end{array}$ \\
\hline SIZE & (DEG $C$ C) & WDEG $(1)$ & (RADIANS) & $\ldots 181$ & (DEG_C) \\
\hline 359 & 19.78 & 5.96 & 2.55 & 75 & 2.46 \\
\hline
\end{tabular}

0.786

0.786

0.000

0.610

\begin{tabular}{|c|c|c|c|c|c|c|}
\hline \multirow{2}{*}{ CONSTITUENT } & \multicolumn{3}{|c|}{ TOTAL } & \multicolumn{3}{|c|}{ DISSOLVED } \\
\hline & $\begin{array}{l}\text { NO. } \\
\text { SAMPLES }\end{array}$ & $\begin{array}{l}\text { MINIMUM } \\
\text { CONC. }\end{array}$ & $\begin{array}{l}\text { MAXIMUM } \\
\text { CONC. }\end{array}$ & $\begin{array}{l}\text { NO. } \\
\text { SAMPLES }\end{array}$ & $\begin{array}{l}\text { MINIMUM } \\
\text { CONC. }\end{array}$ & $\begin{array}{l}\text { MAXIMUM } \\
\text { CONC. }\end{array}$ \\
\hline \multicolumn{7}{|l|}{ MINOR ELEMENTS: } \\
\hline ARSENIC (AS), UG/L & 5 & 0 & 2 & 5 & 0 & 1 \\
\hline CADMIUM $(C D)$, UG/L & 4 & 1 & 1 & 5 & 0 & 2 \\
\hline CHROMIUM (CR), UG/L & 4 & $<10$ & $<10$ & 5 & 0 & 1 \\
\hline COBALT $(C O), U G / L$ & 4 & 0 & 3 & 5 & 0 & 0 \\
\hline COPPER (CU), UG/L & 4 & 0 & 8 & 5 & 0 & 2 \\
\hline IRON (FE), UG/L & 4 & 400 & 880 & 5 & 250 & 800 \\
\hline LEAD $(P B), U G / L$ & 4 & 4 & 15 & 5 & 0 & 8 \\
\hline MANGANESE (MN), UG/L & 4 & 0 & 20 & 5 & 0 & 30 \\
\hline MERCURY (HG), UG/L & 5 & 0.0 & 0.2 & 5 & 0.0 & 0.2 \\
\hline SELENIUM (SE), UG/L & 5 & 0 & 0 & 5 & 0 & 0 \\
\hline ZINC $(Z N), U G / L$ & 4 & 7 & 50 & 5 & 0 & 10 \\
\hline \multicolumn{7}{|l|}{ PERIPHYTON: } \\
\hline BIOMASS, DRY WT., G/SO M & 4 & 3.09 & 57.00 & & & \\
\hline BIOMASS, ASH WT., G/SO M & 5 & 1.50 & 43.00 & & & \\
\hline CHLOROPHYLL A, MG/SO M & 4 & 5.5 & 40.0 & & & \\
\hline CHLOROPHYLL B, MG/SO M & 4 & .8 & 4.7 & & & \\
\hline ORGANIC CARBON, MG/L & 6 & $10 \cdot 0$ & 32.0 & & & \\
\hline
\end{tabular}

0.778
0.817

0.205 .

0.771

-0.536 .

0.004
-0.342

SUMMARY OF HARMONIC ANALYSIS OF STREAM TEMPERATURE

SUMMARY OF MAXIMUM AND MINIMUM CONCENTRATIONS OF CONSTITUENTS SAMPLED AT A FREOUENCY DF QUARTERLY (1975 WY)

02231000 -- ST MARYS RIVER NR MACCLENNY, FLA. 
LAT 29D38M48S LONG $081037 M 32 S$

DRAINAGE AREA: 7065 SQ MI ( 18298 SQ KM)

PERIOD OF RECORD: 10/01/74 - 09/30/75

STATISTICAL SUMMARY OF SELECTED DISSOLVED CHEMICAL CONSTITUENTS AND

REGRESSION RELATIONSHIPS OF CONSTITUENT CONCENTRATIONS TO SPECIFIC CONDUCTANCE

CONSIITUENT

CONSIUUENT IMG/L OB UNII SHOWNL

\begin{tabular}{c} 
SAMP \\
SI2 \\
\hline 15 \\
15 \\
12 \\
14 \\
12 \\
12 \\
12 \\
12 \\
12 \\
11 \\
11 \\
12 \\
12 \\
12 \\
12 \\
12 \\
12 \\
11 \\
12 \\
12 \\
12 \\
12 \\
12 \\
12 \\
12 \\
12
\end{tabular}

\section{STANDARD}

\subsection{7}

$968 \cdot 3$
1946.7

7.61

7.61
0.073

0.073
0.069

1.047

104516.6

10.3

5.43
243.3

12983.1

0.81

0.035

0.068

192911.1

6.0

11.6

53.5

6.17

47.58

17.33

17.33
122.75

4.57
87.6

87.6

0.3
6.83

64.83

225.00
533.4

533.4

592.6

191.2

122.9

0.30

9.4

50.1

5.34

9.02

4.16
35.31

0.84

14.5

0.9

17.45

66.54

162.4

51.3

40.0

0.10
MEAN DEXIALION

95 percent confidence level.

DURAIION IABLE OE DALLY SPECIEIC CONDUCIANCE

DAILY SPECIFIC CONDUCTANCE IN

MICROMHOS AT 25 DEG C, THAT WAS

EQUALLED OR EXCEEDED FOR THE

$1 \% \quad 5 \% \quad 20 \%$

208

$30 \% \quad 50 \%$

BANGE REGRESSION

BEGRESSION SUMMABY

COEFICIENT, CONSTANT,

CORRELATION

ST AND ARD SAMPLE $B$ $\begin{array}{rr}12.0 & 29 . \\ 614 & 138 \\ -26000 & 2770\end{array}$ SIZE

5.4

0.03

0.01

0.73

0.16

0.20
1.61

670000

12

$-27.482$

3898

$-0.00007$

$-0.00011$

0.00063

600.969

$-8$

COEEICIENI

ERROR OF

ESIIMAIE

INDICATEO PERCENTAGE OF TIME

$1360 \quad 1230$

1200

1150

$\begin{array}{rrr}0 & 30 & \\ 0 & 140 & \\ 0.3 & 14.0 & 12 \\ 32.0 & 59.0 & 12 \\ 12.0 & 23.0 & 12 \\ 76.0 & 180.0 & 12 \\ 3.5 & 6.0 & 12 \\ 62 & 116 & 12 \\ 0 & 3 & 11 \\ 37.0 & 89.0 & 12 \\ 140.0 & 330.0 & 12 \\ 340 & 728 & 12 \\ 403 & 935 & 12 \\ 94 & 280 & 12 \\ 76 & 200 & 12 \\ 2 & 7 & 12 \\ 0.2 & 0.5 & 12\end{array}$

0.0079
0.0285
0.0144
0.1243
0.0027
0.019
0.001
0.0616
0.2351
0.485
0.562
0.168
0.139
0.005
0.0001

$$
\begin{array}{r}
-1.5561 \\
19.5460 \\
3.1798 \\
0.4918 \\
1.8738 \\
69.348 \\
-1.174 \\
4.2346 \\
-6.3226 \\
56.114 \\
39.500 \\
26.028 \\
-14.184 \\
-0.046 \\
0.2226
\end{array}
$$
$-0.576$
0.473
$-0.553$

\begin{tabular}{|c|c|c|c|c|c|c|}
\hline \multirow{2}{*}{ CONSTI TUENT } & \multicolumn{3}{|c|}{ TOTAL } & \multicolumn{3}{|c|}{ DISSOLVED } \\
\hline & $\begin{array}{l}\text { NO. } \\
\text { SAMPLES }\end{array}$ & $\begin{array}{l}\text { MIN IMUM } \\
\text { CONC. }\end{array}$ & $\begin{array}{l}\text { MAXIMUM } \\
\text { CONC. }\end{array}$ & $\begin{array}{l}\text { NO. } \\
\text { SAMPLES }\end{array}$ & $\begin{array}{l}\text { MINIMUM } \\
\text { CONC. }\end{array}$ & $\begin{array}{l}\text { MAXIMUM } \\
\text { CONC. }\end{array}$ \\
\hline \multicolumn{7}{|l|}{ MINOR ELEMENTS: } \\
\hline ARSENIC (AS), UG/L & 4 & 0 & 2 & 4 & 0 & 2 \\
\hline CADMIUM $(C D)$, UG/L & 4 & 0 & 1 & 4 & 0 & 2 \\
\hline CHROMIUM (CR), UG/L & 4 & $<10$ & 10 & 4 & 0 & 1 \\
\hline COBALT $(C O), U G / L$ & 4 & 0 & 1 & 4 & 0 & 1 \\
\hline COPPER $(C U), U G / L$ & 4 & 1 & 7 & 4 & 0 & 10 \\
\hline IRON (FE), UG/L & 4 & 90 & 560 & 6 & 0 & 380 \\
\hline LEAD $(P B), U G / L$ & 4 & 4 & 26 & 4 & 0 & 9 \\
\hline MANG ANESE (MN), UG/L & 4 & 10 & 30 & 4 & 0 & 10 \\
\hline MERCURY $(H G), U G / L$ & 4 & 0.1 & 0.2 & 4 & 0.1 & 0.4 \\
\hline SELENIUM (SE), UG $/ L$ & 3 & 0 & 1 & 4 & 0 & 1 \\
\hline$Z I N C(Z N), U G / L$ & 4 & 0 & 50 & 4 & 0 & 10 \\
\hline \multicolumn{7}{|l|}{ PERIPHYTON: } \\
\hline BIOMASS, DRY WT., G/SQ M & 2 & 2.29 & 6.69 & & & \\
\hline BIOMASS, ASH WT., G/SO M & 4 & .79 & 3.50 & & & \\
\hline CHLOROPHYLL A, MG/SO M & 4 & .3 & 8.8 & & & \\
\hline CHLOROPHYLL B, MG/SQ M & 4 & .0 & 1.1 & & & \\
\hline ORGANIC CARBON, MG/L & 8 & 9.0 & 26.0 & & & \\
\hline
\end{tabular}
$-0.435$
0.609

11132.9

0.74

0.031

0.065

0.234
40062.5

0.005

$\begin{array}{lr}0.400^{*} & 5.14 \\ 0.860 & 4.84 \\ 0.940 & 1.49 \\ 0.957 & 10.69 \\ 0.891 & 0.40 \\ 0.3477^{\star} & 14.3 \\ 0.465^{*} & 0.8 \\ 0.960 & 5.09 \\ 0.961 & 19.23 \\ 0.970 & 34.6 \\ 0.942 & 57.4 \\ 0.891 & 24.4 \\ 0.947 & 13.5 \\ 0.789 & 1.0 \\ 0.224 * & 0.10\end{array}$

SUMMARY OF HARMONIC ANALYSIS OF STREAM TEMPERATURE

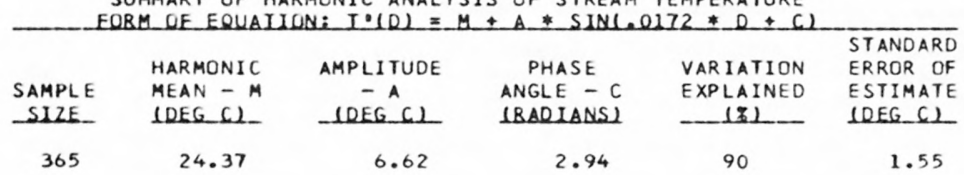

SUMMARY OF MAXIMUM AND MINIMUM CONCENTRATIONS OF CONSTITUENTS SAMPLED AT A FREQUENCY OF QUARTERLY (1975 WY)

02244450 - ST. JOHNS RIVER AT PALATKA, FLA. 
Tab1e 14.--Summary of measurements at each station--Continued

-AT 29D03MO1S LONG $081002 M 49 S$

JRAINAGE AREA: 33 SQ MI

PERIOD OF RECORD: 10/01/74 - 09/30/75

87 SQ KMI

STATISTICAL SUMMARY OF SELECTED DISSOLVED CHEMICAL CONSTITUENTS AND

REGRESSION RELATIONSHIPS OF CONSTITUENT CONCENTRATIONS TO SPECIFIC CONDUCTANCE

\section{CONSIIIUENI}

TEMPERATURE, WATER (DEG C)
SPECIFIC CONDUCTANCE (MICROMHOS)
STREAMFLOW (CUBIC FT/SEC)
PH (STANDARD UNITS)
PHOSPHORUS, TOTAL
NITRI TE, NITRATE, TOTAL
NITROGEN, KJELDAHL, TOTAL
PHYTOPLANKTON, TOTAL (CELLS/ML)
SEDIMENT, SUSPENDED
SEDIMENT, CLAY-SILT (PERCENT)
COLIFORM, FECAL (COL/IOO ML)
STREP TOCOCCI, FECAL (COL/IOO ML)
SILICA, DISSOLVED
CALCIUM, DISSOLVED
MAGNESIUM, DISSOLVEU
SODIUM, DISSOLVED
POTASSIUM, DISSOLVED
BICARBONATE, ION
CARBONATE, ION
SULFATE, DISSOLVED
CHLORIDE, DISSOLVED
OISSOLVED SOLIDS, SUM OF CONST
DISSOLVED SOLIOS, RUE I8O OEG C
HARDNESS, TOTAL
HARDNESS, NONCARBONATE
TURBIDITY (JTU)
FLOURIDE, DISSOLVED

CONSIUUVENT IMG/L OR UNUT SHOWN

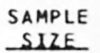

SIZE

STANDARD

*Not significant at the 95 percent confidence leve1.

MEAN DEYIALION

$21.67 \quad 3.63$

405.9

15.2

7.03

0.123

0.079

633.8

633.8
7.6

343.6

376.5

10.96

58.60

4.96

23.38

1.15

180.6
0.0

0.0
12.19

37.10

238.1

288.5

142.2

42.6
5.6

209.6

34.2

0.051

0.042

0.042

0.399
836.9

36.9
4.5

238.2
243.7

243.7
3.83

37.11

2.04

9.71
0.56

0.56
124.7

124.7
0.0

4.24

13.65

126.0

104.2

118.6

2.9

2.9
0.28

NAME: SPRUCE CREEK NEAR SAMSULA, FLA.

DURAIION IABLE OE DALLY SPECIEIC CONDUCIANCE

DAILY SPECIFIC CONDUCTANCE IN

MICROMHOS AT 25 DEG C, THAT WAS

EQUALLED OR EXCEEDED FCR THE

18 . 58

REGRESSION

BEGRESSION SUMMABY

COEFICIENT.

CONSTANT,

CORRELATION SIZE

$\begin{array}{rrr}13.0 & 26.5 & \\ 80 & 690 & \\ 1 & 120 & 12 \\ 4.9 & 7.7 & 12 \\ 0.05 & 0.22 & 12 \\ 0.04 & 0.17 & 12 \\ 0.55 & 1.69 & 12 \\ 9 & 3200 & 11\end{array}$

$$
\begin{array}{r}
-0.103 \\
0.0027 \\
0.00010 \\
-0.00003 \\
-0.00163 \\
1.962
\end{array}
$$

$\begin{array}{ll}75 & 835 \\ 22 & 88\end{array}$

5.0

10.0

2.2

7.8

0.7
14

0
5.5

14.0
61

61
160

20

1

$$
\begin{array}{r}
0.0167 \\
0.1659 \\
0.0091 \\
0.0442 \\
0.0010 \\
0.559 \\
\\
-0.0062 \\
0.0611 \\
0.567 \\
0.456 \\
0.449 \\
-0.008 \\
0.008 \\
-0.0011
\end{array}
$$

$-0.0011$

56.954
5.9382
0.08473
0.09295
1.68037
-148.391

$-0.630$

0.740

0.395 *

$-0.169^{\star}$

$-0.859$

$0.470^{*}$

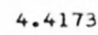

$-7.787$

1.3094

5.1663

0.8598

$-42.870$

14.5462

12.3071

10.741

109.920

$-13.406$

2.984

0.9101
0.979

0.989

0.982

0.997

$0.421 *$

-0.321 *

0.984

0.995

0.981

\begin{tabular}{|c|c|c|c|c|c|}
\hline & & & & & STANDARD \\
\hline $\begin{array}{l}\text { SAMPLE } \\
\text { SLZE }\end{array}$ & $\begin{array}{l}\text { HARMONIC } \\
\text { MEAN - M } \\
\text { (DEG C) }\end{array}$ & $\begin{array}{c}\text { AMPLITUDE } \\
-A \\
\text { (DEG }\end{array}$ & $\begin{array}{c}\text { PHASE } \\
\text { ANGLE - C } \\
\text { (RADIANS) }\end{array}$ & $\begin{array}{l}\text { VAR IATION } \\
\text { EXP LA INEO } \\
(8)\end{array}$ & $\begin{array}{l}\text { ERROR OF } \\
\text { ESTIMATE } \\
\text { IDEG Cl }\end{array}$ \\
\hline & $10 E 6$ C1 & DEG $(1)$ & IBADLANSI & -182 & LEE C C \\
\hline 156 & 22.97 & 3.93 & 2.50 & 78 & 1.21 \\
\hline
\end{tabular}

0.988

$-0.543 *$
$0.545 *$

$-0.875$
STANDARD ESIIMAIE

INDICATED PERCENTAGE OF TIME

752

$-28$

$10 \pi$

$20 \%$

$30 \%$

$50 z$

SAMPLE SIZE $=156$
$202 \quad 258 \quad 298$

$\begin{array}{lll}173 & 125 & 114\end{array}$

SUMMARY OF HARMONIC ANALYSIS OF STREAM TEMPERATURE

SUMMARY OF MAXIMUM AND MINIMUM CONCENTRATIONS OF CONSTITUENTS

SAMPLED AT A FREQUENCY OF QUARTERLY (1975 WY)

02248000 -- SPRUCE CREEK NEAR SAMSULA, FLA.

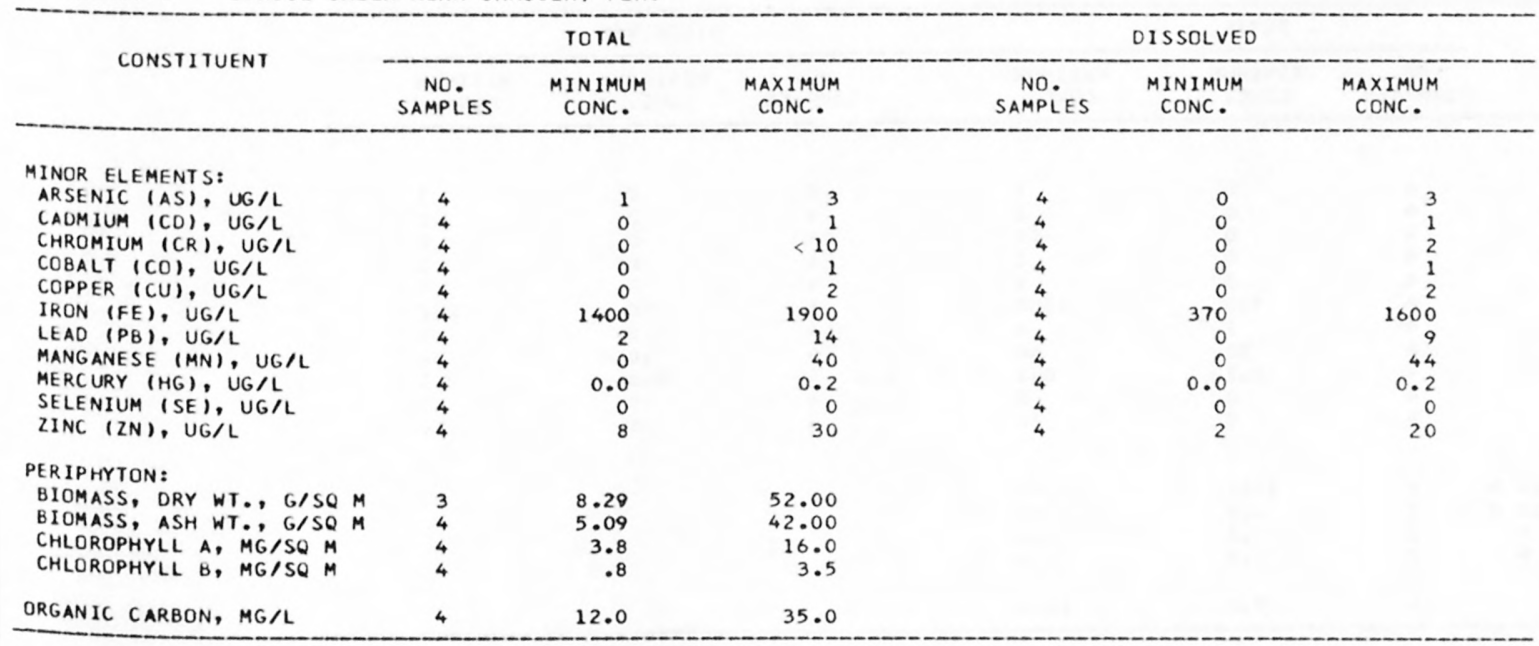


LAT $27038 M 54 S$ LONG 080D24M1OS

DRAINAGE AREA: 0 SQ MI 1

PERIOD OF RECORD: $10 / 01 / 74-09 / 30 / 75$

0 SQ $K M$ I

STATISTICAL SUMMARY OF SELECTED DISSOLVED CHEMICAL CONSTITUENTS AND

REGRESSION RELATIONSHIPS OF CONSTITUENT CONCENTRATIONS TO SPECIFIC CONDUCTANCE

GONSIIIUENI

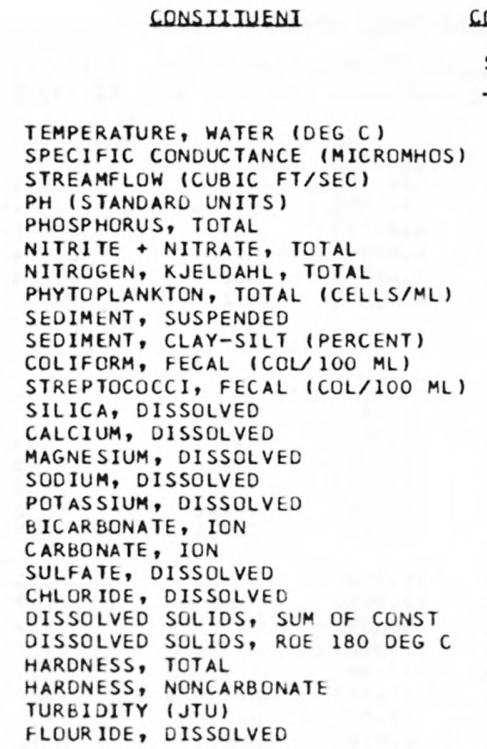

CONSIUTUENI IMG/L OB UNII SHOWNI

\begin{tabular}{c} 
SAMPLE \\
SIZE \\
\hline 12 \\
12 \\
12 \\
12 \\
12 \\
12 \\
12 \\
12 \\
12 \\
0 \\
11 \\
11 \\
9 \\
9 \\
9 \\
9 \\
9 \\
9 \\
3 \\
9 \\
9 \\
9 \\
9 \\
9 \\
9 \\
12 \\
9
\end{tabular}

STANDARD

DEVIALION

$24.88 \quad 3.38$

2474.2

66.3

7.47

0.123

0.169

0.854

4812.5
7.3

262.4

262.4
664.7

664.7
9.98

9.98
95.33

31.33

45.56

8.13
198.0

0.0

92.56

297.78

780.7

898.0

370.0

205.6
5.4

0.63
3.38
230.1

62.4

0.19

0.052

0.133
0.316

0.316
4135.1

7.8

414.5

1173.1

2.35

7.94
7.14

7.14
31.67

2.95
13.0

0.0

13.34

65.53

119.8

135.2

39.4

38.1

4.8
0.17

${ }^{*}$ Not significant at the 95 percent confidence 1 evel.

DURAILN IABLE OE DAILY SPECIEIC CONOUCIANCE

DAILY SPECIFIC CONDUCTANCE IN

MICROMHOS AT 25 DEG C, THAT WAS

EQUALLED OR EXCEEDED FOR THE

$2140 \quad 2010$

1920

1670

$\begin{array}{ll}19.5 & 29.0 \\ 1200 & 1900\end{array}$

$\begin{array}{rr}1 & 202 \\ 7.2 & 7.7\end{array}$

$0.07 \quad 0.23$

0.02

0.47

310
2

0.44

1.42
14000

4000
31

$10 \quad 1400$

6.0

$85.0 \quad 110.0$

$22.0 \quad 43.0$

10.0

5.5
174

74.0

220.0

632

766
320

150

0.3

43.0
200.0

200.0
15.0

214
0

110.0

400.0

475
970

1180

430

260

19
0.9

STANDARD REGRESSION SAMPLE COEFICIENT, CONSTANT, CORRELATION ERROR OF SIZE - B _ _ - B COEEICIENI

ESIIMAIF

$\begin{array}{lrrrr}12 & 0.022 & 33.497 & 0.082 * & 65.2 \\ 12 & 0.0003 & 7.0734 & 0.327 * & 0.19 \\ 12 & 0.00002 & 0.10046 & 0.069 * & 0.054 \\ 12 & -0.00015 & 0.38703 & -0.257 * & 0.134 \\ 12 & -0.00072 & 1.91394 & -0.523 * & 0.283 \\ 12 & -11.852 & 22283.813 & -0.059 & 3260.3\end{array}$

9
9
9
9
9
9
3
9
9
9
9
9
9
12
9

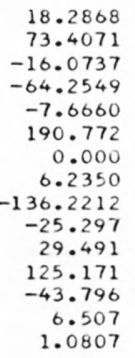

$-0.521 *$
0.407 *
0.978
0.976
0.789
0.082 *
$0.000 *$
0.953
0.975
0.991
0.946
0.916
0.963
-0.035 *
-0.380 *
0.134

260.3

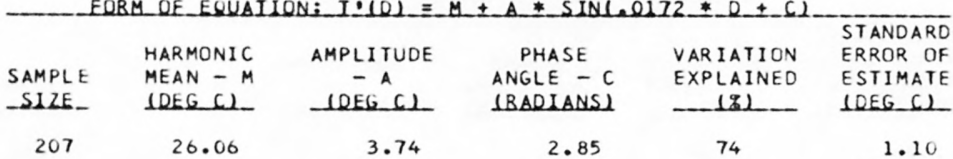

SUMMARY OF MAXIMUM AND MINIMUM CONCENTRATIONS OF CONSTITUENTS

SAMPLED AT A FREQUENCY OF QUARTERLY (1975 WY)

02253000 -- MAIN CANAL AT VERO BEACH, FLA.

\begin{tabular}{|c|c|c|c|c|c|c|}
\hline \multirow{2}{*}{ CONSTI TUENT } & \multicolumn{3}{|c|}{ TOTAL } & \multicolumn{3}{|c|}{ DISSOLVED } \\
\hline & $\begin{array}{l}\text { NO. } \\
\text { SAMPLES }\end{array}$ & $\begin{array}{l}\text { MINIMUM } \\
\text { CONC. }\end{array}$ & $\begin{array}{l}\text { MAXIMUM } \\
\text { CONC. }\end{array}$ & $\begin{array}{l}\text { NO. } \\
\text { SAMPLES }\end{array}$ & $\begin{array}{l}\text { MINIMUM } \\
\text { CONC. }\end{array}$ & $\begin{array}{l}\text { MAXIMUM } \\
\text { CONC. }\end{array}$ \\
\hline \multicolumn{7}{|l|}{ MINOR ELEMENTS: } \\
\hline ARSENIC (AS), UG/L & 4 & 0 & 1 & 4 & 0 & 1 \\
\hline CADMIUM $(C D), U G / L$ & 4 & 0 & 1 & 4 & 0 & 0 \\
\hline CHROMIUM $(C R)$, UG/L & 4 & 0 & $<10$ & 4 & 0 & 0 \\
\hline COBALT $(C O), U G / L$ & 4 & 0 & 1 & 4 & 0 & 1 \\
\hline COPPER (CU), UG/L & 4 & 3 & 9 & 4 & 0 & 7 \\
\hline IRUN (FE), UG/L & 4 & 520 & 1300 & 4 & 50 & 220 \\
\hline LEAD $(P B), U G / L$ & 4 & 1 & 8 & 4 & 0 & 5 \\
\hline MANG ANESE $(M N), U G / L$ & 4 & 30 & 60 & 4 & 10 & 30 \\
\hline MERCURY (HG), UG/L & 4 & 0.1 & 0.1 & 4 & 0.0 & 0.1 \\
\hline SELENIUM (SE), UG/L & 4 & 0 & 0 & 4 & 0 & 0 \\
\hline$Z I N C(Z N), U G / L$ & 4 & 9 & 30 & 4 & 4 & 10 \\
\hline \multicolumn{7}{|l|}{ PERIPHYTON: } \\
\hline BIOMASS, DRY WT., G/SQ M & 2 & 3.89 & 8.50 & & & \\
\hline BIOMASS, ASH WT, , G/SQ M & 2 & .29 & 2.69 & & & \\
\hline CHLOROPHYLL A, MG/SQ M & 2 & .8 & 23.0 & & & \\
\hline CHLOROPHYLL $B, M G / S O M$ & 2 & .0 & 3.5 & & & \\
\hline ORGANIC CARBON, MG/L & 4 & 9.0 & 14.0 & & & \\
\hline
\end{tabular}


LAT 27D13M32S LONG 080D57M46S

DRAINAGE AREA: 0 SQ MI

PERIOD OF RECORD: 10/01/74 - 09/30/75

SO KMI

STATISTICAL SUMMARY OF SELECTED DISSOLVED CHEMICAL CONSTITUENTS AND REGRESSION RELATIONSHIPS OF CONSTITUENT CONCENTRATIONS TO SPECIFIC CONDUCTANCE

\section{CONSIIIUENI}

CONSIUTUENI IMG/L OR UNII SHOWN

TEMPERATURE, WATER (DEG C)
SPECIFIC CONDUCTANCE (MICROMHOS)
STREAMFLOH (CUBIC FT/SEC)
PH (STANDARD UNITS)
PHOSPHORUS, TOTAL,
NITRITE + NITRATE, TOTAL
NITROGEN, KJELDAHL, TOTAL
PHYTOPLANK TON, TOTAL (CELLS/ML)
SEDIMENT, SUSPENDED
SEDIMENT, CLAY-SILT (PERCENT)
COLIFORM, FECAL (COL/IOO ML)
STREPTOCOCCI, FECAL (COL/IOO ML)
SILICA, DISSOLVED
CALCIUM, DISSOLVED
MAGNESIUM, DISSOLVED
SODIUM, DISSOLVED
POTASSIUM, DISSOLVED
BICARBONATE, ION
CARBONATE, ION
SULFATE, DISSOLVED
CHLORIDE, DISSOLVED
DISSOLVED SOLIDS, SUM OF CONST
DISSOLVED SOLIDS, RUE I8O DEG C
HARDNESS, TOTAL
HARDNESS, NONCARBONATE
TURBIDITY (JTU)
FLOUR IDE, OISSOLVED

\begin{tabular}{r} 
SAMPLE \\
SLZE \\
\hline 25 \\
25 \\
25 \\
24 \\
25 \\
25 \\
25 \\
11 \\
12 \\
0 \\
25 \\
11 \\
25 \\
4 \\
4 \\
4 \\
4 \\
4 \\
2 \\
4 \\
4 \\
4 \\
25 \\
4 \\
4 \\
25 \\
6 \\
6
\end{tabular}

STANDARD

MEAN REYIAIIUN

$24.44 \quad 3.89$

$177.7 \quad 67.7$

610.5

6.95

0.074

0.199

0.946

4328.5

3.2

4.4
12.2

12.2
3.55

3.55
17.00

4.07

13.00

1.45

1.45
40.5

0.0
18.47

18.47
21.50

21.50
99.8

99.8
141.2

59.5

26.0

3.2
797.5

0.45

0.058

0.141

5.149

1.9

5.8

20.7
1.08

1.08
7.35

1.24

4.97

0.40

14.6

0.0

10.31
9.47

9.47
41.0

45.4

23.6
11.5

1.2

0.66
FLOUR IDE, DISSOLVED
BANGE

17.5

$\begin{array}{rrr}17.5 & 30.0 & \\ 0 & 320 & \\ 0 & 3200 & 25 \\ 6.1 & 7.8 & 24 \\ 0.03 & 0.25 & 25 \\ 0.01 & 0.41 & 25 \\ 0.63 & 1.33 & 25 \\ 83 & 16000 & 11\end{array}$
COEFICIENT,

BEG

SAMPLE

COEFICIENT,

\begin{tabular}{l} 
CONSTANT, CORRELATION \\
\hline- COEEICIENI
\end{tabular}

STANDARD

ERROR OF

ESIIMAIE

-5.709
0.0034
-0.00035
0.00132
-0.00178
-63.088

1625.109
6.3486
0.13552
-0.03598
1.26195
15512.289

$-0.485$

0.516
$-0.410^{\circ}$

0.634

$-0.805$

$-0.571$

712.6
0.39
0.054
0.112
0.090
5108.9

*Not significant at the 95 percent confidence level.

DURALION IABLE OF DALY SPECIEIC CONOUCIANCE

DAILY SPECIFIC CONDUCTANCE IN

MICROMHOS AT 25 DEG C, THAT WAS

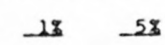

$10 \%$

$20 \%$

$30 z$

$50 \%$

320

299

$289 \quad 265$

229

164

21
70
5.3
26.0
5.7
20.0
2.0
58
0
32.0
35.0
154
252
89
41
5

SUMMARY OF HARMONIC ANALYSIS OF STREAM TEMPERATURE

EORM OF EOUAION: 0 (O) = M $A *$ SINC.0172*0*

\begin{tabular}{|c|c|c|c|c|c|}
\hline & & & & & STANDARD \\
\hline & HARMONIC & AMPLITUDE & PHASE & VARIATION & ERROR OF \\
\hline SAMPLE & MEAN - M & $-A$ & ANGLE $-C$ & EXPLAINED & ESTIMATE \\
\hline SILE_ & LEE 61 & DDEG $(1)$ & (BADIANS) & -181 & LEEG C \\
\hline 360 & 23.63 & 5.82 & 2.81 & 87 & 1.62 \\
\hline
\end{tabular}

SUMMARY OF MAXIMUM AND MINIMUM CONCENTRATIONS OF CONSTITUENTS SAMPLED AT A FREQUENCY OF QUARTERLY (1975 WY)

02273000 -- KISSIMMEE RIVER AT S-65 E

\begin{tabular}{|c|c|c|c|c|c|c|}
\hline \multirow{2}{*}{ CONSTITUENT } & \multicolumn{3}{|c|}{ TOTAL } & \multicolumn{3}{|c|}{ DISSOLVED } \\
\hline & $\begin{array}{l}\text { NO. } \\
\text { SAMPLES }\end{array}$ & $\begin{array}{l}\text { MINIMUM } \\
\text { CONC. }\end{array}$ & $\begin{array}{l}\text { MAXIMUM } \\
\text { CONC. }\end{array}$ & $\begin{array}{l}\text { NO. } \\
\text { SAMPLES }\end{array}$ & $\begin{array}{l}\text { MINIMUM } \\
\text { CONC. }\end{array}$ & $\begin{array}{l}\text { MAXIMUM } \\
\text { CONC. }\end{array}$ \\
\hline \multicolumn{7}{|l|}{ MINOR ELEMENTS: } \\
\hline ARSENIC (AS), UG/L & 4 & 0 & 2 & 4 & 0 & 0 \\
\hline CAUMIUM $(C D)$, UG/L & 4 & 0 & 1 & 4 & 0 & 1 \\
\hline CHRUMIUM (CR), UG/L & 4 & 0 & $<10$ & 4 & 0 & 1 \\
\hline CUBALT $(C O), U G / L$ & 4 & 0 & 1 & 4 & 0 & 1 \\
\hline COPPER (CU), UG/L & 4 & 0 & 2 & 4 & 1 & 2 \\
\hline IRUN (FE), UG/L & 25 & 190 & 1900 & 4 & 20 & 240 \\
\hline LEAD $(P B), U G / L$ & 4 & 1 & 6 & 4 & 0 & 6 \\
\hline MANG ANESE (MN), UG/L & 4 & 0 & 24 & 4 & 0 & 10 \\
\hline MERCURY (HG), UG/L & 4 & 0.0 & 0.2 & 4 & 0.0 & 0.0 \\
\hline SELENIUM (SE), UG/L & 4 & 0 & 0 & 4 & 0 & 0 \\
\hline ZINC $(Z N), U G / L$ & 4 & 0 & 20 & 4 & 0 & 20 \\
\hline \multicolumn{7}{|l|}{ PERIPHYTON: } \\
\hline BIOMASS; DRY WT., G/SO M & 4 & 5.39 & 21.00 & & & \\
\hline BIOMASS, ASH WT., G/SQ M & 4 & 2.29 & 8.89 & & & \\
\hline CHLOROPHYLL A, MG/SQ M & 4 & 35.0 & 130.0 & & & \\
\hline CHLOROPHYLL B, MG/SO M & 4 & 9.5 & 42.0 & & & \\
\hline ORGANIC CARBON, MG/L & 25 & 11.0 & 23.0 & & & \\
\hline
\end{tabular}


Table 14.--Summary of measurements at each station--Continued

STATION NUMBER： 02279000

NAME: WEST PALM BEACH CANAL AT WEST PALM BEACH FLA

LAT 26038M4OS LONG 080003M32S

DRAINAGE AREA: 0 SO MI

PERIOD OF RECORD: $10 / 01 / 74-09 / 30 / 75$

O SQ KM)

STATISTICAL SUMMARY OF SELECTED DISSOLVED CHEMICAL CONSTITUENTS AND

REGRESSION RELATIONSHIPS OF CONSTITUENT CONCENTRATIONS TO SPECIFIC CONDUCTANCE

GONSILIUENI

CONSIUIUENI IMG/L OR UNDI SHOWNI

SAMPLE

SIZE MEAN STANDARD

SIZE MEAN DEYIALION BANGE

TEMPERATURE, WATER (DEG C) SPECIFIC CONDUCTANCE (MICROMHOS)

PH (STANDARD UNITSI

PHCSPHORUS, TOTAL

NITRITE + NITRATE, TOTAL

NITROGEN, KJELDAHL, TOTAL

PHYTUPLANKTON, TOTAL (CELLS/ML)

SEOIMENT, SUSPENDED

SEDIMENT, CLAY-SILT (PERCENT)

COLIFORM, FECAL (COL/100 ML)

STREPTOCOCCI, FECAL (COL/100 ML)

SILICA, DISSOLVED

CALCIUM, DISSOLVED

MAGNESIUM, DISSOLVED

SODIUM, DISSOLVED

POTASSIUM, DISSOLVEL

BICARBONATE, ION

CARBONATE, ION

SULFATE, UISSOLVED

CHLORIOE, DISSOLVED

DISSULVED SOLIDS, SUM OF CONST

DISSOLVED SOLIOS, ROE 180 DEG

HARDNESS, TOTAL

HARDNESS, NONCARBONATE

TUROIDITY (JTU)

FLOURIDE, DISSOLVED

25.04

699.6
39.6

39.6
7.80

0.112

0.326

1.238

31438.2

4.16
79.1

79.1
81.0

81.0
0.44

0.045

0.101
0.167

2833.8

33.8
4.7

16.5
590

7.1
0.07

0.07
0.18

1.07

6.1

$\begin{array}{rr}142.0 & 198.2 \\ 40.7 & 26.7\end{array}$

40.7

8.20

81.15

9.62

49.46
3.75

234.2

0.0

44.46

78.69

78.69
392.2

434.4

243.8

51.0
6.2

0.32

26.7
1.89

1.89
13.86

3.97

12.31

0.66
30.8

30.8

0.17

6.17
17.89

17.89
43.2

59.2
26.6

10.3

5.5
0.14

520
1

20
10
5.2

5.2
60.0

5.9
30.0

30.0
2.8

188

34.0

50.0

303
335

335
200

36
0

0.0

*Not significant at the 95 percent confidence level.

SUMMARY OF HARMONIC ANALYSIS OF STREAM TEMPERATURE

\begin{tabular}{|c|c|c|c|c|c|}
\hline & & & & & STANDARD \\
\hline SAMPLE & $\begin{array}{l}\text { HARMONIC } \\
\text { MEAN - M }\end{array}$ & $\begin{array}{c}\text { AMPLITUDE } \\
-A\end{array}$ & $\begin{array}{c}\text { PHASE } \\
\text { ANGLE - C }\end{array}$ & $\begin{array}{l}\text { VARIATION } \\
\text { EXPLAINED }\end{array}$ & $\begin{array}{l}\text { ERROR OF } \\
\text { ESTIMATE }\end{array}$ \\
\hline SLZE & IDEG CL & $-10 E G(1)$ & (RADIANS) & (18) & LEE CI \\
\hline 13 & 25.11 & 4.81 & 3.19 & 72 & 2.39 \\
\hline
\end{tabular}

\section{BEGRESSION SUMMARY}

REGRESSION

SAMPLE COEFICIENT, CONSTANT, CORRELATION ERROR

SIZE

$B$

$-B$

COEEICIENI_ ES

30.0
900

$\begin{array}{rr}232 & 10 \\ 8.8 & 13 \\ 0.22 & 11 \\ 0.44 & 11 \\ 1.62 & 11 \\ 250000 & 11\end{array}$

-0.205
0.0011
-0.00035
0.00022
0.00132
-310.999

184.689
7.0556
0.35713
0.17093
0.32263

$-0.116^{*}$

$0.192^{*}$

$-0.660$

$0.186^{*}$

0.662

$-0.357^{\star}$

88.7

0.45
0.036

0.105

0.13

16

71723.9

700
100

$\begin{array}{rrr}100 & & \\ 13.0 & 13 & 0.0152\end{array}$

100.0

16.0

70.

284

0.0551

0.0181

0.1107

0.0001

0.149

0.000

0.0363

0.1760

55.0
110.0

110.0
497

0.630

0.228

0.08

$-0.035$

0.0005

$-2.4581$

42.6374

$-3.0598$

$-27.9509$

3.0928

129.745

0.000

.0621

$-44.4111$

51.874

84.408

$-11.583$

30.117

$-0.0598$

0.639

$0.314^{*}$

0.361.

0.711

0.009 .

$0.384^{*}$

$0.000^{*}$

0.465

0.778

0.843

0.077

0.686.

$-0.526^{*}$

$0.304^{*}$

SUMMARY OF MAXIMUM AND MINIMUM CONCENTRATIONS OF CONSTITUENTS SAMPLED AT A FREOUENCY OF QUARTERLY (1975 WY)

G2279000 -- WEST PALM BEACH CANAL AT WEST PALM BEACH FLA

CONSTITUENT
SAMPLES


Table 14.--Sumary of measurements at each station--Continued

STATION NUMBER: 02288600

NAME: MIAMI CANAL AT N.W. 36TH STREET, MIAMI, FLA

AT 25D48M29S LONG 080D15M44S

IAINAGE AREA: 0 SQ MI

ERIOD OF RECORD: $10 / 01 / 74-09 / 30 / 75$

O SO KMI

STATISTICAL SUMMARY OF SELECTED DISSOLVED CHEMICAL CONSTITUENTS AND

REGRESSION RELATIONSHIPS OF CONSTITUENT CONCENTRATIONS TO SPECIFIC CONDUCTANCE

CONSIIIUENI

CONSILIUENI IMG/L_OB UNII SHOWNI

SAMPLE

SIZE

TEMPERATURE, WATER IDEG C) SPECIFIC CONDUCTANCE (MICROMHOS)

STREAMFLOW (CUBIC FT/SEC)

PH (STANDARD UNITS)

PHOSPHORUS, TOTAL

NITRITE + NITRATE, TOTAL

NITROGEN, KJELDAHL, TOTAL

PHYTOPLANKTON, TOTAL (CELLS/ML)

SEDIMENT, SUSPENDED

SEDIMENT, CLAY-SILT (PERCENT)

COLIFORM, FECAL ( $\mathrm{COL} / 100 \mathrm{ML}$ )

STREPTOCOCCI, FECAL I COL $/ 100 \mathrm{ML}$

SILICA, DISSOLVED

CALCIUM, DISSOLVED

MAGNESIUM, DISSOLVED

SODIUM, DISSOLVED

POTASSIUM, DISSOLVED

BICAR BONATE, ION

CARBONATE, ION

SULFATE, DISSOLVED

CHLORIDE, DIS SOLVED

DISSOLVED SOLIDS, SUM OF CONST

DISSOLVED SOLIDS, ROE 180 DEG

HARDNESS, TOTAL

HARDNESS, NONCARBONATE

TURBIDITY (JTU)

FLOURIDE, DISSOLVED

\section{STANDARD}

MEAN

26.05 659.4

37.7

7.66

0.011

0.229

1.304

2445.5

4.2

EYIAUION

$154 \cdot 2$

77.5

6.36

81.00

9.71
42.36

42.36
1.73

1.73

278.0

0.10
6.10

6.10
80.22

80.22
353.5

353.5
387.5

387.5
243.6

15.6

1.4
0.29
3.41
92.0

92.0
59.7

59.7
0.37

0.37
0.007

0.111

0.162

4237.1

8.0

158.6

59.8
1.36

1.36
6.34

6.34
1.02

5.43

0.29

20.7

5.33

29.17

19.8

$26 \cdot 3$
$14 \cdot 3$

$14 \cdot 3$
8.2

1.2
0.14

\section{BANGE}

$20.0 \quad 30.0$ 570

0

6.7
0.00

0.07

1.11

210

20
2
4.1
64.0
8.6
34.0
1.4
219
0
2.0
55.0
328
333
210
0
0
0.0

.63

15000

8.8
88.0

52.0

298

260
31
BEGRESSION_SUMMABY

REGRESSION

$\begin{array}{lccc}\text { SAMPLE } & \begin{array}{c}\text { REGRESSION } \\ \text { COEFICIENT, CONSTANT, }\end{array} & \begin{array}{l}\text { STANDARD } \\ \text { CORELATION }\end{array} \\ \text { SIZEROR OF } & \text { BOEEICIENI } & \text { ESIIMAIE }\end{array}$

SIZE

B COEFICIENI

ERROR OF

*Not significant at the 95 percent confidence level.

1040

$\begin{array}{lll}13899 & 9 & 0.321\end{array}$

$\begin{array}{rrr}8.0 & 11 & 0.0009 \\ 0.02 & 10 & -0.00011\end{array}$

0.00127

$-0.00130$

$-67.010$

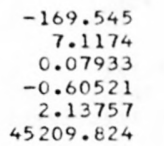

$0.190^{*}$

0.083 .

$-0.534$

$0.502 *$

$-0.280 *$

$-0.574 *$

62.7

0.39

0.007

0.086

0.174

3657.9

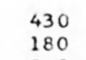

88.0
12.0

21.0
200.0

$428 \quad 11$

$\begin{array}{rr}3 & 11 \\ 0.5 & 11\end{array}$
$-0.0025$

0.0942

$-0.0019$

0.1023

$-0.0053$

0.420

0.000

$-0.0842$

0.3042

0.460

0.220

0.226

$-0.103$

0.016
-0.0012
7.9503

20.8840

10.9142

$-22.953$

5.0953

9.893

0.000

20.3915
59.750

247.428

99.570

81.438

$-8.688$

1.0269
$-0.066$

0.539 .

-0.067 *
0.084

$-0.052$

0.736

0.000 .

$-0.574$

0.960

0.843

0.303

$0.571 *$

$-0.459$

-0.289 .
1.43

5.63

1.07

4.17
0.23

14.8

0.0

8.38

8.38

26.4

12.4

7.6

0.15

SUMMARY OF MAXIMUM AND MINIMUM CONCENTRATIONS OF CONSTITUENTS SAMPLED AT A FREQUENCY OF OUARTERLY (1975 WY)

02288600 -- MIAMI CANAL AT N.W. 36TH STREET, MIAMI, FLA

\begin{tabular}{|c|c|c|c|c|c|c|}
\hline CONSTITUENT & $\begin{array}{l}\text { NO. } \\
\text { SAMPLES }\end{array}$ & $\begin{array}{l}\text { MINIMUM } \\
\text { CONC. }\end{array}$ & $\begin{array}{l}\text { MAXIMUM } \\
\text { CONC. }\end{array}$ & $\begin{array}{l}\text { NO. } \\
\text { SAMPLES }\end{array}$ & $\begin{array}{l}\text { MINIMUM } \\
\text { CONC. }\end{array}$ & $\begin{array}{l}\text { MAXIMUM } \\
\text { CONC. }\end{array}$ \\
\hline \multicolumn{7}{|l|}{ MINOR ELEMENTS: } \\
\hline ARSENIC (AS), UG/L & 4 & 1 & 3 & 4 & 0 & 1 \\
\hline CADMIUM $(C D), U G / L$ & 4 & 0 & 2 & 4 & 0 & 1 \\
\hline CHROMIUM (CR), UG/L & 4 & $<10$ & 50 & 4 & 0 & 1 \\
\hline COBALT $(C O)$, UG/L & 4 & 0 & 2 & 4 & 0 & 2 \\
\hline COPPER (CU), UG/L & 4 & 2 & 6 & 4 & 1 & 2 \\
\hline IRON (FE), UG/L & 4 & 210 & 440 & 4 & 60 & 140 \\
\hline LEAD $(P B), U G / L$ & 4 & 4 & 17 & 4 & 0 & 3 \\
\hline MANGANESE (MN), UG/L & 4 & 0 & 30 & 4 & 0 & 100 \\
\hline MERCURY $(H G), U G / L$ & 4 & 0.0 & 0.1 & 4 & 0.0 & 0.3 \\
\hline SELENIUM (SE), UG/L & 4 & 0 & 0 & 4 & 0 & 0 \\
\hline ZINC $(Z N), U G / L$ & 4 & 8 & 40 & 4 & 0 & 20 \\
\hline \multicolumn{7}{|l|}{ PERIPHYTON: } \\
\hline BIOMASS, DRY WT., G/SO M & 2 & 2.29 & 2.50 & & & \\
\hline BIOMASS, ASH WT., G/SO M & 3 & 1.59 & 8.50 & & & \\
\hline CHLOROPHYLL A, MG/SQ M & 2 & 6.1 & 12.0 & & & \\
\hline CHLOROPHYLL B, MG/SO M & 2 & 1.0 & 1.5 & & & \\
\hline ORGANIC CARBON, MG/L & 5 & 19.0 & 24.0 & & & \\
\hline
\end{tabular}


Table 14.--Summary of measurements at each station--Continued

LAT $26047 M 22 S$ LONG $081018 M 11 S$

PRAINAGE AREA: $\quad 0$ SQ MI 1

O SQ KMI

STATISTICAL SUMMARY OF SELECTED DISSOLVED CHEMICAL CONSTITUENTS AND

REGRESSION RELATIONSHIPS OF CONSTITUENT CONCENTRATIONS TO SPECIFIC CONDUCTANCE

CONSUIUENI

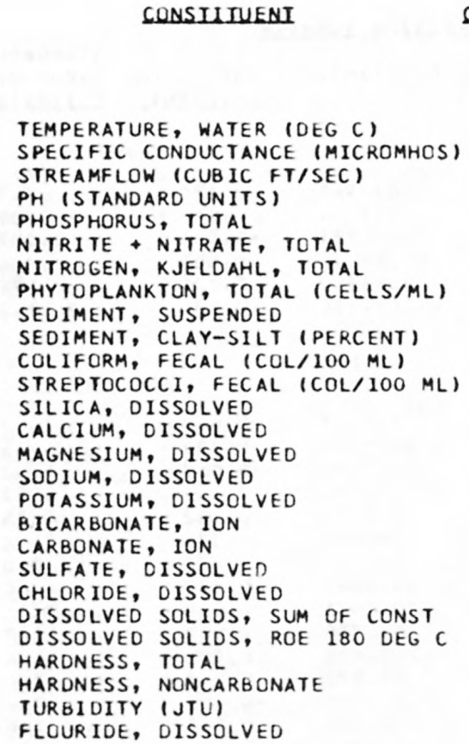

SONSIUUUENI IMG/L OR UNII SHOHNI

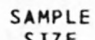

SIZE

STANDARD

DEVIAIIOA

28.22

560.0

560.0
535.3

535.3
7.74

0.134

0.181

1.387

21063.3

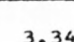

3.34
71.8

71.8
719.9

0.32
0.065

0.065
0.212

0.212
0.129

41387.3

1.1

49.5
48.0

48.0
6.44

6.44
56.67

12.68

40.67

4.36
182.4

182.4
0.0

37.00

63.78

312.9

348.1
195.6

195.6
45.9

3.3
0.43

\section{6}

46.9

2.45

$\begin{array}{r}4.97 \\ 12.06 \\ \hline 2.77\end{array}$

0.63

18.9
0.0

13.44

17.54

44.9

$44 \cdot 3$

18.8
13.7

2.4
0.19

9
9
7
9
9
9
9
9
9
0
8
9
9
9
9
9
9
9
9
9
9
9
9
9
9
9
9

*Not significant at the 95 percent confidence level.

$\begin{array}{rr} & \\ & \\ & \\ 23.0 & \\ 420 & \\ 8 & \\ 7.1 & 2070 \\ 0.05 & 8.0 \\ 0.02 & 0.22 \\ 1.23 & 1.68 \\ 140 & 120000 \\ 2 & 5 \\ & \\ 8 & 150 \\ 6 & 160 \\ 2.2 & 9.7 \\ 45.0 & 68.0 \\ 7.3 & 18.0 \\ 22.0 & 59.0 \\ 3.1 & 5.4 \\ 153 & 211 \\ 0 & 0 \\ 19.0 & 56.0 \\ 36.0 & 90.0 \\ 219 & 356 \\ 263 & 405 \\ 150 & 210 \\ 25 & 61 \\ 0 & 6 \\ 0.1 & 0.8 \\ & \\ 25 & \end{array}$

REGRESSION BESSLION SUMMABY

SAMPLE COEFICIENT, CONSTANT, CORRELATION ERROR SIZE - B - - B COEEICIENI

SUMMARY OF MAXIMUM AND MINIMUM CONCENTRATIONS OF CONSTITUENTS SAMPLED AT A FREQUENCY OF QUARTERLY (1975 WY)

02292480 -- CALOOSAHATCHEE CANAL AT ORTONA LOCK NR LA BELLE

\begin{tabular}{|c|c|c|c|c|c|c|}
\hline \multirow{2}{*}{ CONSTITUENT } & \multicolumn{3}{|c|}{ TOTAL } & \multicolumn{3}{|c|}{ DISSOLVED } \\
\hline & $\begin{array}{l}\text { NO. } \\
\text { SAMPLES }\end{array}$ & $\begin{array}{l}\text { MINIMUM } \\
\text { CONC. }\end{array}$ & $\begin{array}{l}\text { MAXIMUM } \\
\text { CONC. }\end{array}$ & $\begin{array}{l}\text { NO. } \\
\text { SAMPLES }\end{array}$ & $\begin{array}{l}\text { MINIMUM } \\
\text { CONC. }\end{array}$ & $\begin{array}{l}\text { MAXIMUM } \\
\text { CONC. }\end{array}$ \\
\hline \multicolumn{7}{|l|}{ MINOR ELEMENTS: } \\
\hline ARSENIC (AS), UG/L & 3 & 1 & 2 & 3 & 1 & 2 \\
\hline CADMIUM $(C D), U G / L$ & 3 & 0 & 1 & 3 & 0 & 1 \\
\hline CHROMIUM (CR), UG/L & 3 & $<10$ & $<10$ & 3 & 0 & 0 \\
\hline COBALT $(C O)$, UG/L & 3 & 0 & 1 & 3 & 0 & 2 \\
\hline COPPER $(C U), U G / L$ & 3 & 4 & 30 & 3 & 1 & 3 \\
\hline IRON $(F E), U G / L$ & 3 & 130 & 530 & 3 & 30 & 250 \\
\hline LEAD $(P B), U G / L$ & 3 & 4 & 7 & 3 & 1 & 4 \\
\hline MANGANESE (MN), UG/L & 3 & 0 & 32 & 3 & 0 & 20 \\
\hline MERCURY (HG), UG/L & 3 & 0.0 & 0.1 & 3 & 0.0 & 0.1 \\
\hline SELENIUM (SE), UG/L & 3 & 0 & 0 & 3 & 0 & 0 \\
\hline$Z I N C(Z N), U G / L$ & 3 & 10 & 50 & 3 & 0 & 10 \\
\hline \multicolumn{7}{|l|}{ PERIPHYTON: } \\
\hline BIOMASS, DRY WT., G/SO M & 2 & 7.39 & 21.00 & & & \\
\hline BIOMASS, ASH WT., G/SQ M & 2 & 4.89 & 12.00 & & & \\
\hline CHLOROPHYLL A, MG/SO M & 2 & 68.0 & 84.0 & & & \\
\hline CHLOROPHYLL B, MG/SQ M & 2 & 11.0 & 13.0 & & & \\
\hline ORGANIC CARBON, MG/L & 3 . & 21.0 & 26.0 & & & \\
\hline
\end{tabular}


Table 14.--Summary of measurements at each station--Continued

STATION NUMBER: 02296750

NAME: PEACE R AT ARCADIA

LAT 27D13M19S LONG $081052 M 34 \mathrm{~S}$

DRAINAGE AREA: 1367 SO MI ( 3541 SO KM)

PERIOD OF RECORD: 10/01/74-09/30/75

STATISTICAL SUMMARY OF SELECTED DISSOLVED CHEMICAL CONSTITUENIS AND

REGRESSION RELATIONSHIPS OF CONSTITUENT CONCENTRATIONS TO SPECIFIC CONDUCTANCE

CONSIIUUENI

TEMPERATURE, WATER (DEG C)
SPECIFIC CONDUCTANCE (MICROMHOS)
STREAMFLOW (CUBIC FT/SEC)
PH (STANDARD UNITS)
PHOSPHORUS, TOTAL
NITRITE, NITRATE, IOTAL
NITROGEN, KJELDAHL, TOTAL
PHYTOPLANKTON, TOTAL (CELLS/ML)
SEDIMENT, SUSPENDED
SEDIMENT, CLAY-SILT (PERCENT)
COLIFORM, FECAL (COL/IOO ML)
SIREPTOCOCCI, FECAL (COL/IOO ML)
SILICA, DISSOLVED
CALCIUM, DISSOLVED
MAGNESIUM, DISSOLVED
SODIUM, DISSOLVED
POTASSIUM, DISSOLVED
BICARBONATE, ION
CARBONATE, ION
SULFATE, DISSOLVED
CHLORIDE, DISSOLVED
DISSOLVED SOLIDS, SUM OF (ONST
DISSOLVED SOLIDS, ROE I8O DEG C
HARDNESS, TOTAL
HARDNESS, NONCARBONATE
TURBIDITY (JTU)
FLOURIDE, DISSOLVED

CONSIUIUENT IMG/L OR UNDI SHOWNI

SAMPL

MAPLE

15
15
16
14
11
4
4
8
11
0
11
11
8
8
8
8
8
8
0
8
8
8
8
8
8
10
8

\section{STANDARD}

MEAN DEYIAUION

24.43

405.4

536.7

6.90

2.776

0.732

0.732
1.075

790.0

6.1

27.1

68.9

38.50

38.50

14.15
15.30

15.30
2.12

67.9

94.50

17.25

224.8

256.5

156.0

100.0

4.2
1.44

4.2
1.44
3.48

132.3

607.9

0.94
1.435

1.435

0.833
0.607

0.607
442.5

442.5
3.0

27.8

61.9

2.64

14.36

5.15

4.61
0.54

0.54
20.5

46.93
2.12

2.12
80.3

80.5

57.5

43.8

3.0
0.47

\section{BEGRESSION SUMMARY}

SAMPLE COEFICIENT,

CONSTANT,

CORRELATION

STANDARD BANGE SIZE 14.0 170

49

0.14

0.01

0.45

280

28.0

$\begin{array}{rr}590 & \\ 2065 & 13 \\ 8.2 & 13 \\ 4.50 & 7 \\ 1.92 & 3 \\ 1.84 & 3 \\ 1000 & 5 \\ 13 & \end{array}$

$\mathrm{R}$ - B COEEICIENI ERROR OF ESIUMAIE

\footnotetext{
${ }^{*}$ Not significant at the 95 percent confidence level.
}

RURAIION IABLE_OE_DAILY SPECIEIC CONDUCIANCE

DAILY SPECIFIC CONDUCTANCE IN

MICROMHOS AT 25 DEG C, THAT WAS

EQUALLED OR EXCEEDED FOR THE

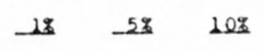

$20 z$

$\begin{array}{rr}2 & 86 \\ 5 & 180 \\ 3.3 & 11.0 \\ 17.0 & 60.0 \\ 6.2 & 23.0 \\ 7.4 & 22.0 \\ 1.0 & 2.6 \\ 32 & 95\end{array}$

86
180

11.0

23.0

22.0
2.6

$13-3.338$

$-0.0005$

0.01264

1927.726

$-0.733$

0.9919
-1.01654

$-0.071^{*}$

0.972.

0.00786

1.27246

$-0.871$.

$-0.321 *$

.00187

203.737

438.9

0.419

0.562

0.724

300.0

0.0565

0.0183

0.0155

$-0.0003$

0.1606

0.0072

0.284

0.327

0.215

0.170

0.0014

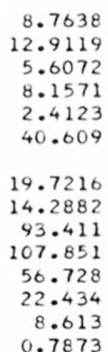

0.7873
-0.174 .

$0.600^{*}$

0.599 *

0.505 .

-0.133 *

0.413.

0.547 *

0.415 *

0.557 .

$0.646^{\circ}$

$0.606^{*}$

$0.616^{*}$

-0.503 *

0.467 *
3.05

10.82

3.51

3.82
0.34

0.34

35.32

2.26

60.9

55.6

40.6

31.2

0.37

INDICATEO PERCENTAGE OF IIME

585

565

555

525

302

502

SAMPLE SIZE $=291$
20\% $20 \%$ 25\% $29 \%$

SUMMARY OF HARMONIC ANALYSIS OF STREAM TEMPERATURE

\begin{tabular}{|c|c|c|c|c|c|}
\hline & & & & & STANDARD \\
\hline & HARMONIC & AMPLITUDE & PHASE & VAR IATION & ERROR OF \\
\hline SAMPLE & MEAN - M & $-A$ & ANGLE - C & EXPLAINED & ESTIMATE \\
\hline SILE_- & $10 E G[1$ & LDEG CL & (BADIANSI & -182 & $10 E G_{C} \quad 1$ \\
\hline
\end{tabular}

291

24.15

5.37

3.06

78

1.97

SUMMARY OF MAXIMUM AND MINIMUM CONCENTRATIONS CF CONSTITUENTS SAMPLED AT A FREQUENCY OF QUARTERLY (1975 WY)

02296750 -- PEACE R AT ARCADIA

\begin{tabular}{|c|c|c|c|c|c|c|}
\hline \multirow{2}{*}{ CONSTITUENT } & \multicolumn{3}{|c|}{ TOTAL } & \multicolumn{3}{|c|}{ DISSOLVED } \\
\hline & $\begin{array}{l}\text { NO. } \\
\text { SAMPLES }\end{array}$ & $\begin{array}{l}\text { MIN IMUM } \\
\text { CONC. }\end{array}$ & $\begin{array}{l}\text { MAXIMUM } \\
\text { CONC. }\end{array}$ & $\begin{array}{l}\text { NO. } \\
\text { SAMPLES }\end{array}$ & $\begin{array}{l}\text { MINIMUM } \\
\text { CONC. }\end{array}$ & $\begin{array}{l}\text { MAXIMUM } \\
\text { CONC. }\end{array}$ \\
\hline
\end{tabular}

MINOR ELEMENTS:

ARSENIC (AS), UG/L

CADMIUM (CD), UG/L

CHROMIUM (CR), UG/L

COBALT $(C O), U G / L$

COPPER (CU), UG/L

IRON (FE), UG/L

LEAD (PB), UG/L

MANG ANESE (MN), UG/

MERCURY (HG), UG $/ L$

SELENIUM (SE), UG/L

ZINC $(Z N), U G / L$

$\begin{array}{rr}6 & 1 \\ 6 & 0 \\ 5 & 1 \\ 5 & 0 \\ 5 & 0 \\ 6 & 60 \\ 6 & 3 \\ 6 & 0 \\ 6 & 0.0 \\ 4 & 0 \\ 5 & 20\end{array}$

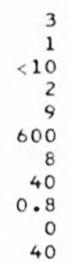

5
5
5
5
6
8
6
6
5
5
6
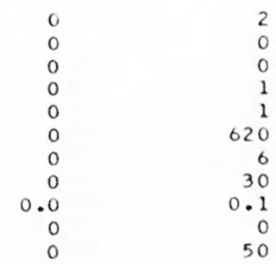

PERIPHYTON :

BIOMASS, DRY WT., G/SO M

BIOMASS, ASH WT., G/SQ M

CHLOROPHYLL A, MG/SO M

CHLOROPHYLL B, MG/SO M

$\begin{array}{lr}1 & 5.69 \\ 1 & 3.09 \\ 1 & 44.0 \\ 1 & 9.6\end{array}$

ORGANIC CARBON, MG/L

3

6.0

11.0 
Table 14.--Summary of measurements at each station--Continued

LAT 28D08M59S LUNG 082013M57S

ORAINAGE AREA: $220 \mathrm{SQMI} 1 \quad 570$ SQ $\mathrm{KM})$

PERIOD OF RECORD: $10 / 01 / 74-09 / 30 / 75$

STATISTICAL SUMMARY OF SELECTED DISSOLVED CHEMICAL CONSTITUENTS AND

REGRESSION RELATIONSHIPS OF CONSTITUENT CONCENTRATIONS TO SPECIFIC CONDUCTANCE

CONSIIUUENI

CONSIUUENI IMG/L OB UNII SHOWNL

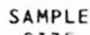

SAZE

MEAN REYIALION

TEMPERATURE, WATER (DEG C) SPECIFIC CONDUCTANCE IMICROMHOS STREAMFLOW (CUBIC FT/SEC)

PH (STANDARD UNITS)

PHOSPHORUS, TOTAL

NITRITE + NITRATE, TOTAL

NITROGEN, KJELDAHL, TOTAL

PHYTOPLANKTON, TOTAL (CELLS/ML)

SEDIMENT, SUSPENDED

SEDIMENT, CLAY-SILT (PERCENT)

COLIFORM, FECAL (COL/1OO ML)

STREPTOCOCCI, FECAL $(\mathrm{COL} / 100 \mathrm{ML})$

SILICA, DISSOLVED

CALCIUM, DISSOLVED

MAGNESIUM, DISSOLVED

SODIUM, DISSOLVED

POTASSIUM, DISSOLVED

BICARBONATE, ION

CARBONATE, ION

SULFATE, DISSOLVED

CHLORIDE, DISSOLVED

DISSOLVED SOLIDS, SUM OF CONST

DISSOLVED SOLIDS, ROE 180 DEG

HARDNESS, TUTAL

TURBIDITY ( JTU)

FLOUR IDE, DISSOLVEO
HARDNESS, NONCARBONATE

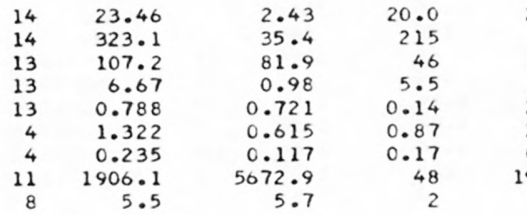

$48 \cdot 3$

$48 \cdot 3$

68.6

10.05

51.38
4.22

4.22
6.90

6.90
1.59

150.1

150.1

16.22

16.22
9.46

9.46
174.8

174.8

193.0
146.5

146.5
23.0

23.0
1.0

0.50
46.0

95.7

0.97

8.80
0.62

1.17

0.71

40.2

0.0

8.35

1.36

23.3

14.9

25.0

13.2

0.6
0.32

1
18
8.2
32.0
3.0
5.2
0.7
72
0
8.9
7.9
120
160
92
4
0
0.1

BEGRESSION SUMMABY REGRESSION SAMPLE COEFICIENT, CONSTANT, CORRELATION ERROR OF SIZE - B - - B COEEICIENI ESIUMAIF

*Not significant at the 95 percent confidence level.

\section{DURAIION IABLE_DE_DAILY SPECIEIC CONDUCIANCE}

DAILY SPECIFIC CONDUCTANCE IN

MAILY SPECIFIC CONDUCTANC

EQUALLED OR EXCEEDED FOR THE

$\begin{array}{llllll}18 & 5 z & 10 \% & 20 z & 30 z & 58 \\ 389 & 352 & 350 & 338 & 330 & 325\end{array}$

INOICATEO PERCENTAGE OF TIME

352

\begin{tabular}{|c|c|c|c|c|c|}
\hline & & & & & STANDARD \\
\hline & HARMONIC & AMPLITUDE & PHASE & VAR IATION & ERROR OF \\
\hline SAMPLE & MEAN - M & $-A$ & ANGLE - C & EXPLAINED & ESTIMATE \\
\hline SIZE_ & DEEG CL & - DEEG CL & (RADIANS) & $-(z)$ & (DEG $C)$ \\
\hline 292 & 22.05 & 1.35 & 3.35 & 16 & 2.23 \\
\hline
\end{tabular}

SUMMARY OF MAXIMUM AND MINIMUM CONCENTRATIONS OF CONSTITUENTS SAMPLED AT A FREQUENCY OF QUARTERLY (1975 WY)

02303000 -- HILLSBOROUGH RIVER NEAR ZEPHYRHILLS, FLA.

\begin{tabular}{|c|c|c|c|c|c|c|}
\hline \multirow{2}{*}{ CONSTITUENT } & \multicolumn{3}{|c|}{ TOTAL } & \multicolumn{3}{|c|}{ DISSOLVED } \\
\hline & $\begin{array}{l}\text { NO. } \\
\text { SAMPLES }\end{array}$ & $\begin{array}{l}\text { MIN IMUM } \\
\text { CONC. }\end{array}$ & $\begin{array}{l}\text { MAXIMUM } \\
\text { CONC. }\end{array}$ & $\begin{array}{l}\text { NO. } \\
\text { SAMPLES }\end{array}$ & $\begin{array}{l}\text { MINIMUM } \\
\text { CONC. }\end{array}$ & $\begin{array}{l}\text { MAXIMUM } \\
\text { CONC. }\end{array}$ \\
\hline \multicolumn{7}{|l|}{ MINOR ELEMENTS: } \\
\hline ARSENIC (AS), UG/L & 5 & 0 & 2 & 4 & 0 & 1 \\
\hline CADM IUM $(C D), \quad U G / L$ & 5 & 0 & 1 & 4 & 0 & 1 \\
\hline CHROMIUM (CR), UG/L & 4 & $<10$ & 20 & 4 & 0 & 1 \\
\hline COBALT $(C O), U G / L$ & 4 & 0 & 10 & 4 & 0 & 1 \\
\hline COPPER (CU), UG/L & 4 & 4 & 9 & 5 & 0 & 2 \\
\hline IRON (FE), UG/L & 5 & 90 & 180 & 5 & 0 & 40 \\
\hline LEAD $(P B), U G / L$ & 5 & 0 & 67 & 5 & 0 & 3 \\
\hline MANG ANESE $(M N), U G / L$ & 5 & 0 & 70 & 5 & 0 & 80 \\
\hline MERCURY (HG), UG/L & 5 & 0.0 & 0.5 & 4 & 0.0 & 0.0 \\
\hline SELENIUM (SE), UG/L & 4 & 0 & 0 & 4 & 0 & 0 \\
\hline$Z I N C(Z N), U G / L$ & 4 & 10 & 30 & 5 & 0 & 30 \\
\hline \multicolumn{7}{|l|}{ PERIPHYTON: } \\
\hline BIOMASS, DRY WT., G/SQ M & 2 & 2.19 & 39.00 & & & \\
\hline BIOMASS, ASH WT., G/SQ M & 2 & 1.19 & 25.00 & & & \\
\hline CHLOROPHYLL A, MG/SO M & 1 & 42.0 & & & & \\
\hline CHLOROPHYLL B, MG/SQ M & 1 & 2.0 & & & & \\
\hline ORGANIC CARBON, MG/L & 4 & 2.0 & 7.0 & & & \\
\hline
\end{tabular}


Table 14.--Summary of measurements at each station--Continued

LAT 28D59M19S LONG 082020M59S

DRAINAGE AREA: 1825 SO MI 144727 SQ KM)

PERIOD OF RECORD: $10 / 01 / 74-09 / 30 / 75$

STATISTICAL SUMMARY OF SELECTED DISSOLVED CHEMICAL CONSTITUENTS AND REGRESSION RELATIONSHIPS OF CONSTITUENT CONCENTRATIONS TO SPECIFIC CONDUCTANCE

CONSILIUENI

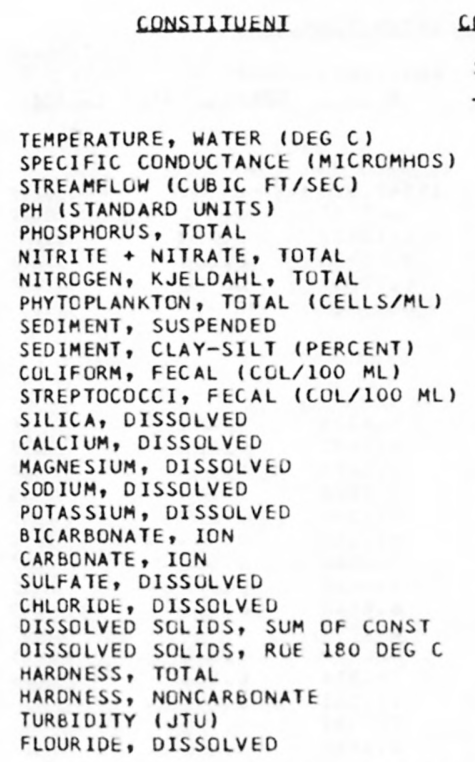

\begin{tabular}{c} 
CONSIUI \\
SAMPLE \\
SIZE \\
\hline 12 \\
12 \\
12 \\
12 \\
12 \\
12 \\
12 \\
12 \\
12 \\
12 \\
0 \\
12 \\
11 \\
11 \\
11 \\
11 \\
11 \\
11 \\
11 \\
4 \\
11 \\
12 \\
11 \\
11 \\
12 \\
12 \\
12 \\
11
\end{tabular}

NI IMG $\angle \perp$ OR UNII SHOWNL

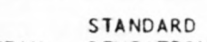

MEAN

22.38

311.3

521.3

7.76

0.027
0.080

0.080
0.437

1101.1

STANDARO

DEYIAIION

5.14

$47 \cdot 3$
$284 \cdot 6$

284.6

0.37
0.013

0.013
0.053

0.183

2204.6
1.5

29.6
94.1

94.1
12.35

51.27
4.69

4.69
4.95

0.38

134.5

0.3

30.36

8.11

181.0

195.4

146.3

33.8

1.5
0.23
33.5

116.0

18.61
8.76

0.64

0.58

0.16
23.8

0.5

18.92

1.70
34.8

34.8

33.3

24.3
26.5

0.8

0.08

\begin{tabular}{|c|c|}
\hline \multicolumn{2}{|c|}{ BANGE } \\
\hline 13.5 & 28.5 \\
\hline 242 & 402 \\
\hline 175 & 1270 \\
\hline 7.2 & 8.4 \\
\hline 0.01 & 0.05 \\
\hline 0.02 & 0.18 \\
\hline 0.27 & 0.85 \\
\hline 87 & 7000 \\
\hline 0 & 5 \\
\hline 0 & 110 \\
\hline 0 & 330 \\
\hline 3.7 & 68.0 \\
\hline 39.0 & 64.0 \\
\hline 3.4 & 5.7 \\
\hline 4.2 & 6.0 \\
\hline 0.2 & 0.7 \\
\hline 100 & 173 \\
\hline 0 & 1 \\
\hline 11.0 & 83.0 \\
\hline 4.3 & 11.0 \\
\hline 140 & 252 \\
\hline 158 & 270 \\
\hline 110 & 190 \\
\hline 2 & 110 \\
\hline 0 & 3 \\
\hline 0.1 & 0.4 \\
\hline
\end{tabular}
\begin{tabular}{lc}
\multicolumn{3}{c}{ REGRESSION_SUMMABY } \\
REGRESSION \\
SAMPLE COEFICIENT, CONSTANT, CORR \\
SIZE
\end{tabular}

12
12
12
12
12
12

$-0.0000$

$-0.00011$

0.00048
-0.00063

$-9.179$
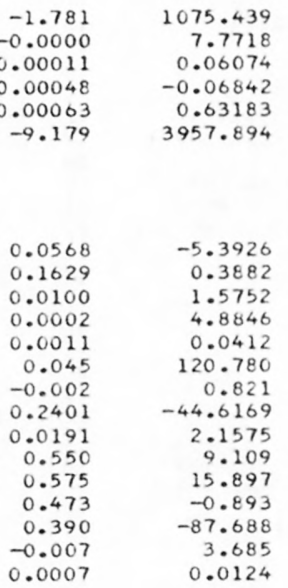

$\begin{array}{ll}1 & 1 \\ 1 & 1 \\ 1 & 1 \\ 1 & 1 \\ 1 & 1 \\ 1 & 1 \\ 4 \\ 1 & 1 \\ 1 & 2 \\ 1 & 1 \\ 1 & 1 \\ 1 & 2 \\ 1 & 2 \\ 1 & 2 \\ 1 & 1\end{array}$

-5.3926
0.3882
1.5752
4.8846
0.0412
120.780
0.821
44.6169
2.1575
9.109
15.897
-0.893
-87.688
3.685
0.0124
$-0.296 *$
-0.006 *

$-0.006$

$-0.397$

0.429.

-0.162 *
-0.197 *

0.38

0.38
0.013

0.013

0.050

0.189

2267.0

*Not significant at the 95 percent confidence level.

$0.151 *$

0.919

0.775

0.017 .

0.337 *

$0.084^{\circ}$

-0.113
0.627

$0.531 *$

0.782

0.854

0.921

0.921

$-0.416$.

$-0.416 *$
$0.433 *$

DAILY SPECIFIC CONDUCTANCE IN

MICROMHOS AT 25 DEG C, THAT WAS

EQUALLED OR EXCEEDED FOR THE

IABLE_OF_DALI SPECIEIC_CONDUCIANCE

$\begin{array}{llllll}18 & -58 & 102 & 202 & 30 \% & 50 \% \\ 370 & 352 & 350 & 337 & 329 & 310\end{array}$

STANDARD

ERROR OF

SUMMARY OF HARMONIC ANALYSIS OF STREAM TEMPERATURE

FORM OF EOUALION: $I \cdot(0)=M+A * S I N C .0172 * 0+C)$

\begin{tabular}{|c|c|c|c|c|c|}
\hline & & & & & STANDARD \\
\hline & HARMONIC & AMPLI TUDE & PHASE & VARIATION & ERROR OF \\
\hline SAMPLE & MEAN - M & - $A$ & ANGLE - C & EXPLAINED & ESTIMATE \\
\hline SLZE. & 10E 6 C) & IDEG $C 1$ & (BADJANS) & $-1 \% 1$ & (DEG_C) \\
\hline 363 & 23.05 & 5.98 & 3.04 & 80 & 2.12 \\
\hline
\end{tabular}

SUMMARY OF MAXIMUM AND MINIMUM CONCENTRATIONS OF CONSTITUENTS SAMPLED AT A FREQUENCY OF OUARTERLY (1975 WY)

\begin{tabular}{|c|c|c|c|c|c|c|}
\hline \multirow{2}{*}{ CONSTITUENT } & \multicolumn{3}{|c|}{ TOTAL } & \multicolumn{3}{|c|}{ DISSOLVED } \\
\hline & $\begin{array}{l}\text { NO. } \\
\text { SAMPLES }\end{array}$ & $\begin{array}{l}\text { MINIMUM } \\
\text { CONC. }\end{array}$ & $\begin{array}{l}\text { MAXIMUM } \\
\text { CONC. }\end{array}$ & $\begin{array}{l}\text { NO. } \\
\text { SAMPLES }\end{array}$ & $\begin{array}{l}\text { MINIMUM } \\
\text { CONC. }\end{array}$ & $\begin{array}{l}\text { MAXIMUM } \\
\text { CONC. }\end{array}$ \\
\hline \multicolumn{7}{|l|}{ MINOR ELEMENTS: } \\
\hline ARSENIC (AS), UG/L & 5 & 0 & 2 & 4 & 0 & 1 \\
\hline CADMIUM $(C D), U G / L$ & 5 & 0 & 1 & 4 & 0 & 1 \\
\hline CHROMIUM (CR), UG & 4 & $<10$ & 10 & 4 & 0 & 0 \\
\hline COBALT $(C O)$, UG/L & 4 & 0 & 1 & 4 & 0 & 1 \\
\hline COPPER $(C U), U G / L$ & 4 & 1 & 8 & 5 & 0 & 2 \\
\hline IRON (FE), UG/L & 5 & 90 & 600 & 5 & 10 & 330 \\
\hline LEAD $(P B), U G / L$ & 5 & 0 & 17 & 5 & 0 & 1 \\
\hline MANG ANESE (MN), UG/L & 5 & 0 & 28 & 5 & 0 & 13 \\
\hline MERCURY (HG), UG/L & 4 & 0.0 & 0.1 & 4 & 0.0 & 0.1 \\
\hline SELENIUM (SE), UG/L & 3 & 0 & 0 & 4 & 0 & 0 \\
\hline ZINC $(Z N), U G / L$ & 4 & 9 & 50 & 5 & 0 & 90 \\
\hline \multicolumn{7}{|l|}{ PERIPHYTON: } \\
\hline BIOMASS, DRY WT., G/SQ M & 2 & 23.00 & 29.00 & & & \\
\hline BIOMASS, ASH WT., G/SO M & 4 & 3.09 & 21.00 & & & \\
\hline CHLOROPHYLL A, MG/SQ M & 4 & 11.0 & 79.0 & & & \\
\hline CHLOROPHYLL B, MG/SQ M & 4 & 2.0 & 13.0 & & & \\
\hline ORGANIC CARBON, MG/L & 11 & 3.0 & 24.0 & & & \\
\hline
\end{tabular}


LAT 29057M20S LONG 082055M40S

DRAINAGE AREA: 7740 SQ MI ( 20047 SQ KM)

PERIOD OF RECORD: $10 / 01 / 74-09 / 30 / 75$

STATISTICAL SUMMARY OF SELECTED DISSOLVED CHEMICAL CONSTITUENTS AND

REGRESS ION RELATIONSHIPS OF CONSTITUENT CONCENTRATIONS TO SPECIFIC CONDUCTANCE

CONSIIIUENI

CONSIITUENI IMG/L OR UNII SHOWNU

TEMPERATURE, WATER (DEG C)
SPECIFIC CONOUCTANCE (MICROMHOS)
STREAMFLOW (CUBIC FT/SEC)
PH (STANDARD UNITS)
PHOSPHORUS, TOTAL
NITRITE, NITRATE, TUTAL
NITROGEN, KJELOAHL, TOTAL
PHYTOPLANKTON, TOTAL (CELLS/ML)
SEDIMENT, SUSPENDED
SEDIMENT, CLAY-SILT (PERCENT)
COLIFORM, FECAL (COL/IOO ML)
STREPTOCOCCI, FECAL (COL/IOO ML)
SILICA, DISSOLVED
CALCIUM, DISSOLVED
MAGNESIUM, DISSOLVED
SODIUM, DISSOLVED
POTASSIUM, OISSOLVED
BICARBONATE, ION
CARBONATE, ION
SULFATE, DISSOLVEU
CHLORIDE, DISSOLVED
DISSOLVE SULIDS, SUM OF (ONST
DISSOLVED SOLIDS, ROE IBO DEG C
HARDNESS, TOTAL
HARDNESS, NONCARBONATE
TURBIDITY (JTU)
FLOURIDE, DISSOLVED

\begin{tabular}{r} 
SAMPLE \\
SIZE \\
\hline 12 \\
12 \\
13 \\
11 \\
12 \\
12 \\
12 \\
12 \\
10 \\
0 \\
11 \\
12 \\
12 \\
12 \\
12 \\
12 \\
12 \\
12 \\
12 \\
12 \\
12 \\
12 \\
12 \\
12 \\
12 \\
12 \\
12
\end{tabular}

STANDARD

DEYIAIIEN

20.33
152.7

152.7
9159.2

9159.2

0.186

0.311

0.490

255.2

6.4

64.8

44.8
6.14

6.14
25.22

25.22
4.32

4.12

0.62

80.2

0.0

11.05
5.61

97.0

122.8

22.8

80.5

14.9
5.8

0.30

4.86

93.2

5022.4
0.36

0.047

0.190

0.195

197.0
3.9

93.9

$$
\begin{aligned}
& 93.9 \\
& 45.6
\end{aligned}
$$

45.6
1.22

1.22
14.95

2.62

0.52

0.22

53.7

4.40

0.91

48.3

49.1

47.4

7.7
3.8

0.06
*Not significant at the 95 percent confidence level.

DAILY SPECIFIC CONDUCTANCE IN

MICROMHOS AT 25 DEG C, THAT WAS

EQUALLED OR EXCEEDED FGR THE
INDICATED PERCENTAGE OF TIME

BAILN IABLE OF DAULY SPECIEIC CONOUCIANCE

$\begin{array}{llllll}18 & -5 \pi & 10 \% & 20 \% & 30 \% & 50 \\ 310 & 304 & 298 & 233 & 220 & 16\end{array}$

BANGE

$11.5 \quad 26.0$

$\begin{array}{rr}42 & 320 \\ 2800 & 20000\end{array}$

6.3

0.12

0.05

0.12
5

2

10
0
4.4

4.4
5.0
0.9

0.9
3.5

0.3

6
0

5.9
4.1
34

24

18
5

2
0.2
$20000 \quad 12$

7.5
0.27

$0.59 \quad 12$

$0.72 \quad 12$

530
14

300

170

$8.3 \quad 12$

49.0
8.7

5.5
1.0

160

19.0
7.3

7.3
175

190

160
30

15
0.4

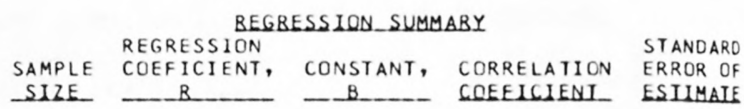

$-38.605$ 0.0024 0.00011 0.00179 $-0.00189$

$-0.585$

0.7527

0.16832

0.03718

0.77871

344.515

$-0.733$

0.658

0.227

0.880

$-0.902$

$-0.277$

3502.8

0.28

0.048

0.095

0.088

198.5
4.4319

3.9432

0.2686

3.5828

0.9356

$-1.880$

0.000

4.6638
6.8140

2.8140

24.29
55.459

55.459
11.318

12.301

10.391

0.3415
0.856

0.869

0.945

0.623

$-0.899$

0.934

0.886

0.886
-0.805

0.920

0.838

0.891

0.207

-0.731
-0.420
0.66

7.75
0.90

0.43

0.10

20.1
0.0

0.0
2.15
0.57
19.9

19.9

28.1
22.6

7.9

2.7

0.06

SUMMARY OF HARMONIC ANALYSIS OF STREAM TEMPERATURE

\begin{tabular}{|c|c|c|c|c|c|}
\hline & & & & & STANDARD \\
\hline & HARMONIC & AMPLITUDE & PHASE & VARIATION & ERROR OF \\
\hline SAMPLE & MEAN - M & $\overline{-A}$ & ANGLE - C & EXPLAINED & ESTIMATE \\
\hline$-512 E_{-}$ & NoEs al & IOEG 61 & (BADIANS) & $-(8)$ & $\left(D E E_{2}(1)\right.$ \\
\hline 318 & 21.04 & 5.79 & 2.64 & 88 & 1.48 \\
\hline
\end{tabular}

SUMMARY OF MAXIMUM AND MINIMUM CONCENTRATIONS DF CONSTITUENTS

SAMPLED AT A FREQUENCY OF QUARTERLY (1975 WY)

02320500 -- SUWANNEE RIVER AT BRANFORD, FLA.

\begin{tabular}{|c|c|c|c|c|c|c|}
\hline \multirow{2}{*}{ CONSTI TUENT } & \multicolumn{3}{|c|}{ TOTAL } & \multicolumn{3}{|c|}{ DISSOLVED } \\
\hline & $\begin{array}{l}\text { NO. } \\
\text { SAMPLES }\end{array}$ & $\begin{array}{l}\text { MIN IMUM } \\
\text { CONC. }\end{array}$ & $\begin{array}{l}\text { MAXIMUM } \\
\text { CONC. }\end{array}$ & $\begin{array}{l}\text { NO. } \\
\text { SAMPLES }\end{array}$ & $\begin{array}{l}\text { MINIMUM } \\
\text { CONC. }\end{array}$ & $\begin{array}{l}\text { MAXIMUM } \\
\text { CONC. }\end{array}$ \\
\hline \multicolumn{7}{|l|}{ MINOR ELEMENTS: } \\
\hline ARSENIC (AS), UG/L & 4 & 0 & 1 & 4 & 0 & 1 \\
\hline CAOMIUM $(C D), U G / L$ & 3 & 0 & 0 & 4 & 0 & 0 \\
\hline CHROMIUM (CR), UG/L & 3 & $<10$ & 20 & 4 & 0 & 0 \\
\hline COBALT $(C O), U G / L$ & 3 & 0 & 1 & 4 & 0 & 0 \\
\hline COPPER (CU), UG/L & 3 & 3 & 9 & 4 & 1 & 12 \\
\hline IRON (FE), UG/L & 3 & 220 & 650 & 4 & 100 & 390 \\
\hline LEAD (PB), UG/L & 3 & 1 & 16 & 4 & 1 & 15 \\
\hline MANGANESE (MN), UG/L & 3 & 20 & 56 & 4 & 10 & 70 \\
\hline MERC URY (HG), UG/L & 4 & 0.0 & 0.3 & 4 & 0.0 & 0.1 \\
\hline SELENIUM (SE), UG/L & 4 & 0 & 0 & 4 & 0 & 1 \\
\hline$Z I N C(Z N), U G / L$ & 3 & 4 & 100 & 4 & 0 & 4 \\
\hline \multicolumn{7}{|l|}{ PERIPHYTON: } \\
\hline BIOMASS, DRY WT., G/SQ M & 1 & 5.09 & & & & \\
\hline BIOMASS, ASH WT., G/SO M & 3 & 1.50 & 7.89 & & & \\
\hline CHLOROPHYLL A, MG/SQ M & 3 & 16.0 & 140.0 & & & \\
\hline CHLOROPHYLL B, MG/SO M & 3 & 1.1 & 19.0 & & & \\
\hline ORGANIC CARBON, MG/L & 11 & 5.0 & 26.0 & & & \\
\hline
\end{tabular}


LAT 30D33M14S LONG $084023 M 03 S$

DRAINAGE AREA: 1140 SQ MI

PERIOD OF RECORD: $10 / 01 / 74-09 / 30 / 75$ SQ KMI

STATISTICAL SUMMARY OF SELECTED DISSOLVED CHEMICAL CONSTITUENTS AND

REGRESSION RELATIONSHIPS OF CONSTITUENT CONCENTRATIONS TO SPECIFIC CONDUCTANCE

CONSIUTUENT.

CONSIUUENT IMG/L OR UNII SHOWNI

\section{TEMPERATURE, HATER (DEG C)}

SPECIFIC CONDUCTANCE (MICROMHOS)

STREAMFLOH (CUBIC FT/SEC)

PH (STANDARD UNITS)

PHOSPHORUS, TOTAL

NITRITE + NITRATE, TOTAL

NITROGEN, KJELDAHL, TOTAL

PHYTOPLANKTON, TOTAL (CELLS/ML)

SEDIMENT, SUSPENDED

SEDIMENT, CLAY-SILT (PERCENT)

COLIFORM, FECAL (COL/100 ML)

STREP TOCOCCI, FECAL (COL/100 ML)

SILICA, DISSOLVED

CALCIUM, DISSOL VED

MAGNESIUM, DISSOLVED

SODIUM, DISSOLVED

POTASSIUM, DISSOLVED

BICARBONATE, ION

CARBONATE, ION

SULFATE, DISSOLVED

CHLORIDE, DISSOLVED

DISSOLVED SOLIDS, SUM OF CONST

DISSOLVED SOLIDS, ROE 180 DEG C

HARONESS, TOTAL

HARDNESS, NONCARBONATE

IURBIDITY (JTU)

FLOURIDE, DISSOLVED

SA

TANDARD

MEAN DEYIAIION

$21.17 \quad 5.64$

$129.0 \quad 104.2$

$1483.9 \quad 1243.5$

$6.56 \quad 0.32$

$0.409 \quad 0.318$

$0.567 \quad 0.158$

217.1

14.5

0.158
160.9

160.9
8.4

BANGE

$\begin{array}{ll}51.0 & 40.4\end{array}$

7.22

5.25

1.96

1.96
10.39

10.39
1.75

18.3

0.0

5.05

15.70

56.9
78.6

21.1

31.3
0.20

1.82

2.92

1.08

0.38

0.38
10.1

0.0

3.08
9.87

30.0

32.9

11.7

28.1

28.1
0.11

2.5

2.5

0.9

4.7
1.3

8
0

2.4

8.0
35

35
50
10

10
7

0.0
$0.191 \quad 0.103$

*Not significant at the 95 percent confidence level.

REGRESSION SUMMARY

REGRESSION \begin{tabular}{l} 
SAMPLE \\
SIZE \\
\hline
\end{tabular} COEFICIENT

CONSTANT, CORRELATION COEEICIENI ST ANDARD ESIIMAIE

$\begin{array}{rrr}9.0 & 26.5 & \\ 41 & 371 & \\ 119 & 3340 & 9 \\ 6.2 & 7.0 & 8 \\ 0.10 & 0.41 & 9 \\ 0.12 & 0.92 & 9 \\ 0.35 & 0.81 & 9 \\ 54 & 490 & 8\end{array}$

$\begin{array}{rr}-5.127 & 2145.300 \\ 0.0011 & 6.4077 \\ 0.00032 & 0.14966 \\ 0.00094 & 0.28755 \\ -0.00049 & 0.63028 \\ -0.351 & 266.237\end{array}$

-0.429 . $0.374 *$ $0.325 *$ $0.308 *$ $-0.325 *$

-0.230 *

1200.5 0.32

0.323

0.160

169.1

$10 \quad 13$

10
4.9
130
220
9.6
11.0
4.0
22.0
2.4
37
0
10.0
32.0
110
131
44
14
80
0.3
0.0008

0.0086

0.0044

0.0085

0.0000

0.030

0.000

0.0061

0.0128

0.057

0.052

0.039

0.016

0.0003
7.1169

4.0453

1.3507

9.1963

1.7462

4.039

4.1967

13.9116

48.871

71.284

15.699

4.0472

0.1568
0.045 .

0.311 *

0.429.

0.008 *

0.314

0.314

0.000.

0.209

0.137 .

0.202 *

0.168

0.350 .

0.376 .

-0.434 *

0.305 .
1.96

1.05

7.47

0.41

10.4

3.25

3.25

10.56

31.7

35.0

11.8
4.4

27.1

0.11

SUMMARY OF MAXIMUM AND MINIMUM CONCENTRATIONS OF CONSTITUENTS

SAMPLED AT A FREQUENCY OF QUARTERLY (1975 WY)

02329000 - OCHLOCKONEE RIVER NR HAVANA FLA

\begin{tabular}{|c|c|c|c|c|c|c|}
\hline \multirow{2}{*}{ CONSTI TUENT } & \multicolumn{3}{|c|}{ TOTAL } & \multicolumn{3}{|c|}{ DISSOLVED } \\
\hline & $\begin{array}{l}\text { NO. } \\
\text { SAMPLES }\end{array}$ & $\begin{array}{l}\text { MINIMUM } \\
\text { CONC. }\end{array}$ & $\begin{array}{l}\text { MAXIMUM } \\
\text { CONC. }\end{array}$ & $\begin{array}{l}\text { NO. } \\
\text { SAMPLES }\end{array}$ & $\begin{array}{l}\text { MINIMUM } \\
\text { CONC. }\end{array}$ & $\begin{array}{l}\text { MAXIMUM } \\
\text { CONC. }\end{array}$ \\
\hline
\end{tabular}

MINOR ELEMENTS:

ARSENIC (AS), UG/L

CADMIUM (CD), UG/L

CHROMIUM (CR), UG/L

COBALT (CO), UG/L

COPPER (CU), UG/L

IRON (FE), UG/L

LEAD (PB), UG/L

MANGANESE (MN), UG/

MERCURY (HG), UG/L

SELENIUM (SE), UG/L

ZINC $(Z N), U G / L$

1
0
$<10$
0
3
1300
3
59
0.0
0
0

2
1
50
0
5
2300
12
80
0.2
0
20

3
3
3
3
3
3
3
3
3
3
3

1
0
0
0
0
180
1
20
0.0
0
0

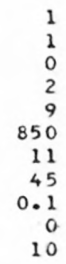

PERIPITTON:

BIOMASS, DRY WT, G/SO M

BIOMASS, ASH WT. G/SO M

CHLOROPHYLL A, MG/SO M

CHLOROPHYLL B, MG/SO M

ORGANIC CARBON, MG/L

8.0

14.0 
LAT 30D42M03S LONG 084D51M33S

LAT $30042 M 03 S$ LONG $084051 M 335$

DRAINAGE AREA: 17100 SQ MI 144289 SQ KMI

PERIOD OF RECORD: $10 / 01 / 74$ - 09/30/75

STATISTICAL SUMMARY OF SELECTED DISSOLVED CHEMICAL CONSTITUENTS AND

REGRESSION RELATIONSHIPS OF CONSTITUENT CONCENTRATIONS TO SPECIFIC CONDUCTANCE

CONSIUIUENI

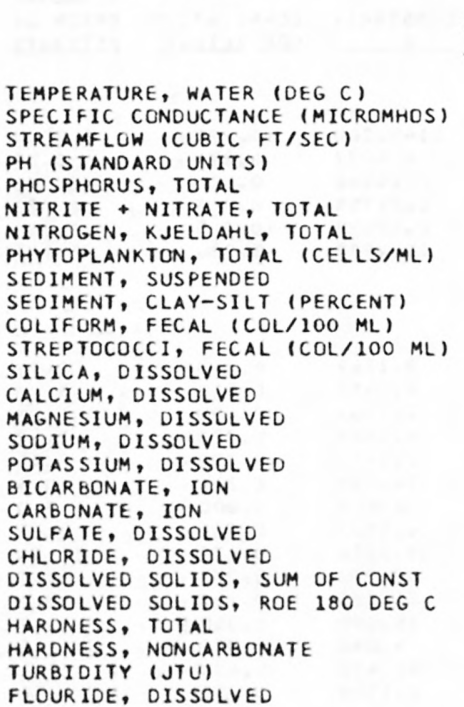

\begin{tabular}{r} 
CONSII \\
SAMPLE \\
SIZE \\
\hline 6 \\
6 \\
6 \\
5 \\
6 \\
6 \\
6 \\
6 \\
6 \\
0 \\
4 \\
5 \\
6 \\
6 \\
6 \\
6 \\
6 \\
6 \\
6 \\
6 \\
6 \\
6 \\
6 \\
6 \\
6 \\
6 \\
6
\end{tabular}

*Not significant at the 95 percent confidence level.

\section{BEGRESS ION SUMMABY}

SAMPLE REGRESSION SONSTANT, CORRELATION STANDARD SIZE COEEICIENI ESIUMAIE MEAN STANDARD

$21.83 \quad 7.00$ $\begin{array}{rr}29.9 \\ 056.7 & 25820.8\end{array}$ $7.40 \quad 25820.8$ 0.042 0.237 0.368 6625.0

16.8

0.32

0.017

0.083

0.042

747.0

$21.8 \quad 19.6$

29.2

6.98

11.58

1.00

4.43
1.23

40.8

0.0

4.78

3.50

3.50
53.8

57.5

33.2

2.0

15.0
0.12

15.6
0.63

0.63
3.42

0.13

1.87

0.18

13.0

0.0

1.57
0.80

0.80
12.3

12.3
19.2

8.6

1.7

0.04

$11.0 \quad 30.0$

$\begin{array}{rr}38 & 112 \\ 10300 & 79800\end{array}$

$\begin{array}{rr}7.1 & 7.9 \\ 0.02 & 0.07\end{array}$

$0.12 \quad 0.34$

0.32

0.42

12000

0.0066

$-0.00044$

$-0.00150$

0.00011

6.8534

0.07999

0.36760

0.37802

$-1639.598$

$-0.836$

$0.643 *$
$-0.764 *$

$-0.544 *$

$-0.079^{*}$

0.758 *

15858.1

0.28

0.012

0.077

0.047

2733.2

750

$\begin{array}{rr}6 & 50 \\ 6.3 & 7.9\end{array}$

$6.1 \quad 16.0$

$\begin{array}{ll}0.8 & 1.1 \\ 2.9 & 7.7\end{array}$

1.0

19

2.8

2.8

34
28

19
0

0.1
6.6409

2.5745

0.8504

4.3076

1.4420

14.339

0.000
4.4778

4.4106

3.4106

16.500

10.391

2.739

5.457
0.1559
0.186 *

0.905

0.406 *

$0.023^{*}$

$-0.409^{*}$

$0.699^{*}$

$0.000^{*}$

0.067 *

0.039 *

$0.029^{*}$

0.909

$-0.152 *$

0.370 *

-0.330 *

\begin{tabular}{|c|c|c|c|c|c|c|}
\hline \multirow{2}{*}{ CONSTI TUENT } & \multicolumn{3}{|c|}{ TOTAL } & \multicolumn{3}{|c|}{ DISSOLVED } \\
\hline & $\begin{array}{l}\text { NO. } \\
\text { SAMPLES }\end{array}$ & $\begin{array}{l}\text { MINIMUM } \\
\text { CONC. }\end{array}$ & $\begin{array}{l}\text { MAXIMUM } \\
\text { CONC. }\end{array}$ & $\begin{array}{l}\text { NO. } \\
\text { SAMPLES }\end{array}$ & $\begin{array}{l}\text { MINIMUM } \\
\text { CONC. }\end{array}$ & $\begin{array}{l}\text { MAXIMUM } \\
\text { CONC. }\end{array}$ \\
\hline \multicolumn{7}{|l|}{ MINOR ELEMENTS: } \\
\hline ARSENIC $(A S), U G / L$ & 4 & 0 & 2 & 4 & 0 & 2 \\
\hline CADMIUM $(C D), U G / L$ & 4 & 0 & 2 & 4 & 0 & 2 \\
\hline CHROMIUM (CR), UG/L & 4 & $<10$ & 20 & 4 & 0 & 1 \\
\hline COBALT $(C O), U G / L$ & 4 & 0 & 4 & 4 & 0 & 9 \\
\hline COPPER $(C U), U G / L$ & 4 & 6 & 14 & 4 & 2 & 6 \\
\hline IRON (FE), UG/L & 4 & 300 & 2800 & 4 & 0 & 100 \\
\hline LEAD $(P B), U G / L$ & 4 & 16 & 26 & 4 & 0 & 12 \\
\hline MANG ANESE (MN), UG/L & 4 & 50 & 150 & 4 & 0 & 30 \\
\hline MERCURY (HG), UG/L & 4 & 0.0 & 0.3 & 4 & 0.0 & 0.1 \\
\hline SELENIUM $(S E)$, UG/L & 4 & 0 & 0 & 4 & 0 & 0 \\
\hline ZINC $(Z N), U G / L$ & 4 & 10 & 70 & 4 & 0 & 30 \\
\hline \multicolumn{7}{|l|}{ PERIPHYTON: } \\
\hline BIUMASS, DRY HT., G/SQ M & 0 & & & & & \\
\hline BIOMASS, ASH WT,, G/SQ M & 0 & & & & & \\
\hline CHLOROPHYLL A, MG/SQ M & 0 & & & & & \\
\hline CHLOROPHYLL B, MG/SO M & 0 & & & & & \\
\hline ORGANIC CARBON, MG/L & 4 & 2.0 & 10.0 & & & \\
\hline
\end{tabular}


LAT $30032 M 02 S$ LONG $085009 M 55 S$
DRAINAGE AREA: 781 SQ MI ( 2023 SQ KM)

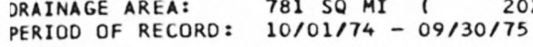

STATISTICAL SUMMARY OF SELECTED DISSOLVED CHEMICAL CONSTITUENTS AND

REGRESSION RELATIONSHIPS OF CONSTITUENT CONCENTRATIONS TO SPECIFIC CONDUCTANCE

CONSILIUENI

$$
\text { CONSIUIUENI IMG/L OR UNII SHOWNI }
$$

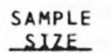

TEMPERATURE, WATER (DEG C)

SPECIFIC CONDUCTANCE (MICROMHOS)

STREAMFLOW (CUBIC FT/SEC)

PH (STANDARD UNITS)

PHOSPHORUS, TOTAL

NITRITE + NITRATE, TOTAL

NITROGEN, KJELDAHL, TOTAL

PHYTOPLANKTON, TOTAL (CELLS/ML)

SEOIMENT, SUSPENDED

SEDIMENT, CLAY-SILT (PERCENT)

COLIFORM, FECAL (COL/100 ML)

STREPTOCOCCI, FECAL (COL/100 ML)

SILICA, DISSOLVED

CALCIUM, DISSOL VED

MAGNE SIUM, DISSOL VED

SODIUM, DISSOLVED

POTASSIUM, DISSOLVED

BICARBONATE, ION

CARBONATE, ION

SULFATE, DISSOLVED

CHLORIDE, DISSOLVED

DISSOLVED SOLIDS, SUM OF CONST

DISSOLVED SOLIDS, ROE 180 DEG C

HARDNESS, TOTAL

HARDNESS, NONCARBONATE

TURBIDITY (JTU)

FLOURIDE, DISSOLVED

)

STANDARD

MEAN DEYIALION

20.88
184.1

184.1
1661.0

1661.0
7.66

0.029

0.567

0.251

131.9

4.63

4.63
31.5

31.5
636.3
0.28

0.28
0.008

0.008
0.148

0.148
0.073

9.5

77.1

38.3

60.0

6.10
30.75

30.75
3.39

3.09

0.49

103.9

0.0

1.71
5.27

5.27
102.3

102.3
112.0

91.5

9.8
7.1

7.1
0.15

22.3

18.3

0.57

5.09

0.77

0.55

0.04

15.1

0.90

0.90
0.85

0.85
12.5

8.9

16.4
4.9

2.0
0.31
NDI

$12.5 \quad 25.0$

$140 \quad 225$

$\begin{array}{rr}618 & 2400 \\ 7.0 & 7.9\end{array}$

$0.02 \quad 0.04$

$0.30 \quad 0.73$

0.12

55

* Not significant at the 95 percent confidence level.

SUMMARY OF MAXIMUM AND MINIMUM CONCENTRATIONS OF CONSTITUENTS

SAMPLED AT A FREQUENCY OF QUARTERLY (1975 WY)

$02359000--$ CHIPOLA RIVER NR ALTHA, FLA.

\begin{tabular}{|c|c|c|c|c|c|c|}
\hline \multirow{2}{*}{ CONSTI TUENT } & \multicolumn{3}{|c|}{ TOTAL } & \multicolumn{3}{|c|}{ DISSOLVED } \\
\hline & $\begin{array}{l}\text { NO. } \\
\text { SAMPLES }\end{array}$ & $\begin{array}{l}\text { MIN IMUM } \\
\text { CONC. }\end{array}$ & $\begin{array}{l}\text { MAXIMUM } \\
\text { CONC. }\end{array}$ & $\begin{array}{l}\text { NO. } \\
\text { SAMPLES }\end{array}$ & $\begin{array}{l}\text { MINIMUM } \\
\text { CONC. }\end{array}$ & $\begin{array}{l}\text { MAXIMUM } \\
\text { CONC. }\end{array}$ \\
\hline \multicolumn{7}{|l|}{ MINOR ELEMENTS: } \\
\hline ARSENIC (AS), UG/L & 4 & 0 & 1 & 4 & 0 & 1 \\
\hline CADMIUM $(C D), U G / L$ & 4 & 0 & 0 & 4 & 0 & 4 \\
\hline CHROMIUM (CR), UG/L & 4 & $<10$ & $<10$ & 4 & 0 & 0 \\
\hline COBALT $(C O), U G / L$ & 4 & 0 & 1 & 4 & 0 & 2 \\
\hline COPPER (CU), UG/L & 4 & 4 & 31 & 4 & 2 & 3 \\
\hline IRON (FE), UG/L & 4 & 150 & 650 & 4 & 0 & 200 \\
\hline LEAD $(P B), U G / L$ & 4 & 1 & 28 & 4 & 1 & 14 \\
\hline MANGANESE (MN), UG/L & 4 & 20 & 40 & 4 & 0 & 20 \\
\hline MERCURY (HG), UG/L & 4 & 0.1 & 0.5 & 4 & 0.0 & 0.2 \\
\hline SELENIUM (SE), UG/L & 4 & 0 & 0 & 4 & 0 & 0 \\
\hline ZINC $(2 N), U G / L$ & 4 & 0 & 30 & 4 & 0 & 10 \\
\hline \multicolumn{7}{|l|}{ PERIPHYTON: } \\
\hline BIOMASS, DRY WT., G/SQ M & 0 & & & & & \\
\hline BIOMASS, ASH WT., G/SO M & 0 & & & & & \\
\hline CHLOROPHYLL A, MG/SO M & 0 & & & & & \\
\hline CHLOROPHYLL B, MG/SQ M & 0 & & & & & \\
\hline ORGANIC CARBON, MG/L & 4 & .0 & 4.0 & & & \\
\hline
\end{tabular}


AT 30027M03S LONG $085053 M 54 S$ RAINAGE AREA: 4384 SQ MI ( 11355 SQ KM)

'ERIOD OF RECORD: $10 / 01 / 74-09 / 30 / 75$

STATISTICAL SUMMARY OF SELECTED DISSOLVED CHEMICAL CONSTITUENTS AND REGRESSION RELATIONSHIPS OF CONSTITUENT CONCENTRATIONS TO SPECIFIC CONDUCTANCE

CONSILIUENI

PEMPRATURE, WATER (DEG C)
SPECIFIC CONDUCTANCE (MICROMHOS)
STREAMFLON (CUBIC, FT/SEC)
PH (STANDARD UNITS)
PHOSPHORUS, TOTAL,
NITRITE, NITRATE, TOTAL
NITROGEN, KJELDAHL, TOTAL
PHYTOPLANKTON, TOTAL (CELLS/ML)
SEDIMENT, SUSPENDED
SEDIMENT, CLAY-SILT (PERCENT)
COLIFORM, FECAL (COL/IOO ML)
STREPTOCOCCI, FECAL (COL/IOO ML)
SILICA, DISSOLVED
CALCIUM, DISSOLVED
MAGNESIUM, DISSOLVED
SODIUM, DISSOLVED
POTASSIUM, DISSOLVED
BICARBONATE, ION
CARBONATE, ION
SULFATE, DISSOLVED
CHLORIDE, DISSOLVED
DISSOLVED SOLIDS, SUM OF CONST
DISSOLVED SOLIDS, ROE I8O DEG C
HARONESS, TOTAL
HARDNESS, NONCARBONATE
TURBIDITY IJTU)
FLOURIDE, DISSOLVED

CONSILUUENT IMG/L OR UNUL SHOHNL

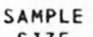

SIZE

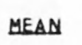

20.22

77.7

7113.3

7.17
0.037

0.037
0.174

0.174

0.306

168.3

5.64

5.64
21.6
2908.4

2908.4

0.15
0.014

0.080

0.080

166.3

68.3
274.0

274.0
6.40

6.40
10.86

1.52

2.98

0.83

37.6

0.0
2.16

4.40

48.1

55.8

33.7
3.1

3.1
23.3

0.12

36.6
182.7

182.7
0.39

0.39
3.26

0.39

0.50

0.10

0.53

0.66

10.9

15.0

9.4

3.1
10.3

0.19

*Not significant at the 95 percent confidence level. SUMMARY OF HARMONIC ANALYSIS OF STREAM TEMPERATURE

\begin{tabular}{|c|c|c|c|c|c|}
\hline & & & & & STANDARD \\
\hline $\begin{array}{l}\text { SAMPLE } \\
\text { SIZE. }\end{array}$ & $\begin{array}{l}\text { HARMONIC } \\
\text { MEAN - M } \\
\text { LDEG CI }\end{array}$ & $\begin{array}{c}\text { AMPLITUDE } \\
-A \\
(D E G(1)\end{array}$ & $\begin{array}{l}\text { PHASE } \\
\text { ANGLE - C } \\
\text { (RADIANS) }\end{array}$ & $\begin{array}{l}\text { VAR IATION } \\
\text { EXP LAINED } \\
\text { (I) }\end{array}$ & $\begin{array}{l}\text { ERROR OF } \\
\text { ESTIMATE } \\
\text { (DEG_C) }\end{array}$ \\
\hline 110 & 20.28 & 5.81 & 2.60 & 77 & 1.64 \\
\hline
\end{tabular}

BEGRESSION_SUMMARY REGRESSION SAMPLE COEFICIENT, CONSTANT, CORRELATION STANDARD SIZE - R COEEICIENI ESIIMAI

\begin{tabular}{|c|c|c|c|c|c|c|}
\hline $\begin{array}{r}10.0 \\
46\end{array}$ & $\begin{array}{r}25.5 \\
110\end{array}$ & & & & & \\
\hline 2110 & 12200 & 9 & -117.935 & 16272.957 & -0.876 & 1499.4 \\
\hline 7.0 & 7.4 & 9 & 0.0043 & 6.8297 & $0.625 *$ & 0.13 \\
\hline 0.02 & 0.06 & 9 & -0.00057 & 0.08097 & -0.871 & 0.007 \\
\hline 0.04 & 0.29 & 9 & 0.00274 & -0.03820 & 0.738 & 0.058 \\
\hline 0.15 & 0.44 & 9 & -0.00132 & 0.40816 & $-0.357 *$ & 0.080 \\
\hline 6 & 510 & 9 & 0.736 & 111.155 & $0.096 *$ & 176.9 \\
\hline
\end{tabular}

$20 \quad 130$

$130 \quad 520$

$\begin{array}{lr}5.8 & 7.0 \\ 7.3 & 18.0\end{array}$

1.1

2.5

0.7

$\begin{array}{r}19 \\ +0 \\ \hline\end{array}$

1.5
3.6
35

25
23

0
10

0.0

18.0
2.1

4.2
1.0

1.0
66

0
3.2

3.2
5.9
72

72
82
54
7
40

9
9
9
9
9
9
9
9
9
9
9
9
9
9
9

0.0120
0.1357
0.0131
0.0178
0.0010
0.559
0.000
-0.0173
0.0189
0.456
0.587
0.387
-0.040
-0.123
-0.0050

5.4681
0.3170
0.5037
1.5939
0.7585
-5.888
0.000
3.4999
2.9314
12.703
10.157
3.590
6.245
32.901
0.5098

0.669

0.900

0.727

0.775
0.208

0.894

0.000 .

$-0.710$

0.616

0.616

0.847

0.887

$-0.285$

$-0.258$

-0.561 *

SUMMARY OF MAXIMUM AND MINIMUM CONCENTRATIONS OF CONSTITUENTS SAMPLED AT A FREQUENCY OF OUARTERLY (1975 WY)

02366500 -- CHOCTAWHATCHEE RIVER NR BRUCE FLA

\begin{tabular}{|c|c|c|c|c|c|c|}
\hline \multirow{2}{*}{ CONSTITUENT } & \multicolumn{3}{|c|}{ TOTAL } & \multicolumn{3}{|c|}{ DISSOLVED } \\
\hline & $\begin{array}{l}\text { NO. } \\
\text { SAMPLES }\end{array}$ & $\begin{array}{l}\text { MINIMUM } \\
\text { CONC. }\end{array}$ & $\begin{array}{l}\text { MAXIMUM } \\
\text { CONC. }\end{array}$ & $\begin{array}{l}\text { NO. } \\
\text { SAMPLES }\end{array}$ & $\begin{array}{l}\text { MINIMUM } \\
\text { CONC. }\end{array}$ & $\begin{array}{l}\text { MAXIMUM } \\
\text { CONC. }\end{array}$ \\
\hline \multicolumn{7}{|l|}{ MINOR ELEMENTS: } \\
\hline ARSENIC (AS), UG/L & 3 & 0 & 1 & 4 & 0 & 1 \\
\hline CADMIUM $(C D)$, UG/L & 3 & 1 & 2 & 4 & 0 & 1 \\
\hline CHROMIUM (CR), UG/L & 3 & $<10$ & 20 & 4 & 0 & 1 \\
\hline COBALT $(C O), U G / L$ & 3 & 0 & 10 & 4 & 0 & 3 \\
\hline COPPER (CU), UG/L & 3 & 3 & 4 & 4 & 0 & 2 \\
\hline IRON (FE), UG/L & 4 & 620 & 2600 & 4 & 60 & 490 \\
\hline LEAD $(P B), U G / L$ & 3 & 14 & 20 & 4 & 2 & 12 \\
\hline MANGANESE (MN), UG/L & 4 & 50 & 220 & 4 & 0 & 50 \\
\hline MERCURY $(H G), U G / L$ & 3 & 0.0 & 0.1 & 3 & 0.0 & 0.1 \\
\hline SELENIUM (SE), UG/L & 4 & 0 & 0 & 4 & 0 & 0 \\
\hline ZINC $(Z N), U G / L$ & 3 & 0 & 30 & 4 & 4 & 20 \\
\hline \multicolumn{7}{|l|}{ PERIPHYTON : } \\
\hline BIOMASS, DRY WT., G/SQ M & 0 & & & & & \\
\hline BIOMASS, ASH WT., G/SO M & 0 & & & & & \\
\hline CHLOROPHYLL A, MG/SQ M & 0 & & & & & \\
\hline CHLOROPHYLL B, MG/SQ M & 0 & & & & & \\
\hline ORGANIC CARBON, MG/L & 4 & 2.0 & 4.0 & & & \\
\hline
\end{tabular}


LAT 30D45MIOS LONG $086037 M 45 \mathrm{~S}$ DRAINAGE AREA: $624 \mathrm{SQ} \mathrm{MI}(1616$ SO KM PERIOD OF RECORD: $10 / 01 / 74-09 / 30 / 75$

STATISTICAL SUMMARY OF SELECTED DISSOLVED CHEMICAL CONSTITUENTS AND

REGRESSION RELATIONSHIPS OF CONSTITUENT CONCENTRATIONS TO SPECIFIC CONDUCTANCE

CONSIUIUENI

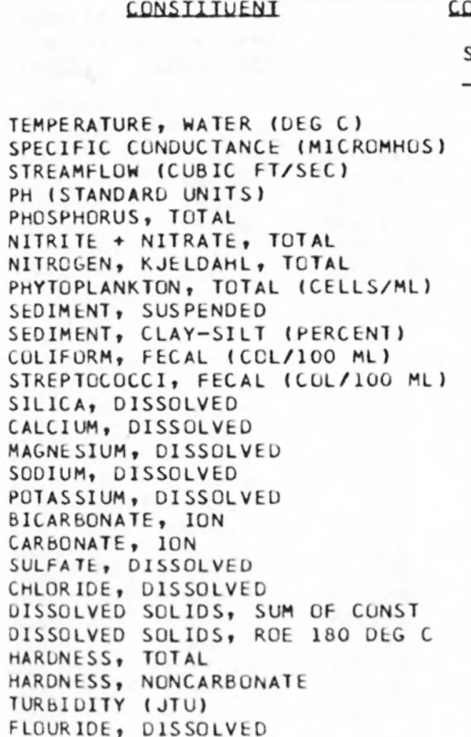

CONSI IUUENI I MGLL OR UNII_SHOHN)

\begin{tabular}{|c|c|c|}
\hline $\begin{array}{l}\text { SAMPLE } \\
\text { SIZE }\end{array}$ & MEAN & $\begin{array}{l}\text { STANDARD } \\
\text { DEYIAIION }\end{array}$ \\
\hline 11 & 18.18 & 5.57 \\
\hline 10 & 46.4 & 7.0 \\
\hline 11 & 982.7 & 674.6 \\
\hline 11 & 6.86 & 0.28 \\
\hline 11 & 0.047 & 0.038 \\
\hline 11 & 0.128 & 0.073 \\
\hline 11 & 0.398 & 0.282 \\
\hline 10 & 259.0 & 190.8 \\
\hline 10 & 22.1 & 11.5 \\
\hline 0 & & \\
\hline 9 & 374.4 & 452.7 \\
\hline 9 & 344.9 & 342.9 \\
\hline 10 & 6.09 & 0.67 \\
\hline 10 & 6.03 & 1.63 \\
\hline 10 & 1.07 & 0.30 \\
\hline 10 & 2.20 & 0.26 \\
\hline 10 & 0.47 & 0.08 \\
\hline 10 & 22.3 & 5.6 \\
\hline 10 & 0.0 & 0.0 \\
\hline 10 & 2.19 & 0.62 \\
\hline 10 & 3.49 & 0.77 \\
\hline 10 & 32.9 & 4.3 \\
\hline 10 & 39.8 & 6.4 \\
\hline 10 & 19.5 & 5.0 \\
\hline 10 & 1.8 & 1.8 \\
\hline 11 & 16.9 & 11.6 \\
\hline 10 & 0.09 & 0.09 \\
\hline
\end{tabular}

*Not significant at the 95 percent confidence level.

REGRESSION SAMPLE COEFICIENT, CONSTANT,

CORRELATION STANDARD COEEICIENI ESIIMAIE SIZE

- B.....

BANGE
8.5
38
272
6.3
0.02
0.02
0.15
110
8
0
40
4.9
3.6
0.7
1.8
0.4
15
0
1.2
2.4
25
28
12
0
5
0.0

25.0
60
2360
7.2
0.14
0.30
1.17
770
41
1200
100
7.3
9.0
1.5
2.7
0.6
33
0
2.9
5.1
39
45
28
5
45
0.3

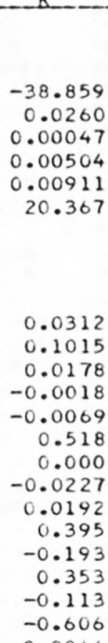

$$
\begin{array}{r}
2787.272 \\
5.6441 \\
0.02638 \\
-0.10566 \\
-0.01985
\end{array}
$$

-0.01985
-661.252

$-0.385$

0.620 *

$0.081 *$

0.463 *

0.216

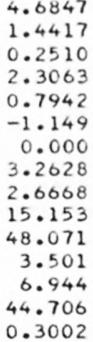

$0.317 *$

0.424 *

0.399 *

-0.050 *

-0.595 .

0.637 *

0.000

$-0.253$

$0.174 *$

-0.212 *

0.481 *

$-0.421 *$

$-0.350$

-0.362 .
696.2

0.25

.043

0.307

143.3

0.72

1.66

0.31

0.28

0.07

SUMMARY OF MAXIMUM AND MINIMUM CONCENTRATIONS OF CONSTITUENTS SAMPLED AT A FREQUENCY OF QUARTERLY (1975 WY)

02368000 -- YELLUW RIVER AT MILLIGAN FLA

CONSTITUENT
SAMPLES


.AT 30D57M25S LONG 087014MOOS

IRAINAGE AREA: 3817 SQ MI ( 9886 SQ KM)

'ERIOD OF RECORD: $10 / 01 / 74-09 / 30 / 75$

STATISTICAL SUMMARY OF SELECTED DISSOLVED CHEMICAL CONSTITUENTS AND

REGRESSION RELATIONSHIPS OF CONSTITUENT CONCENIRATIONS TO SPECIFIC CONDUCTANCE

CONSIIIUENI

TEMPERATURE, WATER (DEG C)
SPECIFIC CONDUCTANCE (MICROMHOS)
STREAMFLOW (CUBIC FT/SEC)
PH (STANDARD UNITS)
PHOSPHORUS, TOTAL
NITRITE + NITRATE, TOTAL
NITROGEN, KJELDAHL, TOTAL
PHYTOPLANKTON, TOTAL (CELLS/ML)
SEDIMENT, SUSPENDED
SEDIMENT, CLAY-SILT (PERCENT)
COLIFORM, FECAL (COL/IOO ML)
STREPTOCOCCI, FECAL (COL/1OO ML)
SILICA, DISSOLVED
CALCIUM, DISSOLVED,
MAGNESIUM, DISSOLVED
SODIUM, DISSOLVED
POTASSIUM, DISSOLVED
BICARBONATE, ION
CARBONATE, ION
SULFATE, DISSOLVED
CHLORIDE, DISSOLVED
DISSOLVED SOLIDS, SUM OF CONST
OISSOLVED SOLIDS, ROE 18O DEG C
HARDNESS, TOTAL
HARDNESS, NONCARBONATE
TURBIDITY (JTU)
FLOURIDE, DISSOLVED
FLO

CONSILUUENI IMGLL OR UNII SHOWNI

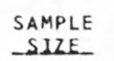

STANDARD

MEAN

18.58

12
12

$\begin{array}{rr}12 & 69.0 \\ 12 & 5940.0 \\ 11 & 6.90\end{array}$

$\begin{array}{rr}11 & 6.90 \\ 9 & 0.029\end{array}$

$9 \quad 0.139$

0.139
0.292

868.8
21.3

\subsection{6}

6.56
17.5

4040.7

0.30
0.009

0.009
0.038

0.038

0.061
1580.9

7.1

632.5

550.4

550.4
7.92

9.40
0.95

0.95
5.05

0.80

28.4

0.0
4.35

4.35
6.35

6.35
49.8

49.8
49.8

49.8
27.5

3.5
19.1

19.1
0.10

420.9

420.9
1002.6

002.6
0.26

0.26
1.35

0.39

2.13

0.14

4.2
0.0

0.83

2.05

7.8

16.9

3.5

3.4
6.6

0.00

*Not significant at the 95 percent confidence leve1.

8.0
41

$41 \quad 100$

6.1

0.01

0.08

0.21

14

160

48
7.7

7.7

7.8
0.5

3.6

0.7

25
0

3.6

4.9

30

24
0

11

0.1

0.40

5200
31

1300

3100

8.3
11.0

11.0
1.4

1.4
8.2

1.0
35

0
5.5
9.3

9.3

61

69
31
8
BEGRESSLON SUMMARY

$\begin{array}{lll} & \text { REGRESSION } & \text { STANDARD } \\ \text { SAMPLE COEFICIENT, CONSTANT, CORRELATION ERROR OF }\end{array}$ SIZE - COEEICIENI

OR OF

$\begin{array}{llllll}16300 & 12 & -108.344 & 13415.746 & -0.470 * & 3740.3\end{array}$

$\begin{array}{lll}7.2 & 11 & 0.0069\end{array}$

0.4189

0.00013

$-0.00071$

$-0.00215$

0.19108

0.45025

$-46.933$

4036.766

0.417 *
0.247 *

-0.323 *

-0.601 .

0.29

0.010

0.038

0.052

4
4
4
4
4
5
5
4
4
4
4
4
9
4

-0.0002
0.0378
-0.0126
0.0874
0.0067
0.206
0.000
0.0312
0.0741
0.314
0.414
0.053
-0.118
-0.219
-0.0000

7.9427
6.6403
1.8699
-1.3301
0.3106
13.712
0.000
2.0739
0.9428
26.812
19.559
23.667
12.109
35.187
0.1000

-0.019 .

0.570 *

-0.661 *

$0.835 *$

0.963 *

0.875 *

0.759 *

0.733 *

0.818 *

$0.497 *$

$0.304 *$

-0.701 *

-0.568 *
0.000 *

SUMMARY OF HARMONIC ANALYSIS OF STREAM TEMPERATURE

\begin{tabular}{|c|c|c|c|c|c|}
\hline & & & & & STANDARD \\
\hline & HARMONIC & AMPLITUDE & PHASE & VARIATION & ERROR OF \\
\hline SAMPLE & MEAN - M & $-A$ & ANGLE - C & EXPLAINED & ESTIMATE \\
\hline SIZE & LEG 61 & -1DEG $(1)$ & (BADIANS) & $-(z)$ & LDEG $C$ ) \\
\hline 12 & 18.74 & 8.24 & 2.93 & 87 & 2.63 \\
\hline
\end{tabular}

SUMMARY OF MAXIMUM AND MINIMUM CONCENTRATIONS OF CONSTITUENTS SAMPLED AT A FREQUENCY OF QUARTERLY (1975 WY)

02375500 -- ESCAMBIA RIVER NEAR CENTURY, FLA.

\begin{tabular}{|c|c|c|c|c|c|c|}
\hline \multirow{2}{*}{ CONSTITUENT } & \multicolumn{3}{|c|}{ TOTAL } & \multicolumn{3}{|c|}{ DISSOLVED } \\
\hline & $\begin{array}{l}\text { NO. } \\
\text { SAMPLES }\end{array}$ & $\begin{array}{l}\text { MIN IMUM } \\
\text { CONC. }\end{array}$ & $\begin{array}{l}\text { MAXIMUM } \\
\text { CONC. }\end{array}$ & $\begin{array}{l}\text { NO. } \\
\text { SAMPLES }\end{array}$ & $\begin{array}{l}\text { MINIMUM } \\
\text { CONC. }\end{array}$ & $\begin{array}{c}\text { MAXIMUM } \\
\text { CONC. }\end{array}$ \\
\hline \multicolumn{7}{|l|}{ MINOR ELEMENTS: } \\
\hline ARSENIC (AS), UG/L & 4 & 1 & 1 & 4 & 0 & 1 \\
\hline CADMIUM $(C D), U G / L$ & 4 & 0 & 1 & 4 & 0 & 0 \\
\hline CHROMIUM (CR), UG/L & 4 & $<10$ & 30 & 4 & 0 & 1 \\
\hline COBALT $(C O)$, UG/L & 4 & 0 & 5 & 4 & 0 & 0 \\
\hline COPPER (CU), UG/L & 4 & 0 & 7 & 4 & 1 & 3 \\
\hline IRON (FE), UG/L & 4 & 890 & 2100 & 4 & 120 & 520 \\
\hline LEAD $(P B), U G / L$ & 4 & 4 & 20 & 4 & 0 & 10 \\
\hline MANGANESE (MN), UG/L & 4 & 50 & 120 & 4 & 23 & 60 \\
\hline MERCURY (HG), UG/L & 3 & 0.1 & 0.3 & 4 & 0.0 & 0.1 \\
\hline SELENIUM (SE), UG $/ L$ & 4 & 0 & 0 & 4 & 0 & 0 \\
\hline$Z I N C(Z N), U G / L$ & 4 & 8 & 30 & 4 & 0 & 20 \\
\hline \multicolumn{7}{|l|}{ PER IPHYTON: } \\
\hline BIOMASS, DRY WT., GISO M & 0 & & & & & \\
\hline BIOMASS, ASH WT., G/SO M & 0 & & & & & \\
\hline CHLOROPHYLL A, MG/SQ M & 0 & & & & & \\
\hline CHLOROPHYLL B, MG/SQ M & 0 & & & & & \\
\hline ORGANIC CARBON, MG/L & 7 & .0 & 7.0 & & & \\
\hline
\end{tabular}


Table 14.--Summary of measurements at each station--Continued

LAT $32024 M 41 S$ LONG $086024 M 30 S$

DRAINAGE AREA: 15100 SO MI 139109 SQ KMI

PERIOD OF RECORD: $10 / 01 / 74-09 / 30 / 75$

STATISTICAL SUMMARY OF SELECTED DISSOLVED CHEMICAL CONSTITUENTS AND

REGRESSION RELATIONSHIPS OF CONSTITUENT CONCENTRATIONS TO SPECIFIC CONDUCTANCE

CONSIUIUENI

CONSIUIUENI
TEMPERATURE, WATER (DEG C)
SPECIFIC CONDUCTANCE (MICROMHOS)
STREAMFLOH (CUBIC, FT/SEC)
PH (STANDARD UNITS)
PHOSPHORUS, TOTAL
NITRITE N NITRATE, TOTAL
NITROGEN, KJELDAHL, TOTAL
PHYTOPLANKTON, TOTAL (CELLS/ML)
SEDIMENT, SUSPENDED
SEDIMENT, CLAY-SILT (PERCENT)
COLIFORM, FECAL (COL/IOO ML)
STREPTOCOCCI, FECAL (COL/IOO ML)
SILICA, DISSOLVED
CALCIUM, DISSOLVED
MAGNESIUM, DISSOLVED
SODIUM, DISSOLVED
POTASSIUM, DISSOLVED
BICARBONATE, ION
CARBONATE, ION
SULFATE, DISSOLVED
CHLORIDE, OISSOLVED
DISSOLVED SOLIDS, SUM OF CONST
DISSOLVED SOLIDS, ROE 18O DEG C
HARDNESS, TOTAL
HARDNESS, NONCARBONATE
TURBIDITY (JTU)
FLOUR IDE, DISSOLVED

SAMPL
SIZE
13
13
10
13
10
10
10
9
10
10
10
10
12
12
12
12
12
13
5
12
12
12
9
12
12
9
12

ENT IMG/L OR UNII SHOWNI)

MPLE
IZE
13
13
10
13
10
10
10
9
10
10
10
10
12
12
12
12
12
13
5
12
12
12
9
12
12
9
12

STANDARD

18.54

98.2

1580.0

7.09

0.050

0.173

0.348

501.1
35.5

35.5
85.5

85.5
782.8

221.7

6.64
8.49

8.49

2.86

4.57
1.42

38.2

0.0

5.97

4.00
55.0

55.0
58.3

33.0

2.1

21.7

33326.2

0.36

8.2

1237.5
376.3

1.96

10.7

7.5
2.4

10.3
BANGE

6.87

0.020

0.050

0.195

296.5

296.5
31.9

376.3
0.92

0.78

1.67

0.46

9.1
0.0
1.19
1.58

1.19
1.58

8.8
7.5

0.05
9.0

15600

5600
6.3
0.01

0.10

0.10
0.15

140

12
73

76
4

4
4.5
5.7

5.7
2.0

2.6

0.9

24

0

4.1
1.6

39
46

22
0
5

0.0

155
129000
7.8
0.08
0.23
0.87
1100
116
97
4000
1200
8.2
13.0
3.9
7.2
2.2
49
0
8.0
6.6
69
71
48
8
40
0.2

$60 \quad 28.0$

BEGRESSION SUMMABY

REGRESSION

SAMPLE COEFICIENT,

CONSTANT, CORRELATION COEEICIENI

STANDARD SIZE
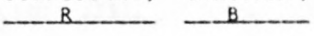

OF

10 0.0048 $-0.00012$

$-0.00155$

0.00121

75684.563 6.6162 0.06104 0.31822

0.23487

665.884

$-0.200 *$

$0.323 *$

$-0.153^{*}$

$-0.809$

$0.161^{*}$

$-0.163 *$

34633.0

0.36
0.021

0.031

0.204

312.7

*Not significant at the 95 percent confidence level.

SUMMARY OF HARMONIC ANALYSIS OF STREAM TEMPERATURE

EORM OF EQUAIION: I. $(0) \equiv M+A * S I N C .0172 * 0+C)$

\begin{tabular}{|c|c|c|c|c|c|}
\hline & & & & & STANDARD \\
\hline & HARMONIC & AMPLITUDE & PHASE & VAR IATION & ERROR OF \\
\hline SAMPLE & MEAN - M & $-A$ & ANGLE $-C$ & EXPLAINED & ESTIMATE \\
\hline SIZE_ & 10EG 61 & $10 E G(1)$ & IRAD JANSI & $-(8)$ & (DEG_C \\
\hline 13 & 18.44 & 9.24 & 2.60 & 96 & 1.48 \\
\hline
\end{tabular}

SUMMARY OF MAXIMUM AND MINIMUM CONCENTRATIONS OF CONSTITUENTS SAMPLED AT A FREOUENCY OF QUARTERLY (1975 WY)

02420000 -- ALABAMA RIVER NEAR MONTGOMERY, ALA.

\begin{tabular}{|c|c|c|c|c|c|c|}
\hline \multirow{2}{*}{ CONSTITUENT } & \multicolumn{3}{|c|}{ TOTAL } & \multicolumn{3}{|c|}{ DISSOLVED } \\
\hline & $\begin{array}{l}\text { NO. } \\
\text { SAMPLES }\end{array}$ & $\begin{array}{l}\text { MIN IMUM } \\
\text { CONC. }\end{array}$ & $\begin{array}{l}\text { MAXIMUM } \\
\text { CONC. }\end{array}$ & $\begin{array}{l}\text { NO. } \\
\text { SAMPLES }\end{array}$ & $\begin{array}{l}\text { MINIMUM } \\
\text { CONC. }\end{array}$ & $\begin{array}{l}\text { MAXIMUM } \\
\text { CONC. }\end{array}$ \\
\hline \multicolumn{7}{|l|}{ MINOR ELEMENTS: } \\
\hline ARSENIC (AS), UG/L & 2 & 1 & 2 & 8 & 0 & 3 \\
\hline CADM IUM $(C D), U G / L$ & 4 & 0 & 4 & 8 & 0 & 2 \\
\hline CHROMIUM (CR), UG/L & 4 & $<10$ & $<10$ & 8 & 0 & 1 \\
\hline COBALT $(C O), U G / L$ & 4 & 0 & 2 & 8 & 0 & 4 \\
\hline COPPER (CU), UG/L & 4 & 6 & 13 & 8 & 0 & 3 \\
\hline IRON (FE), UG/L & 4 & 370 & 2900 & 7 & 0 & 210 \\
\hline LEAD $(P B), U G / L$ & 4 & 0 & 44 & 8 & 0 & 6 \\
\hline MANGANESE $(M N), U G / L$ & 4 & 30 & 260 & 7 & 10 & 70 \\
\hline MERCURY (HG), UG/L & 3 & 0.0 & 0.2 & 8 & 0.0 & 0.5 \\
\hline SELENIUM (SE), UG/L & 2 & 0 & 0 & 4 & 0 & 1 \\
\hline ZINC $(Z N), U G / L$ & 4 & 20 & 80 & 8 & 0 & 9 \\
\hline \multicolumn{7}{|l|}{ PERIPHYTON: } \\
\hline BIOMASS, DRY WT., G/SQ M & 3 & .09 & 45.00 & & & \\
\hline BIOMASS, ASH WT., G/SO M & 3 & .00 & 32.00 & & & \\
\hline CHLOROPHYLL A, MG/SQ M & 3 & .1 & 13.0 & & & \\
\hline CHLOROPHYLL B, MG/SO M & 3 & .0 & 3.8 & & & \\
\hline ORGANIC CARBON, MG/L & 4 & 4.7 & 27.0 & & & \\
\hline
\end{tabular}


LAT $31032 M 48 S$ LONG $087030 M 45 S$ DRAINAGE AREA: 22000 SQ MI ( 56980 SQ KMI

PERIOD OF RECORD: $10 / 01 / 74-09 / 30 / 75$

STATISTICAL SUMMARY OF SELECTED DISSOLVED CHEMICAL CONSTITUENTS AND REGRESSION RELATIONSHIPS OF CONSTITUENT CONCENTRATIONS TO SPECIFIC CONDUCTANCE

CONSIIIUENI

CONSILIUENI IMGLL OR UNII SHOWN

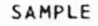

\begin{tabular}{l} 
SAMPLE \\
SIZE \\
\hline
\end{tabular}

MEAN

STANDARD

DEVIAIION

TEMPERATURE, WATER (DEG C) SPECIFIC CONDUCTANCE (MICROMHOS) STREAMFLOW (CUBIC FT/SEC)

PH (STANDARD UNITS)

PHOSPHORUS, TOTAL

NITRITE + NITRATE, TOTAL

NITROGEN, KJELDAHL, TOTAL

PHYTOPLANKTON, TOTAL (CELLS/ML)

SEDIMENT, SUSPENDED

SEDIMENT, CLAY-SILT (PERCENT)

COLIFORM, FECAL (COL/100 ML)

STREPTOCOCCI, FECAL ( $\mathrm{COL} / 100 \mathrm{ML})$

SILICA, DISSOLVED

CALCIUM, DISSULVED

MAGNESIUM, DISSOLVED

SODIUM, DISSOLVED

POTASSIUM, DISSOLVED

BICARBONATE, ION

CAREONATE, ION

SULFATE, DISSOLVED

CHLOR IDE, DISSOLVED

DISSOLVED SOLIDS, SUM OF CONST

DISSOLVED SOLIDS, ROE 180 DEG HARDNESS, TOTAL

HARDNESS, NONCARBONATE

TURBIDITY (JTU)

FLUURIDE, DISSOLVED
$102.6 \quad 20.6$

$5710.0 \quad 49571.3$

7.12

0.070

0.192

0.342

482.5

74.8

81.2

193.3

337.

6.97
10.78

10.78
2.24

4.64

1.32

40.5
0.0

6.22

4.19

58.8

58.5

36.2

3.8
26.6

0.17

0.23

0.035

0.037

0.140

299.6

72.5

17.5
291.8

291.8

484.9

0.88
1.42

0.57

1.73

0.24

0.6
0.0

1.16

1.78

1.78
8.8

8.2

5.3

1.9
16.9

0.06

${ }^{*}$ Not significant at the 95 percent confidence level.

SUMMARY OF HARMONIC ANALYSIS OF STREAM TEMPERATURE

\begin{tabular}{|c|c|c|c|c|c|}
\hline & & & & & STANDARD \\
\hline & HARMONIC & AMPLITUDE & PHASE & VARIATION & ERROR OF \\
\hline $\begin{array}{l}\text { SAMPLE } \\
\text { SIZE. }\end{array}$ & $\begin{array}{l}\text { MEAN - M } \\
\text { LEEG CI }\end{array}$ & $\begin{array}{l}-{ }^{A} \\
(D E G()\end{array}$ & $\begin{array}{l}\text { ANGLE }-\mathrm{C} \\
\text { (BADIANS) }\end{array}$ & $\begin{array}{c}\text { EXPLA INED } \\
(I)\end{array}$ & $\begin{array}{l}\text { ESTIMATE } \\
\text { (DEG C) }\end{array}$ \\
\hline 12 & 19.36 & 8.89 & 2.70 & 91 & 2.21 \\
\hline
\end{tabular}

SUMMARY OF MAXIMUM AND MINIMUM CONCENTRATIONS OF CONSTITUENTS

SAMPLED AT A FREQUENCY OF QUARTERLY (1975 WY) REGRESSION BEGRESSION SUMMARY

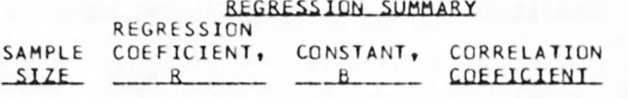

STANDARD ERROR OF ESIUMAIS $9.5 \quad 29.0$ $7120 \quad 142000$ $\begin{array}{rr}6.6 & 7.4 \\ 0.03 & 0.16\end{array}$ $0.14 \quad 0.26$ 0.19 110 20

40
2

6
5.3

8.1

1.5
2.2

1.1

0

4.6
1.6

47

26

9

0.1

0.63

260

98

1000
1600

$8.1 \quad 12$

13.0

$3.1 \quad 12$

7.8
1.7
50

$12-1319.234$

$\begin{array}{rr}12 & 0.0006 \\ 12 & -0.00029\end{array}$

$-0.00029$

$-0.00170$

6.482

191041.438

7.0609

0.09967

0.22849

0.51698

$-182.479$

-0.548 *

0.055 *

-0.169 *

$-0.194^{*}$ *

0.446 *

43483.1

0.25

0.038

0.143

281.3

0.0077

0.0429

0.0225

0.0685

0.0070

6.1792

6.3823

$-0.0688$

$-2.3814$

10.705

0.621

0.817

0.816

0.594
0.912

0.0447

0.0741

0.372

0.218

0.202

$-0.016$

-0.393
-0.0005

1.6319

$-3.4083$

20.619

36.992

15.486

5.360

66.876
0.2217

0.794

0.858

0.874

0.548
0.788

0.788

-0.173 *

-0.478 *

-0.151 *
0.91

1.17

0.34
1.05

0.20

0.74

0.96

4.5

7.2
3.4

1.9

15.6
0.06

\begin{tabular}{|c|c|c|c|c|c|c|}
\hline \multirow{2}{*}{ CONSTI TUENT } & \multicolumn{3}{|c|}{ TOTAL } & \multicolumn{3}{|c|}{ DISSOLVED } \\
\hline & $\begin{array}{l}\text { NO. } \\
\text { SAMPLES }\end{array}$ & $\begin{array}{l}\text { MINIMUM } \\
\text { CONC. }\end{array}$ & $\begin{array}{l}\text { MAXIMUM } \\
\text { CONC. }\end{array}$ & $\begin{array}{l}\text { NO. } \\
\text { SAMPLES }\end{array}$ & $\begin{array}{l}\text { MINIMUM } \\
\text { CONC. }\end{array}$ & $\begin{array}{l}\text { MAXIMUM } \\
\text { CONC. }\end{array}$ \\
\hline \multicolumn{7}{|l|}{ MINOR ELEMENTS: } \\
\hline ARSENIC (AS), UG/L & 2 & 0 & 1 & 4 & 0 & 1 \\
\hline CADMIUM $(C D), U G / L$ & 4 & 0 & 1 & 4 & 0 & 2 \\
\hline CHROMIUM (CR), UG/L & 4 & $<10$ & $<10$ & 4 & 0 & 0 \\
\hline COBALT $(C O), U G / L$ & 3 & 0 & 2 & 4 & 0 & 5 \\
\hline COPPER (CU), UG/L & 4 & 0 & 9 & 4 & 0 & 9 \\
\hline IRON (FE), UG/L & 4 & 780 & 2200 & 4 & 80 & 150 \\
\hline LEAD $(P B), U G / L$ & 4 & 2 & 11 & 4 & 0 & 4 \\
\hline MANGANESE (MN), UG/L & 4 & 44 & 100 & 4 & 7 & 60 \\
\hline MERCURY (HG), UG/L & 4 & 0.0 & 0.3 & 4 & 0.0 & 0.1 \\
\hline SELENIUM (SE), UG/L & 4 & 0 & 0 & 4 & 0 & 0 \\
\hline$Z I N C(Z N), U G / L$ & 4 & 0 & 30 & 4 & 10 & 10 \\
\hline \multicolumn{7}{|l|}{ MERIPHYTON: } \\
\hline BIOMASS, DRY WT., G/SQ M & 3 & .09 & 2.29 & & & \\
\hline BIOMASS, ASH WT., G/SO M & 3 & .00 & 1.50 & & & \\
\hline CHLOROPHYLL A, MG/SO M & 3 & .0 & 40.0 & & & \\
\hline CHLOROPHYLL B, MG/SO M & 3 & .0 & 7.1 & & & \\
\hline ORGANIC CARBON, MG/L & 4 & 5.2 & 29.0 & & & \\
\hline
\end{tabular}


Table 14.--Sumnary of measurements at each station--Continued

LAT $32049 M$ S LONG $088009 M$ S

DRAINAGE AREA: 8700 SQ MI 122533 SQ KMI

PERIOD OF RECORD: $10 / 01 / 74-09 / 30 / 75$

STATISTICAL SUMMARY OF SELECTED DISSOLVED CHEMICAL CONSTITUENTS AND REGRESSION RELATIONSHIPS OF CONSTITUENT CONCENTRATIONS TO SPECIFIC CONDUCTANCE

CONSIIIUENI

TEMPERATURE, WATER (DEG C)
SPECIFIC CONOUCTANCE (MICROMHOS)
STREAMFLOW (CUBIC FT/SEC)
PH (STANDARD UNITS)
PHOSPHORUS, TOTAL
NITRITE, NITRATE, TOTAL
NITROGEN, KJELDAHL, TOTAL
PHYTOPLANKTON, TOTAL (CELLS/ML)
SEDIMENT, SUSPENDED
SEDIMENT, CLAY-SILT (PERCENT)
COLIFORM, FECAL (COL/IOO ML)
STREPTOCOCCI, FECAL (COL/IOO ML)
SILICA, DISSOLVED
CALCIUM, DISSOLVED
MAGNESIUM, OISSOLVED
SODIUM, DISSOLVED
POTASSIUM, DISSOLVED
BICARBONATE, ION
CARBONATE, ION
SULFATE, DISSOLVED
CHLORIDE, DISSOLVED
DISSOLVED SOLIDS, SUM OF CONST
OISSOLVED SOLIDS, ROE I8O DEG C
HARONESS, TOTAL
HARDNESS, NONCARBONATE
TURBIOITY (JTU)
FLOURIDE, DISSOLVED

CONSIUUUENI IMG/L OB UNII SHOWNI)
STANDARD

DEYIAIION

20.18 100.2 22604.5

7.17

0.116

0.200

0.517

5880.0

64.6

85.8

316.0

222.2

6.69
13.87

13.87

1.16

1.44

39.7

39.7
0.0

6.93

4.31
58.5

58.5
68.1

39.5

6.9

45.5

0.21
7.98

34.2
20947.0

0.27

0.053

0.156

0.135

9381.4

40.0

8.3
321.8

321.8
194.1

194.1
1.55

4.15

0.37

0.97

0.22

12.8

0.0
1.33

1.33
1.99

1.99
12.8

11.4

10.9
3.0

3.0
27.7

0.07
BEGRESSION SUMMABY

REGRESSION

SAMPLE COEFICIENT

CONSTANT,

CORRELATION COEEICIENI

STANDARD BANGE SIZE -

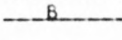

ESIUMATH

$\begin{array}{rr}8.0 & 31.5 \\ 64 & 158 \\ 2210 & 63400 \\ 6.8 & 7.9 \\ 0.05 & 0.22 \\ 0.00 & 0.48 \\ 0.33 & 0.77 \\ 320 & 27000 \\ 14 & 122 \\ 74 & 97 \\ 1 & 860 \\ 17 & 510 \\ 3.4 & 8.4 \\ 9.0 & 21.0 \\ 0.4 & 1.7 \\ 2.2 & 5.0 \\ 1.1 & 1.7 \\ 25 & 62 \\ 0 & 9 \\ 4.8 & 9.1 \\ 1.2 & 7.7 \\ 40 & 81 \\ 48 & 84 \\ 26 & 57 \\ 3 & 12 \\ 5 & 90 \\ 0.1 & 0.3\end{array}$

-407.823
0.0005
-0.00033
0.00112
-0.00197
98.481


0.0231
0.1043
0.0074
0.0170
0.0028
0.306
0.0193
0.0411
0.370
0.322
0.291
0.038
-0.277
0.0007

$-0.655$

17192.1

0.13

0.043

0.131
0.127

0.297

$-0.493$

5421.7

*Not significant at the 95 percent confidence leve1.

SUMMARY OF MAXIMUM AND MINIMUM CONCENTRATIONS OF CONSTITUENTS SAMPLED AT A FREQUENCY OF QUARTERLY (1975 WY)

02449000 -- TOMBIGBEE RIVER AT GAINESVILLE, ALA.

\begin{tabular}{|c|c|c|c|c|c|c|}
\hline \multirow{2}{*}{ CONSTITUENT } & \multicolumn{3}{|c|}{ TOTAL } & \multicolumn{3}{|c|}{ DISSOLVED } \\
\hline & $\begin{array}{l}\text { NO. } \\
\text { SAMPLES }\end{array}$ & $\begin{array}{l}\text { MINIMUM } \\
\text { CONC. }\end{array}$ & $\begin{array}{l}\text { MAXIMUM } \\
\text { CONC. }\end{array}$ & $\begin{array}{l}\text { NO. } \\
\text { SAMPLES }\end{array}$ & $\begin{array}{l}\text { MINIMUM } \\
\text { CONC. }\end{array}$ & $\begin{array}{l}\text { MAXIMUM } \\
\text { CONC. }\end{array}$ \\
\hline \multicolumn{7}{|l|}{ MINUR ELEMENTS: } \\
\hline ARSENIC (AS), UG/L & 4 & 1 & 2 & 4 & 0 & 0 \\
\hline CADMIUM $(C D), U G / L$ & 6 & 0 & 2 & 4 & 0 & 2 \\
\hline CHROMIUM (CR), UG/L & 7 & $<10$ & 10 & 4 & 0 & 0 \\
\hline COBALT $(C O), U G / L$ & 3 & 0 & 1 & 4 & 0 & 4 \\
\hline COPPER (CU), UG/L & 7 & 3 & 10 & 4 & 0 & 3 \\
\hline IRON (FE), UG/L & 7 & 1300 & 5500 & 4 & 30 & 330 \\
\hline LEAD (PB), UG/L & 7 & 1 & 34 & 4 & 0 & 2 \\
\hline MANGANESE (MN), UG/L & 7 & 80 & 180 & 4 & 2 & 60 \\
\hline MERCURY (HG), UG/L & 6 & 0.0 & 0.3 & 4 & 0.0 & 0.1 \\
\hline SELENIUM (SE), UG/L & 5 & 0 & 0 & 4 & 0 & 0 \\
\hline ZINC $(Z N), U G / L$ & 6 & 0 & 40 & 4 & 0 & 5 \\
\hline \multicolumn{7}{|l|}{ PERIPHYTON: } \\
\hline BIOMASS, DRY WT.. G/SO M & 4 & 2.19 & 14.00 & & & \\
\hline BIOMASS, ASH WT., G/SO M & 4 & .79 & 74.00 & & & \\
\hline CHLOROPHYLL A, MG/SQ M & 4 & .6 & 21.0 & & & \\
\hline CHLOROPHYLL B, MG/SO M & 4 & .1 & 1.3 & & & \\
\hline ORGANIC CARBON, MG/L & 6 & 5.5 & 28.0 & & & \\
\hline
\end{tabular}


Table 14.--Summary of measurements at each station--Continued

LAT $31045 M 30$ S LONG $088007 M 45 S$

DRAINAGE AREA: 18500 SQ MI 147915 SQ KMI

PERIOD OF RECORD: $10 / 01 / 74-09 / 30 / 75$

STATISTICAL SUMMARY OF SELECTED DISSOLVED CHEMICAL CONSTITUENTS AND

REGRESSION RELATIONSHIPS OF CONSTITUENT CONCENTRATIONS TO SPECIFIC CONDUCTANCE

CONSIUIUENI

\begin{tabular}{|c|}
\hline 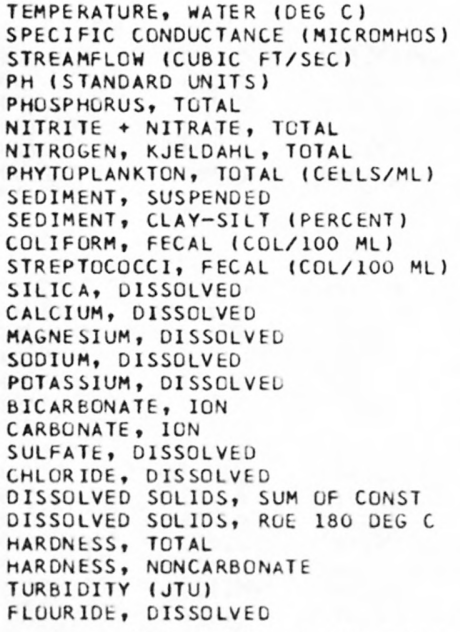 \\
\hline
\end{tabular}

CONSIUUENII_IMG $\angle L$ OR_UNII_SHOWNL

\begin{tabular}{rrr}
$\begin{array}{rrr}\text { SAMPLE } \\
\text { SIZE }\end{array}$ & MEAN & \multicolumn{1}{r}{ STANDARD } \\
DEYIAIION \\
12 & 19.29 & 7.42 \\
12 & 146.5 & 37.5 \\
12 & 45579.3 & 43431.6 \\
12 & 7.14 & 0.22 \\
12 & 0.076 & 0.032 \\
12 & 0.331 & 0.110 \\
12 & 0.435 & 0.105 \\
12 & 627.5 & 383.0 \\
12 & 80.6 & 68.8 \\
12 & 81.3 & 10.1 \\
11 & 1203.6 & 2792.6 \\
12 & 289.3 & 478.5 \\
12 & 7.33 & 1.10 \\
12 & 15.45 & 3.33 \\
12 & 2.40 & 0.57 \\
12 & 6.83 & 2.79 \\
12 & 1.74 & 0.42 \\
12 & 44.3 & 10.8 \\
1 & 0.0 & 0.0 \\
12 & 16.41 & 4.33 \\
12 & 6.79 & 3.55 \\
12 & 81.7 & 18.7 \\
9 & 90.2 & 13.5 \\
12 & 48.4 & 9.9 \\
12 & 12.1 & 3.0 \\
12 & 27.5 & 21.1 \\
12 & 0.23 & 0.10
\end{tabular}

BEGRESSION SUMMABY

REGRESSION

SAMPLE COEFICIENT, CONSTANT, CORRELATION STANDARD SIZE

$R$ COENEICIENI

$9.0 \quad 30.0$

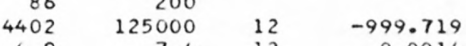

$\begin{array}{llll}6.9 & 7.4 & 12 & 0.0014\end{array}$

$0.04 \quad 0.15 \quad 12$

$0.16 \quad 0.46 \quad 12$

$\begin{array}{lll}0.25 & 0.55 & 12 \\ 250 & 1600 & 12\end{array}$

$-0.00000$

0.00265

$-0.00035$

6.9352

0.07607

$-0.05737$

0.48654

943.090

$-0.864$

$0.241 *$

$-0.002$

0.901

$-0.126 *$

0.22

0.034

0.050

0.109
392.7

$\begin{array}{rr}10 & 186 \\ 10 & 990 \\ 10 & 9500\end{array}$

1500

1500
$8.8 \quad 12$

8.8
23.0

23.0
3.3

12.0
2.3

120.0188

0.0188
0.0613

0.0613

0.0123
0.0630

0.0069

0.206

4.5742

6.4641

0.6034

$-2.3983$

0.7322

14.005

0.691

0.809

0.849

0.621
0.715

0.1003

0.0775

1.7087

$-4.5614$

15.523

23.703

18.446

0.411

0.205

0.034
-0.310

-0.310
0.0005

72.936
0.1549

0.870

0.819

0.907

0.874

0.777

0.416 *

-0.553 *
0.204 *

0.1

0.4

12

*Not significant at the 95 percent confidence level.

SUMMARY OF HARMONIC ANALYSIS OF STREAM TEMPERATURE EOBM OF EQUALION: I. $101=M+A *$ SING.0172* $+C$

\begin{tabular}{|c|c|c|c|c|c|}
\hline & & & & & STANDARD \\
\hline & HARMONIC & AMPLITUDE & PHASE & VARIATION & ERROR OF \\
\hline SAMPLE & MEAN - M & $-A$ & ANGLE - C & EXPLAINED & ESTIMATE \\
\hline SIZE_- & IDEG $(1)$ & DEE $(1)$ & IRADIANSI & (z) & IDEG $C 1$ \\
\hline 12 & 19.56 & 9.77 & 2.67 & 91 & 2.40 \\
\hline
\end{tabular}

SUMMARY OF MAXIMUM AND MINIMUM CONCENTRATIONS OF CONSTITUENTS SAMPLED AT A FREQUENCY OF QUARTERLY (1975 WY)

02469762 -- TOMBIGBEE R BELOW COFFEEVILLE LED NR COFFEEVILLE

\begin{tabular}{|c|c|c|c|c|c|c|}
\hline \multirow{2}{*}{ CONSTITUENT } & \multicolumn{3}{|c|}{ TOTAL } & \multicolumn{3}{|c|}{ DISSOLVED } \\
\hline & $\begin{array}{l}\text { NO. } \\
\text { SAMPLES }\end{array}$ & $\begin{array}{l}\text { MINIMUM } \\
\text { CONC. }\end{array}$ & $\begin{array}{l}\text { MAXIMUM } \\
\text { CONC. }\end{array}$ & $\begin{array}{c}\text { NO. } \\
\text { SAMPLES }\end{array}$ & $\begin{array}{l}\text { MINIMUM } \\
\text { CONC. }\end{array}$ & $\begin{array}{l}\text { MAXIMUM } \\
\text { CONC. }\end{array}$ \\
\hline \multicolumn{7}{|l|}{ MINOR ELEMENTS: } \\
\hline ARSENIC (AS), UG/L & 3 & 1 & 1 & 5 & 0 & 1 \\
\hline CADMIUM $(C D), U G / L$ & 4 & 0 & 1 & 5 & 0 & 7 \\
\hline CHROMIUM (CR), UG/L & 5 & $<10$ & 10 & 5 & 0 & 11 \\
\hline COBALT $(C O)$, UG/L & 5 & 0 & 2 & 5 & 0 & 2 \\
\hline COPPER (CU), UG/L & 5 & 1 & 10 & 5 & 0 & 7 \\
\hline IRON (FE), UG/L & 5 & 610 & 1800 & 5 & 10 & 270 \\
\hline$L E A D(P B), U G / L$ & 5 & 1 & 24 & 5 & 0 & 4 \\
\hline MANGANESE $(M N), U G / L$ & 5 & 52 & 100 & 5 & 10 & 70 \\
\hline MERCURY (HG), UG/L & 5 & 0.0 & 0.3 & 5 & 0.0 & 0.1 \\
\hline SELENIUM (SE), UG/L & 4 & 0 & 0 & 5 & 0 & 0 \\
\hline$Z I N C(Z N), U G / L$ & 4 & 10 & 160 & 5 & 3 & 10 \\
\hline \multicolumn{7}{|l|}{ PERIPHYTON: } \\
\hline BIOMASS, DRY WT., G/SO M & 4 & 2.19 & 34.00 & & & \\
\hline BIOMASS, ASH WT., G/SQ M & 4 & 1.50 & 18.00 & & & \\
\hline CHLOROPHYLL A, MG/SO M & 4 & .1 & 22.0 & & & \\
\hline CHLOROPHYLL B, MG/SQ M & 4 & .0 & 7.5 & & & \\
\hline ORGANIC CARBON, MG/L & 5 & 5.7 & 24.0 & & & \\
\hline
\end{tabular}


Table 14.--Summary of measurements at each station--Continued

IT $30052 M 45 S$ LONG $088046 M 22 S$

IAINAGE AREA: 0 SO MI

IRIOD OF RECORD: $10 / 01 / 74-09 / 30 / 75$

SO KMI

STATISTICAL SUMMARY OF SELECTED DISSOLVED CHEMICAL CONSTITUENTS AND

REGRESSION RELATIONSHIPS OF CONSTITUENT CONCENTRATIONS TO SPECIFIC CONDUCTANCE

CONSILIUENI

\begin{tabular}{r} 
CONS \\
SAM \\
SI \\
\hline 1 \\
1 \\
1 \\
1 \\
1 \\
1 \\
1 \\
\\
\\
1 \\
1 \\
1 \\
1 \\
1 \\
1 \\
1 \\
1 \\
1 \\
1 \\
1 \\
1 \\
1 \\
1
\end{tabular}

BEGRESSION SUMYARY

REGRESSION SAMPLE COEFICIENT, CONSTANT, CORRELATION SAMPLE COEFICIENT, CONSTANT, COEEICIENI STANDARD
ERROR OF 8.0
$8.0 N G E$ DEYIALION

TEMPERATURE, WATER (DEG C) SPECIFIC CONDUCTANCE (MICROMHOS) STREAMFLOH (CUBIC FT/SEC) PH (STANDARD UNITS) PHOSPHORUS, TOTAL

NITRITE + NITRATE, TOTAL NITROGEN, KJELDAHL, TOTAL PHYTOPLANKTON, TOTAL (CELLS/ML) SEDIMENT, SUSPENDED SEDIMENT, CLAY-SILT (PERCENT) COLIFORM, FECAL (COL/100 ML) STREPTOCOCCI, FECAL $/ \mathrm{COL} / 100 \mathrm{ML}$ SILICA, DISSOLVED CALCIUM, DISSOLVED MAGNESIUM, DISSOLVED SODIUM, DISSOLVED POTASSIUM, DISSOLVED BICARBONATE, ION CARBONATE, ION

SULFATE, DISSOLVED

CHLORIDE, DISSOLVED

DISSOLVED SOLIDS, SUM OF CONST

DISSOLVED SOLIDS, ROE 180 DEG C HARDNESS, TOTAL

HARDNESS, NONCARBONATE

TURBIDITY (JTU)

SIZE MEAN

\subsection{2} 81.8 15605.8 6.49 0.076 0.167 0.386 1641.8 1641.8
47.4 7.02
21.0
5457.2 5457.2
0.34 0.044 0.101 0.084 1599.8 1599.8
31.7 8.0
40
3230
5.9 0.03 0.03 0.20 100
14 $196.3 \quad 289.4$ 494.1 9.50 5.38 1.29 6.69

1.22 15.2 0.0 4.74 10.44 47.2 53.8 18.8
6.4 22.3

0.17
289.4
867.4

1.69
1.52

1.52

1.06
2.74

0.28

4.6

0.65

0.65
4.70

4.70
13.1

15.6
7.5

6.6

9.3

0.26
29.0

120
45700
6.9
0.20

0.31

5600

96

900
2400
12.0

$12.0 \quad 12 \quad 0.0668$

7.9
4.6

13.0

13.0
1.8

1.8
22

6.0

6.0
22.0

22.0
74
73

73
39
26

40
12
9
12
12
10
11


12
12
12
12
12
12
9
12
12
12
12
12
12
12
12

-604.813
0.0039
0.00068
0.00325
-0.00327
41.801


0.0668
0.0551
0.0341
0.1145
0.0043
0.166
0.000
0.0134
0.1825
0.561
0.355
0.280
0.147
-0.371
0.0033

65099.668 6.1353 0.01995 $-0.09957$

0.63512

$-1709.839$

4.0301 0.8714 $-1.4960$

0.8692

1.549

0.000

3.6416

$-4.4954$

1.228
24.718

24.718
-4.077

$-5.628$

52.61

$-0.0951$

$\begin{array}{rr}-0.823 & 9214.3 \\ 0.158 * & 0.36 \\ 0.323 * & 0.044 \\ 0.675 & 0.078 \\ -0.680 & 0.066 \\ 0.554 * & 1403.3\end{array}$

0.830

0.762
0.674

0.878

0.327 *

0.753

0.000 *

0.435

0.817
0.898

0.478 *

0.789

0.468 *

$-0.836$

$0.264 *$

SUMMARY OF HARMONIC ANALYSIS OF STREAM TEMPERATURE

\begin{tabular}{|c|c|c|c|c|c|}
\hline & & & & & STANDARD \\
\hline $\begin{array}{l}\text { SAMPLE } \\
\text { SLZE }\end{array}$ & $\begin{array}{l}\text { HARMONIC } \\
\text { MEAN - M } \\
\text { LEEG EI) }\end{array}$ & $\begin{array}{c}\text { AMPLITUDE } \\
-A \\
\text { (DEG C) }\end{array}$ & $\begin{array}{c}\text { PHASE } \\
\text { ANGLE - C } \\
\text { IRADIANSI }\end{array}$ & $\begin{array}{l}\text { VAR IATION } \\
\text { EXPLAINED } \\
(\$)\end{array}$ & $\begin{array}{l}\text { ERROR OF } \\
\text { ESTIMATE } \\
\text { IDEG C) }\end{array}$ \\
\hline
\end{tabular}

\begin{tabular}{l} 
MEAN - M \\
SIZE. $10 E G C 1-{ }^{A}$ ANGLE - C EXPLAINED ESTIMATE \\
\hline
\end{tabular}

$\begin{array}{llllll}12 & 20.46 & 9.01 & 3.91 & 85 & 3.05\end{array}$

SUMMARY OF MAXIMUM AND MINIMUM CONCENTRATIONS OF CONSTITUENTS

SAMPLED AT A FREQUENCY OF QUARTERLY (1975 WY)

02479020 -- PASCAGOULA RIVER NR BENNDALE, MS.

\begin{tabular}{l} 
CONSTITUENT \\
\hline
\end{tabular}


LAT $30047 M 35 S$ LONG 089049M15S

DRAINAGE AREA: 6630 SQ MI 1117172 SQ KMI

PERIOD OF RECORD: $10 / 01 / 74-09 / 30 / 75$

STATISTICAL SUMMARY OF SELECTED DISSOLVED CHEMICAL CONSTITUENTS AND

REGRESSION RELATIONSHIPS OF CONSTITUENT CONCENTRATIONS TO SPECIFIC CONDUCTANCE

CONSILIUENI

GONSIIIUENI IHG L OR UNIT SHOWNI)

\begin{tabular}{r} 
SAM \\
S1 \\
\hline 1 \\
1 \\
1 \\
1 \\
1 \\
1 \\
1 \\
1 \\
\\
1 \\
1 \\
\\
1 \\
1 \\
\end{tabular}

STANDARD

MEAN DEYIALION

20.21

63.9

13957.5

6.53

0.097

0.243

0.603

1163.0

6.41
17.3
12891.8
0.31

0.31

0.125

0.194
796.6

PHYTOPLANKTUN, TOTAL (CELLS/ML)

SEDIMENT, SUSPENDED

SEDIMENT, CLAY-SILT (PERCENT)

COLIFORM, FECAL (COL $100 \mathrm{ML}$ )

SILICA, DISSOLVED

CALCIUM, DISSOL VED

SODIUM, DISSOLVED

POTASSIUM, DISSOLVED

BICARBONATE, ION

CARBONATE, ION

SULFATE, DISSOLVED

CHLORIDE, DISSOLVED

DISSOLVED SOLIDS, SUM OF CONST

DISSOLVED SOLIDS, ROE 180 DEG C

HARDNESS, TOTAL

HARDNESS, NONCARBONATE

FLOURIDE, DISSOLVED

$636.0 \quad 916.7$

$538.1 \quad 783.0$

8.29

1.26

0.83

4.30

4.92

2.07

13.3

8.94

5.47

40.0

65.2

17.0
7.3

37.0

0.19

1.69

5.1

1.0

1.52

5.5

19.9

5.5

27.3

0.15
STREPTOCOCCI, FECAL (COL/100 ML)

MAGNESIUM, DISSOLVED

TURBIDITY (JTU)

REGRESSION SUMMARY

REGRESSION

SAMPLE COEFICIENT, CONSTANT, CORRELATION

BANGE SIZE

COEFICIENT,

CONSTANT, COEEICIENI

STANDARO STANDARO
ERROR OF ESIUMAIF<smiles>[13CH2][AsH]</smiles>

$\begin{array}{rr}38 & 92 \\ 1240 & 34800 \\ 6.0 & 7.1\end{array}$

0.05

0.10

$\begin{array}{rrr}34800 & 12 & -526.471 \\ 7.1 & 12 & 0.0128\end{array}$ 0.0128 $-0.00104$ $-0.00571$ $-0.00571$

47607.777
5.7127
0.16342
-0.12625
0.96853
2278.312

-0.707
0.721 -0.400 *

0.804

$-0.510$

-0.510
-0.384

180
.34

0.97

2278.312

$\begin{array}{rr}5 & 2900 \\ 22 & 2300\end{array}$

22
6.5
3.0
1.0
3.4
1.4
5
0
7.7
3.9
33
44
12
2
9
0.1

10.0

5.3

$1.0-3.0$

7.6
2.8

2.8
21

21
12.0
7.5

48
90

22
17
100

100

0.10 .4

percent confidence level.

DURAIION IABLE OF DALLY SPECIEIC CONDUCIANCE

DAILY SPECIFIC CONDUCTANCE IN

MICROMHOS AT 25 DEG C, THAT WAS

EQUALLED OR EXCEEDED FOR THE

$19 \quad-5$

se

$20 \% \quad 30 \% \quad 50 \%$

502

SAMPLE SIZE $=-113$
$20 \%$ 25\% $29 \pi$

$\begin{array}{rr}0.0652 & 3 \\ 0.0377 & 1 \\ 0.0144 & 0 \\ 0.1625 & -5 \\ 0.0280 & 0 \\ 0.225 & - \\ 0.000 & \\ 0.0069 & 8 \\ 0.0939 & -0 \\ 0.533 & \\ 0.860 & \\ 0.149 & \\ 0.017 & \\ -1.287 & 11 \\ 0.0023 & 0 \\ & \\ & \\ \text { SIE SI2E }=113 \\ 42\end{array}$

SUMMARY OF HARMONIC ANALYSIS OF STREAM TEMPERATURE

\begin{tabular}{|c|c|c|c|c|c|}
\hline & HARMONIC & AMPLITUDE & PHASE & VARIATION & $\begin{array}{l}\text { STANDARD } \\
\text { ERROR OF }\end{array}$ \\
\hline SAMPLE & MEAN - M & $-A$ & ANGLE - C & EXPLAINED & ESTIMATE \\
\hline SIZE_ & IDEG CI & - $10 E G_{C}(1)$ & IBADIANSI & $(z)$ & LEG 61 \\
\hline 112 & 19.77 & 8.76 & 2.70 & 87 & 1.29 \\
\hline
\end{tabular}

SUMMARY OF MAXIMUM AND MINIMUM CONCENTRATIONS OF CONSTITUENTS SAMPLED AT A FREQUENCY OF QUARTERLY (1975 WY)

\begin{tabular}{l} 
CONSTITUENT \\
\hline SAMPLES
\end{tabular}


LAT 30D37M45S LONG 089D53M50S

DRAINAGE AREA: 1210 SQ MI ( 3134 SQ KM)

PERIOD OF RECORD: $10 / 01 / 74-09 / 30 / 75$

STATISTICAL SUMMARY OF SELECTED DISSOLVED CHEMICAL CONSTITUENTS AND REGRESSION RELATIONSHIPS OF CONSTITUENT CONCENTRATIONS TO SPECIFIC CONDUCTANCE

CONSIUIUENI

CONSIITUENI IMG/L OR UNII SHOHNU

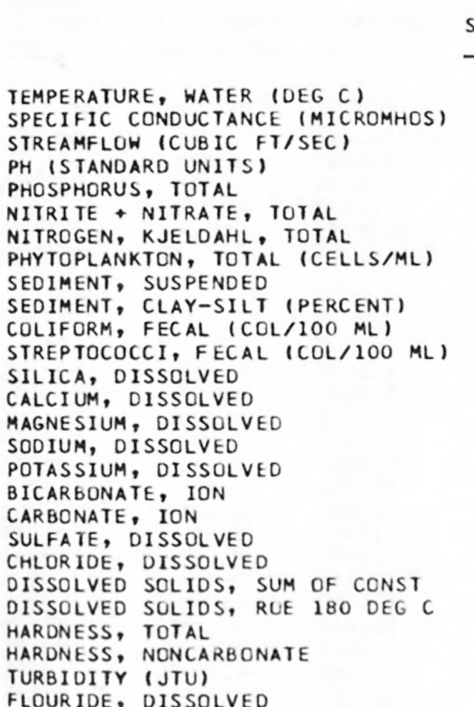

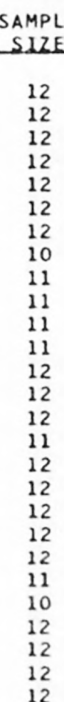

STANDARD DEVIAIION

$\begin{array}{rr}19.92 & 6.26 \\ 48.0 & 14.6 \\ 4027.3 & 3942.2 \\ 6.48 & 0.30 \\ 0.082 & 0.027 \\ 0.177 & 0.058 \\ 0.527 & 0.211 \\ 425.2 & 302.0 \\ 87.6 & 91.2 \\ 73.7 & 10.6 \\ 1278.4 & 2594.8 \\ 763.1 & 1199.0 \\ 8.69 & 2.59 \\ 2.64 & 0.71 \\ 0.88 & 0.16 \\ 4.28 & 2.07 \\ 1.70 & 0.35 \\ 10.5 & 2.2 \\ 0.0 & 0.0 \\ 2.91 & 0.92 \\ 6.63 & 3.18 \\ 33.1 & 7.4 \\ 47.7 & 20.9 \\ 10.2 & 2.0 \\ 1.9 & 2.0 \\ 22.5 & 17.2 \\ 0.09 & 0.12\end{array}$

BANGE

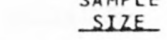

12.0
32
708
5.9
0.05
0.09

28.0
84
11200
7.0

$\begin{array}{rr}1200 & 12 \\ 7.0 & 12\end{array}$

$0.13 \quad 12$

$0.29 \quad 12$

$\begin{array}{ll}0.81 & 12 \\ 1100 & 10\end{array}$

0.13

92
15
53

53
13

13
12

4.9

0.7

0.7

2.0
1.1
7

7
0
1.6

1.6
3.9
25

28
7
0

5
0.0 1100
322

322
85

8800

4000

12.0

12
3.9
1.9

$1.3 \quad 12$

9.811

$\begin{array}{rl}2.3 & 12 \\ 15 & 12\end{array}$

0
4.6

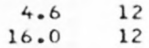

$\begin{array}{ll}94 & 10 \\ 13 & 12\end{array}$

6
50

$0.4 \quad 12$ REGRESSION

$51-11$

*Not significant at the 95 percent confidence level.

\section{DUBAIION IABLE_OE DALLY SPECIEIC CONOUCIANCE}

DAILY SPECIFIC CONDUCTANCE IN

MICROMHOS AT 25 DEG C, THAT WAS

EQUALLED OR EXCEEDED FOR THE
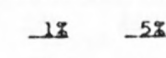

102

$20 z$

302

502

60

48

46

SUMMARY OF HARMONIC ANALYSIS OF STREAM TEMPERATURE

\begin{tabular}{|c|c|c|c|c|c|}
\hline & & & & & ST ANDARD \\
\hline & HARMONIC & AMPLITUDE & PHASE & VARIATION & ERROR OF \\
\hline SAMPLE & MEAN - M & $-A$ & ANGLE - C & EXP LAINED & ESTIMATE \\
\hline SIZE & LEE CI & (DEG 61 & (BADLANS) & -181 & LDEG C \\
\hline 265 & 20.67 & 6.74 & 2.84 & 84 & 2.15 \\
\hline
\end{tabular}

SUMMARY OF MAXIMUM AND MINIMUM CONCENTRATIONS OF CONSTITUENTS

SAMPLED AT A FREQUENCY OF QUARTERLY (1975 WY)

02492000 -- BOGUE CHITTO NEAR BUSH, LOUISIANA

\begin{tabular}{|c|c|c|c|c|c|c|}
\hline \multirow{2}{*}{ CONSTITUENT } & \multicolumn{3}{|c|}{ TOTAL } & \multicolumn{3}{|c|}{ DISSOLVED } \\
\hline & $\begin{array}{l}\text { NO. } \\
\text { SAMPLES }\end{array}$ & $\begin{array}{l}\text { MINIMUM } \\
\text { CONC. }\end{array}$ & $\begin{array}{l}\text { MAXIMUM } \\
\text { CONC. }\end{array}$ & $\begin{array}{l}\text { NO. } \\
\text { SAMPLES }\end{array}$ & $\begin{array}{l}\text { MINIMUM } \\
\text { CONC. }\end{array}$ & $\begin{array}{l}\text { MAXIMUM } \\
\text { CONC. }\end{array}$ \\
\hline \multicolumn{7}{|l|}{ MINOR ELEMENTS: } \\
\hline ARSENIC (AS), UG/L & 4 & 0 & 1 & 4 & 0 & 1 \\
\hline CADMIUM (CD), UG/L & 4 & 0 & 2 & 4 & 0 & 1 \\
\hline CHROMIUM (CR), UG/L & 4 & $<10$ & 20 & 4 & 0 & 0 \\
\hline COBALT $(C O), U G / L$ & 4 & 1 & 3 & 4 & 0 & 0 \\
\hline COPPER $(C U), U G / L$ & 4 & 2 & 7 & 4 & 2 & 18 \\
\hline IRON $(F E), U G / L$ & 4 & 630 & 1100 & 4 & 60 & 180 \\
\hline LEAD $(P B), U G / L$ & 4 & 0 & 7 & 4 & 0 & 2 \\
\hline MANG ANESE (MN), UG/L & 4 & 65 & 120 & 4 & 10 & 100 \\
\hline MERCURY (HG), UG/L & 4 & 0.0 & 0.2 & 4 & 0.0 & 0.1 \\
\hline SELENIUM (SE), UG/L & 4 & 0 & 0 & 4 & 0 & 0 \\
\hline ZINC $(Z N), U G / L$ & 4 & 0 & 20 & 4 & 0 & 10 \\
\hline \multicolumn{7}{|l|}{ PERIPHYTON: } \\
\hline BIOMASS, DRY WT., G/SO M & 1 & 31.00 & & & & \\
\hline BIOMASS, ASH WT., G/SO M & 1 & 29.00 & & & & \\
\hline CHLOROPHYLL A, MG/SQ M & $i$ & 7.7 & & & & \\
\hline CHLOROPHYLL B, MG/SQ M & 1 & 1.6 & & & & \\
\hline ORGANIC CARBON, MG/L & 4 & 2.5 & 9.5 & & & \\
\hline
\end{tabular}


Table 14.--Summary of measurements at each station--Continued

LAT 40D33M52S LONG 079D46M22S

DRAINAGE AREA: 0 SO MI

PERIOD OF RECORD:

$10 / 01 / 74-09 / 30 / 75$

O SQ KM)

STATISTICAL SUMMARY OF SELECTED DISSOLVED CHEMICAL CONSTITUENTS AND

REGRESSION RELATIONSHIPS OF CONSTITUENT CONCENTRATIONS TO SPECIFIC CONDUCTANCE

GONSIUTUENI LHG/L OR UNII_SHOWN

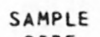

SUZE

TEMPERATURE, HATER (DEG C) SPECIFIC CONDUCTANCE (MICROMHOS) STREAMFLOW (CUBIC FT/SEC) PH (STANDARD UNITS) PH ISTANDARD UNITSI

PHOSPHORUS, TOTAL, TOTAL

NITROGEN, KJELDAHL, TOTAL

PHYTOPLANKTON, TOTAL (CELLS/ML)

SEDIMENT, SUSPENDED

SEDIMENT, CLAY-SILT (PERCENT)

COL IFORM, FECAL (COL $100 \mathrm{ML}$ )

STREPTOCOCCI, FECAL (COL/100 ML)

SILICA, DISSOLVED

SODIUM, DISSOLVED

POTASSIUM, DISSOLVED

BICARBONATE, ION

CARBONATE, ION

SULFATE, DISSOLVED

CHLOR IDE, DISSOLVED

DISSOLVED SOLIDS, SUM OF CONST

DISSOLVED SOLIDS, ROE 180 DEG

HARDNESS, TOTAL

HARDNESS, NONCARBONATE

TURBIDITY (JTU)

FLOURIDE, DISSOLVED
STANDARD

DEYIALION

$\begin{array}{rrr}21 & 11.88 & 8.85 \\ 21 & 250.5 & 61.4 \\ 21 & 21185.2 & 14785.9 \\ 21 & 6.95 & 0.26 \\ 21 & 0.025 & 0.012 \\ 21 & 0.495 & 0.209 \\ 21 & 0.379 & 0.157 \\ 12 & 3193.3 & 2392.6 \\ 19 & 25.2 & 19.7 \\ 19 & 93.9 & 7.5 \\ 21 & 269.4 & 305.0 \\ 21 & 223.3 & 489.0 \\ 21 & 4.34 & 1.12 \\ 21 & 23.19 & 6.00 \\ 21 & 6.57 & 1.49 \\ 21 & 10.39 & 3.45 \\ 21 & 1.81 & 0.56 \\ 21 & 21.4 & 8.5 \\ 19 & 0.0 & 0.0 \\ 21 & 75.29 & 24.30 \\ 21 & 12.64 & 2.53 \\ 21 & 145.2 & 36.5 \\ 21 & 156.3 & 34.9 \\ 21 & 84.5 & 20.3 \\ 21 & 67.4 & 19.7 \\ 21 & 11.9 & 11.6 \\ 21 & 0.18 & 0.09\end{array}$

GONSIIIUENI

CALCIUM, DISSOLVED

MAGNE SIUM, DISSOL VED

BEGRESSION_SUMMABY

REGRESSION

SAMPLE COEFICIENT, CONSTANT, CORRELATION ERROR OF SIZE_ _. B _ _ B COEEICIENI ESIUMAIE

$\begin{array}{rrr}0.5 & & \\ 160 & 26.0 & \\ 3740 & 370 & \\ 6.5 & 56500 & 21 \\ 0.01 & 7.4 & 21 \\ 0.14 & 0.05 & 21 \\ 0.20 & 0.86 & 21 \\ 190 & 0.76 & 21 \\ 5 & 7300 & 7 \\ 77 & 71 & \\ 1 & 100 & \\ 4 & 1000 & \\ 2.3 & 2200 & \\ 14.0 & 5.8 & 21 \\ 4.0 & 35.0 & 21 \\ 5.5 & 8.9 & 21 \\ 1.2 & 19.0 & 21 \\ 9 & 3.4 & 21 \\ 0 & 40 & 21 \\ 36.0 & 120.0 & 19 \\ 9.0 & 18.0 & 21 \\ 92 & 208 & 21 \\ 94 & 224 & 21 \\ 51 & 120 & 21 \\ 31 & 95 & 21 \\ 1 & 40 & 21 \\ 0.0 & 0.4 & 21\end{array}$

*Not significant at the 95 percent confidence level.

DAILY SPECIFIC CONDUCTANCE DURAIION IABLE OF DALIY SPECIEIC CONDUCIANCE

CE IN

EOUALED OR EXCEEDED, THAT WAS

EQUALLED OR EXCEEDED FOR THE

$\begin{array}{llllll}12 & 5 \pi & 10 \% & 208 & 30 \pi & 50 \% \\ 345 & 330 & 315 & 285 & 240 & 220\end{array}$

503

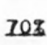

$-169.164$

$-0.0004$

-0.00014
-0.00132

-0.00132
0.00130

$-32.377$

63556.091

7.0489

0.06094

0.82659

0.05283

12611.211

$-0.703$

-0.091 *

$-0.710$

-0.389
0.509

$-0.928$

10793.4

0.27

0.009
0.197

0.139

926.0

-0.0075
0.0818
0.0205
0.0416
0.0061
0.019
0.000
0.3555
0.0285
0.533
0.538
0.282
0.273
-0.043
0.0006

6.2053

2.6958

1.4428

$-0.0378$

0.2860

16.546

0.000

$-13.7473$

5.4982

21.470

13.842

-1.048
22.626

0.0194

-0.410 *

0.838

0.842

0.741

0.662

0.139 *

0.898

0.691

0.896

0.948

0.853
-0.228

-0.228 *
0.408 *
1.04

3.36
0.83

2.37

0.43

8.6
0.0

10.94

1.88

16.6

11.4

10.5

11.6

0.09

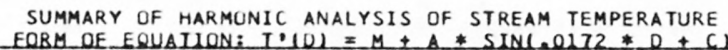

\begin{tabular}{|c|c|c|c|c|c|}
\hline & & & & & STANDARD \\
\hline & HARMONIC & AMPLITUDE & PHASE & VARIATION & ERROR OF \\
\hline $\begin{array}{l}\text { SAMPLE } \\
\text { SUZE }\end{array}$ & MEAN - $M$ & $-A^{A}$ & ANGLE - C & EXPLAINED & ESTIMATE \\
\hline 357 & 12.37 & 12.48 & 2.71 & 96 & 1.88 \\
\hline
\end{tabular}

SUMMARY OF MAXIMUM AND MINIMUM CONCENTRATIONS OF CONSTITUENTS

SAMPLED AT A FREQUENCY OF QUARTERLY (1975 WY)

03049625 - ALLEGHENY R AT NEW KENSINGTON, PA.

\begin{tabular}{|c|c|c|c|c|c|c|}
\hline \multirow{2}{*}{ CONSTITUENT } & \multicolumn{3}{|c|}{ TOTAL } & \multicolumn{3}{|c|}{ DISSOLVED } \\
\hline & $\begin{array}{l}\text { NO. } \\
\text { SAMPLES }\end{array}$ & $\begin{array}{l}\text { MIN IMUM } \\
\text { CONC. }\end{array}$ & $\begin{array}{l}\text { MAXIMUM } \\
\text { CONC. }\end{array}$ & $\begin{array}{l}\text { NO. } \\
\text { SAMPLES }\end{array}$ & $\begin{array}{l}\text { MINIMUM } \\
\text { CONC. }\end{array}$ & $\begin{array}{l}\text { MAXIMUM } \\
\text { CONC. }\end{array}$ \\
\hline \multicolumn{7}{|l|}{ MINOR ELEMENTS: } \\
\hline ARSENIC (AS), UG/L & 7 & 1 & 3 & 7 & 0 & 1 \\
\hline CADM IUM $(C D), U G / L$ & 7 & 0 & 1 & 7 & 0 & 1 \\
\hline CHROMIUM (CR), UG $/ L$ & 7 & 0 & 20 & 7 & 0 & $<10$ \\
\hline COBALT $(C O), U G / L$ & 7 & 2 & 9 & 7 & 0 & 8 \\
\hline COPPER (CU), UG/L & 7 & 0 & 10 & 7 & 0 & 10 \\
\hline IRON $(F E), U G / L$ & 7 & 550 & 3600 & 7 & 10 & 1600 \\
\hline LEAD $(P B), U G / L$ & 7 & 2 & 11 & 7 & 0 & 3 \\
\hline MANGANESE $(M N), U G / L$ & 7 & 190 & 510 & 7 & 140 & 480 \\
\hline MERCURY (HG), UG/L & 7 & $<0.5$ & $<0.5$ & 7 & $<0.5$ & $<0.5$ \\
\hline SELENIUM (SE), UG/L & 7 & 0 & 0 & 7 & 0 & 0 \\
\hline$Z I N C(Z N), U G / L$ & 7 & 20 & 70 & 7 & 10 & 50 \\
\hline \multicolumn{7}{|l|}{ PERIPHYTON: } \\
\hline BIOMASS, DRY WT., G/SQ M & 2 & 2.29 & 7.19 & & & \\
\hline BIOMASS, ASH WT., G/SO M & 2 & 1.50 & 5.50 & & & \\
\hline CHLOROPHYLL A, MG/SO M & 2 & .5 & 4.0 & & & \\
\hline CHLOROPHYLL B, MG/SO M & 2 & .1 & .1 & & & \\
\hline ORGANIC CARBON, MG/L & 8 & 1.0 & 4.5 & & & \\
\hline
\end{tabular}


LAT 40D24M19S LONG $079052 M 535$

ORAINAGE AREA: 7337 SO MI ( 19003 SQ KMI

PERIOD OF RECORD: $10 / 01 / 74-09 / 30 / 75$

STATISTICAL SUMMARY OF SELECTED DISSOLVED CHEMICAL CONSTITUENTS AND

REGRESSION RELATIONSHIPS OF CONSTITUENT CONCENTRATIONS TO SPECIFIC CONDUCTANCE

CONSIIIUENI

CONSIIIUENI IMG/L OB UNII SHOWNI

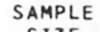

SIZE

STANDARD

MEAN DEYIALION

TEMPERATURE, WATER (DEG C) SPECIFIC CONDUCTANCE (MICROMHOS) STREAMFLOW (CUBIC FT/SEC)

PH (STANDARD UNITS

PHOSPHORUS, TOTAL

NITRITE + NITRATE, TOTAL

NITROGEN, KJELDAHL, TOTAL

PHYTOPLANKTON, TOTAL (CELLS/ML)

SEDIMENT, SUSPENDED

SEDIMENT, CLAY-SILT (PERCENT)

COLIFORM, FECAL (COL/100 ML)

STREP TOCOCCI, FECAL ( COL/100 ML)

SILICA, DISSOLVED

CALCIUM, DISSOLVED

MAGNESIUM, DISSOLVEO

SODIUM, DISSOLVED

POTASSIUM, DISSOLVEO

BICARBONATE, ION

CARBONATE, ION

SULFATE, DISSOLVED

CHLOR IDE, DISSOLVED

DISSOLVED SOLIDS, SUM OF CONST

DISSOLVED SOLIDS, ROE 180 DEG HARDNESS, TOTAL

HARDNESS, NONCARBONAT

TURBIOITY (JTU)

FLOUR IDE, DISSOLVED

$\begin{array}{rrr}13 & 15.31 & 9.51 \\ 12 & 349.6 & 95.5 \\ 13 & 16177.7 & 16969.6 \\ 12 & 7.21 & 0.27 \\ 12 & 0.052 & 0.028 \\ 12 & 0.632 & 0.125 \\ 12 & 0.547 & 0.342 \\ 12 & 5642.9 & 5095.8 \\ 13 & 57.6 & 72.4 \\ 12 & 95.5 & 4.0 \\ 12 & 2257.5 & 2670.0 \\ 12 & 523.3 & 752.3 \\ 12 & 5.14 & 0.62 \\ 12 & 31.92 & 8.33 \\ 12 & 8.51 & 2.15 \\ 12 & 19.83 & 9.26 \\ 12 & 2.37 & 1.06 \\ 12 & 27.7 & 8.1 \\ 12 & 0.0 & 0.0 \\ 12 & 120.33 & 44.75 \\ 12 & 11.40 & 2.97 \\ 12 & 213.4 & 69.1 \\ 12 & 230.1 & 67.1 \\ 12 & 114.3 & 30.2 \\ 12 & 91.8 & 24.4 \\ 12 & 15.2 & 13.9 \\ 12 & 0.20 & 0.14\end{array}$

$\begin{array}{rrr}\text { BANGE } & & \\ 2.0 & & \begin{array}{r}\text { SAMPLE } \\ \text { SIZE }\end{array} \\ 210 & 27.0 & \\ 3190 & 500 & \\ 6.5 & 56700 & 12 \\ 0.01 & 7.5 & 12 \\ 0.42 & 0.11 & 12 \\ 0.14 & 0.86 & 12 \\ 65 & 1.20 & 12 \\ 17 & 13000 & 12 \\ 88 & 230 & \\ 270 & 100 & \\ 21 & 9300 & \\ 3.8 & 2200 & \\ 20.0 & 6.3 & 12 \\ 5.5 & 12.0 & 12 \\ 9.0 & 35.0 & 12 \\ 1.0 & 4.2 & 12 \\ 17 & 42 & 12 \\ 0 & 0 & 12 \\ 63.0 & 190.0 & 12 \\ 7.0 & 15.0 & 12 \\ 125 & 320 & 12 \\ 138 & 341 & 12 \\ 73 & 160 & 12 \\ 54 & 130 & 12 \\ 3 & 40 & 12 \\ 0.0 & 0.4 & 12\end{array}$
REGRESSION

BEGRESSION SUMMARY

COEFICIENT, CONSTANT, CORRELATION

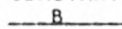

COEFICIENI

SUMMARY OF HARMONIC ANALYSIS OF STREAM TEMPERATURE

\begin{tabular}{|c|c|c|c|c|c|}
\hline & & & & & STANDARD \\
\hline & HARMONIC & AMPLITUDE & PHASE & VAR IATION & ERROR OF \\
\hline SAMPLE & MEAN - M & $-A$ & ANGLE - C & EXPLAINED & ESTIMATE \\
\hline SIZE_ & WDEG C & (DEG () & (BADIANS) & $-(\%)$ & $10 E G(1$ \\
\hline 13 & 15.45 & 12.33 & 2.69 & 96 & 1.96 \\
\hline
\end{tabular}

SUMMARY OF MAXIMUM AND MINIMUM CONCENTRATIONS OF CONSTITUENTS SAMPLED AT A FREQUENCY OF QUARTERLY (1975 WY)

$\begin{array}{rrrr}-94.881 & 45969.762 & -0.734 & 8797.6 \\ 0.0012 & 6.7864 & 0.425 * & 0.26 \\ 0.00005 & 0.03328 & 0.190^{\star} & 0.028 \\ -0.00074 & 0.88992 & -0.563^{\star} & 0.108 \\ 0.00222 & -0.23037 & 0.620 & 0.282 \\ 17.904 & -616.063 & 0.335 * & 5034.8\end{array}$

-0.0007
0.0837
0.0218
0.0911
0.0079
0.057
0.000
0.4596
0.0165
0.707
0.684
0.304
0.248
-0.101
0.0005

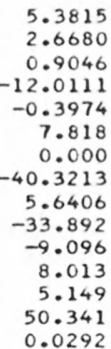

$-0.105$

0.959

0.964

0.939

0.715

0.667

0.000

0.981

$0.530 *$

0.978

0.974

0.961

0.969

-0.693
0.330

\begin{tabular}{|c|c|c|c|c|c|c|}
\hline \multirow{2}{*}{ CONSTITUENT } & \multicolumn{3}{|c|}{ TOTAL } & \multicolumn{3}{|c|}{ DISSOLVED } \\
\hline & $\begin{array}{l}\text { NO. } \\
\text { SAMPLES }\end{array}$ & $\begin{array}{l}\text { MIN IMUM } \\
\text { CONC. }\end{array}$ & $\begin{array}{c}\text { MAXIMUM } \\
\text { CONC. }\end{array}$ & $\begin{array}{c}\text { NO. } \\
\text { SAMPLES }\end{array}$ & $\begin{array}{l}\text { MINIMUM } \\
\text { CONC. }\end{array}$ & $\begin{array}{l}\text { MAXIMUM } \\
\text { CONC. }\end{array}$ \\
\hline \multicolumn{7}{|l|}{$\begin{array}{l}\text { MINOR ELEMENTS: } \\
\text { ARSENIC (AS), UG/L }\end{array}$} \\
\hline CADMIUM $(C D), U G / L$ & 4 & 0 & 1 & 4 & 0 & 0 \\
\hline CHROMIUM (CR), UG/L & 4 & 0 & 20 & 4 & 0 & 10 \\
\hline COBALT $(C O), U G / L$ & 4 & 1 & 6 & 4 & 1 & 5 \\
\hline COPPER (CU), UG/L & 4 & 0 & 10 & 4 & 0 & 10 \\
\hline IRON (FE), UG/L & 4 & 560 & 3400 & 4 & 10 & 120 \\
\hline LEAD $(P B), U G / L$ & 4 & 6 & 11 & 4 & 0 & 1 \\
\hline MANGANESE (MN), UG/L & 4 & 280 & 520 & 4 & 220 & 440 \\
\hline MERCURY (HG), UG/L & 4 & $<0.5$ & 0.6 & 4 & 0.5 & 0.5 \\
\hline SELENIUM (SE), UG $/ L$ & 4 & 0 & 1 & 4 & 0 & 0 \\
\hline ZINC $(Z N), U G / L$ & 4 & 30 & 600 & 4 & 20 & 40 \\
\hline \multicolumn{7}{|l|}{ PERIPHYTON: } \\
\hline BIOMASS, DRY WT., G/SQ M & 4 & .39 & 11.00 & & & \\
\hline BIOMASS, ASH WT., G/SO M & 4 & 1.50 & 8.59 & & & \\
\hline CHLOROPHYLL A, MG/SQ M & 3 & 2.0 & 9.1 & & & \\
\hline CHLOROPHYLL B, MG/SQ M & 3 & $\bullet 0$ & 1.5 & & & \\
\hline ORGANIC CARBON, MG/L & 4 & 1.5 & 4.0 & & & \\
\hline
\end{tabular}


LAT $39038 M 42 S$ LONG $081051 M 00 S$

DRAINAGE AREA: 7422 SQ MI I 19223 SQ KMI

PERIOD OF RECORD: $10 / 01 / 74-09 / 30 / 75$

STATISTICAL SUMMARY OF SELECTED DISSOLVED CHEMICAL CONSTITUENTS AND

REGRESSION RELATIONSHIPS OF CONSTITUENT CONCENTRATIONS TO SPECIFIC CONDUCTANCE

CONSILIUENI (MG/L OR UNII SHOWN)

SAMP
SII
12
11
12
11
12
12
12
12
10

12
12
4
4
4
4
4
4
4
4
4
4
4

STANDARD

DEYIAIION
CONSIIIUENI

co

TEMPERATURE, WATER (DEG C)

SPECIFIC CONDUCTANCE (MICROMHOS )

STREAMFLOW (CUBIC FT/SEC)

PH (STANDARO UNITS)

PHOSPHORUS, TOTAL

NITRITE + NITRATE, TOTAL

NITROGEN, KJELDAHL, TOTAL

PHYTOPLANKTON, TOTAL ICELLS/ML)

SEDIMENT, SUSPENDED

SEDIMENT, CLAY-SILT (PERCENT)

COLIFORM, FECAL (COL/100 ML)

STREP YOCOCCI, FECAL (COL/100 ML)

SILICA, DISSOLVED

CALCIUM, DISSOLVED

MAGNESIUM, DISSOLVED

SODIUM, DISSOLVED

POTASSIUM, DISSOLVED

BICARBONATE, ION

CARBONATE, ION

SULFATE, OISSOLVED

CHLORIDE, DISSOLVED

DISSOLVED SOLIDS, SUM OF CONST

DISSOLVED SOLIDS, ROE 180 DEG

HARDNESS, TOTAL

HARDNESS, NONCARBONATE

FLOUR IDE, DISSOLVED

*Not significant at the 95 percent confidence level.

SUMMARY OF HARMONIC ANALYSIS OF STREAM TEMPERATUR

\begin{tabular}{|c|c|c|c|c|c|}
\hline & & & & & STANDARD \\
\hline & HARMONIC & AMPLITUDE & PHASE & VARIATION & ERROR OF \\
\hline $\begin{array}{l}\text { SAMPLE } \\
\text { SIZE_ }\end{array}$ & $\begin{array}{l}\text { MEAN - M } \\
\text { (DEG C) }\end{array}$ & ${ }_{10 E G}^{-A}(1$ & $\begin{array}{l}\text { ANGLE - C } \\
\text { (RADIANSI) }\end{array}$ & $\begin{array}{l}\text { EXPLAINED } \\
\text { (I) }\end{array}$ & $\begin{array}{l}\text { ESTIMATE } \\
\text { (DEG_E) }\end{array}$ \\
\hline 12 & 13.97 & 12.83 & 2.80 & 94 & 2.66 \\
\hline
\end{tabular}

SUMMARY OF MAXIMUM AND MINIMUM CONCENTRATIONS OF CONSTITUENTS SAMPLED AT A FREQUENCY OF QUARTERLY (1975 WY)

03150000 -- MUSKINGUM R AT MCCONNELSVILLE OH

\begin{tabular}{|c|c|c|c|c|c|c|}
\hline \multirow{2}{*}{ CONSTITUENT } & \multicolumn{3}{|c|}{ TOTAL } & \multicolumn{3}{|c|}{ DISSOLVED } \\
\hline & $\begin{array}{l}\text { NO. } \\
\text { SAMPLES }\end{array}$ & $\begin{array}{l}\text { MINIMUM } \\
\text { CONC. }\end{array}$ & $\begin{array}{l}\text { MAXIMUM } \\
\text { CONC. }\end{array}$ & $\begin{array}{l}\text { NO. } \\
\text { SAMPLES }\end{array}$ & $\begin{array}{l}\text { MINIMUM } \\
\text { CONC. }\end{array}$ & $\begin{array}{l}\text { MAXIMUM } \\
\text { CONC. }\end{array}$ \\
\hline \multicolumn{7}{|l|}{ MINOR ELEMENTS: } \\
\hline ARSENIC (AS), UG/L & 4 & 0 & 2 & 4 & 0 & 1 \\
\hline CADMIUM $(C D), U G / L$ & 4 & 0 & 1 & 4 & 0 & 1 \\
\hline CHROMIUM (CR), UG/L & 4 & 0 & 10 & 4 & 0 & $<10$ \\
\hline COBALT $(C O), U G / L$ & 4 & 1 & 5 & 4 & 1 & 1 \\
\hline COPPER (CU), UG/L & 4 & 0 & 10 & 4 & 0 & 10 \\
\hline IRON $(F E), U G / L$ & 4 & 590 & 1700 & 4 & 20 & 230 \\
\hline LEAD $(P B), U G / L$ & 4 & 4 & 8 & 4 & 0 & 3 \\
\hline MANGANESE (MN), UG/L & 4 & 280 & 680 & 4 & 20 & 580 \\
\hline MERCURY $(H G), U G / L$ & 4 & $<0.5$ & 0.6 & 4 & $<0.5$ & $<0.5$ \\
\hline SELENIUM (SE), UG/L & 4 & 0 & 2 & 4 & 0 & 2 \\
\hline$Z I N C(Z N), U G / L$ & 4 & 10 & 100 & 4 & 10 & 20 \\
\hline \multicolumn{7}{|l|}{ PERIPHYTON: } \\
\hline BIOMASS, DRY WT., G/SQ M & 2 & 19.00 & 28.00 & & & \\
\hline BIOMASS, ASH WT, G/SO M & 3 & 15.00 & 24.00 & & & \\
\hline CHLOROPHYLL $A, M G / S Q M$ & 3 & 22.0 & 39.0 & & & \\
\hline CHLOROPHYLL B, MG/SQ M & 3 & 3.3 & 10.0 & & & \\
\hline ORGANIC CARBON, MG/L & 4 & 2.8 & 9.3 & & & \\
\hline
\end{tabular}


LAT $38031 M 32 S$ LONG 081054 M4OS DRAINAGE AREA: 11809 SO MI ( 30585 SQ KM) PERIOD OF RECORD: $10 / 01 / 74$ - 09/30/75

STATISTICAL SUMMARY OF SELECTED DISSOLVED CHEMICAL CONSTITUENTS AND REGRESSION RELATIONSHIPS OF CONSTITUENT CONCENTRATIONS TO SPECIFIC CONDUCTANCE

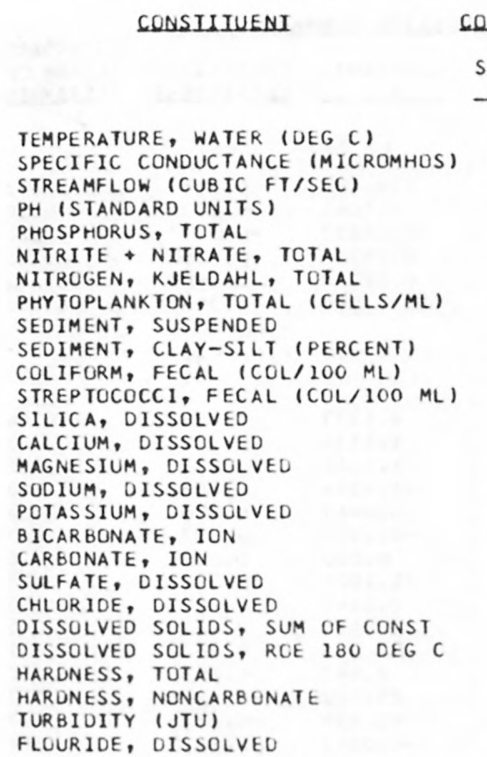

\begin{tabular}{|c|c|c|}
\hline $\begin{array}{l}\text { SAMPLE } \\
\text { SLZE }\end{array}$ & MEAN & $\begin{array}{l}\text { STANDARD } \\
\text { DEYLAIION }\end{array}$ \\
\hline 10 & 15.75 & 10. \\
\hline 10 & 246.5 & 99 \\
\hline 10 & 26051.0 & 42506 \\
\hline 10 & 7.54 & 0. \\
\hline 9 & 0.097 & 0.0 \\
\hline 9 & 0.663 & 0.1 \\
\hline 9 & 1.971 & 1.4 \\
\hline 10 & 934.0 & 625 \\
\hline 8 & 287.3 & 622 \\
\hline 9 & 74.4 & 21 \\
\hline 10 & 597.4 & 568 \\
\hline 10 & 434.6 & 670 \\
\hline 9 & 5.61 & 1. \\
\hline 9 & 15.96 & 4. \\
\hline 9 & 5.19 & 1. \\
\hline 9 & 15.20 & 8. \\
\hline 9 & 5.36 & 2. \\
\hline 9 & 45.1 & 15 \\
\hline 9 & 0.0 & 0 \\
\hline 9 & 32.67 & 11.0 \\
\hline 9 & 20.78 & 9.4 \\
\hline 9 & 123.3 & 39 \\
\hline 10 & 137.9 & 45 \\
\hline 9 & 61.2 & 17 \\
\hline 9 & 24.3 & 8 \\
\hline 9 & 23.9 & 18 \\
\hline 9 & 0.11 & 0.0 \\
\hline
\end{tabular}

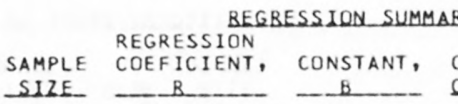

BEGRESSION SUMMARY

$-B$

CORRELATION COEFICIENI

STANDARD ERROR OF ESIIMAIE$$
0.39
$$$$
300
$$$$
\begin{aligned}
& 24 \\
& 38
\end{aligned}
$$$$
4
$$$$
\begin{array}{r}
4 \\
0 \\
3.2 \\
8.6
\end{array}
$$$$
\begin{aligned}
& 3.2 \\
& 8.6 \\
& 3.3
\end{aligned}
$$$$
\begin{aligned}
& 3.3 \\
& 5.0
\end{aligned}
$$$$
\begin{aligned}
& 5.0 \\
& 2.0
\end{aligned}
$$$$
21
$$$$
20.0
$$$$
11.0
$$$$
\begin{aligned}
& 70 \\
& 79 \\
& 35
\end{aligned}
$$$$
\begin{aligned}
& 35 \\
& 17
\end{aligned}
$$$$
0.0
$$

*Not significant at the 95 percent confidence level.

SUMMARY OF HARMONIC ANALYSIS OF STREAM TEMPERATURE $+A *$ SING.0172*D+CI

\begin{tabular}{|c|c|c|c|c|c|}
\hline & & & & & STANDARD \\
\hline & HARMONIC & AMPLITUDE & PHASE & VARIATION & ERROR OF \\
\hline SAMPLE & MEAN - $M$ & $-A$ & ANGLE - C & EXPLAINED & ESTIMATE \\
\hline SIZE_ & $10 E G \mathrm{Cl}$ & IDEG C) & (BADLANS) & $-132 \ldots$ & $10 E G(1)$ \\
\hline 91 & 14.47 & 13.08 & 2.51 & 93 & 1.64 \\
\hline
\end{tabular}

SUMMARY OF MAXIMUM AND MINIMUM CONCENTRATIONS OF CONSTITUENTS SAMPLED AT A FREQUENCY OF QUARTERLY (1975 WY)

$2500 \quad 10$

1820
98

1380

2000

6.9
24.0

7.5

30.0

9.4
65

0
53.0

39.0

194

201

91
43
65

0.2

$$
\begin{array}{r}
-295.670 \\
-0.0018 \\
0.00017 \\
0.00002 \\
0.00767 \\
-2.957 \\
\\
\\
-0.0027 \\
0.0317 \\
0.0101 \\
0.0838 \\
-0.0011 \\
0.092 \\
0.000 \\
0.0947 \\
0.0869 \\
0.349 \\
0.419 \\
0.120 \\
0.045 \\
-0.078 \\
0.0002
\end{array}
$$

98933.625
7.9890
0.05446
0.65958
0.11819

$-0.689$.

-0.604 *

0.541

$0.014^{\circ}$

0.534
-0.468

1662.888$$
\begin{array}{r}
6.2705 \\
8.2879 \\
2.7389 \\
-5.0606 \\
5.6233 \\
22.969 \\
0.000 \\
9.7719 \\
-0.2234 \\
39.041 \\
34.561 \\
32.185 \\
13.560 \\
42.754 \\
0.0723
\end{array}
$$

$-0.244^{*}$

0.719

0.721

0.968

0.968
$-0.054^{\circ}$

0.626 *

0.000

0.888

0.959

0.914

0.908

0.908
0.725

0.725
0.561

0.561
-0.447

-0.447
$0.213^{*}$

32670.6

\begin{tabular}{|c|c|c|c|c|c|c|}
\hline \multirow{2}{*}{ CONSTITUENT } & \multicolumn{3}{|c|}{ TOTAL } & \multicolumn{3}{|c|}{ DISSOLVED } \\
\hline & $\begin{array}{l}\text { NO. } \\
\text { SAMPLES }\end{array}$ & $\begin{array}{l}\text { MINIMUM } \\
\text { CONC. }\end{array}$ & $\begin{array}{l}\text { MAXIMUM } \\
\text { CONC. }\end{array}$ & $\begin{array}{c}\text { NO. } \\
\text { SAMPLES }\end{array}$ & $\begin{array}{l}\text { MINIMUM } \\
\text { CONC. }\end{array}$ & $\begin{array}{l}\text { MAXIMUM } \\
\text { CONC. }\end{array}$ \\
\hline \multicolumn{7}{|l|}{ MINOR ELEMENTS: } \\
\hline $\begin{array}{l}\text { ARSENIC }(A S), U G / L \\
\text { CADMIUM }(C D), U G / L\end{array}$ & 4 & 0 & 1 & 4 & 0 & 3 \\
\hline $\begin{array}{l}\text { CADMIUM (CD), UG/L } \\
\text { CHROMIUM }(C R), U G / L\end{array}$ & 4 & 1 & 22 & 4 & 2 & 23 \\
\hline $\begin{array}{l}\text { CHROMIUM (CR), UG/L } \\
\text { COBALT }(C O), U G / L\end{array}$ & $\begin{array}{l}4 \\
4\end{array}$ & 0 & 10 & 4 & 0 & $<10$ \\
\hline $\begin{array}{l}\text { COBALT }(C O), U G / L \\
\text { COPPER }(C U), U G / L\end{array}$ & 4 & 0 & 1 & 4 & 0 & 1 \\
\hline $\begin{array}{l}\text { COPPER (CU), UG/L } \\
\text { IRON (FE), UG/L }\end{array}$ & $\begin{array}{l}4 \\
4\end{array}$ & $\begin{array}{r}30 \\
630\end{array}$ & $\begin{array}{r}110 \\
1300\end{array}$ & 4 & $\begin{array}{l}20 \\
40\end{array}$ & $\begin{array}{l}100 \\
160\end{array}$ \\
\hline LEAD (PB), UG/L & 4 & $\begin{array}{r}630 \\
24\end{array}$ & 91 & 4 & 3 & $\begin{array}{r}160 \\
34\end{array}$ \\
\hline MANGANESE (MN), UG/L & 4 & 90 & 110 & 4 & 40 & 80 \\
\hline MERCURY (HG), UG/L & 4 & $<0.5$ & 1.2 & 4 & $<0.5$ & $<0.5$ \\
\hline SELENIUM (SE), UG/L & 4 & 0 & $<2$ & 4 & 0 & $<2$ \\
\hline ZINC $(Z N), U G / L$ & 4 & 30 & 260 & 4 & 30 & 260 \\
\hline \multicolumn{7}{|l|}{ PERIPHYTON: } \\
\hline BIOMASS, DRY WT., G/SO M & 2 & .09 & 21.00 & & & \\
\hline BIOMASS, ASH WT, G/SO M & 3 & .00 & 14.00 & & & \\
\hline CHLOROPHYLL A, MG/SO M & 4 & .0 & 90.0 & & & \\
\hline CHLOROPHYLL B, MG/SO M & 4 & .0 & 28.0 & & & \\
\hline ORGANIC CARBON, MG/L & 4 & 2.7 & 18.0 & & & \\
\hline
\end{tabular}

0.25

0.030

0.127

1.346
586.6

0.0723 
LAT 38D23M15S LONG 082D06M46S

DRAINAGE AREA: 256 SO MI

PERIOD OF RECORD: $10 / 01 / 74-09 / 30 / 75$

663 SO KM

STATISTICAL SUMMARY OF SELECTED DISSOLVED CHEMICAL CONSTITUENTS AND

REGRESSION RELATIONSHIPS OF CONSTITUENT CONCENTRATIONS TO SPECIFIC CONOUCTANCE

CONSIIIUENI

\section{SAMPLE

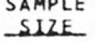

TEMPERATURE, WATER (DEG C) SPECIFIC CONDUCTANCE (MICROMHOS) STREAMFLOW (CUBIC FT/SEC)

PH ISTANDARD UNITS PHOSPHORUS, TOTAL

NITRITE + NITRATE, TOTAL NITROGEN, KJELDAHL, TOTAL PHYTOPLANKTON, TOTAL ICELLS/ML) SEDIMENT, SUSPENDED SEDIMENT, CLAY-SILT (PERCENT) COLIFORM, FECAL (COL/100 ML) STREPTOCOCCI, FECAL (COL/10O ML) SILICA, DISSOLVED

CALCIUM, DISSOLVED MAGNESIUM, DISSOLVED SODIUM, DISSOLVED POTASSIUM, DISSULVED BICARBONATE, ION

CARBONATE, ION

SULFATE, DISSOLVED

CHLORIDE, DISSOLVEO

DISSOLVED SOLIDS, SUM OF CONST

DISSOLVED SOLIDS, RUE 180 DEG

HARDNESS, TOTAL

HARDNESS, NONCARBONATE

TURBIDITY ( JTU)

FLOURIDE, DISSOLVED

\begin{tabular}{rrr} 
SIZE & \multicolumn{1}{r}{ MEAN } & REVIAIUN \\
10 & 14.90 & 8.14 \\
10 & 136.4 & 31.9 \\
10 & 233.0 & 305.1 \\
10 & 7.60 & 0.31 \\
9 & 0.044 & 0.028 \\
9 & 0.201 & 0.108 \\
9 & 0.571 & 0.320 \\
8 & 502.5 & 701.5 \\
9 & 47.8 & 44.1 \\
9 & 85.2 & 20.7 \\
10 & 732.2 & 564.1 \\
10 & 601.0 & 496.2 \\
9 & 5.64 & 0.77 \\
10 & 12.31 & 3.36 \\
10 & 3.51 & 0.66 \\
10 & 5.04 & 1.71 \\
10 & 2.88 & 1.37 \\
10 & 39.2 & 16.0 \\
10 & 0.0 & 0.0 \\
10 & 17.60 & 3.17 \\
10 & 6.23 & 2.15 \\
9 & 74.4 & 13.8 \\
9 & 84.8 & 14.4 \\
10 & 45.3 & 11.0 \\
10 & 13.1 & 5.9 \\
10 & 20.1 & 16.7 \\
9 & 0.09 & 0.08
\end{tabular}

*Not significant at the 95 percent confidence level.

\section{BEGRESSION_SUMMABY} SIZE COEEICIENI ESTIMAI

BANGE $4.5 \quad 25.0$ $100 \quad 185$

$\begin{array}{rr}7.2 & 8.11 \\ 0.02 & 0.11 \\ 0.06 & 0.36\end{array}$

$0.06 \quad 0.36$

$\begin{array}{ll}0.06 & 0.36 \\ 0.18 & 1.20\end{array}$

$120 \quad 2200$

$\begin{array}{rr}5 & 150 \\ 33 & 100\end{array}$

$64 \quad 1900$

$100 \quad 1500$

$4.6 \quad 6.7$

9.0

2.6

2.8

1.2
18

12.0

3.1
54

65

35
2

0.4

18.0
4.8

4.8
7.9

6.3
59

59
22.0

22.0
10.0
92

104

6510

$\begin{array}{ll}21 & 10 \\ 45 & 10\end{array}$

$\begin{array}{rr}45 & 10 \\ 0.2 & \end{array}$

$\begin{array}{rr}10 & -5.434 \\ 10 & -0.0037 \\ 9 & -0.00027 \\ 9 & -0.00026 \\ 9 & 0.00248 \\ 8 & -8.383 \\ & \\ & \\ & \\ 9 & -0.0180 \\ 10 & 0.0821 \\ 10 & 0.0167 \\ 10 & 0.0475 \\ 10 & 0.0215 \\ 10 & 0.426 \\ 10 & 0.000 \\ 10 & -0.0257 \\ 10 & 0.0439 \\ 9 & 0.383 \\ 9 & 0.374 \\ 10 & 0.277 \\ 10 & -0.076 \\ 10 & -0.171 \\ 9 & 0.0009\end{array}$

974.164

8.1061

0.08237

0.23769

0.22310

1701.293

$-0.568^{*}$

$-0.383^{*}$

$-0.300$

$-0.075^{*}$
$0.240^{*}$

$-0.384^{*}$

SUMMARY OF MAXIMUM AND MINIMUM CONCENTRATIONS OF CONSTITUENTS SAMPLED AT A FREQUENCY OF QUARTERLY (1975 WY)

03204500 -- MUD RIVER NEAR MILTON, W. VA.

CONSTI TUENT
SAMPLES


LAT 38DIOMIOS LONG 082D38M05S

DRAINAGE AREA: 3892 SQ MI 110080 SO KMI

PERIOD OF RECORD: $10 / 01 / 74-09 / 30 / 75$

STATISTICAL SUMMARY OF SELECTED DISSOLVED CHEMICAL CONSTITUENTS AND

REGRESSION RELATIONSHIPS OF CONSTITUENT CONCENTRATIONS TO SPECIFIC CONDUCTANCE

CONSIIIUENI

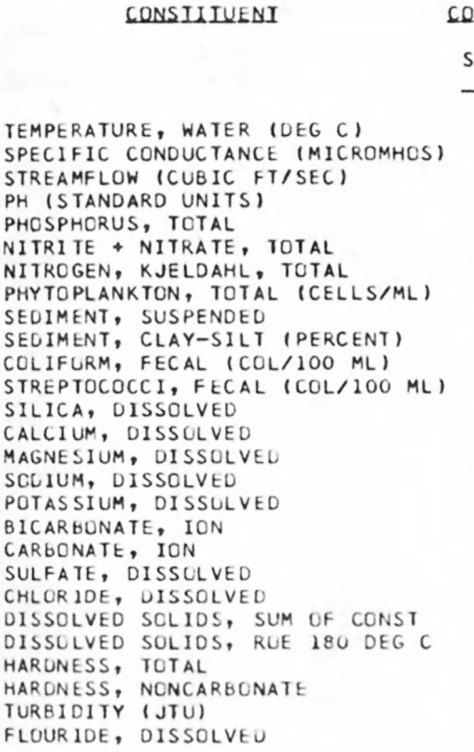

\section{CONSIIIUENI_IMG/L_OR UNII SHOWND}

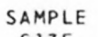

SLE

11
11
11
11
11
11
11
11
7
7
7
7
11
11
11
11
11
11
7
11
11
11
11
11
11
11
11

STANDARD

DEYIAIION

8.32

8.32
114.8

6386.4

6386.4
0.43

5644.6

7.45

0.085
0.425

0.425
0.465

672.7

131.6

90.0

3957.1

1887.1
7.30

7.30
25.82

25.82
10.65

22.33

2.65

69.0
0.0

84.64

84.64
8.80

196.5

194.5

108.3

51.7

83.7

0.11
0.039

0.106

0.285

646.0

6.0

2619.7

2009.0

2009.0
1.15

8.08

2.57

14.13
0.83

37.3

0.0

22.79

4.96

68.8

74.7
30.0

7.3

69.0

0.09
BANGE

3.0
205
758
6.8
0.01
0.27

20.0
550
23400
8.1
0.14
0.56
1.20
2000
389
96
7700
5000
8.8
41.0
14.0
48.0
3.8
140
0
120.0
18.0
315
338
160
67
250
0.3

0.16
100
46

46
81

81
900
210

210

5.5

19.0
7.6

7.6

1.8

30
0

64.0

3.4
142

142
118
82
41

41
6

0.0

*Not significant at the 95 percent confidence level.

DUBAIION IABLE_OF_DAILY SPECIEIC CONDUCIANCE

DAILY SPECIFIC CONDUCTANCE IN

MICROMHOS AT 25 DEG C, THAT WAS

EQUALLED CR EXCEEDED FOR THE

$\begin{array}{llllll}18 & -52 & 108 & 208 & 30 \pi & 508 \\ 549 & 513 & 475 & 448 & 420 & 317\end{array}$

\begin{tabular}{ll} 
& \multicolumn{2}{c}{ REGRESSION SUMMAB } \\
SEGRESSION & \\
SIZE COEFICIENT, CONSTANT, C & B
\end{tabular}
$11-31.084$

$11 \quad-31.084$ 0.00018

0.00061

0.00103

4.527

15404.859

7.2570

0.02684

0.23166

0.14221

$-748.825$

$-0.559$

0.159 *

0.547

0.668

0.413

0.805

0.45

0.034

0.083

0.274

404.4

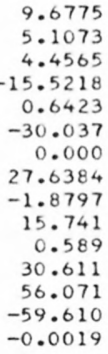

$-0.755$

0.937

0.879

0.979

0.889

0.970

0.000

0.914

0.788

0.961

0.961

0.949

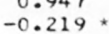

$-0.219$

0.430 *
STANDARD ERROR OF SIIMAIE

INOICATED PERCENTAGE OF TIME

$20 \%$

SAMPLE SIZE $=292$

$202 \quad 252 \quad 293$

$\begin{array}{lll}166 & 148-136\end{array}$

SUMMARY OF HARMUNIC ANALYSIS OF STREAM TEMPERATURE

\begin{tabular}{|c|c|c|c|c|c|}
\hline & & & & & STANDARD \\
\hline & HARMONIC & AMPLI TUDE & PHASE & VARIATICN & ERRCR OF \\
\hline SAMPLE & MEAN - M & $-A$ & ANGLE - C & EXPLA INED & ESTIMATE \\
\hline SIZE & LEE $E$ \& & $-10 E G(1)$ & (BADIANS) & $(8)$ & (DEE_C) \\
\hline 292 & 15.29 & 11.72 & 2.84 & 94 & 2.19 \\
\hline
\end{tabular}

SUMMARY OF MAXIMUM AND MINIMUM CONCENTRATIONS OF CONSTITUENTS SAMPLED AT A FREQUENCY OF QUARTERLY (1975 WY)

03215000 -- BIG SANDY R AT LOUISA, KY

\begin{tabular}{|c|c|c|c|c|c|c|}
\hline \multirow{2}{*}{ CONSTITUENT } & \multicolumn{3}{|c|}{ TOIAL } & \multicolumn{3}{|c|}{ DISSOLVED } \\
\hline & $\begin{array}{l}\text { NO. } \\
\text { SAMPLES }\end{array}$ & $\begin{array}{l}\text { MINIMUM } \\
\text { CONC. }\end{array}$ & $\begin{array}{l}\text { MAXIMUM } \\
\text { CONC. }\end{array}$ & $\begin{array}{l}\text { NO. } \\
\text { SAMPLES }\end{array}$ & $\begin{array}{l}\text { MINIMUM } \\
\text { CONC. }\end{array}$ & $\begin{array}{l}\text { MAXIMUM } \\
\text { CONC. }\end{array}$ \\
\hline \multicolumn{7}{|l|}{ MINOR ELEMENTS: } \\
\hline ARSENIC (AS), UG/L & 5 & 1 & 6 & 5 & 0 & 1 \\
\hline CADMIUM $(C O), U G / L$ & 4 & 0 & 3 & 5 & 0 & 2 \\
\hline CHROMIUM (CR), UG/L & 4 & $<10$ & 10 & 5 & 0 & 3 \\
\hline COBALT $(C O), U G / L$ & 4 & 0 & 5 & 5 & 0 & 2 \\
\hline COPPER (CU), UGIL & 4 & 11 & 22 & 5 & 2 & 13 \\
\hline IRON $(F E), U G / L$ & 3 & 70 & 2500 & 4 & 0 & 1600 \\
\hline LEAD $(P B), U G / L$ & 4 & 12 & 32 & 5 & 0 & 10 \\
\hline MANG ANESE (MN), UG/L & 3 & 30 & 120 & 4 & 0 & 30 \\
\hline MERCURY (HG), UG/L & 5 & 0.0 & 0.4 & 5 & 0.0 & 0.3 \\
\hline SELENIUM (SE), UG/L & 4 & 0 & 3 & 4 & 0 & 2 \\
\hline ZINC $(Z N), U G / L$ & 4 & 30 & 60 & 5 & 0 & 20 \\
\hline \multicolumn{7}{|l|}{ PERIPHYTON: } \\
\hline BIOMASS, DRY WT., G/SO M & 2 & 3.79 & 0.79 & & & \\
\hline BIOMASS, ASH WT., G/SO M & 2 & 3.09 & 5.50 & & & \\
\hline CHLUROPHYLL A, MG/SQ M & 2 & .0 & .7 & & & \\
\hline CHLOROPHYLL B, MG/SO M & 2 & .0 & .2 & & & \\
\hline ORGANIC CARBCN, MG/L & 4 & 2.3 & 12.0 & & & \\
\hline
\end{tabular}


LAT $38038 M 48 S$ LONG $082051 M 38 \mathrm{~S}$

DRAINAGE AREA: $62000 \mathrm{SQ} M 1$ ( 160580 SQ KM)

PERIOD OF RECORD: $10 / 01 / 74-09 / 30 / 75$

STATISTICAL SUMMARY OF SELECTED DISSOLVED CHEMICAL CONSTITUENTS AND

REGRESSION RELATIONSHIPS OF CONSTITUENT CONCENTRATIONS TO SPECIFIC CONDUCTANCE

CONSIIUUENI

TEMPERATURE, WATER (DEG C)
SPECIFIC CONDUCTANCE (MICROMHOS)
STREAMFLOW (CUBIC FT/SEC)
PH (STANDARD UNITS)
PHOSPHORUS, TOTAL
NITRITE, NITRATE, TOTAL
NITROGEN, KJELDAHL, TOTAL
PHYTOFLANKTUN, TOIAL (CELLS/ML)
SEDIMENT, SUSPENDED
SEDIMENT, CLAY-SILT (PERCENT)
COLIFORM, FECAL (CCL/IOO ML)
STREPTOCOCCI, FECAL (COL/IOO ML)
SILICA, DISSOLVED
CALCIUM, DISSOLVED
MAGNESIUM, OISSOLVEU
SODIUM, DISSOLVED
POTASSIUM, DISSOLVED
BICARGONATE, ION
CAREONATE, ION
SULFATE, DISSOLVED
CHLORIDE, DISSOLVED
OISSOLVED SOLIDS, SUM OF CONST
DISSOLVED SOLIDS, RLE I8O DEG C
HARDNESS, TQTAL
HARUNESS, NONCARBONATE
TURBIDITY (JTU)
FLOURIUE, DISSOLVED

CONSILUUENI IMG/L OB UNII SHOWNI

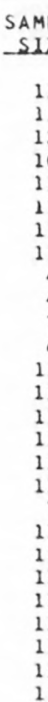

*Not significant at the 95 percent confidence level.
STANDARD

REYIALION

15.91

359.5

109.1

78515.9

0.27
0.040

0.040
0.246

0.069

0.964

0.725

196.4

45.8
84.0

84.0
760.0

228.5

5.16

34.73

9.70

20.44

2.58

49.6
0.0

89.55

24.64

211.6

220.1

126.4

87.0

17.3

0.304

1568.9

27.9
12.8

12.8
605.1

302.2

1.64

9.07

2.07

8.89

0.81
7.4

0.0
30.48

30.48

10.74
61.9

61.9
69.7

31.9

28.8

17.0
0.12

$\begin{array}{rr}\text { BANGE } & \\ 4.5 & 28.0 \\ 220 & 610 \\ 23900 & 295000 \\ 6.8 & 7.6 \\ 0.01 & 0.14 \\ 0.61 & 1.40 \\ 0.42 & 1.40 \\ 560 & 5100 \\ 19 & 84 \\ 69 & 100 \\ 230 & 1900 \\ 3 & 830 \\ 1.3 & 6.6 \\ 22.0 & 52.0 \\ 6.7 & 14.0 \\ 9.8 & 38.0 \\ 1.8 & 3.9 \\ 36 & 61 \\ 0 & 0 \\ 52.0 & 160.0 \\ 13.0 & 47.0 \\ 130 & 342 \\ 140 & 378 \\ 83 & 190 \\ 53 & 150 \\ 4 & 60 \\ 0.0 & 0.4 \\ & \end{array}$

BEGBESSLON_SUMMABY

REGRESSION

SAMPLE COEFICIENT, CONSTANT, $-{ }_{-B}$

CORRELATION ERROR OF

$\begin{array}{ll}\text { CORRELAIION } & \text { ERROR OF } \\ \text { COEELCIENI } & \text { ESIUMAIE }\end{array}$

DAILY SPECIFIC CONOUCTANCE IN

MICROMHOS AT 25 DEG C, THAT WAS

EQUALLED OR EXCEEDED FOR THE

\begin{tabular}{|c|c|c|c|c|c|}
\hline 12 & $-5 z$ & $10 z$ & $20 \%$ & 302 & 202 \\
\hline 480 & 469 & 444 & 420 & 403 & 325 \\
\hline
\end{tabular}

11

-522.369
-0.0002
-0.00020
0.00159
0.00181
4.040
280508.063
7.2414
0.14139
0.39026
0.07524
743.715

-0.699
$-0.072^{*}$
$-0.554^{*}$
0.707
0.048
$0.281^{*}$

61480.0

0.28

0.183

0.184

0.244
1587.1

INDICATED PERCENTAGE OF TIME

$480 \quad 469$

SUMMARY OF HARMUNIC ANALYSIS OF STREAM TEMPERATURE FORM DE EQUAIION: I. $(0)=M+A * S I N(.0172 * 0+C)$

\begin{tabular}{|c|c|c|c|c|c|}
\hline & & & & & STANDARD \\
\hline & HARMONIC & AMPLITUDE & PHASE & VARIATION & ERROR OF \\
\hline SAMPLE & MEAN - M & $-A$ & ANGLE - C & EXPLAINED & ESTIMATE \\
\hline SIZE & 1DEG 61 & IDEG (1) & (BADIANSI) & -181 & 1DEG (1) \\
\hline 249 & 16.66 & 12.90 & 2.59 & 97 & 1.39 \\
\hline
\end{tabular}

SUMMARY UF MAXIMUM AND MINIMUM CONCENTRATIONS OF CONSTITUENTS SAMPLED AT A FREQUENCY OF OUARTERLY (1975 WY)

$03216600-$ OHIO R AT GREENUP DAM NR GREENUP, KY

\begin{tabular}{|c|c|c|c|c|c|c|}
\hline \multirow{2}{*}{ CONSTITUENT } & \multicolumn{3}{|c|}{ TOTAL } & \multicolumn{3}{|c|}{ DISSOLVED } \\
\hline & $\begin{array}{l}\text { NO. } \\
\text { SAMPLES }\end{array}$ & $\begin{array}{l}\text { MINIMUM } \\
\text { CONC. }\end{array}$ & $\begin{array}{l}\text { MAXIMUM } \\
\text { CONC. }\end{array}$ & $\begin{array}{l}\text { NO. } \\
\text { SAMPLES }\end{array}$ & $\begin{array}{l}\text { MINIMUM } \\
\text { CONC. }\end{array}$ & $\begin{array}{l}\text { MAXIMUM } \\
\text { CONC. }\end{array}$ \\
\hline \multicolumn{7}{|l|}{ MINOR ELEMENTS: } \\
\hline ARSENIC (AS), UG/L & 4 & 0 & 4 & 4 & 0 & 0 \\
\hline CADM IUM $(C D), U G / L$ & 3 & 1 & 2 & 4 & 0 & 2 \\
\hline CHROMIUM (CR), UG/L & 3 & $<10$ & $<10$ & 4 & 0 & 4 \\
\hline COBALT $(C O), U G / L$ & 3 & 0 & 7 & 4 & 0 & 1 \\
\hline COPPER $(C U), U G / L$ & 3 & 15 & 17 & 4 & 3 & 10 \\
\hline IRUN (FE), UG/L & 3 & 150 & 2900 & 4 & 0 & 70 \\
\hline LEAD $(P B), U G / L$ & 3 & 11 & 17 & 4 & 0 & 5 \\
\hline MANGANESE $(M N), U G / L$ & 3 & 38 & 320 & 4 & 20 & 250 \\
\hline MERCURY (HG), UG/L & 4 & 0.2 & 0.6 & 4 & 0.0 & 0.1 \\
\hline SELENIUM (SE), UG/L & 4 & 0 & 1 & 4 & 0 & 1 \\
\hline $2 I N C(2 N), U G / L$ & 3 & 30 & 80 & 4 & 8 & 20 \\
\hline \multicolumn{7}{|l|}{ PERIPHYTON: } \\
\hline BIOMASS, DRY WT., G/SQ M & 4 & .50 & 39.00 & & & \\
\hline BIOMASS, ASH WT., G/SQ M & 5 & .00 & 33.00 & & & \\
\hline CHLOROPHYLL A, MG/SO M & 5 & .0 & 58.0 & & & \\
\hline CHLOROPHYLL B, MG/SO M & 5 & .0 & $10 \cdot 0$ & & & \\
\hline ORGANIC CARBON, MG/L & 4 & 2.3 & 5.0 & & & \\
\hline
\end{tabular}


Table 14.--Summary of measurements at each station--Continued

LAT 39D12M44S LONG $082051 M 50 S$

DRAINAGE AREA: 5131 SO MI I 13289 SQ KMI

PERIOD OF RECORD: $10 / 01 / 74-09 / 30 / 75$

STATISTICAL SUMMARY OF SELECTED DISSOLVED CHEMICAL CONSTITUENTS AND

REGRESSION RELATIONSHIPS OF CONSTITUENT CONCENTRATIONS TO SPECIFIC CONDUCTANCE

CONSILIUENI

\begin{tabular}{|c|}
\hline $\begin{array}{l}\text { TEMPERATURE, WATER (DEG C) } \\
\text { SPECIFIC CONDUCTANCE (MICROMHOS) } \\
\text { STREAMFLOW (CUBIC,FT/SEC) } \\
\text { PH (STANDARD UNITS) } \\
\text { PHOSPHORUS, TOTAL } \\
\text { NITRITE + NITRATE, TOTAL } \\
\text { NITROGEN, KJELDAHL, TOTAL } \\
\text { PHYTOPLANKTON, TOTAL (CELLS/ML) } \\
\text { SEDIMENT, SUSPENDED } \\
\text { SEDIMENT, CLAY-SILT (PERCENT) } \\
\text { COLIFORM, FECAL (COL/IOO ML) } \\
\text { STREPTOCOCCI, FECAL (COL/IOO ML) } \\
\text { SILICA, DISSOLVED } \\
\text { CALCIUM, DISSOLVED } \\
\text { MAGNESIUM, DISSOLVED } \\
\text { SODIUM, DISSOLVED } \\
\text { POTASSIUM, DISSOLVED } \\
\text { BICARBONATE, ION } \\
\text { CARBONATE, ION } \\
\text { SULFATE, DISSOLVED } \\
\text { CHLORIDE, DISSOLVED } \\
\text { DISSOLVED SOLIDS, SUM OF CONST } \\
\text { DISSOLVED SOLIDS, ROE I8O DEG C } \\
\text { HARDNESS, TOTAL } \\
\text { HARDNESS, NONCARBONATE } \\
\text { TURBIDITY IJTU) } \\
\text { FLOURIDE, DISSOLVED }\end{array}$ \\
\hline
\end{tabular}

CONSIUUENI_IMGLLOB_UNII_SHOWNI

\begin{tabular}{r} 
SAMPLE \\
S1ZE \\
\hline 13 \\
12 \\
12 \\
12 \\
12 \\
12 \\
12 \\
12 \\
12 \\
0 \\
12 \\
12 \\
4 \\
4 \\
4 \\
4 \\
4 \\
4 \\
4 \\
4 \\
4 \\
4 \\
4 \\
4 \\
4 \\
4 \\
4
\end{tabular}

STANDARD

MEAN DEYIAIUON

13.81 602.1 5176.3 7.72 0.502 2.367

4234.2

4234.2
67.8

3068.3

1997.7

5.42

70.00

25.75
22.75

22.75

3.15

243.3

0.0
77.50

34.25

359.5

401.0

280.0
81.3
31.3

31.3
8.84

63.7

4665.4

0.16

0.218

1.119

27722.4

31.1

4485.4

3273.7

$\begin{array}{r}1.98 \\ \hline .37\end{array}$

3.37

1.71

6.70

11.9

11.9
0.0

12.97

7.68

27.4

30.6
14.1

3.8

16.5

0.13 *Not significant at the 95 percent confidence level.

BANGE

1.0
505

846

0.31

0.70

0.74

410

390

75
2.9

66.0

24.0

14.0

229

0
63.0

23.0

336

363
260

76

0.3
BEC

SAMPLE SIZE COEFICIENT, -

26.5
730

13500

8.2

4.40

4.40
1.20

84000

114

17000

10000

7.1
74.0

28.0

30.0

4.0
254

254
0
92.0

92.0
40.0

40.0
396

438

290
84
50

50
0.6
11
12
12
12
12
12



4
4
4
4
4
4
4
4
4
4
4
4
4
4
4

-39.925
0.0001
0.00213
0.00001
0.00086
-2.190

29615.875

7.6595

$-0.77887$

2.36231

0.45109

25552.706
18.4219

63.4195

3.8933

$-51.7509$

$-6.9548$

156.998

0.000

$-77.1423$

$-24.7397$

0.862

47.532

185.993

47.642

102.931

$-0.8191$
CORRELATION COEEICIENI

STANDARD STANDARD
ERROR OF ESIIMAIE

$\begin{array}{rr}-0.570 * & 4052.0 \\ 0.043 * & 0.17 \\ 0.022 & 0.179 \\ 0.000 * & 1.173 \\ 0.355 * & 0.152 \\ -0.005 * & 29074.8\end{array}$

$-0.494 *$

0.147 *

0.962 *

0.821 *

0.546 .

0.546 *

0.000 .

$0.896 *$

0.578 *

0.983 *
0.867 *

0.500 *

0.669 *

-0.326 *

0.739 *
2.11

4.08

0.57

4.51

12.2

12.2

7.06

7.67

6.2

18.7
15.0

3.4

19.1

0.11

SUMMARY OF HARMUNIC ANALYSIS OF STREAM TEMPERATURE

\begin{tabular}{|c|c|c|c|c|c|}
\hline & & & & & STANDARD \\
\hline $\begin{array}{l}\text { SAMPLE } \\
\text { SIZE }\end{array}$ & $\begin{array}{l}\text { HARMONIC } \\
\text { MEAN - M }\end{array}$ & AMPLI TUDE & $\begin{array}{l}\text { PHASE } \\
\text { ANGLE - C }\end{array}$ & $\begin{array}{l}\text { VAR IATION } \\
\text { EXPLAINED }\end{array}$ & $\begin{array}{l}\text { ERROR OF } \\
\text { ESTIMATE }\end{array}$ \\
\hline
\end{tabular}

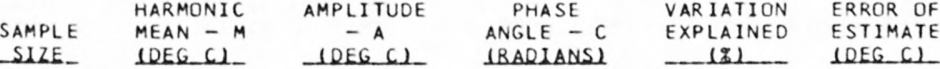
12
13.13
11.68
2.67
93
2.64

SUMMARY OF MAXIMUM AND MINIMUM CONCENTRATIONS OF CONSTITUENTS SAMPLED AT A FREQUENCY OF QUARTERLY (1975 WY)

$03234500--$ SCIOTO R AT HIGBY OH

\begin{tabular}{|c|c|c|c|c|c|c|}
\hline \multirow{2}{*}{ CONSTITUENT } & \multicolumn{3}{|c|}{ TOTAL } & \multicolumn{3}{|c|}{ DISSOLVED } \\
\hline & $\begin{array}{l}\text { NO. } \\
\text { SAMPLES }\end{array}$ & $\begin{array}{l}\text { MINIMUM } \\
\text { CONC. }\end{array}$ & $\begin{array}{l}\text { MAXIMUM } \\
\text { CONC. }\end{array}$ & $\begin{array}{l}\text { NO. } \\
\text { SAMPLES }\end{array}$ & $\begin{array}{l}\text { MINIMUM } \\
\text { CONC. }\end{array}$ & $\begin{array}{l}\text { MAXIMUM } \\
\text { CONC. }\end{array}$ \\
\hline \multicolumn{7}{|l|}{ MINOR ELEMENTS: } \\
\hline ARSENIC (AS), UG/L & 4 & 2 & 5 & 4 & 1 & 5 \\
\hline CADMIUM $(C D), U G / L$ & 4 & 1 & 1 & 4 & 0 & 1 \\
\hline CHROMIUM $(C R), U G / L$ & 4 & 0 & 10 & 4 & 0 & $<10$ \\
\hline COBALT $(C O), U G / L$ & 4 & 0 & 2 & 4 & 0 & 2 \\
\hline COPPER (CU), UG/L & 4 & 0 & 10 & 4 & 0 & 10 \\
\hline IRON $(F E), U G / L$ & 4 & 420 & 2100 & 4 & 30 & 190 \\
\hline LEAD $(P B), U G / L$ & 4 & 3 & 12 & 4 & 1 & 5 \\
\hline MANG ANESE (MN), UG/L & 4 & 50 & 270 & 4 & 10 & 80 \\
\hline MERCURY (HG), UG/L & 4 & $<0.5$ & $<0.5$ & 4 & $<0.5$ & $<0.5$ \\
\hline SELENIUM (SE), UG/L & 4 & 0 & 2 & 4 & 0 & 2 \\
\hline ZINC $(Z N), U G / L$ & 4 & 30 & 70 & 4 & 0 & 30 \\
\hline \multicolumn{7}{|l|}{ PERIPHYTON: } \\
\hline BIOMASS, DRY WT., G/SQ M & 3 & 13.00 & 110.00 & & & \\
\hline BIOMASS, ASH WT., G/SO M & 4 & 3.09 & 100.00 & & & \\
\hline CHLOROPHYLL A, MG/SQ M & 4 & 15.0 & 70.0 & & & \\
\hline CHLOROPHYLL B, MG/SO M & 4 & .0 & 11.0 & & & \\
\hline ORGANIC CARBON, MG/L & 3 & 5.0 & 6.0 & & & \\
\hline
\end{tabular}


Table 14.--Summary of measurements at each station--Continued

LAT 39D1OM17S LONG 084017M53S

DRAINAGE AREA : 1203 SQ MI ( 3116 SO KM)

PERIOD OF RECORD: $10 / 01 / 74-09 / 30 / 75$

STATISTICAL SUMMARY OF SELECTED DISSOLVED CHEMICAL CONSTITUENTS AND

REGRESSION RELATIONSHIPS OF CONSTITUENT CONCENTRATIONS TO SPECIFIC CONDUCTANCE

\section{CONSIIIUENI}

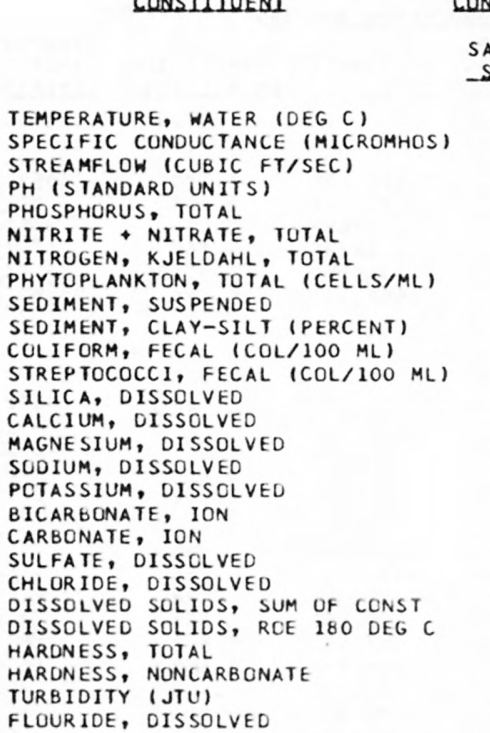

\begin{tabular}{r} 
SAMPL \\
SIZE \\
\hline 10 \\
9 \\
9 \\
9 \\
9 \\
9 \\
9 \\
9 \\
9 \\
0 \\
9 \\
9 \\
3 \\
3 \\
3 \\
3 \\
3 \\
3 \\
3 \\
3 \\
3 \\
3 \\
3 \\
3 \\
3 \\
3 \\
3 \\
\end{tabular}

*Not significant at the 95 percent confidence level.

BEGRESSION SUMMABY

\begin{tabular}{lll}
\multicolumn{3}{c}{ REGRESSION SUMMABY } \\
SAMPLE COEFICIENT, CONSTANT, CORRELATION ERANDARD
\end{tabular}

\section{STANDARD}

MEAN REYIALUON

15.90

641.1

1487.2

7.99

0.433

2.967

0.564

3040.0

135.6

1711.9

1711.9
633.6

633.6
6.90

83.33

29.33

15.33

2.13

311.7

0.0

49.33

30.33

370.

409.7

330.0
73.0

73.0
14.0

14.0
0.27

8.88
83.2
1872.1
0.13
0.264
1.712
0.345
3036.6
212.7
3242.7
1032.2
1.41
2.08
1.53
2.31
0.42
3.2
0.0
4.04
5.13
6.0
8.5
0.0
1.7
13.9
0.12

8.88

83.2
872.1

0.13

0.264

0.345

212.7

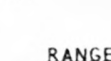

SIZE

COEFICIENT,

CO B

COEEICIENI

SIIMAIE

4.0
530
96
7.8

8.2

$\begin{array}{ll}7.15 & 0.95 \\ 1.80 & 7.40\end{array}$

0.24

160

1.40
8900

8900

9
9
9
9
9
9

$-14.859$

0.0013

0.00036

$-0.00166$

$-0.00156$

11013.383

7.1550

0.20473

4.03260

1.56353

4786.316

$-0.661^{*}$

0.853

$0.113^{*}$

$-0.081^{*}$

$-0.376^{*}$

$\begin{array}{rr}3 & 10000 \\ 8 & 3100\end{array}$

32.2

1.41

2.08

0.42

3.2

4.04

5.13
6.0

8.5

0.0
1.7

13.9
0.12

$\begin{array}{rr}3 & 10000 \\ 8 & 3100 \\ 5.6 & 8.4 \\ 81.0 & 85.0 \\ 28.0 & 31.0 \\ 14.0 & 18.0 \\ 1.8 & 2.6 \\ 308 & 314 \\ 0 & 0 \\ 45.0 & 53.0 \\ 26.0 & 36.0 \\ 365 & 377 \\ 400 & 416 \\ 330 & 330 \\ 72 & 75 \\ 5 & 30 \\ 0.2 & 0.4\end{array}$

0.1499

$-0.2333$

0.1667

0.2667

0.0466

0.233

0.000

$-0.4333$

0.5667

0.033
-0.967

-0.967
0.000

$-0.100$

1.600

$-0.0067$
$-89.8108$

233.8333

$-78.1666$

$-156.6666$

$-27.9554$

161.167

0.000

328.8330

$-335.1663$

$-37.833$

1033.166

330.000

137.500

$-1018.000$

4.5684
$0.920^{*}$

$-0.971$

$0.945^{*}$

$1.000^{*}$

$0.970^{*}$

$0.629^{\star}$

$-0.929^{*}$

$0.956^{*}$

$0.910^{*}$

$-0.984^{*}$

$0.000^{*}$

$-0.500^{*}$

$0.997^{*}$

$-0.500^{*}$
1502.3

0.0

0.280

0.342

3237.2

0.78

0.7

0.71
0.00

0.14

3.5

2.12

2.12

2.1

0.

2.1

1.4
0.14

SUMMARY CF MAXIMUM AND MINIMUM CONCENTRATIONS OF CONSTITUENTS SAMPLED AT A FREQUENCY OF OUARTERLY (1975 WY)

03245500 - L MIAMI R AT MILFORD OH

\begin{tabular}{|c|c|c|c|c|c|c|}
\hline \multirow{2}{*}{ CONSTITUENT } & \multicolumn{3}{|c|}{ TOTAL } & \multicolumn{3}{|c|}{ DISSOLVED } \\
\hline & $\begin{array}{l}\text { NO. } \\
\text { SAMPLES }\end{array}$ & $\begin{array}{l}\text { MINIMUM } \\
\text { CONC. }\end{array}$ & $\begin{array}{l}\text { MAXIMUM } \\
\text { CONC. }\end{array}$ & $\begin{array}{l}\text { NO. } \\
\text { SAMPLES }\end{array}$ & $\begin{array}{l}\text { MINIMUM } \\
\text { CONC. }\end{array}$ & $\begin{array}{l}\text { MAXIMUM } \\
\text { CONC. }\end{array}$ \\
\hline \multicolumn{7}{|l|}{ MINOR ELEMENTS: } \\
\hline ARSENIC (AS), UG/L & 3 & 1 & 2 & 3 & 0 & 2 \\
\hline CADMIUM $(C D), U G / L$ & 3 & 0 & 1 & 3 & 0 & 0 \\
\hline CHROMIUM (CR), UG/L & 3 & 0 & 10 & 3 & 0 & $<10$ \\
\hline COBALT $(C O), U G / L$ & 3 & 0 & 1 & 3 & 0 & 1 \\
\hline COPPER (CU), UG/L & 3 & 10 & 10 & 3 & 0 & 10 \\
\hline IRON (FE), UG/L & 3 & 330 & 1100 & 3 & 30 & 130 \\
\hline LEAD $(P B), U G / L$ & 3 & 2 & 6 & 3 & 1 & 2 \\
\hline MANGANESE (MN), UG/L & 3 & 30 & 70 & 3 & 10 & 40 \\
\hline MERCURY (HG), UG/L & 3 & $<0.5$ & $<0.5$ & 3 & $<0.5$ & $<0.5$ \\
\hline SELENIUM (SE), UG/L & 3 & 0 & 1 & 3 & 0 & 1 \\
\hline$Z I N C(Z N), U G / L$ & 3 & 10 & 60 & 3 & 0 & 10 \\
\hline \multicolumn{7}{|l|}{ PERIPHYTON: } \\
\hline BIUMASS, DRY WT., G/SQ M & 3 & 1.50 & 31.00 & & & \\
\hline BIOMASS, ASH WT., G/SQ M & 3 & 1.09 & 18.00 & & & \\
\hline CHLOROPHYLL A, MG/SQ M & 3 & .0 & 74.0 & & & \\
\hline CHLOROPHYLL B, MG/SO M & 3 & .0 & 21.0 & & & \\
\hline ORGANIC CARBON, MG/L & 3 & 1.7 & 7.0 & & & \\
\hline
\end{tabular}


T 38D47M22S LONG $084021 M 05 S$

AINAGE AREA: 3385 SQ MI ( 8767 SQ KM)

RIOD OF RECORD: $10 / 01 / 74-09 / 30 / 75$

STATISTICAL SUMMARY OF SELECTED DISSOLVED CHEMICAL CONSTITUENTS AND REGRESSION RELATIONSHIPS OF CONSTITUENT CONCENTRATIONS TO SPECIFIC CONDUCTANCE

CONSIIIUENI

\section{CONSILUENI IMGLL OB UNII SHOWN}

SIZE

(EMPERATURE, WATER (DEG C) PPECIFIC CONDUCTANCE (MICROMHOS) STREAMFLOW (CUBIC FT/SEC) 'H (STANDARD UNITS) THOSPHORUS, TOTAL

IITITE + NITRATE, TOTAL

IITROGEN, KJELDAHL, TOTAL

'HYTOPLANKTON, TOTAL (CELLS/ML)

SEDIMENT, SUSPENDED

SEDIMENT, CLAY-SILT (PERCENT)

COLIFORM, FECAL (COL/1OO ML)

STREPTOCOCCI, FECAL $(\mathrm{COL} / 100 \mathrm{ML}$ )

SILICA, DISSOLVED

CALCIUM, DISSOLVED

MAGNE SIUM, DISSOL VED

SODIUM, DISSOLVED

POTASSIUM, DISSOLVED

GICARBONATE, ION

CARBONATE, ION

SULFATE, DISSOLVED

CHLORIDE, DISSOLVED

DISSOLVED SOLIDS, SUM CF CONST

DISSOLVED SOLIDS, ROE 180 DEG C

HARDNESS, TOTAL

HARDNESS, NONCARBONATE

TURBIDITY (JTU)

FLOURIDE, DISSOLVED

$\begin{array}{rrrrr}12 & 14.17 & 8.37 & 3.5 & 27.0 \\ 11 & 236.3 & 52.1 & 175 & 338 \\ 11 & 7137.1 & 9828.8 & 430 & 34200 \\ 11 & 7.15 & 0.56 & 6.1 & 7.9 \\ 12 & 0.272 & 0.415 & 0.05 & 1.50 \\ 12 & 0.542 & 0.202 & 0.10 & 0.86 \\ 12 & 0.633 & 0.615 & 0.15 & 2.50 \\ 12 & 3295.8 & 0608.7 & 230 & 24000 \\ 9 & 77.1 & 76.5 & 13 & 263 \\ 9 & 81.4 & 13.6 & 59 & 100 \\ 8 & 1826.9 & 2340.1 & 40 & 6400 \\ 7 & 1981.7 & 3070.6 & 32 & 7000 \\ 12 & 5.37 & 1.12 & 4.2 & 7.4 \\ 12 & 35.42 & 6.26 & 26.0 & 48.0 \\ 12 & 5.82 & 1.22 & 3.8 & 7.3 \\ 12 & 3.02 & 0.77 & 2.1 & 4.2 \\ 12 & 2.52 & 0.84 & 1.4 & 4.2 \\ 12 & 104.8 & 18.9 & 77 & 144 \\ 8 & 0.0 & 0.0 & 0 & 0 \\ 12 & 24.00 & 4.67 & 16.0 & 32.0 \\ 12 & 3.75 & 1.22 & 2.5 & 6.1 \\ 12 & 131.8 & 21.3 & 105 & 175 \\ 12 & 141.1 & 22.3 & 113 & 182 \\ 12 & 111.8 & 19.8 & 85 & 150 \\ 12 & 26.5 & 6.9 & 16 & 36 \\ 12 & 55.4 & 80.0 & 8 & 300 \\ 12 & 0.20 & 0.11 & 0.0 & 0.4\end{array}$

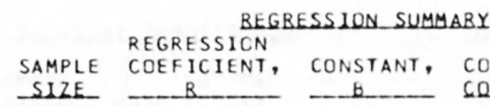

BEGRESSION SUMMABY

SIZE

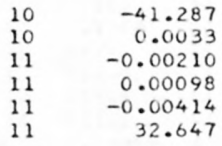

6.3732

0.77614

0.31215

1.61231

$-4227.320$

CORRELATION COEEICIENI

STANDARD ERROR OF ESIIMAIE * Not significant at the 95 percent confidence level.

11
11
11
11
11
11
7
11
11
11
11
11
11
11
11

$-0.224^{*}$

$0.302 *$

$-0.252^{*}$

$0.242^{*}$

$-0.334^{*}$
$0.247^{*}$

10432.8 0.443 0.217 0.641
7044.8

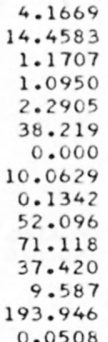

0.227 0.706 0.799 $0.545 *$ $0.023 *$ 0.741 0.000 . 0.653

0.0508
DAILY SPECIFIC CONDUCTANCE IN MICROMHOS AT 25 DEG C, THAT WAS

EQUALLED OR EXCEEDED FOR THE URALION IABLE OE DAILY SPECIEIC CONDUCIANCE

INDICATED PERCENTAGE OF TIME

$\begin{array}{llllll}18 & 58 & 108 & 20 \% & 30 \% & 20 \% \\ 330 & 290 & 282 & 260 & 240 & 225\end{array}$

1.20
4.90
0.81
0.70
0.72
13.9
0.0
3.83
0.99
14.6
18.5
13.4
5.9
81.6
0.10

\section{SAMPLE SIZE_ $=329$}

$70 \% \quad 20 \% \quad 25 \% \quad 29 \%$

$200 \quad 170-160-150$

SUMMARY OF HARMONIC ANALYSIS OF STREAM TEMPERATURE

\begin{tabular}{|c|c|c|c|c|c|}
\hline & & & & & STANDARD \\
\hline & $\begin{array}{l}\text { HARMONIC } \\
\text { MEAN - M }\end{array}$ & $\begin{array}{c}\text { AMPLITUOE } \\
-\quad A\end{array}$ & $\begin{array}{l}\text { PHASE } \\
\text { ANGLE - C }\end{array}$ & $\begin{array}{l}\text { VAR IATION } \\
\text { EXPLAINED }\end{array}$ & $\begin{array}{l}\text { ERROR OF } \\
\text { ESTIMATE }\end{array}$ \\
\hline $\mathrm{S1}$ & LDEG C) & - DEEG $(1$ & (BADIANS) & $\ldots 1 z 1 \ldots$ & LEE 61 \\
\hline
\end{tabular}

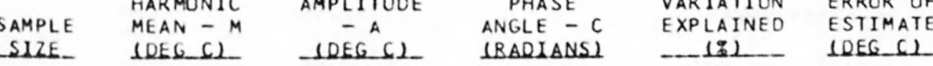

$\begin{array}{llllll}323 & 16.38 & 11.57 & 2.69 & 94 & 2.03\end{array}$

SUMMARY CF MAXIMUM AND MINIMUM CONCENTRATIONS OF CONSTITUENTS SAMPLED AT A FREQUENCY OF QUARTERLY (1975 WY)

03254000 -- LICKING RIVER AT BUTLER, KY.

\begin{tabular}{|c|c|c|c|c|c|c|}
\hline \multirow{2}{*}{ CONSTITUENT } & \multicolumn{3}{|c|}{ TOTAL } & \multicolumn{3}{|c|}{ DISSOLVED } \\
\hline & $\begin{array}{l}\text { NO. } \\
\text { SAMPLES }\end{array}$ & $\begin{array}{l}\text { MINIMUM } \\
\text { CONC. }\end{array}$ & $\begin{array}{l}\text { MAXIMUM } \\
\text { CONC. }\end{array}$ & $\begin{array}{l}\text { NO. } \\
\text { SAMPLES }\end{array}$ & $\begin{array}{l}\text { MINIMUM } \\
\text { CONC. }\end{array}$ & $\begin{array}{l}\text { MAXIMUM } \\
\text { CONC. }\end{array}$ \\
\hline \multicolumn{7}{|l|}{ MINOR ELEMENTS: } \\
\hline ARSENIC (AS), UG/L & 4 & 0 & 2 & 4 & 0 & 0 \\
\hline CAOMIUM $(C D)$, UG/L & 4 & 0 & 2 & 4 & 0 & 2 \\
\hline CHROMIUM (CR), UG/L & 4 & 0 & 10 & 4 & 0 & 1 \\
\hline COBALT $(C O), U G / L$ & 4 & 1 & 5 & 4 & 0 & 1 \\
\hline COPPER (CU), UG/L & 4 & 6 & 30 & 4 & 3 & 22 \\
\hline IRON $(F E), U G / L$ & 4 & 920 & 4200 & 4 & 0 & 50 \\
\hline LEAD $(P B), U G / L$ & 4 & 8 & 25 & 4 & 0 & 7 \\
\hline MANGANESE (MN), UG/L & 4 & 77 & 180 & 4 & 0 & 10 \\
\hline MERC URY $(H G), U G / L$ & 4 & 0.0 & 0.4 & 4 & 0.0 & 0.4 \\
\hline SELENIUM (SE), UG/L & 4 & 0 & 0 & 4 & 0 & 0 \\
\hline ZINC $(Z N), U G / L$ & 4 & 20 & 40 & 4 & 0 & 20 \\
\hline \multicolumn{7}{|l|}{ PERIPHYTON: } \\
\hline BIOMASS, DRY WT., G/SQ M & 3 & .00 & 12.00 & & & \\
\hline BIOMASS, ASH WT., G/SQ M & 3 & .00 & 11.00 & & & \\
\hline CHLOROPHYLL A, MG/SQ M & 3 & .0 & 3.5 & & & \\
\hline CHLOROPHYLL B, MG/SQ M & 3 & .0 & .7 & & & \\
\hline ORGANIC CARBON, MG/L & 4 & 2.0 & 6.1 & & & \\
\hline
\end{tabular}


LAT 39015M47S LONG 084040M04S

DRAINAGE AREA: 3814 SO MI 199878 SO KMI

PERIOD OF RECORD: $10 / 01 / 74-09 / 30 / 75$

STATISTICAL SUMMARY OF SELECTED DISSOLVED CHEMICAL CONSTITUENTS AND

REGRESSION RELATIONSHIPS CF CONSTITUENT CONCENTRATIONS TO SPECIFIC CONDUCTANCE

CONSILIUENI

CONSILIUENI IMGLL OB UNII SHOWN

SAMP

STANDARD

DEYIALION

14.71

633.8

4747.5

7.80

0.537

3.825

1.125

43463.6

121.6

8473.3

12179.2

6.65
74.75

74.75

28.25

21.25

274.0

274.0
0.0

60.00

35.25

371.3

420.0

302.5

78.5

68.8
8.00
65.0

4328.6

328.6
0.17

0.201

1.969

0.273

62455.5
126.8

7703.1

26604.8

0.97

5.50

1.71

6.40

0.76

22.2
0.0

5.35

7.54

26.1

28.0

20.6

88.2

88.2
0.08
3.5
520

520
1020
7.6

7.6

0.32

2.20

0.75

3400
46

580

110
5.7
70.0

70.0

26.0

16.0
2.7

249

60.0

28.0

333

383

280

15
BE REGRESSION
SAMPLE COEFICIENT, CONSTANT, SIZE.

CONSTANT

CORRELATION

STANDARD - 1

\begin{tabular}{|c|c|}
\hline 27.0 & \\
\hline 13100 & 12 \\
\hline 8.2 & 12 \\
\hline 1.00 & 12 \\
\hline 9.50 & 12 \\
\hline 1.70 & 12 \\
\hline 10000 & 11 \\
\hline
\end{tabular}

-51.700
0.0001
-0.00016
-0.00490
0.00167
117.620

37516.945
7.7345
0.63881
6.92875
0.06696
-32304.992

-0.776
$0.039^{*}$
$-0.052^{*}$
$-0.162^{\star}$
$0.397^{*}$
$0.107^{*}$

2862.5

0.18

0.21

2.038

65454.7

22000

80000

8.0
80.0

30.0

29.0

4.2

300
0

73.0
44.0

44.0
390

390
451

320

89
200
0.5

$\begin{array}{lr}4 & 0.0084 \\ 4 & 0.0521 \\ 4 & 0.0302 \\ 4 & 0.0922 \\ 4 & 0.0111 \\ 4 & 0.261 \\ 4 & 0.000 \\ 4 & 0.0842 \\ 4 & 0.1205 \\ 4 & 0.521 \\ 4 & 0.530 \\ 4 & 0.268 \\ 4 & 0.039 \\ 4 & -1.054 \\ 4 & 0.0013\end{array}$

1.1015
40.3227
8.3067
-39.6942
-3.9525
101.083
0.000
10.2924
-44.4120
20.420
69.265
125.350
52.429
1162.291
-0.4913
$0.431 *$

$0.471^{\star}$

$0.878^{*}$

$0.726 *$

$0.720^{*}$

$0.585 *$

$0.000^{*}$

$0.782^{\star}$
$0.794^{*}$

$0.995^{\star}$

$0.943^{*}$

$0.646^{*}$

$0.268^{*}$

$-0.933^{\star}$

$0.821^{*}$

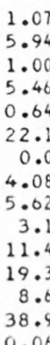

0.06

${ }^{*}$ Not significant at the 95 percent confidence level.

SUMMARY UF HARMONIC ANALYSIS OF STREAM TEMPERATURE

\begin{tabular}{|c|c|c|c|c|c|}
\hline & & & & & STANDARD \\
\hline & HARMONIC & AMPLITUDE & PHASE & VAR IATION & ERROR OF \\
\hline SAMPLE & MEAN - M & $-A$ & ANGLE - C & EXPLAINED & ESTIMATE \\
\hline SIZE. & IDEG CL & - $10 E G(1)$ & (RADIANSI & $-1 \% 2$ & LEEG $C 1$ \\
\hline
\end{tabular}

$\begin{array}{llllll}13 & 14.75 & 10.56 & 2.69 & 92 & 2.59\end{array}$

SUMMARY OF MAXIMUM AND MINIMUM CONCENTRATIONS OF CONSTITUENTS SAMPLED AT A FREQUENCY OF QUARTERLY (1975 WY)

$03274600--6$ MIAMI R AT NEW BALTIMORE OH

CONSTITUENT
SAMPLES


LAT 39024M24S LONG 085000M46S

DRAINAGE AREA: 1224 SQ MI ( 3170 SQ KM)

PERIOD OF RECORD: $10 / 01 / 74-09 / 30 / 75$

STATISTICAL SUMMARY OF SELECTED DISSOLVED CHEMICAL CONSTITUENTS AND REGRESSION RELATICNSHIPS CF CONSTITUENT CONCENTRATIONS TO SPECIFIC CONDUCTANCE

CONSIIIUENI

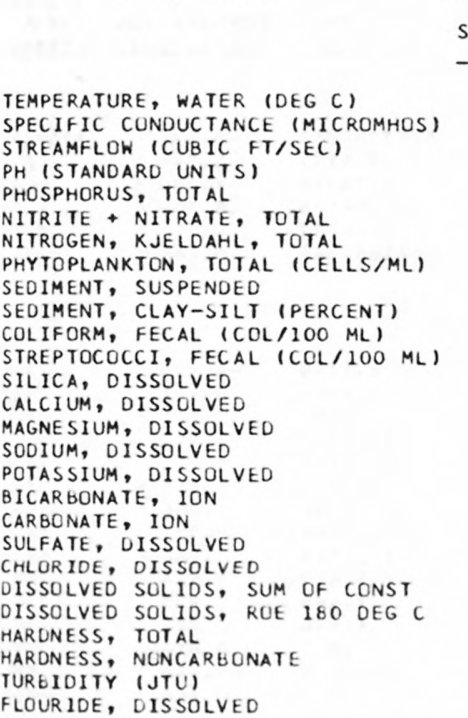

CONSILUUENI (MG $/ \perp$ OR UNII SHOWN)

\begin{tabular}{l} 
SAMPLE \\
SIZE \\
\hline
\end{tabular}

STANDARD

DEVIAUION
13.55

515.5

1898.3

8.04

0.109

2.162

0.661

7918.8

7918.8
165.0

8.90

84.0
2065.6

2065.6
0.30

0.111

0.808

0.653

9301.6

297.7

BANGE

3.5

320
194

194
7.6

0.03

0.92

0.33

140
40

4.61
07.20

67.20
23.10

7.91
7.91

2.30

261.9

261.9
0.0

37.40

14.93
287.0

287.0
308.9

264.0

48.1

58.2

0.26
BEG

REGRESSION

SAMPLE SIZE COEFICIENT,

ESSION SUMMARY

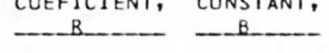

26.0

640

$7040 \quad 10$

8.7
0.40

3.40

3.40
2.50

28000

10
10
10
10

$-0.0015$

$-0.00111$

$-0.00323$

$-0.00636$

8.8004

0.68149

3.82727

3.93793

13.638

920.957

CORRELATICN COEEICIENI.

STANDARD ERROR OF ESIIMAIE

*Not significant at the 95 percent confidence level.

\section{DURALION_IABLE OF_DAILY SPECIEIC CONOUCIANCE}

DAILY SPECIFIC CONDUCTANCE IN

MICROMHOS AT 25 DEG C, THAT WAS

EQUALLED OR EXCEEDED FOR THE

$18 \quad-52 \quad 108$

202

2.9
42.0
12.0
2.8

$\begin{array}{rr}6.1 & 10 \\ 80.0 & 10 \\ 27.0 & 10 \\ 12.0 & 10 \\ 2.9 & 10 \\ 302 & 10 \\ 0 & 10 \\ 45.0 & 10 \\ 22.0 & 10 \\ 338 & 10 \\ 374 & 10 \\ 310 & 10 \\ 69 & 10 \\ 450 & 10 \\ 0.4 & 10\end{array}$
$-0.0005$
0.1165
0.0450
0.0236
$-0.0010$
0.470
0.000
0.0623
0.0396
0.518
0.518
0.473
0.503
0.091
$-1.344$
4. 8701
7.1561
$-0.1053$
$-4.2401$
2.8316
19.537
19.537
0.000
$-5.4942$
64.873
4.478
0.955
750.795
0.4085

0.4085

$-0.839$

$-0.415 *$

$-0.841$

$-0.336 *$

$-0.818$

$0.139 *$

1191.2

0.29
0.064

0.807

0.398

9948.8

307

$50 \%$

SAMPLE SIZE $=319$

$202 \quad 25 \% 298$

INDICATED PERCENTAGE OF TIME

$590 \cdot 570 \quad 560$

540

$440 \quad 410 \quad 330$

SUMMARY OF HARMONIC ANALYSIS OF STREAM TEMPERATURE

\begin{tabular}{|c|c|c|c|c|c|}
\hline & & & & & STANDARD \\
\hline SAMPLE & $\begin{array}{l}\text { HARMONIC } \\
\text { MEAN - M }\end{array}$ & $\begin{array}{c}\text { AMPLI ITUDE } \\
-\quad A\end{array}$ & $\begin{array}{c}\text { PHASE } \\
\text { ANGLE - C }\end{array}$ & $\begin{array}{l}\text { VARIATION } \\
\text { EXPLAINED }\end{array}$ & $\begin{array}{l}\text { ERROR OF } \\
\text { ESTIMATE }\end{array}$ \\
\hline SLZE. & $10 E G$ al & DDEG (1) & IBADIANSI & $(8)$ & (DEG $C)$ \\
\hline 319 & 14.03 & 10.47 & 2.66 & 94 & 2.08 \\
\hline
\end{tabular}

SUMMARY OF MAXIMUM AND MINIMUM CONCENTRATIONS OF CONSTITUENTS SAMPLED AT A FREQUENCY OF QUARTERLY (1975 WY)

03276500 -- WHITEWATER RIVER AT BROOKVILLE, IND

\begin{tabular}{|c|c|c|c|c|c|c|}
\hline \multirow{2}{*}{ CONSTITUENT } & \multicolumn{3}{|c|}{ TOTAL } & \multicolumn{3}{|c|}{ DISSOLVED } \\
\hline & $\begin{array}{l}\text { NO. } \\
\text { SAMPLES }\end{array}$ & $\begin{array}{l}\text { MINIMUM } \\
\text { CONC. }\end{array}$ & $\begin{array}{l}\text { MAXIMUM } \\
\text { CONC. }\end{array}$ & $\begin{array}{c}\text { NO. } \\
\text { SAMPLES }\end{array}$ & $\begin{array}{c}\text { MINIMUM } \\
\text { CONC. }\end{array}$ & $\begin{array}{l}\text { MAXIMUM } \\
\text { CONC. }\end{array}$ \\
\hline \multicolumn{7}{|l|}{ MINOR ELEMENTS: } \\
\hline ARSENIC (AS), UG/L & 2 & 1 & 1 & 2 & 0 & 1 \\
\hline CADMIUM $(C D), U G / L$ & 2 & 0 & 0 & 2 & 0 & 0 \\
\hline CHROMIUM (CR), UG/L & 2 & $<10$ & 10 & 2 & 0 & $<10$ \\
\hline COBALT $(C O)$, UG/L & 2 & 0 & 0 & 2 & 0 & 0 \\
\hline COPPER $(C U), U G / L$ & 2 & 20 & 30 & 2 & 10 & 10 \\
\hline IRON (FE), UG/L & 2 & 330 & 1100 & 2 & 0 & 10 \\
\hline LEAD $(P B), U G / L$ & 2 & 0 & 5 & 2 & 1 & 1 \\
\hline MANGANESE (MN), UG/L & 2 & 40 & 80 & 2 & 20 & 20 \\
\hline MERCURY (HG), UG/L & 2 & $<0.5$ & $<0.5$ & 2 & $<0.5$ & $<0.5$ \\
\hline SELENIUM (SE), UG/L & 2 & 1 & 1 & 2 & 0 & 0 \\
\hline ZINC $(Z N), U G / L$ & 2 & 10 & 20 & 2 & 10 & 10 \\
\hline \multicolumn{7}{|l|}{ PER IPHYTON: } \\
\hline BIOMASS, DRY WT., G/SQ M & 0 & & & & & \\
\hline BIOMASS, ASH WT., G/SO M & 0 & & & & & \\
\hline CHLOROPHYLL A, MG/SO M & 0 & & & & & \\
\hline CHLOROPHYLL B, MG/SQ M & 0 & & & & & \\
\hline ORGANIC CARBON, MG/L & 2 & 2.5 & 5.1 & & & \\
\hline
\end{tabular}


LAT $38046 M 29 S$ LUNG $084057 M 52 S$

DRAINAGE AREA: 83170 SO MI ( 215410 SO KM)

PERICD DF RECORD: $10 / 01 / 74-09 / 30 / 75$

STATISTICAL SUMMARY OF SELECTED DISSOLVED CHEMICAL CCNSTITUENTS AND

REGRESSION RELATIONSHIPS OF CONSTITUENT CONCENTRATIONS TO SPECIFIC CONDUCTANCE

CONSIIIUENI

\begin{tabular}{|c|}
\hline $\begin{array}{l}\text { TEMPERATURE, WATER (OEG C) } \\
\text { SPECIFIC CONDUCTANCE (MICROMHOS) } \\
\text { STREAMFLOW (CUBIC FT/SEC) } \\
\text { PH (STANDARD UNITS) } \\
\text { PHOSPHCRUS, TUTAL } \\
\text { NITRITE + NITRATE, TOTAL } \\
\text { NITROGEN, KJELDAHL, TOTAL } \\
\text { PHYTOPLANKTON, OOTAL (CELLS/ML) } \\
\text { SEDIMENT, SUSPENDED } \\
\text { SEDIMENT, CLAY-SILT (PERCENT) } \\
\text { COLIFORM, FECAL (COL/1OO ML) } \\
\text { STREPTOCOCCI, FECAL (COL/IOO ML) } \\
\text { SILICA, DISSOLVED } \\
\text { CALCIUM, DISSULVED } \\
\text { MAGNESIUM, DISSCLVED } \\
\text { SODIUM, DISSOLVED } \\
\text { POTASSIUM, DISSOLVED } \\
\text { BICARBONATE, ION } \\
\text { CARBONATE, ION } \\
\text { SULFATE, DISSOLVED } \\
\text { CHLCRIOE, DISSOLVED } \\
\text { DISSOLVED SOLIDS, SUM OF CONST } \\
\text { DISSOLVED SOLIDS, ROE I8O DEG C } \\
\text { HARDNESS, TOTAL } \\
\text { HARDNESS, NONCARBONATE } \\
\text { TURBIDITY (JTU) } \\
\text { FLOURIDE, DISSOLVED }\end{array}$ \\
\hline
\end{tabular}

CONSIUIVENI LMG/L QR UNII SHOWNI

SAMP
S12
12
12
13
12
12
12
12
12
4
7
7
10
12
12
12
12
12
9
12
12
12
12
12
12
12
12

\section{STANDARD}

15.17 $350 \cdot 4$ 151253.8 7.27 0.141

1.132

0.682

0.682
5196.7

39.0

92.5

3344.3

015.7

5.82
38.42

38.42

9.74
17.55

17.55
2.95

2.95
77.3

77.3
0.0

69.17

24.92

206.1

223.7

136.4
72.7

41.3

0.28 MEAN DEYLALION

$$
8.87
$$
73.7
50603.8 150603.8 0.082 0.246 0.246 1049 1049.1
21.0 9.0 2872.1 1198.6 0.71 8.93 3.24 7.44 1.46 16.7 16.7
0.0 25.37 13.63 50.5
54.7 29.1 21.3 0.11
$B E$ SAMPLE COEFICIENT, CONSTANT, SIZE. CONSTANT, CORRELATION COEEICIENI

STANCAR: BANGE 4.0
255 27.5

$8.8 \quad 15.0$

$$
\begin{array}{r}
-1322.197 \\
0.0004 \\
-0.00008 \\
0.00168 \\
0.00004 \\
66.735 \\
\\
\\
\\
-0.0069 \\
0.1082 \\
0.0156 \\
0.0949 \\
0.0124 \\
0.128 \\
0.000 \\
0.2498 \\
0.1050 \\
0.633 \\
0.617 \\
0.357 \\
0.235
\end{array}
$$$$
7.1177
$$

0.16789

0.54534

0.00897

$-18188.344$

$-0.030$ $0.084 *$

$-0.070$

0.010

$0.445 *$$$
-0.313
$$$$
\begin{array}{r}
8.1169 \\
0.4855 \\
4.2897 \\
-15.7212 \\
-1.3794 \\
32.545 \\
0.000 \\
-18.3544 \\
-11.8799 \\
-15.687 \\
7.448 \\
11.476 \\
-9.820 \\
151.139 \\
-0.0643
\end{array}
$$
COEFICIENT, $13200 \quad 46999$
6.5 0.06 0.82 0.27 .27
890

890
18 82
110 110
28 $\begin{array}{rr}4.4 & 6.8\end{array}$

2.0

$1.8 \quad 33.0$

\begin{tabular}{|c|c|c|c|c|c|}
\hline & & & & & STANDARD \\
\hline & HARMONIC & AMPLITUDE & PHASE & VARIATICN & ERROR OF \\
\hline SAMPLE & MEAN - M & $-A$ & $A N G L E-C$ & EXPLAINED & ESTIMATE \\
\hline SUZE_ & LEEG 61 & IDEG_L1 & IBADIADSI & -131 & LDEG $(1)$ \\
\hline 305 & 16.18 & 12.65 & 2.63 & 97 & 1.45 \\
\hline
\end{tabular}

1.8
56

22.0

11.0

141

\begin{tabular}{|c|c|c|c|c|c|c|}
\hline \multirow{2}{*}{ CONSTITUENT } & \multicolumn{3}{|c|}{ TOTAL } & \multicolumn{3}{|c|}{ DISSOLVED } \\
\hline & $\begin{array}{l}\text { NO. } \\
\text { SAMPLES }\end{array}$ & $\begin{array}{l}\text { MINIMUM } \\
\text { CONC. }\end{array}$ & $\begin{array}{l}\text { MAXIMUM } \\
\text { CONC. }\end{array}$ & $\begin{array}{l}\text { NC. } \\
\text { SAMPLES }\end{array}$ & $\begin{array}{l}\text { MINIMUM } \\
\text { CONC. }\end{array}$ & $\begin{array}{l}\text { MAXIMUM } \\
\text { CONC. }\end{array}$ \\
\hline \multicolumn{7}{|l|}{ MINOR ELEMENTS: } \\
\hline ARSENIC (AS), UG/L & 4 & 0 & 3 & 4 & 0 & 1 \\
\hline CADMIUM $(C D), U G / L$ & 4 & 0 & 1 & 4 & 0 & 1 \\
\hline CHROMIUM (CR), UG/L. & 4 & $<10$ & 10 & 4 & 0 & 2 \\
\hline COBALT $(C O), U G / L$ & 4 & 0 & 20 & 4 & 0 & 7 \\
\hline COPPER (CU), UG/L & 4 & 5 & 33 & 4 & 3 & 6 \\
\hline IRON (FE), UG/L & 4 & 410 & 6900 & 4 & 0 & 0 \\
\hline LEAD $(P B), U G / L$ & 4 & 1 & 43 & 4 & 0 & 3 \\
\hline MANGANESE $(M N), U G / L$ & 4 & 50 & 400 & 4 & 4 & 110 \\
\hline MERCURY $(H G), U G / L$ & 4 & 0.0 & 0.1 & 4 & 0.0 & 0.1 \\
\hline SELENIUM (SE), UG & 4 & 0 & 1 & 4 & 0 & 1 \\
\hline$Z I N C(Z N), U G / L$ & 4 & 10 & 180 & 4 & 0 & 20 \\
\hline \multicolumn{7}{|l|}{ PERIPHYTON: } \\
\hline BIOMASS, DRY WT., G/SO M & 4 & 2.50 & 48.00 & & & \\
\hline BIUMASS, ASH WT., G/SQ M & 4 & 1.29 & 44.00 & & & \\
\hline CHLOROPHYLL A, MG/SQ M & 4 & .0 & 57.0 & & & \\
\hline CHLOROPHYLL B, MG/SO M & 4 & .0 & 6.5 & & & \\
\hline ORGANIC CARBON, MG/L & 4 & 2.8 & 4.5 & & & \\
\hline
\end{tabular}

156

97
51
5

5

$\begin{array}{rr}69999 & 12 \\ 7.8 & 12 \\ 0.34 & 12 \\ 1.50 & 12 \\ 1.30 & 12 \\ 40000 & 12 \\ 59 & \\ 100 & \\ 8500 & \\ 3300 & \\ 6.8 & 10 \\ 51.0 & 12 \\ 15.0 & 12 \\ 33.0 & 12 \\ 7.0 & 12 \\ 109 & 12 \\ 0 & 9 \\ 120.0 & 12 \\ 57.0 & 12 \\ 312 & 12 \\ 334 & 12 \\ 190 & 12 \\ 120 & 12 \\ 200 & 12 \\ 0.4 & 12\end{array}$

*Not significant at the 95 percent confidence level.
DURAILON IABLE_OE RALL SPECIEIC CONDUCIANCE

DAILY SPECIFIC CONDUCTANCE IN

MICROMHOS AT 25 DEG C, THAT WAS

EQUALLED OR EXCEEDED FOR THE

$\begin{array}{llllll}18 & 5 \% \quad 20 \% & 20 \% & 30 \% & 50 \%\end{array}$

\begin{tabular}{llll} 
& \multicolumn{4}{l}{ SAMPLE SILE $=362$} \\
$70 \%$ & $20 \%$ & 258 & 928 \\
288 & 252 & 240 & 225
\end{tabular}

SUMMARY OF HARMUNIC ANALYSIS OF STREAM TEMPERATURE

SUMMARY OF MAXIMUM AND MINIMUM CONCENTRATIONS OF CONSTITUENTS SAMPLED AT A FREQUENCY OF QUARTERLY (1975 WY)

$03277200-$ OH1O R AT MARKLANO DAM NR WARSAW, KY 
LAT 38D26M2OS LONG 084D57M48S

DRAINAGE AREA: 6180 SQ MI ( 10006 SQ KM)

PERIOD OF RECORD: $10 / 01 / 74-09 / 30 / 75$

STATISTICAL SUMMARY OF SELECTED DISSOLVED CHEMICAL CONSTITUENTS AND REGRESSION RELATIONSHIPS OF CONSTITUENT CONCENTRATIONS TO SPECIFIC CONDUCTANCE

\section{CONSIUIUENI}

CONS

NSILIUENI $1 M G \angle L$ OR UNII SHOWNI

AMPLE

\section{MEAN}

TEMPERATURE, WATER (UEG C) SPECIFIC CONDUCTANCE IMICROMHOS I STREAMFLOW (CUBIC FT/SEC)

PH (STANDARD UNITS)

PHOSPHCRUS, TOTAL

NITRITE + NITRATE, TOTAL

NITROGEN, KJELDAHL, TOTAL

PHYTOPLANKTON, TOTAL ICELLS/ML

SEDIMENT, SUSPENDED

SEDIMENT, CLAY-SILT (PERCENT)

COLIFORM, FECAL (COL/100 ML)

STREPTOCOCCI, FECAL (COL/100 ML)

SILICA, DISSOLVED

MAGNESIUM, DISSOLVED

MAGNESIUM, OISSULVED

PODIUM, DISSOLVED

BICARBONATE, ION

CARBONATE, ION

SULFATE, DISSOLVED

CHLORIDE, DISSOLVED

DISSOLVED SOLIDS, SUM OF CONST

DISSOLVED SOLIDS, ROE 180 DEG

HARDNESS, TOTAL

HARONESS, NONCARBONATE

TURBIDITY (JTU)

FLOURIDE, UISSOLVEU

${ }^{*}$ Not significant at the 95 percent confidence level.

$\begin{array}{rrrrrr}11 & 15.64 & 8.82 & 5.5 & 27.5 & \\ 10 & 243.3 & 47.7 & 185 & 336 & \\ 11 & 8281.1 & 7056.2 & 792 & 20400 & 9 \\ 11 & 7.16 & 0.51 & 6.1 & 7.8 & 9 \\ 12 & 0.167 & 0.070 & 0.11 & 0.37 & 10 \\ 12 & 0.590 & 0.215 & 0.15 & 0.94 & 10 \\ 12 & 0.392 & 0.166 & 0.22 & 0.73 & 10 \\ 12 & 1055.0 & 1300.8 & 130 & 4700 & 10 \\ 7 & 108.9 & 100.0 & 25 & 294 & \\ 7 & 88.1 & 8.5 & 77 & 98 & \\ 8 & 1396.3 & 2385.5 & 130 & 7200 & \\ 7 & 404.0 & 499.0 & 68 & 1400 & \\ 12 & 6.61 & 3.07 & 3.9 & 16.0 & 10 \\ 12 & 34.75 & 6.08 & 27.0 & 47.0 & 10 \\ 12 & 0.83 & 1.26 & 5.4 & 9.1 & 10 \\ 12 & 0.67 & 4.08 & 3.0 & 16.0 & 10 \\ 12 & 2.12 & 0.60 & 1.4 & 3.3 & 10 \\ 12 & 97.5 & 20.6 & 72 & 134 & 10 \\ 8 & 0.0 & 0.0 & 0 & 0 & 7 \\ 12 & 32.67 & 7.41 & 22.0 & 44.0 & 10 \\ 12 & 9.44 & 7.33 & 3.5 & 29.0 & 10 \\ 12 & 146.3 & 28.0 & 114 & 199 & 10 \\ 12 & 159.8 & 34.2 & 118 & 220 & 10 \\ 12 & 114.6 & 18.3 & 90 & 150 & 10 \\ 12 & 35.0 & 8.2 & 19 & 47 & 10 \\ 12 & 40.9 & 35.8 & 1 & 110 & 10 \\ 12 & 0.22 & 0.13 & 0.1 & 0.5 & 10\end{array}$

QURAIION IABLE_OE_DALLYSPECIEIC CONDUCIANCE

DAILY SPECIFIC CONDUCTANCE IN

MICROMHOS AT 25 DEG C, THAT WAS

EQUALLED OR EXCEEUED FCR THE

INDICATED PERCENTAGE OF TIME
REGRESSION

EEGRESSION SUMMABY

COEFICIENT, CONSTANT, CORRELATION ERROR OF COEFICIENT, CONSTANT, CORRELATION ERTOR OF

6932.3

0.076

0.153

0.179

1463.9

$0.992-715.184-0.235$

$$
\begin{array}{r}
-0.0062 \\
0.1217 \\
0.0229 \\
0.0477 \\
0.0083 \\
0.402 \\
0.000 \\
0.0707 \\
0.0739 \\
0.542 \\
0.596 \\
0.379 \\
0.067 \\
-0.591 \\
0.0013
\end{array}
$$$$
\begin{array}{r}
7.2524 \\
4.1929 \\
1.0901 \\
-5.8249 \\
0.0088 \\
-2.482 \\
0.000 \\
14.8045 \\
-10.3098 \\
9.143 \\
9.151 \\
19.350 \\
17.197 \\
189.826 \\
-0.0864
\end{array}
$$

$-0.320$

0.930

0.842

0.728

c. 788

0.872
0.000

0.000

0.441

0.803

0.968

0.877
0.974

0.974
0.397 .

$-0.770$

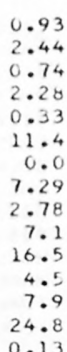

0.93
2.44
0.74
2.28
0.33
11.4
0.0
7.29
2.78
7.1
16.5
4.5
7.9
24.8
0.13

SUMMARY OF HARMUNIC ANALYSIS OF STREAM TEMPERATURE

EORM OF EQVAIION: I.101 = M+A* SINC.0272*0+C)

\begin{tabular}{|c|c|c|c|c|c|}
\hline & & & & & STANDARD \\
\hline & HARMONIC & AMPLITUDE & PHASE & VARIATION & ERROR OF \\
\hline SAMPLE & MEAN - M & $-A$ & ANGLE - C & EXPLA INED & ESTIMATE \\
\hline SIZE_ & COEG 61 & (DEG E) & (BADIANS) & $-(8)$ & $10 E G C 1$ \\
\hline 359 & 10.32 & 11.29 & 2.69 & 96 & 1.72 \\
\hline
\end{tabular}

SUMMARY OF MAXIMUM AND MINIMUM CONCENTRATIONS OF CONSTITUENTS SAMPLED AT A FREQUENCY OF QUARTERLY (1975 WY)

03290500 -- KENTUCKY RIVER AT LOCK 2, AT LOCKPORT, KY.

\begin{tabular}{|c|c|c|c|c|c|c|}
\hline \multirow{2}{*}{ CONSTITUENT } & \multicolumn{3}{|c|}{ TOTAL } & \multicolumn{3}{|c|}{ DISSOLVED } \\
\hline & $\begin{array}{l}\text { NO. } \\
\text { SAMPLES }\end{array}$ & $\begin{array}{l}\text { MINIMUM } \\
\text { CONC. }\end{array}$ & $\begin{array}{l}\text { MAXIMUM } \\
\text { CONC. }\end{array}$ & $\begin{array}{l}\text { NO. } \\
\text { SAMPLES }\end{array}$ & $\begin{array}{l}\text { MINIMUM } \\
\text { CONC. }\end{array}$ & $\begin{array}{l}\text { MAXIMUM } \\
\text { CONC. }\end{array}$ \\
\hline \multicolumn{7}{|l|}{ MINOR ELEMENTS: } \\
\hline ARSENIC (AS), UG/L & 4 & 1 & 2 & 4 & 0 & 0 \\
\hline CADMIUM $(C D), U G / L$ & 4 & 0 & 2 & 4 & 1 & 2 \\
\hline CHROMIUM (CR), UG/L & 4 & $<10$ & $<10$ & 4 & 0 & 1 \\
\hline COBALT $(C O), U G / L$ & 4 & 0 & 3 & 4 & 0 & 3 \\
\hline COPPER (CU), UG/L & 4 & 8 & 16 & 4 & 4 & 7 \\
\hline IRON (FE), UG/L & 4 & 760 & 3600 & 4 & 0 & 10 \\
\hline LEAD $(P B), U G / L$ & 4 & 10 & 19 & 4 & 0 & 6 \\
\hline MANG ANESE (MN), UG/L & 4 & 60 & 130 & 4 & 0 & 10 \\
\hline MERCURY (HG), UG/L & 4 & 0.0 & 0.2 & 4 & 0.0 & 0.1 \\
\hline SELENIUM (SE), UG/L & 4 & 0 & 0 & 4 & 0 & 0 \\
\hline ZINC $(Z N), U G / L$ & 4 & 0 & 90 & 4 & 4 & 20 \\
\hline \multicolumn{7}{|l|}{ PERIPHYTON: } \\
\hline BIOMASS, DRY WT., G/SO M & 4 & .39 & 6.79 & & & \\
\hline BIOMASS, ASH WT., G/SQ M & 4 & .19 & 5.29 & & & \\
\hline CHLOROPHYLL A, MG/SO M & 4 & .0 & 5.7 & & & \\
\hline CHLOROPHYLL B, MG/SO M & 4 & .0 & .5 & & & \\
\hline ORGANIC CARBON, MG/L & 4 & 3.6 & 6.5 & & & \\
\hline
\end{tabular}


Table 14.--Summary of measurements at each station--Continued

STATION NUMBER: 03301630 NAME: ROLLING FORK NR LEBANON JUNCTION,KY.

-AT 37D49M22S LONG 085044M52S

JRAINAGE AREA: 0 SQ MI I

DERIOD OF RECORD: $10 / 01 / 74-09 / 30 / 750$ SO KMI

STATISTICAL SUMMARY OF SELECTED DISSOLVED CHEMICAL CONSTITUENTS AND

REGRESSION RELATIONSHIPS OF CONSTITUENT CONCENTRATIONS TO SPECIFIC CONDUCTANCE

CONSIIUENI

CONSILUEENI IMG/L_OR UNUI_SHOWNI

TEMPERATURE, WATER (DEG C)
SPECIFIC CONDUCTANCE (MICROMHOS)
STREAMFLOW (CUBIC FT/SEC)
PH (STANDARD UNITS)
PHOSPHORUS, TOTAL
NITRITE, NITRATE, TOTAL
NITROGEN, KJELDAHL, TOTAL
PHYTOPLANKTON, TOTAL (CELLS/ML)
SEDIMENT, SUSPENDED (PERCENT)
SEDIMENT, CLAY-SILT (PERC ML)
COLIFORM, FECAL (COL/IOO ML)
STREPTOCOCCI, FECAL (COL/IOO ML)
SILICA, DISSOLVED
CALCIUM, DISSOLVED
MAGNESIUM, DISSOLVED
SODIUM, DISSOLVED
POTASSIUM, DISSOLVED
BICARBONATE, ION
CARGONATE, ION
SULFATE, DISSOLVED
CHLORIDE, DISSOLVED
DISSOLVED SOLIDS, SUM OF CONST
DISSOLVED SOLIDS, ROE I8O DEG C
HARDNESS, TOTAL
HARDNESS, NONCARBONATE
TURBIDITY (JTU)
FLOURIDE, DISSOLVED

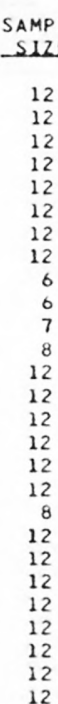

STANDARD

14.04

363.0

1409.4

7.35

0.281

0.547

0.697
1448.3

1448.3
119.3

119.3
93.0

2215.7

5801.5

5.97
54.50

54.50

12.23

4.50
2.71

2.71
187.0

187.0
0.0

0.0
29.92

5.43

207.8

220.3

187.5

32.9

80.4

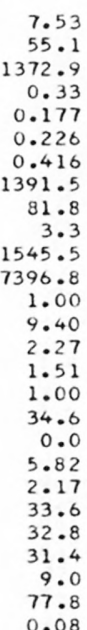

7.53
55.1

1372.9

0.133

0.226

0.416

81.8

3.3

545.5
7396.8

396.8
1.00

9.40

2.27
1.51

1.00

34.6

5.82

2.17

33.6
32.8

31.4

77.8

0.08

*Not significant at the 95 percent confidence level.

DAILY SPECIFIC CONOUCTANCE IN

MICROMHOS AT 25 DEG C, THAT WAS $1 \% \quad-5 \% \quad 10 \% \quad 20 \% \quad 30 \% \quad 50$

BANGE

BEGRESSION SUMMARY

REGRESSION

4.5
230
26
6.9
0.13
0.23
0.39
230
29
89
540
42

SAMPLE COEFICIENT, CONSTANT, CORRELATION

STANDARD SIZE

$\begin{array}{rr}42 & 18000 \\ 4.1 & 7.1\end{array}$

34.0

5.8

2.3

103

20.0

3.0
125

142

110
14

20

0.0

24.5
440

-2.393
0.0020
-0.00123
-0.00203
-0.00121
3.452
2278.160 6.6106 0.72614
1.28525
1.13596
195.290

3.452 COEEICIENI

ERROR OF

ESILMAIE

INDICATED PERCENTAGE FF THE

451

436

$427 \quad 390$

364

314

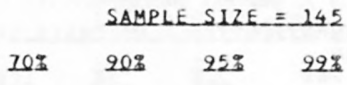

287

$245 \quad 223 \quad 202$

SUMMARY OF HARMONIC ANALYSIS OF STREAM TEMPERATURE

FOBM OE EQUAIION: I.101 = M + A * SIVI.0172 * D + C)

\begin{tabular}{|c|c|c|c|c|c|}
\hline & & & & & STANDARD \\
\hline & HARMONIC & AMPLITUDE & PHASE & VAR IATION & ERROR OF \\
\hline SAMPLE & MEAN - M & $-A$ & ANGLE - C & EXPLAINED & ESTIMATE \\
\hline SLZE_ & DDEG C) & DEE C & (RADIANS) & -131 & LDEG $(1$ \\
\hline 145 & 14.47 & 11.10 & 2.79 & 84 & 1.77 \\
\hline
\end{tabular}

SUMMARY OF MAXIMUM AND MINIMUM CONCENTRATIONS OF CONSTITUENTS

SAMPLED AT A FREQUENCY OF OUARTERLY (1975 WY)

03301630 -- ROLLING FORK NR LEBANON JUNCTION, KY.

\begin{tabular}{|c|c|c|c|c|c|c|}
\hline \multirow{2}{*}{ CONSTITUENT } & \multicolumn{3}{|c|}{ TOTAL } & \multicolumn{3}{|c|}{ DISSOLVED } \\
\hline & $\begin{array}{l}\text { NO. } \\
\text { SAMPLES }\end{array}$ & $\begin{array}{l}\text { MINIMUM } \\
\text { CONC. }\end{array}$ & $\begin{array}{l}\text { MAXIMUM } \\
\text { CONC. }\end{array}$ & $\begin{array}{l}\text { NO. } \\
\text { SAMPLES }\end{array}$ & $\begin{array}{l}\text { MINIMUM } \\
\text { CONC. }\end{array}$ & $\begin{array}{l}\text { MAXIMUM } \\
\text { CONC. }\end{array}$ \\
\hline \multicolumn{7}{|l|}{ MINOR ELEMENTS: } \\
\hline ARSENIC (AS), UG/L & 4 & 1 & 2 & 4 & 0 & 1 \\
\hline CADMIUM $(C D), U G / L$ & 4 & 0 & 3 & 4 & 1 & 7 \\
\hline CHROMIUM (CR), UGIL & 4 & $<10$ & 10 & 4 & 0 & 2 \\
\hline CUBALT (CO), UG/L & 4 & 0 & 3 & 4 & 0 & 3 \\
\hline COPPER $(C U), U G / L$ & 4 & 5 & 28 & 4 & 4 & 7 \\
\hline IRON $(F E), U G / L$ & 4 & 970 & 3800 & 4 & 0 & 720 \\
\hline LEAD $(P B), U G / L$ & 4 & 16 & 37 & 3 & 3 & 10 \\
\hline MANGANESE (MN), UG/L & 4 & 95 & 200 & 4 & 60 & 140 \\
\hline MERCURY $(H G), U G / L$ & 4 & 0.0 & 0.3 & 4 & 0.0 & 0.4 \\
\hline SELENIUM (SE), UG/L & 4 & 0 & 1 & 4 & 0 & 1 \\
\hline$Z I N C(Z N), U G / L$ & 4 & 10 & 30 & 4 & 0 & 130 \\
\hline \multicolumn{7}{|l|}{ PERIPHYTON: } \\
\hline BIOMASS, ORY WT., G/SO M & 0 & & & & & \\
\hline BIOMASS, ASH WT., G/SO M & 0 & & & & & \\
\hline CHLOROPHYLL A, MG/SO M & 0 & & & & & \\
\hline CHLOROPHYLL B, MG/SQ M & 0 & & & & & \\
\hline ORGANIC CARBON, MG/L & 4 & 3.6 & 4.7 & & & \\
\hline
\end{tabular}


Table 14.--Summary of measurements at each station--Continued

LAT 37053M58S LONG 086042M2OS

DRAINAGE AREA: 0 SQ MI

PERIOD OF RECORD: $10 / 01 / 74-09 / 30 / 75$

O SQ KMI

STATISTICAL SUMMARY OF SELECTED DISSOLVED CHEMICAL CONSTITUENTS AND REGRESSION RELATIONSHIPS OF CONSTITUENT CONCENTRATIONS TO SPECIFIC CONDUCTANCE

CONSIITUENI

CONSIUIUENI
TEMPERATURE, WATER (DEG C)
SPECIFIC CONDUCTANCE (MICROMHOS)
STREAMFLOW (CUBIC FT/SEC)
PH (STANDARD UNITS)
PHOSPHORUS, TOTAL
NITRITE, NITRATE, TOTAL
NITROGEN, KJELDAHL, TOTAL
PHYTOPLANKTON, TOTAL (CELLS/ML)
SEDIMENT, SUSPENDED
SEDIMENT, CLAY-SILT (PERCENT)
COLIFORM, FECAL (COL/IOO ML)
STREPTOCOCCI, FECAL (COL/IOO ML)
SILICA, DISSOLVED
CALCIUM, DISSOLVED
MAGNESIUM, DISSOLVED
SODIUM, DISSOLVED
POTASSIUM, DISSOLVED
BICAREONATE, ION
CARBONATE, ION
SULFATE, DISSOLVED
CHLORIDE, DISSOLVED
DISSOLVED SOLIDS, SUM OF CONST
DISSOLVED SOLIDS, ROE I8O DEG C
HARDNESS, TOTAL
HARDNESS, NONCARBONATE
TURBIDITY (JTU)
FLOURIDE, DISSOLVED

\section{CONSIUUUENI IMG/L OB UNII SHOWNI}

STANPLE STARD

$\begin{array}{lr}11 & 14.75 \\ 11 & 344.4 \\ 11 & 176017.9\end{array}$

$11 \quad 7.46$

0.156
1.214
0.702

1.214
0.702

2586.4

40.0

65.0

1947.4

305.0

5.55

38.27

10.22
15.54

15.54
2.55

2.55
82.2

0.0

67.00

20.36
200.1

216.8

139.1

70.6

54.9
QEYIAIION

9.19

159132.3

0.36
0.088

0.088
0.245

0.245
0.368

0.368
2466.8

32.5

24.0

1976.2

497.2

0.81

7.24

2.02
7.01

0.76

14.1

0.0
20.33

20.33
8.26

49.5

57.5

27.4

17.2

59.5
0.10

${ }^{*}$ Not significant at the 95 percent confidence level.

\section{BEGBESSION SUMMARY}

$\begin{array}{ll} & \text { REGRESSION } \\ \text { SAMPLE COEFICIENT, CONSTANT, }\end{array}$

SAMPLE
SIZE

$-B$

- B

CORRELATION

COEEICIENI

STANDARD

ERROR OF

ESIUMAIE

$\begin{array}{rrr}4.2 & 30.0 & \\ 250 & 490 & \\ 22000 & 504999 & 11 \\ 7.1 & 8.4 & 11 \\ 0.06 & 0.38 & 11 \\ 0.88 & 1.60 & 11 \\ 0.31 & 1.50 & 11 \\ 950 & 9400 & 11 \\ 17 & 63 & \\ 48 & 82 & \\ 10 & 5100 & \\ 2 & 1200 & \\ 4.2 & 6.6 & 10 \\ 30.0 & 52.0 & 11 \\ 7.3 & 14.0 & 11 \\ 8.9 & 28.0 & 11 \\ 1.8 & 3.9 & 11 \\ 64 & 113 & 11 \\ 0 & 0 & 8 \\ 50.0 & 110.0 & 11 \\ 11.0 & 34.0 & 11 \\ 153 & 293 & 11 \\ 142 & 326 & 11 \\ 110 & 190 & 11 \\ 52 & 110 & 11 \\ 1 & 200 & 11 \\ 0.1 & 0.4 & 11\end{array}$

$-1267.658$

$-0.0028$

$-0.00034$

0.00175

$-0.00080$

1.094 8.4175 0.27266 0.60999 0.60999

2209.760

$-0.591$

-0.564
-0.286

$-0.286$

$-0.161$

-0.161
0.033

135333.7

0.32

0.088

0.219

0.383
2598.8

DAILY SPECIFIC CONDUCTANCE IN

OURAIUN IABLE OE DAULY SPECIEIC CONOUCIANCE

MICROMHOS AT 25 DEG C, THAT WAS

EQUALLED OR EXCEEDED FOR THE

$\begin{array}{lll}12 & -21 & 102 \\ 561 & 449 & 420\end{array}$

$20 z$

308

$50 \%$

$391 \quad 364$

300

$$
\begin{array}{r}
-0.0050 \\
0.0849 \\
0.0256 \\
0.0867 \\
0.0087 \\
0.164 \\
0.000 \\
0.2514 \\
0.0985 \\
0.631 \\
0.762 \\
0.328 \\
0.193 \\
-0.267 \\
0.0005
\end{array}
$$

\begin{tabular}{|c|c|c|c|c|c|}
\hline & & & & & STANDARD \\
\hline & HARMONIC & AMPLITUDE & PHASE & VARIATION & ERROR OF \\
\hline $\begin{array}{l}\text { SAMPLE } \\
\text { SUZE }\end{array}$ & MEAN - M & $-{ }^{A}$ & ANGLE - C & EXPLAINED & $\begin{array}{l}\text { ESTIMATE } \\
\text { (DEG C) }\end{array}$ \\
\hline
\end{tabular}

$$
\begin{array}{r}
7.2445 \\
9.0361 \\
1.4187 \\
-14.3159 \\
-0.4453 \\
25.753 \\
0.000 \\
-19.5721 \\
-13.5662 \\
-17.314 \\
-45.688 \\
26.001 \\
4.277 \\
146.757 \\
0.0956
\end{array}
$$

\begin{tabular}{|c|c|c|c|c|c|c|}
\hline \multirow{2}{*}{ CONSTITUENT } & \multicolumn{3}{|c|}{ TOTAL } & \multicolumn{3}{|c|}{ DISSOLVED } \\
\hline & $\begin{array}{l}\text { NO. } \\
\text { SAMPLES }\end{array}$ & $\begin{array}{l}\text { MINIMUM } \\
\text { CONC. }\end{array}$ & $\begin{array}{l}\text { MAXIMUM } \\
\text { CONC. }\end{array}$ & $\begin{array}{l}\text { NO. } \\
\text { SAMPLES }\end{array}$ & $\begin{array}{l}\text { MINIMUM } \\
\text { CONC. }\end{array}$ & $\begin{array}{l}\text { MAXIMUM } \\
\text { CONC. }\end{array}$ \\
\hline \multicolumn{7}{|l|}{ MINOR ELEMENTS: } \\
\hline ARSENIC (AS), UG/L & 4 & 0 & 3 & 4 & 0 & 1 \\
\hline CADMIUM $(C D), U G / L$ & 4 & 0 & 9 & 4 & 1 & 2 \\
\hline CHROMIUM (CR), UG/L & 4 & $<10$ & 10 & 4 & 0 & 1 \\
\hline COBALT $(C O)$, UG/L & 4 & 0 & 7 & 4 & 0 & 2 \\
\hline COPPER (CU), UG/L & 4 & 5 & 36 & 4 & 3 & 8 \\
\hline IRON (FE), UG/L & 4 & 260 & $5700^{\circ}$ & 4 & 0 & 10 \\
\hline LEAD $(P B), U G / L$ & 4 & 6 & 34 & 4 & 0 & 6 \\
\hline MANGANESE (MN), UG/L & 4 & 20 & 110 & 4 & 3 & 30 \\
\hline MERCURY (HG), UG/L & 4 & 0.0 & 0.5 & 4 & 0.0 & 0.5 \\
\hline SELENIUM (SE), UG/L & 4 & 0 & 1 & 4 & 0 & 0 \\
\hline ZINC $(Z N), U G / L$ & 4 & 30 & 100 & 4 & 0 & 60 \\
\hline \multicolumn{7}{|l|}{ PERIPHYTON: } \\
\hline BIOMASS, DRY WT., G/SO M & 3 & 6.19 & 46.00 & & & \\
\hline BIOMASS, ASH WT., G/SO M & 3 & 3.09 & 17.00 & & & \\
\hline CHLOROPHYLL A, MG/SQ M & 3 & .0 & 94.0 & & & \\
\hline CHLOROPHYLL $B, M G / S O M$ & 3 & .1 & 29.0 & & & \\
\hline ORGANIC CARBON, MG/L & 4 & 4.3 & 6.5 & & & \\
\hline
\end{tabular}

$$
\begin{array}{r}
-0.463{ }^{*} \\
0.870 \\
0.936 \\
0.917 \\
0.850 \\
0.865 \\
0.000 \\
0.917 \\
0.885 \\
0.945 \\
0.982 \\
0.890 \\
0.830 \\
-0.332 \text { * } \\
0.330 \text { * }
\end{array}
$$

SUMMARY OF HARMONIC ANALYSIS OF STREAM TEMPERATURE

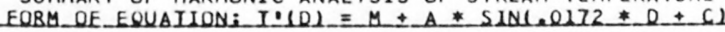

291

16.50

12.04

2.55

96

1.74

SUMMARY OF MAXIMUM AND MINIMUM CONCENTRATIONS OF CONSTITUENTS SAMPLED AT A FREQUENCY OF QUARTERLY (1975 WY)

03303280 - OHIO R AT CANNELTON DAM, KY 
Table 14,--Summary of measurements at each station--Continued

STATION NUMBER: 03321230

NAME: GREEN RIVER NR BEECH GROVE,KY.

LAT 37D35M21S LONG $087024 M 16 S$

DRAINAGE AREA: 0 SQ MI

PERIOD OF RECORD: $10 / 01 / 74-09 / 30 / 75$

O SQ KMI

STATISTICAL SUMMARY OF SELECTED DISSOLVED CHEMICAL CONSTITUENTS AND REGRESSION RELATIONSHIPS OF CONSTITUENT CONCENTRATIONS TO SPECIFIC CONDUCTANCE

CONSIUTUENI

CONSIUIUENI IMG/L OR UNII SHOWN

TEMPERATURE, WATER (DEG C)
SPECIFIC CONDUCTANCE (MICROMHOS)
STREAMFLOW (CUBIC FT/SEC)
PH (STANDARD UNITS)
PHOSPHORUS, TOTAL
NITRITE NITRATE, TOTAL
NITROGEN, KJELDAHL, TOTAL
PHYTOPLANKTON, TOTAL (CELLS/ML)
SEDIMENT, SUSPENDED
SEDIMENT, CLAY-SILT (PERCENT)
COLIFORM, FECAL (COL/IOO ML)
SIREPTOCOCCI, FECAL (COL/IOO ML)
SILICA, DISSOLVED
CALCIUM, DISSOLVED
MAGNESIUM, DISSOLVED
SODIUM, DISSOLVE
POTASSIUM, DISSOLVED
BICARBONATE, ION
CARBONATE, ION
SULFATE, DISSOLVED
CHLORIDE, DISSOLVED
OISSOLVED SOLIDS, SUM OF CONST
DISSOLVED SOLIDS, ROE I8O DEG C
HARDNESS, TOTAL
HARDNESS, NONCARBONATE
TURBIDITY (JTU)
FLOURIDE, DISSOLVED

\begin{tabular}{|c|c|c|c|c|c|}
\hline $\begin{array}{l}\text { SAMPLE } \\
\text { SIZE }\end{array}$ & MEAN & $\begin{array}{l}\text { STANDARD } \\
\text { DEYIAIUON }\end{array}$ & \multicolumn{2}{|c|}{ BANGE } & $\begin{array}{l}\text { SAMPLE } \\
\text { SIZE }\end{array}$ \\
\hline 12 & 17.75 & 8.35 & 7.0 & 30.0 & \\
\hline 12 & 304.8 & 90.3 & 190 & 500 & \\
\hline 12 & 19281.7 & 19900.0 & 1640 & 61300 & 12 \\
\hline 9 & 7.12 & 0.37 & 6.6 & 7.6 & 9 \\
\hline 12 & 0.120 & 0.181 & 0.03 & 0.65 & 12 \\
\hline 12 & 0.599 & 0.166 & 0.29 & 0.83 & 12 \\
\hline 12 & 0.358 & 0.059 & 0.26 & 0.44 & 12 \\
\hline 12 & 3228.7 & 6407.6 & 64 & 23000 & 12 \\
\hline 11 & 39.3 & 14.1 & 24 & 70 & \\
\hline 11 & 92.1 & 9.2 & 75 & 100 & \\
\hline 8 & 160.4 & 103.8 & 42 & 340 & \\
\hline 8 & 98.8 & 80.3 & 24 & 250 & \\
\hline 12 & 5.70 & 0.86 & 4.7 & 7.4 & 12 \\
\hline 12 & 40.58 & 9.73 & 30.0 & 60.0 & 12 \\
\hline 12 & 9.51 & 3.65 & 4.2 & 17.0 & 12 \\
\hline 12 & 6.74 & 3.44 & 3.0 & 15.0 & 12 \\
\hline 12 & 2.36 & 1.24 & 1.5 & 6.0 & 12 \\
\hline 12 & 97.2 & 21.5 & 63 & 129 & 12 \\
\hline 8 & 0.0 & 0.0 & 0 & 0 & 8 \\
\hline 12 & 59.92 & 29.10 & 16.0 & 120.0 & 12 \\
\hline 12 & 6.35 & 3.00 & 3.2 & 14.0 & 12 \\
\hline 12 & 179.3 & 56.5 & 103 & 301 & 12 \\
\hline 12 & 190.9 & 62.9 & 104 & 319 & 12 \\
\hline 12 & 142.1 & 39.2 & 95 & 220 & 12 \\
\hline 12 & 60.5 & 25.1 & 31 & 110 & 12 \\
\hline 12 & 23.9 & 13.6 & 4 & 50 & 12 \\
\hline 12 & 0.15 & 0.11 & 0.0 & 0.4 & 12 \\
\hline
\end{tabular}

\section{DURALION IABLE OE DALLY SPECIEIC CONOUCIANCE}

DAILY SPECIFIC CONDUCTANCE IN

MICROMHOS AT 25 DEG C, THAT WAS

EQUALLED OR EXCEEDED FOR THE

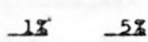

18

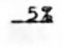

$20 \%$

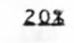

$3 \Omega 2$

$50 \%$

495
REGRESSION

COEFICIENT, CONSTANT,

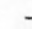

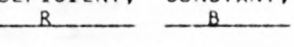

$\begin{array}{rr}-158.337 & 67547.875 \\ -0.0010 & 7.4511 \\ -0.00053 & 0.28134 \\ 0.00017 & 0.54631 \\ -0.00031 & 0.45257\end{array}$

47.175

$-11151.945$

$$
\begin{array}{r}
-0.718 \\
-0.284 * \\
-0.264 * \\
0.094 * \\
-0.472 * \\
0.665
\end{array}
$$

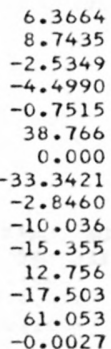

$-0.231$.

0.969

0.977

0.967

0.744

0.805

0.000 *
0.949

0.949
0.907

0.907
0.991

0.971

0.978

0.920

$-0.807$

0.410 *
STANDARO ERROR OF ESILMAIS

14523.8 0.38 0.173 0.173 0.059

0.8

2.5

0.81

0.92

0.87

13.4
0.0

9.62

1.33

7.7
15.9

\begin{tabular}{|c|c|c|c|c|c|}
\hline & & & & & STANDARD \\
\hline & HARMONIC & AMPLITUDE & PHASE & VAR IATION & ERROR OF \\
\hline SAMPLE & MEAN - $M$ & $-A$ & ANGLE - C & EXPLAINED & ESTIMATE \\
\hline SIZE - & DEEG G) & (DEG $C)$ & (RADLANSI & $(z)$ & IDEG C) \\
\hline 354 & 17.64 & 11.86 & 72 & 94 & 2.14 \\
\hline
\end{tabular}

8.6
10.3

8.4

0.10

SUMMARY OF HARMONIC ANALYSIS OF STREAM TEMPERATURE

\begin{tabular}{|c|c|c|c|c|c|c|}
\hline \multirow{2}{*}{ CONSTITUENT } & \multicolumn{3}{|c|}{ TOTAL } & \multicolumn{3}{|c|}{ DISSOLVED } \\
\hline & $\begin{array}{l}\text { NO. } \\
\text { SAMPLES }\end{array}$ & $\begin{array}{l}\text { MINIMUM } \\
\text { CONC. }\end{array}$ & $\begin{array}{l}\text { MAXIMUM } \\
\text { CONC. }\end{array}$ & $\begin{array}{l}\text { NO. } \\
\text { SAMPLES }\end{array}$ & $\begin{array}{l}\text { MINIMUM } \\
\text { CONC. }\end{array}$ & $\begin{array}{l}\text { MAXIMUM } \\
\text { CONC. }\end{array}$ \\
\hline \multicolumn{7}{|l|}{ MINOR ELEMENTS: } \\
\hline ARSENIC (AS), UG/L & 4 & 0 & 2 & 4 & 0 & 0 \\
\hline CADMIUM $(C D), U G / L$ & 4 & 0 & 2 & 4 & 0 & 4 \\
\hline CHROMIUM (CR), UG $/ L$ & 4 & 0 & $<10$ & 4 & 0 & 1 \\
\hline COBALT $(C D), U G / L$ & 4 & 0 & 6 & 4 & 0 & 6 \\
\hline COPPER (CU), UG/L & 4 & 6 & 35 & 4 & 6 & 14 \\
\hline IRON $(F E), U G / L$ & 4 & 1100 & 2700 & 4 & 0 & 30 \\
\hline LEAD $(P B), U G / L$ & 4 & 5 & 35 & 4 & 0 & 9 \\
\hline MANGANESE (MN), UG/L & 4 & 320 & 480 & 4 & 20 & 380 \\
\hline MERCURY $(H G), U G / L$ & 4 & 0.0 & 0.2 & 4 & 0.1 & 0.2 \\
\hline SELENIUM (SE), UG/L & 4 & 0 & 1 & 4 & 0 & 1 \\
\hline ZINC $(Z N), U G / L$ & 4 & 30 & 60 & 4 & 0 & 40 \\
\hline \multicolumn{7}{|l|}{ PERIPHYTON: } \\
\hline BIOMASS, DRY WT, G/SQ M & 3 & .00 & 110.00 & & & \\
\hline BIOMASS, ASH WT., G/SQ M & 3 & .00 & 100.00 & & & \\
\hline CHLOROPHYLL A, MG/SO M & 3 & .0 & 29.0 & & & \\
\hline CHLOROPHYLL $B$, MG/SQ M & 3 & .0 & 12.0 & & & \\
\hline ORGANIC CARBON, MG/L & 4 & 3.1 & 10.0 & & & \\
\hline
\end{tabular}

SUMMARY OF MAXIMUM AND MINIMUM CONCENTRATIONS OF CONSTITUENTS SAMPLED AT A FREQUENCY OF QUARTERLY (1975 WY)

03321230 -- GREEN RIVER NR BEECH GROVE, KY. 
LAT 38D29M23S LONG $087033 M 00 S$

DRAINAGE AREA:

PERIOD OF RECORD: $10 / 01 / 74-09 / 30 / 75$ 0 SO KM)

STATISTICAL SUMMARY OF SELECTED DISSOLVED CHEMICAL CONSTITUENTS AND REGRESSION RELATIONSHIPS OF CONSTITUENT CONCENTRATIONS TO SPECIFIC CONDUCTANCE

GONSIUTUENI

GONSIUTUENI
TEMPERATURE, WATER (DEG C)
SPECIFIC CONDUCTANCE (MICROMHOS)
STREAMFLOW (CUBIC FT/SEC)
PH ISTANDARD UNITS)
PHOSPHORUS, TOTAL
NITRITE, NITRATE, TOTAL
NITROGEN, KJELDAHL, TOTAL
PHYTOPLANKTON, TOTAL (CELLS/ML)
SEDIMENT, SUSPENDED
SEDIMENT, CLAY-SILT (PERCENT)
COLIFORM, FECAL (COL/IOO ML)
STREPTOCOCCI, FECAL (COL/IOO ML)
SILICA, DISSOLVED
CALCIUM, DISSOLVED
MAGNESIUM, DISSOLVED
SODIUM, DISSOLVED
POTASSIUM, DISSOLVED
BICARBONATE, ION
CARBONATE, ION
SULFATE, DISSOLVED
CHLORIDE, DISSOLVED
DISSOLVED SOLIDS, SUM OF CONST
DISSOLVED SOLIDS, ROE I8O DEG C
HARDNESS, TOTAL
HARDNESS, NONCARBONATE
TURBIDITY (JTU)
FLOURIDE, DISSOLVED

\section{CONSIUIUENT IMG/L OB UNIT SHOWNI}

SIZE MEAN

\section{STANDARD}

DEYIALION
10.39

10.39
90.5

14058.0

4058.0
0.42

0.42
0.084

0.084
0.795

0.162

35852.3

67.9

22714.4

146.4

82.0

7200.0

700.0
5.70

5.70
51.45

51.45

16.00

10.79
2.56

2.56
174.7

0.0

50.82

16.00
239.6

239.6

268.5

195.5

60.0

0.18
0.0

0.0
0.0

2.55

2.55
7.78

4.63

4.05

0.84

37.5

0.0

9.91

4.77

43.1

53.3

34.5

30.3

0.09
N) BANG $3.5 \quad 30.5$

300
980

$\begin{array}{rr}980 & 45300 \\ 7.0 & 8.6\end{array}$

$\begin{array}{ll}7.0 & 8.6 \\ 0.08 & 0.34\end{array}$

0.02

0.47

58

82
7200

3700

40.0

11.0

6.7
1.9

1.9
125

35.0

10.0
182

182
202

202
150

150
43

20
0.1

7.5
61.0
24.0
20.0
4.8
223
0
65.0
26.0
293
345
240
70
100
0.4

255

*Not significant at the 95 percent confidence level.

DAILY SPECIFIC CONDUCTANCE IN

MICROMHOS AT 25 DEG C, THAT WAS

RAUION IABLE OF DAILY SPECIEIC CONDUCTANCE

EQUALLED OR EXCEEDED FOR THE

$\begin{array}{llllll}17 & -5 \pi & 108 & 20 \pi & 30 z & 50 \pi \\ 591 & 560 & 537 & 503 & 463 & 409\end{array}$
\begin{tabular}{ll}
\multicolumn{2}{c}{ REGRESSION SUMMARY } \\
SEGRESSION \\
SAMPLE COEFICIENT, CONSTANT, CORF,
\end{tabular} SIZE COEEICIENI

STANDARD ERROR OF ESILMAIE

INDICATED PERCENTAGE OF TIME

11
11
11
11
11

$\begin{array}{rr}-127.093 & 73617.375 \\ 0.0031 & 6.3325 \\ -0.00057 & 0.44943 \\ -0.00224 & 2.42492 \\ 0.00014 & 0.69973 \\ 242.829 & -87368.000\end{array}$

-0.818
0.655
-0.610
$-0.255 *$
$0.079 *$
$0.644 *$

8525.6

0.34

0.070

0.810

29332.6

$\begin{array}{rr}7.5 & 11 \\ 61.0 & 11 \\ 24.0 & 11 \\ 20.0 & 11 \\ 4.8 & 11 \\ 223 & 11 \\ 0 & 11 \\ 65.0 & 11 \\ 26.0 & 11 \\ 293 & 11 \\ 345 & 11 \\ 240 & 11 \\ 70 & 11 \\ 100 & 11 \\ 0.4 & 11\end{array}$

-0.0168
0.0716
0.0461
0.0381
-0.0014
0.366
0.000
0.0925
0.0465
0.456
0.505
0.349
0.069
-0.275
0.0002

13.0729
19.9525
-4.2935
-5.9707
3.1604
13.589
0.000
10.1236
-4.4548
39.174
46.526
41.708
20.600
181.009
0.0877

-0.596 *

0.833

0.902

0.851

$-0.147$

0.882

0.000

0.845

0.881
0.957

0.856

0.917

0.788

$-0.820$

0.221 *

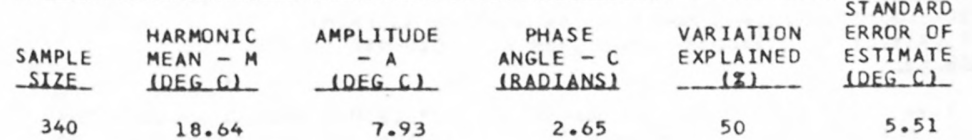

SUMMARY OF MAXIMUM AND MINIMUM CONCENTRATIONS OF CONSTITUENTS SAMPLED AT A FREQUENCY OF QUARTERLY (1975 WY)

03374100 -- WHITE RIVER AT HAZLETON, IND.

\begin{tabular}{|c|c|c|c|c|c|c|}
\hline \multirow{2}{*}{ CONSTITUENT } & \multicolumn{3}{|c|}{ TOTAL } & \multicolumn{3}{|c|}{ DISSOLVED } \\
\hline & $\begin{array}{l}\text { NO. } \\
\text { SAMPLES }\end{array}$ & $\begin{array}{l}\text { MINIMUM } \\
\text { CONC. }\end{array}$ & $\begin{array}{l}\text { MAXIMUM } \\
\text { CONC. }\end{array}$ & $\begin{array}{l}\text { NO. } \\
\text { SAMPLES }\end{array}$ & $\begin{array}{l}\text { MINIMUM } \\
\text { CONC. }\end{array}$ & $\begin{array}{l}\text { MAXIMUM } \\
\text { CONC. }\end{array}$ \\
\hline \multicolumn{7}{|l|}{ MINOR ELEMENTS: } \\
\hline ARSENIC (AS), UG/L & 2 & 2 & 2 & 2 & 1 & 1 \\
\hline CADMIUM $(C D)$, UG/L & 2 & 0 & 1 & 2 & 0 & 0 \\
\hline CHROMIUM (CR), UG/L & 2 & $<10$ & 20 & 2 & 0 & 0 \\
\hline COBALT $(C O), U G / L$ & 2 & 1 & 2 & 2 & 0 & 0 \\
\hline COPPER (CU), UG/L & 2 & 10 & 10 & 2 & 0 & 10 \\
\hline IRON (FE), UG/L & 2 & 870 & 1900 & 2 & 10 & 50 \\
\hline LEAD $(P B), U G / L$ & 2 & 5 & 11 & 2 & 0 & 3 \\
\hline MANG ANESE (MN), UG/L & 2 & 150 & 160 & 2 & 10 & 10 \\
\hline MERCURY (HG), UG/L & 2 & $<0.5$ & $<0.5$ & 2 & $<0.5$ & $<0.5$ \\
\hline SELENIUM (SE), UG/L & 2 & 0 & 1 & 2 & 0 & 0 \\
\hline ZINC $(Z N), U G / L$ & 2 & 10 & 10 & 2 & 10 & 10 \\
\hline \multicolumn{7}{|l|}{ PERIPHYTON: } \\
\hline BIOMASS, DRY WT., G/SO M & 0 & & & & & \\
\hline BIOMASS, ASH WT., G/SQ M & 1 & 15.00 & & & & \\
\hline CHLOROPHYLL A, MG/SQ M & 0 & & & & & \\
\hline CHLOROPHYLL B, MG/SO M & 0 & & & & & \\
\hline ORGANIC CARBON, MG/L & 2 & 5.3 & 8.3 & & & \\
\hline
\end{tabular}


Table 14.--Summary of measurements at each station--Continued

LAT 38D07M55S LONG 087056M25S DRAINAGE AREA: 0 SQ MI

PERIOD OF RECORD: $10 / 01 / 74-09 / 30 / 75$

O SQ KMI

STATISTICAL SUMMARY OF SELECTED DISSOLVED CHEMICAL CONSTITUENTS AND REGRESSION RELATIONSHIPS OF CONSTITUENT CONCENTRATIONS TO SPECIFIC CONDUCTANCE

CONSIUIUENI

CONSIUIUENI IMG $\angle L$ OR UNII SHOWNU

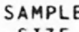

SIZE

TEMPERATURE, WATER (DEG C) SPECIFIC CONDUCTANCE (MICROMHOS) STREAMFLOW (CUBIC FT/SEC)

PH (STANDARD UNITS)

PHOSPHORUS, TOTAL

NITRITE + NITRATE, TOTAL

NITROGEN, KJELDAHL, TOTAL

PHYTOPLANKTON, TOTAL (CELLS/ML)

SEDIMENT, SUSPENDED

SEDIMENT, CLAY-SILT (PERCENT)

COLIFORM, FECAL (COL/100 ML)

STREPTOCOCCI, FECAL (COL/100 ML)

SILICA, DISSOLVED

CALCIUM, DISSOL VED

MAGNESIUM, DISSOLVEO

SODIUM, DISSOLVED

POTASSIUM, DISSOLVED

BICARBONATE, ION

CARBONATE, ION

SULFATE, DISSOLVED

CHLORIDE, DISSOLVED

DISSOLVED SOLIDS, SUM OF CONST

DISSOLVED SOLIDS, ROE 180 DEG C

DISSOLVED SOL IDS,
HARDNESS, TOTAL

HARDNESS, NONCARBONATE

TURBIDITY (JTU)

FLOUR IDE, DISSOLVEO

*Not significant at the 95 percent confidence level.

\begin{tabular}{|c|c|c|c|c|c|}
\hline $\begin{array}{l}\text { AMPLE } \\
\text { SIZE }\end{array}$ & MEAN & $\begin{array}{l}\text { STANDARD } \\
\text { DEYIAIION }\end{array}$ & \multicolumn{2}{|c|}{ BANGE } & $\begin{array}{l}\text { SAMPL } \\
\text { SIZE }\end{array}$ \\
\hline 10 & 15.75 & 10.21 & 4.0 & 29.0 & \\
\hline 10 & 445.5 & 85.3 & 320 & 550 & \\
\hline 10 & 38822.0 & 22644.2 & 8220 & 80300 & 10 \\
\hline 10 & 7.59 & 0.34 & 7.2 & 8.2 & 10 \\
\hline 10 & 0.217 & 0.097 & 0.08 & 0.42 & 10 \\
\hline 10 & 2.165 & 1.173 & 0.95 & 5.00 & 10 \\
\hline 10 & 0.840 & 0.172 & 0.55 & 1.10 & 10 \\
\hline 8 & 18837.5 & 26008.8 & 1000 & 73000 & 8 \\
\hline 10 & 168.5 & 89.2 & 56 & 324 & \\
\hline 1 & 90.0 & 0.0 & 90 & & \\
\hline \multirow{2}{*}{\multicolumn{6}{|c|}{0}} \\
\hline & & & & & \\
\hline 10 & 5.68 & 1.84 & 2.5 & 7.7 & 10 \\
\hline 10 & 53.30 & 11.57 & 40.0 & 74.0 & 10 \\
\hline 10 & 17.00 & 4.22 & 12.0 & 23.0 & 10 \\
\hline 10 & 11.14 & 2.77 & 7.0 & 16.0 & 10 \\
\hline 10 & 2.78 & 0.97 & 1.9 & 5.1 & 10 \\
\hline 10 & 174.9 & 42.7 & 121 & 246 & 10 \\
\hline 10 & 0.0 & 0.0 & 0 & 0 & 10 \\
\hline 10 & 55.30 & 11.35 & 38.0 & 71.0 & 10 \\
\hline 10 & 17.20 & 3.91 & 10.0 & 22.0 & 10 \\
\hline 10 & 249.0 & 49.6 & 176 & 323 & 10 \\
\hline 10 & 295.5 & 75.2 & 210 & 452 & 10 \\
\hline 10 & 203.0 & 45.2 & 150 & 280 & 10 \\
\hline 10 & 59.8 & 14.1 & 31 & 78 & 10 \\
\hline 10 & 102.8 & 109.8 & 18 & 400 & 10 \\
\hline 10 & 0.26 & 0.10 & 0.1 & 0.4 & 10 \\
\hline
\end{tabular}
DURAIION IABLE_OF DALY SPECIEIC CONDUCIANCE

DAILY SPECIFIC CONDUCTANCE IN

MICROMHOS AT 25 DEG C, THAT WAS

EQUALLED OR EXCEEDED FOR THE

18 $\quad-58 \quad 18$

102

202

$30 \%$

010

570

550 BEGRESSION SUMM
REGRESSION
COEFICIENT, CONSTANT,

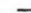

$$
\begin{array}{r}
-158.160 \\
0.0016 \\
-0.00082 \\
0.00173 \\
-0.00065 \\
176.209
\end{array}
$$

176.209

6.8650

0.58128

1.39329

1.13123

$-62108.375$

$0.403 *$
-0.718

0.126 *

$-0.324 *$

0.614 *

0.33
0.072

1.23

0.172

22164.6

$$
\begin{array}{r}
-0.0115 \\
0.1270 \\
0.0483 \\
0.0249 \\
-0.0058 \\
0.482 \\
0.000 \\
0.1127 \\
0.0324 \\
0.567 \\
0.738 \\
0.513 \\
0.122 \\
-0.928 \\
0.0003
\end{array}
$$
10.7826
$-3.2687$
$-4.5020$
0.0433
5.3685
40.021
0.000
2.7474
$-3.751$
$-33.103$
$-33.103$
$\begin{array}{r}5.596 \\ \hline 16.366\end{array}$
516.366
0.1226

-0.530 *

0.936

0.976

\begin{tabular}{|c|c|c|c|c|c|}
\hline & & & & & $\overline{\text { STANDARD }}$ \\
\hline & HARMONIC & AMPLITUDE & PHASE & VARIATION & ERROR OF \\
\hline SAMPLE & MEAN - M & $-A$ & ANGLE - C & EXPLA INEO & ESTIMATE \\
\hline SULE & LDEG C) & LEEG CL & (BADLANS) & $-(z)$ & DEEG C \\
\hline 333 & 15.41 & 12.19 & 2.72 & 95 & 1.96 \\
\hline
\end{tabular}

0.768

-0.512 *

0.964 .

0.847

0.708

0.976

0.836

0.836

0.967

0.735

-0.721
0.272 *

STANDARD ERROR O

SAMPLE SIZE $=336$

$20 \% 252929$

$\begin{array}{lll}380 & 350 \quad 320\end{array}$

SUMMARY OF HARMONIC ANALYSIS OF STREAM TEMPERATURE
EORM OF EQUAIION: I. $101=M+A+$ SINC.0172 $10+C)$

SUMMARY OF MAXIMUM AND MINIMUM CONCENTRATIONS OF CONSTITUENTS SAMPLED AT A FREQUENCY OF QUARTERLY (1975 WY)

03378500 -- WABASH RIVER AT NEW HARMONY, INO.

CONSTITUENT
SAMPLES


Table 14.--Summary of measurements at each station--Continued

LAT 36014M53S LONG 085057M19S DRAINAGE AREA: 10090 SQ MI $(27687$ SQ KM) PERIOD OF RECORD: $10 / 01 / 74-09 / 30 / 75$

STATISTICAL SUMMARY OF SELECTED DISSOLVED CHEMICAL CONSTITUENTS AND REGRESSION RELATIONSHIPS OF CONSTITUENT CONCENTRATIONS TO SPECIFIC CONDUCTANCE

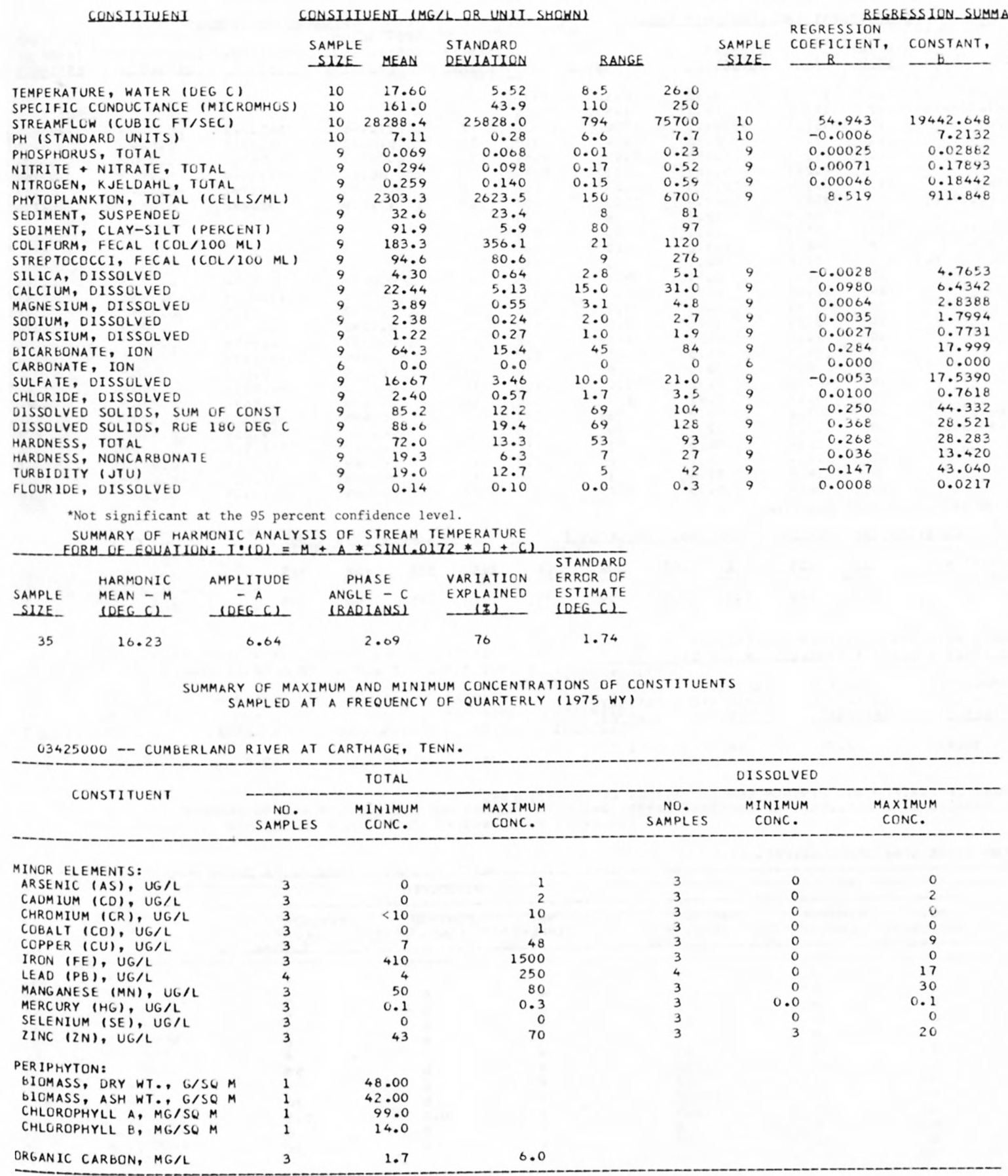


Table 14.--Summary of measurements at each station--Continued

LAT $37001 M 18 S$ LONG 088D13M16S

DRAINAGE AREA: 17598 SQMI ( 45579 SO KM)

PERIOD OF RECORD: $10 / 01 / 74-09 / 30 / 75$

STATISTICAL SUMMARY OF SELECTED DISSOLVED CHEMICAL CONSTITUENTS AND REGRESSION RELATIUNSHIPS OF CONSTITUENT CONCENTRATIONS TO SPECIFIC CONDUCTANCE

CONSIIIUENI

CONSIUIUENT IMGLL_OR UNII SHOWNH

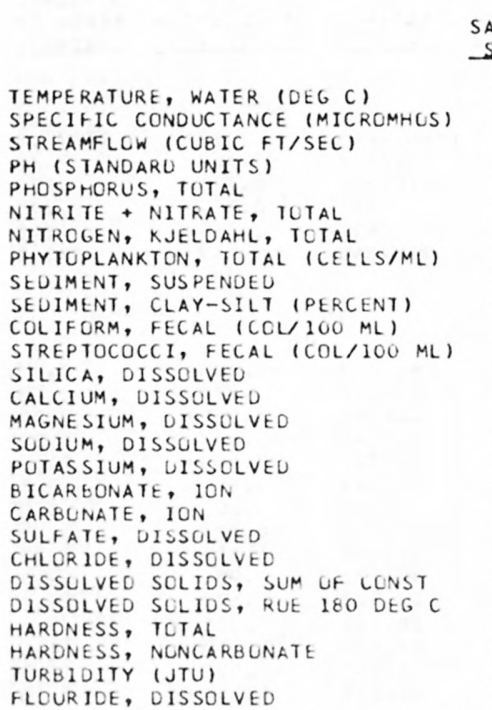

SONSII
SAMPL
SIZE
12
12
12
11
12
12
12
12
11
11
8
8
10
10
10
10
10
10
7
10
10
10
10
10
10
10
10

DISSOLVED
STANDARD

EYIALION

17.38

183.8

50791.7

7.05

0.147

0.297

0.409

316.7
19.9

19.9
91.7

91.7
96.1

57.6

4.35

28.00

3.93

3.29

1.34

89.1

14.50

4.50
3.13

3.13
102.6

102.6
112.3

85.4
13.1

14.4

0.14

$$
\begin{array}{r}
8.46 \\
26.1 \\
32364.1 \\
0.36 \\
0.156 \\
0.187 \\
0.123 \\
6329.4 \\
12.8 \\
11.1 \\
123.2 \\
40.5 \\
0.59 \\
6.32 \\
0.63 \\
1.20 \\
0.23 \\
19.5 \\
0.0 \\
2.92 \\
0.98 \\
19.8 \\
22.7 \\
16.6 \\
4.0 \\
11.4 \\
0.10
\end{array}
$$
*Not significant at the 95 percent confidence level.
BEGBESSION_SUMMABY

REGRESSION SAMPLE COEFICIENT, CONSTANT, TON, CONSTANT, CORRELATIUN ERROR OF

STANDARO BANGE OEEICIENI ESIIMAIE

$\begin{array}{rrr}6.5 & 29.0 & \\ 145 & 229 & \\ 9700 & 119000 & 12 \\ 6.4 & 7.5 & 11 \\ 0.04 & 0.62 & 12 \\ 0.03 & 0.54 & 12 \\ 0.23 & 0.66 & 12 \\ 1200 & 25000 & 12 \\ 6 & 41 & \\ 73 & 100 & \\ 10 & 340 & \\ 6 & 120 & \\ 3.5 & 5.4 & 10 \\ 20.0 & 39.0 & 10 \\ 3.1 & 4.8 & 10 \\ 2.0 & 6.1 & 10 \\ 1.1 & 1.8 & 10 \\ 65 & 117 & 10 \\ 0 & 0 & 7 \\ 10.0 & 14.0 & 10 \\ 1.7 & 5.0 & 10 \\ 78 & 131 & 10 \\ 86 & 148 & 10 \\ 63 & 110 & 10 \\ 6 & 19 & 10 \\ 1 & 40 & 10 \\ 0.0 & 0.3 & 10 \\ & & \end{array}$

$$
\begin{array}{r}
317.445 \\
0.0073 \\
0.00377 \\
0.00365 \\
-0.00070 \\
13.886 \\
\\
\\
0.0077 \\
0.2208 \\
0.0162 \\
0.0140 \\
0.0037 \\
0.069 \\
0.000 \\
0.0810 \\
0.0138 \\
0.685 \\
0.700 \\
0.582 \\
0.069 \\
-0.046 \\
0.0009
\end{array}
$$

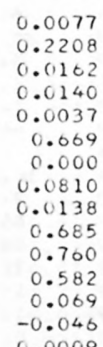

-7565.227
5.7298
-0.54500
-0.37349
0.53791
4763.988

0.256 $0.529 *$

0.630

$0.510 *$

$-0.149 *$

0.32

\begin{tabular}{|c|c|c|c|c|c|}
\hline & & & & & STANDARD \\
\hline & HARMONIC & AMPLI TUDE & PHASE & VAR IATION & ERROR OF \\
\hline SAMPLE & MEAN - M & $-A$ & ANGLE - C & EXPLAINED & ESTIMATE \\
\hline SIZE - & IDEG CL & $\left(0 \pm 6()_{2}\right.$ & $(R A D I A N S)$ & $\ldots(\xi) \ldots$ & $10 E E_{-}(1)$ \\
\hline 349 & 17.16 & 10.67 & 2.75 & 96 & 1.50 \\
\hline
\end{tabular}

0.169

0.169

0627.3

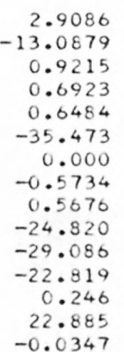

\begin{tabular}{|c|c|c|c|c|c|c|}
\hline \multirow{2}{*}{ CONSTITUENT } & \multicolumn{3}{|c|}{ TOTAL } & \multicolumn{3}{|c|}{ DISSOLVED } \\
\hline & $\begin{array}{l}\text { NO. } \\
\text { SAMPLES }\end{array}$ & $\begin{array}{l}\text { MINIMUM } \\
\text { CONC. }\end{array}$ & $\begin{array}{l}\text { MAXIMUM } \\
\text { CONC. }\end{array}$ & $\begin{array}{l}\text { NO. } \\
\text { SAMPLES }\end{array}$ & $\begin{array}{l}\text { MINIMUM } \\
\text { CONC. }\end{array}$ & $\begin{array}{l}\text { MAXIMUM } \\
\text { CONC. }\end{array}$ \\
\hline \multicolumn{7}{|l|}{ MINOR ELEMENTS: } \\
\hline ARSENIC (AS), UG/L & 4 & 0 & 1 & 4 & 0 & 1 \\
\hline CADMIUM $(C D), U G / L$ & 4 & 0 & 2 & 4 & 0 & 2 \\
\hline CHROMIUM (CR), UG/L & 4 & 0 & 15 & 4 & 0 & 2 \\
\hline COBALT $\quad(C O), U G / L$ & 4 & 0 & 6 & 4 & 0 & 6 \\
\hline COPPER $(C U), U G / L$ & 4 & 4 & 22 & 4 & 3 & 6 \\
\hline IRON (FE), UG/L & 4 & 500 & 1200 & 4 & 0 & 50 \\
\hline LEAD $(P B), U G / L$ & 4 & 1 & 32 & 4 & 0 & 7 \\
\hline MANG ANESE $(M N), U G / L$ & 4 & 70 & 12000 & 4 & 0 & 20 \\
\hline MERCURY $(H G), U G / L$ & 4 & 0.0 & 0.5 & 4 & 0.0 & 0.3 \\
\hline SELENIUM (SE), UG/L & 4 & 0 & 1 & 4 & 0 & 0 \\
\hline$Z I N C(Z N), U G / L$ & 4 & 30 & 60 & 4 & 4 & 30 \\
\hline \multicolumn{7}{|l|}{ PERIPHYTON: } \\
\hline BIOMASS, DRY WT., G/SO M & 3 & 21.00 & 110.00 & & & \\
\hline BIOMASS, ASH WT., G/SO M & 3 & 15.00 & 46.00 & & & \\
\hline CHLORUPHYLL A, MG/SO M & 3 & 27.0 & 86.0 & & & \\
\hline CHLOROPHYLL B, MG/SO M & 3 & 2.0 & 13.0 & & & \\
\hline ORGANIC CARBON, MG/L & 4 & 2.8 & 5.5 & & & \\
\hline
\end{tabular}

0.370

0.980

.715.

0.326 *

0.966
0.000 *

0.780

0.395

0.970

0.938

0.981

0.487 *

$-0.112 *$
0.273 *

DAILY SPECIFIC CONDUCTANCE IN

MICRCMHOS AT 25 DEG C, THAT WAS

EQUALLED UR EXCEEDED FOR THE

$\begin{array}{llllll}-18 & -52 & 10 \% & 20 \% & 30 \% & 50 \%\end{array}$

SAMPLE SLIE $\equiv 352$
$70 \%$ 20\% 25\% 29\%

INDICATED PERCENTAGE OF TIME

$\begin{array}{llllll}235 & 220 & 215 & 205 & 200 & 175\end{array}$

160

$145 \quad 140 \quad 135$

SUMMARY OF HARMONIC ANALYSIS OF STREAM TEMPERATURE

SUMMARY LF MAXIMUM AND MINIMUM CONCENTRATIONS OF CONSTITUENTS SAMPLED AT A FREQUENCY OF QUARTERLY (1975 WY)

U3438220 -- CUMGERLAND RIVER NEAR GRAND RIVERS, KY. 
Table 14.--Sumnary of measurements at each station--Continued

LAT 35D57M3OS LONG 083046M26S

DRAINAGE AREA: 5101 SQ MI I 13212 SQ KM)

PERIOD OF RECORD: $10 / 01 / 74-09 / 30 / 75$

STATISTICAL SUMMARY OF SELECTED DISSOLVED CHEMICAL CONSTITUENTS AND

REGRESSION RELATIONSHIPS OF CONSTITUENT CONCENTRATIONS TO SPECIFIC CONDUCTANCE

CONSIUTUENI

CONSIUUENT MG/L OR UNIT SHOWN

SAMPLE SIZE

TEMPERATURE, WATER (DEG C) SPECIFIC CONDUCTANCE IMICROMHOS STREAMFLOW (CUBIC FT/SEC)

PH (STANDARD UNITS)

PHOSPHORUS, TOTAL

NITRITE + NITRATE, TOTAL

NITROGEN, KJELDAHL, TOTAL PHYTOPLANKTON, TOTAL (CELLS/ML) SEDIMENT, SUSPENDED

SEDIMENT, SUSPENDED

SEDIMENT, CLAY-SILT (PERCENT)

COLIFORM, FECAL (COL/100 ML)

STREP TOCOCCI, FECAL (COL/100 ML)

SILICA, DISSOLVED

CALCIUM, DISSOLVED

MAGNESIUM, DISSOLVED

SODIUM, DISSOLVED

POTASSIUM, DISSOLVED

BICARBONATE, ION

CARBONATE, ION

SULFATE, DISSOLVED

CHLORIDE, DISSOLVED

DISSOLVED SOLIDS, SUM OF CONST

DISSOLVED SOLIDS, ROE 180 DEG C

HARDNESS, TOTAL

HARDNESS, NONCARBONATE

TURBIDITY (JTU)

FLOURIDE, DISSOLVED
STANDARD

EEYIAIUN

7.88
24.4

7869.4

0.49

0.019

0.156

0.130

1283.2

37.9
15.4

15.4
131.0

131.0
19.7

1.19

1.51

3.41

0.25

5.4
0.0

0.0
3.62

3.62
3.72

3.72
13.0

12.3

4.2
3.6

12.2

0.08
79.2

53.4

13.5

0.13
BEGRESSION SUMMABY

REGRESSION

SAMPLE COEFICIENT, CONSTANT, CORRELATION STANDARD

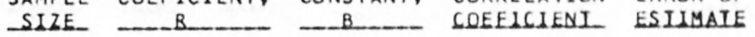

BANGE

$5.0 \quad 26.0$

$\begin{array}{rr}100 & 185 \\ 1460 & 21900 \\ 6.7 & 8.2\end{array}$

$6.7 \quad 8.2$

0.13

3.46

3900
134

100

$\begin{array}{rr}2 & 340 \\ 8 & 59 \\ 5.1 & 8.6 \\ 14.0 & 19.0\end{array}$

$14.0 \quad 19.0$

2.0

13.0

2.011

62

42

8.1
3.2

3.2
63

20.0

20.0
14.0

52
46
5
5
0.0
$11-80.310$

$-0.0025$

$-0.00009$

$-0.00297$

0.00141

29.826 7.8071 0.04927

0.83391

0.04376

$-3013.058$

$-0.123$

$-0.111$

$0.264^{\circ}$

0.568 .

8032.8

0.51

0.020

0.145

113

1113.2

*Not significant at the 95 percent confidence 1 evel.

\section{DURATION IABLE OE DAIL SPECIEIC CONDUCIANCE}

DAILY SPECIFIC CONDUCTANCE IN

MICROMHOS AT 25 DEG C, THAT WAS

EQUALLED OR EXCEEDED FOR THE

$\begin{array}{llllll}18 & 5 \% & 20 \% & 208 & 208\end{array}$

508

SAMPLE SIZE $=212$
$70 \%$ 20\% $25 \%$ 29\%

INOICATED PERCENTAGE OF TIME

$\begin{array}{llllll}185 & 153 & 150 & 147 & 144 & 137\end{array}$

126

$120 \quad 118$

113

SUMMARY OF HARMONIC ANALYSIS OF STREAM TEMPERATURE

\begin{tabular}{|c|c|c|c|c|c|}
\hline & & & & & STANDARD \\
\hline $\begin{array}{l}\text { SAMPLE } \\
\text { SIZE_- }\end{array}$ & $\begin{array}{l}\text { HARMONIC } \\
\text { MEAN - M } \\
\text { LDEG CI }\end{array}$ & $\begin{array}{c}\text { AMPL I TUDE } \\
-A \\
\text { (DEG C) }\end{array}$ & $\begin{array}{c}\text { PHASE } \\
\text { ANGLE - C } \\
\text { (RADIANSI }\end{array}$ & $\begin{array}{l}\text { VAR IATION } \\
\text { EXPLAINED } \\
\text { ( } \delta \text { ) }\end{array}$ & $\begin{array}{l}\text { ERROR OF } \\
\text { ESTIMATE } \\
\text { LOEG CL. }\end{array}$ \\
\hline 112 & 14.81 & 9.91 & 2.24 & 89 & 1.65 \\
\hline
\end{tabular}

SUMMARY OF MAXIMUM AND MINIMUM CONCENTRATIONS OF CONSTITUENTS

SAMPLED AT A FREQUENCY OF QUARTERLY (1975 WY)

03470500 -- FRENCH BROAD RIVER NEAR KNOXVILLE, TENN.

\begin{tabular}{|c|c|c|c|c|c|c|}
\hline \multirow{2}{*}{ CONSTITUENT } & \multicolumn{3}{|c|}{ TOTAL } & \multicolumn{3}{|c|}{ DISSOLVED } \\
\hline & $\begin{array}{l}\text { NO. } \\
\text { SAMPLES }\end{array}$ & $\begin{array}{l}\text { MIN IMUM } \\
\text { CONC. }\end{array}$ & $\begin{array}{l}\text { MAXIMUM } \\
\text { CONC. }\end{array}$ & $\begin{array}{l}\text { NO. } \\
\text { SAMPLES }\end{array}$ & $\begin{array}{l}\text { MINIMUM } \\
\text { CONC. }\end{array}$ & $\begin{array}{l}\text { MAXIMUM } \\
\text { CONC. }\end{array}$ \\
\hline \multicolumn{7}{|l|}{ MINOR ELEMENTS: } \\
\hline ARSENIC (AS), UG/L & 3 & 0 & 2 & 3 & 0 & 2 \\
\hline CADM IUM $(C D), U G / L$ & 3 & 0 & 3 & 3 & 0 & 1 \\
\hline CHROMIUM (CR), UG/L & 3 & $<10$ & $<10$ & 3 & 0 & 1 \\
\hline COBALT $(C O), U G / L$ & 3 & 0 & 1 & 3 & 0 & 1 \\
\hline COPPER (CU), UG/L & 3 & 6 & 9 & 3 & 2 & 3 \\
\hline IRON (FE), UG/L & 3 & 390 & 1300 & 3 & 0 & 40 \\
\hline LEAD (PB), UG/L & 3 & 10 & 62 & 3 & 1 & 3 \\
\hline MANGANESE (MN), UG/L & 3 & 30 & 130 & 2 & 0 & 26 \\
\hline MERCURY (HG), UG/L & 3 & 0.0 & 0.4 & 3 & 0.0 & 0.3 \\
\hline SELENIUM (SE), UG/L & 0 & & & 3 & 0 & 0 \\
\hline ZINC $(Z N), U G / L$ & 3 & 20 & 60 & 3 & 4 & 20 \\
\hline \multicolumn{7}{|l|}{ PER IPHYTON: } \\
\hline BIOMASS, DRY WT., G/SQ M & 0 & & & & & \\
\hline BIOMASS, ASH WT.., G/SQ M & 0 & & & & & \\
\hline CHLOROPHYLL A, MG/SQ M & 0 & & & & & \\
\hline CHLOROPHYLL $B, M G / S Q M$ & 0 & & & & & \\
\hline ORGANIC CARBON, MG/L & 3 & 1.7 & 3.7 & & & \\
\hline
\end{tabular}


LAT $35037 M 135$ LONG 084047MOOS

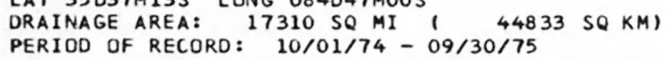

STATISTICAL SUMMARY OF SELECTED DISSOLVED CHEMICAL CONSTITUENTS AND

REGRESSION RELATIONSHIPS OF CONSTITUENT CONCENTRATIONS TO SPECIFIC CONDUCTANCE

CONSILIUENI

CONSILUUENI
TEMPERATURE, WATER (DEG C)
SPECIFIC CONDUCTANCE (MICROMHOS)
STREAMFLOH (CUBIC FT/SEC)
PH (STANDARD UNITS)
PHOSPHORUS, TOTAL
NITRITE, NITRATE, TOTAL
NITROGEN, KJELDAHL, TOTAL
PHYTOPLANKTON, TOTAL (CELLS/ML)
SEDIMENT, SUSPENDED
SEDIMENT, CLAY-SILT (PERCENT)
COLIFORM, FECAL (COL/IOO ML)
STREPTOCOCCI, FECAL (COL/IOO ML)
SILICA, DISSOLVED
CALCIUM, DISSOLVED
MAGNESIUM, DISSOLVED
SODIUM, DISSOLVED
POTASSIUM, DISSOLVED
BICARBONATE, ION
CARBONATE, ION
SULFATE, DISSOLVED
CHLOR IDE, DISSOLVED
DISSOLVED SOLIDS, SUM OF CONST
DISSOLVED SOLIDS, ROE 18O DEG C
HARDNESS, TOTAL
HARDNESS, NONCARBONATE
YURBIDITY I JTU)
FLOURIDE, DISSOLVED

CONSIUUUENI IMGLL_OR UNII SHOWNU

\begin{tabular}{rr}
$\begin{array}{rr}\text { SAMPLE } \\
\text { SIZE }\end{array}$ & \multicolumn{1}{r}{ MEAN } \\
39 & 15.74 \\
22 & 155.7 \\
39 & 39685.9 \\
24 & 7.37 \\
22 & 0.028 \\
22 & 0.380 \\
7 & 0.250 \\
8 & 2382.5 \\
11 & 12.8 \\
11 & 92.6 \\
12 & 20.3 \\
7 & 10.3 \\
16 & 4.81 \\
10 & 20.90 \\
10 & 4.64 \\
10 & 4.65 \\
10 & 1.36 \\
7 & 70.9 \\
3 & 0.0 \\
22 & 12.50 \\
22 & 5.94 \\
7 & 90.6 \\
20 & 89.1 \\
25 & 66.3 \\
7 & 13.4 \\
22 & 9.6 \\
10 & 0.14 \\
&
\end{tabular}

STANDARO

DEYIALION

6.48
18.2
13666.8
0.34
0.012
0.107
0.059
2185.8
11.0
13.3
22.8
14.5
0.94
1.60
0.21
1.74
0.17
3.0
0.0
2.56
1.75
7.2
11.5
9.3
2.8
8.1
0.08

0.08
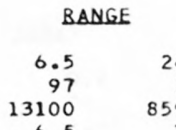

$\begin{array}{rr}13100 & 85900 \\ 6.5 & 7.8\end{array}$

0.02

0.02

0.18
0.16

0.16
580

4
55

3.1

3.1
19.0

4.4

2.9
1.2

1.2
68

0
9.0
3.4

3.4
80

80
60

31

1

0.0

*Not significant at the 95 percent confidence level.

SUMMARY OF HARMONIC ANALYSIS OF STREAM TEMPERATURE

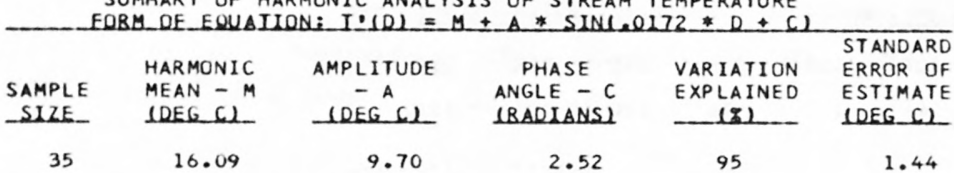

SUMMARY OF MAXIMUM AND MINIMUM CONCENTRATIONS OF CONSTITUENTS SAMPLED AT A FREQUENCY OF QUARTERLY (1975 WY)

BEGRESSION_SUMMABY

SONSTANT, CORRELATION STANDARO SAMPLE COEFICIENT, CONSTANT, CORRELATION SIZE $B-B \quad-B$ COEEICIENI ESIIMAIF

$\begin{array}{rr}26.5 & \\ 180 & \\ 5900 & 22 \\ 7.8 & 22 \\ 0.06 & 18 \\ 0.53 & 18 \\ 0.33 & 7 \\ 6900 & 8 \\ 43 & \\ 100 & \\ 82 & \\ 36 & \\ 6.0 & 14 \\ 23.0 & 10 \\ 5.0 & 10 \\ 7.3 & 10 \\ 1.6 & 10 \\ 77 & 7 \\ 0 & 3 \\ 18.0 & 18 \\ 9.0 & 18 \\ 99 & 7 \\ 116 & 18 \\ 77 & 21 \\ 16 & 7 \\ 34 & 18 \\ 0.3 & 10 \\ & \end{array}$

22
22
18
18
7
8



14
10
10
10
10
7
3
18
18
7
18
21
7
18
10

$$
\begin{array}{r}
102574.625 \\
0.9974 \\
0.06500 \\
0.75104 \\
0.03328 \\
-4632.359
\end{array}
$$

$-0.429 *$

$-0.351 *$

$-0.410 *$

$-0.410 *$

$0.441 *$

44.223

$-4632.359$

0.358

0.0111
0.0185
0.0040
0.0934
0.0085
0.083
0.000
0.0654
0.0678
0.343
0.443
0.374
-0.020
-0.304
0.0003
3.0210
17.9439
4.0099
$-10.2438$
$-0.0008$
57.712
0.000
2.4995
-4.7801
35.957
20.597
7.872
16.59
58.21
0.0943

$0.246 *$

0.183 *

0.301 "

0.847

0.785
0.521 *

0.000 *

0.476

0.725

0.905

0.725

0.684

-0.135 *

\begin{tabular}{|c|c|c|c|c|c|c|}
\hline \multirow{2}{*}{ CONSTITUENT } & \multicolumn{3}{|c|}{ TOTAL } & \multicolumn{3}{|c|}{ DISSOLVED } \\
\hline & $\begin{array}{l}\text { NO. } \\
\text { SAMPLES }\end{array}$ & $\begin{array}{l}\text { MINIMUM } \\
\text { CONC. }\end{array}$ & $\begin{array}{l}\text { MAXIMUM } \\
\text { CONC. }\end{array}$ & $\begin{array}{l}\text { NO. } \\
\text { SAMPLES }\end{array}$ & $\begin{array}{l}\text { MINIMUM } \\
\text { CONC. }\end{array}$ & $\begin{array}{l}\text { MAXIMUM } \\
\text { CONC. }\end{array}$ \\
\hline \multicolumn{7}{|l|}{ MINOR ELEMENTS: } \\
\hline ARSENIC (AS), UG/L & 9 & 0 & $<5$ & 3 & 0 & 2 \\
\hline CADMIUM $(C D)$, UG/L & 9 & 0 & 13 & 3 & 0 & 0 \\
\hline CHROMIUM (CR), UG/L & 9 & $<5$ & $<10$ & 3 & 0 & 0 \\
\hline COBALT $(C O), U G / L$ & 1 & 1 & & 3 & 0 & 0 \\
\hline COPPER (CU), UG/L & 9 & $<10$ & 30 & 3 & 2 & 5 \\
\hline IRON (FE), UG/L & 16 & 220 & 1000 & 9 & 30 & 110 \\
\hline LEAD $(P B), U G / L$ & 9 & $<10$ & 130 & 3 & 3 & 7 \\
\hline MANG ANESE (MN), UG/L & 16 & 30 & 90 & 9 & $<10$ & 23 \\
\hline MERCURY (HG), UG/L & 9 & 0.0 & 0.2 & 3 & 0.0 & 0.3 \\
\hline SELENIUM (SE), UG/L & 8 & $<2$ & $<2$ & 3 & 0 & 0 \\
\hline$Z I N C(Z N), U G / L$ & 9 & $<10$ & 50 & 3 & 0 & 20 \\
\hline \multicolumn{7}{|l|}{ PERIPHYTON : } \\
\hline BIOMASS, DRY WT., G/SQ M & 0 & & & & & \\
\hline BIOMASS, ASH WT., G/SQ M & 0 & & & & & \\
\hline CHLOROPHYLL A, MG/SQ M & 0 & & & & & \\
\hline CHLOROPHYLL B, MG/SO M & 0 & & & & & \\
\hline ORGANIC CARBON, MG/L & 9 & 1.5 & 3.0 & & & \\
\hline
\end{tabular}

$-0.754$

0.054 *

03543005 - TENNESSEE RIVER AT WATTS BAR DAM (TAILHATER), TN 
Table 14.--Summary of measurements at each station--Continued

LAT 35DOOM4IS LONG $085041 M 51 S$

DRAINAGE AREA: 22640 SO MI ( 58638 SQ KM)

PERIOD OF RECORD: $10 / 01 / 74-09 / 30 / 75$

STATISTICAL SUMMARY OF SELECTED DISSOLVED CHEMICAL CONSTITUENTS AND

REGRESSION RELATIONSHIPS OF CONSTITUENT CONCENTRATIONS TO SPECIFIC CONDUCTANCE

\section{CONSIIIUENI}

TEMPERATURE, WATER (DEG C)
SPECIFIC CONDUCTANCE (MICROMHOS)
STREAMFLOH (CUBIC FT/SEC)
PH ISTANDARD UNITS)
PHOSPHORUS, TOTAL
NITRITE + NITRATE, TOTAL
NITROGEN, KJELDAHL, TOTAL
PHYTOPLANKTON, TOTAL (CELLS/ML)
SEDIMENT, SUSPENDED
SEDIMENT, CLAY-SILT (PERCENT)
COLIFORM, FECAL (COL/ IOO ML)
STREPTOCOCCI, FECAL (COL/IOO ML)
SILICA, DISSOLVED
CALCIUM, DISSOLVED
MAGNESIUM, DISSOLVED
SODIUM, DISSOLVED
POTASSIUM, DISSOLVED
BICARBONATE, ION
CARBONATE, ION
SULFATE, DISSOLVED
CHLORIDE, DISSOLVED
DISSOLVED SOLIDS, SUM OF CONST
DISSOLVED SOLIDS, ROE I8O DEG C
HARDNESS, TOTAL
HARDNESS, NONCARBONATE
TURBIDITY (JTU)
FLOURIDE, DISSOLVED

CONSIUUVENI IMGLL OR UNII SHOWNI

SAMPLE

\section{STANDARD}

EVIAIULN
$11 \quad 16.05$

$\begin{array}{rr}11 & 57354.5 \\ 11 & 7.55\end{array}$

110.040

$11 \quad 0.367$

0.367
0.193

0.193
1053.6

1053.6
13.5

96.7

102.5

25.9
4.94

4.94
19.09

19.09
4.07

4.07
4.71

4.71
1.33

1.33
67.5

0.0
11.13

11.13
5.34

5.34
84.1

87.3

64.5

64.5
9.2

10.7
8.02
24.5
28930.5

8930.5
0.41

0.41
0.013

0.078

0.078

717.8

717.8
8.8

3.7

168.8

21.2

0.66

2. 70

0.50
1.75

1.75
0.18

7.2
0.0

0.0
2.32

1.69

10.5

13.0
8.1

6.7

6.7
11.1

0.08
BANGE

7.0
110
30500
7.0

7.0
0.02

0.28

0.28
0.04

190

4
88

4
2

3.8

16.0

3.0

1.1

53

0
8.0

3.2
65

66
52

3

0.0

*Not significant at the 95 percent confidence level.

SUMMARY OF HARMONIC ANALYSIS OF STREAM TEMPERATURE

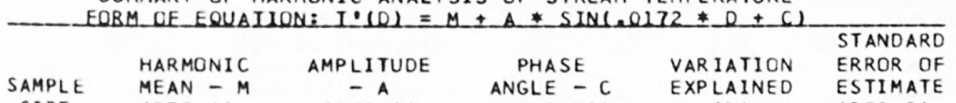

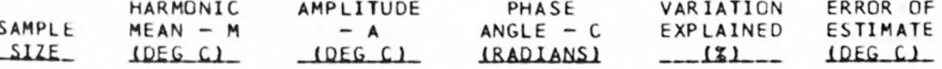

$\begin{array}{llllll}74 & 17.04 & 12.39 & 2.58 & 92 & 1.65\end{array}$

SUMMARY OF MAXIMUM AND MINIMUM CONCENTRATIONS OF CONSTITUENTS

SAMPLED AT A FREQUENCY OF QUARTERLY (1975 WY)

03571850 - TENNESSEE RIVER AT SOUTH PITTSBURG, TENN.

\begin{tabular}{|c|c|c|c|c|c|c|}
\hline \multirow{2}{*}{ CONSTITUENT } & \multicolumn{3}{|c|}{ TOTAL } & \multicolumn{3}{|c|}{ DISSOLVED } \\
\hline & $\begin{array}{l}\text { NO. } \\
\text { SAMPLES }\end{array}$ & $\begin{array}{l}\text { MIN IMUM } \\
\text { CONC. }\end{array}$ & $\begin{array}{l}\text { MAXIMUM } \\
\text { CONC. }\end{array}$ & $\begin{array}{l}\text { NO. } \\
\text { SAMPLES }\end{array}$ & $\begin{array}{l}\text { MINIMUM } \\
\text { CONC. }\end{array}$ & $\begin{array}{l}\text { MAXIMUM } \\
\text { CONC. }\end{array}$ \\
\hline \multicolumn{7}{|l|}{ MINOR ELEMENTS: } \\
\hline ARSENIC (AS), UG/L & 3 & 0 & 2 & 3 & 0 & 1 \\
\hline CADMIUM $(C D), U G / L$ & 3 & 0 & 2 & 3 & 0 & 2 \\
\hline CHROMIUM $(C R), U G / L$ & 3 & $<10$ & $<10$ & 3 & 0 & 1 \\
\hline COBALT $(C O), U G / L$ & 3 & 0 & 0 & 3 & 0 & 0 \\
\hline COPPER (CU), UG/L & 3 & 5 & 9 & 3 & 2 & 3 \\
\hline IRON $(F E), U G / L$ & 3 & 360 & 920 & 3 & 0 & 20 \\
\hline LEAD $(P B), U G / L$ & 3 & 12 & 41 & 3 & 2 & 8 \\
\hline MANGANESE (MN), UG/L & 3 & 50 & 87 & 3 & 7 & 29 \\
\hline MERCURY (HG), UG/L & 2 & 0.0 & 0.4 & 3 & 0.0 & 0.2 \\
\hline SELENIUM (SE), UG/L & 1 & 0 & & 3 & 0 & 0 \\
\hline ZINC $(Z N), U G / L$ & 3 & 10 & 30 & 3 & 0 & 10 \\
\hline \multicolumn{7}{|l|}{ PERIPHYTON: } \\
\hline BIOMASS, DRY WT., G/SQ M & 1 & .00 & & & & \\
\hline $\begin{array}{l}\text { BIOMASS, ASH WT, G/SQ M } \\
\text { CHLOROPHYLL A, MG/SO M }\end{array}$ & $\begin{array}{l}1 \\
0\end{array}$ & 1.19 & & & & \\
\hline CHLOROPHYLL B, MG/SQ M & 0 & & & & & \\
\hline ORGANIC CARBON, MG/L & 3 & 1.7 & 4.5 & & & \\
\hline
\end{tabular}


Table 14.--Summary of measurements at each station--Continued

STATION NUMBER: 03593005

NAME: TENNESSEE RIVER AT PICKWICK LANDING DAM (LL), TN

LAT 35003M54S LONG 088015M08S

DRAINAGE AREA: 32820 SQ MI ( 85004 SQ KM)

PERIOD OF RECORD: $10 / 01 / 74-09 / 30 / 75$

STATISTICAL SUMMARY OF SELECTED DISSOLVED CHEMICAL CONSTITUENTS AND

REGRESSION RELATIONSHIPS OF CONSTITUENT CONCENTRATIONS TO SPECIFIC CONDUCTANCE

CONSIUTUENI

CONSI LUUENI IMGCL OR UNII SHOWN

SAMPLE

SLZE MEAN

STANDARD

DEYIAIION
TEMPERATURE, WATER (DEG C) SPECIFIC CONDUCTANCE (MICROMHOS) STREAMFLOW (CUBIC FT/SEC)

PH (STANDARD UNITS)

PHOSPHORUS, TOTAL

NITRITE + NITRATE, TOTAL

NITROGEN, KJELDAHL, TOTAL

PHYTOPLANKTON, TOTAL (CELLS/ML)

COLIFORM, FECAL (COL/100 ML)

SILICA, DISSOLVED

CALCI UM, DISSOLVED

MAGNESIUM, DISSOLVED

SODIUM, DISSOLVED

POTASSIUM, DISSOLVED

BICARBONATE, ION

CARBONATE, ION

SULFATE, DISSOLVED

CHLOR IDE, DISSOLVED

DISSOLVED SOLIDS, ROE 180 DEG C

HARDNESS, TOTAL

HARDNESS, NONCARBONATE

FLOURIDE, DISSOLVED

${ }^{\star}$ Not significant at the 95 percent confidence level.
SEDIMENT, SUSPENDED

SEDIMENT, CLAY-SILT (PERCENT)

STREPTOCOCCI, FECAL (COL/100 ML)

DISSOLVED SOLIDS, SUM OF CONST
6.84

18.7
35523.7

0.63

0.015

0.139

0.205

4578.1

5.9
21.0

14.3

2137.9

0.51

0.54

0.54
1.37

0.15

3.63

1.30

0.7

10.0
115
29000

29000
6.1

0.04

0.15

0.26

35
5

50
0
5

5
4.0
17.0

17.0

2.5

2.1
1.1
57

9.78

5.63

68.5

86.6

61.6

8.0

0.09

2.42

1.89

0.7

9.8

7.9
4.2

5.9

0.07
REGRESSION SUMMABY

SAMPLE COEFICIENT, CONSTANT, CORRELATION SIZE

CO.

B.

31.0

$183000 \quad 19$

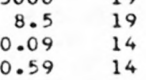

$-1023.157$

$-0.0072$

230690.250

8.5299

0.03088

0.61746

$-0.512$

$-0.215^{*}$

$0.251^{\star}$

$-0.00128$

137.367

$-15578.484$

$0.537^{\star}$

$2000-6$

137.367

33

4300

5.6
21.0

4.0

5.8
1.5

0.0039

0.0609

0.0284

0.0800

10.8348

$-0.4132$

$-7.1065$

0.1488

$0.102^{\star}$
$0.659^{*}$

0.879

0.96

0.930

0.0757

0.0848

$-1.5636$

$-7.0723$

0.612

$\begin{array}{rr}13.0 & 14 \\ 8.0 & 14\end{array}$

0.358

0.176

33.012

35.718

0.712
0.429 *

26.488

-0.130
0.0015

$-0.1196$
STANDARD ERROR O ESIUMAI:

SUMMARY OF HARMONIC ANALYSIS OF STREAM TEMPERATURE EORM OF EQUAIION: I.IDIEM+A*SING.0172*D+C)

\begin{tabular}{|c|c|c|c|c|c|}
\hline & & & & & STANDARL \\
\hline & HARMONIC & AMPLI TUDE & PHASE & VAR IATION & $\begin{array}{l}\text { ERROR } \\
\text { ESTIMA }\end{array}$ \\
\hline $\begin{array}{l}\text { SAMPLE } \\
\text { SUZE }\end{array}$ & MEAN - M & $\begin{array}{c}-A \\
(D E G(1)\end{array}$ & ANGLE - C & EXPLAINED & $\begin{array}{l}\text { ESTIMA } \\
\text { LEEG }\end{array}$ \\
\hline
\end{tabular}

29

18.37

9.74

2.54

81

3.09

SUMMARY OF MAXIMUM AND MINIMUM CONCENTRATIONS OF CONSTITUENTS SAMPLED AT A FREQUENCY OF QUARTERLY (1975 WY)

03593005 - TENNESSEE RIVER AT PICKWICK LANDING DAM (LL), TN

\begin{tabular}{|c|c|c|c|c|c|c|}
\hline \multirow{2}{*}{ CONSTI TUENT } & \multicolumn{3}{|c|}{ TOTAL } & \multicolumn{3}{|c|}{ DISSOLVED } \\
\hline & $\begin{array}{l}\text { NO. } \\
\text { SAMPLES }\end{array}$ & $\begin{array}{l}\text { MIN IMUM } \\
\text { CONC. }\end{array}$ & $\begin{array}{l}\text { MAXIMUM } \\
\text { CONC. }\end{array}$ & $\begin{array}{l}\text { NO. } \\
\text { SAMPLES }\end{array}$ & $\begin{array}{l}\text { MINIMUM } \\
\text { CONC. }\end{array}$ & $\begin{array}{l}\text { MAXIMUM } \\
\text { CONC. }\end{array}$ \\
\hline \multicolumn{7}{|l|}{ MINOR ELEMENTS: } \\
\hline ARSENIC (AS), UG/L & 6 & 0 & 5 & 3 & 0 & 0 \\
\hline CADMIUM $(C D), U G / L$ & 5 & $<1$ & 3 & 3 & 0 & 1 \\
\hline CHROMIUM (CR), UG/L & 5 & $<5$ & $<10$ & 3 & 0 & 0 \\
\hline COBALT $(C O), U G / L$ & 2 & 1 & 10 & 3 & 0 & 4 \\
\hline COPPER $(C U), U G / L$ & 5 & 7 & 40 & 3 & 1 & 4 \\
\hline IRON (FE), UG/L & 13 & 60 & 950 & 2 & 0 & 10 \\
\hline LEAD $(P B), U G / L$ & 5 & 6 & 66 & 3 & 0 & 4 \\
\hline MANG ANESE (MN), UG/L & 13 & 10 & 70 & 2 & 30 & 50 \\
\hline MERCURY (HG), UG/L & 6 & 0.0 & 0.9 & 3 & 0.0 & 0.3 \\
\hline SELENIUM (SE), UG/L & 6 & 0 & $<2$ & 3 & 0 & 0 \\
\hline$Z I N C(Z N), U G / L$ & 5 & $<10$ & 80 & 3 & 0 & 5 \\
\hline \multicolumn{7}{|l|}{ PERIPHYTON: } \\
\hline BIOMASS, DRY WT., GISO M & 3 & 15.00 & 140.00 & & & \\
\hline BIOMASS, ASH WT., G/SQ M & 3 & 11.00 & 91.00 & & & \\
\hline CHLOROPHYLL A, MG/SO M & 3 & 62.0 & 150.0 & & & \\
\hline CHLOROPHYLL B, MG/SO M & 3 & 10.0 & 14.0 & & & \\
\hline ORGANIC CARBON, MG/L & 6 & 1.1 & 3.3 & & & \\
\hline
\end{tabular}


Table 14.--Sumnary of measurements at each station--Continued

LAT 37D02M16S LONG 088D31M46S DRAINAGE AREA: 40330 SQ MI ( 104455 SQ KM) PERIOD OF RECORD: $10 / 01 / 74-09 / 30 / 75$

STATISTICAL SUMMARY OF SELECTED DISSOLVED CHEMICAL CONSTITUENTS AND REGRESSION RELATIONSHIPS OF CONSTITUENT CONCENTRATIONS TO SPECIFIC CONDUCTANCE

CONSIIIUENI

\section{CONSIIIUENI IMG $L$ OR UNII SHOHN}

SAMPL

\section{SIZ}

TEMPERATURE, WATER (DEG C)

SPECIFIC CONDUCTANCE (MICROMHOS)

STREAMFLOW (CUBIC FI/SEC)

PH (STANDARD UNITS)

PHOSPHORUS, TOTAL

NITRITE + NITRATE, TOTAL

NITROGEN, KJELDAHL, TOTAL

PHYTOPLANKTON, TOTAL (CELLS/ML)

SEDIMENT, SUSPENDED

SEDIMENT, CLAY-SILT (PERCENT

COLIFORM, FECAL (COL/10O ML)

STREPTOCOCCI, FECAL (COL/100 ML)

SILICA, DISSOLVED

CALCIUM, DISSOLVED

MAGNESIUM, DISSOLVED

SODIUM, DISSOLVED

POTASSIUM, DISSCLVED

BICARBONATE, ION

CARBONATE, ION

SULFATE, DISSOLVED

CHLORIDE, DISSOLVED

DISSOLVED SOLIDS, SUM OF CONST

DISSOLVED SOLIDS, ROE 180 DEG C

HARONESS, TLTAL

HARONESS, NONCARBONATE

TURBIDITY (JTU)

FLOURIDE, DISSOLVED

$\begin{array}{rrr}12 & 17.75 & 8.48 \\ 12 & 152.3 & 19.0 \\ 12 & 82066.6 & 65380.8 \\ 12 & 7.14 & 0.56 \\ 12 & 0.072 & 0.029 \\ 12 & 0.272 & 0.168 \\ 12 & 0.326 & 0.143 \\ 12 & 4585.8 & 4879.1 \\ 11 & 15.3 & 11.7 \\ 10 & 70.4 & 32.7 \\ 8 & 47.9 & 29.1 \\ 8 & 62.5 & 43.6 \\ 10 & 4.75 & 0.72 \\ 10 & 18.70 & 2.83 \\ 10 & 3.23 & 0.74 \\ 10 & 4.83 & 2.26 \\ 10 & 1.43 & 0.30 \\ 10 & 63.1 & 8.9 \\ 7 & 0.0 & 0.0 \\ 10 & 11.02 & 2.52 \\ 10 & 5.07 & 1.71 \\ 10 & 80.3 & 13.8 \\ 10 & 87.3 & 15.4 \\ 10 & 60.1 & 9.4 \\ 10 & 8.3 & 4.1 \\ 10 & 12.4 & 10.9 \\ 10 & 0.15 & 0.10\end{array}$

*Not significant at the 95

BANGE

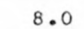

29.0

$30900 \quad 216000 \quad 12$

6.58 .4

0.02

0.07

0.19

750
750

0
0
14

14
14

14
3.5
15.0

15.0
2.4

2.4
2.3

1.0

49

0
7.8

7.8
60

60
67

67
48
3
1

0.15

0.10
8.4
0.1
0.56

$.56 \quad 12$

15000

42
100

100

100
130

130
$5.9 \quad 10$

25.0

4.7
9.2

2.0

76

15.0

15.0
7.2

10

114
78
16

16
30
0.3

DAILY SPECIFIC CONDUC TANGE DURAIION IABLE OE DAILY SPECIEIC CONDUCIANCE MIIY SPECIFIC CONDUCTANC

MICROMHOS AT 25 DEG C, THAT WAS

EQUALLED OR EXCEEDED FOR THE

$\begin{array}{llllll}1 \% & -5 \% & 10 z & 20 z & 30 z & 50 z \\ 190 & 180 & 180 & 170 & 155 & 140\end{array}$

502

INOICATED PERCENTAGE OF TIME

SUMMARY OF HARMONIC ANALYSIS OF STREAM TEMPERATURE

FORM

\begin{tabular}{|c|c|c|c|c|c|}
\hline & & & & & STANDARO \\
\hline & HARMONIC & AMPLITUDE & PHASE & VARIATION & ERROR OF \\
\hline SAMPLE & MEAN - M & $-A$ & $A N G L E-C$ & EXPLAINED & ESTIMATE \\
\hline SIZE_ & WEE CI & - $D E G C L$ & IRADIANSI & 181 & IDEG $(1)$ \\
\hline 361 & 16.50 & 10.91 & 2.09 & 96 & 1.60 \\
\hline
\end{tabular}

SUMMARY OF MAXIMUM ANO MINIMUM CONCENTRATIONS OF CONSTITLENTS

SAMPLED AT A FREQUENCY OF QUARTERLY (1975 WY)

BEGRESSION_SUMMARY

REGRESSION

SAMPLE COEFICIENT, CONSTANT, CORRELATION ERROR OF

$-\mathrm{B}$

$-B$

COEFIGIENT

$\begin{array}{rrrr}-2305.490 & 433077.438 & -0.671 & 50857.0 \\ 0.0097 & 5.6706 & 0.325 * & 0.56 \\ 0.00068 & -0.03218 & 0.449 * & 0.027 \\ -0.00236 & 0.63200 & -0.267 * & 0.170 \\ 0.00315 & -0.15316 & 0.418 * & 0.136 \\ 59.856 & -4527.273 & 0.233 * & 4975.9\end{array}$

0.0134
0.1116
0.0253
0.0843
0.0028
0.388
0.000
0.1046
0.0732
0.014
0.486
0.376
0.070
-0.395
0.0029

2.7251
1.8822
-0.5801
-7.8737
1.0022
4.633
0.000
-4.7430
-5.9688
-12.172
14.1117
3.400
-2.224
71.908
-0.2802

$0.388 *$

0.814

0.709

0.771 .

0.895

0.000

0.858

0.882

0.915

0.650

.825

0.355

-0.748
0.006 .
0.70

1.74

0.55

1.53

0.31

0.0

1.37

0.86

5.9

12.4
5.6

4.0

7.7

0.08

03609750 -- TENNESSEE RIVER AT HIGHWAY 60 , NEAR PADUCAH, KY.

\begin{tabular}{|c|c|c|c|c|c|c|}
\hline \multirow{2}{*}{ CONSTI TUENT } & \multicolumn{3}{|c|}{ TOTAL } & \multicolumn{3}{|c|}{ DISSOLVED } \\
\hline & $\begin{array}{l}\text { NO. } \\
\text { SAMPLES }\end{array}$ & $\begin{array}{l}\text { MINIMUM } \\
\text { CONC. }\end{array}$ & $\begin{array}{l}\text { MAXIMUM } \\
\text { CONC. }\end{array}$ & $\begin{array}{l}\text { NC. } \\
\text { SAMPLES }\end{array}$ & $\begin{array}{l}\text { MINIMUM } \\
\text { CONC. }\end{array}$ & $\begin{array}{l}\text { MAXIMUM } \\
\text { CONC. }\end{array}$ \\
\hline \multicolumn{7}{|l|}{ MINOR ELEMENTS: } \\
\hline ARSENIC (AS), UG/L & 4 & 0 & 1 & 4 & 0 & 1 \\
\hline CADMIUM $(C D), U G / L$ & 4 & 0 & 2 & 4 & 0 & 2 \\
\hline CHROMIUM (CR), UG/L & 4 & 0 & $<10$ & 4 & 0 & 0 \\
\hline COBALT $(C O), U G / L$ & 4 & 0 & 6 & 4 & 0 & 5 \\
\hline COPPER (CU), UG/L & 4 & 3 & 34 & 4 & 5 & 8 \\
\hline IRON $(F E), U G / L$ & 4 & 260 & 1300 & 4 & 0 & 40 \\
\hline LEAD $(P B), U G / L$ & 4 & 2 & 28 & 4 & 0 & 9 \\
\hline MANG ANESE (MN), UG/L & 4 & 60 & 88 & 4 & 0 & 10 \\
\hline MERCURY (HG), UG/L & 4 & 0.0 & 0.2 & 4 & 0.0 & 0.2 \\
\hline SELENIUM (SE), UG/L & 4 & 0 & 0 & 4 & 0 & 0 \\
\hline ZINC $(Z N), U G / L$ & 4 & 40 & 50 & 4 & 4 & 40 \\
\hline \multicolumn{7}{|l|}{ PERIPHYTON: } \\
\hline BIOMASS, DRY WT., GISQ M & 4 & .69 & 93.00 & & & \\
\hline BIOMASS, ASH WT., G/SQ M & 4 & .50 & 69.00 & & & \\
\hline CHLOROPHYLL A, MG/SO M & 4 & .2 & $6 \cdot 3$ & & & \\
\hline CHLOROPHYLL B, MG/SO M & 4 & .0 & $\cdot 7$ & & & \\
\hline ORGANIC CARBON, MG/L & 4 & 2.0 & 5.6 & & & \\
\hline
\end{tabular}


LAT 37D12M11S LONG 089002M30S

DRAINAGE AREA: 203100 SQ MI ( 526029 SQ KM)

PERIOD OF RECORD: $10 / 01 / 74-09 / 30 / 75$

STATISTICAL SUMMARY OF SELECTED DISSOLVED CHEMICAL CONSTITUENTS AND

REGRESSION RELATIONSHIPS OF CONSTITUENT CONCENTRATIONS TO SPECIFIC CONDUCTANCE

CONSIIIUENI

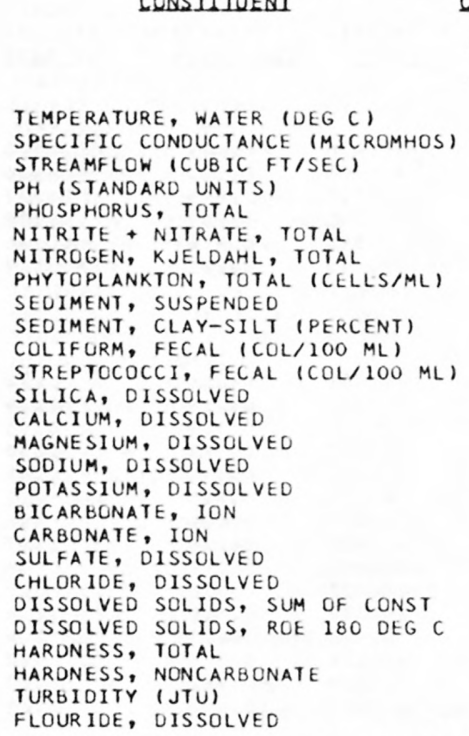

CONSILUUENI IMG/L OR UNII SHOWNL

\begin{tabular}{rr} 
SAMPLE & \\
SIZE & MEAN \\
\cline { 1 - 1 } 12 & 17.33 \\
12 & 292.8 \\
12 & 43463.3 \\
12 & 7.19 \\
12 & 0.231 \\
12 & 0.854 \\
12 & 0.572 \\
12 & 6916.7 \\
11 & 77.5 \\
11 & 87.2 \\
8 & 293.8 \\
8 & 134.8 \\
10 & 4.89 \\
10 & 32.90 \\
10 & 8.37 \\
10 & 10.24 \\
10 & 2.09 \\
10 & 88.4 \\
6 & 0.0 \\
10 & 45.20 \\
10 & 12.67 \\
10 & 160.2 \\
10 & 173.6 \\
10 & 117.0 \\
10 & 44.2 \\
10 & 43.3 \\
10 & 0.23
\end{tabular}

\section{STANDARD}

DEYIALION

8.71
53.8

360089.8

0.03
0.265

0.265
0.262

0.262
0.143

0.143
7758.0

44.1

14.1

232.6

77.1

1.41
5.97

1.97
1.75
4.14

4.14
0.47

0.47
14.0

0.0

11.74

5.34
34.7

34.7
34.7

23.1

13.0

20.2
0.12 ${ }^{*}$ Not significant at the 95 percent confidence level.

BEGBESSION_SUMMABY

SAMPLE COEFICIENT, CONSTANT, CORRELATIUN ERROR OF

SIZE _... - _. B _. CDEEICIENI ESLIMAIE

$\begin{array}{rr}6.0 & 29.0 \\ 190 & 397\end{array}$

$124000 \quad 1150000$

$6.4 \quad 8.3 \quad 12$

$\begin{array}{ll}6.4 & 8.3 \\ 0.08 & 0.98\end{array}$

$0.50 \quad 1.30$

$\begin{array}{rr}0.41 & 0.84 \\ 900 & 25000\end{array}$

$\begin{array}{rr}900 & 25000 \\ 26 & 147 \\ 55 & 100 \\ 70 & 740\end{array}$

70

$\begin{array}{rr}28 & 240 \\ 1.7 & 6.4\end{array}$

$23.0 \quad 6.4 \quad 10$

$\begin{array}{rr}23.0 & 44.0 \\ 5.6 & 11.0\end{array}$

5.0

1.6

11.0

18.010

3.010

$\begin{array}{rr}107 & 10 \\ 0 & 6 \\ 69.0 & 10\end{array}$

$\begin{array}{ll}69.0 & 10 \\ 23.0 & 10\end{array}$

22510

$232 \quad 10$

$\begin{array}{rr}160 & 10 \\ 71 & 10\end{array}$

$\begin{array}{rr}70 & 10 \\ 0.4 & 10\end{array}$

RURAILON_IABLE_OE_DAILY_SPECIEIC_CONDUCIANGE

DAILY SPECIFIC CONDUCTANCE IN

MICROMHOS AT 25 DEG C, THAT WAS

EQUALLED OR EXCEEDED FOR THE

$\begin{array}{llllll}1 \% & -5 \% & 10 \% & 20 \% & 30 \% & 50 \% \\ 465 & 420 & 405 & 355 & 335 & 310\end{array}$

$\begin{array}{llll} & & \text { SAMPLE SIZE } & =-350 \\ 70 \% & 20 \% & 25 \% & 29 \% \\ 285 & 250 & 245 & 230\end{array}$

SUMMARY OF HARMONIC ANALYSIS OF STREAM TEMPERATURE

\begin{tabular}{|c|c|c|c|c|c|}
\hline & & & & & STANDA \\
\hline & HARMONIC & AMPLITUDE & PHASE & VARIATION & ERROR OF \\
\hline SAMPLE & MEAN - M & $-A$ & $A N G L E-C$ & EXPLAINED & ESTIMATE \\
\hline SIZE & $10 E G_{2} C 1$ & DDEG (L) & IRADIANSI & $-(\%)$ & $\left.10 E G_{C} C\right)$ \\
\hline
\end{tabular}

348

16.07

10.95

2.56

96

1.49

SUMMARY OF MAXIMUM AND MINIMUM CONCENTRATIONS OF CONSTITUENTS

SAMPLED AT A FREQUENCY OF QUARTERLY (1975 WY)

03612500 -- OHIO R AT LOCK AND DAM 53 NR GRAND CHAIN ILL

CONSTI TUENT
SAMPLES


Table 14.--Sumary of measurements at each station--Continued

LAT 47020M15S LONG 091D12MOOS

DRAINAGE AREA:

PERIOD OF RECORD: $10 / 01 / 74-09 / 30 / 763$ SQ KMI

STATISTICAL SUMMARY OF SELECTED DISSOLVED CHEMICAL CONSIITUENTS AND

REGRESSION RELATIONSHIPS OF CONSTITUENT CONCENTRATIONS TO SPECIFIC CONDUCTANCE

CONSIIIUENI

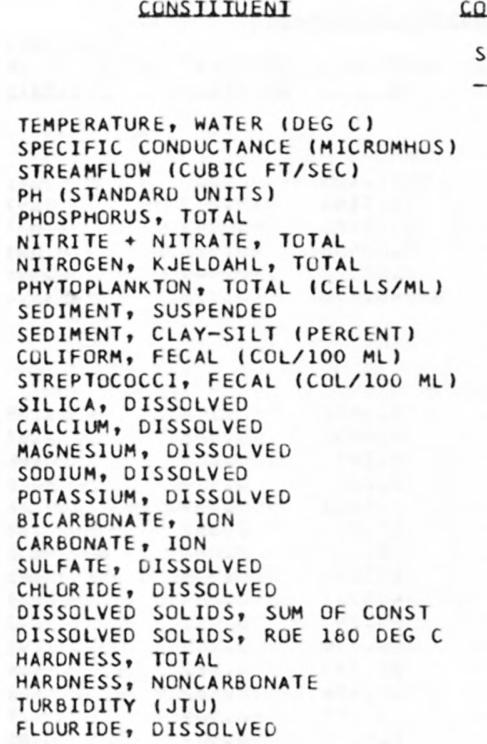

FLOURIDE, DISSOLVED

\begin{tabular}{r} 
CONSI \\
SAMPLE \\
SIZF \\
\hline 14 \\
9 \\
14 \\
9 \\
9 \\
9 \\
8 \\
9 \\
9 \\
0 \\
9 \\
9 \\
9 \\
9 \\
9 \\
9 \\
9 \\
9 \\
6 \\
9 \\
9 \\
9 \\
9 \\
9 \\
9 \\
9 \\
9 \\
\end{tabular}

*Not significant at the 95 percent confidence 1 evel.

$\begin{array}{rrrr}8.14 & 7.68 & 0.0 & 18.0 \\ 92.2 & 18.2 & 60 & 116 \\ 62.0 & 49.5 & 5 & 163 \\ 7.70 & 0.41 & 7.0 & 8.3 \\ 0.012 & 0.010 & 0.00 & 0.03 \\ 0.211 & 0.194 & 0.01 & 0.53 \\ 0.630 & 0.413 & 0.28 & 1.50 \\ 443.3 & 390.3 & 100 & 1300 \\ 9.7 & 6.0 & 3 & 17 \\ 21.1 & 28.9 & 2 & 92 \\ 22.7 & 27.1 & 0 & 74 \\ 10.69 & 2.83 & 6.5 & 14.0 \\ 10.61 & 1.59 & 8.4 & 13.0 \\ 3.36 & 0.78 & 2.6 & 4.7 \\ 3.18 & 0.98 & 1.9 & 4.6 \\ 0.50 & 0.12 & 0.3 & 0.7 \\ 39.4 & 9.4 & 27 & 57 \\ 0.0 & 0.0 & 0 & 0 \\ 6.93 & 1.40 & 5.1 & 9.4 \\ 3.27 & 1.12 & 1.8 & 5.1 \\ 58.1 & 10.1 & 43 & 69 \\ 82.8 & 8.5 & 67 & 96 \\ 40.3 & 6.7 & 32 & 49 \\ 8.1 & 3.6 & 3 & 12 \\ 2.0 & 1.3 & 1 & 5 \\ 0.22 & 0.07 & 0.2 & 0.4\end{array}$

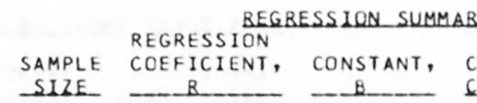

CORRELATION COEELCIENI

STANDARD ERROR OF ESIUMAIE

SUMMARY OF MAXIMUM AND MINIMUM CONCENTRATIONS OF CONSTITUENTS

SAMPLED AT A FREQUENCY OF QUARTERLY (1975 WY)

04014500 -- BAPTISM RIVER NEAR BEAVER BAY, MINN.

\begin{tabular}{|c|c|c|c|c|c|c|}
\hline \multirow{2}{*}{ CONSTI IUENT } & \multicolumn{3}{|c|}{ TOTAL } & \multicolumn{3}{|c|}{ DISSOLVED } \\
\hline & $\begin{array}{l}\text { NO. } \\
\text { SAMPLES }\end{array}$ & $\begin{array}{l}\text { MIN IMUM } \\
\text { CONC. }\end{array}$ & $\begin{array}{l}\text { MAXIMUM } \\
\text { CONC. }\end{array}$ & $\begin{array}{l}\text { NO. } \\
\text { SAMPLES }\end{array}$ & $\begin{array}{l}\text { MINIMUM } \\
\text { CONC. }\end{array}$ & $\begin{array}{l}\text { MAXIMUM } \\
\text { CONC. }\end{array}$ \\
\hline \multicolumn{7}{|l|}{ MINOR ELEMENTS: } \\
\hline ARSENIC (AS), UG $/ L$ & 4 & 0 & 2 & 4 & 0 & 1 \\
\hline CADMIUM $(C D), U G / L$ & 4 & $<10$ & 10 & 4 & 0 & 1 \\
\hline CHROMIUM (CR), UG/L & 4 & 0 & 10 & 4 & 0 & 10 \\
\hline COBALT $(C O), U G / L$ & 4 & $<50$ & $<50$ & 4 & 0 & 1 \\
\hline COPPER $(C U), U G / L$ & 4 & $<10$ & 110 & 4 & 0 & 3 \\
\hline IRON (FE), UG/L & 4 & 90 & 400 & 4 & 40 & 260 \\
\hline LEAD $(P B), U G / L$ & 4 & $<100$ & $<100$ & 4 & 0 & 13 \\
\hline MANG ANESE (MN), UG/L & 4 & 0 & 60 & 4 & 0 & 0 \\
\hline MERCURY $(H G), U G / L$ & 4 & 0.0 & 1.1 & 4 & 0.0 & $1 \cdot 1$ \\
\hline SELENIUM (SE), UG $/ L$ & 4 & 0 & 0 & 4 & 0 & 0 \\
\hline$Z I N C(Z N), U G / L$ & 4 & 20 & 270 & 4 & 6 & 10 \\
\hline \multicolumn{7}{|l|}{ PERIPHYTON: } \\
\hline BIOMASS, DRY WT., G/SO M & 3 & 1.59 & 64.00 & & & \\
\hline BIOMASS, ASH WT., G/SQ M & 3 & 1.50 & 64.00 & & & \\
\hline CHLOROPHYLL A, MG/SQ M & 2 & .0 & 2.0 & & & \\
\hline CHLOROPHYLL $B, M G / S Q M$ & 2 & $\cdot 0$ & .5 & & & \\
\hline ORGANIC CARBON, MG/L & 4 & 4.0 & 16.0 & & & \\
\hline
\end{tabular}


Table 14.--Summary of measurements at each station--Continued

STATION NUMBER: 04024000

NAME: ST. LOUIS RIVER AT SCANLON, MINN.

LAT 46D42M12S LONG 092025M07S

DRAINAGE AREA: 3430 SO MI ( 8884 SO KM)

PERIOD OF RECORD: $10 / 01 / 74-09 / 30 / 75$

STAIISTICAL SUMMARY OF SELECTED DISSOLVED CHEMICAL CONSTITUENTS AND

REGRESSION RELATIONSHIPS OF CONSTITUENT CONCENTRATIONS TO SPECIFIC CONDUCTANCE

CONSIUIUENI

\begin{tabular}{|c|}
\hline $\begin{array}{l}\text { TEMPERATURE, WATER (DEG C) } \\
\text { SPECIFIC CONDUCTANCE (MICROMHOS) } \\
\text { STREAMFLOH (CUBIC FI/SEC) } \\
\text { PH (STANDARD UNITS) } \\
\text { PHOSPHORUS, TOTAL } \\
\text { NITRITE + NITRATE, TOTAL } \\
\text { NITROGEN, KJELDAHL, TOTAL } \\
\text { PHYTOPLANKTON, TOTAL (CELLS/ML) } \\
\text { SEDIMENT, SUSPENDED } \\
\text { SEDIMENT, CLAY-SILT (PERCENT) } \\
\text { COLIFORM, FECAL (COL/IOO ML) } \\
\text { STREPTOCOCCI, FECAL (COL/IOO ML) } \\
\text { SILICA, DISSOLVED } \\
\text { CALCIUM, DISSOLVED } \\
\text { MAGNESIUM, DISSOLVEU } \\
\text { SODIUM, OISSOLVED } \\
\text { POTASSIUM, OISSOLVED } \\
\text { BICARBONATE, ION } \\
\text { CARBONATE, ION } \\
\text { SULFATE, OISSOLVED } \\
\text { CHLORIDE, OISSOLVED } \\
\text { DISSOLVED SOLIDS, SUM OF CONST } \\
\text { DISSOLVED SOLIOS, ROE I8O DEG C } \\
\text { HARONESS, TOTAL } \\
\text { HARONESS, NONCARBONATE } \\
\text { TURBIDITY (JTU) } \\
\text { FLOURIDE, DISSOLVED }\end{array}$ \\
\hline
\end{tabular}

CONSIUUVENI IMGLL OB UNDI SHOWNL

\begin{tabular}{|c|c|c|}
\hline $\begin{array}{l}\text { SAMPL } \\
\text { SIZE }\end{array}$ & MEAN & $\begin{array}{l}\text { STANDARD } \\
\text { DEYIAIUEN }\end{array}$ \\
\hline 14 & 10.29 & 9.60 \\
\hline 9 & 205.9 & 42.2 \\
\hline 14 & 1713.5 & 1470.6 \\
\hline 9 & 7.53 & 0.63 \\
\hline 9 & 0.051 & 0.016 \\
\hline 9 & 0.079 & 0.087 \\
\hline 9 & 0.992 & 0.390 \\
\hline 10 & 11561.0 & 18026.6 \\
\hline 9 & 35.2 & 68.2 \\
\hline 0 & & \\
\hline 7 & 474.3 & 172.8 \\
\hline 9 & 208.3 & 204.2 \\
\hline 9 & 6.96 & 1.87 \\
\hline 9 & 19.11 & 3.48 \\
\hline 9 & 7.21 & 1.20 \\
\hline 9 & 10.19 & 2.96 \\
\hline 9 & 1.44 & 0.31 \\
\hline 9 & 75.9 & 13.7 \\
\hline 6 & 0.0 & 0.0 \\
\hline 9 & 15.56 & 4.25 \\
\hline 9 & 12.18 & 4.01 \\
\hline 9 & 110.7 & 19.4 \\
\hline 9 & 155.1 & 16.8 \\
\hline 9 & 77.3 & $12 \cdot 2$ \\
\hline 9 & 15.2 & 5.8 \\
\hline 9 & 8.7 & 7.5 \\
\hline 9 & 0.14 & 0.05 \\
\hline
\end{tabular}

*Not significant at the 95 percent confidence level.

$\begin{array}{rr} & \\ \text { BANGE } & \\ 0.0 & 22.5 \\ 115 & 244 \\ 877 & 6580 \\ 7.2 & 9.2 \\ 0.03 & 0.08 \\ 0.00 & 0.23 \\ 0.62 & 1.60 \\ 360 & 60000 \\ 5 & 216 \\ & \\ 250 & 800 \\ 32 & 590 \\ 3.7 & 9.8 \\ 14.0 & 23.0 \\ 5.7 & 9.7 \\ 3.2 & 13.0 \\ 1.0 & 2.0 \\ 53 & 98 \\ 0 & 0 \\ 10.0 & 23.0 \\ 3.4 & 16.0 \\ 72 & 133 \\ 127 & 181 \\ 58 & 95 \\ 6 & 24 \\ 3 & 24 \\ 0.1 & 0.2\end{array}$

$B E G B E$ REGRESSION

SAMPLE COEFICIENT, CONSTANT, CORRELATION ERROR OF

$-37.761$

$-0.0125$

$-0.00002$

$-0.00003$

$-0.00500$

$-350.487$

9662.10

10.1166

0.05486

0.08556

2.02172

84740.250

$-0.880$

$-0.837$

$-0.047$

$-0.016^{*}$

$-0.759$

8.8522

4.6935

$-0.0092$

0.0700

0.0190

0.0642

0.0044

0.278
0.000

0.000

0.0740

0.439

0.295

0.253

0.023

$-0.090$

0.0007
3.2917

$-3.0328$

0.5421

18.719

0.000

0.3210

$-4.3741$

20.297

94.290

25.194

10.486

27.270

0.0077
920.1

0.37

0.017

0.093

0.350
13532.4

SUMMARY OF MAXIMUM AND MINIMUM CONCENTRATIONS OF CONSTITUENTS SAMPLED AT A FREQUENCY OF QUARTERLY (1975 WY)

04024000 -- ST. LOUIS RIVER AT SCANLON, MINN.

\begin{tabular}{|c|c|c|c|c|c|c|}
\hline \multirow{2}{*}{ CONSTI TUENT } & \multicolumn{3}{|c|}{ TOTAL } & \multicolumn{3}{|c|}{ DISSOLVED } \\
\hline & $\begin{array}{l}\text { NO. } \\
\text { SAMPLES }\end{array}$ & $\begin{array}{l}\text { MINIMUM } \\
\text { CONC. }\end{array}$ & $\begin{array}{l}\text { MAXIMUM } \\
\text { CONC. }\end{array}$ & $\begin{array}{l}\text { NO. } \\
\text { SAMPLES }\end{array}$ & $\begin{array}{l}\text { MINIMUM } \\
\text { CONC. }\end{array}$ & $\begin{array}{l}\text { MAXIMUM } \\
\text { CONC. }\end{array}$ \\
\hline \multicolumn{7}{|l|}{ MINUR ELEMENTS: } \\
\hline ARSENIC (AS), UG/L & 4 & 1 & 2 & 4 & 0 & 2 \\
\hline CADMIUM $(C D)$, UG/L & 4 & $<10$ & 20 & 4 & 0 & 1 \\
\hline CHROMIUM (CR), UG/L & 4 & 0 & 10 & 4 & 0 & 10 \\
\hline COBALT $(C O), U G / L$ & 4 & $<50$ & 50 & 4 & 0 & 1 \\
\hline COPPER (CU), UG/L & 4 & $<10$ & 170 & 4 & 1 & 4 \\
\hline IRON (FE), UG/L & 4 & 550 & 1000 & 4 & 300 & 650 \\
\hline LEAD $(P B), U G / L$ & 4 & $<100$ & 100 & 4 & 0 & 5 \\
\hline MANG ANESE (MN), UG/L & 4 & 50 & 90 & 4 & 40 & 90 \\
\hline MERCURY (HG), UG/L & 4 & 0.0 & 0.1 & 4 & 0.0 & 0.1 \\
\hline SELENIUM $(S E), U G / L$ & 4 & 0 & 0 & 4 & 0 & 0 \\
\hline$Z I N C(Z N), U G / L$ & 4 & 40 & 140 & 4 & 10 & 80 \\
\hline \multicolumn{7}{|l|}{ PERIPHYTON: } \\
\hline BIOMASS, DRY WT., G/SQ M & 1 & 9.50 & & & & \\
\hline BIOMASS, ASH WT., G/SO M & 1 & 5.19 & & & & \\
\hline CHLOROPHYLL A, MG/SQ M & 0 & & & & & \\
\hline CHLOROPHYLL B, MG/SQ M & 0 & & & & & \\
\hline ORGANIC CARBON, MG/L & 4 & 3.2 & 40.0 & & & \\
\hline
\end{tabular}


Table 14.--Summary of measurements at each station--Continued

LAT $46029 M 15 S$ LONG 090D41M45S

DRAINAGE AREA: $\quad 011$ SO MI 11582 SQ KM)

PERIOD OF RECORD: $10 / 01 / 74-09 / 30 / 75$

STATISTICAL SUMMARY OF SELECTED DISSOLVED CHEMICAL CONSTITUENTS AND

REGRESSION RELATIONSHIPS OF CONSTITUENT CONCENTRATIONS TO SPECIFIC CONDUCTANCE

CONSLIUEN

CONSIHUENT IMG LL OR UNII SHOWNI

SA

STANDARD

DEYIALION

8.39

8.39
128.8

128.8

598.7

7.43
0.024
0.149

0.024
0.149
0.368

0.368

898.9

55.9
63.5

70.3

56.3

11.26

16.70

16.70
4.87

4.87
2.79

0.87

69.8

0.0

6.32

2.63

10.0

93.

61.6
4.8

4.8
6.5
0.24

9.23
40.7

40.7
971.5

0.28

0.014

0.162

259.3

47.4

51.9

48.2

2.70
5.06

1.49

0.66

25.3

0.0

1.47

19.1

13.8

18.6
3.1

0.12

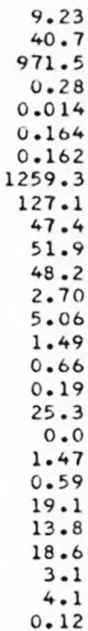

BANGE
0.0
76
92
0.8
0.01
0.00
0.21
0
2
30
14
2
7.0
8.4
2.1
1.8
0.6
30
0
2.9
1.6
48
66
30
0
1
0.0

\begin{tabular}{rr} 
& \\
& SAMPL \\
& SIZE \\
\cline { 2 - 2 } 24.5 & \\
195 & \\
3690 & 12 \\
7.8 & 11 \\
0.05 & 12 \\
0.57 & 12 \\
0.83 & 12 \\
4400 & 12 \\
558 & \\
97 & \\
160 & \\
160 & \\
15.0 & 12 \\
24.0 & 12 \\
6.9 & 12 \\
4.0 & 12 \\
1.1 & 12 \\
110 & 12 \\
0 & 12 \\
8.9 & 12 \\
3.8 & 12 \\
106 & 12 \\
118 & 12 \\
88 & 12 \\
9 & 12 \\
15 & 12 \\
0.5 & 12 \\
& \\
& \\
0
\end{tabular}
REGRESSION

BEGRESSION SUMMARY

SAMPLE COEFICIENT, CONSTANT, CORRELATION ERROR OF - - _ - B._. COEEILIENI

FLOURIDE, DISSOLVED

*Not significant at the 95 percent confidence level.

SUMMARY OF HARMONIC ANALYSIS OF STREAM TEMPERATURE

\begin{tabular}{|c|c|c|c|c|c|}
\hline & & & & & STANDARD \\
\hline & HARMONIC & AMPLITUDE & PHASE & VARIATION & ERROR OF \\
\hline SAMPLE & $M E A N-M$ & $-A$ & ANGLE - C & EXPLAINED & ESTIMATE \\
\hline SIZE_ & $10 E 6(1)$ & WEG $(1)$ & IRADIANSI & -132 & $10 E G_{C} C 1$ \\
\hline 19 & 7.57 & 11.86 & 2.78 & 86 & 3.17 \\
\hline
\end{tabular}

SUMMARY OF MAXIMUM AND MINIMUM CONCENTRATIONS OF CONSTITUENTS SAMPLED AT A FREQUENCY OF QUARTERLY (1975 HY)

04027000 -- BAD RIVER NEAR ODANAH, WIS.

\begin{tabular}{|c|c|c|c|c|c|c|}
\hline \multirow{2}{*}{ CONSTITUENT } & \multicolumn{3}{|c|}{ TOTAL } & \multicolumn{3}{|c|}{ DISSOLVED } \\
\hline & $\begin{array}{l}\text { NO. } \\
\text { SAMPLES }\end{array}$ & $\begin{array}{l}\text { MINIMUM } \\
\text { CONC. }\end{array}$ & $\begin{array}{l}\text { MAXIMUM } \\
\text { CONC. }\end{array}$ & $\begin{array}{l}\text { NO. } \\
\text { SAMPLES }\end{array}$ & $\begin{array}{l}\text { MINIMUM } \\
\text { CONC. }\end{array}$ & $\begin{array}{l}\text { MAXIMUM } \\
\text { CONC. }\end{array}$ \\
\hline \multicolumn{7}{|l|}{ MINOR ELEMENTS: } \\
\hline ARSENIC (AS), UG/L & 2 & 1 & 2 & 4 & 0 & 1 \\
\hline CADMIUM (CD), UG/L & 4 & 0 & 2 & 4 & 0 & 1 \\
\hline CHROMIUM (CR), UG/L & 4 & $<10$ & 20 & 4 & 0 & 1 \\
\hline CCBALT $(C O), U G / L$ & 4 & 0 & 4 & 4 & 0 & 0 \\
\hline COPPER (CU), UG/L & 4 & 7 & 13 & 4 & 0 & 2 \\
\hline IRON $(F E), U G / L$ & 4 & 390 & 930 & 4 & 190 & 290 \\
\hline LEAD $(P B), U G / L$ & 4 & 4 & 37 & 4 & 0 & 2 \\
\hline MANGANESE $(M N), U G / L$ & 4 & 10 & 70 & 4 & 0 & 50 \\
\hline MERCURY (HG), UG/L & 3 & 0.0 & 1.0 & 4 & 0.0 & 0.2 \\
\hline SELENIUM $(S E), U G / L$ & 4 & 0 & 0 & 4 & 0 & 0 \\
\hline ZINC $(Z N), U G / L$ & 4 & 20 & 30 & 4 & 3 & 4 \\
\hline \multicolumn{7}{|l|}{ PERIPHYTON: } \\
\hline BIOMASS, DRY WT., G/SO M & 3 & 1.00 & 3.79 & & & \\
\hline BIOMASS, ASH WT., G/SQ M & 3 & .79 & 3.09 & & & \\
\hline CHLOROPHYLL A, MG/SU M & 3 & .1 & 1.5 & & & \\
\hline CHLOROPHYLL B, MG/SO M & 3 & .0 & 1.2 & & & \\
\hline ORGANIC CARBON, MG/L & 4 & 6.2 & 9.3 & & & \\
\hline
\end{tabular}


Table 14.--Summary of measurements at each station--Continued

LAT 46D43M15S LONG 089D12M25S

DRAINAGE AREA: 1340 SQ MI 133471 SQ KM

PERIOD OF RECORD: $10 / 01 / 74-09 / 30 / 75$

STATISTICAL SUMMARY OF SELECTED DISSOLVED CHEMICAL CONSTITUENTS AND

REGRESSIUN RELATIONSHIPS OF CONSTITUENT CONCENTRATIONS TO SPECIFIC CONDUCTANCE

\section{BEGRESSION SUMMABY}

SAMPLE COEFICIENT, CONSTANT, CURRELATION ERTOR OF SIZE - B - B COEEICIENI

CUNSIIIUEN

CONSIUUENI IMG/L OR UNII SHOWNI

\begin{tabular}{rrr}
$\begin{array}{crr}\text { SAMPLE } \\
\text { SIZE }\end{array}$ & MEAN & \multicolumn{1}{r}{ STANDARD } \\
\cline { 1 - 1 } & & \\
15 & 7.73 & 8.40 \\
12 & 124.8 & 23.7 \\
12 & 2646.3 & 4718.5 \\
12 & 8.07 & 0.32 \\
12 & 0.074 & 0.131 \\
12 & 0.077 & 0.057 \\
12 & 0.468 & 0.339 \\
12 & 607.5 & 456.2 \\
12 & 210.4 & 445.0 \\
11 & 93.5 & 14.4 \\
10 & 18.6 & 29.1 \\
10 & 30.1 & 27.2 \\
12 & 8.22 & 1.48 \\
12 & 19.00 & 3.81 \\
12 & 4.67 & 0.90 \\
12 & 2.11 & 0.49 \\
12 & 1.22 & 0.40 \\
12 & 68.3 & 17.7 \\
12 & 0.2 & 0.6 \\
12 & 6.01 & 0.99 \\
12 & 2.22 & 0.60 \\
12 & 77.7 & 12.4 \\
12 & 87.2 & 12.9 \\
12 & 66.7 & 13.1 \\
12 & 10.8 & 12.0 \\
12 & 46.9 & 77.3 \\
12 & 0.18 & 0.09
\end{tabular}

BANGE 0.0
82 22.5

TEMPERATURE, WATER (DEG C) SPECIFIC CONDUCTANCE (MICROMHOSI STREAMFLOW (CUBIC FT/SEC)

PH ISTANDARE UNITS

PHOSPHORUS, TOTAL

NIIRITE + NITRATE, TUTAL

NITROGEN, KJELDAHL, TUTAL

PHYTOPLANKTON, TOTAL (CELLS/ML)

SEDIMENT, SUSPENDED

SEDIMENT, CLAY-SILT (PERCENT)

COLIFURM, FECAL ( $(\mathrm{OL} / 100 \mathrm{ML})$

STREPTOCOCCI, FECAL ICGL/100 ML

SILICA, DISSOLVED

CALCIUM, DISSOLVED

MAGNESIUM, DISSOL VED

SODIUM, DISSOLVED

POTASSIUM, DISSOLVED

BICARBONATE, ION

CARBONATE, ION

SULFATE, DISSOLVED

CHLORIDE, DISSOLVEO

DISSOLVED SOLIDS, SUM OF CONST

DISSOLVED SOLIDS, ROE 180 DEG C

HARDNESS, TOTAL

HARDNESS, NONCAREONATE

TURBIDITY (JTUI

FLOUR IDE, DISSOLVED

*Not significant at the 95 percent confidence level.

$\begin{array}{rr}82 & 162 \\ 300 & 16800 \\ 7.6 & 8.6 \\ 0.01 & 0.48 \\ 0.00 & 0.16 \\ 0.16 & 1.30 \\ 210 & 1700 \\ 11 & 1400 \\ 63 & 100 \\ 1 & 100 \\ 3 & 86 \\ 5.6 & 10.0 \\ 15.0 & 27.0 \\ 3.4 & 6.0 \\ 1.1 & 2.9 \\ 0.8 & 2.3 \\ 50 & 101 \\ 0 & 2 \\ 4.8 & 7.9 \\ 1.2 & 3.1 \\ 62 & 105 \\ 59 & 110 \\ 51 & 92 \\ 0 & 46 \\ 1 & 220 \\ 0.0 & 0.3\end{array}$

DURALION IABLE OF DALY SPECIEIC CONDUCIANCE

DAILY SPECIFIC CUNDUCTANCE IN

MICROMHOS AT 25 DEG C, THAT WAS

EQUALLED OR EXCEEULD FOR THE

SPECIFIC

\section{$30 \% \quad 50$ ( 200}

1842020

155

145

130

$\begin{array}{ll}1 & 2 \\ 1 & 2 \\ 1 & 1 \\ 1 & 1 \\ 1 & 1 \\ 1 & 1\end{array}$

$$
\begin{array}{r}
-73.037 \\
0.0015 \\
0.00001 \\
-0.00095 \\
-0.00307 \\
3.023
\end{array}
$$
11763.785
7.8766
0.07837
0.18992
0.94125
264.500

-0.367 *

0.114 *

$0.002 *$

$-0.415 *$

$-0.259 *$
$0.160 *$

4003.3

0.33

0.143

0.054

\begin{tabular}{|c|c|c|c|c|c|}
\hline & & & & & STANDARD \\
\hline & HARMONIC & AMPLITUUE & PHASE & VARIATION & ERROR OF \\
\hline $\begin{array}{l}\text { SAMPLE } \\
\text { SIZE }\end{array}$ & $\begin{array}{l}\text { MEAN - M } \\
\text { LDEG } C)^{2}\end{array}$ & $\left.{ }_{\left(D E G^{A}\right.}{ }^{A}()\right)$ & $\begin{array}{l}\text { ANGLE }-C \\
\text { (BADIANS) }\end{array}$ & $\begin{array}{c}\text { EXPLA INED } \\
(8)\end{array}$ & $\begin{array}{l}\text { ESTIMATE } \\
\text { (DEG C) }\end{array}$ \\
\hline
\end{tabular}

0.355

483.3

$\begin{array}{lrrrr}11 & 0.0154 & 0.1502 & 0.202 * & 1.40 \\ 11 & 0.1102 & 4.5000 & 0.719 & 2.92 \\ 11 & 0.0325 & 0.6259 & 0.851 & 0.52 \\ 11 & 0.0135 & 0.4289 & 0.654 & 0.40 \\ 11 & 0.0032 & 0.8548 & 0.193 * & 0.42 \\ 11 & 0.502 & -1.726 & 0.748 * & 13.0 \\ 11 & 0.000 & 0.137 & 0.015 * & 0.6 \\ 11 & -0.0195 & 8.4695 & -0.466 * & 0.96 \\ 11 & -0.0065 & 3.0128 & -0.257 * & 0.63 \\ 11 & 0.427 & 24.401 & 0.813 & 7.9 \\ 11 & 0.084 & 77.258 & 0.154 * & 13.9 \\ 11 & 0.430 & 13.082 & 0.774 & 9.2 \\ 11 & -0.017 & 12.903 & -0.03 \% * & 13.3 \\ 11 & -0.728 & 140.896 & -0.225 * & 82.0 \\ 11 & -0.0000 & 0.1863 & -0.009 * & 0.10\end{array}$

SUMMARY OF HARMONIC ANALYSIS OF STREAM TEMPERATURE

353

9.26

11.62

2.74

89

2.92

SUMMARY UF MAXIMUM AND MINIMUM CONCENTRATIONS OF CONSTITUENTS SAMPLED AT A FREQUENCY OF QUARTERLY (1975 WY)

04040000 -- ONTONAGUN R NR ROCKLAND, MICH

CONSTITUENT


Table 14.--Sumary of measurements at each station--Continued

LAT $46034 M 30 S$ LONG U85D16M1OS DRAINAGE AREA: 790 SO MI 1 2046 SO KM) PERIOD OF RECORD: $10 / 01 / 74-09 / 30 / 75$

STATISTICAL SUMMARY OF SELECTED DISSOLVED CHEMICAL CONSTITUENTS AND REGRESSION RELATIONSHIPS OF CONSTITUENT CONCENTRATIONS TO SPECIFIC CONDUCTANCE

CONSIIIUENI

CONSILIUENI IMGLL OR UNII SHOWN

\begin{tabular}{l}
$S A M P L$ \\
$S 1$ \\
\hline 12 \\
12 \\
12 \\
12 \\
12 \\
12 \\
12 \\
11 \\
10 \\
1 \\
12 \\
11 \\
12 \\
12 \\
12 \\
12 \\
12 \\
12 \\
12 \\
12 \\
12 \\
12 \\
12 \\
12
\end{tabular}

\section{MEAN}

9.67

130.0

920.3

7.46
0.027

0.081

0.437

300.7

5.6

100.0

6.8
19.9

19.9
7.32

7.32
20.12

5.16

1.53

0.79

75.4

0.0

11.42
2.15

2.15
86.0

86.0
102.9

71.7

10.3

2.4
TANDARD

9.87
32.8

1154.2

0.41

0.016

0.165

412.9

3.4

0.0
7.5

35.3

1.67

5.08

1.04
0.31

0.14

17.8

0.0

2.58

0.83
17.0

17.0
24.0

16.7

6.0

0.08

BANGE
0.0
60
281
6.7
0.01
0.02
0.23
8
1
100
1
1
4.2
8.4
2.4
0.8
0.6
44
0
7.1
1.0
47
57
31
0
1
0.1
.1

BEG REGRESSION SAMPLE COEFICIENT, CONSTANT, CORRELATION COEFICIENT, COEFICIENT *Not significant at the 95 percent confidence level.

$\begin{array}{rr}25.5 & \\ 160 & \\ 4500 & 12 \\ 8.1 & 12 \\ 0.07 & 12 \\ 0.15 & 12 \\ 0.78 & 12 \\ 1200 & 11 \\ 11 & \\ 100 & \\ 22 & \\ 120 & \\ 9.5 & 12 \\ 26.0 & 12 \\ 0.7 & 12 \\ 2.0 & 12 \\ 1.1 & 12 \\ 108 & 12 \\ 0 & 12 \\ 16.0 & 12 \\ 4.3 & 12 \\ 108 & 12 \\ 149 & 12 \\ 93 & 12 \\ 20 & 12 \\ 4 & 12 \\ 0.4 & 12\end{array}$

$$
\begin{array}{r}
-28.039 \\
-0.0005 \\
0.00021 \\
0.00028 \\
0.00189 \\
3.387 \\
\\
\\
0.0354 \\
0.1386 \\
0.0255 \\
0.0082 \\
-0.0003 \\
0.459 \\
0.000 \\
0.0514 \\
-0.0079 \\
0.473 \\
0.489 \\
0.452 \\
0.049 \\
0.000 \\
-0.0006
\end{array}
$$

4505.348

7.5178 0.00038 0.04405 0.19195

$-134.403$

$-0.797$

$-0.036^{*}$

0.427 *

$0.198 *$

$0.375 *$

731.2

0.43

0.015

0.048

0.160

$0.278 *$

418.0

DURAILON IABLE OE. DALIY SPECIEIC CONOUCIANCE

UAILY SPECIFIC CONDUCTANCE IN

MICRUMHOS AT 25 DEG C, THAT WAS

EQUALLED UR EXCEEDED FOR THE

$\begin{array}{llllll}18 & -57 & 108 & 203 & 303 & 503\end{array}$

503

\section{$70 \%$}

SAMPLE SLZE $\equiv 160$

2.7156

2.0959

1.8421

0.8312

15.688

0.000

4.7399

3.1633

24.481
39.300

39.300
12.882

3.892

2.417
0.3124

0.694

0.896

0.808

0.867

$-0.072$.

0.846

0.000.

0.653 .

0.915
0.916

0.669

0.889

\begin{tabular}{|c|c|c|c|c|c|}
\hline & & & & & STANDARD \\
\hline & HARMONIC & AMPLITUDE & PHASE & VAKIATION & ERROR OF \\
\hline SAMPLE & MEAN - M & $-A$ & ANGLE - C & EXPLAINED & ESTIMATE \\
\hline SILE_ & 10EG_L) - & $10 E G(1$ & IRAOIANSI & $-(8)$ & $10 E G(1)$ \\
\hline 169 & 9.81 & 12.37 & 2.60 & 90 & 3.25 \\
\hline
\end{tabular}

0.264 .

0.000 *

$-0.250$.

1.26
2.36
0.64
0.16
0.14
10.0
0.0
2.05
0.82
7.1
18.7
8.0
6.0
0.9
0.08

\begin{tabular}{|c|c|c|c|c|c|c|}
\hline \multirow{2}{*}{ CONSTITUENT } & \multicolumn{3}{|c|}{ TOTAL } & \multicolumn{3}{|c|}{ OISSOLVED } \\
\hline & $\begin{array}{c}\text { NO. } \\
\text { SAMPLES }\end{array}$ & $\begin{array}{l}\text { MINIMUM } \\
\text { CONC. }\end{array}$ & $\begin{array}{l}\text { MAXIMUM } \\
\text { CONC. }\end{array}$ & $\begin{array}{l}\text { NO. } \\
\text { SAMPLES }\end{array}$ & $\begin{array}{l}\text { MINIMUM } \\
\text { CONC. }\end{array}$ & $\begin{array}{l}\text { MAXIMUM } \\
\text { CONC. }\end{array}$ \\
\hline \multicolumn{7}{|l|}{ MINGR ELEMENTS: } \\
\hline ARSENIC (AS), UG/L & 4 & 1 & 1 & 4 & 0 & 1 \\
\hline $\begin{array}{l}\text { CADMIUM (CD), UG/L } \\
\text { CHROMIUM (CR), UG/L }\end{array}$ & 4 & 0 & 5 & 4 & 0 & 1 \\
\hline & 4 & 0 & 20 & 4 & 0 & 0 \\
\hline $\begin{array}{l}\text { COBALT }(C O), U G / L \\
\text { COPPER (CU), UG/L }\end{array}$ & 3 & 0 & 1 & 4 & 0 & 1 \\
\hline $\begin{array}{l}\text { COPPER (CU), UG/L } \\
\text { IRON (FE), UG/L }\end{array}$ & 4 & 5 & 13 & 4 & 1 & 10 \\
\hline $\begin{array}{l}\text { IRON (FE), UG/L } \\
\text { LEAD }(P B), U G / L\end{array}$ & 4 & 380 & 670 & 4 & 200 & 440 \\
\hline $\begin{array}{l}\text { LEAD (PB), UG/L } \\
\text { MANGANESE (MN), UG/L }\end{array}$ & 4 & 4 & 51 & 4 & 0 & 7 \\
\hline MANG ANESE (MN), UG/L & 4 & 10 & 40 & 4 & 0 & 13 \\
\hline MERCURY $(H G), U G / L$ & 4 & 0.1 & 0.2 & 4 & 0.1 & 0.1 \\
\hline SELENIUM (SE), UG/L & 4 & 0 & 0 & 4 & 0 & 0 \\
\hline ZINC $(Z N), U G / L$ & 3 & 10 & 40 & 4 & 7 & 20 \\
\hline \multicolumn{7}{|l|}{ PERIPHYTON: } \\
\hline BIOMASS, DRY WT., G/SQ M & 3 & .29 & 9.00 & & & \\
\hline BIOMASS, ASH WT., G/SO M & 3 & .19 & 6.29 & & & \\
\hline CHLOROPHYLL A, MG/SQ M & 3 & .0 & 18.0 & & & \\
\hline CHLOROPHYLL B, MG/SO M & 3 & .0 & 1.0 & & & \\
\hline ORGANIC CARBON, MG/L & 4 & 7.7 & 19.0 & & & \\
\hline
\end{tabular}

$\begin{array}{llllll}204 & 195 & 188 & 175 & 160 & 140\end{array}$

SUMMARY OF HARMONIC ANALYSIS OF STREAM TEMPERATURE

SUMMARY OF MAXIMUM AND MINIMUM CONCENTRATIONS DF CONSTITUENTS

SAMPLED AT A FREQUENCY OF QUARTERLY (1975 WY)

04045500 -- TAHQUAMENON RIVER NR TAHQUAMENON PARADISE, MICH. 
LAT 46029M29S LONG 084025M17S

DRAINAGE AREA:

0 SQ MI

PERIOD OF RECORD: $10 / 01 / 74-09 / 30 / 75$

O SQ KMI

STATISTICAL SUMMARY OF SELECTED DISSOLVED CHEMICAL CONSTITUENTS AND

REGRESSION RELATIONSHIPS OF CONSTITUENT CONCENTRATIUNS TO SPECIFIC CONDUCTANCE

CONSIIIUENI

\begin{tabular}{|c|}
\hline 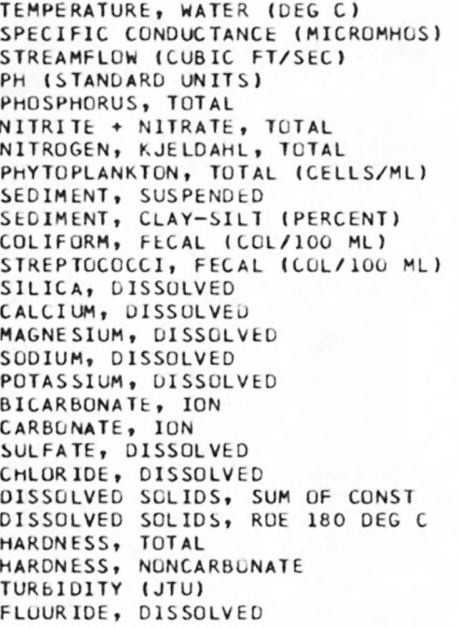 \\
\hline
\end{tabular}

GONSIUIUENI_ $M G \angle L O R$ UNII_SHOWN

SAMP

STANDARD MEAN DEYIALION$$
8.63
$$
89.3 82883.3 7.67 0.012 0.256 0.142 525.0

6.38
6.8
9095.1
0.42
0.021
0.015
0.105
326.4

$$
0.0
$$

80
73000
6.6

73000
6.6
0.00 0.00

0.23

0.00

5.6
15.9

15.9
2.34

13.67

2.92

1.13

0.54

54.8

0.0
3.29

3.29
1.17

1.17
51.5

55.5

46.2

2.3

0.8

14.3

42.6
0.12

0.78

0.31

0.30

0.05

3.5

0.0
0.62

0.62
0.35

1.4

5.9
2.0

2.6

0.6

1
1
2.2
12.0
2.5
0.3
0.5
50
0
2.4
0.5
49
46
43
0
0
0.0

1
1
2.2
12.0
2.5
0.3
0.5
50
0
2.4
0.5
49
46
43
0
0
0.0
${ }^{*}$ Not significant at the 95 percent confidence level.

SAMPLE COEFICIENT, CONSTANT, CORRELATION STANDARD

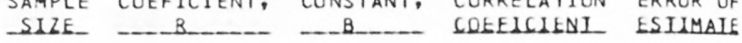
DAILY SPECIFIC CONDUCTANCE IN

MICROMHOS AT 25 DEG C, THAT WAS
EQUALLED OR EXCEEDE FOR THE
INDICATED PERCENTAGE UF TIME

SUMMARY OF HARMONIC ANALYSIS OF STREAM TEMPERATURE

\begin{tabular}{|c|c|c|c|c|c|}
\hline & & & & & STANDARD \\
\hline & HARMONIC & AMPLITUDE & PHASE & VAR IATION & ERROR OF \\
\hline SAMPLE & MEAN - M & $-A$ & ANGLE - C & EXPLAINED & ESTIMATE \\
\hline SIZE_ & $10 E 6 C 1$ & (DEG () & (RADIANSI) & $-13)$ & (DEG_CL \\
\hline 364 & 7.96 & 8.65 & 2.25 & 92 & 1.82 \\
\hline
\end{tabular}

SUMMARY OF MAXIMUM AND MINIMUM CONCENTRATIONS OF CONSTITUENTS SAMPLED AT A FREQUENCY OF QUARTERLY (1975 WY)

04045580 -- ST MARYS RIVER ABOVE SAULT STE MARIE, MICH. .

\begin{tabular}{|c|c|c|c|c|c|c|}
\hline \multirow{2}{*}{ CONSTI TUENT } & \multicolumn{3}{|c|}{ TOTAL } & \multicolumn{3}{|c|}{ DISSOLVED } \\
\hline & $\begin{array}{l}\text { NO. } \\
\text { SAMPLES }\end{array}$ & $\begin{array}{l}\text { MIN IMUM } \\
\text { CONC. }\end{array}$ & $\begin{array}{l}\text { MAXIMUM } \\
\text { CONC. }\end{array}$ & $\begin{array}{l}\text { NO. } \\
\text { SAMPLES }\end{array}$ & $\begin{array}{l}\text { MINIMUM } \\
\text { CONC. }\end{array}$ & $\begin{array}{l}\text { MAXIMUM } \\
\text { CONC. }\end{array}$ \\
\hline \multicolumn{7}{|l|}{ MINOR ELEMENTS: } \\
\hline ARSENIC (AS), UG/L & 5 & 0 & 1 & 5 & 0 & 1 \\
\hline CAUMIUM $(C D), U G / L$ & 3 & 0 & 1 & 5 & 0 & 1 \\
\hline CHROMIUM (CR), UG/L & 5 & 0 & $<10$ & 5 & 0 & 1 \\
\hline COBALT $(C O), U G / L$ & 5 & 0 & 2 & 5 & 0 & 0 \\
\hline COPPER (CU), UG/L & 5 & 6 & 11 & 5 & 1 & 5 \\
\hline IRON (FE), UG/L & 5 & 20 & 250 & 5 & 0 & 10 \\
\hline LEAD $(P B), U G / L$ & 4 & 0 & 12 & 5 & 0 & 8 \\
\hline MANG ANESE $(M N), U G / L$ & 3 & 10 & 20 & 5 & 0 & 36 \\
\hline MERCURY $(H G), U G / L$ & 4 & 0.0 & 0.3 & 5 & 0.0 & 0.4 \\
\hline SELENIUM (SE), UG/L & 5 & 0 & 0 & 5 & 0 & 0 \\
\hline ZINC $(Z N), U G / L$ & 4 & 40 & 70 & 5 & 30 & 60 \\
\hline \multicolumn{7}{|l|}{ PERIPHYTON: } \\
\hline BIOMASS, DRY WT., G/SO M & 5 & 1.50 & 3.50 & & & \\
\hline BIOMASS, ASH WT., G/SO M & 5 & .79 & 2.09 & & & \\
\hline CHLOROPHYLL A, MG/SQ M & 5 & .1 & 4.1 & & & \\
\hline CHLOROPHYLL B, MG/SQ M & 5 & .0 & $\cdot 1$ & & & \\
\hline ORGANIC CARBON, MG/L & 5 & 1.6 & 8.5 & & & \\
\hline
\end{tabular}


LAT 45057MOOS LONG 080D14M54S DRAINAGE AREA: 1450 SQ MI 13756 SQ KMI

PERIOD OF RECORD: $10 / 01 / 74-09 / 30 / 75$

STATISTICAL SUMMARY OF SELECTED DISSOLVED CHEMICAL CONSTITUENTS AND

REGRESSION RELATIONSHIPS OF CONSTITUENT CONCENTRATIONS TO SPECIFIC CONDUCTANCE

CONSIIIUENI

\section{CONSIUIUENI IMG/L OR UNII SHOWN}

\begin{tabular}{c} 
SAMPL \\
SIZE \\
\hline 10 \\
10 \\
10 \\
10 \\
10 \\
10 \\
10 \\
10 \\
10 \\
10 \\
7 \\
8 \\
10 \\
10 \\
10 \\
10 \\
10 \\
10 \\
10 \\
10 \\
10 \\
10 \\
10 \\
10 \\
10 \\
10 \\
10
\end{tabular}

STANDARD

DEYIALION

10.45

170.2

170.2

1765.0
7.57

7.57
0.015

0.164

0.461

2027.0

6.3
98.9

14.9

14.9

27.6

6.48

25.80
5.63

5.63
1.44

0.64

87.3

0.0

19.30

1.77

104.7

113.0

87.5

16.1

5.1
0.22
9.71

29.0

29.0
494.3

494.3
0.34

0.010

0.145

0.305

3015.0

3.9
3.5

3.5
8.5

8.5
52.1

52.1
0.95

0.95
3.33

0.54
0.23

0.23
0.07

0.07
9.3

0.0

3.53

0.26

10.0

12.0
9.9

9.0

2.4
0.10

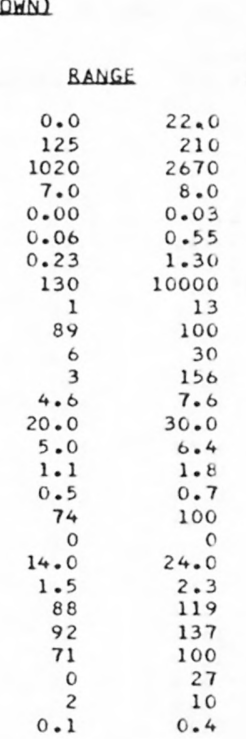

SAMPLE

SIZE.

10

10

\section{QURAIION IABLE OE DALYY SPECIEIC CONOUCIANCE}

DAILY SPECIFIC CONDUCTANCE IN

MICROMHOS AT 25 DEG C. THAT WAS

EQUALLED OR EXCEEDED FCR THE

$\begin{array}{llllll}18 & -52 & 10 z & 20 \% & 30 \% & 50 z \\ 230 & 227 & 220 & 199 & 190 & 175\end{array}$

INOICATED PERCENTAGE OF THE REGRESSION

REGRESS ION SUMYABY COEFICIENT,

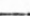

10

10

10

$-11.638$

$-0.00001$

$-0.00203$

$-0.00445$

31.982

ERROR OF

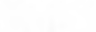

83.6

0.36

0.010

$\begin{array}{rrr}0.51028 & -0.406^{*} & 0.141 \\ 1.21778 & -0.422^{*} & 0.293 \\ 416.254 & 0.307^{*} & 3043.4\end{array}$

$\begin{array}{rrr}0.51028 & -0.406^{*} & 0.141 \\ 1.21778 & -0.422^{*} & 0.293 \\ 416.254 & 0.307^{*} & 3043.4\end{array}$

10
10
10
10
10
10
10
10
10
10
10
10
10
10
10

$$
\begin{array}{r}
0.0177 \\
0.0812 \\
0.0163 \\
0.0047 \\
0.0019 \\
0.238 \\
0.000 \\
0.0471 \\
0.0011 \\
0.285 \\
0.233 \\
0.259 \\
0.066 \\
-0.021
\end{array}
$$$$
3.4651
$$$$
\begin{array}{r}
11.9829 \\
2.8609
\end{array}
$$$$
\begin{aligned}
& 2.8609 \\
& 0.6476
\end{aligned}
$$$$
\begin{aligned}
& 0.6476 \\
& 0.3102
\end{aligned}
$$$$
\begin{aligned}
& 0.3102 \\
& 46.792
\end{aligned}
$$$$
0.000
$$$$
11.2814
$$$$
1.5746
$$$$
1.5746
$$$$
\begin{aligned}
& 56.245 \\
& 73.291
\end{aligned}
$$$$
43.391
$$$$
\begin{array}{r}
4.391 \\
4.914
\end{array}
$$$$
\begin{array}{r}
4.914 \\
8.714
\end{array}
$$$$
0.2886
$$

$0.539^{*}$

0.707

\begin{tabular}{|c|c|c|c|c|c|}
\hline & & & & & STAND ARD \\
\hline & HARMONIC & AMPLITUDE & PHASE & VARIATION & ERRCR OF \\
\hline SAMPLE & MEAN - M & $-A$ & ANGLE - C & EXPLAINED & ESTIMATE \\
\hline SILE_- & LDEG C) & DOEG C & (RADIANS) & -181 & LEE C \\
\hline 125 & 7.01 & 12.26 & 2.69 & 89 & 2.44 \\
\hline
\end{tabular}

0.870
0.581 .

0.802

0.740

$0.000^{*}$

\begin{tabular}{|c|c|c|c|c|c|c|}
\hline \multirow{2}{*}{ CONSTITUENT } & \multicolumn{3}{|c|}{ TOTAL } & \multicolumn{3}{|c|}{ DISSOLVED } \\
\hline & $\begin{array}{l}\text { NO. } \\
\text { SAMPLES }\end{array}$ & $\begin{array}{l}\text { MINIMUM } \\
\text { CONC. }\end{array}$ & $\begin{array}{l}\text { MAXIMUM } \\
\text { CONC. }\end{array}$ & $\begin{array}{l}\text { NO. } \\
\text { SAMPLES }\end{array}$ & $\begin{array}{l}\text { MINIMUM } \\
\text { CONC. }\end{array}$ & $\begin{array}{l}\text { MAXIMUM } \\
\text { CONC. }\end{array}$ \\
\hline \multicolumn{7}{|l|}{ MINOR ELEMENTS: } \\
\hline ARSENIC (AS), UG/L & 4 & 0 & 1 & 4 & 0 & 1 \\
\hline CAUMIUM $(C D), U G / L$ & 1 & 3 & & 4 & 1 & 2 \\
\hline CHROMIUM (CR), UG/L & 4 & $<10$ & $<10$ & 4 & 0 & 0 \\
\hline CUBALT $(C O), U G / L$ & 4 & 0 & 3 & 4 & 0 & 1 \\
\hline COPPER (CU), UG/L & 4 & 8 & 12 & 4 & 2 & 8 \\
\hline IRON (FE), UG/L & 4 & 880 & 1500 & 4 & 400 & 690 \\
\hline LEAD $(P B), U G / L$ & 3 & 8 & 90 & 4 & 1 & 3 \\
\hline MANGANESE (MN), UG/L & 4 & 18 & 70 & 4 & 0 & 40 \\
\hline MERCURY $(H G), U G / L$ & 3 & 0.0 & 0.1 & 4 & 0.0 & 0.2 \\
\hline SELENIUM (SE), UG/L & 4 & 0 & 0 & 4 & 0 & 0 \\
\hline ZINC $(Z N), U G / L$ & 4 & 40 & 110 & 4 & 10 & 20 \\
\hline \multicolumn{7}{|l|}{ PERIPHYTON: } \\
\hline BIOMASS, DRY WT., G/SO M & 2 & 2.69 & 0.09 & & & \\
\hline BIOMASS, ASH WT., G/SO M & 2 & 1.69 & 3.29 & & & \\
\hline CHLOROPHYLL A, MG/SQ M & 2 & 1.1 & 5.8 & & & \\
\hline CHLOROPHYLL B, MG/SQ M & 2 & .2 & 1.0 & & & \\
\hline ORGANIC CARBON, MG/L & 4 & 7.0 & 11.0 & & & \\
\hline
\end{tabular}

0.386 *

$0.127^{\circ}$

0.821 *

0.562
0.754

0.754
0.211 .

0.211
-0.254
-0.113

$-0.113$. SUMMARY UF HARMUNIC ANALYSIS OF STREAM TEMPERATURE
EORM OF EQUAION: I. $101 \equiv M+A+$ SINI. $E I 72 *-0+C)$

SUMMARY OF MAXIMUM AND MINIMUM CONCENTRATIONS OF CONSTITUENTS SAMPLED AT A FREQUENCY OF QUARTERLY (1975 WY)

04057005 -- MANISTIQUE RIVER AT MANISTIQUE, MICH. • 
AT $45054 M 31 S$ LONG $087012 M 49 S$

RAINAGE AREA: 870 SO MI 1 2253 SQ KMI

DERIOD OF RECORD: 10/01/74-09/30/75

STATISTICAL SUMMARY OF SELECTED DISSOLVED CHEMICAL CONSTITUENTS AND

REGRESSION RELATIONSHIPS OF CONSTITUENT CONCENTRATIONS TO SPECIFIC CONDUCTANCE

CUNSILIUENI

CONSILIUENI IMGLL_OR UNII SHOWNL

SAMPLE

SIZE

TEMPERATURE, WATER (DEG C)

SPECIFIC CUNDUCTANCE (MICROMHOS)

STREAMFLOW (CUBIC FT/SEC)

PH (STANDARO UNITS)

PHOSPHORUS, TOTAL

NITRITE + NITRATE, TOTAL

NITRUGEN, KJELDAHI, TOTAL

PHYTOPLANKTON, TOTAL (CELLS/ML)

PHYTIMENT, SUSPENUED

SEDIMENT, SUSPENUED (PERCENT)

COLIMENT, CLAY-SILT (PERCENT)

STREPTOCUCCI, FECAL (COL/100 ML)

SILICA, UISSOLVED

CALCIUM, OISSOLVED

MAGNE SIUM, DISSULVED

SODIUM, DISSOLVED

PCTASSIUM, DISSOLVED

BICAREONATE, ION

CARBONATE, ION

SULFATE, DISSCLVED

CHLORIDE, DISSOLVED

DISSOLVED SOLIDS, SUM OF CONST

DISSOLVED SCLIDS, ROE 180 DEG

HARDNESS, TOTAL

HARDNESS, NONCARBONATE

TURBIDITY (JTU)

FLOURIDE, DISSOLVED

*Not significant at the 95 percent confidence level.
STANDARD

MEAN DEYIAIION

$8.45 \quad 8.94$

$190 \cdot 1$

062.5

7.81

0.013

0.174

0.374

1296.0

3.6

100.0

7.5
116.0

116.0
7.68

22.90

9.09

1.02

107.02

107.2
0.6

0.56
.50

2.72

108.8

112.9

94.8

6.4

1.8

37.9
456.9

456.9
0.53

0.005

0.116

0.082

1575.7

3.0
0.0

0.0
6.0

269.5

1.85

3.63

1.57

0.91

0.19

19.4

1.3
1.58

1.58
0.50

1.50
17.8

16.1

15.9

5.6

0.15

NU
BANGE
0.0
125
233
6.9
0.01
0.00
0.25
510
0
100
1
1
4.5
14.0
5.6
1.6
0.7
66
0
7.1
1.8
68
82
58
0
1
0.0$$
\begin{array}{r} 
\\
\\
22.5 \\
250 \\
1760 \\
8.5 \\
0.02 \\
0.37 \\
0.51 \\
5700 \\
10 \\
100 \\
20 \\
880 \\
9.7 \\
28.0 \\
11.0 \\
4.3 \\
1.3 \\
132 \\
124 \\
3.5 \\
130 \\
127 \\
120 \\
16 \\
3 \\
0.5 \\
\end{array}
$$

SAMPLE SIZE

REGRESSION BEGRESSION SUMMABY

CDEFICIENT, CONSTANT, CURRELATIUN - B... COEEICIENI. STANDARD
ERROR OF ESIUMAIE

22.5

1760

0.02

0.51

5700

9

$-9.772$

$-0.0010$

$-0.00003$

0.00168

$-0.00061$

$$
\begin{array}{r}
2584.017 \\
7.9965 \\
0.01988 \\
-0.14509 \\
0.48774
\end{array}
$$

4074.083

$-0.765$

$-0.067$.

0.542 *

$-0.276$.

$-0.316$.

0.60

0.005

0.106

0.080

1668.9

20
880

$$
\begin{array}{r}
20 \\
880 \\
98
\end{array}
$$

$\begin{array}{lll}9.7 & 9 & 0.0452\end{array}$

0.0452
0.0730

0.0381

0.0193

0.0029

0.454
-0.008

$-0.008$

0.0202

0.0056
0.432

0.432
0.303

0.347

$-0.018$

$-0.001$

$-0.0010$
0.880

0.730
0.883

0.896

0.694

0.844 .

$-0.202$

0.543 "

0.401
0.872

0.700

0.793

$-0.114^{*}$

-0.051 .

$-0.250^{*}$

DAILY SPECIFIC CONDUCTANCE IN

MICKOMHUS AT 25 DEG C, THAT WAS
EQUALLED OR EXCEEDED FOR THE

$18 \quad-5 \% \quad 203$

202

302502

210

SAMPLE SIZE $=233$
$70 \%$ 20\% $25 \%$ 29\%

INDICATED PERCENTAGE OF TIME

332

\begin{tabular}{|c|c|c|c|c|c|}
\hline & & & & & STANDARD \\
\hline & HARMONIC & AMPLITUDE & PHASE & VARIATION & ERROR OF \\
\hline SAMPLE & MEAN - $M$ & $-A$ & ANGLE - C & EXPLAINED & ESTIMATE \\
\hline SIZE. & 1DEG 61 & IDEG $C 1$ & (BADIANS) & -131 & LEE 61 \\
\hline 227 & 10.13 & 15.08 & 2.67 & 87 & 3.93 \\
\hline
\end{tabular}

282

200

$160 \quad 145$

SUMMARY OF HARMONIC ANALYSIS OF STREAM TEMPERATURE

SUMMARY OF MAXIMUM AND MINIMUM CONCENTRATIONS CF CONSTITUENTS SAMPLED AT A FREQUENCY OF QUARTERLY (1975 WY)

04059000 -- ESCANABA RIVER AT CORNELL, MICH. .

CONSTITUENT
SAMPLES


Table 14.--Summary of measurements at each station--Continued

LAT 45D45M20S LONG 087012M05S

DRAINAGE AREA: 450 SQ MI 11166 SQ KMI

PERIOD OF RECORD: $10 / 01 / 74-09 / 30 / 75$

STATISTICAL SUMMARY OF SELECTED DISSOLVED CHEMICAL CONSTITUENTS AND REGRESSION RELATIONSHIPS OF CONSTITUENT CONCENTRATIONS TO SPECIFIC CONOUCTANCE

CONSIUIUENI

CONSILIUENI_LGLL OB UNII SHOWN

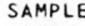

SIZE

\section{ME}

TEMPERATURE, WATER (DEG C) SPECIFIC CONDUCTANCE (MICROMHOS) STREAMFLOW (CUBIC FT/SEC)

PH ISTANDARD UNITS

PHOSPHORUS, TOTAL

NITRITE + NITRATE, TOTAL

NITROGEN, KJELDAHL, TOTAL

PHYTOPLANKTON, TOTAL (CELLS/ML)

SEDIMENT, SUSPENDED

SEDIMENT, CLAY-SILT (PERCENT)

COLIFURM, FECAL (COL/100 ML)

STREPTOCOCCI, FECAL (COL/100 ML)

SILICA, DISSOLVED

CALCIUM, DISSOLVED

MAGNESIUM, DISSULVEO

SODIUM, DISSOLVED

POTASSIUM, DISSOLVED

BICARBONATE, ION

CARBONATE, ION

SULFATE, DISSOLVED

CHLORIDE, UISSOLVED

DISSOLVED SOLIDS, SUM OF CONST

DISSOLVED SOLIDS, ROE 180 DEG C

HARDNESS, TOTAL

HARDNESS, NONCARBONATE

TURBIDITY (JTU)

FLOURIDE, DISSOLVED

\section{STANDARD}

8.30

290.5

313.2

8.03

0.006

0.093

0.379

562.1

5.3

5.3
95.3

15.9

45.8

7.51

42.30

17.50

1.16

0.74

203.1

1.0

9.65

2.04

182.0

181.4

177.0
9.1

1.06
0.21

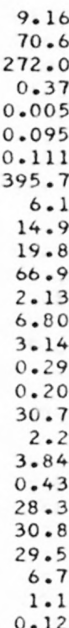

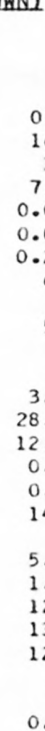
BEGB REGRESSION

SAMPLE

BANGE

SIZE COEFICIENT, ESS ION SUMMARY

- R _ - B

CORRELATION $0.0 \quad 22.0$ $\begin{array}{rr}165 & 390 \\ 35 & 847 \\ 7.4 & 8.5 \\ 0.00 & 0.01\end{array}$ 0.01 0.56 1300

20 100
64 64
220

220
10.0
44.0

44.010

21.0

1.8

1.210

$236 \quad 10$

$\begin{array}{rr}19.0 & 10 \\ 2.5 & 10\end{array}$

$\begin{array}{ll}2.5 & 10 \\ 210 & 10\end{array}$

$\begin{array}{ll}210 & 10 \\ 221 & 10\end{array}$

$210 \quad 10$

$\begin{array}{rr}19 & 10 \\ 3 & 10\end{array}$

0.310 *Not significant at the 95 percent confidence level.

DAILY SPECIFIC DURAIION IABLE_OE DAILY SPECIEIC CONDUCIANCE MICROMHOS AT 25 DEG C, THAT WAS EOUALLED OR EXCEEDED FOR THE

$\begin{array}{llllll}18 & -58 & 10 \% & 20 \% & 30 \% & 50 \% \\ 395 & 380 & 370 & 360 & 354 & 322\end{array}$

\begin{tabular}{lllr} 
& \multicolumn{3}{l}{ SAMPLE_SIZE $\equiv 302$} \\
703 & $20 \%$ & $25 \%$ & 992 \\
284 & 224 & 199 & 174
\end{tabular}

SUMMARY OF HARMONIC ANALYSIS OF STREAM TEMPERATURE

EORM OF EQUALION: IOID) $=M+A *$ SING.0172*D+CI

\begin{tabular}{|c|c|c|c|c|c|}
\hline & & & & & STANDARD \\
\hline & HARMONIC & AMPLITUDE & PHASE & VARIATION & ERROR OF \\
\hline SAMPLE & MEAN - M & $-A$ & ANGLE - C & EXPLAINED & ESTIMATE \\
\hline SIZE. & COEG 61 & DEEG $(1)$ & IRAOIANSI & $-(z)$ & (DEG_C) \\
\hline 292 & 9.65 & 11.28 & 2.06 & 89 & 3.07 \\
\hline
\end{tabular}

SUMMARY OF MAXIMUM AND MINIMUM CONCENTRATIONS OF CONSTITUENTS SAMPLED AT A FREQUENCY OF QUARTERLY (1975 WY)

04059500 -- FORD RIVER NR HYDE, MICH.

\begin{tabular}{|c|c|c|c|c|c|c|}
\hline \multirow{2}{*}{ CONSTITUENT } & \multicolumn{3}{|c|}{ TOTAL } & \multicolumn{3}{|c|}{ DISSOLVED } \\
\hline & $\begin{array}{l}\text { NO. } \\
\text { SAMPLES }\end{array}$ & $\begin{array}{l}\text { MIN IMUM } \\
\text { CONC. }\end{array}$ & $\begin{array}{l}\text { MAXIMUM } \\
\text { CONC. }\end{array}$ & $\begin{array}{l}\text { NO. } \\
\text { SAMPLES }\end{array}$ & $\begin{array}{l}\text { MINIMUM } \\
\text { CONC. }\end{array}$ & $\begin{array}{l}\text { MAXIMUM } \\
\text { CONC. }\end{array}$ \\
\hline \multicolumn{7}{|l|}{ MINOR ELEMENTS: } \\
\hline ARSENIC (AS), UG/L & 4 & 0 & 1 & 4 & 0 & 1 \\
\hline CADMIUM $(C D)$, UG & 3 & 0 & 3 & 4 & 0 & 2 \\
\hline CHROMIUM (CR), UG/L & 4 & $<10$ & $<10$ & 4 & 0 & 0 \\
\hline COBALT $(C O), U G / L$ & 3 & 0 & 2 & 4 & 0 & 2 \\
\hline COPPER (CU), UG/L & 3 & 5 & 7 & 4 & 1 & 4 \\
\hline IRON (FE), UG/L & 4 & 120 & 260 & 4 & 70 & 160 \\
\hline LEAD $(P B), U G / L$ & 2 & 1 & 14 & 4 & 1 & 4 \\
\hline MANG ANESE (MN), UG/L & 4 & 14 & 40 & 4 & 0 & 30 \\
\hline MERCURY (HG), UG/L & 3 & 0.0 & 0.2 & 4 & 0.0 & 0.2 \\
\hline SELENIUM (SE), UG/L & 4 & 0 & 1 & 4 & 0 & 1 \\
\hline ZINC $(Z N), U G / L$ & 3 & 30 & 50 & 4 & 0 & 10 \\
\hline \multicolumn{7}{|l|}{ PERIPHYTON: } \\
\hline BIOMASS, ORY WT., G/SQ M & 2 & 1.39 & 11.00 & & & \\
\hline BIOMASS, ASH WT., G/SO M & 2 & 2.79 & 9.00 & & & \\
\hline CHLOROPHYLL A, MG/SO M & 2 & .0 & 3.7 & & & \\
\hline CHLOROPHYLL B, MG/SO M & 2 & .0 & .1 & & & \\
\hline ORGANIC CARBON, MG/L & 4 & 11.0 & 16.0 & & & \\
\hline
\end{tabular}


Table 14.--Summary of measurements at each station--Continued

STATION NUMBER: 04085000 NAME: FOX RIVER AT WRIGHTSTOWN, WIS.

LAT 44D19M36S LONG $088009 M 54 S$

DRAINAGE AREA: $6210 \mathrm{SQ}$ MI I 16084 SO KMI

DRAINAGE AREA: $\begin{aligned} & 6210 \text { SQ MI } 110084 \\ & \text { PERIOD OF RECORD: } 10 / 01 / 74-09 / 30 / 75\end{aligned}$

STATISTICAL SUMMARY OF SELECTED DISSOLVED CHEMICAL CONSTITUENTS AND

REGRESSION RELATIONSHIPS OF CONSTITUENT CONCENTRATIONS TO SPECIFIC CONDUCTANCE

CONSIIUENI

\begin{tabular}{c} 
CONS \\
SAM \\
SI \\
\hline 1 \\
1 \\
1 \\
1 \\
1 \\
1 \\
1 \\
1 \\
1 \\
1 \\
1 \\
1 \\
1 \\
1 \\
1 \\
1 \\
1 \\
1 \\
12 \\
1 \\
1 \\
12 \\
12 \\
12 \\
12 \\
12
\end{tabular}

GOSIUUENI IME $\angle 1$ OR UNII SHOWNI

SAMPLE STANDARD

MEAN DEXIAIION

10.58

393.3

4480.0

7.67

0.113

0.207

91829.1

16.0

493.4

103.1

7.44

39.50
19.50

19.50
11.07

2.47

185.8

0.0

27.25

14.42

213.8

237.7
179.2

179.2
27.3

27.3
12.8

0.33

\subsection{5}

47.2
2897.3

2897.3
0.34

0.067

0.200
0.527

162045.9

$12 \cdot 1$

590.6

590.6
58.4

58.4
2.76

5.05

2.32

2.81

0.30

25.0

3.77

3.77

3.15

20.4

34.9

21.5
6.2

8.7

0.13

HARDNESS, NONCARBONATE

TURBIDITY (JTU)
FLUURIDE, DISSOLVED

*Not significart at the 95 percent confidence level.

\begin{tabular}{|c|c|}
\hline \multicolumn{2}{|c|}{ BANGE } \\
\hline 0.5 & 27 \\
\hline $\begin{array}{r}325 \\
1740\end{array}$ & \\
\hline 1740 & 117 \\
\hline 7.1 & \\
\hline 0.01 & \\
\hline 0.00 & \\
\hline 0.69 & 2. \\
\hline 750 & 4600 \\
\hline 5 & \\
\hline 57 & 20 \\
\hline 0 & \\
\hline 2.8 & 13 \\
\hline 32.0 & $4 c$ \\
\hline 16.0 & 23 \\
\hline 6.9 & 16 \\
\hline 2.0 & 2 \\
\hline 142 & 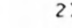 \\
\hline 0 & \\
\hline 20.0 & 34 \\
\hline 10.0 & $2 c$ \\
\hline 181 & \\
\hline 208 & 3 \\
\hline 150 & \\
\hline 20 & \\
\hline 0.1 & \\
\hline
\end{tabular}

\begin{tabular}{l} 
SAMPLE \\
SIZE \\
\hline \\
12 \\
12 \\
12 \\
12 \\
11 \\
12
\end{tabular}

REGRESSIOIN

COEFICIENT, CONSTANT, CORRELATIUN ERROR CF - B _-B__ COEEIGIENI ESIIMAIE

$\begin{array}{rrrr}-22.156 & 13194.805 & -0.361^{*} & 2833.7 \\ -0.0031 & 8.8945 & -0.432^{*} & 0.32 \\ -0.00038 & 0.26307 & -0.267^{*} & 0.068 \\ 0.00130 & -0.30430 & 0.307^{*} & 0.200 \\ -0.00146 & 1.77026 & -0.131^{*} & 0.551 \\ -1172.696 & 553089.563 & -0.342^{*} & 159726.7\end{array}$

DURAILON_IABLE_OF_DAILY SPEGIEIC CONDUCIANGE

DAILY SPECIFIC CONDUCTANCE IN

MICROMHOS AT 25 DEG C, THAT WAS

EQUALLED OR EXCEEDED FOR THE

$\begin{array}{llllll}17 & 52 & 10 \% & 20 \% & 30 \% & 50 \% \\ 630 & 460 & 430 & 390 & 380 & 360\end{array}$

3000

180
13.0

$\begin{array}{ll}13.0 & 12 \\ 46.0 & 12\end{array}$

$23.0 \quad 12$

$16.0 \quad 12$

$2.9 \quad 12$

$\begin{array}{rr}0 & 12 \\ 34.0 & 12\end{array}$

$20.0 \quad 12$

$238 \quad 12$

$210 \quad 12$

$38 \quad 12$

$\begin{array}{rr}35 & 12 \\ 0.5 & 12\end{array}$

$-1172.696$

53089.563

0.0281
0.0671
0.0271
0.0131
-0.0008
0.260
0.000
0.0296
0.0234
0.317
0.257
0.301
0.081
-0.086
-0.0004

-3.6179
13.1077
8.8308
5.9112
2.7904
83.607
0.000
15.6181
5.2181
89.306
136.697
60.709
-4.677
46.683
0.4991

$0.481^{*}$

0.627

$0.553 *$

$0.220 *$

0.490

$0.000 *$

0.370 *

0.351

0.731

0.346

0.661 .

$0.614 *$

-0.468
-0.153

2.5

70\% 20\% 25\% $22 \%$

SUMMARY OF HARMONIC ANALYSIS OF STREAM TEMPERATURE

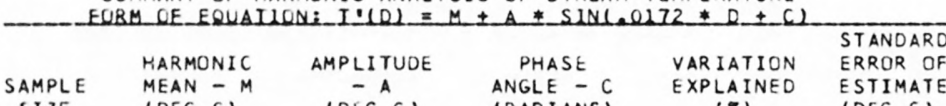

SAMPLE MEAN - M A ANGLE - C EXPLAINED ESTIMATE

$\begin{array}{llllll}204 & 8.15 & 16.18 & 2.74 & 92 & 2.56\end{array}$

SUMMARY OF MAXIMUM AND MINIMUM CONCENTRATIONS OF CCNSTITUENTS

SAMPLED AT A FREQUENCY OF QUARTERLY (1975 WY)

04085000 -- FOX RIVER AT WRIGHTSTOWN, WIS.

\begin{tabular}{|c|c|c|c|c|c|c|}
\hline \multirow{2}{*}{ CONSTITUENT } & \multicolumn{3}{|c|}{ TOTAL } & \multicolumn{3}{|c|}{ DISSOLVED } \\
\hline & $\begin{array}{l}\text { NO. } \\
\text { SAMPLES }\end{array}$ & $\begin{array}{l}\text { MIN IMUM } \\
\text { CONC. }\end{array}$ & $\begin{array}{l}\text { MAXIMUM } \\
\text { CONC. }\end{array}$ & $\begin{array}{l}\text { NO. } \\
\text { SAMPLES }\end{array}$ & $\begin{array}{l}\text { MINIMUM } \\
\text { CONC. }\end{array}$ & $\begin{array}{l}\text { MAXIMUM } \\
\text { CONC. }\end{array}$ \\
\hline \multicolumn{7}{|l|}{ MINOR ELEMENTS: } \\
\hline ARSENIC (AS), UG/L & 2 & 1 & 2 & 4 & 0 & 1 \\
\hline CADMIUM $(C D)$, UG/L & 4 & 0 & 2 & 4 & 0 & 0 \\
\hline CHROMIUM (CR), UG/L & 4 & $<10$ & 10 & 4 & 0 & 3 \\
\hline COBALT $(C O)$, UG/L & 4 & 0 & 1 & 4 & 0 & 1 \\
\hline COPPER (CU), UG/L & 4 & 6 & 12 & 4 & 1 & 2 \\
\hline IRON $(F E), U G / L$ & 4 & 180 & 400 & 4 & 10 & 160 \\
\hline LEAD $(P B), U G / L$ & 4 & 3 & 15 & 4 & 0 & 8 \\
\hline MANGANESE (MN), UG/L & 4 & 0 & 90 & 4 & 10 & 70 \\
\hline MERCURY $(H G), U G / L$ & 4 & 0.0 & 0.2 & 4 & 0.0 & 0.1 \\
\hline SELENIUM (SE), UG/L & 4 & 0 & 0 & 4 & 0 & 0 \\
\hline ZINC $(Z N), U G / L$ & 4 & 20 & 60 & 4 & 0 & 10 \\
\hline \multicolumn{7}{|l|}{ PERIPHYTON: } \\
\hline BIUMASS, ORY WT., G/SQ M & 3 & 5.19 & 12.00 & & & \\
\hline BIOMASS, ASH WT,, G/SQ M & 3 & 1.50 & 5.50 & & & \\
\hline CHLOROPHYLL A, MG/SQ M & 3 & 1.0 & 4.5 & & & \\
\hline CHLOROPHYLL B, MG/SQ M & 3 & .1 & .5 & & & \\
\hline ORGANIC CARBON, MG/L & 4 & 8.0 & $22 \cdot 0$ & & & \\
\hline
\end{tabular}


LAT 43006MOOS LONG $087054 M 32 S$

$\begin{array}{ll}\text { DRAINAGE AREA: } & 686 \text { SQ MI } 11177 \\ \text { PERIOD OF RECORD: } & 10 / 01 / 74-09 / 30 / 7\end{array}$

$087054 M 32 S$
$686 \mathrm{SQ} \mathrm{MI}$

1777 SQ KM

STATISTICAL SUMMARY OF SELECTED DISSOLVED CHEMICAL CONSTITUENTS AND

REGRESSION RELATIONSHIPS OF CONSTITUENT CONCENTRATIONS TO SPECIFIC CONDUCTANCE

CONSIUIUENI

CONSILUUENI IMGCL OB UNII SHOWNI

TEMPERATURE, WATER (OEG C)
SPECIFIC CONDUCTANCE (MICROMHOS)
STREAMFLOW (CUBIC FT/SEC)
PH (STANDARD UNITS)
PHOSPHORUS, TOTAL
NITRITE, NITRATE, TOTAL
NITROGEN, KJELDAHL, TOTAL
PHYTOPLANKTON, TOTAL (CELLS/ML)
SEDIMENT, SUSPENDED
SEDIMENT, CLAY-SILT (PERCENT)
COLIFORM, FECAL (COL/IOO ML)
STREPTOCOCCI, FECAL (COL/IOO ML)
SILICA, DISSOLVED
CALCIUM, DISSOLVED
MAGNESIUM, DISSOLVED
SODIUM, DISSOLVED
POTASSIUM, DISSOLVED
BICARBONATE, ION
CARBONATE, ION
SULFATE, DISSOLVED
CHLORIDE, DISSOLVED
DISSOLVED SOLIDS, SUM OF CONST
DISSOLVED SOLIDS, ROE I8O DEG C
HARDNESS, TOTAL
HARDNESS, NONCARBONATE
TURBIDITY (JTU)
FLOURIOE, DISSOLVED

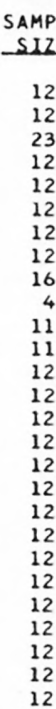

\section{STANDARD}

DEVIAIION

11.08

612.9
725.6

8.11

0.174

0.174
0.885

1.416

16435.8

42.8
59.5

59.5
234.9

7234.9

3216.3

60.33

32.33

32.33
24.38

3.09

277.3

4.8
37.17

37.17
43.67

43.67
348.3

378.5

283.3

48.3
20.8
10.75

134.9

1076.6

0.41

0.064

0.743
0.336

17349.4

41.4
24.4

24.4
7556.2

8922.6

922.6
3.66

3.06
13.04

13.04
8.18

13.06
0.68

0.68
68.3

9.7

9.85
21.84

21.84
79.2

80.7

63.4

14.9

23.8
0.10

${ }^{*}$ Not significant at the 95 percent confidence level.

DURAIION IABLE OF DAILY SPECIEIC CONOUCIANCE

OAILY SPECIFIC CONDUCTANCE IN

EOUALLED AR 25 DEG C, THAT HAS

INDICATED PERCENTAGE OF TIME

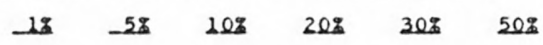

913
BANGE

0.0
330
113
7.5
0.09
0.00
0.93

0.93
730

6
34
1

1
20
0.1

0.1211 .0

$14.0 \quad 41.0$

$7.5 \quad 58.0$

2.0

0

20.0

15.0
163

193

140

29

4
0.2

24.0

800

3850
8.7

0.32

1.90

90

58000

000

100.0

437 \begin{tabular}{ll} 
& \multicolumn{2}{c}{ REGRESSION SUMUAB } \\
REGRESSION \\
SIZE
\end{tabular}

2.00
49000
181
90

12

$58.0 \quad 12$

$\begin{array}{ll}4.0 & 12\end{array}$

379
30 12

$50.0 \quad 12$

$488 \quad 12$

$360 \quad 12$

$70 \quad 12$

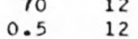

$\begin{array}{lr}12 & -5.207 \\ 12 & 0.0006 \\ 12 & -0.00012 \\ 12 & 0.00165 \\ 12 & -0.00034 \\ 12 & -15.722\end{array}$

7.7586

0.24978

$-0.12485$

1.62119

26072.004

12
12
12
12
12
12
12
12
12
12
12
12
12
12
12

$0.189^{*}$

$-0.260^{*}$

$0.299^{*}$

-0.122 *

STANDARD

ERROR OF

ESIIMAIE

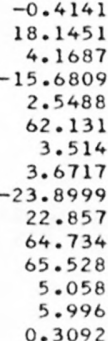

$0.356 *$

0.712

0.757

0.675

0.177 *

0.693

$0.030 *$

0.748

0.681

0.904

0.856

0.756

0.637

0.137.

$0.137 *$
905.4

0.42

0.065

0.743

18059.5

SUMMARY OF HARMONIC ANALYSIS OF STREAM TEMPERATURE

\begin{tabular}{|c|c|c|c|c|c|}
\hline & & & & & STANDARD \\
\hline $\begin{array}{l}\text { SAMPLE } \\
\text { SUZE. }\end{array}$ & $\begin{array}{l}\text { HARMONIC } \\
\text { MEAN - M } \\
\text { WEEGE) }\end{array}$ & $\begin{array}{c}\text { AMPLI TUDE } \\
-\bar{A} \\
\text { (DEG C) }\end{array}$ & $\begin{array}{l}\text { PHASE } \\
\text { ANGLE - C } \\
\text { (RADLANS) }\end{array}$ & $\begin{array}{l}\text { VAR IATION } \\
\text { EXPLAINED } \\
(\delta)\end{array}$ & $\begin{array}{l}\text { ERROR OF } \\
\text { ESTIMATE } \\
\text { (DEG C) }\end{array}$ \\
\hline 142 & 11.10 & 12.92 & 2.69 & 92 & 2.06 \\
\hline
\end{tabular}

SUMMARY OF MAXIMUM AND MINIMUM CONCENTRATIONS OF CONSTITUENTS

SAMPLED AT A FREQUENCY OF QUARTERLY (1975 WY)

04087000 -- MILWAUKEE RIVER AT MILWAUKEE, WIS.

\begin{tabular}{|c|c|c|c|c|c|c|}
\hline \multirow{2}{*}{ CONSTIITUENT } & \multicolumn{3}{|c|}{ TOTAL } & \multicolumn{3}{|c|}{ DISSOLVED } \\
\hline & $\begin{array}{l}\text { NO. } \\
\text { SAMPLES }\end{array}$ & $\begin{array}{l}\text { MINIMUM } \\
\text { CONC. }\end{array}$ & $\begin{array}{l}\text { MAXIMUM } \\
\text { CONC. }\end{array}$ & $\begin{array}{l}\text { NO. } \\
\text { SAMPLES }\end{array}$ & $\begin{array}{l}\text { MINIMUM } \\
\text { CONC. }\end{array}$ & $\begin{array}{l}\text { MAXIMUM } \\
\text { CONC. }\end{array}$ \\
\hline \multicolumn{7}{|l|}{ MINOR ELEMENTS: } \\
\hline ARSENIC (AS), UG/L & 4 & 3 & 5 & 4 & 2 & 4 \\
\hline CADMIUM $(C D), U G / L$ & 3 & 0 & 1 & 4 & 0 & 0 \\
\hline CHROMIUM (CR), UG/L & 3 & 0 & $<10$ & 4 & 0 & 1 \\
\hline COBALT $(C O), U G / L$ & 3 & 1 & 3 & 4 & 0 & 5 \\
\hline COPPER (CU), UG/L & 3 & 8 & 20 & 4 & 1 & 4 \\
\hline IRON $(F E), U G / L$ & 3 & 410 & 3700 & 4 & 50 & 120 \\
\hline$L E A D(P B), U G / L$ & 3 & 14 & 22 & 4 & 0 & 4 \\
\hline MANG ANESE (MN), UG/L & 3 & 60 & 210 & 4 & 10 & 47 \\
\hline MERCURY $(H G), U G / L$ & 3 & 0.0 & 0.3 & 4 & 0.0 & 0.3 \\
\hline SELENIUM $(S E), U G / L$ & 3 & 0 & 1 & 4 & 0 & 1 \\
\hline$Z I N C(Z N), U G / L$ & 3 & 40 & 80 & 4 & 0 & 40 \\
\hline \multicolumn{7}{|l|}{ PERIPHYTON: } \\
\hline BIOMASS, DRY WT., G/SQ M & 3 & .19 & 3.09 & & & \\
\hline BIOMASS, ASH WT., G/SO M & 3 & .19 & 1.50 & & & \\
\hline CHLOROPHYLL A, MG/SQ M & 3 & .0 & 13.0 & & & \\
\hline CHLOROPHYLL B, MG/SQ M & 3 & .0 & 1.3 & & & \\
\hline ORGANIC CARBON, MG/L & 4 & 13.0 & 18.0 & & & \\
\hline
\end{tabular}


LAT 42D38MSOS LONG 086D11M53S

DRAINAGE AREA: 2020 SQ MI 115232 SQ KMI
PERIOD OF RECORD: $10 / 01 / 74-09 / 30 / 75$

STATISTICAL SUMMARY OF SELECTED DISSOLVED CHEMICAL CONSTITUENTS AND

REGRESSION RELATIONSHIPS OF CONSTITUENT CONCENTRATIONS TO SPECIFIC CONDUCTANCE

CONSIIIUENI

\section{GONSILIUENI IMG/L OB UNII SHOWNI}

\begin{tabular}{|c|}
\hline $\begin{array}{l}\text { TEMPERATURE, WATER (DEG C) } \\
\text { SPECIFIC CONDUCTANCE (MICROMHOS) } \\
\text { STREAMFLOW (CUBIC FT/SEC) } \\
\text { PH (STANDARD UNITS) } \\
\text { PHOSPHORUS, TOTAL } \\
\text { NITRITE + NITRATE, TOTAL } \\
\text { NITROGEN, KJELDAHL, TOTAL } \\
\text { PHYTOPLANKTON, TOTAL (CELLS/ML) } \\
\text { SEDIMENT, SUSPENDED } \\
\text { SEDIMENT, CLAY-SILT (PERCENT) } \\
\text { COLIFORM, FECAL (COL/IOO ML) } \\
\text { STREPTOCOCCI, FECAL (COL/IOO ML) } \\
\text { SILICA, DISSOLVED } \\
\text { CALCIUM, DISSOLVED } \\
\text { MAGNESIUM, DISSOLVEU } \\
\text { SODIUM, DISSOLVED } \\
\text { POTASSIUM, DISSOLVED } \\
\text { BICARBONATE, ION } \\
\text { CARBONATE, ION } \\
\text { SULFATE, DISSOLVED } \\
\text { CHLOR IDE, DISSOLVEO } \\
\text { DISSOLVED SOLIDS, SUM OF CONST } \\
\text { OISSOLVED SOLIDS, ROE I8O DEG C } \\
\text { HARDNESS, TOTAL } \\
\text { HARDNESS, NONCARBONATE } \\
\text { TURBI DITY (JTU) } \\
\text { FLOUR IDE, DISSOLVED }\end{array}$ \\
\hline
\end{tabular}

\begin{tabular}{l} 
SAMPL \\
SIZE \\
\hline 12 \\
12 \\
11 \\
12 \\
12 \\
12 \\
12 \\
11 \\
12 \\
12 \\
12 \\
12 \\
12 \\
12 \\
12 \\
12 \\
12 \\
12 \\
12 \\
12 \\
12 \\
12 \\
12 \\
12 \\
12 \\
12 \\
12
\end{tabular}

$$
\text { E }
$$

STANOARD

10.96

525.6
2094.5

7.91

0.097

0.879

700.0

95.8

190.2

158.6

6.86
65.67

19.50

2.16

246.8

44.83

27.50

330.2

243.3

41.5

6.3

9.37
837.7

837.0
0.20

0.028

0.270

5978.3

5.8

14.4
276.0

212.4

2.05

1.98

1.98

0.34

36.5

0.0
6.44

5.92

35.3

49.6

21.5

3.6

3.6
0.08

DUBAIION_IABLE_OE_DALLY SPECIEIC CONDUCIANCE

DAILY SPECIFIC CONDUCTANCE IN

DAILY SPECIFIC CONDUCT ANCE IN
MICROMHOS AT 25 DEG C, THAT WAS

EQUALLED OR EXCEEDED FOR THE

$\begin{array}{llllll}-12 & -52 & 10 z & 20 \% & 30 z & 503 \\ 581 & 572 & 569 & 559 & 548 & 525\end{array}$

REGRESSION, CONSTANT,
COEFICIENT,

BEGRESSION_SUMMABY - B

CORRELATION

STANDARD SAMPLE

0.5
448

26.0

610
3560

$\begin{array}{rr}8500 & 11 \\ 8.3 & 12\end{array}$

0.14

1.30
1.40

20000
23

2100

1
50

10
2
2

2.8
56.0

17.0

12.0

1.7
200

0
34.0
19.0

19.0
264

274

220

0. 1

100
1000

600

10.0

12

25.0

2.9

2.9
0

55.0
37.0

37.0
361

466
280

59
15

15
0.3 SIZE
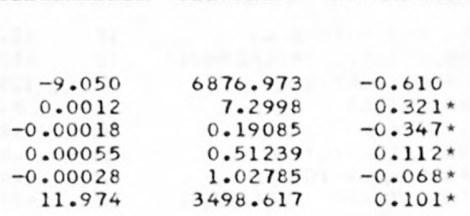

698.9

0.20

0.028

0.281

0.237
6269.7

INDICATED PERCENTAGE OF TIME

572

569

\begin{tabular}{|c|c|c|c|c|c|}
\hline \multirow{4}{*}{$\begin{array}{l}\text { SAMPLE } \\
\text { SIZE_ }\end{array}$} & & & & & STANDARD \\
\hline & HARMONIC & AMPLITUDE & PHASE & VAR IATION & ERROR OF \\
\hline & MEAN - M & $-A$ & ANGLE - C & EXPLAINED & ESTIMATE \\
\hline & WDEG CI_ & DEE 61 & $(B A D \perp A N S)$ & $\ldots(z) \ldots$ & $1 D E G(1$ \\
\hline 160 & 11.41 & 14.23 & 2.91 & 84 & 2.21 \\
\hline
\end{tabular}

SUMMARY OF HARMONIC ANALYSIS OF STREAM TEMPERATURE

SUMMARY OF MAXIMUM AND MINIMUM CONCENTRATIONS OF CONSTITUENTS SAMPLED AT A FREQUENCY OF QUARTERLY (1975 WY)

\begin{tabular}{|c|c|c|c|c|c|c|}
\hline \multirow{2}{*}{ CONSTITUENT } & \multicolumn{3}{|c|}{ TOTAL } & \multicolumn{3}{|c|}{ DISSOLVED } \\
\hline & $\begin{array}{c}\text { NO. } \\
\text { SAMPLES }\end{array}$ & $\begin{array}{l}\text { MIN IMUM } \\
\text { CONC. }\end{array}$ & $\begin{array}{l}\text { MAXIMUM } \\
\text { CONC. }\end{array}$ & $\begin{array}{l}\text { NO. } \\
\text { SAMPLES }\end{array}$ & $\begin{array}{l}\text { MINIMUM } \\
\text { CONC. }\end{array}$ & $\begin{array}{l}\text { MAXIMUM } \\
\text { CONC. }\end{array}$ \\
\hline \multicolumn{7}{|l|}{ MINOR ELEMENTS: } \\
\hline ARSENIC (AS), UG/L & 3 & 1 & 1 & 4 & 0 & 2 \\
\hline CADM IUM $(C D), U G / L$ & 3 & 0 & 4 & 4 & 0 & 1 \\
\hline CHROMIUM (CR), UG/L & 4 & $<10$ & $<10$ & 4 & 0 & 4 \\
\hline COBALT $(C O), U G / L$ & 4 & 0 & 2 & 4 & 0 & 2 \\
\hline COPPER (CU), UG/L & 2 & 6 & 12 & 4 & 1 & 9 \\
\hline IRON (FE), UG/L & 4 & 360 & 530 & 4 & 10 & 290 \\
\hline LEAD $(P B), U G / L$ & 4 & 5 & 35 & 4 & 2 & 35 \\
\hline MANGANESE (MN), UG/L & 4 & 50 & 68 & 4 & 20 & 63 \\
\hline MERCURY $(H G), U G / L$ & 4 & 0.0 & 0.2 & 4 & 0.0 & 0.2 \\
\hline SELENIUM (SE), UG/L & 4 & 0 & 0 & 4 & 0 & 0 \\
\hline ZINC $(Z N), U G / L$ & 4 & 20 & 70 & 4 & 0 & 20 \\
\hline \multicolumn{7}{|l|}{ PERIPHYTON: } \\
\hline BIOMASS, DRY WT., G/SQ M & 4 & 1.50 & 31.00 & & & \\
\hline BIOMASS, ASH WT., G/SQ M & 4 & .79 & 31.00 & & & \\
\hline CHLOROPHYLL A, MG/SQ M & 4 & .0 & 120.0 & & & \\
\hline CHLOROPHYLL $B$, MG/SO M & 4 & .0 & 23.0 & & & \\
\hline ORGANIC CARBON, MG/L & 4 & 5.2 & 9.0 & & & \\
\hline
\end{tabular}

04108090 -- KALAMAZOO RIVER AT SAUGATUCK, MICH. 
Table 14.--Summary of measurements at each station--Continued

LAT 43019M05S LONG $086002 M 11 S$

TRAINAGE AREA: 0 SO MI 1

PERICD OF RECORD: $10 / 01 / 74-09 / 30 / 75$

O SQ KMI

STATISTICAL SUMMARY OF SELECTED DISSOLVED CHEMICAL CONSTITUENTS AND REGRESSION RELATIONSHIPS DF CONSTITUENT CONCENTRATIONS TO SPECIFIC CONDUCTANCE

CONSIIIUENI

CONSIUIUENI IMGLL OR UNII SHOWNI)

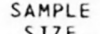

SIZE

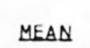

STANDARO

TEMPERATURE, WATER (DEG C) SPECIFIC CONDUCTANCE (MICROMHOS) STREAMFLOW (CUEIC FT/SEC) PH (STANDARO UNITS) PHOSPHORUS, TUTAL

NITRITE + NITRATE, IOTAL

NITROGEN, KJELDAHL, TOTAL PHYTCPLANKTON, TOTAL (CELLS/ML) SEDIMENT, SUSPENDED

SEDIMENT, CLAY-SILT (PERCENT) SEDIFERM, FECAL ICOL/100 MLI)

STREPTOCOCCI, FECAL (COL/100 ML) SILICA, DISSOLVED

CALCIUM, DISSOLVED

MAGNESIUM, DISSCLVEU

SODIUM, DISSOLVED

POTASSIUM, DISSOLVED

BICARBONATE, ION

CARBONATE, ION

SULFATE, DISSCLVED

CHLORIDE, DISSOLVED

DISSOLVED SOLIOS, SUM OF CONST

DISSOLVED SOLIDS, ROE 180 DEG HARDNESS, TOTAL

HARDNESS, NONCAREONAT

TUREIDITY (JTU)

FLOURIDE, DISSOLVEO

* Not significant at the 95 percent confidence level.
REYIAILON

10.38

$\begin{array}{rr}8.31 & 1.0 \\ 55.5 & 244 \\ 1167.1 & 1240 \\ 0.22 & 7.7 \\ 0.012 & 0.01 \\ 0.124 & 0.07 \\ 0.125 & 0.16 \\ 1316.3 & 240 \\ 8.8 & 8 \\ 18.2 & 37 \\ 29.3 & 2 \\ 48.8 & 1 \\ 1.27 & 4.1 \\ 13.08 & 3.3 \\ 1.71 & 10.0 \\ 1.67 & 6.5 \\ 0.37 & 0.9 \\ 30.5 & 146 \\ 0.0 & 0 \\ 2.82 & 15.0 \\ 3.03 & 12.0 \\ 32.2 & 128 \\ 24.8 & 172 \\ 38.5 & 49 \\ 13.4 & 0 \\ 56.9 & 1 \\ 0.10 & 0.0\end{array}$

350.7

2332.5

8.11

0.026

0.244

0.362

1822.0

20.5

94.8

30.4

6.10
43.11

13.25

10.01

1.37

185.8
0.0

19.17

18.50

203.0

215.5

163.3

19.8

21.7
0.20

0.10
BANGE

$\begin{array}{rr} & \\ & \\ 1.0 & \\ 244 & 23.5 \\ 1240 & 410 \\ 7.7 & 5730 \\ 0.01 & 8.3 \\ 0.07 & 0.05 \\ 0.16 & 0.44 \\ 240 & 4700 \\ 8 & 40 \\ 37 & 100 \\ 2 & 100 \\ 1 & 150 \\ 4.1 & 8.0 \\ 3.3 & 52.0 \\ 10.0 & 15.0 \\ 6.5 & 12.0 \\ 0.9 & 2.4 \\ 146 & 242 \\ 0 & 0 \\ 15.0 & 23.0 \\ 12.0 & 24.0 \\ 128 & 239 \\ 172 & 243 \\ 49 & 190 \\ 0 & 36 \\ 1 & 200 \\ 0.0 & 0.4 \\ & \end{array}$
23.5
REGRESSION

SAMPLE COEFICIENT, GBESSION SUMMABY

IENT, CONSTANT, CORRELATIUN ERROR OF 410

$8.3 \quad 12$

$\begin{array}{ll}0.05 & 12 \\ 0.44 & 12\end{array}$

$0.56 \quad 12$

$4700 \quad 10$

100

150

$8.0 \quad 12$

$\begin{array}{ll}52.0 & 12 \\ 15.0 & 12 \\ 12.0 & 12\end{array}$

$12.0 \quad 12$

$2.4 \quad 12$

23. 012

24.012

$\begin{array}{ll}39 & 12\end{array}$

$190 \quad 12$

$\begin{array}{rr}36 & 12 \\ 200 & 12\end{array}$

$0.4 \quad 12$

E COEFIGIENI

ESIIMAIE

DALY SPECIFIC CONDUCTANCE DUBAIION_IABLE_OF_DAILY_SPECIEIC_CONOUCIANCE

EQUALLEU OR 25 DEG C, THAT WAS

INDUCLTEU PE

$\begin{array}{llllll}18 & -5 \% & 20 \% & 20 \% & 30 \% & 50 \% \\ 396 & 389 & 385 & 379 & 370 & 356\end{array}$

SAMPLE S1ZE $=327$
$70 \%$ 20\% $228 \quad 99 \%$

0.0028
0.1909
0.0296
0.0285
-0.0000
0.395
0.000
0.0457
0.0489
0.542
0.405
0.593
0.070
0.169
-0.0002

SUMMARY OF RARMONIC ANALYSIS OF STREAM TEMPERATURE

\begin{tabular}{|c|c|c|c|c|c|}
\hline & & & & & STANDARD \\
\hline & HARMONIC & AMPLITUDE & PHASE & VARIATION & ERROR OF \\
\hline SAMPLE & $M E A N-M$ & $-A$ & ANGLE - C & EXPLAINED & ESTIMATE \\
\hline SIZE & $\left.10 E G_{2}\right)_{-}$ & WEG $(1)$ & $(R A D I A N S)$ & -131 & 1DEG_C \\
\hline 312 & $10 \cdot 36$ & 11.50 & 2.06 & 96 & 1.65 \\
\hline
\end{tabular}

SUMMARY OF MAXIMUM AND MINIMUM CONCENTRATIONS OF CONSTITUENTS

SAMPLED AT A FREQUENCY OF QUARTERLY (1975 WY)

04122030 -- MUSKEGON R NR BRIDGETON, MICH.

\begin{tabular}{|c|c|c|c|c|c|c|}
\hline \multirow{2}{*}{ CONSTITUENT } & \multicolumn{3}{|c|}{ TOTAL } & \multicolumn{3}{|c|}{ DISSOLVED } \\
\hline & $\begin{array}{l}\text { NO. } \\
\text { SAMPLES }\end{array}$ & $\begin{array}{l}\text { MIN IMUM } \\
\text { CONC. }\end{array}$ & $\begin{array}{l}\text { MAXIMUM } \\
\text { CONC. }\end{array}$ & $\begin{array}{l}\text { NC. } \\
\text { SAMPLES }\end{array}$ & $\begin{array}{l}\text { MINIMUM } \\
\text { CONC. }\end{array}$ & $\begin{array}{l}\text { MAXIMUM } \\
\text { CONC. }\end{array}$ \\
\hline \multicolumn{7}{|l|}{ MINOR ELEMENTS: } \\
\hline ARSENIC (AS), UG/L & 4 & 0 & 2 & 4 & 0 & 1 \\
\hline CADMIUM $(C D), U G / L$ & 3 & 0 & 3 & 4 & 0 & 2 \\
\hline CHROMIUM (CR), UG/L & 4 & $<10$ & 20 & 4 & 0 & 1 \\
\hline COBALT $(\mathrm{CO}), U G / L$ & 3 & 0 & 3 & 4 & 0 & 2 \\
\hline COPPER (CU), UG/L & 4 & 5 & 11 & 4 & 0 & 2 \\
\hline IRON $(F E), U G / L$ & 4 & 130 & 310 & 4 & 10 & 140 \\
\hline LEAD $(P B), U G / L$ & 3 & 10 & 16 & 4 & 0 & 9 \\
\hline MANG ANESE (MN), UG/L & 4 & 20 & 40 & 4 & 0 & 40 \\
\hline MERCURY $(H G), U G / L$ & 4 & 0.0 & 0.5 & 4 & 0.0 & 0.2 \\
\hline SELENIUM (SE), UG/L & 4 & 0 & 0 & 4 & 0 & 0 \\
\hline ZINC $(Z N), U G / L$ & 4 & 4 & 70 & 4 & 0 & 20 \\
\hline \multicolumn{7}{|l|}{ PERIPHYTON: } \\
\hline BIUMASS, DRY WT., G/SO M & 4 & 1.50 & 12.00 & & & \\
\hline BIOMASS, ASH WT., G/SO M & 4 & .09 & 10.00 & & & \\
\hline CHLOROPHYLL A, MG/SQ M & 4 & .2 & 21.0 & & & \\
\hline CHLOROPHYLL $B$, MG/SQ M & 4 & .1 & 1.7 & & & \\
\hline ORGANIC CARBON, MG/L & 4 & 5.5 & 12.0 & & & \\
\hline
\end{tabular}


Table 14.--Summary of measurements at each station--Continued

LAT 44D14MS4S LONG 086019M25S

DRAINAGE AREA:

PERIOD OF RECORD: $10 / 01 / 74-09 / 30 / 75$

O SQ KMI

STATISTICAL SUMMARY OF SELECTED DISSOLVED CHEMICAL CONSTITUENTS AND

REGRESSION RELATIONSHIPS OF CONSTITUENT CONCENTRATIONS TO SPECIFIC CONUUCTANCE

CONSIIUENI

\begin{tabular}{|c|}
\hline $\begin{array}{l}\text { TEMPERATURE, WATER (DEG C) } \\
\text { SPECIFIC CONDUCTANCE (MICROMHOS) } \\
\text { SIREAMFLOW (CUBIC FT/SEC) } \\
\text { PH (STANDARD UNITS) } \\
\text { PHOSPHORUS, TUTAL } \\
\text { NITRITE + NITRATE, TOTAL } \\
\text { NITROGEN, KJELDAHL, TOTAL } \\
\text { PHYIOPLANKTON, TOTAL (CELLS/ML) } \\
\text { SEDIMENT, SUSPENOED } \\
\text { SEDIMENT, CLAY-SILT (PERCENT) } \\
\text { COLIFORM, FECAL (COL/1OO ML) } \\
\text { STREPTOCOCCI, FECAL (COL/1OO ML) } \\
\text { SILICA, DISSOLVED } \\
\text { CALCIUM, DISSOLVED } \\
\text { MAGNESIUM, UISSOLVED } \\
\text { SODIUM, DISSOLVED } \\
\text { POTASSIUM, DISSULVEU } \\
\text { BICARLONATE, ION } \\
\text { CARBONATE, ION } \\
\text { SULFATE, DISSOLVED } \\
\text { CHLORIDE, DISSOLVED } \\
\text { DISSOLVED SOLIDS, SUM OF CONST } \\
\text { DISSOLVED SOLIOS, RUE I8O DEG C } \\
\text { HARONESS, TOTAL } \\
\text { HARDNESS, NONCARBONATE } \\
\text { TURBIDIIY (JTU) } \\
\text { FLOURIDE, OISSOLVED }\end{array}$ \\
\hline
\end{tabular}

CONSIUIUENI IMG/L OB UNII SHOHNI

SIZE

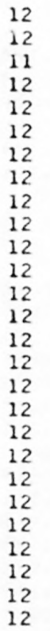

STANDARD

REYIALION

10.13

604.1

2260.4

266.4

0.019

0.019

0.215

0.316
3120.6

6.0

100.0

74.1

40.5

7.80

78.17
12.32

12.32
17.17

2. 30

183.5

0.0
3.47

13.47
89.25

310.8

392.6

392.6
245.0

94.5
4.3

4.3
0.14
8.71

101.2

509.9

0.34

0.011

0.105

0.096

5389.7

3.2

47.8

43.9

0.83

73.29

1.11

3.21

0.45

19.7
0.0

1.98

23.55

42.0

88.0

36.1

34.7

1.1
0.11

$$
\begin{array}{r} 
\\
0 \\
42 \\
1140 \\
7 \\
0 . \\
0 . \\
0.2 \\
\\
1 \\
\\
6 \\
54 \\
9 \\
13 \\
1 \\
15 \\
9 \\
45 \\
25 \\
286 \\
190 \\
\\
0 \\
\end{array}
$$

\section{BEGBESSION SUMMABY
REGRESSION}

SAMPLE COEFICIENT, CONSTANT, CORRELATION ERRORARO SIZE.

$-B_{-1}$ - B B GOEEICIENI

*Not significant at the 95 percent confidence level.

$\begin{array}{rr}0.5 & 25.0 \\ 423 & 729 \\ 1140 & 2870 \\ 7.0 & 8.3 \\ 0.01 & 0.04 \\ 0.03 & 0.35 \\ 0.20 & 0.45 \\ 67 & 16000 \\ 0 & 11 \\ 100 & 100 \\ 13 & 160 \\ 3 & 140 \\ 6.4 & 8.9 \\ 54.0 & 98.0 \\ 9.8 & 14.0 \\ 13.0 & 23.0 \\ 1.5 & 3.0 \\ 152 & 219 \\ 0 & 0 \\ 9.7 & 17.0 \\ 45.0 & 130.0 \\ 259 & 385 \\ 286 & 586 \\ 190 & 300 \\ 15 & 146 \\ 3 & 6 \\ 0.0 & 0.4\end{array}$

DURAIION IABLE OF DAILY SPECIEIC CONOUCIANCS

DAILY SPECIFIC CONDUCTANCE IN

MICRUMHOS AT 25 DEG C, THAT WAS

$\begin{array}{rrrrrr}18 & -58 & 103 & 20 z & 307 & 508 \\ 1040 & 839 & 758 & 653 & 587 & 505\end{array}$

11
12
12
12
12
12



12
12
12
12
12
12
12
12
12
12
12
12
12
12
12

-0.864
-0.0009
-0.00005
0.00039
-0.00041
-29.460

$$
\begin{array}{r}
2802.589 \\
8.4792 \\
0.04765 \\
-0.02138 \\
0.56106 \\
20916.867
\end{array}
$$
$-0.133 *$
$-0.284 *$
-0.440 *
$0.378 *$
-0.427 *
-0.553 *

595.4

0.34

0.010

0.102

0.091
4709.8

EQUALLED OR EXCEEDED FOR THE

1040

839

653

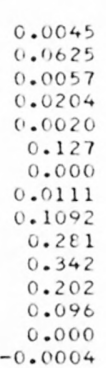
5.1108
40.4217
8.8846
4.8217
1.0815
106.562
0.000
6.7535
23.2727
141.098
186.207
123.226
123.226
36.798
4. 21
0.3672

0.541 *

$0.476 *$

0.516

0.643
0.456 *

0.655

0.000 *

0.568 *

0.469
0.676

0.076 .

$0.393 *$

$0.560 *$
0.278 *

$0.278 *$

$0.005 *$
$-0.345 *$

\begin{tabular}{|c|c|c|c|c|c|}
\hline & & & & & STANDARD \\
\hline & HARMONIC & AMPLITUDE & PHASE & VAR IATION & ERROR OF \\
\hline SAMPLE & MEAN - M & $-A_{1}$ & ANGLE - C & EXP LAINED & ESTIMATE \\
\hline & (DES 6$)_{-}$ & (DEG_C) & (BADIANSI & $\ldots 181 \ldots$ & LEE $C$ C \\
\hline
\end{tabular}

SUMMARY GF HARMONIC ANALYSIS OF STREAM TEMPERATURE

330

10.84

11.50

\begin{tabular}{|c|c|c|c|c|c|c|}
\hline \multirow{2}{*}{ CONSTITUENT } & \multicolumn{3}{|c|}{ TOTAL } & \multicolumn{3}{|c|}{ DISSOLVED } \\
\hline & $\begin{array}{l}\text { NO. } \\
\text { SAMPLES }\end{array}$ & $\begin{array}{l}\text { MIN IMUM } \\
\text { CONC. }\end{array}$ & $\begin{array}{l}\text { MAXIMUM } \\
\text { CONC. }\end{array}$ & $\begin{array}{l}\text { NO. } \\
\text { SAMPLES }\end{array}$ & $\begin{array}{l}\text { MINIMUM } \\
\text { CONC. }\end{array}$ & $\begin{array}{l}\text { MAXIMUM } \\
\text { CONC. }\end{array}$ \\
\hline \multicolumn{7}{|l|}{ MINOR ELEMENTS: } \\
\hline ARSENIC (AS), UG/L & 4 & 0 & 1 & 4 & 0 & 1 \\
\hline CADMIUM $(C D), \quad U G / L$ & 4 & 0 & 1 & 4 & 0 & 0 \\
\hline CHROMIUM (CR), UG/L & 4 & $<10$ & 20 & 4 & 0 & 0 \\
\hline COBALT $(C O), U G / L$ & 3 & 0 & 0 & 4 & 0 & 1 \\
\hline COPPER (CU), UG/L & 4 & 2 & 14 & 4 & 1 & 2 \\
\hline IRON (FE), UG/L & 4 & 160 & 480 & 4 & 10 & 140 \\
\hline LEAD $(P B), U G / L$ & 4 & 2 & 34 & 4 & 0 & 3 \\
\hline MANGANESE $(M N), U G / L$ & 4 & 10 & 40 & 4 & 0 & 40 \\
\hline MERCURY $(H G), U G / L$ & 4 & 0.0 & 0.3 & 4 & 0.0 & 0.2 \\
\hline SELENIUM (SE), UG/L & 4 & 0 & 0 & 4 & 0 & 0 \\
\hline ZINC $(Z N), U G / L$ & 4 & 8 & 30 & 4 & 0 & 10 \\
\hline \multicolumn{7}{|l|}{ PERIPHYTON: } \\
\hline 81OMASS, DRY WT., G/SO M & 4 & .79 & 22.00 & & & \\
\hline BIOMASS, ASH WT., G/SO M & 4 & .79 & 21.00 & & & \\
\hline CHLOROPHYLL A, MG/SO M & 4 & .5 & 25.0 & & & \\
\hline CHLOROPHYLL B, MG/SE M & 4 & .0 & 2.0 & & & \\
\hline ORGANIC CARBON, MG/L & 4 & 4.6 & 10.0 & & & \\
\hline
\end{tabular}

2.68

96

1.67

SUMMARY OF MAXIMUM AND MINIMUM CONCENTRATIONS OF CONSTITUENTS SAMPLED AT A FREQUENCY OF QUARTERLY $(1975$ WY)

04126520 -- MANISTEE R AT MANISTEE, MICH. 
Table 14.--Summary of measurements at each station--Continued

LAT 45038M02S LONG 084028M52S

DRAINAGE AREA: 0 SQ MI

PERIOD OF RECORD: $10 / 01 / 74-09 / 30 / 75$

O SO KMI

STATISTICAL SUMMARY OF SELECTED OISSOLVED CHEMICAL CONSTITUENTS AND

REGRESSION RELATIONSHIPS OF CONSTITUENT CONCENTRATIONS TO SPECIFIC CONDUCTANCE

BEGRESSION SUMMABY

REGRESSION

SAMPLE COEFICIENT, CONSTANT, CORRELATIUN STANDARD

SIZE_ - - B_- - B_- COEEICIENI ESIIYAIE

BANGE
1.0
190
1280
7.8
0.00
0.01
0.16
33
1
100
20
3
6.4
42.0
11.0
2.4
0.7
176
0
9.7
2.4
164
164
150
0
0
0.1

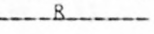

305

3250

8.5
0.08

0.08

0.38

2900
9

$\begin{array}{ll}1 & 1 \\ 1 & 1 \\ 1 & 1 \\ 1 & 1 \\ 1 & 0\end{array}$

$-2.303$

$-0.0004$

$-0.00023$

2457.487

8.3749

0.07315

$-0.0001$

0.07992

$-0.136$

$-0.058 *$

$-6.113^{*}$

1.601

834.424

$-0.043$

618.

0.024

0.032

0.054

1044.7

140
100
8.4

48.0

3.5

212

13.0

13.0
3.9

187
200

200
180
32

32
4

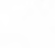

-0.0001
-0.0062
0.0106
0.0018
-0.0003
0.096
0.009
-0.0042
0.0094
0.068
0.041
-0.007
-0.045
-0.008
0.0012

$-0.004$

$-0.080$

$0.365 *$

$-0.134$.

0.326

$0.096^{\circ}$

$-0.132$

0.006

$0.296 *$

0.134 .

-0.022 .

$-0.144^{*}$

$-0.223 *$

$0.365 *$
CONSILIUENI

\begin{tabular}{|c|c|c|}
\hline $\begin{array}{l}\text { SAMPLE } \\
\text { SIZE }\end{array}$ & MEAN & $\begin{array}{l}\text { STANDARD } \\
\text { DEYIAIIO }\end{array}$ \\
\hline 11 & 10.82 & 9. \\
\hline 11 & 273.0 & \\
\hline$y$ & 1831.1 & 584 \\
\hline 11 & 8.25 & 0. \\
\hline 11 & 0.011 & 0.0 \\
\hline 11 & 0.050 & 0.0 \\
\hline 11 & 0.248 & 0.0 \\
\hline 10 & 1274.3 & 986 \\
\hline 10 & 3.4 & \\
\hline 10 & 100.0 & \\
\hline 11 & 52.3 & 40 \\
\hline 10 & 35.4 & 29 \\
\hline 11 & 7.59 & 0. \\
\hline 11 & 45.27 & \\
\hline 11 & 12.36 & \\
\hline 11 & 3.10 & 0 . \\
\hline 11 & 0.85 & 0. \\
\hline 11 & 186.8 & \\
\hline 11 & 1.4 & \\
\hline 11 & 10.79 & 1. \\
\hline 11 & 3.27 & \\
\hline 11 & 176.7 & \\
\hline 11 & 175.3 & \\
\hline 11 & 162.7 & \\
\hline 11 & 10.2 & \\
\hline 11 & 1.7 & \\
\hline
\end{tabular}

IEMPERATURE, WATER (DEG C) SPECIFIC CONDUCTANCE (MICROMHUS)

STREAMFLOW (CUBIC FT/SEC)

PH ISTANDARD UNITS

PHOSPHORUS, TOTAL

NITRITE + NITRATE, TOTAL

MITROGEN, KJELDAHL, TOTAL

PHYTOPLANKTON, TOTAL ICELLS/ML

SEDIMENT, SUSPENDED

SEDIMENT, CLAY-SILT (PERCENT)

COLIFORM, FECAL (COL/100 ML)

STREPTOCOCCI, FECAL (COL) $100 \mathrm{ML}$ )

SILICA, DISSOLVED

CALCIUM, DISSOLVED

MAGNESIUM, DISSOLVED

SODIUM, DISSOLVED

POTASSIUM, DISSOLVED

BICARBONATE, ION

CARBONATE, ION

SULFATE, DISSOLVED

CHLORIDE, DISSOLYED

DISSOLVED SOLIDS, SUM OF CONST

DISSOLVED SOLIDS, ROE 180 DEG

HARDNESS, TOTAL

HARUNESS, NONCARBONATE

TURBIDITY (JTU)

FLOUR IDE, DISSOLVED

$\begin{array}{ll}1 & 1 \\ 1 & 1 \\ 1 & 1 \\ 1 & 1 \\ 1 & 1 \\ 1 & 1 \\ 1 & 1 \\ 1 & 1 \\ 11 \\ 11 \\ 11 \\ 11 \\ 11 \\ 11 \\ 11\end{array}$

* Not significant at the 95 percent confidence 1 evel.

DAILY SPECIFIC CONDUCTANCE IN

MICROMHOS AT 25 DEG C, THAT WAS

EQUALLED OR EXCEEDED FOR THE

$\begin{array}{lllllll}18 & -59 & 10 \% & 20 \% & 30 \% & 50 \%\end{array}$

INDICATED PERCENTAGE OF TIME

880

340

315

SUMMARY OF HARMONIC ANALYSIS OF STREAM TEMPERATURE

\begin{tabular}{|c|c|c|c|c|c|}
\hline & & & & & STANDARD \\
\hline & HARMONIC & AMPLITUDE & PHASE & VAR IATION & ERROR OF \\
\hline $\begin{array}{l}\text { SAMPLE } \\
\text { SIZE }\end{array}$ & $\begin{array}{l}\text { MEAN - M } \\
\text { (DEG G) }\end{array}$ & $\begin{array}{c}-A \\
10 E G(1)\end{array}$ & $\begin{array}{l}\text { ANGLE - C } \\
\text { (BADLANSI }\end{array}$ & $\begin{array}{l}\text { EXP LAINED } \\
(\xi)\end{array}$ & $\begin{array}{l}\text { ES IIMATE } \\
\text { LEG_CI }\end{array}$ \\
\hline 257 & 11.49 & 11.90 & 2.07 & 95 & 2.04 \\
\hline
\end{tabular}

SUMMARY OF MAXIMUM AND MINIMUM CONCENTRATIONS OF CONSTITUENTS

SAMPLED AT A FREQUENCY OF QUARTERLY (1975 WY)

04132052 -- CHEBOYGAN R AT LINCOLN AVE AT CHEBOYGAN, MICH.

\begin{tabular}{|c|c|c|c|c|c|c|}
\hline \multirow{2}{*}{ CONSTITUENT } & \multicolumn{3}{|c|}{ TOTAL } & \multicolumn{3}{|c|}{ DISSOLVED } \\
\hline & $\begin{array}{l}\text { NO. } \\
\text { SAMPLES }\end{array}$ & $\begin{array}{l}\text { MIN IMUM } \\
\text { CONC. }\end{array}$ & $\begin{array}{l}\text { MAXIMUM } \\
\text { CONC. }\end{array}$ & $\begin{array}{l}\text { NO. } \\
\text { SAMPLES }\end{array}$ & $\begin{array}{l}\text { MIN1MUM } \\
\text { CONC. }\end{array}$ & $\begin{array}{l}\text { MAXIMUM } \\
\text { CONC. }\end{array}$ \\
\hline \multicolumn{7}{|l|}{ MINOR ELEMENTS: } \\
\hline ARSENIC (AS), UG/L & 4 & 0 & 1 & 4 & 0 & 1 \\
\hline CADMIUM $(C D), U G / L$ & 4 & 0 & 2 & 4 & 0 & 0 \\
\hline CHROMIUM (CR), UG/L & 4 & $<10$ & $<10$ & 3 & 0 & 0 \\
\hline COBALT $(C O), U G / L$ & 4 & 0 & 1 & 4 & 0 & 0 \\
\hline CUPPER (CU), UG/L & 4 & 5 & 9 & 4 & 0 & 5 \\
\hline IRON (FE), UG/L & 4 & 90 & 150 & 4 & 0 & 40 \\
\hline LEAD (PB), UG/L & 4 & 0 & 24 & 4 & 0 & 5 \\
\hline MANGANESE $(M N), U G / L$ & 4 & 0 & 20 & 3 & 0 & 10 \\
\hline MERCURY (HG), UG/L & 4 & 0.0 & 0.3 & 4 & 0.0 & 0.2 \\
\hline SELENIUM (SE), UG/L & 4 & 0 & 0 & 4 & 0 & 0 \\
\hline$Z I N C(2 N), U G / L$ & 4 & 20 & 40 & 3 & 0 & 10 \\
\hline \multicolumn{7}{|l|}{ PERIPHYTON: } \\
\hline BIOMASS, DRY WT., G/SO M & 3 & .09 & 9.19 & & & \\
\hline BIOMASS, ASH WT., G/SO M & 3 & .09 & 7.50 & & & \\
\hline CHLOROPHYLL A, MG/SQ M & 3 & .0 & 3.5 & & & \\
\hline CHLOROPHYLL B, MG/SE M & 3 & .0 & $\cdot 3$ & & & \\
\hline ORGANIC CARBON, MG/L & 4 & 5.3 & 8.8 & & & \\
\hline
\end{tabular}


LAT 44DO4M21S LONG O84DO1M12S

DRAINAGE AREA: 320 SQ MI 12829 SQ KMI

PERIOD OF RECORD: $10 / 01 / 74$ - 09/30/75

STATISTICAL SUMMARY OF SELECTED DISSOLVED CHEMICAL CONSTITUENTS ANU

REGRESSION RELATIONSHIPS OF CONSTITUENT CONCENTRATIONS TO SPECIFIC CONDUCTANCE

CONSILIUENI

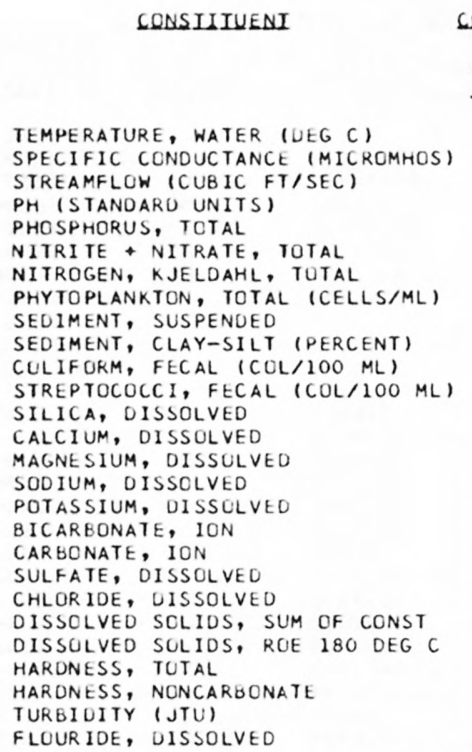

\begin{tabular}{|c|c|c|}
\hline $\begin{array}{l}\text { SAMPLE } \\
\text { SIZE }\end{array}$ & MEAN & $\begin{array}{l}\text { STANDARD } \\
\text { DEYLALION }\end{array}$ \\
\hline 12 & 8.50 & 7.29 \\
\hline 12 & 423.1 & 40.4 \\
\hline 12 & $272 \cdot 3$ & 112.9 \\
\hline 12 & 8.13 & 0.15 \\
\hline 12 & 0.028 & 0.026 \\
\hline 12 & 0.105 & 0.090 \\
\hline 12 & 0.389 & 0.166 \\
\hline 12 & 8720.0 & 22824.7 \\
\hline 12 & 35.6 & 37.5 \\
\hline 12 & 100.0 & 0.0 \\
\hline 12 & 42.8 & 53.4 \\
\hline 12 & 126.6 & 215.5 \\
\hline 12 & 7.57 & 1.46 \\
\hline 12 & 58.17 & 3.33 \\
\hline 12 & 15.08 & 1.24 \\
\hline 12 & 10.46 & 0.78 \\
\hline 12 & 1.14 & 0.22 \\
\hline 12 & 218.3 & 15.5 \\
\hline 12 & 0.2 & 0.6 \\
\hline 12 & 29.17 & 2.69 \\
\hline 12 & 16.25 & 1.14 \\
\hline 12 & 245.3 & 13.8 \\
\hline 12 & 252.0 & 16.6 \\
\hline 12 & 207.5 & 14.2 \\
\hline 12 & 28.6 & 13.0 \\
\hline 12 & 8.3 & 7.7 \\
\hline 12 & 0.23 & 0.09 \\
\hline
\end{tabular}

BEGRESSION SUMMARY

REGRESSION STANDARD SAMPLE COEFICIENT, CONSTANT, CORRELATION ERROR OF

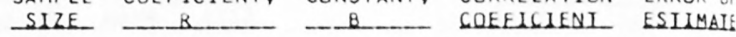
${ }^{\star}$ Not significant at the 95 percent confidence level.

$\begin{array}{rrr} & & \\ 0.5 & 20.0 & \\ 345 & 492 & \\ 157 & 560 & 12 \\ 7.8 & 8.4 & 12 \\ .00 & 0.10 & 12 \\ .00 & 0.24 & 12 \\ .05 & 0.68 & 12 \\ 190 & 81000 & 12 \\ 1 & 129 & \\ 100 & 100 & \\ 7 & 180 & \\ 3 & 630 & \\ 5.0 & 10.0 & 12 \\ 2.0 & 63.0 & 12 \\ 3.0 & 17.0 & 12 \\ 8.5 & 11.0 & 12 \\ 0.9 & 1.5 & 12 \\ 180 & 232 & 12 \\ 0 & 2 & 12 \\ 24.0 & 32.0 & 12 \\ 4.0 & 18.0 & 12 \\ 214 & 265 & 12 \\ 221 & 292 & 12 \\ 180 & 230 & 12 \\ 11 & 59 & 12 \\ 2 & 25 & 12 \\ 0.1 & 0.4 & 12\end{array}$

DURAIUON IABLE OF_DALLY SPECIEIC CONDUCIANCE

DAILY SPECIFIC CONDUCTANCE IN

MICROMHOS AT 25 DEG C, THAT WAS

EQUALLED GR EXCEEDED FOR THE

$\begin{array}{llllll}18 & -5 \% & 10 \% & 20 z & 30 \% & 50 \%\end{array}$

$50 \%$

SAMPLE SIZE $=302$
$70 \% \quad 20 \% \quad 25 \%$

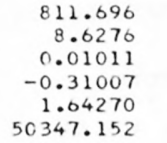

$-0.456 *$

$-0.315 *$

0.067 *

$0.442 *$

$-0.720$

$-0.174 *$
105.3

0.027

0.02

0.08

$0.12 !$
23573.5

SUMMARY OF HARMONIC ANALYSIS OF STREAM TEMPERATURE

EORM DE EQUAION: I. $(0)=M+A *$ SINL.0272*D+C)

\begin{tabular}{|c|c|c|c|c|c|}
\hline & & & & & STANDARD \\
\hline & HARMONIC & AMPLITUDE & PHASE & VAR IATION & ERROR OF \\
\hline $\begin{array}{l}\text { SAMPLE } \\
\text { SUZE }\end{array}$ & $\begin{array}{l}\text { MEAN }-M \\
\text { LOEG }\end{array}$ & $\begin{array}{c}-A \\
(D E G(1)\end{array}$ & ANGLE - C & EXPLAINED & $\begin{array}{l}\text { ESTIMATE } \\
\text { (DEG C) }\end{array}$ \\
\hline 314 & 10.07 & 11.19 & 2.82 & 94 & 2.19 \\
\hline
\end{tabular}

SUMMARY OF MAXIMUM AND MINIMUM CONCENTRATIONS OF CONSTITUENTS SAMPLED AT A FREQUENCY OF QUARTERLY (1975 WY)

04142000 -- RIFLE RIVER NEAR STERLING, MICH.

\begin{tabular}{|c|c|c|c|c|c|c|}
\hline \multirow{2}{*}{ CONSTITUENT } & \multicolumn{3}{|c|}{ TOTAL } & \multicolumn{3}{|c|}{ DISSOLVED } \\
\hline & $\begin{array}{l}\text { NO. } \\
\text { SAMPLES }\end{array}$ & $\begin{array}{l}\text { MINIMUM } \\
\text { CONC. }\end{array}$ & $\begin{array}{l}\text { MAXIMUM } \\
\text { CONC. }\end{array}$ & $\begin{array}{l}\text { NO. } \\
\text { SAMPLES }\end{array}$ & $\begin{array}{l}\text { MINIMUM } \\
\text { CONC. }\end{array}$ & $\begin{array}{l}\text { MAXIMUM } \\
\text { CONC. }\end{array}$ \\
\hline \multicolumn{7}{|l|}{ MINOR ELEMENTS: } \\
\hline ARSENIC (AS), UG/L & 3 & 2 & 4 & 4 & 1 & 4 \\
\hline CAOMIUM $(C D), U G / L$ & 4 & 0 & 1 & 4 & 0 & 1 \\
\hline CHROMIUM (CR), UG/L & 4 & $<10$ & $<10$ & 4 & 0 & 4 \\
\hline COBALT $(C O), U G / L$ & 4 & 0 & 1 & 4 & 0 & 0 \\
\hline COPPER (CU), UG/L & 4 & 1 & 11 & 4 & 1 & 2 \\
\hline IRON (FE), UG/L & 4 & 290 & 930 & 4 & 0 & 70 \\
\hline LEAD $(P B), U G / L$ & 4 & 2 & 13 & 4 & 0 & 2 \\
\hline MANGANESE $(M N), U G / L$ & 4 & 35 & 77 & 4 & 10 & 20 \\
\hline MERCURY $(H G), U G / L$ & 4 & 0.0 & 0.2 & 4 & 0.0 & 0.1 \\
\hline SELENIUM (SE), UG/L & 4 & 0 & 0 & 4 & 0 & 0 \\
\hline ZINC $(Z N), U G / L$ & 4 & 10 & 60 & 4 & 0 & 30 \\
\hline \multicolumn{7}{|l|}{ PERIPHYTON: } \\
\hline BIOMASS, DRY WT., G/SO M & 4 & .19 & 58.00 & & & \\
\hline BIOMASS, ASH WT., G/SO M & 4 & .19 & 49.00 & & & \\
\hline CHLOROPHYLL A, MG/SO M & 4 & .0 & 43.0 & & & \\
\hline CHLOROPHYLL B, MG/SQ M & 4 & .0 & 2.0 & & & \\
\hline ORGANIC CARBON, MG/L & 4 & 3.5 & 12.0 & & & \\
\hline
\end{tabular}


Iadie 14.--Summary of measurements at each station--Continued

LAT 43024M46S LONG 083057M47S

DRAINAGE AREA: 6060 SQ MI ( 15695 SQ KM)

PERIOD OF RECORD: $10 / 01 / 74-09 / 30 / 75$

STATISTICAL SUMMARY OF SELECTED DISSOLVED CHEMICAL CONSTITUENTS AND REGRESSION RELATIONSHIPS OF CONSTITUENT CONCENTRATIONS TO SPECIFIC CONDUCTANCE

CONSIIIUENI

CONSILIUENI IMG/L OR UNII SHOWNI

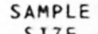

SLZE

MEAN

TANDARD

12

TEMPERATURE, WATER (DEG C) SPECIFIC CONDUCTANCE (MICROMHOS) STREAMFLOW (CUBIC FT/SEC)

PH (STANDARD UNITS)

PHOSPHORUS, TOTAL

NITRITE + NITRATE, TOTAL

NITRCGEN, KJELDAHL, TOTAL

PHYTOPLANKTON, TOTAL (CELLS/ML)

SEDIMENT, SUSPENDED

SEDIMENT, CLAY-SILT (PERCENT)

COLIFORM, FECAL (COL/100 ML)

STREPTOCOCCI, FECAL ( $C O L / 100 \mathrm{ML})$

SILICA, DISSOLVED

CALCIUM, DISSOLVEO

MAGNESIUM, DISSOLVEU

SODIUM, DISSOLVED

POTASSIUM, DISSOLVEU

BICARBONATE, ION

CARBONATE, ION

SULFATE, DISSOLVED

CHLORIDE, DISSOLVED

DISSOLVED SOLIDS, SUM OF CONST

DISSOLVED SOLIDS, ROE 180 DEG C

HARDNESS, TOTAL

HARDNESS, NONCARBONAT

TURBIDITY (JTU)

FLOURIDE, UISSOLVED

8.86
152.9
2333.5

4515.5
7.97

0.264

13702.5

53.9

100.0

965.5
263.2

5.24

74.42
20.42

37.17

3.76

231.3

54.33

84.75

413.6

419.9

270.0

80.4

23.9

2333.5
0.19

0.19
0.124

0.427

0.191

15527.7

53.9
0.0

2028.6

334.2

1.76

11.32
2.84

2.84
13.85

0.95

32.9

8.40

37.67

112.1

98.6
40.5

40.5
33.5

20.6

0.17

*Not significant at the 95 percent confidence level.

DAILY SPECIFIC CONDUCTANCE IN MICROMHOS AT 25 DEG C, THAT WAS

EQUALLED OR EXCEEDED FOR THE

URAILON IABLE OE DAILY SPECIEIC CONOUCIANCE

EQUALLED OR EXCEEDED FOR THE
INDICATED PERCENTAGE UF TIME

$\begin{array}{rrr}-18 & -58 & 10 \% \\ 1030 & 918 & 830\end{array}$

BANGE

$0.0 \quad 23.0$

518

1180
7.7

0.09

0.35

0.96
530

5

100
34

34
2.7

2.7
62.0

17.0

17.0
2.0

192

42.0

37.0

299

160
220

36

0.6

\section{BEGBESSION_SUMMARY} REGRESSION

SAMPLE COEFICIENT,

CONSTANT,

CORRELATIUN

STANDARD ERROR OF SIZE.

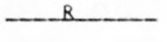

B COEEICIENI

$\begin{array}{rr}953 & \\ 8230 & 11 \\ 8.3 & 12 \\ 0.46 & 11 \\ 1.70 & 12 \\ 1.50 & 11 \\ 50000 & 12 \\ 176 & \\ 100 & \\ 0900 & \\ 1000 & \\ 9.3 & 12 \\ 97.0 & 12 \\ 24.0 & 12 \\ 55.0 & 12 \\ 5.6 & 12 \\ 310 & 12 \\ 0 & 12 \\ 70.0 & 12 \\ 170.0 & 12 \\ 680 & 12 \\ 560 & 12 \\ 340 & 12 \\ 144 & 12 \\ 70 & 12 \\ 0.8 & 12\end{array}$

$$
\begin{array}{r}
-10.0063 \\
0.0007 \\
0.00024 \\
0.00032 \\
-0.00047 \\
-6.547
\end{array}
$$

7.5048
0.09716

0.09716
0.70572

8295.273

$-0.045$

$0.536 *$

$0.302 *$

$0.115 *$

$-0.390 *$

-0.064 *

1878.7

0.17

0.125

0.444

0.186
6251.5

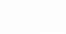

-0.000
0.059

0.0599
0.0141

0.0800

0.0037

0.072

0.000

0.0445

0.1957

0.367

0.458

0.219

0.161

-0.067
-0.0002
5.3530
32.4242
10.5004
$-18.9359$
1.1941
0.000
23.0889
$-52.5356$
156.243
98.979
116.179
$-32.193$
70.883
0.5448

$-0.014$

0.809

0.760

0.883

0.587

0.334 *

c. 000 *

0.811

0.795

0.795

$0.501 *$

0.710

0.829

0.733

-0.497 *

-0.207 .
1.85

6.98

1.94

6.81

0.81

32.5
0.0

5.16

5.16
23.99

101.7

\begin{tabular}{|c|c|c|c|c|c|}
\hline & $\begin{array}{l}\text { MMARY OF } \\
\angle \text { DE EQUUA. }\end{array}$ & $\begin{array}{l}\text { ONIC AN } \\
\text { i.IDI }\end{array}$ & $\begin{array}{l}\text { OF STRE } \\
A_{*}^{*} \text { SIN }\end{array}$ & EMPERATURE & \\
\hline & & & & & STANDAR \\
\hline & HARMONIC & AMPLITUDE & PHASE & VAR IATION & ERROR O \\
\hline $\begin{array}{l}\text { SAMPLE } \\
\text { SIZE }\end{array}$ & $\begin{array}{l}\text { MEAN }-M \\
\text { LEEG CI }\end{array}$ & ${ }_{(D E G}{ }^{A}(1)$ & ANGLE - C & EXPLAINED & $\begin{array}{l}\text { ESTIMAT } \\
\text { (DEG C) }\end{array}$ \\
\hline 307 & 11.17 & 12.82 & 2.76 & 95 & 2.23 \\
\hline
\end{tabular}

101.7
72.9

23.7

23.9

18.8
0.17

\begin{tabular}{|c|c|c|c|c|c|c|}
\hline \multirow{2}{*}{ CONSTITUENT } & \multicolumn{3}{|c|}{ TOTAL } & \multicolumn{3}{|c|}{ DISSOLVED } \\
\hline & $\begin{array}{l}\text { NO. } \\
\text { SAMPLES }\end{array}$ & $\begin{array}{l}\text { MIN IMUM } \\
\text { CONC. }\end{array}$ & $\begin{array}{l}\text { MAXIMUM } \\
\text { CONC. }\end{array}$ & $\begin{array}{l}\text { NO. } \\
\text { SAMPLES }\end{array}$ & $\begin{array}{l}\text { MINIMUM } \\
\text { CONC. }\end{array}$ & $\begin{array}{l}\text { MAXIMUM } \\
\text { CONC. }\end{array}$ \\
\hline \multicolumn{7}{|l|}{ MINOR ELEMENTS: } \\
\hline ARSENIC (AS), UG/L & 4 & 2 & 5 & 4 & 0 & 1 \\
\hline CADMIUM $(C D), U G / L$ & 4 & 0 & 1 & 4 & 0 & 0 \\
\hline CHROMIUM (CR), UG/L & 4 & $<10$ & 10 & 4 & 0 & 1 \\
\hline COBALT $(C O), U G / L$ & 4 & 0 & 2 & 4 & 0 & 1 \\
\hline COPPER (CU), UG/L & 4 & 5 & 16 & 4 & 3 & 4 \\
\hline IRON $(F E), U G / L$ & 4 & 590 & 2300 & 4 & 10 & 260 \\
\hline LEAD (PB), UG/L & 4 & 1 & 22 & 4 & 0 & 2 \\
\hline MANG ANESE $(M N), U G / L$ & 4 & 65 & 150 & 4 & 30 & 47 \\
\hline MERCURY (HG), UG/L & 4 & 0.0 & 0.3 & 4 & 0.0 & 0.3 \\
\hline SELENIUM (SE), UG/L & 4 & 0 & 0 & 4 & 0 & 0 \\
\hline ZINC $(Z N), U G / L$ & 4 & 30 & 50 & 4 & 4 & 40 \\
\hline \multicolumn{7}{|l|}{ PERIPHYTON : } \\
\hline BIUMASS, DRY WT., G/SO M & 4 & 1.79 & 44.00 & & & \\
\hline BIOMASS, ASH WT., G/SQ M & 4 & .79 & 34.00 & & & \\
\hline CHLOROPHYLL A, MG/SO M & 4 & 1.3 & 66.0 & & & \\
\hline CHLOROPHYLL B, MG/SO M & 4 & $\cdot 1$ & 15.0 & & & \\
\hline ORGANIC CARBON, MG/L & 4 & 8.5 & 11.0 & & & \\
\hline
\end{tabular}

SUMMARY OF MAXIMUM AND MINIMUM CONCENTRATIONS OF CONSTITUENTS

SAMPLED AT A FREQUENCY OF QUARTERLY (1975 WY)

04157000 -- SAGINAW RIVER AT SAGINAW, MICH. 
Table 14.--Summary of measurements at each station--Continued

STATION NUMBER: 04165500 NAME: CLINTON RIVER AT MOUNT CLEMENS, MICH.

LAT $42035 M 45 S$ LONG $082054 M 35 S$

DRAINAGE AREA: 734 SQ MI ( 1901 SQ KM)

PERIOD OF RECORD: $10 / 01 / 74-09 / 30 / 75$

STATISTICAL SUMMARY OF SELECTED DISSOLVED CHEMICAL CONSTITUENTS AND

REGRESSION RELATIONSHIPS OF CONSTITUENT CONCENTRATIONS TO SPECIFIC CONDUCTANCE

CONSLIUENI

\begin{tabular}{c} 
CONS \\
SAM \\
SII \\
\hline 1 \\
1 \\
1 \\
1 \\
1 \\
1 \\
1 \\
1 \\
1 \\
1 \\
1 \\
1 \\
1 \\
12 \\
12 \\
1 \\
1 \\
1 \\
12 \\
12 \\
12 \\
12 \\
1 \\
12 \\
12 \\
12 \\
12
\end{tabular}

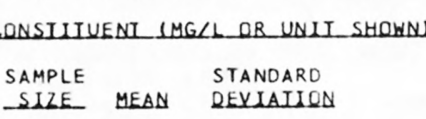

TEMPERATURE, WATER (DEG C)

SPECIFIC CONDUCTANCE IMICROMHOS

STREAMFLOW (CUBIC FI/SEC)

PH ISTANDARD UNITS

NITRITE + NITRATE, TOTAL

NITROGEN, KJELDAHL, TOTAL

PHYTOPLANKTON, TOTAL (CELLS/ML)

SEDIMENT, SUSPENDED

SEDIMENT, CLAY-SILT (PERCENT)

COLIFORM, FECAL (COL/100 ML)

STREPTOCOCCI, FECAL ICOL/100 ML

SILICA, DISSOLVED

CALCIUM, DISSULVED

MAGNESIUM, DISSOLVED

SOOIUM, DISSOLVED

POTASSIUM, DISSOLVED

BICARBCNATE, ION

CARBONATE, ION

SULFATE, DISSOLVEO

CHLURIDE, DISSOLVED

DISSOLVED SOLIDS, SUM OF CONST

DISSULVEO SULIDS, RUE 180 DEG

HARDNESS, TOTAL

HARDNESS, NONCARBONATE

UITY (JTU)

DE, DISSOLVED
9.92

718.7
096.5

096.5
7.97

0.366

1.942

1.714

8941.7

35.9

2337.5

950.2

5.54
70.33

19.92

43.17

4.50

237.7

0.0

55.33

77.33

393.6

445.6

257.5

31.4

0.49
QEYIAIJON

8.32
165.9

474.4

0.18

0.212

0.904

8302.7

20.4

0.6

4886.6

1132.5
1.02

1.02

0.21
1.68

1.68
20.21

1.56

32.4

0.0

5.61
32.63

32.63
71.6

71.6
102.8

20.5

23.5

62.7

0.18
BES

REGRESSION

SAMPLE BESS ION SUMMABY

BANGE

DURAILON IABLE OE DAILY SPECIEIC CONDUCIANCE

DAILY SPECIFIC CONDUCTANCE IN

DAILY SPECIFIC CONDUCTANCE IN

EQUALLED OR EXCEEDEO FOR THE

INDICATED PERCENTAGE OF TIME

$\begin{array}{rrrrr}18 & -52 & 108 & 20 z & 302 \\ 1280 & 1040 & 934 & 814 & 721\end{array}$

0.0
525
286
7.5
0.09
1.10
0.81
2100
13
98

23.0

1080

$1750 \quad 12$

8.2
0.76

3.50

3.50
31000

74
100

100
17000

17000
3630

$\begin{array}{rr}64 & 3630 \\ 3.1 & 7.0 \\ 63.0 & 84.0 \\ 17.0 & 23.0\end{array}$

$17.0 \quad 23.0$

28.0
3.2

188

50.0
56.0

56.0
322

346

230

8
0.3
100.0
9.0

309

65.0
170.0

170.0
574
670
300

300
83

83
230
0.9
SIZE

12
12
12
12

12

12
12
12
12
12
12
12
12
12
12
12
12
12
12
12 COEFICIENT,

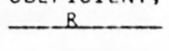

CONSTANT,

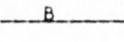

$$
\begin{array}{r}
-1.388 \\
0.0004 \\
0.00081 \\
-0.00138 \\
0.00301 \\
28.546
\end{array}
$$

0.0022
0.0306
0.0080
0.1119
0.0071
0.114
0.000
0.0231
0.1807
0.419
0.361
0.108
0.016
-0.150
0.0001

3.9381

48.3199

14.1733

$-37.2676$

$-0.6033$

155.831

38.7079

$-52.5037$

92.255
186.302

179.945

51.307

139.419

0.4442

\section{2}

670
CORRELATION COEEICIENI

STANDARD

\begin{tabular}{|c|c|c|c|c|c|}
\hline & & & & & STANDARD \\
\hline $\begin{array}{l}\text { SAMPLE } \\
\text { SIZE }\end{array}$ & $\begin{array}{l}\text { MEAN - M } \\
\text { LDEG }\end{array}$ & (DEG & $\begin{array}{l}\text { ANGLE - C } \\
\text { (RADIANS) }\end{array}$ & $\begin{array}{c}\text { EXPLAINED } \\
(\&)\end{array}$ & ESTIMATE \\
\hline 342 & 12.37 & 11.70 & 2.76 & 93 & 2.28 \\
\hline
\end{tabular}
ERROR O ESIUMAI:

SUMMARY UF HARMUNIC ANALYSIS OF STREAM TEMPERATURE

\begin{tabular}{|c|c|c|c|c|c|c|}
\hline \multirow{2}{*}{ CONSTITUENT } & \multicolumn{3}{|c|}{ TOTAL } & \multicolumn{3}{|c|}{ DISSOLVED } \\
\hline & $\begin{array}{l}\text { NO. } \\
\text { SAMPLES }\end{array}$ & $\begin{array}{l}\text { MIN IMUM } \\
\text { CONC. }\end{array}$ & $\begin{array}{l}\text { MAXIMUM } \\
\text { CONC. }\end{array}$ & $\begin{array}{l}\text { NU. } \\
\text { SAMPLES }\end{array}$ & $\begin{array}{l}\text { MINIMUM } \\
\text { CONC. }\end{array}$ & $\begin{array}{l}\text { MAXIMUM } \\
\text { CONC. }\end{array}$ \\
\hline \multicolumn{7}{|l|}{ MINOR ELEMENTS: } \\
\hline ARSENIC (AS), UG/L & 4 & 1 & 5 & 3 & 1 & 3 \\
\hline CADMIUM $(C D), U G / L$ & 4 & 0 & 2 & 4 & 0 & 1 \\
\hline CHROMIUM (CR), UG L & 4 & $<10$ & 10 & 4 & 0 & 8 \\
\hline COBALT $(C O), U G / L$ & 4 & 0 & 1 & 4 & 0 & 1 \\
\hline COPPER (CU), UG/L & 4 & 9 & 14 & 4 & 4 & 7 \\
\hline IRON (FE), UG/L & 4 & 460 & 1400 & 4 & 10 & 250 \\
\hline LEAD $(P B), U G / L$ & 4 & 10 & 15 & 4 & 0 & 14 \\
\hline MANGANESE (MN), UG/L & 4 & 65 & 80 & 4 & 10 & 51 \\
\hline MERCURY (HG), UG/L & 4 & 0.0 & 0.6 & 4 & 0.0 & 0.4 \\
\hline SELENIUM (SE), UG/L & 4 & 0 & 1 & 4 & 0 & 1 \\
\hline$Z I N C(Z N), U G / L$ & 4 & 40 & 70 & 4 & 0 & 30 \\
\hline \multicolumn{7}{|l|}{ PERIPHYTON: } \\
\hline BIOMASS, ORY WT., G/SG M & 4 & 12.00 & 90.00 & & & \\
\hline BIOMASS, ASH WT., G/SO M & 4 & 9.69 & 82.00 & & & \\
\hline CHLOROPHYLL A, MG/SO M & 4 & .7 & 62.0 & & & \\
\hline CHLORCPHYLL B, MG/SQ M & 4 & .1 & 6.0 & & & \\
\hline ORGANIC CARBON, MGIL & 4 & 7.5 & 12.0 & & & \\
\hline
\end{tabular}

SUMMARY OF MAXIMUM AND MINIMUM CONCENTRATIONS OF CONSTITUENTS

SAMPLED AT A FREQUENCY OF QUARTERLY (1975 WY)

04165500 -- CLINTON RIVER AT MOUNT CLEMENS, MICH. - 
Table 14.--Summary of measurements at each station--Continued

STATION NUMBER: 04165700 NAME: DETROIT R AT DETROIT, MICH. .

AT $42021 M 02 S$ LONG 082057M52S

LARAINAGE AREA: 0 SQ MI

PERIOD OF RECORD: 10/01/74 - 09/30/75

STATISTICAL SUMMARY OF SELECTED DISSOLVED CHEMICAL CONSTITUENTS AND

REGRESSION RELATIONSHIPS OF CONSTITUENT CONCENTRATIONS IO SPECIFIC CONDUCTANCE

CONSIIUUENI

TEMPERATURE, WATER (DEG C)
SPECIFIC CONDUCTANCE (MICROMHOS)
STREAMFLOW (CUBIC FT/SEC)
PH (STANDARD UNITS)
PHOSPHORUS, TOTAL,
NITRITE, NITRATE, TOTAL
NITROGEN, KJELDAHL, TOTAL
PHYTOPLANKTON, TOTAL (CELLS/ML)
SEDIMENT, SUSPENDED
SEDIMENT, CLAY-SILT (PERCENT)
COLIFORM, FECAL (COL/IOO ML)
STREPTOCOCCI, FECAL (COL/IOO ML)
SILICA, DISSOLVED
CALCIUM, DISSOLVED
MAGNESIUM, DISSOLVED
SODIUM, DISSOLVED
POTASSIUM, DISSOLVED
BICARBONATE, ION
CARBONATE, ION
SULFATE, DISSOLVED
CHLORIDE, DISSOLVED
DISSOLVED SOLIDS, SUM OF CONST
OISSOLVED SOLIDS, ROE I8O DEG C
HARONESS, TOTAL
HARDNESS, NONCARBONATE
TURBIDITY (JTU)
FLOURIDE, DISSOLVED

CONSIUIUENT IMG $L$ OR UNII SHOWNI

SAMPLE

SIZE

8
12
12
12
12
12
12
12
12
12
11
11
12
12
12
12
12
12
12
12
12
12
12
12
12
12
12
STANDARD

MEAN DEYIALION

14.88

215.5

10.7
6112.0
0.26

0.26
0.010

7.90

0.012

0.263

0.149

2145.8
10.3

10.3
98.9

98.9
21.2

8.1

0.97
28.42

28.42

7.16

4.32

0.92

107.7
0.0

0.0
16.50

7.75

119.3

130.7

100.3

14.5
4.0

4.0
0.27
0.010

0.046
0.071

1596.8

$\begin{array}{r}8.1 \\ \hline\end{array}$

3.8

59.4

15.1

0.38

1.31

0.31

0.73

16.4

0.0

1.51
1.20

1.20
7.3

34.4

4.8
10.4

3.2
0.27

*Not significant at the 95 percent confidence level.

DURAIION IABLE OF DALLY SPECIEIC CONDUCIANCE

DAILY SPECIFIC CONDUCTANCE IN

MICROMHOS AT 25 DEG C, THAT WAS

EQUALLED OR EXCEEDED FOR THE
INDICATED PERCENTAGE OF TIME

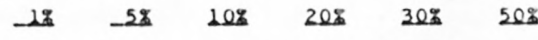

BANGE

BEGRESSION SUMMARY

$\begin{array}{rrr}0.0 & 23.0 & \\ 203 & 235 & \\ 219000 & 240000 & 12 \\ 7.3 & 8.2 & 12 \\ 0.00 & 0.04 & 12 \\ 0.21 & 0.36 & 12 \\ 0.03 & 0.28 & 12 \\ 570 & 5900 & 12 \\ 1 & 24 & \\ 87 & 100 & \\ 1 & 200 & \\ 1 & 52 & \\ 0.4 & 1.5 & 12 \\ 27.0 & 31.0 & 12 \\ 6.4 & 7.7 & 12 \\ 3.2 & 6.3 & 12 \\ 0.7 & 1.2 & 12 \\ 80 & 144 & 12 \\ 0 & 0 & 12 \\ 15.0 & 20.0 & 12 \\ 6.4 & 11.0 & 12 \\ 112 & 135 & 12 \\ 104 & 222 & 12 \\ 96 & 110 & 12 \\ 0 & 34 & 12 \\ 0 & 10 & 12 \\ 0.1 & 1.0 & 12\end{array}$
REGRESSION
COEFICIENT,

SAMPLE

CONSTANT, COR,

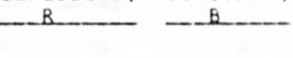

ORRELATION

$\begin{array}{rrrr}-199.851 & 274507.813 & -0.351^{*} & 0002.6 \\ 0.0041 & 7.0191 & 0.167^{*} & 0.27 \\ -0.00029 & 0.07450 & -0.304^{*} & 0.010 \\ 0.00030 & 0.19877 & 0.070^{*} & 0.048 \\ -0.00126 & 0.42175 & -0.191^{*} & 0.073 \\ 43.014 & -7123.773 & 0.289^{*} & 1603.1\end{array}$

43.014

$-7123.773$

0.289 *

278

228

222

217

215

0.0098
-0.0225
-0.0171
0.0304
0.0016
-0.095
0.000
0.0898
0.0570
0.095
0.795
-0.185
-0.036
-0.097
-0.0018

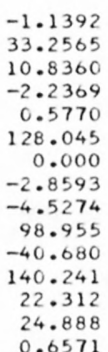

0.276

$-0.184 *$

$-0.588$

0.449 *

0.152

$-0.062^{*}$

$0.000^{\circ}$

0.640
$0.510^{*}$

0.139 .

0.248 *

$-0.417$

-0.038 *

$-0.323^{\circ}$

$-0.070^{\circ}$

STAND ARD SIIMAIE

02.6

.048

003.1

0.38

1.35

0.26

0.12

17.

0.0

1.21

1.08

7.6

34.9

4.6
10.9

3.2

0.29

SUMMARY OF HARMONIC ANALYSIS OF STREAM TEMPERATURE

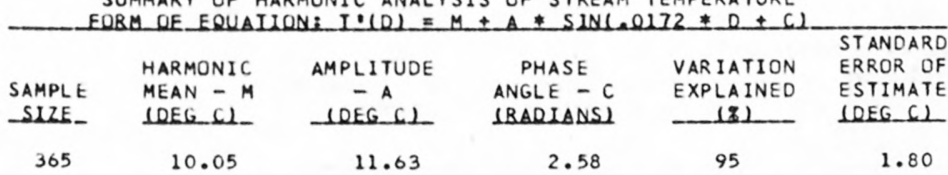

SUMMARY OF MAXIMUM AND MINIMUM CONCENTRATIONS OF CONSTITUENTS

SAMPLED AT A FREQUENCY OF QUARTERLY (1975 WY

04165700 -- DETROIT R AT DETROIT, MICH. •

\begin{tabular}{|c|c|c|c|c|c|c|}
\hline \multirow{2}{*}{ CONSTITUENT } & \multicolumn{3}{|c|}{ TOTAL } & \multicolumn{3}{|c|}{ DISSOLVED } \\
\hline & $\begin{array}{l}\text { NO. } \\
\text { SAMPLES }\end{array}$ & $\begin{array}{l}\text { MIN IMUM } \\
\text { CONC. }\end{array}$ & $\begin{array}{l}\text { MAXIMUM } \\
\text { CONC. }\end{array}$ & $\begin{array}{l}\text { NO. } \\
\text { SAMPLES }\end{array}$ & $\begin{array}{l}\text { MINIMUM } \\
\text { CONC. }\end{array}$ & $\begin{array}{l}\text { MAXIMUM } \\
\text { CONC. }\end{array}$ \\
\hline \multicolumn{7}{|l|}{ MINOR ELEMENTS: } \\
\hline ARSENIC (AS), UG/L & 4 & 0 & 1 & 4 & 0 & 1 \\
\hline CADMIUM $(C D), U G / L$ & 2 & 0 & 2 & 4 & 0 & 1 \\
\hline CHROMIUM (CR), UG/L & 3 & $<10$ & $<10$ & 4 & 0 & 18 \\
\hline COBALT $(C O)$, UG/L & 2 & 3 & 5 & 4 & 1 & 2 \\
\hline COPPER (CU), UG/L & 4 & 9 & 15 & 4 & 3 & 5 \\
\hline IRON (FE), UG/L & 4 & 160 & 3800 & 4 & 0 & 10 \\
\hline LEAD $(P B), U G / L$ & 3 & 9 & 29 & 4 & 0 & 9 \\
\hline MANGANESE (MN), UG/L & 4 & 0 & 40 & 4 & 0 & 20 \\
\hline MERCURY $(H G), U G / L$ & 4 & 0.0 & 0.2 & 4 & 0.0 & 0.1 \\
\hline SELENIUM (SE), UG & 4 & 0 & 0 & 4 & 0 & 0 \\
\hline ZINC $(Z N), U G / L$ & 3 & 30 & 320 & 4 & 0 & 20 \\
\hline \multicolumn{7}{|l|}{ PERIPHYTON: } \\
\hline BIOMASS, DRY WT., G/SQ M & 2 & 5.29 & 24.59 & & & \\
\hline BIOMASS, ASH WT., G/SO M & 2 & 3.89 & 14.00 & & & \\
\hline CHLOROPHYLL A, MG/SO M & 2 & 2.6 & 3.0 & & & \\
\hline CHLOROPHYLL B, MG/SO M & 2 & .5 & .7 & & & \\
\hline ORGANIC CARBON, MG/L & 4 & 1.5 & 8.0 & & & \\
\hline
\end{tabular}


Table 14.--Summary of measurements at each station--Continued

LAT $41030 M O O S$ LONG $083042 \mathrm{M} 46 \mathrm{~S}$

DRAINAGE AREA: 6330 SQ MI ( 16395 SQ KM)

PERIOD OF RECORD: $10 / 01 / 74-09 / 30 / 75$

STATISTICAL SUMMARY OF SELECTED DISSOLVED CHEMICAL CONSTITUENTS AND

REGRESSION RELATIONSHIPS OF CONSTITUENT CONCENTRATIONS TO SPECIFIC CONDUCTANCE

CONSIIUENI

CONSIUUVENI IMG/LOR UNII SHOHNI

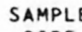

SAMPLE STANOARD

SI

TEMPERATURE, WATER IDEG CI

SPECIFIC CONOUCTANCE (MICROMHOS)

STREAMFLOH (CUBIC FT/SEC)

PH (STANDARO UNITS)

PHOSPHORUS, TOTAL

NITRITE + NITRATE, TOTAL

NITROGEN, KJELDAHL, TOTAL

PHYTOPLANKTON, TOTAL (CELLS/ML)

SEDIMENT, SUSPENDED

SEDIMENT, CLAY-SILT IPERCENT

COLIFGRM, FECAL (COL/100 ML)

STREPTOCOCCI, FECAL I COL/100 ML)

SILICA, DISSOLVED

CALCIUM, DISSOLVED

MAGNESIUM, DISSOLVED

SODIUM, DISSOLVED

POTASSIUM, DISSOLVED

BICARBONATE, ION

CARBONATE, ION

SULFATE, DISSOLVED

CHLORIDE, DISSOLVED

DISSOLVED SOLIDS, SUM OF CONST

DISSOLVED SOLIDS, ROE 180 DEG C

HARONESS, TOTAL

HARDNESS, NONCARBONATE

TURBIDITY (JTU

FLOURIDE, DISSOLVED

\section{MEAN}

10.72 $552 \cdot 1$

11375.6

7.76

0.312

5.074

1.247

7860.9

290.6

98.8

736.0

8427.3
5.05

5.05
62.00

62.00
17.25

17.25
28.50

4.12

163.5

0.3

89.25

38.25

38.25
325.8

325.8
380.8

227.5

91.0

109.8
0.50

137.6

13176.0

0.70

0.129

3.489

0.402

300.3

1.0

859.5

2772.0

3.36
7.39

7.39
5.68

29.67

2.15

39.8

47.35

47.35

27.22
119.6

119.6
116.2

33.0

7.0

104.6
0.35

*Not significant at the 95 percent confidence level.

SUMMARY OF HARMONIC ANALYSIS OF STREAM TEMPERATURE

\begin{tabular}{|c|c|c|c|c|c|}
\hline & & & & & STANDARD \\
\hline & HARMONIC & AMPLITUDE & PHASE & VAR IATION & ERROR OF \\
\hline $\begin{array}{l}\text { SAMPLE } \\
\text { SIZE }\end{array}$ & $\begin{array}{l}\text { MEAN - M } \\
\text { LDEG } C 1\end{array}$ & $\begin{array}{c}-{ }^{A} \\
(0 E G)\end{array}$ & $\begin{array}{l}\text { ANGLE - C } \\
\text { (BADIANSI) }\end{array}$ & EXPLAINED & $\begin{array}{l}\text { ESTIMATE } \\
\text { (DEG C) }\end{array}$ \\
\hline 16 & 13.17 & 13.17 & 2.70 & 94 & 2.73 \\
\hline
\end{tabular}

\section{BEGRESSION SUMMARY}

REGRESSION

SAMPLE COEFICIENT.

CONSTANT,

CORRELATION COEEICIENI

STANDARD

BANGE

31.0
840

$405 \quad 840$

$\begin{array}{llll}291 & 49200 & 12 & -13.719\end{array}$

6.2

$0.10 \quad 0.50$

$0.02 \quad 9.80$

$2.10 \quad 12$

$$
\begin{array}{r}
0.0017 \\
-0.00030 \\
-0.01126 \\
-0.00038 \\
35.077
\end{array}
$$

12808.027

6.8263

0.48001

11.28920

1.45964

$-11575.070$

$-0.390$

0.330 *

-0.326 *

$-0.131$.

0.629

4671.5

0.7

3.279

0.418

6583.2

$\begin{array}{rr}13 & 892 \\ 98 & 100 \\ 15 & 2700 \\ 62 & 80000\end{array}$

80000
7.2

$\begin{array}{rr}0.1 & 7.2 \\ 53.0 & 71.0\end{array}$

$13.0 \quad 25.0$

73.0

$\begin{array}{lr}4 & -0.0174 \\ 4 & 0.0072 \\ 4 & 0.0297 \\ 4 & 0.1550 \\ 4 & 0.0112 \\ 4 & 0.131 \\ 4 & 0.003 \\ 4 & 0.2513 \\ 4 & 0.1429 \\ 4 & 0.649 \\ 4 & 0.627 \\ 4 & 0.148 \\ 4 & 0.026 \\ 4 & -0.443 \\ 4 & 0.0019\end{array}$

15.057

57.8603

0.2054

$-60.4191$

88.436

$-1.250$

$-54.9426$

$-43.7625$

$-46.506$

20.744

142.805

75.877

363.856

$-0.5729$
$-0.956$

0.180 .

0.964 .

0.963 .

0.963 .

0.606

0.963

0.978

0.968

1.000

0.995

0.823

0.096 *

-0.780 .

0.995 .
1.20
8.91
1.85
9.86
0.71
38.8
0.2
12.10
8.41
4.0
14.5
23.0
6.1
80.1
0.04

0.0

\begin{tabular}{|c|c|c|c|c|c|c|}
\hline \multirow{2}{*}{ CONSTITUENT } & \multicolumn{3}{|c|}{ TOTAL } & \multicolumn{3}{|c|}{ DISSOLVED } \\
\hline & $\begin{array}{l}\text { NO. } \\
\text { SAMPLES }\end{array}$ & $\begin{array}{l}\text { MIN IMUM } \\
\text { CONC. }\end{array}$ & $\begin{array}{l}\text { MAXIMUM } \\
\text { CONC. }\end{array}$ & $\begin{array}{l}\text { NO. } \\
\text { SAMPLES }\end{array}$ & $\begin{array}{l}\text { MINIMUM } \\
\text { CONC. }\end{array}$ & $\begin{array}{l}\text { MAXIMUM } \\
\text { CONC. }\end{array}$ \\
\hline \multicolumn{7}{|l|}{ MINOR ELEMENTS: } \\
\hline ARSENIC (AS), UG/L & 4 & 2 & 6 & 4 & 1 & 2 \\
\hline CADMIUM $(C D), U G / L$ & 4 & 0 & 2 & 4 & 0 & 1 \\
\hline CHROMIUM (CR), UG/L & 4 & 0 & 20 & 4 & 0 & $<10$ \\
\hline COBALT $(C O), U G / L$ & 4 & 0 & 3 & 4 & 0 & 1 \\
\hline COPPER $(C U), U G / L$ & 4 & 10 & 20 & 4 & 0 & 20 \\
\hline IRUN (FE), UG/L & 4 & 400 & 10000 & 4 & 10 & 70 \\
\hline LEAD $(P B), U G / L$ & 4 & 5 & 14 & 4 & 0 & 4 \\
\hline MANGANESE (MN), UG/L & 4 & 70 & 220 & 4 & 0 & 20 \\
\hline MERCURY $(H G), U G / L$ & 4 & $<0.5$ & $<0.5$ & 4 & $<0.5$ & $<0.5$ \\
\hline SELENIUM (SE), UG/L & 4 & 1 & 3 & 4 & 1 & 3 \\
\hline$Z I N C(Z N), U G / L$ & 4 & 20 & 140 & 4 & 0 & 20 \\
\hline \multicolumn{7}{|l|}{ PERIPHYTON: } \\
\hline BIOMASS, DRY WT., G/SO M & 1 & 2.19 & & & & \\
\hline BIOMASS, ASH WT., G/SO M & 2 & .00 & 4.59 & & & \\
\hline CHLOROPHYLL A, MG/SO M & 2 & 10.0 & 29.0 & & & \\
\hline CHLOROPHYLL B, MG/SO M & 2 & 2.0 & $3 \cdot 0$ & & & \\
\hline ORGANIC CARBON, MG/L & 4 & 3.3 & 13.0 & & & \\
\hline
\end{tabular}

SUMMARY OF MAXIMUM AND MINIMUM CONCENTRATIONS OF CONSTITUENTS SAMPLED AT A FREQUENCY OF OUARTERLY (1975 WY

04193500 - MAUMEE R AT WATERVILLE OH 
LAT $41023 M 43 S$ LONG $081037 M 48 S$ DRAINAGE AREA: 707 SQ MI 11831 SQ KMI

PERIOD OF RECORD: $10 / 01 / 74-09 / 30 / 75$

STATISTICAL SUMMARY OF SELECTED DISSOLVED CHEMICAL CONSTITUENTS AND REGRESSION RELATIONSHIPS OF CONSTITUENT CONCENTRATIONS TO SPECIFIC CONDUCTANCE

CONSILIUENI

CONSIUUENI IMG $\angle L O R$ UNII_SHOWN

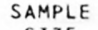

SIZE

TEMPERATURE, WATER (DEg C)

SPECIFIC CONDUCTANCE (MICROMHOS)

STREAMFLOW (CUBIC FT/SEC)

PH ISTANDARD UNITS

PHOSPHORUS, TOTAL

NITRITE + NITRATE, TOTAL

NITROGEN, KJELDAHL, TOTAL

PHYTOPLANKTON, TOTAL (CELLS/ML)

SEDIMENT, SUSPENDED

SEDIMENT, CLAY-SILT (PERCENT)

COLIFORM, FECAL (COL/100 ML)

STREPTOCOCCI, FECAL (COL/100 ML)

SILICA, DISSOLVED

CALCIUM, DISSOLVED

MAGNE SIUM, DISSOLVEL

SODIUM, DISSOLVED

POTASSIUM, DISSOLVED

BICARGONATE, ION

CARBONATE, ION

SULFATE, DISSOLVED

CHLORIDE, DISSOLVED

DISSOLVED SOLIDS, SUM OF CONST

DISSOLVED SOLIDS, ROE 180 DEG

HARDNESS, TOTAL

HARDNESS, NONCARBCNATE

TURBIDITY (JTU)

FLOURIDE, DISSOLVED
STANDARD

MEAN DEYIALION

$\begin{array}{rrrr}13 & 11.77 & 7.96 & 1.5 \\ 12 & 604.2 & 145.4 & 400 \\ 12 & 1309.0 & 754.0 & 264 \\ 12 & 7.45 & 0.09 & 7.3 \\ 12 & 0.403 & 0.182 & 0.13 \\ 12 & 1.458 & 0.741 & 0.71 \\ 12 & 1.179 & 0.346 & 0.64 \\ 12 & 4530.0 & 4323.1 & 330 \\ 12 & 73.6 & 48.6 & 10 \\ 0 & & & \\ 12 & 10950.0 & 8790.2 & 1500 \\ 12 & 6721.7 & 15694.4 & 160 \\ 4 & 7.12 & 2.33 & 4.7 \\ 4 & 56.50 & 13.99 & 38.0 \\ 4 & 14.25 & 5.12 & 9.0 \\ 4 & 54.50 & 16.94 & 30.0 \\ 4 & 4.80 & 2.13 & 3.1 \\ 4 & 140.3 & 43.3 & 88 \\ 4 & 0.0 & 0.0 & 0 \\ 4 & 88.75 & 25.10 & 61.0 \\ 4 & 81.25 & 25.05 & 44.0 \\ 4 & 377.0 & 105.0 & 235 \\ 4 & 417.0 & 122.0 & 260 \\ 4 & 197.5 & 53.2 & 130 \\ 4 & 84.3 & 21.1 & 60 \\ 4 & 15.0 & 10.2 & 8 \\ 4 & 0.32 & 0.17 & 0.1\end{array}$

BANGE

${ }^{*}$ Not significant at the 95 percent confidence level.

SUMMARY OF HARMONIC ANALYSIS OF STREAM TEMPERATURE

\begin{tabular}{|c|c|c|c|c|c|}
\hline & & & & & STANDARD \\
\hline & HARMONIC & AMPLITUDE & PHASE & VARIATION & ERROR OF \\
\hline SAMPLE & MEAN - M & $-A$ & ANGLE - C & EXPLAINED & ESTIMATE \\
\hline SIZE_ & DEE 61 & (DEG C) & IBADIANSI & $-1 \xi 1 \ldots$ & IDEG_CI_ \\
\hline
\end{tabular}

12.59

\begin{abstract}
10.75
\end{abstract}

\begin{abstract}
2.70
\end{abstract}
99

1.00
BEGRESSION SUMMARY REGRESSION

SAMPLE COEFICIENT, CONSTANT, CORRELATION ERROR OF SIZE - B _ _ B - COEEICIENI ESILMAIE 23.5 800 2680 7.6
0.76 0.76
3.20 1.80 13000 189

$12-4.438$ $\begin{array}{ll}12 & 0.0002 \\ 12 & 0.00107\end{array}$ 0.00107 0.0014

1.305
.00142

3990.295 7.3499 $-0.24382$ $-0.72467$ 0.31887

3741.784

$-0.856$ 0.266
0.857 0.857
0.709 0.709
0.599 0.599
0.044.

409.0 0.09
0.098 0.548 0.291
4529.7

31000
50000

50000

$\begin{array}{lll}10.0 & 4 & 0.0087\end{array}$

70.0
20.0

68.0
7.7

7.7
189

180
110.0
459

459
530

240

110
30

0.5

4529.7

SUMMARY OF MAXIMUM AND MINIMUM CONCENTRATIONS OF CONSTITUENTS SAMPLED AT A FREQUENCY OF QUARTERLY (1975 WY)

04208000 -- CUYAHOGA R AT INDEPENDENCE OH

\begin{tabular}{|c|c|c|c|c|c|c|}
\hline \multirow{2}{*}{ CONSTITUENT } & \multicolumn{3}{|c|}{ TOTAL } & \multicolumn{3}{|c|}{ DISSOLVED } \\
\hline & $\begin{array}{l}\text { NO. } \\
\text { SAMPLES }\end{array}$ & $\begin{array}{l}\text { MINIMUM } \\
\text { CONC. }\end{array}$ & $\begin{array}{l}\text { MAXIMUM } \\
\text { CONC. }\end{array}$ & $\begin{array}{l}\text { NO. } \\
\text { SAMPLES }\end{array}$ & $\begin{array}{l}\text { MINIMUM } \\
\text { CONC. }\end{array}$ & $\begin{array}{l}\text { MAXIMUM } \\
\text { CONC. }\end{array}$ \\
\hline \multicolumn{7}{|l|}{ MINOR ELEMENTS: } \\
\hline ARSENIC (AS), UG/L & 4 & 3 & 6 & 4 & 1 & 5 \\
\hline CADMIUM (CD), UG/L & 4 & 0 & 1 & 4 & 0 & 1 \\
\hline CHROMIUM (CR), UG/L & 4 & 10 & 20 & 4 & 0 & $<10$ \\
\hline COBALT $(C O)$, UGIL & 4 & 0 & 2 & 4 & 0 & 0 \\
\hline COPPER (CU), UG/L & 4 & 10 & 60 & 4 & 10 & 10 \\
\hline IRON (FE), UG/L & 4 & 520 & 2800 & 4 & 30 & 90 \\
\hline LEAD $(P B), U G / L$ & 4 & 4 & 24 & 4 & 1 & 6 \\
\hline MANGANESE (MN), UG/L & 4 & 110 & 290 & 4 & 70 & 120 \\
\hline MERCURY (HG), UG/L & 4 & $<0.5$ & 0.8 & 4 & $<0.5$ & 0.6 \\
\hline SELENIUM $(S E), U G / L$ & 4 & 0 & 2 & 4 & 0 & 2 \\
\hline ZINC $(Z N), U G / L$ & 4 & 20 & 160 & 4 & 10 & 30 \\
\hline \multicolumn{7}{|l|}{ PERIPHYTON: } \\
\hline BIOMASS, DRY WT., G/SQ M & 2 & 6.00 & 19.00 & & & \\
\hline BIOMASS, ASH WT., G/SQ M & 4 & 3.89 & 12.00 & & & \\
\hline CHLOROPHYLL A, MG/SQ M & 4 & .0 & 46.0 & & & \\
\hline CHLOROPHYLL B, MG/SO M & 4 & .0 & 7.0 & & & \\
\hline ORGANIC CARBON, MG/L & 3 & 5.0 & 11.0 & & & \\
\hline
\end{tabular}


Table 14.--Summary of measurements at each station--Continued

LAT 43D15M4OS LONG 079003M47S

DRAINAGE AREA: 0 SQ MI 1

PERIOD OF RECORD: $10 / 01 / 74-09 / 30 / 75$

SO KM)

STATISTICAL SUMMARY OF SELECTED DISSOLVED CHEMICAL CONSTITUENTS AND REGRESSION RELATIONSHIPS OF CONSTITUENT CONCENTRATIONS TO SPECIFIC CONDUCTANCE

CONSIUIUENI

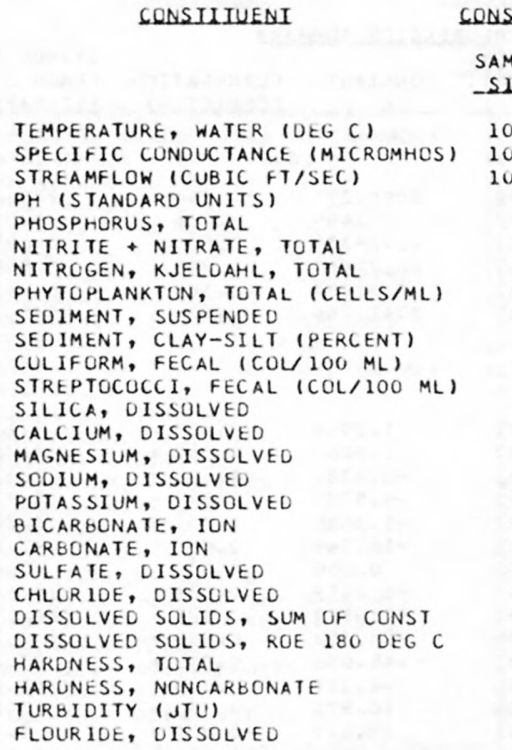

CONSIUTUENI IMG/L OR UNII SHOWNL

\begin{tabular}{|c|c|c|c|c|}
\hline $\begin{array}{l}\text { SAMPLE } \\
\text { SIZE }\end{array}$ & MEAN & $\begin{array}{l}\text { STANDARO } \\
\text { DEYIAIION }\end{array}$ & \multicolumn{2}{|c|}{$B A N G E$} \\
\hline 102 & 14.40 & 7.42 & 0.5 & 23.0 \\
\hline 102 & 317.1 & 14.1 & 285 & 350 \\
\hline 1022 & 239026.8 & 23579.2 & 23900 & 252000 \\
\hline 9 & 7.73 & 0.29 & 7.3 & 8.2 \\
\hline 9 & 0.030 & 0.007 & 0.02 & 0.04 \\
\hline 9 & 0.206 & 0.140 & 0.09 & 0.52 \\
\hline 9 & 0.364 & 0.045 & 0.29 & 0.42 \\
\hline 9 & 1485.8 & 1171.7 & 72 & 3900 \\
\hline 8 & 7.9 & 3.4 & 4 & 15 \\
\hline 8 & 74.0 & 15.8 & 57 & 100 \\
\hline 9 & 203.1 & 148.6 & 47 & 500 \\
\hline 9 & 33.1 & 37.4 & 1 & 100 \\
\hline 9 & 0.36 & 0.45 & 0.0 & 1.5 \\
\hline 9 & 38.33 & 2.50 & 36.0 & \\
\hline 9 & 8.22 & 1.13 & 5.5 & 9.5 \\
\hline 9 & 10.89 & 0.00 & 10.0 & 12.0 \\
\hline 9 & 1.41 & 0.06 & 1.3 & 1.5 \\
\hline 9 & 112.9 & 2.6 & 108 & \\
\hline 9 & 0.0 & 0.0 & 0 & \\
\hline 9 & 25.22 & 0.44 & 25.0 & \\
\hline 9 & 24.00 & 2.06 & 22.0 & 29. \\
\hline 9 & 164.2 & 2.6 & 160 & 168 \\
\hline 9 & 191.8 & 12.7 & 167 & 209 \\
\hline 9 & 131.1 & 3.3 & 130 & 140 \\
\hline 9 & 37.0 & 3.5 & 32 & \\
\hline 9 & 3.8 & 1.6 & 1 & \\
\hline 9 & 0.22 & 0.16 & 0.1 & 0 \\
\hline
\end{tabular}
*Not significant at the 95 percent confidence level.

BEGBESSION SUMMABY

REGRESSION

SAMPLE SIZE. COEFICIENT,

CONSTANT,

CORRELATION - - B COEEICIENI ESILMAI:

102

$\begin{array}{rr}-449.458 & 381571.188 \\ -0.0184 & 13.5587 \\ -0.00056 & 0.20791 \\ -0.00088 & 0.48355 \\ -0.00337 & 1.43007\end{array}$

$-0.269$ $-0.489 *$ $-0.016 *$ $-0.049^{*}$ $-0.570^{*}$

-1995.8420 .073 *

22826.3 0.27 0.150 0.150 1249.2

11.002

1249 . DAILY SPECIFIC CONDULTANCE IN MICRUMHOS AT 25 DEG C, THAT WAS $\begin{array}{llllll}12 & 53 & 20 z & 20 z & 20 z\end{array}$

EQUALLED OR EXCEEDED FUR THE
INDICATED PERCENTAGE OF TIME

$\begin{array}{llllll}364 & 360 & 357 & 354 & 350 & 333\end{array}$

708

315

$$
\begin{array}{r}
-0.0146 \\
0.0410 \\
0.0596 \\
0.0030 \\
0.0022 \\
-0.012 \\
0.000 \\
-0.0268 \\
-0.0729 \\
-0.023 \\
0.200 \\
0.178 \\
0.364 \\
0.050 \\
-0.0031
\end{array}
$$

4.9831 25.3739

$-10.6312$

9.9371

0.7158

116.550

0.000

33.7154

47.0034

171.397

128.591
74.734

$-78.317$

$-11.964$

-11.964
1.2032

$-0.252 *$ 0.127 * 0.039 *

0.283 *

$-0.035 *$

$-0.035^{*}$

\begin{tabular}{|c|c|c|c|c|c|}
\hline & & & & & STANDARD \\
\hline & HARMONIC & AMPLITUDE & PHASE & VARIATION & ERROR OF \\
\hline SAMPLE & MEAN - M & $-A$ & $A N G L E-C$ & EXPLAINEO & ESTIMATE \\
\hline SLZE_ & $10 E 6 \quad C 2$ & $10 E 6 \mathrm{CL}$ & (RADIANS) & $-(\%)$ & DEEG CL \\
\hline 190 & 11.02 & 13.11 & 2.34 & 96 & 1.97 \\
\hline
\end{tabular}

-0.472 *

$-0.472 *$
$-0.274 *$

$-0.274 *$
$-0.007 *$

$0.121 *$

\begin{tabular}{|c|c|c|c|c|c|c|c|}
\hline \multirow{2}{*}{ CONSTITUENT } & \multicolumn{3}{|c|}{ TOTAL } & \multicolumn{3}{|c|}{ DISSOLVED } & \\
\hline & $\begin{array}{l}\text { NO. } \\
\text { SAMPLES }\end{array}$ & $\begin{array}{l}\text { MIN IMUM } \\
\text { CONC. }\end{array}$ & $\begin{array}{l}\text { MAXIMUM } \\
\text { CONC. }\end{array}$ & $\begin{array}{l}\text { NO. } \\
\text { SAMPLES }\end{array}$ & $\begin{array}{l}\text { MINIMUM } \\
\text { CONC. }\end{array}$ & $\begin{array}{l}\text { MAXIMUM } \\
\text { CONC. }\end{array}$ & \\
\hline \multicolumn{8}{|l|}{ MINOR ELEMENTS: } \\
\hline ARSENIC (AS), UG/L & 5 & 1 & 11 & 4 & 0 & 1 & \\
\hline CADMIUM $(C D), U G / L$ & 5 & 0 & 8 & 5 & 0 & 5 & \\
\hline CHROMIUM (CR), UG/L & 5 & 0 & 10 & 5 & 0 & 10 & \\
\hline COBALT $(C O), U G / L$ & 5 & 0 & 1 & 5 & 0 & 1 & \\
\hline COPPER (CU), UG/L & 5 & 0 & 20 & 5 & 0 & 10 & \\
\hline IRON (FE), UG/L & 5 & 130 & 280 & 5 & 10 & 30 & \\
\hline LEAD $(P B)$, UG/L & 5 & 5 & 46 & 5 & 1 & 9 & \\
\hline MANG ANESE (MN), UG/L & 5 & 0 & 20 & 5 & 0 & 10 & \\
\hline MERCURY $(H G), U G / L$ & 5 & $<0.5$ & $<0.5$ & 5 & $<0.5$ & $<0.5$ & \\
\hline SELENIUM (SE), UG/L & 5 & 0 & 1 & 5 & 0 & 1 & \\
\hline$Z I N C(Z N), U G / L$ & 5 & 10 & 60 & 5 & 0 & 30 & \\
\hline \multicolumn{8}{|l|}{ PERIPHYTON: } \\
\hline BIOMASS, ORY WT., G/SO M & 4 & 5.19 & 35.00 & & & & \\
\hline $\begin{array}{l}\text { GIOMASS, ASH WT., G/SQ M } \\
\text { CHLOROPHYLL A, MG/SO M }\end{array}$ & 4 & $\begin{array}{r}2.39 \\
9.5\end{array}$ & $\begin{array}{r}28.00 \\
31.0\end{array}$ & & & & \\
\hline CHLOROPHYLL B, MG/SO M & 4 & .0 & 8.2 & & & & \\
\hline ORGANIC CAREON, MG/L & 5 & 2.8 & 9.2 & & & & \\
\hline
\end{tabular}

0.414

0.799

$0.247 *$

-0.154 *

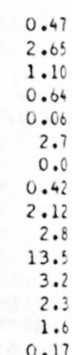

SAMPLE SIZE_ $\equiv-188$

$202 \quad 251 \quad 29 \%$

$309308 \quad 306$

SUMMARY OF MARMONIC ANALYSIS OF STREAM TEMPERATURE

SUMMARY OF MAXIMUM AND MINIMUM CONCENTRATIONS OF CONSTITUENTS SAMPLED AT A FREQUENCY OF QUARTERLY (1975 WY)

U4219040 -- NIAGARA R(L ONTARIO) AT FORT NIAGARA NY 
AT 43013M26S LONG 077036M59S

IRAINAGE AREA: 0 SQ MI

IERIOD UF RECORD: $10101 / 74-09 / 30 / 75$

SQ KMI

STATISTICAL SUMMARY OF SELECTED DISSOLVED CHEMICAL CONSTITUENTS AND

REGRESSION RELATIONSHIPS OF CONSTITUENT CONCENTRATIONS TO SPECIFIC CONDUCTANCE

CONSIIIUENI

\begin{tabular}{|c|}
\hline 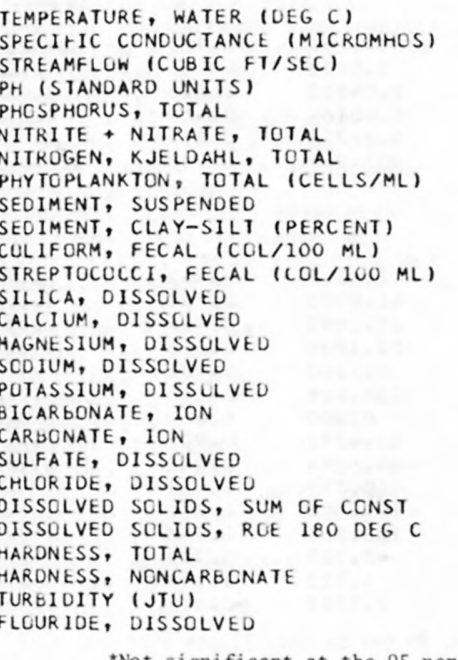 \\
\hline
\end{tabular}

CONSIIIUENI IMGLL OR UNII SHOWNI

\begin{tabular}{r} 
SAMPL \\
S1ZE \\
\hline \\
88 \\
88 \\
9 \\
9 \\
9 \\
9 \\
9 \\
9 \\
9 \\
9 \\
9 \\
9 \\
9 \\
9 \\
9 \\
9 \\
9 \\
9 \\
9 \\
9 \\
9 \\
9 \\
9 \\
9 \\
9 \\
9 \\
9
\end{tabular}

STANDARD DEYIAIION

16.14 620.5 2641.1 7.60 0.150 0.604 0.902 5531.1

531.1
83.3 91.3 14060.0 1252.8 2.06
59.89 12.50 38.00 3.03 3.03
142.9 142.9
0.0 78.00 78.00
64.67 64.67
329.6 329.6
369.0 201.1 84.2 36.6

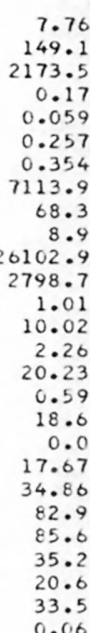

7.76
149.1

2173.5

0.17

0.059

0.354

113.9 68.3 26102.9 2798.7 1.01 20.23

0.59

18.6 17.67 34.86
82.9 82.9
85.6

\section{1} BANGE

*Not significant at the 95 percent confidence level.

DAILY SPECIFIC CONDUCTANCE DURAIION_IABLE_OF_DAILY SPECIEIC CONDUCIANCE

DAILY SPECIFIC CONDUCTANCE IN

MICRCMHUS AT 25 DEG C, THAT WAS

EUUALLED OR EXCEEDED FOR THE

$\begin{array}{llllll}-18 & -58 & 10 \% & 208 & 30 \% & 50 \% \\ 770 & 701 & 672 & 630 & 597 & 542\end{array}$

$\begin{array}{rr}1.5 & 26.5 \\ 418 & 950 \\ 940 & 7780 \\ 7.4 & 8.0 \\ 0.06 & 0.25 \\ 0.38 & 1.20 \\ 0.36 & 1.60 \\ 480 & 24000 \\ 27 & 226 \\ 72 & 99 \\ 50 & 72000 \\ 20 & 8600 \\ 1.2 & 4.6 \\ 45.0 & 80.0 \\ 9.6 & 16.0 \\ 17.0 & 66.0 \\ 2.0 & 3.7 \\ 107 & 171 \\ 0 & 0 \\ 51.0 & 110.0 \\ 27.0 & 110.0 \\ 222 & 469 \\ 235 & 525 \\ 150 & 270 \\ 59 & 130 \\ 10 & 100 \\ 0.1 & 0.3\end{array}$

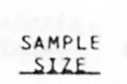
REGRESSION

BEGBESSION_SUMMABY

COEFICIENT,

CONSTANT,

CORRELATION COEEICIENI STANDARD ESILMAIE

$\begin{array}{rr}-8.854 & \\ 0.0004 & 730.313 \\ -0.00005 & 0.18312 \\ -0.00061 & 0.98527 \\ 0.00110 & 0.22259 \\ 19.828 & -6761.996\end{array}$

$\begin{array}{rr}-0.082 & 1699.3 \\ 0.419 * & 0.17 \\ -0.154 * & 0.062 \\ -0.400 * & 0.252 \\ 0.519 * & 0.323 \\ 0.467 * & 6726.2\end{array}$

99
2000
8600
4.6
80.0
16.0
66.0
3.7
171
0
10.0
10.0
469
525
270
130
100
0.3

.80
25
20
60
00
26
99
00
00
.6
.0
.0$$
19 .
$$

$\begin{array}{rrr}9 & -0.0048 & 5.6339 \\ 9 & 0.0310 & 40.6882 \\ 9 & 0.0092 & 0.8065 \\ 9 & 0.1050 & -27.0749 \\ 9 & 0.0025 & 1.0675 \\ 9 & 0.050 & 112.016 \\ 9 & 0.000 & 0.000 \\ 9 & 0.0931 & 20.2626 \\ 9 & 0.1796 & -46.6723 \\ 9 & 0.439 & 57.214 \\ 9 & 0.436 & 98.431 \\ 9 & 0.129 & 121.018 \\ 9 & 0.080 & 34.864 \\ 9 & -0.148 & 128.473 \\ 9 & 0.0002 & 0.0750\end{array}$

-0.796
0.518
0.680
0.869
0.720
$0.448 *$
$0.000 *$
0.882
0.862
0.887
0.853
$0.015 *$
0.647
-0.740
0.512.

0.65

9.16
1.77

10.71

0.44

17.8

0.0

8.89

18.87

40.9

47.7

29.6

24.1

0.00

INDICATED PERCENTAGE OF TIME

SUMMARY UF HARMONIC ANALYSIS OF STREAM TEMPERATURE

\begin{tabular}{|c|c|c|c|c|c|}
\hline & & & & & STANDARD \\
\hline & HARMONIC & AMPLITUDE & $\begin{array}{l}\text { PHASE } \\
\text { ANGLE }\end{array}$ & $\begin{array}{l}\text { VARIATION } \\
\text { EXP LAINED }\end{array}$ & $\begin{array}{l}\text { ERROR OF } \\
\text { ESTIMATE }\end{array}$ \\
\hline SIZE. & MEAN $101^{M}$ & IDEG $\left.{ }^{A}\right)$ & (BADIANSI) & $-(\xi)$ & (DEG_L) \\
\hline 154 & 11.98 & 11.79 & 2.75 & 94 & 1.52 \\
\hline
\end{tabular}

SUMMARY UF MAXIMUM AND MINIMUM CONCENTRATIONS OF CONSTITUENTS

SAMPLED AT A FREQUENCY OF OUARTERLY (1975 WY)

U4232006 -- GENESEE RIVER(CHARLOITE DOCKS)AT ROCHESTER NY

\begin{tabular}{|c|c|c|c|c|c|c|}
\hline \multirow{2}{*}{ CONSTITUENT } & \multicolumn{3}{|c|}{ TOTAL } & \multicolumn{3}{|c|}{ DISSOLVED } \\
\hline & $\begin{array}{l}\text { NO. } \\
\text { SAMPLES }\end{array}$ & $\begin{array}{l}\text { MIN IMUM } \\
\text { CONC. }\end{array}$ & $\begin{array}{l}\text { MAXIMUM } \\
\text { CONC. }\end{array}$ & $\begin{array}{l}\text { NO. } \\
\text { SAMPLES }\end{array}$ & $\begin{array}{l}\text { MINIMUM } \\
\text { CONC. }\end{array}$ & $\begin{array}{l}\text { MAXIMUM } \\
\text { CONC. }\end{array}$ \\
\hline \multicolumn{7}{|l|}{ MINOR ELEMENTS: } \\
\hline ARSENIC (AS), UG/L & 5 & 1 & 3 & 5 & 1 & 2 \\
\hline CADMIUM $(C D), U G / L$ & 5 & 0 & 5 & 5 & 0 & 3 \\
\hline CHROMIUM (CRI, UG/L & 5 & 0 & 10 & 5 & 0 & $<10$ \\
\hline COBALT $(C O), U G / L$ & 5 & 0 & 3 & 5 & 0 & 1 \\
\hline COPPER (CU), UG/L & 5 & 10 & 50 & 5 & 0 & 20 \\
\hline IRON $(F E), U G / L$ & 5 & 820 & 7400 & 5 & 40 & 60 \\
\hline LEAD (PG), UG/L & 5 & 12 & 29 & 5 & 0 & 4 \\
\hline MANGANESE (MN), UGIL & 5 & 50 & 180 & 5 & 30 & 70 \\
\hline MERCURY $(H G), U G / L$ & 5 & $<0.5$ & 0.7 & 5 & $<0.5$ & 0.5 \\
\hline SELENIUM (SE), UG/L & 5 & 0 & 1 & 5 & 0 & 0 \\
\hline ZINC $(Z N), U G / L$ & 5 & 30 & 40 & 5 & 10 & 30 \\
\hline \multicolumn{7}{|l|}{ PERIPHYTON: } \\
\hline GICMASS, ORY WT., G/SO M & 3 & 22.00 & 45.00 & & & \\
\hline GIOMASS, ASH WT., G/SO M & 3 & 16.00 & 37.00 & & & \\
\hline CHLOROPHYLL A, MG/SQ M & 3 & 19.0 & $100 \cdot 0$ & & & \\
\hline CHLOROPHYLL B, MG/SO M & 3 & .7 & 23.0 & & & \\
\hline ORGANIC CARBON, MG/L & 5 & 3.7 & 7.7 & & & \\
\hline
\end{tabular}


LAT 43027MOOS LONG 076030M20S

DRAINAGE AREA: 5098 SO MI ( 13204 SQ KM)

PERIOD OF RECORD: 10/01/74-09/30/75

STATISTICAL SUMMARY OF SELECTED DISSOLVED CHEMICAL CONSTITUENTS AND REGRESSION RELATIONSHIPS OF CONSTITUENT CONCENTRATIONS TU SPECIFIC CONDUCTANCE

CONSIIJUENI

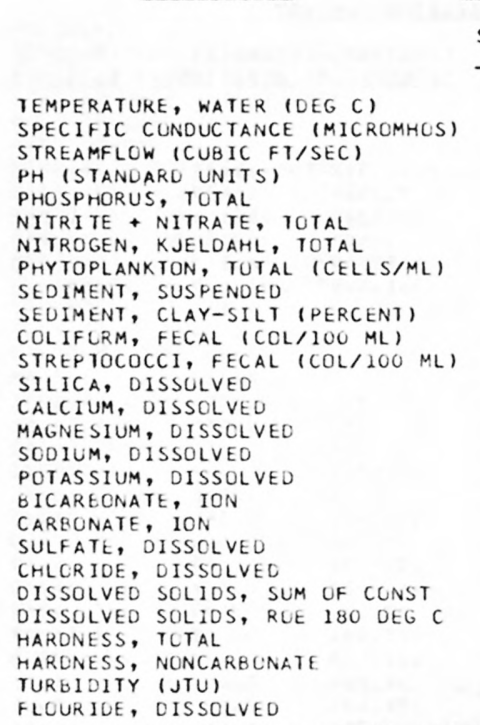

CONSIUIUENI IMG $\angle L O R$ UNII_SHOWN

SAMPL
SIZE
20
20
9
9
9
9
9
9
7
7
9
9
9
9
9
9
9
9
9
9
9
9
9
9
9
9
9

STANDARO MEAN REYIALION 18.20 1268.0 5883.3 7.61 0.098 0.807

21660.7

1660.7
16.3 $16 \cdot 3$
82.1 13487.3

143.2

0.88
92.67

13.00
46.67

3.34

131.3

0.0

71.56
223.89
567.6

567.6
690.7

285.6

178.9

5.1
0.78
6.59

372.6

3229.0

0.24

0.025

0.175

0.183
3527.7

527.7

4.8
7.8

20585.8

136.8

0.59
23.78

23.78

1.41
42.53

4.53

1.00

16.7
0.0

0.0
7.95

103.62

172.6

232.2

59.8
67.5

67.5
2.4

0.76

NAME: OSWEGO RIVER AT LOCK 7 AT OSWEGO NY

BEGRESSION_SUMMABY

REGRESSION

SAMPLE COEFICIENT,

CONSTANT,

CORRELATION

STANDARO SIZE.

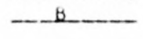
COEEICIENI

ERROR OF

BANGE

25.5

$\begin{array}{ll}5.00 & 25.5 \\ 7 & 1800\end{array}$

$\begin{array}{rr}3400 & 11800 \\ 7.3 & 8.1\end{array}$

0.07

0.13

$0.14 \quad 0.68$

0.57

12000

1.00

0.0000

0.00004

$-0.00018$

0.00039

12394.090 7.5651
0.04852

0.60164

0.34702

1083.957

$\begin{array}{rr}-0.702 & 2458.5 \\ 0.068 * & 0.25 \\ 0.675 & 0.020 \\ -0.419 * & 0.170 \\ 0.877 & 0.094 \\ 0.530 * & 12266.3\end{array}$

80000
430

$\begin{array}{llll}430 & & & \\ 1.9 & 9 & -0.0006 & 1.6362\end{array}$

$\begin{array}{rr}70.0 & 140.0 \\ 11.0 & 15.0\end{array}$

$\begin{array}{rr}70.0 & 140.0 \\ 11.0 & 15.0\end{array}$

42.0

2.0

160.8
4.8

$\begin{array}{rr}109 & 154 \\ 0 & 0\end{array}$

60.0

95.0

83.0

380.0

817
1080

433

230

110

0.2

${ }^{*}$ Not significant at the 95 percent confidence 1 evel.

SUMMARY OF HARMONIC ANALYSIS OF STREAM TEMPERATURE

\begin{tabular}{|c|c|c|c|c|c|}
\hline & & & & & STANDA \\
\hline SAM & $\begin{array}{l}\text { HARMONIC } \\
\text { MEAN - M }\end{array}$ & $\begin{array}{c}\text { AMPLITUDE } \\
-A\end{array}$ & PHASE & $\begin{array}{l}\text { VARIATION } \\
\text { EXPLAINED }\end{array}$ & $\begin{array}{l}\text { ERROR OF } \\
\text { ESTIMATE }\end{array}$ \\
\hline SIZE_ & (DEG_E) & $10 E E^{4}(1)$ & IBADIANSI & (z) & IDEG C. \\
\hline
\end{tabular}

32

9.14

16.41

2.70

93

1.57

SUMMARY OF MAXIMUM AND MINIMUM CONCENTRATIONS OF CONSTITUENTS SAMPLED AT A FREQUENCY OF QUARTERLY (1975 WY)

14249000 -- OSWEGO RIVER AT LOCK 7 AT OSWEGO NY

\begin{tabular}{|c|c|c|c|c|c|c|}
\hline \multirow{2}{*}{ CONSTITUENT } & \multicolumn{3}{|c|}{ TOTAL } & \multicolumn{3}{|c|}{ DISSOLVED } \\
\hline & $\begin{array}{l}\text { NO. } \\
\text { SAMPLES }\end{array}$ & $\begin{array}{l}\text { MIN IMUM } \\
\text { CONC. }\end{array}$ & $\begin{array}{l}\text { MAXIMUM } \\
\text { CONC. }\end{array}$ & $\begin{array}{l}\text { NO. } \\
\text { SAMPLES }\end{array}$ & $\begin{array}{l}\text { MINIMUM } \\
\text { CONC. }\end{array}$ & $\begin{array}{l}\text { MAXIMUM } \\
\text { CONC. }\end{array}$ \\
\hline \multicolumn{7}{|l|}{ MINOR ELEMENTS: } \\
\hline ARSENIC (AS), UG/L & 5 & 1 & 2 & 5 & 0 & 2 \\
\hline CADMIUM $(C D), U G / L$ & 5 & 0 & 2 & 5 & 0 & 1 \\
\hline CHROMIUM (CR), UG/L & 5 & 0 & 10 & 5 & 0 & 20 \\
\hline COBALT $(C O), U G / L$ & 5 & 0 & 3 & 5 & 0 & 3 \\
\hline CUPPER (CU), UG/L & 5 & 0 & 40 & 5 & 0 & 10 \\
\hline IRON $(F E), U G / L$ & 5 & 240 & 570 & 5 & 30 & 50 \\
\hline LEAD $(P B), U G / L$ & 5 & 2 & 24 & 5 & 0 & 3 \\
\hline MANGANESE $(M N), U G / L$ & 5 & 40 & 70 & 5 & 10 & 30 \\
\hline MERCURY $(H G), U G / L$ & 5 & $<0.5$ & $<0.5$ & 5 & $<0.5$ & $<0.5$ \\
\hline SELENIUM (SE), UG/L & 5 & 0 & 1 & 5 & 0 & 0 \\
\hline ZINC $(Z N), U G / L$ & 5 & 10 & 20 & 5 & 10 & 20 \\
\hline \multicolumn{7}{|l|}{ PERIPHYTON: } \\
\hline SIOMASS, DRY WT., G/SO M & 1 & 69.00 & & & & \\
\hline GIUMASS, ASH WT., G/SQ M & $i$ & 68.00 & & & & \\
\hline CHLOROPHYLL A, MG/SC M & 1 & .2 & & & & \\
\hline CHLOROPHYLL B, MG/SQ M & 1 & .0 & & & & \\
\hline ORGANIC CARBON, MG/L & 5 & 4.2 & 6.8 & & & \\
\hline
\end{tabular}


Table 14.--Summary of measurements at each station--Continued

LAT 43059M08S LONG 075055M30S

DRAINAGE AREA: 1870 SQ MI 14859 SO KM)

PERIOD OF RECORD: 10/01/74 - 09/30/75

STATISTICAL SUMMARY OF SELECTED DISSOLVED CHEMICAL CONSTITUENTS AND

REGRESSION RELATICNSHIPS OF CONSTITUENT CONCENTRATIONS TO SPECIFIC CONDUCTANCE

CONSIUIUENI

CONSIUIUENI
TEMPERATURE, WATER (DEG C)
SPECIFIC CONDUCTANCE (MICROMHOS)
STREAMFLOW (CUB IC FT/SEC)
PH (STANDARD UNITS)
PHOSPHORUS, TOTAL
NITRITE, NITRATE, TOTAL
NITROGEN, KJELDAHL, TOTAL
PHYTOPLANKTON, TOTAL (CELLS/ML)
SEDIMENT, SUSPENDED
SEDIMENT, CLAY-SILT (PERCENT)
COLIFORM, FECAL (COL/IOO ML)
STREPTOCOCCI, FECAL (COL/IOO ML)
SILICA, DISSOLVED
CALCIUM, DISSOLVED
MAGNESIUM, DISSOLVED
SODIUM, DISSOLVED
POTASSIUM, DISSOLVED
BICARBONATE, ION
CARBONATE, ION
SULFATE, DISSOLVED
CHLOR IDE, DISSOLVED
OISSOLVED SOLIDS, SUM OF CONST
DISSOLVED SOLIDS, ROE I8O DEG C
HARDNESS, TOTAL
HARDNESS, NONCAREONATE
TURBIDITY (JTU)
FLOURIDE, DISSOLVED

CONSIUIUENI IMG/L OR UNII SHOWIN)

SAMPLE
SUZE

16
16
16
16
16
16
16
10
11
11
11
11
8
8
8
8
8
16
16
16
16
8
7
8
8
16
8

STANDARD

MEAN DEYIALION

8.66

80.7

5478.8

7.44

0.028

0.545

0.333

1251.5

8.7
73.1

$73 \cdot 1$
728,1

280.3

5.55

13.13

2.70

2.70
0.74

0.74
33.9

33.9
0.0

9.28

2.27

53.4

63.1
37.8

8.6

4.6

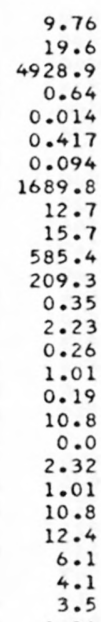

9.76
19.6
4928.9
0.64
0.014
0.417
0.094
1689.8
12.7
15.7
585.4
209.3
0.35
2.23
0.26
1.01
0.19
10.8
0.0
2.32
1.01
10.8
12.4
6.1
4.1
3.5
0.06

0.06
$B E S$

SAMPLE SIZE

BANGE

"Not significant at the 95 percent confidence level.

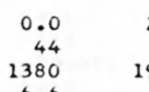

25.0

117
19000
8.5
0.06

0.01

0.14

0.13

25
1

54
82

82
60

5.0

11.0

0.8

1.6
0.5

23

23
0
4.5
0.6

0.6
46

46
50
32

0
1
0.1
$1.60 \quad 16$

800

95

2200

650
6.2

6.2
18.0
1.6

1.6
4.5

4.5

1.1
61
0

13.0
4.2

4.2
77

82
50

50
14
15

0.3
$0.58 \quad 16$

\section{COEFICIENT,}

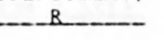

CONSTANT

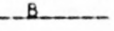

-127.899
-0.0006
-0.00019
0.01110
0.00079
9.335


0.0039
0.0992
0.0083
0.0445
-0.0011
0.449
0.000
0.0393
0.0344
0.470
0.546
0.291
-0.170
-0.067
-0.0008

5.1976

4.2610

0.4621

-1.2813
0.8339

$-5.023$

-5.023
0.000

5.8759

$-0.7037$

11.400

14.376

11.747

23.794

10.427

$\begin{array}{rrr}16565.980 & -0.507 & 4396.3 \\ 7.4950 & -0.018 * & 0.67 \\ 0.04474 & -0.272 * & 0.014 \\ -0.41754 & 0.520 & 0.369 \\ 0.26428 & 0.165 * & 0.096 \\ 478.519 & 0.113 * & 1898.5\end{array}$

0.2849

SUMMARY OF HARMONIC ANALYSIS OF STREAM TEMPERATURE FOBH OF_EQUALON:_I'SOL_E_H_A * SINC.0172*D+C)

HARMONIC MEAN - $M$

(DEG C)

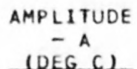

10.58

13.30

ANGLE - C

EXPLAINED

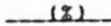

2.79

93

ERROR OF

ESTIMATE

IDEG_CL.

2.99

SUMMARY OF MAXIMUM AND MINIMUM CONCENTRATIONS OF CONSTITUENTS SAMPLED AT A FREQUENCY OF QUARTERLY (1975 WY)

04260500 - BLACK RIVER AT WATERTOWN, NY

\begin{tabular}{l} 
CONSTITUENT \\
\cline { 2 - 2 }
\end{tabular}


Table 14.--Summary of measurements at each station--Continued

LAT 45000M22S LONG $074047 M 43 S$

DRAINAGE AREA: 299000 SQ MI 1774410 SQ KMI

PERIOD OF RECORD: $10 / 01 / 74-09 / 30 / 75$

STATISTICAL SUMMARY OF SELECTED DISSOLVED CHEMICAL CONSTITUENTS AND

REGRESSION RELATIONSHIPS OF CONSTITUENT CONCENTRATIONS TO SPECIFIC CUNDUCTANCE

CONSIIIUENI

GONSIUIUENI IMG/L OB UNUI SHOWNI)

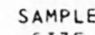

SIZE

MEAN

TANDARD

REYIAILON

TEMPERATURE, WATER (DEG C) SPECIFIC CONDUCTANCE (MICROMHOS) STREAMFLOW (CUBIC FT/SEC)

PH (STANDARD UNITS)

PHOSPHORUS, TOTAL

NITRITE + NITRATE, TOTAL

NITROGEN, KJELDAHL, TOTAL

PHYTOPLANKTON, TOTAL (CELLS/ML)

SEDIMENT, SUSPENDED

SEDIMENT, CLAY-SILT (PERCENT)

COLIFORM, FECAL (COL/1OO ML)

STREPTOCOCCI, FECAL (COL/100 ML)

SILICA, DISSOLVED

CALCIUM, DISSOLVED

MAGNESIUM, DISSOLVED

SODIUM, DISSOLVED

POTASSIUM, DISSULVED

BICAREONATE, ION

CARBONATE, ION

SULFATE, DISSOLVED

CHLORIDE, OISSOLVED

DISSOLVED SOLIDS, SUM OF CONST

DISSOLVED SOLIDS, ROE 180 DEG

HARDNESS, TOTAL

HARONESS, NONCARBONATE

TURBIDITY (JTU)

FLOUR IDE, DISSOLVED

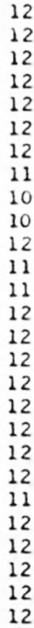

9.63

344.6

283583.1

7.84

0.022

0.191

0.287

3340.0

74.8

$74 \cdot 8$

9.8

0.32

0.32
37.50

37.50
7.89

12.83

1.35

109.6

0.0

27.08

27.00

169.0

193.0

124.2
36.3

36.3
2.8

0.15

8.52

4418.5

0.34
0.008

0.008
0.190

0.064

1830.8

6.1
23.7

23.7

13.5

18.9

0.09
1.45

0.45
0.88

0.88
0.72

0.18

5.1

1.24

1.04

1.04
3.1

3.1
15.2

5.1

5.7
3.6

0.08

0.
31
3000
7.4
0.0
0.06
0.21
320
40

0.2
35.0
6.5
12.0
1.0
100
26.0
26.0
163
16
12
2
0.0

BANGE

REGRESSION

BEGBESSION_SUMMABY

MMARY OF HARMONIC ANALYSIS OF STREAM TEMPERATURE

\begin{tabular}{|c|c|c|c|c|c|}
\hline & & & & & STANDARD \\
\hline $\begin{array}{l}\text { SAMPLE } \\
\text { SUZE. }\end{array}$ & $\begin{array}{l}\text { HARMONIC } \\
\text { MEAN - M } \\
\text { LDEG E) }\end{array}$ & $\begin{array}{c}\text { AMPLITUDE } \\
-{ }^{A} \\
(D E G(1) \\
\end{array}$ & $\begin{array}{l}\text { PHASE } \\
\text { ANGLE - C } \\
\text { (RADIANS) }\end{array}$ & $\begin{array}{l}\text { VAR IATION } \\
\text { EXPLAINED } \\
\end{array}$ & $\begin{array}{l}\text { ERROR OF } \\
\text { ESTIMATE } \\
\text { LEEG C) }\end{array}$ \\
\hline 365 & 10.23 & 11.81 & 2.48 & 97 & 1.53 \\
\hline
\end{tabular}

SUMMARY GF MAXIMUM ANO MINIMUM CONCENTRATIONS OF CONSTITUENTS

SAMPLED AT A FREQUENCY OF QUARTERLY (1975 WY)

04264331 - - ST LAWRENCE R AT CORNWALL ONT NR MASSENA, NY

CONSTITUENT


Table 14.--Summary of measurements at each station--Continued

STATION NUMBER: 04269000

NAME: ST REGIS RIVER AT BRASHER CENTER NY

LAT 44D51M49S LONG 074046M45S

DRAINAGE AREA: 616 SQ MI $(1595$ SQ KM)

PERIOD OF RECORD: $10 / 01 / 74-09 / 30 / 75$

STATISTICAL SUMMARY OF SELECTED DISSOLVED CHEMICAL CONSTITUENTS AND

REGRESSION RELATIONSHIPS OF CONSTITUENT CONCENTRATIONS TO SPECIFIC CONDUCTANCE

CONSIIIUENI

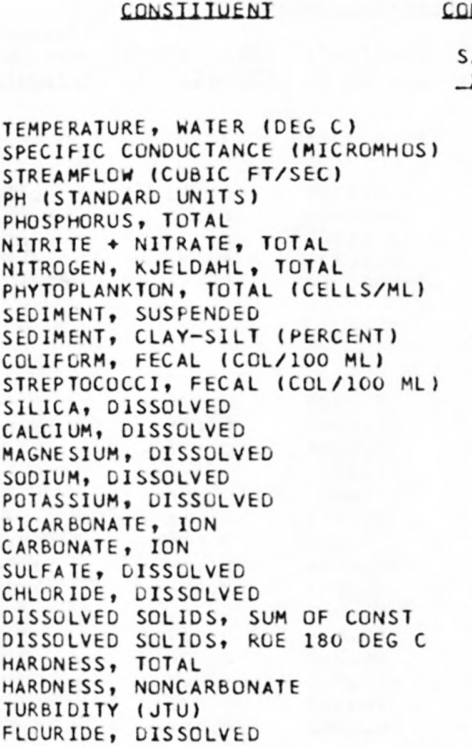

CONSIUIUENI IMG/L OR UNII_SHOWNI

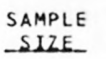

12
12
12
10
12
12
12
12
12
12
12
11
12
12
12
12
12
12
10
12
12
12
12
12
12
12
12

\section{STANDARD}

9.33

73.8

73.8
843.2

843.2
7.43

7.43
0.016

0.221

0.246

790.0

3.9

142.8

142.8

55.6

6.67

8.96
2.64

2.64
1.50

0.49

29.1
0.0

7.83

1.32

4.32
52.4

33.3

9.3

1.8
0.17
9.49

18.3
532.9

532.9
0.65

0.007

0.141

0.082

766.9

3.4
23.7

210.7

41.8

1.54

2.13

0.82
0.30

0.30
0.22

8.5
0.0

0.90

0.52

7.7
14.4
8.0

8.0
3.7
0.6

0.09

$\begin{array}{rr} & \\ \text { BANGE } & \\ 0.0 & 26.5 \\ 52 & 100 \\ 201 & 1940 \\ 6.6 & 8.4 \\ 0.01 & 0.03 \\ 0.04 & 0.45 \\ 0.13 & 0.41 \\ 260 & 2700 \\ 1 & 11 \\ 26 & 100 \\ 13 & 770 \\ 8 & 130 \\ 4.0 & 8.9 \\ 5.9 & 12.0 \\ 1.5 & 3.5 \\ 0.9 & 1.9 \\ 0.1 & 0.8 \\ 15 & 42 \\ 0 & 0 \\ 6.1 & 9.3 \\ 0.3 & 2.0 \\ 29 & 52 \\ 21 & 72 \\ 21 & 44 \\ 2 & 14 \\ 1 & 3 \\ 0.1 & 0.4 \\ & \end{array}$
BEGRESSION_SUMMARY

*Not significant at the 95 percent confidence level.

SUMMARY OF HARMONIC ANALYSIS OF STREAM TEMPERATURE

\begin{tabular}{|c|c|c|c|c|c|}
\hline & & & & & STANDARD \\
\hline & HARMONIC & AMPLITUDE & PHASE & VARIATION & ERROR OF \\
\hline $\begin{array}{l}\text { SAMPLE } \\
\text { SIZE }\end{array}$ & MEAN - M & $-A$ & ANGLE $-\mathrm{C}$ & EXPLA INED & ESTIMATE \\
\hline SDEF & loEg C & COEG $(1)$ & (RADIANS) & $-(x)$ & \\
\hline 364 & 9.45 & 12.75 & 2.79 & 89 & 3.19 \\
\hline
\end{tabular}

$12-12-17.101$
SAMPLE
SIZE. REGRESSION
COEFICIENT,

$-{ }^{-}$

CONSTANT,

C

CORRELATION

STANDARD
ERROR OF

10

$-17.161$

$-0.0020$

7.5729

0.00523

0.25090

0.20015

$-0.00041$

0.00062
7.441

240.586

$-0.591$.

$-0.056^{*}$

$0.394^{*}$

$-0.053^{\star}$

$0.139^{*}$
$0.178^{\circ}$

450.9

0.69

0.006

0.147

0.085

791.5

$$
\begin{array}{r}
-0.0007 \\
0.0856 \\
0.0172 \\
0.0114 \\
0.0016 \\
0.355 \\
0.000 \\
-0.0233 \\
0.0155 \\
0.292 \\
0.327 \\
0.284 \\
-0.002 \\
-0.008 \\
0.0009
\end{array}
$$

2.6406

1.3721

0.6548

0.3744

2.905

.5566

0.1797

22.610

28.239

12.308

9.480

2.338
0.1102

-0.009 *

0.736

0.380 *

0.690

0.133 *

0.705

$0.000^{*}$

$-0.473^{*}$

$0.548^{\circ}$

0.694 .

0.417

0.652 .

$-0.010^{\circ}$

$-0.235^{*}$
$0.186^{*}$
1.61

1.52

0.79

0.23

\begin{tabular}{|c|c|c|c|c|c|c|}
\hline \multirow{2}{*}{ CONSTITUENT } & \multicolumn{3}{|c|}{ TOTAL } & \multicolumn{3}{|c|}{ DISSOLVED } \\
\hline & $\begin{array}{l}\text { NO. } \\
\text { SAMPLES }\end{array}$ & $\begin{array}{l}\text { MINIMUM } \\
\text { CONC. }\end{array}$ & $\begin{array}{l}\text { MAXIMUM } \\
\text { CONC. }\end{array}$ & $\begin{array}{l}\text { NO. } \\
\text { SAMPLES }\end{array}$ & $\begin{array}{l}\text { MINIMUM } \\
\text { CONC. }\end{array}$ & $\begin{array}{l}\text { MAXIMUM } \\
\text { CONC. }\end{array}$ \\
\hline \multicolumn{7}{|l|}{ MINOR ELEMENTS: } \\
\hline ARSENIC (AS), UG/L & 4 & 0 & 1 & 4 & 0 & 1 \\
\hline CADMIUM $(C D), U G / L$ & 4 & 0 & 1 & 4 & 0 & 2 \\
\hline CHROMIUM (CR), UG/L & 4 & 0 & 10 & 4 & 0 & $<10$ \\
\hline COBALT $(C O), U G / L$ & 4 & 0 & 1 & 4 & 0 & 0 \\
\hline COPPER (CU), UG/L & 4 & 0 & 40 & 4 & 0 & 20 \\
\hline IRON (FE), UG/L & 4 & 230 & 520 & 4 & 170 & 320 \\
\hline LEAD $(P B), U G / L$ & 4 & 3 & 44 & 4 & 0 & 17 \\
\hline MANG ANESE (MN), UG/L & 4 & 10 & 40 & 4 & 0 & 20 \\
\hline MERCURY (HG), UG/L & 4 & $<0.5$ & $<0.5$ & 4 & $<0.5$ & $<0.5$ \\
\hline SELENIUM $(S E), U G / L$ & 4 & 0 & 3 & 4 & 0 & 2 \\
\hline ZINC $(Z N), U G / L$ & 3 & 10 & 30 & 4 & 0 & 40 \\
\hline \multicolumn{7}{|l|}{ PERIPHYTON: } \\
\hline BICMASS, DRY WT., G/SQ M & 5 & 3.39 & 11.00 & & & \\
\hline BIOMASS, ASH WT., G/SQ M & 5 & 1.09 & 9.00 & & & \\
\hline CHLOROPHYLL A, MG/SQ M & 5 & .2 & 11.0 & & & \\
\hline CHLOROPHYLL $B, M G / S Q M$ & 5 & .1 & $2 \cdot 1$ & & & \\
\hline ORGANIC CARBON, MG/L & 4 & 4.0 & 6.3 & & & \\
\hline
\end{tabular}

0.23

5.7
0.0

0.84

0.40

5.8
13.7

13.7

6.3

3.9

0.09

SUMMARY OF MAXIMUM AND MINIMUM CONCENTRATIONS OF CONSTITUENTS

SAMPLED AT A FREQUENCY OF QUARTERLY (1975 WY)

04269000 -- ST REGIS RIVER AT BRASHER CENTER NY 
LAT 44059M45S LONG 073021M40S

DRAINAGE AREA: 8277 SO MI ( 21437 SQ KM)

PERIGD OF RECORD: $10 / 01 / 74-09 / 30 / 75$

STATISTICAL SUMMARY CF SELECTED DISSOLVED CHEMICAL CONSTITUENTS AND

REGRESSION RELATIONSHIPS OF CUNSTITUENT CONCENTRATIONS TO SPECIFIC CONOUCTANCE

CONSIIIUENI

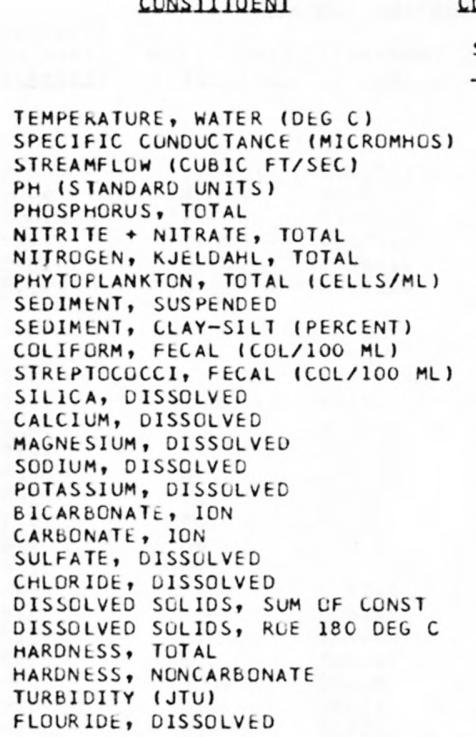

\begin{tabular}{c} 
CONSIUUS \\
SAMPLE \\
SIZE \\
\hline 9 \\
98 \\
0 \\
8 \\
9 \\
9 \\
9 \\
8 \\
8 \\
6 \\
8 \\
7 \\
8 \\
8 \\
8 \\
8 \\
8 \\
9 \\
8 \\
9 \\
9 \\
8 \\
8 \\
8 \\
8 \\
9 \\
8
\end{tabular}

*Not significant at the 95 percent confidence level.

OB UNDI SHOWN

MEAN STANDARD
DEYIALION

13.17
141.6

7.55

0.020

0.352

0.321

0.321
2508.8

2.8
2.8

56.7

254.0

8.0
0.80

0.86
6.38

3.85

4.50

1.12

52.1
0.0

12.22

6.24
70.8

70.8
83.5

56.8

14.4

2.3

0.33

0.33
0.012

0.458

0.096

0.096
1667.7

2.1

31.7

705.5

16.3

0.37

0.74

0.40

0.25

0.09

2.8

0.97

0.96

2.7

8.7

3.1

2.2

0.10

SUMMARY DF MAXIMUM AND MINIMUM CONCENTRATIONS OF CONSTITUENTS SAMPLED AT A FREQUENCY OF QUARTERLY (1975 WY)

64295000 -- RICHELIEU RIVER AT ROUSES POINT, N.Y.

\begin{tabular}{|c|c|c|c|c|c|c|}
\hline \multirow{2}{*}{ CONSTITUENT } & \multicolumn{3}{|c|}{ TOTAL } & \multicolumn{3}{|c|}{ DISSOLVED } \\
\hline & $\begin{array}{l}\text { NO. } \\
\text { SAMPLES }\end{array}$ & $\begin{array}{l}\text { MINIMUM } \\
\text { CONC. }\end{array}$ & $\begin{array}{l}\text { MAXIMUM } \\
\text { CONC. }\end{array}$ & $\begin{array}{l}\text { NO. } \\
\text { SAMPLES }\end{array}$ & $\begin{array}{l}\text { MINIMUM } \\
\text { CONC. }\end{array}$ & $\begin{array}{l}\text { MAXIMUM } \\
\text { CONC. }\end{array}$ \\
\hline \multicolumn{7}{|l|}{ MINOR ELEMENTS: } \\
\hline ARSENIC (AS), UG/L & 5 & 0 & 1 & 5 & 0 & 1 \\
\hline CAUMIUM (CD), UG/L & 5 & 0 & 1 & 5 & 0 & $i$ \\
\hline CHROMIUM (CR), UG/L & 5 & 0 & 20 & 5 & 0 & 10 \\
\hline COEALT $(C O), U G / L$ & 5 & 0 & 0 & 5 & 0 & 1 \\
\hline COPPER (CU), UG/L & 5 & 0 & 10 & 5 & 0 & 10 \\
\hline IRUN $(F E), U G / L$ & 6 & 60 & 150 & 5 & 10 & 70 \\
\hline LEAD $(P B), U G / L$ & 5 & 7 & 57 & 5 & 0 & 42 \\
\hline MANG ANESE $(M N), U G / L$ & 6 & 10 & 80 & 5 & 0 & 10 \\
\hline MERCURY $(H G), U G / L$ & 5 & $<0.5$ & $<0.5$ & 5 & $<0.5$ & $<0.5$ \\
\hline SELENIUM (SE), UG/L & 5 & 0 & 1 & 5 & 0 & $<2$ \\
\hline ZINC $(Z N), U G / L$ & 5 & 0 & 20 & 5 & 0 & 20 \\
\hline \multicolumn{7}{|l|}{ PERIPHYTON: } \\
\hline BIOMASS, DRY WT., G/SO M & 5 & 3.50 & 13.00 & & & \\
\hline BIOMASS, ASH WT., G/SO M & 5 & 1.00 & 12.00 & & & \\
\hline CHLOROPHYLL A, MG/SO M & 5 & .1 & 17.0 & & & \\
\hline CHLOROPHYLL 8 , MG/SO M & 5 & .1 & 2.7 & & & \\
\hline ORGANIC CARBON, MGIL & 5 & 3.3 & 48.0 & & & \\
\hline
\end{tabular}


Table 14.--Summary of measurements at each station--Continued

LAT 44D56M22S LONG $072011 M 23 \mathrm{~S}$
DRAINAGE AREA: 142 SO MI $1 \quad 368$ SO KM)

PERIOD OF RECORD: $10 / 01 / 74-09 / 30 / 75$

STATISTICAL SUMMARY OF SELECTED DISSOLVED CHEMICAL CONSTITUENTS AND

REGRESSION RELATIONSHIPS OF CONSTITUENT CONCENTRATIONS TO SPECIFIC CONDUCTANCE

CONSIIIUENI

CONSIIUUENI IMG $\angle L O R$ UNII SHOWN

SAMPLE

SIZE

TEMPERATURE, WATER (DEG C)

SPECIFIC CUNDUCTANCE (MICROMHOS)

STREAMFLOW (CUBIC FT/SEC)

PH (STANDARD UNITS)

PHOSPHORUS, TOTAL

NITRITE + NITRATE, TOTAL

NITROGEN, KJELDAHL, TOTAL

PHYTOPLANKTON, TOTAL (CELLS/ML)

SEDIMENT, SUSPENDED

SEDIMENT, CLAY-SILT (PERCENT)

COLIFURM, FECAL (COL/100 ML)

STREPTOCOCCI, FECAL (COL/1OU ML)

SILICA, DISSOLVED

CALCIUM, DISSOLVED

MAGNESIUM, DISSOLVED

POTASSIUM, DISSOLVED

BICARBONATE, ION

CARGONATE, ION

SULFATE, DISSOLVED

CHLORIDE, DISSOLVED

DISSOLVED SOLIDS, SUM OF CONST

HARDNESS, TOTAL

HARONESS, NONCARBONATE

TURBIDITY (JTU)

FLOURIDE, DISSOLVED

STANDARD

MEAN DEYIAIION

9.09

134.9

325.4

7.48
0.022

0.248

0.248

2099.1

9.82
19.2

19.2
196.9

0.32

0.010

0.134

0.098

2589.6

4.70
16.00

16.00
1.70

3.60

1.07

50.0

0.0
6.50

6.50
5.90

5.90
64.3

74.7

47.3

6.0
2.3

0.82
1.00

0.26

0.26

0.06

2.6

0.0

1.39
0.96

0.96
3.2

3.5

3.5

5.6

0.06
SODIUM, DISSOLVED

DISSOLVED SOLIDS, ROE 180 DEG C ${ }^{*}$ Not significant at the 95 percent confidence level.

BANGE

$\begin{array}{rrrr}321.0 & 669.9 & 20 & 2100 \\ 605.3 & 1168.3 & 8 & 3500\end{array}$

$0.0-22.5$

$103 \quad 163$

$\begin{array}{rr}22 & 749 \\ 6.8 & 7.9 \\ 0.01 & 0.04\end{array}$

0.48

110

8200

SAMPLE REGRESSION BEGRESSION_SUMMABY

SIZE. RERICIENT,

CONSTANT, CORRELATION

STANDARD ERROR OF ESIUMAIE

$\begin{array}{rr}10 & -7.054 \\ 9 & -0.0069 \\ 10 & -0.00006 \\ 10 & 0.00079 \\ 10 & -0.00030\end{array}$

1269.685 8.4391 0.02775 0.16107 0.32896

3195.016

$-0.056$

$-0.354^{\circ}$
-0.135.

$-0.135 *$

$0.120^{*}$

$-0.142 *$

164.9

0.32

0.009

0.132

788.5

$\begin{array}{rr}8 & 3500 \\ 3.8 & 5.4 \\ 15.0 & 17.0 \\ 1.5 & 2.0 \\ 3.4 & 3.9 \\ 1.0 & 1.1 \\ 48 & 53 \\ 0 & 0 \\ 4.9 & 7.3 \\ 5.2 & 7.0 \\ 62 & 68 \\ 71 & 78 \\ 44 & 51 \\ 0 & 11 \\ 2 & 3 \\ 0.2 & 0.3\end{array}$

5.4
17.0

2.0

1.1
53

0
7.3

7.0
68

78
51
21
3

$0 \cdot 2$

0.3

DURAIION_IABLE_OF QALLY SPECLEIC CONOUCIANCE

DAILY SPECIFIC CONDUCTANCE IN

MICROMHOS AT 25 DEG C, THAT WAS

EQUALLED OR EXCEEDED FOR THE

$18 \quad-53 \quad 108$

$208 \quad 30 \% \quad 508$

INDICATED PERCENTAGE OF TIME

$\begin{array}{llll}172 & 162 & 158 & 153\end{array}$

151

703 $20 \%$ SAMPLE SLE $=341$

SUMMARY OF HARMONIC ANALYSIS OF STREAM TEMPERATURE

\begin{tabular}{|c|c|c|c|c|c|}
\hline & & & & & STANDARD \\
\hline & HARMONIC & AMPLITUDE & PHASE & VARIATION & ERROR OF \\
\hline SAMPLE & MEAN - M & $-A$ & ANGLE - C & EXPLAINED & ESTIMATE \\
\hline SIZE_ & $10 E G \quad C 1$ & DEEG (1) & IRADLANSI & -131 & (DEG_C) \\
\hline 341 & 9.24 & 11.87 & 2.68 & 90 & 2.88 \\
\hline
\end{tabular}

SUMMARY OF MAXIMUM AND MINIMUM CONCENTRATIONS OF CONSTITUENTS SAMPLED AT A FREOUENCY OF QUARTERLY (1975 WY

04296500 -- CLYDE RIVER AT NEWPORT, VT .

\begin{tabular}{|c|c|c|c|c|c|c|}
\hline \multirow{2}{*}{ CONSTITUENT } & \multicolumn{3}{|c|}{ TOTAL } & \multicolumn{3}{|c|}{ DISSOLVED } \\
\hline & $\begin{array}{l}\text { NO. } \\
\text { SAMPLES }\end{array}$ & $\begin{array}{l}\text { MIN IMUM } \\
\text { CONC. }\end{array}$ & $\begin{array}{l}\text { MAXIMUM } \\
\text { CONC. }\end{array}$ & $\begin{array}{l}\text { NO. } \\
\text { SAMPLES }\end{array}$ & $\begin{array}{l}\text { MINIMUM } \\
\text { CONC. }\end{array}$ & $\begin{array}{l}\text { MAXIMUM } \\
\text { CONC. }\end{array}$ \\
\hline \multicolumn{7}{|l|}{ MINOR ELEMENTS: } \\
\hline ARSENIC (AS), UG/L & 3 & 0 & 1 & 3 & 0 & 1 \\
\hline CADMIUM $(C D), U G / L$ & 3 & 0 & 0 & 3 & 0 & 1 \\
\hline CHROMIUM (CR), UG/L & 3 & 0 & 10 & 3 & 0 & 20 \\
\hline COBALT (CO), UG/L & 3 & 0 & 0 & 3 & 0 & 0 \\
\hline COPPER $(C U), U G / L$ & 3 & 0 & 0 & 3 & 0 & 0 \\
\hline IRON (FE), UG/L & 3 & 170 & 340 & 3 & 50 & 70 \\
\hline LEAD (PB), UG/L & 3 & 0 & 3 & 3 & 0 & 1 \\
\hline MANGANESE (MN), UG/L & 3 & 20 & 50 & 3 & 0 & 30 \\
\hline MERCURY (HG), UG/L & 3 & $<0.5$ & $<0.5$ & 3 & $<0.5$ & $<0.5$ \\
\hline SELENIUM (SE), UG/L & 3 & 0 & 0 & 3 & 0 & 0 \\
\hline ZINC $(Z N), U G / L$ & 3 & 0 & 10 & 3 & 0 & 0 \\
\hline \multicolumn{7}{|l|}{ PERIPHYTON: } \\
\hline BIOMASS, DRY WT., G/SQ M & 0 & & & & & \\
\hline BIOMASS, ASH WT, G/SQ M & 0 & & & & & \\
\hline CHLOROPHYLL A, MG/SO M & 0 & & & & & \\
\hline CHLOROPHYLL B, MG/SQ M & 0 & & & & & \\
\hline ORGANIC CARBON, MG/L & 2 & 13.0 & 20.0 & & & \\
\hline
\end{tabular}


Table 14.--Summary of measurements at each station--Continued

LAT 46D55M5OS LONG $096047 M 05 S$

DRAINAGE AREA: 6820 SQ MI 117664 SQ KM)

PERIOD OF RECORD: $10 / 01 / 74-09 / 30 / 75$

STATISTICAL SUMMARY OF SELECTED DISSOLVED CHEMICAL CONSTITUENTS AND

REGRESSION RELATIONSHIPS OF CONSTITUENT CONCENTRATIONS TO SPECIFIC CONDUCTANCE

CONSIIIUENI

CONSIUUUENT IMG/L OR UNAI SHOWNL

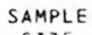

SIZE

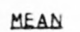

MEAN DEVIALION

TEMPERATURE, WATER (DEG C) SPECIFIC CONDUCTANCE (MICROMHOS) STREAMFLOW (CUBIC FT/SEC)

PH (STANDARD UNITS)

PHOSPHORUS, TOTAL

NITRITE + NITRATE, TOTAL

NITROGEN, KJELDAHL, TUTAL

PHYTOPLANKTON, TOTAL (CELLS/ML)

SEUIMENT, SUSPENDED

SEDIMENT, CLAY-SILT (PERCENT)

COLIFORM, FECAL (COL/100 ML)

STREP TOCOCCI, FECAL ( $\mathrm{COL} / 100 \mathrm{ML}$ )

SILICA, DISSOLVED

CALCIUM, DISSOLVED

MAGNESIUM, DISSULVED

SODIUM, DISSOLVED

POTASSIUM, DISSOLVED

BICARBONATE, ION

CARBONATE, ION

SULFATE, DISSOLVED

CHLORIDE, UISSOLVEO

DISSOLVED SOLIDS, SUM OF CONST

DISSOLVED SOLIDS, ROE 180 DEG

HARDNESS, TOTAL

HARDNESS, NONCARBONAT

TUREIDITY (JTU)

FLOURIDE, DISSOLVEO

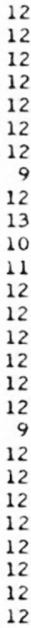

9.08

467.2

1074.2

8.17

0.342

0.334

1.362

10913.3

118.3

79.4

4115.3

863.3

12.97

44.75

30.50
15.23

15.23
5.29

249.4

249.4
0.1

55.00

9.18

296.1

311.6

237.5
33.2

33.2
39.8

0.17 REGRESSION

BEGRESS $10 N$ SUMMARY

$\begin{array}{lll}9.55 & 0.0 & 23.5\end{array}$

63.5
1489.8

1489.8

0.25
0.087

0.087
0.367

0.341

15037.1

141.6

15.7
7787.4

7787.4

1081.4
3.43

6.02

5.18

3.47
1.02

46.6

0.3

32.00

3.64

41.5

46.9

34.4

28.8

43.7
0.09

$0.0 \quad 23$.

$\begin{array}{lr}391 & 585 \\ 185 & 5000\end{array}$

7.7

0.24
0.01

0.88

200

4
45

1

1
7.5
36.0

36.0
18.0

9.8

3.8

145

26.0
4.8

236

255

160

3

0.1

5000
8.5
0.55

0.55
1.30

$1.30 \quad 1$

46000

436
98

400

24000

3200
18.0

18.0
55.0

38.0

21.0

303

303
1
10.0

110.0

19.0

371

290

88
120

0.4

SAMPLE

R

CORRELATION

STANDARO SIZE - B COEEICIENI ESIUA

SUMMARY OF HARMONIC ANALYSIS OF STREAM TEMPERATURE

\begin{tabular}{|c|c|c|c|c|c|}
\hline & & & & & STANDARD \\
\hline & HARMONIC & AMPLITUDE & PHASE & VAR IATION & ERROR OF \\
\hline SAMPLE & MEAN - $M$ & $-A$ & ANGLE - C & EXPLAINED & ESTIMATE \\
\hline SIZE_ & $10 E G(1$ & (DEG $(1)$ & (BADIANSI) & -181 & CDEG $(1)$ \\
\hline 12 & 9.11 & 12.90 & 2.82 & 92 & 2.93 \\
\hline
\end{tabular}

SUMMARY OF MAXIMUM AND MINIMUM CONCENTRATIONS OF CONSTITUENTS SAMPLED AT A FREQUENCY OF QUARTERLY (1975 WY)

05054020 -- RED RIVER OF THE NORTH BELOW FARGO, NO

\begin{tabular}{|c|c|c|c|c|c|c|}
\hline \multirow{2}{*}{ CONSTI TUENT } & \multicolumn{3}{|c|}{ TOTAL } & \multicolumn{3}{|c|}{ DISSOLVED } \\
\hline & $\begin{array}{c}\text { NO. } \\
\text { SAMPLES }\end{array}$ & $\begin{array}{l}\text { MINIMUM } \\
\text { CONC. }\end{array}$ & $\begin{array}{l}\text { MAXIMUM } \\
\text { CONC. }\end{array}$ & $\begin{array}{l}\text { NO. } \\
\text { SAMPLES }\end{array}$ & $\begin{array}{l}\text { MINIMUM } \\
\text { CONC. }\end{array}$ & $\begin{array}{l}\text { MAXIMUM } \\
\text { CONC. }\end{array}$ \\
\hline \multicolumn{7}{|l|}{ MINOR ELEMENTS: } \\
\hline ARSENIC (AS), UG/L & 4 & 4 & 9 & 4 & 3 & $?$ \\
\hline CAOMIUM $(C D), U G / L$ & 4 & $<10$ & 20 & 4 & 0 & 1 \\
\hline CHROMIUM (CR), UG/L & 3 & 0 & 20 & 4 & 0 & $<10$ \\
\hline COBALT $(C O), U G / L$ & 4 & $<50$ & 50 & 4 & 0 & 4 \\
\hline COPPER (CU), UG/L & 4 & $<10$ & 40 & 4 & 5 & 9 \\
\hline IRON (FE), UG/L & 3 & 230 & 2500 & 4 & 20 & 70 \\
\hline LEAD $(P B), U G / L$ & 4 & $<100$ & $<100$ & 4 & 0 & 4 \\
\hline MANG ANESE (MN), UG/L & 4 & 20 & 260 & 4 & 0 & 20 \\
\hline MERCURY (HG), UG/L & 4 & 0.0 & 0.1 & 4 & 0.0 & $<0.1$ \\
\hline SELENIUM (SE), UG/L & 3 & 0 & 2 & 4 & 0 & 2 \\
\hline ZINC $(Z N), U G / L$ & 4 & 30 & 50 & 4 & 0 & 10 \\
\hline \multicolumn{7}{|l|}{ PERIPHYTON: } \\
\hline BIOMASS, URY WT., G/SQ M & 3 & 2.09 & 22.00 & & & \\
\hline BIOMASS, ASH WT., G/SQ M & 3 & 1.69 & 21.00 & & & \\
\hline CHLOROPHYLL A, MG/SO M & 3 & .0 & 7.5 & & & \\
\hline CHLOROPHYLL $B, M G / S O M$ & 3 & .0 & 3.0 & & & \\
\hline ORGANIC CARBON, MG/L & 3 & 12.0 & 22.0 & & & \\
\hline
\end{tabular}


Table 14.--Summary of measurements at each station--Continued

LAT $48011 M O O S$ LONG 097009MOOS

ORAINAGE AREA: 31200 SO MI 180808 SO KMI

PERIOD OF RECORD: $10 / 01 / 74-09 / 30 / 75$

STATISTICAL SUMMARY OF SELECTED DISSOLVED CHEMICAL CONSTITUENTS AND

REGRESSIGN RELATIONSHIPS OF CONSTITUENT CONCENTRATIONS TO SPECIFIC CONDUCTANCE

CONSIIIUENI

CONSIIIUENI IMG/L.OB UNAI SHOWNL

SAMPLE

SLZE

IEMPERATURE, WATER (DEG C) SPECIFIC CUNDUCTANCE (MICROMHOS) STREAMFLOW (CUBIC FT/SEC)

PH (STANDARD UNITS)

PHOSPHORUS, TOTAL

NITRITE + NITRATE, TCTAL

NITRCGEN, KJELDAHL, TUTAL

PHYTOPLANKTON, TOTAL (CELLS/ML)

SEDIMENT, SUSPENDED

SEDIMENT, CLAY-SILT (PERCENT)

COLIFURM, FECAL (CUL/100 ML)

STREP TOCOCCI, FECAL ( COL/1OO ML)

SILICA, DISSOLVED

CALCIUM, DISSOLVED

MAGNESIUM, DISSOL VEL

SODIUM, DISSOLVEO

POTASSIUM, DISSCLVEO

BICARBONATE, ION

CARBONATE, ION

SULFATE, DISSOLVED

CHLORIDE, DISSOLVED

DISSOLVED SOLIDS, SUM OF CONST

DISSCLVED SOLIDS, RCE 180 DEG

MARDNESS, TOTAL

HARDNESS, NONCARBONAT

TUREIDITY (JTU)

FLOURIDE, DISSOLVED

STANDARU

DEYIAIION

14

$14 \quad 8577.1$

8577.1
8.02

8.02
0.252

0.42

1.432

15354.5

110.3

79.0

468.5

715.6

715.6
10.34

10.34
53.15

53.15
22.69

22.69
15.62

4.32

233.4

0.0

50.92

11.72

283.8

305.1

225.4

$34 \cdot 5$

37.0
0.17

*Not significant at the 95 percent confidence level.

SUMMARY OF MARMONIL ANALYSIS OF STREAM TEMPERATURE

\begin{tabular}{|c|c|c|c|c|c|}
\hline & & & & & STANDARD \\
\hline & HARMONIC & AMPLI TUDE & PHASE & VARIATION & ERROR OF \\
\hline $\begin{array}{l}\text { SAMPLE } \\
\text { SIZE }\end{array}$ & $\begin{array}{l}\text { MEAN - M } \\
\text { (DEG } C 1\end{array}$ & $\begin{array}{c}-{ }^{A} \\
\text { (DEG }\end{array}$ & $\begin{array}{l}\text { ANGLE - C } \\
\text { (BADIANSI }\end{array}$ & $\begin{array}{c}\text { EXPLAINED } \\
111\end{array}$ & $\begin{array}{l}\text { ESTIMATE } \\
\text { (DEG_CI }\end{array}$ \\
\hline 14 & 8.98 & 12.47 & 2.84 & 92 & 2.88 \\
\hline
\end{tabular}

\section{BEGRESSION_SUMMARY}

REGRESSION

SAMPLE

COEFICIENT,

CONSTANT,

CORRELATION

STANDARD

ERROR OF

ESIIMAIE $\begin{array}{lll}9.45 & 0.0 & 23.5\end{array}$

3838.7

$0.22 \quad 7.7$

$0.132 \quad 0.08$

$0.716 \quad 0.00$

18775.0

94.7

16.5

571.3

884.

3.21

4.58
3.12

3.40

0.92

0.

19.86

4.39

33.1

36.9

4.

21.9

43.4

42400

0.54

2.70

2.70

50000

318
97

97
2000

2000

2500

61.0

29.0

19.0

10.0

2.9

162

30.0
5.5

5.5

224

248
190

6
$57.8 \quad 370 \quad 575$
SIZE

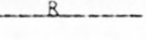

$10.0 \quad 13$

0.1
$8.4 \quad 13$

$\begin{array}{rr}-80.489 & 42554.387 \\ -0.0001 & 8.0686 \\ 0.00026 & 0.13357 \\ -0.00436 & 2.40372 \\ -0.00488 & 3.64736 \\ 20.869 & 5796.547\end{array}$

$-0.455$

$-0.031$

$0.114^{\circ}$

$-0.352^{\circ}$

$-0.485$

9523.1

0.23

0.137

0.700

0.532

19744.5
5.3440 25.4669 6.8750 $-5.6877$ 2.8380 39.553 0.000 37.7485

11.0785 11.0713
80.872 0.872

100.668

84.777

56.404

117.919

$-0.177$

0.0004

$-0.0174$ $0.198^{\circ}$

0.769

0.645

0.790

0.200

0.728

$0.000^{\circ}$

$0.084^{*}$

0.061

0.779

0.705

0.745

-0.128 .

-0.235 .

0.316

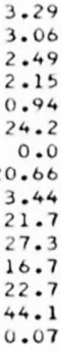

.29

2.49

2.15

24.2

0.0

3.44

16.7

44.1

0.07

SUMMARY OF MAXIMUM ANO MINIMUM CONCENTRATIONS OF CONSTITUENTS

SAMPLED AT A FREQUENCY OF QUARTERLY (1975 WY)

\begin{tabular}{|c|c|c|c|c|c|c|}
\hline \multirow{2}{*}{ CONSTITUENI } & \multicolumn{3}{|c|}{ TOTAL } & \multicolumn{3}{|c|}{ OISSOLVED } \\
\hline & $\begin{array}{l}\text { NO. } \\
\text { SAMPLES }\end{array}$ & $\begin{array}{l}\text { MINIMUM } \\
\text { CONC. }\end{array}$ & $\begin{array}{l}\text { MAXIMUM } \\
\text { CONC. }\end{array}$ & $\begin{array}{l}\text { NO. } \\
\text { SAMPLES }\end{array}$ & $\begin{array}{l}\text { MINIMUM } \\
\text { CONC. }\end{array}$ & $\begin{array}{l}\text { MAXIMUM } \\
\text { CONC. }\end{array}$ \\
\hline MINOR ELEMENTS: & & & & & & \\
\hline ARSENIC (AS), UG/L & 4 & 2 & 10 & 4 & 1 & 0 \\
\hline CADMIUM $(C D)$, UG/L & 4 & $<10$ & 10 & 4 & 0 & 2 \\
\hline CHROMIUM (CR), UG/L & 4 & 0 & 10 & 4 & 0 & 0 \\
\hline COBALT $(C O), U G / L$ & 4 & 0 & $<50$ & 4 & 0 & 0 \\
\hline COPPER $(C U), U G / L$ & 4 & $<10$ & 60 & 4 & 3 & 6 \\
\hline IRON $(F E), U G / L$ & 4 & 400 & 4800 & 4 & 10 & 30 \\
\hline LEAD $(P B), U G / L$ & 4 & $<100$ & $<100$ & 4 & 1 & 3 \\
\hline MANGANESE $(M N), U G / L$ & 4 & 40 & 210 & 4 & 0 & 30 \\
\hline MERCURY (HG), UG IL & 4 & 0.0 & 0.6 & 4 & 0.0 & 0.1 \\
\hline SELENIUM (SE), UG/L & 4 & 0 & 1 & 4 & 0 & 0 \\
\hline ZINC $(Z N), U G / L$ & 4 & 30 & 90 & 4 & 0 & 30 \\
\hline PERIPHYTON: & & & & & & \\
\hline GIOMASS, URY WT., G/SC M & 3 & .50 & 58.00 & & & \\
\hline BIOMASS, ASH WT., G/SO M & 3 & .50 & 55.00 & & & \\
\hline CHLOROPHYLL A, MG/SQ M & 2 & .1 & 12.0 & & & \\
\hline CHLOROPHYLL B, MG/SO M & 2 & .0 & 16.0 & & & \\
\hline ORGANIC CARBON, MG/L & 4 & 14.0 & 16.0 & & & \\
\hline
\end{tabular}


Table 14.--Summary of measurements at each station--Continued

LAT 48D58M54S LONG 096027M46S

DRAINAGE AREA: 1570 SQ MI 14066 SQ KM)

PERIOD OF RECORD: 10/01/74 - 09/30/75

STATISTICAL SUMMARY OF SELECTED DISSOLVED CHEMICAL CONSTITUENTS ANU REGRESSION RELATIONSHIPS OF CONSTITUENT CONCENTRATICNS TO SPECIFIC CONUUCTANCE

CUNSIIIUENI

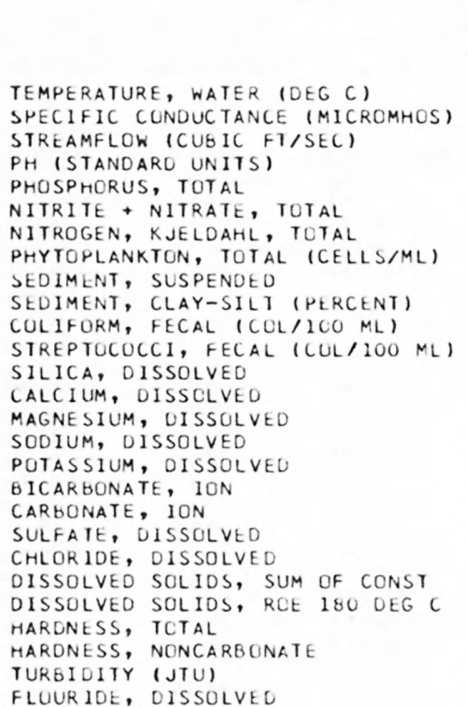

\begin{tabular}{l} 
CONSIUIU \\
SAMPLE \\
SIZE \\
\hline 15 \\
10 \\
15 \\
10 \\
9 \\
9 \\
9 \\
9 \\
8 \\
0 \\
9 \\
9 \\
9 \\
9 \\
9 \\
9 \\
9 \\
9 \\
6 \\
9 \\
9 \\
9 \\
9 \\
9 \\
9 \\
9 \\
9
\end{tabular}

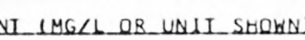

\begin{tabular}{rr} 
MEAN & \multicolumn{1}{r}{ STANOARD } \\
DEYIAIJON \\
7.13 & 8.29 \\
462.0 & 132.3 \\
549.5 & 738.5 \\
7.82 & 0.36 \\
0.067 & 0.021 \\
0.120 & 0.190 \\
0.939 & 0.391 \\
783.7 & 1310.6 \\
22.6 & 9.1 \\
& \\
13.3 & 17.6 \\
24.1 & 25.2 \\
11.48 & 5.31 \\
56.78 & 16.50 \\
23.44 & 7.78 \\
6.42 & 2.91 \\
2.16 & 0.99 \\
277.8 & 95.3 \\
0.0 & 0.0 \\
16.53 & 6.25 \\
2.83 & 1.27 \\
257.1 & 79.3 \\
295.0 & 79.7 \\
237.8 & 70.1 \\
11.3 & 8.5 \\
6.2 & 4.0 \\
0.14 & 0.07
\end{tabular}

BANGE
0.0
0.0
205
15
7.4
0.04
0.00
0.12
26
9
0
1
5.3
32.0
12.0
2.8
1.3
126
0
5.8
1.6
148
176
130
0
1
0.1

BEGRESS ION SUMMABY

REGRESSION SAMPLE COEFICIENT,
SIZE_

CONSTANT, CORRELATION C.... GOEEIGIENI STANDARO
ERRUR OF ESIIVAIE

22.5
680
2100
8.5
0.09
0.58
1.40
4000
42
54
80
19.0
82.0
34.0
10.0
4.5
401
0
26.0
5.5
365
406
340
26
13
0.3

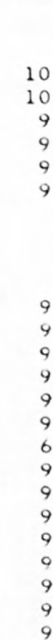

10
10
9
9
9
9



9
9
9
9
9
9
6
9
9
9
9
9
9
9
9

$$
\begin{array}{r}
-4.272 \\
-0.0017 \\
-0.00009 \\
-0.00046 \\
0.00065 \\
-4.014 \\
\\
\\
\\
0.0259 \\
0.1184 \\
0.0534 \\
0.0182 \\
-0.0015 \\
0.0680 \\
0.000 \\
0.0175 \\
-0.0011 \\
0.568 \\
0.574 \\
0.498 \\
-0.034 \\
-0.011 \\
0.0002
\end{array}
$$

0.0002
2495.414 8.5894 0.10659 0.32720 0.04643 2872.905

$-0.2402$ 3.1483 $-0.7308$ $-1.8400$

2.8273

$-30.233$

0.000

8.6028

3.3131

$-0.055$

35.092

12.135

11.283

0.0572
$-0.719$ $-0.004^{*}$

$-0.569^{\circ}$

0.226

-0.482 *
579.9 0.01

0.19

0.192

1227.6

0.668

0.979

0.939

0.858
-0.205

0.977

$0.000 *$

$0.384^{*}$

$-0.114^{*}$

0.981

0.986

0.973
-0.547.

$-0.386$

0.363

*Not significant at the 95 percent confidence level.

SUMMARY OF MAXIMUM AND MINIMUM CONCENTRATIONS OF CONSTITUENTS SAMPLED AT A FREQUENCY OF QUARTERLY (1975 WY)

05112000 -- RUSEAU RIVER BEL STATE DITCH 51 NR CARIBOU, MIN

CGNSTITUENT
SAMPLES


Table 14.--Summary of measurements at each station--Continued

LAT 48D59M47S LONG 100D57M29S

DRAINAGE AREA: 16900 SQ MI ( 43771 SQ KM)

PERIOD OF RECORD: $10 / 01 / 74-09 / 30 / 75$

STATISTICAL SUMMARY OF SELECTED DISSOLVED CHEMICAL CONSTITUENTS AND REGRESSION RELATIONSHIPS OF CONSTITUENT CONCENTRATIONS TO SPECIFIC CONDUCTANCE

CONSIIIUENI

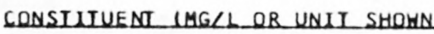

SAMPLE

SI

\section{STANDARD}

MEAN

8.72 1076.2 1463.2

8.27

0.340

0.104

2.414

20557.0

22.6

61.6

45.3

276.0

9.25

73.73

50.55

122.45

15.24

469.5

6.8

220.00

30.27

759.7

761.3

392.7

17.0

14.5
0.25
DEVIAUION

7.99

561.6

2204.2

0.55

0.184

.250
.855

21633.5

9.6

9.6
29.7

29.7
161.2

841.1

5.49

40.25

29.07
74.53

74.53
6.27

277.3

10.3

10.3
129.07

129.07
22.03

436.5

419.6

220.9

25.0
13.8

0.14
(2)

0.0

$475 \quad 2370$

$20 \quad 6500 \quad 25$

$0.11 \quad 0.68$

0.00

1.30

1.30
670

670
8

$11 \quad 38$
1

$\begin{array}{ll}4.30 & 21 \\ 6000 & 10\end{array}$

REGRESSION

SAMPLE COEFICIENT EGRESS ION SUMMARY

$\begin{array}{rr}1 & 3400 \\ 0.8 & 18.0\end{array}$

$42.0 \quad 150.0$

$26.0 \quad 110.0$

$51.0 \quad 270.0$

$181 \quad 1010$

$\begin{array}{rr}181 & 24 \\ 0 & 470.0\end{array}$

11.0

392
302

302
210

210
3
0.1

0.1

*Not significant at the 95 percent confidence level.

SUMMARY OF HARMONIC ANALYSIS OF STREAM TEMPERATURE FORM OF EOUALION: $I \cdot(D)=M+A *$ SINC.0172*0+C)

\begin{tabular}{|c|c|c|c|c|c|}
\hline & & & & & STANDARD \\
\hline $\begin{array}{l}\text { SAMPLE } \\
\text { SIZE }\end{array}$ & $\begin{array}{l}\text { HARMONIC } \\
\text { MEAN - M }\end{array}$ & AMPLITUDE & $\begin{array}{l}\text { PHASE } \\
\text { ANGLE }-C\end{array}$ & $\begin{array}{l}\text { VAR IATION } \\
\text { EXPLAINED }\end{array}$ & $\begin{array}{l}\text { ERROR OF } \\
\text { ESTIMATE }\end{array}$ \\
\hline
\end{tabular}

25

8.03

10.88

2.73

84

3.35

SUMMARY OF MAXIMUM AND MINIMUM CONCENTRATIONS OF CONSTITUENTS SAMPLED AT A FREQUENCY OF QUARTERLY (1975 WY)

05124000 -- SOURIS RIVER NR HESTHOPE, ND

\begin{tabular}{|c|c|c|c|c|c|c|}
\hline \multirow{2}{*}{ CONSTITUENT } & \multicolumn{3}{|c|}{ TOTAL } & \multicolumn{3}{|c|}{ DISSOLVED } \\
\hline & $\begin{array}{l}\text { NO. } \\
\text { SAMPLES }\end{array}$ & $\begin{array}{l}\text { MIN IMUM } \\
\text { CONC. }\end{array}$ & $\begin{array}{l}\text { MAXIMUM } \\
\text { CONC. }\end{array}$ & $\begin{array}{l}\text { NO. } \\
\text { SAMPLES }\end{array}$ & $\begin{array}{l}\text { MINIMUM } \\
\text { CONC. }\end{array}$ & $\begin{array}{l}\text { MAXIMUM } \\
\text { CONC. }\end{array}$ \\
\hline \multicolumn{7}{|l|}{ MINOR ELEMENTS: } \\
\hline ARSENIC (AS), UG/L & 3 & 2 & 6 & 3 & 2 & 5 \\
\hline CADMIUM $(C D)$, UG/L & 3 & $<10$ & $<10$ & 3 & 0 & 1 \\
\hline CHROMIUM (CR), UG/L & 3 & 0 & $<10$ & 3 & 0 & $<10$ \\
\hline COBALT $(C O), U G / L$ & 3 & $<50$ & $<50$ & 3 & 0 & 2 \\
\hline COPPER (CU), UG/L & 3 & $<10$ & 50 & 3 & 0 & 3 \\
\hline IRON (FE), UG/L & 3 & 140 & 640 & 3 & 20 & 60 \\
\hline LEAD $(P B), U G / L$ & 3 & $<100$ & 200 & 3 & 0 & 5 \\
\hline MANGANESE (MN), UG/L & 3 & 70 & 130 & 3 & 0 & 5 \\
\hline MERCURY (HG), UG/L & 2 & 0.0 & 0.2 & 3 & 0.0 & 0.2 \\
\hline SELENIUM (SE), UG/L & 3 & 0 & 0 & 3 & 0 & 0 \\
\hline ZINC $(Z N), U G / L$ & 3 & 6 & 60 & 3 & 0 & 20 \\
\hline \multicolumn{7}{|l|}{ PERIPHYTON: } \\
\hline BIOMASS, DRY WT., G/SO M & 2 & 1.00 & 4.69 & & & \\
\hline BIOMASS, ASH WT., G/SQ M & 2 & .29 & 1.39 & & & \\
\hline CHLOROPHYLL A, MG/SQ M & 1 & 5.8 & & & & \\
\hline CHLOROPHYLL $B$, MG/SO M & 1 & 2.0 & & & & \\
\hline ORGANIC CARBON, MG/L & 21 & 13.0 & 41.0 & & & \\
\hline
\end{tabular}


Table 14.--Summary of measurements at each station--Continued

LAT 48D23M55S LONG 093033M56S

$\begin{array}{llll}\text { DRAINAGE AREA: } & 1730 S Q M I & 4481 \text { SO KM) } \\ \text { PERIOD OF RECORD: } & 10 / 01 / 74-09 / 30 / 75 & \end{array}$

STATISTICAL SUMMARY OF SELECTED DISSOLVED CHEMICAL CONSTITUENTS AND

REGRESSION RELATIONSHIPS OF CONSTITUENT CONCENTRATIONS TO SPECIFIC CONOUCTANCE

GONSIIIUENI

TEMPERATURE, WATER (DEG C)
SPECIFIC CONDUCTANCE (MICROMHOS)
STREAMFLOW (CUBIC FT/SEC)
PH (STANDARD UNITS)
PHOSPHORUS, TOTAL
NITRITE, NITRATE, TOTAL
NITKOGEN, KJELDAHL, TOTAL
PHYTOPLANKTON, TOTAL (CELLS/ML)
SEDIMENT, SUSPENDED
SEDIMENT, CLAY-SILT (PERCENT)
COLIFORM, FECAL (COL/IOO ML)
STREPTOCOCCI, FECAL (COL/IOO ML)
SILICA, DISSOLVED
CALCIUM, DISSOLVED
MAGNESIUM, DISSOLVED
SODIUM, DISSOLVED
POTASSIUM, DISSOLVED
BICARBONATE, ION
CARBONATE, ION
SULFATE, DISSOLVED
CHLORIDE, DISSOLVED
DISSOLVED SOLIDS, SUM OF CONST
DISSOLVED SOLIDS, ROE I8O DEG C
HARDNESS, TOTAL
HARDNESS, NONCARBONATE
TURBIDITY (JTU)
FLOURIDE, DISSOLVED

SAMP
SIZ
78
78
10
9
9
9
9
9
1
0
8
8
9
9
9
9
9
9

STANDARD
MEAN REYIALION

11.05

115.7

997.0

0.042

0.042

0.836

0.836
183.0

$\begin{array}{r}16.0 \\ \hline\end{array}$

7.05

22.1

19.4
8.43

8.43

6.44

2.83

1.47

84.8

0.2

9.20

2.36
94.2

94.2
132.9

78.4

9.6

13.9

$$
0.0
$$

40.0

25.7
3.27

5.71

1.82

1.10

0.33
28.2

28.2
0.4

0.4
3.27

0.24

27.5

24.8

20.5

9.4
0.10

7.05
34.4
1312.3
0.46
0.020
0.076
0.260
4492.2
0.0

BANGE

0.0
80
199
7.5

199
7.5
0.01

0.02

0.43

0.43
6

1
1
3.7
12.0
3.7
1.4
0.9
49
0
6.1
2.0
56
87
45
5
5
0.1

0.1

SUMMARY OF HARMONIC ANALYSIS OF STREAM TEMPERATURE

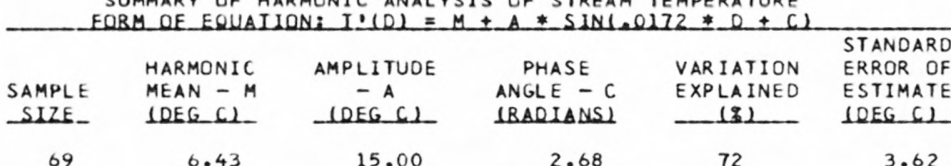

BEGRESS ION SUMMABY

ESSIENT, CONSTANT, CORRELATION E SIZE -B - B - COEEICLENI ESIUMAIE

23.0

227
$4460 \quad 9 \quad-21.937$

$-0.0013$

$-0.00017$

0.00098

$-15.458$

8.0376

0.06986

$-0.06500$

1.28612

$-0.138 *$

$0.624^{*}$

-0.533 *

-0.168 *

910.5

1.10

11000

5630.582

0.019

0.064

0.235

0.235
4734.3

$\begin{array}{rlr}120 & & \\ 71 & & \\ 13.0 & 9 & 0.0576 \\ 27.0 & 9 & 0.1151 \\ 8.9 & 9 & 0.0369 \\ 4.5 & 9 & 0.0213 \\ 2.0 & 9 & 0.0050 \\ 118 & 9 & 0.568 \\ 1 & 6 & -0.001 \\ 17.0 & 9 & 0.0428 \\ 2.7 & 9 & 0.0003 \\ 132 & 9 & 0.557 \\ 166 & 9 & 0.480 \\ 100 & 9 & 0.414 \\ 16 & 9 & -0.026 \\ 33 & 8 & -0.126 \\ 0.4 & 9 & 0.0011\end{array}$

0.857

0.982

0.990

0.939

0.739

0.983.

-0.116 *
0.039 *

0.064 *

0.987

0.943

0.985

$-0.310^{*}$

$-0.697$

0.513 *

SUMMARY OF MAXIMUM AND MINIMUM CONCENTRATIONS OF CONSTITUENTS SAMPLED AT A FREQUENCY OF QUARTERLY (1975 WY)

05131500 - LITTLE FURK RIVER AT LITTLEFORK, MINNESOTA

CONSTITUENT


Table 14.--Summary of measurements at each station--Continued

STATION NUMBER: 05132000 NAME: BIG FORK RIVER AT BIG FALLS, MINN.

LAT 48D11M45S LONG 093048M25S

DRAINAGE AREA: 1460 SQ MI 13781 SQ KMI

PERIOD OF RECORD: $10 / 01 / 74$ - 09/30/75

STATISTICAL SUMMARY OF SELECTED DISSOLVED CHEMICAL CONSTITUENTS AND

REGRESSION RELATIONSHIPS OF CONSTITUENT CONCENTRATIONS TO SPECIFIC CONOUCTANCE

CONSIIIUENI

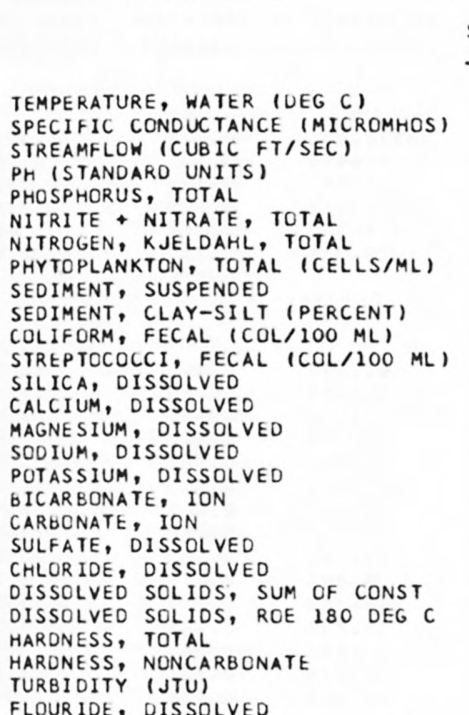

CONSIUTUENI IMG L OR UNUI SHOWN

\begin{tabular}{r} 
SAMPLE \\
SIZE \\
\hline 12 \\
9 \\
12 \\
9 \\
9 \\
9 \\
9 \\
8 \\
9 \\
0 \\
9 \\
8 \\
9 \\
9 \\
8 \\
9 \\
9 \\
9 \\
5 \\
9 \\
9 \\
8 \\
9 \\
8 \\
8 \\
9 \\
9
\end{tabular}

STANDARD

DEVIALION

8.00

222.8
914.6

7.72

0.030

0.107

0.816

349.9

14.9

34.7

25.9

9.31
30.67

30.67
9.20

3.00

1.64

131.64
131.2

0.0
5.64

5.64
2.07

126.5

158.0

113.4

6.8
5.8

5.8
0.09

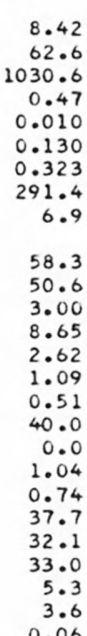

8.42

62.6

0.47

0.010

0.130
0.323

291.4
6.9

58.3

50.6

.65

2.62

0.51

40.0

0.0
1.04

0.74
37.7

5.3

3.6
0.06

*Not significant at the 95 percent confidence level.

SUMMARY OF MAXIMUM AND MINIMUM CONCENTRATIONS OF CONSTITUENTS

SAMPLED AT A FREQUENCY OF QUARTERLY (1975 WY)

05132000 -- EIG FORK RIVER AT BIG FALLS, MINN.

\begin{tabular}{|c|c|c|c|c|c|c|}
\hline \multirow{2}{*}{ CONSTITUENT } & \multicolumn{3}{|c|}{ TOTAL } & \multicolumn{3}{|c|}{ DISSOLVED } \\
\hline & $\begin{array}{l}\text { NO. } \\
\text { SAMPLES }\end{array}$ & $\begin{array}{l}\text { MINIMUM } \\
\text { CONC. }\end{array}$ & $\begin{array}{l}\text { MAXIMUM } \\
\text { CONC. }\end{array}$ & $\begin{array}{l}\text { NO. } \\
\text { SAMPLES }\end{array}$ & $\begin{array}{l}\text { MINIMUM } \\
\text { CONC. }\end{array}$ & $\begin{array}{l}\text { MAXIMUM } \\
\text { CONC. }\end{array}$ \\
\hline \multicolumn{7}{|l|}{ MINOR ELEMENTS: } \\
\hline ARSENIC (AS), UG/L & 4 & 0 & 2 & 4 & 0 & 2 \\
\hline CAOMIUM $(C D)$, UG/L & 4 & $<10$ & 40 & 4 & 0 & 2 \\
\hline CHROMIUM (CR), UG/L & 4 & 0 & 10 & 4 & 0 & 0 \\
\hline COBALT $(C O), U G / L$ & 4 & $<50$ & 50 & 4 & 0 & 1 \\
\hline COPPER (CUI, UGIL & 4 & 10 & 30 & 4 & 1 & 8 \\
\hline IRON (FE), UG/L & 4 & 170 & 660 & 4 & 70 & 240 \\
\hline LEAD $(P B), U G / L$ & 4 & $<100$ & $<100$ & 4 & 3 & 6 \\
\hline MANGANESE (MN), UG/L & 3 & 30 & 50 & 4 & 10 & 30 \\
\hline MERCURY (HG), UG/L & 4 & 0.0 & 0.0 & 3 & 0.0 & 0.0 \\
\hline SELENIUM (SE), UG/L & 4 & 0 & 1 & 4 & 0 & 0 \\
\hline ZINC $(Z N), U G / L$ & 4 & 20 & 110 & 4 & 0 & 20 \\
\hline \multicolumn{7}{|l|}{ PERIPHYTON: } \\
\hline BIOMASS, ORY WT., G/SQ M & 5 & 1.79 & 16.00 & & & \\
\hline BIOMASS, ASH WT., G/SO M & 5 & .89 & 15.00 & & & \\
\hline CHLOROPHYLL A, MG/SQ M & 5 & .1 & 15.0 & & & \\
\hline CHLOROPHYLL $B, M G / S Q M$ & 5 & .0 & 1.7 & & & \\
\hline ORGANIC CARBON, MG/L & 4 & 14.0 & 25.0 & & & \\
\hline
\end{tabular}


LAT $45051 M 40 S$ LONG 094D21M3OS DRAINAGE AREA: 11600 SQ MI PERIOD OF RECORD: $10 / 01 / 74-09 / 30 / 754$ SQ KMI

STATISIICAL SUMMARY OF SELECTED DISSOLVED CHEMICAL CONSTITUENTS AND REGRESSION RELATIONSHIPS OF CONSTITUENT CONCENTRATIONS TO SPECIFIC CONOUCTANCE

\section{CONSIILUENI}

CONSIUIUENI
TEMPERATURE, WATER (OEG C)
SPECIFIC CUNOUCTANCE (MICROMHOS)
STREAMILOW (CUBIC FT/SEC)
PH (STANDARD UNITS)
PHOSPHORUS, TOTAL
NITRITE + NITRATE, TUTAL
NITROGEN, KJELDAHL, TOTAL
PHYTOPLANKTON, TOTAL (CELLS/ML)
SEDIMENT, SUSPENDED
SEDIMENT, CLAY-SILT (PERCENT)
COLIFORM, FECAL (COL/IOO ML)
STREPTOCOCC, FECAL (CUL/LO ML)
SILICA, DISSOLVE
CALCIUM, DISSOLVED
MAGNESIUM, DISSOLVED
SODIUM, DISSOLVED
POTASSIUM, DISSOLVED
BICARBONATE, ION
CARBONATE, ION
SULFATE, DISSOLVEO
CHLURIDE, DISSOLVED
DISSOLVED SOLIDS, SUM OF CONST
OISSOLVED SOLIDS, ROE IBO DEG C
HARDNESS, TOTAL
HARDNESS, NONCARBONATE
TURBIDITY (JTU)
FLOURIDE, DISSOLVED

CONSIUUENI_IMGLL OR UNII_SHOWNI

SAMPLE MEAN STANDARD MEAD DEYIAIIION

11.62
270.3
8390.0
7.87
0.057
0.101
1.149
1442.9
17.0
399.7
176.0
9.73
35.29
12.10
4.34
1.80
161.4
0.0
6.67
2.27
151.9
187.6
139.6
6.03
5.0
0.13

BEGRESSION SUMMARY

REGRESSION SAMPLE COEFICIENT, CONSTANT, C....

CURRELATION BANGE SIZE. B....

$\begin{array}{rr}0.0 & 25.5 \\ 190 & 354 \\ 4070 & 22490 \\ 7.5 & 8.3 \\ 0.04 & 0.14 \\ 0.01 & 0.21 \\ 0.50 & 3.90 \\ 250 & 3600 \\ 2 & 50\end{array}$

-109.266
-0.0021
-0.00018
0.00085
-0.00873
-6.830


0.0343
0.1054
0.0481
0.0189
0.0040
0.629
0.000
-0.0037
0.0012
0.516
0.948
0.464
-0.047
-0.023
0.0002

38578.652
8.4448
0.10787
-0.13333
3.56152
3329.877

$-0.872$ STANDARO
ERROR OF ESIIMAIE

*Not significant at the 95 percent confidence level.
16.5

$\begin{array}{rr}26 & 1000 \\ 9 & 580 \\ 5.8 & 12.0 \\ 26.0 & 42.0 \\ 7.7 & 15.0 \\ 2.8 & 5.5 \\ 1.3 & 2.4 \\ 100 & 195 \\ 0 & 0 \\ 5.2 & 7.7 \\ 1.5 & 3.0 \\ 104 & 182 \\ 121 & 305 \\ 97 & 170 \\ 0 & 15 \\ 2 & 10 \\ 1 & 0.2\end{array}$

0.1
3329.877

0.2650 6.1698 $-1.1936$

$-0.8663$

0.6919

$-12.456$

0.000

7.7031

1.9424

$-74.359$

11.253

19.289

11.224

11.224
0.0603 $-0.404 *$

0.540 *

$0.540^{*}$
$-0.379 *$

$-0.379$.

3593.1

0.28

0.039

0.078

1206.7

$0.742 * 1.8$

0.983

.0957

0.953

0.537

0.963

0.000
-0.260

0.125

0.976

0.891

0.981

-0.538 *

-0.388 .

-0.388 *
1.15

0.85

0.35

0.3

10.3
0.0

0.81

0.55

SUMMARY OF MAXIMUM AND MINIMUM CONCENTRATIONS OF CONSTITUENTS SAMPLED AT A FREQUENCY OF QUARTERLY (1975 WY)

05267000 -- MISSISSIPPI RIVER NEAR ROYALTON, MINN.

\begin{tabular}{|c|c|c|c|c|c|c|}
\hline \multirow{2}{*}{ CONSTIIUENT } & \multicolumn{3}{|c|}{ TOTAL } & \multicolumn{3}{|c|}{ DISSOLVED } \\
\hline & $\begin{array}{l}\text { NO. } \\
\text { SAMPLES }\end{array}$ & $\begin{array}{l}\text { MINIMUM } \\
\text { CONC. }\end{array}$ & $\begin{array}{l}\text { MAXIMUM } \\
\text { CONC. }\end{array}$ & $\begin{array}{l}\text { NO. } \\
\text { SAMPLES }\end{array}$ & $\begin{array}{l}\text { MINIMUM } \\
\text { CONC. }\end{array}$ & $\begin{array}{l}\text { MAXIMUM } \\
\text { CONC. }\end{array}$ \\
\hline \multicolumn{7}{|l|}{ MINOR ELEMENTS: } \\
\hline ARSENIC (AS), UG/L & 3 & 0 & 2 & 3 & 0 & 2 \\
\hline CADMIUM $(C D), U G / L$ & 3 & $<10$ & 10 & 3 & 1 & 2 \\
\hline CHROMIUM (CR), UG/L & 3 & 0 & 10 & 3 & 0 & 10 \\
\hline COBALT $(C O), U G / L$ & 3 & $<50$ & 100 & 3 & 0 & 1 \\
\hline COPPER (CU), UG/L & 3 & $<10$ & 70 & 3 & 2 & 4 \\
\hline IRON $(F E), U G / L$ & 3 & 260 & 810 & 3 & 40 & 200 \\
\hline LEAD $(P B), U G / L$ & 3 & 100 & 200 & 3 & 6 & 23 \\
\hline MANG ANESE $(M N), U G / L$ & 3 & 50 & 110 & 3 & 20 & 30 \\
\hline MERCURY $(H G), U G / L$ & 3 & 0.0 & 1.8 & 3 & 0.1 & 1.2 \\
\hline SELENIUM (SE), UG & 3 & 0 & 0 & 3 & 0 & 0 \\
\hline ZINC $(Z N), U G / L$ & 3 & 20 & 30 & 3 & 0 & 20 \\
\hline \multicolumn{7}{|l|}{ PERIPHYTON: } \\
\hline BIOMASS, DRY WT., G/SQ M & 1 & 3.19 & & & & \\
\hline BIOMASS, ASH WT., G/SQ M & $i$ & 2.50 & & & & \\
\hline CHLOROPHYLL A, MG/SQ M & 1 & .0 & & & & \\
\hline CHLOROPHYLL B, MG/SO M & 1 & .0 & & & & \\
\hline ORGANIC CARBON, MG/L & 3 & 0.7 & 12.0 & & & \\
\hline
\end{tabular}


LAT 44D41M35S LONG 093038M30S DRAINAGE AREA: 16200 SQ MI $(141958$ SQ KM)

STATISTICAL SUMMARY OF SELECTED DISSOLVED CHEMICAL CONSTITUENTS AND REGRESSION RELATIONSHIPS OF CONSTITUENT CONCENTRATIONS TO SPECIFIC CONDUCTANCE

CONSIIIUENI

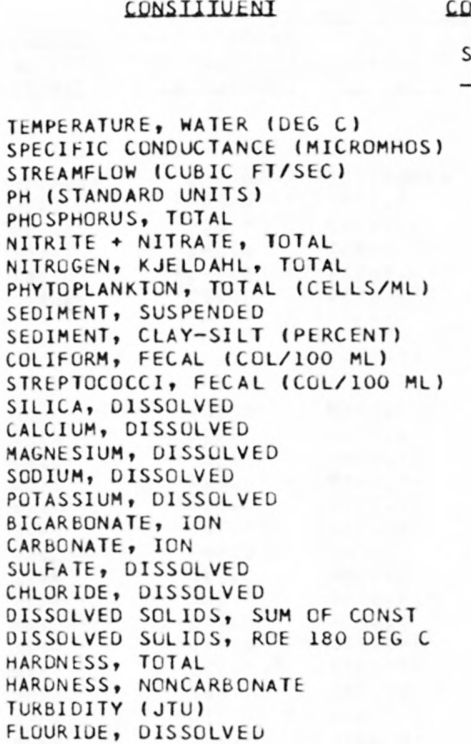

CONSIIUUENI IMGLL OR UNII SHOWN

SAMPLE STANDARD

SIZE

$\begin{array}{rrr}15 & 10.20 & 11.18 \\ 12 & 839.3 & 177.6 \\ 15 & 192.8 & 4569.4 \\ 12 & 8.15 & 0.33 \\ 11 & 0.256 & 0.105 \\ 12 & 2.762 & 4.008 \\ 12 & 1.384 & 0.615 \\ 12 & 60626.7 & 76142.3 \\ 11 & 204.3 & 236.7 \\ 0 & & \\ 12 & 164.8 & 295.2 \\ 12 & 139.5 & 196.3 \\ 12 & 18.75 & 6.06 \\ 12 & 94.08 & 19.70 \\ 12 & 41.25 & 10.13 \\ 12 & 35.52 & 17.61 \\ 12 & 5.14 & 0.93 \\ 12 & 337.3 & 81.8 \\ 7 & 0.0 & 0.0 \\ 12 & 139.42 & 49.11 \\ 12 & 34.58 & 12.35 \\ 12 & 547.6 & 132.6 \\ 12 & 568.3 & 137.9 \\ 12 & 404.2 & 87.5 \\ 12 & 128.9 & 33.6 \\ 12 & 36.1 & 49.4 \\ 12 & 0.25 & 0.07\end{array}$

BANGE

$$
0.0
$$
$\begin{array}{ll}0.0 & 2000 \\ 500 & 1100\end{array}$ $259 \quad 14100$ 7.7 0.14
0.01 0.01
0.16 $0.16 \quad 2.30$
0.00 $680 \quad 230000$ 34 799

$\begin{array}{rrr}0 & 1020 & \\ 0 & 664 & \\ 10.0 & 31.0 & 12 \\ 58.0 & 120.0 & 12 \\ 22.0 & 54.0 & 12 \\ 9.3 & 56.0 & 12 \\ 3.6 & 6.3 & 12 \\ 187 & 437 & 12 \\ 0 & 0 & 7 \\ 54.0 & 220.0 & 12 \\ 18.0 & 53.0 & 12 \\ 318 & 733 & 12 \\ 324 & 782 & 12 \\ 240 & 520 & 12 \\ 82 & 190 & 12 \\ 2 & 170 & 12 \\ 0.1 & 0.3 & 12\end{array}$

*Not significant at the 95 percent confidence level.

\section{BEGRESSION SUMMARY} REGRESSION SAMPLE COEFICIENT, CONSTANT, COR STANDARD
ERROR OF SIZE - B - B - B COEEICIENI ESILMAIE

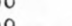

$12-20.019$ -0.0003
-0.00018 $-0.01620$ -0.01620
-0.00145 $-88.050$

19862.555
8.3825
0.41381
16.35672
2.59697
134522.813

$-0.769$ $-0.150$ -0.258 * $-0.718$ $-0.418$ -0.205 . 0.34 0.106 2.926 0.586
78154.8 DAILY SPECIFIC CONDUCTANCE IN MICROMHOS AT 25 DEG C, THAT WAS EQUALLED OR EXCEEDED FOR THE BAIION IABLE OE DALY SPECIEIC CONDUCIANCE EQUALLED OR EXCEEDED FOR THE

$\begin{array}{rrrrrr}12 & 5 z & 10 z & 20 z & 30 z & 50 z \\ 1280 & 1000 & 983 & 966 & 954 & 847\end{array}$

$$
\begin{array}{r}
8.9501 \\
7.1904 \\
-5.1414 \\
-41.0696 \\
1.9513 \\
-33.905 \\
0.000 \\
-76.8207 \\
-16.3807 \\
-65.996 \\
-66.357 \\
-0.784 \\
28.227 \\
234.942 \\
0.2770
\end{array}
$$

5.97

7.39

\begin{tabular}{|c|c|c|c|c|c|}
\hline & & & & & STANDARD \\
\hline & HARMONIC & AMPLITUDE & PHASE & VARIATION & ERROR OF \\
\hline SAMPLE & MEAN - M & $-A$ & ANGLE - C & EXPLAINED & ESTIMATE \\
\hline SUZE_ & $10 E G \quad 61$ & (DEG $(1)$ & (RADIANS) & -181 & $10 E G C)$ \\
\hline 256 & 11.47 & 12.58 & 2.71 & 80 & 4.33 \\
\hline
\end{tabular}

2.60

7.21

0.67
24.0

24.0
0.0

\begin{tabular}{|c|c|c|c|c|c|c|}
\hline \multirow{2}{*}{ CONSTI TUENT } & \multicolumn{3}{|c|}{ TOTAL } & \multicolumn{3}{|c|}{ DISSOLVED } \\
\hline & $\begin{array}{l}\text { NO. } \\
\text { SAMPLES }\end{array}$ & $\begin{array}{l}\text { MIN IMUM } \\
\text { CONC. }\end{array}$ & $\begin{array}{l}\text { MAXIMUM } \\
\text { CONC. }\end{array}$ & $\begin{array}{l}\text { NO. } \\
\text { SAMPLES }\end{array}$ & $\begin{array}{l}\text { MINI MUM } \\
\text { CONC. }\end{array}$ & $\begin{array}{l}\text { MAXIMUM } \\
\text { CONC. }\end{array}$ \\
\hline \multicolumn{7}{|l|}{ MINOR ELEMENTS: } \\
\hline ARSENIC (AS), UG/L & 5 & 3 & 6 & 4 & 2 & 4 \\
\hline CADMIUM $(C D), U G / L$ & 5 & $<10$ & 20 & 4 & 0 & 5 \\
\hline CHROMIUM (CR), UG $/ L$ & 5 & 0 & 10 & 4 & 0 & 10 \\
\hline COBALT $(C O), U G / L$ & 5 & $<50$ & 50 & 4 & 0 & 1 \\
\hline COPPER (CU), UG/L & 5 & $<10$ & 20 & 5 & 0 & 9 \\
\hline IRON (FE), UG/L & 5 & 330 & 9500 & 5 & 0 & 40 \\
\hline LEAD $(P B), U G / L$ & 5 & $<100$ & 100 & 4 & 2 & 33 \\
\hline MANG ANESE (MN), UG/L & 4 & 260 & 530 & 5 & 5 & 380 \\
\hline MERCURY (HG), UG/L & 5 & 0.0 & 0.7 & 4 & 0.0 & 0.7 \\
\hline SELENIUM (SE), UG/L & 5 & 0 & 3 & 4 & 0 & 3 \\
\hline$Z I N C(Z N), U G / L$ & 5 & 10 & 70 & 5 & 0 & 20 \\
\hline \multicolumn{7}{|l|}{ PERIPHYTON: } \\
\hline BIOMASS, ORY WT., G/SQ M & 1 & 66.00 & & & & \\
\hline BIOMASS, ASH WT., G/SQ M & 1 & 60.00 & & & & \\
\hline CHLOROPHYLL A, MG/SO M & $i$ & 58.0 & & & & \\
\hline CHLOROPHYLL B, MG/SO M & 1 & 5.7 & & & & \\
\hline ORGANIC CARBON, MG/L & 3 & 7.2 & 19.0 & & & \\
\hline
\end{tabular}

18.69

6.32

27.9

32.8

$18 \cdot 7$

27.2

0.07

SUMMARY OF HARMONIC ANALYSIS OF STREAM TEMPERATURE

EURM OF EQUALUN: I.LOI $\equiv M+A * S I N C .0172 * 0+C$

SUMMARY OF MAXIMUM AND MINIMUM CONCENTRATIONS OF CONSTITUENTS SAMPLED AT A FREQUENCY OF QUARTERLY (1975 WY)

05330000 -- MINNESOTA RIVER NEAR JORDAN, MINN. 
LAT 44D56M40S LONG 093005M20S

DRAINAGE AREA: 36800 SO MI 195312 SQ KMI

PERIOD OF RECORD: $10 / 01 / 74-09 / 30 / 75$

STATISTICAL SUMMARY OF SELECTED DISSOLVED CHEMICAL CONSTITUENTS AND REGRESSION RELATIONSHIPS OF CONSTITUENT CONCENTRATIONS TO SPECIFIC CONDUCTANCE

\section{CONSIIIUENI}

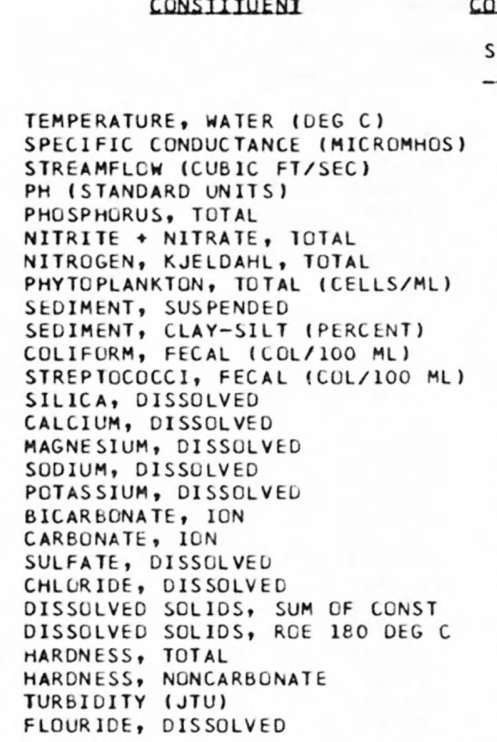

GONSIUIUENI_IMG/L OB UNII_SHOWN

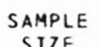

SIZE

$\begin{array}{rrr}13 & 9.85 & 8.55 \\ 11 & 408.3 & 60.7 \\ 11 & 13579.1 & 16179.2 \\ 11 & 8.23 & 0.22 \\ 10 & 0.160 & 0.065 \\ 11 & 1.088 & 1.704 \\ 11 & 1.130 & 0.368 \\ 7 & 9000.0 & 9086.1 \\ 11 & 49.8 & 64.4 \\ 0 & & \\ 10 & 491.0 & 550.5 \\ 10 & 190.6 & 197.2 \\ 10 & 10.50 & 2.99 \\ 11 & 50.00 & 6.13 \\ 11 & 17.64 & 3.01 \\ 11 & 10.83 & 4.28 \\ 11 & 2.77 & 0.47 \\ 11 & 205.5 & 33.6 \\ 7 & 0.0 & 0.0 \\ 11 & 28.73 & 7.00 \\ 11 & 12.24 & 5.36 \\ 10 & 234.2 & 33.0 \\ 11 & 250.1 & 38.4 \\ 11 & 198.2 & 26.8 \\ 11 & 28.8 & 18.6 \\ 11 & 12.5 & 14.4 \\ 11 & 0.16 & 0.07\end{array}$

*Not significant at the 95 percent confidence level'.

SUMMARY OF HARMONIC ANALYSIS OF STREAM TEMPERATURE

\begin{tabular}{|c|c|c|c|c|c|}
\hline \multirow{4}{*}{$\begin{array}{l}\text { SAMPLE } \\
\text { SIZE }\end{array}$} & & & & & STANDARD \\
\hline & HARMONIC & AMPLITUDE & PHASE & VARIATION & ERROR OF \\
\hline & MEAN - $M$ & $-A$ & ANGLE - C & EXPLAINED & ESTIMATE \\
\hline & DEEG CL & (DEG $C)$ & (RADIANS) & -181 & IDEG $C)$ \\
\hline 13 & 10.56 & 11.46 & 2.66 & 93 & 2.44 \\
\hline
\end{tabular}

SUMMARY OF MAXIMUM AND MINIMUM CONCENTRATIONS OF CONSTITUENTS SAMPLED AT A FREQUENCY OF QUARTERLY (1975 WY)

05331000 -- MISSISSIPPI RIVER AT ST.PAUL, MINN.

\begin{tabular}{|c|c|c|c|c|c|c|}
\hline \multirow{2}{*}{ CONSTITUENT } & \multicolumn{3}{|c|}{ TOTAL } & \multicolumn{3}{|c|}{ DISSOLVED } \\
\hline & $\begin{array}{l}\text { NO. } \\
\text { SAMPLES }\end{array}$ & $\begin{array}{l}\text { MIN IMUM } \\
\text { CONC. }\end{array}$ & $\begin{array}{l}\text { MAXIMUM } \\
\text { CONC. }\end{array}$ & $\begin{array}{l}\text { NO. } \\
\text { SAMPLES }\end{array}$ & $\begin{array}{l}\text { MINIMUM } \\
\text { CONC. }\end{array}$ & $\begin{array}{l}\text { MAXIMUM } \\
\text { CONC. }\end{array}$ \\
\hline \multicolumn{7}{|l|}{ MINOR ELEMENTS: } \\
\hline ARSENIC (AS), UG/L & 3 & 1 & 2 & 3 & 0 & 2 \\
\hline CADMIUM $(C D), U G / L$ & 2 & $<10$ & $<10$ & 3 & 0 & 1 \\
\hline CHROMIUM (CR), UG/L & 2 & 0 & 35 & 3 & 0 & 10 \\
\hline COBALT $(C O), U G / L$ & 2 & $<50$ & $<50$ & 3 & 0 & 1 \\
\hline COPPER (CU), UG/L & 2 & $<10$ & 20 & 3 & 4 & 8 \\
\hline IRON $(F E), U G / L$ & 2 & 570 & 680 & 3 & 20 & 270 \\
\hline LEAD $(P B), U G / L$ & 2 & $<100$ & 200 & 3 & 2 & 11 \\
\hline MANG ANESE $(M N), U G / L$ & 2 & 100 & 130 & 3 & 0 & 100 \\
\hline MERCURY $(H G), U G / L$ & 3 & 0.0 & 1.8 & 3 & 0.0 & 0.1 \\
\hline SELENIUM (SE), UG/L & 3 & 0 & 0 & 3 & 0 & 0 \\
\hline ZINC $(Z N), U G / L$ & 2 & 60 & 100 & 3 & 10 & 40 \\
\hline \multicolumn{7}{|l|}{ PERIPHYTON: } \\
\hline GIOMASS, DRY WT., G/SQ M & 2 & 9.19 & 18.00 & & & \\
\hline BIOMASS, ASH WT., G/SQ M & 2 & 6.19 & 14.00 & & & \\
\hline CHLOROPHYLL A, MG/SO M & 2 & 8.5 & 65.0 & & & \\
\hline CHLOROPHYLL B, MG/SQ M & 2 & 2.1 & 3.6 & & & \\
\hline ORGANIC CARBON, MG/L & 4 & 8.0 & 24.0 & & & \\
\hline
\end{tabular}


LAT 45024M25S LONG 092D38M49S

DRAINAGE AREA: 5930 SQ MI ( 15359 SQ KM)

PERIOD OF RECURD: $10 / 01 / 74-09 / 30 / 75$

STATISTICAL SUMMARY OF SELECTED DISSOLVED CHEMICAL CONSTIIUENTS AND REGRESSION RELATIONSHIPS OF CONSTITUENT CONCENTRATIONS TO SPECIFIC CONDUCTANCE

CONSIUIUENI

CONSIIIUENI IMGLL OR UNII SHOWNL

SAMPLE

SIZE

TEMPERATURE, WATER (DEG C) SPECIFIC CONDUCTANCE (MICROMHOS)

STREAMFLOW (CUBIC FT/SEC)

PH (STANDARD UNITS)

PMOSPHORUS, TOTAL

NITRITE + NITRATE, TOTAL

NITROGEN, KJELDAHL, TOTAL

PHYTOPLANKTON, TOTAL (CELLS/ML)

SEUIMENT, SUSPENDED

SEDIMENT, CLAY-SILT (PERCENT)

COLIFORM, FECAL (COL/100 ML)

STREPTOCOCCI, FECAL (COL/100 ML)

SILICA, DISSOLVED

CALCIUM, DISSOLVED

MAGNESIUM, DISSULVEU

SODIUM, DISSOLVED

POTASSIUM, DISSOLVED

BICARBONATE, ION

CARGONATE, ION

SULFATE, DISSOLVED

CHLURIDE, DISSOLVED

DISSOLVED SOLIDS, SUM OF CONST

DISSOLVED SOLIDS, ROE 180 DEG C

HARUNESS, TOTAL

HARDNESS, NONCARBONATE

TURBIDITY (JTU)

FLUURIDE, DISSOLVED

$\begin{array}{rrr}12 & 9.46 & 9.38 \\ 12 & 189.6 & 41.0 \\ 12 & 5403.3 & 5371.9 \\ 11 & 7.52 & 0.34 \\ 12 & 0.038 & 0.019 \\ 12 & 0.279 & 0.152 \\ 12 & 0.548 & 0.331 \\ 12 & 7627.6 & 13777.0 \\ 11 & 9.1 & 9.8 \\ 0 & & \\ 12 & 25.7 & 22.3 \\ 12 & 91.2 & 107.3 \\ 12 & 13.17 & 3.08 \\ 12 & 22.58 & 3.73 \\ 12 & 7.09 & 1.42 \\ 12 & 2.97 & 0.53 \\ 12 & 1.07 & 0.19 \\ 12 & 97.5 & 20.2 \\ 12 & 0.0 & 0.0 \\ 12 & 5.32 & 0.49 \\ 12 & 2.84 & 0.65 \\ 12 & 103.7 & 17.8 \\ 12 & 114.4 & 16.9 \\ 12 & 85.4 & 14.8 \\ 12 & 5.0 & 3.1 \\ 12 & 4.2 & 5.2 \\ 12 & 0.37 & 0.65\end{array}$

$\begin{array}{rr}\text { BANGE } & \\ & \\ 0.0 & 24.5 \\ 85 & 230 \\ 1760 & 20900 \\ 7.0 & 8.0 \\ 0.02 & 0.08 \\ 0.09 & 0.56 \\ 0.26 & 1.40 \\ 2 & 41600 \\ 2 & 35 \\ & \\ 2 & 67 \\ 2 & 345 \\ 6.9 & 17.0 \\ 14.0 & 27.0 \\ 3.7 & 8.9 \\ 1.7 & 3.5 \\ 0.9 & 1.5 \\ 45 & 115 \\ 0 & 0 \\ 4.9 & 6.4 \\ 2.1 & 4.4 \\ 61 & 120 \\ 78 & 136 \\ 50 & 100 \\ 3 & 13 \\ 1 & 20 \\ 0.1 & 2.4 \\ & \end{array}$

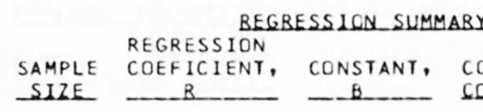

CORRELATION

STANDARD

STANDARD
ERROR OF SIZE

B

$\begin{array}{rrr}12 & -113.915 & 26999.664 \\ 11 & -0.0035 & 8.2081 \\ 12 & -0.00012 & 0.06042 \\ 12 & 0.00194 & -0.08925 \\ 12 & -0.00434 & 1.37184 \\ 12 & 67.559 & -5180.496\end{array}$

$-0.870$

$-0.262^{*}$

$-0.258^{*}$

$0.523^{*}$

$-0.539 *$

$0.201 *$

2776.0

0.35

0.019

0.136

0.292

14153.7

*Not significant at the 95 percent confidence level.

DAILY SPECIFIC CONDUCTANCE IN

MICROMHOS AT 25 DEG C, THAT WAS

BALION IABLE OE DALIY SPECIEIC CONDUCIANCE

EQUALLED OR EXCEEDED FOR THE

$\begin{array}{llllll}1 & 58 & 10 \% & 208 & 30 \% & 503 \\ 310 & 240 & 230 & 210 & 205 & 195\end{array}$

12
12
12
12
12
12
12
12
12
12
12
12
12
12
12

$$
\begin{array}{r}
0.0627 \\
0.0814 \\
0.0314 \\
0.0114 \\
-0.0029 \\
0.463 \\
0.000 \\
-0.0043 \\
0.0044 \\
0.402 \\
0.224 \\
0.331 \\
-0.045 \\
0.014 \\
-0.0130
\end{array}
$$$$
\begin{array}{r}
1.2855 \\
7.1497 \\
1.1355 \\
0.7987 \\
1.0239 \\
9.760 \\
0.000 \\
6.1245 \\
2.0106 \\
27.381 \\
71.869 \\
22.706 \\
14.202 \\
1.446 \\
2.8350
\end{array}
$$

\begin{tabular}{|c|c|c|c|c|c|}
\hline & & & & & STANDARD \\
\hline & HARMONIC & AMPLITUDE & PHASE & VARIATION & ERROR OF \\
\hline SAMPLE & MEAN - M & $-A$ & ANGLE $-C$ & EXPLAINED & ESTIMATE \\
\hline SIZE & LEE 61 & $-(D E G()$ & (BADIANS) & - $1 \% 1$ & $10 E G \quad 61$ \\
\hline 106 & 9.01 & 13.79 & 2.85 & 90 & 2.53 \\
\hline
\end{tabular}

\begin{tabular}{|c|c|c|c|c|c|c|}
\hline \multirow{2}{*}{ CONSTITUENT } & \multicolumn{3}{|c|}{ TOTAL } & \multicolumn{3}{|c|}{ DISSOLVED } \\
\hline & $\begin{array}{l}\text { NO. } \\
\text { SAMPLES }\end{array}$ & $\begin{array}{l}\text { MINIMUM } \\
\text { CONC. }\end{array}$ & $\begin{array}{l}\text { MAXIMUM } \\
\text { CONC. }\end{array}$ & $\begin{array}{l}\text { NO. } \\
\text { SAMPLES }\end{array}$ & $\begin{array}{l}\text { MINIMUM } \\
\text { CONC. }\end{array}$ & $\begin{array}{l}\text { MAXIMUM } \\
\text { CONC. }\end{array}$ \\
\hline \multicolumn{7}{|l|}{ MINOR ELEMENTS: } \\
\hline ARSENIC (AS), UG/L & 3 & 1 & 2 & 4 & 0 & 1 \\
\hline CADMIUM $(C D)$, UG/L & 4 & 0 & 2 & 4 & 0 & 1 \\
\hline CHROMIUM (CR), UG/L & 4 & $<10$ & 20 & 4 & 0 & 1 \\
\hline COBALT $(C O), U G / L$ & 4 & 0 & 4 & 4 & 0 & 2 \\
\hline COPPER (CU), UG/L & 4 & 5 & 10 & 4 & 0 & 1 \\
\hline IRON $(F E), U G / L$ & 4 & 310 & 4000 & 4 & 80 & 780 \\
\hline LEAD $(P B), U G / L$ & 4 & 3 & 26 & 4 & 0 & 2 \\
\hline MANGANESE (MN), UG/L & 4 & 10 & 140 & 4 & 0 & 40 \\
\hline MERCURY $(H G), U G / L$ & 4 & 0.2 & 0.6 & 4 & 0.0 & 0.4 \\
\hline SELENIUM (SE), UG/L & 3 & 0 & 0 & 4 & 0 & 0 \\
\hline $21 N C(2 N), U G / L$ & 4 & 10 & 380 & 4 & 0 & 10 \\
\hline \multicolumn{7}{|l|}{ PERIPHYTON: } \\
\hline BIOMASS, DRY WT., G/SO M & 2 & 1.29 & 1.50 & & & \\
\hline BIOMASS, ASH WT., G/SO M & 2 & .79 & 1.09 & & & \\
\hline CHLORCPHYLL A, MG/SC M & 2 & .0 & .7 & & & \\
\hline CHLOROPHYLL B, MG/SQ M & 2 & .0 & .0 & & & \\
\hline ORGANIC CARBON, MG/L & 4 & 3.8 & 13.0 & & & \\
\hline
\end{tabular}

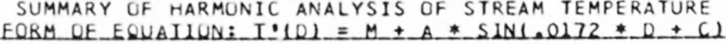

SUMMARY OF MAXIMUM AND MINIMUM CONCENTRATIONS CF CONSTITUENTS SAMPLED AT A FREQUENCY OF QUARTERLY (1975 WY)

05340500 -- ST. CROIX RIVER AT ST. CROIX FALLS, WIS. 
LAT 44D37M4OS LONG 091058M10S DRAINAGE AREA: 9010 SO MI ( 23336 SQ KM) PERIOD OF KECORD: $10 / 01 / 74-09 / 30 / 75$

STATISTICAL SUMMARY OF SELECTED DISSOLVED CHEMICAL CONSTITUENTS ANU REGRESSION RELATIONSHIPS OF CONSTITUENT CONCENTRATIONS TO SPECIFIC CONDUCTANCE

CONSIIIUENI

GONSILIUENI_IMG/L QB.UNII_SHOWNU

SAMPLE STANDARD

(12)

TEMPERATURE, WATER (DEG C) SPECIFIC CONOUCTANCE (MICRCMHUS) STREAMFLOW (CUBIC FT/SEC)

PH (STANDARD UNITS)

PHOSPHORUS, TOTAL

NITRITE + NITRATE, TUTAL

NITROGEN, KJELDAHL, TOTAL

PHYTOPLANKTON, TOTAL (CELLS/ML)

SEDIMENT, SUSPENDEU

SEDIMENT, CLAY-SILT (PERCENT)

COLIFORM, FECAL (COL/ $100 \mathrm{ML}$ )

STREPTOCOCCI, FECAL $(\mathrm{COL} / 100 \mathrm{ML})$

SILICA, DISSCLVED

CALCIUM, DISSOLVED

MAGNESIUM, DISSOLVED

SODIUM, DISSOLVED

POTASSIUM, DISSOLVED

BICARBONATE, ION

B TCARBONATE, ION

SULFATE, DISSOLVED

CHLURIDE, DISSOLVED

DISSOLVED SOLIDS, SUM OF CONST

DISSOLVED SOLIDS, ROE 180 OEG

HARDNESS, TOTAL

HARDNESS, NONCARBONATE

TURBIDITY (JTUI

FLOURIDE, DISSOLVED

$\begin{array}{rrrrr}13 & 10.96 & 9.97 & 0.0 & 24.0 \\ 12 & 135.4 & 36.3 & 05 & 180 \\ 14 & 8113.6 & 4991.4 & 3260 & 18600 \\ 12 & 7.32 & 0.26 & 0.9 & 7.8 \\ 12 & 0.117 & 0.093 & 0.06 & 0.40 \\ 12 & 0.483 & 0.160 & 0.23 & 0.71 \\ 12 & 0.796 & 0.333 & 0.43 & 1.50 \\ 12 & 7319.3 & 11683.2 & 1 & 36000 \\ 0 & & & & \\ 0 & & & & \\ 12 & 1651.6 & 3460.3 & 13 & 12000 \\ 12 & 444.7 & 560.8 & 5 & 1500 \\ 12 & 9.97 & 2.13 & 7.0 & 13.0 \\ 12 & 15.77 & 2.86 & 9.3 & 20.0 \\ 12 & 5.43 & 0.98 & 3.4 & 0.8 \\ 12 & 2.85 & 0.53 & 1.7 & 3.5 \\ 12 & 1.39 & 0.57 & 0.8 & 2.4 \\ 12 & 63.2 & 12.8 & 32 & 77 \\ 12 & 0.0 & 0.0 & 0 & 0 \\ 12 & 7.47 & 0.82 & 5.4 & 8.4 \\ 12 & 3.78 & 0.73 & 2.5 & 5.0 \\ 12 & 78.1 & 12.4 & 51 & 92 \\ 12 & 91.4 & 12.8 & 70 & 112 \\ 12 & 61.8 & 10.7 & 37 & 75 \\ 12 & 10.1 & 3.0 & 3 & 15 \\ 12 & 7.0 & 10.5 & 2 & 40 \\ 12 & 0.32 & 0.22 & 0.1 & 0.8\end{array}$
*Not significant at the 95 percent confidence 1 evel.

RURAIION IABLE OE DAILY SPECIEIC CONDUCIANCE

DAILY SPECIFIC CONDUCTANCE IN

MICROMHOS AT 25 DEG C, THAT WAS

EQUALLED OR EXCEEDED FOR THE
INDICATED PERCENTAGE OF TIME

$\begin{array}{llllll}18 & -58 & 103 & 208 & 328 & 508 \\ 280 & 240 & 210 & 190 & 180 & 155\end{array}$

\begin{tabular}{ll}
\multicolumn{2}{c}{ BEGRESSION SUMMA } \\
REGRESSION \\
SAMPLE COEFICIENT, CONSTANT, \\
SIZE
\end{tabular}

CORRELATION STANDARD

SILE.

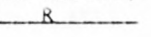

COEEICIENI

ESIUMAI:

280

SUMMARY OF HARMONIC ANALYSIS OF STREAM TEMPERATURE

\begin{tabular}{|c|c|c|c|c|c|}
\hline & & & & & STANDARD \\
\hline & HARMONIC & AMPLITUDE & PHASE & VARIATION & ERROR OF \\
\hline SAMPLE & MEAN - M & $-A$ & ANGLE - C & EXPLAINED & ESTIMATE \\
\hline SIZE_ & 10EG CI & $\triangle D E G(1)$ & (BADIANS) & $-(z) \ldots$ & $10 E G(1)$ \\
\hline
\end{tabular}

185

9.51

16.28

$2 \cdot 75$

2.32

SUMMARY UF MAXIMUM AND MINIMUM CONCENTRATIONS OF CONSTITUENTS SAMFLED AT A FREQUENCY OF QUARTERLY (1975 WY)

U5369500 -- CHIPPEWA RIVER AT DURAND, WIS.

\begin{tabular}{|c|c|c|c|c|c|c|}
\hline \multirow{2}{*}{ CONSTIIUENT } & \multicolumn{3}{|c|}{ TO TAL } & \multicolumn{3}{|c|}{ DISSOLVED } \\
\hline & $\begin{array}{l}\text { NO. } \\
\text { SAMPLES }\end{array}$ & $\begin{array}{l}\text { MINIMUM } \\
\text { CONC. }\end{array}$ & $\begin{array}{l}\text { MAXIMUM } \\
\text { CONC. }\end{array}$ & $\begin{array}{l}\text { ND. } \\
\text { SAMPLES }\end{array}$ & $\begin{array}{l}\text { MINIMUM } \\
\text { CONC. }\end{array}$ & $\begin{array}{l}\text { MAXIMUM } \\
\text { CONC. }\end{array}$ \\
\hline \multicolumn{7}{|l|}{ MINOR ELEMENTS: } \\
\hline ARSENIC (AS), UG/L & 2 & 1 & 2 & 4 & 0 & 1 \\
\hline CADMIUM ICD), UG/L & 4 & 0 & 2 & 4 & 0 & 1 \\
\hline CHROMIUM (CR), UG/L & 4 & $<10$ & 10 & 4 & 0 & 1 \\
\hline COBALT $(C O), U G / L$ & 3 & 0 & 5 & 4 & 0 & 0 \\
\hline COPPER (CU), UG/L & 4 & 7 & 11 & 4 & 2 & 3 \\
\hline IRUN $(F E), U G / L$ & 4 & 520 & 6500 & 4 & 170 & 420 \\
\hline LEAD $(P B), U G / L$ & 4 & 1 & 20 & 4 & 0 & 2 \\
\hline MANG ANESE (MN), UG/L & 4 & 30 & 1400 & 4 & 0 & 60 \\
\hline MERCURY (HG), UG/L & 4 & 0.0 & 0.7 & 4 & 0.0 & 0.2 \\
\hline SELENIUM (SE), UG/L & 4 & 0 & 1 & 4 & 0 & 0 \\
\hline$Z I N C(Z N), U G / L$ & 4 & 10 & 330 & 4 & 0 & 10 \\
\hline \multicolumn{7}{|l|}{ PERIPHYTON: } \\
\hline BIUMASS, URY WT, G/SOM & 3 & .09 & 17.00 & & & \\
\hline GIOMASS, ASH WT., G/SO M & 3 & .09 & 16.00 & & & \\
\hline CHLOKOPHYLL A, MG/SQ M & 3 & .5 & 5.3 & & & \\
\hline CHLOROPHYLL B, MG/SO M & 3 & .0 & 1.0 & & & \\
\hline ORGANIC CARBON, MG/L & 4 & 7.0 & 16.0 & & & \\
\hline
\end{tabular}


LAT 44DO3M2OS LONG U91D38M15S DRAINAGE AREA: 59200 SQ MI I 153328 SQ KMI PERIOD OF RECORD: $10 / 01 / 74-09 / 30 / 75$

STATISTICAL SUMMARY OF SELECTED DISSOLVED CHEMICAL CONSTITUENTS AND REGRESSION RELATIONSHIPS OF CONSTITUENT CONCENTRATIONS TO SPECIFIC CONOUCTANCE

GONSILIUENI

CONSIIIUENI IMG/L OB UNII_SHOWNI)

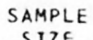

SIZE

TEMPERATURE, WATER IDEG CI

SPECIHIC CONDUCTANCE IMICROMHOS )

STREAMFLOW (CUBIC FT/SEC)

PH (STANDARD UNITS)

PHOSPRORUS, TUTAL

NITRITE + NITRATE, TOTAL

NITROGEN, KJELDAHL, TOTAL

PHYTOPLANKTON, TOTAL (CELLS/ML)

SEOIMENT, SUSPENDED

SEDIMENT, CLAY-SILT (PERCENT)

CULIFORM, FECAL (COL/10O ML)

SIREPTOCOCCI, FECAL (CCL/100 ML)

SILICA, DISSOLVEO

CALCIUM, DISSOLVED

MAGNESIUM, DISSOLVED

SOUIUM, DISSOLVED

POTASSIUM, DISSOLVED

BICARBONATE, ION

CARBONATE, ION

SULFATE, DISSOLVED

CHLORIOE, DISSOLVED

DISSOLVED SOLIDS, SUM OF CONST

OISSOLVED SOLIDS, ROE 180 DEG

MARDNESS, TOTAL

HARDNESS, NONCARBONATE

TURDIDITY (JTU)

FLOURIDE, DISSOLVED

*Not significant at the 95 percent confidence level.

SUMMARY OF HARMUNIC ANALYSIS OF SIREAM TEMPERATURE

\begin{tabular}{|c|c|c|c|c|c|}
\hline & & & & & STANDARD \\
\hline & HARMONIC & AMPLITUDE & PHASE & VARIATION & ERROR OF \\
\hline $\begin{array}{l}\text { SAMPLE } \\
\text { SUZE }\end{array}$ & MEAN - M & ${ }^{-} A$ & $\begin{array}{l}\text { ANGLE }-C \\
\text { (BADIANS) }\end{array}$ & $\begin{array}{l}\text { EXPLAINED } \\
\text { (I) }\end{array}$ & $\begin{array}{l}\text { ESTIMATE } \\
\text { (DEG_C) }\end{array}$ \\
\hline
\end{tabular}
13
10.60
13.43
2.60
94
2.68

BEGRESSION SUMMABY REGRESSION

SAMPLE COEFICIENT,

CONSTANT,

CORRELATIUN COEEICIENI

SUMMARY OF MAXIMUM AND MINIMUM CONCENTRATIONS OF CONSTITUENTS SAMPLED AT A FREQUENCY OF QUARTERLY (1975 WY)

25.0
330

165000

0.25

2.10

38000

$\begin{array}{rr}10 & -594.912 \\ 10 & 0.0003 \\ 10 & 0.00015 \\ 10 & -0.00651 \\ 10 & 0.02458\end{array}$

222467.938 8.0024 0.13245 2.74353 $-6.21425$ 44361.320

$-0.257$

0.010

0.083.

$-0.248$

0.469 .

-0.185 *

46883.6 0.51 0.037 0.533 0.970

11964.8

0.0
$\begin{array}{rrr}235.3 & 10 & 800 \\ 554.9 & 4 & 1600\end{array}$ 54.9 3.44 1.42 1.87 18.1 3.8 2.41

14.8

17.7

13.4
9.1

10.3

0.07

$\begin{array}{rr}3.0 & 14.0 \\ 31.0 & 42.0\end{array}$

11.0

4.5
1.8

109

15.0

7.2
145

172

120
11

0.1

42.0
15.0

10.0

3.2
173

10
33.0

33.0
15.0

194
230

230
160
30

39
31

0.3

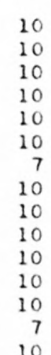

-0.0642
0.1103
0.0439
0.0160
0.0028
0.420
0.004
0.1217
0.0367
0.477
0.462
0.444
0.110
-0.091
0.0001

$$
\begin{array}{r}
30.4570 \\
3.5513 \\
-0.1695 \\
2.8525 \\
1.3921 \\
20.765 \\
0.248 \\
17.4473 \\
-1.1661 \\
29.610 \\
50.420 \\
10.556 \\
-10.001 \\
39.140
\end{array}
$$

0.1063

$-0.358$.

0.033

0.011 .

0.168 *

0.125 .

0.457 *

0.018 *

0.436

0.300.

0.638

0.516 .

0.656

0.240 *

-0.197 *

0.040 .

\begin{tabular}{|c|c|c|c|c|c|c|}
\hline \multirow{2}{*}{ CONSTITUENT } & \multicolumn{3}{|c|}{ TOTAL } & \multicolumn{3}{|c|}{ DISSOLVED } \\
\hline & $\begin{array}{c}\text { NO. } \\
\text { SAMPLES }\end{array}$ & $\begin{array}{l}\text { MINIMUM } \\
\text { CONC. }\end{array}$ & $\begin{array}{l}\text { MAXIMUM } \\
\text { CONC. }\end{array}$ & $\begin{array}{c}\text { NO. } \\
\text { SAMPLES }\end{array}$ & $\begin{array}{l}\text { MINIMUM } \\
\text { CONC. }\end{array}$ & $\begin{array}{l}\text { MAXIMUM } \\
\text { CONC. }\end{array}$ \\
\hline \multicolumn{7}{|l|}{ MINOR ELEMENTS: } \\
\hline AKSENIC (AS), UG/L & 2 & 0 & 3 & 2 & 0 & 2 \\
\hline CADMIUM $(C D), U G / L$ & 2 & $<10$ & 20 & 2 & 0 & 0 \\
\hline CHRUMIUM $(C R)$, UG/L & 2 & 0 & 10 & 2 & 0 & 0 \\
\hline COBALT $(C O), U G / L$ & 2 & $<50$ & $<50$ & 2 & 0 & 0 \\
\hline COPPER (CU), UG/L & 2 & 10 & 20 & 2 & 3 & 6 \\
\hline IKON (FE), UG/L & 9 & 280 & 2500 & 2 & 60 & 100 \\
\hline$L E A D(P B), U G / L$ & 2 & $<100$ & 100 & 2 & 3 & 4 \\
\hline MANG ANESE (MN), UG/L & 9 & 70 & 170 & 2 & 10 & 20 \\
\hline MERC URY $(H G), U G / L$ & 2 & 0.1 & 0.4 & 2 & 0.1 & 0.4 \\
\hline SELENIUM $(S E), U G / L$ & 2 & 0 & 0 & 2 & 0 & 0 \\
\hline ZINC $(Z N), U G / L$ & 2 & 20 & 60 & 2 & 0 & 10 \\
\hline \multicolumn{7}{|l|}{ PERIPHYTON: } \\
\hline BIUMASS, URY WT., G/SQ & M & 2.30 & 6300.00 & & & \\
\hline BIOMASS, ASH WT., G/SO & M & .79 & 41.00 & & & \\
\hline CHLOROPHYLL A, MG/SQ M & 3 & .0 & 90.0 & & & \\
\hline CHLOROPHYLL B, MG/SG M & 3 & .0 & 7.5 & & & \\
\hline ORGANIC CARBON, MG/L & 2 & 15.0 & 15.0 & & & \\
\hline
\end{tabular}

$10 \quad-594.912$

05378500 -- MISSISSIPPI RIVER AT WINONA, MINNESOTA 
LAT $43011 M 54 S$ LONG 090D26M26S DRAINAGE AREA: 10300 SQ MI ( 26677 SQ KM)

PERIUD OF RECORD: $10 / 01 / 74-09 / 30 / 75$

STATISTICAL SUMMARY OF SELECTED DISSOLVED CHEMICAL CONSTITUENTS ANU REGRESSION RELATIONSHIPS OF CONSTITUENT CONCENTRATIONS TC SPECIFIC CONDUCTANCE

CONSLIUUENI

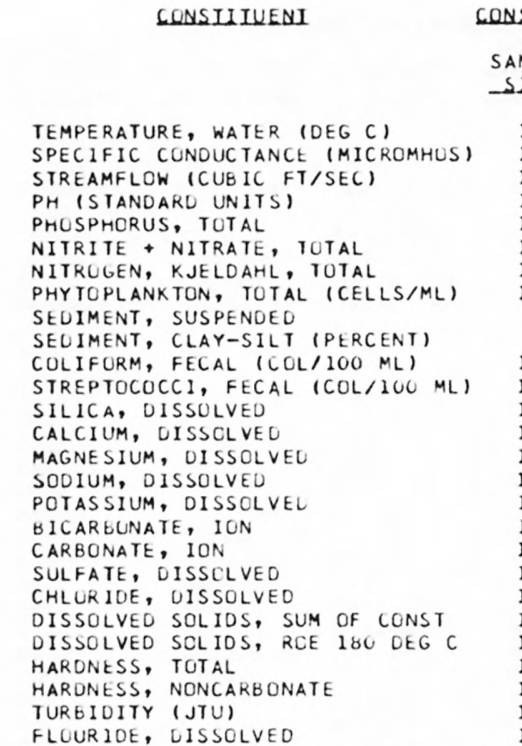

CONSIUIUENL IMG/L OR UNII SHOHNI
STANDARD

DEYIALION

HEAN

10.46

252.9

7840.8

7.67

0.075

22687.5

2687.5

26.0
86.0

86.0

216.4

230.4
5.28

24.58

11.54

11.54
6.78

6.78

111.7

0.0

16.67

9.11

31.2

146.5

108.8

17.3

5.5

0.19
9.53

3002.7

0.022

.215

0.156

0.0

0.0

594.3

621.3

3.35

3.40

1.50

2.15

0.21

14.6
0.0

3.63

2.41

18.8

19.8

14.0

5.2

0.09 \begin{tabular}{l} 
SAMPLE \\
SIZE \\
\hline
\end{tabular}

REGRESSION

EGBESSION SUMMABY

CUEFICIENT, CONSTANT, - B COEEICIENI $\begin{array}{rr}0.0 & 25.0 \\ 215 & 295 \\ 3840 & 14800\end{array}$

$\begin{array}{lll}3840 & 14800 & 12\end{array}$

$0.05 \quad 8.3$

$0.13 \quad 0.74$

0.59

120000

12
12
12
12
12
12

-79.012
0.0045
-0.00017
-0.00291
0.00092
-21.846
27824.243
6.5307
0.11702
1.13389
0.55674
28212.645

$0.280^{\circ}$
$-0.192^{\circ}$

$-0.349^{\circ}$

$-0.343^{\circ}$

$-0.010^{*}$

86
5 2100

$14 \quad 2200$

$0.7 \quad 10.0$

$\begin{array}{rr}0.0 & 30.0 \\ 9.6 & 14.0\end{array}$

$3.5 \quad 9.3$

1.5

1.5
92

12.0

$5 \cdot 3$

101

113

91
9
0

0.0

* Not significant at the 95 percent confidence level.

SUMMARY UF MARMUNIC ANALYSIS OF STREAM TEMPERATURE

\begin{tabular}{|c|c|c|c|c|c|}
\hline & & & & & STANDARD \\
\hline & HARMONIC & AMPLITUDE & PHASE & VARIATION & ERROR OF \\
\hline SAMPLE & MEAN - M & - A & ANGLE - C & EXPLAINED & ESTIMATE \\
\hline SIZE_ & $10 E 6(1)$ & $10 E 6(1)$ & (BADLANS) & $-1 \% 1$ & 10EG_CI_ \\
\hline 91 & 10.47 & 15.19 & 2.76 & 89 & 2.29 \\
\hline
\end{tabular}

SUMMARY OF MAXIMUM AND MINIMUM CONCENTRATIONS OF CONSTITUENTS SAMPLED AT A FREQUENCY OF QUARTERLY (1975 WY)

US407000 -- WISCONSIN RIVER AT MUSCODA, WIS.

\begin{tabular}{|c|c|c|c|c|c|c|}
\hline \multirow{2}{*}{ CONSTI TUENT } & \multicolumn{3}{|c|}{ TOTAL } & \multicolumn{3}{|c|}{ DISSOLVEO } \\
\hline & $\begin{array}{l}\text { NO. } \\
\text { SAMPLES }\end{array}$ & $\begin{array}{l}\text { MINIMUM } \\
\text { CONC. }\end{array}$ & $\begin{array}{l}\text { MAXIMUM } \\
\text { CONC. }\end{array}$ & $\begin{array}{l}\text { NO. } \\
\text { SAMPLES }\end{array}$ & $\begin{array}{l}\text { MINIMUM } \\
\text { CONC. }\end{array}$ & $\begin{array}{l}\text { MAXIMUM } \\
\text { CONC. }\end{array}$ \\
\hline \multicolumn{7}{|l|}{ MINOR ELEMENTS: } \\
\hline ARSENIC (AS), UG/L & 4 & 0 & 1 & 4 & 0 & 1 \\
\hline CADMIUM $(C D), U G / L$ & 4 & 0 & 1 & 4 & 0 & 1 \\
\hline CHROMIUM (CR), UG/L & 4 & $<10$ & $<10$ & 4 & 0 & 0 \\
\hline COBALT $(C O), U G / L$ & 4 & 0 & 7 & 4 & 0 & 7 \\
\hline CCPPER (CU), UG/L & 4 & 9 & 11 & 4 & 0 & 4 \\
\hline IRON (FE), UG/L & 4 & 930 & 1500 & 4 & 220 & 520 \\
\hline$L E A D(P B), U G / L$ & 4 & 6 & 29 & 4 & 0 & 9 \\
\hline MANGANESE (MN), UG/L & 4 & 80 & 140 & 4 & 10 & 53 \\
\hline MERCURY (HG), UG/L & 4 & 0.0 & 0.4 & 4 & 0.0 & 0.3 \\
\hline SELENIUM (SE), UG $/ L$ & 4 & 0 & 0 & 4 & 0 & 0 \\
\hline ZINC $(Z N), U G / L$ & 4 & 30 & 80 & 4 & 0 & 10 \\
\hline \multicolumn{7}{|l|}{ PERIPHYTON: } \\
\hline BIOMASS, DRY WT., G/SO M & 2 & 1.50 & 140.00 & & & \\
\hline BIOMASS, ASH WT., G/SQ M & 2 & .79 & 130.00 & & & \\
\hline CHLOROPHYLL A, MG/SO M & 2 & .2 & 13.0 & & & \\
\hline CHLOROPHYLL 8 , MG/SO M & 2 & .0 & 1.7 & & & \\
\hline ORGANIC CARBON, MG/L & 4 & 8.1 & 11.0 & & & \\
\hline
\end{tabular}


Table 14.--Summary of measurements at each station--Continued

STATION NUMBER : 05420500

NAME: MISSISSIPPI RIVER AT CLINTON, IOWA

LAT $41046 M 53 S$ LONG 090015 MO4S

DRAINAGE AREA: 85600 SQ MI ( 221704 SQ KM)

PERIOD OF RECORD: $10 / 01 / 74-09 / 30 / 75$

STATISTICAL SUMMARY OF SELECTED DISSOLVEO CHEMICAL CONSIITUENTS AND

REGRESSION RELATIONSHIPS OF CONSTITUENT CONCENTRATIONS TO SPECIFIC CONDUCTANCE

CONSIIIUENI

\section{CONSIUI \\ SAMPLE \\ SIZE}

TEMPERATURE, WATER (DEG C)

SPECIFIC CONDUCTANCE (MICROMHOS)

STREAMFLOW (CUBIC FT/SEC)

PH ISTANDARD UNITS

PHOSPHORUS, TOTAL

NITRIIE + NITRATE, TOTAL

NITROGEN, KJELOAHL, TOTAL

PHYTOPLANKTON, TOTAL (CELLS/ML)

SEDIMENT, SUSPENDED

SEDIMENT, CLAY-SILT (PERCENT)

COLIFURM, FECAL (COL/IOO ML)

STREPTOCOCCI, FECAL (CUL/100 ML)

SILICA, DISSOLVED

CALCIUM, DISSOLVED

SODIUM, DISSOLVED

POTASSIUM, DISSOLVED

BICARBONATE, ION

SULFATE, DISSOLVED

CHLORIDE, DISSOLVED

DISSOLVED SOLIDS, SUM OF CONST

DISSOLVED SOLIDS, ROE 180 DEG

HARONESS, TOTAL

HARDNESS, NONCARBONATE

TURBIDITY (JTU)

FLOURIDE, DISSOLVED
MAGNESIUM, DISSOLVED

CARBONATE, ION

$\begin{array}{rrr}12 & 14.39 & 12.41 \\ 11 & 334.5 & 47.8 \\ 12 & 58466.7 & 29124.0 \\ 11 & 8.46 & 0.36 \\ 10 & 0.207 & 0.208 \\ 10 & 0.592 & 0.426 \\ 9 & 1.578 & 0.987 \\ 11 & 14681.8 & 10386.4 \\ 9 & 59.0 & 59.1 \\ 0 & & \\ 8 & 528.1 & 571.3 \\ 8 & 307.3 & 573.8 \\ 11 & 6.78 & 3.52 \\ 11 & 40.18 & 5.91 \\ 11 & 15.64 & 2.11 \\ 11 & 8.50 & 2.47 \\ 11 & 2.54 & 0.89 \\ 11 & 169.0 & 23.9 \\ 7 & 0.6 & 1.5 \\ 11 & 21.55 & 6.28 \\ 11 & 9.74 & 1.06 \\ 11 & 189.0 & 21.7 \\ 11 & 207.2 & 34.5 \\ 11 & 164.5 & 22.5 \\ 11 & 25.5 & 11.6 \\ 11 & 16.5 & 13.5 \\ 11 & 0.33 & 0.20\end{array}$

*Not significant at the 95 percent confidence level. SUMMARY OF HARMONIC ANALYSIS OF STREAM TEMPERATURE

\begin{tabular}{|c|c|c|c|c|c|}
\hline & & & & & STANDARD \\
\hline & HARMONIC & AMPLITUDE & PHASE & VARIATION & ERROR OF \\
\hline SAMPLE & MEAN - M & $-A$ & ANGLE $-C$ & EXPLAINED & ESTIMATE \\
\hline SIZE & LEE_Cl_ & (DEG C) & IBADIANSI & $-(z)$ & $10 E G(1$ \\
\hline 100 & 12.31 & 15.39 & 2.90 & 92 & 1.85 \\
\hline
\end{tabular}

\section{REGBESSION SUMMARY}

REGRESSION

SAMPLE COEFICIENT, CONSTANT,

CORRELATION

STANDARD

ERROR OF

ESIUMAIE

SIZE.

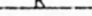

$\begin{array}{rr}0.0 & 29.0 \\ 220 & 390\end{array}$

$21000 \quad 102000$

$\begin{array}{rr}7.8 & 8.8\end{array}$

0.02

0.02
0.08

0.08
0.70

0.76
1.20
3.90

3.90
34000

$11 \quad-259.302$

$-0.0013$

$-0.00347$

$-0.00319$

-0.00319
-0.01074

8.171

142960.250

8.8905

1.37033

1.66077

5.19276

11948.094

-0.421 *

$-0.172$

$-0.840$

$-0.378$.

$-0.578 *$
0.038.

28136.2

0.37

0.120

0.418

10940.4

SUMMARY OF MAXIMUM AND MINIMUM CONCENTRATIONS OF CONSTITUENTS SAMPLED AT A FREQUENCY OF QUARTERLY $(1975$ WY

05420500 -- MISSISSIPPI RIVER AT CLINTON, IOWA

\begin{tabular}{|c|c|c|c|c|c|c|}
\hline \multirow{2}{*}{ CONSTITUENT } & \multicolumn{3}{|c|}{ TOTAL } & \multicolumn{3}{|c|}{ DISSOLVED } \\
\hline & $\begin{array}{l}\text { NO. } \\
\text { SAMPLES }\end{array}$ & $\begin{array}{l}\text { MIN IMUM } \\
\text { CONC. }\end{array}$ & $\begin{array}{l}\text { MAXIMUM } \\
\text { CONC. }\end{array}$ & $\begin{array}{l}\text { NO. } \\
\text { SAMPLES }\end{array}$ & $\begin{array}{l}\text { MINIMUM } \\
\text { CONC. }\end{array}$ & $\begin{array}{l}\text { MAXIMUM } \\
\text { CONC. }\end{array}$ \\
\hline \multicolumn{7}{|l|}{ MINOR ELEMENTS: } \\
\hline ARSENIC (AS), UG/L & 3 & 0 & 7 & 3 & 0 & 2 \\
\hline CADMIUM $(C D)$, UG/L & 2 & 0 & 0 & 4 & 0 & 3 \\
\hline CHROMIUM (CR), UG/L & 2 & 10 & 20 & 2 & 0 & 0 \\
\hline COBALT $(C O), U G / L$ & 2 & 0 & 3 & 4 & 0 & 1 \\
\hline COPPER (CU), UG/L & 2 & 7 & 21 & 4 & 4 & 19 \\
\hline IRON $(F E), U G / L$ & 2 & 1400 & 9700 & 4 & 70 & 190 \\
\hline LEAD $(P B), U G / L$ & 2 & 12 & 28 & 4 & 0 & 10 \\
\hline MANG ANESE (MN), UG/L & 2 & 190 & 1000 & 3 & 10 & 40 \\
\hline MERCURY $(H G), U G / L$ & 3 & 0.2 & 0.7 & 2 & 0.3 & 0.7 \\
\hline SELENIUM (SE), UG/L & 3 & 0 & 0 & 2 & 0 & 0 \\
\hline ZINC $(Z N), U G / L$ & 2 & 30 & 130 & 3 & 10 & 70 \\
\hline \multicolumn{7}{|l|}{ PERIPHYTON: } \\
\hline BIOMASS, DRY WT., G/SO M & 2 & 3.09 & 66.00 & & & \\
\hline BIOMASS, ASH WT., G/SQ M & 2 & 2.29 & 61.00 & & & \\
\hline CHLOROPHYLL A, MG/SO M & 2 & .0 & 39.0 & & & \\
\hline CHLOROPHYLL B, MG/SQ M & 2 & .0 & 1.0 & & & \\
\hline ORGANIC CARBON, MG/L & 2 & 13.0 & 16.0 & & & \\
\hline
\end{tabular}


Table 14.--Summary of measurements at each station--Continued

LAT $41033 M 35 S$ LONG 090010M55S

DRAINAGE AREA: 9551 SQ MI ( 24737 SQ KM)

PERIOD OF RECORD: $10 / 01 / 74-09 / 30 / 75$

STATISTICAL SUMMARY OF SELECTED DISSOLVED CHEMICAL CONSTITUENTS AND REGRESSION RELATIONSHIPS OF CONSTITUENT CONCENTRATIONS TO SPECIFIC CONDUCTANCE

CONSIIIUENI

CONSIIUUENI CMGLL OR UNII SHOWNI

TEMPERATURE, WATER IDEG C) STREAMFLOW (CUBIC FT/SEC)

PH (STANDARD UNITS)

PHOSPHORUS, TOTAL

NITRITE + NITRATE, TOTAL

NITRUGEN, KJELDAHL, TOTAL

PHYTOPLANKTON, TOTAL (CELLS/ML)

SEDIMENT, SUSPENDED

SEDIMENT, CLAY-SILT IPERCENT

COLIFURM, FECAL (COL/1OO ML)

STREPTOCOCCI, FECAL ICOL/100 ML

CALCIUM, DISSOLVED

MAGNESIUM, DISSULVED

SODIUM, DISSOLVED

POTASSIUM, DISSULVED

BICARBONATE, ION

CARBONATE, ION

SULFATE, DISSOLVED

CHLORIDE, DISSOLVED

DISSOLVED SOLIDS, SUM OF CONST

DISSOLVED SOLIDS, RUE 180 DEG C

HARUNESS, TOTAL

HARDNESS, NONCARBONATE

TURBIDITY (JTU)

FLOUR IDE, DISSOLVED

\begin{tabular}{r} 
SAM \\
$S 1$ \\
\hline 2 \\
1 \\
2 \\
1 \\
1 \\
1 \\
1 \\
\\
\\
1 \\
1 \\
1 \\
1 \\
1 \\
1 \\
1 \\
1 \\
1 \\
1 \\
1 \\
1 \\
1 \\
1 \\
1 \\
1 \\
1 \\
1 \\
\end{tabular}

$\begin{array}{ll} & \text { STANDARD } \\ \text { SIZE MEAN REYIAILON }\end{array}$ 630.5 8785.7

7.89

0.299

2.474

1.173

37233.3

$\begin{array}{r}130.0 \\ \hline\end{array}$

234.5

385.9

6.02

61.91

31.64

13.13

2.75
292.5

292.5
0.0

39.00

23.91

322.7

355.9

283.6

22.7

0.20
$21 \quad 12.38$
SPECIFIC CONDUCTANCE IMICROMHOS

SILICA, DISSOLVED
BANGE

9.68

88.9

7728.7

0.32

0.087

0.886

56481.4

$\begin{array}{r}56.4 \\ \hline\end{array}$

188.8

463.4

2.26

9.49

5.97

3.51

0.41

40.2

0.0
5.60

4.72

42.9

46.8

37.0

20.1

0.08
0.5

$\begin{array}{rr}485 & 786 \\ 3080 & 33500\end{array}$

7.4

0.09

0.11

0.73

7100

43

$\begin{array}{rr}40 & 730 \\ 60 & 1500\end{array}$

$\begin{array}{rr}0.1 & 8.1 \\ 42.0 & 75.0\end{array}$

23.0

$8 \cdot 1$

2.2

218
0

31.0

18.0
260

260
272

240

5

8.3
0.41

500
8.1
75.0

75.0
42.0
18.0

18.0

352

49.0
32.0

32.0
400

400
432

432
360
71

50
REGRESSION

SAMPLE COEFICIENT, SIZE

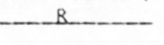

CONSTANT,

MARY

$\begin{array}{lll}3500 & 11 \quad-22.522\end{array}$

0.00623

$-0.00202$

11

$-671.341$

21587.699

8.3687

0.11624

$-1.45634$

2.44770

424372.875

$-0.208^{*}$

0.625

$-0.004$

-0.730 *

0.3

11
11
11
11
11
11
11
11
11
11
11
11
11
11
11

$$
\begin{array}{r}
0.0170 \\
0.0811 \\
0.0284 \\
0.0223 \\
-0.0022 \\
0.325 \\
0.000 \\
0.0383 \\
0.0289 \\
0.375 \\
0.417 \\
0.324 \\
0.053 \\
-0.016
\end{array}
$$

-0.016
0.0005
0.672 0.759

$0.423^{*}$

$0.5666^{\circ}$

$-0.470^{*}$

0.719

0.000 *

0.608

\begin{tabular}{|c|c|c|c|c|c|}
\hline & & & & & STANDARD \\
\hline & HARMONIC & AMPLITUDE & PHASE & VARIATION & ERROR OF \\
\hline $\begin{array}{l}\text { SAMPLE } \\
\text { SIZE }\end{array}$ & MEAN - M & $-A$ & ANGLE - C & EXPLAINED & ESTIMATE \\
\hline SIZE_ & LEEG 61 - & $-10 E 6 \quad 61$ & (BADIANSI) & $-1 z 1 \ldots$ & 1DEG_CL \\
\hline
\end{tabular}

0.544 *

0.776

0.791

0.779

\begin{tabular}{|c|c|c|c|c|c|c|}
\hline \multirow{2}{*}{ CONSTITUENT } & \multicolumn{3}{|c|}{ TOTAL } & \multicolumn{3}{|c|}{ DISSOLVED } \\
\hline & $\begin{array}{l}\text { NO. } \\
\text { SAMPLES }\end{array}$ & $\begin{array}{l}\text { MIN IMUM } \\
\text { CONC. }\end{array}$ & $\begin{array}{l}\text { MAXIMUM } \\
\text { CONC. }\end{array}$ & $\begin{array}{l}\text { NO. } \\
\text { SAMPLES }\end{array}$ & $\begin{array}{l}\text { MINIMUM } \\
\text { CONC. }\end{array}$ & $\begin{array}{l}\text { MAXIMUM } \\
\text { CONC. }\end{array}$ \\
\hline \multicolumn{7}{|l|}{ MINOR ELEMENTS: } \\
\hline ARSENIC (AS), UG/L & 3 & 1 & 3 & 3 & 0 & 1 \\
\hline CADMIUM $(C D)$, UG/L & 3 & 0 & 1 & 3 & 0 & $i$ \\
\hline CHROMIUM (CR), UG/L & 3 & 0 & $<10$ & 3 & $<10$ & $<10$ \\
\hline COBALT $(C O), U G / L$ & 3 & 0 & 2 & 3 & 0 & 1 \\
\hline COPPER $(C U), U G / L$ & 3 & 0 & 10 & 3 & 0 & 20 \\
\hline IRON $(F E), U G / L$ & 3 & 440 & 3000 & 3 & 20 & 30 \\
\hline LEAD $(P B), U G / L$ & 3 & 4 & 15 & 3 & 0 & 3 \\
\hline MANGANESE $(M N), U G / L$ & 3 & 70 & 220 & 3 & 0 & 60 \\
\hline MERCURY $(H G), U G / L$ & 3 & $<0.5$ & 0.9 & 3 & $<0.5$ & $<0.5$ \\
\hline SELENIUM (SE), UG/L & 3 & 0 & 1 & 3 & 0 & 1 \\
\hline ZINC $(Z N), U G / L$ & 3 & 20 & 50 & 3 & 10 & 20 \\
\hline \multicolumn{7}{|l|}{ PERIPHYTON: } \\
\hline GIOMASS, DRY WT., G/SQ M & 0 & & & & & \\
\hline BIOMASS, ASH WT., G/SO M & 0 & & & & & \\
\hline CHLUROPHYLL A, MG/SQ M & 0 & & & & & \\
\hline CHLOROPHYLL $B$, MG/SO M & 0 & & & & & \\
\hline ORGANIC CARBON, MG/L & 3 & 7.5 & 9.0 & & & \\
\hline
\end{tabular}

0.234 *

$-0.087^{*}$

0.522 *
-0.411 *

STANDARD ESIIMAIE

SUMMARY OF HARMONIC ANALYSIS OF SIREAM TEMPERATURE

SUMMARY OF MAXIMUM AND MINIMUM CONCENTRATIONS DF CONSTITUENTS

SAMPLED AT A FREQUENCY OF OUARTERLY (1975 WY)

$05446500--$ ROCK RIVER NEAR JOSLIN, IL 
Table 14.--Summary of measurements at each station--Continued

LAT $40023 M 37 S$ LONG 091D22M27S

DRAINAGE AREA: 119000 SQ MI ( 308210 SO KM)

PERIOD OF RECORD: 10/01/74-09/30/75

STATISTICAL SUMMARY OF SELECTED DISSOLVED CHEMICAL CONSTITUENTS AND

REGRESSION RELATIONSHIPS OF CONSTITUENT CONCENTRATIONS TO SPECIFIC CONDUCTANCE

CONSIIIUENI

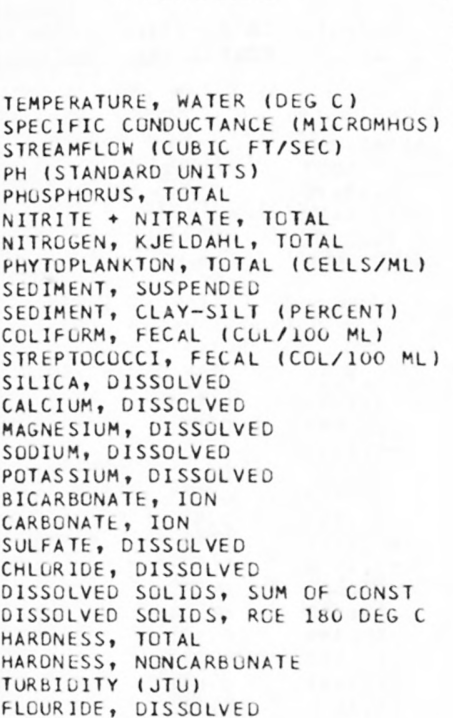

CONSILIUENI IMG/L OR UNII SHOWNU

SAMPLE
SIZE

1115.9

$11 \quad 390.9$

$11 \quad 73527.3$

8.35

0.201

1.345
1.375

17581.8

89.4

STANDARD

DEYIAIION

11.84

36488.0

0.26

0.039

0.838

0.530

8400.9

65.2

561.4

1168.0

6.31
47.82

47.82
18.91

10.05

10.05
2.47

2.47
195.8

195.8
0.0

29.27

13.27

225.2

250.9

197.3

36.6

19.5
0.25

1167.1

3312.4

3.72

6.74

2.12

0.32

23.6

0.0

3.07
2.10

2.10
23.6

32.6

23.3

12.1

0.09
BEGBESSION_SUMMARY

REGRESSION

SAMPLE COEFICIENT,

CONSTANT,

correlation

STANDARD

BANGE

SIZE

$\begin{array}{rr}0.0 & 30.0 \\ 280 & 490 \\ 40900 & 137000 \\ 7.8 & 8.6 \\ 0.16 & 0.30\end{array}$

0.15

$\begin{array}{ll}0.89 & 3.00 \\ 0.89 & 2.80\end{array}$

$5600 \quad 29000$

29000
183

$11 \quad-186.349$

0.0034
-0.00028

0.00070

0.00115

146372.875

7.0125

0.31028

1.07186

$-9045.320$

0.856
-0.461

$0.054^{*}$

$0.139 *$

0.519.

$\begin{array}{rr}7 & 3800 \\ 10 & 10000\end{array}$

$\begin{array}{rr}10 & 10000 \\ 0.4 & 11.0 \\ 38.0 & 59.0 \\ 15.0 & 22.0\end{array}$

15.0

* Not significant at the 95 percent confidence level.

DAILY SPECIFIC CONOUCTANCE IN

MICROMHOS AT 25 DEG C, THAT WAS

EOUALLED OR EXCEEDEO FOR THE

$\begin{array}{llllll}-18 & 58 \quad 20 \% \quad 30 \% \quad 20 \%\end{array}$

$50 \%$

\begin{tabular}{llll} 
& \multicolumn{2}{l}{ SAMPLE S1ZE $=331$} \\
$70 \%$ & $90 \%$ & $25 \%$ & $99 \%$ \\
370 & 342 & 331 & 290
\end{tabular}

SUMMARY OF HARMONIC ANALYSIS OF STREAM TEMPERATURE

FORM UE EOUAIION: I. D) = $+A *$ SING.0172*D+C

\begin{tabular}{|c|c|c|c|c|c|}
\hline & & & & & STANDARD \\
\hline & HARMONIC & AMPLITUDE & PHASE & VARIATION & ERROR OF \\
\hline SAMPLE & $M E A N-M$ & $-A$ & ANGLE $-C$ & EXPLAINED & ESTIMATE \\
\hline SLIE_ & IDEG_L & $-10 E G(1)$ & (BADIADSI & $-(z)$ & $10 E G(1$ \\
\hline 331 & 12.52 & 14.58 & 2.68 & 97 & 1.94 \\
\hline
\end{tabular}

SUMMARY OF MAXIMUM AND MINIMUM CONCENTRATIONS OF CONSTITUENTS

SAMPLED AT A FREQUENCY OF QUARTERLY (1975 WY)

05474500 -- MISSISSIPPI RIVER AT KEOKUK, IOWA

\begin{tabular}{|c|c|c|c|c|c|c|}
\hline \multirow{2}{*}{ CONSTITUENT } & \multicolumn{3}{|c|}{ TOTAL } & \multicolumn{3}{|c|}{ DISSOLVED } \\
\hline & $\begin{array}{l}\text { NO. } \\
\text { SAMPLES }\end{array}$ & $\begin{array}{l}\text { MIN IMUM } \\
\text { CONC. }\end{array}$ & $\begin{array}{l}\text { MAXIMUM } \\
\text { CONC. }\end{array}$ & $\begin{array}{l}\text { NO. } \\
\text { SAMPLES }\end{array}$ & $\begin{array}{l}\text { MINIMUM } \\
\text { CONC. }\end{array}$ & $\begin{array}{l}\text { MAXIMUM } \\
\text { CONC. }\end{array}$ \\
\hline \multicolumn{7}{|l|}{ MINUR ELEMENTS: } \\
\hline ARSENIC (AS), UG/L & 3 & 2 & 3 & 3 & 0 & 2 \\
\hline CADMIUM $(C D)$, UG/L & 3 & 0 & 3 & 4 & 0 & 3 \\
\hline $\begin{array}{l}\text { CHROMIUM (CR), UG/L } \\
\text { COBALT (CO), UG/L }\end{array}$ & 3 & $<10$ & $<10$ & 3 & 0 & 2 \\
\hline $\begin{array}{l}\text { COBALT }(C O), U G / L \\
\text { COPPER }(C U), U G / L\end{array}$ & 3 & 0 & 2 & 4 & 0 & 2 \\
\hline $\begin{array}{l}\text { COPPER }(C U), U G / L \\
\text { IRON }(F E), U G / L\end{array}$ & 3 & 5 & 20 & 4 & 4 & 19 \\
\hline $\begin{array}{l}\text { IRON }(F E), U G / L \\
\text { LEAD }(P B), U G / L\end{array}$ & 3 & 650 & 4700 & 3 & 100 & 2200 \\
\hline $\begin{array}{l}\text { LEAD }(P B), U G / L \\
\text { MANGANESE (MN), UG/L }\end{array}$ & 3 & 10 & 41 & 4 & 0 & 12 \\
\hline $\begin{array}{l}\text { MANG ANESE }(M N), U G / L \\
\text { MERCURY }(H G), U G / L\end{array}$ & 3 & 140 & 210 & 3 & 10 & 200 \\
\hline $\begin{array}{l}\text { MERCURY }(H G) ; U G / L \\
\text { SELENIUM }(S E), U G / L\end{array}$ & 3 & 0.3 & 0.4 & 3 & 0.0 & 0.1 \\
\hline SELENIUM (SE), UG/L & 3 & 0 & 1 & 3 & 0 & 1 \\
\hline $2 I N C(Z N), U G / L$ & 3 & 20 & 40 & 4 & 0 & 30 \\
\hline \multicolumn{7}{|l|}{ PERIPHYTON: } \\
\hline BIOMASS, DRY WT., G/SO M & 3 & .69 & 38.00 & & & \\
\hline BIOMASS, ASH WT., G/SO M & 3 & .50 & 22.00 & & & \\
\hline CHLOROPHYLL A, MG/SQ M & 3 & .3 & 32.0 & & & \\
\hline CHLOROPHYLL B, MG/SO M & 3 & .0 & 1.8 & & & \\
\hline ORGANIC CARBON, MG/L & 3 & 11.0 & 20.0 & & & \\
\hline
\end{tabular}


Table 14.--Sumary of measurements at each station--Continued

LAT $40027 M 45 S$ LONG $091034 M 00 S$
JRAINAGE AREA:
0 SQ MI

PERIOD OF RECORD: $10 / 01 / 74-09 / 30 / 75$ O SO KM)

STATISTICAL SUMMARY OF SELECTED DISSOLVED CHEMICAL CONSTITUENTS AND

REGRESSION RELATIONSHIPS OF CONSTITUENT CONCENTRATIONS TO SPECIFIC CONDUCTANCE

CONSIUIUENI

\section{CONSILIUENI_IMG/L_OR UNII SHOWN}

$$
\begin{aligned}
& \text { SAMPLE } \\
& \text { SIZE. }
\end{aligned}
$$

TEMPERATURE, WATER (DEG C) SPECIFIC CONDUCTANCE (MICROMHOS) STREAMFLOW (CUBIC FT/SEC)

PH (STANDARD UNITS)

PHOSPHCRUS, TCTAL

NITRITE + NITRATE, TOTAL

NITROGEN, KJELDAHL, TOTAL

PHYTOPLANKTON, TOTAL (CELLS/ML)

SEDIMENT, SUSPENDED

SEDIMENT, CLAY-SILT (PERCENT)

COLIFORM, FECAL (COL/1OO ML)

STREPTOCOCCI, FECAL (COL/100 ML)

SILICA, DISSOLVED

CALCIUM, DISSULVEU

MAGNESIUM, DISSOLVED

SODIUM, DISSOLVED

POTASSIUM, DISSOLVED

BICARBONATE, ION

CARBCNATE, ION

SULFATE, DISSOLVED

CHLORIDE, DISSOLVED

DISSOLVED SCLIDS, SUM OF CONST

DISSOLVEO SOLIDS, RUE 180 OEG HARDNESS, TOTAL

HARUNESS, NONCARGONATE

TURBIDITY ( JTU)

FLOURIUE, DISSOLVED
STANDARD

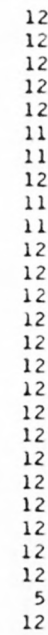

$\begin{array}{rr}13.54 & 11.18 \\ 559.8 & 117.8 \\ 9226.7 & 9854.4 \\ 8.33 & 0.37 \\ 0.207 & 0.113 \\ 2.187 & 2.338 \\ 1.635 & 0.679 \\ 53000.0 & 78142.2 \\ 453.3 & 649.3 \\ 56.5 & 27.2 \\ 1219.2 & 2056.4 \\ 2049.3 & 3452.1 \\ 8.67 & 3.90 \\ 62.67 & 16.86 \\ 24.08 & 6.72 \\ 15.04 & 6.51 \\ 3.84 & 0.80 \\ 185.8 & 41.2 \\ 5.7 & 7.9 \\ 88.33 & 36.75 \\ 19.78 & 6.10 \\ 320.4 & 78.7 \\ 339.8 & 72.2 \\ 258.3 & 58.3 \\ 93.5 & 29.4 \\ 27.4 & 24.1 \\ 0.34 & 0.07\end{array}$

DEYIATION

*Not significant at the 95 percent confidence level.

BANGE

0.029 .0

$328 \quad 840$

$\begin{array}{rr}960 & 28700 \\ 7.8 & 8.8\end{array}$

0.06

0.00

0.00

0.90

1400
18

18
2

4
4
1.9

4
1.9
39.0

10.0

6.7

2.8
130

130
0

36.0
9.4

9.4
180

191

140

27

0.2

BEGRESSION SUMMABY

SAMPLE COEFICIENT, CONSTANT, CORRELATION ERROR CF SIZE CB. B - B COEEICIENI ESLIMAIS

SUMMARY OF HARMONIC ANALYSIS OF STREAM TEMPERATURE

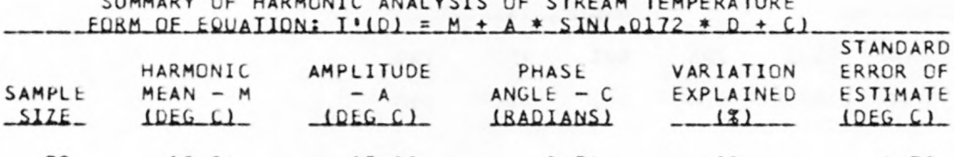

73

12.36

15.09

2.74

83

2.75

SUMMARY OF MAXIMUM AND MINIMUM CONCENTRATIONS OF CONSTITUENTS SAMPLED AT A FREQUENCY OF QUARTERLY (1975 HY)

05490600 -- DES MOINES RIVER AT ST. FRANCISVILLE, MO.

CONSIITUENT
SAMPLES


Table 14.--Summary of measurements at each station--Continued

LAT $41019 M 40 S$ LONG 088D43M1OS

DRAINAGE AREA: 8259 SO MI 121391 SO KMI

PERIOD OF RECORD: $10 / 01 / 74-09 / 30 / 75$

STATISTICAL SUMMARY OF SELECTED DISSOLVED CHEMICAL CONSTITUENTS AND

REGRESSION RELATIONSHIPS OF CONSTITUENT CONCENTRATIONS TO SPECIFIC CONDUCTANCE

\section{CONSIIIUENI}

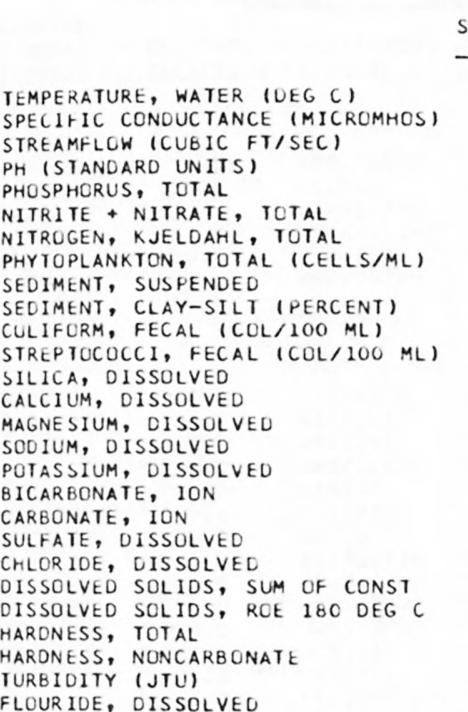

CONSIIUENI IMG L OR UNII SHOWNI

SAMPLE
SIZE

SIZE

STANDARD

DEYIALION 787.4 10296.7 7.46 0.690 4.073

$$
\begin{aligned}
& 4.073 \\
& 1.980
\end{aligned}
$$

13450.0

3450.0
69.2

9.74
73.3
2808.4
0.28

0.284

1.029

0.725

0.725
9414.0

33.5

252.6
1098.0

1098.2
6.71

68.64

24.55

43.73

4.25
206.7

206.7
0.0

102.27

63.45

416.1

466.4

271.8

102.6

24.4

0.52

149.6

3284.7

1.24
7.72

3.39

3.39
12.28

1.08
15.04

15.4

0.0
14.10

14.10
18.64

18.64
42.6

34.9

31.9

25.2

12.4
0.22
BANGE

*Not significant at the 95 percent confidence level

7.1

0.37

2.20

1.10

2400
REGRESSION

REGBESSION SUMMABY

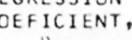

CONSTANT,

CORRELATICN COEEICIENI

STANDARD STANDARD ESIIMAIE

$\begin{array}{rr}2.0 & 30.0 \\ 700 & 918 \\ 7510 & 14100 \\ 7.1 & 7.9\end{array}$

$\begin{array}{rr}7.9 & 10 \\ 1.40 & 11 \\ 6.00 & 11 \\ 3.70 & 10 \\ 26000 & 6\end{array}$

0.0021
0.00140
0.00051
0.00627
4.199

5.7653
-0.40857

10233.844

0.562

0.036

0.599.

0.026 *

0.25
0.280
1.084

1.084

0.616
0521.7

$\begin{array}{lr}9 & 490 \\ 4 & 11000\end{array}$

490
11000
8.2
83.0

8.2
83.0
32.0

32.0
62.0

6.2

230

130.0
98.0

98.0
483

483
519

340

40
0.9
$-0.0113$

$-0.0008$

0.0162

0.0844

$-0.0001$

0.042
0.000

0.0459

0.1412

0.297

0.178

0.034

$-0.018$

0.0004
15.5744

69.2306

11.7086

$-22.7510$

4.3424

0.537

60.1631

$-47.7387$

182.585

326.354

223.855

75.664

38.425

0.1939
-0.065
-0.007

0.351

0.504

$-0.008$

$-0.008$

0.000

0.238 .

0.555

0.510

0.373

0.140 .

0.100 *

-0.106 .

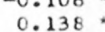

0.98

8.14

3.34
11.18

1.13

15.9

14.43

16.33

38.6

34.2

33.3
26.4

13.0

0.23

SUMMARY OF HARMONIC ANALYSIS OF STREAM TEMPERATURE

\begin{tabular}{|c|c|c|c|c|c|}
\hline & & & & & STANDARD \\
\hline & HARMONIC & AMPLITUDE & PHASE & $\begin{array}{l}\text { VARIATION } \\
\text { EXP }\end{array}$ & $\begin{array}{l}\text { ERROR OF } \\
\text { ERIMATE }\end{array}$ \\
\hline $\begin{array}{l}\text { SAMPLE } \\
\text { SIZE_ }\end{array}$ & $\begin{array}{l}\text { MEAN - M } \\
\text { (DEG } C)^{2}\end{array}$ & $\begin{array}{c}-A \\
-10 E G(1)\end{array}$ & $\begin{array}{l}\text { ANGLE - C } \\
\text { (BADIANSI }\end{array}$ & $\begin{array}{l}\text { EXPLAINED } \\
-181\end{array}$ & $\begin{array}{l}\text { ESTIMATE } \\
\text { IDEG_CI }\end{array}$ \\
\hline 106 & 15.17 & 13.25 & 2.76 & 95 & 1.60 \\
\hline
\end{tabular}

SUMMARY OF MAXIMUM AND MINIMUM CONCENTRATIONS OF CONSTITUENTS SAMPLED AT A FREQUENCY OF QUARTERLY (1975 WY)

05543500 - 1LLINOIS RIVER AT MARSEILLES, IL

CONSTI TUENT
SAMPLES


LAT 39042MIOS LONG $090038 M 40 S$

DRAINAGE AREA: 0 SO MI

PERIOD UF RECURD: $10 / 01 / 74-09 / 30 / 75$ SO KMI

STATISTICAL SUMMARY OF SELECTED DISSOLVED CHEMICAL CONSTITUENTS AND

REGRESSION RELATICNSHIPS OF CONSTITUENT CONCENTRATIONS TO SPECIFIC CONDUCTANCE

CONSIIIUENI

GONSIIUUENI IMG L OR UNAI_SHOWNI

SAMPLE

SIZE

TEMPERATURE, WATER (DEG C) SPECIFIC CONDUCTANCE (MICROMHOS) STREAMFLCW (CUBIC FT/SEC)

PH (STANDARD UNITS)

PHOSPHORUS, TOTAL

NITRITE + NITRATE, TOTAL

NITRUGEN, KJELDAHL, TOTAL

PHYTOPLANKTON, TOTAL (CELLS/ML)

SEDIMENT, SUSPENDED

SEDIMENT, CLAY-SILT (PERCENT)

COLIFORM, FECAL (COL/100 ML)

STREPTOCOCCI, FECAL (COL/100 ML)

SILICA, DISSULVED
CALCIUM, DISSOLVED

MAGNESIUM, DISSOLVEO

SODIUM, DISSOLVED

POTASSIUM, DISSCLVEO

BICAREUNATE, ION

CARBONATE, ION

SULFATE, DISSOLVED

CHLURIDE, DISSOLVED

DISSOLVED SOLIDS, SUM OF CONST

DISSOLVED SOLIDS, ROE 180 DEG C

HARDNESS, TOTAL

HARDNESS, NONCARBONATE

TURBIDITY (JTU)

FLOURIDE, DISSOLVED

10
10
10
10
10
10
1

14
1
10
10
10
10
10
10
10
10
10
10

\section{STANOARD}

14.10

638.6

28577.0

7.87

0.413

4.300

1.031

9766.7
259.5

10.54
37.0

15032.6

0.47
0.178

0.178

1.695

0.198

3708.0

108.3

652.8

436.7

6.21

62.80

25.70

25.00

25.00
2.94

2.94
220.6

0.0
68.60

68.60
36.60

336.9

390.6

262.0

81.9

51.6

0.36

404.8

1.11

4.29

2.98

7.35

0.72

16.6
0.0

22.50

8.64

45.3
44.2

20.4

15.3

24.6

3.0
581
8980
7.0
0.22
2.20
0.78
5300
148
15
120
3.9
56.0
21.0
16.0
2.1
199
0
11.0
27.0
250
324
230
60
10
0.3

NGE

REGRESSION

EGRESS ION SUMMARY

*Not significant at the 95 percent confidence level.

DAILY SPECIFIC CURAIION_IABLE_OE_DALY SPECIEIC CONQUCIANCE

MATLY SPECIFIC CONOUCTANCE IN

MICRUMHOS AT 25 DEG C, THAT WAS

EQUALLED OR EXCEEDED FOR THE

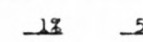

$$
52 \quad 20 \%
$$

$20 \%$

$30 \%$

$\begin{array}{lll}720 & 704 & 700\end{array}$

660

$650 \quad 624$

SAMPLE

COEFICIENT,

CONSTANT,

CORRELATION

STANDARO

C..... COEEICIENI. ESIIMAI:

INUICATED PERCENTAGE OF TIME

SUMMARY OF HARMCNIC ANALYSIS OF STREAM TEMPERATURE

\begin{tabular}{|c|c|c|c|c|c|}
\hline & & & & & STANUARD \\
\hline & HARMONIC & AMPLITUDE & PHASE & VARIATION & ERROR OF \\
\hline SAMPLE & MEAN - M & $-A$ & ANGLE $-C$ & EXPLAINED & ESTIMATE \\
\hline SLZE_ & 1DEG $C \perp_{-}$ & IDEG (1) & $(B A D \perp A N S)$ & $-(3)$ & $10 E G_{2}()_{1}$ \\
\hline 113 & 14.06 & 14.34 & 2.73 & 91 & 1.63 \\
\hline
\end{tabular}

SUMMARY OF MAXIMUM AND MINIMUM CONCENTRATIONS OF CONSTITUENTS

SAMPLED AT A FREQUENCY OF QUARTERLY (1975 WY)

05586100 -- ILLINO1S RIVER AT VALLEY CITY, IL

\begin{tabular}{|c|c|c|c|c|c|c|}
\hline \multirow{2}{*}{ CONSTITUENT } & \multicolumn{3}{|c|}{ TOTAL } & \multicolumn{3}{|c|}{ DISSOLVED } \\
\hline & $\begin{array}{l}\text { NO. } \\
\text { SAMPLES }\end{array}$ & $\begin{array}{l}\text { MINIMUM } \\
\text { CONC. }\end{array}$ & $\begin{array}{l}\text { MAXIMUM } \\
\text { CONC. }\end{array}$ & $\begin{array}{c}\text { NC. } \\
\text { SAMPLES }\end{array}$ & $\begin{array}{l}\text { MINIMUM } \\
\text { CONC. }\end{array}$ & $\begin{array}{l}\text { MAXIMUM } \\
\text { CONC. }\end{array}$ \\
\hline \multicolumn{7}{|l|}{ MINOR ELEMENTS: } \\
\hline ARSENIC (AS), UG/L & 4 & 3 & 5 & 4 & 1 & 2 \\
\hline CADMIUM $(C D), U G / L$ & 4 & 0 & 1 & 4 & 0 & 0 \\
\hline CHROMIUM (CR), UG/L & 4 & 0 & 10 & 4 & 0 & $<10$ \\
\hline COBALT $(C O), \quad U G / L$ & 4 & 0 & 3 & 4 & 0 & 1 \\
\hline COPPER (CU), UG/L & 4 & 10 & 10 & 4 & 10 & 10 \\
\hline IRON (FE), UG/L & 4 & 810 & 4500 & 4 & 20 & 70 \\
\hline LEAD $(P B), U G / L$ & 3 & 2 & 10 & 4 & 0 & 4 \\
\hline MANGANESE (MN), UG/L & 3 & 40 & 220 & 3 & 0 & 30 \\
\hline MERCURY $(H G), U G / L$ & 3 & $<0.5$ & 1.6 & 3 & $<0.5$ & $<0.5$ \\
\hline SELENIUM (SE), UG/L & 3 & 0 & 2 & 3 & 0 & 1 \\
\hline ZINC $(Z N), U G / L$ & 3 & 10 & 50 & 3 & 0 & 10 \\
\hline \multicolumn{7}{|l|}{ PERIPHYTON: } \\
\hline BIUMASS, DRY WT., G/SQ M & 0 & & & & & \\
\hline BIOMASS, ASH WT., G/SQ M & 0 & & & & & \\
\hline CHLOROPHYLL A, MG/SQ M & 0 & & & & & \\
\hline CHLOROPHYLL $8, M G / S O \mathrm{M}$ & 0 & & & & & \\
\hline ORGANIC CARBON, MG/L & 3 & 7.3 & 9.7 & & & \\
\hline
\end{tabular}


Table 14.--Summary of measurements at each station--Continued

LAT 38051M4IS LONG 090008M15S

DRAINAGE AREA: O SQ MI I

PEKIOD OF RECORD:

0 SQ KM)

STATISTICAL SUMMARY OF SELECTED DISSOLVED CHEMICAL CONSTITUENTS AND REGRESSION RELATIONSHIPS OF CONSTITUENT CONCENTRATIONS TO SPECIFIC CONDUCTANCE

CONSILIUENI

CONSILIUENT IMGLL OR UNII SHOHNI

SAMPLE
SIZE

TEMPERATURE, WATER (DEG C)

SPECIFIC CONDUCTANCE (MICROMHOS)

STREAMFLOW (CUBIC FT/SEC)

PH (STANDARD UNITS)

PHOSPHORUS, TOTAL

NITRITE + NITRATE, TOTAL

NITROGEN, KJELDAHL, TOTAL

PHYTOPLANKTON, TOTAL (CELLS/ML)

SEDIMENT, SUSPENDED

SEDIMENT, CLAY-SILT (PERCENT)

COLIFORM, FECAL (COL/100 ML)

STREPTOCOCC 1 , FECAL (COL/100 ML)

CALCIUM, DISSOLVED

MAGNESIUM, DISSOL VED

SODIUM, DISSOLVED

POTASSIUM, DISSOLVED

BICAREONATE, ION

CARBONATE, ION

SULFATE, DISSOLVED

CHLORIDE, DISSOLVED

DISSOLVED SOLIDS, SUM OF CONST

DISSOLVED SOLIDS, ROE 180 DEG

HARDNESS, TOTAL

HARDNESS, NONCARBONATE

TURBIDITY (JTU)

FLOURIDE, DISSOLVED
STANDARD

DEYIAIION

22
22

19

7

7

8
8
17

17

7550.3

$9 \begin{array}{ll}9 & 9.7 \\ 9 & 47.00\end{array}$$$
18.11
$$

11.88

3.02
187.3

187.3
0.8

41.00

17.22

236.4

259.4

192.2

43.9

115.0 $\begin{array}{rr}21 & 119366.6\end{array}$
SILICA, DISSOLVED
10.52

74922.2

0.45

0.135

0.135
0.757

0.530

10620.0

326.2

17.

588.1
613.0

613.0
10.24

6.84

2.32

2.42

25.4

25.2

7.26

2.64

34.1

25.8
27.3

17.6

84.2

0.59

\section{BANGE}

1.033 .5

$33500 \quad 283000$

$\begin{array}{rr}7.3 & 8.9 \\ 0.17 & 0.53\end{array}$

$1.50 \quad 3.70$

$0.66 \quad 2.10$

$\begin{array}{rr}5200 & 36000 \\ 33 & 920\end{array}$

33

49
67

67
92
0.3

92
0.3
36.0

36.0
15.0

8.1

2.5

144

29.0

13.0

191

221
150

12

3
0.2

96
2100

2100
1800

36.0

58.0

22.0

16.0
3.8

224

53.0

20.0

305
300

300
240

240
69
220

220
2.0
BEG

REGRESSION

SAMPLE COEFICIENT, CONSTANT, CORRELATION

B COEEICIENI

SIZE

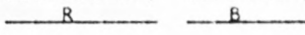

$21 \quad-574.215 \quad 389794.563$

0.0027

0.00090

0.00551

0.00618

6.7609

$-0.07891$

$-1.50884$

84627.375

$-153.794$

(1)

$-0.540$

0.426

0.382 .

0.612 .

$-0.489 *$

64677.6

0.42
0.132

0.766

0.459

12072.5

*Not significant at the 95 percent confidence level.

DAILY SPECIFIC CONDUCTANCE IN DURAION IABLE OF DALLY SPECIEIC CONDUCIANCE

MICROMHOS AT 25 DEG C, THAT WAS

$18 \quad 58 \quad 208$

208

302

$50:$

INDICATED PERCENTAGE OF TIME

625

595

$580 \quad 560$

$545 \quad 520$

708

495
$-37.6060$

1.00681
1.0681

2.2294

5.7723

61.108

$-6.526$

0.3980

8.3980

4.2442

$-9.204$

$-1.748$

$-20.851$

46.078

$-2.7702$
$0.007 *$

0.882

0.901

0.416 *

$-0.776$

0.765

0.524

0.590 .

0.647 *

0.946

0.95

0.934

0.484 .

0.093

SUMMARY OF HARMONIC ANALYSIS OF STREAM TEMPERATURE

\begin{tabular}{|c|c|c|c|c|c|}
\hline & & & & & STANDARD \\
\hline & HARMONIC & AMPLITUDE & PHASE & VARIATION & ERROR OF \\
\hline $\begin{array}{l}\text { SAMPLE } \\
\text { SIZE }\end{array}$ & $\begin{array}{l}\text { MEAN - M } \\
\text { LDEG CI }\end{array}$ & $\begin{array}{c}-A \\
(D E G(1)\end{array}$ & $\begin{array}{l}\text { ANGLE - C } \\
\text { (RADIANS) }\end{array}$ & $\begin{array}{c}\text { EXPLAINED } \\
(\Omega)\end{array}$ & $\begin{array}{l}\text { ESTIMATE } \\
\text { (DEG C) }\end{array}$ \\
\hline 325 & 15.14 & 13.20 & 2.74 & 96 & 1.81 \\
\hline
\end{tabular}

SUMMARY OF MAXIMUM AND MINIMUM CONCENTRATIONS OF CONSTITUENTS SAMPLED AT A FREQUENCY OF QUARTERLY (1975 WY)

05587550 -- MISSISSIPPI RIVER BELOW ALTON, ILL

\begin{tabular}{|c|c|c|c|c|c|c|}
\hline \multirow{2}{*}{ CONSTITUENT } & \multicolumn{3}{|c|}{ TOTAL } & \multicolumn{3}{|c|}{ DISSOLVEO } \\
\hline & $\begin{array}{l}\text { NO. } \\
\text { SAMPLES }\end{array}$ & $\begin{array}{l}\text { MINIMUM } \\
\text { CONC. }\end{array}$ & $\begin{array}{l}\text { MAXIMUM } \\
\text { CONC. }\end{array}$ & $\begin{array}{l}\text { NO. } \\
\text { SAMPLES }\end{array}$ & $\begin{array}{l}\text { MINIMUM } \\
\text { CONC. }\end{array}$ & $\begin{array}{l}\text { MAXIMUM } \\
\text { CONC. }\end{array}$ \\
\hline \multicolumn{7}{|l|}{ MINOR ELEMENTS: } \\
\hline ARSENIC (AS), UG/L & 4 & 2 & 31 & 4 & 0 & 3 \\
\hline CADMIUM $(C D), \quad U G / L$ & 4 & 10 & 20 & 4 & 1 & 3 \\
\hline CHROMIUM (CR), UG $/ L$ & 4 & 20 & 40 & 4 & 0 & 10 \\
\hline COBALT $(C O), U G / L$ & 4 & $<50$ & 50 & 4 & 0 & 2 \\
\hline COPPER (CU), UG/L & 4 & 30 & 70 & 4 & 5 & 11 \\
\hline IRON (FE), UG/L & 4 & 2000 & 15000 & 4 & 30 & 360 \\
\hline LEAD (PB), UG/L & 4 & $<100$ & 100 & 4 & 4 & 38 \\
\hline MANGANESE (MN), UG/L & 4 & 130 & 540 & 4 & 0 & 40 \\
\hline MERGURY (HG), UG/L & 3 & 0.0 & 0.2 & 4 & 0.0 & 0.3 \\
\hline SELENIUM $(S E), U G / L$ & 4 & 0 & 1 & 4 & 0 & 1 \\
\hline$Z I N C(Z N), U G / L$ & 4 & 20 & 130 & 4 & 20 & 50 \\
\hline \multicolumn{7}{|l|}{ PERIPHYTON: } \\
\hline BIOMASS, DRY WT., G/SO M & 2 & 20.00 & 52.00 & & & \\
\hline BIOMASS, ASH WT., G/SO M & 2 & 19.00 & 39.00 & & & \\
\hline CHLOROPHYLL A, MG/SO M & 2 & .5 & 43.0 & & & \\
\hline CHLOROPHYLL B, MG/SQ M & 2 & .0 & 12.0 & & & \\
\hline ORGANIC CARBON, MGIL & 4 & 8.2 & 17.0 & & & \\
\hline
\end{tabular}


Table 14.--Sumnary of measurements at each station--Continued

LAT 38D27MO2S LONG $089037 M 395$

ORAINAGE AREA: 4393 SQ MI 111378 SQ KM)

PERIOD OF RECORD: $10 / 01 / 74-09 / 30 / 75$

STATISTICAL SUMMARY OF SELECTED DISSOLVED CHEMICAL CONSTITUENTS AND

REGRESSION RELATIONSHIPS OF CONSTITUENT CONCENTRATIONS TO SPECIFIC CONDUCTANCE

GONSIIIUENI

\section{CONSIIIUENI_IMGLL OR UNII SHOWNU \\ STANDARD}

SIZE

TEMPERATURE, WATER (DEG C) SPECIFIC CONOUCTANCE (MICROMHOS) STREAMFLOW (CUBIC FT/SEC)

PH (STANDARD UNITS)

PHUSPHORUS, TOTAL

NITRITE + NITRATE, TOTAL

NITROGEN, KJELDAHL, TOTAL

PHYTUPLANKTON, TOTAL (CELLS/ML)

SEDIMENT, SUSPENDEL

SEDIMENT, CLAY-SILT (PERCENT)

COLIFORM, FECAL (COL/100 ML)

STREPTOCOCCI, FECAL (COL/100 ML)

SILICA, DISSOLVED

CALCIUM, DISSOLVED

MAGNESIUM, DISSOLVED

SODIUM, DISSOLVED

POTASSIUM, DISSOLVEU

BICAREONATE, ION

CARBCNATE, ION

SULFATE, UISSOLVED

CHLORIOE, UISSOLVED

DISSULVED SOLIDS, SUM OF CONST

DISSCLVED SOLIDS, ROE 180 DEG C

HARDNESS, TUTAL

HARDNESS, NONCARBUNATE

TURBIDITY (JTU)

FLOURIDE, DISSOLVED
DEVIALION

13.36

413.9

4130.9

7.52

0.209

1.337

0.740

7200.0

194.2

9.69

51.4

3834.0

3834.0
0.33

0.106

0.633

0.249
7149.5

7149.5
109.3

$\begin{array}{rr}558.9 & 495.5 \\ 1056.7 & 1215.5\end{array}$

1056.7

4.08

40.45

15.91

17.18

2.97
151.5

151.5
0.0

46.09

21.45

223.6

248.0

166.4

166.4
42.1

62.9

0.25

1.17

4.74

4.74
2.59

2.60

0.64

26.4
0.0

5.61

3.56

25.2

28.3

22.0

6.1
45.6

45.6
0.09
$1.0 \quad 26.5$

$\begin{array}{lr}314 & 476 \\ 665 & 13000\end{array}$

$\begin{array}{rr}605 & 13000\end{array}$

0.10

0.55

0.52

1300
100

0.44

1.40
20000

10000
382

$\begin{array}{ll}30 & 1400 \\ 40 & 3700\end{array}$

40
2.8

2.8
30.0

30.0
11.0

11.0
12.0

2.4
93

39.0

15.0

164

120

120
35

10
0.1

*Not significant at the 95 percent confidence level.

SUMMARY OF HARMONIC ANALYSIS OF STREAM TEMPERATURE

\begin{tabular}{|c|c|c|c|c|c|}
\hline & & & & & STANDARD \\
\hline & HARMONIC & AMPLITUDE & PHASE & VARIATION & ERROR OF \\
\hline SAMPLE & MEAN - M & $-A$ & ANGLE - C & EXPLAINED & ESTIMATE \\
\hline SLIE_ & IDEG C & COEG 81 & (BADIANS) & $-(z)$ & $\left(D E G_{2}()\right.$ \\
\hline
\end{tabular}

91

13.69

12.68

2.61

92

1.56

SUMMARY UF MAXIMUM AND MINIMUM CONCENTRATIONS OF CONSTITUENTS SAMPLED AT A FREQUENCY OF QUARTERLY (1975 WY)

05594100 -- KASKASKIA RIVER NEAR VENEDY STATION, IL

\begin{tabular}{|c|c|c|c|c|c|c|}
\hline \multirow{2}{*}{ CONSTITUENT } & \multicolumn{3}{|c|}{ TOTAL } & \multicolumn{3}{|c|}{ DISSOLVED } \\
\hline & $\begin{array}{l}\text { NO. } \\
\text { SAMPLES }\end{array}$ & $\begin{array}{l}\text { MINIMUM } \\
\text { CONC. }\end{array}$ & $\begin{array}{l}\text { MAXIMUM } \\
\text { CONC. }\end{array}$ & $\begin{array}{c}\text { NO. } \\
\text { SAMPLES }\end{array}$ & $\begin{array}{l}\text { MINIMUM } \\
\text { CONC. }\end{array}$ & $\begin{array}{l}\text { MAXIMUM } \\
\text { CONC. }\end{array}$ \\
\hline \multicolumn{7}{|l|}{ MINOR ELEMENTS: } \\
\hline ARSENIC (AS), UG/L & 3 & 0 & 5 & 3 & 0 & 1 \\
\hline CADMIUM $(C D), U G / L$ & 3 & 0 & 0 & 3 & 0 & 1 \\
\hline CHROMIUM (CR), UG/L & 3 & 0 & 10 & 3 & 0 & $<10$ \\
\hline COBALT $(C O), U G / L$ & 3 & 2 & 4 & 3 & 0 & 1 \\
\hline COPPER (CU), UG/L & 3 & 0 & 10 & 3 & 0 & 10 \\
\hline IRON (FE), UG/L & 3 & 660 & 7500 & 3 & 40 & 100 \\
\hline LEAD $(P B), U G / L$ & 3 & 3 & 11 & 3 & 0 & 6 \\
\hline MANGANESE $(M N), U G / L$ & 3 & 90 & 450 & 3 & 10 & 30 \\
\hline MERCURY (HG), UG/L & 3 & $<0.5$ & 0.8 & 3 & $<0.5$ & $<0.5$ \\
\hline SELENIUM (SE), UG/L & 3 & 0 & 1 & 3 & 0 & 1 \\
\hline ZINC $(2 N), U G / L$ & 3 & 10 & 40 & 3 & 10 & 40 \\
\hline \multicolumn{7}{|l|}{ PERIPHYTON: } \\
\hline DIOMASS, DRY WT., G/SQ M & 0 & & & & & \\
\hline BIOMASS, ASH WT., G/SQ M & 0 & & & & & \\
\hline CHLOROPHYLL A, MG/SO M & 0 & & & & & \\
\hline CHLOROPHYLL $B, M G / S Q M$ & 0 & & & & & \\
\hline ORGANIC CARGON, MG/L & 3 & 8.3 & 17.0 & & & \\
\hline
\end{tabular}


Table 14.--Sumnary of measurements at each station--Continued

LAT $37044 M 55 S$ LONG $089020 M 45 S$

DRAINAGE AREA: 2102 SO MI 155600 SO KMI

PERIOD CF RECORD: 10/01/74-09/30/75

STATISTICAL SUMMARY OF SELECTED DISSOLVED CHEMICAL CONSTITUENTS AND

REGRESSION RELATIONSHIPS OF CONSTITUENT CONCENTRATIONS TO SPECIFIC CONUUCTANCE

CONSIIIUENI

\begin{tabular}{|c|}
\hline 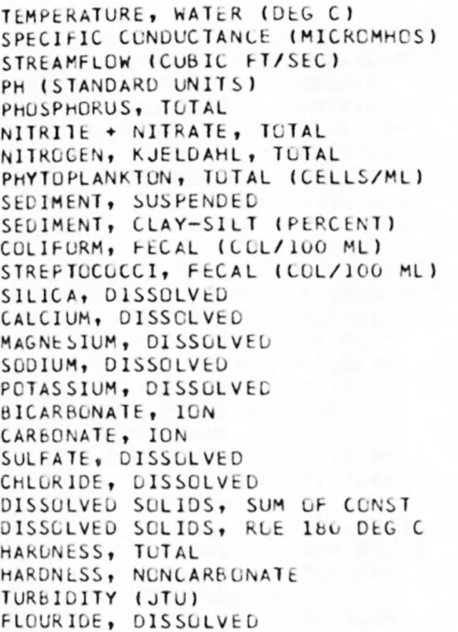 \\
\hline
\end{tabular}

CONSIIIUENT IMG/L QR UNII SHOWNI

SAMP

\section{BEGBESS ION SUMMABY}

REGRESSION

SAMPLE COEFICIENT, CONSTANT,

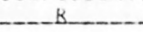

-...

CORRELATIUN STANDARD COEEILIEDIN ERROR OH BADGE 27.0
805 11100

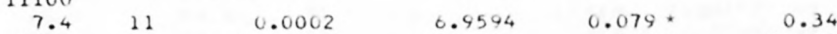
$0.30 \quad 110.0002 \quad 0.9594$ $\begin{array}{llllll}0.30 & 11 & 0.00002 & 0.17471 & 0.042 * & 0.084 \\ 1.10 & 11 & 0.00053 & 0.20442 & 0.382 * & 0.213\end{array}$ $\begin{array}{llllll}1.10 & 11 & 0.00053 & 0.20442 & 0.382 * & 0.213 \\ 0.98 & 11 & 0.00032 & 0.52151 & 0.329 * & 0.155\end{array}$

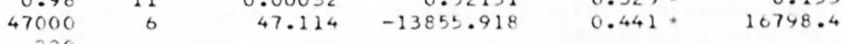
$\begin{array}{rrrr}14883.3 & 16739.1 & 1900 & 47000\end{array}$

$\begin{array}{rr}2000 & \\ 14000 & \\ 0.8 & 11 \\ 70.0 & 10 \\ 30.0 & 10 \\ 62.0 & 10 \\ 7.0 & 10 \\ 133 & 11 \\ 0 & 10 \\ 330.0 & 11 \\ 48.0 & 11 \\ 566 & 10 \\ 593 & 11 \\ 300 & 10 \\ 230 & 10 \\ 94 & 11 \\ 0.4 & 11\end{array}$

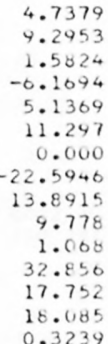

0.054 0.719 0.725 0.743

0.7253
-0.185.

0.697

0.000 .

c. 724

0.200 0.740 0.785 0.700 0.706
0.627. 0.027
6.398 0.398
-0.240.

* Not significant at the 95 percent confidence level. SUMMARY UF HARMONIC ANALYSIS OF STREAM TEMPERATURE

\begin{tabular}{|c|c|c|c|c|c|}
\hline & & & & & STANDARD \\
\hline & HARMONIC & AMPLITUDE & PHASE & VARIATION & ERROR OF \\
\hline SAMPLE & $M E A N-M$ & $-A$ & ANGLE $-C$ & EXPLAINED & ESTIMATE \\
\hline S12E. & DNES GI & $10 E 6()$ & IRADIANSI & $\ldots(z) \ldots$ & $1056 \_61$ \\
\hline 101 & 14.27 & 13.54 & 2.84 & 94 & 1.82 \\
\hline
\end{tabular}

SUMMARY OF MAXIMUM AND MINIMUM CONCENTRATIONS OF CONSTITUENTS SAMPLED AT A FREQUENCY OF QUARTERLY (1975 WY)

U5599500 -- GIG MUUDY RIVER AT MURPHYSBORO, IL

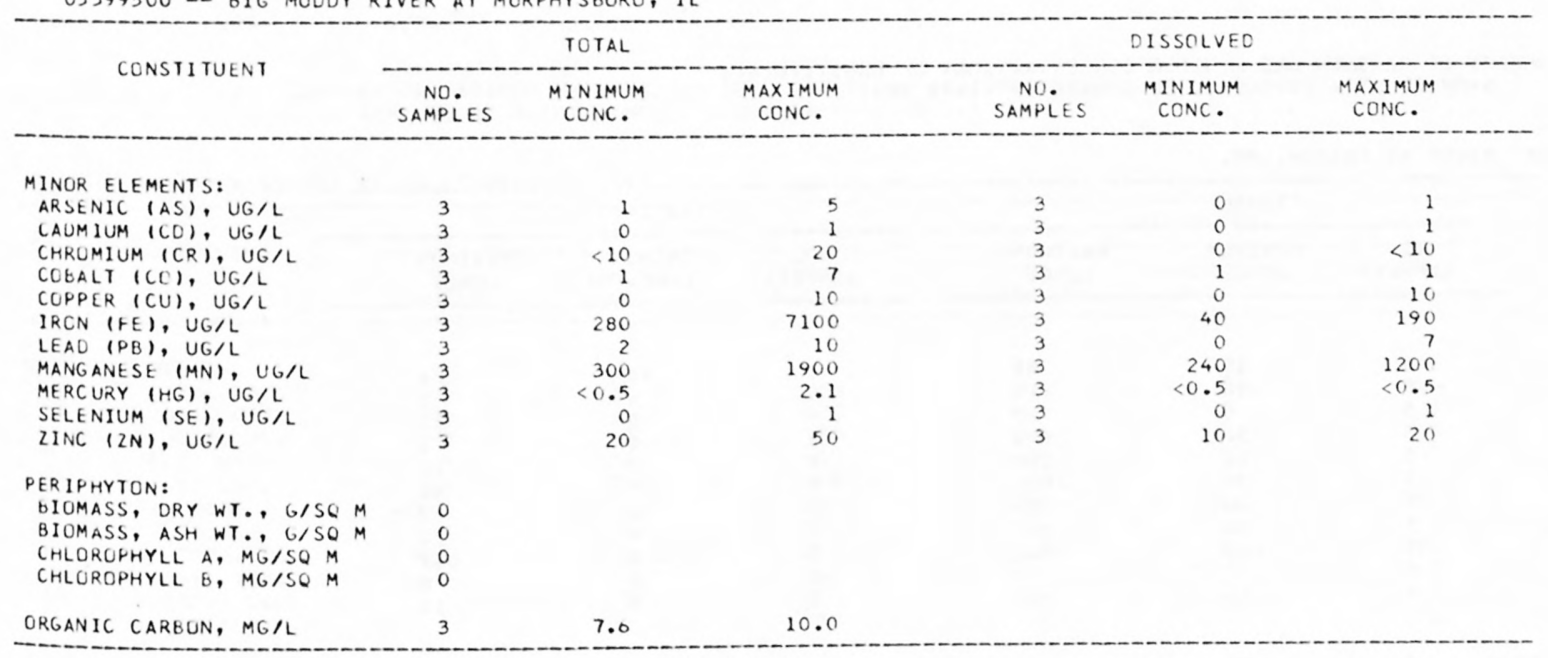


Table 14.--Summary of measurements at each station--Continued

LAT $46008 M 46 S$ LONG $111025 M 18 \mathrm{~S}$

DRAINAGE AREA: 14009 SO MI ( 37993 SQ KM)

PEKIOU UF RECORD: 10/01/74-09/30/75

STATISTICAL SUMMARY OF SELECTED DISSOLVED CHEMICAL CONSTITUENTS ANE

REGRESSIUN RELATIONSHIPS OF CONSTITUENT CONCENTRATIUNS TO SPELIFIC CONDUCTANCE

CONSILIUENI

CONSIUUENI IMG $\angle L$ OR UNAI SHOWNI

SAMPLE

SIZE

TEMPERATURE, WATER (OEG C)

STREAMFLOW (CUBIC FT/SEC)

PH (STANDARL UNITS)

PHOSPHORUS, TOTAL

NITRITE + NITRATE, IOTAL

NITROGEN, KJELDAHL, TOTAL

PHYTOPLANKTON, TOTAL (CELLS/ML)

SEDIMENT, SUSPENDED

SEDIMENT, CLAY-SILT (PERCENT)

COLIFGRM, FECAL (CCL/100 ML)

STREPTOCOCCI, FECAL (COL/100 ML)

SILICA, DISSOLVED

CALCIUM, DISSCLVEO

MAGNESIUM, DISSCLVED

SODIUM, DISSOLVED

POTASSIUM, DISSCLVED

BICARBONATE, ION

CAREUNATE, ION

SULFATE, DISSOLVEO

DISSOLVED SOLIDS, RUE 180 DEG

HARDNESS, TOTAL

HARONESS, NONCARBONATE

TUREIUITY ( JTU)

FLOURIDE, DISSULVEL

12
12
12
12
12
12
12
12
12
12
12
12
12
12
12
12
12
12
8
12
12
12
12
12
12
12
12

MEAN STANDARU
DEYIALION

8.21

370.9

0259.2

8.09

0.044

0.127

0.507

3596.7

3596.7
51.5

51.5
60.0

36.2

46.8

42.8
22.58

39.50

11.42

18.84

3.82

165.8

165.8
0.0

38.50

9.69

227.1

229.8

146.5

10.0

7.8
0.95
SPECIFIC CONDUCTANCE (MICROMHOS)

CHLORIOE, OISSOLVEO

DISSULVED SOLIDS, SUM OF CONST
6.74

64.6

4364.4

0.34

0.033

0.086

2060.4

060.4
52.1

52.1
17.1

60.0

50.6

3.55

2.33

2.33
4.55

0.75

25.9

0.0
8.68

2.89

39.8

36.5

26.5

8.4
9.5

0.31

0.5
205
3500
7.5

0.00

0.00

0.14

860
10

32

2
16.0

21.0

6.1

$2.1 \quad 23.0$

$98 \quad 5$.

10.0

3.8

123

135
78

0
2

0.5
BEGRESSION SUMMABY

REGRESSION SAMPLE COEFICIENT,

CONSTANT, CORRELATIUN STANDARO SIZE

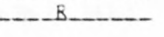

- D - -

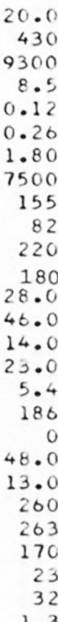

12

$-64.098$

$-0.0014$

30034.137 8.6283 0.19560

$-0.12628$

1.52796

0.00068

$-0.00275$

0550.117

$-0.949$

$-0.275$

$-0.789$

$0.510^{*}$
-0.395.

$-0.395$

*Not significant at the 95 percent confidence level.

DAILY SPECIFIC CONDUTANG QUBAIION_IABLE_OE_DALLY SPECIEIC_CONOUCIANCE

DAILY SPECIFIC CONDUCTANCE IN

MICROMHOS AT 25 DEG C. THAT WAS

EOUALLED UR EXCEEDEU FOR THE

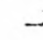

02

$20 \%$

302

$50 \%$

448

420

413

405

385
5.9071

1.2628

$-0.5245$

$-5.0213$

2.1025

20.445

0.000

$-9.6627$

$-3.8013$

20.051

3.440

$-11.925$

20.962

$-0.2600$
0.818

0.945

0.914

0.914

0.978

0.967

0.812

0.993

0.940

$0.454^{*}$

-0.242 .

0.689
1438.1

0.022

0.078

0.436

2092.4
$-0.036$

SAMPLE SIZE $\equiv 365$

70: $20 \% \quad 223 \quad 298$

$246 \quad 232$

212

SUMMARY OF HARMONIC ANALYSIS OF STREAM TEMPERATURE

\begin{tabular}{|c|c|c|c|c|c|}
\hline & & & & & STANUARD \\
\hline & HARMONIC & AMPLITUDE & PHASE & VARIATION & ERROR OF \\
\hline SAMPLE & MEAN - $M$ & $-A$ & ANGLE - C & EXPLAINED & ESTIMATE \\
\hline SIZE - & $10 E G_{6}(1)$ & $1016(1)$ & (BAD IANSI) & (8) & 1DEG_C) \\
\hline 305 & 7.88 & 9.43 & 2.70 & 93 & 1.77 \\
\hline
\end{tabular}

SUMMARY OF MAXIMUM AND MINIMUM CONCENTRATIONS CF CONSTITUENTS

SAMPLED AT A FREQUENCY OF QUARTERLY (1975 WY)

06054500 -- MISSOURI RIVER AT TOSTON, MT.

CONSTITUENT
SAMPLES


Table 14.--Sumary of measurements at each station--Continued

LAT 48DOOM14S LONG 110015M19S DRAINAGE AREA: 34379 SQ MI ( 89042 SO KM)

PERIOD OF RECORD: $10 / 01 / 74-09 / 30 / 75$

STATISTICAL SUMMARY OF SELECTED DISSOLVED CHEMICAL CONSTITUENTS AND

REGRESSION RELATIONSHIPS OF CONSTITUENT CONCENTRATIONS TO SPECIFIC CONDUCTANCE

CONSIIIUENI

CONSILIUENI IMG $\angle L$ OR_UNDI SHOWNL

SAMPLE

SIZE

SPECIFIC CONDUCTANCE (MICROMHUS)

PH (STANDARD UNITS)

PHOSPHURUS, TOTAL

NITRITE + NITRATE, TOTAL

NITROGEN, KJELDAHL, TUTAL

PHYTOPLANKTON, TOTAL (CELLS/ML)

SEDIMENT, SUSPENDED

SEDIMENT, CLAY-SILT (PERCENT)

COLIFURM, FECAL (CCL/100 ML)

SILICA, DISSOLVED

CALCIUM, DISSOLVED

MAGNESIUM, DISSOLVED

SODIUM, DISSOLVED

POTASSIUM, DISSOLVED

BICARBONATE, ION

SULFATE, DISSOLVED

CHLORIDE, DISSOLVED

DISSOLVED SOLIDS, SUM OF CONST

DISSOLVED SOLIDS, KLE 180 DEG

HARDNESS, TOTAL

HARDNESS, NONCARBONATE

TUREIOITY (JTU)

FLOURIDE, DISSOLVED

\section{STANDARU}

MEAN REYLAIION

11
11
11
11
11
11
11
11
10
10
11
11
11
11
11
11
11
11
11
11
11
11
11
11
11
10
11
9.73

418.2
13586.4

8.46

0.175

0.192

0.532

6035.5

283.5

67.1

35.8

54.0
13.89

43.45

15.82

3.10

165.0

1.7

66.82

7.25

254.3
260.9

260.9
174.5

35.5

71.1
6.56

38.8
9607.0

9607.0
0.30

0.30
0.271

0.212

0.515

5156.1

439.9

19.7
41.0

70.0

2.54

1.86
1.78

1.78

4.21
0.55

12.2

12.2
2.7

14.74

2.61

24.7
28.8

28.8

10.3

112.1

12.1
0.18
TEMPERATURE, WATER (DEG C)

STREAMFLOW (CUBIC FT/SEC)

STREP TOCOCCI, FECAL (COL/100 ML)

CARBONATE, ION
BEGBESSION SUMMABY

SAMPLE COEFICIENT,

CONSTANT,

CORRELATION

STANDARD

BANGE

SIZE.

$\begin{array}{rr}0.5 & 20.0 \\ 373 & 520\end{array}$

8.0

0.00

$0.00 \quad 0.78$

$0.08 \quad 1.90$

$790 \quad 16000$

1180

$\begin{array}{rr}6 & 1180 \\ 38 & 95 \\ 1 & 130\end{array}$

$\begin{array}{rr}1 & 130 \\ 5 & 180 \\ 9.8 & 18.0\end{array}$

$40.0 \quad 47.0$

$\begin{array}{ll}14.0 & 20.0 \\ 16.0 & 32.0\end{array}$

$2.3 \quad 4.4$

$144 \quad 183$

$\begin{array}{rr}0 & 8 \\ 52.0 & 100.0\end{array}$

52.0
4.1

221

226
160

160
26

0
0.4
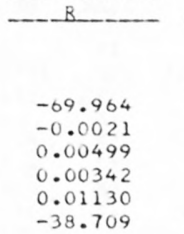

-

ESILMAIE

13.0
317

317
336

330
200
59

59
300

1.0

$0.310 *$

0.782

0.949

0.968

0.885

$0.522^{\circ}$
$-0.195^{\circ}$

0.195

0.709

0.704
0.979

0.979
0.974

0.865

0.005

0.726
0.144

0.160
1.988

0.0007

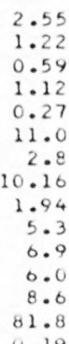

$\begin{array}{rr}373 & 520 \\ 5400 & 29700\end{array}$

COEEISIENI

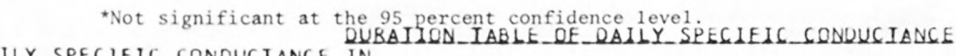

MICROMHOS AT 25 DEG C, THAT WAS

MQUALLED GR EXCEEDED FUR THE

$18 \quad-5 \% \quad 10$

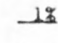

521

$20 \%$

$30 \%$

502

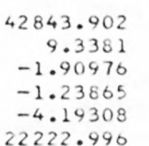

$-0.283$

$-0.273$

0.626

0.853

$-0.291^{*}$

9713.3

0.199

0.174

0.283

5198.9

SUMMARY OF HARMONIC ANALYSIS OF STREAM TEMPERATURE

\begin{tabular}{|c|c|c|c|c|c|}
\hline & & & & & STANDARD \\
\hline & HARMONIC & AMPLITUDE & PHASE & VARIATION & ERROR OF \\
\hline SAMPLE & MEAN - M & $-A$ & ANGLE $-C$ & EXPLAINED & ESTIMATE \\
\hline SLIE_ & $10 E 6$ C & $-10 E G(1$ & IBAD $\triangle A N S)$ & $-(z)$ & DEE $C 1$ \\
\hline 354 & 8.13 & 9.94 & 2.62 & 95 & 1.57 \\
\hline
\end{tabular}

SUMMARY OF MAXIMUM AND MINIMUM CONCENTRATIONS OF CONSTITUENTS SAMPLED AT A FREQUENCY OF QUARTERLY $(1975$ WY

06109500 -- MISSOURI RIVER AT VIRGELLE, MT.

\begin{tabular}{|c|c|c|c|c|c|c|}
\hline \multirow{2}{*}{ CONSTI TUENT } & \multicolumn{3}{|c|}{ TOTAL } & \multicolumn{3}{|c|}{ DISSOLVED } \\
\hline & $\begin{array}{l}\text { NO. } \\
\text { SAMPLES }\end{array}$ & $\begin{array}{l}\text { MIN IMUM } \\
\text { CONC. }\end{array}$ & $\begin{array}{l}\text { MAXIMUM } \\
\text { CONC. }\end{array}$ & $\begin{array}{l}\text { NO. } \\
\text { SAMPLES }\end{array}$ & $\begin{array}{l}\text { MINIMUM } \\
\text { CONC. }\end{array}$ & $\begin{array}{l}\text { MAXIMUM } \\
\text { CONC. }\end{array}$ \\
\hline \multicolumn{7}{|l|}{ MINUR ELEMENTS: } \\
\hline ARSENIC (AS), UG/L & 4 & 10 & 16 & 4 & 7 & 16 \\
\hline CADMIUM (CD), UG/L & 4 & $<10$ & $<10$ & 4 & 0 & 1 \\
\hline CHROMIUM (CR), UG/L & 4 & 0 & 20 & 4 & 0 & 10 \\
\hline COBALT $(C O), U G / L$ & 4 & $<50$ & $<50$ & 4 & 0 & 0 \\
\hline COPPER (CU), UG/L & 4 & 30 & 80 & 4 & 3 & 13 \\
\hline IRON (FE), UG/L & 4 & 120 & 4100 & 4 & 10 & 20 \\
\hline LEAO $(P B), U G / L$ & 4 & $<100$ & $<100$ & 4 & 0 & 3 \\
\hline MANG ANESE (MN), UG/L & 4 & 20 & 120 & 4 & 0 & 10 \\
\hline MERCURY (HG), UG/L & 4 & 0.0 & 0.1 & 4 & 0.0 & 0.1 \\
\hline SELENIUM (SE), UG $/ L$ & 4 & 0 & 1 & 4 & 0 & 1 \\
\hline ZINC $(2 N), U G / L$ & 4 & 20 & 50 & 4 & 0 & 20 \\
\hline \multicolumn{7}{|l|}{ PERIPHYTON: } \\
\hline BIOMASS, DRY WT., G/SQ M & 1 & 200.00 & & & & \\
\hline BIUMASS, ASH WT., G/SQ M & 2 & 1.50 & 250.00 & & & \\
\hline CHLOROPHYLL A, MG/SO M & 2 & 44.0 & 61.0 & & & \\
\hline CHLUROPHYLL $E, M G / S O M$ & 2 & 7.3 & $9 \cdot 5$ & & & \\
\hline ORGANIC CARBON, MG/L & 3 & 4.3 & 6.0 & & & \\
\hline
\end{tabular}


LAT 46059M41S LONG $107053 M 185$

DRAINAGE AREA: 7846 SQ MI 120321 SO KMI

PERIOD OF RECORD: $10 / 01 / 74-09 / 30 / 75$

STATISTICAL SUMMARY OF SELECTED DISSOLVED CHEMICAL CONSTITUENTS AND

REGRESSION RELATIONSHIPS OF CONSTITUENT CONCENTRATIONS TO SPECIFIC CONDUCTANCE

CONSIIUENI

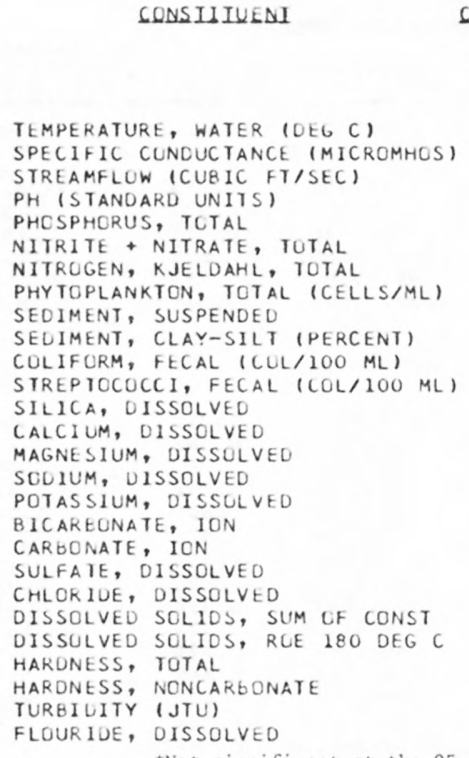

CONSIIIUENI (MGLL OR UNDI_SHOWNI

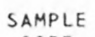

SIZE

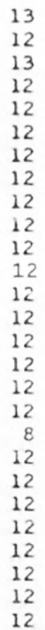

MEAN

9.15
1754.2

1754.2
878.2

878.2
8.30

0.223

0.156

0.916

2756.7

901.6

83.3

85.5

130.2

6.40

114.83

74.83

201.67

5.37

295.9

0.0
27.50

727.50

16.32
1292.5

1292.5

401.5

597.5

352.5
169.3

0.36
STANDARD

DEYIAILON

8.13
553.3

553.3
1114.2

1114.2
0.27

0.335

0.122

0.861

2596.1

1405.9

3.7
97.0

97.0
135.6

135.6

2.00
36.89

36.89
31.48

31.48
93.61

1.12

77.3

0.0

340.11

7.10

536.8
593.3

593.3
224.3

224.3
163.2

225.4

0.07

*Not significant at the 95 percent confidence 1 evel.

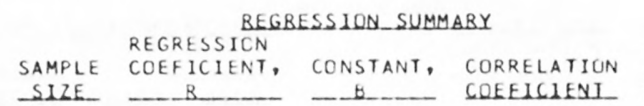

STANDARD

ERROR OF

SIZE

B...

- B COEEICIENI

ESLUAIF

0.523.

$1020 \quad 2650$

$50 \quad 3500 \quad 12$

$\begin{array}{rrr}7.8 & 8.6 & 12 \\ 0.00 & 1.20 & 12\end{array}$

$0.01 \quad 0.40 \quad 12$

0.15

570

$\begin{array}{ll}36 & 4880\end{array}$

69
0

$\begin{array}{rr}0 & 290 \\ 14 & 520\end{array}$

$3.4 \quad 9.6$

78.0

$42.0 \quad 140.0$

$77.0 \quad 360.0$

183

310.021400 .0

6.81400.

$6.8 \quad 27.0$

$600 \quad 2370$

705

170

10
0.3

100

690
750

0.5

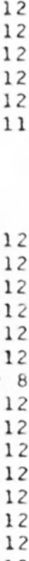

$-1.444$

$-0.0004$

$-0.00027$

0.00000

$-0.00065$

$-1.297$

8.9372

0.09925

0.14968

2.05387

4573.242

$-0.720$

$-0.755$

-0.448 .

$0.016^{\circ}$

$-0.417$

12
12
12
12
12
12
8
12
12
12
12
12
12
12
12$$
\begin{array}{r}
-0.0023 \\
0.0530 \\
0.0495 \\
0.1584 \\
-0.0004 \\
0.096 \\
0.000 \\
0.5534 \\
0.0122 \\
0.87 \\
0.97 \\
0.33 \\
0.25 \\
-0.23 \\
0.000
\end{array}
$$

10.4579

21.8043

$-12.0025$

$-76.2037$

0.0620

127.194

0.000

$-243.3384$

$-5.0983$

$-236.610$

$-308.273$

7.427

$-101.075$

576.068

0.3463
792.8

0.18

0.127

0.821

2038.8

1.62

23.45

16.26
34.47

34.4
1.1

0.

155.20

2.29

247.2

259.3

131.3
82.3

194.3

DAILY SPECIFIC CONDUCTANCE DUBAIION IABLE_OE_DALLY SPECIEIC CONOUCIANCE

MICROMHOS AT 25 DEG C THAT IN

MICRUMHOS DTT

INDICATED PERCENTAGE OF TIME

$\begin{array}{rrrrrr}-12 & -51 & 10 z & 20 \% & 30 \% & 50 z \\ 3110 & 2770 & 2600 & 2370 & 2200 & 1620\end{array}$

$\begin{array}{cccc}\text { SAMPLE SLE } & =321 \\ 70 \% & 90 \% & 25 \% & 29 \% \\ 1280 & 1040 & 993 & 950\end{array}$

SUMMARY UF HARMUNIC ANALYSIS OF STREAM TEMPERATURE

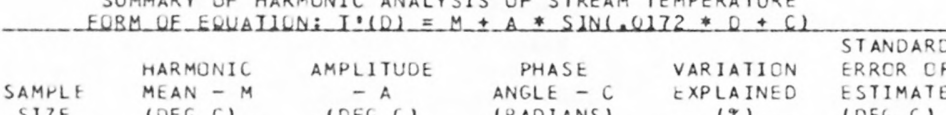

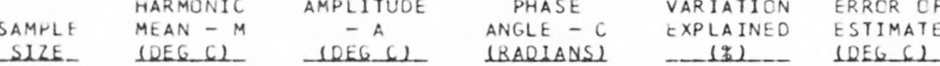

$\begin{array}{llllll}329 & 8.65 & 10.78 & 2.72 & 93 & 2.14\end{array}$

SUMMARY OF MAXIMUM AND MINIMUM CONCENTRATIONS OF CONSTITUENTS

SAMPLED AT A FREQUENCY OF OUARTERLY (1975 WY)

O6130500 -- MUSSELSHELL RIVER AT MOSBY, MT.

\begin{tabular}{|c|c|c|c|c|c|c|}
\hline \multirow{2}{*}{ CONSTITUENT } & \multicolumn{3}{|c|}{ TOTAL } & \multicolumn{3}{|c|}{ DISSCLVED } \\
\hline & $\begin{array}{l}\text { NO. } \\
\text { SAMPLES }\end{array}$ & $\begin{array}{l}\text { MINIMUM } \\
\text { CONC. }\end{array}$ & $\begin{array}{l}\text { MAXIMUM } \\
\text { CONC. }\end{array}$ & $\begin{array}{l}\text { NO. } \\
\text { SAMPLES }\end{array}$ & $\begin{array}{l}\text { MINIMUM } \\
\text { CONC. }\end{array}$ & $\begin{array}{l}\text { MAXIMUM } \\
\text { CONC. }\end{array}$ \\
\hline \multicolumn{7}{|l|}{ MINOR ELEMENTS: } \\
\hline ARSENIC (AS), UG/L & 5 & 1 & 52 & 5 & 0 & 1 \\
\hline CADMIUM $(C O), U G / L$ & 5 & $<10$ & 10 & 5 & 0 & 1 \\
\hline CHROMIUM (CR), UG/L & 5 & 0 & 90 & 5 & 0 & 40 \\
\hline COBALT $(C O), U G / L$ & 5 & $<50$ & 100 & 5 & 0 & 2 \\
\hline COPPER (CU), UGIL & 5 & $<10$ & 130 & 5 & 2 & 13 \\
\hline IRON $(F E), U G / L$ & 5 & 460 & 110000 & 5 & 0 & 80 \\
\hline$L E A D(P B), U G / L$ & 5 & $<100$ & 100 & 5 & 0 & 7 \\
\hline MANG ANESE (MN), UG/L & 4 & 30 & 1200 & 5 & 0 & 30 \\
\hline MERCURY (HG), UG/L & 5 & 0.1 & 1.4 & 5 & 0.0 & 1.0 \\
\hline SELENIUM (SE), UG/L & 5 & 1 & 4 & 5 & 1 & 2 \\
\hline$Z I N C(Z N), U G / L$ & 5 & 40 & 430 & 5 & 0 & 30 \\
\hline \multicolumn{7}{|l|}{ PEKIPHYTON: } \\
\hline BIUMASS, DRY WT., G/SO M & 0 & & & & & \\
\hline GICMASS, ASH WT, G/SQ M & 0 & & & & & \\
\hline CHLOROPHYLL A, MG/SQ M & 0 & & & & & \\
\hline CHLOROPHYLL B, MG/SO M & 0 & & & & & \\
\hline ORGANIC CARBON, MG/L & 5 & 2.5 & 32.0 & & & \\
\hline
\end{tabular}


LAT $48002 M 39 S$ LONG $106021 M 21 S$

DRAINAGE AREA: 57556 SQ MI ( 149070 SO KM)

PERIOD OF RECORD: $10 / 01 / 74-09 / 30 / 75$

STATISTICAL SUMMARY OF SELECTED OISSOLVED CHEMICAL CONSTITUENTS AND

REGRESSION REL.ATIONSHIPS OF CONSTITUENT CONCENTRATICNS TU SPECIFIC CONDUCTANCE

GOASILIUENI

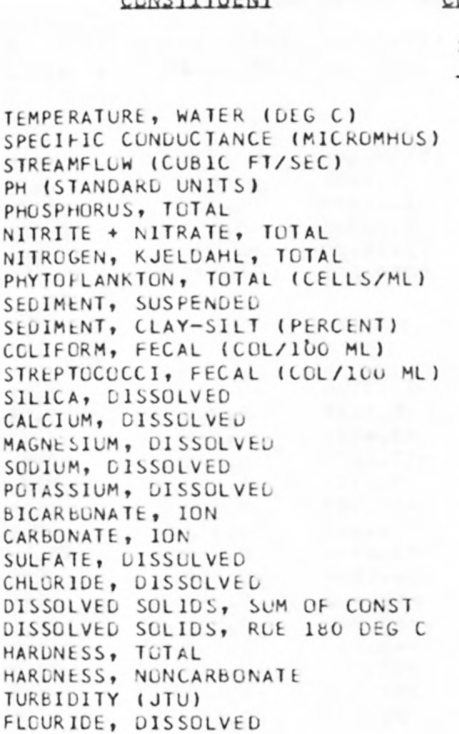

\begin{tabular}{r} 
CONS \\
SAM \\
S1 \\
\hline 1 \\
1 \\
1 \\
1 \\
1 \\
1 \\
1 \\
1 \\
1 \\
1 \\
1 \\
1 \\
12 \\
12 \\
1 \\
12 \\
1 \\
1 \\
1 \\
12 \\
12 \\
1 \\
12 \\
12 \\
12 \\
12 \\
\end{tabular}

CASIUUENI IMG LL OB UNDI SHOWNI

12
12
12
12
12
12
12
11
10
10
12
12
12
12
12
12
12
12
8
12
12
12
12
12
12
12
12

\section{STANDARD}

DEYIAIION

7.13

637.7

13529.2

8.37

0.019

0.019
0.024

0.024
0.264

0.264
440.6

440.6
34.5

44.8

0.8

3.6

7.91
55.67

5.67

20.75

42.75
3.69

3.69
187.8

87.8
1.3

145.00

8.35

378.3

382.5

223.3

68.9

3.3
0.77

4.61
66.9
7739.0
0.35
0.027
0.036
0.142
494.1
52.9
17.5
1.3
4.6
0.48
1.23
1.14
0.45
0.54
5.3
2.5
9.05
0.83
9.9
7.5
0.5
5.1
2.4
0.13

BEGRESSION_SUMMABY

REGRESSION SAMPLE COEFICIENT, CONSTANT, CORRELATIUN _- COEELCIENI STANDARD
ERROK UF ESIIMAIE

$\begin{array}{rr}0.5 & 13.0 \\ 540 & 822 \\ 6950 & 35000 \\ 7.5 & 8.7 \\ 0.00 & 0.10 \\ 0.00 & 0.11 \\ 0.10 & 0.57 \\ 39 & 1400 \\ 4 & 170 \\ 21 & 82 \\ 0 & 4 \\ 0 & 14 \\ 7.3 & 8.8 \\ 54.0 & 58.0 \\ 19.0 & 23.0 \\ 42.0 & 43.0 \\ 2.0 & 4.0 \\ 180 & 190 \\ 0 & 7 \\ 130.0 & 160.0 \\ 7.4 & 10.0 \\ 361 & 391 \\ 371 & 393 \\ 220 & 240 \\ 62 & 70 \\ 1 & 10 \\ 0.6 & 1.0\end{array}$

$\begin{array}{rr}12 & -2.821 \\ 12 & -0.0037 \\ 12 & -0.00001 \\ 12 & 0.00000 \\ 12 & 0.00110 \\ 11 & -0.58\end{array}$
15328.023
10.7204
0.02815
0.02162
$-0.43414$
812.990

$-6.024^{*}$
-0.704
$-0.034^{*}$
$0.008^{*}$
$0.514 *$
$-0.083 *$

8114.3

0.20

0.029

0.128

519.1

*Not significant at the 95 percent confidence level.

DAILY SPECIFIC CONDUCTANCE IN

MICROMHOS AT 25 DEG C, THAT WAS

EQUALLEO OR EXCEEDEU FOK THE

$\begin{array}{llllll}18 & 52 & 103 & 203 & 302 & 503 \\ 749 & 656 & 642 & 628 & 618 & 606\end{array}$

INDICATED PERCENTAGE CF TIME

ERTURE

SUMMARY OF HARMONIC ANALYSIS OF STREAM TEMPERATURE

\begin{tabular}{|c|c|c|c|c|c|}
\hline & & & & & STANDARD \\
\hline & HARMONIC & AMPLITUDE & PHASE & VAR IATION & ERROR OF \\
\hline SAMPLE & MEAN - M & $-A$ & ANGLE - C & EXPLAINED & ESTIMATE \\
\hline SILE & $10 E 6(1)$ & IDEG $C_{1}$ & (BADIANS) & (8) & $1 D E G(1)$ \\
\hline
\end{tabular}

363

6.98

5.30

2.14

94

0.95

SUMMARY LF MAXIMUM AND MINIMUM CONCENTRATIONS OF CONSTITUENTS SAMPLED AT A FREQUENCY OF OUARTERLY (1975 WY)

00132000 -- MISSCURI RIVER BELOW FCRT PECK DAM, MT.

\begin{tabular}{|c|c|c|c|c|c|c|}
\hline \multirow{2}{*}{ CONSTIIUENT } & \multicolumn{3}{|c|}{ TOTAL } & \multicolumn{3}{|c|}{ DISSOLVED } \\
\hline & $\begin{array}{l}\text { NO. } \\
\text { SAMPLES }\end{array}$ & $\begin{array}{l}\text { MINIMUM } \\
\text { CONC. }\end{array}$ & $\begin{array}{l}\text { MAXIMUM } \\
\text { CONC. }\end{array}$ & $\begin{array}{l}\text { NO. } \\
\text { SAMPLES }\end{array}$ & $\begin{array}{l}\text { MINIMUM } \\
\text { CONC. }\end{array}$ & $\begin{array}{l}\text { MAXIMUM } \\
\text { CUNC. }\end{array}$ \\
\hline \multicolumn{7}{|l|}{ MINGR ELEMENTS: } \\
\hline ARSENIC (AS), LG/L & 5 & 3 & 0 & 5 & 2 & 6 \\
\hline CADMIUM $(C D), U G / L$ & 5 & $<10$ & $<10$ & 5 & 0 & 1 \\
\hline CHRUMIUM (CR), UG/L & 5 & 0 & 10 & 5 & 0 & 10 \\
\hline COBALT $(C O), U G / L$ & 5 & 0 & $<50$ & 5 & 0 & 0 \\
\hline COPPER (CU), UG/L & 5 & $<10$ & 60 & 5 & 2 & 16 \\
\hline IRON $(F E), U G / L$ & 5 & 40 & 880 & 5 & 10 & 200 \\
\hline LEAD $(P B), U G / L$ & 5 & $<100$ & 100 & 5 & 0 & 5 \\
\hline MANGANESE $(M N), U G / L$ & 5 & 0 & 20 & 5 & 0 & 10 \\
\hline MERCURY (HG), UG/L & 5 & 0.0 & 2.4 & 5 & 0.0 & 1.8 \\
\hline SELENIUM (SE), UG/L & 5 & 1 & 1 & 5 & 1 & 1 \\
\hline ZINC $(Z N), U G / L$ & 5 & 10 & 120 & 5 & 6 & 20 \\
\hline \multicolumn{7}{|l|}{ PERIPHYTON: } \\
\hline BIOMASS, DRY WT., G/SO M & 0 & & & & & \\
\hline BIOMASS, ASH WT., G/SO M & 1 & 2.29 & & & & \\
\hline CHLOROPHYLL A, MG/SQ M & 1 & .0 & & & & \\
\hline CHLOROPHYLL B, MG/SQ M & 1 & $\cdot 1$ & & & & \\
\hline ORGANIC CARBON, MG/L & 5 & 2.5 & 4.5 & & & \\
\hline
\end{tabular}


Table 14.--Summary of measurements at each station--Continued

LAT 48007MS2S LONG IOSO21MSOS

DRAINAGE AREA: 22332 SQ MI I 57840 SQ KM)

PERIOD OF RECORD: $10 / 01 / 74$ - 09/30/75

STATISTICAL SUMMARY OF SELECTED DISSCLVED CHEMICAL CONSTITUENTS ANO REGRESSION RELATIONSHIPS OF CONSTITUENT CONCENTRATIONS TO SPECIFIC CONDUCTANCE

CONSIIIUENI

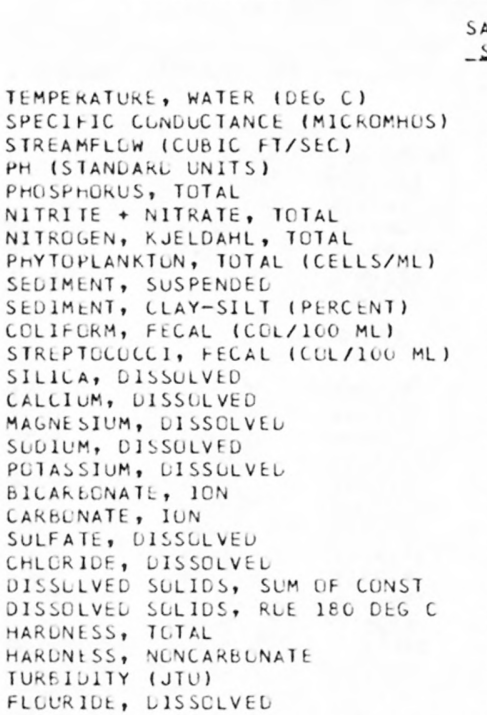

CONSIIUENI_ $1 M G / 1$ OR UNII SHOWNI

SAMPLE
$-S 12 E$
12
12
12
12
12
12
12
12
12
12
12
0
12
12
12
12
12
12
7
12
12
12
12
12
12
12
12
12

STANDARD MEAN REYLALIUN 9.54 1095.8 1212.3 8.17 0.279 0.089 0.789 5320.0 320.0 428.8
76.0 76.0
135.8

5.02 63.58 30.83 126.75 6.17 294.0 294.0
0.3 0.3
292.50 292.50
19.20 19.20
689.9 689.9
706.8 706.8
285.8 285.8 $44 \cdot 3$ 160.9

9.92
310.2
2227.6
0.31
0.487
0.107
0.817
7170.0
783.6
22.3
154.7
2.65
21.29
11.26
44.32
1.26
96.0
0.8
105.41
9.87
234.1
231.8
98.4
24.9
285.3
0.11

9.92
310.2 2227.6 0.487 0.107 .817 70.0 883.6 154.7 2.65 1.26 44.32 96.0 0.8 0.41
9.87 9.87
234.1 931.8 24.9 0.11
BEGRESSION SUMMABY REGRESSION SAMPLE COEFICIENT, CONSTANT, CORRELATION SIZE BANGE - B CONSTANT GREEICIENI

STANOARD $0.5 \quad 26.0$ $730 \quad 1700$ $\begin{array}{rr}127 & 7920 \\ 7.6 & 8.6\end{array}$ 0.02 0.02 0.00 0.00

110 12
38 1.70
0.29

12

12 2.70 $25000 \quad 12$ 2230 100 $\begin{array}{rr}2 & 500 \\ 0.9 & 9.8\end{array}$

$\begin{array}{rr}0.9 & \\ 34.0 & 100.0 \\ 16.0 & 49.0 \\ 74.0 & 190.0\end{array}$

$\begin{array}{rr}9.8 & 12 \\ 100.0 & 12 \\ 49.0 & 12\end{array}$ 190.0

74.0

2.6
126

126
0
60.0

7.6
453

$60.0 \quad 476.0$

5.0
405
429

150

11

c. 0

$\begin{array}{rr}-3.875 & 5459.109 \\ -0.0004 & 8.6454 \\ -0.00089 & 1.25144 \\ -0.00014 & 0.23730 \\ -0.00142 & 2.34079 \\ -3.998 & 9700.609\end{array}$

$-0.540^{*}$ -0.433 *

$-0.565 *$

$-0.394^{*}$

-0.173 *

$-3.998$

9700.609

$-0.0061$

0.0028

.0349

0.1318

0.0003
0.285

$-0.000$

0.3159

0.0303

0.712

0.704

0.300

0.008

$-0.018$

11.7264 $-5.2625$

$-7.4633$

$-17.6698$

$-17.939$

5.01772
0.045

$-53.0194$

$-14.0044$

$-90.440$

$-65.069$

$-43.273$

$-30.717$

837.733

0.2832

$\begin{array}{rr}-0.716 & 1.94 \\ 0.910 & 8.98 \\ 0.963 & 3.18 \\ 0.922 & 17.95 \\ 0.080^{*} & 1.32 \\ 0.920 & 39.4 \\ -0.136^{*} & 0.8 \\ 0.929 & 40.78 \\ 0.952 & 3.10 \\ 0.944 & 81.1 \\ 0.943 & 81.1 \\ 0.947 & 33.2 \\ 0.853 & 13.0 \\ -0.672 & 221.7 \\ 0.000 * & 0.12\end{array}$

*Not significant at the 95 percent confidence level.

DAILY SPELIFIC CONDUCTANCE IN INAIIUN IAELE OE_RALLY SPECIEIC SONEUCIAACE

MICROMHOS AT 25 DEG C, THAT WAS

$\begin{array}{rrrrrr}-18 & -52 & 102 & 202 & 302 & 502 \\ 1540 & 1490 & 1400 & 1420 & 1340 & 935\end{array}$

\begin{tabular}{llll} 
& \multicolumn{2}{l}{ SAMPLE_SIZL } & $=-362$ \\
703 & 923 & 252 & 928 \\
844 & 632 & 598 & 532
\end{tabular}

INDICATED PFRCENTSGE UF TIME

SUMMARY OF HARMUNIC ANALYSIS OF STREAM TEMPERATURE

FUBM OF EQUAILUN: $I \cdot(D)=Y+A * S I N(\cdot 0172 * 2 \pm C)$

\begin{tabular}{|c|c|c|c|c|c|}
\hline & & & & & STANDARL \\
\hline & HARMONIC & AMPLITUDE & PHASE & VARIATION & ERROR OF \\
\hline SAMPLE & $M E A N-M$ & $-A$ & ANGLE - C & EXPLAINED & ESTIMATE \\
\hline -SLLE- & 1DEG 12 & LDEG $(1)$ & IBADLANSI & $-181 \ldots$ & $10 E 6-61$ \\
\hline 305 & 6.99 & 12.77 & 2.74 & 92 & 2.58 \\
\hline
\end{tabular}

SUMMARY UF MAXIMUM AND MINIMUM CONCENTRATIONS OF CONSTITUENTS SAMPLED AT A FREQUENCY OF QUARTERLY (1975 WY)

10174500 -- MILK RIVER AT NASHUA, MT.

CONSTITUENT
SAMPLES


Table 14.--Summary of measurements at each station--Continued

LAT $48007 M 24 S$ LONG $104028 M 30 S$

DRAINAGE AREA: 91557 SO MI I 237133 SO KMI

PERIOD OF RECORD: $10 / 01 / 74-09 / 30 / 75$

STATISTICAL SUMMARY OF SELECTED DISSOLVED CHEMICAL CONSTITUENTS AND

REGRESSION RELATIONSHIPS OF CONSTITUENT CONCENTRATIONS TO SPECIFIC CONDUCTANCE

CONSIIIUENI

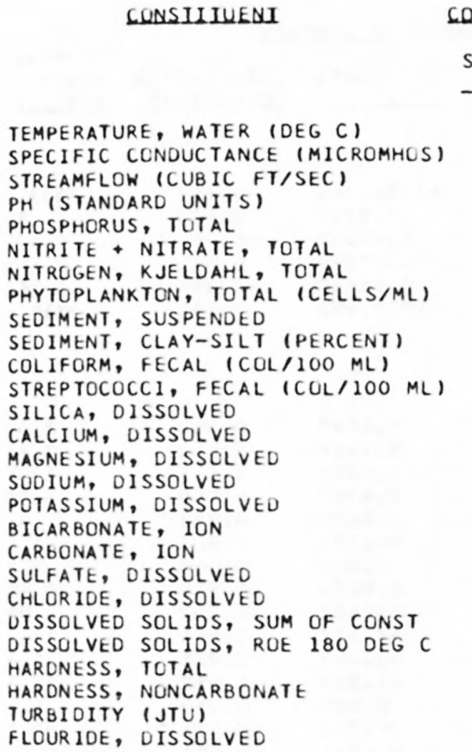

CONSIIIUENI_IMG LL_OB UNII_SHOWNW

SAMPLE

(1)

STANDARD

DEXIAIION

7.76

652.1
16685.3

16685.3
8.21

8.21
0.067

0.066

0.456

1222.9

510.7

17.5

31.6

7.90

52.92
21.08

21.08
48.83

4.15

192.3
0.0

0.0
47.50

8.40

386.3

386.3

220.0

220.0
61.2

61.2
67.7

67.7
0.75
6.91

41.3
8844.1

0.28

0.069

0.071

0.339

1616.4

560.5

11.4
17.6

34.9

0.62
5.92

5.92
1.83

1.83
4.06

0.86

13.4

0.0

1.01

20.7

21.1

21.7

12.9

82.9
0.16

${ }^{*}$ Not significant at the 95 percent confidence level.

BANGE

0.5
580

$580 \quad 725$

5200
7.8

0.01

0.00

0.12

22
27

27

6.2

6.8
38.0

16.0

41.0

1.8

162

130.0

6.8

341

341
346

160

28
0

0
0.4

36800
8.6

8.6
0.21
0.25

0.25
1.40

1.40
5400

2150

62
50

8.6
62.0

24.0

57.0

5.4
218
0

160.0
9.8

9.8
430

438

250
75

270
1.1

DURAIION IABLE OF DAILY SPECIEIC CONOUCIANCE

DAILY SPECIFIC CONDUCTANCE IN

MICROMHOS AT 25 DEG C, THAT WAS

EQUALLED OR EXCEEDED FOR THE

12

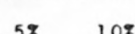

208

302

$50 z$

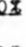

100
8.6
62.0

SAMPL
SIZE

12
12
12
12
12
11


12
12
12
12
12
12
7
12
12
12
12
12
12
12
12

REGRESSION

BEGBESSION SUMMARY

$\begin{array}{ll} & \text { REGRESSION } \\ \text { SAMPLE COEFICIENT, CONSTANT, CORRELATION ERTARO OR }\end{array}$

SIZE _-B COEEICIENI

SIIMAIE

INDICATED PERCENTAGE OF TIME

709

661650

632

$\begin{array}{rr}-113.123 & 90286.250 \\ -0.0032 & 10.2994 \\ -0.00052 & 0.40595 \\ -0.00127 & 0.89593 \\ -0.00568 & 4.16033 \\ -24.757 & 17367.063\end{array}$

$-0.466^{*}$
$-0.471^{*}$

$-0.471 *$
$-0.313^{*}$

$-0.743$

$-0.693$

$-0.629$

9305.0

0.26

0.068

0.050

0.256

1383.5

12
12
12
12
12
12
7
12
12
12
12
12
12
12
12

0.0089
0.1130
0.0324
-0.0248
-0.0091
0.273
0.000
0.1338
0.0174
0.405
0.304
0.413
0.193
-1.345
0.0030

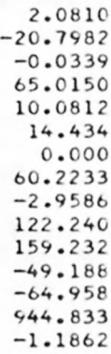

0.594

0.789

0.730

$-0.252$.

-0.436 *

0.638

0.000 *

0.573 .

0.712

0.810

0.714

0.784

0.619

$-0.671$

0.755

\begin{tabular}{|c|c|c|c|c|c|}
\hline & & & & & STANDARD \\
\hline & HARMONIC & AMPLITUDE & PHASE & VARIATION & ERROR OF \\
\hline SAMPLE & MEAN - M & $-A$ & ANGLE - C & EXPLAINED & ESTIMATE \\
\hline SUZE_ & $10 E G$ G) & IDEG $(1)$ & (BAD LANS) & (8) & (DEG_C $C$ \\
\hline 305 & 7.21 & 9.40 & 2.62 & 93 & 1.84 \\
\hline
\end{tabular}

SUMMARY DF MAXIMUM AND MINIMUM CONCENTRATIONS OF CONSTITUENTS SAMPLED AT A FREQUENCY OF QUARTERLY 11975 WY

G6185500 -- MISSOURI RIVER NEAR CULBERTSON, MT.

\begin{tabular}{|c|c|c|c|c|c|c|}
\hline \multirow{2}{*}{ CONSTITUENT } & \multicolumn{3}{|c|}{ TOTAL } & \multicolumn{3}{|c|}{ DISSOLVED } \\
\hline & $\begin{array}{l}\text { NO. } \\
\text { SAMPLES }\end{array}$ & $\begin{array}{l}\text { MINIMUM } \\
\text { CONC. }\end{array}$ & $\begin{array}{l}\text { MAXIMUM } \\
\text { CONC. }\end{array}$ & $\begin{array}{l}\text { NO. } \\
\text { SAMPLES }\end{array}$ & $\begin{array}{l}\text { MINIMUM } \\
\text { CONC. }\end{array}$ & $\begin{array}{l}\text { MAXIMUM } \\
\text { CONC. }\end{array}$ \\
\hline \multicolumn{7}{|l|}{ MINOR ELEMENTS: } \\
\hline ARSENIC (AS), UG/L & 5 & 4 & 15 & 5 & 1 & 4 \\
\hline CADMIUM $(C O)$, UG/L & 5 & $<10$ & 10 & 5 & 0 & 3 \\
\hline CHROMIUM (CR), UG/L & 5 & 0 & 30 & 5 & 0 & 10 \\
\hline COBALT $(C O), U G / L$ & 5 & $<50$ & $<50$ & 5 & 0 & 2 \\
\hline COPPER (CU), UG/L & 5 & $<10$ & 170 & 5 & 3 & 14 \\
\hline IRON (FE), UGIL & 5 & 740 & 20000 & 5 & 20 & 250 \\
\hline LEAD $(P B), U G / L$ & 5 & $<100$ & 400 & 5 & 1 & 8 \\
\hline MANGANESE (MN), UG/L & 5 & 20 & 370 & 5 & 0 & 5 \\
\hline MERCURY $(H G), U G / L$ & 5 & 0.0 & 1.6 & 5 & 0.0 & 0.7 \\
\hline SELENIUM (SE), UG/L & 5 & 1 & 2 & 5 & 0 & 1 \\
\hline ZINC $(Z N), U G / L$ & 5 & 50 & 180 & 5 & 10 & 20 \\
\hline \multicolumn{7}{|l|}{ PERIPHYTON: } \\
\hline GIOMASS, DRY WT., G/SO M & 0 & & & & & \\
\hline BIOMASS, ASH WT., G/SO M & 0 & & & & & \\
\hline CHLOROPHYLL A, MG/SQ M & 0 & & & & & \\
\hline CHLOROPHYLL B, MG/SQ M & 0 & & & & & \\
\hline ORGANIC CARBON, MG/L & 4 & 2.6 & 16.0 & & & \\
\hline
\end{tabular}


LAT $45047 M 48 S$ LONG 108D28M12S

DRAINAGE AREA: 11795 SQ MI 130549 SQ KMI

PERIOD CF RECORD: $10 / 01 / 74-09 / 30 / 75$

STATISTICAL SUMMARY OF SELECTED DISSOLVED CHEMICAL CONSTITUENTS AND

REGRESSION RELATIONSHIPS OF CUNSTITUENT CONCENTRATIONS TO SPECIFIC CONDUCTANCE

CONSIIIUENI

SONSIUIUENI IMGLL OR UNII_SHOWNU

SAMPLE

SIZE

TEMPERATURE, WATER (DEG C)

SPECIFIC CONDUCTANCE (MICROMHOS)

STREAMFLOW (CUBIC FT/SEC)

PH (STANDARD UNITS)

NITRITE + NITRATE, TOTAL

NITROGEN, KJELDAHL, TOTAL

NITRUGEN, KJELDAHL, TOTAL
PHYTOPLANKTON, TOTAL (CELLS/ML)

PHYTOPLANKTON, TOTAL

SEDIMENT, CLAY-SILT (PERCENT)

COLIFURM, FECAL (COL/100 ML)

STREPTOCOCCI, FECAL (COL/100 ML)

SILICA, DISSOLVED

CALCIUM, DISSOLVED

MAGNE SIUM, DISSOLVED

SODIUM, DISSOLVEO

POTASSIUM, DISSOLVEO

BICARGONATE, ION

CARBONATE, ION

SULFATE, DISSOLVED

CHLORIDE, DISSOLVED

DISSOLVED SOLIDS, SUM OF CONST
DISSOLVED SOLIDS, ROE 180 DEG C

HARDNESS, TUTAL

HARONESS, NCNCARBONATE

TURBIDITY (JTU)

FLCURIDE, OISSOLVED

(1)

STANDARD MEAN DEXIAILUN

8.50

12

1210052 .

128.23

0.083

0.244

0.464

2936.0

204.4
48.3

48.3
228.1

151.0

13.75

38.17

12.82

12.82
25.30

3.20

146.1

0.0
70.42

70.42
6.56

0.56
242.8

242.8
245.0

148.1

28.3

36.2

0.46
7.13

142.3
13439.3

0.28

0.101

0.185

0.374

2810.4

270.9

20.3
285.7

134.2

2.83

10.92

4.15
9.09

9.09

1.50

40.5
0.0

26.71

2.24
74.2

78.7

44.4

13.3

52.1

0.16

BEGRESSION SUMMARY

REGRESSION SAMPLE COEFICIENT, CONSTANT, $-{ }_{-}$

CORRELATION

STANOARO BANGE SIZE

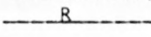

0.0
138

19.0

$\begin{array}{rr}39500 & 12 \\ 8.7 & 12 \\ 0.33 & 11 \\ 0.53 & 11 \\ 1.20 & 11 \\ 10000 & 10 \\ 741 & \\ 79 & \\ 900 & \\ 480 & \\ 19.0 & 12 \\ 53.0 & 12 \\ 18.0 & 12 \\ 37.0 & 12 \\ 6.2 & 12 \\ 201 & 12 \\ 0 & 9 \\ 110.0 & 12 \\ 9.2 & 12 \\ 350 & 12 \\ 352 & 12 \\ 210 & 12 \\ 50 & 12 \\ 170 & 12 \\ 0.7 & 12\end{array}$

$\begin{array}{rr}-79.671 & 41976.348 \\ 0.0013 & 7.7299 \\ -0.00025 & 0.18652 \\ 0.00076 & -0.07396 \\ -0.00121 & 0.96660 \\ 3.730 & 1522.992\end{array}$

0.843

-0.843
0.649

$-0.302 *$

$0.507 *$

-0.398 .

$-0.398 *$
$0.203 *$

*Not significant at the 95 percent confidence level.

DAILY SPECIFIC CONDUCTANCE IN

MICROMHOS AT 25 DEG C, THAT WAS

EQUALLED OR EXCEEDED FOR THE

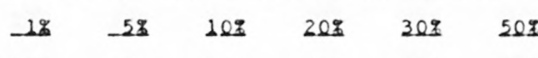

501

\begin{tabular}{lllr} 
& \multicolumn{2}{l}{ SAMPLE_SIZE_E } & 364 \\
703 & $20 \%$ & 258 & 297 \\
388 & 206 & 167 & 143
\end{tabular}

$\begin{array}{rr}0.0116 & 9 \\ 0.0722 & 9 \\ 0.0277 & 1 \\ 0.0606 & 1 \\ 0.0029 & 2 \\ 0.274 & 3 \\ 0.000 & \\ 0.1743 & 1 \\ 0.0127 & 1 \\ 0.497 & 47 \\ 0.512 & 4 \\ 0.297 & 31 \\ 0.070 & \\ -0.136 & 89 \\ 0.0007 & 0 \\ & \\ & \\ & \\ & \\ 1657 & 292 \\ & \end{array}$

SUMMARY OF HARMONIC ANALYSIS OF STREAM TEMPERATURE

\begin{tabular}{|c|c|c|c|c|c|}
\hline & & & & & STANDARD \\
\hline & HARMONIC & AMPLITUDE & PHASE & VAR IATION & ERROR OF \\
\hline SAMPLE & MEAN - M & $-A$ & ANGLE - C & EXPLAINED & ESTIMATE \\
\hline SILE_- & $10 E 6$ - 61 & $\triangle D E G(1$ & (BADIANS) & $-(z)$ & 10EG C) \\
\hline 365 & 7.89 & 9.83 & 2.62 & 92 & 2.06 \\
\hline
\end{tabular}

SUMMARY CF MAXIMUM AND MINIMUM CONCENTRATIONS OF CONSTITUENTS SAMPLED AT A FREQUENCY OF QUARTERLY (1975 WY)

06214500 -- YELLOWSTONE RIVER AT BILLINGS MT

\begin{tabular}{|c|c|c|c|c|c|c|}
\hline \multirow{2}{*}{ CONSTITUENT } & \multicolumn{3}{|c|}{ TOTAL } & \multicolumn{3}{|c|}{ DISSOLVED } \\
\hline & $\begin{array}{l}\text { NO. } \\
\text { SAMPLES }\end{array}$ & $\begin{array}{l}\text { MINIMUM } \\
\text { CONC. }\end{array}$ & $\begin{array}{l}\text { MAXIMUM } \\
\text { CONC. }\end{array}$ & $\begin{array}{l}\text { NO. } \\
\text { SAMPLES }\end{array}$ & $\begin{array}{l}\text { MINIMUM } \\
\text { CONC. }\end{array}$ & $\begin{array}{l}\text { MAXIMUM } \\
\text { CONC. }\end{array}$ \\
\hline \multicolumn{7}{|l|}{ MINOR ELEMENTS: } \\
\hline ARSENIC (AS), UG/L & 4 & 9 & 13 & 4 & 2 & 10 \\
\hline CADMIUM $(C D)$, UG/L & 4 & $<10$ & 10 & 4 & 0 & 1 \\
\hline CHROMIUM (CR), UG/L & 4 & 0 & 20 & 4 & 0 & 0 \\
\hline COBALT $(C O), U G / L$ & 4 & $<50$ & $<50$ & 4 & 0 & 1 \\
\hline COPPER (CU), UG/L & 4 & $<10$ & 50 & 4 & 1 & 12 \\
\hline IRON $(F E), U G / L$ & 4 & 200 & 12000 & 4 & 20 & 40 \\
\hline LEAD $(P B), U G / L$ & 4 & $<100$ & $<100$ & 4 & 1 & 5 \\
\hline MANGANESE (MN), UG/L & 4 & 10 & 390 & 4 & 0 & 20 \\
\hline MERCURY (HG), UG/L & 4 & 0.0 & 1.3 & 4 & 0.0 & 0.3 \\
\hline SELENIUM (SE), UG/L & 4 & 0 & 2 & 4 & 0 & 1 \\
\hline ZINC $(Z N), U G / L$ & 4 & 40 & 100 & 4 & 0 & 30 \\
\hline \multicolumn{7}{|l|}{ PERIPHYTON: } \\
\hline BIOMASS, ORY WT., G/SO M & 1 & 170.00 & & & & \\
\hline BIOMASS, ASH WT., G/SQ M & 1 & 160.00 & & & & \\
\hline CHLOROPHYLL A, MG/SQ M & 1 & 13.0 & & & & \\
\hline CHLOROPHYLL B, MG/SQ M & 1 & 1.3 & & & & \\
\hline ORGANIC CARBON, MG/L & 3 & 3.2 & 17.0 & & & \\
\hline
\end{tabular}


Table 14.--Summary of measurements at each station--Continued

LAT 46008M5OS LONG 107D28MOOS DRAINAGE AREA: 22885 SQ MI ( 59272 SO KM) PERIOD OF RECORD: $10 / 01 / 74-09 / 30 / 75$

STATISTICAL SUMMARY OF SELECTED DISSOLVED CHEMICAL CONSTITUENTS AND REGRESSION RELATIONSHIPS OF CONSTITUENT CONCENTRATIONS TO SPECIFIC CONDUCTANCE

CONSIIIUENI

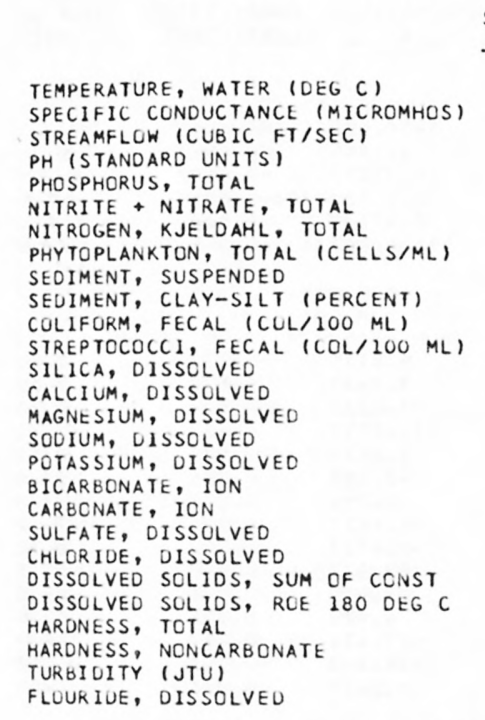

CONSILIUENI_IMGLL OB_UNII_SHOWNI
SAMPLE STANDARO SIZE

$\begin{array}{rrr}12 & 9.08 & 6.84 \\ 12 & 822.9 & 118.8 \\ 12 & 5530.8 & 1892.3 \\ 12 & 8.27 & 0.31 \\ 12 & 0.109 & 0.095 \\ 12 & 0.270 & 0.103 \\ 12 & 0.516 & 0.202 \\ 9 & 1516.7 & 1023.5 \\ 12 & 177.1 & 191.5 \\ 12 & 57.3 & 22.5 \\ 12 & 67.1 & 82.2 \\ 12 & 215.1 & 373.0 \\ 12 & 9.11 & 0.95 \\ 12 & 73.25 & 10.15 \\ 12 & 27.17 & 5.72 \\ 12 & 73.58 & 11.33 \\ 12 & 3.56 & 0.64 \\ 12 & 202.9 & 26.5 \\ 10 & 0.9 & 1.9 \\ 12 & 262.50 & 51.72 \\ 12 & 9.95 & 1.83 \\ 12 & 560.3 & 91.3 \\ 12 & 588.3 & 100.3 \\ 12 & 294.2 & 48.3 \\ 12 & 126.5 & 29.7 \\ 12 & 41.9 & 45.4 \\ 12 & 0.38 & 0.08\end{array}$

\begin{tabular}{rrr} 
BANGE & & SIZ \\
\cline { 3 - 3 } 0.0 & 19.0 & \\
630 & 975 & \\
3300 & 10000 & 12 \\
7.4 & 8.5 & 12 \\
0.01 & 0.33 & 12 \\
0.03 & 0.38 & 12 \\
0.23 & 0.82 & 12 \\
620 & 3600 & 9 \\
21 & 555 & \\
3 & 89 & \\
3 & 310 & \\
7 & 1300 & \\
7.3 & 11.0 & 12 \\
53.0 & 90.0 & 12 \\
19.0 & 38.0 & 12 \\
52.0 & 94.0 & 12 \\
2.6 & 4.6 & 12 \\
155 & 256 & 12 \\
0 & 5 & 10 \\
70.0 & 350.0 & 12 \\
6.1 & 13.0 & 12 \\
388 & 693 & 12 \\
419 & 750 & 12 \\
210 & 380 & 12 \\
83 & 170 & 12 \\
3 & 120 & 12 \\
0.3 & 0.6 & 12 \\
& &
\end{tabular}
REGRESSION $\begin{array}{ll} & \text { REGRESSION } \\ \text { SAMPLE COEFICIENT, CONSTANT, CORRELATICN ERROR OF }\end{array}$

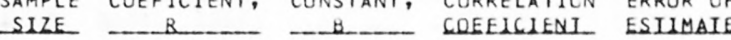

$\begin{array}{rrrrr}12 & -3.442 & 8363.477 & -0.210 * & 1937.8 \\ 12 & 0.0014 & 7.1080 & 0.537 * & 0.28 \\ 12 & 0.00023 & -0.08192 & 0.290^{*} & 0.095 \\ 12 & 0.00044 & -0.09255 & 0.507 * & 0.093 \\ 12 & 0.00034 & 0.23624 & 0.200 * & 0.207 \\ 9 & -3.789 & 4646.906 & -0.41 \varepsilon^{*} & 993.8\end{array}$

$\begin{array}{lrrlr}12 & 0.0051 & 4.9427 & 0.630 & 0.78 \\ 12 & 0.0709 & 14.8773 & 0.830 & 5.94 \\ 12 & 0.0329 & 0.1331 & 0.683 & 4.38 \\ 12 & 0.0766 & 10.5321 & 0.804 & 7.06 \\ 12 & 0.0026 & 1.3950 & 0.485 * & 0.59 \\ 12 & 0.152 & 77.590 & 0.683 & 20.3 \\ 10 & 0.002 & -0.448 & 0.109^{*} & 2.0 \\ 12 & 0.3457 & -21.9861 & 0.794 & 32.95 \\ 12 & 0.0117 & 0.3609 & 0.758 & 1.25 \\ 12 & 0.622 & 48.708 & 0.810 & 56.2 \\ 12 & 0.677 & 31.113 & 0.803 & 62.7 \\ 12 & 0.313 & 36.734 & 0.769 & 32.4 \\ 12 & 0.187 & -27.108 & 0.748 & 20.7 \\ 12 & 0.158 & -87.701 & 0.413^{*} & 43.3 \\ 12 & 0.0003 & 0.0995 & 0.491^{*} & 0.08\end{array}$

*Not significant at the 95 percent confidence level.

DAILY SPECIFIC CONDUCTANCE IN MICROMHOS AT 25 DEG C, THAT WAS

EQUALLED CR EXCEEDED FOR THE

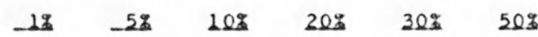

$1140 \quad 1040 \quad 1010$

SUMMARY OF HARMONIC ANALYSIS OF STREAM TEMPERATURE

\begin{tabular}{|c|c|c|c|c|c|}
\hline & & & & & STANDARD \\
\hline & $\begin{array}{l}\text { HARMONIC } \\
\text { MEAN - M }\end{array}$ & $\begin{array}{c}\text { AMPLI TUDE } \\
-A\end{array}$ & PHASE & VAR IATION & ERROR CF \\
\hline SIZE & MEAN $-{ }^{M}$ & $\left(D E G^{A}()\right)$ & ANGLE - C & EXPLA INED & ESTIMATE \\
\hline
\end{tabular}

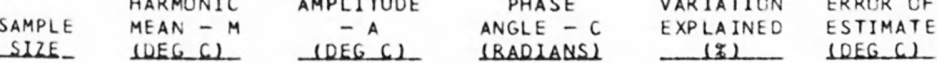

$\begin{array}{llllll}365 & 8.01 & 9.02 & 9.40 & 93 & 1.69\end{array}$

SUMMARY OF MAXIMUM AND MINIMUM CONCENTRATIONS OF CONSTITUENTS

SAMPLED AT A FREQUENCY OF QUARTERLY (1975 WY)

06294700 - BIGHURN RIVER AT BIGHORN, MT.

\begin{tabular}{|c|c|c|c|c|c|c|}
\hline \multirow{2}{*}{ CONSTITUENT } & \multicolumn{3}{|c|}{ TOTAL } & \multicolumn{3}{|c|}{ DISSOLVED } \\
\hline & $\begin{array}{l}\text { NO. } \\
\text { SAMPLES }\end{array}$ & $\begin{array}{l}\text { MINIMUM } \\
\text { CONC. }\end{array}$ & $\begin{array}{l}\text { MAXIMUM } \\
\text { CONC. }\end{array}$ & $\begin{array}{l}\text { NO. } \\
\text { SAMPLES }\end{array}$ & $\begin{array}{l}\text { MINIMUM } \\
\text { CONC. }\end{array}$ & $\begin{array}{l}\text { MAXIMUM } \\
\text { CONC. }\end{array}$ \\
\hline \multicolumn{7}{|l|}{ MINOR ELEMENTS: } \\
\hline ARSENIC (AS), UG/L & 4 & 2 & 3 & 4 & 1 & 2 \\
\hline CADMIUM $(C D), U G / L$ & 4 & $<10$ & 20 & 4 & 0 & 0 \\
\hline CHROMIUM (CR), UG/L & 4 & 0 & 10 & 4 & 0 & 0 \\
\hline COBALT $(C O), U G / L$ & 4 & $<50$ & $<50$ & 4 & 0 & 0 \\
\hline COPPER (CU), UG/L & 4 & $<10$ & 50 & 4 & 1 & 3 \\
\hline IRON (FE), UG/L & 4 & 500 & 8200 & 4 & 10 & 40 \\
\hline LEAD $(P B), U G / L$ & 4 & $<100$ & 100 & 4 & 1 & 3 \\
\hline MANG ANESE $(M N), U G / L$ & 4 & 20 & 220 & 4 & 0 & 20 \\
\hline MERCURY (HG), UG/L & 4 & 0.0 & 0.1 & 4 & 0.0 & 0.0 \\
\hline SELENIUM (SE), UG/L & 4 & 2 & 4 & 4 & 1 & 3 \\
\hline ZINC $(Z N), U G / L$ & 4 & 30 & 50 & 4 & 2 & 20 \\
\hline \multicolumn{7}{|l|}{ PERIPHYTON: } \\
\hline BIOMASS, DRY WT., G/SQ M & 2 & 2.00 & 5.19 & & & \\
\hline BIOMASS, ASH WT., G/SO M & 2 & 1.39 & 4.79 & & & \\
\hline CHLOROPHYLL A, MG/SO M & 2 & .5 & 8.0 & & & \\
\hline CHLOROPHYLL B, MG/SQ M & 2 & .0 & $\cdot 8$ & & & \\
\hline ORGANIC CARBON, MG/L & 4 & 4.7 & $11 \cdot 0$ & & & \\
\hline
\end{tabular}


Table 14.--Summary of measurements at each station--Continued

LAT $46021 M 30 S$ LONG 105048M24S

DRAINAGE AREA: 5379 SO MI ( 13932 SQ KM)

PERIOD OF RECORD: $10 / 01 / 74-09 / 30 / 75$

STATISTICAL SUMMARY OF SELECTED DISSOLVED CHEMICAL CONSTITUENTS ANO

REGRESSION RELATIONSHIPS OF CONSTITUENT CONCENTRATIONS TO SPECIFIC CONDUCTANCE

CONSIIUENI

CONSIUIUENI_MGGL OR UNII_SHOHNU

SAMPL

STANDARD

DEYIALION

9.58

764.2

903.3

8.32

0.262

0.091

065.6

762.8
73.8

73.8
301.6

542.4
5.83

58.17

39.92

39.92

4.73
258.7

258.7

0.9
205.67

3.84

503.3

524.5

310.0

95.3

191.8

0.29
8.85

199.7

1094.6

0.17
0.371

0.101

0.905

7243.7

1331.2
13.1

832.5

1010.8

14.84

14.84
12.47

15.01

0.97

62.4

1.9
60.99

1.38

127.4

134.5

86.9

38.3

0.08

*Not significant at the 95 percent confidence level.

BANGE
0.0
440
140
8.0
.01
.00
.19
260
9
53
4
16
3.6
27.0
4.0
29.0
3.2
142
0
98.0
1.8
290
296
130
9
1
0.2

REGRESSION_SUMMABY

REGRESSION CONSTANT, CORRELATION STANOARO SAMPLE COEFICIENT, CONSTANT, CORRELATION ERROR OF SIZE _- B _ _ B COEEICIENI ESIIUBIE 23.5

$\begin{array}{rrrrr}4140 & 12 & -3.318 & 3438.492 & -0.605\end{array}$

4140

$\begin{array}{rr}6.5 & 12 \\ 1.00 & 12\end{array}$

1.00

0.32

20000

4360

2800

3400

$\begin{array}{llllll}8.2 & 12 & -0.0050 & 9.6175 & -0.579 & 1.40\end{array}$

55.0

80.0

80.0

$\begin{array}{ll}6.0 & 12 \\ 353 & 12\end{array}$

$\begin{array}{rr}353 & 12 \\ 5 & 10\end{array}$

$-0.0001$

$-0.00087$

$-0.00004$

$-0.00183$

$-12.390$

0.92282

0.12521

. 37137

15848.801

-0.005 .

-0.096 .

-0.089 *

-0.404 .

-0.345 .

0.0660

0.0562

0.0466

0.0027

0.283
0.001

0.2763

0.0059

0.589

0.603

0.397

0.161

0.0000

7.7437

$-3.0230$

0.8811

2.6510
42.287

42.287
0.296

$-5.4821$

$-0.6717$

63.979

6.923

$-27.419$

938.303

938.303
0.2631

0.888

0.900

0.620 .

0.559

0.906

0.089 .

0.905

0.852

0.922

0.895

0.912

0.937

$-0.837$.

$-0.543^{*}$
$0.094^{*}$
DUBAIION IABLE_OE DAJLY SPECIEIC GONOUCIANCI

DAILY SPECIFIC CONDUCTANCE IN

MICROMHOS AT 25 DEG C, THAT WAS

EQUALLED OR EXCEEDEL FOR THE

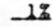

$-5$

150

1110

$20 z$

302

502

857
SAMPLE SIZE $=228$

$702 \quad 20 \% \quad 2529$

394

SUMMARY OF HARMONIC ANALYSIS OF STREAM TEMPERATURE

\begin{tabular}{|c|c|c|c|c|c|}
\hline & & & & & STANDARD \\
\hline & HARMONIC & AMPLI TUDE & PHASE & VAR IATION & ERROR OF \\
\hline SAMPLE & MEAN - M & $-A$ & ANGLE - C & EXPLAINED & ESTIMATE \\
\hline SIZE_ & $10 E G \mathrm{Cl}$ & DEEG C) & (RADLANSI) & $-(x)$ & $10 E G(C)$ \\
\hline 299 & 7.85 & 9.99 & 2.82 & 89 & 2.22 \\
\hline
\end{tabular}

SUMMARY OF MAXIMUM AND MINIMUM CONCENTRATIONS OF CONSTITUENTS

SAMPLED AT A FREQUENCY OF QUARTERLY (1975 WY)

06308500 -- TONGUE RIVER AT MILES CITY, MT.

\begin{tabular}{|c|c|c|c|c|c|c|}
\hline \multirow{2}{*}{ CONSTITUENT } & \multicolumn{3}{|c|}{ TOTAL } & \multicolumn{3}{|c|}{ DISSOL VED } \\
\hline & $\begin{array}{l}\text { NO. } \\
\text { SAMPLES }\end{array}$ & $\begin{array}{l}\text { MINIMUM } \\
\text { CONC. }\end{array}$ & $\begin{array}{l}\text { MAXIMUM } \\
\text { CONC. }\end{array}$ & $\begin{array}{l}\text { NO. } \\
\text { SAMPLES }\end{array}$ & $\begin{array}{l}\text { MINIMUM } \\
\text { CONC. }\end{array}$ & $\begin{array}{l}\text { MAXIMUM } \\
\text { CONC. }\end{array}$ \\
\hline \multicolumn{7}{|l|}{ MINOR ELEMENTS: } \\
\hline ARSENIC (AS), UG/L & 4 & 1 & 26 & 4 & 0 & 1 \\
\hline CADMIUM (CD), UG/L & 4 & $<10$ & 20 & 4 & 0 & 1 \\
\hline CHROMIUM (CR), UG/L & 4 & 0 & 80 & 4 & 0 & 10 \\
\hline COBALT $(C O), U G / L$ & 4 & $<50$ & 100 & 4 & 0 & 1 \\
\hline COPPER (CUI, UGIL & 4 & $<10$ & 170 & 4 & 1 & 7 \\
\hline IRUN $(F E), U G / L$ & 4 & 250 & 74000 & 4 & 20 & 150 \\
\hline LEAD $(P B), U G / L$ & 4 & $<100$ & $<100$ & 4 & 1 & 4 \\
\hline MANG ANESE $(M N), U G / L$ & 3 & 30 & 680 & 4 & 0 & 10 \\
\hline MERCURY $(H G), U G / L$ & 4 & 0.0 & 0.2 & 4 & 0.0 & 0.2 \\
\hline SELENIUM (SE), UG/L & 4 & 1 & 2 & 4 & 0 & 1 \\
\hline$Z I N C(Z N), U G / L$ & 4 & 40 & 340 & 4 & 10 & 20 \\
\hline \multicolumn{7}{|l|}{ PERIPHYTON: } \\
\hline BIUMASS, DRY WT., G/SQ M & 2 & .50 & 13.00 & & & \\
\hline BIOMASS, ASH WT., G/SO M & 2 & .39 & 12.00 & & & \\
\hline CHLOROPHYLL A, MG/SO M & 2 & .0 & .0 & & & \\
\hline CHLOROPHYLL $B$, MG/SO M & 2 & .0 & .1 & & & \\
\hline ORGANIC CARBON, MG/L & 4 & 8.6 & 27.0 & & & \\
\hline
\end{tabular}


AT 4OD27MOOS LONG $105019 M 00 S$

JRAINAGE AREA: 13194 SQ MI $(34172$ SQ KM)

PERIOD OF RECORD: $10 / 01 / 74-09 / 30 / 75$

STATISTICAL SUMMARY OF SELECTED DISSOLVED CHEMICAL CONSTITUENTS AND

REGRESSION RELATIONSHIPS OF CONSTITUENT CONCENTRATIONS TO SPECIFIC CONDUCTANCE

\begin{tabular}{|c|}
\hline $\begin{array}{l}\text { TEMPERATURE, WATER (DEG C) } \\
\text { SPECIFIC CONDUCTANCE (MICROMHOS) } \\
\text { STREAMFLOH (CUBIC FI/SEC) } \\
\text { PH (STANDARD UNITS) } \\
\text { PHOSPHORUS, TOTAL } \\
\text { NITRITE + NIIRATE, TOTAL } \\
\text { NITROGEN, KJELDAHL, TOTAL } \\
\text { PHYTOPLANKTON, TOTAL (CELLS/ML) } \\
\text { SEDIMENT, SUSPENDED } \\
\text { SEDIMENT, CLAY-SILT (PERCENT) } \\
\text { COLIFORM, FECAL (COL/IOO ML) } \\
\text { STREPTOCOCCI, FECAL (COL/IOO ML) } \\
\text { SILICA, DISSOLVED } \\
\text { CALCIUM, UISSOLVED } \\
\text { MAGNESIUM, OISSOLVED } \\
\text { SODIUM, DISSOLVED } \\
\text { POTASSIUM, DISSOLVED } \\
\text { BICARGONATE, ION } \\
\text { CARBONATE, ION } \\
\text { SULFATE, DISSOLVED } \\
\text { CHLORIDE, DISSOLVEO } \\
\text { OISSOLVED SOLIDS, SUM OF CONST } \\
\text { OISSOLVED SOLIDS, ROE } 180 \text { DEG C } \\
\text { HARONESS, TOTAL } \\
\text { HARONESS, NONCARBONATE } \\
\text { TURBIOITY (JTU) } \\
\text { FLOURIDE, DISSOLVED }\end{array}$ \\
\hline
\end{tabular}

CONSIIIUENI
CONSIUUVENI IMG/L OR UNII SHOWNU

SAMPLE

SIZE. MEAN

13

12
13

$\begin{array}{rr}13 & 1687.5 \\ 12 & 8.20\end{array}$

$\begin{array}{ll}12 & 0.514 \\ 12 & 0.290\end{array}$

$12 \quad 1.542$

104406.0

5209.3

70.9

194.6
289.8

8.93

8.93
110.50

110.50
49.92

49.92
239.17

7.09

273.3
0.2

609.17

107.50

1268.0

1268.0
1350.8

1350.8
481.7

481.7
258.3

258.3
468.2

0.40
STANDARD

DEYIAIION

7.85

520.2

2990.1

0.23
0.485

0.485
0.228

1.615

4467.0

6763.6

370.0

2.35

28.81

14.99
79.02

79.02
1.48

87.0

0.7
95.75

195.75

51.49

411.1

411.1
132.5

132.5
77.8

505.0

0.06

$\begin{array}{rr} & \\ \text { BANGE } & \\ 0.0 & 23.5 \\ 920 & 2370 \\ 33 & 10800 \\ 7.7 & 8.5 \\ 0.01 & 1.50 \\ 0.00 & 0.74 \\ 0.44 & 5.80 \\ 120 & 13000 \\ 31 & 19000 \\ 18 & 95 \\ 3 & 1300 \\ 31 & 970 \\ 5.5 & 12.0 \\ 64.0 & 150.0 \\ 26.0 & 74.0 \\ 110.0 & 350.0 \\ 4.3 & 8.7 \\ 158 & 454 \\ 0 & 2 \\ 320.0 & 970.0 \\ 31.0 & 220.0 \\ 642 & 1760 \\ 668 & 1870 \\ 270 & 680 \\ 140 & 370 \\ 4 & 1200 \\ 0.3 & 0.5\end{array}$
SAMPLE
SIZE. REGRESSION COEFICIENT, BEGRESSION_SUMMABY*

${ }^{*}$ Not significant at the 95 percent confidence leve1. DURAIION IABLE OE DALLY SPECIEIC CONDUCIANCE DAILY SPECIFIC CONDUCTANCE IN MICROMHOS AT 25 DEG C, THAT WAS

EQUALLED OR EXCEEDED FOR THE

28

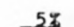

103

$20 z$

$30 \%$

$2740 \quad 2630$

2460

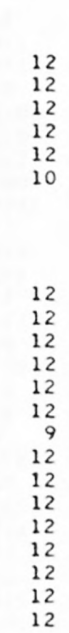
CONSTANT, CORRELATION
COEEICIENI

STANDARD ERROR OF ESIIMAIE

SUMMARY OF HARMONIC ANALYSIS OF STREAM TEMPERATURE

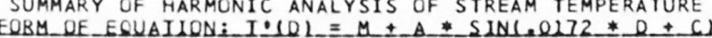

\begin{tabular}{|c|c|c|c|c|c|}
\hline & & & & & STANDARD \\
\hline & HARMONIC & AMPLITUDE & PHASE & VARIATION & ERROR OF \\
\hline SAMPLE & MEAN - M & $-A$ & $A N G L E-C$ & EXPLAINED & ESTIMATE \\
\hline SIZE & (DEG C) & WDEG 61 & (RADIANS) & $-1 \% 1 \ldots$ & DEE $C 1$ \\
\hline 362 & 8.13 & 11.17 & 2.89 & 88 & 2.88 \\
\hline
\end{tabular}

SUMMARY OF MAXIMUM AND MINIMUM CONCENTRATIONS OF CONSTITUENTS SAMPLED AT A FREQUENCY OF QUARTERLY (1975 WY)

$$
\begin{array}{r}
-1.049 \\
0.0001 \\
-0.00063 \\
-0.00013 \\
-0.00173 \\
-2.984 \\
\\
\\
0.0010 \\
0.0515 \\
0.0266 \\
0.1357 \\
0.0019 \\
0.135 \\
0.000 \\
0.3109 \\
0.0760 \\
0.672 \\
0.736 \\
0.238 \\
0.125 \\
-0.621 \\
-0.0000
\end{array}
$$

7.9577

1.04164

0.51434

9475.105

$-0.683$

0.307

$-0.677$

-0.286 *

$-0.558 *$
-0.353

961.1

0.23

0.374

0.229

1.405
4433.0
0.220

0.930

\begin{tabular}{|c|c|c|c|c|c|c|}
\hline \multirow{2}{*}{ CONSTITUENT } & \multicolumn{3}{|c|}{ TOTAL } & \multicolumn{3}{|c|}{ DISSOLVED } \\
\hline & $\begin{array}{l}\text { NO. } \\
\text { SAMPLES }\end{array}$ & $\begin{array}{l}\text { MINIMUM } \\
\text { CONC. }\end{array}$ & $\begin{array}{l}\text { MAXIMUM } \\
\text { CONC. }\end{array}$ & $\begin{array}{l}\text { NO. } \\
\text { SAMPLES }\end{array}$ & $\begin{array}{l}\text { MINIMUM } \\
\text { CONC. }\end{array}$ & $\begin{array}{l}\text { MAXIMUM } \\
\text { CONC. }\end{array}$ \\
\hline \multicolumn{7}{|l|}{ MINOR ELEMENTS: } \\
\hline ARSENIC (AS), UG/L & 4 & 2 & 60 & 4 & 0 & 2 \\
\hline CADMIUM $(C D), U G / L$ & 4 & $<10$ & 10 & 4 & 0 & 1 \\
\hline CHROMIUM (CR), UG IL & 4 & 0 & 100 & 4 & 0 & 10 \\
\hline COBALT $(C O), U G / L$ & 4 & $<50$ & 150 & 4 & 0 & 1 \\
\hline COPPER (CU), UG/L & 4 & 20 & 200 & 4 & 3 & 8 \\
\hline IRUN (FE), UG/L & 4 & 1600 & 170000 & 4 & 20 & 150 \\
\hline LEAD $(P B), U G / L$ & 4 & $<100$ & 200 & 4 & 0 & 2 \\
\hline MANG ANESE (MN), UG/L & 4 & 30 & 3500 & 4 & 0 & 10 \\
\hline MERCURY (HG), UG/L & 4 & 0.1 & 0.3 & 4 & 0.0 & 0.3 \\
\hline SELENIUM (SE), UG/L & 4 & 1 & 5 & 4 & 1 & 3 \\
\hline ZINC $(Z N), U G / L$ & 4 & 60 & 670 & 4 & 20 & 40 \\
\hline \multicolumn{7}{|l|}{ PERIPHYTON: } \\
\hline BIOMASS, DRY WT., G/SQ M & 2 & .79 & 8.39 & & & \\
\hline BIOMASS, ASH WT.., G/SQ M & 2 & .50 & 6.19 & & & \\
\hline CHLOROPHYLL A, MG/SQ M & 2 & .0 & .1 & & & \\
\hline CHLOROPHYLL B, MG/SQ M & 2 & .0 & $\cdot 0$ & & & \\
\hline ORGANIC CARBON, MG/L & 4 & 6.5 & 53.0 & & & \\
\hline
\end{tabular}

0.925

0.893

0.665

0.809

0.350.

0.826

0.768

0.708

0.915

0.932

0.934

0.836

-0.040
-0.159

06326500 -- POWOER RIVER NEAR LOCATE, MT. 
Table 14.--Summary of measurements at each station--Continued

LAT $47040 M 42 S$ LONG 104D09M22S

DRAINAGE AREA: 69103 SQ MI ( 178977 SO KM)

PERIOD OF RECORD: $10 / 01 / 74-09 / 30 / 75$

STATISTICAL SUMMARY OF SELECTED DISSOLVED CHEMICAL CONSTITUENTS AND REGRESSION RELATIONSHIPS OF CONSTITUENT CONCENTRATIONS TO SPECIFIC CONDUCTANCE

GONSIUUUENI

\begin{tabular}{c} 
CONS \\
SAM \\
SI \\
\hline 2 \\
24 \\
2 \\
2 \\
24 \\
24 \\
24 \\
1 \\
1 \\
2 \\
2 \\
1 \\
1 \\
1 \\
1 \\
1 \\
1 \\
1 \\
1 \\
1 \\
24 \\
1 \\
1 \\
24 \\
1 \\
\end{tabular}

CONSIUIUENI IMG/L OR UNII SHOWNI

$\begin{array}{rrr}24 & 9.79 & 8.52 \\ 23 & 711.7 & 178.9 \\ 24 & 17201.7 & 14175.0 \\ 22 & 8.31 & 0.36 \\ 24 & 0.198 & 0.283 \\ 24 & 0.224 & 0.202 \\ 24 & 0.927 & 1.080 \\ 12 & 6514.2 & 9064.0 \\ 14 & 1080.0 & 1109.1 \\ 6 & 46.8 & 7.6 \\ 21 & 221.9 & 554.4 \\ 22 & 92.4 & 162.5 \\ 13 & 10.17 & 1.51 \\ 13 & 54.77 & 13.52 \\ 13 & 22.35 & 5.54 \\ 13 & 62.54 & 20.47 \\ 13 & 3.98 & 0.99 \\ 13 & 184.5 & 39.3 \\ 8 & 0.1 & 0.4 \\ 13 & 193.23 & 57.73 \\ 13 & 10.68 & 3.81 \\ 13 & 449.2 & 117.3 \\ 24 & 452.3 & 119.6 \\ 13 & 229.2 & 56.8 \\ 13 & 77.2 & 25.4 \\ 24 & 146.7 & 254.6 \\ 13 & 0.38 & 0.10\end{array}$

BEGBESS $10 N$ SUMMABY

REGRESSION

SAMPLE COEFICIENT.

CONSIANT,

CORRELATION

STANDARD ERROR OF SIZE
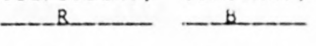
COEEICIENI

ESIIMAIE

IEMPERATURE, WATER (DEG C)

SPECIFIC CONDUCTANCE (MICROMHOS

STREAMFLOW (CUBIC FT/SEC)

PH (STANDARD UNITS)

NITRITE + NITRATE, TOTAL

NITROGEN, KJELDAHL, TOTAL

PHYTOPLANKTON, TOTAL ICELLS/ML

SEDIMENT, SUSPENDED

SEDIMENT, CLAY-SILT (PERCENT)

COLIFORM, FECAL (COL/IOO ML)

STREPTOCOCCI, FECAL ICOL $/ 100 \mathrm{ML}$

SILICA, DISSOLVED

CALCIUM, DISSOLVED

MAGNE SIUM, DISSOLVEO

PUTASSIUM, DISSOLVEO

BICARBONATE, ION

CARBONATE, ION

SULFATE, DISSOLVED

CHLORIDE, DISSOLVED

DISSOLVED SOLIDS, SUM OF CONST

DISSOLVED SOLIDS, ROE 180 DEG

HARDNESS, TOTAL

HARDNESS, NGNCARBONATE

FLCURIDE, DISSOLVED

0.5
320
360
7.0
0.00
0.00
0.14
160
4
87.0
9.5
2.0
72.0
4.0
194
110
200

25.5

980
50100

80100
8.9

1.00

$23 \quad-51.595$

$-0.0006$

0.00054

0.00170

54270.988

8.7054

0.13481

$-0.16217$

1360.242

$-0.282 *$

0.472

0.278

$-0.122$

11298.1

0.36

0.294

0.186

$\begin{array}{rl}5.000 & 23 \\ 27000 & 11\end{array}$

27000
3230

(6.120

2500

700

73.0

23.0

91.0

5.5

232

260.1

17.0
562

562
587

$587 \quad 23$

$300 \quad 13$

$\begin{array}{ll}110 & 13 \\ 920 & 23\end{array}$

*Not significant at the 95 percent confidence leve1.

DURALION IABLE OF DALIY SPECIEIC CONDUCIANCE

MICROMHOS AT 25 DEG C. THAT WAS

EQUALLED OR EXCEEDED FOR THE
INDICATED PERCENTAGE OF TIME

$\begin{array}{llllll}-18 & -52 & 10 \% & 20 \% & 302 & 505 \\ 958 & 925 & 891 & 843 & 790 & 720\end{array}$

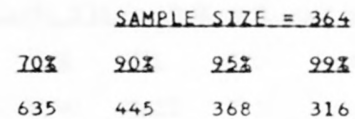

SUMMARY OF HARMONIC ANALYSIS OF STREAM TEMPERATURE

\begin{tabular}{|c|c|c|c|c|c|}
\hline & & & & & STANDARD \\
\hline & HARMONIC & AMPLITUDE & PHASE & VARIATION & ERROR OF \\
\hline SAMPLE & MEAN - M & $-A$ & ANGLE - C & EXPLAINED & ESTIMATE \\
\hline SIZE & LDEG $(1)$ & IDEG $(1)$ & $(B A D I A N S)$ & $-(3)$ & $10 E G(1)$ \\
\hline 365 & 8.63 & 11.38 & 2.73 & 93 & 2.23 \\
\hline
\end{tabular}

SUMMARY OF MAXIMUM AND MINIMUM CONCENTRATIONS OF CONSTITUENTS

SAMPLED AT A FREQUENCY OF QUARTERLY (1975 WY)

06329500 -- YELLOWSTONE RIVER NEAR SIDNEY, MT.

\begin{tabular}{|c|c|c|c|c|c|c|}
\hline \multirow{2}{*}{ CONSTITUENT } & \multicolumn{3}{|c|}{ TOTAL } & \multicolumn{3}{|c|}{ DISSOLVED } \\
\hline & $\begin{array}{l}\text { NO. } \\
\text { SAMPLES }\end{array}$ & $\begin{array}{l}\text { MINIMUM } \\
\text { CONC. }\end{array}$ & $\begin{array}{l}\text { MAXIMUM } \\
\text { CONC. }\end{array}$ & $\begin{array}{l}\text { NO. } \\
\text { SAMPLES }\end{array}$ & $\begin{array}{l}\text { MINIMUM } \\
\text { CONC. }\end{array}$ & $\begin{array}{l}\text { MAXIMUM } \\
\text { CONC. }\end{array}$ \\
\hline \multicolumn{7}{|l|}{ MINOR ELEMENTS: } \\
\hline ARSENIC (AS), UG/L & 5 & 4 & 34 & 5 & 1 & 5 \\
\hline CADMIUM $(C D), U G / L$ & 5 & $<10$ & 10 & 5 & 0 & 3 \\
\hline CHROMIUM (CR), UG/L & 5 & 0 & 50 & 5 & 0 & 10 \\
\hline COBALT $(C O), U G / L$ & 2 & $<50$ & $<50$ & 2 & 0 & 0 \\
\hline COPPER (CU), UGIL & 5 & $<10$ & 140 & 5 & 2 & 10 \\
\hline IRUN (FE), UG/L & 5 & 400 & 53000 & 9 & 20 & 120 \\
\hline LEAD $(P B), U G / L$ & 5 & $<100$ & 100 & 5 & 0 & 15 \\
\hline MANG ANESE $(M N), U G / L$ & 5 & 20 & 970 & 5 & 0 & 10 \\
\hline MERCURY (HG), UG/L & 4 & 0.1 & 0.8 & 5 & 0.0 & 4.6 \\
\hline SELENIUM (SE), UG/L & 5 & 1 & 3 & 5 & 1 & 2 \\
\hline ZINC $(Z N), U G / L$ & 5 & 10 & 330 & 5 & 10 & 20 \\
\hline \multicolumn{7}{|l|}{ PERIPHYTON: } \\
\hline BIUMASS, URY WT., G/SO M & 0 & & & & & \\
\hline BIOMASS, ASH WT, G/SQ M & 0 & & & & & \\
\hline $\begin{array}{l}\text { CHLOROPHYLL A, MG/SO M } \\
\text { CHLOROPHYLL B, MG/SO M }\end{array}$ & 0 & & & & & \\
\hline ORGANIC CARBON, MG/L & 23 & 2.0 & 22.0 & & & \\
\hline
\end{tabular}


Table 14.--Summary of measurements at each station--Continued

LAT 47035 M25S LONG 103D15M05S

DRAINAGE AREA: 8310 SQ MI ( 21523 SO KM)

PERIOD OF RECORD: $10 / 01 / 74-09 / 30 / 75$

STATISTICAL SUMMARY OF SELECTED DISSOLVED CHEMICAL CONSTITUENTS AND

REGRESSION RELATIONSHIPS OF CONSTITUENT CONCENTRATIONS TO SPECIFIC CONDUCTANCE

CONSILIUENI

$$
\text { CONSILUENI IMGLL OR UNII_SHOWNI }
$$

SA

STANDARD

SAMPLE MEAN

TEMPERATURE, WATER (DEG C)

SPECIFIC CONDUCTANCE (MICROMHOS)

STREAMFLOW (CUBIC FT/SEC)

PH (STANDARD UNITS)

PHOSPHORUS, TOTAL

NITRITE + NITRATE, TOTAL

NITROGEN, KJELDAHL, TOTAL

PHYTOPLANKTON, TUTAL (CELLS/ML)

SEDIMENT, SUSPENDED

SEDIMENT, CLAY-SILT (PERCENT)

COLIFORM, FECAL (COL/1OO ML)

SILICA, DISSULVED

CALCIUM, DISSOLVED

MAGNESIUM, DISSOLVEO

SODIUM, DISSOLVED

POTASSIUM, DISSOLVED

BICARBONATE, ION

CARBONATE, ION

SULFATE, DISSOLVED

CHLURIDE, DISSOLVED

DISSOLVED SOLIDS, SUM OF CONST

DISSOLVEO SOLIDS, ROE 180 DEG

HARDNESS, TOTAL

HARDNESS, NONCARBONATE

TURBIDITY (JTU)

FLOURIDE, DISSOLVED
STREPTOCOCCI, FECAL (COL/100 ML)

\section{DEYIAIION}

11.67
2104.4

1228.3

$\begin{array}{r}8.34 \\ \hline\end{array}$

1.244

0.361

2296.3

2296.3

5314.8
81.5

81.5
341.2

341.2
242.8

9.56

72.56

36.44

313.67

10.61

380.3

0.1

673.33

9.88
312.9

1459.9

331.1

40.9

1009.3

0.34
6.60
1290.6

2012.1

0.21

2.448

0.381

2.790

1973.7

6587.6

23.8

639.9

367.0

2.36

35.43

19.62

195.64

3.67

254.1

0.4
363.28

363.28
5.41

739.2

815.2

165.4
41.6

2225.2

0.09
REGBESSION SUMMARY

REGRESSION

SAMPLE

CONSTANT, STANDARD SIZE

$-1-B$

CONSTANT, CORRELATION COEEICIENI

ESTIM

$\begin{array}{rr}\text { BANGE } & \\ 0.0 & 22.0 \\ 790 & 5000 \\ 5 & 6100 \\ 7.9 & 8.6 \\ 0.02 & 7.50 \\ 0.01 & 1.10 \\ 0.55 & 8.90 \\ 0 & 5900 \\ 81 & 14600 \\ 46 & 90 \\ 1 & 2000 \\ 10 & 1180 \\ 6.1 & 14.0 \\ 24.0 & 140.0 \\ 12.0 & 61.0 \\ 83.0 & 710.0 \\ 5.6 & 17.0 \\ 127 & 947 \\ 0 & 1 \\ 170.0 & 1300.0 \\ 4.4 & 22.0 \\ 368 & 2730 \\ 412 & 2980 \\ 110 & 600 \\ 0 & 110 \\ 2 & 6800 \\ 0.2 & 0.5\end{array}$

*Not significant at the 95 percent confidence level.

\section{DURAIION IABLE OF OALIY SPECIEIC CONDUCIANCE}

DAILY SPECIFIC CONDUCTANCE IN

MILROMHOS AT 25 DEG C, THAT WAS

EQUALLED OR EXCEEDED FOR THE

$\begin{array}{lllll}18 & -5 \pi & 10 \% & 208 & 30 \%\end{array}$

502

$4400 \quad 3900 \quad 3690$

2760

2400

$1950-1500$

1500
$-0.593^{*}$

-0.639 *

$-0.463 *$

$-0.545 *$

$-0.612 *$

0.764
$-1228.712$

1731.8

2.320

0.342

2.359

1374.6

SUMMARY OF HARMONIC ANALYSIS OF STREAM TEMPERATURE

FORM OF EQUATION: I. (D) $=M+A *$ SING.0172*D+C)

\begin{tabular}{|c|c|c|c|c|c|}
\hline & & & & & STANDARD \\
\hline SAM & HARMONIC & AMPLITUDE & $\begin{array}{l}\text { PHASE } \\
\text { PNGLE - }\end{array}$ & $\begin{array}{l}\text { VARIATION } \\
\text { EXPLAINED }\end{array}$ & $\begin{array}{l}\text { ERROR OF } \\
\text { ESTIMATE }\end{array}$ \\
\hline SIZE. & $10 E 6$ CI & (DEE $G^{A}(1)$ & IBADIANSI & (I) & IDEG () \\
\hline 214 & 7.48 & 13.01 & 2.74 & 81 & 2.88 \\
\hline
\end{tabular}

SUMMARY OF MAXIMUM AND MINIMUM CONCENTRATIONS OF CONSTITUENTS SAMPLED AT A FREQUENCY OF QUARTERLY (1975 WY)

06337000 -- LITTLE MISSOURI RIVER NR WATFORD CITY, ND

\begin{tabular}{|c|c|c|c|c|c|c|}
\hline \multirow{2}{*}{ CONSTITUENT } & \multicolumn{3}{|c|}{ TOTAL } & \multicolumn{3}{|c|}{ DISSOLVED } \\
\hline & $\begin{array}{l}\text { NO. } \\
\text { SAMPLES }\end{array}$ & $\begin{array}{l}\text { MIN IMUM } \\
\text { CONC. }\end{array}$ & $\begin{array}{l}\text { MAXIMUM } \\
\text { CONC. }\end{array}$ & $\begin{array}{l}\text { NO. } \\
\text { SAMPLES }\end{array}$ & $\begin{array}{l}\text { MINIMUM } \\
\text { CONC. }\end{array}$ & $\begin{array}{l}\text { MAXIMUM } \\
\text { CONC. }\end{array}$ \\
\hline \multicolumn{7}{|l|}{ MINOR ELEMENTS: } \\
\hline ARSENIC (AS), UG/L & 4 & 1 & 240 & 4 & 1 & 2 \\
\hline CADMIUM $(C D)$, UG $/ L$ & 4 & $<10$ & 30 & 4 & 0 & 2 \\
\hline CHROMIUM (CR), UG/L & 4 & 10 & 250 & 4 & 0 & $<10$ \\
\hline COBALT $(C O), U G / L$ & 4 & 50 & 300 & 4 & 0 & 0 \\
\hline COPPER (CU), UG/L & 4 & 20 & 610 & 4 & 6 & 30 \\
\hline IRON $(F E), U G / L$ & 4 & 610 & 410000 & 4 & 20 & 340 \\
\hline LEAD $(P B), U G / L$ & 4 & $<100$ & 500 & 4 & 1 & 3 \\
\hline MANG ANESE $(M N), U G / L$ & 4 & 50 & 11000 & 4 & 0 & 50 \\
\hline MERCURY $(H G), U G / L$ & 3 & $<0.1$ & 0.8 & 4 & $<0.1$ & 0.7 \\
\hline SELENIUM (SE), UG/L & 4 & 0 & 5 & 4 & 0 & 2 \\
\hline ZINC $(Z N), U G / L$ & 4 & 20 & 1900 & 4 & 10 & 40 \\
\hline \multicolumn{7}{|l|}{ PERIPHYTON: } \\
\hline BIOMASS, DRY WT., G/SO M & 2 & 7.69 & 18.00 & & & \\
\hline BIOMASS, ASH WT., G/SO M & 2 & 6.19 & 15.00 & & & \\
\hline CHLOROPHYLL A, MG/SQ M & 2 & .2 & 1.2 & & & \\
\hline CHLOROPHYLL B, MG/SO M & 2 & .0 & 0.8 & & & \\
\hline JRGANIC CARBON, MG/L & 4 & 13.0 & 78.0 & & & \\
\hline
\end{tabular}


Table 14.--Summary of measurements at each station--Continued

LAT 47030 MO8S LONG $101025 M 50 S$

DRAINAGE AREA: 181400 SQ MI ( 469826 SQ KM)

PERICD OF RECORD: $10 / 01 / 74-09 / 30 / 75$

STATISTICAL SUMMARY OF SELECTED DISSOLVED CHEMICAL CONSTITUENTS AND REGRESSION RELATIONSHIPS OF CONSTITUENT CONCENTRATIONS TO SPECIFIC CONOUCTANCE

CONSIIIUENI

\begin{tabular}{|c|}
\hline $\begin{array}{l}\text { TEMPERATURE, WATER (DEG () } \\
\text { SPECIFIC CONDUCTANCE (MICROMHOS) } \\
\text { STREAMFLOW (CUBIC FT/SEC) } \\
\text { PH (STANDARD UNITS) } \\
\text { PHOSPMORUS, TOTAL } \\
\text { NITRITE + NITRATE, TCTAL } \\
\text { NITRUGEN, KJELDAHL, TOTAL } \\
\text { PHYTOPLANKTON, TOTAL (CELLS/ML) } \\
\text { SEDIMENT, SUSPENDED } \\
\text { SEDIMENT, CLAY SILT (PERCENT) } \\
\text { COLIFORM, FECAL (COL/IOO ML) } \\
\text { STREPTOCOCCI, FECAL (COL/IOO ML) } \\
\text { SILICA, DISSOLVED } \\
\text { CALCIUM, DISSOLVED } \\
\text { MAGNESIUM, DISSOLVED } \\
\text { SODIUM, DISSOLVED } \\
\text { POTASSIUM, DISSULVED } \\
\text { BICARBONATE, ION } \\
\text { CARGONATE, ION } \\
\text { SULFATE, DISSOLVED } \\
\text { CHLORIDE, DISSOLVED } \\
\text { DISSOLVED SOLIDS, SUM OF CONST } \\
\text { DISSOLVED SOLIDS, ROE I8O DEG C } \\
\text { HARDNESS, TOTAL } \\
\text { HARDNESS, NONCARBONATE } \\
\text { TURBIDITY (JTU) } \\
\text { FLOURIDE, DISSOLVED }\end{array}$ \\
\hline
\end{tabular}

\begin{tabular}{lr}
\multicolumn{2}{c}{ CONSILUUENI IMG } \\
SAMPLE \\
SIZE_
\end{tabular}

1.0
7.38

52.15

20.46
58.31

4.07

0.4

9.00

415.2

423.5

61.9

0.50
STANOARD

DEYIAIION

5.34

18.4

13530.7

13530.7
0.23

0.018

0.050
0.607

0.607
89.9

89.9
0.0

$0.9 \quad 0.3$

0.3
0.4
0.32
2.15
1.39
3.30
0.19
0.3
1.0
7.07
0.56
11.7
11.3
8.5
5.6
1.8
0.06

SADGE

0.0
630

$630 \quad 16.0$

$21600-685$

7.9

0.00

0.08

0.10

1
5
5

0
0
6.7
49.0
18.0
54.0
3.8
175
0
160.0
8.6
395
408
200
53
1
0.4

2.40
240
BEGRESSION SUMMARY REGRESSION

SAMPLE COEFICIENT, CONSTANT, CORRELATION SIZE.

B...B. COEELCIENI

STANDARO ERROR OF ESIIMAIE

*Not significant at the 95 percent confidence level. QUBAIION_IABLE OE DAILY SPECIEIC CONDUCIANCE DAILY SPECIFIC CONDUCTANCE IN MICROMHOS AT 25 DEG C, THAT WAS

EQUALLED OR EXCEEDED FOR THE

$\begin{array}{llllll}18 & -5 \% & 108 & 20 \% & 30 \% & 50 \% \\ 700 & 695 & 690 & 687 & 681 & 671\end{array}$

$\begin{array}{rr}-348.907 & 269205.438 \\ 0.0054 & 4.6295 \\ -0.00020 & 0.14962 \\ -0.00074 & 0.02268 \\ -0.00929 & 6.61079 \\ -2.806 & 1930.414\end{array}$

$-0.474 *$

$0.433 *$

-0.197 *

-0.272 .

-0.281 .

$-0.550^{\circ}$.

$\begin{array}{rr}1 & \\ 2 & \\ 7.8 & 13 \\ 57.0 & 13 \\ 22.0 & 13 \\ 64.0 & 13 \\ 4.4 & 13 \\ 201 & 13 \\ 3 & 10 \\ 180.0 & 13 \\ 10.0 & 13 \\ 433 & 13 \\ 440 & 13 \\ 230 & 13 \\ 71 & 13 \\ 7 & 11 \\ 0.6 & 13\end{array}$

$$
\begin{array}{r}
0.0036 \\
0.0543 \\
0.0506 \\
0.1185 \\
-0.0020 \\
0.180 \\
0.032 \\
0.1112 \\
0.0192 \\
0.458 \\
0.462 \\
0.272 \\
0.161 \\
-0.021 \\
0.0002
\end{array}
$$

5.0212

$-12.9522$

$-19.9294$

5.3747

66.963

$-21.033$

96.5775

$-3.2423$

112.915

118.738

33.733

-44.023
16.410

0.3374

0.208 *

0.463 .

0.668

\begin{tabular}{|c|c|c|c|c|c|}
\hline & & & & & $\overline{\text { STANDARD }}$ \\
\hline & HARMONIC & AMPLITUDE & PHASE & VARIATION & ERROR OF \\
\hline SAMPLE & MEAN - M & $-A$ & ANGLE - C & EXPLAINED & ESTIMATE \\
\hline _SIZE_ & (DEG $C)_{-}$ & LEEG (1) & (BADIANS) & 181 & $10 E 6(6)$ \\
\hline 365 & 6.07 & 7.11 & 2.04 & 95 & 1.12 \\
\hline
\end{tabular}

0.660

-0.192 *

0.563 .

0.289 .

\begin{tabular}{|c|c|c|c|c|c|c|}
\hline \multirow{2}{*}{ CONSTITUENT } & \multicolumn{3}{|c|}{ TOTAL } & \multicolumn{3}{|c|}{ DISSOLVED } \\
\hline & $\begin{array}{l}\text { NO. } \\
\text { SAMPLES }\end{array}$ & $\begin{array}{l}\text { MIN IMUM } \\
\text { CONC. }\end{array}$ & $\begin{array}{l}\text { MAXIMUM } \\
\text { CONC. }\end{array}$ & $\begin{array}{l}\text { NO. } \\
\text { SAMPLES }\end{array}$ & $\begin{array}{l}\text { MINIMUM } \\
\text { CONC. }\end{array}$ & $\begin{array}{l}\text { MAXIMUM } \\
\text { CONC. }\end{array}$ \\
\hline \multicolumn{7}{|l|}{ MINOR ELEMENTS: } \\
\hline ARSENIC (AS), UG/L & 6 & 1 & 4 & 13 & 0 & 4 \\
\hline CADMIUM $(C D), U G / L$ & 6 & $<10$ & $<10$ & 13 & 0 & 1 \\
\hline CHROMIUM (CR), UG/L & 6 & 0 & 10 & 6 & 0 & 0 \\
\hline COBALT $(C O), U G / L$ & 4 & $<50$ & 50 & 6 & 0 & 0 \\
\hline COPPER $(C U), U G / L$ & 6 & $<10$ & 40 & 6 & 1 & 4 \\
\hline IRON $(F E), U G / L$ & 6 & 40 & 200 & 6 & 10 & 60 \\
\hline LEAD $(P B), U G / L$ & 6 & $<100$ & $<100$ & 6 & 0 & 5 \\
\hline MANGANESE $(M N), U G / L$ & 4 & 0 & 20 & 6 & 0 & 10 \\
\hline MERCURY $(H G), U G / L$ & 6 & 0.0 & 0.1 & 6 & 0.0 & 0.1 \\
\hline SELENIUM (SE), UG/L & 6 & 1 & 1 & 6 & 1 & 1 \\
\hline $2 I N C(2 N), U G / L$ & 5 & 20 & 70 & 5 & 0 & 20 \\
\hline \multicolumn{7}{|l|}{ PERIPHYTON: } \\
\hline BIOMASS, DRY WT., G/SQ & 1 & 1.00 & & & & \\
\hline BIUMASS, ASH WT., G/SQ & 1 & .59 & & & & \\
\hline CHLOROPHYLL A, MG/SO M & 1 & .0 & & & & \\
\hline CHLOROPHYLL B, MG/SO M & 1 & .0 & & & & \\
\hline ORGANIC CARBON, MG/L & 4 & 3.0 & 4.0 & & & \\
\hline
\end{tabular}

0.635

0.719
0.748

0.748

0.584

0.530

-0.206 *

0.078 .

\begin{tabular}{llll} 
& \multicolumn{2}{l}{ SAMPLE SIZE $=$} & 362 \\
708 & 203 & 258 & 292 \\
649 & 632 & 632 & 631
\end{tabular}

SUMMARY OF MARMONIC ANALYSIS OF STREAM TEMPERATURE

SUMMARY OF MAXIMUM AND MINIMUM CONCENTRATIONS DF CONSTITUENTS SAMPLED AT A FREQUENCY OF QUARTERLY (1975 WY)

06338490 -- MISSOURI RIVER AT GARRISON DAM, ND 
Table 14.--Summary of measurements at each station--Continued

LAT 47017MO6S LONG 101037M26S

DRAINAGE AREA: 2350 SQ MI ( 6087 SQ KM)

PERIOD OF RECORD: 10/01/74 - 09/30/75

STATISTICAL SUMMARY OF SELECTED DISSOLVED CHEMICAL CONSTITUENTS AND

REGRESSION RELATIONSHIPS OF CONSTITUENT CONCENTRATIONS TO SPECIFIC CONDUCTANCE

REGBESSION SUMHABY

REGRESSION

SAMPLE COEFICIENT, CONSTANT,

CORRELATION STANDARD COEFICIENI ESIUMAIE SIZE

C - B
CONSIUTUENI

CONSILIUENT IAG/L OR UNII SHOYNI

\begin{tabular}{|c|c|c|}
\hline $\begin{array}{l}\text { SAMPLE } \\
\text { SUZE }\end{array}$ & MEAN & $\begin{array}{l}\text { STANDARD } \\
\text { DEYIAIUN }\end{array}$ \\
\hline 24 & 6.88 & 8.03 \\
\hline 25 & 1651.2 & 812.4 \\
\hline 25 & 846.1 & 2003.4 \\
\hline 21 & 8.46 & 0.28 \\
\hline 11 & 0.072 & 0.048 \\
\hline 11 & 0.168 & 0.167 \\
\hline 11 & 1.465 & 1.889 \\
\hline 11 & 30444.5 & 49864.0 \\
\hline 12 & 597.2 & 1183.2 \\
\hline 7 & 75.7 & 16.9 \\
\hline 9 & 460.1 & 788.2 \\
\hline 10 & 1831.1 & 3838.3 \\
\hline 9 & 13.01 & 3.45 \\
\hline 12 & 66.50 & 20.28 \\
\hline 12 & 40.58 & 12.82 \\
\hline 12 & 241.42 & 92.98 \\
\hline 12 & 8.77 & 1.04 \\
\hline 1 & 459.0 & 0.0 \\
\hline 1 & 0.0 & 0.0 \\
\hline 12 & 412.92 & 133.44 \\
\hline 12 & 5.91 & 3.62 \\
\hline 1 & 884.0 & 0.0 \\
\hline 12 & 1052.5 & 332.2 \\
\hline 12 & 334.0 & 100.5 \\
\hline 1 & 0.0 & 0.0 \\
\hline 4 & 58.8 & 48.2 \\
\hline 9 & 0.42 & 0.08 \\
\hline
\end{tabular}

TEMPERATURE, WATER (DEG C)

SPECIFIC CONDUCTANCE (MICROMHOS STREAMFLOW (CUBIC FT/SEC)

PH (STANDARD UNITS)

PHOSPHORUS, TOTAL

NITROGEN, KJELDAHL, TOTAL

PHYTOPLANKTON, TOTAL ICELLSIML

SEDIMENT, SUSPENDED

SEDIMENT, CLAY-SILT (PERCENT)

COLIFORM, FECAL (COL/100 ML)

SILICA, DISSOLVED

MAGNE SIUM, DISSOLVED

SODIUM, DISSOLVED

POTASSIUM, DISSOLVED

BICARBONATE, ION

CARBONATE, ION

SULFATE, DISSOLVED

CHLORIDE, DISSOLVED

DISSOLVED SOLIDS, SUM OF CONST

DISSOLVED SOLIDS,

HARDNESS, NONCARBONATE

TURBIDITY (JTU)

* Not significant at the 95 percent confidence level

DURAYION IABLE OF DAILY SPECIEIC CONOUCIANCE

DAILY SPECIFIC CONDUCTANCE IN

MICROMHOS AT 25 DEG C, THAT HAS

EQUALLED OR EXCEEDED FOR THE

$\begin{array}{lr}18 & -58 \\ 2400 & 2220\end{array}$

108

208

302508

$2150 \quad 2030$
BANGE

22.0

3100
8
7

$7.7 \quad 8.7$

0.02

0.00

430

25
52

$\begin{array}{rr}52 & 96 \\ 11 & 2500 \\ 28 & 12000\end{array}$

$9.1 \quad 19.0$

$10.0 \quad 113.0$

$65.0 \quad 400.0$

11.0

25

$21-1.579$

-0.0001
-0.00002

0.00002

$-0.00176$

$-15.031$

8.6052

0.12406

4.69254

58060.068

$-0.640$

$-0.204 *$

$-0.369 *$
0.103

$-0.668$

$-0.216 *$

0.28

0.047

0.175

1.482

3780

96

500

$\begin{array}{rrrrr}9 & 0.0047 & 3.9122 & 0.827 & 2.08 \\ 12 & 0.0256 & 20.9958 & 0.873 & 10.38\end{array}$

$1200.0176 \quad 9.2109 \quad 0.952 \quad 4.13$

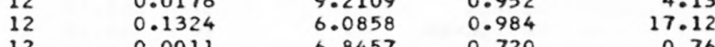

$625.0 \quad 12$

$15.0 \quad 12$

$1610 \quad 12$

102.8191

1.6850

0.904

$0.454 *$

59.85

$530 \quad 12$

$130 \quad 4$

0.404

0.137

334.570
91.071

0.841

0.941

278.256

$-0.144$

0.2422

0.677
188.7

35.7

45.2
SAMPLE SIZE $=345$

$20 \% \quad 25 \% \quad 298$

$1100 \quad 640 \quad 355$

SUMMARY OF HARMONIC ANALYSIS OF STREAM TEMPERATURE

\begin{tabular}{|c|c|c|c|c|c|}
\hline & & & & & $\overline{\text { STANDARD }}$ \\
\hline & HARMONIC & AMPLITUDE & PHASE & VARIATION & ERROR OF \\
\hline SAMPLE & MEAN - M & $-A$ & ANGLE - C & EXP LAINED & ESTIMATE \\
\hline SIZE_ & (DEG C) & DEE $(1)$ & (RADLANS) & -181 & LEEG $(1)$ \\
\hline
\end{tabular}

345

8.26

11.41

2.75

90

2.84

SUMMARY OF MAXIMUM AND MINIMUM CONCENTRATIONS OF CONSTITUENTS

SAMPLED AT A FREQUENCY OF QUARTERLY (1975 WY)

06340500 -- KNIFE RIVER AT HAZEN, ND

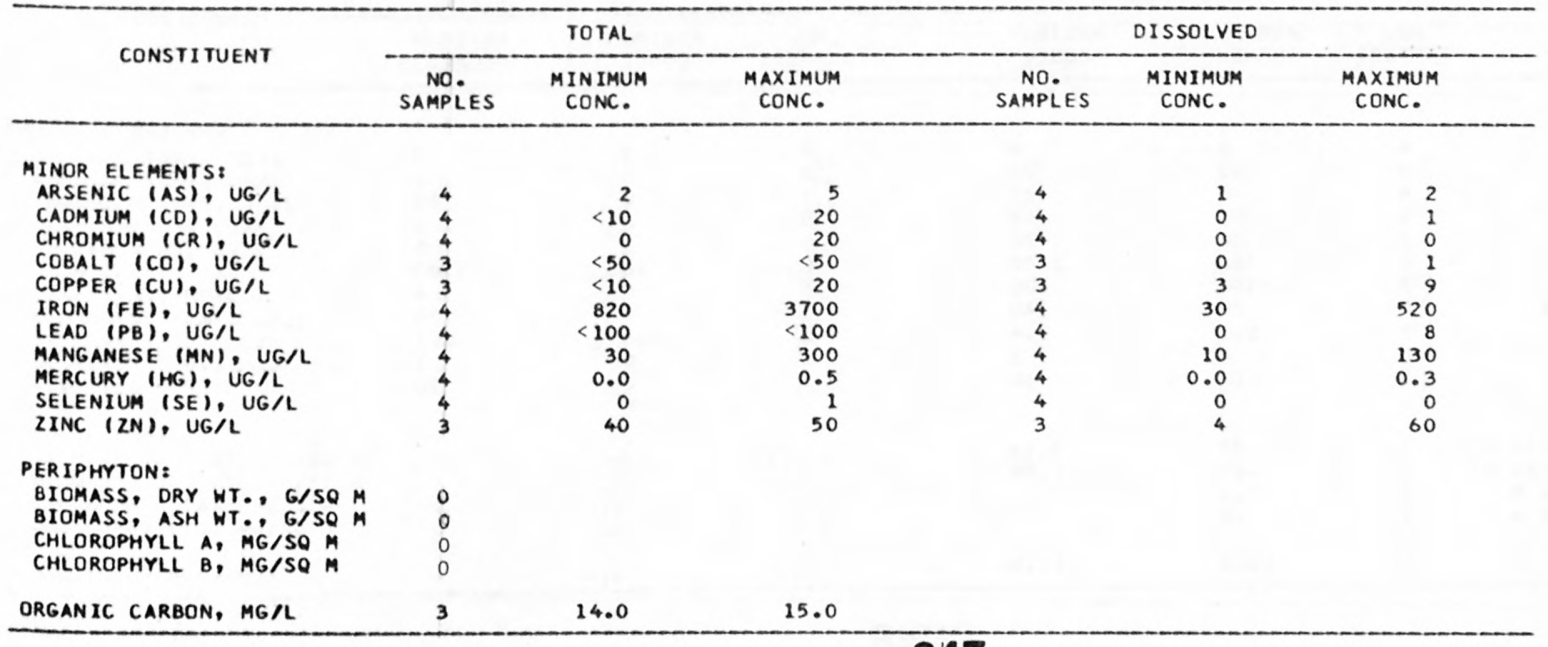


Table 14.--Summary of measurements at each station--Continued

LAT 46D22M33S LONG 100056M03S DRAINAGE AREA: 4100 SQ MI ( 10619 SQ KM)

PERIOD OF RECORD: $10 / 01 / 74-09 / 30 / 75$

STATISTICAL SUMMARY OF SELECTED DISSOLVED CHEMICAL CONSTITUENTS AND

REGRESSION RELATIONSHIPS OF CONSTITUENT CONCENTRATIONS TO SPECIFIC CONDUCTANCE

CONSIUIUENI

CONSIUUENT IMGLL OR UNII SHOWNL

\begin{tabular}{|c|c|c|}
\hline $\begin{array}{l}\text { SAMPLE } \\
\text { SIZE }\end{array}$ & MEAN & $\begin{array}{l}\text { STANDARD } \\
\text { DEYIAIION }\end{array}$ \\
\hline 19 & 6.92 & 8.73 \\
\hline 19 & 1740.6 & 1160.8 \\
\hline 19 & 1179.3 & 1995.1 \\
\hline 12 & 8.28 & 0.40 \\
\hline 12 & 0.141 & 0.304 \\
\hline 12 & 0.248 & 0.711 \\
\hline 12 & 1.663 & 1.283 \\
\hline 10 & 35884.0 & 79128.6 \\
\hline 5 & 1382.0 & 832.2 \\
\hline 2 & 80.5 & 9.2 \\
\hline 9 & 92.9 & 121.2 \\
\hline 9 & 354.2 & 662.8 \\
\hline 12 & 7.02 & 2.26 \\
\hline 12 & 75.42 & 28.29 \\
\hline 12 & 65.33 & 26.39 \\
\hline 12 & 345.17 & 181.61 \\
\hline 12 & 10.95 & 2.87 \\
\hline 12 & 502.5 & 275.3 \\
\hline 10 & 14.7 & 21.7 \\
\hline 12 & 746.67 & 331.62 \\
\hline 12 & 20.09 & 17.16 \\
\hline 12 & 1531.3 & 662.5 \\
\hline 11 & 1496.8 & 647.3 \\
\hline 12 & 458.3 & 174.7 \\
\hline 12 & 96.3 & 108.3 \\
\hline 12 & 180.6 & 413.4 \\
\hline 12 & 0.52 & 0.31 \\
\hline
\end{tabular}

0.520 .31
BEGRESSION_SUMHABY

REGRESSION SAMPLE COEFICIENT, CONSTANT, CORRELATION ERROR OF SIZE - B C B B BEICIENI ESIIMAIE

TEMPERATURE, WATER (DEG C) SPECIFIC CONDUCTANCE (MICROMHOS)

$\begin{array}{rrr}0.0 & 25.5 & \\ 300 & 3800 & \\ 1 & 6940 & 19 \\ 7.5 & 9.0 & 12 \\ 0.01 & 1.10 & 12 \\ 0.00 & 2.50 & 12 \\ 0.74 & 4.90 & 12 \\ 320 & 260000 & 10 \\ 30 & 2060 & \\ 74 & 87 & \\ 1 & 320 & \\ 48 & 2100 & \\ 4.1 & 10.0 & 12 \\ 33.0 & 120.0 & 12 \\ 22.0 & 100.0 & 12 \\ 72.0 & 630.0 & 12 \\ 6.1 & 16.0 & 12 \\ 122 & 951 & 12 \\ 0 & 55 & 10 \\ 220.0 & 1200.0 & 12 \\ 4.1 & 62.0 & 12 \\ 427 & 2520 & 12 \\ 460 & 2610 & 11 \\ 180 & 710 & 12 \\ 0 & 290 & 12 \\ 4 & 1400 & 12 \\ 0.2 & 1.3 & 12\end{array}$
STREAMFLOH (CUBIC FT/SEC)

PH (STANDARD UNITS )

PHOSPHORUS, TOTAL

NITRITE + NITRATE, TOTAL

NITROGEN, KJELDAHL, TOTAL

PHYTOPLANKTON, TOTAL (CELLS/ML)

SEDIMENT, SUSPENDED

SEDIMENT, CLAY-SILT (PERCENT)

COLIFORM, FECAL (COL/100 ML)

STREP TOCOCCI, FEC

CALCIUM, DISSOLVED

MAGNE SIUM, DI SSOLVED

SODIUM, DISSOLVED

POTASSIUM, DISSOLVED

BICARBONATE, ION

CARBONATE, ION

SULFATE, DISSOL VED

CHLORIDE, DISSOLVED

ISSOLVED SOLIDS, SUM OF CONST

OISSOLVED SOLIDS,

HARDNESS, NONCARBONATE

TURBIDITY (JTU)

FLOURIDE, DISSOLVED

*Not significant at the 95 percent confidence level.

DURATION IABLE OF DALY SPECIEIC CONOUCIANCE

DAILY SPECIFIC CONDUCTANCE IN

MICROMHOS AT 25 DEG C, THAT WAS

EQUALLED OR EXCEEDED FOR THE

$\begin{array}{llllll}18 & 5 \% & 208 & 208 & 508\end{array}$

$50870 x$

$-0.845$

$-0.00013$

$-0.00026$

$-0.00046$

0.870

$-0.085 *$

$-0.451 *$

$-0.385 *$

$0.013 *$

0.42

0.285

0.684

1.241

INDICATED PERCENTAGE OF TIME

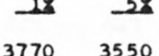

3350

3200

1740

$$
\begin{array}{r}
5.4161 \\
39.7710 \\
25.0096 \\
-0.6624 \\
7.7554 \\
24.317 \\
-10.782 \\
193.3748 \\
-4.0622 \\
278.679 \\
341.670 \\
200.537 \\
170.072 \\
322.416 \\
0.1910
\end{array}
$$

0.013 *

0.356 *

\begin{tabular}{|c|c|c|c|c|c|}
\hline & & & & & STANDARD \\
\hline $\begin{array}{l}\text { SAMPLE } \\
\text { SIZE }\end{array}$ & $\begin{array}{l}\text { HARMONIC } \\
\text { MEAN - M } \\
\text { LOEG C) }\end{array}$ & $\begin{array}{c}\text { AMPLITUDE } \\
-A \\
\text { (DEG }\end{array}$ & $\begin{array}{c}\text { PHASE } \\
\text { ANGLE - C } \\
\text { (BADIANS) }\end{array}$ & $\begin{array}{l}\text { VARIATION } \\
\text { EXPLAINED } \\
181 \\
\end{array}$ & $\begin{array}{l}\text { ERROR OF } \\
\text { ESTIMATE } \\
\text { (DEG C) }\end{array}$ \\
\hline
\end{tabular}

0.630

0.764

0.953

0.869
0.628

0.628
0.835

0.704

0.946

0.928

0.738

$-0.340 *$

\begin{tabular}{|c|c|c|c|c|c|c|}
\hline \multirow{2}{*}{ CONSTI IUENT } & \multicolumn{3}{|c|}{ TOTAL } & \multicolumn{3}{|c|}{ DISSOLVED } \\
\hline & $\begin{array}{l}\text { NO. } \\
\text { SAMPLES }\end{array}$ & $\begin{array}{l}\text { MIN IMUM } \\
\text { CONC. }\end{array}$ & $\begin{array}{l}\text { MAXIMUM } \\
\text { CONC. }\end{array}$ & $\begin{array}{l}\text { NO. } \\
\text { SAMPLES }\end{array}$ & $\begin{array}{l}\text { MINIMUM } \\
\text { CONC. }\end{array}$ & $\begin{array}{l}\text { MAXIMUM } \\
\text { CONC. }\end{array}$ \\
\hline \multicolumn{7}{|l|}{ MINOR ELEMENTS: } \\
\hline ARSENIC (AS), UG/L & 4 & 0 & 4 & 5 & 0 & 3 \\
\hline CADMIUM (CD), UGIL & 5 & $<10$ & 20 & 5 & 0 & 1 \\
\hline CHROMIUM (CR), UG/L & 4 & 0 & 20 & 5 & 0 & 10 \\
\hline COBALT $(C O)$, UG/L & 5 & $<50$ & 50 & 5 & 0 & 1 \\
\hline COPPER (CU), UG/L & 5 & $<10$ & 20 & 5 & 3 & 5 \\
\hline IRON (FE), UG/L & 5 & 260 & 2100 & 5 & 10 & 1700 \\
\hline LEAD $(P B), U G / L$ & 5 & $<100$ & 100 & 5 & 0 & 4 \\
\hline MANGANESE (MN), UG/L & 5 & 20 & 140 & 5 & 0 & 120 \\
\hline MERCURY (HG), UG/L & 5 & 0.0 & 0.4 & 5 & 0.0 & 0.1 \\
\hline SELENIUM (SE), UG/L & 5 & 0 & 2 & 5 & 0 & 1 \\
\hline$Z I N C(Z N), U G / L$ & 5 & 10 & 60 & 5 & 0 & 30 \\
\hline \multicolumn{7}{|l|}{ PERIPHYTON: } \\
\hline BIOMASS, DRY WT., G/SO M & 2 & .39 & 3.10 & & & \\
\hline BIOMASS, ASH WT., G/SQ M & 2 & .29 & 2.29 & & & \\
\hline CHLOROPHYLL A, MG/SQ M & 1 & .0 & & & & \\
\hline CHLOROPHYLL B, MG/SO M & 1 & .0 & & & & \\
\hline ORGANIC CARBON, MG/L & 5 & 10.0 & 17.0 & & & \\
\hline
\end{tabular}

$-0.172 *$
$0.543^{*}$
83921.

SUMMARY OF HARMONIC ANALYSIS OF STREAM TEMPERATURE

296

7.70

11.46

2.82

85

3.25

SUMMARY OF MAXIMUM AND MINIMUM CONCENTRATIONS OF CONSTITUENTS SAMPLED AT A FREQUENCY OF QUARTERLY (1975 WY)

06354000 - CANNONBALL RIVER AT BREIEN, ND 
Table 14.--Summary of measurements at each station--Continued

LAT 45D30M28S LONG 100049M04S

DRAINAGE AREA: 5370 SQ MI ( 13908 SQ KM)

DRAINAGE AREA:

STATISTICAL SUMMARY OF SELECTED DISSOLVED CHEMICAL CONSTITUENTS AND

REGRESSION RELATIONSHIPS OF CONSTITUENT CONCENTRATIONS TO SPECIFIC CONDUCTANCE

\section{CONSIIIUENI}

\section{CONSILUUENI IMGLL OR UNII SHOWNI}

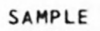

SIZE

IEMPERATURE, WATER (DEG C) SPECIFIC CONDUCTANCE (MICROMHOS) STREAMFLOW (CUBIC FT/SEC)

PH (STANDARD UNITSI

PHOSPHORUS, TOTAL

NITRITE + NITRATE, TOTAL

NITROGEN, KJELDAHL, TOTAL

PHYTOPLANKTON, TOTAL (CELLS/ML)

SEDIMENT, SUSPENDED

SEDIMENT, CLAY-SILT (PERCENT)

COLIFORM, FECAL (COL/100 ML)

STREPTOCOCCI, FECAL (COL/100 ML)

CALCIUM, DISSOLVED

MAGNESIUM, DISSOLVED

SODIUM, DISSOLVED

POTASSIUM, DISSOLVED

BICAREONATE, ION

CARBONATE, ION

SULFATE, DISSOLVED

CHLORIDE, DISSOLVED

DISSOLVED SOLIDS, SUM OF CONST

DISSOLVED SOLIDS, ROE 180 DEG

HARDNESS, TOTAL

HARDNESS, NONCARBONAT

TURBIDITY (JTU)

FLOUR IDE, DISSOLVED
SILICA, DISSOLVED
STANDARD

MEAN REYLALION BANGE

\subsection{7}

1805.0

1002.9

8.74

0.302

0.105

2.062

2923.0

5222.9

1247.9

936.8

7.65
42.62

42.62
29.13

29.13
376.36

9.62

408.1

8.7

565.91

134.24
1376.2

1376.2
1298.9

225.7

14.2

365.5
0.38
10.36

798.4

1828.6

0.46
0.355

0.355

0.168

1.976

3793.6

1860.3

1446.6

1377.8

4.22
41.25

41.25
18.78

168.30

2.62

202.2

292.65

209.24

209.24
575.6

620.9

164.6

34.6

547.8
0.08
0.0

430

8.1

0.00

0.00

0.68

3480

3

2.1

2.0
8.4

8.4
200.0

5.8

136

85.0

6.6
839

839
545
71

0
4
0.3

\section{BEG} REGRESSION

SAMPLE COEFICIENT,

CONSTANT,

STANDARD
CORRELATION ERROR OF SIZE

$$
32.0
$$$$
3300
$$$$
5720
$$

9.5
1.10

0.55

7.20

13000

8270

\section{0}

4100

18.0

150.0

73.0
700.0

15.0

795
48

1100.0

680.0

2730

2610

680
110

1100
0.5 *Not significant at the 95 percent confidence level.

DAILY SPECIFIC CONDUCTANCE IN MAICRYMHOS AT 25 DEG C O THAT

MICRALIED OR EXCEEDED FOR THE

EQUALLED OR EXCEEDED FOR THE
INDICATED PERCENTAGE OF TIME

BAIION IABLE OF DAULY SPECIEIC CONOUCIANCE

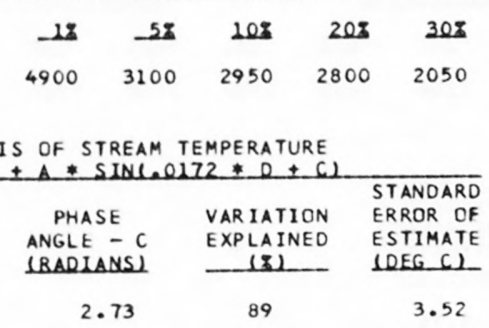

SUMMARY OF HARMONIC ANALYSIS OF

\begin{tabular}{|c|c|c|c|c|c|}
\hline & & & & & STANDARD \\
\hline $\begin{array}{l}\text { SAMPLE } \\
\text { SIZE }\end{array}$ & $\begin{array}{l}\text { HARMONIC } \\
\text { MEAN - M } \\
\text { (OEG C) }\end{array}$ & $\begin{array}{c}\text { AMPLITUDE } \\
-A \\
\text { (DEG }\end{array}$ & $\begin{array}{c}\text { PHASE } \\
\text { ANGLE - C } \\
\text { (BADLANS) }\end{array}$ & $\begin{array}{l}\text { VAR IATION } \\
\text { EXPLA INED } \\
\text { (I) }\end{array}$ & $\begin{array}{l}\text { ERROR OF } \\
\text { ESTIMATE } \\
\text { LOEG CI }\end{array}$ \\
\hline 208 & 10.78 & 13.33 & 2.73 & 89 & 3.52 \\
\hline
\end{tabular}

SUMMARY OF MAXIMUM AND MINIMUM CONCENTRATIONS OF CONSTITUENTS

SAMPLED AT A FREQUENCY OF QUARTERLY (1975 WY)

06357800 -- GRAND RIVER AT LITTLE EAGLE,S.D.

\begin{tabular}{|c|c|c|c|c|c|c|}
\hline \multirow{2}{*}{ CONSTITUENT } & \multicolumn{3}{|c|}{ TOTAL } & \multicolumn{3}{|c|}{ DISSOLVED } \\
\hline & $\begin{array}{l}\text { NO. } \\
\text { SAMPLES }\end{array}$ & $\begin{array}{l}\text { MINIMUM } \\
\text { CONC. }\end{array}$ & $\begin{array}{l}\text { MAXIMUM } \\
\text { CONC. }\end{array}$ & $\begin{array}{l}\text { NO. } \\
\text { SAMPLES }\end{array}$ & $\begin{array}{l}\text { MINIMUM } \\
\text { CONC. }\end{array}$ & $\begin{array}{l}\text { MAXIMUM } \\
\text { CONC. }\end{array}$ \\
\hline \multicolumn{7}{|l|}{ MINOR ELEMENTS: } \\
\hline ARSENIC (AS), UG/L & 4 & 1 & 15 & 4 & 1 & 6 \\
\hline CADMIUM $(C D), U G / L$ & 4 & $<10$ & 20 & 4 & 0 & 1 \\
\hline CHROMIUM (CR), UG/L & 4 & 0 & 34 & 4 & 0 & 4 \\
\hline COBALT $(C O)$, UG/L & 4 & 30 & 50 & 4 & 0 & 1 \\
\hline $\begin{array}{l}\text { COPPER (CU), UG/L } \\
\text { IRON (FE), UG/L }\end{array}$ & 4 & $\begin{array}{r}10 \\
480\end{array}$ & $\begin{array}{r}60 \\
43000\end{array}$ & & 4 & 11 \\
\hline $\begin{array}{l}\text { IRON }(F E), U G / L \\
\text { LEAD }(P B), U G / L\end{array}$ & 4 & $\begin{array}{l}480 \\
400\end{array}$ & $\begin{array}{l}43000 \\
<100\end{array}$ & $\begin{array}{l}4 \\
4\end{array}$ & $\begin{array}{r}10 \\
1\end{array}$ & $\begin{array}{r}70 \\
6\end{array}$ \\
\hline $\begin{array}{l}\text { LEAD }(P B), U G / L \\
\text { MANGANESE }(M N), U G / L\end{array}$ & 4 & 110 & 1200 & 4 & 0 & 30 \\
\hline MERCURY (HG), UG/L & 4 & 0.0 & 0.2 & 4 & 0.0 & 0.0 \\
\hline SELENIUM (SE), UG/L & 4 & 0 & 2 & 4 & 0 & 1 \\
\hline ZINC $(Z N), U G / L$ & 4 & 30 & 260 & 4 & 0 & 6 \\
\hline \multicolumn{7}{|l|}{ PERIPHYTON: } \\
\hline BIOMASS, DRY WT., G/SQ M & 3 & .50 & 46.00 & & & \\
\hline BIOMASS, ASH WT., G/SO M & 4 & .29 & 44.00 & & & \\
\hline CHLOROPHYLL A, MG/SQ M & 4 & .1 & 3.0 & & & \\
\hline CHLOROPHYLL $B$, MG/SQ M & 4 & .0 & .8 & & & \\
\hline ORGANIC CARBON, MG/L. & 4 & 8.8 & 25.0 & & & \\
\hline
\end{tabular}


LAT 44022MIIS LONG 102033M56S

DRAINAGE AREA: 7210 SO MI ( 18674 SO KM)

PERIOD OF RECORD: $10 / 01 / 74-09 / 30 / 75$

STATISTICAL SUMMARY OF SELECTED DISSOLVED CHEMICAL CONSTITUENTS AND

REGRESSION RELATIONSHIPS OF CONSTITUENT CONCENTRATIONS TO SPECIFIC CONDUCTANCE

CONSILIUENI

\section{CONSTUIUENI_LGGL_OR_UNII_SHOHNI}

SA

STANDARD

DEYIALION

SIZE

TEMPERATURE, WATER (DEG C) SPECIFIC CONDUCTANCE (MICROMHOS)

STREAMFLOW (CUBIC FT/SEC)

PH (STANDARD UNITS)

PHOSPHORUS, TOTAL

NITRITE + NITRATE, TOTAL

NITROGEN, KJELDAHL, TOTAL

PHYTOPLANKTON, TOTAL (CELLS/ML)

SEDIMENT, SUSPENDED

SEDIMENT, CLAY-SILT (PERCENT)

COLIFORM, FECAL (COL/100 ML)

STREPTOCOCCI, FECAL (COL/100 ML)

SILICA, DISSOLVED

CALCIUM, DISSOLVED

MAGNESIUM, DISSOLVED

SODIUM, DISSOLVED

POTASSIUM, DISSOLVED

BICAREONATE, ION

CARBONATE, ION

SULFATE, DISSOLVED

CHLORIDE, DISSOLVED

DISSOLVED SOLIDS, SUM OF CONST

DISSOLVED SOLIDS, ROE 180 DEG C

HARDNESS, TOTAL

HARONESS, NONCARBONATE

TURBIDITY (JTU)

FLOURIDE, DISSOLVED

$\begin{array}{rrrrr}12 & 10.38 & 9.59 & 0.0 & 25.5 \\ 12 & 2384.2 & 924.4 & 1280 & 4000 \\ 12 & 336.8 & 451.5 & 6 & 1000 \\ 11 & 8.11 & 0.54 & 6.9 & 8.7 \\ 12 & 0.273 & 0.390 & 0.01 & 1.40 \\ 12 & 2.134 & 1.778 & 0.41 & 5.90 \\ 12 & 1.567 & 1.410 & 0.12 & 4.20 \\ 11 & 8133.6 & 10216.2 & 0 & 28000 \\ 11 & 1110.1 & 1433.3 & 294 & 4480 \\ 0 & & & & \\ 12 & 410.8 & 721.5 & 3 & 2600 \\ 12 & 337.2 & 072.5 & 6 & 2400 \\ 12 & 7.02 & 1.60 & 4.7 & 10.0 \\ 12 & 227.75 & 92.22 & 83.0 & 380.0 \\ 12 & 110.50 & 63.06 & 36.0 & 230.0 \\ 12 & 164.17 & 89.32 & 64.0 & 330.0 \\ 12 & 15.27 & 5.47 & 7.5 & 25.0 \\ 12 & 234.1 & 112.4 & 96 & 499 \\ 7 & 0.1 & 0.4 & 0 & 1 \\ 12 & 1105.00 & 528.57 & 440.0 & 2100.0 \\ 12 & 22.82 & 13.97 & 8.9 & 48.0 \\ 12 & 1769.2 & 838.6 & 734 & 3360 \\ 12 & 1973.9 & 962.2 & 780 & 3720 \\ 12 & 1025.0 & 486.8 & 360 & 1900 \\ 12 & 837.5 & 410.0 & 280 & 1500 \\ 12 & 393.1 & 1010.5 & 2 & 3500 \\ 12 & 0.50 & 0.12 & 0.2 & 0.7\end{array}$

*Not significant at the 95 percent confidence level.

\begin{tabular}{|c|c|c|c|c|c|c|c|c|c|c|}
\hline U. & I & Ut & $I S T$ & I16 & . & & & SA & SI & $=3$ \\
\hline OMHOS AT 25 DEG C, THAT WAS & 18 & -52 & 102 & 209 & $30 \%$ & $50 z$ & 702 & 208 & $25 \%$ & 298 \\
\hline $\begin{array}{l}\text { QUALLED OR EXCEEDED FOR THE } \\
\text { NDICATED PERCENTAGE OF TIME }\end{array}$ & 4220 & 4000 & 3800 & 3220 & 2700 & 1820 & 1700 & 1280 & 1120 & 10 \\
\hline
\end{tabular}

BEGRESSION SUMMARY

REGRESSION, CONSTANT, CORRELATION ERANDARD
SAMPLE COEFICIENT, CONOR CF SIZE - R - B - COEEICIENI ESIIMAIE

$12 \quad \begin{array}{llll}-0.304 & 1062.459 & -0.623 & 370.4\end{array}$

$11-0.0005$

$-0.00021$

0.00157

$-0.00048$

$-5.600$

$-1.62023$

2.70045

20663.141

-0.623
-0.875

-0.503 *

0.819

0.311.

$-0.311^{*}$

0.27

0.354

1.071

9650.6

$\begin{array}{rr}0.0005 & 5 \\ 0.0926 & 6 \\ 0.0663 & -47 \\ 0.0929 & -57 \\ 0.0055 & 2 \\ 0.107 & -2 \\ -0.000 & \\ 0.5572 & -223 \\ 0.0141 & -10 \\ 0.882 & -33 \\ 1.013 & -440 \\ 0.506 & -18 \\ 0.428 & -183 \\ -0.320 & 115 \\ 0.0001 & 0 \\ & \\ & \\ \text { SLLE } & \\ 2125 & 234 \\ 1120 & 1020\end{array}$

SUMMARY OF HARMONIC ANALYSIS OF STREAM TEMPERATURE

\begin{tabular}{|c|c|c|c|c|c|}
\hline & & & & & STANDARD \\
\hline SAMPLE & $\begin{array}{l}\text { MARMONIC } \\
\text { MEAN - M }\end{array}$ & $\begin{array}{c}\text { AMPLITUDE } \\
-\quad A\end{array}$ & $\begin{array}{l}\text { PHASE } \\
\text { ANGLE - C }\end{array}$ & $\begin{array}{l}\text { VAR IATION } \\
\text { EXPLAINED }\end{array}$ & $\begin{array}{l}\text { ERROR OF } \\
\text { ESTIMATE }\end{array}$ \\
\hline SIZE & LDEG C) & (OEG $\mathrm{CI}$ & (BADIANS) & (z) & (DEG C) \\
\hline
\end{tabular}

335

9.40

11.69

2.76

88

3.11

SUMMARY OF MAXIMUM AND MINIMUM CONCENTRATIONS OF CONSTITUENTS

SAMPLED AT A FREQUENCY OF QUARTERLY (1975 WY)

06438000 -- BELLE FOURCHE R NR ELM SPRINGS, S. DAK.

\begin{tabular}{|c|c|c|c|c|c|c|}
\hline \multirow{2}{*}{ CONSTITUENT } & \multicolumn{3}{|c|}{ TOTAL } & \multicolumn{3}{|c|}{ DISSOLVED } \\
\hline & $\begin{array}{l}\text { NO. } \\
\text { SAMPLES }\end{array}$ & $\begin{array}{l}\text { MINIMUM } \\
\text { CONC. }\end{array}$ & $\begin{array}{l}\text { MAXIMUM } \\
\text { CONC. }\end{array}$ & $\begin{array}{l}\text { NO. } \\
\text { SAMPLES }\end{array}$ & $\begin{array}{l}\text { MINIMUM } \\
\text { CONC. }\end{array}$ & $\begin{array}{l}\text { MAXIMUM } \\
\text { CONC. }\end{array}$ \\
\hline \multicolumn{7}{|l|}{ MINOR ELEMENTS: } \\
\hline ARSENIC (AS), UG/L & 3 & 75 & 2300 & 3 & 13 & 65 \\
\hline CADMIUM $(C D), U G / L$ & 3 & $<10$ & $<10$ & 3 & 0 & 1 \\
\hline CHROMIUM (CR), UG/L & 3 & 0 & 120 & 3 & 0 & 0 \\
\hline COBALT $(C O), U G / L$ & 3 & $<50$ & 50 & 3 & 0 & 0 \\
\hline COPPER (CU), UG/L & 3 & 10 & 180 & 3 & 3 & 9 \\
\hline IRON (FE), UG/L & 3 & 300 & 200000 & 3 & 10 & 220 \\
\hline LEAD $(P B), U G / L$ & 3 & $<100$ & 100 & 3 & 0 & 2 \\
\hline MANG ANESE (MN), UG/L & 3 & 170 & 2100 & 3 & 10 & 140 \\
\hline MERCURY (HG), UG/L & 3 & 0.1 & 1.7 & 3 & 0.1 & 1.0 \\
\hline SELENIUM $(S E), U G / L$ & 3 & 2 & 5 & 3 & 4 & 5 \\
\hline$Z I N C(Z N), U G / L$ & 3 & 50 & 490 & 3 & 0 & 30 \\
\hline \multicolumn{7}{|l|}{ PERIPHYTON : } \\
\hline BIOMASS, DRY WT., G/SQ M & 0 & & & & & \\
\hline BIOMASS, ASH WT., G/SO M & 1 & .79 & & & & \\
\hline CHLOROPHYLL A, MG/SO M & 1 & .0 & & & & \\
\hline CHLOROPHYLL $B$, MG/SO M & $i$ & .0 & & & & \\
\hline ORGANIC CARBON, MG/L & 3 & 3.8 & 27.0 & & & \\
\hline
\end{tabular}


LAT 44D36M1OS LONG 101029M24S

DRAINAGE AREA: 23900 SQ MI ( 61901 SQ KM)

PERIOD OF RECORD: $10 / 01 / 74-09 / 30 / 75$

STATISTICAL SUMMARY OF SELECTED DISSOLVED CHEMICAL CONSTITUENTS AND

REGRESSION RELATIONSHIPS OF CONSTITUENT CONCENTRATIONS TO SPECIFIC CONDUCTANCE

LONSIUIUENI

CONSILIUENI IMGLL_B UNII SHOWNI

SAMPLE

SAMPLE STANDARD

MEAN DEYLALLON

TEMPERATURE, WATER (DEG C) SPECIFIC CONDUCTANCE (MICROMHOS) STREAMFLOW (CUBIC FT/SEC)

PH (STANDARD UNITS)

PHOSPHORUS, TOTAL

NITRITE + NITRATE, TOTAL

NITROGEN, KJELDAHL, TOTAL

PHYTOPLANKTON, TOTAL (CELLS/ML)

SEDIMENT, SUSPENDED

SEDIMENT, CLAY-SILT (PERCENT)

COLIFURM, FECAL (CCL/100 ML)

STREPTOCOCCI, FECAL (COL/100 ML)

SILICA, DISSOLVED

CALCIUM, DISSOLVED

MAGNESIUM, DISSOLVED

SODIUM, DISSOLVED

POTASSIUM, DISSOLVED

BICARBONATE, ION

CARGONATE, ION

SULFATE, DISSOLVED

CHLORIDE, DISSOLVED

DISSULVED SOLIDS, SUM OF CONST

DISSOLVED SULIDS, ROE 180 DEG HARDNESS, TOTAL

HARONESS, NCNCARBONATE

TURBIDITY (JTU)

FLOUR IDE, DISSOLVED

9.38

765.1
2226.8

$1460.4 \quad 2226.8$

8.31

0.406

0.837

1.752

11430.8

16595.6

0.54
0.549

0.549

0.832
2.084

19451.6

10022.0

$1815.7 \quad 3659.7$

$7.25 \quad 2.29$

$145.92 \quad 97.86$

145.92

61.79
225.38

225.38
12.36

12.36
195.8

0.0

845.38

57.62
1454.3

1454.3

1571.0

617.4

462.5

162.8

31.45

95.62
4.06

4.06
75.2

0.0
50.54

350.54
63.67

584.7

641.8

641.8
340.0

340.0

309.3

379.7
0.12
$1708.9 \quad 3831.0$

nfidence level.

\section{DURAIION IABLE_OF_DAILY SPECIEIG CONDUCIANCE}

DAILY SPECIFIC CONDUCTANCE IN

MICROMHOS AT 25 DEG C, THAT WAS

EQUALLED OR EXCEEDED FCR THE

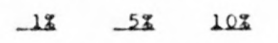

20:

$30 \%$

3400

INDICATED PERCENTAGE OF TIME
$0.0 \quad 30.5$

610
42

$\begin{array}{rr}42 & 7120 \\ 7.4 & 9.2\end{array}$

0.02

0.01

$570 \quad 70000$

30700

11600

$\begin{array}{rr}1 & 12600 \\ 3 & 12600\end{array}$

$\begin{array}{rr}3.8 & 13.0 \\ 18.0 & 300.0\end{array}$

0.3

120.0

4.6
96

190.0

3.1

396

46
0
2

2
0.2

300.0
110.0

360.0

2300

1400

$19.0 \quad 13$

$361 \quad 13$

$\begin{array}{rr}0 & 10 \\ 1200.0 & 13 \\ 240.0 & 13\end{array}$

$2320 \quad 13$

13

1200
$910 \quad 13$
1400 $\begin{array}{ll} & \text { REGRESSICN } \\ \text { SAMPLE COEFICIENT, }\end{array}$

EGRESSION SUMMARY

COEFICIENT, CONSTANT,

CORRELATION

STANDARD

SIZE - B - - B _ COEEICIENI

ERROR CF

ESILIMAIE

SUMMARY OF HARMUNIC ANALYSIS OF STREAM TEMPERATURE

EOBM_OE EQUALON: I. $101 \equiv M \pm A+S I N C .0272 * 0+C)$

\begin{tabular}{|c|c|c|c|c|c|}
\hline & & & & & STANDARD \\
\hline & HARMONIC & AMPLITUDE & PHASE & VARIATICN & ERRCR OF \\
\hline SAMPLE & MEAN - M & $-A$ & ANGLE $-C$ & EXPLAINED & ESTIMATE \\
\hline SLZE & $10 E G \quad 61$ & (DEG $C)$ & (RADLANS) & $\ldots(8)$ & $10 E G(1)$ \\
\hline
\end{tabular}

278

10.33

11.43

2.62

3.86

SUMMARY OF MAXIMUM AND MINIMUM CONCENTRATIONS OF CONSTITUENTS SAMPLED AT A FREQUENCY OF QUARTERLY (1975 WY)

00439300 -- CHEYENNE RIVER AT CHERRY CREEK,S.D.

\begin{tabular}{|c|c|c|c|c|c|c|}
\hline \multirow{2}{*}{ CONSTITUENT } & \multicolumn{3}{|c|}{ TOTAL } & \multicolumn{3}{|c|}{ DISSOLVED } \\
\hline & $\begin{array}{l}\text { NO. } \\
\text { SAMPLES }\end{array}$ & $\begin{array}{l}\text { MIN IMUM } \\
\text { CONC. }\end{array}$ & $\begin{array}{l}\text { MAXIMUM } \\
\text { CONC. }\end{array}$ & $\begin{array}{l}\text { NO. } \\
\text { SAMPLES }\end{array}$ & $\begin{array}{l}\text { MINIMUM } \\
\text { CONC. }\end{array}$ & $\begin{array}{l}\text { MAXIMUM } \\
\text { CONC. }\end{array}$ \\
\hline \multicolumn{7}{|l|}{ MINOR ELEMENTS: } \\
\hline ARSENIC (AS), UG/L & 4 & 19 & 85 & 4 & 3 & 20 \\
\hline CADMIUM $(C D), U G / L$ & 4 & $<10$ & 20 & 4 & 0 & 1 \\
\hline CHROMIUM (CR), UGIL & 4 & 0 & 20 & 4 & 0 & 0 \\
\hline COBALT $(C O), U G / L$ & 4 & $<50$ & $<50$ & 4 & 0 & 0 \\
\hline COPPER (CU), UG/L & 4 & $<10$ & 30 & 4 & 2 & 4 \\
\hline IRON $(F E), U G / L$ & 4 & 230 & 17000 & 4 & 10 & 60 \\
\hline LEAD $(P B), U G / L$ & 4 & $<100$ & 400 & 4 & 4 & 10 \\
\hline MANGANESE (MN), UG/L & 3 & 60 & 540 & 4 & 0 & 20 \\
\hline MERCURY (HG), UG/L & 4 & 0.0 & 0.1 & 4 & 0.0 & 0.3 \\
\hline SELENIUM (SE), UG/L & 4 & 3 & 4 & 4 & 1 & 4 \\
\hline $\mathrm{ZINC}(Z N), \mathrm{UG} / \mathrm{L}$ & 4 & 30 & 120 & 4 & 0 & 30 \\
\hline \multicolumn{7}{|l|}{ PERIPHYTON: } \\
\hline BIOMASS, DRY WT., G/SQ M & 3 & .50 & 130.00 & & & \\
\hline BIOMASS, ASH WT., G/SO M & 4 & .50 & 120.00 & & & \\
\hline CHLOROPHYLL A, MG/SO M & 4 & .0 & 51.0 & & & \\
\hline CHLOROPHYLL B, MG/SQ M & 4 & .0 & 2.1 & & & \\
\hline ORGANIC CARBON, MG/L & 4 & 4.0 & 9.1 & & & \\
\hline
\end{tabular}


Tab1e 14.--Summary of measurements at each station--Continued

LAT 44D22M25S LONG 100D22M2US

DRAINAGE AREA: 243500 SQ MI ( 630665 SQ KM)

PERIOD GF RECORD: 10/01/74 - 09/30/75

STATISTICAL SUMMARY OF SELECTED DISSOLVED CHEMICAL CONSTITUENTS AND

REGRESSION RELATIONSHIPS OF CONSTITUENT CONCENTRATIONS TO SPECIFIC CONDUCTANCE

CONSIIIUENI

CONSIUIUENI
TEMPERATURE, WATER (DEG C)
SPECIFIC CCNDUCTANCE (MICROMHOS)
STREAMFLOW (CUBIC FI/SEC)
PH (STANDARD UNITS)
PHOSPHORUS, TOTAL
NITRITE, NITRATE, TOTAL
NITRCGEN, KJELDAHL, TOTAL
PHYTOPLANKTON, TOTAL (CELLS/ML)
SEDIMENT, SUSPENDED
SEDIMENT, CLAY-SILT (PERCENT)
COLIFORM, FECAL (COL/IOO ML)
STREPTOCOCCI, FECAL (COL/IOU ML)
SILICA, DISSOLVED
CALCIUM, DISSOLVED
MAGNESIUM, UISSOLVED
SODIUM, DISSOLVED
POTASSIUM, DISSULVED
BICARGONATE, ION
CARBONATE, ION
SULFATE, DISSOLVED
CHLCRIDE, DISSOLVED
DISSOLVED SOLIDS, SUM OF CONST
DISSOLVE SOLIDS, ROE I8O DEG C
HARDNESS, TOTAL
HARDNESS, NONCARBONATE
TURBIDITY (JTU)
FLOURIDE, OISSOLVED

CONSIIIUENT IMG L OR UNII_SHOHNI

SAMPLE
S1ZE
20
18
18
16
16
12
12
11
10
0
10
9
16
16
16
16
16
16
15
16
16
16
10
16
16
10
16

0.038

1320

132.0
181.9

16.6

0.06

28.11

6.95
57.86

0.45

9.9

9.64

1.32

36.7

24.4

95.0

39.6

1.9

*Not significant at the 95 percent confidence level.

QURAIION IABLE_OF_DAILY SPECIEIC CONDUCIANCE

QURAIION IABLE_OF_DALY SPECIEIC CONDUCIANCE
DAILY SPECIFIC CONDUCTANCE IN
MICROMHOS AT 25 DEG C, THAT WAS
EUUALLED OR EXCEEDE FOR THE

BEGRESS ION SUMMABY

REGRESSION

SAMPLE COEFICIENT.

CONSTANT,

CORRELATION

STANDARO ESIIMAIE

0.0

$650 \quad 22.0$

$\begin{array}{rr}11100 & 870\end{array}$

0.05

0.13

0.18

0.57
480

17
16
16

-119.864
0.0060

$-0.00004$

0.00021

135268.125

$-0.565$

0.550 .

0.05690

$-0.05718$

0.64807

296.516

-0.136
0.365

$-0.246^{*}$

-0.091 *

11531.4

0.59

0.018

0.122

0.122
138.6

$9.6 \quad 12.5$

0
0
5.4
1.1
0.5
65.0
3.9
181
0
190.0
9.2
448
455
5
0
2
0.4

630

$-0.184$

296.516

\begin{tabular}{|c|c|c|c|c|}
\hline \multirow{2}{*}{\multicolumn{5}{|c|}{40}} \\
\hline & & & & \\
\hline 50 & & & & \\
\hline $\begin{array}{r}8.0 \\
65.0\end{array}$ & 16 & & 0019 & \\
\hline 65.0 & 16 & & 3108 & 26 \\
\hline 23.0 & 16 & & 0666 & \\
\hline 240.0 & 16 & & 6962 & -4 \\
\hline 5.9 & 16 & & 0007 & \\
\hline 211 & 16 & & .110 & \\
\hline 7 & 15 & & .005 & \\
\hline 230.0 & 16 & & 0884 & 1 \\
\hline 14.0 & 16 & & 0003 & \\
\hline 576 & 16 & & .455 & \\
\hline 530 & 10 & & .308 & \\
\hline 260 & 16 & & .051 & \\
\hline 91 & 16 & & .426 & \\
\hline 7 & 10 & & .006 & \\
\hline 0.6 & 16 & & 0001 & \\
\hline & & SAM & 512 & 365 \\
\hline 502 & 703 & $20 \%$ & $25 \%$ & 298 \\
\hline 760 & 755 & 720 & 710 & 700 \\
\hline
\end{tabular}

SUMMARY OF HARMONIC ANALYSIS OF STREAM TEMPERATURE

\begin{tabular}{|c|c|c|c|c|c|}
\hline & & & & & STANDARD \\
\hline & HARMONIC & AMPLITUDE & PHASE & VARIATION & ERROR OF \\
\hline SAMPLE & MEAN - M & $-A$ & ANGLE - C & EXPLAINED & ESTIMATE \\
\hline SIZE & DEEG C) & (DEG $(1)$ & (BAD IANS) & (2) & $10 E E_{C} C 1$ \\
\hline 305 & 9.81 & 9.82 & 2.29 & 97 & 1.17 \\
\hline
\end{tabular}

SUMMARY OF MAXIMUM AND MINIMUM CONCENTRATIONS OF CONSIITUENTS SAMPLED AT A FREQUENCY OF QUARTERLY (1975 WY)

06440000 -- MISSOURI RIVER AT PIERRE S DAK

\begin{tabular}{|c|c|c|c|c|c|c|}
\hline \multirow{2}{*}{ CONSTI TUENT } & \multicolumn{3}{|c|}{ TOTAL } & \multicolumn{3}{|c|}{ DISSOLVED } \\
\hline & $\begin{array}{l}\text { NO. } \\
\text { SAMPLES }\end{array}$ & $\begin{array}{l}\text { MIN IMUM } \\
\text { CONC. }\end{array}$ & $\begin{array}{l}\text { MAXIMUM } \\
\text { CONC. }\end{array}$ & $\begin{array}{l}\text { NO. } \\
\text { SAMPLES }\end{array}$ & $\begin{array}{l}\text { MINIMUM } \\
\text { CONC. }\end{array}$ & $\begin{array}{l}\text { MAXIMUM } \\
\text { CONC. }\end{array}$ \\
\hline \multicolumn{7}{|l|}{ MINOR ELEMENTS: } \\
\hline ARSENIC (AS), UG/L & 5 & 1 & 3 & 5 & 1 & 3 \\
\hline CADMIUM $(C D), U G / L$ & 5 & $<10$ & 10 & 5 & 0 & 1 \\
\hline CHROMIUM (CR), UG/L & 5 & 0 & 20 & 5 & 0 & 20 \\
\hline COBALT $(C O), U G / L$ & 5 & $<50$ & 50 & 5 & 0 & 1 \\
\hline COPPER (CU), UG/L & 5 & $<10$ & 470 & 5 & 2 & 6 \\
\hline IRON (FE), UG/L & 5 & 0 & 310 & 5 & 0 & 20 \\
\hline$L E A D(P B), U G / L$ & 5 & $<100$ & $<100$ & 5 & 1 & 7 \\
\hline MANGANESE (MN), UG/L & 4 & 0 & 60 & 5 & 0 & 20 \\
\hline MERCURY $(H G), U G / L$ & 5 & 0.0 & 0.1 & 5 & 0.0 & 0.0 \\
\hline SELENIUM (SE), UG/L & 5 & 1 & 2 & 5 & 1 & 2 \\
\hline ZINC $(2 N), U G / L$ & 5 & 0 & 70 & 5 & 0 & 7 \\
\hline \multicolumn{7}{|l|}{ PERIPHYTON: } \\
\hline BIOMASS, DRY WT., G/SQ M & 3 & .19 & 2.39 & & & \\
\hline BIOMASS, ASH WT., G/SO M & 4 & .09 & 2.29 & & & \\
\hline CHLOROPHYLL A, MG/SO M & 4 & .0 & 1.8 & & & \\
\hline CHLOROPHYLL $B$, MG/SO M & 4 & .0 & .5 & & & \\
\hline ORGANIC CARBON, MG/L & 5 & 2.1 & 3.8 & & & \\
\hline
\end{tabular}


Table 14.--Summary of measurements at each station--Continued

LAT 43044M54S LONG 099033M22S

DRAINAGE AREA: 10200 SQ MI 126418 SO KMI

PERIOD OF RECORD: $10 / 01 / 74-09 / 30 / 75$

STATISTICAL SUMMARY OF SELECTED DISSOLVED CHEMICAL CONSTITUENTS AND REGRESSION RELATIONSHIPS OF CONSTITUENT CONCENTRATIONS TO SPECIFIC CONDUCTANCE

CONSIULUENI

CONSIIIUENI CMG/L_OB_UNII SHOWN

SAMPLE

SUZE

IEMPERATURE, WATER (DEG C)

STREAMFLOW (CUBIC FT/SEC)

PH (STANDARD UNITS)

PHOSPHORUS, TOTAL

NITRITE + NITRATE, TOTAL

NITROGEN, KJELDAHL, TOTAL

PHYTOPLANKTON, TOTAL (CELLS/ML)

SEDIMENT, SUSPENDED

SEDIMENT, CLAY-SILT (PERCENT)

COLIFCRM, FECAL (COL/100 ML)

STREPTOCOCCI, FECAL (COL/1GO ML)

SILICA, DISSOLVED

CALCIUM, DISSOLVEO

MAGNESIUM, DISSOLVED

SODIUM, DISSOLVED

POTASSIUM, DISSOLVED

BICAR LCNATE, ION

CARBONATE, ION

SULFATE, DISSOLVED

CHLORIDE, DISSOLVED

DISSOLVED SOLIDS, ROE 180 DEG

HARUNESS, TOTAL

HARDNESS, NONCARBONATE

TURBIDITY (JTU)

FLOURIDE, DISSOLVED

*Not significant at the 95 percent confidence level.

DURALION IABLE OF DALY SPECIEIC CONDUCIANCE

DAILY SPECIFIC CONUUCTANCE IN

MICROMHOS AT 25 DEG C, THAT WAS

EQUALLED OR EXCEEDED FOR THE

INDICATED PERCENTAGE OF TIME

950

830

795

$20 \%$

680

\section{$30 x$}

650
SPECIFIC CONDUCTANCE (MICROMHUS)

DISSOLVED SOLIDS, SUM OF CONST

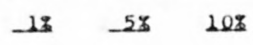

BANGE

0.0

480

$7.2 \quad 3200$

$0.12 \quad 18.00$

0.02

0.27

5110

1.90
8.00

60000

55100

$\begin{array}{rr}0 & 6600 \\ 10 & 120000\end{array}$

$\begin{array}{rr}10 & 120000 \\ 22.0 & 70.0\end{array}$

$1.2 \quad 210.0$

$41.0 \quad 290.0$

4.3

1.70

157.6

34.51

281.59

273.3

151.2

112.4

348.2

0
45.0

45.0
5.8
272

272
307

5
0

10
0.3
BEGRESS ION SUMMABY REGRESSION

SAMPLE COEFICIENT,

CONSTANT,

CORRELATION ION ERROR OF SIZE

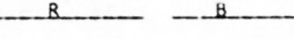

COEFICIENI

ESIUMALE

$\begin{array}{rrrrr}12 & -0.223 & 232.242 & -0.222 * & 86.7 \\ 12 & -0.0001 & 8.4832 & -0.010 * & 0.74 \\ 12 & -0.00778 & 10.49593 & -0.092 * & 7.440 \\ 12 & -0.00017 & 0.88587 & -0.027 * & 0.577 \\ 12 & 0.00739 & -2.30532 & 0.290 * & 2.153 \\ 11 & 274.556 & -125654.188 & 0.484 * & 45764.7\end{array}$

SUMMARY OF HARMONIC ANALYSIS OF STREAM TEMPERATURE.

\begin{tabular}{|c|c|c|c|c|c|}
\hline & & & & & STANDARD \\
\hline & HARMONIC & AMPLITUDE & PHASE & VAR IATION & ERROR OF \\
\hline SAMPLE & $M E A N$ - $M$ & $-A$ & ANGLE - C & EXPLAINED & ESTIMATE \\
\hline SILE_ & (DEG C) & IDEG $C 1$ & IBADLANSI & -121 & WEE $C 1$ \\
\hline 349 & 11.10 & 13.32 & 2.69 & 91 & 3.07 \\
\hline
\end{tabular}

SUMMARY OF MAXIMUM AND MINIMUM CONCENTRATIONS OF CONSTITUENTS

SAMPLED AT A FREQUENCY OF QUARTERLY (1975 WY)

U6452000 -- WHITE RIVER NEAR OACOMA S DAK

\begin{tabular}{|c|c|c|c|c|c|c|}
\hline \multirow{2}{*}{ CONSTITUENT } & \multicolumn{3}{|c|}{ TOTAL } & \multicolumn{3}{|c|}{ DISSOLVED } \\
\hline & $\begin{array}{l}\text { NO. } \\
\text { SAMPLES }\end{array}$ & $\begin{array}{l}\text { MINIMUM } \\
\text { CONC. }\end{array}$ & $\begin{array}{l}\text { MAXIMUM } \\
\text { CONC. }\end{array}$ & $\begin{array}{l}\text { NO. } \\
\text { SAMPLES }\end{array}$ & $\begin{array}{l}\text { MINIMUM } \\
\text { CONC. }\end{array}$ & $\begin{array}{l}\text { MAXIMUM } \\
\text { CONC. }\end{array}$ \\
\hline \multicolumn{7}{|l|}{ MINUR ELEMENTS: } \\
\hline ARSENIC (AS), UG/L & 5 & 7 & 220 & 5 & 7 & 38 \\
\hline CADMIUM $(C D), U G / L$ & 4 & 0 & 20 & 5 & 0 & $<1$ \\
\hline CHROMIUM (CR), UG/L & 4 & 20 & 170 & 5 & 0 & 0 \\
\hline COBALT $(C O), U G / L$ & 4 & $<50$ & 150 & 5 & 0 & 2 \\
\hline COPPER $(C U), U G / L$ & 4 & 10 & 370 & 5 & 3 & 35 \\
\hline IRON $(F E), U G / L$ & 4 & 1100 & 180000 & 5 & 10 & 360 \\
\hline LEAD $(P B), U G / L$ & 4 & $<100$ & 600 & 5 & 0 & 5 \\
\hline MANG ANESE (MN), UG/L & 4 & 30 & 8000 & 5 & 0 & 10 \\
\hline MERCURY (HG), UG/L & 4 & 0.0 & 0.3 & 4 & 0.0 & 0.0 \\
\hline SELENIUM (SE), UG/L & 5 & 2 & 4 & 3 & 2 & 3 \\
\hline ZINC $(Z N), U G / L$ & 4 & 40 & 550 & 5 & 0 & 20 \\
\hline \multicolumn{7}{|l|}{ PERIPHYTON: } \\
\hline BIOMASS, DRY WT., G/SQ M & 2 & 1.50 & 30.00 & & & \\
\hline BICMASS, ASH WT., G/SQ M & 3 & 1.39 & 13.00 & & & \\
\hline CHLOROPHYLL A, MG/SO M & 3 & .1 & 13.0 & & & \\
\hline CHLOROPHYLL E, MG/SO M & 3 & .0 & 3.8 & & & \\
\hline ORGANIC CARBON, MG/L & 4 & 5.5 & 46.0 & & & \\
\hline
\end{tabular}


Table 14.--Summary of measurements at each station--Continued

LAT $43003 M 54 S$ LONG 098033M11S

DRAINAGE AREA: 263500 SQ MI 1682465 SO KMI

PERIOD OF RECORD: $10 / 01 / 74-09 / 30 / 75$

STATISTICAL SUMMARY OF SELECTED DISSOLVED CHEMICAL CONSTITUENTS AND

REGRESSION RELATIONSHIPS OF CONSTITUENT CONCENTRATIONS TO SPECIFIC CONDUCTANCE

CONSIIIUENI

TEMPERATURE, WATER (DEG C)
SPECIFIC CONDUCTANCE (MICROMHOS)
SIREAMFLOW (CUBIC FT/SEC)
PH (STANDARD UNITS)
PHOSPHORUS, TOTAL
NITRITE, NITRATE, TOTAL
NITROGEN, KJELDAHL, TOTAL
PHYTOPLANKTON, TOTAL (CELLS/ML)
SEDIMENT, SUSPENDED
SEDIMENT, CLAY-SILT (PERCENT)
COLIFORM, FECAL (COL/IOO ML)
STREPTOCOCCI, FECAL (COL/IOO ML)
SILICA, DISSOLVED
CALCIUM, DISSOLVED
MAGNESIUM, DISSOLVED
SODIUM, OISSOLVED
POTASSIUM, DISSOLVED
BICARBONATE, ION
CARBONATE, ION
SULFATE, DISSOLVED
CHLORIDE, DISSOLVED
DISSOLVED SOLIDS, SUM OF CONST
DISSOLVED SOLIDS, ROE IBO DEG C
HARUNESS, TOTAL
HARDNESS, NONCARBONATE
TURBIDITY IJTU)
FLOURIDE, DISSOLVED

CONSIIIUENT IMG/L OR UNII SHOWNI \begin{tabular}{l} 
SAMPLE \\
SIZE \\
\hline
\end{tabular}

12
12
12
12
12
12
12
11
9
0
8
8
12
12
12
12
12
12
8
12
12
12
12
12
12
12
12

STANDARD MEAN REYIALION 9.92 662.5 36908.3 8.29 0.010 0.129 0.269 0.269

946.1

$60 \cdot 3$

0.3
1.4
6.42

6.42
03.00 22.50 69.92

4.78

187.3

0.1

204.17

11.67

471.2

500.6

236.7
82.3

82.3

4.2
0.47

8.56 68.8

14481.7 0.31 0.006 0.307 0.122 1212.0 1212.0
18.4

0.5

2. 3

1.95
156.55

156.55

1.83

0.91

25.4

9.04

9.00
2.15

2.15
16.9

16.9
10.7

9.8
17.6

17.6
2.3

2.3
0.14

\section{BANGE}

0.5
530

$530 \quad 23.0$

$13000 \quad 60000$

0.00

0.01

0.04

0.04
8

0.02

$1.10 \quad 12$

$2900 \quad 12$

2900
98

$\begin{array}{rr}0 & 1 \\ 0 & 5 \\ 4.7 & 12.0 \\ 52.0 & 600.0 \\ 21.0 & 24.0\end{array}$

67.0

2.5

110

190.0

10.0
435

435
485

485
220

60

0.1

$73.0 \quad 12$

$6.6 \quad 12$

$\begin{array}{rr}205 & 12 \\ 1 & 8\end{array}$

$220.0 \quad 12$

$18.0 \quad 12$

$\begin{array}{ll}491 & 12 \\ 520 & 12\end{array}$

$250 \quad 12$

$130 \quad 12$

$0.6 \quad 12$
BEGBESS DON_SUMMABY

REGRESSION

SAMPLE COEFICIENT, CONSTANT, CTANDARD SIZE - B - B - B COEEICIENI ESIIMAIE

$\begin{array}{rr}2.993 & 34925.465 \\ 0.0006 & 7.9069 \\ -0.00001 & 0.01764 \\ -0.00283 & 2.00584 \\ -0.00080 & 0.80239 \\ -6.232 & 5087.293\end{array}$

-0.0141
0.4746
0.0007

0.0087

0.0001

0.013

0.002

$-0.0015$

0.005

$-0.007$

$-0.056$

$-0.078$

$-0.002$

0.0013
0.014 *

0.129 *

-0.132 *

$-0.635$

-0.454 *

-0.369 *

$-211.4067$

22.0543

64.1544

4.7261

78.81

178.81

200.6520

12.6854

68.04

505.388

273.596

133.792

5.758

$-0.3623$
-0.499 .

0.208 *

0.058 *

0.007 *

0.034 *

0.305 .

0.305 *

-0.049 .

0.019 *

-0.047 *

-0.389 *

-0.305 *

-0.071 *

0.641
15186.8 0.32

0.006

0.249

1187.4

1.77
100.58
0.84
1.82
0.96
26.7
0.4
9.43
2.25
17.7
11.2
9.5
17.5
2.4
0.4

*Not significant at the 95 percent confidence level.

DAILY SPECIFIC CONDUCTANCE IN DURALON IABLE_OE DAILY SPECIEIC CONDUCIANCE

MICROMHOS AT 25 DEG C, THAT WAS

EQUALLED OR EXCEEDED FOR THE

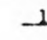

$202 \quad 302 \quad 502$

SAMPLE SIZE $=365$
$70 z \quad 20 \% \quad 25 \% \quad 998$

$\begin{array}{llllll}847 & 832 & 830 & 822 & 797 & 779\end{array}$

720

702

SUMMARY OF HARMONIC ANALYSIS OF STREAM TEMPERATURE

\begin{tabular}{|c|c|c|c|c|c|}
\hline & & & & & STANDARD \\
\hline & HARMONIC & AMPLITUDE & PHASE & VARIATION & ERROR OF \\
\hline SAMPLE & MEAN - M & $-A$ & ANGLE - C & EXPLAINED & ESTIMATE \\
\hline SIZE_ & $14 E G \mathrm{Cl}$ & LEEG $(1)$ & IBAD IANS & -132 & (DEG_C) \\
\hline 364 & 10.31 & 12.05 & 2.36 & 95 & 1.88 \\
\hline
\end{tabular}

SUMMARY OF MAXIMUM AND MINIMUM CONCENTRATIONS OF CONSTITUENTS SAMPLED AT A FREQUENCY OF QUARTERLY (1975 WY)

06453000 -- MISSOURI RIVER AT FORT RANDALL DAM,S.DAK.

CONSTI TUENT
SAMPLES


LAT 42044M25S LONG 098D12M45S

DRAINAGE AREA: 12600 SQ MI ( 32634 SQ KM)

PERIOD OF RECORD: $10 / 01 / 74-09 / 30 / 75$

STATISTICAL SUMMARY OF SELECTED DISSOLVEO CHEMICAL CONSTITUENTS AND

REGRESSION RELATIONSHIPS OF CONSTITUENT CONCENTRATIONS TO SPECIFIC CONDUCTANCE

CONSILIUENI

CONSIUTUENI IHG/L OR UNII SHOWNL

SAM
$S I$
1
1
1
3
1
1
1
1
1
1
1

1
1

STANDARD

SIZE MEAN DEYIALION

TEMPERATURE, WATER (DEG C)

SPECIFIC CONDUCTANCE IMICROMHOS

STREAMFLOW (CUBIC FT/SEC)

PH (STANDARD UNITS)

PHOSPHORUS, TOTAL

NITRITE + NITRATE, TOTAL

NITROGEN, KJELDAHL, TOTAL

PHYTOPLANKTON, TOTAL (CELLS/ML)

SEDIMENT, SUSPENDED

SEDIMENT, CLAY-SILT (PERCENT

COLIFURM, FECAL (COL/100 ML)

STREP TOCOCCI, FECAL (COL/100 ML)

SILICA, DISSOLVED

CALCIUM, DISSOL VED

MAGNESIUM, DISSOLVED

SUDIUM, DISSOLVED

POTASSIUM, DISSCLVED

BICARBONATE, ION

CARBONATE, ION

SULFATE, DISSCLVED

CHLORIDE, DISSOLVED

DISSOLVED SOLIDS, SUM OF CONST

DISSOLVED SOLIDS, ROE 180 DEG C

HARDNESS, TUTAL

HARDNESS, NONCARBONATE

TURBIDITY (JTU)

FLOURIDE, DISSOLVED ${ }^{*}$ Not significant at the 95 percent confidence level.

$9.93 \quad 10.71$

$\begin{array}{rr}959.0 & 15.8\end{array}$

1162.0

7.52

$0.425 \quad 0.074$

0.387

0.806

31167.8

33234.4

$3234 \cdot 4$

34.0

31.2

136.0

49.29

36.29

4.46

97.3

5.68

3.64

0.54

9.90

6.80
141.0

0.60

1.04
6.2

6.2
0.0

0.0
15.60

15.60
1.74

1.74
195.1

191.8

110.7

0.7

38.0

4.30

0.34

11.6
7.8

11.6

1.9

20.6

0.06
BEGRESSION SUMMARY

REGRESSION

SAMPLE COEFICIENT, CONSTANT, CORRELATION SIZE -B - B B COEEICIENI ESIIMAIE

BANGE

0.5
233

$233 \quad 27.0$

$\begin{array}{ll}554 & 2450 \\ 7.1 & 7.9\end{array}$

0.10

0.01

0.23

470
.23

470
244

0.33

2.90

2.90
95000

95000
1300

$\begin{array}{rr}8 & 100 \\ 44 & 340\end{array}$

$\begin{array}{rr}44 & 340 \\ 41.0 & 57.0 \\ 32.0 & 42.0 \\ 3.7\end{array}$

3.7

9.0

5.0
132

132
0
9.2

9.2
1.3

1.3
179

178
97

0
15

0.3

$5 \cdot 1$

11.0

149

149
22.0

22.0
2.6

2.6
208
206

206
130

5
75
0.5

0.5

11
11
11
11
11
9

9.058
-0.0053
-0.00074
0.00757
-0.01479 8.8956
0.38447
4.53474

$-1492.702$

$-0.362 *$

0.308 *

$-0.313 *$

$-0.691$

540.4

0.23

0.388

0.746

5679.4

DURAILON IABLE OE DAILY SPECIEIC CONDUCIANCE

DAILY SPECIFIC CONDUCTANCE IN

MICROMHOS AT 25 DEG C, THAT WAS

EQUALLED OR EXCEEDED FOR THE

$18 \quad 5 \% \quad 20 \pi$

$20 \%$

$30 \%$

503

362

322

292

280

271

$257 \quad 248$

SUMMARY OF HARMONIC ANALYSIS OF STREAM TEMPERATURE

\begin{tabular}{|c|c|c|c|c|c|}
\hline & & & & & STANDARD \\
\hline & HARMONIC & AMPLITUDE & PHASE & VARIATION & ERROR OF \\
\hline $\begin{array}{l}\text { SAMPLE } \\
\text { SIZE }\end{array}$ & $\begin{array}{l}\text { MEAN - M } \\
\text { (DEG } E)\end{array}$ & $\begin{array}{c}-A \\
(D E G(C)\end{array}$ & $\begin{array}{l}\text { ANGLE - C } \\
\text { IBADIANSII }\end{array}$ & $\begin{array}{l}\text { EXPLA INED } \\
(z)\end{array}$ & $\begin{array}{l}\text { ESTIMATE } \\
\text { IDEG CLI }\end{array}$ \\
\hline 270 & 13.21 & 14.35 & 2.69 & 93 & 3.03 \\
\hline
\end{tabular}

SUMMARY OF MAXIMUM AND MINIMUM CONCENTRATIONS OF CONSTITUENTS SAMPLED AT A FREQUENCY OF QUARTERLY (1975 WY)

06465500 -- NIOBRARA RIVER NR. VERDEL, NEBR.

\begin{tabular}{|c|c|c|c|c|c|c|}
\hline \multirow{2}{*}{ CONSTITUENT } & \multicolumn{3}{|c|}{ TOTAL } & \multicolumn{3}{|c|}{ DISSOLVED } \\
\hline & $\begin{array}{l}\text { NO. } \\
\text { SAMPLES }\end{array}$ & $\begin{array}{l}\text { MIN IMUM } \\
\text { CONC. }\end{array}$ & $\begin{array}{l}\text { MAXIMUM } \\
\text { CONC. }\end{array}$ & $\begin{array}{l}\text { NO. } \\
\text { SAMPLES }\end{array}$ & $\begin{array}{l}\text { MINIMUM } \\
\text { CONC. }\end{array}$ & $\begin{array}{l}\text { MAXIMUM } \\
\text { CONC. }\end{array}$ \\
\hline \multicolumn{7}{|l|}{ MINOR ELEMENTS: } \\
\hline ARSENIC (AS), UG/L & 3 & 9 & 10 & 3 & 3 & 9 \\
\hline CADMIUM $(C D)$, UG/L & 3 & $<10$ & $<10$ & 3 & 0 & 3 \\
\hline CHROMIUM (CR), UG/L & 3 & 0 & 10 & 3 & 0 & 20 \\
\hline COBALT $(C O), U G / L$ & 3 & $<50$ & 100 & 3 & 0 & 0 \\
\hline COPPER $(C U), U G / L$ & 3 & 10 & 20 & 3 & 1 & 23 \\
\hline IRON $(F E), U G / L$ & 3 & 1300 & 11000 & 7 & 10 & 110 \\
\hline$L E A D(P B), U G / L$ & 3 & $<100$ & $<100$ & 3 & 2 & 7 \\
\hline MANG ANESE (MN), UG/L & 3 & 120 & 610 & 7 & 0 & 40 \\
\hline MERCURY (HG), UG/L & 3 & 0.0 & 0.0 & 3 & 0.0 & 0.0 \\
\hline SELENIUM (SE), UG/L & 3 & 1 & 4 & 3 & 1 & 1 \\
\hline$Z I N C(Z N), U G / L$ & 3 & 20 & 60 & 3 & 0 & 40 \\
\hline \multicolumn{7}{|l|}{ PERIPHYTON: } \\
\hline BIOMASS, DRY WT., G/SQ M & 4 & 1.09 & 4.79 & & & \\
\hline BIOMASS, ASH WT., G/SQ M & 4 & .89 & 2.39 & & & \\
\hline CHLOROPHYLL A, MG/SO M & 4 & .0 & 14.0 & & & \\
\hline CHLOROPHYLL B, MG/SQ M & 4 & .0 & 3.6 & & & \\
\hline ORGANIC CARBON, MG/L & 2 & 11.0 & $12 \cdot 0$ & & & \\
\hline
\end{tabular}


Table 14.--Summary of measurements at each station--Continued

LAT 43D11M09S LONG 097038M07S

DRAINAGE AREA: 21550 SQ MI 155815 SQ KM

PERIOD OF RECORD: $10 / 01 / 74-09 / 30 / 75$

STATISTICAL SUMMARY OF SELECTED DISSOLVED CHEMICAL CONSTITUENTS AND

REGRESSION RELATIONSHIPS OF CONSTITUENT CONCENTRATIONS TO SPECIFIC CONDUCTANCE

CONSIIIUENI

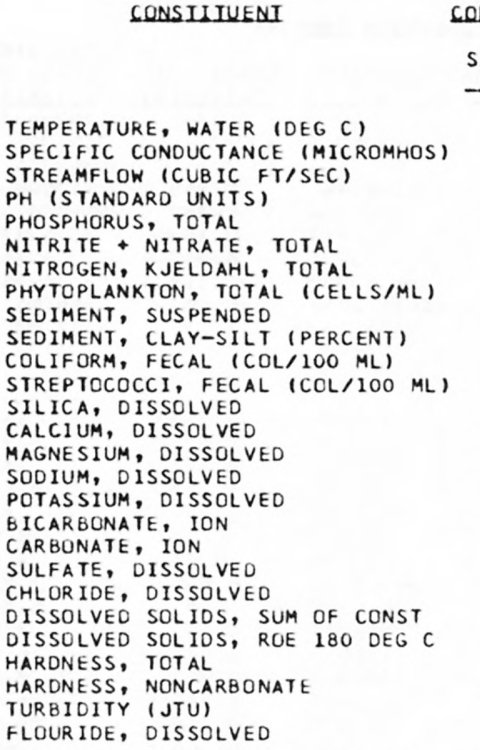

CONSIUIUENI_IMG LL_OR UNII_SHOWN

SIZE.

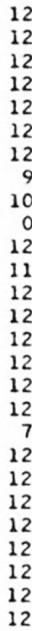

STANDARD

DEYIAIION

$10.29 \quad 10.83$

$267.6 \quad 316.7$

$8.03 \quad 0.54$

0.319

1.787

38954.4

175.0

0.329

0.546

0.662

41555.5

54.6

59.2

156.4

11.44

138.08
64.00

64.00
130.17

130.17
18.00

18.00
332.8

0.1

508.92

70.92

$1106 \cdot 2$

1187.2

613.3

334.1
13.8

13.8
0.48
$1394.2 \quad 577.3$
63.6

144.1

7.13

71.30

29.66
55.70

4.33

62.2

0.4

319.17

524.9

574.7

303.8

260.3

260.3
11.4

0.22

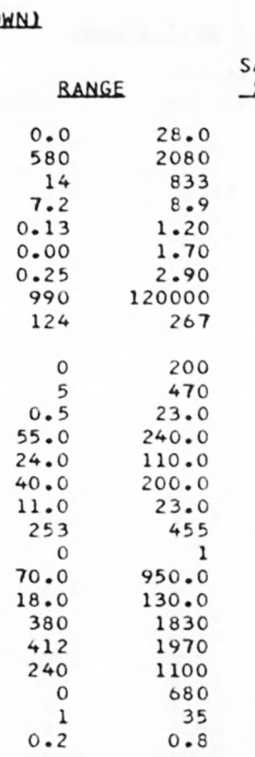

*Not significant at the 95 percent confidence level.
REGRESSION SUMYABY REGRESSION

SAMPLE COEFICIENT, CONSTANT, CORRELATION ERROR OF SLZE

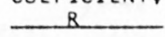

B

DAILY SPECIFIC CONDUCTANCE IN

IN

EQUALLED OR EXCEEDED FOR THE

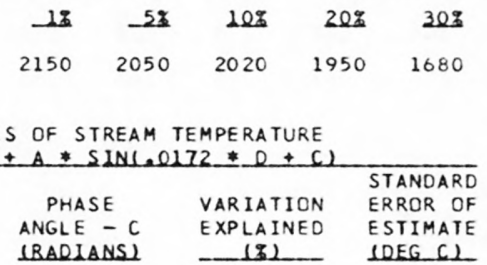

SUMMARY OF HARMONIC ANALYSIS DF STREAM TEMPERATURE

\begin{tabular}{|c|c|c|c|c|c|}
\hline & & & & & STANDARD \\
\hline & HARMONIC & AMPLITUDE & PHASE & VARIATION & ERROR OF \\
\hline $\begin{array}{l}\text { SAMPLE } \\
\text { SLZE }\end{array}$ & $\begin{array}{l}\text { MEAN - M } \\
\text { (DEG } C)^{-}\end{array}$ & ${ }_{10 E} \bar{A}^{A}(1)$ & $\begin{array}{l}\text { ANGLE - C } \\
\text { (RADIANS) }\end{array}$ & $\begin{array}{c}\text { EXPLAINED } \\
(I)\end{array}$ & $\begin{array}{l}\text { ESTIMATE } \\
\text { (DEG C) }\end{array}$ \\
\hline
\end{tabular}

365

10.56

13.45

2.81

83

4.25

SUMMARY OF MAXIMUM AND MINIMUM CONCENTRATIONS OF CONSTITUENTS

SAMPLED AT A FREQUENCY OF QUARTERLY (1975 WY)

06478500 -- JAMES RIVER NEAR SCOTLAND, S.DAK.

\begin{tabular}{|c|c|c|c|c|c|c|}
\hline \multirow{2}{*}{ CONSTITUENT } & \multicolumn{3}{|c|}{ TOTAL } & \multicolumn{3}{|c|}{ DISSOLVED } \\
\hline & $\begin{array}{l}\text { NO. } \\
\text { SAMPLES }\end{array}$ & $\begin{array}{l}\text { MIN IMUM } \\
\text { CONC. }\end{array}$ & $\begin{array}{l}\text { MAXIMUM } \\
\text { CONC. }\end{array}$ & $\begin{array}{l}\text { NO. } \\
\text { SAMPLES }\end{array}$ & $\begin{array}{l}\text { MINIMUM } \\
\text { CONC. }\end{array}$ & $\begin{array}{l}\text { MAXIMUM } \\
\text { CONC. }\end{array}$ \\
\hline \multicolumn{7}{|l|}{ MINOR ELEMENTS: } \\
\hline ARSENIC (AS), UG/L & 4 & 2 & 4 & 4 & 2 & 6 \\
\hline CADMIUM $(C D), U G / L$ & 4 & $<10$ & 30 & 4 & 0 & 2 \\
\hline CHROMIUM (CR), UG/L & 4 & 0 & 10 & 4 & 0 & 0 \\
\hline COBALT $(C O), U G / L$ & 4 & 50 & 50 & 4 & 0 & 2 \\
\hline COPPER $(C U), U G / L$ & 4 & $<10$ & 40 & 4 & 1 & 3 \\
\hline IRON (FE), UG/L & 4 & 150 & 1200 & 4 & 0 & 50 \\
\hline$L E A D(P B), U G / L$ & 4 & $<100$ & 100 & 4 & 3 & 6 \\
\hline MANGANESE (MN), UG/L & 4 & 400 & 720 & 4 & 20 & 610 \\
\hline MERCURY (HG), UG/L & 4 & 0.0 & 0.3 & 4 & 0.0 & 0.3 \\
\hline SELENIUM (SE), UG/L & 4 & 0 & 2 & 4 & 0 & 1 \\
\hline ZINC $(Z N), U G / L$ & 4 & 10 & 40 & 4 & 20 & 30 \\
\hline \multicolumn{7}{|l|}{ PERIPHYTON: } \\
\hline BIOMASS, DRY WT., G/SO M & 3 & .79 & 20.00 & & & \\
\hline BIOMASS, ASH WT., G/SO M & 3 & .39 & 10.00 & & & \\
\hline $\begin{array}{l}\text { CHLOROPHYLL A, MG/SO M } \\
\text { CHLOROPHYLL B, MG/SQ M }\end{array}$ & $\begin{array}{l}3 \\
3\end{array}$ & $\begin{array}{l}.2 \\
.0\end{array}$ & $\begin{array}{r}6.1 \\
.5\end{array}$ & & & \\
\hline ORGANIC CARBON, MG/L & 4 & 12.0 & 25.0 & & & \\
\hline
\end{tabular}


Tab1e 14.--Summary of measurements at each station--Continued

LAT 42D49M42S LONG 096033M45S

DRAINAGE AREA: 9030 SQ MI I 23388 SQ KMI

PERIOD OF RECORD: $10 / 01 / 74-09 / 30 / 75$

STATISTICAL SUMMARY OF SELECTED DISSOLVED CHEMICAL CONSTITUENTS AND

REGRESSION RELATIONSHIPS OF CONSTITUENT CONCENTRATIONS TO SPECIFIC CONDUCTANCE

CONSILIUENI

CONSIUUENI IMGLL OB_UNII_SHOWNI

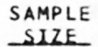

TEMPERATURE, WATER (DEG C)

SPECIFIC CONDUCTANCE (MICROMHOS)

STREAMFLOW (CUBIC FT/SEC)

PH (STANDARD UNITS)

PHOSPHORUS, TOTAL

NITRITE + NITRATE, TOTAL

NITROGEN, KJELDAHL, TOTAL

PHYTOPLANKTON, TOTAL (CELLS/ML)

SEDIMENT, SUSPENDED

SEDIMENT, CLAY-SILT (PERCENT)

COLIFORM, FECAL (COL/100 ML)

STREPTOCOCCI, FECAL (COL/100 ML)

SILICA, DISSOLVED

CALCIUM, DISSOLVED

MAGNE SIUM, DI SSOL VED

SODIUM, DISSOLVED

POTASSIUM, DISSOLVED

BICARBONATE, ION

CARBONATE, ION

SULFATE, DISSOLVED

CHLORIDE, DISSOLVED

DISSOLVED SOLIDS, SUM OF CONST
OISSOLVED SOLIDS, ROE 180 DEG

HARDNESS, TOTAL

HARDNESS, NONCARBONATE

TURBIDITY (JTU)

FLOURIDE, DISSOLVED
STANDARD

SIZE MEAN DEYIALION

12

12

12

121.841

$12 \quad 2.661$

11105863.6

10192.1

0
12
12 273.6

$\begin{array}{rr}12 & 919.5 \\ 12 & 9.05\end{array}$

89.50

38.33

54.42

245.9

245.9
0.0

196.08

196.08
66.17

66.17
582.6

582.6
618.2

381.7

180.3

21.5
0.40
128

$\begin{array}{ll}12 & 273.6 \\ 12 & 919.5\end{array}$
BES

REGRESSION

SAMPLE COEFICIENT,

SS $10 \mathrm{~N}$ SUMMABY

RANGE

SIZE B.-

CONSTANT,

CORRELATION

ST ANDARD ERROR OF ESIUMAIE

*Not significant at the 95 percent confidence level.

DURALION IABLE_OE_DALY SPECIEIC CONDUCIANCE

DAILY SPECIFIC CONDUCTANCE IN

MICROMHOS AT 25 DEG C, THAT WAS

EQUALLED OR EXCEEDED FOR THE

$\begin{array}{llllll}12 & -5 \% & 10 \% & 20 \% & 30 \% & 50 \%\end{array}$

$50 \%$

$1570 \quad 1480$

1400

1360

1280

890

785

1498.967
8.1476
-1.06812
2.42895
3.34297
13044.188

$-0.646$

$-0.120^{*}$

0.923

$-0.127^{\star}$

$-0.253^{*}$

$-0.309^{*}$

-1.223
-0.0002
0.00240
-0.00069
-0.00080

SUMMARY OF HARMONIC ANALYSIS OF STREAM TEMPERATURE

\begin{tabular}{|c|c|c|c|c|c|}
\hline & & & & & STANDARD \\
\hline $\begin{array}{l}\text { SAMPLE } \\
\text { SIZE. }\end{array}$ & $\begin{array}{l}\text { HARMONIC } \\
\text { MEAN - M } \\
\text { DEEG CI }\end{array}$ & $\begin{array}{c}\text { AMPLITUDE } \\
-A \\
\text { (DEG C) }\end{array}$ & $\begin{array}{c}\text { PHASE } \\
\text { ANGLE - C } \\
\text { [RADIANSI }\end{array}$ & $\begin{array}{l}\text { VARIATION } \\
\text { EXPLAINED } \\
(\xi)\end{array}$ & $\begin{array}{l}\text { ERROR OF } \\
\text { ESTIMATE } \\
\text { LDEG_EI }\end{array}$ \\
\hline 328 & 11.12 & 12.83 & 2.75 & 91 & 2.97 \\
\hline
\end{tabular}

SUMMARY OF MAXIMUM AND MINIMUM CONCENTRATIONS OF CONSTITUENTS SAMPLED AT A FREQUENCY OF QUARTERLY (1975 WY)

06485500 -- BIG SIOUX RIVER AT AKRON, IOWA

\begin{tabular}{|c|c|c|c|c|c|c|}
\hline \multirow{2}{*}{ CONSTITUENT } & \multicolumn{3}{|c|}{ TOTAL } & \multicolumn{3}{|c|}{ DI SSOL VEO } \\
\hline & $\begin{array}{l}\text { NO. } \\
\text { SAMPLES }\end{array}$ & $\begin{array}{l}\text { MINIMUM } \\
\text { CONC. }\end{array}$ & $\begin{array}{l}\text { MAXIMUM } \\
\text { CONC. }\end{array}$ & $\begin{array}{l}\text { NO. } \\
\text { SAMPLES }\end{array}$ & $\begin{array}{l}\text { MINIMUM } \\
\text { CONC. }\end{array}$ & $\begin{array}{l}\text { MAXIMUM } \\
\text { CONC. }\end{array}$ \\
\hline \multicolumn{7}{|l|}{ MINOR ELEMENTS: } \\
\hline ARSENIC (AS), UG/L & 4 & 3 & 13 & 4 & 0 & 9 \\
\hline CADMIUM $(C D), U G / L$ & 4 & $<10$ & 20 & 4 & 0 & 1 \\
\hline CHROMIUM (CR), UG/L & 4 & 0 & 10 & 4 & 0 & 0 \\
\hline COBALT $(C O)$, UG/L & 4 & $<50$ & $<50$ & 4 & 0 & 1 \\
\hline COPPER (CU), UG/L & 4 & $<10$ & 30 & 4 & 1 & 3 \\
\hline IRON (FE), UG/L & 4 & 650 & 9200 & 4 & 0 & 50 \\
\hline LEAD $(P B), U G / L$ & 4 & $<100$ & 100 & 4 & 2 & 9 \\
\hline MANGANESE (MN), UG/L & 4 & 310 & 1600 & 4 & 10 & 1500 \\
\hline MERCURY (HG), UG/L & 4 & 0.0 & 0.2 & 4 & 0.0 & 0.1 \\
\hline SELENIUM (SE), UG/L & 4 & 2 & 4 & 4 & 2 & 6 \\
\hline ZINC $(Z N), U G / L$ & 4 & 50 & 90 & 4 & 0 & 30 \\
\hline \multicolumn{7}{|l|}{ PERIPHYTON: } \\
\hline BIOMASS, DRY WT., G/SO M & 1 & 73.00 & & & & \\
\hline BIOMASS, ASH WT., G/SQ M & 1 & 34.00 & & & & \\
\hline CHLOROPHYLL A, MG/SQ M & $i$ & 22.0 & & & & \\
\hline CHLOROPHYLL B, MG/SQ M & $i$ & 2.6 & & & & \\
\hline ORGANIC CARBON, MG/L & 3 & 6.6 & 26.0 & & & \\
\hline
\end{tabular}


Table 14,--Summary of measurements at each station--Continued

LAT 42D29MIOS LONG 096024M47S

DRAINAGE AREA: 314600 SQ MI ( 814814 SQ KMI

PERIOD OF RECORD: $10 / 01 / 74-09 / 30 / 75$

STATISTICAL SUMMARY OF SELECTED DISSOLVED CHEMICAL CONSTITUENTS AND

REGRESSION RELATIONSHIPS OF CONSTITUENT CONCENTRATIONS TO SPECIFIC CONDUCTANCE

CONSIITUENI

CONSIUTUENI IHG/L OR UNII SHOWNU

\begin{tabular}{r} 
SAMP \\
S1 \\
\hline 46 \\
22 \\
46 \\
22 \\
22 \\
22 \\
22 \\
15 \\
24 \\
12 \\
22 \\
12 \\
22 \\
12 \\
12 \\
12 \\
12 \\
22 \\
22 \\
12 \\
12 \\
12 \\
22 \\
12 \\
12 \\
22 \\
12
\end{tabular}

STANDARD

MEAN DEYIALION

TEMPERATURE, WATER (DEG C) SPECIFIC CONDUCTANCE (MICROMHOS) STREAMFLOH (CUBIC FT/SEC)

PH (STANDARD UNITS)

PHOSPHORUS, TOTAL

NITRITE + NITRATE, TOTAL

NITROGEN, KJELDAHL, TOTAL

PHYTOPLANKTON, TOTAL (CELLS/ML)

SEDIMENT, SUSPENDED

SEDIMENT, CLAY-SILT (PERCENT)

COLIFORM, FECAL ( $\mathrm{COL} / 100 \mathrm{ML})$

STREPTOCOCCI, FECAL (COL/100 ML)

SILICA, DISSOLVED

CALCIUM, DISSOLVED

MAGNESIUM, DISSOL VED

SODIUM, DISSOLVED

POTASSIUM, DISSOL VED

BICARBONATE, ION

CARBONATE, ION

SULFATE, DISSOLVED

CHLORIDE, DISSOLVED

DISSOLVED SOLIDS, SUM OF CONST

DISSOLVED SOLIDS, ROE 180 DEG

HARDNESS, TOTAL

HARDNESS, NONCARBONATE

TURBIDITY (JTU)

FLOURIDE, DISSOLVED
9.90

735.7

33126.1

8.06
0.044

0.044
0.054

0.348

2698.7

375.7

38.3

305.1

305.1
86.4

86.4
8.32

8.32
59.75

21.92

67.92

5.18

186.7

2.3

201.6

10.08
469.4

469.4
487.3

240.0

82.9

21.8
0.58
9.40

57.3

14021.7
0.29

0.29
0.020

0.049

0.208

2015.7

162.9

20.8
1029.9

1029.9
108.1

1.18

2.42

1.08

4.62
0.35

13.9

13.9
6.0

11.15

0.44

17.5

23.3

6.0

14.2

31.9
BANGE

$\begin{array}{ll}0.0 & 26.5\end{array}$

580
17200

7.6
0.01

0.00

0.17

350

141

5
15
19

19
6.1

6.1
54.0

20.0

60.0

170

180.0

9.7
440

440
428

230
57

4
0.3

*Not significant at the 95 percent confidence level.

SUMMARY OF HARMONIC ANALYSIS OF STREAM TEMPERATURE

\begin{tabular}{|c|c|c|c|c|c|}
\hline & & & & & STANDARD \\
\hline $\begin{array}{l}\text { SAMPLE } \\
\text { SIZE }\end{array}$ & $\begin{array}{l}\text { HARMONIC } \\
\text { MEAN - M } \\
\text { WOEG CI }\end{array}$ & $\begin{array}{c}\text { AMPLITUDE } \\
-A \\
(D E G()\end{array}$ & $\begin{array}{l}\text { PHASE } \\
\text { ANGLE - C } \\
\text { IBADIANSI }\end{array}$ & $\begin{array}{l}\text { VAR IATION } \\
\text { EXP LAINED } \\
\text { (Z) }\end{array}$ & $\begin{array}{l}\text { ERROR OF } \\
\text { ESTIMATE } \\
\text { (DEG_C) }\end{array}$ \\
\hline
\end{tabular}

$\begin{array}{llllll}93 & 10.74 & 13.02 & 2.66 & 92 & 2.64\end{array}$

SUMMARY OF MAXIMUM AND MINIMUM CONCENTRATIONS OF CONSTITUENTS

SAMPLED AT A FREQUENCY OF QUARTERLY (1975 WY)

06486000 -- MISSOURI RIVER AT SIOUX CITY, IOWA

\begin{tabular}{|c|c|c|c|c|c|c|}
\hline \multirow{2}{*}{ CONSTITUENT } & \multicolumn{3}{|c|}{ TOTAL } & \multicolumn{3}{|c|}{ DISSOLVED } \\
\hline & $\begin{array}{l}\text { NO. } \\
\text { SAMPLES }\end{array}$ & $\begin{array}{l}\text { MIN IMUM } \\
\text { CONC. }\end{array}$ & $\begin{array}{l}\text { MAXIMUM } \\
\text { CONC. }\end{array}$ & $\begin{array}{l}\text { NO. } \\
\text { SAMPLES }\end{array}$ & $\begin{array}{l}\text { MINIMUM } \\
\text { CONC. }\end{array}$ & $\begin{array}{l}\text { MAXIMUM } \\
\text { CONC. }\end{array}$ \\
\hline \multicolumn{7}{|l|}{ MINOR ELEMENTS: } \\
\hline ARSENIC (AS), UG/L & 4 & 1 & 3 & 20 & 0 & 2 \\
\hline CADMIUM $(C D), U G / L$ & 4 & 0 & 2 & 20 & 0 & 1 \\
\hline CHROMIUM (CR), UG/L & 4 & $<10$ & 20 & 20 & 0 & 2 \\
\hline COBALT $(C O)$, UG/L & 4 & 0 & 6 & 4 & 0 & 10 \\
\hline COPPER $(C U), U G / L$ & 4 & 2 & 8 & 20 & 1 & 6 \\
\hline IRON (FE), UG/L & 20 & 260 & 26000 & 4 & 0 & 20 \\
\hline LEAD $(P B), U G / L$ & 4 & 3 & 10 & 20 & 0 & 12 \\
\hline MANG ANESE (MN), UG/L & 4 & 27 & 80 & 20 & 0 & 60 \\
\hline MERCURY (HG), UG/L & 4 & 0.2 & 0.9 & 4 & 0.0 & 1.1 \\
\hline SELENIUM (SE), UG/L & 4 & 2 & 3 & 4 & 0 & 3 \\
\hline ZINC $(Z N), U G / L$ & 4 & 30 & 70 & 20 & 0 & 30 \\
\hline \multirow{2}{*}{\multicolumn{7}{|c|}{$\begin{array}{l}\text { PERIPHYTON: } \\
\text { BIOMASS, DRY WT., G/SO M }\end{array}$}} \\
\hline BIOMASS, DRY WT., G/SO M & 3 & 3.09 & 13.00 & & & \\
\hline BIOMASS, ASH WT., G/SO M & 3 & 1.50 & 6.19 & & & \\
\hline CHLOROPHYLL A, MG/SQ M & 3 & 2.8 & 19.0 & & & \\
\hline CHLOROPHYLL B, MG/SQ M & 3 & $\cdot 2$ & 6.0 & & & \\
\hline ORGANIC CARBON, MG/L & 20 & 1.0 & 31.0 & & & \\
\hline
\end{tabular}


LAT $41030 M O O S$ LONG 102D38MOOS

DRAINAGE AREA: 30700 SQ MI

PERIOD OF RECORD: $10 / 01 / 74$ - $09 / 3019513$ SQ KM)

STATISTICAL SUMMARY OF SELECTED DISSOLVED CHEMICAL CONSTITUENTS AND

REGRESSION RELATIONSHIPS OF CONSTITUENT CONCENTRATIONS TO SPECIFIC CONDUCTANCE

CONSIIIUENI

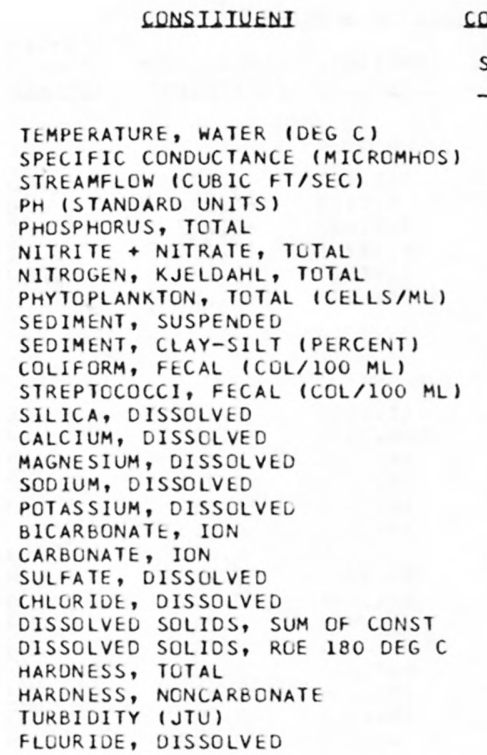

\begin{tabular}{|c|c|c|}
\hline $\begin{array}{l}\text { SAMPLE } \\
\text { SIZE }\end{array}$ & MEAN & $\begin{array}{l}\text { STANDARO } \\
\text { DEYLALION }\end{array}$ \\
\hline 35 & 12.77 & 8.66 \\
\hline 33 & 862.0 & 62.4 \\
\hline 35 & 1296.9 & 416.4 \\
\hline 33 & 7.56 & 0.15 \\
\hline 10 & 0.282 & 0.263 \\
\hline 11 & 2.055 & 0.579 \\
\hline 11 & 0.965 & 0.433 \\
\hline 11 & 15763.6 & 13475.0 \\
\hline 12 & 481.8 & 468.3 \\
\hline 0 & & \\
\hline 12 & 76.6 & 132.0 \\
\hline 12 & 227.8 & 288.2 \\
\hline 11 & 36.36 & 5.22 \\
\hline 11 & 78.91 & 5.74 \\
\hline 11 & 19.91 & 1.70 \\
\hline 11 & 84.18 & 4.21 \\
\hline 11 & 10.04 & 0.91 \\
\hline 11 & 283.9 & 18.5 \\
\hline 8 & 0.0 & 0.0 \\
\hline 11 & 189.09 & 11.36 \\
\hline 11 & 20.73 & 1.35 \\
\hline 11 & 587.5 & 26.2 \\
\hline 2 & 562.5 & 33.2 \\
\hline 11 & 280.0 & 15.5 \\
\hline 11 & 46.1 & 13.7 \\
\hline 32 & 52.0 & 31.7 \\
\hline 4 & 0.50 & 0.00 \\
\hline
\end{tabular}

\section{BEGRESSION SUMMABY}

REGRESSION

SAMPLE COEFICIENT, CONSTANT,

STANDARD
CORRELATICN ERROR CF COEEICIENI. ESIIMAIE

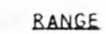

$$
\begin{aligned}
& 0.5 \\
& 640
\end{aligned}
$$

$640 \quad 960$
431

$431 \quad 2010$

7.2

0.11

1.20
0.50

0.50
1100

1100
200

$$
\begin{array}{r}
7.8 \\
1.00
\end{array}
$$

1.00
2.80

2.80
1.90
40000

40000
1920

0
31
29

29.0

71.0

16.0
76.0

76.0
8.3

8.3
257

170.0

170.0
19.0

528

539

260

260
23

0.5

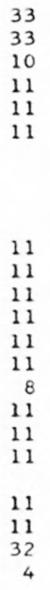

33
33
10
11
11
11


11
11
11
11
11
11
8
11
11
11
11
11
32
4

-3.572
0.0002
0.00018
-0.00051
0.00337
-96.959
7.4030 0.12690 2.49220 2.49220
-1.95243 98689.813 -0.523
$0.073 *$ 0.028 * $-0.034 *$ $0.306 *$ -0.311 *

$$
\begin{array}{r}
0.0303 \\
0.0492 \\
0.0022 \\
0.0230 \\
0.0071 \\
0.037 \\
0.000 \\
0.2189 \\
-0.0062 \\
0.331 \\
0.116 \\
0.098 \\
0.085 \\
0.0000
\end{array}
$$

10.1194 36.3341 18.0312 64.2582 3.9091 251.990 0.000 $-0.3845$ 26.1216 301.246

179.766 $-38.967$ $-20.772$ 0.5000
369.5

0.16
0.278 0.278 0.609 13499.0

*Not significant at the 95 percent confidence level. DAILY SPECIFIC CONDUCTANCE IN URA ILN IABLE OF DAILY SPECIEIC CONDUCIANCE MICROMHOS AT 25 DEG C, THAT WAS

EQUALLEO OR EXCEEDED FOR THE

$\begin{array}{llllll}18 & 52 & 10 z & 20 \% & 30 \% & 50 \% \\ 997 & 912 & 893 & 885 & 881 & 869\end{array}$

$\begin{array}{lllr} & \text { SAMPLE SIZE }=365 \\ 703 & 20 \% & 228 & 99 \% \\ 858 & 832 & 815 & 794\end{array}$

\begin{tabular}{|c|c|c|c|c|c|}
\hline & & & & & STANDARD \\
\hline & HARMONIC & AMPLITUDE & PHASE & VARIATION & ERROR OF \\
\hline SAMPLE & MEAN - M & $-A$ & ANGLE - C & EXPLAINED & ESTIMATE \\
\hline SIZE & $10 E G \quad C 1$ & (REG C) & (RADLANS) & $-(\%)$ & IDEG $C 1$ \\
\hline
\end{tabular}

SUMMARY UF HARMONIC ANALYSIS OF STREAM TEMPERATURE

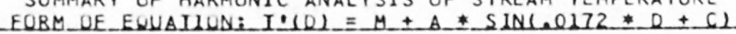

363

10.01

9.81

2.76

87

2.61

SUMMARY OF MAXIMUM ANO MINIMUM CONCENTRATIONS OF CONSTITUENTS

\begin{tabular}{|c|c|c|c|c|c|c|}
\hline \multirow{2}{*}{ CUNSTITUENT } & \multicolumn{3}{|c|}{ TOTAL } & \multicolumn{3}{|c|}{ DISSOLVED } \\
\hline & $\begin{array}{l}\text { NO. } \\
\text { SAMPLES }\end{array}$ & $\begin{array}{l}\text { MIN IMUM } \\
\text { CONC. }\end{array}$ & $\begin{array}{l}\text { MAXIMUM } \\
\text { CONC. }\end{array}$ & $\begin{array}{l}\text { NO. } \\
\text { SAMPLES }\end{array}$ & $\begin{array}{l}\text { MINIMUM } \\
\text { CONC. }\end{array}$ & $\begin{array}{l}\text { MAXIMUM } \\
\text { CONC. }\end{array}$ \\
\hline \multicolumn{7}{|l|}{ MINOR ELEMENTS: } \\
\hline ARSENIC (AS), UG/L & 4 & 6 & 11 & 4 & 6 & 10 \\
\hline CADMIUM $(C D)$, UG $/ L$ & 4 & $<10$ & 40 & 4 & 0 & 1 \\
\hline CHROMIUM (CR), UG $/ L$ & 4 & 0 & 10 & 4 & 0 & 10 \\
\hline COBALI $(C O), U G / L$ & 4 & $<50$ & 150 & 4 & 0 & 1 \\
\hline COPPER (CU), UG/L & 3 & $<10$ & 130 & 3 & 2 & 30 \\
\hline IRON (FE), UG/L & 4 & 950 & 6000 & 4 & 0 & 40 \\
\hline$L E A D(P B), U G / L$ & 4 & $<100$ & $<100$ & 4 & 0 & 6 \\
\hline MANG ANESE (MN), UG/L & 4 & 40 & 290 & 4 & 0 & 58 \\
\hline MERCURY (HG), UG/L & 3 & 0.0 & 0.4 & 3 & 0.0 & 0.2 \\
\hline SELENIUM (SE), UG/L & 4 & 4 & 4 & 4 & 3 & 4 \\
\hline$Z I N C(Z N), U G / L$ & 4 & 40 & 260 & 4 & 30 & 360 \\
\hline \multicolumn{7}{|l|}{ PERIPHYTON: } \\
\hline BIUMASS, DRY WT., G/SO M & 5 & 48.00 & 170.00 & & & \\
\hline BIOMASS, ASH WT., G/SO M & 7 & 43.00 & 150.00 & & & \\
\hline CHLOROPHYLL A, MG/SQ M & 7 & 5.0 & 48.0 & & & \\
\hline CHLUROPHYLL B, MG/SG M & 7 & .3 & 12.0 & & & \\
\hline ORGANIC CARBON, MG/L & 3 & 5.5 & 12.0 & & & \\
\hline
\end{tabular}
SAMPLED AT A FREQUENCY OF QUARTERLY (1975 WY)

06080000 -- NORTH PLATTE RIVER AT LISCO, NEBR. 
LAT $40058 M 46 S$ LONG 102015M15S

DRAINAGE AREA: 23138 SO MI ( 59927 SQ KM)

PERIOD OF RECORD: $10 / 01 / 74-09 / 30 / 75$

STATISTICAL SUMMARY OF SELECTED DISSOLVED CHEMICAL CONSTITUENTS AND

REGRESSION RELATIONSHIPS OF CONSTITUENT CONCENTRATIONS TO SPECIFIC CONDUCTANCE

CONSIIIUENI

\begin{tabular}{r} 
CONSI \\
SAMP \\
SIZ \\
\hline 12 \\
12 \\
12 \\
12 \\
10 \\
12 \\
12 \\
12 \\
12 \\
5 \\
7 \\
12 \\
12 \\
12 \\
12 \\
12 \\
12 \\
12 \\
12 \\
12 \\
12 \\
12 \\
12 \\
12 \\
12 \\
12 \\
12 \\
12 \\
\end{tabular}

LIUENI IMG/L OR UNII_SHOWNI

\begin{tabular}{rrr} 
PLEE & & \multicolumn{1}{c}{ STANDARD } \\
ZE & MEAN & DEYIALUN \\
2 & 11.96 & 9.94 \\
2 & 1769.2 & 245.6 \\
2 & 231.8 & 163.3 \\
0 & 7.82 & 0.48 \\
2 & 0.239 & 0.313 \\
2 & 1.466 & 0.886 \\
2 & 1.327 & 1.599 \\
2 & 28616.7 & 42786.5 \\
5 & 121.4 & 64.3 \\
7 & 56.4 & 28.0 \\
2 & 139.2 & 236.8 \\
2 & 250.0 & 263.6 \\
2 & 23.00 & 3.28 \\
2 & 196.67 & 18.75 \\
2 & 60.92 & 6.49 \\
2 & 184.17 & 20.21 \\
2 & 15.92 & 2.47 \\
2 & 289.9 & 27.7 \\
2 & 0.0 & 0.0 \\
2 & 745.83 & 75.97 \\
2 & 83.08 & 9.59 \\
2 & 1453.3 & 137.7 \\
2 & 1564.2 & 150.0 \\
2 & 742.5 & 59.7 \\
2 & 504.2 & 43.6 \\
2 & 27.8 & 55.5 \\
2 & 0.73 & 0.09
\end{tabular}

BEGBESSION SUMMABY

REGRESSION

SAMPLE

BANGE SIZE. $0.0 \quad 28.0$ $1400 \quad 2140$ $\begin{array}{rrr}42 & 527 & 12\end{array}$ $0.02 \quad 8.8$ 0.38 0.38 1200 2.70 6.10 140000 190 $\begin{array}{rr}16 & 88 \\ 5 & 720\end{array}$ $\begin{array}{rr}5 & 720 \\ 30 & 800\end{array}$ $\begin{array}{lll}17.0 & 27.0 & 12\end{array}$ $150.0 \quad 220.0$ $49.0 \quad 72.0$ $130.0 \quad 210.0$ 11.0 233 233
0
550.0 550.0
58.0 58.0
1080 1080
1150 1150
580 390

0.6
11.6906

100.7320

44.9410

73.3591

10.1308

179.546

0.000

350.3799

42.2698

714.962

802.636

437.824

293.334

144.159

0.7539

* Not significant at the 95 percent confidence level.

\section{QURAIION IABLE OF DAULY SPECIEIC CONOUCIANCE} DAILY SPECIFIC CONDUCTANCE IN MICROMHOS AT 25 DEG C, THAT WAS EQUALLED OR EXCEEDED FOR THE

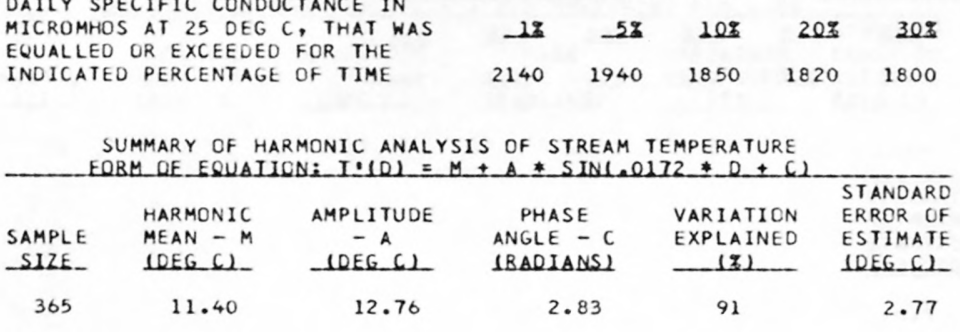
COEFICIENT,

$-1 .-1$

CONSTANT,

CORRELATION COEEICIENI STANDARD
ERROR OF ESILMAIE

12
10
12
12
12
12



12
12
12
12
12
12
12
12
12
12
12
12
12
12
12

$$
\begin{array}{r}
-0.182 \\
-0.0011 \\
-0.00027 \\
0.00119 \\
-0.00094 \\
-20.716
\end{array}
$$

552.927
9.7117
0.71639
-0.63703
2.98217
65260.641

$-0.273$

$-0.002$.

$0.329 *$

$-0.144^{*}$

-0.119 *

164.8

0.321

0.877

1.879

44556.1
$0.479 * \quad 3.01$

$0.710 \quad 13.84$

$0.342+6.39$

13.75

$0.326 *$

$0.553 *-24.2$

$0.000 * \quad 0.0$

$0.722 \quad 55.09$

$0.591 \quad 8.1$

$0.744 \quad 96.4$

$0.705 \quad 111.6$

$0.708 \quad 44.2$

\begin{tabular}{|c|c|c|c|c|c|c|}
\hline \multirow{2}{*}{ CONSTITUENT } & \multicolumn{3}{|c|}{ TOTAL } & \multicolumn{3}{|c|}{ DISSOLVED } \\
\hline & $\begin{array}{l}\text { NO. } \\
\text { SAMPLES }\end{array}$ & $\begin{array}{l}\text { MIN IMUM } \\
\text { CONC. }\end{array}$ & $\begin{array}{l}\text { MAXIMUM } \\
\text { CONC. }\end{array}$ & $\begin{array}{l}\text { NO. } \\
\text { SAMPLES }\end{array}$ & $\begin{array}{l}\text { MINIMUM } \\
\text { CONC. }\end{array}$ & $\begin{array}{l}\text { MAXIMUM } \\
\text { CONC. }\end{array}$ \\
\hline \multicolumn{7}{|l|}{ MINOR ELEMENTS: } \\
\hline ARSENIC (AS), UG/L & 4 & 0 & 8 & 4 & 1 & 4 \\
\hline CADMIUM $(C D), U G / L$ & 4 & $<10$ & 30 & 4 & 0 & 1 \\
\hline CHROMIUM (CR), UG/L & 4 & 0 & 40 & 4 & 0 & 20 \\
\hline COBALT $(C O)$, UG/L & 4 & $<50$ & 50 & 4 & 0 & 0 \\
\hline COPPER (CU), UG/L & 4 & $<10$ & 40 & 4 & 1 & 3 \\
\hline IRON (FE), UG/L & 4 & 680 & 2500 & 4 & 10 & 60 \\
\hline LEAD $(P B), U G / L$ & 4 & $<100$ & $<100$ & 4 & 2 & 5 \\
\hline MANG ANESE (MN), UG/L & 4 & 70 & 210 & 4 & 10 & 70 \\
\hline MERCURY $(H G), U G / L$ & 3 & $<0.1$ & 0.6 & 4 & 0.0 & 0.6 \\
\hline SELENIUM (SE), UG/L & 4 & 2 & 5 & 4 & 2 & 5 \\
\hline ZINC $(Z N), U G / L$ & 4 & 20 & 110 & 4 & 10 & 30 \\
\hline \multicolumn{7}{|l|}{ PERIPHYTON: } \\
\hline BIOMASS, DRY WT., G/SO M & 1 & 340.00 & & & & \\
\hline BIOMASS, ASH WT, G/SO M & 1 & 290.00 & & & & \\
\hline CHLOROPHYLL A, MG/SQ M & 1 & 200.0 & & & & \\
\hline CHLOROPHYLL B, MG/SO M & 1 & 37.0 & & & & \\
\hline ORGANIC CARBON, MG/L & 4 & 1.7 & 12.0 & & & \\
\hline
\end{tabular}

$0.671 * 33.9$
$-0.291 *$
$-0.032 *$

-0.032.
-0.09

SUMMARY OF MAXIMUM AND MINIMUM CONCENTRATIONS OF CONSTITUENTS SAMPLED AT A FREQUENCY OF QUARTERLY (1975 WY)

06764000 -- SOUTH PLATTE RIVER AT JULESBURG, CO. 
LAT 41023M31S LONG 097049M20S

DRAINAGE AREA: 0 SQ MI 1

PERIOD OF RECORD: $10 / 01 / 74-09 / 30 / 75$ O SQ KM)

STATISTICAL SUMMARY OF SELECTED DISSOLVED CHEMICAL CONSTITUENTS AND

REGRESSION RELATIONSHIPS OF CONSTITUENT CONCENTRATIONS TO SPECIFIC CONDUCTANCE

CONSIUIUENI

CONSILIUENI IMGLL OB UNII SHOWN)

SAMPLE
SIZE

(1)

\section{STANDARD}

TEMPERATURE, WATER (DEG C) SPECIFIC CONDUCTANCE (MICROMHOS) STREAMFLOW (CUBIC FT/SEC)

PH (STANDARO UNITS)

PHOSPHORUS, TOTAL

NITRITE + NITRATE, TOTAL

NITROGEN, KJELDAHL, TOTAL

PHYTOPLANKTON, TOTAL (CELLS/ML)

SEDIMENT, SUSPENDED

SEDIMENT, CLAY-SILT (PERCENT)

COLIFORM, FECAL (COL/100 ML)

SILICA, DISSOLVED

CALCIUM, DISSOLVED

MAGNESIUM, DISSOLVEO

SODIUM, DISSOLVED

POTASSIUM, DISSOLVED

BICARBONATE, ION

CARBONATE, ION

SULFATE, UISSOLVED

CHLORIDE, DISSOLVED

DISSOLVED SOLIDS, SUM OF CONST

DISSOLVED SOLIDS, ROE 180 DEG

HARDNESS, TOTAL

HARONESS, NUNCARBONATE

TUREIDITY (JTU)

FLOURIDE, DISSOLVED
12.53

278.4

1527.0

7.65

7.65
0.285

0.324

0.600

59372.7

148.3

11.58

25.4
733.7

0.60

0.072

0.301

0.38

$1006.7 \quad 2172.6$

$246.1 \quad 296.9$

246.1
47.09

37.45

37.45
6.06

9.56
7.50

7.50
159.5

159.5
0.7

10.78

2.33

$200 \cdot 5$

202.9

119.1

0.0
40.7
0.32

5.36
4.72

4.72
1.01

1.01
1.03

1.13

17.2

2.4
2.27

0.69

18.6

18.5

15.8

0.0
47.9

47.9
0.04
STREPTOCOCCI, FECAL (COL/100 ML)

SAMPLE REGRESSION

BEGRESSION SUMMABY

COEFICIENT, CONSTANT,

CORRELATION

STANDARD

ERROR OF

$0.0 \quad 30.0$

$258 \quad 346$

365

6.8

0.18

0.00

0.21
2100

$2670 \quad 11$

8.6

0.40

0.65
1.30

1.30
220000

10
11
11

11
11
11
11

$\begin{array}{rr}-17.962 & 6385.434 \\ 0.0020 & 7.0892 \\ 0.00074 & 0.07922 \\ -0.00557 & 1.87446 \\ 0.00323 & -0.30021 \\ 1625.471 & -393099.063\end{array}$

$-0.662$

0.090 *

$0.263^{*}$

$-0.471 *$

$0.212 *$

0.592 *

10
33

38.0

32.0

5.0

8.3

6.2

144

7.9

174

176

100

0
15
0.3

6900

54.0

$\begin{array}{ll}54.0 & 11 \\ 49.0 & 11\end{array}$

8.7

11.0

201

201
8
15.0

15.0
3.5

246

100
0

$180^{\circ}$

"Not significant at the 95 percent confidence level.

AAILY SPECIFIC CONDUCTANCE INAIION IABLE OE DALY SPECIEIC CONDUCIANCE

MICROMHOS AT 25 DEG C. THAT HAS

EUUALLED OR EXCEEDED FOR THE

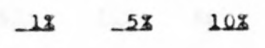

202

$30 \%$

$50 \%$

291

270
$0.224^{*}$

0.913

0.755

0.022

0.749

0.970

$-0.083 *$
0.451.

0.451 *
0.032

0.039

0.952

0.921

0.021 *

$-0.241$.

$-0.241$.
545.5

0.63

0.280

.399

59240.3

SUMMARY OF HARMONIC ANALYSIS OF STREAM TEMPERATURE

\begin{tabular}{|c|c|c|c|c|c|}
\hline & & & & & STANDARD \\
\hline & HARMONIC & AMPLITUDE & PHASE & VAR IATION & ERROR OF \\
\hline SAMPLE & MEAN - M & $-A$ & ANGLE - C & EXPLAINED & ESTIMATE \\
\hline SIZE_- & $10 E 6 C 1$ & IDEG $(1)$ & (BADIANS & $-(x)$ & LEEG $C)$ \\
\hline
\end{tabular}

305

13.04

15.49

2.80

93

2.91

SUMMAKY OF MAXIMUM AND MINIMUM CONCENTRATIONS OF CONSTITUENTS

SAMPLED AT A FREQUENCY OF QUARTERLY (1975 WY)

06792499 -- LOUP R POWER CA AT DIV NR GENOA, NEBR.

\begin{tabular}{|c|c|c|c|c|c|c|}
\hline \multirow{2}{*}{ CONSTITUENT } & \multicolumn{3}{|c|}{ TOTAL } & \multicolumn{3}{|c|}{ DISSCLVED } \\
\hline & $\begin{array}{l}\text { NO. } \\
\text { SAMPLES }\end{array}$ & $\begin{array}{l}\text { MIN IMUM } \\
\text { CONC. }\end{array}$ & $\begin{array}{l}\text { MAXIMUM } \\
\text { CONC. }\end{array}$ & $\begin{array}{l}\text { NO. } \\
\text { SAMPLES }\end{array}$ & $\begin{array}{l}\text { MINIMUM } \\
\text { CONC. }\end{array}$ & $\begin{array}{l}\text { MAXIMUM } \\
\text { CONC. }\end{array}$ \\
\hline \multicolumn{7}{|l|}{ MINOR ELEMENTS: } \\
\hline ARSENIC (AS), UG/L & 4 & 4 & 17 & 4 & 4 & 8 \\
\hline CADMIUM $(C D), U G / L$ & 4 & $<10$ & 10 & 4 & 0 & 4 \\
\hline CHRUMIUM (CR), UG/L & 4 & 0 & 40 & 4 & 0 & $<10$ \\
\hline COBALT $(C O), U G / L$ & 4 & $<50$ & $<50$ & 4 & 0 & 0 \\
\hline COPPER (CU), UGIL & 4 & 20 & 70 & 4 & 1 & 10 \\
\hline IRUN $(F E), U G / L$ & 4 & 1100 & 15000 & 0 & 30 & 160 \\
\hline LEAD $(P B)$, UG/L & 4 & $<100$ & $<100$ & 4 & 0 & 4 \\
\hline MANG ANESE $(M N), U G / L$ & 4 & 20 & 580 & 0 & 0 & 120 \\
\hline MERCURY (HG), UG/L & 4 & 0.1 & 0.7 & 4 & 0.0 & 0.2 \\
\hline SELENIUM (SE), UG/L & 4 & 1 & 1 & 4 & 1 & 1 \\
\hline ZINC $(Z N), U G / L$ & 4 & 40 & 160 & 4 & 0 & 30 \\
\hline \multicolumn{7}{|l|}{ PERIPHYTON: } \\
\hline BIOMASS, DRY WT., G/SQ M & 0 & & & & & \\
\hline BIOMASS, ASH WT., G/SO M & 1 & .79 & & & & \\
\hline CHLOROPHYLL A, MG/SO M & 1 & .2 & & & & \\
\hline CHLOROPHYLL B, MG/SO M & 1 & .2 & & & & \\
\hline ORGANIC CARBON, MG/L & 3 & .7 & 12.0 & & & \\
\hline
\end{tabular}


LAT $41027 M 10 S$ LONG 096045MSOS

DRAINAGE AREA: 77800 SQ MI ( 201502 SQ KM)

PERIOD OF RECORD: $10 / 01 / 74-09 / 30 / 75$

STATISTICAL SUMMARY OF SELECTED DISSOLVED CHEMICAL CONSTITUENTS AND

REGRESSION RELATIONSHIPS OF CONSTITUENT CONCENTRATIONS TO SPECIFIC CONDUCTANCE

CONSIIIUENI

CONSIIIUENI IMGLL OB UNII SHOWN

TEMHERATURE, WATER (DEG C)
SPECIFIC CUNDUCTANCE (MICROMHOS)
STREAMFLOW (CUBIC FI/SEC)
PH (STANDARD UNITS)
PHOSPHORUS, TOTAL
NITRITE, NITRATE, TOTAL
NITROGEN, KJELDAHL, TOTAL
PHYTOPLANKTON, TOTAL (CELLS/ML)
SEOIMENT, SUSPENDED
SEDIMENT, CLAY-SILT (PERCENT)
COLIFCRM, FECAL (COL/IOO ML)
SIREPTOCOCCI, FECAL (COL/IOO ML)
SILICA, DISSOLVED
CALCIUM, DISSOLVED
MAGNESIUM, DISSOLVED
SODIUM, DISSOLVED
POTASSIUM, DISSOLVED
BICARBONATE, ION
CARBONATE, ION
SULFATE, CISSOLVED
CHLURIDE, DISSOLVED
DISSOLVED SULIDS, SUM OF CONST
DISSOLVED SOLIDS, ROE IEO DEG C
HARDNESS, TUTAL
HARDNESS, NONCARBONATE
TURBIDITY (JTU)
FLOURIDE, DISSOLVED

$\begin{array}{ll}\text { SAMPLE } & \text { STANDARD } \\ \text { SIZE MEAN DEYIAILON } & \text { BANGE }\end{array}$

23
15
23
15
1
15
15
1
1
1
1
1
15
15
15
15
15
15
15
15
15
15
15
14

14.52

484.2

3717.8

7.56

0.301

0.499

$38053 \cdot 8$
518.5

8310.4

666.6

34.67

48.60

11.41

30.47

9.15

177.2

0.0
74.53

74.53
11.69

11.69
309.4

309.4
307.2

168.0

23.0

111.4
0.37
10.96

90.3

2602.7

0.26

0.554

0.554

34103.5

493.9

30132.2

1718.2

6.70

5.05

1.93

5.88
2.35

2.35

16.0

16.04
4.16

4.16
38.1

38.2

38.2
19.7
12.5

12.5

202.0
0.07
0.2

$362 \quad 29.0$

$\begin{array}{rr}362 & 739 \\ 304 & 10400\end{array}$

7.2

0.16

0.00

0.40

3300

3300
164

$5 \quad 113000$

$\begin{array}{rr}44 & 6600 \\ 21.0 & 44.0 \\ 36.0 & 57.0\end{array}$

$\begin{array}{rr}36.0 & 57.0 \\ 8.1 & 14.0\end{array}$

$19.0 \quad 38.0$

$134 \quad 196$

39.0

39.0
7.7

7.7
230

238

120
0

10
0.3

*Not significant at the 95 percent confidence level.

DURAILON IABLE OF DALIY SPECIELC CONOUCIANCE

DAILY SPECIFIC CONDUCTANCE IN

MICROMHOS AT 25 DEG C, THAT WAS
EQUALLED OR EXCEEDED FOR THE
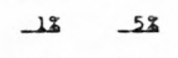

102

202

$30 \%$

$50 \Omega$

INDICATED PERCENTAGE OF TIME

707

650

602

56

SUMARY OF HARMCNIC ANALYSIS OF STREAM TEMPERATURE

\begin{tabular}{|c|c|c|c|c|c|}
\hline & & & & & STANDARD \\
\hline & HARMONIC & AMPLITUDE & PHASE & VARIATION & ERROR OF \\
\hline SAMPLE & MEAN - M & $-A$ & ANGLE - C & EXPLAINED & ESTIMATE \\
\hline SIZE_ & $10 E G(1$ & - DEEG 61 & IRADIANSI & $(8)$ & 10EG $E 1$ \\
\hline 365 & 13.80 & 15.33 & 3.00 & 96 & 2.17 \\
\hline
\end{tabular}

SUMMARY OF MAXIMUM AND MINIMUM CONCENTRATIONS OF CONSTITUENTS

SAMPLED AT A FREQUENCY OF QUARTERLY (1975 WY)

06796000 -- PLATTE RIVER AT NORTH BEND, NEBR.

\begin{tabular}{|c|c|c|c|c|c|c|}
\hline \multirow{2}{*}{ CONSTITUENT } & \multicolumn{3}{|c|}{ TOTAL } & \multicolumn{3}{|c|}{ DISSOLVED } \\
\hline & $\begin{array}{l}\text { NO. } \\
\text { SAMPLES }\end{array}$ & $\begin{array}{l}\text { MINIMUM } \\
\text { CONC. }\end{array}$ & $\begin{array}{l}\text { MAXIMUM } \\
\text { CONC. }\end{array}$ & $\begin{array}{l}\text { NO. } \\
\text { SAMPLES }\end{array}$ & $\begin{array}{l}\text { MINIMUM } \\
\text { CONC. }\end{array}$ & $\begin{array}{l}\text { MAXIMUM } \\
\text { CONC. }\end{array}$ \\
\hline \multicolumn{7}{|l|}{ MINOR ELEMENTS: } \\
\hline ARSENIC (AS), UG/L & 6 & 4 & 62 & 6 & 2 & 8 \\
\hline CADMIUM $(C D), U G / L$ & 6 & $<10$ & 10 & 6 & 0 & 1 \\
\hline CHROMIUM (CR), UG/L & 6 & $<10$ & 70 & 6 & 0 & 10 \\
\hline COBALT $(C O), U G / L$ & 6 & $<50$ & $<50$ & 6 & 0 & 1 \\
\hline COPPER (CU), UGIL & 6 & $<10$ & 70 & 6 & 2 & 14 \\
\hline IRON (FE), UG/L & 6 & 980 & 82000 & 15 & 0 & 370 \\
\hline LEAD $(P B), U G / L$ & 6 & $<100$ & 100 & 6 & 0 & 2 \\
\hline MANGANESE $(M N), U G / L$ & 6 & 40 & 1900 & 15 & 0 & 30 \\
\hline MERCURY (HG), UG/L & 6 & 0.1 & 0.7 & 6 & 0.0 & 0.1 \\
\hline SELENIUM (SE), UG/L & 6 & 1 & 2 & 6 & 1 & 2 \\
\hline$Z I N C(Z N), U G / L$ & 6 & 20 & 380 & 6 & 0 & 340 \\
\hline \multicolumn{7}{|l|}{ PERIPHYTON: } \\
\hline BIOMASS, DRY WT., G/SQ M & 2 & 8.19 & 8.19 & & & \\
\hline BIOMASS, ASH WT., G/SQ M & 3 & 6.19 & 23.00 & & & \\
\hline CHLOROPHYLL A, MG/SO M & 3 & .5 & 2.5 & & & \\
\hline CHLOROPHYLL $B$, MG/SO M & 3 & .5 & .6 & & & \\
\hline ORGANIC CARBON, MG/L & 4 & 1.1 & 35.0 & & & \\
\hline
\end{tabular}


Table 14.--Summary of measurements at each station--Continued

LAT 41DOOM55S LONG 096009M28S

DRAINAGE AREA: 88800 SQ MI I 229992 SQ KMI

PERIOD OF RECORD: $10 / 01 / 74-09 / 30 / 75$

STATISTICAL SUMMARY OF SELECTED DISSOLVED CHEMICAL CONSTITUENTS AND

REGRESSION RELATIONSHIPS OF CONSTITUENT CONCENTRATIONS TO SPECIFIC CONDUCTANCE

CONSIUTUENI

CONSIUTUENI
TEMPERATURE, WATER (DEG C)
SPECIFIC CONDUCTANCE (MICROMHOS)
STREAMFLOH (CUBIC FT/SEC)
PH (STANDARD UNITS)
PHOSPHORUS, TOTAL
NITRITE, NITRATE, TOTAL
NITROGEN, KJELDAHL, TOTAL
PHYTOPLANKTON, TOTAL (CELLS/ML)
SEDIMENT, SUSPENDED
SEDIMENT, CLAY-SILT (PERCENT)
COLIFORM, FECAL (COL/IOO ML)
STREPTOCOCCI, FECAL (COL/IOO ML)
SILICA, DISSOLVED
CALCIUM, DISSOLVED
MAGNESIUM, DISSOLVED
SODIUM, DISSOLVED
POTASSIUM, DISSOLVED
BICARBONATE, ION
CARBONATE, ION
SULFATE, DISSOLVED
CHLORIDE, DISSOLVED
DISSOLVED SOLIDS, SUM OF CONST
DISSOLVED SOLIDS, ROE 18O DEG C
HARDNESS, TOTAL
HARDNESS, NONCARBONATE
TURBIDITY (JTU)
FLOURIDE, DISSOLVED

CONSIUIUENI IHG/L OR UNII SHOHNI

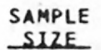

SIZE

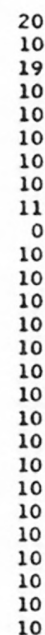

STANDARD DEVIALION

MEAN$$
\begin{aligned}
& 11.52 \\
& 723.4
\end{aligned}
$$$$
4678.4
$$$$
\begin{array}{r}
4678.4 \\
7.80
\end{array}
$$$$
0.534
$$$$
0.684
$$$$
1.722
$$$$
75706.0
$$$$
723.0
$$

1375.2

1846.9

32.90
58.30

58.30
13.66

74.40

74.40
9.62

9.62
216.3

0.8

80.90
74.40

74.40
452.7

452.7
470.0

202.0

23.8

83.4

1652.0
9.30

177.9
4199.5

4199.5
0.46

0.203

0.538

0.96

90652.5
883.3

3318.0

7.11
6.78

2.19

2.19
31.01

1.63

22.1

2.5
17.59

17.59
42.89

104.7

120.9

25.7

12.0

0.08
BANGE

0.0

6.9

0.34

0.06

0.71

130
222

12

11
26.0

49.0
9.6

9.6
34.0

7.5

179

50.0

20.0
303

303
318

160
2

6
0.2

3270

4800

11000

70.0

18.0

120.0

140.0

605
$478 \quad 25.0$

$1230 \quad 18200$

BEG

REGRESSION

SA MPLE COEFICIENT,

, CONSTANT, COR SIZE

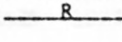

$\begin{array}{rr}18200 & 10 \\ 8.4 & 10 \\ 0.96 & 10 \\ 1.50 & 10\end{array}$

$\begin{array}{rr}-7.966 & 9771.410 \\ -0.0015 & 8.9126 \\ -0.00009 & 0.60059 \\ -0.00127 & 1.60279 \\ 0.00031 & 1.49530 \\ 392.850 & -208481.875\end{array}$

$-0.526$ -0.589 .

-0.081 *

$-0.420$

0.077

$3.30 \quad 10$

392.850

208481.875

44.0 10

$\begin{array}{rr}247 & 10 \\ 8 & 10\end{array}$

$110.0 \quad 10$

$710 \quad 10$

$240 \quad 10$

46
260

$\begin{array}{ll}260 & 10 \\ 0.5 & 10\end{array}$

*Not significant at the 95 percent confidence level.

DURATION IABLE OF DALY SPECIFIC CONOUCIANCE

DAILY SPECIFIC CONDUCTANCE IN

MICROMHOS AT 25 DEG C, THAT WAS

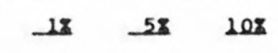

208

$30 \pi$

502

INDICATED PERCENTAGE OF TIME

1100

961

812

750

632

$70 \%$

560
32.1902

37.0401

5.8476

-50.6355
7.9544

152.174

52.174

15.8046

15.8046
-98.5037

28.962

$-8.094$

113.819
-8.485

248.299

0.2518
STANDARD

ERROR OF ESIIMAIE

SUMMARY OF HARMONIC ANALYSIS OF STREAM TEMPERATURE FORM OF EOUAIION: T.(D) = + * SINC.0172*D+C)

\begin{tabular}{|c|c|c|c|c|c|}
\hline $\begin{array}{l}\text { SAMPLE } \\
\text { SUZE }\end{array}$ & $\begin{array}{l}\text { HARMONIC } \\
\text { MEAN - M } \\
\text { LEEG CI }\end{array}$ & $\begin{array}{c}\text { AMPLITUDE } \\
-A \\
\text { (DEG }\end{array}$ & $\begin{array}{c}\text { PHASE } \\
\text { ANGLE - C } \\
\text { IBADIANSI }\end{array}$ & $\begin{array}{l}\text { VAR IATION } \\
\text { EXPLAINED } \\
181 \\
\end{array}$ & $\begin{array}{l}\text { STANDARD } \\
\text { ERROR OF } \\
\text { ESTIMATE } \\
\text { LDEG L) }\end{array}$ \\
\hline 335 & 13.13 & 15.51 & 2.78 & 93 & 3.05 \\
\hline
\end{tabular}

SUMMARY OF MAXIMUM AND MINIMUM CONCENTRATIONS OF CONSTITUENTS SAMPLED AT A FREQUENCY OF QUARTERLY (1975 WY)

06805500 -- PLATTE R AT LOUISVILLE NE

\begin{tabular}{|c|c|c|c|c|c|c|}
\hline \multirow{2}{*}{ CONSTITUENT } & \multicolumn{3}{|c|}{ TOTAL } & \multicolumn{3}{|c|}{ DISSOLVED } \\
\hline & $\begin{array}{l}\text { NO. } \\
\text { SAMPLES }\end{array}$ & $\begin{array}{l}\text { MIN IMUM } \\
\text { CONC. }\end{array}$ & $\begin{array}{l}\text { MAXIMUM } \\
\text { CONC. }\end{array}$ & $\begin{array}{c}\text { NO. } \\
\text { SAMPLES }\end{array}$ & $\begin{array}{l}\text { MINIMUM } \\
\text { CONC. }\end{array}$ & $\begin{array}{l}\text { MAXIMUM } \\
\text { CONC. }\end{array}$ \\
\hline \multicolumn{7}{|l|}{ MINOR ELEMENTS: } \\
\hline ARSENIC (AS), UG/L & 3 & 7 & 15 & 3 & 5 & 11 \\
\hline CADMIUM $(C D), U G / L$ & 3 & $<10$ & 10 & 3 & 0 & 2 \\
\hline CHROMIUM (CR), UG/L & 3 & 1 & 10 & 1 & $<10$ & \\
\hline COBALT $(C O), U G / L$ & 3 & $<50$ & 100 & 3 & 0 & 0 \\
\hline COPPER $(C U)$, UG/L & 3 & 20 & 50 & 3 & 4 & 8 \\
\hline IRON (FE), UG/L & 3 & 880 & 15000 & 4 & 10 & 7800 \\
\hline LEAD (PB), UG/L & 3 & $<100$ & 100 & 3 & 0 & 4 \\
\hline MANGANESE (MN), UG/L & 3 & 70 & 540 & 4 & 10 & 50 \\
\hline MERCURY (HG), UG/L & 2 & 0.1 & 0.1 & 3 & 0.0 & 0.1 \\
\hline SELENIUM (SE), UG/L & 3 & 1 & 3 & 3 & 1 & 2 \\
\hline ZINC $(Z N), U G / L$ & 3 & 80 & 200 & 2 & 10 & 20 \\
\hline \multicolumn{7}{|l|}{ PERIPHYTON : } \\
\hline BIOMASS, DRY WT., G/SQ M & 0 & & & & & \\
\hline BIOMASS, ASH WT., G/SO M & 1 & .79 & & & & \\
\hline CHLOROPHYLL A, MG/SO M & 1 & .1 & & & & \\
\hline CHLOROPHYLL B, MG/SO M & 1 & $\bullet 1$ & & & & \\
\hline ORGANIC CARBON, MG/L & 3 & 3.5 & 18.0 & & & \\
\hline
\end{tabular}


Table 14.--Summary of measurements at each station--Continued

LAT 40D40M55S LONG 095D50M48S

DRAINAGE AREA: 414400 SQ MI ( 1073296 SQ KM)

PERIOD OF RECORD: 10/01/74 - 09/30/75

STATISTICAL SUMMARY OF SELECTED DISSOLVED CHEMICAL CONSTIITUENTS AND

REGRESSION RELATIONSHIPS OF CONSTITUENT CONCENTRATIONS TO SPECIFIC CONDUCTANCE

CONSIITUENI

CONSIUTUENI
TEMPERATURE, WATER (DEG C)
SPECIFIC CONDUCTANCE (MICROMHOS)
STREAMFLOW (CUBIC FT/SEC)
PH (STANDARD UNITS)
PHOSPHORUS, TOTAL
NITRITE, NITRATE, TOTAL
NITROGEN, KJELOAHL, TOTAL
PHYTOPLANKTON, TOTAL (CELLS/ML)
SEDIMENT, SUSPENDED
SEDIMENT, CLAY-SILT (PERCENT)
COLIFORM, FECAL (COL/IOO ML)
STREPTOCOCCI, FECAL (COL/IOO ML)
SILICA, DISSOLVED
CALCIUM, DISSOLVED
MAGNESIUM, DISSOLVED
SODIUM, DISSOLVE
POTASSIUM, DISSOLVED
BICARBONATE, ION
CARBONATE, ION
SULFATE, DISSOLVED
CHLORIDE, DISSOLVED
DISSOLVED SOLIDS, SUM OF CONST
DISSOLVED SOLIDS, ROE I8O DEG C
HARDNESS, TOTAL
HARDNESS, NONCARBONATE
TURBIDITY (JTU)
FLOURIDE, DISSOLVED

CONSIUIUENT IMG/L OR UNU SHOYNL

SAMPL

STANDARD

11.46 720.0

41145.0

7.80

0.179

0.625

0.816

12700.0

666.9

70258.3

2565.0

2565.0
11.27

63.33

22.25

64.67

5.79

213.5

182.50

17.50

473.2

473.2
491.8

249.2

74.6

31.3

0.57
9.66

9.66
100.1
15891.7

0.29
0.115

0.663

0.309

18526.8

702.9

151667.8

3316.4

3316.4
2.58

2.58
5.97

1.36

9.66

0.49

14.2
0.0

18.65

18.65
2.81

31.6

33.3

18.8

11.5
25.9

0.12

$\begin{array}{rr} & \\ & \\ & \\ 0.0 & 28.0 \\ 540 & 890 \\ 15000 & 67700 \\ 7.5 & 8.4 \\ 0.10 & 0.52 \\ 0.06 & 2.30 \\ 0.51 & 1.60 \\ 2500 & 67000 \\ 253 & 3890 \\ 12 & 86 \\ 8200 & 549999 \\ 430 & 11000 \\ 8.0 & 16.0 \\ 51.0 & 73.0 \\ 20.0 & 25.0 \\ 46.0 & 80.0 \\ 5.1 & 6.5 \\ 196 & 239 \\ 0 & 0 \\ 150.0 & 200.0 \\ 14.0 & 22.0 \\ 426 & 517 \\ 437 & 550 \\ 220 & 280 \\ 50 & 95 \\ 5 & 95 \\ 0.4 & 0.8\end{array}$

*Not significant at the 95 percent confidence leve1.

BEGRESSION SUMMABY $\begin{array}{lll} & \text { REGRESSION } & \text { STANDARD } \\ \text { SAMPLE COEFICIENT, CONSTANT, CORRELATION ERROR OF }\end{array}$ SIZE $\mathrm{B}$ B COEEICIENI

\section{DURAIDON IABLE OE DAUY SPECIEIC CONDUCIANCE}

DAILY SPECIFIC CONDUCTANCE IN MICROMHOS AT 25 DEG C, THAT WAS

EQUALLED OR EXCEEDED FOR THE

$\begin{array}{llllll}12 & 52 & 10 \% & 208 & 30 \% & 50 \pi \\ 900 & 800 & 770 & 750 & 744 & 730\end{array}$

$\begin{array}{lrr}12 & -65.303 & 86976.188 \\ 12 & -0.0008 & 8.3946 \\ 12 & -0.00018 & 0.30657 \\ 12 & -0.00307 & 2.83861 \\ 12 & -0.00078 & 1.37714 \\ 11 & -19.310 & 26550.586\end{array}$

-0.382 *

$-0.289 *$

$-0.154 *$

-0.464 *

$-0.253 *$
$-0.109 *$

16580.4

0.29

0.119

0.616

0.313
19412.6

$\begin{array}{rr}-0.158 * & 2.67 \\ 0.372 * & 5.82 \\ 0.643 & 1.09 \\ 0.410 * & 9.24 \\ -0.405 * & 0.47 \\ 0.506 * & 12.9 \\ 0.000 * & 0.0 \\ 0.521 * & 16.69 \\ 0.055 * & 2.95 \\ 0.630 & 25.7 \\ 0.370 * & 32.5 \\ 0.579 & 16.1 \\ 0.290 * & 11.5 \\ -0.555 * & 22.6 \\ -0.189 * & 0.12\end{array}$

INDICATED PERCENTAGE OF THE

$900 \quad 800 \quad 770 \quad 750$

SAMPLE SIZE $\equiv 365$

$202 \quad 25 \% \quad 298$

$630 \quad 600 \quad 560$

SUMMARY OF HARMONIC ANALYSIS OF STREAM TEMPERATURE

EORH OE EOUAIUON: I.UD $=M+A * S I N C O 272 * 0+C)$

\begin{tabular}{|c|c|c|c|c|c|}
\hline & & & & & STANDARD \\
\hline $\begin{array}{l}\text { SAMPLE } \\
\text { SIZE } \\
\end{array}$ & $\begin{array}{l}\text { HARMONIC } \\
\text { MEAN - M } \\
\text { LDEG } C)^{2}\end{array}$ & $\begin{array}{c}\text { AMPLITUDE } \\
-A \\
(D E G \text { C }\end{array}$ & $\begin{array}{c}\text { PHASE } \\
\text { ANGLE - C } \\
\text { (RADIANS) }\end{array}$ & $\begin{array}{l}\text { VARIATION } \\
\text { EXPLA INED } \\
\text { (X) }\end{array}$ & $\begin{array}{l}\text { ERROR OF } \\
\text { ESTIMATE } \\
\text { (DEG C) }\end{array}$ \\
\hline
\end{tabular}

$\begin{array}{llllll}365 & 11.76 & 14.07 & 2.73 & 96 & 2.11\end{array}$

SUMMARY OF MAXIMUM AND MINIMUM CONCENTRATIONS OF CONSTITUENTS

SAMPLED AT A FREQUENCY OF QUARTERLY (1975 WY)

06807000 -- MISSOURI RIVER AT NEBRASKA CITY, NEBR.

\begin{tabular}{|c|c|c|c|c|c|c|}
\hline \multirow{2}{*}{ CONSTI TUENT } & \multicolumn{3}{|c|}{ TOTAL } & \multicolumn{3}{|c|}{ DISSOLVED } \\
\hline & $\begin{array}{l}\text { NO. } \\
\text { SAMPLES }\end{array}$ & $\begin{array}{l}\text { MINIMUM } \\
\text { CONC. }\end{array}$ & $\begin{array}{l}\text { MAXIMUM } \\
\text { CONC. }\end{array}$ & $\begin{array}{l}\text { NO. } \\
\text { SAMPLES }\end{array}$ & $\begin{array}{l}\text { MINIMUM } \\
\text { CONC. }\end{array}$ & $\begin{array}{l}\text { MAXIMUM } \\
\text { CONC. }\end{array}$ \\
\hline \multicolumn{7}{|l|}{ MINOR ELEMENTS: } \\
\hline ARSENIC (AS), UG/L & 4 & 3 & 5 & 4 & 1 & 5 \\
\hline CADMIUM $(C D), U G / L$ & 4 & 0 & 4 & 4 & 0 & 2 \\
\hline CHROMIUM (CR), UG/L & 4 & $<10$ & $<10$ & 4 & 0 & 1 \\
\hline COBALT $(C O), U G / L$ & 4 & 0 & 6 & 4 & 0 & 1 \\
\hline COPPER (CU), UG/L & 4 & 4 & 16 & 4 & 0 & 4 \\
\hline IRON (FE), UG/L & 4 & 600 & 4900 & 4 & 0 & 50 \\
\hline LEAD $(P B), U G / L$ & 4 & 1 & 30 & 4 & 0 & 3 \\
\hline MANG ANESE (MN), UG/L & 4 & 60 & 260 & 4 & 4 & 20 \\
\hline MERCURY (HG), UG/L & 4 & 0.1 & 0.7 & 4 & 0.0 & 0.9 \\
\hline SELENIUM (SE), UG/L & 4 & 2 & 5 & 4 & 2 & 4 \\
\hline$Z I N C(Z N), U G / L$ & 4 & 20 & 60 & 4 & 5 & 30 \\
\hline \multicolumn{7}{|l|}{ PERIPHYTON: } \\
\hline BIOMASS, DRY WT., G/SQ M & 3 & 6.89 & 20.00 & & & \\
\hline BIOMASS, ASH WT., G/SO M & 3 & 6.19 & 20.00 & & & \\
\hline CHLOROPHYLL A, MG/SQ M & 3 & 2.7 & 52.0 & & & \\
\hline CHLOROPHYLL B, MG/SQ M & 3 & 1.0 & 9.5 & & & \\
\hline ORGANIC CARBON, MG/L & 4 & 5.8 & 15.0 & & & \\
\hline
\end{tabular}


Table 14.--Sumary of measurements at each station--Continued

LAT 39D48M14S LONG 094D52M34S

DRAINAGE AREA: 424300 SQ MI 11098937 SQ KMI

PERIOD OF RECORD: 10/01/74 - 09/30/75

STATISTICAL SUMMARY OF SELECTED DISSOLVED CHEMICAL CONSTITUENTS AND

REGRESSION RELATIONSHIPS OF CONSTITUENT CONCENTRATIONS TO SPECIFIC CONDUCTANCE

CONSIIIUENI

\begin{tabular}{|c|}
\hline $\begin{array}{l}\text { TEMPERATURE, WATER (DEG C) } \\
\text { SPECIFIC CONDUCTANCE (MICROMHOS) } \\
\text { SIREAMFLOW (CUBIC FT/SEC) } \\
\text { PH (STANDARD UNITS) } \\
\text { PHOSPHORUS, TOTAL } \\
\text { NITRITE + NITRATE, TOTAL } \\
\text { NITROGEN, KJELDAHL, TOTAL } \\
\text { PHYTOPLANKTON, TOTAL (CELLS/ML) } \\
\text { SEDIMENT, SUSPENDED } \\
\text { SEDIMENT, CLAY-SILT (PERCENT) } \\
\text { COLIFORM, FECAL (COL/1OO ML) } \\
\text { STREPTOCOCCI, FECAL (COL/1OO ML) } \\
\text { SILICA, DISSOLVED } \\
\text { CALCIUM, DISSOLVED } \\
\text { MAGNESIUM, DISSOLVED } \\
\text { SODIUM, DISSOLVED } \\
\text { POTASSIUM, DISSOLVED } \\
\text { BICARBONATE, ION } \\
\text { CARBONATE, ION } \\
\text { SULFATE, DISSOLVED } \\
\text { CHLORIDE, DISSOLVED } \\
\text { DISSOLVED SOLIDS, SUM OF CONST } \\
\text { DISSOLVED SOLIDS, ROE 180 DEG C } \\
\text { HARDNESS, TOTAL } \\
\text { HARDNESS, NONCARBONATE } \\
\text { TURBIDITY (JTU) } \\
\text { FLOURIDE, DISSOLVED }\end{array}$ \\
\hline
\end{tabular}

CONSIUIUENI IMG/L OR UNII_SHOHN)

\begin{tabular}{|c|c|c|c|c|c|}
\hline $\begin{array}{l}\text { SAMPLE } \\
\text { SUZE }\end{array}$ & MEAN & $\begin{array}{l}\text { STANDARD } \\
\text { DEYIAIION }\end{array}$ & \multicolumn{2}{|c|}{ BANGE } & $\begin{array}{l}\text { SAMPL } \\
\text { SIZE }\end{array}$ \\
\hline 12 & 12.46 & 10.70 & 0.0 & 27.0 & \\
\hline 12 & 722.9 & 88.4 & 525 & 875 & \\
\hline 12 & 49775.0 & 21346.1 & 16900 & 90500 & 12 \\
\hline 12 & 8.02 & 0.23 & 7.5 & 8.4 & 12 \\
\hline 12 & 0.296 & 0.213 & 0.14 & 0.91 & 12 \\
\hline 12 & 0.826 & 0.847 & 0.00 & 2.40 & 12 \\
\hline 12 & 1.602 & 2.689 & 0.16 & 10.00 & 12 \\
\hline 11 & 5909.1 & 3160.2 & 1300 & 13000 & 10 \\
\hline 12 & 1131.8 & 1073.4 & 73 & 4060 & \\
\hline 11 & 50.1 & 24.9 & 11 & 93 & \\
\hline 12 & 8608.3 & 9179.1 & 1200 & 36000 & \\
\hline 12 & 10391.7 & 14945.0 & 250 & 38000 & \\
\hline 12 & 10.62 & 2.35 & 7.4 & 14.0 & 12 \\
\hline 12 & 61.17 & 6.60 & 49.0 & 77.0 & 12 \\
\hline 12 & 20.92 & 3.45 & 12.0 & 26.0 & 12 \\
\hline 12 & 58.75 & 11.70 & 35.0 & 69.0 & 12 \\
\hline 12 & 5.85 & 0.70 & 5.1 & 7.8 & 12 \\
\hline 12 & 213.2 & 23.0 & 172 & 268 & 12 \\
\hline 12 & 0.3 & 1.2 & 0 & 4 & 12 \\
\hline 12 & 164.08 & 35.19 & 99.0 & 200.0 & 12 \\
\hline 12 & 16.25 & 2.83 & 12.0 & 21.0 & 12 \\
\hline 12 & 443.8 & 60.4 & 310 & 530 & 12 \\
\hline 12 & 455.3 & 56.6 & 330 & 532 & 12 \\
\hline 12 & 239.2 & 30.0 & 170 & 300 & 12 \\
\hline 12 & 63.4 & 14.3 & 31 & 90 & 12 \\
\hline 5 & 60.8 & 84.9 & 9 & 210 & 5 \\
\hline 12 & 0.52 & 0.17 & 0.4 & 0.9 & 12 \\
\hline
\end{tabular}

*Not significant at the 95 percent confidence level.

\section{BEGRESSION SUMMARY}

COEFICIENT, CONSTANT, CORRELATION STANDARD SIZE -

$\begin{array}{rrrrr}12 & -173.283 & 175044.438 & -0.717 & 15000.1 \\ 12 & 0.0012 & 7.1739 & 0.452 * & 0.22 \\ 12 & -0.00180 & 1.59399 & -0.744 & 0.150 \\ 12 & -0.00670 & 5.67198 & -0.700 & 0.634 \\ 12 & -0.02309 & 18.29601 & -0.759 & 1.837 \\ 10 & -9.008 & 13080.887 & -0.209 * & 3023.9\end{array}$

DURALION IABLE_OE DALLY SPECIEIC CONDUCIANCE

DAILY SPECIFIC CONDUCTANCE IN

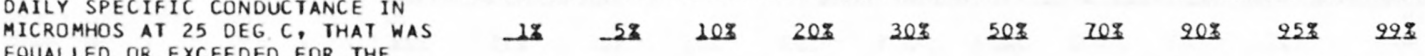

$\begin{array}{llllllllll}\text { EQUALLED OR EXCEEDED FOR THE } & 875 & 850 & 805 & 760 & 750 & 737 & 710 & 658 & 638\end{array}$

SUMMARY OF HARMONIC ANALYSIS OF STREAM TEMPERATURE

\begin{tabular}{|c|c|c|c|c|c|}
\hline & & & & & STANDARD \\
\hline & HARMONIC & AMPLITUDE & PHASE & VARIATION & ERROR OF \\
\hline SAMPLE & MEAN - M & $-A$ & ANGLE - C & EXPLAINED & ESTIMATE \\
\hline SIZE_ & DEEG $(1$ & $10 E G(1)$ & (RADIANSI & $-(z)$ & (DEG $C)$ \\
\hline 362 & 12.56 & 13.67 & 2.71 & 97 & 16 \\
\hline
\end{tabular}

$\begin{array}{rr}-0.0016 & 1 \\ 0.0653 & 1 \\ 0.0339 & - \\ 0.1087 & -1 \\ -0.0023 & \\ 0.222 & \\ 0.001 & \\ 0.2865 & -4 \\ 0.0166 & \\ 0.620 & \\ 0.596 & \\ 0.312 & \\ 0.118 & -2 \\ -0.436 & 3 \\ 0.0005 & \\ & \\ & \\ & \\ 252 & 292 \\ 038 & 540\end{array}$

11.7679 13.9885

$-3.5634$

$-19.8253$

7.4894

52.544

$-0.579$

43.0206

4.2853
-4.143

24.782

13.306

$-21.907$

390.849

0.1451

$\begin{array}{rr}-0.060 * & 2.46 \\ 0.873 & 3.38 \\ 0.867 & 1.80 \\ 0.821 * & 7.01 \\ -0.285 * & 0.71 \\ 0.853 & 12.6 \\ 0.097 * & 1.2 \\ 0.719 & 25.64 \\ 0.516 * & 2.54 \\ 0.906 & 26.8 \\ 0.929 & 21.9 \\ 0.921 & 12.3 \\ 0.727 & 10.3 \\ -0.375 * & 90.9 \\ 0.280 * & 0.17\end{array}$

SUMMARY OF MAXIMUM AND MINIMUM CONCENTRATIONS OF CONSTITUENTS SAMPLED AT A FREOUENCY OF OUARTERLY (1975 WY)

06818000 -- MISSOURI RIVER AT ST. JOSEPH, MO.

\begin{tabular}{|c|c|c|c|c|c|c|}
\hline \multirow{2}{*}{ CONSTITUENT } & \multicolumn{3}{|c|}{ TOTAL } & \multicolumn{3}{|c|}{ DISSOLVED } \\
\hline & $\begin{array}{l}\text { NO. } \\
\text { SAMPLES }\end{array}$ & $\begin{array}{l}\text { MIN IMUM } \\
\text { CONC. }\end{array}$ & $\begin{array}{l}\text { MAXIMUM } \\
\text { CONC. }\end{array}$ & $\begin{array}{l}\text { NO. } \\
\text { SAMPLES }\end{array}$ & $\begin{array}{l}\text { MINIMUM } \\
\text { CONC. }\end{array}$ & $\begin{array}{l}\text { MAXIMUM } \\
\text { CONC. }\end{array}$ \\
\hline \multicolumn{7}{|l|}{ MINOR ELEMENTS: } \\
\hline ARSENIC (AS), UG/L & 4 & 5 & 11 & 4 & 2 & 4 \\
\hline CADMIUM $(C D), U G / L$ & 4 & $<10$ & 10 & 4 & 0 & 6 \\
\hline CHROMIUM (CR), UG/L & 4 & 0 & 30 & 4 & 0 & 0 \\
\hline COBALT $(C O)$, UG/L & 4 & $<50$ & 50 & 4 & 0 & 1 \\
\hline COPPER (CU), UG/L & 4 & $<10$ & 60 & 4 & 1 & 8 \\
\hline IRON $(F E), U G / L$ & 4 & 1300 & 11000 & 11 & 0 & 990 \\
\hline LEAD $(P B), U G / L$ & 4 & $<100$ & 100 & 4 & 2 & 10 \\
\hline MANGANESE (MN), UG/L & 4 & 130 & 210 & 11 & 0 & 130 \\
\hline MERCURY $(H G), U G / L$ & 3 & 0.0 & 0.3 & 4 & 0.0 & 0.9 \\
\hline SELENIUM (SE), UG/L & 3 & 0 & 2 & 4 & 1 & 2 \\
\hline ZINC $(Z N), U G / L$ & 4 & 30 & 320 & 4 & 0 & 70 \\
\hline \multicolumn{7}{|l|}{ PERIPHYTON: } \\
\hline BIOMASS, DRY WT., G/SO M & 3 & 5.89 & 280.00 & & & \\
\hline BIOMASS, ASH WT,, G/SO M & 4 & 4.59 & 270.00 & & & \\
\hline CHLOROPHYLL A, MG/SO M & 4 & .0 & 91.0 & & & \\
\hline CHLOROPHYLL B, MG/SQ M & 4 & .0 & 5.0 & & & \\
\hline ORGANIC CARBON, MG/L & 4 & 4.3 & 12.0 & & & \\
\hline
\end{tabular}


Table 14.--Summary of measurements at each station--Continued

LAT 39021 IH2OS LONG $097007 M 34 S$

DRAINAGE AREA: 24542 SO MI 103564 SQ KM)

PERIOD OF RECORO: $10 / 01 / 74-09 / 30 / 75$

STATISTICAL SUMMARY OF SELECTED DISSOLVED CHEMICAL CONSTITUENTS AND

REGRESSION RELATIONSHIPS OF CONSTITUENT CONCENTRATIONS TO SPECIFIC CONDUCTANCE

CONSIIIUENI

CONSTUUUENI IMG/L OB UNII SHOWN

TEMPERATURE, WATER (DEG C)
SPECIFIC CONOUCTANCE (MICROMHOS)
STREAMFLOW (CUBIC FT/SEC)
PH (STANDARD UNITS)
PHOSPHORUS, TOTAL
NITRITE, NITRATE, TOTAL
NITROGEN, KJELDAHL, TOTAL
PHYTOPLANKTON, TOTAL (CELLS/ML)
SEDIMENT, SUSPENDED (PERCENT)
SEDIMENT, CLAY-SILT (PAM
COLIFORM, FECAL (COL/IOO ML)
STREPTOCOCCI, FECAL (COL/IOO ML)
SILICA, DISSOLVED
CALCIUM, DISSOLVED
MAGNESIUM, DISSOLVED
SODIUM, DISSOLVED
POTASSIUM, DISSOLVED
BICARBONATE, ION
CARBONATE, ION
SULFATE, DISSOLVED
CHLORIDE, DISSOLVED
DISSOLVED SOLIDS, SUM OF CONST
DISSOLVED SOLIDS, ROE 18O DEG C
HARDNESS, TOTAL
HARDNESS, NONCARBONATE
TURBIDITY (JTU)
FLOURIDE, DISSOLVED

\begin{tabular}{r} 
CONSII \\
SAMPL \\
SIZE \\
\hline 13 \\
13 \\
12 \\
13 \\
12 \\
12 \\
12 \\
13 \\
0 \\
0 \\
12 \\
12 \\
12 \\
12 \\
12 \\
12 \\
12 \\
12 \\
12 \\
12 \\
12 \\
12 \\
12 \\
12 \\
12 \\
12 \\
12
\end{tabular}

STANDARD

12.81

472.2

0.353

0.684

1.646

41057.7

2542.5
3335.3

3335.3

18.92

18.42

64.92

11.40

274.0

130.17

60.42

528.6

542.3

296.7

70.7

43.7
0.40
MEAN DEYIAILON

9.80
277.0
488.0
0.30
0.096
0.065
1.205

62402.9

6175.4

10296.0

5.45
27.46

27.46
5.50

18.16

2.33

76.5

1.0

32.81

19.09

135.2

138.2

85.2

48

48.4
0.07 *Not significant at the 95 percent confidence level.

NAME: REPUBLICAN R AT CLAY CENTER, KS

\section{DURAIUON IABLE OF DALLY SPECIEIC CONOUCIANCE}

DAILY SPECIFIC CONDUCTANCE IN

MICROMHOS AT 25 DEG C, THAT WAS

EQUALLED OR EXCEEDED FOR THE
INDICATED PERCENTAGE OF TIME

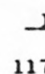

118

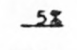

108

$20 \%$

308503

201708

31

REGRESSION

BEGRESSION_SUMMARY

STANDARD
ERROR OF

$1.0 \quad 28.0$

$\begin{array}{ll}292 & 1420 \\ 140 & 1740\end{array}$

$\begin{array}{rr}7.7 & 8.6 \\ 0.25 & 0.53\end{array}$

$0.00 \quad 1.90$

$550-220000$ SIZE

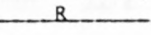

-

COEEICIENI

ESIIMAIE

SUMMARY OF HARMONIC ANALYSIS OF STREAM TEMPERATURE

\begin{tabular}{|c|c|c|c|c|c|}
\hline $\begin{array}{l}\text { SAMPLE } \\
\text { SIZE }\end{array}$ & $\begin{array}{l}\text { HARMONIC } \\
\text { MEAN - M } \\
\text { IDEG CI }\end{array}$ & $\begin{array}{c}\text { AMPLITUDE } \\
-A \\
\text { (DEG } \\
\end{array}$ & $\begin{array}{c}\text { PHASE } \\
\text { ANGLE - C } \\
\text { (RADIANS) }\end{array}$ & $\begin{array}{l}\text { VAR IATION } \\
\text { EXPLA INED } \\
\text { (I) }\end{array}$ & $\begin{array}{l}\text { STANDARD } \\
\text { ERROR OF } \\
\text { ESTIMATE } \\
\text { IDEG_CI }\end{array}$ \\
\hline 365 & 14.39 & 13.44 & 2.86 & 94 & 2.41 \\
\hline
\end{tabular}

SUMMARY OF MAXIMUM AND MINIMUM CONCENTRATIONS OF CONSTITUENTS SAMPLED AT A FREQUENCY OF QUARTERLY (1975 WY)

06856600 - REPUBLICAN R AT CLAY CENTER, KS

\begin{tabular}{|c|c|c|c|c|c|c|}
\hline \multirow{2}{*}{ CONSTI TUENT } & \multicolumn{3}{|c|}{ TOTAL } & \multicolumn{3}{|c|}{ DISSOLVED } \\
\hline & $\begin{array}{l}\text { NO. } \\
\text { SAMPLES }\end{array}$ & $\begin{array}{l}\text { MIN IMUM } \\
\text { CONC. }\end{array}$ & $\begin{array}{l}\text { MAXIMUM } \\
\text { CONC. }\end{array}$ & $\begin{array}{l}\text { NO. } \\
\text { SAMPLES }\end{array}$ & $\begin{array}{l}\text { MINIMUM } \\
\text { CONC. }\end{array}$ & $\begin{array}{l}\text { MAXIMUM } \\
\text { CONC. }\end{array}$ \\
\hline \multicolumn{7}{|l|}{ MINOR ELEMENTS: } \\
\hline ARSENIC (AS), UG/L & 4 & 4 & 15 & 4 & 6 & 8 \\
\hline CADM IUM $(C D), U G / L$ & 4 & $<10$ & 10 & 4 & 1 & 4 \\
\hline CHROMIUM (CR), UG/L & 4 & 0 & 20 & 4 & 0 & 0 \\
\hline COBALT $(C O), U G / L$ & 4 & $<50$ & 50 & 4 & 0 & 1 \\
\hline COPPER $(C U), U G / L$ & 4 & $<10$ & 200 & 4 & 3 & 5 \\
\hline IRON (FE), UG/L & 4 & 360 & 5700 & 4 & 10 & 30 \\
\hline LEAO $(P B)$, UG/L & 4 & $<100$ & 100 & 4 & 4 & 14 \\
\hline MANGANESE (MN), UG/L & 4 & 70 & 180 & 4 & 0 & 50 \\
\hline MERCURY (HG), UG/L & 3 & 0.0 & 0.4 & 4 & 0.0 & 2.0 \\
\hline SELENIUM (SE), UG/L & 4 & 2 & 3 & 4 & 2 & 3 \\
\hline$Z I N C(Z N), U G / L$ & 4 & 20 & 110 & 4 & 10 & 20 \\
\hline \multicolumn{7}{|l|}{ PERIPHYTON: } \\
\hline BIOMASS, DRY WT., G/SQ M & 2 & 2.29 & 24.00 & & & \\
\hline BIOMASS, ASH WT., G/SO M & 2 & 1.79 & 21.00 & & & \\
\hline CHLOROPHYLL A, MG/SQ M & 2 & .0 & 5.1 & & & \\
\hline CHLOROPHYLL $\widehat{B}, M G / S Q M$ & 2 & .0 & 1.0 & & & \\
\hline ORGANIC CARBON, MG/L & 4 & 3.7 & 14.0 & & & \\
\hline
\end{tabular}


Table 14.--Summary of measurements at each station--Continued

LAT 38054M24S LONG 097007M12S

DRAINAGE AREA: 19260 SO MI ( 49883 SO KM)

PERIOD OF RECORD: $10 / 01 / 74$ - 09/30/75

STATISTICAL SUMMARY OF SELECTED DISSOLVED CHEMICAL CONSIITUENTS AND

REGRESSION RELATIONSHIPS OF CONSTITUENT CONCENTRATIONS TO SPECIFIC CONDUCTANCE

CONSILIUENI

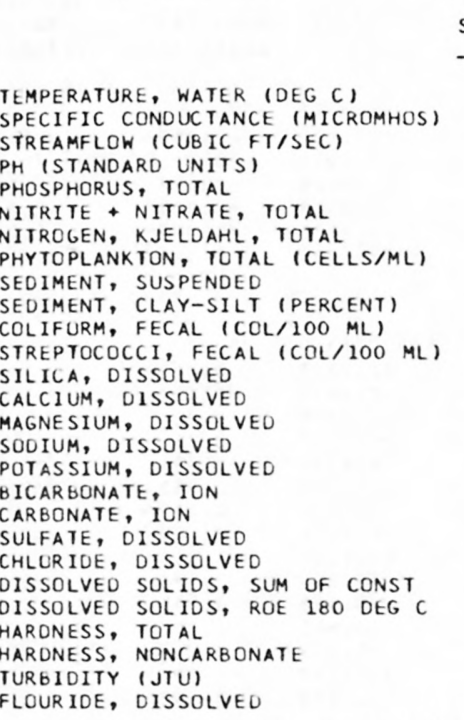

CONSIUUENI IMG L OR UNDI SHOHNL

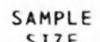

SIZE

26
26
27
25
25
11
11
12
3
0
11
12
25
25
25
25
25
25
20
25
25
25
25
25
25
26
25

STANDARD

DEYLALION

14.42

14.42

1924.8

1780.4
7.79

7.79
0.243

0.735

1.681

16740.8

1202.3

1936.5

2840.4
11.45

130.12

28.49

223.40

8.57
250.3

250.3
0.0

261.40

321.60

1110.0

1143.6

440.8

236.3

204.3
0.36
9.28

747.9

2803.2

0.24
0.158

0.158
0.456

1.22

14861.4

1032.1

2139.4

8249.7

2.30
41.37

41.37
10.26

107.51

1.59

67.9

99.45

101.56

434.5

434.5
447.6

142.9

93.

410.6
0.06
BANGE

$0.5 \quad 26.5$

$510 \quad 2960$

$387 \quad 13100$

7.4

0.10
0.02

0.54

0.54
890
523

260

260
70
7.0

7.0
50.0

50.0
7.2

32.0

4.5
130

63.0

63.0
44.0

298

298
318

160

42

2
0.3

0.78

2390

8000

29000

15.0
190.0

190.0
41.0

370.0

12.0
360

410.0

560.0

1740

1780

400

1500
0.5 REGRESSION

BEGRESSION SUMMARY

SAMPLE COEFICIENT, CONSTANT, CORRELATION ERTANDARD OF

SIZE -B. B - B COEEICIENI ESIIMAIE

*Not significant at the 95 percent confidence level.

DURAIION IABLE OE DAILY SPECIEIC CONOUCIANCE

DAILY SPECIFIC CONDUCTANCE IN

MICROMHOS AT 25 DEG C, THAT WAS

EQUALLED OR EXCEEDED FOR THE

$\begin{array}{rrrrrr}12 & -52 & 20 \% & 20 \% & 302 & 501 \\ 2880 & 2740 & 2650 & 2520 & 2400 & 1990\end{array}$

$\begin{array}{ll}8.3 & 26 \\ 8.3 & 25\end{array}$

$1.60 \quad 11$

$\begin{array}{rl}4.100 & 11 \\ 52000 & 12\end{array}$

25
25
25
25
25
25
20
25
25
25
25
25
25
26
25

$-2.588$

0.0001

$-0.00012$

$-0.00014$

$-0.00127$

3.074

7.5304

0.46892

1.01065

4.11808

10756.578

$-0.705$

0.389

$-0.568$

$-0.246 *$

$-0.811$

0.155

1988.4

0.22

0.133

0.465

0.754

15397.0

0.0011
0.0512
0.0119
0.1393
-0.0002
0.078
0.000
0.1188
0.2080
0.568
0.584
0.176
0.113
-0.372
0.0000

9.346

32.1586

5.7182

$-42.9901$

8.9340

101.097

34.1263

$-76.2906$

23.370

25.983

104.140

20.364

919.560
0.3419

0.364

0.942

0.882

0.986

$-0.090$

0.871

0.000

0.909

0.980

0.995

0.995

0.993

0.937

0.918

-0.677
0.124
2.19

14.20

4.93

18.63

1.62

34.1
0.0

42.35

33.19

45.5

54.0

50.9

308.5

308.5
0.06

INDICATED PERCENTAGE OF THE

$\begin{array}{llllll}2880 & 2740 \quad 2650 \quad 2520 \quad 2400 \quad 1990\end{array}$

\section{$70 \%$}

SAMPLE SIZE $=362$

$208 \quad 25 \% \quad 298$

$1080 \quad 868 \quad 550$

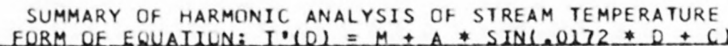

\begin{tabular}{|c|c|c|c|c|c|}
\hline & & & & & STANDARD \\
\hline & HARMONIC & AMPLITUDE & PHASE & VARIATION & ERROR OF \\
\hline SAMPLE & MEAN - M & $-A$ & ANGLE - C & EXPLAINED & ESTIMATE \\
\hline SLZE. & $10 E 6$ (1) & $10 E G(C)$ & (BADIANS) & $-(z)$ & $(D E G \quad C)$ \\
\hline
\end{tabular}

365

10.54

14.01

2.86

93

2.63

SUMMARY OF MAXIMUM AND MINIMUM CONCENTRATIONS OF CONSTITUENTS

SAMPLED AT A FREQUENCY OF QUARTERLY 11975 WY

06877600 -- SMOKY HILL R AT ENTERPRISE, KS

\begin{tabular}{|c|c|c|c|c|c|c|}
\hline \multirow{2}{*}{ CONSTI TUENT } & \multicolumn{3}{|c|}{ TOTAL } & \multicolumn{3}{|c|}{ DISSOLVED } \\
\hline & $\begin{array}{l}\text { NO. } \\
\text { SAMPLES }\end{array}$ & $\begin{array}{l}\text { MINIMUM } \\
\text { CONC. }\end{array}$ & $\begin{array}{l}\text { MAXIMUM } \\
\text { CONC. }\end{array}$ & $\begin{array}{l}\text { NOD } \\
\text { SAMPLES }\end{array}$ & $\begin{array}{l}\text { MINIMUM } \\
\text { CONC. }\end{array}$ & $\begin{array}{l}\text { MAXIMUM } \\
\text { CONC. }\end{array}$ \\
\hline \multicolumn{7}{|l|}{ MINOR ELEMENTS: } \\
\hline $\begin{array}{ll}\text { ARSENIC } & (A S), U G / L \\
\text { CADMIUM } & (C D), U G / L\end{array}$ & 4 & 1 & 23 & 4 & 1 & 3 \\
\hline $\begin{array}{l}\text { CADMIUM (CD), UG/L } \\
\text { CHROMIUM (CR), UG/L }\end{array}$ & 4 & 10 & 10 & 4 & 2 & 8 \\
\hline $\begin{array}{l}\text { CHROMIUM ICR), UG/L } \\
\text { COBALT }(C O), U G / L\end{array}$ & 4 & 0 & 30 & 4 & 0 & 10 \\
\hline $\begin{array}{l}\text { COBALT (CO), UG/L } \\
\text { COPPER (CU), UG/L }\end{array}$ & 4 & $<50$ & 50 & 4 & 0 & 1 \\
\hline $\begin{array}{l}\text { COPPER (CU), UG/L } \\
\text { IRON (FE), UG/L }\end{array}$ & 4 & 10 & 40 & 4 & 2 & 7 \\
\hline $\begin{array}{l}\text { IRON }(F E), U G / L \\
\text { LEAD }(P B), U G / L\end{array}$ & 4 & 470 & 19000 & 6 & 10 & 130 \\
\hline $\begin{array}{l}\text { LEAD }(P B), U G / L \\
\text { MANG ANESE (MN), UG/L }\end{array}$ & 4 & $<100$ & 100 & 4 & 4 & 12 \\
\hline $\begin{array}{l}\text { MANG ANESE }(M N), U G / L \\
\text { MERCURY }(H G), U G / L\end{array}$ & 4 & 190 & 700 & 6 & 0 & 190 \\
\hline $\begin{array}{l}\text { MERCURY (HG), UG/L } \\
\text { SELENIUM (SE), UG/L }\end{array}$ & 3 & 0.0 & 0.4 & 4 & 0.0 & 0.6 \\
\hline SELENIUM (SE), UG $/ L$ & 4 & 1 & 5 & 4 & 1 & 5 \\
\hline ZINC $(Z N), U G / L$ & 4 & 10 & 120 & 4 & 10 & 30 \\
\hline \multicolumn{7}{|l|}{ PERIPHYTON: } \\
\hline BIOMASS, DRY WT., G/SQ M & 0 & & & & & \\
\hline BIOMASS, ASH WT., G/SO M & 0 & & & & & \\
\hline CHLOROPHYLL A, MG/SQ M & 0 & & & & & \\
\hline CHLOROPHYLL $B$, MG/SO M & 0 & & & & & \\
\hline ORGANIC CARGON, MG/L & 3 & 8.3 & 19.0 & & & \\
\hline
\end{tabular}


Table 14.--Summary of measurements at each station--Continued

LAT 39D14M14S LONG 096034M1OS DRAINAGE AREA: 9640 SQ MI 124968 SQ KM) PERIOD OF RECORD: 10/01/74 - 09/30/75

STATISTICAL SUMMARY OF SELECTED DISSOLVED CHEMICAL CONSTITUENTS AND REGRESSION RELATIONSHIPS OF CONSTITUENT CONCENTRATIONS TO SPECIFIC CONDUCTANCE

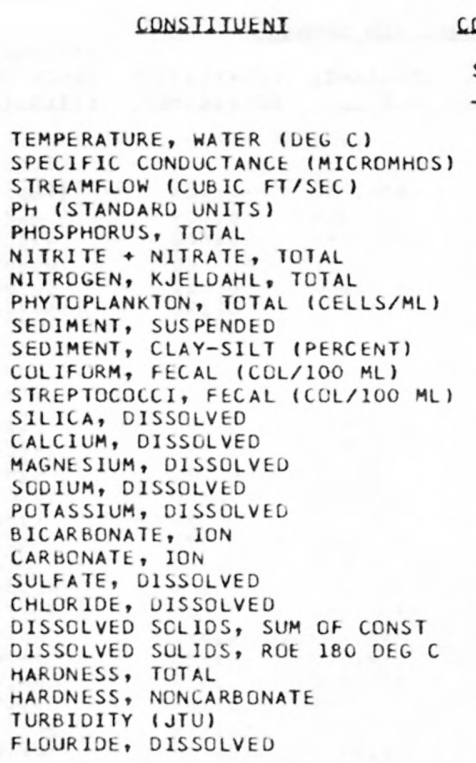

CONSILIUENI_IMG/L OR UNII SHOWNI

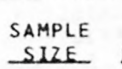

SIZE

$\begin{array}{rrr}23 & 14.41 & 8.15 \\ 23 & 519.5 & 105.7 \\ 25 & 2515.0 & 3784.4 \\ 23 & 7.92 & 0.27 \\ 23 & 0.148 & 0.047 \\ 12 & 0.897 & 0.583 \\ 12 & 1.070 & 1.057 \\ 11 & 3207.5 & 3154.9 \\ 7 & 52.0 & 37.1 \\ 0 & & \\ 11 & 998.1 & 1345.2 \\ 12 & 191.3 & 221.3 \\ 23 & 7.16 & 3.75 \\ 23 & 60.70 & 14.23 \\ 23 & 14.78 & 4.45 \\ 23 & 22.83 & 6.12 \\ 23 & 6.60 & 1.10 \\ 23 & 218.6 & 56.0 \\ 21 & 0.1 & 0.4 \\ 23 & 55.35 & 14.94 \\ 23 & 19.51 & 5.61 \\ 23 & 297.0 & 62.1 \\ 23 & 309.0 & 64.7 \\ 23 & 212.6 & 54.1 \\ 23 & 33.2 & 10.5 \\ 23 & 29.8 & 23.3 \\ 23 & 0.33 & 0.06\end{array}$
*Not significant at the 95 percent confidence level.

DURAILN IABLE_OE DAILY SPECLEIC CONOUCIANCE

DAILY SPECIFIC CONDUCTANCE IN
MICROMHOS AT 25 DEG C THAT WAS
EQUALLED IR EXCEEDE FOR THE

INDICATED PERCENTAGE OF TIME

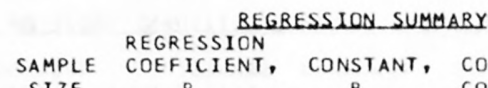

SIZE.

R

CORRELATION $0.5 \quad 25.5$ $\begin{array}{rr}358 & 713 \\ 12 & 10600\end{array}$

7.3

0.08 0.01

0.49

13
31

10600
8.5
0.22

0.22
1.70

1.70
4.00

9000
135

23
23
23
12

$$
\begin{array}{r}
-12.413 \\
0.0000 \\
-0.00036 \\
-0.00450 \\
-0.00015 \\
10.158
\end{array}
$$

$\begin{array}{rr}30 & 3200 \\ 10 & 620 \\ 1.9 & 13.0\end{array}$

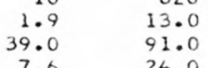

7.6
13.0

4.3

138

30.0

9.9

193
193

193

130
10

5

24.0

30.0

8.2

$343 \quad 23$

$\begin{array}{rr}2 & 21 \\ 74.0 & 23\end{array}$

$27.0 \quad 23$

$398 \quad 23$

$409 \quad 23$

$330 \quad 23$

46

0.5
$-0.0107$

0.1279

0.0382

0.0444

$-0.0065$

0.494
0.001

0.0974

0.0447

0.570

0.596

0.488

$-0.0000$

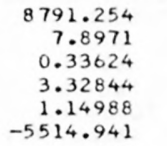

-0.355 .

0.015 *

$-0.818$

$-0.929$

-0.017 .

0.646

12.7227

$-5.7677$

$-5.0735$

$-0.2482$

9.9633

$-38.266$

$-0.259$

4.7574
-3.7233

$-3.7233$

0.994
-0.692

$-0.692$

-40.64
-5.82

109.339

0.3493
3532.8

0.27

0.02

\begin{tabular}{|c|c|c|c|c|c|}
\hline & & & & & STANDARD \\
\hline & HARMONIC & AMPLITUDE & PHASE & VARIATION & ERROR OF \\
\hline SAMPLE & MEAN - M & $-A$ & ANGLE - C & EXPLA INED & ESTIMATE \\
\hline SUZE. & LDE 6 CL & DEG $(1)$ & (RADIANS) & (I) & LDEG $C)$ \\
\hline 365 & 13.78 & 11.86 & 2.65 & 96 & 1.69 \\
\hline
\end{tabular}

0.22

1.108
2539.9

SUMMARY OF HARMONIC ANALYSIS OF STREAM TEMPERATURE FORM OF EOUAJON. I IOI M A SINI.0172*0+C

\begin{tabular}{|c|c|c|c|c|c|c|}
\hline \multirow{2}{*}{ CONSTITUENT } & \multicolumn{3}{|c|}{ TOTAL } & \multicolumn{3}{|c|}{ DISSOLVED } \\
\hline & $\begin{array}{l}\text { NO. } \\
\text { SAMPLES }\end{array}$ & $\begin{array}{l}\text { MIN IMUM } \\
\text { CONC. }\end{array}$ & $\begin{array}{l}\text { MAXIMUM } \\
\text { CONC. }\end{array}$ & $\begin{array}{l}\text { NO. } \\
\text { SAMPLES }\end{array}$ & $\begin{array}{l}\text { MINIMUM } \\
\text { CONC. }\end{array}$ & $\begin{array}{l}\text { MAXIMUM } \\
\text { CONC. }\end{array}$ \\
\hline \multicolumn{7}{|l|}{ MINOR ELEMENTS: } \\
\hline ARSENIC (AS), UG/L & 4 & 2 & 5 & 4 & 1 & 3 \\
\hline CADMIUM $(C D), U G / L$ & 4 & $<10$ & 10 & 4 & 1 & 2 \\
\hline CHROMIUM (CR), UG/L & 4 & 0 & 10 & 4 & 0 & 0 \\
\hline COBALT $(\mathrm{CO}), U G / L$ & 4 & $<50$ & 50 & 4 & 0 & 1 \\
\hline COPPER (CU), UG/L & 4 & $<10$ & 120 & 4 & 3 & 320 \\
\hline IRON (FE), UG/L & 4 & 560 & 3100 & 6 & 10 & 60 \\
\hline LEAD $(P B), U G / L$ & 4 & $<100$ & 100 & 4 & 0 & 4 \\
\hline MANGANESE $(M N), U G / L$ & 4 & 0 & 490 & 6 & 0 & 400 \\
\hline MERCURY $(H G), U G / L$ & 3 & 0.0 & 0.2 & 4 & 0.0 & 0.2 \\
\hline SELENIUM (SE), UG/L & 4 & 1 & 1 & 4 & 1 & 1 \\
\hline$Z I N C(Z N), U G / L$ & 4 & 20 & 320 & 4 & 10 & 30 \\
\hline \multicolumn{7}{|l|}{ PERIPHYTON: } \\
\hline BIOMASS, DRY WT., G/SO M & 0 & & & & & \\
\hline BIOMASS, ASH WT., G/SO M & 0 & & & & & \\
\hline CHLOROPHYLL A, MG/SQ M & 0 & & & & & \\
\hline CHLOROPHYLL B, MG/SO M & 0 & & & & & \\
\hline ORGANIC CARBON, MG/L & 4 & 4.8 & 19.0 & & & \\
\hline
\end{tabular}

SUMMARY OF MAXIMUM AND MINIMUM CONCENTRATIONS OF CONSTITUENTS SAMPLED AT A FREQUENCY OF QUARTERLY (1975 WY)

O6887000 -- BIG BLUE R NR MANHATTAN, KS 
Table 14.--Summary of measurements at each station--Continued

LAT 38D59MOOS LONG 094D57M52S

DRAINAGE AREA: 59756 SO MI I 154768 SO KMI

PERIOD OF RECORD: $10 / 01 / 74-09 / 30 / 75$

STATISTICAL SUMMARY OF SELECTED DISSOLVED CHEMICAL CONSTITUENTS AND

REGRESSION RELATIONSHIPS OF CONSTITUENT CONCENTRATIONS TO SPECIFIC CONDUCTANCE

GONSIIIUENI

CONSIUUENIIMG $\angle L$ OR UNII_SHOKN

SAMPLE

SIZE

TEMPERATURE, WATER (DEG C) SPECIFIC CONDUCTANCE (MICROMHOS)

PH (STANDARD UNITS)

PH ISTANDARD UNITSI

PHOSPHORUS, TOTAL, TOTAL

NITRITE + NITRATE, TOTAL.

PHYTOPLANKTON, TOTAL (CELLS/ML)

SEDIMENT, SUSPENDED

SEDIMENT, CLAY-SILT (PERCENT)

COLIFORM, FECAL ICOL 100 MLI

STREPTOCOCCI, FECAL (COL/100 ML)

SILICA, DISSOLVED

CALCIUM, DISSOLVED

MAGNESIUM, DISSOLVED

SODIUM, DISSOLVED

POTASSIUM, DISSOLVEU

BICARBONATE, ION

CARBONATE, ION

SULFATE, DISSOLVED

CHLORIDE, DISSOLVED

DISSOLVED SOLIDS, SUM OF CONST

OISSOLVED SOLIDS, ROE 180 DEG

HARDNESS, TOTAL

TURBIDITY (JTU)

FLOURIDE, DISSOLVED
STANDARD

DEYIAIION

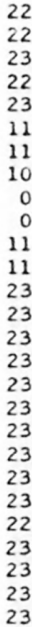

MEAN

15.00

818.3

7040.0

7.93

0.277

0.892

2.025

19010.0

15290.9

13344.5

3344.5
8.75

8.75
79.04

17.29

65.30

5.91
224.9

224.9

107.48

80.96

80.96
479.0

491.2

491.2
267.4

267.4
83.8

298.4
0.33

8.99
238.7

7052.5

0.36

0.193
0.601

0.601

24552.4

16710.8
38720.6

38720.6
1.85

1.85
20.41

5.08

26.05

1.56
57.8

1.0

32.07

34.57

137.2

142.

69.7
26.5

26.5
510.7

0.09 STREAMFLOW (CUBIC FT/SEC)

HARDNESS, NONCARBONAT
BANGE

$0.5 \quad 25.5$

$450 \quad 1310$

0.13

0.02

0.37

1200

8.6
1.10
2.20

2.20
4.90

82000

2200
330

$4.7 \quad 12.0$

49.0

6.7
20.0

20.0
3.2

150

58.0

20.0

264

272
170

44
5

0.2
$1890 \quad 27900$
$12.0 \quad 22$

110.0
26.0

120.0

22

320

$\begin{array}{ll}150.0 & 22 \\ 738 & 22\end{array}$

$738-22$

760

380

120
2000

0.5
$160.0 \quad 22$

SAMPLE REGRESSION BEGRESSION_SUMMARY COEFICIENT, CONSTANT, CORRELATION STANDARD COEEICIENI. ESIIMAIE

$\begin{array}{rrrrr}22 & -20.962 & 24343.863 & -0.697 & 5277.6 \\ 22 & 0.0008 & 7.2923 & 0.521 & 0.31 \\ 22 & -0.00010 & 0.36572 & -0.125 * & 0.200 \\ 11 & -0.00129 & 2.02983 & -0.539 & 0.534 \\ 11 & -0.00190 & 3.69206 & -0.370 * & 1.259 \\ 10 & 34.993 & -11927.488 & 0.377 * & 24125.4\end{array}$

DAILY SPECIFIC CONDUCTANCE IN

URAIIOH IABLE OE DAILY SPECIEIC CONDUCIANCE

MICROMHOS AT 25

EQUALLED OR EXCEEDED FOR THE

INDICATED PERCENTAGE OF TIME

$\begin{array}{rrrrr}17 & -5 \pi & 108 & 20 \% & 30 \% \\ 1320 & 1210 & 1150 & 1030 & 928\end{array}$

$50 \%$

861

22
22
22
22
22
22
22
22
22
22
22
22
22
22
22

0.0020
0.0765
0.0186
0.1082
0.0003
0.203
0.000
0.1217
0.1409
0.505
0.580
0.264
0.099
-1.322
-0.0001

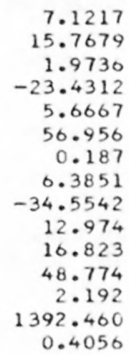

0.249

0.886

0.859

0.969

0.052

0.827

0.908

0.951

0.951

0.969

0.896

0.896
0.877

$-0.608$

$-0.241$

1.88

9.81

2.71

0.74
1.62

33.8

1.1

13.75

11.24

35.2

33.6

31.9

13.2
422.6

422.6
0.09

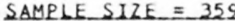

$20 \% \quad 25 \% \quad 99 \%$

$630 \quad 587 \quad 488$

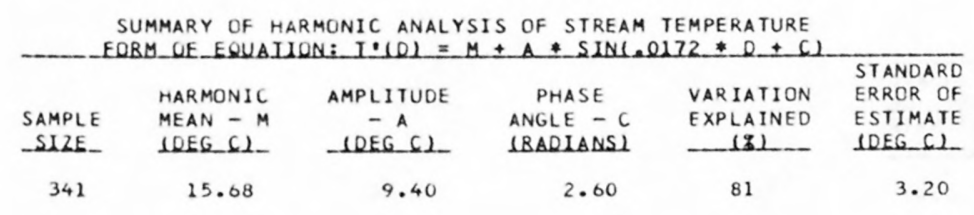

SUMMARY OF MAXIMUM AND MINIMUM CONCENTRATIONS OF CONSTITUENTS SAMPLED AT A FREQUENCY OF QUARTERLY (1975 WY)

06892350 - - KANSAS R AT DESOTO, KS

\begin{tabular}{|c|c|c|c|c|c|c|}
\hline \multirow{2}{*}{ CONSTITUENT } & \multicolumn{3}{|c|}{ TOTAL } & \multicolumn{3}{|c|}{ DISSOLVED } \\
\hline & $\begin{array}{l}\text { NO. } \\
\text { SAMPLES }\end{array}$ & $\begin{array}{l}\text { MINIMUM } \\
\text { CONC. }\end{array}$ & $\begin{array}{l}\text { MAXIMUM } \\
\text { CONC. }\end{array}$ & $\begin{array}{l}\text { NO. } \\
\text { SAMPLES }\end{array}$ & $\begin{array}{l}\text { MINIMUM } \\
\text { CONC. }\end{array}$ & $\begin{array}{l}\text { MAXIMUM } \\
\text { CONC. }\end{array}$ \\
\hline \multicolumn{7}{|l|}{ MINOR ELEMENTS: } \\
\hline ARSENIC (AS), UG/L & 3 & 2 & 9 & 3 & 2 & 4 \\
\hline CADMIUM $(C D), U G / L$ & 3 & $<10$ & 10 & 3 & 1 & 6 \\
\hline CHROMIUM (CR), UG/L & 3 & 0 & 10 & 3 & 0 & 0 \\
\hline COBALT $(C O), U G / L$ & 3 & $<50$ & 50 & 3 & 0 & 0 \\
\hline COPPER (CU), UG/L & 3 & 10 & 50 & 3 & 2 & 7 \\
\hline IRON $(F E), U G / L$ & 3 & 810 & 14000 & 5 & 20 & 120 \\
\hline$L E A D(P B), U G / L$ & 3 & $<100$ & 100 & 3 & 1 & 11 \\
\hline MANGANESE (MN), UG/L & 3 & 70 & 400 & 5 & 0 & 40 \\
\hline MERCURY $(H G), U G / L$ & 3 & 0.0 & 0.3 & 3 & 0.0 & 0.3 \\
\hline SELENIUM $(S E)$, UG/L & 3 & 1 & 2 & 3 & 1 & 1 \\
\hline ZINC $(Z N), U G / L$ & 3 & 30 & 100 & 3 & 0 & 30 \\
\hline \multicolumn{7}{|l|}{ PERIPHYTON: } \\
\hline BIOMASS, DRY WT., G/SQ M & 1 & 53.00 & & & & \\
\hline BIOMASS, ASH WT., G/SQ M & 1 & 46.00 & & & & \\
\hline CHLOROPHYLL A, MG/SO M & 1 & .2 & & & & \\
\hline CHLOROPHYLL $B, M G / S O M$ & 1 & .0 & & & & \\
\hline ORGANIC CARBON, MG/L & 2 & 3.3 & 20.0 & & & \\
\hline
\end{tabular}


LAT 39D38M25S LONG 093016M25S

DRAINAGE AREA: 6880 SQ MI ( 17819 SO KM)

PERIOD OF RECORD: 10/01/74-09/30/75

STATISTICAL SUMMARY OF SELECTED DISSOLVED CHEMICAL CONSTITUENTS AND

REGRESSION RELATIONSHIPS OF CONSTITUENT CONCENTRATIONS TO SPECIFIC CONDUCTANCE

CONSIIIUENI

CONSIIIUENI IMGCL OB UNII SHOWNI

\begin{tabular}{c} 
SAM \\
$S 1$ \\
\hline 1 \\
1 \\
1 \\
1 \\
1 \\
1 \\
1 \\
1 \\
1 \\
1 \\
1 \\
1 \\
1 \\
1 \\
1 \\
1 \\
12 \\
1 \\
1 \\
1 \\
1 \\
1 \\
12 \\
12 \\
12 \\
1
\end{tabular}

13.67

361.7

2295.4

7.87

0.986

2.252

10422.5

1316.1

64.4
5105.8

5105.8
6676.7

9.02

46.92

8.89
9.73

4.32

165.7

35.42

$\begin{array}{r}35.72 \\ \hline\end{array}$

203.0

214.4

153.3

19.4

222.8

STANDARD

DEYIAIION

10.84

1844.1

0.23

0.346

0.795
1.956

18301.1

1484.3
33.1

5973.6

7676.5

2.54

11.46

3.19
2.47

0.56

48.4

0.0
8.83

1.58

46.8

40.5

40.5

148.3

148.3
0.09

${ }^{\star}$ Not significant at the 95 percent confidence level.

DAILY SPECIFIC CONDUCTANCE IN

QURALION IABLE OF DALYY SPECIEIC CONDUCIANCE

MICROMHOS AT 25 DEG C, THAT WAS

EQUALLED OR EXCEEDEO FOR THE

$\begin{array}{llllll}1 \% & -5 \% & 10 \% & 20 \% & 30 z & 50 \% \\ 530 & 500 & 480 & 458 & 425 & 365\end{array}$

BEGRESSION_SUMMARY

REGRESSION SAMPLE COEFICIENT,
SIZE CONSTANT, CONSTANT, CORRELATION STANDARD
ERROR OF

\begin{tabular}{rr}
\multicolumn{1}{c}{ BANGE } & \\
0.0 & 29.0 \\
243 & 550 \\
240 & 6000 \\
7.6 & 8.3 \\
.00 & 1.30 \\
.00 & 2.50 \\
0.51 & 7.30 \\
470 & 66000 \\
12 & 5130 \\
0 & 97 \\
120 & 18500 \\
140 & 22000 \\
6.2 & 14.0 \\
32.0 & 70.0 \\
5.8 & 18.0 \\
6.6 & 15.0 \\
3.5 & 5.3 \\
124 & 296 \\
0 & 0 \\
22.0 & 47.0 \\
3.6 & 8.8 \\
145 & 310 \\
145 & 309 \\
100 & 250 \\
2 & 43 \\
4 & 400 \\
0.1 & 0.4 \\
&
\end{tabular}

$\begin{array}{rrr}12 & -7.164 & 4886.449 \\ 12 & 0.0019 & 7.1884 \\ 12 & -0.00116 & 0.85739 \\ 12 & -0.00383 & 2.37248 \\ 12 & -0.01126 & 6.32241 \\ 12 & 127.826 & -35807.738\end{array}$

$-0.347$

ESIIUAIE

INDICATED PERCENTAGE OF TIME 0.737 -0.300 *

-0.430 *

$-0.514$ 0.623

$$
\begin{array}{r}
0.0235 \\
0.1259 \\
0.0320 \\
0.0250 \\
0.0002 \\
0.487 \\
0.000 \\
0.0554 \\
0.0151 \\
0.518 \\
0.542 \\
0.442 \\
0.040 \\
-1.146 \\
-0.0001
\end{array}
$$$$
\begin{array}{r}
0.5143 \\
1.3663 \\
-2.6985 \\
0.6930 \\
4.2379 \\
-10.638 \\
0.000 \\
15.3632 \\
1.2468 \\
15.818 \\
18.470 \\
-6.516 \\
4.814 \\
000.403 \\
0.2682
\end{array}
$$

\begin{tabular}{|c|c|c|c|c|c|}
\hline & & & & & STANDARD \\
\hline & HARMONIC & AMPLITUDE & PHASE & VARIATION & ERROR OF \\
\hline SAMPLE & $M E A N-M$ & $-A$ & ANGLE - C & EXPLAINED & ESTIMATE \\
\hline SIZE - & DEE 6 ( ) & $-1 D E G(1)$ & IBADIAASI & $(\pi)$ & LEE $C$ C \\
\hline 293 & 12.92 & 13.88 & 2.82 & 94 & 2.47 \\
\hline
\end{tabular}

1814.1

\begin{tabular}{|c|c|c|c|c|c|c|}
\hline \multirow{2}{*}{ CONSTITUENT } & \multicolumn{3}{|c|}{ TOTAL } & \multicolumn{3}{|c|}{ DISSOLVED } \\
\hline & $\begin{array}{l}\text { NO. } \\
\text { SAMPLES }\end{array}$ & $\begin{array}{l}\text { MIN IMUM } \\
\text { CONC. }\end{array}$ & $\begin{array}{l}\text { MAXIMUM } \\
\text { CONC. }\end{array}$ & $\begin{array}{l}\text { NO. } \\
\text { SAMPLES }\end{array}$ & $\begin{array}{l}\text { MINIMUM } \\
\text { CONC. }\end{array}$ & $\begin{array}{l}\text { MAXIMUM } \\
\text { CONC. }\end{array}$ \\
\hline \multicolumn{7}{|l|}{ MINOR ELEMENTS: } \\
\hline ARSENIC $(A S), U G / L$ & 4 & 4 & 32 & 4 & 0 & 2 \\
\hline CADMIUM $(C D), U G / L$ & 4 & $<10$ & 10 & 4 & 0 & 2 \\
\hline CHROMIUM (CR), UG/L & 4 & 0 & 50 & 4 & 0 & 0 \\
\hline COBALT $(C O)$, UGIL & 4 & $<50$ & $<50$ & 4 & 0 & 2 \\
\hline COPPER (CU), UG/L & 4 & $<10$ & 40 & 4 & 1 & 20 \\
\hline IRON $(F E), U G / L$ & 4 & 3000 & 22000 & 11 & 10 & 150 \\
\hline LEAD $(P B), U G / L$ & 4 & $<100$ & $<100$ & 4 & 0 & 5 \\
\hline MANGANESE $(M N), U G / L$ & 4 & 290 & 690 & 11 & 0 & 240 \\
\hline MERCURY $(H G), U G / L$ & 4 & 0.0 & 0.7 & 4 & 0.0 & 1.4 \\
\hline SELENIUM (SE), UG/L & 3 & 0 & 1 & 4 & 0 & 1 \\
\hline$Z I N C(Z N), U G / L$ & 4 & 40 & 280 & 4 & 0 & 40 \\
\hline \multicolumn{7}{|l|}{ PERIPHYTON: } \\
\hline BIOMASS, DRY WT., G/SO M & 3 & .59 & 71.00 & & & \\
\hline BIUMASS, ASH WT., G/SO M & 4 & .39 & 58.00 & & & \\
\hline CHLOROPHYLL A, MG/SO M & 4 & .0 & 2.2 & & & \\
\hline CHLOROPHYLL B, MG/SQ M & 4 & .0 & .5 & & & \\
\hline ORGANIC CARBON, MG/L & 4 & 9.5 & 44.0 & & & \\
\hline
\end{tabular}

0.16

0.346

0.753
1.760

15010.0

\section{SAMPLE SIZE $=295$}

$20 \% \quad 952 \quad 999$

$234 \quad 200 \quad 136$

SUMMARY CF HARMCNIC ANALYSIS CF STREAM TEMPERATURE

SUMMARY OF MAXIMUM AND MINIMUM CONCENTRATIONS OF CONSTITUENTS SAMPLED AT A FREQUENCY OF QUARTERLY (1975 WY)

06902000 -- GRAND RIVER NEAR SUMNER MO 
Table 14.--Summary of measurements at each station--Continued

LAT 38D25M18S LONG 092D12M31S

DRAINAGE AREA: 0 SQ MI 1

PERIOD OF RECORD: 10/01/74 - 09/30/75

O SQ KMI

STATISTICAL SUMMARY OF SELECTED DISSOLVED CHEMICAL CONSTITUENTS AND

REGRESSION RELATIONSHIPS OF CONSTITUENT CONCENTRATIONS TO SPECIFIC CONDUCTANCE

CONSILIUENI

CONSIUIUENI IMG/L OR UNII SHOWNI

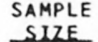

TEMPERATURE, WATER (DEG C)

SPECIFIC CONDUCTANCE (MICROMHOS)

STREAMFLOW (CUBIC FT/SEC)

PH (STANDARD UNITS)

PHOSPHORUS, TOTAL

NITRITE + NITRATE, TOTAL

NITROGEN, KJELDAHL, TOTAL

PHYTOPLANKTON, TOTAL (CELLS/ML)

SEDIMENT, SUSPENDED

SEDIMENT, CLAY-SILT (PERCENT)

COLIFORM, FECAL (COL/100 ML)

STREPTOCOCCI, FECAL (COL/100 ML)

SILICA, DISSOLVED

CALCIUM, DISSOLVED

MAGNESIUM, DISSOLVED

SODIUM, DISSOLVED

POTASSIUM, DISSOL VED

BICARBONATE, ION

CARBONATE, ION

SULFATE, DISSOLVED

CHLORIDE, DISSOLVED

DISSOLVED SOLIDS, SUM OF CONST

DISSOLVED SOLIDS, ROE 180 DEG

HARONESS, TOTAL

HARDNESS, NONCARBONATE

TURBIDITY (JTU)

FLOUR IDE, DISSOLVED

*Not significant at the 95 percent confidence 1 evel.
STANDARD

SLZE MEAN DEYIAILON

$12 \quad 13.29$

$$
\begin{array}{ll}
12 & 294 \\
12 & 14534
\end{array}
$$

$294.4 \quad 31.1$

$7.85 \quad 10424.0$

$0.062 \quad 0.02$

$0.407 \quad 0.148$

0.450

592.7

592.7
53.2

80.6

589.1

468.8

5.60
36.75

36.75

10.02
5.35

5.35

2.70
134.3

134.3
0.0

29.92

4.95

161.8

174.7

133.0
23.0

16.0

0.116

474.9

23.2

9.5
1555.1

1555.1
1120.1

1.40

4.37

2.13

0.76

0.60

20.8

0.0
3.96

0.76

17.6

15.0

18.5

5.0
7.7
0.05

\section{N)}

2.026.

$\begin{array}{rr}2.0 & 26.0 \\ 230 & 327\end{array}$

$\begin{array}{rr}4080 & 3500 \\ 7.5 & 8.2\end{array}$

$\begin{array}{lll}0.02 & 0.09 & 12\end{array}$

$\begin{array}{lll}0.16 & 0.60 & 12 \\ 0.22 & 0.64 & 12\end{array}$

.22

0.64
1600
110

$\begin{array}{rr}20 & 110 \\ 66 & 96 \\ 4 & 5500\end{array}$

$\begin{array}{rr}4 & 5500 \\ 0 & 4000 \\ 4.0 & 8.4 \\ 28.0 & 42.0\end{array}$

6.4

1.9

92

25.0

3.8

127

147

13

0.1

42.0
14.0

$\begin{array}{rr}14.0 & 12\end{array}$

$3.7 \quad 12$

$\begin{array}{rr}3.7 & 12 \\ 155 & 12 \\ 0 & 12\end{array}$

$\begin{array}{rr}37.0 & 12 \\ 6.0 & 12\end{array}$

$\begin{array}{ll}6.0 & 12 \\ 185 & 12\end{array}$

$196 \quad 12$

$\begin{array}{rr}150 & 12 \\ 29 & 12\end{array}$

$30 \quad 12$

REGRESSION

BEGRESSION SUMMARY

SAMPLE COEFICIENT, CONSTANT,

STANDARD COEEICIENI ESIUUAIE

DAILY SPECIFIC CONDUCTANCE IN

MICROMHOS AT 25 DEG C, THAT WAS

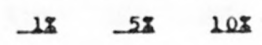

$202 \quad 303 \quad 502$

02708

INDICATED PERCENTAGE OF TIME

344

337

325

$318 \quad 30$

280

$20 \% 252 \quad 298$

$238 \quad 223 \quad 213$

SUMMARY OF HARMONIC ANALYSIS OF STREAM TEMPERATURE

\begin{tabular}{|c|c|c|c|c|c|}
\hline \multirow{4}{*}{$\begin{array}{l}\text { SAMPLE } \\
\text { SUZE. }\end{array}$} & & & & & STANDARD \\
\hline & HARMONIC & AMPLITUDE & PHASE & VAR IATION & ERROR OF \\
\hline & MEAN - $M$ & $-A$ & ANGLE - C & EXPLA INED & ESTIMATE \\
\hline & LDEG Cl & (DEG C) & (RADIANSI & $-(8)$ & WEEG $C)$ \\
\hline 359 & 14.67 & 11.02 & 2.53 & 97 & 1.26 \\
\hline
\end{tabular}

SUMMARY OF MAXIMUM AND MINIMUM CONCENTRATIONS OF CONSTITUENTS SAMPLED AT A FREQUENCY OF QUARTERLY (1975 WY)

06926510 -- OSAGE RIVER BELOW ST. THOMAS, MISSOURI

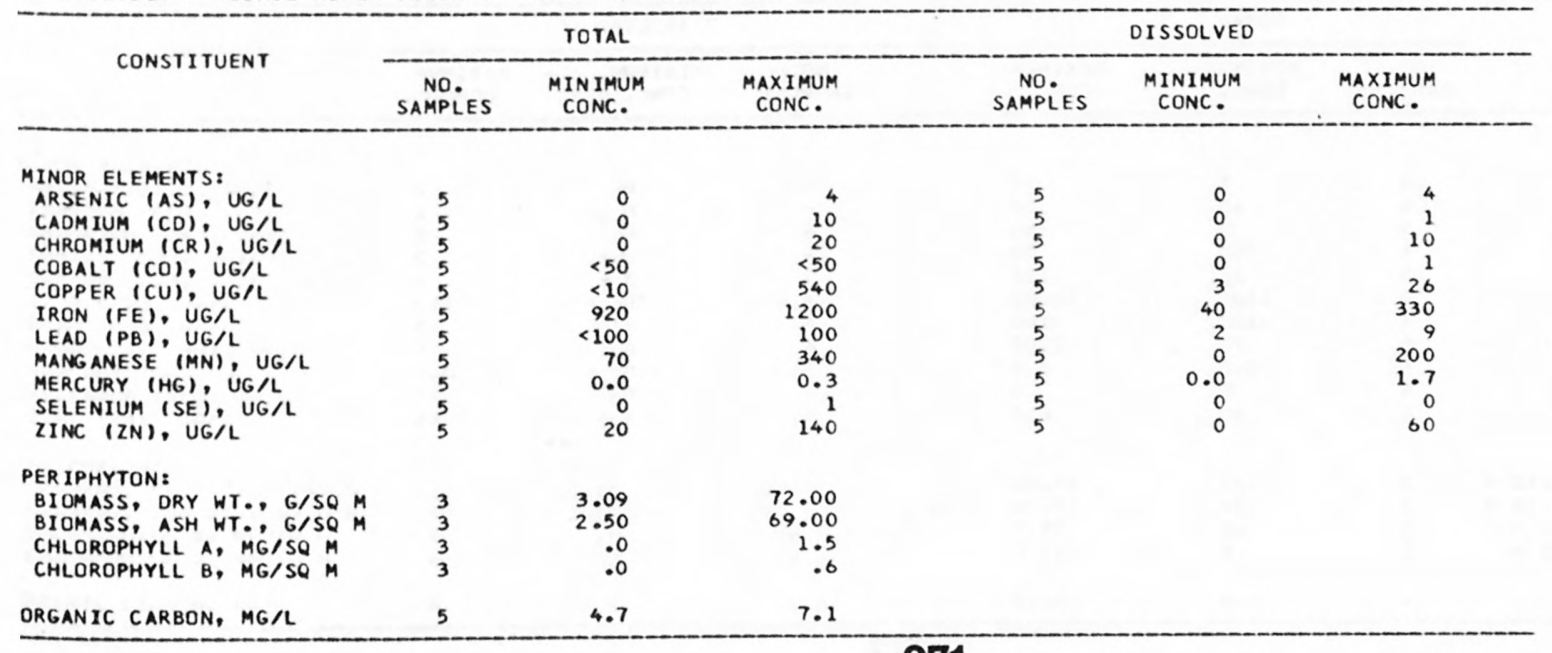


Table 14,--Summary of measurements at each station--Continued

LAT $38042 M 36 S$ LONG 091D26M21S

DRAINAGE AREA: 528200 SQ MI ( 1368038 SQ KM)

PERIOD OF RECORD: 10/01/74 - 09/30/75

STATISTICAL SUMMARY OF SELECTED DISSOLVED CHEMICAL CONSTITUENTS AND REGRESSION RELATIONSHIPS OF CONSTITUENT CONCENTRATIONS TO SPECIFIC CONDUCTANCE

CONSIIIUENI

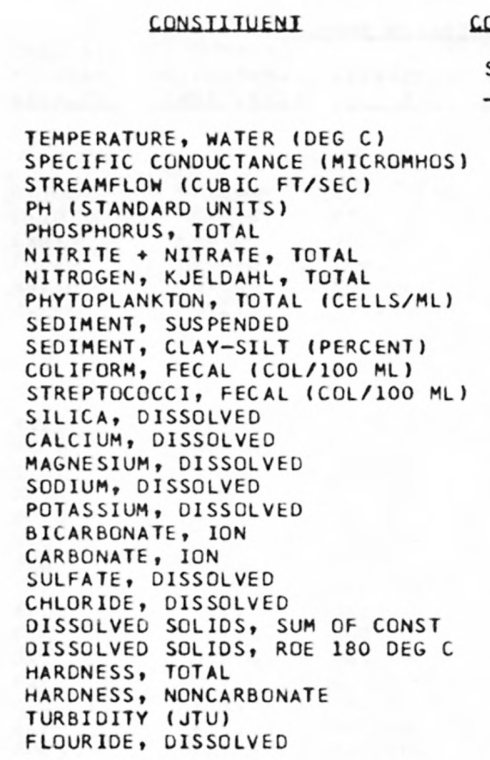

CONSIUIUENI_IMG/L OR UNII SHOWN

SIZE

$\begin{array}{rrr}22 & 11.68 & 8.75 \\ 22 & 540.0 & 145.7 \\ 22 & 92459.1 & 47118.3 \\ 22 & 8.02 & 0.19 \\ 12 & 0.309 & 0.267 \\ 12 & 0.780 & 0.608 \\ 12 & 1.276 & 1.611 \\ 11 & 10510.9 & 11062.1 \\ 12 & 786.9 & 781.6 \\ 12 & 53.2 & 28.1 \\ 22 & 3530.5 & 5832.3 \\ 12 & 2418.3 & 3015.6 \\ 4 & 8.02 & 0.96 \\ 4 & 49.25 & 9.43 \\ 4 & 15.50 & 4.93 \\ 4 & 32.50 & 23.87 \\ 4 & 4.47 & 1.38 \\ 22 & 168.3 & 26.3 \\ 22 & 0.0 & 0.0 \\ 6 & 120.83 & 66.40 \\ 6 & 15.83 & 5.27 \\ 4 & 306.5 & 126.3 \\ 6 & 366.8 & 117.7 \\ 4 & 187.5 & 41.1 \\ 4 & 43.3 & 17.7 \\ 6 & 123.7 & 214.9 \\ 4 & 0.32 & 0.13\end{array}$

REGRESS ION SUMMABY

REGRESSION

SAMPLE COEFICIENT, CONSTANT,

BANGE

$\begin{array}{rr}0.0 & 27.5 \\ 243 & 770\end{array}$

$243 \quad 770$

256000

$\begin{array}{rr}7.7 & 8.3 \\ 0.10 & 1.10\end{array}$

0.00

0.44
720

720
66

8
50

$\begin{array}{ll}50 & 26000 \\ 50 & 8400\end{array}$

$7.0 \quad 8400$

$\begin{array}{rr}7.0 & 9.3 \\ 38.0 & 61.0 \\ 10.0 & 22.0\end{array}$

10.0

18.0

3.0

116

49.0

11.0

205

218

140
25

25
20

0.2 
Table 14.--Sumnary of measurements at each station--Continued

LAT 37D13MOOS LONG $089027 M 50 S$

DRAINAGE AREA: 717200 SQ MI ( 1857548 SQ KM)

PERIOD OF RECORD: $10 / 01 / 74-09 / 30 / 75$

STATISTICAL SUMMARY OF SELECTED DISSOLVED CHEMICAL CONSTITUENTS AND REGRESSION RELATIONSHIPS OF CONSTITUENT CONCENTRATIONS TO SPECIFIC CONDUCTANCE

CONSIUIUENI

CONSIUIUENT IMG/L OR UNII SHOWN

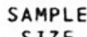

SIZE

TEMPERATURE, WATER (DEG C) SPECIFIC CONDUCTANCE (MICROMHOS) STREAMFLOW (CUBIC FT/SEC)

PH (STANDARD UNITS)

PHOSPHORUS, TOTAL

NITRITE + NITRATE, TOTAL

NITROGEN, KJELDAHL, TOTAL

PHYTOPLANKTON, TOTAL (CELLS/ML)

SEDIMENT, SUSPENDED

SEDIMENT, CLAY-SILT (PERCENT)

COLIFORM, FECAL (COL $100 \mathrm{ML}$ )

STREPTOCOCCI, FECAL ( $\mathrm{COL} / 100 \mathrm{ML})$

SILICA, DISSOLVED

CALCIUM, DISSOLVED

MAGNESIUM, DISSOLVED

SODIUM, DISSOLVED

POTASSIUM, DISSOLVED

BICARBONATE, ION

CARBONATE, ION

SULFATE, DISSOLVED

CHLORIDE, DISSOLVED

DISSOLVED SOLIDS, SUM OF CONST

DISSOLVED SOLIDS, ROE 180 DEG

HARDNESS, TOTAL

HARDNESS, NONCARBONATE

TURBIDITY (JTU)

FLOUR IDE, DISSOLVED
STANDARD

DEYIAIION

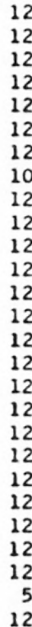

14.08 541.0 196333.3 7.97 0.272 1.420 1.344 9110.0

302.3

60.0

6236.7

456.7

7.24

52.42

18.75

26.58

3.82

193.5

0.0
77.67

19.58

301.9

317.

208.3

49.5
34.8

0.27
10.50

68.7
81377.1

81377.1

0.15
0.102

1.025

1.518

6488.4

294.3

19.2

248.9

1.76

5.21

2.05

9.96

19.7

0.0

21.79

3.15

44.2

44.7

19.0

6.1
9.0

0.08
2.0

104000

7.8
0.13

0.00

0.47

2500
73

26
700

700
80

4.1
42.0

42.0
16.0

14.0

2.9

152

48.0

13.0
225

225

170

38
28

28
0.2
BANGE

- Not significant at the 95 percent confidence level.

DURAIION IABLE OF DAULY SPECIEIC CONDUCIANCE

DAILY SPECIFIC CONDUCTANCE IN

MICROMHOS AT 25 DEG C T THAT HAS

EQUALLED OR EXCEEDED FOR THE

INDICATED PERCENTAGE OF TIME

$\begin{array}{llllll}18 & 5 \pi & 108 & 208 & 30 z & 508 \\ 660 & 625 & 605 & 575 & 545 & 500\end{array}$

REGRESSION

BEGRESSION SUMMABY

SAMPLE COEFICIENT, CONSTANT, CORRELATION ERTANOR OF

SIZE
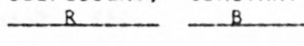

COEFICIENI

$\begin{array}{rrrr}-1038.699 & 758269.688 & -0.876 & 41111.2 \\ 0.0013 & 7.2697 & 0.603 & 0.12 \\ -0.00032 & 0.44256 & -0.213^{*} & 0.104 \\ -0.00307 & 3.07844 & -0.205^{*} & 1.052 \\ -0.00539 & 4.26240 & -0.244^{*} & 1.544 \\ 69.173 & -28914.184 & 0.682 & 5035.1\end{array}$

1170

3500

980

10.0
59.0

59.0
22.0

49.0
5.0

216

130.0

25.0

392

397
230

61
50

0.4

$\begin{array}{ll}33 & 1 \\ 51 & 1 \\ 60 & 12 \\ 0 & 1 \\ 0 & 1 \\ 0 & \\ 3 & \\ 0 & \\ 0 & \\ 0 & 12 \\ 0 & 12 \\ 0 & 12 \\ 0 & 1 \\ 0 & 1 \\ 6 & 1 \\ 0 & 12 \\ 0 & 12 \\ 0 & 12 \\ 2 & 12 \\ 7 & 12 \\ 0 & 12 \\ 1 & 12 \\ 0 & 1 \\ 4 & 12\end{array}$

-0.0115
0.0649
0.0236
0.1191
0.0056
0.261
0.000
0.2497
0.0329
0.613
0.638
0.254
0.048
-0.104
0.0006

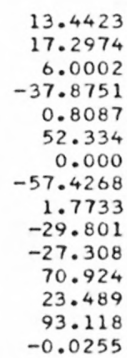

$-0.448$

0.855

0.789

0.821

0.627

0.908

0.000

0.787

0.718

0.953

0.981

0.918

0.539

-0.951
0.506

$-0.0255$

\begin{tabular}{|c|c|c|c|c|c|}
\hline $\begin{array}{l}\text { SAMPLE } \\
\text { SIZE }\end{array}$ & $\begin{array}{l}\text { HARMONIC } \\
\text { MEAN - M } \\
\text { LDEG_CI }\end{array}$ & $\begin{array}{c}\text { AMPLITUDE } \\
-A \\
\text { (DEG C) }\end{array}$ & $\begin{array}{l}\text { PHASE } \\
\text { ANGLE - C } \\
\text { IBADIANS) }\end{array}$ & $\begin{array}{c}\text { VARIATION } \\
\text { EXPLAINED } \\
(X) \\
\end{array}$ & $\begin{array}{l}\text { STANDARD } \\
\text { ERROR OF } \\
\text { ESTIMATE } \\
\text { LDEG CI }\end{array}$ \\
\hline 340 & 15.45 & 13.29 & 2.66 & 97 & 1.57 \\
\hline
\end{tabular}

07022000 -- MISSISSIPPI RIVER AT THEBES ILL

\begin{tabular}{|c|c|c|c|c|c|c|}
\hline \multirow{2}{*}{ CONSTITUENT } & \multicolumn{3}{|c|}{ TOTAL } & \multicolumn{3}{|c|}{ DISSOLVED } \\
\hline & $\begin{array}{l}\text { NO. } \\
\text { SAMPLES }\end{array}$ & $\begin{array}{l}\text { MINIMUM } \\
\text { CONC. }\end{array}$ & $\begin{array}{l}\text { MAXIMUM } \\
\text { CONC. }\end{array}$ & $\begin{array}{l}\text { NO. } \\
\text { SAMPLES }\end{array}$ & $\begin{array}{l}\text { MINIMUM } \\
\text { CONC. }\end{array}$ & $\begin{array}{l}\text { MAXIMUM } \\
\text { CONC. }\end{array}$ \\
\hline \multicolumn{7}{|l|}{ MINOR ELEMENTS: } \\
\hline ARSENIC (AS), UG/L & 4 & 1 & 3 & 4 & 0 & 2 \\
\hline CADMIUM $(C D), U G / L$ & 4 & $<10$ & 10 & 3 & 0 & 1 \\
\hline CHROMIUM (CR), UG/L & 4 & 0 & 20 & 4 & 0 & 10 \\
\hline COBALT $(C O)$, UG/L & 4 & $<50$ & $<50$ & 3 & 0 & 1 \\
\hline COPPER (CU), UG/L & 4 & 10 & 70 & 3 & 8 & 11 \\
\hline IRON (FE), UG/L & 4 & 2300 & 4600 & 11 & 20 & 1300 \\
\hline LEAD $(P B), U G / L$ & 4 & $<100$ & $<100$ & 4 & 1 & 3 \\
\hline MANG ANESE (MN), UG/L & 4 & 70 & 260 & 11 & 0 & 250 \\
\hline MERCURY (HG), UG/L & 4 & 0.1 & 0.4 & 4 & 0.0 & 0.0 \\
\hline SELENIUM (SE), UG/L & 4 & 0 & 1 & 4 & 0 & 1 \\
\hline ZINC $(Z N), U G / L$ & 4 & 30 & 180 & 4 & 10 & 190 \\
\hline \multicolumn{7}{|l|}{ PERIPHYTON: } \\
\hline BIOMASS, DRY WT., G/SQ M & 3 & 1.69 & 100.00 & & & \\
\hline BIOMASS, ASH WT., G/SQ M & 4 & 1.50 & 170.00 & & & \\
\hline CHLOROPHYLL A, MG/SO M & 4 & .0 & 78.0 & & & \\
\hline CHLOROPHYLL B, MG/SQ M & 4 & .0 & 16.0 & & & \\
\hline ORGANIC CARBON, MG/L & 4 & 6.5 & 9.0 & & & \\
\hline
\end{tabular}


Table 14,--Summary of measurements at each station--Continued

LAT 36D15M04S LONG 089011M33S

ORAINAGE AREA: 1852 SQ MI ( 4797 SQ KM)

PERIOD OF RECORD: $10 / 01 / 74-09 / 30 / 75$

STATISTICAL SUMMARY OF SELECTED DISSOLVED CHEMICAL CONSTITUENTS AND REGRESSION RELATIONSHIPS OF CONSTITUENT CONCENTRATIONS TO SPECIFIC CONDUCTANCE

CONSIUIUENI

CONSILIUENI
TEMPERATURE, WATER (DEG C)
SPECIFIC CONDUCTANCE (MICROMHOS)
STREAMFLOW (CUBIC FT/SEC)
PH (STANDARD UNITS)
PHOSPHORUS, TOTAL
NITRITE, NITRATE, TOTAL
NITROGEN, KJELDAHL, TOTAL
PHYTOPLANKTON, TOTAL (CELLS/ML)
SEDIMENT, SUSPENDED
SEDIMENT, CLAY-SILT (PERCENT)
COLIFORM, FECAL (COL/IOO ML)
STREPTOCOCCI, FECAL (COL/IOO ML)
SILICA, DISSOLVED
CALCIUM, DISSOLVED
MAGNESIUM, DISSOLVED
SODIUM, DISSOLVE
POTASSIUM, DISSOLVED
BICARBONATE, ION
CARBONATE, ION
SULFATE, DISSOLVED
CHLORIDE, DISSOLVED
DISSOLVED SOLIDS, SUM OF CONST
DISSOLVED SOLIDS, ROE I8O DEG C
HARDNESS, TOTAL
HARDNESS, NONCARBCNATE
TURBIDITY (JTU)
FLOURIDE, DISSOLVED

CONSIUTUENI IMGLL OR UNUI SHOWN

SAMPLE

SIZE
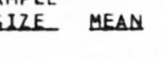

STANDARD

DEYIAIION
21.33

73.2
2354.0

2354.0
7.03

7.03
0.167

0.417

0.753

3101.7

115.7

90.1

508.0

357.0

10.48

6.37
2.43

2.43
5.22

5.22
1.57

33.3

$$
5.91
$$

9.3
2682.5

2682.5
0.53

0.53
0.073

0.073
0.093

0.292

4403.8

82.6

$10 \cdot 3$

351.2

197.0

2.73
0.50

0.50
0.39

0.39
1.28

1.28
0.19

6.9

$\begin{array}{ll}4.90 & 1.45 \\ 3.72 & 0.18\end{array}$

3.72

51.2

60.5
26.0

1.0

45.0
0.13

6.3
9.6

9.3
9.6
2.6

2.0

31.8
0.14
INU

BANGE

$12.0 \quad 28.0$

$59 \quad 85$

674

6.2
0.10

0.10
0.26

0.41

510

20
68
160
93

93

6.1
5.8

1.8

3.0

1.3
21

$3 \cdot 2$

3.5
39

39
48

22
0

10

0.0

*Not significant at the 95 percent confidence level SUMMARY OF HARMONIC ANALYSIS OF STREAM TEMPERATURE

\begin{tabular}{|c|c|c|c|c|c|}
\hline & & & & & STANDARD \\
\hline $\begin{array}{l}\text { SAMPLE } \\
\text { SUZE. }\end{array}$ & $\begin{array}{l}\text { HARMONIC } \\
\text { MEAN - M } \\
\text { LEEG CI) }\end{array}$ & $\begin{array}{c}\text { AMPLITUDE } \\
-A \\
(D E G \quad C)\end{array}$ & $\begin{array}{l}\text { PHASE } \\
\text { ANGLE - C } \\
\text { (RADIANS) }\end{array}$ & $\begin{array}{l}\text { VAR IATION } \\
\text { EXPLAINED } \\
(\xi)\end{array}$ & $\begin{array}{l}\text { ERROR OF } \\
\text { ESTIMATE } \\
\text { (DEG G) }\end{array}$ \\
\hline 71 & 18.73 & 6.52 & 2.70 & 28 & 2.44 \\
\hline
\end{tabular}

BEGRESSION_SUMMABY

$\begin{array}{lll} & \text { REGRESSION } & \text { STANDARD } \\ \text { SAMPLE COEFICIENT, CONSTANT, CORRELATION ERROR OF }\end{array}$
GOEFICIENI ESIUMAI

SUMMARY OF MAXIMUM AND MINIMUM CONCENTRATIONS OF CONSTITUENTS SAMPLED AT A FREQUENCY OF QUARTERLY (1975 WY)

07026000 -- OBION RIVER AT OBION, TENN.

\begin{tabular}{|c|c|c|c|c|c|c|}
\hline \multirow{2}{*}{ CONSTI TUENT } & \multicolumn{3}{|c|}{ TOTAL } & \multicolumn{3}{|c|}{ DISSOLVED } \\
\hline & $\begin{array}{l}\text { NO. } \\
\text { SAMPLES }\end{array}$ & $\begin{array}{l}\text { MIN IMUM } \\
\text { CONC. }\end{array}$ & $\begin{array}{l}\text { MAXIMUM } \\
\text { CONC. }\end{array}$ & $\begin{array}{l}\text { NO. } \\
\text { SAMPLES }\end{array}$ & $\begin{array}{l}\text { MINIMUM } \\
\text { CONC. }\end{array}$ & $\begin{array}{l}\text { MAXIMUM } \\
\text { CONC. }\end{array}$ \\
\hline \multicolumn{7}{|l|}{ MINOR ELEMENTS: } \\
\hline ARSENIC (AS), UG/L & 3 & 2 & 3 & 3 & 0 & 1 \\
\hline CADMIUM (CD), UG/L & 3 & 0 & 3 & 3 & 0 & 0 \\
\hline CHROMIUM (CR), UG/L & 3 & $<10$ & $<10$ & 3 & 0 & 0 \\
\hline COBALT $(C O), U G / L$ & 3 & 1 & 8 & 3 & 0 & 0 \\
\hline COPPER (CU), UG/L & 3 & 5 & 21 & 3 & 0 & 3 \\
\hline IRON (FE), UG/L & 3 & 2000 & 8700 & 3 & 50 & 100 \\
\hline LEAD (PB), UG/L & 3 & 7 & 56 & 3 & 0 & 0 \\
\hline MANG ANESE (MN), UG/L & 3 & 280 & 320 & 3 & 80 & 120 \\
\hline MERCURY $(H G), U G / L$ & 3 & 0.0 & 0.4 & 3 & 0.0 & 0.3 \\
\hline SELENIUM (SE), UG/L & 3 & 0 & 0 & 3 & 0 & 0 \\
\hline$Z I N C(Z N), U G / L$ & 3 & 20 & 70 & 3 & 5 & 20 \\
\hline \multicolumn{7}{|l|}{ PER IPHYTON : } \\
\hline BIOMASS, DRY WT., G/SO M & 0 & & & & & \\
\hline BIOMASS, ASH WT., G/SO M & 0 & & & & & \\
\hline CHLOROPHYLL A, MG/SO M & 0 & & & & & \\
\hline CHLOROPHYLL B, MG/SQ M & 0 & & & & & \\
\hline ORGANIC CARBON, MG/L & 3 & 3.1 & $8 \cdot 3$ & & & \\
\hline
\end{tabular}


Table 14.--Summary of measurements at each station--Continued

LAT 35007M37S LONG 090D04M25S

DRAINAGE AREA: 932800 SQ MI ( 2415952 SQ KM)

PERIOD OF RECORD: 10/01/74 - 09/30/75

STATISTICAL SUMMARY OF SELECTED DISSOLVED CHEMICAL CONSTITUENTS AND

REGRESSION RELATIONSHIPS OF CONSTITUENT CONCENTRATIONS TO SPECIFIC CONDUCTANCE

\section{CUNSIIUUENI}

TEMPERATURE, WATER (UEG C)
SPECIFIC CONOUCTANCE (MICROMHOS)
STREAMFLOW (CUBIC FT/SEC)
PH (STANDARD UNITS)
PHOSPHORUS, TOTAL
NITRITE, NITRATE, TOTAL
NIIROGEN, KJELDAHL, TOTAL
PHYTOPLANKION, TOTAL (CELLS/ML)
SEDIMENT, SUSPENDED
SEDIMENT, CLAY-SILT (PERCENT)
COLIFORM, FECAL (COL/IOO ML)
STREPTOCOCCI, FECAL (COL/IOO ML)
SILICA, DISSOLVED
CALCIUM, DISSOLVED
MAGNESIUM, DISSULVED
SODIUM, DISSOLVED
POTASSIUM, DISSOLVED
BICARBONATE, ION
CARBONATE, ION
SULFATE, DISSOLVED
CHLORIDE, DISSOLVED
OISSOLVED SOLIDS, SUM OF CONST
DISSOLVED SOLIDS, ROE IBO DEG C
HARDNESS, TOTAL
HARDNESS, NONCARBONATE
TUREIDITY IJTU)
FLOURIDE, DISSOLVED

CONSIUIUENI (MG $/ \perp$ OR UNH SHOWN)
STANDARD

DEYLAIUON

\subsection{0} 387. 570583.3 7.75 0.201 1.309 1.309
0.776 0.776
7420.9 7420.9
126.1 126.1
90.6 90.6
670.2 670.2 191.5 5.91
41.08
12.75 12.75 17.68 17.68
2.92 2.92
131.8
0.2 0.2
58.67
15.67 15.67
220.3 220.3 236.6 156.7
47.3 47.3 45.8
0.23
9.38 83.9 351077.5 0.36 0.061 0.739 0.176 6930.3 36.2 8.1 908.3 175.4 0.82 5.33 2.53 6.48 0.67 22.2 0.6 17.40
2.93 2.93
41.3 40.9 21.5$$
\begin{array}{r}
6.5 \\
18.1
\end{array}
$$$$
0.07
$$

SAMPL
*Not significant at the 95 percent confidence leve
BANGE

$\begin{array}{rr}5.0 & 29.0 \\ 228 & 490 \\ 204000 & 1490000\end{array}$
$204000 \quad 1490000$

7.3

0.03

0.56

0.47
930

930
74
73

73
67

8
4.4

29.0

8.0

9.2

1.5
84

0
37.0

11.0

143

153

110

20
BEG

SAMPLE SIZE

COEFICIENT, CONSTANT,

\section{$B Y$}

$\begin{array}{rrrrrr}490000 & 12 & -3811.417 & 2045918.000 & -0.911 & 151806.3 \\ 8.4 & 12 & 0.0012 & 7.2805 & 0.284^{*} & 0.36 \\ 0.27 & 12 & 0.00053 & -0.00403 & 0.723 & 0.044 \\ 3.20 & 12 & -0.00183 & 2.01790 & -0.208^{*} & 0.759 \\ 1.10 & 12 & -0.00076 & 1.07097 & -0.363^{*} & 0.172 \\ 26000 & 11 & 46.454 & -10721.473 & 0.584^{*} & 5930.3\end{array}$

DUBAILN IABLE_OE_DAUL SPECIEIC CONDUCIANCE

DAILY SPECIFIC CONDUCTANCE IN

MICROMHOS AT 25 DEG C, THAT WAS

EQUALLED OR EXCEEDED FOR THE

$\begin{array}{llllll}28 & 58 & 20 \% & 20 \% & 20 \%\end{array}$

20\% $70 \%$

$\begin{array}{llll}496 & 481 & 470 & 457\end{array}$

$445 \quad 424$
174
17000

99
3000
540

540
6.8

$\begin{array}{rr}6.8 & 12 \\ 49.0 & 12\end{array}$

$16.0 \quad 12$

$28.0 \quad 12$

$3.9 \quad 12$

$\begin{array}{rr}2 & 12 \\ 90.0 & 12\end{array}$

$20.0 \quad 12$

$\begin{array}{ll}276 & 12 \\ 288 & 12\end{array}$

$180 \quad 12$

$\begin{array}{ll}58 & 12 \\ 76 & 12\end{array}$

$0.3 \quad 12$$$
46.454
$$

correlation

STANDARD
ERROR OF ESILMAIE

INDICATED PERCENTAGE OF TIME

SUMMARY OF HARMONIC ANALYSIS OF STREAM TEMPERATURE

\begin{tabular}{|c|c|c|c|c|c|}
\hline & & & & & STANDARD \\
\hline & HARMONIC & AMPLITUDE & PHASE & VAR IATION & ERROR OF \\
\hline SAMPLE & MEAN - $M$ & $-A$ & $A N G L E-C$ & EXPLAINED & ESTIMATE \\
\hline SLZE_ & 1DEG C) & COEG CL & (BADIANS) & $-(\pi)$ & DEEG $C 1$ \\
\hline 270 & 16.33 & 12.54 & 2.57 & 95 & 2.32 \\
\hline
\end{tabular}

SUMMARY OF MAXIMUM AND MINIMUM CONCENTRATIONS OF CONSTITUENTS SAMPLED AT A FREQUENCY OF QUARTERLY (1975 WY)

07032000 -- MISSISSIPPI RIVER AT MEMPHIS, TENN.

\begin{tabular}{|c|c|c|c|c|c|c|}
\hline \multirow{2}{*}{ CONSTITUENT } & \multicolumn{3}{|c|}{ TOTAL } & \multicolumn{3}{|c|}{ DISSOLVED } \\
\hline & $\begin{array}{c}\text { NO. } \\
\text { SAMPLES }\end{array}$ & $\begin{array}{l}\text { MIN IMUM } \\
\text { CONC. }\end{array}$ & $\begin{array}{l}\text { MAXIMUM } \\
\text { CONC. }\end{array}$ & $\begin{array}{l}\text { ND. } \\
\text { SAMPLES }\end{array}$ & $\begin{array}{l}\text { MINIMUM } \\
\text { CONC. }\end{array}$ & $\begin{array}{l}\text { MAXIMUM } \\
\text { CONC. }\end{array}$ \\
\hline \multicolumn{7}{|l|}{ MINOR ELEMENTS: } \\
\hline ARSENIC (AS), UG/L & 4 & 0 & 6 & 4 & 0 & 3 \\
\hline CADMIUM $(C D)$, UG/L & 4 & $<10$ & 840 & 4 & 0 & 190 \\
\hline CHROMIUM (CR), UG/L & 4 & 0 & 20 & 4 & 0 & 0 \\
\hline COBALT $(C O), U G / L$ & 4 & $<50$ & 50 & 4 & 0 & 1 \\
\hline COPPER $(C U), U G / L$ & 4 & 40 & 110 & 4 & 7 & 25 \\
\hline IRON (FE), UG/L & 4 & 1100 & 5100 & 4 & 0 & 40 \\
\hline$L E A D(P B), U G / L$ & 4 & $<100$ & 200 & 4 & 0 & 3 \\
\hline MANGANESE $(M N), U G / L$ & 4 & 100 & 250 & 4 & 0 & 100 \\
\hline MERCURY (HG), UG/L & 3 & 0.0 & 0.1 & 4 & 0.0 & 0.1 \\
\hline SELENIUM (SE), UG/L & 4 & 0 & 1 & 4 & 0 & 1 \\
\hline$Z I N C(Z N), U G / L$ & 4 & 60 & 100 & 4 & 10 & 40 \\
\hline \multicolumn{7}{|l|}{ PERIPHYTON: } \\
\hline BIOMASS, DRY WT., G/SQ M & 1 & 59.00 & & & & \\
\hline BIOMASS, ASH WT., G/SO M & 1 & 55.00 & & & & \\
\hline CHLOROPHYLL A, MG/SO M & 1 & 2.1 & & & & \\
\hline CHLOROPHYLL B, MG/SO M & 1 & $\cdot 1$ & & & & \\
\hline ORGANIC CARBON, MG/L & 2 & 5.2 & 7.0 & & & \\
\hline
\end{tabular}


Table 14,--Sumnary of measurements at each station--Continued

LAT $35016 M 235$ LONG 090033M33S

DRAINAGE AREA: O SQ MI

STATISTICAL SUMMARY OF SELECTED DISSOLVED CHEMICAL CONSTITUENTS AND REGRESSION RELATIONSHIPS OF CONSTITUENT CONCENTRATIONS TO SPECIFIC CONDUCTANCE

CONSILIUENI

CONS
SAM
S1
1
1
1
1
1
1
1
1
1


1
1
1
1
13
1
1
1
1
1
1
13
13
1
1
13

CONSIUUUENI IMG/L OR UNII SHOWN
SAMPLE
SIZE MEAN STANDARO
REYIAIION

NU
BANGE
0.5
72
685
7.1
0.10
0.06
0.47
240
47
93
25
17
4.7
7.3
2.1
4.5
1.6
30
0
9.8
2.4
47
62
27
0
0
0.1

$$
\begin{array}{r}
8.71 \\
119.3 \\
2438.5 \\
0.30 \\
0.186 \\
0.279 \\
0.651 \\
1089.6 \\
134.5 \\
2.5 \\
396.5 \\
609.1 \\
4.75 \\
10.17 \\
4.38 \\
2.00 \\
0.54 \\
69.8 \\
0.0 \\
5.00 \\
1.89 \\
66.4 \\
63.7 \\
58.2 \\
4.4 \\
119.3
\end{array}
$$$$
6.8
$$$$
130.8
$$$$
0.07
$$

BANGE

$$
\text { SAMPLE }
$$$$
\text { SIZE }
$$

REGRESSION COEFICIENT, EGESS ION SUMMABY

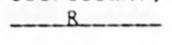

CONSTANT, CORRELATION STANOARD 30.5 489

$9440 \quad 11$ 0.79 0.95

0.9513

$3.00 \quad 13$

$\begin{array}{rr}-14.474 & 6758.156 \\ 0.0015 & 7.1923 \\ -0.00094 & 0.67649 \\ -0.00147 & 0.85434 \\ -0.00070 & 1.36523 \\ 8.210 & 444.383\end{array}$

$-0.735$ -0.735
0.616 $-0.005$ $-0.630$ -0.128 *

\begin{tabular}{|c|c|c|c|c|c|}
\hline & & & & & STANDARD \\
\hline & HARMONIC & AMPLITUDE & PHASE & VAR IATION & ERROR OF \\
\hline SAMPLE & MEAN - $M$ & $-{ }^{A}$ & ANGLE - C & EXPLAINED & ESTIMATE \\
\hline$-512 E$ & LEE & DQEG CL & (RADIANS) & -181 & $10 E 6$ C 1 \\
\hline 362 & 17.70 & 11.49 & 2.84 & 93 & 2.20 \\
\hline
\end{tabular}
0.580

366

100

1200

\begin{tabular}{|c|c|c|c|c|c|c|}
\hline \multirow{2}{*}{ CONSTI TUENT } & \multicolumn{3}{|c|}{ TOTAL } & \multicolumn{3}{|c|}{ DISSOLVED } \\
\hline & $\begin{array}{l}\text { NO. } \\
\text { SAMPLES }\end{array}$ & $\begin{array}{l}\text { MIN IMUM } \\
\text { CONC. }\end{array}$ & $\begin{array}{l}\text { MAXIMUM } \\
\text { CONC. }\end{array}$ & $\begin{array}{l}\text { NO. } \\
\text { SAMPLES }\end{array}$ & $\begin{array}{l}\text { MINIMUM } \\
\text { CONC. }\end{array}$ & $\begin{array}{l}\text { MAXIMUM } \\
\text { CONC. }\end{array}$ \\
\hline \multicolumn{7}{|l|}{ MINOR ELEMENTS: } \\
\hline ARSENIC (AS), UG/L & 4 & 7 & 10 & 4 & 0 & 2 \\
\hline CADMIUM (CD), UG/L & 4 & $<10$ & 10 & 4 & 0 & 2 \\
\hline CHROMIUM (CR), UG $/ L$ & 4 & 0 & 10 & 4 & 0 & 0 \\
\hline COBALT $(C O), U G / L$ & 4 & $<50$ & $<50$ & 4 & 0 & 2 \\
\hline COPPER (CU), UG/L & 4 & 10 & 120 & 4 & 3 & 15 \\
\hline IRON (FE), UG/L & 4 & 7200 & 16000 & 4 & 0 & 80 \\
\hline LEAO $(P B), U G / L$ & 4 & $<100$ & $<100$ & 4 & 1 & 2 \\
\hline MANG ANESE $(M N), U G / L$ & 4 & 260 & 400 & 4 & 0 & 30 \\
\hline MERCURY (HG), UG/L & 3 & 0.1 & 0.3 & 4 & 0.0 & 0.3 \\
\hline SELENIUM (SE), UG/L & 4 & 0 & 2 & 4 & 0 & 0 \\
\hline$Z I N C(Z N), U G / L$ & 4 & 60 & 100 & 4 & 30 & 40 \\
\hline \multicolumn{7}{|l|}{ PERIPHYTON: } \\
\hline BIOMASS, DRY WT., G/SO M & 1 & 1.50 & & & & \\
\hline BIOMASS, ASH WT., G/SO M & $i$ & .79 & & & & \\
\hline CHLOROPHYLL A, MG/SO M & 1 & .0 & & & & \\
\hline CHLOROPHYLL B, MG/SU M & 1 & .1 & & & & \\
\hline ORGANIC CARBON, MG/L & 4 & 6.8 & 12.0 & & & \\
\hline
\end{tabular}

2000

2000
21.0
60.0
17.0

11.0
3.7
278

278

26.0
8.6

2.6

$286 \quad 13$

$230 \quad 13$

$\begin{array}{rr}13 & 13 \\ 400 & 13\end{array}$

$0.3 \quad 13$

*Not significant at the 95 percent confidence level.

QURAIION IABLE OF DALIY SPECIEIC CONDUCIANCE

DAILY SPECIFIC CONDUCTANCE IN

MAILY SPECIFIC CONDUC TANCE IN

EQUALLED OR EXCEEDED FOR THE

$12 \quad-5$

$Y$ SPECIELC CONDUCIANCE
$10 \% \quad 20 z \quad 30 z \quad 508$

$\begin{array}{llllll}535 & 519 & 476 & 416 & 389 & 323\end{array}$

\begin{tabular}{rrrr} 
& & \multicolumn{2}{c}{ SAMPLE S12K_ $=364$} \\
708 & 208 & $95 \%$ & $99 \%$ \\
249 & 130 & 47 & 55
\end{tabular}

SUMMARY OF HARMONIC ANALYSIS OF STREAM TEMPERATURE

SUMMARY CF MAXIMUM AND MINIMUM CONCENTRATIONS OF CONSTITUENTS SAMPLED AT A FREQUENCY OF QUARTERLY (1975 WY)

07047800 -- ST. FRANCIS RIVER AT PARKIN, ARK. 
Table 14.--Summary of measurements at each station--Continued

LAT 35D15M34S LONG 090040M48S

DRAINAGE AREA: 0 SO MI

PERIOD OF RECORD: $10 / 01 / 74-09 / 30 / 75$ SQ KM

STATISTICAL SUMMARY OF SELECTED DISSOLVED CHEMICAL CONSTITUENTS AND

REGRESSION RELATIONSHIPS OF CONSTITUENT CONCENTRATIONS TO SPECIFIC CONDUCTANCE

CONSIIUUEN

CONSIUUUENI IMG/L OR UNDISSHOHNU

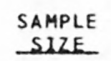

TEMPERATURE, WATER (DEG C) SPECIFIC CONDUCTANCE (MICROMHOS) STREAMFLOW (CUBIC FT/SEC) PH (STANDARD UNITS) PHOSPHORUS, TOTAL

NITRITE + NITRATE, TOTAL NITROGEN, KJELDAHL, TOTAL PHYTOPLANKTON, TOTAL (CELLS/ML) SEDIMENT, SUSPENDED

SEDIMENT, CLAY-SILT (PERCENT) COLIFORM, FECAL (COL/100 ML) STREPTOCOCCI, FECAL (COL/100 ML) SILICA, DISSOLVED

CALCIUM, DISSOL VED

MAGNE SIUM, DISSOLVED

SODIUM, DISSOLVED

POTASSIUM, DISSOLVED

BICARBONATE, ION

CARBONATE, ION

SULFATE, DISSOLVED

CHLORIDE, DISSOLVED

DISSOLVED SOLIDS, SUM OF CONST

DISSOLVED SOLIDS, ROE 180 DEG

HARDNESS, TOTAL

HARDNESS, NONCARBONATE

TURBIDITY (JTU)

FLOURIDE, DISSOLVED
STANDARD

DEYIALION

$16.79 \quad 9.69$

$\begin{array}{ll}16.79 & 9.69 \\ 231.4 & 81.7\end{array}$

$8402.7 \quad 10937.2$

7.64

0.279
0.161

0.161

0.927
8369.1

8369.1
143.4

96.0

193.9

484.0

10.83

26.67

8.52
6.97

6.97
1.97

1.97
119.4

119.4
0.0
12.08
5.52

5.52

131.7

143.2

102.8

4.4
86.8

86.8
0.17

0.36
0.156

0.156
0.096

0.501

9565.0

86.6

252.1

252.1

715.0

3.78

10.25
3.25

3.25
1.47

0.37

46.9

0.0
3.41

1.88

44.3

43.1

39.5

3.9
81.8

81.8
0.10

\section{N}

BANGE

$$
\begin{array}{rr}
4.0 & 30.0 \\
68 & 318
\end{array}
$$

2170
7.2

0.10

$0.02 \quad 0.61$

0.47

350

47

87

8
25

25
3.9

3.9
7.0
2.3

2.3
4.6

4.6
1.3

30

0.6
2.8

2.8

44
55

55
27

0
3

0.1

2.20
34000

331

100
770

2000

16.0

39.0

13.0
9.2

9.2
2.5

179

18.0

8.3
186

186

190
150
12

12
300
0.4
REGRESSION_SUMMARY

REGRESSION

SAMPLE COEFICIENT, CONSTANT, CORRELATION STANDARD SIZE - R - B COEEICIENI ESIUMAIE

$\begin{array}{rrrrr}11 & -112.493 & 33672.840 & -0.845 & 0172.2 \\ 12 & 0.0021 & 7.1477 & 0.491^{*} & 0.32 \\ 12 & -0.00117 & 0.55096 & -0.616 & 0.129 \\ 12 & -0.00096 & 0.38332 & -0.817 & 0.058 \\ 12 & -0.00205 & 1.40251 & -0.335 * & 0.495 \\ 11 & 64.824 & -6546.316 & 0.580 * & 8212.4\end{array}$

*Not significant at the 95 percent confidence level.

DAILY SPECIFIC CONDUCTANCE IN

MICROMHOS AT 25 DEG C, THAT WAS

URAIION IABLE OF DAUL SPECIEIC CONOUCIANCE

EQUALLED OR EXCEEDED FOR THE

$\begin{array}{lll}18 & -58 & 108 \\ 396 & 378 & 365\end{array}$

208

302

508

12
12
12
12
12
12
12
12
12
12
12
12
12
12
12

0.0452
0.1241
0.0381
0.0155
0.0033
0.568
0.000
0.0195
0.0138
0.539
0.523
0.477
0.007
-0.829
-0.0002

0.3784

$-2.0528$

-2.0528
-0.2957

-0.2957
3.3807

1.1926

$-11.919$

0.000
7.5735

2.3259

6.981

22.088

22.088
-7.464

$-7.464$

278.671

278.671
0.2319

0.977

0.989

0.960

0.859

0.744
0.989

$0.000^{*}$

0.467 *

0.599

0.995

0.992

0.986 .

$-0.828$

$-0.208 *$

0.84
1.57
0.96
0.79
0.26
7.2
0.0
3.16
1.58
4.8
5.6
7.0
4.0
48.1
0.10

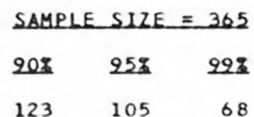

SUMMARY OF HARMONIC ANALYSIS OF STREAM TEMPERATURE

\begin{tabular}{|c|c|c|c|c|c|}
\hline & & & & & STANDARD \\
\hline & HARMONIC & AMPLITUDE & PHASE & VARIATION & ERROR OF \\
\hline SAMPLE & MEAN - M & $-A$ & ANGLE - C & EXP LA INED & ESTIMATE \\
\hline SIZE & DEG C) & $10 E G(1)$ & (RADLANS) & $-(2)$ & WEG C) \\
\hline 365 & 16.93 & 12.09 & 2.85 & 93 & 2.32 \\
\hline
\end{tabular}

SUMMARY OF HARMONIC ANALYSIS OF STREAM TEMPERATURE

SUMMARY OF MAXIMUM AND MINIMUM CONCENTRATIONS OF CONSTITUENTS

SAMPLED AT A FREQUENCY OF QUARTERLY (1975 WY)

\begin{tabular}{|c|c|c|c|c|c|c|}
\hline \multirow{2}{*}{ CONSTITUENT } & \multicolumn{3}{|c|}{ TOTAL } & \multicolumn{3}{|c|}{ DISSOLVED } \\
\hline & $\begin{array}{l}\text { NO. } \\
\text { SAMPLES }\end{array}$ & $\begin{array}{l}\text { MINIMUM } \\
\text { CONC. }\end{array}$ & $\begin{array}{l}\text { MAXIMUM } \\
\text { CONC. }\end{array}$ & $\begin{array}{l}\text { NO. } \\
\text { SAMPLES }\end{array}$ & $\begin{array}{l}\text { MINIMUM } \\
\text { CONC. }\end{array}$ & $\begin{array}{l}\text { MAXIMUM } \\
\text { CONC. }\end{array}$ \\
\hline \multicolumn{7}{|l|}{ MINOR ELEMENTS: } \\
\hline ARSENIC (AS), UG/L & 4 & 3 & 7 & 4 & 0 & 2 \\
\hline CADMIUM $(C D), U G / L$ & 4 & $<10$ & $<10$ & 4 & 0 & 3 \\
\hline CHROMIUM (CR), UGIL & 4 & 0 & 10 & 4 & 0 & 0 \\
\hline COBALT $(C O), U G / L$ & 4 & $<50$ & $<50$ & 4 & 0 & 1 \\
\hline COPPER (CU), UG/L & 4 & $<10$ & 110 & 4 & 3 & 13 \\
\hline IRON (FE), UG/L & 4 & 2900 & 10000 & 4 & 10 & 30 \\
\hline LEAD $(P B), U G / L$ & 4 & $<100$ & $<100$ & 4 & 1 & 2 \\
\hline MANG ANESE (MN), UG/L & 4 & 150 & 390 & 4 & 0 & 10 \\
\hline MERCURY (HG), UG/L & 2 & 0.0 & 0.3 & 4 & 0.0 & 0.0 \\
\hline SELENIUM (SE), UG/L & 4 & 0 & 0 & 4 & 0 & 0 \\
\hline ZINC $(Z N), U G / L$ & 4 & 40 & 50 & 4 & 10 & 30 \\
\hline \multicolumn{7}{|l|}{ PERIPHYTON: } \\
\hline BIOMASS, DRY WT., G/SQ M & 0 & & & & & \\
\hline BIOMASS, ASH WT,, G/SQ M & 0 & & & & & \\
\hline CHLOROPHYLL $A, M G / S Q M$ & 0 & & & & & \\
\hline CHLOROPHYLL B, MG/SQ M & 0 & & & & & \\
\hline ORGANIC CARBON, MG/L & 4 & 4.0 & 14.0 & & & \\
\hline
\end{tabular}

07047900 -- ST. FRANCIS BAY AT RIVERFRONT, ARK. 
Table 14.--Summary of measurements at each station--Continued

LAT 34D41M08S LONG 091018M55S

DRAINAGE AREA: 25497 SQ MI 106037 SQ KMI

PERIOD OF RECORD: $10 / 01 / 74-09 / 30 / 75$

STATISTICAL SUMMARY OF SELECTED DISSOLVED CHEMICAL CONSTITUENTS AND

REGRESSION RELATIONSHIPS OF CONSTITUENT CONCENTRATIONS TO SPECIFIC CONDUCTANCE

CONSIIIUENI

CONSILIUENT IMG/L OR UNII SHOWNI

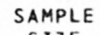

SLZE

MEAN

DEVIAIION

TEMPERATURE, WATER (DEG C) SPECIFIC CONDUCTANCE (MICROMHOS) STREAMFLOW (CUBIC FT/SEC)

PH (STANDARD UNITS)

PHOSPHORUS, TOTAL

NITRITE + NITRATE, TOTAL

NITROGEN, KJELOAHL, TOTAL

PHYTOPLANKTON, TOTAL (CELLS/ML)

SEDIMENT, SUSPENDED

SEDIMENT, CLAY-SILT (PERCENT)

COLIFORM, FECAL (COL/100 ML)

STREPTOCOCCI, FECAL (COL $/ 100 \mathrm{ML})$

SILICA, DISSOLVED

CALCIUM, DISSOLVED

MAGNESIUM, DISSOLVED

SODIUM, DISSOLVED

POTASSIUM, DISSOLVED

BICARBONATE, ION

CARBONATE, ION

SULFATE, DISSOLVED

CHLORIDE, DISSOLVED

CHLORIDE, DISSOLVED

OISSOLVED SOLIDS, SUM OF CONST DISSOLVED SOLIDS,

HARDNESS, TOTAL
HARONESS, NONCARBONATE

HARONESS, NONCA
TURBIDITY (JTU)

FLOUR IDE, DISSOLVED

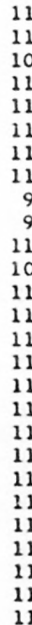

17.09

228.5

39240.0

7.75
0.092

0.092

0.191

2247.3

76.0

91.0

1207.5

263.4

5.86

27.00

10.41

3.98
1.61

1.61
130.5

130.5
0.0

5.90

4.78

124.0

125.9

110.7

3.9
36.1

0.10

8.73

42.6
20891.4

0.28

0.040

0.071

0.106

1914.2

34.7
9.0

3583.0

268.4

1.55

5.29

2.36

1.25

0.28

25.4

0.76

1.50

22.0

19.8

23.1

3.7
18.8

0.04

$6.0 \quad 31.0$

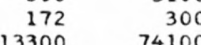

$13300 \quad 74100 \quad 10$

$0.01 \quad 0.16 \quad 11$

0.31

0.32

0.65
6100

$\begin{array}{ll}32 & 129\end{array}$

$3 \quad 12000$

3
24
2.7

20.0
7.1

2.4

1.3

0

4.7
3.2

3.2
95

105

0
10

12000
870

$\begin{array}{rr}870 & \\ 8.5 & 11\end{array}$

15.0

6.8
2.1

2.1
173
0

7. 3

8.6

160

159
150
10

80
0.2

*Not significant at the 95 percent confidence level.

\section{DURA WON IABLE OE DALLY SPECIEIC CONDUCIANCE}

DAILY SPECIFIC CONDUCTANCE IN

MICROMHOS AT 25 DEG C, THAT WAS

EQUALLED OR EXCEEDED FOR THE

$\begin{array}{llllll}18 & -52 & 108 & 208 & 308 & 508 \\ 303 & 291 & 279 & 263 & 248 & 220\end{array}$

BEGRESSION SUMMABY REGRESSION

SAMPLE COEFICIENT, CONSTANT, CORRELATION STANDARD SIZE

$\mathrm{R}$

0.0052

$-0.00025$

0.00071

36.956

0.5664
0.14875

0.02904

0.5708

$-6198.863$

$-0.913$

0.793
-0.267 *

$0.425^{*}$

$-0.123^{\star}$

0.822

9058.0

0.18

0.040

0.068

0.111
1147.7

11
11
11
11
11
11
11
11
11
11
11
11
11
11
11

0.0239

0.1206

0.0533

0.0119

$-0.0022$

0.580

0.000
-0.0000

0.0188

0.0188

0.447

0.536

0.052

$-0.237$

0.0005

0.4070

$-0.5533$

$-1.7638$

1.2629

2.1198

$-2.152$

0.000

5.9076

0.4838

7.415

23.673

$-11.709$

-8.023
90.222

$-0.0221$

0.655

0.971
0.961

0.406 *

$-0.339 *$

0.974

-0.002 *

0.533 *

0.987

0.963

0.988

0.597 .

-0.538 *
0.509 *

SAMPLE SIZE $=327$

$702 \quad 203 \quad 252998$

163

11201

SUMMARY OF HARMONIC ANALYSIS OF STREAM TEMPERATURE

\begin{tabular}{|c|c|c|c|c|c|}
\hline & & & & & STANDARD \\
\hline & HARMONIC & AMPLITUDE & PHASE & VARIATION & ERROR OF \\
\hline $\begin{array}{l}\text { SAMPLE } \\
\text { SUZE }\end{array}$ & $\begin{array}{l}\text { MEAN - M } \\
\text { LEEG C) }\end{array}$ & $\begin{array}{c}-A \\
\text { DEE }\end{array}$ & $\begin{array}{l}\text { ANGLE }-C \\
\text { (RADIANS) }\end{array}$ & $\begin{array}{c}\text { EXPLAINED } \\
(\Omega)\end{array}$ & $\begin{array}{l}\text { ESTIMATE } \\
\text { (DEG C) }\end{array}$ \\
\hline 332 & 17.13 & 9.36 & 2.77 & 95 & 1.52 \\
\hline
\end{tabular}

SUMMARY OF MAXIMUM AND MINIMUM CONCENTRATIONS OF CONSTITUENTS SAMPLED AT A FREQUENCY OF QUARTERLY (1975 WY)

07077800 -- WHITE RIVER AT CLARENDON, ARK.

\begin{tabular}{|c|c|c|c|c|c|c|}
\hline \multirow{2}{*}{ CONSTITUENT } & \multicolumn{3}{|c|}{ TOTAL } & \multicolumn{3}{|c|}{ DISSOLVEO } \\
\hline & $\begin{array}{l}\text { NO. } \\
\text { SAMPLES }\end{array}$ & $\begin{array}{l}\text { MINIMUM } \\
\text { CONC. }\end{array}$ & $\begin{array}{l}\text { MAXIMUM } \\
\text { CONC. }\end{array}$ & $\begin{array}{l}\text { NO. } \\
\text { SAMPLES }\end{array}$ & $\begin{array}{l}\text { MINIMUM } \\
\text { CONC. }\end{array}$ & $\begin{array}{l}\text { MAXIMUM } \\
\text { CONC. }\end{array}$ \\
\hline \multicolumn{7}{|l|}{ MINOR ELEMENTS: } \\
\hline ARSENIC (AS), UG/L & 4 & 1 & 3 & 4 & 0 & 1 \\
\hline CADMIUM $(C D), U G / L$ & 4 & 0 & $<10$ & 4 & 0 & 1 \\
\hline CHROMIUM (CR), UG/L & 4 & 0 & 10 & 4 & 0 & 10 \\
\hline COBALT $(C O), U G / L$ & 4 & $<50$ & 50 & 4 & 0 & 0 \\
\hline COPPER (CU), UG/L & 4 & 4 & 30 & 4 & 2 & 18 \\
\hline IRON $(F E), U G / L$ & 4 & 880 & 5300 & 4 & 0 & 40 \\
\hline LEAD $(P B), U G / L$ & 4 & $<100$ & $<100$ & 4 & 0 & 2 \\
\hline MANG ANESE (MN), UG/L & 4 & 80 & 230 & 4 & 0 & 40 \\
\hline MERCURY $(H G), U G / L$ & 4 & 0.0 & 0.5 & 4 & 0.0 & 0.5 \\
\hline SELENIUM $(S E), U G / L$ & 4 & 0 & 1 & 4 & 0 & 0 \\
\hline$Z I N C(Z N), U G / L$ & 4 & 20 & 120 & 4 & 0 & 50 \\
\hline \multicolumn{7}{|l|}{ PERIPHYTON : } \\
\hline BIOMASS, DRY WT., G/SQ M & 5 & 3.09 & 1000.00 & & & \\
\hline BIOMASS, ASH WT., G/SQ M & 5 & 1.50 & 970.00 & & & \\
\hline CHLOROPHYLL A, MG/SQ M & 4 & .2 & 48.0 & & & \\
\hline CHLOROPHYLL B, MG/SQ M & 4 & .2 & 11.0 & & & \\
\hline ORGANIC CARBON, MG L & 4 & 3.6 & 6.3 & & & \\
\hline
\end{tabular}


Table 14,--Summary of measurements at each station--Continued

LAT 38D01M34S LONG 102000M41S

DRAINAGE AREA: 25410 SO MI ( 65812 SQ KMI

PERIOD OF RECORD: $10 / 01 / 74-09 / 30 / 75$

STATISTICAL SUMMARY OF SELECTED DISSOLVED CHEMICAL CONSTITUENTS AND REGRESSION RELATIONSHIPS OF CONSTITUENT CONCENTRATIONS TO SPECIFIC CONDUCTANCE

CONSIUTUENI

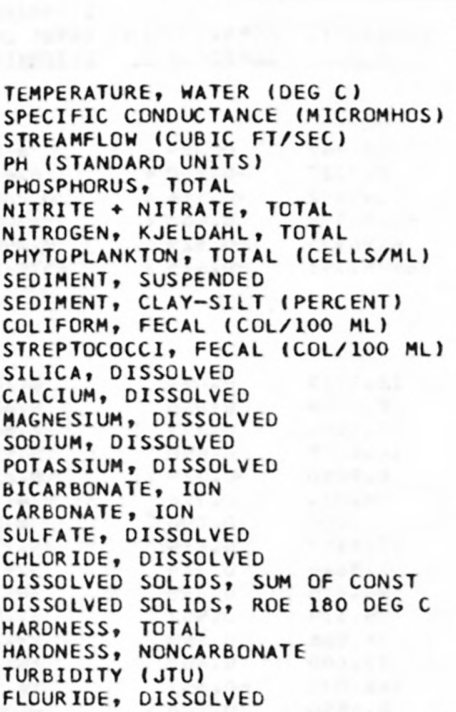

*Not significant at the 95 percent confidence level.

\section{SAMPLE}

SIZE

(5)

\section{STANDARD}

MEAN DEYIALION

20.20 4240.0

59.0

8.30

0.110

1.800

21400.0

387.8

256.7

256.7
583.3

583.3
13.56

356.00

160.00

526.00

12.80

266.0

2120.00

161.80

3482.0

3840 . 0

1560.0

1332.0

42.8
0.72

10.95

801.9

86.8

0.38

0.179

0.574

35245.7

339.1

384.8

384.8
631.2

631.2
2.96

66.56

37.42

123.21

1.79

0.0

460.43

41.31

866.8

866.8
279.3

279.3
277.7

60.8
0.04
41.31
728.7.

\section{BANGE}

1.5
3000

7
7.8

7.8
0.02

1.10

0.43

2800
46

10
110

110
8.8
240.0

240.0
110.0

110.0
310.0

11.0

231

1300.0

1300.0
89.0

2190

2310

1100
860

860
1
REGRESSION SUMMARY

REGRESSION

SAMPLE COEFICIENT,

CONSTANT, CORRELATION COEEICIENI

ST ANDARD ERROR OF 28.5 5200
212 212
8.6
0.43 0.43
2.60 1.10 84000

7000 B $B$

ESIUMAIE

SUMMARY OF MAXIMUM AND MINIMUM CONCENTRATIONS OF CONSTITUENTS SAMPLED AT A FREQUENCY OF QUARTERLY (1975 WY)

\section{0}

1300

16.0
400.0

190.0

620.0

15.0

300
0

2400.0

190.0

3970

4440
1800

1500

150

0.8

$\begin{array}{rrr}5 & -0.096 & 464.869 \\ 4 & 0.0003 & 6.8735 \\ 5 & -0.00020 & 0.94416 \\ 5 & 0.00035 & 0.33282 \\ 5 & -0.00024 & 1.74068 \\ 5 & 5.568 & -2207.055\end{array}$

$-0.885$

-0.885
$0.812 *$

-0.881 *

$0.483^{*}$

$-0.650^{*}$

$0.127^{*}$

46.7

0.27

0.098

0.581

0.255

40370.1

$\begin{array}{rr} & \\ 5 & -0.0016 \\ 5 & 0.0722 \\ 5 & 0.0156 \\ 5 & 0.1185 \\ 5 & 0.0004 \\ 5 & 0.013 \\ 4 & 0.000 \\ 5 & 0.4767 \\ 5 & 0.0423 \\ 5 & 0.732 \\ 5 & 0.896 \\ 5 & 0.209 \\ 5 & 0.234 \\ 5 & -0.066 \\ 5 & -0.0000\end{array}$

$-0.422^{*}$

$0.870^{*}$

$0.333^{*}$

$0.771^{*}$

$0.330^{*}$

$0.000^{*}$

$0.830^{*}$

$0.821^{*}$

$0.825^{*}$

$0.805^{*}$

$0.829^{*}$

0.601 *

$0.675^{*}$

$-0.877^{*}$

$-0.098^{*}$
3. 10

37.85

40.73

90.55

34.1

0.0

296.42

27.20

499.2

560.2

257.8

236.5

33.7

0.05

07137500 - ARKANSAS RIVER NEAR COOLIDGE, KANS.

\begin{tabular}{|c|c|c|c|c|c|c|}
\hline \multirow{2}{*}{ CONSTI TUENT } & \multicolumn{3}{|c|}{ TOTAL } & \multicolumn{3}{|c|}{ DISSOLVED } \\
\hline & $\begin{array}{l}\text { NO. } \\
\text { SAMPLES }\end{array}$ & $\begin{array}{l}\text { MINIMUM } \\
\text { CONC. }\end{array}$ & $\begin{array}{l}\text { MAXIMUM } \\
\text { CONC. }\end{array}$ & $\begin{array}{l}\text { NO. } \\
\text { SAMPLES }\end{array}$ & $\begin{array}{l}\text { MINIMUM } \\
\text { CONC. }\end{array}$ & $\begin{array}{l}\text { MAXIMUM } \\
\text { CONC. }\end{array}$ \\
\hline \multicolumn{7}{|l|}{ MINOR ELEMENTS: } \\
\hline ARSENIC (AS), UG/L & 2 & 0 & 0 & 2 & 0 & 1 \\
\hline CAOMIUM $(C D), U G / L$ & 2 & 20 & 20 & 2 & 0 & 0 \\
\hline CHROMIUM (CR), UG/L & 2 & 10 & 10 & 2 & 10 & 10 \\
\hline COBALT $(C O), U G / L$ & 2 & $<50$ & 100 & 2 & 0 & 0 \\
\hline COPPER $(C U), U G / L$ & 2 & 20 & 30 & 2 & 1 & 3 \\
\hline IRON (FE), UG/L & 2 & 650 & 1500 & 2 & 0 & 10 \\
\hline LEAD $(P B), U G / L$ & 2 & $<100$ & 100 & 2 & 0 & 0 \\
\hline MANGANESE $(M N), U G / L$ & 2 & 50 & 160 & 2 & 30 & 110 \\
\hline MERCURY (HG), UG/L & 2 & 0.0 & 0.2 & 2 & 0.0 & 0.0 \\
\hline SELENIUM (SE), UG/L & 2 & 21 & 25 & 2 & 21 & 25 \\
\hline ZINC $(Z N), U G / L$ & 2 & 20 & 70 & 2 & 10 & 30 \\
\hline \multicolumn{7}{|l|}{ PERIPHYTON: } \\
\hline BIOMASS, DRY WT., G/SO M & 1 & 2.19 & & & & \\
\hline BIOMASS, ASH WT., G/SO M & 1 & .39 & & & & \\
\hline CHLOROPHYLL A, MG/SO M & 1 & 1.0 & & & & \\
\hline CHLOROPHYLL B, MG/SO M & 1 & $\cdot 3$ & & & & \\
\hline ORGANIC CARBON, MG/L & 2 & 5.3 & 8.5 & & & \\
\hline
\end{tabular}


LAT 37044M51S LONG 100001M08S

DRAINAGE AREA: 30600 SQ MI $(79254$ SQ KM)

PERIOD OF RECORD: $10 / 01 / 74-09 / 30 / 75$

STATISTICAL SUMMARY OF SELECTED DISSOLVED CHEMICAL CONSTITUENTS AND REGRESSION RELATIONSHIPS OF CONSTITUENT CONCENTRATICNS TO SPECIFIC CONDUCTANCE

CONSIITUENI

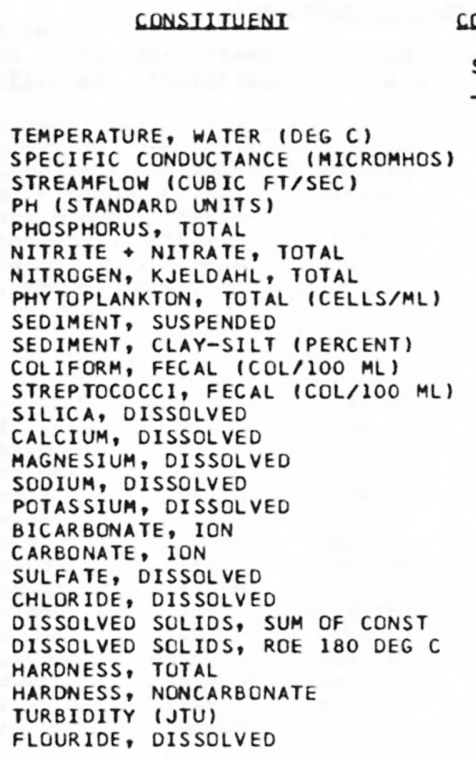

CONSIUIUENT_MGLL OR UNII_SHOHN

\begin{tabular}{c} 
SAMPLE \\
SIZE \\
\hline 21 \\
21 \\
29 \\
21 \\
21 \\
10 \\
10 \\
9 \\
11 \\
0 \\
10 \\
10 \\
21 \\
21 \\
22 \\
21 \\
21 \\
21 \\
17 \\
21 \\
21 \\
21 \\
21 \\
21 \\
21 \\
21 \\
21
\end{tabular}

\section{STANDARD}

DEYIAIION

14.83

15.1

15.1
7.89

0.151

2.194

0.818

2364.1
60.0

3978.4

2926.0

15.04

129.57

42.00

116.00

6.62
266.0

266.0
0.0

440.95

42.33

928.8

973.1

494.8

275.2

14.0
0.88
10.80

125.0

8.2

0.41
0.260

1.391

0.657

2648.6

44.7

9439.1

8810.9

6.03

14.52

3.90

10.95
0.65

34.6

0.0

43.23
5.56

5.56

85.3

86.4

47.7

27.1
21.2
0.09
BANGE

$\begin{array}{ll}0.5 & 32.0 \\ 940 & 1660\end{array}$

$\begin{array}{rr}940 & 1660 \\ 0 & 24 \\ 7.0 & 8.7 \\ 0.00 & 1.20\end{array}$

0.00

0.14

0.43

47
17

$10 \quad 30000$

$\begin{array}{rr}10 & 30000 \\ 6 & 28000 \\ 5.8 & 27.0\end{array}$

$\begin{array}{rr}5.8 & 27.0 \\ 91.0 & 150.0\end{array}$

29.0
76.0

5.6

205

280.0

27.0

636

673

350
170

170
1

0.7

150.0
47.0

47.0
130.0

130.0
8.0

325
0

490.0
50.0

1040

$1+20$

560

300
95

95
1.1

*Not significant at the 95 percent confidence level.

DURAIION IABLE OF PAILY SPECIEIC CONDUCIANCE

DAILY SPECIFIC CONDUCTANCE IN

MICROMHOS AT 25 DEG C, THAT WAS

EQUALLED OR EXCEEDED FOR THE

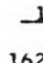

18

$5210 x$

208

$30 z$

503

$1410 \quad 1400 \quad 1390$

BEGRESSION SUMMARY

REGRESSION

SAMPLE COEFICIENT, CONSTANT, CORRELATION ERROR OF SIZE - B - B COEEICIENI ESIUMAIE

$\begin{array}{rrrrr}21 & 0.022 & -15.442 & 0.329 * & 8.0 \\ 21 & -0.0006 & 8.7327 & -0.190 * & 0.41 \\ 21 & -0.00024 & 0.47392 & -0.114 * & 0.265 \\ 10 & 0.00364 & -2.76374 & 0.468 * & 1.304 \\ 10 & -0.00305 & 4.96975 & -0.829 & 0.390 \\ 9 & -10.388 & 16999.348 & -0.415 * & 2575.8\end{array}$

$\begin{array}{lrrrr}21 & 0.0026 & 11.4715 & 0.054^{*} & 6.18 \\ 21 & 0.0948 & 0.4609 & 0.816 & 8.62 \\ 21 & 0.0245 & 8.4596 & 0.777 & 2.54 \\ 21 & 0.0745 & 14.4615 & 0.850 & 5.92 \\ 21 & -0.0017 & 8.9080 & -0.324 * & 0.63 \\ 21 & 0.198 & -4.014 & 0.716 * & 24.7 \\ 17 & 0.000 & 0.000 & 0.000 * & 0.0 \\ 21 & 0.2816 & 57.3357 & 0.814 & 25.77 \\ 21 & 0.0324 & -1.8644 & 0.729 & 3.91 \\ 21 & 0.609 & 98.610 & 0.893 & 39.3 \\ 21 & 0.658 & 76.539 & 0.952 & 27.1 \\ 21 & 0.336 & 36.966 & 0.880 & 23.2 \\ 21 & 0.174 & 37.800 & 0.803 & 16.6 \\ 21 & -0.112 & 166.075 & -0.657 & 16.4 \\ 21 & 0.0001 & 0.6850 & 0.206 * & 0.09\end{array}$

SUMMARY OF HARMONIC ANALYSIS OF STREAM TEMPERATURE FORM OF EOUAIION: I. (D) $=M+A+$ SINC.0172 $+0+C$

\begin{tabular}{|c|c|c|c|c|c|}
\hline $\begin{array}{l}\text { SAMPLE } \\
\text { SIZE- }\end{array}$ & $\begin{array}{l}\text { HARMONIC } \\
\text { MEAN - M } \\
\text { LDEG_L }\end{array}$ & $\begin{array}{c}\text { AMPLITUDE } \\
-A \\
\text { (DEG_CL }\end{array}$ & $\begin{array}{c}\text { PHASE } \\
\text { ANGLE - C } \\
\text { IBADIANSI }\end{array}$ & $\begin{array}{l}\text { VAR IATION } \\
\text { EXPLAINED } \\
(\xi) \\
\end{array}$ & $\begin{array}{l}\text { STANDARD } \\
\text { ERROR OF } \\
\text { ESTIMATE } \\
\text { (DEG_C) }\end{array}$ \\
\hline 305 & 14.74 & 13.28 & 2.84 & 91 & 3.00 \\
\hline
\end{tabular}

SUMMARY OF MAXIMUM AND MINIMUM CONCENTRATIONS OF CONSTITUENTS SAMPLED AT A FREQUENCY OF QUARTERLY (1975 WY)

07139500 -- ARKANSAS R AT DODGE CITY, KS

\begin{tabular}{|c|c|c|c|c|c|c|}
\hline \multirow{2}{*}{ CONSTI TUENT } & \multicolumn{3}{|c|}{ TOTAL } & \multicolumn{3}{|c|}{ DISSOLVED } \\
\hline & $\begin{array}{l}\text { NO. } \\
\text { SAMPLES }\end{array}$ & $\begin{array}{l}\text { MIN IMUM } \\
\text { CONC. }\end{array}$ & $\begin{array}{l}\text { MAXIMUM } \\
\text { CONC. }\end{array}$ & $\begin{array}{l}\text { NO. } \\
\text { SAMPLES }\end{array}$ & $\begin{array}{c}\text { MINIMUM } \\
\text { CONC. }\end{array}$ & $\begin{array}{l}\text { MAXIMUM } \\
\text { CONC. }\end{array}$ \\
\hline \multicolumn{7}{|l|}{ MINOR ELEMENTS: } \\
\hline ARSENIC (AS), UG/L & 5 & 0 & 2 & 5 & 0 & 2 \\
\hline CADMIUM $(C D)$, UG/L & 5 & $<10$ & 10 & 5 & 0 & 3 \\
\hline CHROMIUM (CR), UG/L & 5 & 0 & 10 & 5 & 0 & 0 \\
\hline COBALT $(C O), U G / L$ & 5 & 0 & $<50$ & 5 & 0 & 1 \\
\hline COPPER (CU), UG/L & 5 & $<10$ & 50 & 5 & 1 & 4 \\
\hline IRON (FE), UG/L & 5 & 110 & 660 & 7 & 10 & 90 \\
\hline LEAD $(P B), U G / L$ & 5 & $<100$ & 100 & 5 & 1 & 6 \\
\hline MANGANESE (MN), UG/L & 5 & 0 & 70 & 7 & 0 & 20 \\
\hline MERCURY (HG), UG/L & 4 & 0.0 & 0.3 & 5 & 0.0 & 1.2 \\
\hline SELENIUM (SE), UG/L & 4 & 10 & 34 & 4 & 10 & 15 \\
\hline ZINC $(Z N), U G / L$ & 5 & 20 & 450 & 4 & 0 & 20 \\
\hline \multicolumn{7}{|l|}{ PER IPHYTON: } \\
\hline BIOMASS, DRY WT.. G/SO M & 1 & 16.00 & & & & \\
\hline BIOMASS, ASH WT., G/SO M & 1 & 11.00 & & & & \\
\hline CHLOROPHYLL A, MG/SQ M & 1 & 4.1 & & & & \\
\hline CHLOROPHYLL B, MG/SO M & 1 & .2 & & & & \\
\hline ORGANIC CARBON, MG/L & 4 & 4.2 & 9.5 & & & \\
\hline
\end{tabular}


Table 14.--Summary of measurements at each station--Continued

LAT 37D03M23S LONG 097003M32S

DRAINAGE AREA: 43713 SQ MI ( 113217 SQ KM)

PERIOD OF RECORD: 10/01/74 - 09/30/75

STATISTICAL SUMMARY OF SELECTED DISSOLVED CHEMICAL CONSTITUENTS AND REGRESSION RELATIONSHIPS OF CONSTITUENT CONCENTRATIONS TO SPECIFIC CONDUCTANCE

CONSIIUENI

CONSIUUUENT MMGLL OR UNII SHOWNW

TEMPERATURE, WATER (DEG C) SPECIFIC CONDUCTANCE (MICROMHOS) STREAMFLOW (CUBIC FT/SEC) PH (STANDARD UNITS) PHOSPHORUS, TOTAL

NITRITE + NITRATE, TOTAL

NITROGEN, KJELDAHL, TOTAL

PHYTOPLANKTON, TOTAL (CELLS/ML)

SEDIMENT, SUSPENDED

SEDIMENT, CLAY-SILT (PERCENT)

COLIFORM, FECAL (COL/100 ML)

STREPTOCOCCI, FECAL $(\mathrm{COL} / 100 \mathrm{ML})$

SILICA, DISSOLVED

CALCIUM, DISSOLVED

MAGNESIUM, DISSOLVED

SODIUM, DISSOLVED

POTASSIUM, DISSOLVED

BICARBONATE, ION

CARBONATE, ION

SULFATE, DISSOLVED

CHLORIDE, DISSOLVED

DISSOLVED SOLIDS, SUM OF CONST

DISSOLVED SOLIDS, ROE 180 DEG

HARDNESS, TOTAL

HARDNESS, NONCARBONATE

TURBIDITY (JTU)

FLOURIDE, DISSOLVED

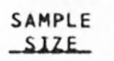

$\begin{array}{ll}\text { SAMPLE } & \text { STANDARD } \\ \text { SIZE MEAN } & \\ & \text { DEYIAIION }\end{array}$

2

$$
\begin{aligned}
& 4.5 \\
& 280
\end{aligned}
$$

7.3
0.05

$\begin{array}{rrr}15 & 16.50 & 7.33 \\ 14 & 1493.9 & 744.2 \\ 21 & 6380.3 & 9616.3 \\ 14 & 8.13 & 0.47 \\ 14 & 0.586 & 0.340 \\ 12 & 0.913 & 0.901 \\ 12 & 2.242 & 0.776 \\ 11 & 88840.0 & 104385.8 \\ 5 & 1315.0 & 478.8 \\ 0 & & \\ 13 & 6482.5 & 12629.8 \\ 13 & 1411.8 & 2775.7 \\ 14 & 8.13 & 3.91 \\ 14 & 73.14 & 32.75 \\ 14 & 16.71 & 7.84 \\ 14 & 188.93 & 103.72 \\ 14 & 7.88 & 5.86 \\ 14 & 186.6 & 66.9 \\ 11 & 0.0 & 0.0 \\ 14 & 108.79 & 59.43 \\ 14 & 283.71 & 160.31 \\ 14 & 781.9 & 388.8 \\ 14 & 798.4 & 393.5 \\ 14 & 250.1 & 109.1 \\ 14 & 97.3 & 57.3 \\ 15 & 91.7 & 76.7 \\ 14 & 0.39 & 0.11\end{array}$

$280 \quad 26.0$

$586 \quad 30500$

0.05

0.01
1.50

440

655

9.0
1.30

1.30
2.40

2.40
4.10

4.10
280000

1900

100
19

0.6

17.0
4.2

4.2
21.0

21.0
5.2

74
0

16.0

30.0

136

142

60

20
0.2

46000
9900
14.0
120.0
26.0
320.0
28.0
264
0
220.0
500.0
1210
1240
350
170
250
0.5

\begin{tabular}{l} 
SAMPL \\
SIZE \\
\hline \\
\\
14 \\
14 \\
14 \\
12 \\
12 \\
11 \\
\\
\\
14 \\
14 \\
14 \\
14 \\
14 \\
14 \\
11 \\
14 \\
14 \\
14 \\
14 \\
14 \\
14 \\
14 \\
14 \\
\end{tabular}

\section{BEGRESSION SUMMABY}

$\begin{array}{ll} & \text { REGRESSION } \\ \text { SAMPLE COEFICIENT, CONSTANT, CORRELATION ERTOARO }\end{array}$

- $R$ - B COEEICIENI

ERROR OF

ESIUMAIE

*Not significant at the 95 percent confidence level.

DAILY SPECIFIC CONDUCTANCE IN

MICROMHOS AT 25 DEG C, THAT WAS

EQUALLED OR EXCEEDED FOR THE

RAILON IABLE OF DALLY SPECIEIC CONDUCIANCE

INDALATED PERCENT

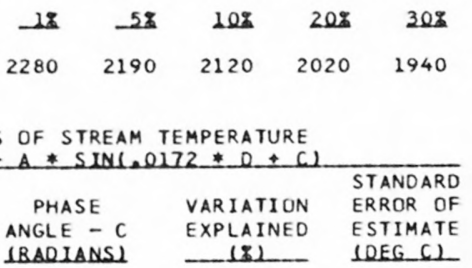

SUMMARY OF HARMONIC ANALYSIS OF STREAM TEMPERATURE

FORM OF EOUALION: I. $(D)=M+A * S I N C .0172 * 0+C$

\begin{tabular}{|c|c|c|c|c|c|}
\hline & & & & & STANDARD \\
\hline & HARMONIC & AMPLITUDE & PHASE & VARIATION & ERROR OF \\
\hline $\begin{array}{l}\text { SAMPLE } \\
\text { SIZE }\end{array}$ & $\begin{array}{l}\text { MEAN }-{ }^{M} \\
(D E G(C)\end{array}$ & $\left(0 \bar{E}{ }^{-A}(1)\right.$ & $\begin{array}{l}\text { ANGLE - C } \\
\text { (RADIANS) }\end{array}$ & $\begin{array}{c}\text { EXPLAINED } \\
(\%)\end{array}$ & $\begin{array}{l}\text { ESTIMATE } \\
\text { (DEG C) }\end{array}$ \\
\hline 364 & 14.66 & 12.36 & 2.83 & 91 & 2.74 \\
\hline
\end{tabular}

SUMMARY OF MAXIMUM AND MINIMUM CONCENTRATIONS OF CONSTITUENTS

SAMPLED AT A FREQUENCY OF QUARTERLY (1975 WY)

07146500 -- ARKANSAS R AT ARKANSAS CITY, KS

\begin{tabular}{|c|c|c|c|c|c|c|}
\hline \multirow{2}{*}{ CONSTITUENT } & \multicolumn{3}{|c|}{ TOTAL } & \multicolumn{3}{|c|}{ DISSOLVED } \\
\hline & $\begin{array}{l}\text { NO. } \\
\text { SAMPLES }\end{array}$ & $\begin{array}{l}\text { MIN IMUM } \\
\text { CONC. }\end{array}$ & $\begin{array}{l}\text { MAXIMUM } \\
\text { CONC. }\end{array}$ & $\begin{array}{l}\text { NO. } \\
\text { SAMPLES }\end{array}$ & $\begin{array}{l}\text { MINIMUM } \\
\text { CONC. }\end{array}$ & $\begin{array}{l}\text { MAXIMUM } \\
\text { CONC. }\end{array}$ \\
\hline \multicolumn{7}{|l|}{ MINOR ELEMENTS: } \\
\hline ARSENIC (AS), UG/L & 4 & 3 & 11 & 4 & 1 & 4 \\
\hline CADMIUM $(C D)$, UG/L & 4 & $<10$ & 20 & 4 & 0 & 2 \\
\hline CHROMIUM (CR), UG/L & 4 & 0 & 20 & 4 & 0 & 0 \\
\hline COBALT $(C O)$, UG/L & 4 & 50 & $<50$ & 4 & 0 & 0 \\
\hline COPPER $(C U), U G / L$ & 4 & $<0$ & 40 & 4 & 2 & 5 \\
\hline IRON (FE), UG/L & 4 & 770 & 19000 & 5 & 10 & 70 \\
\hline LEAD $(P B), U G / L$ & 4 & $<100$ & $<100$ & 4 & 1 & 8 \\
\hline MANGANESE (MN), UG/L & 3 & 60 & 280 & 5 & 0 & 20 \\
\hline MERCURY (HG), UG/L & 4 & 0.0 & 0.1 & 4 & 0.0 & 0.3 \\
\hline SELENIUM (SE), UG/L & 4 & 0 & 3 & 4 & 0 & 2 \\
\hline ZINC $(Z N), U G / L$ & 4 & 30 & 90 & 4 & 0 & 30 \\
\hline \multicolumn{7}{|l|}{ PERIPHYTON: } \\
\hline BIOMASS, DRY WT., G/SQ M & 2 & 30.00 & 47.00 & & & \\
\hline BIOMASS, ASH WT., G/SO M & 2 & 27.00 & 35.00 & & & \\
\hline CHLOROPHYLL A, MG/SO M & 2 & 2.3 & 54.0 & & & \\
\hline CHLOROPHYLL B, MG/SQ M & 2 & $\cdot 2$ & 4.1 & & & \\
\hline ORGANIC CARBON, MG/L & 4 & 7.1 & 20.0 & & & \\
\hline
\end{tabular}


Table 14,--Summary of measurements at each station--Continued

LAT 36055M28S LONG 099023M56S

DRAINAGE AREA: 11930 SQ MI 130899 SQ KM

PERIOD OF RECORD: $10 / 01 / 74-09 / 30 / 75$

STATISTICAL SUMMARY OF SELECTED DISSOLVED CHEMICAL CONSTITUENTS AND

REGRESSION RELATIONSHIPS OF CONSTITUENT CONCENTRATIONS TO SPECIFIC CONDUCTANCE

CONSIUIUENT

CONSIUIUENI
TEMPERATURE, WATER (DEG C)
SPECIFIC CONDUCTANCE (MICROMHOS)
STREAMFLOW (CUBIC FT/SEC)
PH (STANDARD UNITS)
PHOSPHORUS, TOTAL
NITRITE, NITRATE, TOTAL
NITROGEN, KJELDAHL, TOTAL
PHYTOPLANKTON, TOTAL (CELLS/ML)
SEDIMENT, SUSPENDED
SEDIMENT, CLAYSILT (PERCENT)
COLIFORM, FECAL (COL/IOO ML)
STREPTOCOCCI, FECAL (COL/1OO ML)
SILICA, DISSOLVED
CALCIUM, DISSOLVED
MAGNESIUM, DISSOLVED
SODIUM, DISSOLVED
POTASSIUM, DISSOLVED
BICARBONATE, ION
CARBONATE, ION
SULFATE, DISSOLVED
CHLORIDE, DISSOLVED
DISSOLVED SOLIDS, SUM OF CONST
DISSOLVED SOLIDS, ROE IBO DEG C
HARDNESS, TOTAL
HARDNESS, NONCARBONATE
TURBIDITY (JTU)
FLOURIDE, DISSOLVED
FONOTS,

CONSIUTUENI IMG/L OR UNII SHOHN

\begin{tabular}{rrr}
$\begin{array}{rrr}\text { SAMPLE } \\
\text { SIZE }\end{array}$ & MEAN & \multicolumn{1}{r}{ STANDARD } \\
\cline { 1 - 1 } & \multicolumn{1}{r}{ DEYIAIION } \\
10 & 15085 & 10.90 \\
41 & 8315.6 & 4716.2 \\
43 & 135.8 & 83.8 \\
43 & 8.11 & 0.33 \\
11 & 0.165 & 0.230 \\
12 & 0.200 & 0.168 \\
11 & 2.149 & 4.044 \\
6 & 23316.7 & 26697.7 \\
8 & 887.5 & 2024.2 \\
8 & 73.0 & 38.9 \\
10 & 1399.0 & 2418.6 \\
10 & 2092.0 & 2686.9 \\
10 & 16.80 & 2.94 \\
43 & 147.23 & 63.59 \\
43 & 52.91 & 17.68 \\
33 & 1768.18 & 1504.73 \\
38 & 8.25 & 1.98 \\
43 & 215.6 & 32.2 \\
43 & 0.6 & 2.4 \\
43 & 356.53 & 151.60 \\
40 & 2562.75 & 1779.90 \\
13 & 6615.2 & 5287.7 \\
41 & 5195.3 & 3584.5 \\
43 & 587.4 & 219.7 \\
43 & 408.3 & 216.8 \\
8 & 145.1 & 318.0 \\
10 & 0.62 & 0.20
\end{tabular}

BEGRESSION SUMMABY $\begin{array}{lll} & \text { REGRESSION } & \text { STANDARO } \\ \text { SAMPLE COEFICIENT, CONSTANT, CORRELATION ERROR OF }\end{array}$ BANGE SIZE R $B$ COEEICIENI ESIUMAIE

$\begin{array}{rr}0.5 & 31.0 \\ 1040 & 27000 \\ 2 & 392 \\ 7.1 & 8.9 \\ 0.03 & 0.83 \\ 0.01 & 0.50 \\ 0.27 & 14.00 \\ 2700 & 69000 \\ 55 & 5890 \\ 1 & 99 \\ 0 & 6200 \\ 0 & 7000 \\ 13.0 & 21.0 \\ 63.0 & 450.0 \\ 13.0 & 96.0 \\ 120.0 & 6700.0 \\ 0.4 & 12.0 \\ 158 & 273 \\ 0 & 11 \\ 81.0 & 1000.0 \\ 180.0 & 8900.0 \\ 795 & 18900 \\ 601 & 18900 \\ 210 & 1500 \\ 53 & 1300 \\ 4 & 930 \\ 0.3 & 0.9\end{array}$

$\begin{array}{rr}0.006 & 87.623 \\ -0.0000 & 8.3426 \\ -0.00001 & 0.26985 \\ -0.00000 & 0.24219 \\ -0.00014 & 3.68225 \\ -0.248 & 16668.660\end{array}$

0.330 $-0.395$ $-0.300^{*}$ -0.162 * $-0.233^{*}$ $-0.151 *$$$
\begin{array}{r}
0.00014 \\
-0.248
\end{array}
$$

16668.660

$$
\begin{array}{r}
-0.0001 \\
0.0079 \\
0.0028 \\
0.2242 \\
0.0000 \\
0.001 \\
-0.000 \\
0.0209 \\
0.3617 \\
0.580 \\
0.617 \\
0.031 \\
0.031 \\
-0.019 \\
-0.0000
\end{array}
$$

\begin{tabular}{|c|c|c|c|c|c|}
\hline & & & & & STANDARD \\
\hline & HARMONIC & AMPLITUDE & PHASE & VARIATION & ERROR OF \\
\hline $\begin{array}{l}\text { SAMPLE } \\
\text { SIZE - }\end{array}$ & $\begin{array}{l}\text { MEAN - M } \\
\text { (DEE C) }\end{array}$ & (DEG ${ }^{A}()$ & $\begin{array}{l}\text { ANGLE - C } \\
\text { (BADLANS) }\end{array}$ & $\begin{array}{l}\text { EXPLAINED } \\
(\pi)\end{array}$ & $\begin{array}{l}\text { ESTIMATE } \\
\text { IDEG E) }\end{array}$ \\
\hline
\end{tabular}

$\begin{array}{rr}-0.274^{*} & 2.77 \\ 0.581 & 52.56 \\ 0.822 & 9.24 \\ 0.991 & 104.96 \\ 0.109^{*} & 2.00 \\ 0.094^{*} & 33.2 \\ -0.281^{*} & 2.4 \\ 0.668 & 111.28 \\ 0.990 & 247.15 \\ 0.994^{*} & 438.4 \\ 0.997 & 213.4 \\ 0.691 & 157.1 \\ 0.688 & 155.2 \\ -0.457^{*} & 331.7 \\ -0.661^{*} & 0.17\end{array}$

DURAIION IABLE OE DAUY SPECIEIC CONDUCIANCE

DAILY SPECIFIC CONDUCTANCE IN MICROMHOS AT 25 DEG C, THAT WAS

EQUALLED OR EXCEEDED FOR THE

$\begin{array}{lrrrrr}2 \pi & -52 & 20 \% & 20 \% & 30 \% & 50 \%\end{array}$

SAMPLE SIZE $=324$

INDICATED PERCENT AGE OF TIME

$\begin{array}{llll}26700 \quad 16320 & 13277 \quad 10300\end{array}$

\begin{tabular}{|c|c|c|c|c|c|c|}
\hline \multirow{2}{*}{ CONSTITUENT } & \multicolumn{3}{|c|}{ TOTAL } & \multicolumn{3}{|c|}{ DISSOLVED } \\
\hline & $\begin{array}{l}\text { NO. } \\
\text { SAMPLES }\end{array}$ & $\begin{array}{l}\text { MINIMUM } \\
\text { CONC. }\end{array}$ & $\begin{array}{l}\text { MAXIMUM } \\
\text { CONC. }\end{array}$ & $\begin{array}{l}\text { NO. } \\
\text { SAMPLES }\end{array}$ & $\begin{array}{l}\text { MINIMUM } \\
\text { CONC. }\end{array}$ & $\begin{array}{l}\text { MAXIMUM } \\
\text { CONC. }\end{array}$ \\
\hline \multicolumn{7}{|l|}{ MINOR ELEMENTS: } \\
\hline ARSENIC (AS), UG/L & 3 & 4 & 28 & 3 & 2 & 4 \\
\hline CADMIUM (CD), UG/L & 3 & $<10$ & 40 & 3 & 1 & 3 \\
\hline CHROMIUM (CR), UG/L & 3 & 20 & 60 & 3 & 0 & 10 \\
\hline COBALT $(C O), U G / L$ & 3 & 50 & 350 & 3 & 0 & 0 \\
\hline COPPER $(C U), U G / L$ & 3 & 40 & 550 & 3 & 3 & 8 \\
\hline IRON (FE), UG/L & 3 & 3300 & 45000 & 3 & 30 & 110 \\
\hline LEAD $(P B), U G / L$ & 3 & $<100$ & 100 & 3 & 2 & 4 \\
\hline MANGANESE (MN), UG/L & 3 & 120 & 1300 & 3 & 10 & 70 \\
\hline MERC URY (HG), UG/L & 2 & 0.1 & 0.2 & 3 & 0.0 & 0.0 \\
\hline SELENIUM (SE), UG/L & 3 & 0 & 3 & 3 & 0 & 3 \\
\hline ZINC $(Z N), U G / L$ & 3 & 40 & 450 & 3 & 0 & 200 \\
\hline \multirow{2}{*}{\multicolumn{7}{|c|}{$\begin{array}{l}\text { PERIPHYTON: } \\
\text { BIOMASS, DRY WT., G/SQ M }\end{array}$}} \\
\hline & & & & & & \\
\hline BIOMASS, ASH WT, G/SO M & 0 & & & & & \\
\hline CHLOROPHYLL A, MG/SO M & 0 & & & & & \\
\hline CHLOROPHYLL B, MG/SQ M & 0 & & & & & \\
\hline ORGANIC CARBON, MG/L & 2 & 17.0 & 24.0 & & & \\
\hline
\end{tabular}

$252 \quad 29 \pi$

$2500 \quad 1940 \quad 1040$

SUMMARY OF HARMONIC ANALYSIS OF STREAM TEMPERATURE

337

14.77

10.66

2.85

86

3.08

SUMMARY OF MAXIMUM AND MINIMUM CONCENTRATIONS OF CONSTITUENTS SAMPLED AT A FREQUENCY OF QUARTERLY (1975 WY)

07157950 -- CIMARRON RIVER NR BUFFALO, OK 
Table 14.--Summary of measurements at each station--Continued

LAT 35057M32S LONG 097001M49S

DRAINAGE AREA: 17852 SQ MI 1446237 SQ KM

PERIOD OF RECORD: $10 / 01 / 74-09 / 30 / 75$

STATISTICAL SUMMARY OF SELECTED DISSOLVED CHEMICAL CONSTITUENTS AND

REGRESSION RELATIONSHIPS OF CONSTITUENT CONCENTRATIONS TO SPECIFIC CONDUCTANCE

CONSIIIUENI

TEMPERATURE, WATER (DEG C)
SPECIFIC CONDUCTANCE (MICROMHOS)
STREAMFLOW (CUBIC FT/SEC)
PH (STANDARD UNITS)
PHOSPHORUS, TOTAL
NITRITE NITRATE, TOTAL
NITROGEN, KJELDAHL, TOTAL
PHYTOPLANKTON, TOTAL (CELLS/ML)
SEDIMENT, SUSPENDED
SEDIMENT, CLAY-SILT (PERCENT)
COLIFORM, FECAL (COL/IOO ML)
STREPTOCOCCI, FECAL (COL/IOO ML)
SILICA, DISSOLVED
CALCIUM, DISSOLVED
MAGNESIUM, DISSOLVED
SODIUM, DISSOLVED
POTASSIUM, DISSOLVED
BICARBONATE, ION
CARBONATE, ION
SULFATE, DISSOLVED
CHLORIDE, DISSOLVED
DISSOLVED SOLIDS, SUM OF CONST
DISSOLVED SOLIDS, ROE I8O OEG C
HARDNESS, TOTAL
HARDNESS, NONCARBONATE
TURBIDITY (JTU)
FLOURIDE, DISSOLVED
FIS

CONSIUTUENI IHG LL OB UNDI SHOWNW

SAMPLE

$\begin{array}{rrr}17 & 13.35 & 9.21 \\ 45 & 4413.8 & 2017.1 \\ 50 & 4874.0 & 11478.3 \\ 49 & 8.06 & 0.35 \\ 45 & 0.391 & 0.288 \\ 11 & 0.667 & 0.425 \\ 14 & 1.948 & 2.159 \\ 11 & 21373.6 & 27015.3 \\ 9 & 579.9 & 705.6 \\ 8 & 67.9 & 25.9 \\ 12 & 3523.3 & 10259.5 \\ 11 & 2416.4 & 7170.5 \\ 10 & 12.00 & 2.95 \\ 47 & 130.85 & 46.89 \\ 49 & 44.40 & 17.46 \\ 43 & 809.12 & 413.65 \\ 43 & 6.45 & 1.19 \\ 49 & 261.4 & 81.9 \\ 49 & 0.2 & 1.1 \\ 45 & 314.91 & 128.31 \\ 44 & 1252.27 & 623.94 \\ 13 & 2417.0 & 831.3 \\ 47 & 2790.9 & 1232.6 \\ 47 & 507.9 & 183.5 \\ 47 & 291.5 & 124.2 \\ 11 & 174.6 & 289.6 \\ 11 & 0.37 & 0.16\end{array}$

BANGE

3.5
730
225
7.2
0.11
0.01
0.27
310
62

significant at the 95 percent confidence level.
DURALION_IABLE_OF_DALY SPECIEIC_CONDUCIANCE

DAILY SPECIFIC CONDUCTANCE IN

MICROMHOS AT 25 DEG C, THAT WAS

EQUALLED OR EXCEEDED FOR THE

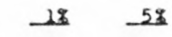

$11000 \quad 9120$

10\% 20\% $30 \% \quad 50 \%$

$7440 \quad 6550$

$\begin{array}{rr}32 & 99 \\ 0 & 36000 \\ 0 & 24000 \\ 7.3 & 18.0 \\ 39.0 & 200.0 \\ 7.7 & 74.0 \\ 82.0 & 1900.0 \\ 4.7 & 9.4 \\ 103 & 400 \\ 0 & 8 \\ 46.0 & 510.0 \\ 120.0 & 2900.0 \\ 991 & 3610 \\ 414 & 5570 \\ 130 & 790 \\ 41 & 490 \\ 7 & 1000 \\ 0.1 & 0.6\end{array}$
699 24000 18.0 74.0 74.0
900.0

\section{BEGRESSION SUMMARY}

SAMPLE REGRESSION

SIZE COEFICIENT,

CONSTANT CORRELATION ERROR OF 28.0 8970 75000 9.4
1.40 1.20 8.60 73000 2260
99 0.0001
-0.00005 $-0.00005$ $-0.00025$

12.092 876.461
0.8372 7.8372
0.63927 1.66135 6.28987

$-15125.707$

$-0.480$

0.303

$-0.358$

-0.618 *

$-0.720$

0.463 *

10707.9

0.32

0.279

0.416

1.792

30633.6
13.2453

37.2982

11.5533

$-117.5129$

6.2270

118.104

04.7874

$-171.5067$

136.276

$-94.788$

142.979
46.032

1382.531

0.1993
$-0.254 *$

0.887

0.813

0.992

0.101 *

0.772

-0.017 .

0.858

0.991

0.980

0.995

0.881

0.870

-0.871
0.529
3.15

21.82

10.43

56.06

1.22

50.3

67.77

89.10

182.2

182.2

122.3

63.3

200.2

0.13

SUMMARY OF HARMONIC ANALYSIS OF STREAM TEMPERATURE

EORM OE EOUAIION: I.1OI = M + A * SINL.0172*0+C

\begin{tabular}{|c|c|c|c|c|c|}
\hline & & & & & STANDARD \\
\hline & HARMONIC & AMPLITUDE & PHASE & VARIATION & ERROR OF \\
\hline SAMPLE & MEAN - M & $-A$ & ANGLE - C & EXPLAINED & ESTIMATE \\
\hline SIZE & $10 E G(1)$ & IDEG $(1)$ & (BADIANS) & (z) & (DEG $C)$ \\
\hline
\end{tabular}

363

15.85

12.77

2.81

91

2.83

SUMMARY OF MAXIMUM AND MINIMUM CONCENTRATIONS OF CONSTITUENTS

SAMPLED AT A FREQUENCY OF QUARTERLY (1975 WY)

07161000 -- CIMARRON RIVER AT PERKINS, OK

\begin{tabular}{|c|c|c|c|c|c|c|}
\hline \multirow{2}{*}{ CONSTITUENT } & \multicolumn{3}{|c|}{ TOTAL } & \multicolumn{3}{|c|}{ DISSOLVED } \\
\hline & $\begin{array}{l}\text { NO. } \\
\text { SAMPLES }\end{array}$ & $\begin{array}{l}\text { MINIMUM } \\
\text { CONC. }\end{array}$ & $\begin{array}{l}\text { MAXIMUM } \\
\text { CONC. }\end{array}$ & $\begin{array}{l}\text { NC. } \\
\text { SAMPLES }\end{array}$ & $\begin{array}{l}\text { MINIMUM } \\
\text { CONC. }\end{array}$ & $\begin{array}{l}\text { MAXIMUM } \\
\text { CONC. }\end{array}$ \\
\hline \multicolumn{7}{|l|}{ MINOR ELEMENTS: } \\
\hline ARSENIC (AS), UG/L & 3 & 4 & 11 & 3 & 2 & 9 \\
\hline CADMIUM $(C D)$, UG/L & 2 & 10 & 10 & 3 & 1 & 8 \\
\hline CHROMIUM (CR), UG/L & 2 & 10 & 20 & 3 & 0 & 10 \\
\hline COBALT (CO), UG/L & 2 & 50 & 60 & 3 & 0 & 2 \\
\hline COPPER $(C U), U G / L$ & 2 & 10 & 20 & 3 & 5 & 10 \\
\hline IRON $(F E), U G / L$ & 2 & 3800 & 6000 & 3 & 0 & 40 \\
\hline LEAD $(P B), U G / L$ & 2 & $<100$ & $<100$ & 3 & 2 & 4 \\
\hline MANGANESE $(M N), U G / L$ & 2 & 160 & 400 & 3 & 0 & 70 \\
\hline MERCURY $(H G), U G / L$ & 2 & 0.1 & 0.1 & 2 & 0.1 & 0.1 \\
\hline SELENIUM (SE), UG/L & 3 & 1 & 2 & 3 & 1 & 2 \\
\hline ZINC $(Z N), U G / L$ & 2 & 30 & 90 & 3 & 30 & 60 \\
\hline \multicolumn{7}{|l|}{ PERIPHYTON: } \\
\hline BIOMASS, DRY WT., G/SQ M & 0 & & & & & \\
\hline BIOMASS, ASH WT., G/SO M & 0 & & & & & \\
\hline CHLOROPHYLL A, MG/SQ M & 0 & & & & & \\
\hline CHLOROPHYLL B, MG/SO M & 0 & & & & & \\
\hline ORGANIC CARBON, MG/L & 6 & 4.8 & 20.0 & & & \\
\hline
\end{tabular}


Table 14.--Summary of measurements at each station--Continued

STATION NUMBER: 07164400

NAME: ARKANSAS RIVER AT SAND SPRINGS NR TULSA, OK

LAT 36006M48S LONG 096006M49S

DRAINAGE AREA: 74615 SO MI ( 193253 SQ KMI

PERIOD OF RECORD: 10/01/74 - 09/30/75

STATISTICAL SUMMARY OF SELECTED DISSOLVED CHEMICAL CONSTITUENTS AND

REGRESSION RELATIONSHIPS OF CONSTITUENT CONCENTRATIONS TO SPECIFIC CONDUCTANCE

CONSILTUENI

CONSIUIUENI IMG/L OR UNII SHOHNU

SAMP

STANDARD

DEXIAIION

8.81
447.5

18282.7

0.41

0.284

0.618

58731.3

114.7

32.4
3257.3

1342.6

2.12

14.87

5.86

5.86
65.46

65.46
1.24

43.3

0.6
32.35

32.35
108.91

108.91
161.9

247.8

61.1

34.7

34.7
69.3
0.08
BANGE

$\begin{array}{rr}4.0 & 31 . \\ 482 & 244 \\ 307 & 10000\end{array}$

$6.8 \quad 100000$

6.8

0.01

0.01
0.10

370
12

12

0
0
3.7

3.7
27.0

6.0

60.0

60.0
3.5

82
0

28.0

88.0
502

502
269

92

24

0.1

0.42

1.10
3.00

180000

99
16000
6600
REGRESSION SUMMABY $\begin{array}{lll} & \text { REGRESSION } & \text { STANDARD } \\ \text { SAMPLE COEFICIENT, CONSTANT, CORRELATION ERROR OF }\end{array}$ SIZE -B B - B COEEICIENI ESIIMAIE

0.42
1.10

351
99

$\begin{array}{llll}9.7 & 5 & -0.0028 & 9.9012\end{array}$

18.3134

1.1307

$-32.5847$

7.0643

61.455

0.227

$-1.7847$

$-48.9065$

$-32.472$

$-17.138$

41.176

$-15.174$

0.2170

$\begin{array}{rr}-0.502 & 16319.0 \\ 0.021^{*} & 0.42 \\ -0.616 & 0.055 \\ 0.257 & 0.289 \\ -0.023^{*} & 0.651 \\ -0.137^{*} & 78738.1\end{array}$

1.75

0.884

0.813

0.986

0.793

-0.051
0.911

0.987

0.975 *

0.997

0.892

0.883

$-0.676$

*Not significant at the 95 percent confidence level.

DAILY SPECIFIC CONDUCTANCE IN
MICROMHOS AT 25 DEG C, THAT WAS
EQULLED OR EXCEEDE FOR THE

SUMMARY OF HARMONIC ANALYSIS OF STREAM TEMPERATURE

\begin{tabular}{|c|c|c|c|c|c|}
\hline $\begin{array}{l}\text { SAMPLE } \\
\text { SUZE }\end{array}$ & $\begin{array}{l}\text { HARMONIC } \\
\text { MEAN - M } \\
\text { LEEG CI }\end{array}$ & $\begin{array}{c}\text { AMPLI TUDE } \\
-A \\
\text { (DEG CLI }\end{array}$ & $\begin{array}{c}\text { PHASE } \\
\text { ANGLE - C } \\
\text { LRADLANSI }\end{array}$ & $\begin{array}{l}\text { VAR IATION } \\
\text { EXPLAINED } \\
\text { (I) }\end{array}$ & $\begin{array}{l}\text { STANDARD } \\
\text { ERROR OF } \\
\text { ESTIMATE } \\
\text { LOEG CL }\end{array}$ \\
\hline 365 & 15.82 & 12.16 & 2.63 & 97 & 1.55 \\
\hline
\end{tabular}

SUMMARY OF MAXIMUM AND MINIMUM CONCENTRATIONS OF CONSTITUENTS SAMPLED AT A FREOUENCY OF OUARTERLY (1975 WY)

$07164400-$ - ARKANSAS RIVER AT SAND SPRINGS NR TULSA, OK

\begin{tabular}{|c|c|c|c|c|c|c|}
\hline \multirow{2}{*}{ CONSTITUENT } & \multicolumn{3}{|c|}{ TOTAL } & \multicolumn{3}{|c|}{ DISSOLVED } \\
\hline & $\begin{array}{l}\text { NO. } \\
\text { SAMPLES }\end{array}$ & $\begin{array}{l}\text { MIN IMUM } \\
\text { CONC. }\end{array}$ & $\begin{array}{l}\text { MAXIMUM } \\
\text { CONC. }\end{array}$ & $\begin{array}{l}\text { NO. } \\
\text { SAMPLES }\end{array}$ & $\begin{array}{l}\text { MINIMUM } \\
\text { CONC. }\end{array}$ & $\begin{array}{l}\text { MAXIMUM } \\
\text { CONC. }\end{array}$ \\
\hline \multicolumn{7}{|l|}{ MINOR ELEMENTS: } \\
\hline ARSENIC (AS), UG/L & 23 & 1 & 9 & 4 & 1 & 4 \\
\hline CADMIUM $(C D), U G / L$ & 23 & 0 & 10 & 4 & 1 & 2 \\
\hline CHROMIUM (CR), UG IL & 22 & 0 & 30 & 4 & 0 & 20 \\
\hline COBALT $(C O), U G / L$ & 4 & $<50$ & 50 & 4 & 0 & 1 \\
\hline COPPER (CU), UG/L & 4 & $<10$ & 50 & 4 & 2 & 13 \\
\hline IRON $(F E), U G / L$ & 23 & 300 & 26000 & 4 & 10 & 190 \\
\hline LEAD $(P B), U G / L$ & 23 & $<100$ & $<100$ & 4 & 1 & 6 \\
\hline MANG ANESE (MN), UG/L & 4 & 70 & 220 & 3 & 50 & 140 \\
\hline MERCURY $(H G), U G / L$ & 21 & 0.0 & 1.0 & 4 & 0.0 & 8.2 \\
\hline SELENIUM (SE), UG/L & 4 & 0 & 1 & 4 & 0 & 1 \\
\hline ZINC $(Z N), U G / L$ & 21 & 10 & 280 & 4 & 20 & 70 \\
\hline \multicolumn{7}{|l|}{ PERIPHYTON: } \\
\hline BIOMASS, DRY WT., G/SO M & 0 & & & & & \\
\hline BIOMASS, ASH WT., G/SO M & 0 & & & & & \\
\hline CHLOROPHYLL A, MG/SO M & 0 & & & & & \\
\hline CHLOROPHYLL B, MG/SO M & 0 & & & & & \\
\hline ORGANIC CARBON, MG/L & 19 & 4.0 & 21.0 & & & \\
\hline
\end{tabular}


Table 14,--Summary of measurements at each station---Continued

LAT 36D03M29S LONG 095032M06S

DRAINAGE AREA: 0 SO MI

PERIOD OF RECORD: $10 / 01 / 74-09 / 30 / 75$

O SQ KM)

STATISTICAL SUMMARY OF SELECTED DISSOLVED CHEMICAL CONSTITUENTS AND

REGRESSION RELATIONSHIPS OF CONSTITUENT CONCENTRATIONS TO SPECIFIC CONDUCTANCE

CONSIIIUENI

CONSIUUENI IMG/L_OR UNII SHOHNI

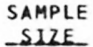

TEMPERATURE, WATER (DEG C)

SPECIFIC CONDUCTANCE (MICROMHOS)

STREAMFLOH (CUBIC FT/SEC)

PH (STANDARD UNITS)

PHOSPHORUS, TOTAL

NITRITE + NITRATE, TOTAL

NITROGEN, KJELDAHL, TOTAL

PHYTOPLANKTON, TOTAL (CELLS/ML)

SEOIMENT, SUSPENDED

SEDIMENT, CLAY-SILT (PERCENT)

COL IFORM, FECAL (COL/100 ML)

STREPTOCOCCI, FECAL (COL/100 ML)

SILICA, DISSOLVED

CALCIUM, DISSOLVED

MAGNESIUM, DISSOL VED

SODIUM, DISSOLVED

POTASSIUM, DISSOLVED

BICARBONATE, ION

CARBONATE, ION

SULFATE, DISSOLVED

CHLORIDE, DISSOLVED

OISSOLVED SOLIDS, SUM OF CONST

DISSOLVED SOLIDS, ROE 180 DEG C

HARDNESS, TOTAL

HARDNESS, NONCARBONATE

TURBIDITY (JTU)

FLOUR IDE, DISSOLVED

\section{STANDARD}

SIZE

\section{MEAN}

17.69

398.6

9665.0

7.77

0.155

0.446

0.635

218.8

153.0

88.2
877.0

877.0
226.3

6.45

45.23

8.51

27.62

3.00

135.9

0.

36.11
45.90

45.90
264.3

264.3
248.9

148.5

37.5

29.3

0.26
EYIAIION

7.92
112.1

112.1
8528.2

0.50

0.100

0.258

0.241

6000.7

222.6

1495.1

261.7

1.20

9.84

2.88

32.27

26.8

0.0
16.26

16.26
49.94

49.94
146.3

117.2

35.2

18.6

0.07
$B E G$

SAMPLE COEFICIENT, CONSTANT, CORRELATION ERROR OF SIZE

BANGE

$\begin{array}{rr}4.0 & 31.0 \\ 132 & 665\end{array}$

$\begin{array}{rr}132 & 665 \\ 176 & 28200\end{array}$

5.4

0.01

0.60

$0.21 \quad 1.20$

$890 \quad 19000$

$20 \quad 604$

$\begin{array}{rr}77 & 99 \\ 0 & 4100\end{array}$

$\begin{array}{rr}0 & 680 \\ 4.5 & 8.3\end{array}$

$15.0 \quad 73.0$

2.322 .0

$\begin{array}{ll}6.1 & 210.0 \\ 1.8 & 5.3\end{array}$

$50 \quad 191$

$\begin{array}{rr}0 & 120 \\ 12.0 & 120.0\end{array}$

$\begin{array}{rr}12.0 & 120.0 \\ 7.6 & 320.0\end{array}$

$\begin{array}{rl}164 & 851 \\ 88 & 887\end{array}$

$\begin{array}{ll}88 & 887 \\ 47 & 270\end{array}$

$\begin{array}{rr}6 & 120 \\ 14 & 66 \\ 0.2 & 0.4\end{array}$ -

$11 \quad-46.788$

$41 \quad 0.0004$ 0.00001

0.00025

0.00040

27.746

7.6292

0.15418

0.32062

0.46358

$-6960.984$

$0.078^{\circ}$

$0.007^{*}$

0.107

0.142
0.558

$-0.481$

0.739

0.670

0.410

$0.196^{*}$

0.629

$0.000^{*}$

0.441

0.505

0.406 *

0.569

0.727

0.671

$-0.036$

*Not significant at the 95 percent confidence leve1.

DAILY SPECIFIC CONDUCTANCE DURAIION IABLE OF DAILY SPECIEIC CONDUCIANCE

MICROMHOS AT 25 DE

EQUALLED OR EXCEEDED FOR THE

$\begin{array}{llllll}18 & 52 & 102 \quad 208 \quad 30 \% \quad 502\end{array}$

502

SAMPLE SIZE $=365$
$70 \%$ 20\% $25 \% \quad 293$

INDICATED PERCENTAGE OF TIME

701

$641 \quad 584$

441

410

$275 \quad 248 \quad 164$

SUMMARY OF HARMONIC ANALYSIS OF STREAM TEMPERATURE

\begin{tabular}{|c|c|c|c|c|c|}
\hline & & & & & STANDARD \\
\hline & HARMONIC & AMPLITUDE & PHASE & VARIATION & ERROR OF \\
\hline $\begin{array}{l}\text { SAMPLE } \\
\text { SIZE }\end{array}$ & MEAN - $M$ & $-A$ & ANGLE - C & EXPLAINED & $\begin{array}{l}\text { ESTIMATE } \\
\text { (DEG G) }\end{array}$ \\
\hline 364 & 16.24 & 12.77 & 2.67 & 96 & 1.86 \\
\hline
\end{tabular}

SUMMARY OF MAXIMUM AND MINIMUM CONCENTRATIONS OF CONSTITUENTS

SAMPLED AT A FREQUENCY OF QUARTERLY (1975 WY)

07178620 -- NEWT GRAHAM LOCK AND DAM NR INOLA, OK

\begin{tabular}{|c|c|c|c|c|c|c|}
\hline \multirow{2}{*}{ CONSTITUENT } & \multicolumn{3}{|c|}{ TOTAL } & \multicolumn{3}{|c|}{ DISSOLVEO } \\
\hline & $\begin{array}{l}\text { NO. } \\
\text { SAMPLES }\end{array}$ & $\begin{array}{l}\text { MINIMUM } \\
\text { CONC. }\end{array}$ & $\begin{array}{l}\text { MAXIMUM } \\
\text { CONC. }\end{array}$ & $\begin{array}{l}\text { NO. } \\
\text { SAMPLES }\end{array}$ & $\begin{array}{l}\text { MINIMUM } \\
\text { CONC. }\end{array}$ & $\begin{array}{l}\text { MAXIMUM } \\
\text { CONC. }\end{array}$ \\
\hline \multicolumn{7}{|l|}{ MINOR ELEMENTS: } \\
\hline ARSENIC (AS), UG/L & 2 & 1 & 4 & 2 & 1 & 3 \\
\hline CAUMIUM $(C D), U G / L$ & 2 & $<10$ & $<10$ & 2 & 0 & 1 \\
\hline CHROMIUM (CR), UGIL & 2 & 0 & 10 & 2 & 0 & 10 \\
\hline COBALT $(C O), U G / L$ & 2 & $<50$ & $<50$ & 2 & 0 & 0 \\
\hline COPPER (CU), UGIL & 2 & $<10$ & 10 & 2 & 3 & 4 \\
\hline IRON (FE), UG/L & 2 & 590 & 3000 & 2 & 30 & 130 \\
\hline LEAD $(P B), U G / L$ & 2 & $<100$ & $<100$ & 2 & 0 & 11 \\
\hline MANGANESE (MN), UG/L & 2 & 140 & 590 & 2 & 20 & 370 \\
\hline MERCURY $(H G), U G / L$ & 2 & 0.1 & 0.3 & 2 & 0.0 & 0.3 \\
\hline SELENIUM (SE), UG/L & 2 & 0 & 0 & 2 & 0 & 0 \\
\hline ZINC $(Z N), U G / L$ & 2 & 10 & 60 & 2 & 0 & 60 \\
\hline \multicolumn{7}{|l|}{ PERIPHYTON: } \\
\hline BIOMASS, DRY WT., G/SQ M & 0 & & & & & \\
\hline BIOMASS, ASH WT.. G/SO M & 0 & & & & & \\
\hline CHLOROPHYLL A, MG/SO M & 0 & & & & & \\
\hline CHLOROPHYLL B, MG/SO M & 0 & & & & & \\
\hline ORGANIC CARBON, MG/L & 2 & 6.6 & 9.1 & & & \\
\hline
\end{tabular}


Tab1e 14.--Summary of measurements at each station--Continued

-AT 35D51M15S LONG 095D13M45S

JRAINAGE AREA: 12495 SO MI 132362 SQ KM)

PERIOD OF RECORD: $10 / 01 / 74-09 / 30 / 75$

STATISTICAL SUMMARY OF SELECTED DISSOLVED CHEMICAL CONSTITUENTS AND REGRESSION RELATIONSHIPS OF CONSTITUENT CONCENTRATIONS TO SPECIFIC CONDUCTANCE

\section{GONSIUTUENI}

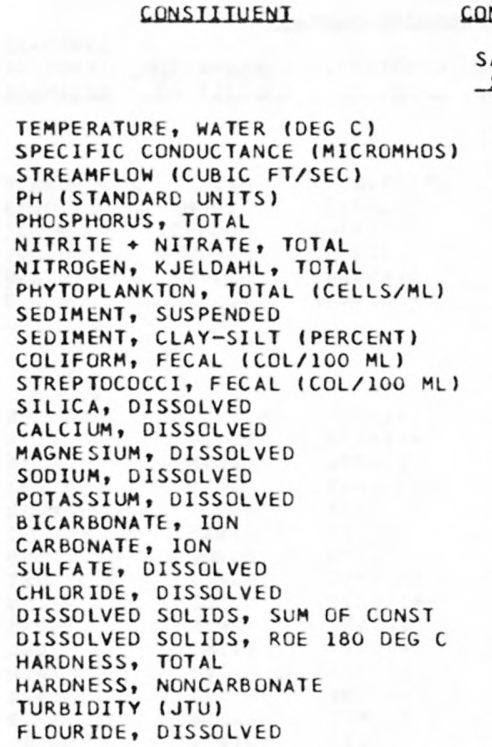

CONSIUIUENT_IMG LL OR UNII_SHOWNI

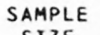

SIZE

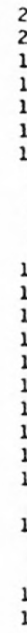

STANDARD

DEYIALION

17.62

192.2
16668.2

6668.2
7.63

7.63
0.082

0.082
0.785

0.785
0.628

0.628

2227.1

129.6

81.4

46.0

91.9

5.76
33.73

33.73
4.85

4.85
7.89

2.76

99.2

0.0

28.72

8.40
146.8

155.5

155.5
105.1

22.4

29.7
0.14

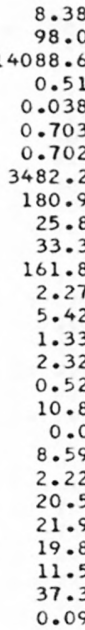

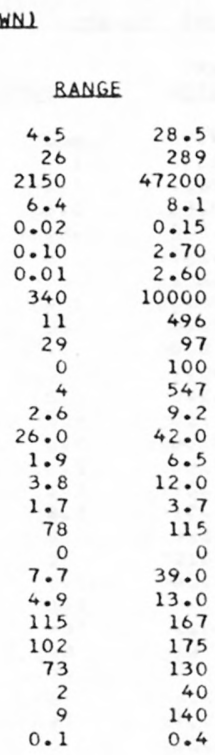

8.5

289
200

8.1
.15

.70

.60

496
97000

496
97

100

547

2.0
6.5

2.0

3.7
115

9.0

3.0

187

130
40

140
0.4

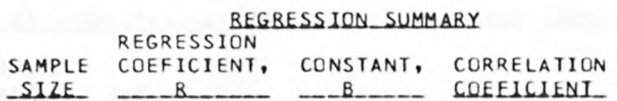

BEC SIZE C_B_ COEEICIENI

9
10
10
9
9
6


9
9
9
9
10
9
9
10
10
5
10
8
7
9
9

$$
\begin{array}{r}
62.768 \\
0.0002 \\
0.00024 \\
-0.00726 \\
-0.00261 \\
40.428
\end{array}
$$

7.6458

0.02286

2.73847

1.27894

$0.241^{*}$
$0.014^{*}$

$0.014^{*}$

$-0.238 *$

$-0.084 *$

-0.0096
0.1260
0.0322
0.0415
0.0074
0.232
0.000
0.2277
0.0317
0.739
0.559
0.448
0.254
-0.448
0.0025

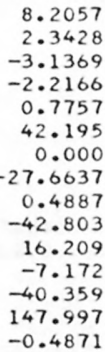

$-0.093$

0.879

0.941

0.647
0.672

0.768

0.000

0.954

$0.528 *$

0.934

0.926

0.93

0.934

-0.266
0.589

* Not significant at the 95 percent confidence level.

DAILY SPECIFIC CONDUCTANCE IN

DURALION IABLE OE DALLY SPECLEIC CONOUCIANCE

MICROMHOS AT 25 DEG C, THAT HAS

$\begin{array}{llllll}18 & 5 \pi & 10 \% & 20 z & 30 z & 50 \% \\ 316 & 294 & 292 & 283 & 276 & 260\end{array}$

10654.3

0.54

0.040

0.770

0.811
3960.0

EQUALLED OR EXCEEDED FOR THE

316

\begin{tabular}{|c|c|c|c|c|c|}
\hline & & & & & STANDARD \\
\hline & HARMONIC & AMPLITUDE & PHASE & VARIATION & ERROR OF \\
\hline SAMPLE & MEAN - M & $-A$ & ANGLE - C & EXPLAINED & ESTIMATE \\
\hline SIZE_ & 10EG ( ) & (DEG $C 1$ & (RADIANS) & $\ldots 182 \ldots$ & LOEG $C 1$ \\
\hline 350 & 16.02 & 11.78 & 2.58 & 96 & 1.69 \\
\hline
\end{tabular}

$294 \quad 292$

283

SUMMARY OF HARMONIC ANALYSIS OF STREAM TEMPERATURE EORM DE EQUALION: IO(O) $=M+A *$ SINC.0172*D+C

\begin{tabular}{|c|c|c|c|c|c|c|}
\hline \multirow{2}{*}{ CONSTITUENT } & \multicolumn{3}{|c|}{ TOTAL } & \multicolumn{3}{|c|}{ DISSOLVED } \\
\hline & $\begin{array}{l}\text { NO. } \\
\text { SAMPLES }\end{array}$ & $\begin{array}{l}\text { MINIMUM } \\
\text { CONC. }\end{array}$ & $\begin{array}{l}\text { MAXIMUM } \\
\text { CONC. }\end{array}$ & $\begin{array}{l}\text { NO. } \\
\text { SAMPLES }\end{array}$ & $\begin{array}{l}\text { MINIMUM } \\
\text { CONC. }\end{array}$ & $\begin{array}{l}\text { MAXIMUM } \\
\text { CONC. }\end{array}$ \\
\hline \multicolumn{7}{|l|}{ MINOR ELEMENTS: } \\
\hline ARSENIC (AS), UG/L & 2 & 1 & 2 & 2 & 1 & 2 \\
\hline CADMIUM $(C D), U G / L$ & 1 & $<10$ & & 2 & 1 & 2 \\
\hline CHROMIUM (CR), UG/L & 1 & 20 & & 2 & 10 & 10 \\
\hline COBALT $(C O)$, UG/L & 1 & $<50$ & & 2 & 0 & 0 \\
\hline COPPER (CU), UG/L & 1 & 10 & & 2 & 7 & 9 \\
\hline IRON $(F E), U G / L$ & 1 & 580 & & 2 & 10 & 30 \\
\hline LEAD $(P B), U G / L$ & $i$ & $<100$ & & 2 & 1 & 2 \\
\hline MANGANESE (MN), UG/L & 2 & 150 & 170 & 2 & 60 & 60 \\
\hline MERCURY (HG), UG/L & 1 & 0.1 & & 2 & 0.1 & 12.0 \\
\hline SELENIUM $(S E), U G / L$ & 2 & 0 & 0 & 2 & 0 & 0 \\
\hline ZINC $(Z N), U G / L$ & 2 & 40 & 870 & 2 & 10 & 170 \\
\hline \multicolumn{7}{|l|}{ PERIPHYTON: } \\
\hline BIOMASS, DRY WT., G/SQ M & 0 & & & & & \\
\hline BIOMASS, ASH WT., G/SQ M & 0 & & & & & \\
\hline CHLOROPHYLL A, MG/SO M & 0 & & & & & \\
\hline CHLOROPHYLL B, MG/SO M & 0 & & & & & \\
\hline ORGANIC CARBON, MG/L & 4 & 3.5 & 7.3 & & & \\
\hline
\end{tabular}

SUMMARY OF MAXIMUM AND MINIMUM CONCENTRATIONS OF CONSTITUENTS

SAMPLED AT A FREQUENCY OF QUARTERLY (1975 WY)

07193500 -- NEOSHO RIVER BLW FT GIBSON LAKE NR FT GIBSON, OK 
LAT 35023M24S LONG 103002M36S DRAINAGE AREA: 0 SO MI PERIOD OF RECORD: $10 / 01 / 74-09 / 30 / 75$

STATISTICAL SUMMARY OF SELECTED DISSOLVED CHEMICAL CONSTITUENTS AND

REGRESSION RELATIONSHIPS OF CONSTITUENT CONCENTRATIONS TO SPECIFIC CONDUCTANCE

CONSIITUENI

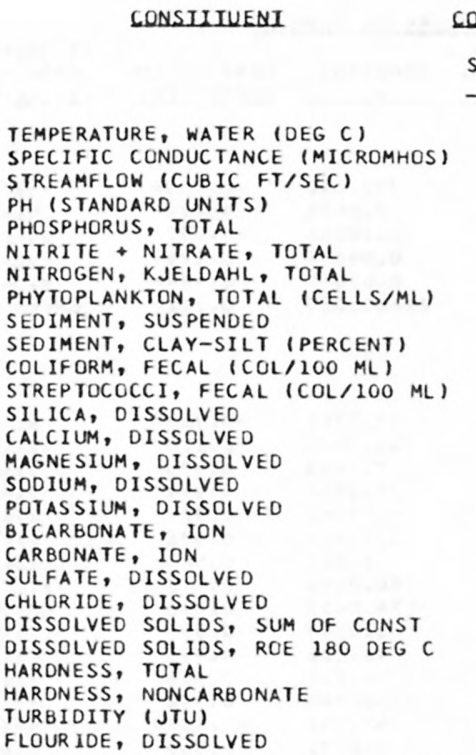

CONSIUUENT IMG L OR UNDI SHOWNI

\begin{tabular}{rrr}
$\begin{array}{rrr}\text { SAMPLE } \\
\text { SIZE }\end{array}$ & MEAN & \multicolumn{1}{r}{ STANDARO } \\
\cline { 1 - 1 } & DEYIALION \\
9 & 17.22 & 7.75 \\
9 & 5690.4 & 2792.7 \\
9 & 50.8 & 102.3 \\
9 & 8.34 & 0.21 \\
9 & 0.384 & 0.947 \\
9 & 0.339 & 0.153 \\
9 & 1.429 & 2.288 \\
8 & 6197.5 & 11222.2 \\
9 & 3617.4 & 8496.5 \\
9 & 89.0 & 8.0 \\
9 & 4793.9 & 9735.1 \\
9 & 2503.9 & 5266.5 \\
9 & 9.48 & 1.97 \\
9 & 96.11 & 42.92 \\
9 & 55.98 & 30.56 \\
9 & 1108.89 & 564.79 \\
9 & 7.44 & 2.88 \\
9 & 264.3 & 69.1 \\
8 & 0.0 & 0.0 \\
9 & 388.44 & 177.28 \\
9 & 1594.44 & 859.14 \\
9 & 3394.1 & 1690.6 \\
9 & 3361.4 & 1683.4 \\
9 & 470.1 & 229.2 \\
9 & 264.4 & 162.9 \\
9 & 2648.4 & 7272.9 \\
9 & 0.57 & 0.14
\end{tabular}

REGRESSION

SAMPLE COEFICIENT, CONSTANT, CORRELATION STANDARD SIZE -B _ _-B COEEICIENI ESIUMAIE

BANGE

$\begin{array}{ll}5.5 & 27.0 \\ 670 & 8000\end{array}$

$670 \quad 8000$

$\begin{array}{rr}5 & 321 \\ 8.0 & 8.8\end{array}$

$0.02 \quad 2.90$

$0.04 \quad 0.53$

$0.14 \quad 6.40$

$240 \quad 31000$

25700

99
26000

15000

12.0
130.0

$\begin{array}{rr}17.0 & 130.0 \\ 5.8 & 84.0 \\ 10.0 & 1600.0\end{array}$

$\begin{array}{rr}110.0 & 1600.0 \\ 3.7 & 12.0\end{array}$

$130 \quad 327$

$46.0 \quad 610.0$

$130.0 \quad 2300.0$

$385 \quad 4740$

$\begin{array}{rr}369 & 4800 \\ 67 & 650\end{array}$

650
410

22000

$\begin{array}{rr}0.3 & 22000\end{array}$

9
9
9
9
9
8

$-0.02$

0.0000

$-0.00002$

$-0.00078$

$-0.278$

8.0795

1.70025

0.47527

5.88489

7701.117

$-0.694$

0.611 *

$-0.682$

$-0.439 *$

-0.956
$-0.070 *$

0.0006

0.0152

0.0107

0.2018

0.0008

0.023

0.000

0.0584

0.3059

0.605

0.602

0.602

0.082

$-1.057$

-1.685
0.0000
0.911

0.987

0.978

0.998

0.807

0.920

0.000 *

0.919

0.994

0.999

0.998

0.997

0.977
-0.647 *

$-0.647 *$
0.707

*Not significant at the 95 percent confidence level.

SUMMARY OF MAXIMUM AND MINIMUM CONCENTRATIONS OF CONSTITUENTS SAMPLED AT A FREQUENCY OF QUARTERLY (1975 WY)

07227140 -- CANADIAN R AB NM-TX STATE LINE, NM

\begin{tabular}{|c|c|c|c|c|c|c|}
\hline \multirow{2}{*}{ CONSTITUENT } & \multicolumn{3}{|c|}{ TOTAL } & \multicolumn{3}{|c|}{ DISSOLVED } \\
\hline & $\begin{array}{l}\text { NO. } \\
\text { SAMPLES }\end{array}$ & $\begin{array}{l}\text { MINIMUM } \\
\text { CONC. }\end{array}$ & $\begin{array}{l}\text { MAXIMUM } \\
\text { CONC. }\end{array}$ & $\begin{array}{l}\text { NO. } \\
\text { SAMPLES }\end{array}$ & $\begin{array}{l}\text { MINIMUM } \\
\text { CONC. }\end{array}$ & $\begin{array}{l}\text { MAXIMUM } \\
\text { CONC. }\end{array}$ \\
\hline \multicolumn{7}{|l|}{ MINOR ELEMENTS: } \\
\hline ARSENIC (AS), UG/L & 3 & 1 & 80 & 3 & 1 & 4 \\
\hline CADMIUM $(C D), U G / L$ & 2 & $<10$ & 20 & 3 & 0 & 1 \\
\hline CHROMIUM (CR), UG/L & 2 & 1 & 120 & 3 & 0 & $<10$ \\
\hline COBALT $(C O), U G / L$ & 2 & $<50$ & 50 & 3 & 0 & 0 \\
\hline COPPER $(C U), U G / L$ & 2 & $<10$ & 150 & 3 & 0 & 9 \\
\hline IRON (FE), UG/L & 2 & 290 & 91000 & 9 & 10 & 40 \\
\hline LEAD $(P B), U G / L$ & 2 & $<100$ & 100 & 3 & 0 & 1 \\
\hline MANG ANESE (MN), UG/L & 2 & 230 & 3000 & 2 & 0 & 200 \\
\hline MERCURY (HG), UG/L & 2 & 0.1 & 0.3 & 2 & 0.0 & 0.3 \\
\hline SELENIUM $(S E), U G / L$ & 3 & 0 & 1 & 3 & 0 & 1 \\
\hline$Z I N C(Z N), U G / L$ & 2 & 20 & 370 & 3 & 0 & 30 \\
\hline \multicolumn{7}{|l|}{ PERIPHYTON: } \\
\hline BIOMASS, DRY WT., G/SO M & 3 & 16.00 & 23.00 & & & \\
\hline BIOMASS, ASH WT., G/SO M & 3 & 14.00 & 21.00 & & & \\
\hline CHLOROPHYLL A, MG/SQ M & 3 & .2 & 1.0 & & & \\
\hline CHLOROPHYLL B, MGISQ M & 3 & .0 & .0 & & & \\
\hline ORGANIC CARBON, MG/L & 8 & 1.3 & 102.0 & & & \\
\hline
\end{tabular}


Table 14.--Summary of measurements at each station--Continued

LAT 35D56MO6S LONG 100022M13S

DRAINAGE AREA: 22866 SQ MI ( 59223 SQ KM)

PERIOD OF RECORD: $10 / 01 / 74-09 / 30 / 75$

STATISTICAL SUMMARY OF SELECTED DISSOLVED CHEMICAL CONSTITUENTS AND REGRESSION RELATIONSHIPS OF CONSTITUENT CONCENTRATIONS TO SPECIFIC CONDUCTANCE

CONSIIIUENI

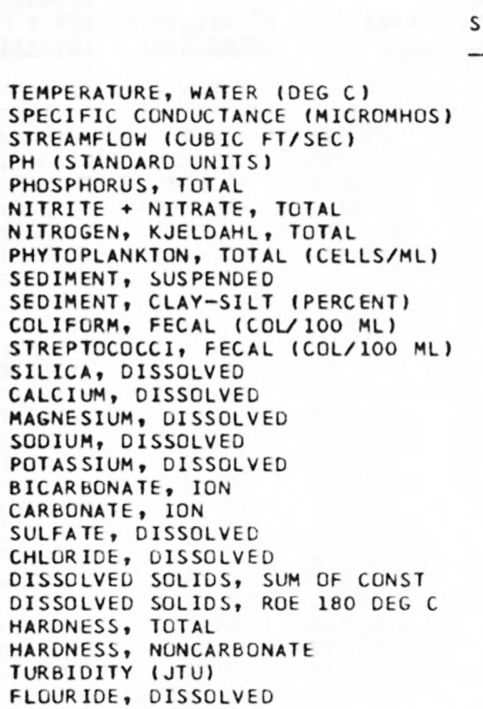

CONSIUUENT IMG $\angle L$ OR UNII SHOWNI

\begin{tabular}{|c|c|c|}
\hline $\begin{array}{l}\text { SAMPLE } \\
\text { SIZE }\end{array}$ & MEAN & $\begin{array}{l}\text { STANDARD } \\
\text { DEYIAIION }\end{array}$ \\
\hline 12 & 15.25 & 10.99 \\
\hline 12 & 2312.3 & 769.0 \\
\hline 12 & 369.9 & 811.4 \\
\hline 12 & 8.09 & 0.30 \\
\hline 12 & 0.156 & 0.123 \\
\hline 12 & 0.182 & 0.232 \\
\hline 12 & 0.938 & 0.548 \\
\hline 12 & 34458.3 & 38087.7 \\
\hline 13 & 749.0 & 1717.0 \\
\hline 13 & 61.9 & 22.5 \\
\hline 12 & 2068.1 & 5279.2 \\
\hline 12 & 3443.1 & 9402.4 \\
\hline 12 & 21.83 & 6.69 \\
\hline 12 & 103.92 & 25.50 \\
\hline 12 & 42.67 & 13.61 \\
\hline 12 & 312.17 & 117.17 \\
\hline 12 & 12.59 & 5.38 \\
\hline 12 & 276.5 & 34.1 \\
\hline 12 & 1.4 & 3.6 \\
\hline 12 & 179.86 & 88.40 \\
\hline 12 & 498.08 & 212.42 \\
\hline 12 & 1311.3 & 441.2 \\
\hline 12 & 1373.3 & 492.2 \\
\hline 12 & 436.7 & 118.6 \\
\hline 12 & 209.8 & 131.8 \\
\hline 12 & 26.0 & 43.1 \\
\hline 10 & 1.38 & 0.25 \\
\hline
\end{tabular}

BEGRESSION SUMMARY

REGRESSION

SAMPLE SIZE.

COEFICIENT,

CONSTANT,

CORRELATION

STANDARD
ERROR OF

BANGE

32.0

3100

2900
8.5

8.5
0.50

0.58

1.90

120000
5350
88

88
18000

18000
33000

33000
36.0

36.0
140.0

59.0

410.0

$20.0 \quad 12$

$345 \quad 12$

$\begin{array}{rr}345 & 12 \\ 12 & 12 \\ 80.0 & 12\end{array}$

280.0

740.0

1770
1910

1910
600

430
160

160
1.8 $\begin{array}{rr}12 & -0.176 \\ 12 & 0.0001 \\ 12 & -0.00001 \\ 12 & 0.00006 \\ 12 & 0.00013 \\ 12 & 5.532\end{array}$
777.692

7.8428

0.18246

0.04397

0.63047

21666.027

0.279 *

$-0.072 *$

$0.199 *$

0.187
37.2760

34.1491

39.1104

$-2.3442$

337.904

337.904
7.525

$-80.0243$

$-138.0457$

$-11.567$

$-96.126$

94.812

$-166.996$

43.102

0.8531
ESUMAIE
-0.768
0.910
0.975
0.997
0.924
-0.598
-0.560
0.978
0.996
0.997
0.993
0.959
0.950
-0.132
0.760
*Not significant at the 95 percent confidence level.

\section{DURA LION IABLE OF DALY SPECIEIC CONDUCIANCE}

DAILY SPECIFIC CONDUCTANCE IN

MICROMHOS AT 25 DEG C, THAT WAS

EQUALLED OR EXCEEDED FOR THE

$18 \quad 5 \pi$

208208

$30 z$

502

$\begin{array}{lllll}3830 & 3220 & 3080 & 2940 & 2830\end{array}$

2720

$70 \%$

SAMPLE SIZE_ $\equiv 365$

$202 \quad 25292 \%$

2530

$1020 \quad 832 \quad 771$

SUMMARY OF HARMONIC ANALYSIS OF STREAM TEMPERATURE

\begin{tabular}{|c|c|c|c|c|c|}
\hline & & & & & STANDARD \\
\hline & HARMONIC & AMPLITUDE & PHASE & VARIATION & ERROR OF \\
\hline SAMPLE & MEAN - $M$ & $-A$ & ANGLE $-C$ & EXPLAINED & ESTIMATE \\
\hline SUZE_- & IDEG CI & (DEG 6$)$ & (RADLANS) & $-(\%)$ & (DEG C) \\
\hline 329 & 18.25 & 12.55 & 2.94 & 86 & 3.60 \\
\hline
\end{tabular}

SUMMARY OF MAXIMUM ANO MINIMUM CONCENTRATIONS OF CONSTITUENTS

SAMPLED AT A FREQUENCY OF OUARTERLY (1975 WY)

$07228000--$ CANADIAN $R$ NR CANADIAN, TX

\begin{tabular}{|c|c|c|c|c|c|c|}
\hline \multirow{2}{*}{ CONSTI TUENT } & \multicolumn{3}{|c|}{ TOTAL } & \multicolumn{3}{|c|}{ DISSOLVED } \\
\hline & $\begin{array}{l}\text { NO. } \\
\text { SAMPLES }\end{array}$ & $\begin{array}{l}\text { MIN IMUM } \\
\text { CONC. }\end{array}$ & $\begin{array}{l}\text { MAXIMUM } \\
\text { CONC. }\end{array}$ & $\begin{array}{l}\text { NO. } \\
\text { SAMPLES }\end{array}$ & $\begin{array}{l}\text { MINIMUM } \\
\text { CONC. }\end{array}$ & $\begin{array}{l}\text { MAXIMUM } \\
\text { CONC. }\end{array}$ \\
\hline \multicolumn{7}{|l|}{ MINOR ELEMENTS: } \\
\hline ARSENIC (AS), UG/L & 4 & 3 & 7 & 4 & 3 & 7 \\
\hline CADMIUM $(C D), U G / L$ & 4 & $<10$ & 10 & 4 & 0 & 1 \\
\hline CHROMIUM (CR), UG/L & 4 & 0 & 0 & 4 & 0 & 10 \\
\hline COBALT $(C O), U G / L$ & 4 & $<50$ & 50 & 4 & 0 & 1 \\
\hline COPPER $(C U), U G / L$ & 4 & $<10$ & 10 & 4 & 0 & 4 \\
\hline IRON $(F E), U G / L$ & 4 & 290 & 840 & 4 & 0 & 80 \\
\hline$L E A O \quad(P B), U G / L$ & 4 & $<100$ & $<100$ & 4 & 0 & 1 \\
\hline MANGANESE (MN), UG/L & 3 & 30 & 70 & 4 & 0 & 50 \\
\hline MERCURY (HG), UG/L & 4 & 0.0 & 0.2 & 4 & 0.0 & 0.1 \\
\hline SELENIUM (SE), UG/L & 4 & 0 & 3 & 4 & 0 & 2 \\
\hline ZINC $(Z N), U G / L$ & 4 & 0 & 190 & 4 & 0 & 20 \\
\hline \multicolumn{7}{|l|}{ PERIPHYTON: } \\
\hline BIOMASS, DRY WT., G/SO M & 5 & 3.1 & 91.00 & & & \\
\hline BIOMASS, ASH WT., G/SO M & 5 & $2 \cdot 3$ & 36.00 & & & \\
\hline CHLOROPHYLL A, MG/SO M & 5 & .2 & 22.0 & & & \\
\hline CHLOROPHYLL B, MG/SQ M & 5 & .2 & 6.2 & & & \\
\hline ORGANIC CARBON, MG/L & 4 & 1.0 & 6.4 & & & \\
\hline
\end{tabular}


Table 14.--Summary of measurements at each station--Continued

LAT 34058M32S LONG 096014M24S

DRAINAGE AREA: 27952 SQ MI ( 72396 SQ KMI

PERIOD OF RECORD: $10 / 01 / 74$ - 09/30/75

STATISTICAL SUMMARY OF SELECTED DISSOLVED CHEMICAL CONSTITUENTS AND

REGRESSION RELATIONSHIPS OF CONSTITUENT CONCENTRATIONS TO SPECIFIC CONDUCTANCE

GONSIUTUENI

CONSUIUENI IMG/L OR UNUL SHOWNI

SAMPLE
SIZE

SAMPLE STANDARD

$\begin{array}{rrrrrr}24 & 15.23 & 7.62 & 4.0 & 28.5 & \\ 53 & 1027.7 & 356.2 & 190 & 1650 & \\ 52 & 3029.9 & 4227.3 & 156 & 17500 & 50 \\ 48 & 7.94 & 0.46 & 6.5 & 9.0 & 47 \\ 21 & 0.308 & 0.290 & 0.06 & 1.20 & 20 \\ 6 & 0.238 & 0.288 & 0.00 & 0.70 & 5 \\ 6 & 1.622 & 1.516 & 0.88 & 4.70 & 5 \\ 7 & 2028.6 & 2360.7 & 230 & 7100 & 5 \\ 2 & 1986.0 & 2494.7 & 222 & 3750 & \\ 2 & 68.5 & 4.9 & 65 & 72 & \\ 8 & 227.6 & 263.8 & 0 & 810 & \\ 9 & 334.2 & 391.6 & 0 & 1280 & \\ 4 & 7.97 & 1.88 & 5.8 & 10.0 & 3 \\ 31 & 85.23 & 25.80 & 41.0 & 140.0 & 30 \\ 35 & 29.95 & 10.81 & 8.4 & 50.0 & 34 \\ 32 & 92.25 & 38.41 & 23.0 & 150.0 & 31 \\ 8 & 5.31 & 1.40 & 4.2 & 8.6 & 7 \\ 34 & 236.4 & 63.3 & 128 & 334 & 33 \\ 34 & 0.0 & 0.0 & 0 & 0 & 33 \\ 33 & 134.27 & 58.37 & 26.0 & 280.0 & 32 \\ 33 & 141.64 & 59.73 & 30.0 & 240.0 & 32 \\ 5 & 676.0 & 230.6 & 330 & 893 & 4 \\ 42 & 631.2 & 220.9 & 85 & 1060 & 41 \\ 31 & 339.4 & 105.2 & 160 & 560 & 30 \\ 36 & 218.1 & 281.1 & 36 & 1300 & 30 \\ 5 & 236.0 & 371.7 & 50 & 900 & 4 \\ 5 & 0.38 & 0.04 & 0.3 & 0.4 & 4 \\ & & & & & \end{array}$

TEMPERATURE, WATER (DEG C) SPECIFIC CONDUCTANCE (MICROMHOS) STREAMFLOW (CUBIC FT/SEC)

PH (STANDARD UNITS)

PHOSPHORUS, TOTAL

NITRITE + NITRATE, TOTAL

NITROGEN, KJELDAHL, TOTAL

PHYTOPLANKTON, TOTAL (CELLS/ML)

SEDIMENT, SUSPENDED

SEDIMENT, CLAY-SILT (PERCENT)

COLIFORM, FECAL (COL/100 ML)

STREPTOCOCCI, FECAL (COL/100 ML)

SILICA, DISSOLVED

CALCIUM, DISSOLVED

MAGNESIUM, DIS\$OL VED

SODIUM, DISSOLVED

POTASSIUM, DISSOLVED

BICARBONATE, ION

CARBONATE, ION

SULFATE, DISSOLVED

CHLORIDE, DISSOLVED

DISSOLVED SOLIDS, SUM OF CONST

DISSOLVED SOLIDS, ROE 180 DEG

HARDNESS, TOTAL

HARDNESS, NONCARBONATE

TURBIDITY (JTU)

FLOURIDE, DISSOLVED
VIAIION
REGRESSION SUMMARY

REGRESSION CONSTANT, CORRELATION STANDARD SAMPLE COEFICIENT, CONSTANT, CORRELATION ERROR OF SIZE - B - B. SOEEICIENI ESIIYAIE

$\begin{array}{rrrrr}50 & -8.944 & 12581.336 & -0.701 * & 3088.7 \\ 47 & 0.0005 & 7.4115 & 0.389 * & 0.43 \\ 20 & -0.00058 & 1.00578 & -0.513 & 0.260 \\ 5 & 0.00054 & -0.40300 & 0.635 * & 0.287 \\ 5 & -0.00408 & 6.57938 & -0.942 * & 0.640 \\ 5 & 1.154 & 304.535 & 0.677 * & 785.8\end{array}$

5.0346

11.8081

$-0.7853$

$-14.9025$

4.6487

65.858

0.000
-18.6767

$-18.6767$

-25.1511
-9.210

$-12.588$

26.123

$-25.515$

1333.643

0.3755
$0.552 *$

0.913

0.972

0.981

$0.156 *$

0.927

0.000

0.911

0.961

0.987 *

0.915

0.957

0.905

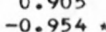

-0.954 *

$$
\begin{array}{r}
2.54 \\
10.88 \\
2.60 \\
7.67 \\
0.52 \\
24.5 \\
0.0 \\
24.58 \\
17.00 \\
52.4 \\
91.1 \\
31.8 \\
25.8 \\
151.9 \\
0.06
\end{array}
$$

\begin{tabular}{|c|c|c|c|c|c|}
\hline & & & & & STANDARD \\
\hline $\begin{array}{l}\text { SAMPLE } \\
\text { SIZE }\end{array}$ & $\begin{array}{l}\text { HARMONIC } \\
\text { MEAN - M } \\
\text { LEEG CI }\end{array}$ & $\begin{array}{c}\text { AMPLITUDE } \\
-A \\
(D E G \text { C }\end{array}$ & $\begin{array}{c}\text { PHASE } \\
\text { ANGLE - } C \\
\text { (BADIANS) }\end{array}$ & $\begin{array}{c}\text { VAR IATION } \\
\text { EXP LAINED } \\
\text { (8) }\end{array}$ & $\begin{array}{l}\text { ERROR OF } \\
\text { ESTIMATE } \\
\text { LOEG_CI }\end{array}$ \\
\hline
\end{tabular}$$
-0.920
$$

*Not significant at the 95 percent confidence level.

DAILY SPECIFIC CONDUCTANCE IN

IN

MICROMHOS AT 25 DEG C, THAT WAS

EQUALLED OR EXCEEDED FOR THE

$\begin{array}{rrrrrr}18 & -58 & 108 & 208 & 308 & 50 z \\ 1640 & 1570 & 1450 & 1340 & 1250 & 1070\end{array}$

702

SAMPLE SIZE $=343$

$20 \% 25292$

$567 \quad 476 \quad 360$

SUMMARY OF HARMONIC ANALYSIS OF STREAM TEMPERATURE

337

15.32

11.65

2.85

91

2.61

SUMMARY OF MAXIMUM AND MINIMUM CONCENTRATIONS OF CONSTITUENTS SAMPLED AT A FREQUENCY OF QUARTERLY (1975 WY)

07231500 -- CANADIAN RIVER AT CALVIN, OK

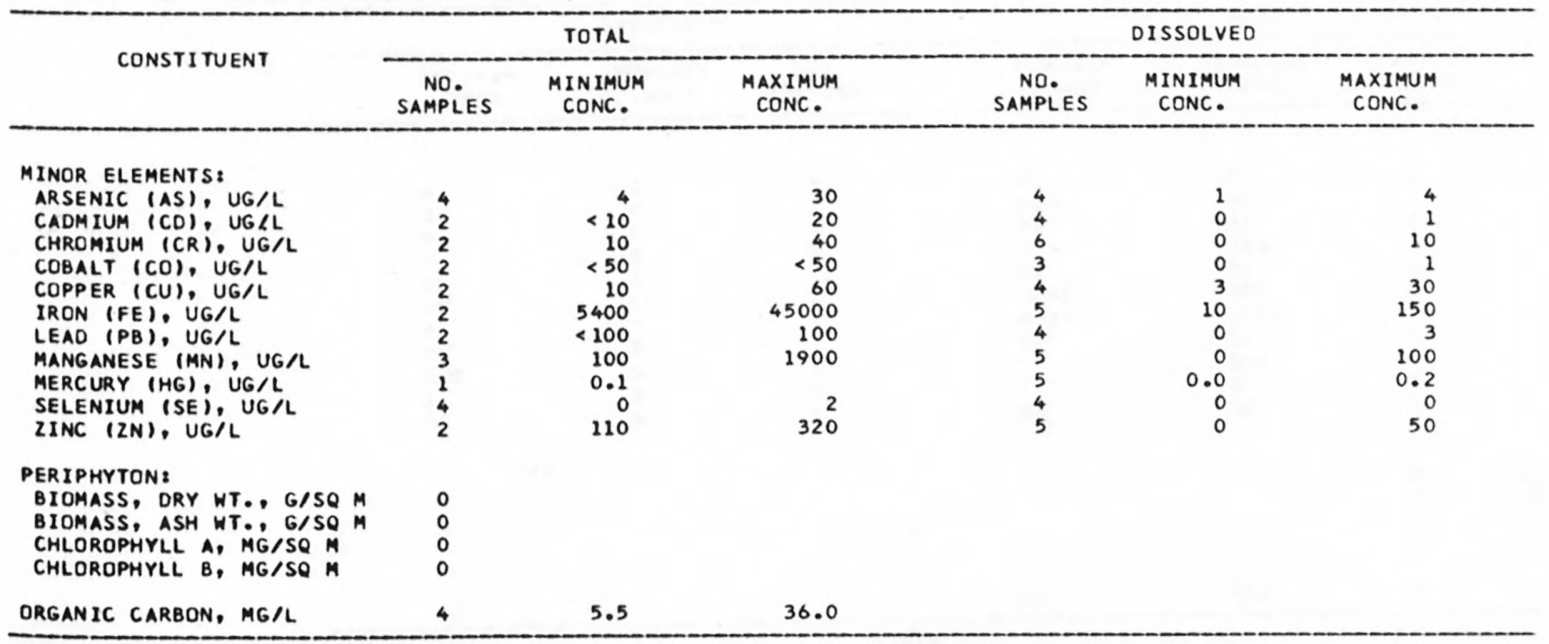


Table 14,--Sumary of measurements at each station--Continued

LAT $36043 M 24 S$ LONG 101D29M30S

DRAINAGE AREA: 2139 SQ MI $1 \quad 5540$ SQ KMI

PERIOD OF RECORD: $10 / 01 / 74-09 / 30 / 75$

STATISTICAL SUMMARY OF SELECTED DISSOLVED CHEMICAL CONSTITUENTS AND REGRESSION RELATIONSHIPS OF CONSTITUENT CONCENTRATIONS TO SPECIFIC CONDUCTANCE

CONSIUTUENI

\begin{tabular}{|c|}
\hline $\begin{array}{l}\text { TEMPERATURE, WATER (DEG C) } \\
\text { SPECIFIC CONOUCTANCE (MICROMHOS) } \\
\text { STREAMFLOW (CUBIC FT/SEC) } \\
\text { PH (STANDARD UNITS) } \\
\text { PHOSPHORUS, TOTAL, } \\
\text { NITRITE + NITRATE, TOTAL } \\
\text { NITROGEN, KJELDAHL, TOTAL } \\
\text { PHYTOPLANKTON, TOTAL (CELLS/ML) } \\
\text { SEDIMENT, SUSPENDED, } \\
\text { SEDIMENT, CLAY-SILT (PERCENT) } \\
\text { COLIFORM, FECAL (COL/IOO ML) } \\
\text { STREPTOCOCCI, FECAL (COL/1OO ML) } \\
\text { SILICA, DISSOLVED } \\
\text { CALCIUM, DISSOLVED } \\
\text { MAGNESIUM, DISSOLVED } \\
\text { SODIUM, DISSOLVED } \\
\text { POTASSIUM, DISSOLVED } \\
\text { BICARBONATE, ION } \\
\text { CARBONATE, ION } \\
\text { SULFATE, DISSOLVED } \\
\text { CHLORIDE, DISSOLVED } \\
\text { DISSOLVED SOLIDS, SUM OF CONST } \\
\text { DISSOLVED SOLIDS, ROE I8O DEG C } \\
\text { HARDNESS, TOTAL } \\
\text { HARDNESS, NONCARBONATE } \\
\text { TURBIDITY (JTU) } \\
\text { FLOURIDE, DISSOLVED }\end{array}$ \\
\hline
\end{tabular}

CONSIUUUENT (HG/L OR UNII SHOWNI)

SUZE

8
7
8
8
6
6
6
5
2
2
7
7
6
6
6
5
6
6
5
6
6
5
6
6
5
6
6

\section{STANDARD}

$$
\begin{array}{r}
9.12 \\
42.3 \\
2.3 \\
0.24 \\
0.039 \\
0.375 \\
0.041 \\
945.0 \\
1.4 \\
9.9 \\
50.1 \\
77.1 \\
3.94 \\
6.85 \\
1.05 \\
3.05 \\
0.66 \\
22.5 \\
0.0 \\
3.51 \\
2.07 \\
15.5 \\
14.4 \\
15.1 \\
7.0 \\
1.8
\end{array}
$$$$
\begin{array}{r}
1.8 \\
0.33
\end{array}
$$

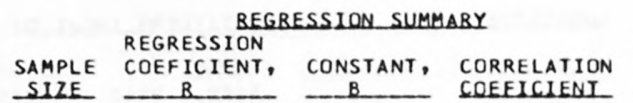
STANDARD
ERROR OF SIZE COEFICIENT, B COEEICIENI

*Not significant at the 95 percent confidence level. DAILY SPECIFIC CONDUCTANCE IN MICROMHOS AT 25 DEG C, THAT WAS

EQUALLED OR EXCEEDED FOR THE

AIION IABLE_OE DAUY SPECLEIC GONDUCTANCE

EQUALLED OR EXCEEDED FOR THE

$\begin{array}{llllll}18 & 58 & 108 & 208 & 308 & 50 \\ 619 & 579 & 546 & 538 & 530 & 515\end{array}$

$\begin{array}{rr}26.0 \\ 620 \\ 10 & \\ 8.3 & 7 \\ 0.12 & 5 \\ 1.00 & 5 \\ 0.32 & 5 \\ 5200 & 3 \\ 36 & \\ 95 & \\ 220 & \\ 300 & \\ 25.0 & 5 \\ 50.0 & 5 \\ 27.0 & 5 \\ 31.0 & 4 \\ 5.7 & 5 \\ 280 & 5 \\ 0 & 4 \\ 50.0 & 5 \\ 17.0 & 5 \\ 325 & 4 \\ 326 & 5 \\ 230 & 5 \\ 16 & 4 \\ 21 & 5 \\ 2.4 & 5\end{array}$

$\begin{array}{rr}7 & 0.022 \\ 7 & -0.0011 \\ 5 & -0.00062 \\ 5 & 0.00811 \\ 5 & 0.00085 \\ 3 & 35.000 \\ & \\ & \\ & \\ 5 & -0.0155 \\ 5 & 0.1457 \\ 5 & -0.0376 \\ 4 & -0.0331 \\ 5 & -0.0151 \\ 5 & 0.588 \\ 4 & 0.000 \\ 5 & 0.0083 \\ 5 & -0.0342 \\ 4 & 0.364 \\ 5 & 0.443 \\ 5 & 0.292 \\ 4 & -0.125 \\ 5 & -0.009 \\ 5 & 0.0084 \\ & \end{array}$

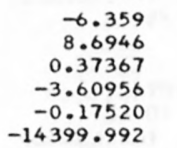

$0.373 *$

-0.193 *

$0.558 *$

$0.416 *$

$-14399.99$

30.8418

$-29.3724$

44.8859

43.1912

12.4947

$-41.067$

0.000

41.4698

31.9332

128.897

81.384

66.443

69.500

25.046

25.046
-2.5818
-0.134 *

0.621 *

-0.739 .

-0.185 .

-0.586 *

0.863 .

0.000 *

0.055 *

-0.336 .

-0.336 .

0.981 .

0.598 .

-0.315 .

-0.469 .

0.506 .
2.5

\begin{tabular}{|c|c|c|c|c|c|}
\hline $\begin{array}{l}\text { SAMPLE } \\
\text { SIZE }\end{array}$ & $\begin{array}{l}\text { HARMONIC } \\
\text { MEAN - M } \\
\text { LOEG CL }\end{array}$ & $\begin{array}{c}\text { AMPLITUDE } \\
-A \\
\text { (DEG C) }\end{array}$ & $\begin{array}{c}\text { PHASE } \\
\text { ANGLE - C } \\
\text { (BADIANS) }\end{array}$ & $\begin{array}{l}\text { VAR IATION } \\
\text { EXPLAINED } \\
\text { (I) }\end{array}$ & $\begin{array}{l}\text { STANDARD } \\
\text { ERROR OF } \\
\text { ESTIMATE } \\
\text { (OEG C) }\end{array}$ \\
\hline
\end{tabular}
0.2

0.047

0.312

0.048

424.3

2.96

4.7

0.89

4.10

\begin{tabular}{|c|c|c|c|c|c|c|}
\hline \multirow{2}{*}{ CONSTITUENT } & \multicolumn{3}{|c|}{ TOTAL } & \multicolumn{3}{|c|}{ DISSOLVEO } \\
\hline & $\begin{array}{l}\text { NO. } \\
\text { SAMPLES }\end{array}$ & $\begin{array}{l}\text { MINIMUM } \\
\text { CONC. }\end{array}$ & $\begin{array}{l}\text { MAXIMUM } \\
\text { CONC. }\end{array}$ & $\begin{array}{l}\text { NO. } \\
\text { SAMPLES }\end{array}$ & $\begin{array}{l}\text { MINIMUM } \\
\text { CONC. }\end{array}$ & $\begin{array}{l}\text { MAXIMUM } \\
\text { CONC. }\end{array}$ \\
\hline \multicolumn{7}{|l|}{ MINOR ELEMENTS: } \\
\hline ARSENIC (AS), UG/L & 2 & 3 & 5 & 2 & 2 & 6 \\
\hline CADMIUM $(C D)$, UG $/ L$ & 2 & $<10$ & $<10$ & 2 & 0 & 2 \\
\hline CHROMIUM (CR), UG/L & 2 & 10 & 20 & 2 & 0 & 0 \\
\hline COBALT $(C O), U G / L$ & 2 & $<50$ & $<50$ & 2 & 0 & 0 \\
\hline COPPER (CU), UG & 2 & 20 & 90 & 2 & 1 & 20 \\
\hline IRON (FE), UG/L & 2 & 800 & 1000 & 2 & 20 & 90 \\
\hline LEAD $(P B), U G / L$ & 2 & $<100$ & $<100$ & 2 & 2 & 6 \\
\hline MANG ANESE (MN), UG/L & 2 & 50 & 70 & 2 & 5 & 20 \\
\hline MERCURY (HG), UG/L & 1 & 0.0 & & 2 & 0.0 & 0.0 \\
\hline SELENIUM (SE), UG/L & 2 & 0 & 1 & 2 & 0 & 1 \\
\hline ZINC $(Z N), U G / L$ & 2 & 10 & 30 & 2 & 2 & 20 \\
\hline \multicolumn{7}{|l|}{ PER IPHYTON : } \\
\hline BIOMASS, DRY WT., G/SQ M & 0 & & & & & \\
\hline BIOMASS, ASH WT., G/SO M & 0 & & & & & \\
\hline CHLOROPHYLL A, MG/SQ M & 0 & & & & & \\
\hline CHLOROPHYLL B, MG/SQ M & 0 & & & & & \\
\hline ORGANIC CARBON, MG/L & 2 & 1.7 & 7.6 & & & \\
\hline
\end{tabular}

0.54

8.9

3.94

2.48

2.48

2.3

10.1

8.8

0.5
0.37

SUMMARY OF HARMONIC ANALYSIS OF STREAM TEMPERATURE

147

17.44

12.58

2.92

3.77

SUMMARY OF MAXIMUM AND MINIMUM CONCENTRATIONS OF CONSTITUENTS SAMPLED AT A FREQUENCY OF QUARTERLY (1975 WY)

07232500 -- BEAVER RIVER NR GUYMON, OK 
Table 14.--Summary of measurements at each station--Continued

LAT 36049M2OS LONG 100031MO5S

DRAINAGE AREA: 7955 SQ MI 120603 SQ KMI

PERIOD OF RECORD: $10 / 01 / 74-09 / 30 / 75$

STATISTICAL SUMMARY OF SELECTED DISSOLVED CHEMICAL CONSTITUENTS AND REGRESSION RELATIONSHIPS OF CONSTITUENT CONCENTRATIONS TO SPECIFIC CONDUCTANCE

\section{CONSIIIUENI}

CONSILIUENI IMG/L_OR_UNII_SHOWNI

SAMPLE

$\begin{array}{ll}\text { SAMPLE } & \text { STANDARD } \\ \text { SIZE_ MEAN } & \text { DEYIAIUON }\end{array}$

TEMPERATURE, WATER (DEG C) SPECIFIC CONDUCTANCE (MICROMHOS) STREAMFLOW (CUBIC FT/SEC)

PH (STANDARD UNITS)

PHOSPHORUS, TOTAL

NITRITE + NITRATE, TOTAL

NITROGEN, KJELOAHL, TOTAL

PHYTOPLANKTON, TOTAL (CELLS/ML)

SEDIMENT, SUSPENDED

SEDIMENT, CLAY-SILT (PERCENT)

COLIFURM, FECAL (COL/100 ML)

STREPTOCOCCI, FECAL (COL/100 ML)

SILICA, DISSOLVEO

CALCIUM, DISSOLVED

MAGNESIUM, DISSOLVEO

SODIUM, DISSOLVED

POTASSIUM, DISSOLVED

BICARBONATE, ION

CARBONATE, ION

SULFATE, DISSOLVED

CHLORIDE, DISSOLVED

DISSOLVED SOLIDS, SUM OF CONST

DISSULVED SOLIDS, ROE 180 DEG

HARONESS, TOTAL

HARDNESS, NONCARBONATE

TURBIUITY (JTU)

FLOURIDE, DISSOLVEO
15.00

EVIAIUON

0.00

$\begin{array}{rr}2927.5 & 1776.9 \\ 77.4 & 231.5\end{array}$

77.4

7.82

0.060

0.010

0.36

0.000

0.000

640.0

36.0

100.0

580.0

970.0

142.53

69.89

401.86

11.66

231.9

0.0

410.20

684.67

1981.9

644.0

644.0
454.9
0.0
0.0
0.0

0.0
0.0
0.0

0.0

75.75

45.34
265.90

265.90

55.6

0.0

275.69

445.48

1215.1

373.1

335.4

\section{REGRESSION SUMMARY}

REGRESSION

SAMPLE COEFICIENT,

CONSTANT,

CORRELATION COEEICIENI

STANDARD ERROR OF

BANGE

15.0 404

7.3

0.06

0.01

4970
902
8.4

$\begin{array}{ll}902 & 14 \\ 8.4 & 13\end{array}$

$-0.066$

-0.066
0.0001

276.272
7.4803

$-0.491 *$
0.570

216.9
0.28

640

36

100

580

40.0

7.3230 .0

28.0

7.7

159

21.0

21.0
41.0

130.0
730.0
18.0

14

0.0421

0.0254

0.1517
-0.0004

0.025

0.000

0.1558

0.2509

0.686

0.210

14.4044

$-7.4145$

$-38.6443$

12.9528

153.985

0.000

$-61.5017$

$-79.6506$

219
140

$-106.301$

5.920

$-120.394$

0.982

0.990

0.999

$-0.245 *$

0.819

0.000

0.992

0.998

0.999

0.994

0.994
0.995
14.80

6.55

2.89

32.3

36.91

36.91

44.0
42.7

35.7

DAILY SPECIFIC CONDUCTANCE IN

MICROMHOS AT 25 DEG C, THAT WAS

EQUALLED OR EXCEEDED FOR THE

URAIION IABLE_OE DAILY SPECIEIC CONDUCIANCE

INDICATED PERCENTAGE CF TIME

$\begin{array}{rrrrrr}11 & 5 z & 10 z & 20 z & 30 z & 50 \\ 5080 & 4890 & 4820 & 4650 & 4480 & 381\end{array}$

SAMPLE SIZE $=129$

$730 \quad 570 \quad 458$

SUMMARY OF HARMONIC ANALYSIS OF STREAM TEMPERATURE

EOBM OF EQUAIION: I'(D) = M A * SINL.0172* $+C$

\begin{tabular}{|c|c|c|c|c|c|}
\hline & & & & & STANDARD \\
\hline & HARMONIC & AMPLI TUDE & PHASE & VARIATION & ERROR OF \\
\hline SAMPLE & MEAN - M & $-A$ & ANGLE - C & EXPLAINED & ESTIMATE \\
\hline SUZE_ & 10EG C1 & (DEG $C)$ & (RADIANS) & 181 & (DEG C) \\
\hline 121 & 17.81 & 13.79 & 2.84 & 90 & $3 \cdot 30$ \\
\hline
\end{tabular}

SUMMARY OF MAXIMUM AND MINIMUM CONCENTRATIONS OF CONSTITUENTS

SAMPLED AT A FREQUENCY OF QUARTERLY (1975 WY)

07234000 -- BEAVER RIVER AT BEAVER, OK

\begin{tabular}{|c|c|c|c|c|c|c|}
\hline \multirow{2}{*}{ CONSTITUENT } & \multicolumn{3}{|c|}{ TOTAL } & \multicolumn{3}{|c|}{ DISSOLVED } \\
\hline & $\begin{array}{l}\text { NO. } \\
\text { SAMPLES }\end{array}$ & $\begin{array}{l}\text { MINIMUM } \\
\text { CONC. }\end{array}$ & $\begin{array}{l}\text { MAXIMUM } \\
\text { CONC. }\end{array}$ & $\begin{array}{l}\text { NO. } \\
\text { SAMPLES }\end{array}$ & $\begin{array}{l}\text { MINIMUM } \\
\text { CONC. }\end{array}$ & $\begin{array}{l}\text { MAXIMUM } \\
\text { CONC. }\end{array}$ \\
\hline \multicolumn{7}{|l|}{ MINOR ELEMENTS: } \\
\hline ARSENIC (AS), UG/L & 0 & & & 0 & & \\
\hline CADMIUM $(C D), U G / L$ & 0 & & & 0 & & \\
\hline CHROMIUM (CR), UG/L & 0 & & & 0 & & \\
\hline COBALT $(C O)$, UGIL & 0 & & & 0 & & \\
\hline COPPER (CU), UG/L & 0 & & & 0 & & \\
\hline $\begin{array}{l}\text { IRON }(F E), U G / L \\
\text { LEAD }(P B), U G / L\end{array}$ & $\begin{array}{l}0 \\
0\end{array}$ & & & $\begin{array}{l}0 \\
0\end{array}$ & & \\
\hline MANGANESE (MN), UG/L & 0 & & & 0 & & \\
\hline MERCURY (HG), UG /L & 0 & & & 0 & & \\
\hline SELENIUM (SE), UG/L & 0 & & & 0 & & \\
\hline ZINC $(Z N), U G / L$ & 0 & & & 0 & & \\
\hline \multicolumn{7}{|l|}{ PERIPHYTON: } \\
\hline BIOMASS, DRY WT., G/SO M & 0 & & & & & \\
\hline BIOMASS, ASH WT., G/SQ M & 0 & & & & & \\
\hline CHLOROPHYLL A, MG/SG M & 0 & & & & & \\
\hline CHLOROPHYLL B, MG/SQ M & 0 & & & & & \\
\hline ORGANIC CARBON, MG/L & 0 & & & & & \\
\hline
\end{tabular}


LAT 36D26M18S LONG 099016M40S

DRAINAGE AREA: 11589 SQ MI 130016 SQ KM

PERIOD OF RECORD: $10 / 01 / 74-09 / 30 / 75$

STATISTICAL SUMMARY OF SELECTED DISSOLVED CHEMICAL CONSTITUENTS AND

REGRESSION RELATIONSHIPS OF CONSTITUENT CONCENTRATIONS TO SPECIFIC CONDUCTANCE

CONSIIIUENI

\section{CONSIUUVER \\ SAMPLE \\ SIZE}

TEMPERATURE, WATER (DEG C) SPECIFIC CONDUCTANCE (MICROMHOS) STREAMFLOW (CUBIC FT/SEC)

PH ISTANDARD UNITS I PHOSPHORUS, TOTAL

NITRITE + NITRATE, TOTAL

NITROGEN, KJELDAHL, TOTAL

PHYTOPLANKTON, TOTAL (CELLS/ML)

SEDIMENT, SUSPENDED

SEDIMENT, CLAY-SILT (PERCENT)

COLIFORM, FECAL (COL/100 ML)

STREPTOCOCCI, FECAL (COL/100 ML)

SILICA, DISSOLVED

CALCIUM, DISSOLVED

MAGNESIUM, DISSOLVED

SOUIUM, DISSOLVED

POTASSIUM, DISSOLVED

BICARBONATE, ION

CARBONATE, ION

SULFATE, DISSOLVED

CHLORIDE, DISSOLVED

DISSOLVED SOLIDS, SUM OF CONST

DISSOLVED SOLIDS, ROE 180 DEG

HARDNESS, TOTAL

HARDNESS, NONCARBONATE

TURBIDITY (JTU)

FLOURIDE, DISSOLVED

$\begin{array}{rrr}11 & 15.50 & 11.19 \\ 11 & 1794.5 & 661.6 \\ 11 & 75.9 & 101.5 \\ 11 & 8.01 & 0.25 \\ 11 & 0.456 & 0.635 \\ 11 & 0.213 & 0.200 \\ 11 & 1.094 & 0.782 \\ 6 & 22216.7 & 21903.5 \\ 6 & 44.0 & 34.8 \\ 6 & 85.7 & 19.1 \\ 10 & 1235.0 & 2043.8 \\ 10 & 12317.6 & 23543.5 \\ 11 & 19.82 & 4.92 \\ 10 & 136.80 & 57.03 \\ 11 & 41.18 & 13.83 \\ 11 & 207.27 & 84.15 \\ 11 & 6.74 & 1.27 \\ 11 & 243.9 & 58.6 \\ 10 & 0.0 & 0.0 \\ 10 & 340.00 & 170.16 \\ 11 & 307.27 & 138.64 \\ 9 & 1237.4 & 491.5 \\ 11 & 1197.1 & 477.0 \\ 10 & 512.0 & 198.5 \\ 11 & 304.5 & 171.9 \\ 11 & 23.0 & 44.7 \\ 11 & 0.70 & 0.15\end{array}$

REGRESSION SUMMABY REGRESSION SAMPLE COEFICIENT, CONSTANT, SIZE - B

CORRELATION

STANDARD ERROR OF ESIUMAIE

*Not significant at the 95 percent confidence level.

$\begin{array}{rrr}0.0 & 33.0 & \\ 1050 & 3010 & \\ 2 & 359 & 10 \\ 7.5 & 8.3 & 10 \\ 0.02 & 2.10 & 10 \\ 0.06 & 0.76 & 10 \\ 0.33 & 2.50 & 10 \\ 2000 & 51000 & 6 \\ 12 & 106 & \\ 48 & 99 & \\ 0 & 5900 & \\ 67 & 67000 & \\ 8.0 & 26.0 & 10 \\ 75.0 & 220.0 & 9 \\ 21.0 & 63.0 & 10 \\ 100.0 & 360.0 & 10 \\ 5.2 & 9.7 & 10 \\ 111 & 353 & 10 \\ 0 & 0 & 9 \\ 170.0 & 580.0 & 9 \\ 140.0 & 570.0 & 10 \\ 596 & 1930 & 8 \\ 626 & 1950 & 10 \\ 270 & 790 & 9 \\ 120 & 590 & 10 \\ 1 & 150 & 10 \\ 0.3 & 0.8 & 10 \\ & & \end{array}$

258.810
7.9007
-0.68806
0.01158
0.26279
-20049.004

-0.645
$0.172 *$
0.693
$0.407 *$
$0.423 *$
$0.724 *$

84.7

$-0.097$ 0.0001 0.00065 0.00012

0.00049
23.117

$-20049.004$

0.500

0.77

16895.7

11.0101
-16.1280
6.0833
-24.0978
4.7881
192.122
0.000
-126.2744
-72.7981
-138.238
-104.787
-17.331
-159.802
89.331
0.5966

0.665

0.983

0.927

0.997

0.603 *

0.322 *

0.000

0.981

0.991

0.996

0.983

0.983
0.976

0.976
-0.528 *

0.253 *
3.73

11.41

5.41

7.19
1.10

48.8

0.0

36.19

20.34

43.1

44.7
39.6

39.6
41.4

41.4

0.16

\begin{tabular}{|c|c|c|c|c|c|c|c|c|c|c|}
\hline $\begin{array}{l}\text { EQUALLED OR EXCEEDED FOR THE } \\
\text { INDICATED PERCENTAGE OF TIME }\end{array}$ & 3720 & 3540 & 2970 & 2700 & 2510 & 1910 & 1630 & 1350 & 1280 & 106 \\
\hline
\end{tabular}

$\begin{array}{llll}3720 & 3540 \quad 2970 \quad 2700\end{array}$

$2510 \quad 1910 \quad 1630$

\section{3}

SUMMARY OF HARMONIC ANALYSIS OF STREAM TEMPERATURE

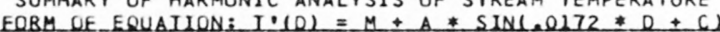

\begin{tabular}{|c|c|c|c|c|c|}
\hline & & & & & STANDARD \\
\hline $\begin{array}{l}\text { SAMPLE } \\
\text { SLZE }\end{array}$ & $\begin{array}{l}\text { HARMONIC } \\
\text { MEAN - M } \\
\text { DEEG CI }\end{array}$ & $\begin{array}{c}\text { AMPLI IUDE } \\
-A \\
\text { (DEG C) }\end{array}$ & $\begin{array}{l}\text { PHASE } \\
\text { ANGLE - C } \\
\text { (BADIANS) }\end{array}$ & $\begin{array}{l}\text { VARIAIION } \\
\text { EXPLAINED } \\
\end{array}$ & $\begin{array}{l}\text { ERROR OF } \\
\text { ESTIMATE } \\
\text { (DEG C) }\end{array}$ \\
\hline 320 & 12.73 & 6.32 & 3.19 & 47 & 4.83 \\
\hline
\end{tabular}

SUMMARY OF MAXIMUM AND MINIMUM CONCENTRATIONS OF CONSTITUENTS SAMPLED AT A FREQUENCY OF QUARTERLY (1975 WY)

07237500 -- NORTH CANADIAN RIVER AT WOODWARD, OK

\begin{tabular}{|c|c|c|c|c|c|c|}
\hline \multirow{2}{*}{ CONSTITUENT } & \multicolumn{3}{|c|}{ TOTAL } & \multicolumn{3}{|c|}{ DISSOLVED } \\
\hline & $\begin{array}{l}\text { NOP. } \\
\text { SAMPLES }\end{array}$ & $\begin{array}{l}\text { MINIMUM } \\
\text { CONC. }\end{array}$ & $\begin{array}{l}\text { MAXIMUM } \\
\text { CONC. }\end{array}$ & $\begin{array}{c}\text { NO. } \\
\text { SAMPLES }\end{array}$ & $\begin{array}{l}\text { MINIMUM } \\
\text { CONC. }\end{array}$ & $\begin{array}{l}\text { MAXIMUM } \\
\text { CONC. }\end{array}$ \\
\hline \multicolumn{7}{|l|}{ MINOR ELEMENTS: } \\
\hline ARSENIC (AS), UG/L & 2 & 5 & 10 & 2 & 3 & 4 \\
\hline CADMIUM $(C D), U G / L$ & 2 & $<10$ & $<10$ & 2 & 0 & 1 \\
\hline CHROMIUM (CR), UG/L & 2 & 10 & 30 & 2 & 0 & 0 \\
\hline COBALT $(C O), U G / L$ & 2 & $<50$ & 50 & 2 & 0 & 0 \\
\hline COPPER (CU), UG/L & 2 & 20 & 30 & 2 & 1 & 3 \\
\hline IRON (FE), UG/L & 2 & 110 & 8200 & 2 & 40 & 140 \\
\hline LEAD $(P B), U G / L$ & 2 & $<100$ & $<100$ & 2 & 3 & 4 \\
\hline MANG ANESE $(M N), U G / L$ & 2 & 280 & 530 & 2 & 90 & 470 \\
\hline MERCURY $(H G), U G / L$ & 2 & 0.0 & 0.1 & 2 & 0.0 & 0.1 \\
\hline SELENIUM (SE), UG/L & 2 & 0 & 0 & 2 & 0 & 0 \\
\hline ZINC $(Z N), U G / L$ & 2 & 50 & 440 & 2 & 0 & 30 \\
\hline \multicolumn{7}{|l|}{ PERIPHYTON : } \\
\hline BIUMASS, DRY WT., G/SO M & 0 & & & & & \\
\hline BIOMASS, ASH WT, G/SO M & 0 & & & & & \\
\hline $\begin{array}{l}\text { CHLOROPHYLL A, MG/SQ M } \\
\text { CHLOROPHYLL B, MG/SQ }\end{array}$ & $\begin{array}{l}0 \\
0\end{array}$ & & & & & \\
\hline ORGANIC CARBON, MG/L & 2 & 8.6 & 11.0 & & & \\
\hline
\end{tabular}


LAT 35015M45S LONG 095014M19S

DRAINAGE AREA: 47576 SQ MI ( 123222 SQ KM)

PERIOD OF RECORD: $10 / 01 / 74-09 / 30 / 75$

STATISTICAL SUMMARY OF SELECTED DISSOLVED CHEMICAL CONSTITUENTS AND

REGRESSION RELATIONSHIPS OF CONSTITUENT CONCENTRATIONS TO SPECIFIC CONDUCTANCE

CONSIITUENI

CONSIUIUENT IMG $L 1$ OR UNII_SHOWN

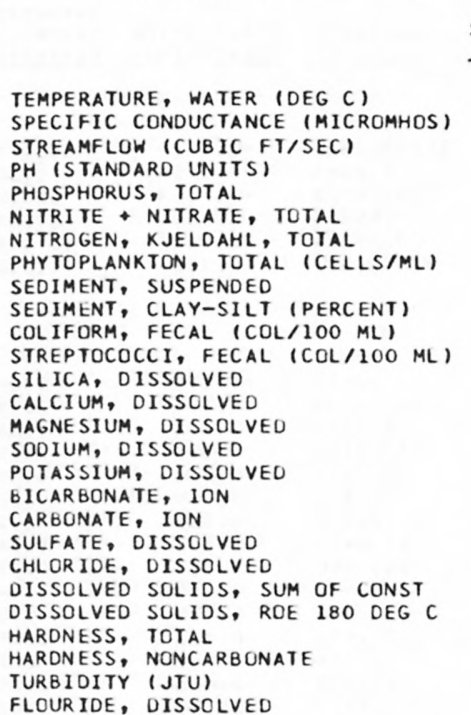

SAMPLE

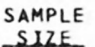

\section{STANOARD}

$\begin{array}{rrr}10 & 16.15 & 9.20 \\ 41 & 385.7 & 76.4 \\ 36 & 8958.3 & 10912.3 \\ 47 & 7.79 & 0.45 \\ 38 & 0.083 & 0.062 \\ 11 & 0.261 & 0.109 \\ 16 & 0.856 & 1.033 \\ 5 & 1128.0 & 1511.2 \\ 10 & 78.9 & 93.2 \\ 10 & 122.7 & 147.5 \\ 6 & 171.0 & 132.6 \\ 6 & 158.8 & 115.3 \\ 8 & 6.00 & 1.70 \\ 43 & 30.65 & 7.40 \\ 45 & 10.12 & 2.22 \\ 43 & 32.10 & 6.72 \\ 41 & 3.21 & 0.51 \\ 45 & 102.3 & 23.8 \\ 45 & 0.0 & 0.0 \\ 44 & 31.17 & 9.62 \\ 47 & 50.83 & 12.24 \\ 7 & 240.1 & 34.9 \\ 43 & 229.9 & 40.3 \\ 41 & 118.6 & 27.0 \\ 39 & 34.9 & 13.1 \\ 8 & 22.0 & 11.4 \\ 8 & 0.24 & 0.07\end{array}$

MEAN DEYIAIION BANGE

$\begin{array}{rrr}5.0 & 28.0 & \\ 129 & 492 & \\ 212 & 35400 & 34 \\ 5.6 & 8.4 & 41 \\ 0.02 & 0.35 & 32 \\ 0.08 & 0.43 & 8 \\ 0.13 & 3.60 & 13 \\ 180 & 3800 & \\ 21 & 306 & \\ 6 & 520 & \\ 20 & 400 & \\ 10 & 310 & \\ 2.3 & 8.2 & 5 \\ 14.0 & 52.0 & 38 \\ 2.7 & 14.0 & 39 \\ 9.3 & 46.0 & 37 \\ 1.9 & 4.8 & 35 \\ 46 & 184 & 39 \\ 0 & 0 & 39 \\ 8.3 & 57.0 & 38 \\ 12.0 & 86.0 & 41 \\ 167 & 273 & 4 \\ 137 & 350 & 37 \\ 46 & 180 & 36 \\ 8 & 66 & 34 \\ 2 & 40 & 5 \\ 0.2 & 0.4 & 5\end{array}$
REGRESSION SAMPLE COEFICIENT, CONSTANT, CORRELATION ERROR OF SIZE

$\begin{array}{rr}21.764 & 933.988 \\ 0.0001 & 7.7674 \\ -0.00037 & 0.21222 \\ -0.00386 & 1.97522 \\ 0.00176 & 0.21983\end{array}$
COEEICIENI ESIIMAIE

*Not significant at the 95 percent confidence level.

$$
\text { DURAIION IABLE OF DALLY SPECIEIC CONOUCIANCE }
$$

DAILY SPECIFIC CONDUCTANCE IN MICROMHOS AT 25 DEG C, THAT WAS

EQUALLED OR EXCEEDED FOR THE

$\begin{array}{llllll}-18 & 52 & 10 \% & 208 & 30 \% & 50 \% \\ 489 & 474 & 455 & 446 & 438 & 417\end{array}$

417

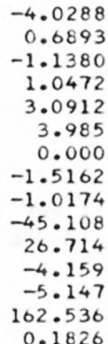

$0.828 *$
0.884
0.962
0.955
$0.037 *$
0.803
$0.000 *$
0.095
0.904
$0.960 *$
0.966
0.930
0.058
$-0.959 *$
$0.061 *$

0.62

$\begin{array}{rr}0.0241 & -4.0288 \\ 0.0768 & 0.6893 \\ 0.0288 & -1.1380 \\ 0.0745 & 1.0472 \\ 0.0003 & 3.0912 \\ 0.254 & 3.985 \\ 0.000 & 0.000 \\ 0.0848 & -1.5162 \\ 0.1312 & -1.0174 \\ 0.649 & -45.108 \\ 0.515 & 26.714 \\ 0.313 & -4.159 \\ 0.099 & -5.147 \\ -0.324 & 162.536 \\ 0.0001 & 0.1826\end{array}$

$0.153 *$

$0.013^{*}$

$-0.655$

$-0.823$

0.091 *

11188.1

0.47

0.034

0.075

INDICATED PERCENTAGE OF TIME

-- CANADIAN RIVER NR WHITEFIELD, OK

\begin{tabular}{|c|c|c|c|c|c|c|}
\hline \multirow{2}{*}{ CONSTITUENT } & \multicolumn{3}{|c|}{ TOTAL } & \multicolumn{3}{|c|}{ DISSOLVED } \\
\hline & $\begin{array}{l}\text { NO. } \\
\text { SAMPLES }\end{array}$ & $\begin{array}{l}\text { MIN IMUM } \\
\text { CONC. }\end{array}$ & $\begin{array}{l}\text { MAXIMUM } \\
\text { CONC. }\end{array}$ & $\begin{array}{l}\text { NO. } \\
\text { SAMPLES }\end{array}$ & $\begin{array}{l}\text { MINIMUM } \\
\text { CONC. }\end{array}$ & $\begin{array}{l}\text { MAXIMUM } \\
\text { CONC. }\end{array}$ \\
\hline \multicolumn{7}{|l|}{ MINOR ELEMENTS: } \\
\hline ARSENIC (AS), UG/L & 2 & 0 & 2 & 2 & 0 & 1 \\
\hline CADMIUM $(C D), U G / L$ & 2 & $<10$ & $<10$ & 2 & 1 & 1 \\
\hline CHROMIUM (CR), UG/L & 2 & 0 & 0 & 2 & 0 & 0 \\
\hline COBALT $(C O), U G / L$ & 2 & $<50$ & $<50$ & 2 & 0 & 0 \\
\hline COPPER (CU), UG/L & 2 & 10 & 20 & 2 & 5 & 11 \\
\hline IRON (FE), UG/L & 2 & 640 & 800 & 2 & 40 & 60 \\
\hline LEAD $(P B), U G / L$ & 2 & $<100$ & 100 & 2 & 1 & 3 \\
\hline MANGANESE (MN), UG/L & 2 & 10 & 120 & 2 & 10 & 20 \\
\hline MERCURY (HG), UG/L & 2 & 0.1 & 0.1 & 2 & 0.0 & 0.1 \\
\hline SELENIUM (SE), UG/L & 2 & 0 & 1 & 2 & 0 & 0 \\
\hline ZINC $(Z N), U G / L$ & 2 & 40 & 50 & 2 & 0 & 20 \\
\hline \multicolumn{7}{|l|}{ PERIPHYTON: } \\
\hline BIOMASS, DRY WT., G/SO M & 0 & & & & & \\
\hline BIOMASS, ASH WT., G/SQ M & 0 & & & & & \\
\hline CHLOROPHYLL A, MG/SO M & 0 & & & & & \\
\hline CHLOROPHYLL B, MG/SO M & 0 & & & & & \\
\hline ORGANIC CARBON, MG/L & 1 & 9.2 & & & & \\
\hline
\end{tabular}


Table 14.--Summary of measurements at each station--Continued

LAT 35020MS6S LONG 094017M54S

DRAINAGE AREA: 150547 SQ MI ( 389917 SQ KM)

PERIOD OF RECORD: $10 / 01 / 74$ - 09/30/75

STATISTICAL SUMMARY OF SELECTED DISSOLVED CHEMICAL CONSTITUENTS AND REGRESSION RELATIONSHIPS OF CONSTITUENT CONCENTRATIONS TO SPECIFIC CONDUCTANCE

CONSIIUUENI

TEMPERATURE, WATER (DEG C)
SPECIFIC CONDUCTANCE (MICROMHOS)
STREAMFLOW (CUBIC FT/SEC)
PH (STANDARD UNITS)
PHOSPHORUS, TOTAL
NITRITE, NITRATE, IOTAL
NITROGEN, KJELDAHL, TOTAL
PHYTOPLANKTON, TOTAL (CELLS/ML)
SEDIMENT, SUSPENDED
SEDIMENT, CLAY-SILT (PERCENT)
COLIFORM, FECAL (CUL/IOO ML)
STREPTOCOCCI, FECAL (COL/IOO ML)
SILICA, DISSOLVED
CALCIUM, DISSOLVED
MAGNESIUM, DISSOLVED
SODIUM, DISSOLVED
POTASSIUM, DISSOLVED
BICARBONATE, ION
CARBONATE, ION
SULFATE, DISSOLVED
CHLOR IDE, DISSOLVED
DISSOLVED SOLIDS, SUM OF CONST
DISSOLVED SOLIDS, ROE I8O DEG C
HARDNESS, TOTAL
HARONESS, NONCARBONATE
TURBIDITY IJTU)
FLOURIDE, DISSOLVED

\begin{tabular}{c} 
SONSIUIU \\
SAMPLE \\
SIZE \\
\hline 10 \\
11 \\
11 \\
11 \\
11 \\
11 \\
11 \\
11 \\
10 \\
8 \\
8 \\
10 \\
10 \\
10 \\
10 \\
10 \\
10 \\
10 \\
11 \\
11 \\
10 \\
10 \\
10 \\
10 \\
10 \\
10 \\
10 \\
10
\end{tabular}

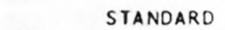

MEAN 555.8 68973.6 7.66 0.118 0.462 0.610 3263.0

43.6 43.6
92.3

5162.3

242.0

6.24
38.60

38.60

8.94

3.25
110.7

110.7

0.0

42.90

93.70

310.0

325.6

133.1
41.0

34.0

0.19
STANDARD

9.90
145.4

49636.2

9636.2
0.28

0.023

0.156

0.212
3129.6

26.4

8.7
12699.3

145.1

1.32

4.86
1.89

1.89

20.38

0.43

11.5

8.12

35.13

70.0

73.7

19.2

10.1

14.0

0.03
BANGE

*Not significant at the 95 percent confidence level.

SUMMARY OF HARMONIC ANALYSIS OF STREAM TEMPERATURE

\begin{tabular}{|c|c|c|c|c|c|}
\hline & & & & & STANDARD \\
\hline SAMPLE & $\begin{array}{l}\text { HARMONIC } \\
\text { MEAN - M }\end{array}$ & AMPLITUDE & $\begin{array}{l}\text { PHASE } \\
\text { PNGE- }\end{array}$ & $\begin{array}{l}\text { VAR IATION } \\
\text { EXPLAINED }\end{array}$ & $\begin{array}{l}\text { ERROR OF } \\
\text { ESIMATE }\end{array}$ \\
\hline SIZE & $10 E G_{C} C{ }_{-}$ & $10 E G(1)$ & (RADIANS) & $-(z)$ & (DEG C) \\
\hline 248 & 17.23 & 12.27 & 2.70 & 96 & 1.74 \\
\hline
\end{tabular}

$4.0 \quad 29.5$

$\begin{array}{rr}325 & 768 \\ 2810 & 154000\end{array}$

$\begin{array}{rr}1.2 & 154000\end{array}$

$0.09 \quad 0.17$

0.10

0.34
360

1.00

11000

101

99
41000
500

500
8.4
43.0

43.0

89.0

4.0

4.010

126

56.0

140.0

403
421

421
150
49

49

64
0.2
BEG

REGRESSION

SAMPLE COEFICIENT,

GRESSION SUMMARY

CONSTANT, CORRELATION SIZE - B CORE

STANDARD ESIUMAIE

$\begin{array}{rrrrr}11 & -150.864 & 152826.625 & -0.442 * & 46936.7 \\ 11 & 0.0000 & 7.6364 & 0.025 * & 0.30 \\ 11 & -0.00009 & 0.16903 & -0.585 * & 0.019 \\ 11 & -0.00018 & 0.55984 & -0.164 * & 0.162 \\ 11 & 0.00092 & 0.09784 & 0.632 & 0.173 \\ 10 & 8.126 & -1440.863 & 0.338 * & 3123.8\end{array}$

$\begin{array}{rr}10 & -0.0014 \\ 10 & 0.0275 \\ 10 & 0.0108 \\ 10 & 0.1539 \\ 10 & 0.0009 \\ 11 & 0.056 \\ 11 & 0.000 \\ 10 & 0.0550 \\ 10 & 0.2590 \\ 10 & 0.535 \\ 10 & 0.563 \\ 10 & 0.108 \\ 10 & 0.062 \\ 10 & -0.050 \\ 10 & 0.0000\end{array}$

$-0.137^{*}$

0.736

0.747

0.984
0.261 .

0.261 .

0.705

0.883 *

0.960

0.995

0.995

0.733

0.796

-0.468 *
1.39
3.49

1.33

0.84

0.44
8.6

0.0
4.04
10.37

10.37

7.4

8.0
13.9

6.5

13.2

0.03

SUMMARY OF MAXIMUM AND MINIMUM CONCENTRATIONS OF CONSTITUENTS SAMPLED AT A FREQUENCY OF QUARTERLY (1975 WY)

07250550 -- ARKANSAS R. AT DAM NO. 13, NR VAN BUREN, ARK.

CONSTITUENT
SAMPLES


Table 14.--Summary of measurements at each station--Continued

LAT 34D40MO7S LONG 092009M18S

DRAINAGE AREA: 0 SQ MI

PERIOD OF RECORD: 10/01/74 - 09/30/75

O SQ KMI

STATISTICAL SUMMARY OF SELECTED DISSOLVED CHEMICAL CONSTITUENTS AND

REGRESSION RELATIONSHIPS OF CONSTITUENT CONCENTRATIONS TO SPECIFIC CONDUCTANCE

NAME: ARKANSAS R

DAVID D TERRY LED BL LITTLE ROCK AR

CONSIUIUENI

CONSIUTUENI (MG/L OB UNII SHOWNI)

TEMPERATURE, WATER (DEG C)
SPECIFIC CONDUCTANCE (MICROMHOS)
STREAMFLOW (CUBIC FT/SEC)
PH (STANDARD UNITS)
PHOSPHORUS, TOTAL
NITRITE, NITRATE, TOTAL
NITROGEN, KJELDAHL, TOTAL,
PHYTOPLANKTON, TOTAL (CELLS/ML)
SEDIMENT, SUSPENDED
SEDIMENT, CLAY-SILT (PERCENT)
COLIFORM, FECAL (COU IOO ML)
STREPTOCOCCI, FECAL (COL/IOO ML)
SILICA, DISSOLVED
CALCIUM, DISSOLVED
MAGNESIUM, DISSOLVED
SODIUM, DISSOLVED
POTASSIUM, DISSOLVED
BICARBONATE, ION
CARBONATE, ION
SULFATE, DISSOLVED
CHLORIDE, DISSOLVED
DISSOLVED SOLIDS, SUM OF CONST
DISSOLVED SOLIDS, ROE I8O DEG C
HARDNESS, TOTAL
HARDNESS, NONCARBONATE
TURBIDITY (JTU)
FLOURIDE, DISSOLVED

STANDARD

DEVIAIION

16.91

507.8

86333.3

7.83

0.103

0.363

0.568

5084.2
112.6

112.6
89.3

89.3
1544.4

219.6

4.92
33.50

33.50

7.97
52.92

52.92

3.17

100.3
0.0

0.0
38.75

38.75
79.25

270.1

281.9

115.9

115.9
34.1

29.0
7.83

122.6

51582.9

0.19
0.026

0.026

0.156

5764.5

200.3

11.0
2227.7

326.2

2.28

6.93

2.20

16.13

0.93
19.8
0.0

9.11

25.32

64.9

63.0

25.2

11.3

17.7
0.05

$\begin{array}{rrr}\text { BANGE } & & \\ & & \text { SAMPL } \\ 5.5 & & \text { SIZF } \\ 277 & 29.0 & \\ 10800 & 162000 & 12 \\ 7.4 & 8.1 & 12 \\ 0.06 & 0.15 & 12 \\ 0.02 & 0.58 & 12 \\ 0.38 & 0.85 & 12 \\ 270 & 18000 & 12 \\ 19 & 644 & \\ 64 & 99 & \\ 90 & 8300 & \\ 8 & 1200 & \\ 0.5 & 7.4 & 12 \\ 24.0 & 46.0 & 12 \\ 5.1 & 11.0 & 12 \\ 22.0 & 78.0 & 12 \\ 1.5 & 5.0 & 12 \\ 72 & 137 & 12 \\ 0 & 0 & 12 \\ 22.0 & 49.0 & 12 \\ 31.0 & 120.0 & 12 \\ 153 & 370 & 12 \\ 163 & 371 & 12 \\ 82 & 160 & 12 \\ 16 & 50 & 12 \\ 4 & 60 & 12 \\ 0.1 & 0.2 & 12 \\ & & \end{array}$

*Not significant at the 95 percent confidence level.

DAILY SPECIFIC CONDUCTANCE IN

MICROMHOS AT 25 DEG C, THAT WAS

EQUALLED OR EXCEEDED FOR THE

$\begin{array}{llllll}18 & 5 \pi & 108 & 208 & 308 & 508 \\ 945 & 867 & 769 & 662 & 632 & 552\end{array}$

REGRESSION REGESSLLN_SUMMARY

COEFICIENT, CONSTANT,

CORRELATION ERROR OF COEEICIENI ESIUMAIE

$-0.505^{*}$

$0.320^{*}$

-0.128 *

$-0.555 *$

0.426 *

46694.2

0.19

0.027

0.147

00054

0.458 *

5374.2

$$
\begin{array}{r}
-0.0127 \\
0.0524 \\
0.0148 \\
0.1290 \\
0.0044 \\
0.140 \\
0.000 \\
0.0688 \\
0.2017 \\
0.528 \\
0.512 \\
0.189 \\
0.078 \\
-0.002 \\
0.0003
\end{array}
$$
11.3628
6.8793
0.4335
$-12.6011$
0.9543
29.307
0.000
3.8083
$-23.1572$
21.995
20.067
$-5.550$
30.181
$-0.0119$

$-0.682$

0.927

0.828

0.981

0.577

0.866

0.000

0.927

\begin{tabular}{|c|c|c|c|c|c|}
\hline & & & & & STANDARD \\
\hline $\begin{array}{l}\text { SAMPLE } \\
\text { SIZE }\end{array}$ & $\begin{array}{l}\text { HARMONIC } \\
\text { MEAN - M } \\
\text { LDEG C) }\end{array}$ & $\begin{array}{c}\text { AMPLITUDE } \\
-A \\
\text { (OEE C) }\end{array}$ & $\begin{array}{c}\text { PHASE } \\
\text { ANGLE - C } \\
\text { (RADLANS) }\end{array}$ & $\begin{array}{l}\text { VAR IATION } \\
\text { EXPLAINED } \\
\text { (I) }\end{array}$ & $\begin{array}{l}\text { ERROR OF } \\
\text { ESTIMATE } \\
\text { (DEG_E) }\end{array}$ \\
\hline 236 & 17.49 & 12.42 & 2.72 & 97 & 1.60 \\
\hline
\end{tabular}

0.977

0.998

0.996

0.919

\begin{tabular}{|c|c|c|c|c|c|c|}
\hline \multirow{2}{*}{ CONSTI IUENT } & \multicolumn{3}{|c|}{ TOTAL } & \multicolumn{3}{|c|}{ DISSOLVED } \\
\hline & $\begin{array}{l}\text { NO. } \\
\text { SAMPLES }\end{array}$ & $\begin{array}{l}\text { MINIMUM } \\
\text { CONC. }\end{array}$ & $\begin{array}{c}\text { MAXIMUM } \\
\text { CONC. }\end{array}$ & $\begin{array}{l}\text { NO. } \\
\text { SAMPLES }\end{array}$ & $\begin{array}{l}\text { MINIMUM } \\
\text { CONC. }\end{array}$ & $\begin{array}{l}\text { MAXIMUM } \\
\text { CONC. }\end{array}$ \\
\hline \multicolumn{7}{|l|}{ MINOR ELEMENTS: } \\
\hline ARSENIC (AS), UG/L & 4 & 1 & 4 & 4 & 1 & 2 \\
\hline CADMIUM $(C D), U G / L$ & 4 & $<10$ & 10 & 4 & 0 & 1 \\
\hline CHROMIUM (CR), UG/L & 4 & 0 & 20 & 4 & 0 & 20 \\
\hline COBALT $(C O), U G / L$ & 4 & 0 & $<50$ & 4 & 0 & 0 \\
\hline COPPER $(C U), U G / L$ & 4 & $<10$ & 110 & 4 & 4 & 6 \\
\hline IRON (FE), UG/L & 4 & 520 & 2000 & 4 & 0 & 40 \\
\hline LEAD (PB), UG/L & 4 & $<100$ & $<100$ & 4 & 0 & 2 \\
\hline MANG ANESE (MN), UG/L & 4 & 50 & 100 & 4 & 0 & 20 \\
\hline MERCURY (HG), UG/L & 3 & 0.0 & 0.2 & 4 & 0.0 & 0.2 \\
\hline SELENIUM $(S E), U G / L$ & 4 & 0 & 1 & 4 & 0 & 1 \\
\hline$Z I N C(Z N), U G / L$ & 4 & 10 & 40 & 4 & 0 & 40 \\
\hline \multicolumn{7}{|l|}{ PERIPHYTON: } \\
\hline BIOMASS, DRY WT.. G/SQ M & 3 & 14.00 & 63.00 & & & \\
\hline BIOMASS, ASH WT., G/SO M & 3 & 11.00 & 52.00 & & & \\
\hline CHLOROPHYLL A, MG/SQ M & 3 & 9.2 & 87.0 & & & \\
\hline CHLOROPHYLL B, MG/SQ M & 3 & .5 & 16.0 & & & \\
\hline ORGANIC CARBON, MG/L & 5 & 2.6 & 7.3 & & & \\
\hline
\end{tabular}

0.919

$-0.016$.

0.799

$$
\begin{array}{r}
1.75 \\
2.72 \\
1.29 \\
3.28 \\
0.79 \\
10.4 \\
0.0 \\
3.59 \\
5.65 \\
4.1 \\
6.0 \\
10.4 \\
6.3 \\
18.6 \\
0.03
\end{array}
$$

\begin{tabular}{llll} 
& \multicolumn{2}{c}{ SAMPLE SIZE $=169$} \\
$70 \%$ & $20 \%$ & $25 \%$ & 298 \\
488 & 354 & 310 & 290
\end{tabular}

SUMMARY OF HARMONIC ANALYSIS OF STREAM TEMPERATURE

SUMMARY OF MAXIMUM AND MINIMUM CONCENTRATIONS OF CONSTITUENTS SAMPLED AT A FREQUENCY OF QUARTERLY (1975 WY)

07263620 -- ARKANSAS R D DAVID D TERRY LED BL LITTLE ROCK AR 
LAT 33D33M55S LONG $091014 M 35 S$

DRAINAGE AREA: $1130600 \mathrm{SQ}$ MI ( 2928254 SQ KM)

PERIOD OF RECORD: $10 / 01 / 74$ - 09/30/75

STATISTICAL SUMMARY OF SELECTED DISSOLVED CHEMICAL CONSTITUENTS AND

REGRESSION RELATIONSHIPS OF CONSTITUENT CONCENTRATIONS TO SPECIFIC CONDUCTANCE

GONSIITUENI

CONSIUUUENI IHG/L OR UNII SHOHNU

SAMPLE

SIZE

TEMPERATURE, WATER (DEG C) SPECIFIC CONDUCTANCE (MICROMHOS) STREAMFLOW (CUBIC FT/SEC)

PH IS TANDARD UNITS

PHOSPHORUS, TOTAL

NITRITE + NITRATE, TOTAL

NITROGEN, KJELDAHL, TOTAL

PHYTOPLANKTON, TOTAL (CELLS/ML)

SEDIMENT, SUSPENDED

SEDIMENT, CLAY-SILT (PERCENT)

COL IFORM, FECAL (COL 100 ML)

STREPTOCOCCI, FECAL (COL/100 ML)

SILICA, DISSOLVED

CALCIUM, DISSOLVED

MAGNE SIUM, DISSOLVED

SODIUM, DISSOLVED

POTASSIUM, DISSOLVED

BICARBONATE, ION

CARBONATE, ION

SULFATE, DISSOLVED

CHLORIDE, DISSOLVED

DISSOLVED SOLIDS, SUM OF CONST

DISSOLVED SOLIDS, ROE 180 DEG

HARDNESS, TOTAL

HARDNESS, NONCARBONATE

TURBIDITY (JTU)

FLOUR IDE, DISSOLVED

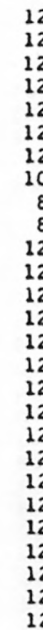

STANDARD

17.54

$12 \quad 7.74$

0.231

1.004

4.032

4650.0

140.4

88.0

895.8

259.3

5.96
38.75

38.75
11.50

11.50
20.33

20.33
2.80

126.0

0.0

51.08

22.00
214.8

214.8
227.5

227.5
145.0

145.0
40.8

62.8

0.19
384.0
9.06
74.2

348073.0

0.31
0.118

0.332

11.329

3058.1

47.7

8.1

665.0

241.3

0.97
5.55

5.55
2.71

8.00

0.55

21.0

13.91

13.91
9.37

39.4

39.4
39.7

23.9

10.6

45.8

0.08

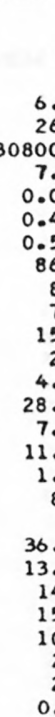

RANGE

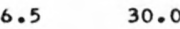

$267 \quad 30.0$

1469000

7.2

$\begin{array}{ll}0.03 & 0.51 \\ 0.48 & 1.40\end{array}$

$.54 \quad 40.00$

860
81

$73 \quad 97$

150

20

4.5
28.0

7.3
11.0

11.0
1.6

1.6
82

36.0

13.0

153

100
24

25
0.0

97
2400

2400
840
7.3

17.0

39.0

3.5
162

82.0

49.0

264

281

190
62

62
200
0.3

$\begin{array}{rl}7.3 & 12 \\ 48.0 & 12\end{array}$

SAMPLE REGRESSION

BEGRESSION_SUMMARY

DURAULON TABLE OE DAULY SPECIEIC CONOUCTANCE

DAILY SPECIFIC CONDUCTANCE IN

MICROMHOS AT 25 DEG C, THAT WAS

EQUALLED OR EXCEEDED FOR THE

12

52108

$20 z$

307

502

448

$433 \quad 355$

$476 \quad 466$

\begin{tabular}{|c|c|c|c|c|c|}
\hline $\begin{array}{l}\text { SAMPLE } \\
\text { SIZE }\end{array}$ & $\begin{array}{l}\text { HARMONIC } \\
\text { MEAN - M } \\
\text { LDEG CI }\end{array}$ & $\begin{array}{c}\text { AMPLITUDE } \\
-A \\
\text { (DEG C) }\end{array}$ & $\begin{array}{l}\text { PHASE } \\
\text { ANGLE - C } \\
\text { (BADLANS) }\end{array}$ & $\begin{array}{c}\text { VAR IATION } \\
\text { EXPLAINED } \\
\text { (Z) }\end{array}$ & $\begin{array}{l}\text { STANDARD } \\
\text { ERROR OF } \\
\text { ESTIMATE } \\
\text { LOEG_C) }\end{array}$ \\
\hline 327 & 17.35 & 11.38 & 2.68 & 97 & 1.51 \\
\hline
\end{tabular}

SUMMARY OF MAXIMUM AND MINIMUM CONCENTRATIONS OF CONSTITUENTS SAMPLED AT A FREQUENCY OF QUARTERLY (1975 WY)

07265450 -- MISSISSIPPI RIV NR ARKANSAS CITY, ARK.

\begin{tabular}{|c|c|c|c|c|c|c|}
\hline \multirow{2}{*}{ CONSTI TUENT } & \multicolumn{3}{|c|}{ TOTAL } & \multicolumn{3}{|c|}{ DISSOLVED } \\
\hline & $\begin{array}{l}\text { NO. } \\
\text { SAMPLES }\end{array}$ & $\begin{array}{l}\text { MINIMUM } \\
\text { CONC. }\end{array}$ & $\begin{array}{l}\text { MAXIMUM } \\
\text { CONC. }\end{array}$ & $\begin{array}{l}\text { NO. } \\
\text { SAMPLES }\end{array}$ & $\begin{array}{l}\text { MINIMUM } \\
\text { CONC. }\end{array}$ & $\begin{array}{l}\text { MAXIMUM } \\
\text { CONC. }\end{array}$ \\
\hline \multicolumn{7}{|l|}{ MINOR ELEMENTS: } \\
\hline ARSENIC (AS), UG/L & 4 & 3 & 8 & 4 & 1 & 2 \\
\hline CADMIUM $(C D), U G / L$ & 4 & $<10$ & 30 & 4 & $<i$ & 14 \\
\hline CHROMIUM (CR), UG/L & 4 & 0 & 10 & 4 & 0 & 0 \\
\hline COBALT $(C O), U G / L$ & 4 & $<50$ & $<50$ & 4 & 0 & 1 \\
\hline COPPER (CU), UG/L & 4 & 30 & 80 & 4 & 8 & 10 \\
\hline IRON $(F E), U G / L$ & 4 & 3500 & 12000 & 4 & 0 & 40 \\
\hline$L E A D(P B), U G / L$ & 4 & $<100$ & 100 & 4 & 0 & 1 \\
\hline MANGANESE (MN), UG/L & 4 & 150 & 550 & 4 & 0 & 20 \\
\hline MERCURY (HG), UG/L & 2 & 0.0 & 0.1 & 4 & 0.0 & 0.1 \\
\hline SELENIUM (SE), UG/L & 4 & 1 & 4 & 4 & 0 & 1 \\
\hline ZINC $(Z N), U G / L$ & 4 & 40 & 230 & 4 & 10 & 40 \\
\hline \multicolumn{7}{|l|}{ PERIPHYTON: } \\
\hline BIOMASS, DRY WT., G/SQ M & 1 & .59 & & & & \\
\hline BIOMASS, ASH WT., G/SO M & $i$ & .59 & & & & \\
\hline CHLOROPHYLL A, MG/SQ M & 1 & .1 & & & & \\
\hline CHLOROPHYLL B, MG/SQ M & 1 & .1 & & & & \\
\hline ORGANIC CARBON, MG/L & 2 & 7.1 & 11.0 & & & \\
\hline
\end{tabular}


LAT 33023M48S LONG 090D16M19S

DRAINAGE AREA: 7650 SQ MI $(19814$ SQ KM)

PERIOD OF RECORD: 10/01/74-09/30/75

STATISTICAL SUMMARY OF SELECTED DISSOLVED CHEMICAL CONSTITUENTS AND

REGRESSION RELATIONSHIPS OF CONSTITUENT CONCENTRATIONS TO SPECIFIC CONDUCTANCE

CONSIITUENI

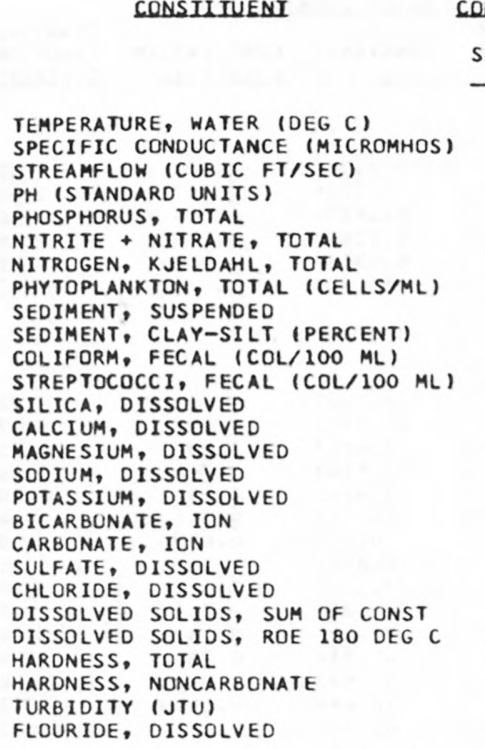

CONSIUUENI GMG/L OR UNII SHOHND

SAMPLE
SIZE

\section{STANDARD}

18.42

72.4

18125.0

8125.0
6.42

6.42
0.228

0.222

0.734

1776.9

290.3

10.5
6697.0

6697.0

0.32
0.119

0.119
0.141

0.141
0.345

1292.9

237.5

2047.9

1274.6
5.97

5.97
6.22

2.06

3.89

1.95

25.3
0.0

6.51
3.29

42.6

51.8

24.0

3.3
117.9

3252.4

1491.6

1.85
0.49

0.18
7.33

0.64
1.85

0.61

0.52

5.0
0.0

0.94

0.70

5.7

14.3

6.2
3.7

9.5
48

10000

10000
6.1

0.05

0.05

0.29

43
104

20

$\begin{array}{rr}20 & 10000 \\ 60 & 4800 \\ 4.8 & 7.1\end{array}$

4.8
3.1

1.2

2.9
1.4

16
0

5.2
2.5

2.5
30

30

30
13
0
30

76.4
0.12
BEGRE

REGRESSION

SAMPLE COEFICIENT, CONSTANT, CORRELATION

SIZE

B ESIIMAIE

*Not significant at the 95 percent confidence level.

SUMMARY OF HARMONIC ANALYSIS OF STREAM TEMPERATURE EORM OF EOUAIION: I. ADI = MI + O SINC.0172 * + CI

\begin{tabular}{|c|c|c|c|c|c|}
\hline & & & & & STANDARD \\
\hline $\begin{array}{l}\text { SAMPLE } \\
\text { SIZE }\end{array}$ & $\begin{array}{l}\text { HARMONIC } \\
\text { MEAN - M } \\
\text { LOEG }\end{array}$ & $\begin{array}{l}\text { AMPLITUDE } \\
-A\end{array}$ & $\begin{array}{c}\text { PHASE } \\
\text { ANGLE - C } \\
\text { (RADIANS) }\end{array}$ & $\begin{array}{c}\text { VARIATION } \\
\text { EXPLAINED } \\
\text { (X) }\end{array}$ & $\begin{array}{l}\text { ERROR OF } \\
\text { ESTIMATE } \\
\text { (DEG_C) }\end{array}$ \\
\hline 12 & 18.45 & 9.59 & 2.69 & 94 & 2.00 \\
\hline
\end{tabular}

SUMMARY OF MAXIMUM AND MINIMUM CONCENTRATIONS OF CONSTITUENTS SAMPLED AT A FREQUENCY OF QUARTERLY (1975 WY)

07287120 -- YAZOO RIVER AT SHELL BLUFF NR MORGAN CITY, MS.

\begin{tabular}{|c|c|c|c|c|c|c|}
\hline \multirow{2}{*}{ CONSTITUENT } & \multicolumn{3}{|c|}{ TOTAL } & \multicolumn{3}{|c|}{ DISSOLVED } \\
\hline & $\begin{array}{l}\text { NO. } \\
\text { SAMPLES }\end{array}$ & $\begin{array}{l}\text { MINIMUM } \\
\text { CONC. }\end{array}$ & $\begin{array}{l}\text { MAXIMUM } \\
\text { CONC. }\end{array}$ & $\begin{array}{l}\text { NO. } \\
\text { SAMPLES }\end{array}$ & $\begin{array}{l}\text { MINIMUM } \\
\text { CONC. }\end{array}$ & $\begin{array}{l}\text { MAXIMUM } \\
\text { CONC. }\end{array}$ \\
\hline \multicolumn{7}{|l|}{ MINOR ELEMENTS: } \\
\hline ARSENIC (AS), UG/L & 4 & 2 & 8 & 4 & 0 & 2 \\
\hline CADMIUM $(C D)$, UG/L & 4 & 0 & 3 & 4 & 0 & 1 \\
\hline CHROMIUM (CR), UG/L & 4 & $<10$ & $<10$ & 4 & 0 & 4 \\
\hline COBALT $(C O), U G / L$ & 4 & 0 & 8 & 4 & 0 & 2 \\
\hline COPPER $(C U), U G / L$ & 4 & 14 & 18 & 4 & 4 & 15 \\
\hline IRON (FE), UG/L & 4 & 3100 & 9200 & 4 & 0 & 560 \\
\hline LEAD $(P B), U G / L$ & 4 & 9 & 30 & 4 & 0 & 7 \\
\hline MANGANESE (MN), UG/L & 4 & 210 & 330 & 4 & 14 & 91 \\
\hline MERCURY $(H G), U G / L$ & 4 & 0.0 & 0.1 & 4 & 0.0 & 0.1 \\
\hline SELENIUM (SE), UG/L & 4 & 0 & 0 & 4 & 0 & 0 \\
\hline ZINC $(Z N), U G / L$ & 4 & 40 & 90 & 4 & 10 & 80 \\
\hline \multicolumn{7}{|l|}{ PERIPHYTON: } \\
\hline BIOMASS, DRY WT., G/SO M & 1 & 2.69 & & & & \\
\hline BIOMASS, ASH WT., G/SO M & 2 & 1.09 & 2.29 & & & \\
\hline CHLOROPHYLL A, MG/SO M & 1 & .0 & & & & \\
\hline CHLOROPHYLL B, MG/SQ M & $i$ & .0 & & & & \\
\hline ORGANIC CARBON, MG/L & 4 & 4.1 & 11.0 & & & \\
\hline
\end{tabular}


Table 14,--Summary of measurements at each station--Continued

LAT 32018M45S LONG 090054M25S

DRAINAGE AREA: 1144500 SQ MI ( 2964255 SQ KM

PERIOD OF RECORD: 10/01/74 - 09/30/75

STATISTICAL SUMMARY OF SELECTED DISSOLVED CHEMICAL CONSTITUENTS AND

REGRESSION RELATIONSHIPS OF CONSTITUENT CONCENTRATIONS TO SPECIFIC CONDUCTANCE

CONSIITUENI

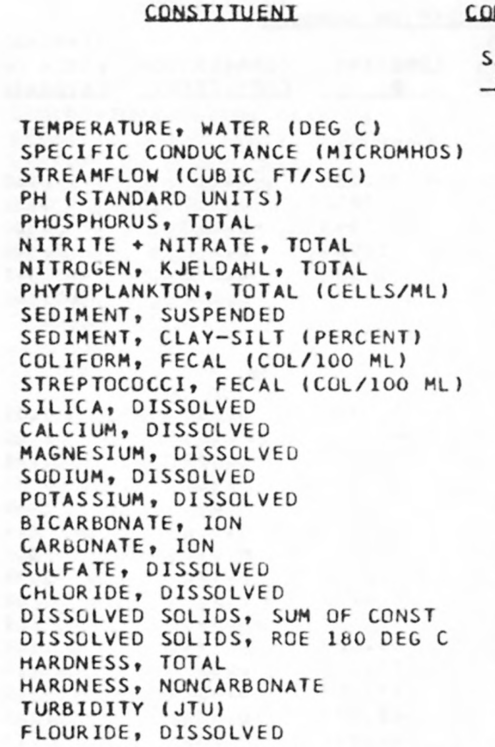

CONSIUTUENT IMG/L OR UNII SHOWNL

\section{SAMPLE \\ SIZE}

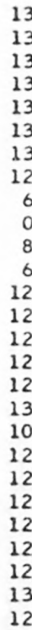

STANDARD

MEAN REVIAIION

$17.64 \quad 9.13$

$358.8 \quad 76.3$

$\begin{array}{lr}3 & 358.8 \\ 1383.9\end{array}$

7.18
0.221

0.221
1.070

1.070
0.693

0.693
3545.0

3545.0
400.8

427166.4

0.56
0.058

0.058
0.401

0.180

4078.6

223.8

$1777.4 \quad 2007.3$

896.2

5.94
37.58

875.5

1.08

5.76

2.15

8.85

0.48

10.82

17.50
2.76

122.8

0.0

46.58

19.75

200.5

213.3

140.0

140.0

39.7

60.0
0.33

25.5
0.0

10.46

9.61

42.1

44.1

22.2

5.2

0.31 REGRESSION

BEGRESSLION SUMMABY

COEFICIENT, CONSTANT,

CORRELATION

STANDARO SAMPLE 6.0
260 $350999 \quad 1679996$

$\begin{array}{rrr}6.0 & 7.8 & 13\end{array}$

6.0
0.15

0.15
0.57

0.57
0.28

0.28
580

7.8
0.35

2.00

0.95
14000

120

606

$100 \quad 4500$

$\begin{array}{rr}1 & 2500 \\ 27.1 & 8.0\end{array}$

$\begin{array}{rr}27.0 & 44.0 \\ 7.9 & 15.0\end{array}$

1.0

2.0
85

0
32.0
12.0

32.0
12.0
132

132
141
100

100

30

0.0

15.0
37.0

37.0
3.3

152
0

68.0
48.0

48.0
274

274

170
48

48
100
1.2

$\begin{array}{rr}13 & -3235.860 \\ 13 & 0.0039\end{array}$

0.0039

0.00011

$-0.00014$

12.483

1933309.000

5.7705

1.11879

0.43168

$-865.789$

$-0.578$

0.537 *

-0.026 *

0.309 *

0.236 *

364193.3

0.49

0.060

0.419

0.178
4157.2

* Not significant at the 95 percent confidence level.

SUMMARY OF HARMONIC ANALYSIS OF STREAM TEMPERATURE

\begin{tabular}{|c|c|c|c|c|c|}
\hline & & & & & STANDARD \\
\hline SAMPLE & $\begin{array}{l}\text { HARMONIC } \\
\text { MEAN - M }\end{array}$ & $\begin{array}{c}\text { AMPLITUDE } \\
-A\end{array}$ & $\begin{array}{c}\text { PHASE } \\
\text { ANGLE - C }\end{array}$ & $\begin{array}{l}\text { VAR IATION } \\
\text { EXPLAINED }\end{array}$ & $\begin{array}{l}\text { ERROR OF } \\
\text { ESTIMATE }\end{array}$ \\
\hline SUZE & DEEG C) & (DEG C) & (RADIANS) & (2) & (DEG C) \\
\hline
\end{tabular}

SLZE

DEG C)

(DEG C)
11.59
2.58
95
16.78

2.59

SUMMARY OF MAXIMUM AND MINIMUM CONCENTRATIONS OF CONSTITUENTS SAMPLED AT A FREQUENCY OF QUARTERLY (1975 WY)

07289000 -- MISSISSIPPI RIVER AT VICKSBURG, MS.

\begin{tabular}{|c|c|c|c|c|c|c|}
\hline \multirow{2}{*}{ CONSTITUENT } & \multicolumn{3}{|c|}{ TOTAL } & \multicolumn{3}{|c|}{ DISSOLVED } \\
\hline & $\begin{array}{l}\text { NO. } \\
\text { SAMPLES }\end{array}$ & $\begin{array}{l}\text { MIN IMUM } \\
\text { CONC. }\end{array}$ & $\begin{array}{l}\text { MAXIMUM } \\
\text { CONC. }\end{array}$ & $\begin{array}{l}\text { NO. } \\
\text { SAMPLES }\end{array}$ & $\begin{array}{l}\text { MINIMUM } \\
\text { CONC. }\end{array}$ & $\begin{array}{l}\text { MAXIMUM } \\
\text { CONC. }\end{array}$ \\
\hline \multicolumn{7}{|l|}{ MINOR ELEMENTS: } \\
\hline ARSENIC (AS), UG/L & 4 & 2 & 4 & 4 & 0 & 4 \\
\hline CADMIUM $(C D), U G / L$ & 4 & 0 & 4 & 4 & 0 & 2 \\
\hline CHROMIUM (CR), UG/L & 4 & $<10$ & 50 & 4 & 0 & 0 \\
\hline COBALT $(C O)$, UG/L & 4 & 1 & 5 & 4 & 0 & 1 \\
\hline COPPER (CU), UG/L & 4 & 11 & 18 & 4 & 2 & 5 \\
\hline IRON (FE), UG/L & 4 & 1700 & 6400 & 4 & 20 & 50 \\
\hline LEAD $(P B), U G / L$ & 4 & 6 & 30 & 4 & 0 & 10 \\
\hline MANG ANESE (MN), UG/L & 4 & 150 & 360 & 4 & 0 & 10 \\
\hline MERC URY (HG), UG $/ L$ & 4 & 0.0 & 0.1 & 4 & 0.0 & 0.1 \\
\hline SELENIUM (SE), UG/L & 4 & 0 & 1 & 4 & 0 & 1 \\
\hline$Z I N C(Z N), U G / L$ & 4 & 60 & 90 & 4 & 6 & 20 \\
\hline \multicolumn{7}{|l|}{ PERIPHYTON: } \\
\hline BIOMASS, DRY WT., G/SO M & 0 & & & & & \\
\hline BIOMASS, ASH WT, G/SO M & 0 & & & & & \\
\hline $\begin{array}{l}\text { CHLOROPHYLL A, MG/SQ } M \\
\text { CHLOROPHYLL } B, M G / S Q M\end{array}$ & $\begin{array}{l}0 \\
0\end{array}$ & & & & & \\
\hline ORGANIC CARBON, MG/L & 4 & 4.2 & 10.0 & & & \\
\hline
\end{tabular}


Table 14,--Summary of measurements at each station--Continued

LAT $32020 M 51 S$ LONG 090D41M48S

DRAINAGE AREA: 2810 SQ MI ( 7278 SQ KM

PERIOD OF RECORD: $10 / 01 / 74-09 / 30 / 75$

STATISTICAL SUMMARY OF SELECTED DISSOLVED CHEMICAL CONSTITUENTS AND REGRESSION RELATIONSHIPS OF CONSTITUENT CONCENTRATIONS TO SPECIFIC CONDUCTANCE

\section{CONSIIIUENI}

TEMPERATURE, WATER (DEG C)
SPECIFIC CONDUCTANCE (MICROMHOS)
STREAMFLOW (CUBIC FT/SEC)
PH (STANDARD UNITS)
PHOSPHORUS, TOTAL
NITRITE, NITRATE, TOTAL
NITROGEN, KJELDAHL, TOTAL
PHYTOPLANKTON, TOTAL (CELLS/ML)
SEDIMENT, SUSPENDED (PERCENT)
SEDIMENT, CLAY-SILT (PERC ML)
COLIFORM, FECAL (COL/IOO MLC
STREPTOCOCCI, FECAL (COL/1OO ML)
SILICA, DISSOLVED
CALCIUM, DISSOLVED
MAGNESIUM, DISSOLVED
SODIUM, DISSOLVE
POTASSIUA, DISSOLVED
BICARBONATE, ION
CARBONATE, ION
SULFATE, DISSOLVED
CHLORIDE, DISSOLVED
DISSOLVED SOLIDS, SUM OF CONST
DISSOLVED SOLIOS, ROE I8O DEG C
HARDNESS, TOTAL
HARDNESS, NONCARBONATE
TURBIDITY (JTU)
FLOURIDE, DISSOLVED

CONSIUTUENI IMG/L OR UNII SHOWNI

\begin{tabular}{|c|c|c|}
\hline $\begin{array}{l}\text { SAMPLE } \\
\text { SIZE }\end{array}$ & MEAN & $\begin{array}{l}\text { STANDARD } \\
\text { REYIAIION }\end{array}$ \\
\hline 12 & 18.95 & 7.29 \\
\hline 12 & 146.3 & 65.9 \\
\hline 12 & $5388 \cdot 0$ & 5083.6 \\
\hline 12 & 6.65 & 0.49 \\
\hline 12 & 0.271 & 0.149 \\
\hline 12 & 0.217 & 0.145 \\
\hline 12 & 0.873 & 0.314 \\
\hline 12 & 2618.3 & 4413.3 \\
\hline 7 & 162.4 & 118.2 \\
\hline 0 & & \\
\hline 9 & 7363.8 & 20868.3 \\
\hline 9 & 1245.9 & 2021.3 \\
\hline 12 & 9.67 & 3.00 \\
\hline 12 & 9.83 & 4.15 \\
\hline 12 & 3.82 & 1.87 \\
\hline 12 & 11.94 & 6.92 \\
\hline 12 & 2.62 & 0.67 \\
\hline 12 & 42.2 & 20.4 \\
\hline 9 & 0.0 & 0.0 \\
\hline 12 & 8.50 & 1.97 \\
\hline 12 & 16.16 & 11.79 \\
\hline 12 & 83.9 & 34.0 \\
\hline 12 & 96.7 & 49.3 \\
\hline 12 & 40.3 & 17.9 \\
\hline 12 & 5.8 & 3.8 \\
\hline 12 & $104 \cdot 6$ & 79.8 \\
\hline 12 & 0.34 & 0.26 \\
\hline
\end{tabular}

\section{BEGRESSION SUMMARY}

REGRESSION

SAMPLE COEFICIENT,

CONSTANT,

CORRELATION

STANDARD BANGE SIZE

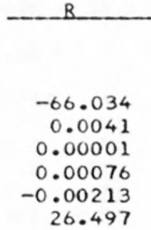

15045.426
6.0432
0.26888
0.10656
1.18493
-1256.796

$-0.855$ 0.553 * 0.006 * $0.344^{*}$

-0.447 *

0.395 *

$1.40 \quad 12$

12000

411

63000

6500

14.0

19.0

7.6
28.0

$28.0 \quad 12$

3.6
85

$\begin{array}{rr}85 & 12 \\ 0 & 9 \\ 12.0 & 12\end{array}$

$\begin{array}{ll}12.0 & 12 \\ 44.0 & 12\end{array}$

$\begin{array}{rr}44.0 & 12 \\ 143 & 12\end{array}$

170

79
14

290

0.9
1256.796

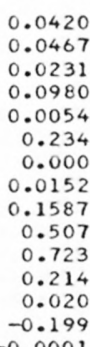

0.924

0.741

0.815

0.933

0.535

0.756

0.000 *

0.508 *
0.886

0.982

0.967

0.787

0.346 *

$-0.164 *$

$-0.023 *$
STROR OF ESIIMAIE
*Not significant at the 95 percent confidence level.

SUMMARY OF HARMONIC ANALYSIS OF STREAM TEMPERATURE

\begin{tabular}{|c|c|c|c|c|c|}
\hline \multirow{4}{*}{$\begin{array}{l}\text { SAMPLE } \\
\text { SIZE_- }\end{array}$} & & & & & STANDARD \\
\hline & HARMONIC & AMPLITUDE & PHASE & VARIATION & $\begin{array}{l}\text { ERROR OF } \\
\text { ESTIMATE }\end{array}$ \\
\hline & MEAN - $M$ & $-A$ & ANGLE - C & EXPLAINED & $\begin{array}{l}\text { ESTIMATE } \\
\text { (DEG C) }\end{array}$ \\
\hline & DEE $C 1$ & CEEGCL & (BADIANS) & $-181 \ldots$ & (DEG_C) \\
\hline 12 & 19.04 & 9.19 & 2.77 & 88 & 2.85 \\
\hline
\end{tabular}

SUMMARY OF MAXIMUM AND MINIMUM CONCENTRATIONS OF CONSTITUENTS

SAMPLED AT A FREQUENCY OF QUARTERLY (1975 WY)

07290000 -- BIG BLACK RIVER NR BOVINA, MS.

\begin{tabular}{|c|c|c|c|c|c|c|}
\hline \multirow{2}{*}{ CONSTITUENT } & \multicolumn{3}{|c|}{ TOTAL } & \multicolumn{3}{|c|}{ DISSOLVED } \\
\hline & $\begin{array}{l}\text { NO. } \\
\text { SAMPLES }\end{array}$ & $\begin{array}{l}\text { MINIMUM } \\
\text { CONC. }\end{array}$ & $\begin{array}{l}\text { MAXIMUM } \\
\text { CONC. }\end{array}$ & $\begin{array}{l}\text { NO. } \\
\text { SAMPLES }\end{array}$ & $\begin{array}{l}\text { MINIMUM } \\
\text { CONC. }\end{array}$ & $\begin{array}{l}\text { MAXIMUM } \\
\text { CONC. }\end{array}$ \\
\hline \multicolumn{7}{|l|}{ MINOR ELEMENTS: } \\
\hline ARSENIC (AS), UG $/ L$ & 4 & 2 & 6 & 4 & 0 & 2 \\
\hline CADMIUM $(C D)$, UG $/ L$ & 4 & 1 & 3 & 4 & 0 & 3 \\
\hline CHROMIUM (CR), UG/L & 4 & $<10$ & 20 & 4 & 0 & 0 \\
\hline COBALT $(C O), U G / L$ & 4 & 1 & 5 & 4 & 0 & 1 \\
\hline COPPER $(C U), U G / L$ & 4 & 9 & 18 & 4 & 8 & 22 \\
\hline IRON (FE), UG/L & 4 & 630 & 5200 & 4 & 60 & 380 \\
\hline LEAD $(P B), U G / L$ & 4 & 10 & 28 & 4 & 3 & 6 \\
\hline MANGANESE (MN), UG/L & 4 & 150 & 510 & 4 & 90 & 300 \\
\hline MERCURY $(H G), U G / L$ & 4 & 0.0 & 0.3 & 4 & 0.0 & 0.3 \\
\hline SELENIUM (SE), UG/L & 4 & 0 & 0 & 4 & 0 & 0 \\
\hline ZINC $(Z N), U G / L$ & 4 & 30 & 130 & 4 & 40 & 70 \\
\hline \multicolumn{7}{|l|}{ PERIPHYTON: } \\
\hline BIOMASS, DRY WT., G/SQ M & 0 & & & & & \\
\hline BIOMASS, ASH WT., G/SQ M & 0 & & & & & \\
\hline CHLOROPHYLL A, MG/SQ M & 0 & & & & & \\
\hline CHLOROPHYLL B, MG/SO M & 0 & & & & & \\
\hline ORGANIC CARBON, MGIL & 4 & 4.7 & 10.0 & & & \\
\hline
\end{tabular}


LAT 31DI9M2OS LONG 091006M20S

$\begin{array}{ll}\text { DRAINAGE AREA: } & 750 \text { SQ MI } 111943 \text { SO KMI } \\ \text { PERIOD OF RECORD: } & 10 / 01 / 74-09 / 30 / 75\end{array}$

STATISTICAL SUMMARY OF SELECTED DISSOLVED CHEMICAL CONSTITUENTS AND REGRESSION RELATIONSHIPS OF CONSTITUENT CONCENTRATIONS TO SPECIFIC CONDUCTANCE

\begin{tabular}{|c|c|c|c|c|c|c|c|c|c|c|}
\hline \multirow[t]{2}{*}{ CONSIIIUENI } & \multicolumn{6}{|c|}{ CONSIUIUENI IMG $/ L$ OB UNII SHOWN } & \multicolumn{3}{|c|}{$\begin{array}{l}\text { BEGRESSION SUMMABY } \\
\text { REGRESSION }\end{array}$} & \multirow[b]{2}{*}{$\begin{array}{l}\text { STANDARD } \\
\text { ERROR OF } \\
\text { ESIIMAIE }\end{array}$} \\
\hline & $\begin{array}{l}\text { SAMPLE } \\
\text { SIZE }\end{array}$ & MEAN & $\begin{array}{l}\text { STANDARD } \\
\text { DEYIAIION }\end{array}$ & \multicolumn{2}{|c|}{ BANGE } & $\begin{array}{l}\text { SAMPLE } \\
\text { SIZE }\end{array}$ & COEFICIENT, & $\begin{array}{l}\text { CONSTANT, } \\
-\end{array}$ & $\begin{array}{l}\text { CORRELATION } \\
\text { COEEICIENI }\end{array}$ & \\
\hline TEMPERATURE, WATER (DEG C) & 12 & 20.61 & 7.48 & 9.0 & 31.0 & & & & & \\
\hline SPECIFIC CONDUC TANCE (MICROMHOS) & 12 & 77.7 & 20.8 & $\begin{array}{r}44 \\
150\end{array}$ & $\begin{array}{r}120 \\
2900\end{array}$ & & & & & \\
\hline $\begin{array}{l}\text { STREAMFLOW (CUBIC FT/SEC) } \\
\text { PH (STANDARD UNITS) }\end{array}$ & 12 & $\begin{array}{r}1250.8 \\
6.37\end{array}$ & $\begin{array}{r}884.6 \\
0.38\end{array}$ & $\begin{array}{l}150 \\
5.9\end{array}$ & $\begin{array}{r}2900 \\
7.1\end{array}$ & $\begin{array}{l}12 \\
12\end{array}$ & $\begin{array}{r}-30.027 \\
0.0120\end{array}$ & $\begin{array}{r}3582.902 \\
5.4375\end{array}$ & $\begin{array}{r}-0.706 \\
0.051\end{array}$ & $\begin{array}{r}657.5 \\
0.30\end{array}$ \\
\hline PHOSPHORUS, TOTAL & 12 & 0.055 & 0.056 & 0.01 & 0.19 & 12 & -0.00076 & 0.11432 & $-0.286^{*}$ & 0.056 \\
\hline NITRITE + NITRATE, TOTAL & 12 & 0.046 & 0.024 & 0.01 & 0.10 & 12 & -0.00053 & 0.08712 & $-0.462^{\star}$ & 0.022 \\
\hline NITROGEN, KJELDAHL, TOTAL & 11 & 0.308 & 0.263 & 0.08 & 0.97 & 11 & -0.00517 & 0.70879 & $-0.428 \star$ & 0.251 \\
\hline PHYTOPLANKTON, TOTAL (CELLS/ML) & 12 & 631.5 & 536.0 & 59 & 1600 & 12 & 4.887 & 251.915 & $0.190^{*}$ & 552.0 \\
\hline SEDIMENT, SUSPENDED & 9 & 299.3 & 310.1 & 56 & 909 & & & & & \\
\hline SEDIMENT, CLAY-SILT (PERCENT) & 0 & & & & & & & & & \\
\hline COLIFURM, FECAL $(C O L / 100 \mathrm{ML})$ & 7 & 6077.6 & 12844.9 & 100 & 35000 & & & & & \\
\hline STREPTOCOCCI, FECAL (COL/100 ML) & 7 & 1341.7 & 858.1 & 175 & 2800 & & & & & \\
\hline SILICA, DISSOLVED & 12 & 12.95 & 1.74 & 8.4 & 14.0 & 12 & 0.0553 & 8.6587 & 0.662 & 1.36 \\
\hline CALCIUM, DISSOLVED & 12 & 4.13 & 1.56 & 2.2 & 6.8 & 12 & 0.0528 & 0.0327 & 0.702 & 1.17 \\
\hline MAGNESIUM, DISSOLVED & 12 & 1.22 & 0.42 & 0.5 & 2.0 & 12 & 0.0105 & 0.3985 & $0.517^{*}$ & 0.38 \\
\hline SODIUM, DISSOLVED & 12 & 8.37 & 2.61 & 4.3 & 13.0 & 12 & 0.0997 & 0.6198 & 0.795 & 1.66 \\
\hline POTASSIUM, DISSOLVED & 12 & 1.31 & 0.27 & 1.0 & 1.9 & 12 & -0.0014 & 1.4157 & $-0.106 *$ & 0.28 \\
\hline BICARBONATE, ION & 12 & $15 \cdot 3$ & 4.8 & 7 & 27 & 12 & 0.197 & -0.001 & 0.850 & 2.7 \\
\hline CARBONATE, ION & 9 & 0.0 & 0.0 & 0 & 0 & 9 & 0.000 & 0.000 & $0.000 *$ & 0.0 \\
\hline SULFATE, DISSOLVED & 12 & 3.82 & 2.06 & 2.1 & 9.8 & 12 & -0.0050 & 4.2106 & $-0.050 *$ & 2.16 \\
\hline CHLORIDE, DISSOLVED & 12 & 12.59 & 4.43 & 5.8 & 20.0 & 12 & 0.1589 & 0.2494 & 0.746 & 3.10 \\
\hline OISSOLVED SOLIDS, SUM OF CONST & 12 & 52.3 & 11.1 & 33 & 72 & 12 & 0.467 & 15.971 & 0.872 & 5.7 \\
\hline OISSOLVED SOLIDS, ROE 180 DEG C & 12 & 54.8 & 19.6 & 12 & 80 & 12 & 0.409 & 23.043 & $0.435 *$ & 18.5 \\
\hline HARDNESS, TOTAL & 12 & 15.4 & 4.8 & 8 & 23 & 12 & 0.175 & 1.793 & 0.766 & 3.2 \\
\hline HARDNESS, NONCARBONATE & 12 & 2.7 & 3.3 & 0 & 12 & 12 & 0.017 & 1.365 & $0.105 *$ & 3.5 \\
\hline TURBIDITY (JTU) & 12 & 36.7 & 40.3 & 10 & 130 & 12 & -1.338 & 140.573 & -0.690 & 30.6 \\
\hline FLOUR IDE, DISSOLVED & 12 & 0.19 & 0.24 & 0.0 & 0.9 & 12 & -0.0062 & 0.6710 & $-0.536 *$ & 0.21 \\
\hline \multicolumn{11}{|c|}{${ }^{*}$ Not significant at the 95 percent confidence level. } \\
\hline \multicolumn{11}{|c|}{$\begin{array}{l}\text { SUMMARY OF HARMONIC ANALYSIS OF STREAM TEMPERATURE } \\
\text { EOBY OE EQUAILN:IIDLE }\end{array}$} \\
\hline & & & & STANDARD & & & & & & \\
\hline AMPLITUDE & $\mathrm{PH}$ & ASE & VARIATION & ERROR OF & & & & & & \\
\hline MEAN - M & ANGLE & $E-C$ & EXPLAINED & ESTIMATE & & & & & & \\
\hline LEEG CL & IBAD & IANSI & 181 & IDEG CL & & & & & & \\
\hline 20.73 & & 2.76 & 89 & 2.69 & & & & & & \\
\hline
\end{tabular}

SUMMARY OF MAXIMUM AND MINIMUM CONCENTRATIONS OF CONSTITUENTS SAMPLED AT A FREQUENCY OF QUARTERLY (1975 WY)

07292500 -- HOMOCHITTO RIVER AT ROSETTA, MS.

\begin{tabular}{|c|c|c|c|c|c|c|}
\hline \multirow{2}{*}{ CONSTI TUENT } & \multicolumn{3}{|c|}{ TOTAL } & \multicolumn{3}{|c|}{ DISSOLVED } \\
\hline & $\begin{array}{l}\text { NO. } \\
\text { SAMPLES }\end{array}$ & $\begin{array}{l}\text { MINIMUM } \\
\text { CONC. }\end{array}$ & $\begin{array}{l}\text { MAXIMUM } \\
\text { CONC. }\end{array}$ & $\begin{array}{l}\text { NO. } \\
\text { SAMPLES }\end{array}$ & $\begin{array}{l}\text { MINIMUM } \\
\text { CONC. }\end{array}$ & $\begin{array}{l}\text { MAXIMUM } \\
\text { CONC. }\end{array}$ \\
\hline \multicolumn{7}{|l|}{ MINOR ELEMENTS: } \\
\hline ARSENIC (AS), UG/L & 4 & 1 & 5 & 4 & 0 & 0 \\
\hline CADMIUM $(C D), U G / L$ & 4 & 0 & 3 & 4 & 0 & 2 \\
\hline CHROMIUM (CR), UG/L & 4 & $<10$ & 10 & 4 & 0 & 0 \\
\hline COBALT $(C D), U G / L$ & 4 & 0 & 5 & 4 & 0 & 3 \\
\hline COPPER (CU), UG/L & 4 & 3 & 14 & 4 & 1 & 13 \\
\hline IRON (FE), UG/L & 4 & 1200 & 4500 & 4 & 60 & 180 \\
\hline LEAD $(P B), U G / L$ & 4 & 4 & 35 & 4 & 1 & 10 \\
\hline MANG ANESE (MN), UG/L & 4 & 150 & 240 & 4 & 95 & 200 \\
\hline MERCURY (HG), UG/L & 4 & 0.0 & 0.3 & 4 & 0.0 & 0.3 \\
\hline SELENIUM (SE), UG/L & 4 & 0 & 0 & 4 & 0 & 0 \\
\hline$Z I N C(Z N), U G / L$ & 4 & 30 & 60 & 4 & 20 & 70 \\
\hline \multicolumn{7}{|l|}{ PERIPHYTON: } \\
\hline BIOMASS, DRY WT., G/SO M & 0 & & & & & \\
\hline BIOMASS, ASH WT., G/SQ M & 0 & & & & & \\
\hline CHLOROPHYLL A, MG/SQ M & 0 & & & & & \\
\hline CHLOROPHYLL B, MG/SO M & 0 & & & & & \\
\hline ORGANIC CARBON, MG/L & 4 & 3.7 & 11.0 & & & \\
\hline
\end{tabular}


LAT 34D5OM15S LONG 101024M49S

DRAINAGE AREA: 4211 SQ MI 110906 SO KM

PERIOD OF RECORD: $10 / 01 / 74$ - 09/30/75

STATISTICAL SUMMARY OF SELECTED OISSOLVED CHEMICAL CONSTITUENTS AND

REGRESSION RELATIONSHIPS OF CONSTITUENT CONCENTRATIONS TO SPECIFIC CONDUCTANCE

CONSIIIUENI

TEMPERATURE, WATER (DEG C)
SPECIFIC CONOUCTANCE (MICROMHOS)
STREAMFLOW (CUBIC FT/SEC)
PH (STANDARD UNITS)
PHOSPHORUS, TOTAL
NITRITE, NITRATE, TOTAL
NITROGEN, XJELDAHL, TOTAL
PHYTOPLANKTON, TOTAL (CELLS/ML)
SEDIMENT, SUSPENDED
SEDIMENT, CLAY-SILT (PERCENT)
COLIFORM, FECAL (COL IOO ML)
STREPTOCOCCI, FECAL (COL/1OO ML)
SILICA, DISSOLVED
CALCIUM, DISSOLVED
MAGNESIUM, DISSOLVED
SODIUM, DISSOLVED
POTASSIUM, DISSOLVED
BICAREONATE, ION
CARBONATE, ION
SULFATE, DISSOLVED
CHLORIDE, DISSOLVED
DISSOLVED SOLIDS, SUM OF CONST
DISSOLVED SOLIDS, ROE I8O DEG C
HARDNESS, TOTAL
HARDNESS, NONCARBONATE
TURBIDITY (JTU)
FLOURIDE, DISSOLVED
FONOE

CONSIUUUENI_MGLL OR UNII SHOHN

\begin{tabular}{l} 
SAMPLE \\
SIZE \\
\hline
\end{tabular}

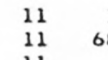

11

1180.4

$10 \quad 0.392$

$\begin{array}{rr}11 & 1.710 \\ 11 & 6942.7\end{array}$

6942.7

78.6

11783.3

11783.3
9982.7

20.45

378.64

82.99

1109.27

21.85
143.3

143.3
0.0

1252.7

1252.73
1592.27

4533.1

4724.5

4724.5
1297.3

1297.3
1172.5

1172.5
2511.1

2511.1
1.09
STANDARD

DEYIAUION

7.56
4177.4

4177.4

68.2
0.18

0.880

0.638

2.434

11505.4

9342.5
28.7

21245.8

17621.2

7.01

216.94

47.43

708.70
12.76

12.76
22.3

0.0

689.20

1090.25
2738.3

2839.3

742.8
7

723.6

5398.1
0.24

5.5
521
0.28
7.6
0.00
0.00
0.08

570

2

4

12

8.8
31.0

6.2
62.0
4.0

4.0

101
0

$\begin{array}{rr}130.0 & 1800.0 \\ 17.0 & 3000.0\end{array}$

$320 \quad 7640$

3327980

$100 \quad 1900$

$\begin{array}{ll}8 & 1800 \\ 1 & 17500\end{array}$

26.0
12000

8.3

2.80

6.70
37000

28500

54000

45000

570.0

130.0

2000.0

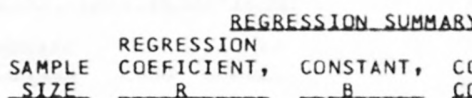

SAMPLE COEFICIENT,

11

11
11
11
10
11

$$
\begin{array}{r}
-0.012 \\
0.0000 \\
-0.00017 \\
-0.00012 \\
-0.00051 \\
-1.969
\end{array}
$$

7.9427

1.60902

1.15041

5.21353

20501.133

0.278

$-0.798$

$-0.77$

-0.873
-0.715

ST ANDARD

*Not significant at the 95 percent confidence level.

DURAUION IABLE OF DAILY SPECIEIC CONDUCIANCE

DAILY SPECIFIC CONDUCTANCE IN

MICROMHOS AT 25 DEG C, THAT WAS

EQUALLED OR EXCEEDED FOR THE

18

52108

$20 \%$

$30 \%$

508

702

11
11
11
11
11
11
11
11
11
11
11
11
11
11
9

10.0848

36.3723

7.2254

$-54.5222$

1.2138

114.058
0.000

160.2239

$-194.9426$

29.227

57.207

121.687

0.013

0.8030

46.3

0.19

0.559

0.430

1.251
8480.1

INDICATED PERCENTAGE OF TIME

$29900 \quad 26400 \quad 19900 \quad 14200 \quad 11200$

$8790 \quad 5880$

SAMPLE SIZE $\equiv 325$

203252992

\begin{tabular}{|c|c|c|c|c|c|}
\hline & HARMONIC & AMPLITUDE & PHASE & VARIATION & $\begin{array}{l}\text { STANDARD } \\
\text { ERROR OF }\end{array}$ \\
\hline $\begin{array}{l}\text { SAMPLE } \\
\text { SUZE }\end{array}$ & $\begin{array}{l}\text { MEAN - M } \\
\text { LOEG CI }\end{array}$ & $\begin{array}{c}-A \\
\text { (DEG }\end{array}$ & $\begin{array}{l}\text { ANGLE - C } \\
\text { (RADIANSI) }\end{array}$ & $\begin{array}{l}\text { EXPLAINED } \\
(1)\end{array}$ & $\begin{array}{l}\text { ESTIMATE } \\
\text { (DEG C) }\end{array}$ \\
\hline
\end{tabular}

$1820 \quad 792 \quad 30236$

SUMMARY OF HARMONIC ANALYSIS OF STREAM TEMPERATURE

EORM OE EQUAIUON: I. $101=M+A * S I N C .0172 * D+C$

324

18.89

10.52

2.84

74

4.44

\begin{tabular}{|c|c|c|c|c|c|c|}
\hline \multirow{2}{*}{ CONSTITUENT } & \multicolumn{3}{|c|}{ TOTAL } & \multicolumn{3}{|c|}{ DISSOLVED } \\
\hline & $\begin{array}{l}\text { NO. } \\
\text { SAMPLES }\end{array}$ & $\begin{array}{l}\text { MIN IMUM } \\
\text { CONC. }\end{array}$ & $\begin{array}{l}\text { MAXIMUM } \\
\text { CONC. }\end{array}$ & $\begin{array}{l}\text { NO. } \\
\text { SAMPLES }\end{array}$ & $\begin{array}{l}\text { MINIMUM } \\
\text { CONC. }\end{array}$ & $\begin{array}{l}\text { MAXIMUM } \\
\text { CONC. }\end{array}$ \\
\hline \multicolumn{7}{|l|}{ MINOR ELEMENTS: } \\
\hline ARSENIC (AS), UG/L & 4 & 3 & 240 & 4 & 3 & 7 \\
\hline CADMIUM $(C D), U G / L$ & 4 & $<10$ & 20 & 4 & 0 & $<1$ \\
\hline CHROMIUM (CR), UG/L & 4 & 10 & 290 & 4 & 0 & 10 \\
\hline COBALT $(C O), U G / L$ & 4 & $<50$ & 250 & 4 & 0 & 0 \\
\hline COPPER (CU), UG/L & 4 & 10 & 360 & 4 & 0 & 20 \\
\hline IRON $(F E), U G / L$ & 4 & 60 & 180000 & 4 & 0 & 1700 \\
\hline LEAD $(P B), U G / L$ & 4 & $<100$ & 400 & 4 & 0 & 3 \\
\hline MANGANESE (MN), UG/L & 3 & 110 & 2900 & 4 & 5 & 130 \\
\hline MERCURY $(H G), U G / L$ & 4 & 0.1 & 0.2 & 4 & 0.0 & 0.1 \\
\hline SELENIUM (SE), UG/L & 4 & 1 & 5 & 4 & 1 & 5 \\
\hline ZINC $(Z N), U G / L$ & 4 & 20 & 790 & 4 & 0 & 20 \\
\hline \multicolumn{7}{|l|}{ PERIPHYTON: } \\
\hline BIOMASS, DRY WT., G/SO M & 3 & 4.59 & 6.79 & & & \\
\hline BIOMASS, ASH WT,, G/SQ M & 3 & 3.79 & 5.50 & & & \\
\hline CHLOROPHYLL A, MG/SQ M & 3 & .6 & 3.0 & & & \\
\hline CHLOROPHYLL B, MG/SQ M & 3 & .0 & .5 & & & \\
\hline ORGANIC CARBON, MG/L & 3 & .5 & 110.0 & & & \\
\hline
\end{tabular}

SUMMARY OF MAXIMUM AND MINIMUM CONCENTRATIONS OF CONSTITUENTS

SAMPLED AT A FREQUENCY OF QUARTERLY (1975 WY)

07297910 -- PDTF RED RIVER NEAR WAYSIDE, TEX. 
Table 14.--Summery of measurements at each station--Continued

STATION NUMBER: 07300000 NAME: SALT FORK RED RIVER NR WELLINGTON, TX

LAT 34D57M27S LONG 100D13M14S

DRAINAGE AREA: 1222 SQ MI 13165 SO KMI

PERIOD OF RECORD: $10 / 01 / 74-09 / 30 / 75$

STATISTICAL SUMMARY OF SELECTED DISSOLVED CHEMICAL CONSTITUENTS ANO

REGRESSION RELATIONSHIPS OF CONSTITUENT CONCENTRATIONS TO SPECIFIC CONDUCTANCE

CONSIIUENI

CONSIIIUENI IMGLL OR UNII SHOWNI)

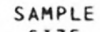

SIZE

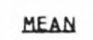

STANDARD

TEMPERATURE, WATER (DEG C)

SPECIFIC CONOUCTANCE (MICROMHOS)

STREAMFLOW (CUBIC FT/SEC)

PH ISTANDARD UNITS

PHOSPHORUS, TOTAL

NITRITE + NITRATE, TOTAL

NITROGEN, KJELDAHL, TOTAL

PHYTOPLANKTON, TOTAL (CELLS/ML)

SEDIMENT, SUSPENDED

SEOIMENT, CLAY-SILT (PERCENT)

COLIFORM, FECAL (COL/100 ML)

STREPTOCOCCI, FECAL (COL/100 ML)

SILICA, DISSOLVED

CALCIUM, DISSOLVED

MAGNESIUM, DISSOLVEL

SODIUM, DISSOLVED

POTASSIUM, DISSOLVED

BICARBONATE, ION

CARBONATE, ION

SULFATE, DISSOLVED

CHLORIDE, DISSOLVED

DISSOLVED SOLIDS, SUM OF CONST

DISSOLVED SOLIDS, ROE 180 DEG C

HARDNESS, TOTAL

HARONESS, NONCARBONATE

TURBIDITY (JTU)

FLOURIDE, DISSOLVED

*Not significant at the 95 percent confidence level.

QURAILON IABLE OE DALLY SPECIEIC GONDUC IANCE

DAILY SPECIFIC CONDUCTANCE IN

MICROMHOS AT 25 DEG C, THAT WAS

EQUALLED OR EXCEEDED FOR THE

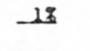

$-5$

$\begin{array}{llllll}3520 & 3430 & 3390 & 3330 & 3270 & 3170\end{array}$

17.46

2953.1

25.1

7.88

0.068

0.583

3673.3

242.8

66.3

850.8

1477.2

19.08
402.31

79.69

213.85

5.14

193.8
0.0

1163.85

291.54

2271.5

2481.7

1341.5

1160.8

76.8
0.65

9.34

378.2

27.7
0.22

0.22
0.075

0.371

0.398

3110.1

298.9
28.9

1788.2

2841.3

1.66

103.86

10.23

20.63

0.85

16.0
0.0

270.02

33.13

407.4

382.5

303.8

279.1

0.10

INDICATED PERCENTAGE OF TIME
BEGRESSION SUMMABY
REGRESSION

SAMPLE COEFICIENT, CONSTANT, CORRELATION ERROR OF SIZE

$B$ - B COEEICIENI

$2.0 \quad 29.0$ 2270
7330
7.5

$\begin{array}{lll}7.5 & 135 & 13 \\ 0.3 & 8.3 & 13\end{array}$

$0.01 \quad 0.24 \quad 12$

$601.40 \quad 12$

0.010

$-0.00015$

0.00086

$-0.0007$

$-0.386$

7.8135

0.52633

$-1.62655$

2.69905

4835.512

0.042 *

$-0.675$

0.769

$-0.586$

-0.041 *

28.7

0.058

0.249

0.338

$\begin{array}{lr}17 & 94\end{array}$

$\begin{array}{rr}6 & 6100 \\ 31 & 10000\end{array}$

$\begin{array}{rrr}151 & 10000 \\ 15.0 & 22.0 & 13\end{array}$

250.0

59.0

22.0
540.0

540.0
95.0.

240.0

6.7

$\begin{array}{rr}104 & 0 \\ 750.0 & 1600.0\end{array}$

$240.0 \quad 350.0$

1600

2810

2900
1700

1500

400
0.8

0.5

13
13
13
13
13
13
13
13
13
13
12
13
13
12
11
22.4379

$-366.7568$

9.6845

130.9928

9.9239

151.67

0.000

$-835.2917$

99.0795

$-849.248$

$-948.225$

$-947.407$

$-944.742$

625.83

1.2001
-0.260 *

0.948

0.876

0.514 *

$-0.723$

0.338 .

0.000 *

0.948

0.744

0.981

0.988

0.966

-0.530 *

$-0.710$

$70 \%$ SAMPLE SIZE $=365$
EOBM_OE EQUAIUIN: I. $(0)=M+A *$ SINL.0172*D+C

\begin{tabular}{|c|c|c|c|c|c|}
\hline & & & & & STANDARD \\
\hline & HARMONIC & AMPLITUDE & PHASE & VARIATION & ERROR OF \\
\hline SAMPLE & MEAN - M & $-A$ & ANGLE - C & EXPLAINED & ESTIMATE \\
\hline SIZE & 1DEG Cl & $-1 D E G(1$ & (RADIANSI & $-(8)$ & IDEG_CL \\
\hline 322 & 19.44 & 11.47 & 2.80 & 74 & 4.80 \\
\hline
\end{tabular}

SUMMARY OF MAXIMUM AND MINIMUM CONCENTRATIONS OF CONSTITUENTS SAMPLED AT A FREQUENCY OF QUARTERLY (1975 WY)

07300000 -- SALT FORK RED RIVER NR WELLINGTON, TX

\begin{tabular}{|c|c|c|c|c|c|c|}
\hline \multirow{2}{*}{ CONSTITUENT } & \multicolumn{3}{|c|}{ TOTAL } & \multicolumn{3}{|c|}{ DISSOLVED } \\
\hline & $\begin{array}{l}\text { NO. } \\
\text { SAMPLES }\end{array}$ & $\begin{array}{l}\text { MIN IMUM } \\
\text { CONC. }\end{array}$ & $\begin{array}{l}\text { MAXIMUM } \\
\text { CONC. }\end{array}$ & $\begin{array}{l}\text { NO. } \\
\text { SAMPLES }\end{array}$ & $\begin{array}{l}\text { MINIMUM } \\
\text { CONC. }\end{array}$ & $\begin{array}{l}\text { MAXIMUM } \\
\text { CONC. }\end{array}$ \\
\hline \multicolumn{7}{|l|}{ MINOR ELEMENTS: } \\
\hline ARSENIC (AS), UG/L & 4 & 0 & 18 & 4 & 0 & 4 \\
\hline CADMIUM $(C D), U G / L$ & 4 & $<10$ & $<10$ & 3 & 0 & 0 \\
\hline CHROMIUM (CR), UG/L & 4 & 0 & 40 & 3 & 0 & 10 \\
\hline COBALT $(C O)$, UG/L & 4 & $<50$ & $<50$ & 3 & 0 & 2 \\
\hline COPPER $(C U), U G / L$ & 4 & 10 & 20 & 3 & 0 & 1 \\
\hline IRON $(F E), U G / L$ & 4 & 60 & 14000 & 3 & 10 & 40 \\
\hline LEAD (PB), UG/L & 4 & $<100$ & $<100$ & 3 & 0 & 1 \\
\hline MANG ANESE $(M N), U G / L$ & 3 & 40 & 520 & 3 & 10 & 40 \\
\hline MERCURY (HG), UG/L & 4 & 0.0 & 0.2 & 3 & 0.0 & 0.1 \\
\hline SELENIUM (SE), UG/L & 4 & 3 & 11 & 4 & 0 & 8 \\
\hline ZINC $(Z N), U G / L$ & 4 & 20 & 230 & 3 & 0 & 0 \\
\hline \multicolumn{7}{|l|}{ PERIPHYTON: } \\
\hline BIOMASS, DRY WT., G/SQ M & 4 & 2.3 & 70.00 & & & \\
\hline BIOMASS, ASH WT., G/SQ M & 4 & 1.5 & 65.00 & & & \\
\hline CHLOROPHYLL A, MG/SQ M & 4 & .2 & 8.7 & & & \\
\hline CHLOROPHYLL $B$, MG/SO M & 4 & .0 & 1.1 & & & \\
\hline ORGANIC CARBON, MG/L & 4 & .9 & 12.0 & & & \\
\hline
\end{tabular}


Table 14,--Sumary of messurements at each station--Continued

LAT 34D38M04S LONG 099D05M47S

DRAINAGE AREA: 4244 SQ MI ( 10992 SQ KM)

PERIOD OF RECORD: $10 / 01 / 74-09 / 30 / 75$

STATISTICAL SUMMARY OF SELECTED DISSOLVED CHEMICAL CONSTITUENTS AND

REGRESSION RELATIONSHIPS OF CONSTITUENT CONCENTRATIONS TO SPECIFIC CONDUCTANCE

CONSIUTUENI

CONSILIUENI MGLL OR UNII SHOWNL

SAMPLE
SIZE

TEMPERATURE, WATER (DEG C)

SPECIFIC CONDUCTANCE (MICROMHOS)

STREAMFLOW (CUBIC FT/SEC)

PH (STANDARD UNITS)

PHOSPHORUS, TOTAL

NITRITE + NITRATE, TOTAL

NITROGEN, KJELDAHL, TOTAL

PHYTOPLANKTON, TOTAL (CELLS/ML)

SEDIMENT, SUSPENDED

SEDIMENT, CLAY-SILT (PERCENT)

COLIFORM, FECAL (COL/100 ML)

STREPTOCOCCI, FECAL (COL/100 ML)

SILICA, DISSOLVED

CALCIUM, DISSOLVED

MAGNESIUM, DISSOL VED

SODIUM, DISSOLVED

POTASSIUM, DISSOLVED

BICARBONATE, ION

CARBONATE, ION

SULFATE, DISSOLVED

CHLORIDE, DISSOLVED

DISSOLVED SOLIDS, SUM OF CONST

DISSOLVED SOLIDS, ROE 180 DEG C

HARDNESS, TOTAL

HARDNESS, NONCARBONATE

TURBIDITY (JTU)

FLOURIDE, DISSOLVED
STANDARD

DEYIAIION

BANGE

$\begin{array}{rr}43 & 5240.8 \\ 48 & 622.0\end{array}$

$\begin{array}{rr}48 & 622.0 \\ 46 & 7.98\end{array}$

7.98
0.138

0.703

1.310

6956.3

6956.3
469.8

469.8
83.0

83.0
385.4

178.0

7.67

250.28

76.22

909.27

8.90

203. 7

0.0

713.63

1479.35

3786.0

3796.5

920.5
740.0

125.1

0.34
9.12
2542.9

1476.0

1476
0.37

0.126

0.420

0.891

6880.0
540.5

540.5
33.3

371.6
171.6

371.6
171.5

2.57

97.49
35.40

35.40

520.64

59.5

59.5
0.0

280.72

806.42

1520.1

1746.7

359.6

349.5
238.3

238.3
0.12
0.02

42

11

40.0

8.2

54.0
5.3

100.0
1200

1200
316

130

3
0.1
$10 \quad 19.05$
BEGRESSION SUMMARY

REGRESSION

SAMPLE

REGRESSION

BANGE SIZE

COEFICIENT, CONSTANT,

$\begin{array}{rr}4.5 & 30.0 \\ 706 & 11300\end{array}$

$\begin{array}{rr}24 & 7840 \\ 7.2 & 8.8\end{array}$

$\begin{array}{ll}0.00 & 0.48 \\ 0.47 & 1.50\end{array}$

$0.47 \quad 3.00$

22000

22000
1440

850
$20 \quad 453$

$1.6 \quad 11.0$

2200.0

13.0

$\begin{array}{rr}98 & 309 \\ 0 & 0 \\ 44.0 & 1100.0\end{array}$

3600.0

6290

7530

1400

1300
700

0.6

*Not significant at the 95 percent confidence level.

DAILY SPECIFIC CONDUCTANCE DUBAUION IABLE OE DAULY SPECIEIC CONOUCIANCE

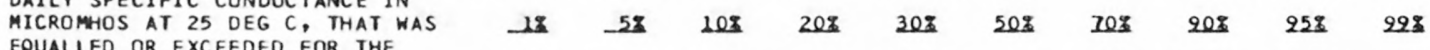

EQUALLED OR EXCEEDED FOR THE

\begin{tabular}{|c|c|c|c|c|}
\hline $1 \%$ & -58 & $10 x$ & $20 \pi$ & 308 \\
\hline & 01 & 8590 & 8120 & 7470 \\
\hline
\end{tabular}

4930

$2800 \quad 2200$

1590

SUMMARY OF HARMONIC ANALYSIS OF STREAM TEMPERATURE

EORM OF EOUAIION: IO(D) $=M+A+S I N(.0172 * 0+C)$

\begin{tabular}{|c|c|c|c|c|c|}
\hline & & & & & STANDARD \\
\hline $\begin{array}{l}\text { SAMPLE } \\
\text { SLZE }\end{array}$ & $\begin{array}{l}\text { HARMONIC } \\
\text { MEAN - M } \\
\text { LOEG C.) }\end{array}$ & $\begin{array}{c}\text { AMPLITUDE } \\
-{ }^{A} \\
\text { (DEG C) }\end{array}$ & $\begin{array}{c}\text { PHASE } \\
\text { ANGLE - C } \\
\text { (RADIANS) }\end{array}$ & $\begin{array}{l}\text { VARIATION } \\
\text { EXPLAINED } \\
(\Sigma) \\
\end{array}$ & $\begin{array}{l}\text { ERROR OF } \\
\text { ESTIMATE } \\
\text { LOEG C) }\end{array}$ \\
\hline 364 & 16.14 & 11.54 & 2.98 & 87 & 3.11 \\
\hline
\end{tabular}

SUMMARY OF MAXIMUM AND MINIMUM CONCENTRATIONS OF CONSTITUENTS

SAMPLED AT A FREQUENCY OF QUARTERLY (1975 WY)

07305000 -- NORTH FORK RED RIVER NR HEADRICK, OK

\begin{tabular}{|c|c|c|c|c|c|c|}
\hline \multirow{2}{*}{ CONSTIIUENT } & \multicolumn{3}{|c|}{ TOTAL } & \multicolumn{3}{|c|}{ DISSOLVED } \\
\hline & $\begin{array}{c}\text { NO. } \\
\text { SAMPLES }\end{array}$ & $\begin{array}{l}\text { MINIMUM } \\
\text { CONC. }\end{array}$ & $\begin{array}{l}\text { MAXIMUM } \\
\text { CONC. }\end{array}$ & $\begin{array}{l}\text { NO. } \\
\text { SAMPLES }\end{array}$ & $\begin{array}{l}\text { MINIMUM } \\
\text { CONC. }\end{array}$ & $\begin{array}{l}\text { MAXIMUM } \\
\text { CONC. }\end{array}$ \\
\hline \multicolumn{7}{|l|}{ MINOR ELEMENTS: } \\
\hline ARSENIC (AS), UG/L & 3 & 4 & 24 & 4 & 2 & 10 \\
\hline CADMIUM $(C D), U G / L$ & 4 & $<10$ & 10 & 4 & 0 & 8 \\
\hline CHROMIUM (CR), UG/L & 4 & 0 & 50 & 4 & 0 & 20 \\
\hline COBALT $(C O), U G / L$ & 4 & 0 & 100 & 4 & 0 & 0 \\
\hline COPPER (CU), UG/L & 4 & 20 & 50 & 4 & 4 & 50 \\
\hline IRON (FE), UG/L & 4 & 810 & 36000 & 4 & 20 & 130 \\
\hline LEAD $(P B), U G / L$ & 4 & $<100$ & 100 & 4 & 1 & 14 \\
\hline MANG ANESE (MN), UG/L & 5 & 60 & 760 & 4 & 20 & 60 \\
\hline MERCURY (HG), UG/L & 3 & 0.0 & 0.9 & 4 & 0.0 & 0.6 \\
\hline SELENIUM (SE), UG/L & 4 & 2 & 3 & 4 & 1 & 2 \\
\hline ZINC $(Z N), U G / L$ & 4 & 80 & 770 & 4 & 0 & 460 \\
\hline \multicolumn{7}{|l|}{ PERIPHYTON: } \\
\hline BIOMASS, DRY HT., G/SQ M & 0 & & & & & \\
\hline BIOMASS, ASH WT., G/SQ M & 0 & & & & & \\
\hline CHLOROPHYLL A, MG/SO M & 0 & & & & & \\
\hline CHLOROPHYLL B, MG/SQ M & 0 & & & & & \\
\hline ORGANIC CARBON, MG/L & 7 & 3.7 & 24.0 & & & \\
\hline
\end{tabular}


Table 14.--Summary of measurements at each station---Continued

LAT 34D06M30S LONG 098D32MOOS

DRAINAGE AREA: 20570 SQ MI 153276 SQ KM)

PERIOD OF RECORD: $10 / 01 / 74-09 / 30 / 75$

STATISTICAL SUMMARY OF SELECTED DISSOLVED CHEMICAL CONSTITUENTS AND

REGRESSION RELATIONSHIPS OF CONSTITUENT CONCENTRATIONS TO SPECIFIC CONDUCTANCE

CONSIIUENI

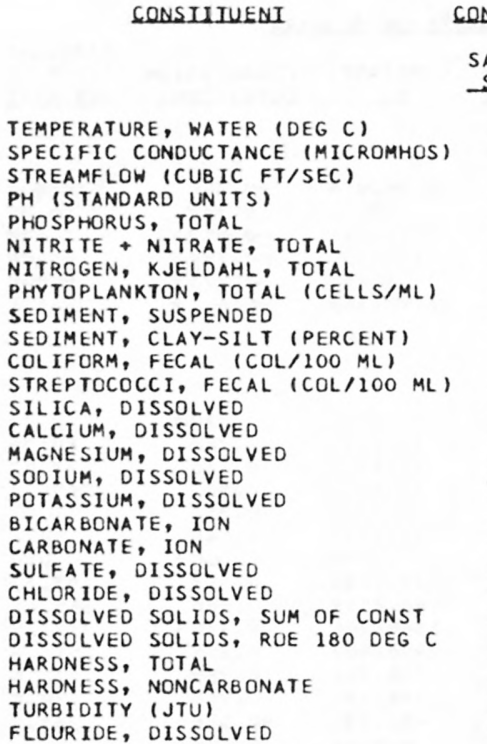

CONSIITUENI UMGLL OR UNII SHOWN

\begin{tabular}{r} 
SAM \\
SI \\
\hline 1 \\
15 \\
1 \\
1 \\
1 \\
1 \\
1 \\
1 \\
1 \\
1 \\
1 \\
1 \\
1 \\
15 \\
15 \\
15 \\
15 \\
15 \\
15 \\
15 \\
15 \\
15 \\
15 \\
1 \\
15 \\
15 \\
1 \\
15
\end{tabular}

STANDARD

DEYIAIION

17.47

6503.3

6503.3

1775.3
7.84

7.84
0.263

0.352

1.595

39484.5

1554.3

46.6
335.2

$335 \cdot 2$

929.3

308.87

84.27

1016.00

10.59

167.5
0.0

867.33

1624.00

4004.3

4619.2

4619.2

1116.7

980.7
340.0

340.0
0.39
8.05

8.05
2407.5

2390.7

0.20
0.239

0.239
0.421

0.858

42119.1

2178.4

26.4
534.2

1499.4

1499.4
3.12

3.12
102.92

33.91

421.93

2.14
49.6

0.0

318.76

669.24

1535.5

1184.7

388.9

370.6
489.9

489
0.10

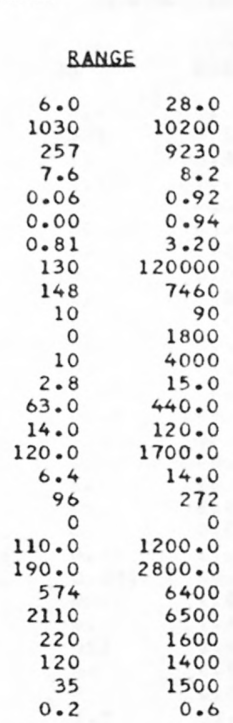

BEGRESS ION SUMMABY REGRESSION SAMPLE COEFICIENT, CONSTANT, CORRELATION ERTORD OF SIZE - $R$ COEEICIENI ESIUMAI

$\begin{array}{rrrrr}15 & -0.815 & 7156.355 & -0.800 & 1526.7 \\ 15 & 0.0000 & 7.7480 & 0.171 * & 0.20 \\ 12 & -0.00010 & 0.99376 & -0.789 & 0.154 \\ 12 & 0.00002 & 0.20459 & 0.090^{*} & 0.440 \\ 12 & -0.00032 & 3.87562 & -0.685 & 0.656 \\ 11 & 0.544 & 35521.172 & 0.025 * & 44382.9\end{array}$

$\begin{array}{rrrrr}15 & -0.0001 & 9.6116 & -0.084^{*} & 3.23 \\ 15 & 0.0407 & 44.1201 & 0.952 & 32.60 \\ 15 & 0.0132 & -1.5700 & 0.937 & 12.28 \\ 15 & 0.1739 & -115.0989 & 0.992 & 53.93 \\ 15 & 0.0004 & 8.0979 & 0.431 * & 2.00 \\ 15 & 0.010 & 101.082 & 0.495 * & 44.7 \\ 15 & 0.000 & 0.000 & 0.000^{*} & 0.0 \\ 15 & 0.1255 & 51.3789 & 0.948 & 105.67 \\ 15 & 0.2764 & -173.6475 & 0.994 & 73.65 \\ 15 & 0.635 & -126.972 & 0.996 & 142.1 \\ 12 & 0.622 & 117.023 & 0.980 & 249.0 \\ 15 & 0.155 & 106.260 & 0.962 & 110.7 \\ 15 & 0.147 & 26.140 & 0.954 & 115.8 \\ 12 & -0.185 & 1680.045 & -0.705 & 364.3 \\ 13 & 0.0000 & 0.2208 & 0.600 & 0.09\end{array}$

"Not significant at the 95 percent confidence level.

DURALION IABLE OF DALL SPECIEIC CONDUCTANCE

DAILY SPECIFIC CONDUCTANCE IN

MICROMHOS AT 25 DEG C, THAT WAS

EQUALLED OR EXCEEDED FOR THE

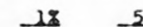

$10 \% \quad 20 \% \quad 30 \% \quad 508$

502

$70 \% \quad 20 \% \quad 25 \% \quad 29 \%$

INDICATED PERCENTAGE OF TIME

10000

$8670 \quad 8330 \quad 7280$

6230

$4000 \quad 2980-1210$

SUMMARY OF HARMONIC ANALYSIS OF STREAM TEMPERATURE

EORM OE EQUATION: I. (D) = M A

\begin{tabular}{|c|c|c|c|c|c|}
\hline & & & & & $\overline{\text { STANDARD }}$ \\
\hline & HARMONIC & AMPLITUDE & PHASE & VARIATION & ERROR OF \\
\hline SAMPLE & MEAN - M & $-A$ & ANGLE - C & EXPLAINED & ESTIMATE \\
\hline SIZE. & LDEG CL & (DEG $(1)$ & (RADIANS) & $(8)$ & (DEG $(1)$ \\
\hline 280 & 17.22 & 10.81 & 2.84 & 84 & 3.32 \\
\hline
\end{tabular}

SUMMARY OF MAXIMUM AND MINIMUM CONCENTRATIONS OF CONSTITUENTS

SAMPLED AT A FREQUENCY OF QUARTERLY (1975 WY)

07308500 -- RED RIVER NR BURKBURNETT, TX

\begin{tabular}{|c|c|c|c|c|c|c|}
\hline \multirow{2}{*}{ CONSTITUENT } & \multicolumn{3}{|c|}{ TOTAL } & \multicolumn{3}{|c|}{ DISSOĻVED } \\
\hline & $\begin{array}{l}\text { NO. } \\
\text { SAMPLES }\end{array}$ & $\begin{array}{l}\text { MIN IMUM } \\
\text { CONC. }\end{array}$ & $\begin{array}{l}\text { MAXIMUM } \\
\text { CONC. }\end{array}$ & $\begin{array}{l}\text { NO. } \\
\text { SAMPLES }\end{array}$ & $\begin{array}{l}\text { MINIMUM } \\
\text { CONC. }\end{array}$ & $\begin{array}{l}\text { MAXIMUM } \\
\text { CONC. }\end{array}$ \\
\hline \multicolumn{7}{|l|}{ MINOR ELEMENTS: } \\
\hline ARSENIC (AS), UG/L & 4 & 5 & 19 & 4 & 3 & 7 \\
\hline CADM IUM $(C D)$, UG/L & 4 & $<10$ & 10 & 4 & 0 & 4 \\
\hline CHROMIUM (CR), UG/L & 4 & 0 & 50 & 4 & 0 & 10 \\
\hline COBALT $(C O), U G / L$ & 4 & $<50$ & 100 & 4 & 0 & 3 \\
\hline COPPER (CU), UG/L & 4 & $<10$ & 60 & 4 & 1 & 80 \\
\hline IRON $(F E), U G / L$ & 4 & 1500 & 34000 & 4 & 20 & 6700 \\
\hline LEAD $(P B), U G / L$ & 4 & $<100$ & 100 & 4 & 0 & 50 \\
\hline MANG ANESE $(M N), U G / L$ & 4 & 130 & 1200 & 4 & 0 & 50 \\
\hline MERCURY $(H G), U G / L$ & 4 & 0.0 & 0.1 & 4 & 0.0 & 0.0 \\
\hline SELENIUM (SE), UG/L & 4 & 1 & 3 & 4 & 1 & 2 \\
\hline$Z I N C(Z N), U G / L$ & 4 & 60 & 190 & 4 & 0 & 120 \\
\hline \multicolumn{7}{|l|}{ PERIPHYTON: } \\
\hline BIOMASS, DRY WT., G/SO M & 1 & 6.29 & & & & \\
\hline BIOMASS, ASH WT., G/SQ M & 1 & 2.19 & & & & \\
\hline CHLOROPHYLL A, MG/SQ M & 1 & .1 & & & & \\
\hline CHLOROPHYLL $B, M G / S O M$ & 1 & .0 & & & & \\
\hline ORGANIC CARBON, MG/L & 4 & 10.0 & 30.0 & & & \\
\hline
\end{tabular}


LAT 34014M03S LONG 096058M32S

DRAINAGE AREA: 7202 SQ MI ( 18653 SO KM)

PERIOD OF RECORD: $10 / 01 / 74-09 / 30 / 75$

STATISTICAL SUMMARY OF SELECTED DISSOLVED CHEMICAL CONSTITUENTS AND

REGRESSION RELATIONSHIPS OF CONSTITUENT CONCENTRATIONS TO SPECIFIC CONDUCTANCE

CONSIUIUENI

CONSILTUENI IMGLL_OR UNII SHOWN

SAMPLE

SIZE

TEMPERATURE, HATER (DEG C)

SPECIFIC CONDUCTANCE (MICROMHOS)

STREAMFLOH (CUBIC FT/SEC)

PH (STANDARD UNITS)

PHOSPHORUS, TOTAL

NITRITE + NITRATE, TOTAL

NITROGEN, KJELDAHL, TOTAL

PHYTOPLANKTON, TOTAL (CELLS/ML)

SEOIMENT, SUSPENDED

SEDIMENT, CLAY-SILT (PERCENT)

COLIFORM, FECAL (COL/100 ML)

STREP TOCOCCI, FECAL (COL/100 ML)

SILICA, DISSOLVED

CALCIUM, DISSOL VED

MAGNE SIUM, DISSOLVED

SODIUM, DISSOLVED

POTASSIUM, DISSOL VED

BICARBONATE, ION

CARBONATE, ION

SULFATE, DISSOLVED

CHLORIDE, DISSOLVED

DISSOLVED SOLIDS, SUM OF CONST

DISSOLVED SOLIDS, ROE 180 DEG C

HARDNESS, TOTAL

HARDNESS, NONCARBONATE

TURBIDITY (JTU)

FLOURIDE, DISSOLVED

*Not significant at the 95 percent confidence level.

DAILY SPECIFIC CONDUCTANCE IN

MICROMHOS AT 25 DEG C, THAT WAS

MICROMHOS AT 25 DEG C, THAT WAS
EQUALLED OR EXCEEDED FOR THE

EQUALLED OR EXCEEDED FOR THE
INDICATED PERCENTAGE OF TIME

$\begin{array}{rrrrrr}18 & 58 & 108 & 208 & 308 & 508 \\ 1580 & 1500 & 1440 & 1320 & 1230 & 1030\end{array}$

STANDARD

MEAN DEVIAIION

18.50

895.2
3668.9

3668.9
8.08

8.08
0.292

0.388

18658.9

18658.9
780.2

780.2
79.5

1145.0

450.3

9.29
93.93

93.93
37.46

37.46
50.81

4.68

250.0

0.0

205.06
66.06

66.06
594.2

660.5

380.7

183.3

225.1
0.32
7.44
378.7

378.7
5759.3

0.42

0.138

0.215
0.917

28565.7

522.0

35.0

360.6
767.4

1.60

35.46

17.14
24.03

1.12

71.1

113.19

113.19
31.59

237.7

242.8

157.6

200.3

0.06
BANGE

5.0
248
404
7.4
0.13
0.01

$0.01 \quad 0.69$

$730 \quad 76000$

$\begin{array}{rr}135 & 1420 \\ 11 & 100\end{array}$

$\begin{array}{rr}11 & 100\end{array}$

$\begin{array}{rr}40 & 2000 \\ 6.8 & 13.0\end{array}$

$\begin{array}{rr}6.8 & 13.0 \\ 35.0 & 150.0\end{array}$

3.27 .0

$\begin{array}{rr}130 & 380 \\ 0 & 0\end{array}$

$\begin{array}{ll}18.0 & 400.0 \\ 17.0 & 110.0\end{array}$

$\begin{array}{rr}17.0 & 110.0 \\ 294 & 924\end{array}$

294

120

9
2
0.2 $\begin{array}{rr}6.9 & 68.0 \\ 13.0 & 89.0\end{array}$
BEGRE

$\begin{array}{ll} & \text { REGRESSION } \\ \text { SAMPLE COEFICIENT, CONSTANT, CORRELATION ERROR OF }\end{array}$ SUZE R

ESTIMATE

$$
\begin{array}{rr}
16 & -9.847 \\
15 & 0.0003 \\
9 & -0.00035 \\
12 & -0.00013 \\
12 & -0.00138 \\
7 & 44.708
\end{array}
$$

12520.477

520.477
7.8469
0.61105
0.52566

$-18524.543$

-0.611
0.232

0.232
-0.863

$-0.244$

$-0.492 *$

$0.458 *$

4967.4

0.46
0.076

0.202

0.904

30633.0

9
13
15
14
11
15
15
15
15
7
14
13
13
9
9

0.0029
0.0984
0.0455
0.0647
-0.0004
0.184
0.000
0.2942
0.0765
0.722
0.722
0.432
0.280
-0.433
0.0001

$0.585 *$

0.986

0.932

0.940

-0.116 .

0.908

0.000 *

0.917

0.922

0.950

0.948

0.973

0.899

-0.746
0.533
1.53

6.66

6.87

8.94

1.26
32.9

0.0

49.77

12.47

12.47

$92 \cdot 3$

85.8

40.8

54.0
145.0

0.05

SUMMARY OF HARMONIC ANALYSIS OF STREAM TEMPERATURE

\begin{tabular}{|c|c|c|c|c|c|}
\hline $\begin{array}{l}\text { SAMPLE } \\
\text { SIZE. }\end{array}$ & $\begin{array}{l}\text { HARMONIC } \\
\text { MEAN - M } \\
\text { IDEG CI }\end{array}$ & $\begin{array}{c}\text { AMPLITUDE } \\
-A \\
\text { IDEG }\end{array}$ & $\begin{array}{c}\text { PHASE } \\
\text { ANGLE - C } \\
\text { IRADIANSI) }\end{array}$ & $\begin{array}{c}\text { VAR IATION } \\
\text { EXPLAINED } \\
\text { (X) } \\
\end{array}$ & $\begin{array}{l}\text { STANDARD } \\
\text { ERROR OF } \\
\text { ESTIMATE } \\
\text { IDEG C) }\end{array}$ \\
\hline 361 & 19.63 & 10.35 & 2.78 & 87 & 2.80 \\
\hline
\end{tabular}

SUMMARY OF MAXIMUM AND MINIMUM CONCENTRATIONS OF CONSTITUENTS SAMPLED AT A FREQUENCY OF QUARTERLY (1975 WY)

07331000 -- WASHITA RIVER NR DURWOOD, OK

\begin{tabular}{|c|c|c|c|c|c|c|}
\hline \multirow{2}{*}{ CONSTITUENT } & \multicolumn{3}{|c|}{ TOTAL } & \multicolumn{3}{|c|}{ DISSOLVED } \\
\hline & $\begin{array}{l}\text { NO. } \\
\text { SAMPLES }\end{array}$ & $\begin{array}{l}\text { MINIMUM } \\
\text { CONC. }\end{array}$ & $\begin{array}{l}\text { MAXIMUM } \\
\text { CONC. }\end{array}$ & $\begin{array}{l}\text { NO. } \\
\text { SAMPLES }\end{array}$ & $\begin{array}{l}\text { MINIMUM } \\
\text { CONC. }\end{array}$ & $\begin{array}{l}\text { MAXIMUM } \\
\text { CONC. }\end{array}$ \\
\hline \multicolumn{7}{|l|}{ MINOR ELEMENTS: } \\
\hline ARSENIC (AS), UG/L & 3 & 4 & 26 & 3 & 3 & 8 \\
\hline CADMIUM (CD), UG/L & 3 & 10 & 10 & 3 & 0 & 4 \\
\hline CHROMIUM (CR), UG/L & 3 & 0 & 40 & 3 & 0 & 0 \\
\hline COBALT $(C O)$, UG/L & 3 & $<50$ & 100 & 3 & 0 & 3 \\
\hline COPPER (CU), UG/L & 3 & 20 & 50 & 3 & 2 & 40 \\
\hline IRON (FE), UG/L & 3 & 3700 & 26000 & 3 & 20 & 2800 \\
\hline LEAD $(P B), U G / L$ & 3 & $<100$ & 100 & 3 & 2 & 17 \\
\hline MANGANESE (MN), UG/L & 3 & 130 & 1100 & 3 & 0 & 810 \\
\hline MERCURY (HG), UG/L & 3 & 0.1 & 0.2 & 3 & 0.1 & 0.1 \\
\hline SELENIUM (SE), UG/L & 2 & 0 & 1 & 3 & 0 & 0 \\
\hline ZINC $(Z N), U G / L$ & 3 & 70 & 440 & 3 & 0 & 370 \\
\hline $\begin{array}{l}\text { PERIPHYTON: } \\
\text { BIOMASS, DRY WT., G/SO M } \\
\text { BIOMASS, ASH WT:; G/SO M } \\
\text { CHLOROPHYLL A, MG/SO M } \\
\text { CHLOROPHYLL B, MG/SO M }\end{array}$ & $\begin{array}{l}0 \\
0 \\
0 \\
0\end{array}$ & & & & & \\
\hline ORGANIC CARBON, MG/L & 5 & 5.5 & 16.0 & & & \\
\hline
\end{tabular}


Table 14,--Summary of measurements at each station--Continued

LAT 33D49M08S LONG 096033M47S

DRAINAGE AREA: 39720 SQ MI ( 102875 SQ KM)

PERIOD OF RECORD: $10 / 01 / 74-09 / 30 / 75$

STATISTICAL SUMMARY OF SELECTED DISSOLVED CHEMICAL CONSTITUENTS AND

REGRESSION RELATIONSHIPS OF CONSTITUENT CONCENTRATIONS TO SPECIFIC CONDUCTANCE

CONSIUTUENI

CONSILIUENI
TEMPERATURE, WATER (DEG C)
SPECIFIC CONDUCTANCE (MICROMHOS)
STREAMFLOH (CUBIC FT/SEC)
PH (STANDARD UNITS)
PHOSPHORUS, TOTAL,
NITRITE, NITRATE, TOTAL
NITROGEN, KJELDAHL, TOTAL
PHYTOPLANKTON, TOTAL (CELLS/ML)
SEDIMENT, SUSPENDED
SEDIMENT, CLAY-SILT (PERCENT)
COLIFORM, FECAL (COL/IOO ML)
STREPTOCOCCI, FECAL (COL/IOO ML)
SILICA, DISSOLVED
CALCIUM, DISSOLVED
MAGNESIUM, DISSOLVED
SODIUM, DISSOLVED
POTASSIUM, DISSOLVED
BICARBONATE, ION
CARBONATE, ION
SULFATE, DISSOLVED
CHLOR IDE, DISSOLVED
DISSOLVED SOLIDS, SUM OF CONST
DISSOLVED SOLIDS, ROE IBO DEG C
HARDNESS, TOTAL
HARDNESS, NONCARBONATE
TURBIDITY (JTU)
FLOURIDE, DISSOLVED
FOU

CONSIUTUENT MGCL OR UNUI SHOHN

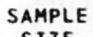

SIZE

13

16.58 $12 \quad 10509.2$

$12 \quad 7.76$

7.76
0.033

0.105

0.515

10555.8

7.4
85.7

85.7

50.0

41.6

3.89

81.17

23. 08

159.17

5.67
154.8

154.8

158.33

248.33

758.33

756.6

795.4

297.5

170.8
2.2

0.25
STANDARD

DEXIALION

6.15

143.7

9786.1
0.22

0.22
0.015

0.052

0.178

10432.8

4.6
9.4

98.6

60.2

1.73

6.93

1.78
21.93

1.24

14.9

18.01

38.10

38.10
79.7

89.4
21.8

21.8
18.8

1.0

0.05

$\begin{array}{rr}r & \\ \text { BANGE } & \\ 9.0 & 26.0 \\ 1100 & 1550 \\ 2850 & 37700 \\ 7.3 & 8.1 \\ 0.02 & 0.06 \\ 0.02 & 0.19 \\ 0.13 & 0.86 \\ 270 & 28000 \\ 3 & 18 \\ 70 & 98 \\ 0 & 300 \\ 0 & 160 \\ 0.7 & 5.6 \\ 72.0 & 92.0 \\ 21.0 & 27.0 \\ 130.0 & 200.0 \\ 4.7 & 9.0 \\ 131 & 176 \\ 0 & 0 \\ 130.0 & 190.0 \\ 200.0 & 310.0 \\ 647 & 886 \\ 630 & 941 \\ 270 & 330 \\ 130 & 200 \\ 1 & 4 \\ 0.2 & 0.3\end{array}$

BEG

$\begin{array}{llll} & \text { REGRESSION } & \text { STANDARD } \\ \text { SAMPLE COEFICIENT, CONSTANT, CORRELATION } & \text { ERROR OF } \\ \text { SIZE } & \text { B } & \text { C } & \text { COEEICIENI ESIUMAIE }\end{array}$

SIZE

- B

ESIUMAI

*Not significant at the 95 percent confidence level.

DURATION TABIF OF DAUIY SPECIEIC CONDUCTANCE

DAILY SPECIFIC CONDUCTANCE IN

MICROMHOS AT 25 DEG C, THAT WAS

EQUALLED OR EXCEEDED FOR THE

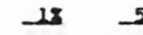

$58 \quad 108$

1560

1540
207302508

1450

14401370

$\begin{array}{rrr}12 & 19.172 & -15325.078 \\ 12 & 0.0012 & 6.1622 \\ 12 & -0.00006 & 0.11508 \\ 12 & 0.00002 & 0.08280 \\ 12 & 0.00003 & 0.46963 \\ 12 & -22.016 & 40222.215\end{array}$

$0.258 *$

0.712

$-0.534 *$

$0.042 *$

$0.025 *$
$-0.278 *$

9915.3

0.16

0.01

0.055

0.187
0509.9

10509.9
17.1982

31.2379

18.6965

$-57.7149$

8.6558

169.032

0.000

$-14.6777$

$-127.6342$

20.848

$-67.102$

158.494

2.934

$-0.335$

0.4100
$-0.755$

0.705

0.241 .

0.968

$-0.236 *$

$-0.094 *$

$0.000 *$

0.940

0.966

0.979

0.944

0.624

0.873

$0.238 *$
-0.252
1. 19

1.81

5.81

1.26

15.6
0.0

6.44

10.39

17.2

30.8

17.9

9.6

1.0
0.05

SUMMARY OF HARMONIC ANALYSIS OF STREAM TEMPERATURE

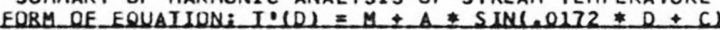

\begin{tabular}{|c|c|c|c|c|c|}
\hline $\begin{array}{l}\text { SAMPLE } \\
\text { SIZE }\end{array}$ & $\begin{array}{l}\text { HARMONIC } \\
\text { MEAN - M } \\
\text { LDEG CI }\end{array}$ & $\begin{array}{c}\text { AMPLITUDE } \\
-A \\
\text { (DEG } C)\end{array}$ & $\begin{array}{c}\text { PHASE } \\
\text { ANGLE - C } \\
\text { (RADIANS) }\end{array}$ & $\begin{array}{l}\text { VAR IATION } \\
\text { EXPLAINED } \\
\text { (I) }\end{array}$ & $\begin{array}{l}\text { STANDARD } \\
\text { ERROR OF } \\
\text { ESTIMATE } \\
\text { IOEG C) }\end{array}$ \\
\hline 232 & 17.08 & 11.29 & 2.44 & 98 & 1.06 \\
\hline
\end{tabular}

SUMMARY OF MAXIMUM AND MINIMUM CONCENTRATIONS OF CONSTITUENTS SAMPLED AT A FREQUENCY OF QUARTERLY (1975 WY)

07331600 -- RED RIVER AT DENISON DAM NR DENISON, TX

\begin{tabular}{|c|c|c|c|c|c|c|}
\hline \multirow{2}{*}{ CONSTI IUENT } & \multicolumn{3}{|c|}{ TOTAL } & \multicolumn{3}{|c|}{ DISSOLVED } \\
\hline & $\begin{array}{l}\text { NO. } \\
\text { SAMPLES }\end{array}$ & $\begin{array}{l}\text { MIN IMUM } \\
\text { CONC. }\end{array}$ & $\begin{array}{l}\text { MAXIMUM } \\
\text { CONC. }\end{array}$ & $\begin{array}{l}\text { NO. } \\
\text { SAMPLES }\end{array}$ & $\begin{array}{l}\text { MINIMUM } \\
\text { CONC. }\end{array}$ & $\begin{array}{l}\text { MAXIMUM } \\
\text { CONC. }\end{array}$ \\
\hline \multicolumn{7}{|l|}{ MINOR ELEMENTS: } \\
\hline ARSENIC (AS), UG/L & 4 & 2 & 4 & 4 & 1 & 3 \\
\hline CADMIUM $(C D), U G / L$ & 4 & $<10$ & 10 & 4 & 0 & 0 \\
\hline CHROMIUM (CR), UG/L & 4 & 0 & 10 & 4 & 0 & 10 \\
\hline COBALT $(C O), U G / L$ & 4 & $<50$ & $<50$ & 4 & 0 & 2 \\
\hline COPPER $(C U), U G / L$ & 4 & $<10$ & 20 & 4 & 0 & 3 \\
\hline IRON (FE), UG/L & 4 & 20 & 350 & 4 & 10 & 80 \\
\hline LEAD $(P B), U G / L$ & 4 & $<100$ & $<100$ & 4 & 0 & 2 \\
\hline MANG ANESE $(M N), U G / L$ & 4 & 10 & 160 & 4 & 0 & 140 \\
\hline MERCURY (HG), UG/L & 4 & 0.0 & 0.1 & 4 & 0.0 & 0.0 \\
\hline SELENIUM (SE), UG/L & 4 & 0 & 1 & 4 & 0 & 1 \\
\hline$Z I N C(Z N), U G / L$ & 4 & 10 & 80 & 4 & 0 & 20 \\
\hline \multicolumn{7}{|l|}{ PERIPHYTON: } \\
\hline BIOMASS, DRY WT., G/SO M & 0 & & & & & \\
\hline BIOMASS, ASH WT, G/SO M & 0 & & & & & \\
\hline $\begin{array}{l}\text { CHLOROPHYLL A, MG/SQ } M \\
\text { CHLOROPHYLL } \\
B, M G / S Q \\
M\end{array}$ & 0 & & & & & \\
\hline CHLOROPHYLL B, MG/SQ M & 0 & & & & & \\
\hline ORGANIC CARBON, MG/L & 4 & 3.3 & 6.0 & & & \\
\hline
\end{tabular}


Table 14.---Summary of measurements at each station--Continued

LAT 32D32M57S LONG 093045M51S DRAINAGE AREA: 0 SQ MI

$\begin{array}{lcc}\text { DRAINAGE AREA: } & 0 \text { SQ MI } 1 & 0 \text { SQ KM) } \\ \text { PERIOD OF RECORD: } & 10 / 01 / 74-09 / 30 / 75 & \end{array}$

STATISTICAL SUMMARY OF SELECTED DISSOLVED CHEMICAL CONSTITUENTS AND REGRESSION RELATIONSHIPS OF CONSTITUENT CONCENTRATIONS TO SPECIFIC CONDUCTANCE

CONSIIIUENI

CONSTUIUENI IMGLL OR UNII SHOWNI

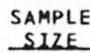

SLZE

TEMPERATURE, WATER (DEG C) SPECIFIC CONDUCTANCE (MICROMHOS

STREAMFLOW (CUBIC FT/SEC)

PH (STANDARD UNITS)

PHOSPHORUS, TOTAL

NITRITE + NITRATE, TOTAL

NITROGEN, KJELDAHL, TOTAL

PHYTOPLANKTON, TOTAL (CELLS/ML)

SEDIMENT, SUSPENDED

SEDIMENT, CLAY-SILT (PERCENT)

COL IFORM, FECAL (COL/100 ML)

STREPTOCOCCI, FECAL ( $\mathrm{COL} / 100 \mathrm{ML})$

SILICA, DISSOLVED

CALCIUM, DISSOLVED

MAGNESIUM, DISSOLVED

SODIUM, DISSOLVED

POTASSIUM, DISSOLVED

BICARBONATE, ION

CARBONATE, ION

SULFATE, DISSOLVED

CHLORIDE, DISSOLVED

DISSOLVED SOLIDS, SUM OF CONST

DISSOLVED SOLIDS, ROE 180 DEG C

HARDNESS, TOTAL

HARDNESS, NONCARBONATE

TURBIDITY (JTU)

FLOUR IDE, DISSOLVED
STANDARD

REYIALION

$\begin{array}{rrr}26 & 19.23 & 7.96 \\ 26 & 579.0 & 256.3 \\ 26 & 44096.2 & 37521.3 \\ 26 & 7.67 & 0.21 \\ 24 & 0.140 & 0.073 \\ 25 & 0.128 & 0.119 \\ 25 & 0.739 & 0.264 \\ 12 & 18311.7 & 42339.8\end{array}$

$397.7 \quad 732.4$

$\begin{array}{rr}397.7 & 732.4 \\ 329.4 & 446.5 \\ 5.64 & 1.83\end{array}$

40.83

9.93

48.48
3.05

118.7

118.7
0.0

54.04

78.20

273.2

333.7
142.7

142.7
56.6

56.6
73.8

0.19
1.83
15.33

5.15

29.51
0.63

41.2

41.2
0.0

28.78

43.09

132.6

58.8

58.6
50.0

55.4

0.09
5
5
0.5
21.0
4.1
10.0
2.2
65
0
13.0
12.0
118
128
73
1
10
0.0

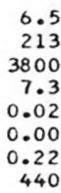

\section{BANGE}

6.530 .0

$213 \quad 1020$

$\begin{array}{rr}3800 & 133000 \\ 7.3 & 8.1\end{array}$

$\begin{array}{rr}7.3 & 8.1 \\ 0.02 & 0.33\end{array}$

$0.00 \quad 0.53$

1.30

150000

3400
2000
8.4
72.0
20.0
110.0
4.7
216
0
110.0
170.0
559
618
260
220
260
0.3

3400

2000
8.4

72.0

20.0

4.7

216

110.0

170.0

618

260
220

260
0.3

Not significant at the 95 percent confidence level.

DURAIION IABLE OF DAWY SPECIEIC CONDUCIANCE

DAILY SPECIFIC CONDUCTANCE IN

MICROMHOS AT 25 DEG C, THAT WAS

EQUALLED OR EXCEEDED FOR THE

$\begin{array}{rrrr}18 & -58 & 108 & 208 \\ 1181 & 1080 & 984 & 886\end{array}$

$30 \pi 503$

INDICATEO PERCENTAGE OF TIME

$1181 \quad 1080$

EMPERTURE

SUMMARY OF HARMONIC ANALYSIS OF STREAM TEMPERATURE

\begin{tabular}{|c|c|c|c|c|c|}
\hline & & & & & STANDARD \\
\hline & HARMONIC & AMPLITUDE & PHASE & VARIATION & ERROR OF \\
\hline SAMPLE & MEAN - $M$ & $-A$ & ANGLE - C & EXPLAINED & ESTIMATE \\
\hline SIZE & 10EG C) & WEE () & (RADLANSI & $(x)$ & (DEG $(1)$ \\
\hline 346 & 19.78 & 9.46 & 2.75 & 90 & 2.22 \\
\hline
\end{tabular}

SUMMARY OF MAXIMUM AND MINIMUM CONCENTRATIONS OF CONSTITUENTS SAMPLED AT A FREQUENCY OF QUARTERLY (1975 WY)

07344410 -- RED RIVER AB SHREVEPORT

\begin{tabular}{|c|c|c|c|c|c|c|}
\hline \multirow{2}{*}{ CONSTITUENT } & \multicolumn{3}{|c|}{ TOTAL } & \multicolumn{3}{|c|}{ DISSOLVED } \\
\hline & $\begin{array}{l}\text { NO. } \\
\text { SAMPLES }\end{array}$ & $\begin{array}{l}\text { MINIMUM } \\
\text { CONC. }\end{array}$ & $\begin{array}{l}\text { MAXIMUM } \\
\text { CONC. }\end{array}$ & $\begin{array}{l}\text { NO. } \\
\text { SAMPLES }\end{array}$ & $\begin{array}{l}\text { MINIMUM } \\
\text { CONC. }\end{array}$ & $\begin{array}{l}\text { MAXIMUM } \\
\text { CONC. }\end{array}$ \\
\hline \multicolumn{7}{|l|}{ MINOR ELEMENTS: } \\
\hline ARSENIC (AS), UG/L & 26 & 1 & 10 & 13 & 0 & 2 \\
\hline CADMIUM (CD), UG/L & 26 & 0 & 4 & 14 & 0 & 2 \\
\hline CHROMIUM (CR), UG/L & 25 & 2 & 30 & 13 & 0 & 1 \\
\hline COBALT $(C O), U G / L$ & 25 & 0 & 22 & 14 & 0 & 3 \\
\hline COPPER (CU), UG/L & 25 & 2 & 23 & 14 & 1 & 9 \\
\hline IRON $(F E), U G / L$ & 26 & 540 & 25000 & 14 & 0 & 110 \\
\hline LEAD $(P B), U G / L$ & 25 & 0 & 22 & 14 & 0 & 4 \\
\hline MANGANESE (MN), UG/L & 25 & 100 & 690 & 13 & 0 & 160 \\
\hline MERCURY (HG), UG/L & 26 & 0.0 & 0.7 & 12 & 0.0 & 0.3 \\
\hline SELENIUM (SE), UG/L & 25 & 0 & 1 & 13 & 0 & 1 \\
\hline ZINC $(Z N), U G / L$ & 26 & 4 & 140 & 14 & 0 & 90 \\
\hline \multicolumn{7}{|l|}{ PERIPHYTON: } \\
\hline BIOMASS, DRY WT., G/SQ M & 0 & & & & & \\
\hline BIOMASS, ASH WT., G/SO M & 0 & & & & & \\
\hline CHLOROPHYLL A, MG/SQ M & 0 & & & & & \\
\hline CHLOROPHYLL B, MG/SQ M & 0 & & & & & \\
\hline ORGANIC CARBON, MG $/ L$ & 26 & 4.0 & 26.0 & & & \\
\hline
\end{tabular}


Table 14,--Summary of measurements at each station--Continued

LAT $31018 M 46 S$ LONG 092026M34S

DRAINAGE AREA: 67500 SQ MI I 174825 SQ KMI

PERIOD OF RECORD: $10 / 01 / 74-09 / 30 / 75$

STATISTICAL SUMMARY OF SELECTED DISSOLVED CHEMICAL CONSTITUENTS AND

REGRESSION RELATIONSHIPS OF CONSTITUENT CONCENTRATIONS TO SPECIFIC CONOUCTANCE

CONSIUTUENI

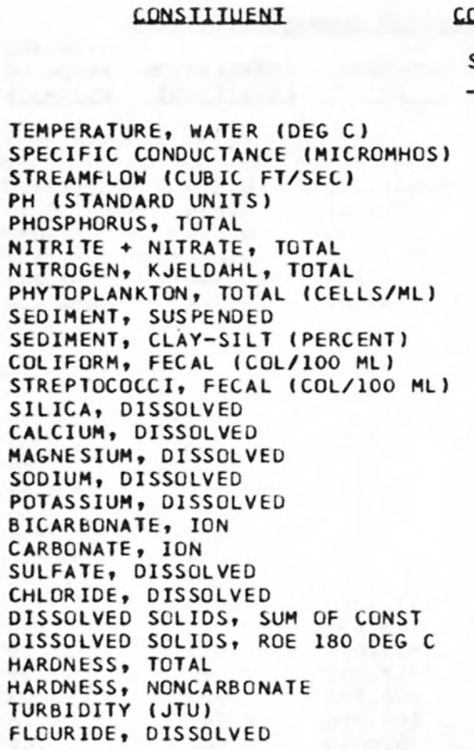

CONSILTUENT IMG LL OB UNII_SHOHN

\begin{tabular}{c} 
SAMPL \\
SIZE \\
\hline 11 \\
12 \\
0 \\
12 \\
11 \\
12 \\
12 \\
12 \\
28 \\
28 \\
12 \\
12 \\
12 \\
12 \\
12 \\
11 \\
12 \\
11 \\
12 \\
12 \\
12 \\
10 \\
11 \\
12 \\
11 \\
12 \\
12
\end{tabular}

STANOARD

MEAN

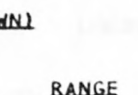

462.2

7.57

0.221

0.132

0.812

5795.3

1144.4
81.6

1922.5

600.5

5.93

34.42

8.47
42.00

42.00
2.82

92.5

0.0
4.50

42.50

64.83

247.0

275.6

120.6

44.3
101.7

101.7
0.18
EEVIAIUN

8.01
242.5

242.5

0.28

0.118
0.090

0.198

13377.9

965.6
8.7

1309.9

562.3

1.36

15.32

4.52
30.11

30.11
0.63

30.5

0.0

29.89

44.73
149.6

149.6

155.3
57.3

57.3

36.0

55.7
0.08
BANGE

$\begin{array}{ll}8.5 & 30.0 \\ 209 & \end{array}$

1010

$\begin{array}{lll}7.2 & 8.2 & 12\end{array}$

0.120 .54

0.01

0.48

44
111

60

10

2.4
18.0

18.0
3.9

15.0
2.2

2.2
58

11.0

20.0

116

114

64
16

16
45

0.0
0.33

$1.10 \quad 12$

$48000 \quad 12$

4210
95

5000

1900

$7.6 \quad 12$

$\begin{array}{rr}7.6 & 12 \\ 66.0 & 12\end{array}$

18.0

110.0
4.4

$4.4 \quad 12$

$148 \quad 11$

110.0

170.0

554

554
605

240

120
250

0.3

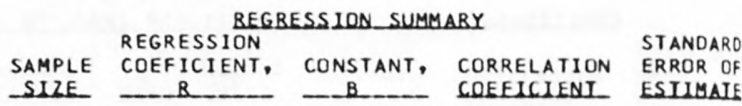

R.

- B....

OEEICIENI.

STANOARO

ESIUYAIE

*Not significant at the 95 percent confidence level.

DURAIJON IABLE OF DAILY SPECIEIC CONDUCIANCE

DAILY SPECIFIC CONDUCTANCE IN

MICROMHOS AT 25 DEG C, THAT WAS

EQUALLED OR EXCEEDED FOR THE

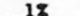

108208

308

502

0.0004 $-0.00007$ 0.00007 0.00004

17.196

0.25341

0.10051

0.79147

$-2152.266$

0.380 *

-0.142 *

0.186 *

0.054 *

0.312 *

0.27

0.123

0.093

0.207

13331.6

$-0.0000$

0.0622

0.0181

0.1180

0.0024

0.106

0.1212

0.1832

0.558

0.558

0.630

0.232

0.140

-0.033
0.0002

5.9403
5.6669
0.1184
-12.1431
1.7148
43.410
0.000
-13.5104
-19.8448
-9.384
-26.764
13.240
-20.343
116.951
0.0701

$-0.003 *$
0.985
0.970
0.996
0.931
0.885
$0.000^{*}$
0.983
0.993
0.999
0.997
0.982
0.986
$-0.144 *$
0.711

1.42

2.79

1.15

2.96
0.24

15.0

0.0
5.73

5.44

5.44
5.7

12.4

11.3

6.4
57.8

0.06

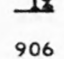

SAMPLE SIZE $=344$

907957997

INDICATED PERCENTAGE OF TIME

708

571

468

346

$226-216-189$

SUMMARY OF HARMONIC ANALYSIS OF STREAM TEMPERATURE

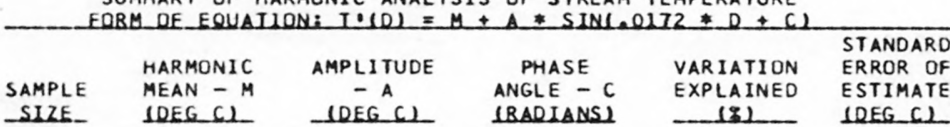

$\begin{array}{llllll}331 & 19.28 & 9.97 & 2.76 & 92 & 2.12\end{array}$

SUMMARY OF MAXIMUM AND MINIMUM CONCENTRATIONS OF CONSTITUENTS

SAMPLED AT A FREQUENCY OF QUARTERLY (1975 WY)

07355500 - RED R AT ALEXANDRIA

\begin{tabular}{|c|c|c|c|c|c|c|}
\hline \multirow{2}{*}{ CONSTITUENT } & \multicolumn{3}{|c|}{ TOTAL } & \multicolumn{3}{|c|}{ DISSOLVED } \\
\hline & $\begin{array}{l}\text { NO. } \\
\text { SAMPLES }\end{array}$ & $\begin{array}{l}\text { MINIIMUM } \\
\text { CONC. }\end{array}$ & $\begin{array}{l}\text { MAXIMUM } \\
\text { CONC. }\end{array}$ & $\begin{array}{l}\text { NO. } \\
\text { SAMPLES }\end{array}$ & $\begin{array}{l}\text { MINIMUM } \\
\text { CONC. }\end{array}$ & $\begin{array}{l}\text { MAXIMUM } \\
\text { CONC. }\end{array}$ \\
\hline \multicolumn{7}{|l|}{ MINOR ELEMENTS: } \\
\hline ARSENIC (AS), UG/L & 4 & 2 & 7 & 4 & 0 & 1 \\
\hline CADMIUM $(C D), U G / L$ & 4 & 0 & 2 & 4 & 0 & 0 \\
\hline CHROMIUM (CR), UG/L & 4 & $<10$ & 20 & 4 & 0 & 1 \\
\hline COBALT $(C O), U G / L$ & 4 & 7 & 14 & 4 & 0 & 3 \\
\hline COPPER $(C U), U G / L$ & 4 & 6 & 24 & 4 & 3 & 32 \\
\hline IRON $(F E), U G / L$ & 4 & 2700 & 6200 & 4 & 20 & 80 \\
\hline LEAD $(P B), U G / L$ & 4 & 8 & 32 & 4 & 1 & 2 \\
\hline MANGANESE (MN), UG/L & 4 & 110 & 540 & 4 & 0 & 20 \\
\hline MERCURY (HG), UG/L & 4 & 0.0 & 0.4 & 4 & 0.0 & 0.2 \\
\hline SELENIUM (SE), UG/L & 4 & 0 & 1 & 4 & 0 & 1 \\
\hline ZINC $(Z N), U G / L$ & 4 & 20 & 60 & 4 & 4 & 20 \\
\hline \multicolumn{7}{|l|}{ PER IPHYTON: } \\
\hline BIOMASS, DRY WT., G/SO M & 0 & & & & & \\
\hline BIOMASS, ASH WT., G/SO M & 0 & & & & & \\
\hline CHLOROPHYLL A, MG/SQ M & 0 & & & & & \\
\hline CHLOROPHYLL B, MG/SO M & 0 & & & & & \\
\hline ORGANIC CARBON, MG/L & 4 & 8.0 & 13.0 & & & \\
\hline
\end{tabular}


AT 33D35M47S LONG 092049M05S IRAINAGE AREA: 5391 SQ MI 113963 SQ KMI DERIOD OF RECORD: $10 / 01 / 74-09 / 30 / 75$

STATISTICAL SUMMARY OF SELECTED DISSOLVED CHEMICAL CONSTITUENTS ANU REGRESSION RELATIONSHIPS OF CONSTITUENT CONCENTRATIONS TO SPECIFIC CONDUCTANCE

CONSILIUENI

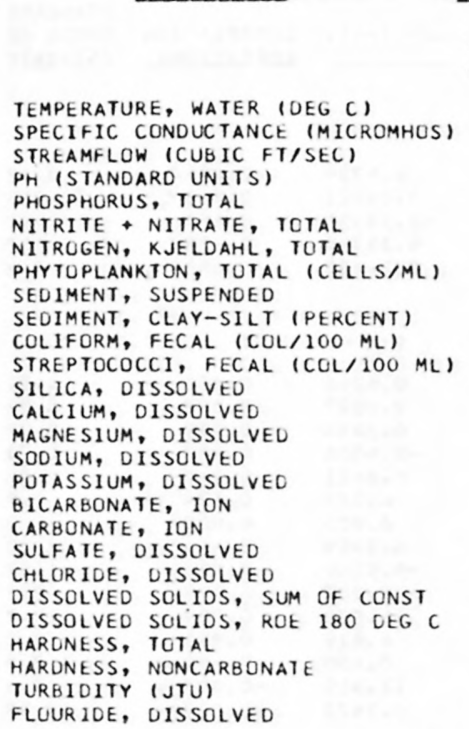

\begin{tabular}{|c|c|c|}
\hline $\begin{array}{l}\text { SAMPLE } \\
\text { SIZE }\end{array}$ & MEAN & $\begin{array}{l}\text { STANDARD } \\
\text { DEYIAIION }\end{array}$ \\
\hline 11 & 16.05 & 7.11 \\
\hline 11 & 82.7 & 15.0 \\
\hline 10 & 9386.7 & 9466.7 \\
\hline 11 & 7.02 & 0.38 \\
\hline 11 & 0.070 & 0.080 \\
\hline 11 & 0.221 & 0.132 \\
\hline 11 & 0.507 & 0.155 \\
\hline 10 & 532.0 & 625.6 \\
\hline 6 & 126.3 & 251.4 \\
\hline 6 & 84.7 & 28.4 \\
\hline 10 & 235.1 & 434.1 \\
\hline 10 & 540.7 & 1262.3 \\
\hline 11 & 0.38 & 1.12 \\
\hline 11 & 7.40 & 1.72 \\
\hline 11 & 1.47 & 0.25 \\
\hline 11 & 5.66 & 1.27 \\
\hline 11 & 1.46 & 0.48 \\
\hline 11 & 19.2 & 5.9 \\
\hline 11 & 0.0 & 0.0 \\
\hline 11 & 7.90 & 1.95 \\
\hline 11 & 7.98 & 2.68 \\
\hline 11 & 48.2 & 6.7 \\
\hline 11 & 55.6 & 8.1 \\
\hline 11 & 24.6 & 4.7 \\
\hline 11 & 9.1 & 4.2 \\
\hline 11 & 19.9 & 12.2 \\
\hline 11 & 0.16 & 0.13 \\
\hline
\end{tabular}

\section{BEGRESSION SUMMABY}

\begin{tabular}{lll}
\multicolumn{4}{c}{ REGRESSION } & STANDARD \\
SAMPLE & COEFICIENT, CONSTANT, CORRELATION ERROR OF \\
SIZE & $-B$
\end{tabular}

\section{BANGE}

SIZE

$\begin{array}{rr}7.0 & 28.5 \\ 62 & 112 \\ 957 & 29700 \\ 6.3 & 7.4\end{array}$

$\begin{array}{rr}957 & 29700 \\ 6.3 & 7.4 \\ 0.02 & 0.29\end{array}$

0.10

0.22

120

12

11

11
8
5.0

5.0
5.2

5.2
1.0

3.8

0.7

11
0
5.7

5.7
5.5
37

40

40
19
0

0
2
0.1
$0.29 \quad 11$

0.53

0.77
2200

639
99

1400

1400

4100
8.8

8.8
11.0

1.9

8.6

2.5
32

12.0

14.0

60

67
34

34
14
40

0.5
COEFICTENT,

$B$

$10 \quad-377.706$

10.0012

0.00055

$\begin{array}{ll}11 \\ 1 & 1 \\ 1 & 1 \\ 1 & 1 \\ 1 & 1 \\ 1 & 1 \\ 1 & 1 \\ 1 & 1 \\ 1 & 1 \\ 1 & 1 \\ 1 & 1 \\ 1 & 1 \\ 1 & 1 \\ 1 & 1 \\ 1 & 1\end{array}$
$-0.347 *$ 0.843

0.165 *

0.473

0.502 .

0.294 *

$0.000 *$

$0.111 *$

0.886

0.828

0.629

0.780

0.513 *

0.326 *

0.592 *
0.00126

21.741

40623.008

6.9148

$-0.13358$

0.11682

0.46216

$-1237.699$

$-0.657$

0.052 *

0.478 *

0.149 *

0.055 *
8.4330 $-0.2926$

1.2587

2. 4730

0.1869

10.017

0.000

6.7519

$-4.5800$

18.862

28.709

5.000
-2.266

-1.219
-0.2392
7567.8

0.40

0.074

0.137

554.4

1.10

0.98

0.26

1.18

0.44

0.25

0.0049

07362000 -- OUACHITA RIVER AT CAMDEN, ARK.

\begin{tabular}{|c|c|c|c|c|c|c|}
\hline \multirow{2}{*}{ CONSTIIUENT } & \multicolumn{3}{|c|}{ TOTAL } & \multicolumn{3}{|c|}{ DISSOLVED } \\
\hline & $\begin{array}{l}\text { NO. } \\
\text { SAMPLES }\end{array}$ & $\begin{array}{l}\text { MIN IMUM } \\
\text { CONC. }\end{array}$ & $\begin{array}{l}\text { MAXIMUM } \\
\text { CONC. }\end{array}$ & $\begin{array}{c}\text { NO. } \\
\text { SAMPLES }\end{array}$ & $\begin{array}{l}\text { MINIMUM } \\
\text { CONC. }\end{array}$ & $\begin{array}{l}\text { MAXIMUM } \\
\text { CONC. }\end{array}$ \\
\hline \multicolumn{7}{|l|}{ MINOR ELEMENTS: } \\
\hline ARSENIC (AS), UG/L & 5 & 0 & 2 & 5 & 0 & 2 \\
\hline CADMIUM $(C D), U G / L$ & 5 & $<10$ & 10 & 5 & 0 & 2 \\
\hline CHROMIUM (CR), UG $/ L$ & 5 & 0 & 160 & 5 & 0 & 10 \\
\hline COBALT $(C O), U G / L$ & 5 & $<50$ & $<50$ & 5 & 0 & 2 \\
\hline COPPER (CU), UG/L & 5 & 10 & 55 & 5 & 2 & 25 \\
\hline IRON (FE), UG/L & 5 & 1100 & 7200 & 5 & 50 & 870 \\
\hline$L E A D(P B), U G / L$ & 5 & $<100$ & $<100$ & 5 & 0 & 3 \\
\hline MANGANESE (MN), UG/L & 5 & 80 & 610 & 5 & 40 & 170 \\
\hline MERCURY $(H G), U G / L$ & 4 & 0.0 & 0.2 & 5 & 0.0 & 0.2 \\
\hline SELENIUM (SE), UGIL & 5 & 0 & 1 & 5 & 0 & 0 \\
\hline ZINC $(Z N), U G / L$ & 5 & 30 & 90 & 5 & 10 & 40 \\
\hline \multicolumn{7}{|l|}{ PERIPHYTON: } \\
\hline BIOMASS, DRY WT., G/SO M & 2 & 8.89 & 10.00 & & & \\
\hline BIOMASS, ASH WT., G/SO M & 2 & 6.79 & 16.00 & & & \\
\hline CHLOROPHYLL A, MG/SQ M & 2 & 1.1 & 12.0 & & & \\
\hline CHLORQPHYLL B, MG/SQ M & 2 & $\cdot 1$ & $3 \cdot 3$ & & & \\
\hline ORGANIC CARBON, MG/L & 5 & 2.2 & 7.5 & & & \\
\hline
\end{tabular}


LAT 32 D06M28S LONG 092004M27S

DRAINAGE AREA: 0 SQ MI

PERIOD OF RECORD: $10 / 01 / 74-09 / 30 / 75$ SQ KMI

STATISTICAL SUMMARY OF SELECTED DISSOLVED CHEMICAL CONSTITUENTS AND

REGRESSION RELATIONSHIPS OF CONSTITUENT CONCENTRATIONS TO SPECIFIC CONDUCTANCE

CONSIIIUENI

CONSILIUENI IMGLL OR UNII SHCWNU

$$
\begin{aligned}
& \text { SAMPLE } \\
& \text { SIZE }
\end{aligned}
$$

STANDARD

MEAN DEYIALION

TEMPERATURE, WATER (DEG C) SPECIFIC CONDUCTANCE (MICROMHOS)

STREAMFLOW (CUBIC FT/SEC)

PH (STANDARD UNITS)

PHOSPHORUS, TOTAL

NITRITE + NITRATE, TOTAL

NITROGEN, KJELDAHL, TOTAL

PHYTOPLANKTON, TOTAL (CELLS/ML)

SEDIMENT, SUSPENDED

SEDIMENT, CLAY-SILT (PERCENT)

COLIFORM, FECAL (COL/100 ML)

STREPTOCCCCI, FECAL (COL/100 ML)

SILICA, DISSOLVED

CALCIUM, DISSOLVED

MAGNESIUM, DISSOLVED

SODIUM, DISSOLVED

POTASSIUM, DISSOLVED

BICARBONATE, ION

CARBONATE, ION

SULFATE, DISSOL VED

CHLOR IDE, DISSOLVED

DISSOLVED SOLIDS, SUM OF CONST

DISSOLVED SOLIDS, ROE 180 DEG C

HARDNESS, TOTAL

HARDNESS, NONCARBONATE

TURBIDITY (JTU)

FLOURIDE, DISSOLVEO

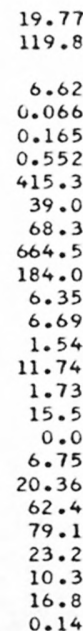

119.8

7.99
35.0

REGRESSION
SAMPLE COEFICIENT, CONSTANT,

BEGRESSION_SUMMABY

SAMPLE
SIZE

$\begin{array}{rr}10.0 & 30.5 \\ 75 & 171\end{array}$

0.620 .21

0.066

0.165

0.552
415.3

415.3
39.0

68.3

64.

184.0

6.35

6.69

1.54

1.74

15.5

0.0
6.75

20.36

62.4

33.1

10.3

16.8

0.013
0.114

0.114

423.4

19.5

21.7
1147.9
240.1

240.1
2.09

2.09

1.56
0.34

0.34

4.36
0.36

0.36
3.8

0.0

1.29

7.50
17.2

22.5

5.1

4.0

0.09

$\begin{array}{rrr}6.2 & 7.0 & 12 \\ 0.04 & 0.08 & 12 \\ 0.06 & 0.45 & 12 \\ 0.34 & 0.82 & 11 \\ 43 & 1500 & 12 \\ 14 & 68 & \\ 32 & 100 & \\ 120 & 4000 & \\ 10 & 830 & \\ 2.3 & 9.0 & 12 \\ 4.6 & 10.0 & 12 \\ 1.0 & 2.0 & 12 \\ 6.2 & 20.0 & 11 \\ 1.3 & 2.2 & 12 \\ 11 & 23 & 12 \\ 0 & 0 & 12 \\ 4.8 & 9.3 & 12 \\ 11.0 & 36.0 & 11 \\ 41 & 91 & 11 \\ 53 & 136 & 12 \\ 16 & 33 & 12 \\ 3 & 18 & 12 \\ 10 & 20 & 12 \\ 0.0 & 0.3 & 12 \\ & & \end{array}$

*Not significant at the 95 percent confidence level.

DAILY SPECIFIC CONDUCTANCE IN INAION IABLE OF DALLY SPECIEIC CONDUCIANCE

MICROMHOS AT 25 DEG C, THAT WAS

EQUALLED OR EXCEEDED FOR THE

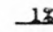

58

102

$20 \%$

271

196

173

139

$30 \%$

203

103

$\begin{array}{rrrr}0.0012 & 0.4739 & 0.196^{*} & 0.22 \\ 0.00021 & 0.04121 & 0.548^{*} & 0.012 \\ 0.00224 & -0.10354 & 0.687 & 0.087 \\ 0.00191 & 0.31799 & 0.428^{*} & 0.152 \\ -0.977 & 532.188 & -0.081 * & 442.6\end{array}$

0.0478
0.0392
0.0096
0.1317
0.0074
0.073
0.000
0.0171
0.2247
0.522
0.519
0.137
0.079
-0.009
-0.0000

0.6246
2.0017
0.3938
-3.4308
0.8481
6.724
0.000
4.6989
-5.5146
2.207
16.930
6.819
0.850
17.815
0.1423

0.802

0.877

0.979

0.987

0.718

0.674

0.000 *

0.464 *

0.980

0.992

0.992

0.807

0.931

0.691

$-0.097 *$
$-0.002 *$

SAMPLE SIZE $=161$

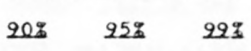

$81 \quad 76$
STANDARD

STANDARD
ERROR OF

ERROR OF
ESIIMAIE

SUMMARY OF MAXIMUM AND MINIMUM CONCENTRATIONS OF CONSTITUENTS SAMPLED AT A FREQUENCY OF QUARTERLY (1975 WY)

07367640 -- OUACHITA RIVER AT COLUMBIA, LA.

CONSTITUENT
SAMPLES


Table 14.--Sumary of measurements at each station--Continued

LAT 32025M55S LONG 091022MOOS

$\begin{array}{ll}\text { DRAINAGE AREA: } & 309 \text { SQ MI } 1 \\ \text { PERIOD OF RECORD: } & 10 / 01 / 74-09 / 30 / 75\end{array}$

STATISTICAL SUMMARY OF SELECTED DISSOLVED CHEMICAL CONSTITUENTS AND

REGRESSION RELATIONSHIPS OF CONSTITUENT CONCENTRATIONS TO SPECIFIC CONDUCTANCE

CONSILIUENI

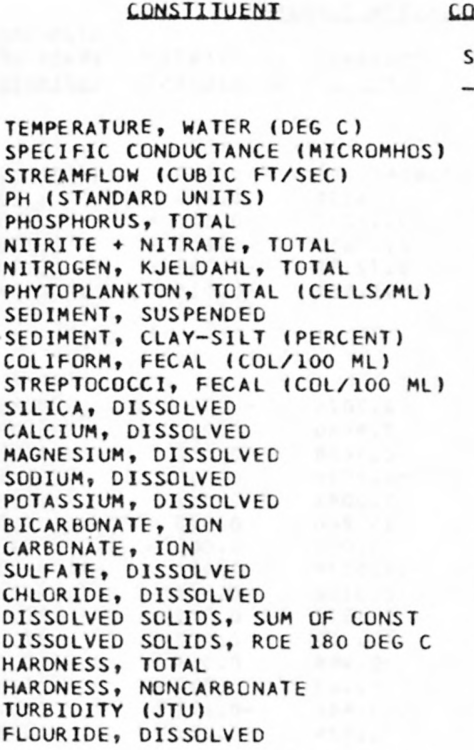

CONSIUIUENI_IMG $\angle L$ OR UNII_SHOWNI

\begin{tabular}{rrr}
$\begin{array}{rrr}\text { SAMPLE } \\
\text { SIZE }\end{array}$ & \multicolumn{1}{r}{ MEAN } & \multicolumn{1}{r}{ STANDARD } \\
\cline { 1 - 2 } & & \\
12 & 19.51 & \\
12 & 19.58 & 6.83 \\
12 & 264.3 & 168.5 \\
12 & 765.3 & 1036.5 \\
12 & 7.30 & 0.32 \\
12 & 0.309 & 0.169 \\
12 & 0.428 & 0.457 \\
12 & 1.052 & 0.459 \\
12 & 2412.5 & 3894.5 \\
12 & 187.8 & 155.5 \\
12 & 89.1 & 14.7 \\
10 & 1136.5 & 1146.7 \\
9 & 3310.1 & 4459.5 \\
12 & 11.18 & 5.29 \\
12 & 28.80 & 18.89 \\
12 & 9.22 & 6.45 \\
11 & 9.58 & 8.01 \\
12 & 3.90 & 1.06 \\
12 & 142.8 & 98.3 \\
12 & 0.0 & 0.0 \\
12 & 6.46 & 2.66 \\
12 & 7.74 & 5.84 \\
11 & 141.2 & 93.7 \\
10 & 146.7 & 93.9 \\
12 & 110.4 & 73.6 \\
12 & 0.5 & 1.2 \\
12 & 97.2 & 86.3 \\
12 & 0.22 & 0.09
\end{tabular}

BEGRESSION SUMMABY

SAMPLE COEFICIENT, CONSTANT, CORRELATION

ST ANDARD ERROR OF ESIUMAIE

$\begin{array}{rrr}9.0 & 29.5 & \\ 55 & 538 & \\ 17 & 3630 & 12 \\ 6.8 & 7.9 & 12 \\ 0.11 & 0.58 & 12 \\ 0.14 & 1.80 & 12 \\ 0.53 & 2.20 & 12 \\ 110 & 11000 & 12 \\ 30 & 461 & \\ 47 & 99 & \\ 30 & 2800 & \\ 60 & 14000 & \\ 4.9 & 21.0 & 12 \\ 5.8 & 59.0 & 12 \\ 1.4 & 20.0 & 12 \\ 1.4 & 26.0 & 11 \\ 2.0 & 5.6 & 12 \\ 28 & 302 & 12 \\ 0 & 0 & 12 \\ 2.3 & 9.5 & 12 \\ 1.5 & 18.0 & 12 \\ 35 & 306 & 11 \\ 56 & 306 & 10 \\ 20 & 230 & 12 \\ 0 & 4 & 12 \\ 6 & 300 & 12 \\ 0.1 & 0.4 & 12\end{array}$

$\begin{array}{rrrr}-4.265 & 1892.713 & -0.693 & 783.4 \\ 0.0016 & 6.8882 & 0.823 & 0.19 \\ -0.00081 & 0.52291 & -0.807 & 0.105 \\ -0.00064 & 0.59797 & -0.237^{*} & 0.466 \\ -0.00133 & 1.40323 & -0.487^{*} & 0.420 \\ 18.075 & -2365.383 & 0.782 & 2545.6\end{array}$

*Not significant at the 95 percent confidence level.

DURAIION IABLE OF DAILY SPECIEIC CONDUCIANCE

DAILY SPECIFIC CONDUCTANCE IN

MICROMHOS AT 25 DEG C, THAT WAS

EQUALLED OR EXCEEDED FOR THE

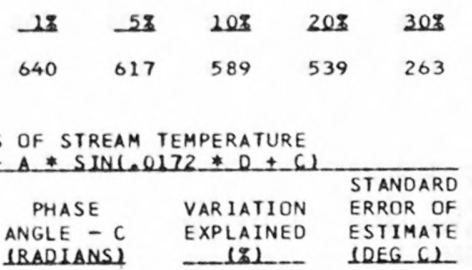

SUMMARY OF HARMONIC ANALYSIS OF STREAM TEMPERATURE FORM OF EQUAIUON: I.SOI $=M+A *$ SINC.0172 * $0+6$

\begin{tabular}{|c|c|c|c|c|c|}
\hline & HARMONIC & AMPLITUDE & PHASE & VARIATION & $\begin{array}{l}\text { STANDARD } \\
\text { ERROR OF }\end{array}$ \\
\hline $\begin{array}{l}\text { SAMPLE } \\
\text { SIZE }\end{array}$ & $\begin{array}{l}\text { MEAN }-M \\
\text { (DEG } C \text { ) }\end{array}$ & ${ }^{-A}{ }^{A}(D)$ & $\begin{array}{l}\text { ANGLE }-C \\
\text { (RADIANSI) }\end{array}$ & $\begin{array}{c}\text { EXPLAINED } \\
\text { (8) }\end{array}$ & $\begin{array}{l}\text { ESTIMATE } \\
\text { (DEG_CI) }\end{array}$ \\
\hline 105 & 19.57 & 9.74 & 2.71 & 85 & 1.7 \\
\hline
\end{tabular}

SUMMARY OF MAXIMUM AND MINIMUM CONCENTRATIONS OF CONSTITUENTS

SAMPLED AT A FREQUENCY OF QUARTERLY (1975 WY)

07369500 - TENSAS RIVER AT TENDAL, LOUISIANA

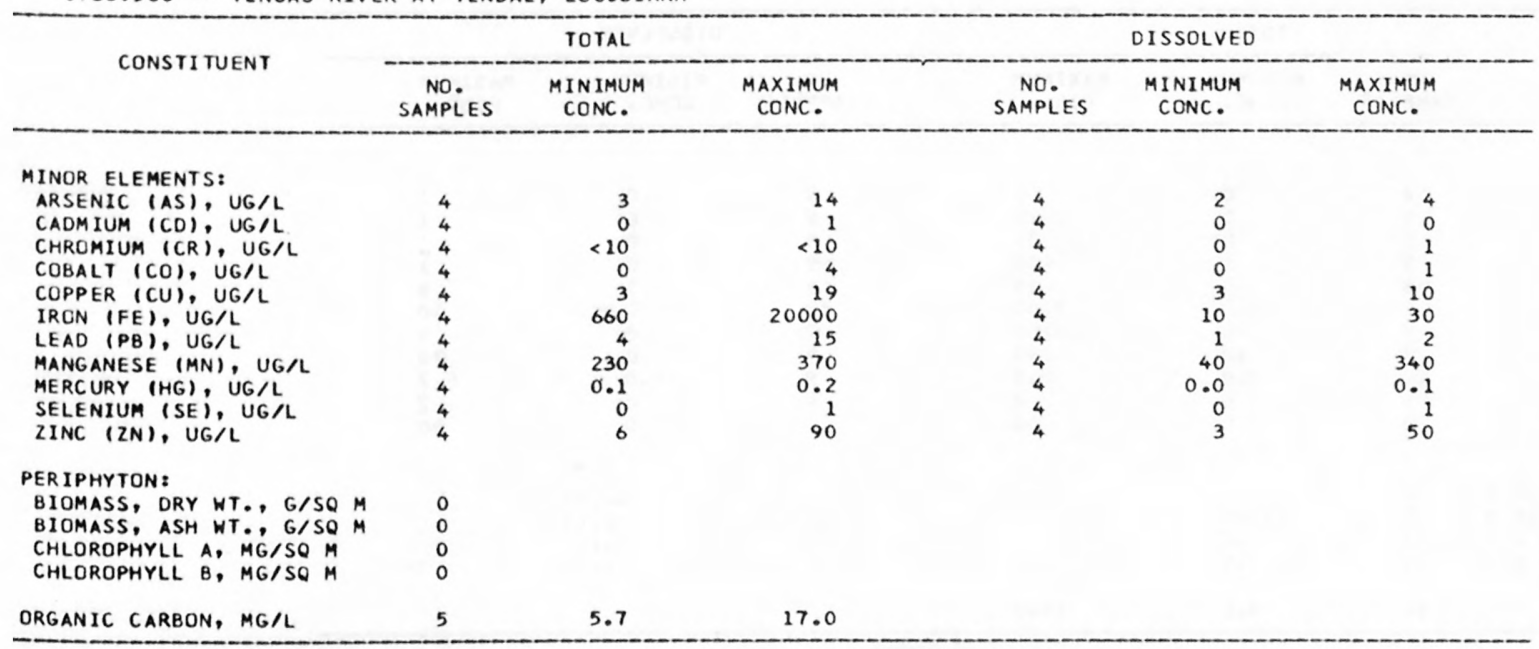


LAT 30D45M30S LONG 091023M45S

DRAINAGE AREA: 1243000 SO MI ( 3219370 SO KM

PERIOD OF RECORD: $10 / 01 / 74-09 / 30 / 75$

STATISTICAL SUMMARY OF SELECTED DISSOLVED CHEMICAL CONSTITUENTS AND

REGRESSION RELATIONSHIPS OF CONSTITUENT CONCENTRATIONS TO SPECIFIC CONDUCTANCE

CONSTIUENI

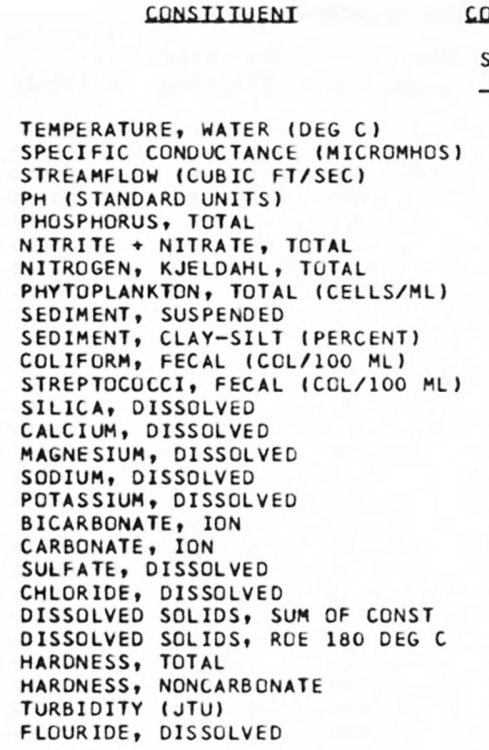

CONSTUTUENI LMG/L OR UNII SHOWN

SAMPLE STANDARD

$\begin{array}{ll}\text { SAMPLE } & \text { STANDARD } \\ \text { SIZE MEAN DEYIAIION } & \text { BANGE }\end{array}$

9
10
10
10
8
9
9
10
0
0
9
8
9
10
10
9
10
10
10
10
10
8
8
10
10
10
10

14.83

349.0

594200.0

7.60

0.121

0.874

0.506
7187.0

187.0

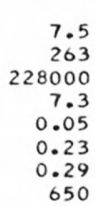

$\begin{array}{rr}311.3 & 209.9 \\ 222.5 & 171.2 \\ 5.98 & 0.68 \\ 35.00 & 6.16 \\ 10.32 & 2.38 \\ 16.89 & 6.53 \\ 2.78 & 0.46 \\ 115.4 & 22.5 \\ 0.0 & 0.0 \\ 46.20 & 14.38 \\ 18.80 & 6.70 \\ 180.0 & 34.3 \\ 203.9 & 47.8 \\ 129.8 & 24.8 \\ 35.3 & 7.3 \\ 56.0 & 23.3 \\ 0.25 & 0.16\end{array}$

$91382.0 \quad 228000 \quad 1050000$
BEGRESSION SUMMABY

$\begin{array}{ll} & \text { REGRESSION } \\ \text { SAMPLE COEFICIENT, CONSTANT, CORRELATION ERANDARD }\end{array}$ SIZE -

*Not significant at the 95 percent confidence level.

DAILY SPECIFIC CONDUCTANCE IN

MICROMHOS AT 25 DEG C, THAT WAS

EQUALLED OR EXCEEDED FOR THE

$\begin{array}{llllll}12 & -52 & 20 z & 20 \% & 308 & 502 \\ 487 & 450 & 437 & 422 & 405 & 358\end{array}$

24.5
475

$\begin{array}{rrrr}000 & 10 & -3365.802 & 1768864.000 \\ 8.2 & 10 & 0.0028 & 6.6258\end{array}$

8.2
0.27
1.30
0.88

0.0028

-0.00012
-0.00342

-0.00342
-0.00063

6.6258

0.16212

2.07656
0.72576

7896.563

$-0.884$

0.20

$-0.840 \quad 0.191$

$-0.265 * 0.197$

0.88
34000

$\begin{array}{rr}9 & -0.00063 \\ 10 & -2.033\end{array}$

$\begin{array}{rrrr}50 & 600 & & \\ 40 & 570 & & \\ 4.8 & 6.7 & 9 & -0.0081 \\ 27.0 & 45.0 & 10 & 0.0775 \\ 7.4 & 15.0 & 10 & 0.0285 \\ 10.0 & 29.0 & 9 & 0.0754 \\ 2.2 & 3.4 & 10 & 0.0051 \\ 90 & 150 & 10 & 0.287 \\ 0 & 0 & 10 & 0.000 \\ 32.0 & 80.0 & 10 & 0.1736 \\ 13.0 & 35.0 & 10 & 0.0538 \\ 142 & 252 & 8 & 0.517 \\ 154 & 284 & 8 & 0.592 \\ 98 & 170 & 10 & 0.312 \\ 24 & 46 & 10 & 0.078 \\ 20 & 95 & 10 & -0.211 \\ 0.0 & 0.6 & 10 & 0.0003\end{array}$

8.7024
7.9560
0.3688
-8.9094
1.0081
15.260
0.000
-14.3829
0.0166
11.872
6.176
20.989
8.163
129.480
0.1429

-0.791
0.963
0.917
0.899
0.851
0.975
0.000
0.924
0.615
0.963
0.901
0.964
0.812
-0.692
0.142.

0.45

1.77

1.01
3.05

3.05
0.25

5.3

0.0
5.83

5.60

10.0

22.4

7.0

4.5

0.0003

0.1429

0.17

SUMMARY OF HARMONIC ANALYSIS OF STREAM TEMPERATURE

\begin{tabular}{|c|c|c|c|c|c|}
\hline & & & & & STANDARD \\
\hline SAMPLE & $\begin{array}{l}\text { HARMONIC } \\
\text { MEAN - M } \\
\text { IDEG C) }\end{array}$ & $\begin{array}{c}\text { AMPLITUDE } \\
-A \\
\text { (DEG }\end{array}$ & $\begin{array}{l}\text { PHASE } \\
\text { ANGLE - C }\end{array}$ & $\begin{array}{l}\text { VAR IATION } \\
\text { EXPLA INED } \\
\text { (q) }\end{array}$ & $\begin{array}{l}\text { ERROR OF } \\
\text { ESTIMATE } \\
\text { (DEG C) }\end{array}$ \\
\hline
\end{tabular}

363

17.85

11.07

2.62

98

1.18

SUMMARY OF MAXIMUM AND MINIMUM CONCENTRATIONS OF CONSTITUENTS SAMPLED AT A FREQUENCY OF QUARTERLY (1975 HY)

07373420 -- MISSISSIPPI RIVER NEAR ST. FRANCISVILLE, LA

\begin{tabular}{|c|c|c|c|c|c|c|}
\hline \multirow{2}{*}{ CONSTI TUENT } & \multicolumn{3}{|c|}{ TOTAL } & \multicolumn{3}{|c|}{ DISSOLVED } \\
\hline & $\begin{array}{l}\text { NO. } \\
\text { SAMPLES }\end{array}$ & $\begin{array}{l}\text { MINIMUM } \\
\text { CONC. }\end{array}$ & $\begin{array}{l}\text { MAXIMUM } \\
\text { CONC. }\end{array}$ & $\begin{array}{l}\text { NO. } \\
\text { SAMPLES }\end{array}$ & $\begin{array}{l}\text { MINIMUM } \\
\text { CONC. }\end{array}$ & $\begin{array}{l}\text { MAXIMUM } \\
\text { CONC. }\end{array}$ \\
\hline \multicolumn{7}{|l|}{ MINOR ELEMENTS: } \\
\hline ARSENIC (AS), UG/L & 8 & 0 & 5 & 9 & 0 & 1 \\
\hline CADMIUM $(C D)$, UG/L & 9 & 0 & 20 & 9 & 0 & 1 \\
\hline CHROMIUM (CR), UG/L & 9 & 0 & 20 & 9 & 0 & 1 \\
\hline COBALT $(C O)$, UG/L & 9 & 1 & $<50$ & 9 & 0 & 1 \\
\hline COPPER (CU), UG/L & 8 & 0 & 10 & 9 & 3 & 8 \\
\hline IRON $(F E), U G / L$ & 9 & 960 & 7200 & 10 & 0 & 50 \\
\hline LEAD $(P B), U G / L$ & 9 & 0 & $<100$ & 9 & 0 & 4 \\
\hline MANGANESE (MN), UG/L & 9 & 50 & 290 & 9 & 0 & 70 \\
\hline MERCURY (HG), UG/L & 10 & 0.0 & 0.5 & 9 & 0.0 & 0.2 \\
\hline SELENIUM (SE), UG/L & 9 & 0 & 2 & 9 & 0 & 2 \\
\hline ZINC $(Z N), U G / L$ & 9 & 5 & 50 & 10 & 0 & 40 \\
\hline \multicolumn{7}{|l|}{ PERIPHYTON: } \\
\hline BIOMASS, DRY WT., G/SQ M & 0 & & & & & \\
\hline BIOMASS, ASH WT., G/SO M & 1 & 15.00 & & & & \\
\hline CHLOROPHYLL A, MG/SQ M & 1 & .0 & & & & \\
\hline CHLOROPHYLL B, MG/SQ M & $i$ & .0 & & & & \\
\hline ORGANIC CARBON, MG/L & 10 & 4.0 & 16.0 & & & \\
\hline
\end{tabular}


Table 14.--Summary of measurements at each station--Continued

LAT 29057M03S LONG 090008MI7S

DRAINAGE AREA: 0 SO MI 1

PERIOD OF RECORD: $10 / 01 / 74-09 / 30 / 75$ SQ KMI

STATISTICAL SUMMARY OF SELECTED DISSOLVED CHEMICAL CONSTITUENTS AND

REGRESSION RELATIONSHIPS OF CONSTITUENT CONCENTRATIONS TO SPECIFIC CONDUCTANCE

CONSIITUENI

CONSIUTUENI_IMGLL OR UNII SHOWN

SAMPLE

SIZE

TEMPERATURE, WATER (DEG C) SPECIFIC CONDUCTANCE (MICROMHOS) STREAMFLOW (CUBIC FT/SEC)

PH (STANDARD UNITS

PHOSPHORUS, TOTAL

NITRITE + NITRATE, TOTAL

NITROGEN, KJELDAHL, TOTAL

PHYTOPLANKTON, TOTAL (CELLS/ML)

SEDIMENT, SUSPENDED

SEDIMENT, CLAY-SILT (PERCENT)

COLIFORM, FECAL (COL/100 ML)

STREPTOCOCCI, FECAL (COL/100 ML)

SILICA, DISSOLVED

CALCIUM, DISSOLVED

MAGNESIUM, DISSOLVED

SODIUM, DISSOLVED

POTASSIUM, DISSOL VED

BICARBONATE, ION

CARBONATE, ION

SULFATE, DISSOLVED

CHLORIDE, DISSOLVED

DISSOLVED SOLIDS, SUM OF CONST

OISSOLVED SOLIDS, ROE 180 DEG

HARDNESS, TOTAL

HARDNESS, NONCARBONATE

TURBIDITY (JTU)

FLOURIDE, DISSOLVED

STANDARD

DEYIAIION

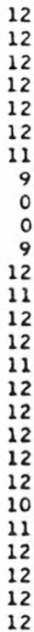

12
12
12
12
12
12
11
9
0
0
9
12
11
12
12
11
12
12
12
12
12
10
11
12
12
12
12

0.733
4052.2

8.23
70.7
299142.1
0.28
0.192
0.439
0.293
5286.0

BANGE
7.5
257
197000
7.1
0.13
0.30
0.39
240

SAMPLE SAMPLE
SIZE REGRESSION

BEGRESS ION SUMMABY

OEFICIENT, CONSTANT,

YY

ERROR OF OEEICIENI ESIIMAIE

30.5
492

$\begin{array}{llll}1200000 & 12 & -3897.164 & 2094599.000\end{array}$

$\begin{array}{lll}8.1 & 12 & 0.0024\end{array}$

$0.86 \quad 12 \quad 0.0024$

$-0.00252$

$-0.00222$

$-0.00348$

6.6869

0.06119

1.95896

2.12548

2.00
1.40

1.40
17000

55.870

$-16508.090$

-0.921
0.607
$0.228^{*}$
$-0.357^{*}$
-0.715
0.722

122442.1

0.24

0.196

0.430

3908.8

$\begin{array}{rrrrr}350.0 & 442.5 & 100 & 1500 & \\ 368.7 & 296.3 & 24 & 1000 & \\ 6.30 & 0.64 & 5.0 & 7.4 & 11 \\ 39.50 & 5.84 & 29.0 & 48.0 & 12 \\ 10.89 & 1.94 & 7.5 & 14.0 & 12 \\ 20.64 & 8.16 & 9.0 & 35.0 & 11 \\ 2.89 & 0.51 & 2.0 & 3.4 & 12 \\ 120.4 & 18.5 & 90 & 145 & 12 \\ 0.0 & 0.0 & 0 & 0 & 12 \\ 50.25 & 12.80 & 30.0 & 76.0 & 12 \\ 25.25 & 9.29 & 11.0 & 45.0 & 12 \\ 204.8 & 37.3 & 139 & 261 & 10 \\ 237.7 & 42.4 & 145 & 290 & 11 \\ 142.5 & 23.0 & 100 & 170 & 12 \\ 43.4 & 8.3 & 26 & 52 & 12 \\ 61.3 & 45.6 & 5 & 180 & 12 \\ 0.51 & 0.25 & 0.3 & 1.1 & 12\end{array}$

0.0003
0.0755
0.0235
0.1075
0.0061
0.240
0.000
0.1685
0.1092
0.580
0.486
0.299
0.101
-0.031

6.1727

10.2199

1.7884

$-20.4131$

0.5258

27.449
0.000

$-15.1182$

$-17.1164$

$-10.106$

47.107

26.397
4.242

4.242
73.397

73.397
-0.2876

$0.034^{*}$

0.913

0.857

0.930

0.841

0.916 .

$0.000^{*}$
0.930

0.830

0.991

0.832

0.919

0.865 .

$-0.048^{*}$

0.579

DURALION IABLE OE DALY SPECIEIC CONOUCIANCE

DAILY SPECIFIC CONDUCTANCE IN

MICROMHOS AT 25 DEG C, THAT WAS

$\begin{array}{llllll}12 & 52 & 108 & 208 & 302 & 508 \\ 485 & 468 & 458 & 436 & 419 & 370\end{array}$

SAMPLE SIZE $\equiv 341$

20225292

INDICATED PERCENTAGE OF TIME

485

468

436

$269 \quad 254 \quad 245$

SUMMARY OF HARMONIC ANALYSIS OF STREAM TEMPERATURE

\begin{tabular}{|c|c|c|c|c|c|}
\hline & & & & & STANDARD \\
\hline & HARMONIC & AMPLITUDE & PHASE & VARIATION & ERROR OF \\
\hline $\begin{array}{l}\text { SAMPLE } \\
\text { SIZE }\end{array}$ & MEAN - M & ${ }^{-A}$ & ANGLE - C & EXPLAINED & $\begin{array}{l}\text { ESTIMATE } \\
(0 E G \quad C)\end{array}$ \\
\hline
\end{tabular}

337

17.82

11.56

2.56

98

1.14

SUMMARY OF MAXIMUM AND MINIMUM CONCENTRATIONS OF CONSTITUENTS

SAMPLED AT A FREQUENCY OF QUARTERLY (1975 WY)

07374508 -- MISSISSIPPI RIVER AT NEW ORLEANS, LA.

\begin{tabular}{|c|c|c|c|c|c|c|}
\hline \multirow{2}{*}{ CONSTITUENT } & \multicolumn{3}{|c|}{ TOTAL } & \multicolumn{3}{|c|}{ DISSOLVED } \\
\hline & $\begin{array}{l}\text { NO. } \\
\text { SAMPLES }\end{array}$ & $\begin{array}{l}\text { MINIMUM } \\
\text { CONC. }\end{array}$ & $\begin{array}{l}\text { MAXIMUM } \\
\text { CONC. }\end{array}$ & $\begin{array}{l}\text { NO. } \\
\text { SAMPLES }\end{array}$ & $\begin{array}{l}\text { MINIMUM } \\
\text { CONC. }\end{array}$ & $\begin{array}{l}\text { MAXIMUM } \\
\text { CONC. }\end{array}$ \\
\hline \multicolumn{7}{|l|}{ MINOR ELEMENTS: } \\
\hline ARSENIC (AS), UG/L & 3 & 1 & 4 & 4 & 0 & 2 \\
\hline CADMIUM $(C D), U G / L$ & 4 & 0 & 20 & 4 & 0 & 0 \\
\hline CHROMIUM (CR), UG/L & 4 & 0 & 10 & 4 & 0 & 10 \\
\hline COBALT $(C O), U G / L$ & 4 & 0 & $<50$ & 4 & 0 & 1 \\
\hline COPPER (CU), UGIL & 4 & 0 & 17 & 4 & 4 & 8 \\
\hline IRON $(F E), U G / L$ & 4 & 740 & 6700 & 4 & 0 & 40 \\
\hline LEAD $(P B), U G / L$ & 4 & 4 & $<100$ & 4 & 1 & 3 \\
\hline MANGANESE (MN), UG/L & 4 & 40 & 300 & 4 & 0 & 20 \\
\hline MERCURY $(H G), U G / L$ & 4 & 0.0 & 0.1 & 4 & 0.0 & 0.1 \\
\hline SELENIUM (SE), UG/L & 4 & 0 & 1 & 4 & 0 & 0 \\
\hline ZINC $(Z N), U G / L$ & 4 & 10 & 60 & 4 & 0 & 30 \\
\hline \multicolumn{7}{|l|}{ PERIPHYTON: } \\
\hline BIGMASS, DRY WT.. G/SO M & 1 & 48.00 & & & & \\
\hline BIOMASS, ASH WT., G/SO M & 2 & 43.00 & 120.00 & & & \\
\hline CHLOROPHYLL A, MG/SO M & 1 & 11.0 & & & & \\
\hline CHLOROPHYLL $B, M G / S O M$ & 1 & 1.7 & & & & \\
\hline ORGANIC CARBON, MG/L & 4 & 5.3 & 7.1 & & & \\
\hline
\end{tabular}


Table 14,--Summary of measurements at each station--Continued

STATION NUMBER: 07378510 NAME: AMITE R AT 4H CAMP NR DENHAM SPRINGS

LAT 30D26M30S LONG 090058M20S

DRAINAGE AREA: O SQ MI

PERIOD OF RECORD: 10/01/74 - 09/30/75

O SQ KM)

STATISTICAL SUMMARY OF SELECTED DISSOLVED CHEMICAL CONSTITUENTS AND

REGRESSION RELATIONSHIPS OF CONSTITUENT CONCENTRATIONS TO SPECIFIC CONDUCTANCE

CONSILIUENI

CONSILUUENI IMGLL OR UNLI_SHOHNI

$\begin{array}{ll}\text { SAMPLE } & \text { STANDARD } \\ \text { SIZE MEAN DEYLILION }\end{array}$

TEMPERATURE, HATER (DEG C)

SPECIFIC CONDUCTANCE (MICROMHOS)

STREAMFLOW (CUBIC FT/SEC)

PH (STANDARD UNITS)

PHOSPHORUS, TOTAL

NITRITE + NITRATE, TOTAL

NITROGEN, KJELDAHL, TOTAL

PHYTOPLANKTON, TOTAL (CELLS/ML)

SEDIMENT, SUSPENDED

SEDIMENT, CLAY-SILT (PERCENT)

COLIFORM, FECAL (COL/100 ML)

STREPTOCOCCI, FECAL ( COL/100 ML)

SILICA, DISSOLVED

CALCIUM, DISSOLVED

MAGNESIUM, DISSOLVED

SODIUM, DISSOLVED

POTASSIUM, DISSOLVED

BICARBONATE, ION

CARBONATE, ION

SULFATE, DISSOLVED

CHLOR IDE, DISSOLVED

DISSOLVED SOLIDS, SUM OF CONST

DISSOLVED SOLIDS, ROE 180 DEG C

HARDNESS, TOTAL

HARDNESS, NONCARBONATE

TURBIDITY (JTU)

FLOUR IDE, DISSOLVED

*Not significant at the 95 percent confidence level.

\begin{tabular}{|c|c|c|c|c|}
\hline \multirow{2}{*}{$\begin{array}{l}\text { SAMPLE } \\
\text { SIZE } \\
11\end{array}$} & \multirow{2}{*}{$\begin{array}{l}\text { MEAN } \\
20.77\end{array}$} & \multirow{2}{*}{$\begin{array}{r}\text { STANDARD } \\
\text { DEXIAIION } \\
6.71\end{array}$} & \multicolumn{2}{|c|}{ BANGE } \\
\hline & & & 12.0 & 28.0 \\
\hline 12 & 54.4 & 10.3 & 39 & 76 \\
\hline 12 & 1640.1 & 815.0 & 446 & 3020 \\
\hline 11 & 6.67 & 0.38 & 6.0 & 7.4 \\
\hline 12 & 0.086 & 0.031 & 0.05 & 0.15 \\
\hline 12 & 0.158 & 0.072 & 0.00 & 0.25 \\
\hline 12 & 0.651 & 0.411 & 0.30 & 1.80 \\
\hline 11 & 1876.4 & 2163.2 & 100 & 6600 \\
\hline 12 & 109.8 & 53.2 & 38 & 234 \\
\hline 12 & $80 \cdot 3$ & 16.9 & 48 & 99 \\
\hline 11 & 1495.2 & 3828.4 & 25 & 13000 \\
\hline 10 & 443.6 & 630.1 & 20 & 2100 \\
\hline 4 & 11.20 & 2.14 & 8.8 & 13.0 \\
\hline 4 & 2.92 & 0.68 & 1.9 & 3.3 \\
\hline 4 & 1.22 & 0.19 & 1.1 & 1.5 \\
\hline 3 & 4.07 & 0.12 & 4.0 & 4.2 \\
\hline 4 & 1.82 & 0.29 & 1.6 & 2.2 \\
\hline 10 & 15.5 & 3.7 & 11 & 22 \\
\hline 11 & 0.0 & 0.0 & 0 & 0 \\
\hline 4 & 2.77 & 0.95 & 1.8 & 4.0 \\
\hline 4 & 5.52 & 0.59 & 4.7 & 6.0 \\
\hline 3 & 36.0 & 2.0 & 34 & 38 \\
\hline 3 & 60.7 & 11.7 & 52 & 74 \\
\hline 4 & 12.5 & 1.0 & 11 & 13 \\
\hline 4 & 1.3 & 1.5 & 0 & 3 \\
\hline 12 & 35.0 & 15.2 & 15 & 55 \\
\hline 4 & 0.07 & 0.05 & 0.0 & \\
\hline
\end{tabular}

DURAIION IABLE OE DAILY SPECIEIC CONDUCIANCE

DAILY SPECIFIC CONDUCTANCE IN

MICROM

EQUALLED OR EXCEEDED FOR THE

SAMPLE REGRESSION

SIZE.

COEFICIENT,

GRESSION SUMMABY

$-\mathrm{B}$

CONSTANT, CORRELATION

COEEICIENI

STANDARD

ERROR OF

ESIIMAIE

INDICATED PERCENTAGE OF TIME

$\begin{array}{rrrrrr}18 & 5 z & 10 z & 20 z & 30 z & 508 \\ 84 & 65 & 59 & 54 & 51 & 47\end{array}$

12
11
12
12
12

$-48.888$

0.0183
0.00033

$-0.00064$

0.00543

165.694

4300.391

5.6669

0.06801

0.19303

0.35530

$-7206.695$

$-0.617$

$0.520 *$

$-0.091 *$

0.136

672.8

0.033

0.075

0.428

1310.3

100

$\begin{array}{llll}.04 & 4 & 0.2316 & -0.2633\end{array}$

0.0851

$-0.0237$

0.0083

-1.2868
2.3974

2.3974

2.4763

0.0132

0.264
0.000

$-0.1202$

$-0.1202$

-0.0096
0.250

0.250
1.095

0.123

$-0.096$

$-0.632$

0.992

0.000

8.7238

6.0025

24.250
7.000

7.000
6.421

6.026

69.393

0.818

0.819

0.938

$-0.945 *$

$-0.346$.

0.806

$0.000 *$

-0.952 .

$-0.123 *$

-0.123
0.866.

0.857 *

0.927

$-0.486$

$-0.427$

1.50
0.29
0.08
0.14
0.33
2.3
0.0
0.36
0.72
1.4
8.6
0.5
1.6
14.4
0.05

SAMPLE SIZE $=317$

$70 \% \quad 20 \% \quad 258 \quad 298$

43

38

$35 \quad 31$

SUMMARY OF HARMONIC ANALYSIS OF STREAM TEMPERATURE

\begin{tabular}{|c|c|c|c|c|c|}
\hline & & & & & STANDARD \\
\hline & HARMONIC & AMPLITUDE & PHASE & VAR IATION & ERROR OF \\
\hline SAMPLE & MEAN - M & $-A$ & ANGLE - C & EXPLAINED & ESTIMATE \\
\hline SIZE_ & 10EG C1 & DOEG C) & (RADIANS) & -181 & 1DEG_CL \\
\hline 324 & 20.51 & 6.46 & 2.86 & 79 & 2.43 \\
\hline
\end{tabular}

SUMMARY OF MAXIMUM AND MINIMUM CONCENTRATIONS OF CONSTITUENTS SAMPLED AT A FREQUENCY OF QUARTERLY (1975 WY)

07378510 -- AMITE R AT 4 H CAMP NR DENHAM SPRINGS

\begin{tabular}{|c|c|c|c|c|c|c|}
\hline \multirow{2}{*}{ CONSTITUENT } & \multicolumn{3}{|c|}{ TOTAL } & \multicolumn{3}{|c|}{ DISSOLVED } \\
\hline & $\begin{array}{l}\text { NO. } \\
\text { SAMPLES }\end{array}$ & $\begin{array}{l}\text { MIN IMUM } \\
\text { CONC. }\end{array}$ & $\begin{array}{l}\text { MAXIMUM } \\
\text { CONC. }\end{array}$ & $\begin{array}{l}\text { NO. } \\
\text { SAMPLES }\end{array}$ & $\begin{array}{l}\text { MINIMUM } \\
\text { CONC. }\end{array}$ & $\begin{array}{l}\text { MAXIMUM } \\
\text { CONC. }\end{array}$ \\
\hline \multicolumn{7}{|l|}{ MINOR ELEMENTS: } \\
\hline ARSENIC (AS), UG/L & 4 & 1 & 2 & 4 & 0 & 1 \\
\hline CADMIUM $(C D), U G / L$ & 4 & 0 & 1 & 4 & 0 & 0 \\
\hline CHROMIUM (CR), UG/L & 4 & $<10$ & $<10$ & 4 & 0 & 0 \\
\hline COBALT $(C O), U G / L$ & 4 & 0 & 7 & 4 & 0 & 0 \\
\hline COPPER $(C U), U G / L$ & 4 & 4 & 21 & 4 & 2 & 13 \\
\hline IRON (FE), UG/L & 4 & 860 & 3000 & 4 & 50 & 210 \\
\hline LEAD $(P B), U G / L$ & 4 & 2 & 13 & 4 & 0 & 3 \\
\hline MANGANESE (MN), UG/L & 4 & 220 & 330 & 4 & 30 & 230 \\
\hline MERCURY (HG), UG/L & 4 & 0.0 & 0.2 & 4 & 0.0 & 0.1 \\
\hline SELENIUM (SE), UG/L & 4 & 0 & 0 & 4 & 0 & 0 \\
\hline$Z I N C(Z N), U G / L$ & 4 & 3 & 20 & 4 & 0 & 4 \\
\hline \multicolumn{7}{|l|}{ PERIPHYTON: } \\
\hline BIOMASS, DRY WT., G/SQ M & 1 & .79 & & & & \\
\hline BIOMASS, ASH WT., G/SQ M & 1 & .50 & & & & \\
\hline CHLOROPHYLL A, MG/SO M & 1 & .0 & & & & \\
\hline CHLOROPHYLL B, MG/SQ M & $i$ & .0 & & & & \\
\hline ORGANIC CARBON, MG/L & 5 & 3.0 & 6.1 & & & \\
\hline
\end{tabular}


LAT 30058M57S LONG $091047 M 54 \mathrm{~S}$ DRAINAGE AREA: 0 SQ MI PERIOD OF RECORD: $10 / 01 / 74-09 / 30 / 75$ - SQ KM) STATISTICAL SUMMARY OF SELECTED DISSOLVED CHEMICAL CONSTITUENTS AND REGRESSION RELATIONSHIPS OF CONSTITUENT CONCENTRATIONS TO SPECIFIC CONDUCTANCE

CONSIIIUENI

SON

\section{ONSILUENI IMG/L OB_UNII SHOWN) \\ SAMPLE SIZE \\ STANDARD \\ DEYIAIION}

TEMPERATURE, WATER (DEG C) SPECIFIC CONDUCTANCE (MICROMHOS) STREAMFLOW (CUBIC FT/SEC)

PH (STANDARD UNITS)

PHOSPHORUS, TOTAL

NITRITE + NITRATE, TOTAL NITROGEN, KJELDAHL, TOTAL PHYTOPLANKTON, TOTAL (CELLS/ML) SEDIMENT, SUSPENDED

SEDIMENT, CLAY-SILT (PERCENT)

COLIFORM, FECAL (COL/100 ML)

STREPTOCOCCI, FECAL (COL/100 ML)

SILICA, DISSOLVED

CALCIUM, DISSOLVED

MAGNESIUM, DISSOLVED

SODIUM, DISSOLVED

POTASSIUM, DISSOLVED

BICARGONATE, ION

CARBONATE, ION
SULFATE, DISSOLVED

SULFATE, DISSOLVED

CHLORIDE, DISSOLVED

DISSOLVED SOLIDS, SUM OF CONST

DISSOLVED SOLIDS,

HARDNESS, NONCARBONATE

TURB IOITY (JTU)

FLOURIDE, DISSOLVED

$\begin{array}{rr}2 & 19.75 \\ 4 & 432.3 \\ 3 & 149000.0 \\ 4 & 7.75 \\ 1 & 0.160 \\ 1 & 0.450 \\ 1 & 0.560 \\ 1 & 5200.0 \\ 66 & 459.2 \\ 66 & 80.7 \\ 2 & 1650.0 \\ 2 & 252.0 \\ 4 & 5.25 \\ 4 & 37.50 \\ 4 & 10.50 \\ 3 & 31.00 \\ 4 & 3.07 \\ 4 & 123.5 \\ 2 & 0.0 \\ 4 & 50.00 \\ 4 & 37.50 \\ 3 & 242.3 \\ 4 & 259.5 \\ 4 & 137.5 \\ 4 & 35.8 \\ 2 & 180.0 \\ 4 & 0.25\end{array}$

2.47
45.3
28688.0
0.31
0.000
0.000
0.000
0.0
327.6
11.7
777.8
294.2
1.00
5.57
1.78
2.65
0.29
9.8
0.00
7.53
2.08
18.4
40.6
22.2
13.1
169.7
0.06

(2)
REGRESSION \begin{tabular}{l} 
SAMPLE COEFICIENT, CONSTANT, \\
SIZE \\
\hline
\end{tabular}
$18.0 \quad 21.5$ $376 \quad 470$

$\begin{array}{rr}130000 & 182000 \\ 7.4 & 8.1\end{array}$

0.16

0.45

0.56

5200

115
52
1100

1100
44

3.8

30.0

8.5
28.0

28.0
2.7

2.7
111

41.0

35.0

222

224

110

23

60
0.2

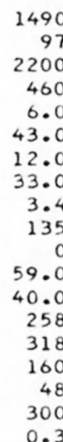

$3 \quad-532.948$

$-0.0008$
$382431 \cdot 375$

$$
8.1111
$$

$-0.998 *$

2773.3
0.38

\footnotetext{
*Not significant at the 95 percent confidence level.
}

DAILY SPECIFIC CONDUCTANCE IN

MICROMHOS AT 25 DEG C, THAT WAS

EQUALLED OR EXCEEDED FOR THE

\section{RAILON IABLE OF DAUL SPECIEIC CONDUCIANCE}

4

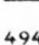

\begin{abstract}
IEIC
\end{abstract}

72

\section{$30 \%$}

413

$$
\begin{array}{r}
-0.0100 \\
0.1180 \\
0.0326 \\
0.0838 \\
0.0054 \\
0.186 \\
0.1101 \\
0.0328 \\
0.570 \\
0.643 \\
0.482 \\
0.277
\end{array}
$$$$
-0.0003
$$

$$
-1
$$

9.5587

$-13.5097$

$-3.5934$

$-6.7764$

0.7454

43.112

2.3910

\begin{tabular}{|c|c|c|c|c|c|}
\hline & & & & & STANDARD \\
\hline & HARMONIC & AMPLITUDE & PHASE & VARIATION & ERROR OF \\
\hline SAMPLE & MEAN - M & $-A$ & ANGLE $-\mathrm{C}$ & EXPLAINED & ESTIMATE \\
\hline SIZE_ & IDEG_CI_ & - DEG C) & (RADIANS) & -181 & (DEG C) \\
\hline 320 & 16.47 & 11.84 & 2.68 & 87 & 3.43 \\
\hline
\end{tabular}

23.3014

$-14.685$

$-18.336$

$-70.921$

\begin{tabular}{|c|c|c|c|c|c|c|}
\hline \multirow{2}{*}{ CONSTITUENT } & \multicolumn{3}{|c|}{ TOTAL } & \multicolumn{3}{|c|}{ DISSOLVED } \\
\hline & $\begin{array}{l}\text { NO. } \\
\text { SAMPLES }\end{array}$ & $\begin{array}{l}\text { MINIMUM } \\
\text { CONC. }\end{array}$ & $\begin{array}{l}\text { MAXIMUM } \\
\text { CONC. }\end{array}$ & $\begin{array}{l}\text { NO. } \\
\text { SAMPLES }\end{array}$ & $\begin{array}{l}\text { MINIMUM } \\
\text { CONC. }\end{array}$ & $\begin{array}{l}\text { MAXIMUM } \\
\text { CONC. }\end{array}$ \\
\hline \multicolumn{7}{|l|}{ MINOR ELEMENTS: } \\
\hline ARSENIC (AS), UG/L & 1 & 6 & & 2 & 1 & 2 \\
\hline CADMIUM $(C D)$, UG/L & 1 & 0 & & 2 & 0 & 0 \\
\hline CHROMIUM (CR), UG/L & 1 & $<10$ & & 1 & 0 & \\
\hline COBALT $(C O)$, UG/L & 1 & 3 & & 1 & 0 & \\
\hline COPPER (CU), UG/L & 1 & 5 & & 2 & 3 & 4 \\
\hline IRON $(F E), U G / L$ & 1 & 4700 & & 2 & 10 & 30 \\
\hline LEAD $(P B), U G / L$ & $i$ & 4 & & 2 & 0 & 4 \\
\hline MANGANESE (MN), UG/L & 1 & 190 & & 2 & 22 & 150 \\
\hline MERCURY $(H G), U G / L$ & 2 & 0.0 & 0.3 & 1 & 0.2 & \\
\hline SELENIUM (SE), UG/L & 1 & 0 & & 1 & 0 & \\
\hline ZINC $(Z N), U G / L$ & 1 & 10 & & 2 & 3 & 8 \\
\hline \multicolumn{7}{|l|}{ PERIPHYTON: } \\
\hline BIOMASS, DRY WT., G/SQ M & 0 & & & & & \\
\hline BIOMASS, ASH WT, G/SQ M & 0 & & & & & \\
\hline CHLOROPHYLL A, MG/SQ M & 0 & & & & & \\
\hline CHLOROPHYLL B, MG/SQ M & 0 & & & & & \\
\hline ORGANIC CARBON, MG/L & 1 & 6.8 & & & & \\
\hline
\end{tabular}

$-84 \cdot 167$

0.3797
STANDARD STANDARD
CORRELATION ERROR OF COEEICIENI ESIUMAIE

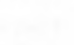

SUMMARY OF HARMONIC ANALYSIS OF STREAM TEMPERATURE

SUMMARY OF MAXIMUM AND MINIMUM CONCENTRATIONS OF CONSTITUENTS

SAMPLED AT A FREQUENCY OF QUARTERLY (1975 WY)

07381490 -- ATCHAFALAYA RIVER AT SIMMESPORT, LA. 
Table 14.--Summary of measurements at each station--Continued

LAT 20DO4MISS LONG 091049M45S

$\begin{array}{lcl}\text { DRAINAGE AREA: } & 0 \text { SQ MI } & 1 \\ \text { PERIOD OF RECORD: } & 10 / 01 / 74-09 / 30 / 75\end{array}$

O SO KM

STATISTICAL SUMMARY OF SELECTED DISSOLVED CHEMICAL CONSTITUENTS AND

REGRESSION RELATIONSHIPS OF CONSTITUENT CONCENTRATIONS TO SPECIFIC CONOUCTANCE

CONSILIUEN

CONSIUUENI IMGLL OR UNLI SHOWNI

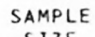

SIZE

TEMPERATURE, WATER IDEG C I SPECIFIC CONDUCTANCE (MICROMHOS) STREAMFLOW (CUBIC FT/SEC)

PH (STANDARD UNITS)

PHOSPHCRUS, TOTAL

NITRITE + NITRATE, TOTAL

NITROGEN, KJELDAHL, TUTAL

PHYTOPLANKTON, TUTAL (CELLS/ML)

SEDIMENT, SUSPENDED

SEUIMENT, CLAY-SILT (PERCENT)

COLIFORM, FECAL (COL/10O ML)

STREPTOCOCCI, FECAL (COL/100 ML)

SILICA, DISSOLVED

MAGNESIUM, DISSOLVED

SODIUM, DISSOLVED

POTASSIUM, DISSOL VED

BICARBONATE, ION

CARBONATE, ION

SULFATE, DISSOLVED

DISSOLVED SOLIDS, SUM OF CONST

DISSOLVED SOLIDS, ROE 180 DEG

HARDNESS, TOTAL

TURBIDITY (JTU)

FLOURIDE, DISSOLVED
STANDARD

DEYIAIION

11
12
10
12
12
8
8
12
12
12
12
12
11
12
12
11
12
11
12
12
12
10
11
12
11
12
12
20.59

20.59
116.8

116.8
604.6

604.6
7.14

0.244

0.177

0.716

166.8

128.4

81.0

1523.3

391.2

8.50

9.53
3.98

3.98
6.69

2.81

46.0

5.86

9.16

67.7

81.2

40.1
3.1

3.1
37.9

0.22
6.17

21.7
229.1

229.1
0.25

0.067

0.071

0.181

112.8

18.0

4503.5

440.6

1.80

2.23

1.08
1.32

1.32
0.80

9.4

0.0
1.57

2.88

11.6

24.0
9.8

2.7

18.8

0.11
CALCIUM, DISSOLVED

CHLORIDE, DISSOLVED

HARONESS, NCNCARBONATE

BEGRESS LON_SUMMABY REGRESSICN

SAMPLE COEFICIENT, CONSTANT, CORRELATION ETANOARO SIZE

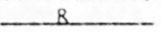

B COEEICIENI ESILMAI

$\begin{array}{rrr}11.0 & 28.5 & \\ 87 & 157 & \\ 269 & 1010 & 10 \\ 6.8 & 7.7 & 12 \\ 0.15 & 0.40 & 12 \\ 0.08 & 0.31 & 8 \\ 0.51 & 1.10 & 8 \\ 31 & 380 & 12 \\ 34 & 422 & \\ 44 & 99 & \\ 31 & 16000 & \\ 32 & 1400 & \\ 0.0 & 11.0 & 11 \\ 6.5 & 14.0 & 12 \\ 2.4 & 3.6 & 12 \\ 5.2 & 8.9 & 11 \\ 2.2 & 5.0 & 12 \\ 32 & 64 & 11 \\ 0 & 0 & 12 \\ 3.8 & 8.4 & 12 \\ 6.1 & 17.0 & 12 \\ 56 & 91 & 10 \\ 52 & 126 & 11 \\ 27 & 57 & 12 \\ 0 & 8 & 11 \\ 20 & 75 & 12 \\ 0.1 & 0.5 & 12\end{array}$

QUB

DAILY SPECIFIC CONDUCTANCE IN

MICROMHOS AT 25 DEG C, THAT WAS

EQUALLED CR EXCEEDED FOR THE

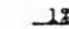

12

OE DAILY SPECIEIC CONDUCIANCE

INDICATED PERCENTAGE OF TIME

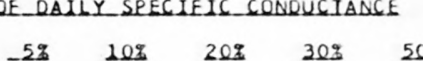

$16-190-172$

$141-128=112$

SUMMARY OF HARMONIC ANALYSIS OF STREAM TEMPERATURE

EOBM OE EUUAIUUN: I. $101=M \pm A * S I N G .0272 * 0 \pm C$

\begin{tabular}{|c|c|c|c|c|c|}
\hline & & & & & STANDARD \\
\hline & HARMONIC & AMPLITUDE & PHASE & VAR IATION & ERROR OF \\
\hline SAMPLE & MEAN - M & $-A$ & ANGLE - C & EXPLAINED & ESTIMATE \\
\hline SLZE & $10 E G \mathrm{Cl}$ & DDEG $C 1$ & (RADIANSI & $-(z)$ & (DEG $C)$ \\
\hline 360 & 21.08 & 7.56 & 2.84 & 85 & 2.22 \\
\hline
\end{tabular}

360

21.08

7.56

2.84

85

2.22

SUMMARY UF MAXIMUM AND MINIMUM CONCENTRATIONS OF CONSTITUENTS SAMPLEO AT A FREQUENCY OF QUARTERLY (1975 WY)

07385700 - BAYOU TECHE AT KEYSTONE LOCK, NR ST.MARTINVILLE

\begin{tabular}{|c|c|c|c|c|c|c|}
\hline \multirow{2}{*}{ CONSTITUENT } & \multicolumn{3}{|c|}{ TOTAL } & \multicolumn{3}{|c|}{ DISSOLVED } \\
\hline & $\begin{array}{l}\text { NO. } \\
\text { SAMPLES }\end{array}$ & $\begin{array}{l}\text { MINIMUM } \\
\text { CONC. }\end{array}$ & $\begin{array}{l}\text { MAXIMUM } \\
\text { CONC. }\end{array}$ & $\begin{array}{l}\text { NO. } \\
\text { SAMPLES }\end{array}$ & $\begin{array}{l}\text { MINIMUM } \\
\text { CONC. }\end{array}$ & $\begin{array}{l}\text { MAXIMUM } \\
\text { CONC. }\end{array}$ \\
\hline \multicolumn{7}{|l|}{ MINOR ELEMENTS: } \\
\hline ARSENIC (AS), UG/L & 4 & 2 & 4 & 4 & 1 & 2 \\
\hline CADMIUM $(C D), U G / L$ & 4 & 0 & 0 & 4 & 0 & 2 \\
\hline CHROMIUM (CR), UG/L & 4 & $<10$ & $<10$ & 4 & 0 & 0 \\
\hline COBALT $(C O), U G / L$ & 4 & 0 & 7 & 4 & 0 & 1 \\
\hline COPPER (CU), UG/L & 4 & 7 & 9 & 4 & 6 & 8 \\
\hline IRON (FE), UG/L & 4 & 1000 & 3000 & 4 & 80 & 320 \\
\hline LEAD $(P B), U G / L$ & 4 & 3 & 9 & 4 & 1 & 5 \\
\hline MANGANESE $(M N), U G / L$ & 4 & 64 & 150 & 4 & 13 & 140 \\
\hline MERCURY (HG), UG/L & 4 & 0.0 & 0.2 & 4 & 0.0 & 0.1 \\
\hline SELENIUM $(S E), U G / L$ & 4 & 0 & 0 & 4 & 0 & 0 \\
\hline$Z I N C(Z N), U G / L$ & 4 & 10 & 30 & 4 & 5 & 20 \\
\hline \multicolumn{7}{|l|}{ PERIPHYTON : } \\
\hline BIOMASS, DRY WT, G/SO M & 1 & 53.00 & & & & \\
\hline BIOMASS, ASH WT., G/SO M & 2 & 1.50 & 45.00 & & & \\
\hline CHLOROPHYLL A, MG/SQ M & 2 & 7.5 & 98.0 & & & \\
\hline CHLOROPHYLL B, MG/SO M & 2 & 5.7 & 12.0 & & & \\
\hline ORGANIC CARBON, MG/L & 5 & 9.0 & 16.0 & & & \\
\hline
\end{tabular}


Table 14.--Sumnary of measurements at each station--Continued

LAT $30017 M 59 S$ LONG 093D11M18S

DRAINAGE AREA: 2310 SQ MI $1 \quad 5983$ SQ KM

PERIOD OF RECURD: $10 / 01 / 74-09 / 30 / 75$

STATISTICAL SUMMARY OF SELECTED DISSOLVED CHEMICAL CONSTITUENTS AND

REGRESSION RELATIONSHIPS OF CUNSTITUENT CONCENTRATIONS TO SPFCIFIC CONDUCTANCE

CONSIIIUENI

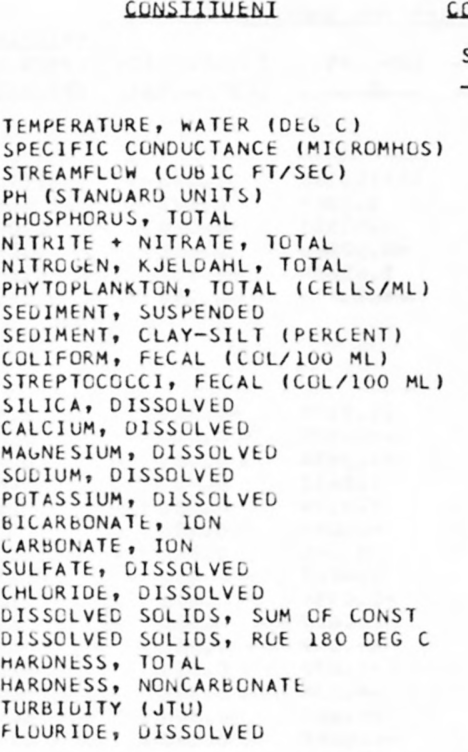

CONSILIUENI IMG L OB UNII_SHOWNI

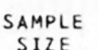

SAMPLE
SIZE

12

12
0

126.58

110.07

$\begin{array}{ll}12 & 0.143 \\ 12 & 0.672\end{array}$

11459.2

193.4
85.6

229.9

459.9

9.93

10.87

10.87
18.92

18.92
178.37

178.37
8.24
18.2

18.2
0.0

0.0
47.65

304.23

587.3

587.3
607.4

607.4

105.8

89.7
22.3
0.22
STANDARD

DEYIAIION

5.61
2119.2

119.2

0.35
0.025

0.025
0.163

0.195

408.7

341.7

10.1

231.4

775.5

3.79
15.18

15.18
38.82

38.82
381.99

15.22

11.9

0.0

94.46

048.12

1200.2

1216.7

199.2

188.

9.9
0.23

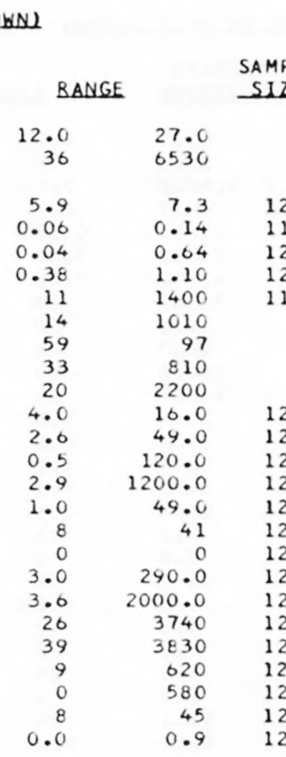

*Not significant at the 95 percent confidence level.
BEGRESSION_SUMMABY

$\begin{array}{ll} & \text { REGRESSION } \\ \text { SAMPLE COEFICIENT, CONSTANT, CORRELATION ERROR OF }\end{array}$ SIZE - B - - B COEEICIENI ESILMAIE

QURAIION IABLE OF DAILY SPECIEIC CONDUCIANCE

UAILY SPECIFIC CONDUCTANCE IN

MICROMHOS AT 25 DEG C, THAT WAS

EUUALLED CR EXCEEDED FOR THE

$\begin{array}{rrrrrr}-18 & -58 & 108 & 208 & 308 & 508 \\ 12300 & 9430 & 1962 & 239 & 105 & 60\end{array}$

SAMPLE SIZE $=329$
$70 \%$ 20\% 258 292

INDICATED PERLENTAGE DF TIME

$12300 \quad 9430 \quad 1962$

FORM UF UF HARMUNIC ANALYSIS OF STREAM TEMPERATURE

\begin{tabular}{|c|c|c|c|c|c|}
\hline & & & & & STANDARD \\
\hline & HARMONIC & AMPLITUDE & PHASE & VARIATION & ERROR OF \\
\hline SAMPLE & $M E A N-M$ & $-A$ & ANGLE $-\mathrm{C}$ & EXPLAINED & ESTIMATE \\
\hline SLZE_ & $10 E G(1)$ & 1DEG $(1)$ & (RADLANSI & $-(3)$ & $10 E G_{2}(1)$ \\
\hline
\end{tabular}

SLZE.

DEG C)

DEE 61

RADLANSI

329

21.01

7.95

2.73

88

2.07

SUMMARY OF MAXIMUM AND MINIMUM CONCENTRATIONS OF CONSTITUENTS

SAMPLED AT A FREQUENCY OF QUARTERLY (1975 WY)

08015900 - CALCASIEU R NR LAKE CHARLES

CONSTITUENT
SAMPLES


Table 14.--Summary of measurements at each station--Continued

LAT 30D18M13S LONG 093044M37S

DRAINAGE AREA: 9329 SQ MI

PERIOD OF RECORD: $10 / 01 / 74-09 / 30 / 752$ SO KM)

STATISTICAL SUMMARY OF SELECTED DISSOLVED CHEMICAL CONSTITUENTS AND

REGRESSION RELATIONSHIPS OF CONSTITUENT CONCENTRATIONS TO SPECIFIC CONDUCTANCE

CONSILIUENI

\section{CONSIUIUENI IMG/L OB UNII SHOWNI}

TEMPERATURE, WATER (DEG C)
SPECIFIC CONDUCTANCE (MICROMHOS)
STREAMFLOW (CUBIC FT/SEC)
PH ISTANDARD UNITS)
PHOSPHORUS, TOTAL
NITRITE NITRATE, TOTAL
NITROGEN, KJELDAHL, TOTAL
PHYTOPLANKTON, TOTAL (CELLS/ML)
SEDIMENT, SUSPENDED
SEDIMENT, CLAY-SILT (PERCENT)
COLIFORM, FECAL (COL/IOO ML)
STREPTOCOCCI, FECAL (COL/IOO ML)
SILICA, DISSOLVED
CALCIUM, DISSOLVED
MAGNESIUM, DISSOLVEO
SODIUM, DISSOLVED
POTASSIUM, DISSOLVED
BICARBONATE, ION
CARBUNATE, ION
SULFATE, DISSOLVED
CHLORIDE, DISSOLVED
DISSOLVED SOLIDS, SUM OF CONST
DISSOLVED SOLIDS, ROE I8O DEG C
HARONESS, TOTAL
HARDNESS, NONCARBONATE
TUREIDITY (JTU)
FLOURIDE, DISSOLVED

SAMP
-512
61
60
60
17
13
13
13
12
12
12
12
12
17
17
17
17
17
17
17
60
60
17
12
17
17
12
15

\section{STANDARD}

MEAN QEYLALION

20.27

124.8

14810.4

6.75

0.042

0.081

0.692
2185.6

185.6
39.7

39.7
71.1

238.2

332.3

7.97

6.55

2.20

11.47
2.25

20.5

20.5
0.0

12.62

18.32

68.6

82.7

25.5

8.7

28.8

0.08

0.27
22.6
9181.1
0.22
0.017
0.052
0.242
4745.6
16.0
20.7
216.0
568.7
2.48
1.28
0.73
1.73
0.53
4.6
0.0
3.69
4.30
9.0
8.8
5.6
3.7
12.1
0.04

BEGRESSLON_SUMYABY

REGRESSION

SAMPLE

BANGE

SIZE DEF ICIENT,

CONSTANT, CORRELATION STANDARO COEEICIENI. ESIUMAIE

9.0
75
76
6.
0.0
0.0
0.40
27
2
4
6
2
5.0
4.
1.0
7.
1.4
1
3.2
9.
4
7
1
15
15

30.0 B - B

* Not significant at the 95 percent confidence level.

DURAIION IABLE OF DALLY SPECIEIC CONDUCIANCE
DAILY SPECIFIC CONDUCTANCE IN
MICROMHOS AT 25 DEG C, THAT WAS
EQUALLED OR EXCEEDD FOR THE

SUMMARY OF HARMONIC ANALYSIS OF STREAM TEMPERATURE

\begin{tabular}{|c|c|c|c|c|c|}
\hline & & & & & STANDARD \\
\hline & HARMONIC & AMPLITUDE & PHASE & VARIATION & ERROR OF \\
\hline SAMPLE & $M E A N-M$ & $-A$ & ANGLE - C & EXPLAINED & ESTIMATE \\
\hline SIZE_ & WEE 61 & $-1 D E G \quad C)$ & (BADIANSI) & $(\pi)$ & LEE $(1)$ \\
\hline 362 & 20.60 & 7.47 & 2.71 & 91 & 6 \\
\hline
\end{tabular}

SUMMARY OF MAXIMUM AND MINIMUM CONCENTRATIONS OF CONSTITUENTS SAMPLED AT A FREQUENCY OF OUARTERLY (1975 WY)

08030500 -- SABINE RIVER NR RULIFF, TEX.

CONSTITUENT
SAMPLES


Table 14.--Summary of measurements at each station--Continued

AT $30021 M 22 S$ LONG 094D05M36S

PAINAGE AREA: 7951 SQ MI ( 20593 SQ KM)

ERIOD OF RECORD: $10 / 01 / 74-09 / 30 / 75$

STATISTICAL SUMMARY OF SELECTED DISSOLVED CHEMICAL CONSTITUENTS AND

REGRESSION RELATIONSHIPS OF CONSTITUENT CONCENTRATIONS TO SPECIFIC CONDUCTANCE

CONSIUIUENI

CONSILUUENT IMG/L OB UNII SHOWNI

SAMPLE

$$
\text { SIZE }
$$

TEMPERATURE, WATER (DEG C) SPECIFIC CONDUCTANCE (MICROMHOS) STREAMFLOW (CUBIC FT/SEC)

PH (STANUARD UNITS)

PHOSPHORUS, TOTAL

NITRITE + NITRATE, TOTAL

NITROGEN, KJELDAHL, TOTAL

PHYTOPLANKTON, TOTAL (CELLS/ML)

SEDIMENT, SUSPENDED

SEDIMENT, CLAY-SILT (PERCENT)

COL IFURM, FECAL (COL/100 ML)

STREPTOCOCCI, FECAL (COL/100 ML)

SILICA, DISSOLVED

CALCIUM, DISSOLVED

MAGNESIUM, DISSOLVED

SODIUM, DISSOLVED

POTASSIUM, DISSOLVED

BICARBONATE, ION

CARBONATE, ION

SULFATE, DISSOLVED

CHLOR IDE, DISSOLVED

DISSOLVED SOLIDS, SUM OF CONST

DISSOLVED SOLIDS, ROE 180 DEG

HARDNESS, TOTAL

HARDNESS, NONCARBONATE

TURBIDITY ( JTUI)

FLOUR IDE, DISSOLVED

$\begin{array}{rr}12 & 20.42 \\ 12 & 138.3 \\ 12 & 9908.3 \\ 12 & 6.72 \\ 12 & 0.050 \\ 12 & 0.050 \\ 12 & 0.762 \\ 11 & 1840.0 \\ 12 & 28.8 \\ 12 & 88.4 \\ 12 & 163.9 \\ 12 & 288.6 \\ 12 & 9.87 \\ 12 & 7.42 \\ 12 & 2.67 \\ 12 & 12.27 \\ 12 & 2.50 \\ 12 & 20.6 \\ 12 & 0.0 \\ 12 & 16.00 \\ 12 & 17.50 \\ 12 & 78.6 \\ 11 & 101.5 \\ 12 & 29.6 \\ 12 & 12.8 \\ 12 & 32.5 \\ 10 & 0.09\end{array}$

STANDARD

DEVIAIION

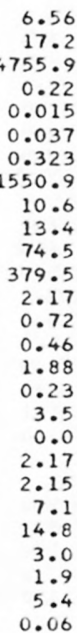

BANGE

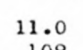

11.0
109

2200

6.3
0.02

0.02
0.00

0.00
0.39

0.39
180

16
52

56
47

47
6.4
6.2
1.7

1.7

9.5

2.1

13.0
13.0

13.0

68
83

24

9
25
0.0

ME: NECHES RIVER AT EVADALE, TEX.

*Not significant at the 95 percent confidence level.

DURAIION IABLE OE DALY SPECIEIC CONDUCIANCE
DAILY SPECIFIC CONDUCTANCE IN
MICROMHOS AT 25 DEG C, THAT WAS
EQUALLE OR EXCEEDE FOR THE

SUMMARY OF HARMONIC ANALYSIS OF STREAM TEMPERATURE

\begin{tabular}{|c|c|c|c|c|c|}
\hline & & & & & STANDARD \\
\hline & HARMONIC & AMPLITUDE & PHASE & VARIATION & ERROR OF \\
\hline SAMPLE & MEAN - M & $-A$ & ANGLE - C & EXPLAINED & ESTIMATE \\
\hline SIZE & IDEG $(1)$ & DDEG $(1$ & (RADIANS) & $\ldots(z)$ & IDEG_CL \\
\hline
\end{tabular}

$\begin{array}{llllll}354 & 20.26 & 20.73 & 7.95 & 2.73 & 21\end{array}$

SUMMARY OF MAXIMUM AND MINIMUM CONCENTRATIONS OF CONSTITUENTS

SAMPLED AT A FREQUENCY OF QUARTERLY (1975 WY)

08041000 -- NECHES RIVER AT EVADALE, TEX.

\begin{tabular}{|c|c|c|c|c|c|c|}
\hline \multirow{2}{*}{ CONSTITUENT } & \multicolumn{3}{|c|}{ TOTAL } & \multicolumn{3}{|c|}{ DISSOLVED } \\
\hline & $\begin{array}{l}\text { NO. } \\
\text { SAMPLES }\end{array}$ & $\begin{array}{l}\text { MINIMUM } \\
\text { CONC. }\end{array}$ & $\begin{array}{l}\text { MAXIMUM } \\
\text { CONC. }\end{array}$ & $\begin{array}{l}\text { NO. } \\
\text { SAMPLES }\end{array}$ & $\begin{array}{l}\text { MINIMUM } \\
\text { CONC. }\end{array}$ & $\begin{array}{l}\text { MAXIMUM } \\
\text { CONC. }\end{array}$ \\
\hline \multicolumn{7}{|l|}{ MINOR ELEMENTS: } \\
\hline ARSENIC (AS), UG/L & 4 & 1 & 2 & 4 & 0 & 2 \\
\hline CADMIUM $(C D), U G / L$ & 4 & $<10$ & 20 & 4 & 0 & $<1$ \\
\hline CHROMIUM (CR), UG/L & 4 & 0 & 0 & 4 & 0 & 0 \\
\hline COBALT $(C O), U G / L$ & 4 & $<50$ & $<50$ & 4 & 0 & 1 \\
\hline COPPER $(C U), U G / L$ & 4 & $<10$ & 10 & 4 & 2 & 8 \\
\hline IRON (FE), UG/L & 4 & 1300 & 2000 & 4 & 90 & 210 \\
\hline LEAD $(P B), U G / L$ & 4 & $<100$ & 100 & 4 & 0 & 7 \\
\hline MANG ANESE (MN), UG/L & 4 & 0 & 180 & 4 & 10 & 20 \\
\hline MERCURY (HG), UG/L & 4 & 0.0 & 0.0 & 4 & 0.0 & 0.0 \\
\hline SELENIUM (SE), UG/L & 4 & 0 & 1 & 4 & 0 & 0 \\
\hline ZINC $(Z N), U G / L$ & 4 & 20 & 220 & 4 & 30 & 210 \\
\hline \multicolumn{7}{|l|}{ PERIPHYTON: } \\
\hline BIOMASS, DRY WT., G/SO M & 3 & 3.39 & 25.00 & & & \\
\hline BIOMASS, ASH WT., G/SQ M & 3 & 1.50 & 11.00 & & & \\
\hline CHLOROPHYLL A, MG/SQ M & 3 & .0 & .2 & & & \\
\hline CHLOROPHYLL $B, M G / S O M$ & 3 & .0 & $\cdot 0$ & & & \\
\hline ORGANIC CARBON, MG/L & 11 & 3.1 & 20.0 & & & \\
\hline
\end{tabular}


LAT 31D20MO8S LONG 095039M27S

DRAINAGE AREA: 13911 SQ MI 136029 SQ KMI

PERIOD OF RECORD: $10 / 01 / 74$ - 09/30/75

STATISIICAL SUMMARY OF SELECTED DISSOLVED CHEMICAL CONSTITUENTS AND

REGRESSION RELATIONSHIPS CF CONSTITUENT CONCENTRATIONS TO SPECIFIC CONDUCTANCE

CONSILIUENI

SA

STANDARD

DEYIALION

SIZE

TEMPERATURE, WATER (DEG C) SPECIFIC CONDUCTANCE (MICROMHOS) STREAMFLOW (CUBIC FT/SEC) PH (STANDARD UNITS) PHOSPHORUS, TOTAL

NITRITE + NITRATE, TOTAL NITROGEN, KJELDAHL, TOTAL PHYTOPLANKTON, TOTAL ICELLS/ML SEDIMENT, SUSPENDED SEDIMENT, CLAY-SILT (PERCENT) COLIFORM, FECAL (COL/100 ML) STREP TOCOCCI, FECAL $(C O L / 100 \mathrm{ML})$ SILICA, DISSOLVED

CALCI UM, DISSOLVED MAGNESIUM, DISSOLVED SODIUM, DISSOLVED POTASSIUM, DISSOL VED BICARBONATE, ION

CARBONATE, ION

SULFATE, DISSOLVED

CHLORIDE, DIS SOLVED

DISSOLVED SOLIDS, SUM OF CONST

DISSOLVED SOLIDS, ROE 180 DEG HARDNESS, TOTAL

HARONESS, NONCARBONATE

TURBIDITY I JTUI

FLOURIDE, DISSOLVED

$\begin{array}{rrr}15 & 18.17 & 7.87 \\ 12 & 433.4 & 123.7 \\ 15 & 15367.3 & 13027.3 \\ 12 & 7.40 & 0.28 \\ 12 & 0.624 & 0.545 \\ 10 & 1.135 & 0.691 \\ 12 & 1.081 & 0.581 \\ 11 & 6702 & 4993 \\ 15 & 258.9 & 150.4 \\ 15 & 77.6 & 23.0 \\ 12 & 978.1 & 888.9 \\ 12 & 623.1 & 1237.0 \\ 12 & 8.16 & 2.53 \\ 12 & 46.33 & 9.37 \\ 12 & 4.82 & 1.25 \\ 12 & 30.67 & 16.77 \\ 12 & 5.05 & 1.52 \\ 12 & 138.0 & 29.8 \\ 12 & 0.0 & 0.0 \\ 12 & 45.42 & 13.41 \\ 12 & 33.08 & 14.66 \\ 12 & 242.1 & 67.1 \\ 11 & 249.5 & 49.8 \\ 12 & 134.7 & 26.9 \\ 12 & 22.4 & 10.0 \\ 12 & 68.3 & 38.6 \\ 10 & 0.36 & 0.15\end{array}$

GONSIIUUENI IMG L OB UNII_SHOHN

$\begin{array}{rr} & \\ & \\ & \\ 9 & \\ 9.0 & \\ 282 & \\ 760 & 730.0 \\ 7.0 & 71300 \\ 0.11 & 7.8 \\ 0.30 & 2.20 \\ 0.57 & 2.40 \\ 930 & 15000 \\ 14 & 585 \\ 25 & 100 \\ 0 & 3100 \\ 32 & 4500 \\ 4.7 & 13.0 \\ 25.0 & 58.0 \\ 2.8 & 7.0 \\ 16.0 & 78.0 \\ 2.3 & 8.8 \\ 76 & 191 \\ 0 & 0 \\ 28.0 & 77.0 \\ 18.0 & 71.0 \\ 156 & 403 \\ 178 & 330 \\ 76 & 170 \\ 6 & 36 \\ 10 & 150 \\ 0.2 & 0.7 \\ & \end{array}$

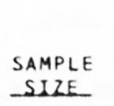
REGRESSION

BEGRESSION SUMMARY COEFICIENT, SIZE - $B$ CONSTANT C.-

CORRELATION COEEICIENI ESIUMAIE

*Not significant at the 95 percent confidence level.

$\begin{array}{rrrrr}10 & -79.046 & 48155.125 & -0.481^{*} & 13308.8 \\ 12 & 0.0010 & 6.9468 & 0.468^{*} & 0.26 \\ 12 & 0.00415 & -1.17417 & 0.942 & 0.192 \\ 10 & 0.00494 & -1.06139 & 0.945 & 0.240 \\ 12 & 0.00290 & -0.17536 & 0.617 & 0.480 \\ 10 & 17.747 & -2159.746 & 0.541^{*} & 3786.9\end{array}$

DURAIION IABLE OE_DAUY SPECIEIC CONDUCIANCE

DAILY SPECIFIC CONDUCTANCE IN

MICROMHOS AT 25 DEG C, THAT WAS

EQUALLED OR EXCEEDED FOR THE

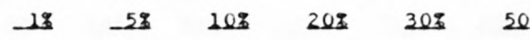

INDICATED PERCENTAGE OF

814

$740 \quad 687$

533

$479 \quad 411$

SUMMARY OF HARMONIC ANALYSIS OF STREAM TEMPERATURE

\begin{tabular}{|c|c|c|c|c|c|}
\hline & & & & & STANDARD \\
\hline & HARMONIC & AMPLIIUDE & PHASE & VAR IATION & ERROR OF \\
\hline $\begin{array}{l}\text { SAMPLE } \\
\text { SUZE_ }\end{array}$ & $\begin{array}{l}\text { MEAN }-M \\
\text { LOEG }\end{array}$ & $\begin{array}{c}-A \\
10 E G(1)\end{array}$ & $\begin{array}{l}\text { ANGLE }-C \\
\text { (BAD IANSI) }\end{array}$ & $\begin{array}{l}\text { EXPLAINED } \\
\text { (I) }\end{array}$ & $\begin{array}{l}\text { ESTIMATE } \\
\text { LEEG CI }\end{array}$ \\
\hline
\end{tabular}

211

19.76

10.33

2.69

95

1.40

SUMMARY OF MAXIMUM AND MINIMUM CONCENTRATIONS OF CONSTITUENTS SAMPLED AT A FREQUENCY OF QUARTERLY (1975 WY)

08065350 -- TRINIIY RIVER NR CROCKETT, TEX.

CONSTI TUENT
SAMPLES


Table 14.--Summary of measurements at each station--Continued

LAT 30D25M30S LONG 094D51M02S

DRAINAGE AREA: 17186 SQ MI 144512 SQ KMI

DERIOD OF RECORD: $10 / 01 / 74-09 / 30 / 75$

STATISTICAL SUMMARY OF SELECTED DISSOLVED CHEMICAL CONSTITUENTS AND

REGRESSION RELATIONSHIPS OF CONSTITUENT CONCENTRATIONS TO SPECIFIC CONDUCTANCE

CONSIITUENI

CONSIUUUENT IMG/L OR UNII SHOWN

SAMPLE

SIZE

MEAN STANDARD

DEVIAIION

TEMPERATURE, WATER (DEG C) SPECIFIC CONDUCTANCE (MICROMHOS) STREAMFLOW (CUBIC FT/SEC)

PH (STANDARD UNITS

PHOSPHORUS, TOTAL

NITRITE + NITRATE, TOTAL

NITROGEN, KJELDAHL, TOTAL

PHYTOPLANKTON, TOTAL (CELLS/ML)

SEDIMENT, SUSPENDED

SEDIMENT, CLAY-SILT (PERCENT)

COLIFORM, FECAL (COL/100 ML)

STREPTOCOCCI, FECAL (COL/100 ML)

SILICA, DISSOLVED

CALCIUM, DISSOLVED

MAGNESIUM, DISSOL VED

SODIUM, DISSOLVED

POTASSIUM, DI SSOLVED

BICARBONATE, ION

CARBONATE, ION

SULFATE, DISSOLVED

CHLORIDE, DISSOLVED

DISSOLVED SOLIDS, SUM OF CONST

DISSOLVEO SOLIDS, ROE 180 DEG

HARDNESS, TOTAL

HARDNESS, NONCARBONATE

TURBIDITY (JTU)

FLOURIDE, DISSOLVED

$\begin{array}{rrr}15 & 19.27 & 6.24 \\ 12 & 328.4 & 28.6 \\ 15 & 17240.0 & 11815.2 \\ 12 & 7.13 & 0.49 \\ 12 & 0.162 & 0.039 \\ 12 & 0.293 & 0.189 \\ 12 & 0.763 & 0.198 \\ 12 & 49975.0 & 95514.7 \\ 15 & 75.7 & 100.9 \\ 15 & 60.5 & 25.8 \\ 12 & 277.2 & 598.4 \\ 12 & 330.8 & 698.3 \\ 12 & 6.52 & 2.02 \\ 12 & 37.42 & 3.45 \\ 12 & 3.41 & 0.49 \\ 12 & 19.83 & 3.33 \\ 12 & 4.23 & 0.44 \\ 12 & 111.3 & 12.7 \\ 12 & 0.0 & 0.0 \\ 12 & 30.17 & 4.80 \\ 12 & 22.17 & 2.72 \\ 12 & 179.0 & 13.1 \\ 12 & 186.6 & 15.5 \\ 12 & 109.1 & 12.3 \\ 12 & 16.4 & 7.6 \\ 12 & 27.1 & 30.3 \\ 10 & 0.22 & 0.04\end{array}$

25.8

98.4

2.02

3.45

0.49

0.44

12.7

0.0

4.80
2.72

13.1

15.5
12.3

7.6
30.3

0.04
BEG

REGRESSION

SAMPLE COEFICIENT, CONSTANT, CORRELATION B COEEICIENI

BANGE

SUZE

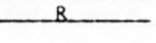

$10.5 \quad 29.0$

$\begin{array}{rr}293 & 367 \\ 1240 & 40000\end{array}$

$\begin{array}{rr}6.3 & 7.8 \\ 0.10 & 0.22\end{array}$

0.01

0.52

0.52

1.10

$\begin{array}{rr}1000 & 280000 \\ 17 & 385 \\ 5 & 92\end{array}$

18
14
3.5
33.0
2.6
16.0
3.6
96
0
23.0
19.0
160
160
96
0
10
0.2

2100
2500

2500
9.3

$\begin{array}{rr}9.3 & 12 \\ 44.0 & 12\end{array}$

4.0

27.0

132
0

40.0
28.0

28.0
197

211

130
33

33
120
0.3

$12-295.362$

$12 \quad 0.0050$

$-0.00057$

$-0.00426$

0.00271

1819.161

114093.375

5.5071

0.34939

1.69209

$-547467.375$

$-0.668$

$0.287 *$
-0.416

$-0.416$

$-0.645$

0.390 *

$0.544 *$

12
12
12
12
12
12
12
12
12
12
12
12
12
10

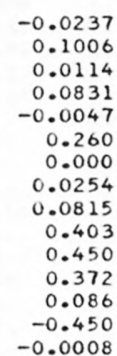

14.3008

14.3008
4.3691

$-0.3490$

$-7.4648$

5.7694

25.785

0.000

21.8156

$-4.5947$

46.505

38.896
-13.002

$-11.873$

174.783
0.4933

$-0.335$

0.833

0.663

0.714
-0.301.

0.585

0.000 .

0.151 *

0.854

0.877

0.830

0.867

0.323 *

-0.423.
-0.550

$-0.550$

ESIUMAIE

* Not significant at the 95 percent confidence level.

\section{DURALION IABLE OE DALY SPECIEIC CONDUCIANCE} DAILY SPECIFIC CONDUCTANCE IN MICROMHOS AT 25 DEG C, THAT WAS EQUALLED OR EXCEEDED FOR THE

$\begin{array}{llllll}18 & -5 \pi & 10 \pi & 208 & 308 & 508 \\ 377 & 368 & 362 & 355 & 348 & 325\end{array}$

9857.2

0.49

0.037

0.151

0.191

84058.0

SUMMARY OF HARMONIC ANALYSIS OF STREAM TEMPERATURE

EORM OF EOUAUION: IO(D) $=M+A *$ SINI.0172*D+C

\begin{tabular}{|c|c|c|c|c|c|}
\hline & & & PHASE & YARIAUION & $\begin{array}{l}\text { STANDARD } \\
\text { ERROR }\end{array}$ \\
\hline $\begin{array}{l}\text { SAMPLE } \\
\text { SIZE }\end{array}$ & $\begin{array}{l}\text { MEAN - M } \\
\text { (DEG G) }\end{array}$ & ${ }_{\text {LEG }}{ }^{A}(1)$ & $\begin{array}{l}\text { ANGLE - C } \\
\text { IRADIANSI }\end{array}$ & $\begin{array}{l}\text { EXPLA INED } \\
(x)\end{array}$ & $\begin{array}{l}\text { ESTIMATE } \\
\text { (DEG_C) }\end{array}$ \\
\hline 283 & 19.26 & 8.18 & 2.74 & 92 & 1.66 \\
\hline
\end{tabular}

SUMMARY OF MAXIMUM AND MINIMUM CONCENTRATIONS OF CONSTITUENTS SAMPLED AT A FREQUENCY OF QUARTERLY 11975 WY

08066500 -- IRINITY R AT ROMAYOR, TEXAS

\begin{tabular}{|c|c|c|c|c|c|c|}
\hline \multirow{2}{*}{ CONSTITUENT } & \multicolumn{3}{|c|}{ TOTAL } & \multicolumn{3}{|c|}{ DISSOLVED } \\
\hline & $\begin{array}{l}\text { NO. } \\
\text { SAMPLES }\end{array}$ & $\begin{array}{l}\text { MINIMUM } \\
\text { CONC. }\end{array}$ & $\begin{array}{l}\text { MAXIMUM } \\
\text { CONC. }\end{array}$ & $\begin{array}{l}\text { NO. } \\
\text { SAMPLES }\end{array}$ & $\begin{array}{l}\text { MINIMUM } \\
\text { CONC. }\end{array}$ & $\begin{array}{c}\text { MAXIMUM } \\
\text { CONC. }\end{array}$ \\
\hline \multicolumn{7}{|l|}{ MINOR ELEMENTS: } \\
\hline ARSENIC (AS), UG/L & 4 & 1 & 8 & 4 & 0 & 7 \\
\hline CADMIUM $(C D), U G / L$ & 4 & $<10$ & 10 & 4 & 0 & 0 \\
\hline CHROMIUM (CR), UG/L & 4 & 0 & 10 & 4 & 0 & 0 \\
\hline COBALT $(C O), U G / L$ & 4 & $<50$ & 50 & 4 & 0 & 0 \\
\hline COPPER (CU), UG/A & 4 & $<10$ & 10 & 4 & 1 & 5 \\
\hline IRON $(F E), U G / L$ & 4 & 630 & 2300 & 4 & 10 & 430 \\
\hline LEAD $(P B), U G / L$ & 4 & $<100$ & $<100$ & 4 & 1 & 15 \\
\hline MANGANESE $(M N), U G / L$ & 4 & 60 & 100 & 4 & 0 & 0 \\
\hline MERCURY (HG), UG/L & 4 & 0.0 & 0.1 & 4 & 0.0 & 0.1 \\
\hline SELENIUM (SE), UG/L & 4 & 0 & 1 & 4 & 0 & 1 \\
\hline ZINC $(Z N), U G / L$ & 4 & 0 & 180 & 4 & 0 & 30 \\
\hline \multicolumn{7}{|l|}{ PER IPHYTON: } \\
\hline BIOMASS, DRY WT., G/SO M & 2 & 21.00 & 330.00 & & & \\
\hline BIOMASS, ASH WT., G/SQ M & 2 & 16.00 & 330.00 & & & \\
\hline CHLOROPHYLL A, MG/SO M & 2 & .3 & $7 \cdot 3$ & & & \\
\hline CHLOROPHYLL B, MG/SO M & 2 & .0 & 1.0 & & & \\
\hline ORGANIC CARBON, MG/L & 10 & 6.5 & 11.0 & & & \\
\hline
\end{tabular}


LAT 30D14M4IS LONG 095D27M26S

DRAINAGE AREA: 809 SQ MI ( 2095 SO KM)

PERIOD OF RECORD: $10 / 01 / 74-09 / 30 / 75$

STATISTICAL SUMMARY OF SELECTED DISSOLVED CHEMICAL CONSTITUENTS AND

REGRESSION RELATIONSHIPS OF CONSTITUENT CONCENTRATIONS TO SPECIFIC CONDUCTANCE

CONSILIUEN

TEMPERATURE, WATER (DEG C)
SPECIFIC CONDUCTANCE (MICROMHOS)
STREAMFLOW (CUBIC FT/SEC)
PH (STANDARD UNITS)
PHOSPHORUS, TOTAL
NIIRITE + NITRATE, TOTAL
NITROGEN, KJELDAHL, TOTAL
PHYTOPLANKTON, TOTAL (CELLS/ML)
SEDIMENT, SUSPENDED
SEDIMENT, CLAY-SILT (PERCENT)
COLIFORM, FECAL (COL/IOO ML)
STREPTOCOCCI, FECAL (COL/IOO ML)
SILICA, DISSOLVED
CALCIUM, DISSOLVED
MAGNESIUM, DISSOLVED
SODIUM, DISSOLVED
POTASSIUM, DISSOLVED
BICARBONATE, ION
CARBONATE, ION
SULFATE, DISSOLVED
CHLORIDE, DISSOLVED
DISSOLVED SOLIDS, SUM OF CONST
DISSOLVED SOLIDS, ROE I8O DEG C
HARDNESS, TOTAL
HARDNESS, NONCARBONATE
TURBIDITY (JTU)
FLOUR IDE, DISSOLVED
FLO

CONSIUIUENI IMG/L OR UNII SHOWNI

\begin{tabular}{rrr}
$\begin{array}{crr}\text { SAMPLE } \\
\text { SIZE }\end{array}$ & MEAN & \multicolumn{1}{r}{ STANDARO } \\
DEYIAIION
\end{tabular}

BEGRESSION SUMMABY REGRESSION $\begin{array}{lll} & \text { REGRESSION } & \text { STANDARD } \\ \text { SAMPLE } & \text { COEFICIENT, CONSTANT, CORRELATION ERROR OF }\end{array}$

R COEEICIENI ESTIMAIE

$\begin{array}{rrr}13.5 & 26.5 & \\ 210 & 366 & \\ 55 & 2200 & 12 \\ 6.4 & 7.5 & 12 \\ 0.06 & 0.26 & 12 \\ 0.09 & 0.35 & 12 \\ 0.34 & 1.70 & 12 \\ 1200 & 36000 & 12 \\ 12 & 244 & \\ 41 & 100 & \\ 21 & 2300 & \\ 31 & 3900 & \\ 5.5 & 19.0 & 12 \\ 19.0 & 36.0 & 12 \\ 1.9 & 3.6 & 12 \\ 9.6 & 28.0 & 12 \\ 2.4 & 3.3 & 12 \\ 53 & 97 & 12 \\ 0 & 0 & 12 \\ 3.2 & 8.6 & 12 \\ 18.0 & 57.0 & 12 \\ 112 & 198 & 12 \\ 126 & 222 & 12 \\ 57 & 110 & 12 \\ 3 & 30 & 12 \\ 10 & 55 & 12 \\ 0.0 & 0.3 & 10\end{array}$

*Not significant at the 95 percent confidence level.

-5.162
0.0020
0.00068
0.00097
-0.00345
-35.461

$$
\begin{array}{r}
1966.240 \\
6.2784 \\
-0.06801 \\
-0.09198 \\
1.73417 \\
14873.000
\end{array}
$$

$-0.363^{*}$
$0.280^{*}$
$0.520^{*}$
0.067
$-0.467 *$
$-0.167^{*}$

636.8

0.33

0.052

0.314

10093.7

0.0537
0.0718
0.0098
0.1111
-0.0004
0.126
0.000
0.0205
0.2338
0.563
0.641
0.242
0.114
-0.125
0.0001

0.490 *

0.712

0.841

0.897

$-0.058 *$

0.000 *

0.661

0.661
0.911

0.963

0.987

0.805

0.676

-0.408 *
0.053 *
4.59

3.40
0.30

2.63

0.32
12.6
0.0

0.0

1.12

5.10
7.5

5.0

8.6

6.0

DAILY SPECIFIC CONDUCTANCE IN MICROMHOS AT 25 DEG C, THAT HAS

EQUALLED OR EXCEEDED FOR THE

12

$5 \% 20$

202208

\begin{tabular}{|c|c|c|c|c|c|c|}
\hline \multirow{2}{*}{ CONSTITUENT } & \multicolumn{3}{|c|}{ TOTAL } & \multicolumn{3}{|c|}{ DISSOLVED } \\
\hline & $\begin{array}{l}\text { NO. } \\
\text { SAMPLES }\end{array}$ & $\begin{array}{l}\text { MINIMUM } \\
\text { CONC. }\end{array}$ & $\begin{array}{l}\text { MAXIMUM } \\
\text { CONC. }\end{array}$ & $\begin{array}{l}\text { NO. } \\
\text { SAMPLES }\end{array}$ & $\begin{array}{l}\text { MINIMUM } \\
\text { CONC. }\end{array}$ & $\begin{array}{l}\text { MAXIMUM } \\
\text { CONC. }\end{array}$ \\
\hline \multicolumn{7}{|l|}{ MINOR ELEMENTS: } \\
\hline ARSENIC (AS), UG/L & 4 & 1 & 3 & 4 & 1 & 2 \\
\hline CADMIUM $(C D), U G / L$ & 4 & $<10$ & 10 & 4 & 0 & 1 \\
\hline CHROMIUM (CR), UG/L & 4 & 0 & $<10$ & 4 & 0 & $<10$ \\
\hline COBALT $(C O), U G / L$ & 4 & $<50$ & $<50$ & 4 & 0 & 3 \\
\hline COPPER (CU), UG/L & 4 & $<10$ & 90 & 4 & 0 & 3 \\
\hline IRON (FE), UG/L & 4 & 510 & 2200 & 4 & 50 & 80 \\
\hline LEAD $(P B), U G / L$ & 4 & $<100$ & 200 & 4 & 0 & 2 \\
\hline MANG ANESE (MN), UG/L & 3 & 20 & 160 & 4 & 0 & 60 \\
\hline MERCURY $(H G), U G / L$ & 4 & $<0.1$ & 0.3 & 4 & 0.0 & 0.1 \\
\hline SELENIUM (SE), UG $/ L$ & 4 & 0 & 0 & 4 & 0 & 0 \\
\hline ZINC $(Z N), U G / L$ & 4 & 10 & 290 & 4 & 10 & 30 \\
\hline \multicolumn{7}{|l|}{ PERIPHYTON: } \\
\hline BIOMASS, DRY WT., G/SQ M & 3 & .19 & 11.00 & & & \\
\hline BIOMASS, ASH WT., G/SO M & 3 & .19 & 7.79 & & & \\
\hline CHLOROPHYLL A, MG/SO $\mathrm{M}$ & 3 & .0 & 7.8 & & & \\
\hline CHLOROPHYLL B, MGISQ M & 3 & .0 & 2.3 & & & \\
\hline ORGANIC CARBON, MG/L & 12 & 7.0 & 18.0 & & & \\
\hline
\end{tabular}

SUMMARY OF HARMONIC ANALYSIS OF STREAM TEMPERATURE

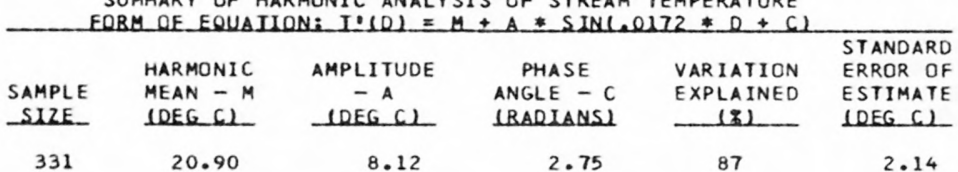

SUMMARY OF MAXIMUM AND MINIMUM CONCENTRATIONS OF CONSTITUENTS SAMPLED AT A FREQUENCY OF QUARTERLY (1975 WY)

08068000 -- WEST FORK SAN JACINTO RIVER NR CONROE, TX 
LAT 3302OMO2S LONG $100014 M 24 \mathrm{~S}$

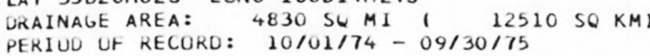

STATISIICAL SUMMARY OF SELECTED DISSOLVED CHEMICAL CONSTITUENTS AND

REGRESSION RELATIONSHIPS OF CUNSTITUENT CONCENTRATIONS TO SPECIFIC CONDUCTANCE (MICRUMHUS)

CONSIUUENI

CONSIIIUENI IMGLL OR UNII SHOWNI

SAMPLE STANDARO

(1)

IEMPERATURE, WATER (UEG () SPECIFIC CONOUCTANCE (MICRGMHCS) STREAMFLOW ICUBIC FT/SEC,

PH (STANUARU UNITS)

PHOSPHCRUS, TOTAL

NITRITE + NITRATE, TOTAL

NITROGEN, KJELDAHL, TOTAL

PHYTUPLANKTON, TOTAL (CELLS/ML)

SEDIMENT SUSPENUED

SEOIMENT, CLAY-SILT (PERCENT)

COLIFORM, FECAL (COL/100 ML)

STREPTOCUCCI, FECAL (COL/IW ML)

SILICA, DISSOLVEO

CALCIUM, OISSULVED

MAGNESIUM, UISSOLVED

SUDIUM, DISSOLVED

POTASSIUM, UISSULVEO

GICARBONATE, ION

CARBUNATE, IUN

SULFATE, DISSOLVED

CHLORIOE, OISSOLVEU

OISSOLVED SULIDS, SUM OF CINST

DISSOLVED SULIDS, RUE 180 DEG

MARUNESS, TOTAL

HARUNESS, NONCARBUNATE

IUREIOITY (JTU)

FLOURIDE, DISSOLVEC

*Not significant at the 95 percent confidence leve1.
STANDARO

REVIAILEN BANGE

$\begin{array}{ll}13 & \\ 13 & 3076 \\ 13 & \\ 13 & \end{array}$

$13-7.2$

110.332

$11 \quad 0.804$

13180.8

362.7
69.0

69.0

2346.2

7.20
7.20

802.31

200.09

8083.67

29.53

142.4

2128.40

2915.36

24230.9

25974.2
2840.2

2840.

2715.4
503.1
8.45

19755.0

174.0

0.20

0.499

0.179
1.830

39975.2

945.0

27.6

0896.1

458

2.7
259.27

259.27
86.20

4893.88

15.25

42.5

0.0
.47 .33

7806.71

13581.9

13500.6

976.1

458.2

1577.8
0.10 $\begin{array}{rr}8.0 & 34.0 \\ 6220 & 72000 \\ 1 & 646\end{array}$

$\begin{array}{rrr}1 & 646 & 13\end{array}$

7.4
0.01

0.01
0.04
0.00

300
5

5
15

0
4
2.0

2.0

280.0

84.0

980.0
7.9

89

770.0

1600.0

3790

3920

1100

1000

0.3
8.2
1.70
0.57

0.57

$6.30 \quad 11$

140000
3310

99

24000

20000

$\begin{array}{rr}1200.0 & 13 \\ 310.0 & 13\end{array}$

000.0

62.0
198

$\begin{array}{rr}0 & 13 \\ 3000.0 & 13\end{array}$

8000.0

49600

50900

4300

4200

4200
5500

0.6 \begin{tabular}{ll}
$198-13$ \\
\hline
\end{tabular} \begin{tabular}{ll} 
REGBB & \multicolumn{1}{c}{ REGRESSION } \\
SAMPLE \\
SHZE
\end{tabular} EGRESS LON SUMMABY

COEFICIENT, CONSTANT, -

CORRELATION ERROK CF COEEICIENI_ ESLIMALE
$-0.573$

0.185

$-0.650$

$0.532 *$

$-0.606$

-0.279 .

$-0.00007$

.00007
-0.576

$-0.0000$

0.0119

0.0037

0.2472

0.0007

0.001

0.000
0.0291

0.3944

0.687

0.699

0.045

0.044

$-0.040$

$-0.0000$
$-0.319 *$

0.903

0.030

0.998

0.941

0.540 *

0.000

0.888

0.998

0.995

0.998

0.998

0.918

$-0.504$.

$-0.564$
0.4424
149.5

0.20

0.400

0.160

1.439
40200.6

SAMPLE SLEE $=362$

DAILY SPECIFIC CONDUCTANCE IN MICRCMHOS AI 25 UEG C, THAT WAS

EQUALLED OR EXCEEUEU FOR THE

URAILN IABLE OE DALLY SPECIEIC CONOUCIANCE

INDICATED PERCEN

$\begin{array}{llllll}27 & -23 & 103 & 20 \% & 302 & 50 \%\end{array}$

Q3 $70 \%$

$20 \% \quad 923 \quad 29 \%$

$80200 \quad 07700 \quad 60500 \quad 52700 \quad 48100-40200$

$27800 \quad 12800$

9230

4710

SUMMARY UF HAKMUNIC ANALYSIS UF STREAM TEMPERATURE

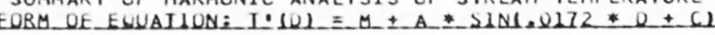

\begin{tabular}{|c|c|c|c|c|c|}
\hline & & & & & STANDARD \\
\hline & HARMONIC & AMPL ITUDE & PHASE & VARIATION & ERROR OF \\
\hline SAMPLE & MLAN - M & $-A$ & ANGLE - C & EXPLAINED & ESTIMATE \\
\hline SILE & $10 \pm 6(1)$ & $-10 E E_{2}(1$ & IBADLANSI & $-12)$ & $10 E G(1)$ \\
\hline
\end{tabular}

355

10.09

10.69

2.85

83

3.45

SUMMARY OF MAXIMUM AND MINIMUM CONCENTRATIONS OF CONSTITUENTS

SAMPLED AT A FREQUENCY OF QUARTERLY (1975 WY)

08082000 -- SALT FK BRAZUS R NR ASPERMONT, TX

\begin{tabular}{l} 
CONSTI TUENT \\
\cline { 2 - 3 }
\end{tabular}


Table 14.--Summary of measurements at each station--Continued

LAT 33D34M51S LONG 099D16M02S

DRAINAGE AREA: 14490 SQ MI ( 37529 SO KM)

PERIOD OF RECORD: $10 / 01 / 74-09 / 30 / 75$

STATISTICAL SUMMARY OF SELECTED DISSOLVED CHEMICAL CONSTITUENTS AND

REGRESSION RELATIONSHIPS OF CONSTITUENT CONCENTRATIONS TO SPECIFIC CONDUCTANCE

GONSIIIUENI

CONSILUUENI IMG/L_OR UNDI SHOHN

SAM

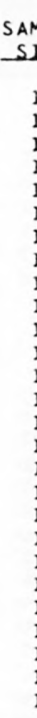

\section{STANDARD \\ MEAN DEYLALION}

TEMPERATURE, WATER (UEG C) SPECIFIC CONDUCTANCE (MICROMHOS) STREAMFLOW (CUBIC FT/SEC)

PH (STANDARD UNITS)

PHOSPHORUS, TOTAL

NITRITE + NITRATE, TOTAL

NITROGEN, KJELDAHL, TOTAL

PHYTOPLANKTON, TOTAL (CELLS/ML)

SEDIMENT, SUSPENDED

SEDIMENT, CLAY-SILT (PERCENT)

COLIFORM, FECAL (COL/100 ML)

STREP TOCOCCI, FECAL 1 COL/100 ML)

SILICA, DISSOLVED

CALCIUM, DISSOLVED

MAGNESIUM, DISSOLVED

SODIUM, DISSOLVED

POTAS SIUM, DISSOLVED

BICARBONATE, ION

CARBONATE, ION

SULFATE, DISSOLVED

CHLORIDE, DISSOLVED

DISSOLVED SOLIDS, SUM OF CONST

DISSOLVED SOLIDS,
HARONESS, TOTAL

HARDNESS, NONCARBONATE

TUREIDITY (JTU)

BANGE

10.00
7336.2

814.8

4722.5

7.86

0.290

0.215

1.342

21810.0

21810.0
1118.9

1118.9
92.0

1718.7

1839.4

6.57
505.83

505.83

129.08

2811.67

16.25
151.23

151.3
0.0

1395.00

4479.16

9415.0

9850.9

1792.5

1670.8

714.9
0.54

0.494

0.494
0.203

0.203
1.987

34133.5

2121.8

15.2

4839.0

3849.9
2.98

2.98

196.12

73.76
549.34

1549.34

0.18
44.3

44.3
0.0

548.01

2516.26

4880.1

5291.1
779.7

779.7

754.1
1672.9

1672.9
0.12

2.5
4370
13
7.6
0.00
0.00
0.25
180
4
1
11
1.
190.0
21.0
710.0
7.0
82
5
540.0
950.0
2650
2710
620
530
2
0.3

SIZE

REGRESSION

BEGRESSION SUMMABY

COEFICIENT, CONSTANT,

CORRELATION STANDARD

SAMPLE COEFICIENT, CONSTANT, CORRELATION

COEEICIENI ESILMAIE

*Not significant at the 95 percent confidence level.

DAILY SPECIFIC CONDUCTANCE DUBALION IABLE OE DALIY SPECIEAC CONDUCIANCE

DAILY SPECIFIC CONDUCTANCE IN

MICROMHOS AT 25 DEG C. THAT WAS 2I $28 \quad 10 \% \quad 20 \% \quad 30 z$

EQUALLED OR EXCEEDED FOR THE

\begin{tabular}{rrrrrr}
\hline 18 & -58 & $10 z$ & $20 z$ & $30 z$ & $50 z$ \\
25400 & 22900 & 21600 & 19900 & 18900 & 14000
\end{tabular}

24000

2910

8.0
1.60
0.50

12
12
12

12

0.56

7.50

93000

11
12
12

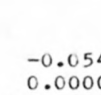

0.0000
-0.00004

-0.00004
-0.000000

$-0.00013$

$-1.249$

1159.560

7.6650

0.92903
0.22647

0.22647
3.27081

40204.402

$-0.482$.

$-0.644$

$-0.029 *$

$-0.484$.

$-0.269 *$

INDICATED PERCENTAGE OF TIME

SUMMARY OF HARMONIC ANALYSIS OF STREAM TEMPERATURE

\begin{tabular}{|c|c|c|c|c|c|}
\hline & & & & & STANDARD \\
\hline & HARMONIC & AMPLITUDE & PHASE & VARIATION & ERROR OF \\
\hline SAMPLE & MEAN - M & $-A$ & ANGLE - C & EXPLAINED & ESTIMATE \\
\hline SLIE_ & LEEG C) & JDEG (1) & [RADLANS] & $\ldots 181 \ldots$ & IDEG_C \\
\hline 321 & 20.87 & 10.49 & 2.95 & 78 & 3.97 \\
\hline
\end{tabular}

SUMMARY OF MAXIMUM AND MINIMUM CONCENTRATIONS OF CONSTITUENTS SAMPLED AT A FREQUENCY OF QUARTERLY (1975 WY)

08082500 -- BRAZOS RIVER AT SEYMOUR, TEX.

\begin{tabular}{|c|c|c|c|c|c|c|}
\hline \multirow{2}{*}{ CONSTITUENT } & \multicolumn{3}{|c|}{ TOTAL } & \multicolumn{3}{|c|}{ DISSOLVED } \\
\hline & $\begin{array}{l}\text { NO. } \\
\text { SAMPLES }\end{array}$ & $\begin{array}{l}\text { MIN IMUM } \\
\text { CONC. }\end{array}$ & $\begin{array}{l}\text { MAXIMUM } \\
\text { CONC. }\end{array}$ & $\begin{array}{l}\text { NO. } \\
\text { SAMPLES }\end{array}$ & $\begin{array}{l}\text { MINIMUM } \\
\text { CONC. }\end{array}$ & $\begin{array}{l}\text { MAXIMUM } \\
\text { CONC. }\end{array}$ \\
\hline \multicolumn{7}{|l|}{ MINOR ELEMENTS: } \\
\hline ARSENIC (AS), UG/L & 4 & 0 & 200 & 4 & 1 & 6 \\
\hline CADMIUM $(C D)$, UG/L & 4 & $<10$ & 20 & 4 & 0 & 0 \\
\hline CHROMIUM (CR), UG/L & 4 & 20 & 110 & 4 & 0 & 10 \\
\hline COBALT $(C O), U G / L$ & 4 & $<50$ & 50 & 4 & 0 & 1 \\
\hline COPPER (CU), UG/L & 4 & 20 & 160 & 4 & 2 & 4 \\
\hline IRON $(F E), U G / L$ & 4 & 120 & 74000 & 4 & 10 & 110 \\
\hline LEAD $(P B), U G / L$ & 4 & $<100$ & 200 & 4 & 0 & 4 \\
\hline MANGANESE (MN), UG/L & 3 & 50 & 5600 & 4 & 0 & 30 \\
\hline MERCURY (HG), UG/L & 4 & 0.0 & 0.3 & 4 & 0.0 & 0.1 \\
\hline SELENIUM (SE), UG/L & 4 & 1 & 4 & 4 & 1 & 4 \\
\hline ZINC $(Z N), U G / L$ & 4 & 30 & 680 & 4 & 0 & 30 \\
\hline \multicolumn{7}{|l|}{ PERIPHYTON: } \\
\hline BIOMASS, DRY WT., G/SQ M & 4 & .59 & 96.00 & & & \\
\hline BIOMASS, ASH WT, G/SO M & 4 & .09 & 87.00 & & & \\
\hline CHLOROPHYLL A, MG/SO M & 4 & .0 & 12.0 & & & \\
\hline CHLOROPHYLL B, MG/SO M & 4 & $\cdot 0$ & .8 & & & \\
\hline ORGANIC CARBON, MG/L & 4 & 4.1 & 59.0 & & & \\
\hline
\end{tabular}


Table 14.--Summary of measurements at each station--Continued

LAT $31008 M 02 S$ LONG 096049M29S

DRAINAGE AREA: 29421 SQ MI 176200 SO KM)

PERIOD OF RECORD: $10 / 01 / 74-09 / 30 / 75$

STATISTICAL SUMMARY OF SELECTED DISSOLVED CHEMICAL CONSTITUENTS AND

REGRESSION RELATIONSHIPS OF CONSTITUENT CONCENTRATIONS TO SPECIFIC CONDUCTANCE

\section{CONSIITUEN}

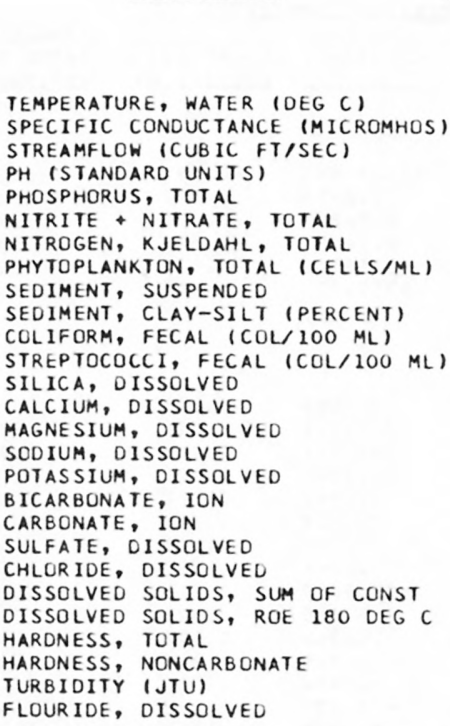

CONSIUUENT IMG/L OR UNII SHOWNU

SIZE

$\begin{array}{rrr}12 & 19.83 & 7.65 \\ 12 & 1184.8 & 293.0 \\ 12 & 5092.5 & 6420.9 \\ 12 & 7.78 & 0.42 \\ 12 & 0.217 & 0.198 \\ 11 & 0.356 & 0.316 \\ 12 & 1.023 & 0.687 \\ 11 & 26370.0 & 46256.2 \\ 12 & 359.5 & 468.1 \\ 12 & 78.2 & 23.9 \\ 12 & 1271.9 & 2089.6 \\ 12 & 1006.9 & 1970.2 \\ 12 & 6.38 & 1.66 \\ 12 & 81.50 & 14.68 \\ 12 & 15.27 & 4.96 \\ 12 & 139.00 & 47.38 \\ 12 & 4.42 & 0.87 \\ 12 & 179.8 & 33.2 \\ 12 & 1.1 & 3.8 \\ 12 & 123.00 & 33.00 \\ 12 & 207.17 & 76.93 \\ 12 & 667.0 & 176.1 \\ 12 & 691.3 & 183.3 \\ 12 & 266.7 & 54.8 \\ 12 & 116.3 & 43.0 \\ 12 & 78.8 & 96.0 \\ 10 & 0.31 & 0.06\end{array}$

\section{BANGE}

$10.0 \quad 30.5$

$583 \quad 1580$

32516900

$\begin{array}{rr}6.8 & 8.5 \\ 0.08 & 0.83\end{array}$

0.00

0.35

.35
570

12

19
12
9

9
3.1

3.1
59.0

6.2

65.0
2.4

2.4
123

123

72.0

96.0

376

391
170

64
10

0.2

130000

1210

59

5800
6900

6900
10.0

22.0

200.0

5.4

222

170.0

310.0

901

927
370

370
180

180
280
0.4 \begin{tabular}{clc}
\multicolumn{2}{c}{ REGRESSLION SUMMARY } & \\
SAMPLE COERESSION & STANDARD \\
SICIENT, CONSTANT, CORRELATION ERROR OF
\end{tabular} SIZE CIENT, CONSTANT, COEEICLENI *Not significant at the 95 percent confidence level.

\section{QURAIION IABLE OE DAILY SPECLEIC CONDUCIANCE}

DAILY SPECIFIC CONDUCTANCE IN MICROMHOS AT 25 DEG C, THAT HAS

EQUALLED OR EXCEEDED FOR THE

$\begin{array}{rrrrrr}12 & 58 & 108 & 208 & 308 & 508 \\ 1790 & 1660 & 1610 & 1550 & 1500 & 1350\end{array}$

$\begin{array}{rr}12 & -9.748 \\ 12 & 0.0006 \\ 12 & 0.00004 \\ 11 & -0.00025 \\ 12 & -0.00069 \\ 11 & 7.764\end{array}$

$\begin{array}{rr}10.0 & 12 \\ 110.0 & 12\end{array}$

$0.4 \quad 10$

12
12
12
12
12
12
12
12
12
12
12
12
12
12
10

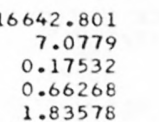

$$
\begin{array}{r}
-0.445 * \\
0.420^{*} \\
0.053^{*} \\
-0.204^{*} \\
-0.293^{*} \\
0.052^{*}
\end{array}
$$

6031.0

\begin{tabular}{|c|c|c|c|c|c|}
\hline & & & & & STANDARD \\
\hline & HARMONIC & AMPLITUDE & PHASE & VARIATION & ERROR OF \\
\hline $\begin{array}{l}\text { SAMPLE } \\
\text { SLZE }\end{array}$ & $\begin{array}{l}\text { MEAN }-M \\
\text { LEEG }\end{array}$ & $\overline{D E G}^{-A}$ & $\begin{array}{l}\text { ANGLE - C } \\
\text { (RADIANS) }\end{array}$ & $\begin{array}{c}\text { EXPLAINED } \\
\text { (I) }\end{array}$ & $\begin{array}{l}\text { ESTIMATE } \\
\text { (DEG C) }\end{array}$ \\
\hline
\end{tabular}

0.40
0.208

0.326

0.689

4692.8

INDICATED PERCENTAGE OF TIME

365

20.57

10.96

2.78

\begin{tabular}{|c|c|c|c|c|c|c|}
\hline \multirow{2}{*}{ CONSTITUENT } & \multicolumn{3}{|c|}{ TOTAL } & \multicolumn{3}{|c|}{ DISSOLVED } \\
\hline & $\begin{array}{l}\text { NO. } \\
\text { SAMPLES }\end{array}$ & $\begin{array}{l}\text { MIN IMUM } \\
\text { CONC. }\end{array}$ & $\begin{array}{l}\text { MAXIMUM } \\
\text { CONC. }\end{array}$ & $\begin{array}{l}\text { NO. } \\
\text { SAMPLES }\end{array}$ & $\begin{array}{l}\text { MINIMUM } \\
\text { CONC. }\end{array}$ & $\begin{array}{l}\text { MAXIMUM } \\
\text { CONC. }\end{array}$ \\
\hline \multicolumn{7}{|l|}{ MINOR ELEMENTS: } \\
\hline ARSENIC (AS), UG/L & 4 & 4 & 24 & 4 & 2 & 4 \\
\hline CADMIUM $(C D), U G / L$ & 3 & $<10$ & $<10$ & 4 & 0 & 1 \\
\hline CHROMIUM (CR), UG/L & 3 & 10 & 10 & 4 & 0 & 20 \\
\hline COBALT $(C O), U G / L$ & 3 & $<50$ & 100 & 4 & 0 & 2 \\
\hline COPPER (CU), UG/L & 3 & $<10$ & 10 & 4 & 1 & 6 \\
\hline IRON (FE), UG/L & 3 & 1100 & 13000 & 4 & 10 & 60 \\
\hline LEAD $(P B), U G / L$ & 3 & $<100$ & $<100$ & 4 & 0 & 1 \\
\hline MANGANESE (MN), UG/L & 2 & 100 & 500 & 4 & 0 & 0 \\
\hline MERCURY (HG), UG/L & 3 & 0.0 & 0.1 & 4 & 0.0 & 0.1 \\
\hline SELENIUM (SE), UG/L & 4 & 0 & 0 & 4 & 0 & 0 \\
\hline ZINC $(Z N), U G / L$ & 3 & 20 & 40 & 4 & 0 & 10 \\
\hline \multicolumn{7}{|l|}{ PERIPHYTON: } \\
\hline BIOMASS, DRY WT., G/SQ M & 2 & 80.00 & 160.00 & & & \\
\hline BIOMASS, ASH WT., G/SO M & 2 & 68.00 & 140.00 & & & \\
\hline CHLOROPHYLL A, MG/SQ M & 2 & 44.0 & 67.0 & & & \\
\hline CHLOROPHYLL B, MG/SQ M & 2 & .0 & 3.0 & & & \\
\hline ORGANIC CARBON, MG/L & 7 & 5.5 & 14.0 & & & \\
\hline
\end{tabular}

90

2.42

SUMMARY OF MAXIMUM AND MINIMUM CONCENTRATIONS OF CONSTITUENTS SAMPLED AT A FREQUENCY OF QUARTERLY (1975 WY)

08098290 -- BRAZOS RIVER NR HIGHBANK, TEX. 
LAT 29020M58S LONG 095034M56S

DRAINAGE AREA: 44340 SQ MI ( 114841 SQ KM)

PERIOD OF RECORD: $10 / 01 / 74-09 / 30 / 75$

STATISTICAL SUMMARY OF SELECTED DISSOLVED CHEMICAL CONSTITUENTS AND

REGRESSION RELATIONSHIPS OF CONSTITUENT CONCENTRATIONS TO SPECIFIC CONDUCTANCE

CONSIUIUENI

CONSIUUENI IMG/L OR UNII SHOWN

SAMPLE

\section{SIZE}

TEMPERATURE, WATER (DEG C) SPECIFIC CONDUCTANCE (MICROMHOS) STREAMFLOH (CUBIC FT/SEC)

PH ISTANDARD UNITS

PHOSPHORUS, TOTAL

NITRITE + NITRATE, TOTAL

NITROGEN, KJELOAHL, TOTAL

PHYTOPLANKTON, TOTAL (CELLS/ML)

SEDIMENT, SUSPENDED

SEDIMENT, CLAY-SILT (PERCENT)

COLIFORM, FECAL (COL/100 ML)

STREP TOCOCCI, FECAL $(\mathrm{COL} / 100 \mathrm{ML})$

SILICA, DISSOLVED

MAGNESIUM, DISSOLVED

SODIUM, DISSOLVED

POTASSIUM, DISSOL VED

CARBONATE, ION

SULFATE, DISSOLVED

CHLORIDE, DISSOLVED

OISSOLVED SOLIDS, SUM OF CONST

DISSOLVED SOLIDS, ROE 180 DEG HARDNESS, TOTAL

HARDNESS, NONCARBONAT

TURBIDITY (JTU)

FLOUR IDE, DISSOLVED
CALCIUM, DISSOLVED

BICARBONATE, ION

$\begin{array}{rrrr}12 & 20.75 & 6.82 & 10 \\ 12 & 696.6 & 254.3 & 355 \\ 12 & 13466.7 & 9580.4 & 27 \\ 12 & 7.01 & 0.51 & 6 \\ 12 & 0.375 & 0.234 & 0 . \\ 9 & 0.374 & 0.275 & 0.01 \\ 12 & 0.921 & 0.550 & 0.3 \\ 11 & 21701.5 & 38955.4 & \\ 11 & 773.5 & 676.6 & 15 \\ 10 & 90.6 & 8.2 & \\ 12 & 722.5 & 934.2 & \\ 12 & 514.5 & 560.2 & \\ 12 & 9.06 & 1.91 & 6 \\ 12 & 57.08 & 14.51 & 38 \\ 12 & 11.12 & 4.25 & 5 \\ 12 & 62.67 & 32.39 & 22 \\ 12 & 4.07 & 0.53 & 2 \\ 12 & 166.6 & 45.6 & 1 \\ 12 & 0.0 & 0.0 & \\ 12 & 61.75 & 23.42 & 32 \\ 12 & 91.08 & 47.79 & 30 \\ 12 & 379.5 & 136.6 & 201 \\ 12 & 390.8 & 136.8 & 2 \\ 12 & 190.8 & 54.3 & 1 \\ 12 & 51.9 & 23.6 & \\ 12 & 203.8 & 94.1 & \\ 10 & 0.25 & 0.05 & 0\end{array}$

BANGE

$10.0 \quad 29.0$

$355 \quad 1150$

$\begin{array}{rr}2700 & 37000 \\ 6.3 & 7.9\end{array}$

$\begin{array}{ll}6.3 & 7.9 \\ 0.15 & 0.86\end{array}$

$0.01 \quad 0.68$

$\begin{array}{rr}.39 & 2.50 \\ 27 & 100000\end{array}$

$157 \quad 2300$

71
23
15

$\begin{array}{ll}23 & 3300 \\ 15 & 1700\end{array}$

$6.9 \quad 14.0$

$\begin{array}{rl}38.0 & 76.0\end{array}$

$\begin{array}{rr}5.6 & 18.0 \\ 2.0 & 120.0\end{array}$

$2.9 \quad 5.0$

$\begin{array}{rr}112 & 244 \\ 0 & 0\end{array}$

$32.0 \quad 99.0$

170.0

$205 \quad 621$

$\begin{array}{rr}120 & 270 \\ 21 & 91\end{array}$

45
0.2
SAMPLE

SIZE

REGRESSION

REGRESSION SUMMARY

COEFICIENT, CONSTANT, CORRELATION

B COEEICIENI ESILIMAI

$\begin{array}{rrrrr}12 & -14.587 & 23627.492 & -0.387^{*} & 9264.4 \\ 12 & 0.0011 & 6.2496 & 0.542^{*} & 0.45 \\ 12 & -0.00028 & 0.56841 & -0.302^{*} & 0.234 \\ 9 & -0.00050 & 0.74683 & -0.480^{*} & 0.258 \\ 12 & -0.00091 & 1.55562 & -0.421^{*} & 0.524 \\ 11 & 98.881 & -48755.770 & 0.661 & 30823.0\end{array}$

DURAUION IABLE OF DALYY SPECIFIC CONDUCIANCE

MICROMHOS AT 25 DEG C, THAT WAS 18
EQUALLED OR EXCEEDED FOR THE

$\begin{array}{llllllll} & & & & & & \end{array}$

$\begin{array}{rr}0.0027 & \\ 0.0523 & \\ 0.0159 & \\ 0.1241 & -2 \\ 0.0008 & \\ 0.136 & \\ 0.000 & \\ 0.0912 & -1 \\ 0.1815 & -3 \\ 0.536 & \\ 0.537 & \\ 0.201 & \\ 0.084 & \\ -0.294 & 4 \\ 0.0002 & \\ & \\ & \\ 2512 E & =365 \\ & \\ & \\ & \end{array}$

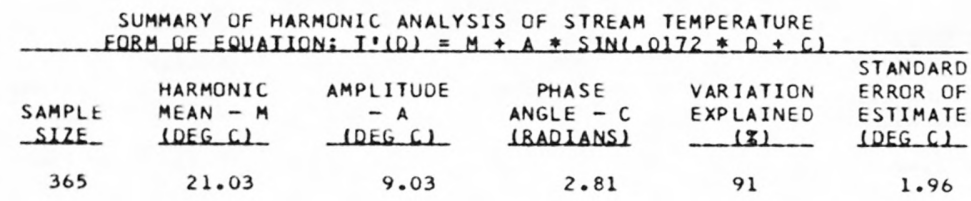

08116650 -- BRAZOS RIVER NR ROSHARON, TEX.

\begin{tabular}{|c|c|c|c|c|c|c|}
\hline \multirow{2}{*}{ CONSTITUENT } & \multicolumn{3}{|c|}{ TOTAL } & \multicolumn{3}{|c|}{ DISSOLVED } \\
\hline & $\begin{array}{l}\text { NO. } \\
\text { SAMPLES }\end{array}$ & $\begin{array}{l}\text { MINIMUM } \\
\text { CONC. }\end{array}$ & $\begin{array}{l}\text { MAXIMUM } \\
\text { CONC. }\end{array}$ & $\begin{array}{l}\text { NO. } \\
\text { SAMPLES }\end{array}$ & $\begin{array}{l}\text { MINIMUM } \\
\text { CONC. }\end{array}$ & $\begin{array}{l}\text { MAXIMUM } \\
\text { CONC. }\end{array}$ \\
\hline \multicolumn{7}{|l|}{ MINOR ELEMENTS: } \\
\hline ARSENIC (AS), UG/L & 5 & 4 & 34 & 5 & 2 & 5 \\
\hline CADMIUM $(C D), U G / L$ & 5 & $<10$ & $<10$ & 5 & 0 & 0 \\
\hline CHROMIUM (CR), UG/L & 5 & 10 & 60 & 5 & 0 & 0 \\
\hline COBALT $(C O)$, UGLL & 5 & $<50$ & 50 & 5 & 0 & 0 \\
\hline COPPER (CU), UG/L & 5 & 10 & 60 & 5 & 1 & 6 \\
\hline IRON $(F E), U G / L$ & 5 & 2000 & 43000 & 5 & 30 & 70 \\
\hline LEAD $(P B), U G / L$ & 5 & $<100$ & $<100$ & 5 & 0 & 5 \\
\hline MANGANESE (MN), UG/L & 5 & 180 & 1300 & 5 & 0 & 10 \\
\hline MERCURY (HG), UG IL & 5 & 0.0 & 0.6 & 5 & 0.0 & 0.3 \\
\hline SELENIUM (SE), UG/L & 5 & 0 & 1 & 5 & 0 & 0 \\
\hline$Z I N C(Z N), U G / L$ & 5 & 40 & 210 & 5 & 10 & 70 \\
\hline \multicolumn{7}{|l|}{ PERIPHYTON: } \\
\hline BIOMASS, DRY WT., G/SO M & 2 & .50 & 40 & & & \\
\hline BIOMASS, ASH WT., G/SQ M & 1 & 31.00 & 31 & & & \\
\hline CHLOROPHYLL A, MG/SQ M & 2 & .0 & .1 & & & \\
\hline CHLOROPHYLL B, MG/SQ M & 2 & .0 & .2 & & & \\
\hline ORGANIC CARBON, MG/L & 6 & 5.2 & 32.0 & & & \\
\hline
\end{tabular}


LAT 32011M57S LONG 101000 M49S

DRAINAGE AREA: 9903 SQ MI ( 25649 SQ KM)

PERIOD OF RECORD: $10 / 01 / 74-09 / 30 / 75$

STATISTICAL SUMMARY OF SELECTED DISSOLVED CHEMICAL CONSTITUENTS AND

REGRESSION RELATIONSHIPS OF CONSTITUENT CONCENTRATIONS TO SPECIFIC CONDUCTANCE

CONSILIUENI

CONSIUIUENI IMG/L OR UNII SHOWNI

\begin{tabular}{|c|}
\hline $\begin{array}{l}\text { TEMPERATURE, WATER (DEG C) } \\
\text { SPECIFIC CONDUCTANCE (MICROMHOS) } \\
\text { STREAMFLOW (CUBIC FT/SEC) } \\
\text { PH (STANDARD UNITS) } \\
\text { PHOSPHORUS, TOTAL } \\
\text { NITRITE + NITRATE, TOTAL } \\
\text { NITROGEN, KJELDAHL, TOTAL } \\
\text { PHYTOPLANKTON, TOTAL (CELLS/ML) } \\
\text { SEDIMENT, SUSPENDED } \\
\text { SEDIMENT, CLAY-SILT (PERCENT) } \\
\text { COLIFORM, FECAL (COL/IOO ML) } \\
\text { STREPTOCOCCI, FECAL (COL/IOO ML) } \\
\text { SILICA, DISSOLVED } \\
\text { CALCIUM, DISSOLVED } \\
\text { MAGNESIUM, DISSOLVED } \\
\text { SODIUM, DLSSOLVED } \\
\text { POTASSIUM, DISSOLVED } \\
\text { BICARBONATE, ION } \\
\text { CARBONATE, ION } \\
\text { SULFATE, DISSOLVED } \\
\text { CHLORIDE, DISSOLVED } \\
\text { DISSOLVED SOLIDS, SUM OF CONST } \\
\text { DISSOLVED SOLIDS, ROE I8O DEG C } \\
\text { HARDNESS, TOTAL } \\
\text { HARDNESS, NONCARBONATE } \\
\text { TURBIDITY (JTU) } \\
\text { FLOURIDE, DISSOLVED }\end{array}$ \\
\hline
\end{tabular}

SAMPLE

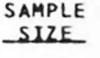

\begin{tabular}{rrr}
$\begin{array}{rrr}\text { SAMPLE } \\
\text { SIZE }\end{array}$ & MEAN & \multicolumn{1}{r}{$\begin{array}{r}\text { STANDARD } \\
\text { DEYIAIION }\end{array}$} \\
12 & 17.25 & 7.65 \\
12 & 8178.3 & 3836.9 \\
13 & 20.1 & 37.1 \\
12 & 8.39 & 0.52 \\
12 & 1.096 & 0.913 \\
12 & 0.914 & 1.217 \\
12 & 1.826 & 0.838 \\
12 & 16466.7 & 26027.6 \\
11 & 367.4 & 1044.0 \\
11 & 85.3 & 25.8 \\
12 & 3525.6 & 11802.2 \\
12 & 6637.5 & 21850.9 \\
12 & 5.53 & 3.62 \\
12 & 255.08 & 113.66 \\
12 & 283.75 & 152.14 \\
12 & 1216.67 & 620.27 \\
12 & 32.50 & 12.04 \\
12 & 180.0 & 74.3 \\
12 & 9.9 & 10.5 \\
12 & 1250.00 & 639.10 \\
12 & 2126.67 & 1101.36 \\
12 & 5271.3 & 2634.3 \\
12 & 5647.5 & 2764.2 \\
12 & 1802.5 & 880.6 \\
12 & 1649.2 & 865.0 \\
12 & 277.9 & 859.1 \\
10 & 0.55 & 0.17 \\
& &
\end{tabular}

0.17
BANGE

5.0
1710

$\begin{array}{rr}2710 & 1330 \\ 2 & 140\end{array}$

$\begin{array}{rrr}7.2 & 9.0 & 12 \\ 0.36 & 3.70 & 12\end{array}$

$\begin{array}{lll}0.36 & 3.70 & 12 \\ 0.01 & 3.70 & 12\end{array}$

0.01

0.91

1300
6

3.70

3.50

92000
3510

3510
100

100
41000

76000

$11.0 \quad 12$

0.7

61.0

$50.0 \quad 530.0$

200.02300 .0

15.0

15.0

106
0

210.0

350.0
945

945
1030

360

270

4
0.2

2100.0

$49.0 \quad 12$

$\begin{array}{rr}30 & 12 \\ 2100.0 & 12\end{array}$

$\begin{array}{ll}2100.0 & 12 \\ 3700.0 & 12\end{array}$

$8930 \quad 12$

$9460 \quad 12$

$\begin{array}{ll}3000 & 12 \\ 2900 & 12\end{array}$

$3000 \quad 12$

0.7

REGRESSIONERESSION SUMMARY

SAMPLE COEFICIENT, CONSTANT, COR

STANDARD
CORRELATION ERROR OF $-\mathrm{R}-\mathrm{B}$ COEEICIENI ESIUMAIE

*Not significant at the 95 percent level.

DAILY SPECIFIC CONDUCTANCE IN

IN

MICROMHOS AT 25 DEG C, THAT HAS

INDICATED PERCENTAGE FOR THE

$\begin{array}{rrrrrr}18 & -58 & 108 & 20 \% & 30 \% & 50 \% \\ 13700 & 12600 & 11700 & 10800 & 10400 & 9810\end{array}$

\section{2}

SAMPLE SIZE $=365$

$$
\begin{array}{r}
0.0001 \\
0.0276 \\
0.0385 \\
0.1610 \\
0.0026 \\
0.006 \\
0.001 \\
0.1646 \\
0.2860 \\
0.685 \\
0.720 \\
0.227 \\
0.222 \\
-0.124
\end{array}
$$

0.0000

70.667
7.5086
0.28667
-0.42067
2.28750
28170.758

$-0.601$

0.792

0.416 *

$0.514 *$
-0.258.

-0.258 .
-0.211 .

28170.758

-0.211 *

5.0469
29.6060

29.0060
-31.2903

$-100.3057$

1.0455

11.0455

132.973
-1.717

$-96.0291$

$-212.6963$

$-330.414$

$-240.645$

-56.725
-170.254

1294.706

0.3409
0.063 *

0.930

0.971

0.996

0.836

0.297 .

0.509 .

0.988

0.997

0.998

0.999

0.991

0.987

-0.555 *

0.639
32.1

0.870

1.095

1.095

26683.2

3.78

43.69

57.24

57.24
6.93

7.93
74.4

9.5

103.13

\begin{tabular}{|c|c|c|c|c|c|c|}
\hline \multirow{2}{*}{ CONSTITUENT } & \multicolumn{3}{|c|}{ TOTAL } & \multicolumn{3}{|c|}{ DISSOLVED } \\
\hline & $\begin{array}{l}\text { NO. } \\
\text { SAMPLES }\end{array}$ & $\begin{array}{l}\text { MIN IMUM } \\
\text { CONC. }\end{array}$ & $\begin{array}{l}\text { MAXIMUM } \\
\text { CONC. }\end{array}$ & $\begin{array}{l}\text { NO. } \\
\text { SAMPLES }\end{array}$ & $\begin{array}{l}\text { MINIMUM } \\
\text { CONC. }\end{array}$ & $\begin{array}{l}\text { MAXIMUM } \\
\text { CONC. }\end{array}$ \\
\hline \multicolumn{7}{|l|}{ MINOR ELEMENTS: } \\
\hline ARSENIC (AS), UG/L & 4 & 3 & 10 & 4 & 2 & 11 \\
\hline CADMIUM $(C D), U G / L$ & 4 & $<10$ & 20 & 4 & 0 & 1 \\
\hline CHROMIUM (CR), UG/L & 4 & 0 & 100 & 4 & 0 & 10 \\
\hline COBALT $(C O)$, UG/L & 4 & $<50$ & 100 & 4 & 0 & 3 \\
\hline COPPER (CU), UG/L & 4 & $<10$ & 70 & 4 & 1 & 4 \\
\hline IRON (FE), UG/L & 4 & 140 & 47000 & 4 & 10 & 80 \\
\hline LEAD $(P B), U G / L$ & 4 & $<100$ & 100 & 4 & 0 & 3 \\
\hline MANGANESE (MN), UG/L & 3 & 70 & 850 & 4 & 20 & 770 \\
\hline MERCURY (HG), UG/L & 4 & 0.0 & 0.4 & 4 & 0.0 & 0.1 \\
\hline SELENIUM (SE), UGAL & 4 & 0 & 1 & 4 & 0 & 1 \\
\hline ZINC $(Z N), U G / L$ & 4 & 20 & 200 & 4 & 10 & 30 \\
\hline \multicolumn{7}{|l|}{ PER IPHYTON: } \\
\hline BIOMASS, DRY WT., G/SO M & 4 & 4.00 & 62.00 & & & \\
\hline BIOMASS, ASH WT., G/SO M & 4 & 2.39 & 58.00 & & & \\
\hline CHLOROPHYLL A, MG/SO M & 4 & 1.8 & 16.0 & & & \\
\hline CHLOROPHYLL B, MG/SO M & 4 & .0 & $4 \cdot 5$ & & & \\
\hline ORGANIC CARBON, MG/L & 3 & 13.0 & 24.0 & & & \\
\hline
\end{tabular}

96.32

189.9

103.3

126.9

147.1

749.3

0.14

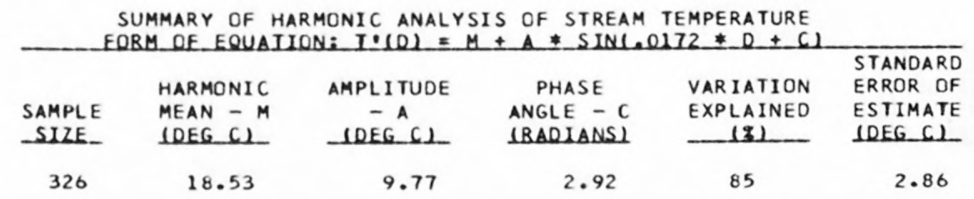

SUMMARY OF MAXIMUM AND MINIMUM CONCENTRATIONS OF CONSTITUENTS SAMPLED AT A FREQUENCY OF QUARTERLY (1975 WY)

08123800 -- BEALS CRK NR WESTBROOK, TX 
LAT 31029M37S LONG 099034M25S

DRAINAGE AREA: 24040 SQ MI ( 62264 SQ KMI

PERIOD OF RECORD: $10 / 01 / 74-09 / 30 / 75$

STATISTICAL SUMMARY OF SELECTED DISSOLVED CHEMICAL CONSTITUENTS AND REGRESSION RELATIONSHIPS OF CONSTITUENT CONCENTRATIONS TO SPECIFIC CONDUCTANCE

CONSIITUENI

\begin{abstract}
CONSIUTUENI IMG L OR UNII SHOWN
\end{abstract}

SAMPLE
SIZE MEAN DENDARD
DEYIALION

TEMPERATURE, WATER (DEG C) SPECIFIC CONDUCTANCE (MICROMHOS) STREAMFLOW (CUBIC FT/SEC)

PH (STANDARD UNITS)

PHOSPHORUS, TOTAL

NITRITE + NITRATE, TOTAL

NITROGEN, KJELDAHL, TOTAL

PHYTOPLANKTON, TOTAL (CELLS/ML)

SEDIMENT, SUSPENDED

SEDIMENT, CLAY-SILT (PERCENT)

COLIFORM, FECAL (COL/100 ML)

STREPTOCOCCI, FECAL (COL/100 ML)

SILICA, DISSOLVED

CALCIUM, DISSOLVED

MAGNESIUM, DISSOLVED

SODIUM, DISSOLVED

POTASSIUM, DISSOLVED

BICARBONATE, ION

CARBONATE, ION

SULFATE, DISSOLVED

CHLORIDE, DISSOLVED

DISSOLVED SOLIDS, SUM OF CONST

DISSOLVED SOLIDS, ROE 180 DEG

HARDNESS, TOTAL

HARDNESS, NONCARBONATE

TURBIDITY (JTU)

FLOURIDE, DISSOLVED

$\begin{array}{rrr}13 & 19.65 & 8.27 \\ 13 & 1399.8 & 406.3 \\ 13 & 729.5 & 1035.2 \\ 13 & 8.01 & 0.15 \\ 12 & 0.080 & 0.054 \\ 12 & 1.959 & 1.366 \\ 12 & 1.043 & 0.407 \\ 12 & 55833.3 & 98726.1 \\ 12 & 119.7 & 166.9 \\ 12 & 96.9 & 1.9 \\ 12 & 138.2 & 207.1 \\ 12 & 350.7 & 432.5 \\ 13 & 11.39 & 5.60 \\ 13 & 97.62 & 21.67 \\ 13 & 42.31 & 14.63 \\ 13 & 125.69 & 44.52 \\ 13 & 5.39 & 0.70 \\ 13 & 193.2 & 46.6 \\ 13 & 0.0 & 0.0 \\ 13 & 182.08 & 81.38 \\ 13 & 245.23 & 91.43 \\ 13 & 806.1 & 244.0 \\ 12 & 842.5 & 276.5 \\ 13 & 416.9 & 109.6 \\ 13 & 259.3 & 111.1 \\ 12 & 51.3 & 31.8 \\ 11 & 0.40 & 0.06\end{array}$

$\begin{array}{rr}5.0 & 30.0 \\ 703 & 2000 \\ 86 & 3650 \\ 7.7 & 8.2 \\ 0.01 & 0.18 \\ 0.50 & 4.20 \\ 0.42 & 1.90 \\ 1500 & 330000 \\ 28 & 525 \\ 93 & 99 \\ 3 & 740 \\ 7 & 1500 \\ 3.9 & 24.0 \\ 60.0 & 130.0 \\ 18.0 & 64.0 \\ 54.0 & 190.0 \\ 4.2 & 7.0 \\ 133 & 249 \\ 0 & 0 \\ 54.0 & 320.0 \\ 90.0 & 390.0 \\ 387 & 1160 \\ 405 & 1260 \\ 220 & 560 \\ 62 & 450 \\ 10 & 120 \\ 0.3 & 0.5\end{array}$

*Not significant at the 95 percent confidence level.

DAILY SPECIFIC CONDUCTANCE IN

MICROMHOS AT 25 DEG C, THAT WAS

UBAIION_IABLE OE DALY SPECIEIC CONDUCIANCE

EQUALLED OR EXCEEDED FOR THE

OF $D$

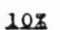

$20 \%$

$30 \%$

2170

$2050 \quad 2010$

1910

$1760 \quad 1540$

\begin{tabular}{ll} 
& \multicolumn{2}{c}{ BEGBESSION SUMMAB } \\
SAMPLESSION & COEFICIENT, CONSTANT, C \\
SIZE & B
\end{tabular}
CORRELATION

13
13
12
12
12
12

$$
-1.428
$$

$-0.00005$

0.00165

0.00006
101.773

7.8548

0.14372

$-0.31839$

0.96394

$-84681.563$

$-0.560$

$0.296^{*}$

$-0.358^{*}$

$0.505^{\star}$

$0.059^{*}$
$0.431^{*}$

$$
\begin{array}{r}
-0.0046 \\
0.0464 \\
0.0355 \\
0.1083 \\
0.0003 \\
-0.004 \\
0.000 \\
0.1957 \\
0.2199 \\
0.599 \\
0.659 \\
0.265 \\
0.264 \\
-0.039 \\
0.0001
\end{array}
$$

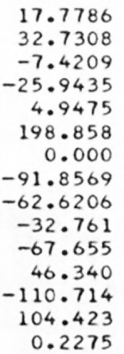

$-0.331^{\star}$

0.869

0.987

0.989

$0.184^{*}$

$-0.035^{*}$

$0.000^{*}$

0.977

\begin{tabular}{|c|c|c|c|c|c|}
\hline & & & & & STANDARD \\
\hline & HARMONIC & AMPLITUDE & PHASE & VARIATION & ERROR OF \\
\hline $\begin{array}{l}\text { SAMPLE } \\
\text { SIZE. }\end{array}$ & $\begin{array}{l}\text { MEAN }-M \\
\text { (DEG } C)^{-}\end{array}$ & $\begin{array}{c}-A \\
(D E G(1)\end{array}$ & $\begin{array}{l}\text { ANGLE - C } \\
\text { (BADLANS) }\end{array}$ & $\begin{array}{l}\text { EXPLA INED } \\
(z)\end{array}$ & $\begin{array}{l}\text { ESTIMATE } \\
(D E G \quad C)\end{array}$ \\
\hline 301 & 19.11 & 9.80 & 2.83 & 88 & 2.60 \\
\hline
\end{tabular}

0.977

0.998

0.997

0.981

\begin{tabular}{|c|c|c|c|c|c|c|}
\hline \multirow{2}{*}{ CONSTITUENT } & \multicolumn{3}{|c|}{ TOTAL } & \multicolumn{3}{|c|}{ DISSOLVED } \\
\hline & $\begin{array}{l}\text { NO. } \\
\text { SAMPLES }\end{array}$ & $\begin{array}{l}\text { MINIMUM } \\
\text { CONC. }\end{array}$ & $\begin{array}{l}\text { MAXIMUM } \\
\text { CONC. }\end{array}$ & $\begin{array}{l}\text { NO. } \\
\text { SAMPLES }\end{array}$ & $\begin{array}{l}\text { MINIMUM } \\
\text { CONC. }\end{array}$ & $\begin{array}{l}\text { MAXIMUM } \\
\text { CONC. }\end{array}$ \\
\hline \multicolumn{7}{|l|}{ MINOR ELEMENTS: } \\
\hline ARSENIC (AS), UG/L & 4 & 2 & 6 & 4 & 1 & 5 \\
\hline CADMIUM $(C D), U G / L$ & 4 & $<10$ & 10 & 4 & 0 & 0 \\
\hline CHROMIUM (CR), UG/L & 4 & 0 & 20 & 4 & 0 & 0 \\
\hline COBALT $(C O), U G / L$ & 4 & $<50$ & $<50$ & 4 & 0 & 2 \\
\hline COPPER $(C U), U G / L$ & 4 & $<10$ & 10 & 4 & 1 & 2 \\
\hline IRON $(F E), U G / L$ & 4 & 670 & 1600 & 4 & 0 & 50 \\
\hline LEAD $(P B), U G / L$ & 4 & $<100$ & $<100$ & 4 & 0 & 3 \\
\hline MANG ANESE $(M N), U G / L$ & 3 & 50 & 100 & 4 & 0 & 0 \\
\hline MERCURY $(H G), U G / L$ & 4 & 0.0 & 0.0 & 4 & 0.0 & 0.0 \\
\hline SELENIUM (SE), UG/L & 4 & 1 & 2 & 4 & 0 & 1 \\
\hline ZINC $(Z N), U G / L$ & 4 & 30 & 210 & 4 & 0 & 30 \\
\hline \multicolumn{7}{|l|}{ PERIPHYTON: } \\
\hline GIOMASS, DRY WT., G/SQ M & 4 & 40.00 & 82.00 & & & \\
\hline BIOMASS, ASH WT., G/SQ M & 4 & 36.00 & 77.00 & & & \\
\hline CHLOROPHYLL A, MG/SQ M & 4 & 2.2 & 33.0 & & & \\
\hline CHLOROPHYLL E, MG/SQ M & 4 & 1.5 & 3.3 & & & \\
\hline ORGANIC CARBON, MG/L & 4 & 5.7 & 11.0 & & & \\
\hline
\end{tabular}

0.967

$-0.506^{*}$

0.694
ST ANDARO

ESIIMAI

SAMPLE SIZE $\equiv 364$

$20 \% 25 \% 29 \%$

$875 \quad 700-585$

SUMMARY OF HARMONIC ANALYSIS OF STREAM TEMPERATURE

SUMMARY OF MAXIMUM AND MINIMUM CONCENTRATIONS OF CONSTITUENTS

SAMPLED AT A FREQUENCY OF QUARTERLY (1975 WY)

08136700 - COLORADO RIVER NEAR STACY, TEX. 
Table 14.--Summary of measurement at each station--Continued

LAT 30D14M4OS LONG 097041M39S

DRAINAGE AREA: 38400 SQ MI 199456 SQ KMI

PERIOD OF RECORD: $10 / 01 / 74-09 / 30 / 75$

STATISTICAL SUMMARY OF SELECTED DISSOLVED CHEMICAL CONSTITUENTS ANU

REGRESSION RELATIONSHIPS OF CONSTITUENT CONCENTRATIONS TO SPECIFIC CONDUCTANCE

CONSILIUENI

CONSTUUEENT IMGLL OR UNII SHOWNI

\begin{tabular}{|c|}
\hline $\begin{array}{l}\text { TEMPERATURE, WATER (DEG C) } \\
\text { SPECIFIC CONOUCTANCE (MICROMHOS) } \\
\text { STREAMFLOW (CUBIC FT/SEC) } \\
\text { PH (STANDARD UNITS) } \\
\text { PHOSPHORUS, TOTAL } \\
\text { NITRITE + NITRATE, IOTAL } \\
\text { NITROGEN, KJELDAHL, TOTAL } \\
\text { PHYTOPLANKTON, TOTAL (CELLS/ML) } \\
\text { SEDIMENT, SUSPENDED } \\
\text { SEDIMENT, CLAY-SILT (PERCENT) } \\
\text { COLIFORM, FECAL (CUL/IOO ML) } \\
\text { STREPIOCOCCI, FECAL (COL/IOO ML) } \\
\text { SILICA, DISSOLVED } \\
\text { CALCIUM, DISSOLVED } \\
\text { MAGNESIUM, OISSOLVED } \\
\text { SODIUM, DISSOLVED } \\
\text { POTASSIUM, DISSOLVED } \\
\text { BICARBONATE, ION } \\
\text { CARBONATE, ION } \\
\text { SULFATE, DISSOLVED } \\
\text { CHLORIDE, OISSOLVED } \\
\text { DISSOLVED SOLIDS, SUM OF CONST } \\
\text { DISSOLVED SOLIDS, ROE I8O DEG C } \\
\text { HARDNESS, TUTAL } \\
\text { HARDNESS, NONCARBONATE } \\
\text { TURBIDITY IJTU) } \\
\text { FLOURIDE, DISSOLVED }\end{array}$ \\
\hline
\end{tabular}

STANDARD

SAMPLE

SIZE

\begin{tabular}{rr} 
MEAN & \multicolumn{1}{r}{ STANOARD } \\
DEYIAIION \\
19.83 & 5.42 \\
489.2 & 26.3 \\
4536.1 & 1736.6 \\
7.53 & 0.20 \\
0.027 & 0.021 \\
0.310 & 0.076 \\
0.463 & 0.186 \\
1214.5 & 1502.7 \\
15.8 & 17.2 \\
75.4 & 23.7 \\
210.8 & 272.5 \\
261.3 & 558.4 \\
8.94 & 0.94 \\
45.67 & 3.50 \\
17.83 & 1.53 \\
24.75 & 1.91 \\
3.57 & 0.48 \\
186.5 & 10.9 \\
0.0 & 0.0 \\
30.08 & 2.75 \\
44.50 & 3.21 \\
267.7 & 16.1 \\
273.1 & 15.1 \\
187.5 & 13.6 \\
35.0 & 7.1 \\
7.4 & 5.4 \\
0.23 & 0.05
\end{tabular}

$\begin{array}{rr}\text { BANGE } & \\ & \\ 13.5 & \\ 437 & 29.0 \\ 205 & 531 \\ 7.2 & 6420 \\ 0.01 & 7.8 \\ 0.14 & 0.08 \\ 0.23 & 0.38 \\ 100 & 4900 \\ 0 & 63 \\ 9 & 91 \\ 27 & 760 \\ 15 & 2000 \\ 7.9 & 11.0 \\ 40.0 & 50.0 \\ 15.0 & 21.0 \\ 21.0 & 28.0 \\ 3.0 & 4.8 \\ 167 & 204 \\ 0 & 0 \\ 25.0 & 35.0 \\ 37.0 & 49.0 \\ 233 & 289 \\ 245 & 292 \\ 160 & 210 \\ 23 & 45 \\ 2 & 20 \\ 0.2 & 0.3 \\ & \\ & \\ 23 & \end{array}$

\begin{tabular}{r} 
\\
SAMPLE \\
S1ZE \\
\hline \\
\\
12 \\
12 \\
12 \\
9 \\
12 \\
11 \\
\\
\\
12 \\
12 \\
12 \\
12 \\
12 \\
12 \\
12 \\
12 \\
12 \\
12 \\
12 \\
12 \\
12 \\
12 \\
10
\end{tabular}

$$
\begin{aligned}
& \text { REGB } \\
& \text { REGRESSION } \\
& \text { COEFICIENT, }
\end{aligned}
$$

REGRESSION SUMMABY

constant, correlation

STANDARD

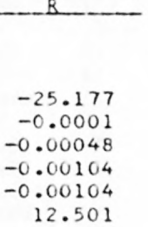

$-B$

COEEICIENI

ERROR OF

ESILMAIE

*Not significant at the 95 percent confidence level.

DAILY SPECIFIC CONDUCTANCE IN

DUBAILN_IABLE_OE_DAILYSPECIEIC_CONDUCIANCE

MICRCMHOS AT 25 DEG C, THAT WAS

EQUALLED OR EXCEEDED FOR THE

$\begin{array}{llllll}-16 & -52 & 10 \% & 202 & 302 & 50 \% \\ 554 & 543 & 534 & 523 & 517 & 501\end{array}$

\begin{tabular}{|c|c|}
\hline-0.0056 & \\
\hline $\begin{array}{r}-0.0050 \\
0.1208\end{array}$ & $\begin{array}{r}11 \\
-13\end{array}$ \\
\hline 0.0484 & 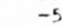 \\
\hline 0.0048 & \\
\hline 0.0026 & \\
\hline 0.398 & \\
\hline 0.000 & \\
\hline 0.0660 & \\
\hline 0.0895 & \\
\hline 0.586 & \\
\hline 0.514 & \\
\hline 0.479 & \\
\hline 0.170 & \\
\hline 0.000 & \\
\hline 0.0004 & \\
\hline LE SII & 3 \\
\hline 25. & 292 \\
\hline 445 & 432 \\
\hline
\end{tabular}

$70 \%$ SAMPLE SDZE_E_ 365

SUMMARY OF HARMONIC ANALYSIS OF STREAM TEMPERATURE

\begin{tabular}{|c|c|c|c|c|c|}
\hline & & & & & STANDARD \\
\hline & HARMONIC & AMPLITUDE & PHASE & VARIATION & ERROR OF \\
\hline SAMPLE & MEAN - $M$ & $-A$ & ANGLE - C & EXPLAINED & ESTIMATE \\
\hline SLZE_ & WDEG_Cl & DEEG (1) & (BADIANSI & $\ldots|z| \ldots$ & DDEG $(1)$ \\
\hline
\end{tabular}
EOBM OE EGUALUON: I $(0)=M+A *$ SIN $.0172 * 0+C)$

269

17.85

6.62

2.37

92

1.35

SUMMARY OF MAXIMUM AND MINIMUM CONCENTRATIONS OF CONSTITUENTS

SAMPLED AT A FREQUENCY OF QUARTERLY (1975 WY)

\begin{tabular}{|c|c|c|c|c|c|c|}
\hline \multirow{2}{*}{ CONSTI TUENT } & \multicolumn{3}{|c|}{ TOTAL } & \multicolumn{3}{|c|}{ DISSOLVED } \\
\hline & $\begin{array}{l}\text { NO. } \\
\text { SAMPLES }\end{array}$ & $\begin{array}{l}\text { MINIMUM } \\
\text { CONC. }\end{array}$ & $\begin{array}{l}\text { MAXIMUM } \\
\text { CONC. }\end{array}$ & $\begin{array}{l}\text { NC. } \\
\text { SAMPLES }\end{array}$ & $\begin{array}{l}\text { MINIMUM } \\
\text { CONC. }\end{array}$ & $\begin{array}{l}\text { MAXIMUM } \\
\text { CONC. }\end{array}$ \\
\hline \multicolumn{7}{|l|}{ MINOR ELEMENTS: } \\
\hline ARSENIC (AS), UG/L & 4 & 0 & 5 & 4 & 1 & 4 \\
\hline CADMIUM $(C D)$, UG $/ L$ & 3 & $<10$ & $<10$ & 4 & 0 & 1 \\
\hline CHROMIUM (CR), UG/L & 3 & 0 & 10 & 4 & 0 & 10 \\
\hline COBALT $(C O)$, UG/L & 3 & $<50$ & $<50$ & 4 & 0 & 1 \\
\hline COPPER (CU), UG/L & 3 & $<10$ & 10 & 4 & 1 & 4 \\
\hline IRON (FE), UG/L & 3 & 110 & 170 & 4 & 0 & 10 \\
\hline LEAD $(P B), U G / L$ & 3 & $<100$ & $<100$ & 4 & 0 & 2 \\
\hline MANG ANESE $(M N), U G / L$ & 3 & 10 & 30 & 4 & 0 & 10 \\
\hline MERCURY $(H G), U G / L$ & 3 & 0.0 & $<0.1$ & 4 & 0.0 & $<0.1$ \\
\hline SELENIUM (SE), UG/L & 4 & 0 & 1 & 4 & 0 & 1 \\
\hline ZINC $(Z N), U G / L$ & 3 & 10 & 20 & 4 & 0 & 10 \\
\hline \multicolumn{7}{|l|}{ PERIPHYTON: } \\
\hline BIOMASS, DRY WT., G/SG M & 3 & 33.00 & 200.00 & & & \\
\hline BIOMASS, ASH WT., G/SQ M & 3 & 24.00 & 87.00 & & & \\
\hline CHLOROPHYLL A, MG/SQ M & 3 & 27.0 & 130.0 & & & \\
\hline CHLOROPHYLL $B$, MG/SQ M & 3 & 2.5 & 29.0 & & & \\
\hline ORGAN IC CARBON, MG/L & 10 & 3.2 & 27.0 & & & \\
\hline
\end{tabular}

08158000 -- COLORADO RIVER AT AUSTIN, TEX. 
LAT 29018M32S LONG 096006M13S

DRAINAGE AREA: 41380 SQ MI ( 107174 SO KM)

PERIOD OF RECORD: $10 / 01 / 74-09 / 30 / 75$

STATISTICAL SUMMARY OF SELECTED DISSOLVED CHEMICAL CONSTITUENTS AND

REGRESSION RELATIONSHIPS OF CONSTITUENT CONCENTRATIONS TO SPECIFIC CONDUCTANCE

CONSIIUEEN

CONSIUUUENI IMG/L OR UNII SHOWNI

\begin{tabular}{|c|}
\hline $\begin{array}{l}\text { TEMPERATURE, WATER (DEG C) } \\
\text { SPECIFIC CONOUCTANCE (MICROMHOS) } \\
\text { STREAMFLOW (CUBIC FT/SEC) } \\
\text { PH (STANDARD UNITS) } \\
\text { PHOSPHORUS, TOTAL, } \\
\text { NITRITE + NITRATE, TOTAL } \\
\text { NITROGEN, KJELDAHL, TOTAL } \\
\text { PHYTOPLANKTON, TOTAL (CELLS/ML) } \\
\text { SEDIMENT, SUSPENDED } \\
\text { SEDIMENT, CLAY-SILT (PERCENT) } \\
\text { COLIFORM, FECAL (COL/IOO ML) } \\
\text { STREPTOCOCCI, FECAL (COL/IOO ML) } \\
\text { SILICA, DISSOLVED } \\
\text { CALCIUM, DISSOLVED } \\
\text { MAGNESIUM, DISSOLVEO } \\
\text { SOUIUM, DISSOLVED } \\
\text { POTASSIUM, DISSOLVED } \\
\text { BICARBONATE, ION } \\
\text { CARBONATE, ION } \\
\text { SULFATE, DISSOLVED } \\
\text { CHLORIDE, DISSOLVED } \\
\text { OISSOLVED SOLIDS, SUM OF CONST } \\
\text { DISSOLVED SOLIDS, ROE I8O DEG C } \\
\text { HARUNESS, TOTAL } \\
\text { HARDNESS, NONCARBCNATE } \\
\text { TURBIDITY (JTU) } \\
\text { FLOURIDE, DISSOLVED }\end{array}$ \\
\hline
\end{tabular}

SAMPLE

SIZE MEAN DEYIALION

12
12
13
12
12
11
12
12
12
12
12
12
12
12
12
12
12
12
12
12
12
12
11
12
12
12
10

$\begin{array}{rr}21.17 & 6.28 \\ 521.0 & 47.0 \\ 4868.5 & 2436.3 \\ 7.25 & 0.52 \\ 0.172 & 0.080 \\ 0.519 & 0.166 \\ 0.541 & 0.202 \\ 1072.9 & 1028.6 \\ 217.2 & 148.3 \\ 70.7 & 25.7 \\ 391.7 & 702.8 \\ 418.2 & 947.0 \\ 10.13 & 1.89 \\ 51.75 & 4.63 \\ 16.83 & 2.08 \\ 26.67 & 2.99 \\ 3.72 & 0.22 \\ 196.2 & 17.1 \\ 0.0 & 0.0 \\ 33.75 & 4.07 \\ 44.25 & 4.31 \\ 284.3 & 24.3 \\ 290.9 & 21.2 \\ 198.3 & 17.5 \\ 37.8 & 7.1 \\ 60.0 & 20.6 \\ 0.26 & 0.05\end{array}$

60.0

0.05

REGRESSI

SAMPLE COEFICIENT,

SION SUMMABY

$12.5 \quad 29.5$

$\begin{array}{rr}433 & 575 \\ 1600 & 10500\end{array}$

$\begin{array}{rrr}4600 & 10500 & 12 \\ 0.3 & 8.0 & 12\end{array}$

$0.06 \quad 0.32$

0.25

0.78

$0.85 \quad 11$

0.12

3400

630
98

$\begin{array}{rr}22 & 98 \\ 100 & 2000\end{array}$

$\begin{array}{rr}32 & 3400 \\ 7.8 & 15.0\end{array}$

$\begin{array}{rl}42.0 & 15.0 \\ 13.0 & 27.0\end{array}$

$13.0 \quad 20.0$

$21.0 \quad 30.0$

159

4.1

$\begin{array}{rr}0 & 0 \\ 25.0 & 38.0\end{array}$

36.0

49.0

248

160

27

0.2

*Not significant at the 95 percent confidence level.

QURALION_IABLE_OE_DALY SPECIEIC CONOUCIANCE
DAILY SPECIFIC CONDUCTANCE IN
MICROMHOS AT 25 OEG C THAT WAS

SUMMARY OF HARMONIC ANALYSIS OF STREAM TEMPERATURE

FORM OF EOUAIION: $I \cdot 10)=M+A *$ SINI.0172*0+C

\begin{tabular}{|c|c|c|c|c|c|}
\hline & & & & & $\begin{array}{l}\text { STANDARD } \\
\text { ERROR OF }\end{array}$ \\
\hline SAMPLE & $\begin{array}{l}\text { HARMONIC } \\
\text { MEAN - M }\end{array}$ & $\begin{array}{c}\text { AMPLITUDE } \\
-\quad-A\end{array}$ & $\begin{array}{l}\text { PHASE } \\
\text { ANGLE - C }\end{array}$ & $\begin{array}{l}\text { VAR IATION } \\
\text { EXPLAINED }\end{array}$ & $\begin{array}{l}\text { ERROR } \\
\text { ESTIMA }\end{array}$ \\
\hline SLZE & $10 E G \mathrm{Cl}$ & (DEG $C)$ & $(B A D I A N S)$ & $(z)$ & IDEG $C)$ \\
\hline 353 & 21.03 & 7.80 & 2.80 & 87 & 2.12 \\
\hline
\end{tabular}

SUMMARY OF MAXIMUM AND MINIMUM CONCENTRATIONS OF CONSTITUENTS SAMPLED AT A FREQUENCY OF QUARTERLY (1975 WY)

08162000 -- COLORADO RIVER AT WHARTON, TEX.

\begin{tabular}{|c|c|c|c|c|c|c|}
\hline \multirow{2}{*}{ CONSTITUENT } & \multicolumn{3}{|c|}{ TOTAL } & \multicolumn{3}{|c|}{ DISSOLVED } \\
\hline & $\begin{array}{l}\text { NO. } \\
\text { SAMPLES }\end{array}$ & $\begin{array}{l}\text { MIN IMUM } \\
\text { CONC. }\end{array}$ & $\begin{array}{l}\text { MAXIMUM } \\
\text { CONC. }\end{array}$ & $\begin{array}{l}\text { NO. } \\
\text { SAMPLES }\end{array}$ & $\begin{array}{l}\text { MINIMUM } \\
\text { CONC. }\end{array}$ & $\begin{array}{l}\text { MAXIMUM } \\
\text { CONC. }\end{array}$ \\
\hline \multicolumn{7}{|l|}{ MINOR ELEMENTS: } \\
\hline ARSENIC (AS), UG/L & 4 & 1 & 3 & 4 & 1 & 2 \\
\hline CADMIUM $(C D)$, UG/L & 4 & $<10$ & 10 & 4 & 0 & 0 \\
\hline CHROMIUM (CR), UG/L & 4 & $<10$ & 20 & 4 & 0 & $<10$ \\
\hline COBALT $(C O), U G / L$ & 4 & $<50$ & $<50$ & 4 & 0 & 4 \\
\hline COPPER (CU), UG/L & 4 & $<10$ & 10 & 4 & 1 & 2 \\
\hline IRON (FE), UG/L & 4 & 3100 & 5700 & 4 & 10 & 30 \\
\hline LEAD $(P B), U G / L$ & 4 & $<100$ & $<100$ & 4 & 1 & 5 \\
\hline MANGANESE (MN), UG/L & 4 & 70 & 210 & 4 & 0 & 0 \\
\hline MERCURY $(H G), U G / L$ & 4 & 0.0 & 0.2 & 4 & 0.0 & 0.2 \\
\hline SELENIUM (SE), UG/L & 3 & 0 & 1 & 3 & 0 & 1 \\
\hline ZINC $(Z N), U G / L$ & 4 & 30 & 60 & 4 & 0 & 110 \\
\hline \multicolumn{7}{|l|}{ PERIPHYTON: } \\
\hline BIOMASS, DRY WT., G/SQ M & 4 & 2.3 & 13.00 & & & \\
\hline BIOMASS, ASH WT., G/SO M & 4 & .79 & 12.00 & & & \\
\hline CHLOROPHYLL A, MG/SO M & 4 & .0 & 1.2 & & & \\
\hline CHLOROPHYLL B, MG/SO M & 4 & .0 & .1 & & & \\
\hline ORGANIC CARBON, MG/L & 10 & 4.0 & 13.0 & & & \\
\hline
\end{tabular}


LAT 29001M32S LONG 096033M08S DRAINAGE AREA: 1063 SQ MI 12753 SO KM)

PERIOD OF RECORD: $10 / 01 / 74-09 / 30 / 75$

STATISTICAL SUMMARY OF SELECTED DISSOLVED CHEMICAL CONSTITUENTS AND

REGRESSION RELATIONSHIPS OF CONSTITUENT CONCENTRATIONS TO SPECIFIC CONDUCTANCE

CONSIIIUENT

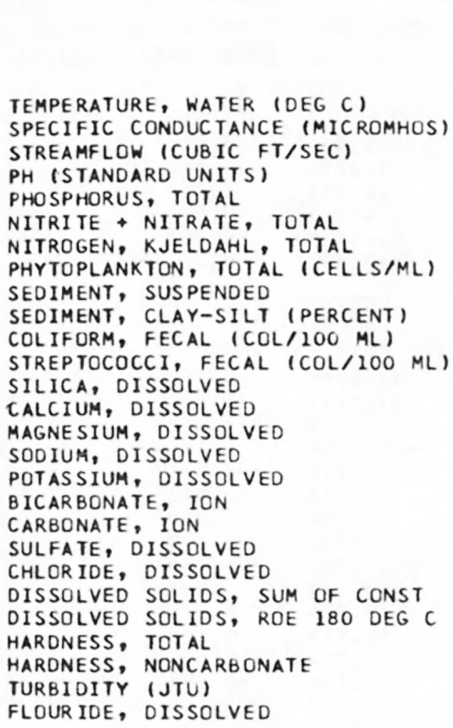

CONSUUUENI IMG $O$ OB UNL SHOWNL

\begin{tabular}{|c|c|c|c|c|c|}
\hline $\begin{array}{l}\text { SAMPLE } \\
\text { SLZE }\end{array}$ & MEAN & $\begin{array}{l}\text { STANDARD } \\
\text { DEYIAIION }\end{array}$ & \multicolumn{2}{|c|}{ BANGE } & $\begin{array}{l}\text { SAMP } \\
\text { SIZ }\end{array}$ \\
\hline 12 & 22.17 & 5.79 & 12.5 & 30.5 & \\
\hline 12 & 559.5 & 226.1 & 144 & 801 & \\
\hline 12 & 426.8 & 540.0 & 98 & 1980 & 12 \\
\hline 12 & 7.76 & 0.35 & 7.0 & 8.0 & 1 \\
\hline 12 & 0.108 & 0.041 & 0.06 & 0.18 & 12 \\
\hline 12 & 0.232 & 0.169 & 0.05 & 0.58 & 12 \\
\hline 12 & 0.770 & 0.321 & 0.38 & 1.30 & 12 \\
\hline 11 & 2894.5 & 3019.1 & 560 & 8800 & 1 \\
\hline 12 & 97.0 & 85.0 & 15 & 255 & \\
\hline 12 & 82.0 & 16.9 & 56 & 100 & \\
\hline 12 & 954.3 & 2293.0 & 31 & 8200 & \\
\hline 12 & 1439.4 & 2753.8 & 63 & 10000 & \\
\hline 12 & 20.84 & 6.11 & 8.1 & 30.0 & 1 \\
\hline 12 & 71.08 & 35.62 & 14.0 & 110.0 & \\
\hline 12 & 5.95 & 2.07 & 2.2 & 11.0 & \\
\hline 12 & 40.83 & 15.44 & 11.0 & 58.0 & 12 \\
\hline 12 & 3.50 & 1.05 & 2.1 & 5.4 & 1 \\
\hline 12 & 236.6 & 106.6 & 51 & 340 & \\
\hline 12 & 0.0 & 0.0 & 0 & 0 & \\
\hline 12 & 15.57 & 5.72 & 6.8 & 25.0 & \\
\hline 12 & 57.25 & 21.15 & 17.0 & 82.0 & \\
\hline 12 & 332.3 & 130.6 & 88 & 473 & 1 \\
\hline 11 & 341.6 & 126.4 & 124 & 467 & 1 \\
\hline 12 & 201.5 & 89.4 & 44 & 300 & 1 \\
\hline 12 & 8.8 & 8.1 & 0 & 25 & 1 \\
\hline 12 & 31.2 & 45.4 & 3 & 170 & 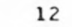 \\
\hline 10 & 0.31 & 0.09 & 0.1 & 0.4 & 1 \\
\hline
\end{tabular}

REGRESSION BEGRSSION SUMMARY

SAMPLE COEFICIENT, CONSTANT, CORRELATION STANDARD B B B B COEEICIENI ESIIMAIE

*Not significant at the 95 percent confidence level.

DURAIION IABLE OE DAILY SPECIEIC CONDUCIANCE

DAILY SPECIFIC CONDUCTANCE IN

MICROMHOS AT 25 DEG C, THAT WAS

EQUALLED OR EXCEEDED FOR THE

$\begin{array}{llllll}18 & 58 & 208 & 208 & 308 & 508\end{array}$

508702

702

$$
\begin{array}{r}
-1.868 \\
0.0015 \\
-0.00014 \\
0.00049 \\
-0.00112 \\
3.778
\end{array}
$$

$-0.782$

0.959

$-0.799$

0.658

-0.792
0.242

353.0

0.18910

$-0.04279$

638.171

3087.8

INDICATED PERCENTAGE OF TIME

$\begin{array}{llll}830 \quad 778 & 752 \quad 678\end{array}$

637

0.0158
0.1543
0.0018
0.0651
-0.0020
0.465
0.000
0.0233
0.0881
0.577
0.534
0.392
0.013
-0.150
0.0004

11.9865
-15.2464
4.9685
4.4006
4.0250
-23.558
0.000
2.5192
7.9808
9.569
46.881
-17.570
1.460
115.044
0.0815

0.585

0.979

0.192

0.953

$-0.431$.

0.986

0.921

0.941
0.999

0.999

0.991

0.369

\begin{tabular}{|c|c|c|c|c|c|}
\hline & & & & & STANDARD \\
\hline & HARMONIC & AMPLITUDE & PHASE & VAR IATION & ERROR OF \\
\hline SAMPLE & MEAN - M & $-A$ & ANGLE - C & EXPLAINED & ESTIMATE \\
\hline SIZE & DEEG C) & (DEG C) & (RADIANSI & $-(\xi)-$ & $1 D E G \quad C 1$ \\
\hline 243 & 20.18 & 7.53 & 2.93 & 76 & 2.84 \\
\hline
\end{tabular}

-0.746
0.900

5.20
7.53
2.13
4.89
1.00
18.7
0.0
2.34
7.49
5.9
13.4
12.7
7.9
31.7
0.04

SUMMARY OF HARMONIC ANALYSIS OF STREAM TEMPERATURE

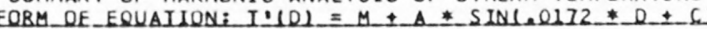

\begin{tabular}{|c|c|c|c|c|c|c|}
\hline \multirow{2}{*}{ CONSTI TUENT } & \multicolumn{3}{|c|}{ TOTAL } & \multicolumn{3}{|c|}{ DISSOLVED } \\
\hline & $\begin{array}{l}\text { NO. } \\
\text { SAMPLES }\end{array}$ & $\begin{array}{l}\text { MINIMUM } \\
\text { CONC. }\end{array}$ & $\begin{array}{l}\text { MAXIMUM } \\
\text { CONC. }\end{array}$ & $\begin{array}{l}\text { NO. } \\
\text { SAMPLES }\end{array}$ & $\begin{array}{l}\text { MINIMUM } \\
\text { CONC. }\end{array}$ & $\begin{array}{l}\text { MAXIMUM } \\
\text { CONC. }\end{array}$ \\
\hline \multicolumn{7}{|l|}{ MINOR ELEMENTS: } \\
\hline ARSENIC (AS), UG/L & 4 & 2 & 8 & $4^{\circ}$ & 1 & 7 \\
\hline CADMIUM $(C D), U G / L$ & 4 & $<10$ & 10 & 4 & 0 & 0 \\
\hline CHROMIUM (CR), UG/L & 4 & 0 & 30 & 4 & 0 & 10 \\
\hline COBALT $(C O), U G / L$ & 4 & $<50$ & 50 & 4 & 0 & 2 \\
\hline COPPER $(C U), U G / L$ & 4 & $<10$ & 10 & 4 & 0 & 1 \\
\hline IRON (FE), UG/L & 4 & 0 & 1000 & 4 & 0 & 470 \\
\hline LEAD $(P B), U G / L$ & 4 & $<100$ & $<100$ & 4 & 0 & 1 \\
\hline MANGANESE (MN), UG/L & 4 & 50 & 100 & 4 & 0 & 20 \\
\hline MERC URY $(H G), U G / L$ & 4 & 0.0 & 0.5 & 4 & 0.0 & 0.1 \\
\hline SELENIUM (SE), UG/L & 4 & 0 & 1 & 4 & 0 & 1 \\
\hline ZINC $(Z N), U G / L$ & 4 & 0 & 30 & 4 & 0 & 10 \\
\hline \multicolumn{7}{|l|}{ PERIPHYTON: } \\
\hline BIOMASS, DRY WT., G/SO M & 0 & & & & & \\
\hline BIOMASS, ASH WT., G/SQ M & 0 & & & & & \\
\hline CHLOROPHYLL A, MG/SO M & 0 & & & & & \\
\hline CHLOROPHYLL B, MG/SQ M & 0 & & & & & \\
\hline ORGANIC CARBON, MG/L & 12 & 4.5 & 21.0 & & & \\
\hline
\end{tabular}

SUMMARY OF MAXIMUM AND MINIMUM CONCENTRATIONS OF CONSTITUENTS SAMPLED AT A FREQUENCY OF QUARTERLY (1975 WY)

08164500 - NAVIDAD RIVER NR GANADO, TEX. 
Table 14.--Summary of measurement at each station--Continued

LAT 28D47M34S LONG 097000M46S

DRAINAGE AREA: 5198 SQ MI 113463 SQ KMI

PERIOD OF RECORD: $10 / 01 / 74-09 / 30 / 75$

STATISTICAL SUMMARY OF SELECTED DISSOLVED CHEMICAL CONSTITUENTS AND

REGRESSION RELATIONSHIPS OF CONSTITUENT CONCENTRATIONS TO SPECIFIC CONDUCTANCE

CONSIIIUENI

CONSIIIUENI IMG/L OR UNII SHOWN

SAMPLE

SIZE

TEMPERATURE, WATER IDEG C)

SPECIFIC CUNDUCTANCE (MICROMHOS)

STREAMFLOW (CUBIC FT/SEC)

PH ISTANDARD UNITS

PHOSPHORUS, TOTAL

NITRITE + NITRATE, TOTAL

NITROGEN, KJELDAHL, TOTAL

PHYTOPLANKTON, TOTAL (CELLS/ML)

SEDIMENT, SUSPENDED

SEDIMENT, CLAY-SILT (PERCENT)

COLIFORM, FECAL (COL/16O ML)

STREPTOCOCCI, FECAL ( $\mathrm{COL} / 100 \mathrm{ML})$

SILICA, DISSOLVED

CALCIUM, DISSOLVED

MAGNESIUM, DISSOLVED

SODIUM, DISSOLVED

POTASSIUM, DISSOLVED

BICARBONATE, ION

CARBONATE, ION

SULFATE, DISSOLVED

SULFATE, DISSOLVED

CHLORIDE, DISSOLVED

DISSOLVED SOLIDS, ROE 180 DEG

DISSOLVED SOLIDS,
HARDNESS, TOTAL

HARDNESS, NONCARBONATE

TURBIDITY (JTU)

FLOURIDE, DIS SOLVED
STANDARD

MEAN DEYIAIION

22.88

529.8

2839.2

7.83

0.082

0.976

0.445

340.3

224.0

85.9

1593.0

916.0

11.81
68.42

15.83

23.17
2.57

2.57
255.0

255.0
0.0

29.08

33.17

310.3

313.3

236.7

27.2

37.3
0.24

5.20

5.20
56.4

1555.7

0.10
0.043

0.228

0.080

224.7

225.9

13.3

2772.0

2915.3

1.24
6.11

6.11
1.47

4.75
0.32

0.32

21.2

0.0
3.48

3.48
6.35

0.35
29.2

28.1

28.1
17.2

6.3

25.1

0.05

${ }^{*}$ Not significant at the 95 percent confidence level.

REGRESSION

SAMPL

COEFICIENT,

B........

CONSTANT,

CORRELATION STANDARO

BANGE

30.0

$\begin{array}{rr}14.0 & 30.0 \\ 422 & 598\end{array}$

$1230 \quad 6200 \quad 12$

$\begin{array}{ll}7.7 & 8.0 \\ 0.02 & 0.16\end{array}$

$0.72 \quad 1.50$

0.30

0.59

$810 \quad 12$

-19.033
-0.0001

$-0.00022$

0.00261

0.00001

12923.668

7.8774
0.19991

0.19991

$-0.42782$

0.44105

$-112.534$

$-0.048 *$

$-0.292$

0.588

0.005 *

$0.215 *$

1180.1

0.043

0.197

0.08

602
99

8400
8800

8800
13.0

13.0
77.0

77.0
18.0

29.0

282

0

36.0
44.0

44.0
348

348

260
34

34
75
0.3

DURAIION IABLE OE DAILY SPECIEIC CONDUCIANCE

DAILY SPECIFIC CONDUCTANCE IN MICROMHOS AT 25 DEG C THAT WAS

EQUALLED OR EXCEEDED FOR THE

$\begin{array}{llllll}19 & -59 & 10 \% & 20 \% & 30 \% & 5 \\ 671 & 619 & 603 & 580 & 570 & 5\end{array}$

$50 \% 70$

INDICATED PERCENTAGE OF TIME

SUMMARY OF HARMONIC ANALYSIS OF STREAM TEMPERATURE

\begin{tabular}{|c|c|c|c|c|c|}
\hline & & & & & STANDARD \\
\hline & HARMONIC & AMPLITUDE & PHASE & VAR IATION & ERROR OF \\
\hline SAMPLE & MEAN - M & $-A$ & ANGLE $-C$ & EXPLAINED & ESTIMATE \\
\hline SIZE & $10 E G(1)$ & (DEG $C)$ & (BADLANSI) & $-1 \xi 1$ & IDEG_CL \\
\hline 350 & 20.94 & 7.29 & 2.82 & 89 & 1.86 \\
\hline
\end{tabular}

SUMMARY OF MAXIMUM AND MINIMUM CONCENTRATIONS OF CONSTITUENTS

SAMPLED AT A FREQUENCY OF QUARTERLY (1975 WY)

08176500 -- GUADALUPE RIVER AT VICTORIA, TEX.

\begin{tabular}{|c|c|c|c|c|c|c|}
\hline \multirow{2}{*}{ CONSTI TUENT } & \multicolumn{3}{|c|}{ TOTAL } & \multicolumn{3}{|c|}{ DISSOLVED } \\
\hline & $\begin{array}{l}\text { NO. } \\
\text { SAMPLES }\end{array}$ & $\begin{array}{l}\text { MIN IMUM } \\
\text { CONC. }\end{array}$ & $\begin{array}{l}\text { MAXIMUM } \\
\text { CONC. }\end{array}$ & $\begin{array}{l}\text { NC. } \\
\text { SAMPLES }\end{array}$ & $\begin{array}{l}\text { MINIMUM } \\
\text { CONC. }\end{array}$ & $\begin{array}{l}\text { MAXIMUM } \\
\text { CONC. }\end{array}$ \\
\hline \multicolumn{7}{|l|}{ MINOR ELEMENTS: } \\
\hline ARSENIC (AS), UG/L & 4 & 0 & 4 & 4 & 0 & 2 \\
\hline CADMIUM $(C D), U G / L$ & 4 & $<10$ & $<10$ & 4 & 0 & 0 \\
\hline CHROMIUM (CR), UG/L & 4 & 0 & 20 & 4 & 0 & 10 \\
\hline COBALT $(C O), U G / L$ & 4 & $<50$ & 50 & 4 & 0 & 3 \\
\hline COPPER (CU), UGIL & 4 & 10 & $<10$ & 4 & 1 & 1 \\
\hline IRON $(F E), U G / L$ & 4 & 0 & 3700 & 4 & 0 & 710 \\
\hline LEAD $(P B), U G / L$ & 4 & $<100$ & $<100$ & 4 & 0 & 0 \\
\hline MANGANESE $(M N), U G / L$ & 4 & 10 & 100 & 4 & 0 & 0 \\
\hline MERCURY (HG), UG/L & 4 & 0.0 & 1.2 & 4 & 0.0 & 0.2 \\
\hline SELENIUM (SE), UG/L & 4 & 0 & 1 & 4 & 0 & 1 \\
\hline$Z I N C(Z N), U G / L$ & 4 & 0 & 30 & 4 & 0 & 10 \\
\hline \multicolumn{7}{|l|}{ PERIPHYTON: } \\
\hline BIOMASS, DRY WT., G/SQ M & 0 & & & & & \\
\hline BIOMASS, ASH WT., G/SQ M & 0 & & & & & \\
\hline CHLOROPHYLL A, MG/SO M & 0 & & & & & \\
\hline CHLOROPHYLL B, MG/SO M & 0 & & & & & \\
\hline ORGANIC CARBON, MGIL & 4 & 3.0 & 5.0 & & & \\
\hline
\end{tabular}


Table 14.--Summary of measurement at each station--Continued

LAT 28D38M58S LONG 097023M04S

DRAINAGE AREA: 3921 SO MI I 10155 SQ KMI

PERIOD OF RECORD: $10 / 01 / 74-09 / 30 / 75$

STATISTICAL SUMMARY OF SELECTED DISSOLVED CHEMICAL CONSTITUENTS AND

REGRESSION RELATIONSHIPS OF CONSTITUENT CONCENTRATIONS TO SPECIFIC CONDUCTANCE

GONSIUIUENI

CONSIUIVENI IMG/L OR UNII SHOWN

SIZE

TEMPERATURE, WATER IDEG C) SPECIFIC CONDUCTANCE (MICROMHOS) STREAMFLOH (CUBIC FT/SEC)

PH (STANDARD UNITS)

PHOSPHORUS, TOTAL

NITRITE + NITRATE, TOTAL

NITROGEN, KJELDAHL, TOTAL

PHYTOPLANKTON, TOTAL (CELLS/ML)

SEDIMENT, SUSPENDED

SEDIMENT, CLAY-SILT (PERCENT)

COLIFORM, FECAL ( $\mathrm{COL} / 100 \mathrm{ML})$

STREPTOCOCCI, FECAL (COL/100 ML)

SILICA, DISSOLVED

CALCIUA, DISSOLVED

MAGNESIUM, DI SSOLVED

SODIUM, DISSOLVED

POTASSIUM, DISSOLVED

BICARBONATE, ION

CARBONATE, ION

SULFATE, DISSOLVED

CHLORIDE, DISSOLVED

DISSOLVED SOLIDS, SUM OF CONST

DISSOLVED SOLIDS, ROE 180 DEG C

HARDNESS, TOTAL

HARDNESS, NONCARBONATE

TURBIDITY (JTU)

FLOUR IDE, DISSOLVED

$\begin{array}{rrrrrr}12 & 22.75 & 5.38 & 12.0 & 29.5 & \\ 12 & 889.0 & 130.1 & 673 & 1100 & \\ 12 & 775.8 & 274.5 & 483 & 1350 & 1 \\ 12 & 7.82 & 0.06 & 7.7 & 7.9 & 1 \\ 12 & 1.382 & 0.595 & 0.59 & 2.20 & 1 \\ 12 & 3.492 & 0.897 & 1.70 & 4.60 & 1 \\ 12 & 0.969 & 0.293 & 0.59 & 1.60 & 1 \\ 11 & 2193.6 & 1741.9 & 370 & 5900 & 1 \\ 12 & 277.2 & 252.9 & 95 & 885 & \\ 12 & 97.6 & 1.6 & 95 & 100 & \\ 12 & 1540.5 & 2048.3 & 56 & 6300 & \\ 12 & 1965.8 & 2421.3 & 150 & 8100 & \\ 12 & 16.08 & 1.88 & 12.0 & 19.0 & 1 \\ 12 & 93.00 & 11.34 & 77.0 & 110.0 & 1 \\ 12 & 18.92 & 2.50 & 15.0 & 24.0 & 1 \\ 12 & 69.42 & 18.17 & 35.0 & 98.0 & 1 \\ 12 & 5.69 & 0.97 & 4.3 & 7.6 & 1 \\ 12 & 282.4 & 28.2 & 242 & 328 & 12 \\ 12 & 0.0 & 0.0 & 0 & 120 & 1 \\ 12 & 94.08 & 18.27 & 64.0 & 130.0 & 1 \\ 12 & 90.58 & 22.62 & 53.0 & 130.0 & 1 \\ 12 & 527.9 & 83.3 & 395 & 881 & 1 \\ 12 & 557.3 & 88.2 & 407 & 700 & 1 \\ 12 & 311.7 & 37.6 & 260 & 380 & 12 \\ 12 & 79.2 & 16.2 & 53 & 110 & 12 \\ 12 & 77.9 & 47.1 & 35 & 200 & 12 \\ 10 & 0.35 & 0.07 & 0.3 & 0.5 & 10\end{array}$

*Not significant at the 95 percent confidence level.

DAILY SPECIFIC CONDUCTANCE IN

MICROMHOS AT 25 DEG C, THAT WAS

EQUALLED OR EXCEEDED FOR THE
INDICATED PERCENTAGE OF TIME

\begin{tabular}{|c|c|c|c|c|}
\hline 18 & -58 & 108 & $20 \pi$ & $30 z$ \\
\hline 0 & 1110 & 1070 & 1010 & 974 \\
\hline \multicolumn{5}{|c|}{$\begin{array}{l}\text { S OF STREAM TEMPERATURE } \\
\pm \text { A * SING } 0172 * 0+C 1 .\end{array}$} \\
\hline \multirow{2}{*}{\multicolumn{2}{|c|}{ PHASE }} & \multicolumn{3}{|r|}{ STANDARD } \\
\hline & & VAR IATION & & ERROR OF \\
\hline \multicolumn{2}{|c|}{ ANGLE - C } & EXPLAINED & & ESTIMATE \\
\hline \multicolumn{2}{|c|}{ IRADIANSI } & -181 & \multicolumn{2}{|r|}{ IDEG $(1)$} \\
\hline & 7 & & 2.82 \\
\hline
\end{tabular}

SUMMARY OF HARMONIC ANALYSIS OF STREAM TEMPERATURE

\begin{tabular}{|c|c|c|c|c|c|}
\hline & & & & & STANDARD \\
\hline & HARMONIC & AMPLITUDE & PHASE & VARIATION & ERROR OF \\
\hline SAMPLE & MEAN - M & $-A$ & ANGLE - C & EXPLAINED & ESTIMATE \\
\hline SIZE & 10EG C1 & SDEG_L & IRADIANSI & -181 & IDEG $(1)$ \\
\hline 365 & 19.09 & 7.44 & 2.62 & 77 & 2.82 \\
\hline
\end{tabular}

SUMMARY OF MAXIMUM AND MINIMUM CONCENTRATIONS OF CONSTITUENTS

SAMPLED AT A FREQUENCY OF QUARTERLY (1975 WY)

08188500 -- SAN ANTONIO RIVER AT GOLIAD, TEX.

\begin{tabular}{|c|c|c|c|c|c|c|}
\hline \multirow{2}{*}{ CONSTITUENT } & \multicolumn{3}{|c|}{ TOTAL } & \multicolumn{3}{|c|}{ DISSOLVED } \\
\hline & $\begin{array}{l}\text { NO. } \\
\text { SAMPLES }\end{array}$ & $\begin{array}{l}\text { MINIMUM } \\
\text { CONC. }\end{array}$ & $\begin{array}{l}\text { MAXIMUM } \\
\text { CONC. }\end{array}$ & $\begin{array}{l}\text { NO. } \\
\text { SAMPLES }\end{array}$ & $\begin{array}{l}\text { MINIMUM } \\
\text { CONC. }\end{array}$ & $\begin{array}{l}\text { MAXIMUM } \\
\text { CONC. }\end{array}$ \\
\hline \multicolumn{7}{|l|}{ MINOR ELEMENTS: } \\
\hline CADMIUM $(C D)$, UG/L & $\begin{array}{l}4 \\
4\end{array}$ & $\begin{array}{r}1 \\
<10\end{array}$ & $\begin{array}{r}9 \\
<10\end{array}$ & $\begin{array}{l}4 \\
4\end{array}$ & $\begin{array}{l}0 \\
0\end{array}$ & $\begin{array}{l}4 \\
0\end{array}$ \\
\hline CHROMIUM (CR), UG/L & 4 & 0 & 30 & 4 & 0 & 10 \\
\hline COBALT $(C O)$, UG/L & 4 & $<50$ & $<50$ & 4 & 0 & 0 \\
\hline COPPER (CU), UG/L & 4 & 10 & 20 & 4 & 1 & 2 \\
\hline IRON $(F E), U G / L$ & 4 & 2400 & 5100 & 4 & 10 & 1100 \\
\hline LEAD $(P B), U G / L$ & 4 & $<100$ & $<100$ & 4 & 0 & 1 \\
\hline MANGANESE (MN), UG/L & 4 & 90 & 170 & 4 & 0 & 120 \\
\hline MERCURY $(H G), U G / L$ & 4 & 0.0 & 0.1 & 4 & 0.0 & 0.1 \\
\hline SELENIUM (SE), UG/L & 4 & 1 & 2 & 4 & 1 & 1 \\
\hline ZINC $(Z N), U G / L$ & 4 & 0 & 50 & 4 & 0 & 20 \\
\hline \multicolumn{7}{|l|}{ PERIPHYTON: } \\
\hline BIOMASS, DRY WT., G/SO M & 1 & 1.09 & & & & \\
\hline BIOMASS, ASH WT., G/SO M & 1 & 1.09 & & & & \\
\hline CHLOROPHYLL A, MG/SO M & 2 & .0 & .5 & & & \\
\hline CHLOROPHYLL B, MG/SQ M & 2 & .0 & $\cdot 1$ & & & \\
\hline ORGANIC CARBON, MG/L & 12 & 4.2 & 24.0 & & & \\
\hline
\end{tabular}


Table 14.--Summary of measurement at each station--Continued

LAT 28D26M1OS LONG 098011 MO6S

DRAINAGE AREA: 15600 SQ MI $(40404$ SQ KMI

PERIOD OF RECORD: $10 / 01 / 74$ - 09/30/75

STATISTICAL SUMMARY OF SELECTED DISSOLVED CHEMICAL CONSTITUENTS AND

REGRESSION RELATIONSHIPS OF CONSTITUENT CONCENTRATIONS TO SPECIFIC CONDUCTANCE

CONSIUTUENI

\begin{tabular}{|c|c|c|}
\hline $\begin{array}{l}\text { SAMPLE } \\
\text { SIZE }\end{array}$ & MEAN & $\begin{array}{l}\text { STANDARD } \\
\text { DEYIATION }\end{array}$ \\
\hline 12 & 22.25 & 5.70 \\
\hline 12 & 1182.1 & 479.0 \\
\hline 12 & 598.2 & 746.3 \\
\hline 12 & 7.77 & 0.18 \\
\hline 12 & 0.131 & 0.085 \\
\hline 12 & 2.040 & 1.140 \\
\hline 12 & 0.795 & 0.312 \\
\hline 12 & 5945.8 & 11317.4 \\
\hline 12 & 222.8 & 421.1 \\
\hline 12 & 93.9 & 7.8 \\
\hline 12 & 1188.1 & 2032.6 \\
\hline 12 & 1789.3 & 3300.2 \\
\hline 12 & 13.42 & 3.58 \\
\hline 12 & 108.58 & 39.64 \\
\hline 12 & 19.77 & 8.85 \\
\hline 12 & 109.42 & 49.45 \\
\hline 12 & 5.76 & 1.29 \\
\hline 12 & 202.8 & 43.2 \\
\hline 12 & 0.0 & 0.0 \\
\hline 12 & 136.92 & 67.78 \\
\hline 12 & 198.42 & 100.88 \\
\hline 12 & 693.0 & 276.8 \\
\hline 12 & 737.9 & 301.4 \\
\hline 12 & 353.3 & 133.1 \\
\hline 12 & 186.8 & 109.2 \\
\hline 12 & 82.3 & 113.5 \\
\hline 10 & 0.23 & 0.08 \\
\hline
\end{tabular}

BEGRESSION SUMMARY SAMPLE COEFICIENT, CONSTANT, CORRELATION ERANDARD SUZE

$\mathrm{R}$ B COEEICIENI ESIUMAIE

TEMPERATURE, WATER (DEG C) SPECIFIC CONDUCTANCE (MICROMHOS) STREAMFLOW (CUBIC FT/SEC) PH (STANDARD UNITS) PHOSPHORUS, TOTAL

NITRITE + NITRATE, TOTAL NITROGEN, KJELDAHL, TOTAL PHYTOPLANKTON, TOTAL ICELLS/ML SEDIMENT, SUSPENDED

SEDIMENT, CLAY-SILT (PERCENT) COLIFORM, FECAL (COL/100 ML) STREPTOCOCCI, FECAL I COL/100 ML SILICA, DISSOLVED CALCIUM, DISSOLVED MAGNESIUM, DISSOL VED SODIUA, DISSOLVED POTASSIUM, DISSOLVED BICARBONATE, ION CARBONATE, ION SULFATE, DISSOLVED CHLORIDE, DISSOLVED DISSOLVED SOLIDS, SUM OF CONST DISSOLVED SOLIDS, ROE 180 DEG HARDNESS, TOTAL HARDNESS, NONCARBONATE TURBIDITY (JTU)

FLOURIDE, DISSOLVED *Not significant at the 95 percent confidence level.

DURATION IABLE OE DAHY SPECIEIC CONDUCTANCE

DAILY SPECIFIC CONDUCTANCE IN MICROMHOS AT 25 DEG C, THAT WAS

EQUALLED OR EXCEEDED FOR THE

$\begin{array}{rrrrrr}18 & -5 \pi & 10 \pi & 208 & 308 & 508 \\ 2060 & 1840 & 1760 & 1540 & 1450 & 1230\end{array}$

$11.0 \quad 30.0$

$\begin{array}{ll}332 & 1800 \\ 130 & 2400\end{array}$

$\begin{array}{rrr}130 & 2400 & 12 \\ 7.4 & 7.9 & 12\end{array}$

$\begin{array}{rr}7.9 & 12 \\ 0.28 & 12\end{array}$

0.17

3.50

1.40

$40000 \quad 12$

24

1540
100

7300

7300
12000

$\begin{array}{rr}44 & 12000 \\ 7.0 & 20.0 \\ 31.0 & 160.0\end{array}$

$31 \cdot 0$

160.0
32.0

32.0
180.0

180.0
7.9

3.5

00

$32.0 \quad 360.0$

$193-1050$

1050

1140

510
360

360
330
0.4

8
0.1

12
2
2
2
12
12


12
12
12
12
12
12
12
12
12
12
12
12
12
12
10

$$
\begin{array}{r}
-1.045 \\
0.0003 \\
-0.00015 \\
0.00222 \\
-0.00029 \\
3.490
\end{array}
$$

7.4564

0.30585

$-0.58697$

1.13945

1820.555

$-0.671$

0.732

$-0.834$

-0.448 *

0.148 *

0.049

0.428

0.292
11739.5

-0.0021
0.0815
0.0175
0.1024
-0.0008
0.063
0.000
0.1377
0.2088
0.577
0.628
0.275
0.226
-0.097
0.0000

$$
\begin{array}{r}
15.9392 \\
12.2025 \\
-0.9281 \\
-11.6819 \\
6.6544 \\
128.416 \\
0.000 \\
-25.8075 \\
-48.3864 \\
11.109 \\
-4.246 \\
28.505 \\
-80.078 \\
197.409 \\
0.1950
\end{array}
$$

\begin{tabular}{|c|c|c|c|c|c|}
\hline & & & & & STANDARD \\
\hline SAMPLE & $\begin{array}{l}\text { HARMONIC } \\
\text { MEAN - M } \\
\text { IDEG CI }\end{array}$ & $\begin{array}{c}\text { AMPLITUDE } \\
-A \\
\text { (DEG }\end{array}$ & $\begin{array}{l}\text { PHASE } \\
\text { ANGLE - C } \\
\text { (RADIANS) }\end{array}$ & $\begin{array}{l}\text { VARIATION } \\
\text { EXPLAINED } \\
\text { (I) }\end{array}$ & $\begin{array}{l}\text { ERROR OF } \\
\text { ESTIMATE } \\
\text { IDEG G) }\end{array}$ \\
\hline
\end{tabular}

197.409
0.1950

-0.286 *
0.985
0.948
0.992
$-0.282^{\star}$
0.697
$0.000^{*}$
0.973
0.991
0.998
0.998
0.989
0.990
-0.411 *
0.181 *

3.60

7.14

2.95

\begin{tabular}{|c|c|c|c|c|c|c|}
\hline \multirow{2}{*}{ CONSTITUENT } & \multicolumn{3}{|c|}{ TOTAL } & \multicolumn{3}{|c|}{ DISSOLVED } \\
\hline & $\begin{array}{l}\text { NO. } \\
\text { SAMPLES }\end{array}$ & $\begin{array}{l}\text { MINIMUM } \\
\text { CONC. }\end{array}$ & $\begin{array}{l}\text { MAXIMUM } \\
\text { CONC. }\end{array}$ & $\begin{array}{l}\text { NO. } \\
\text { SAMPLES }\end{array}$ & $\begin{array}{l}\text { MINIMUM } \\
\text { CONC. }\end{array}$ & $\begin{array}{l}\text { MAXIMUM } \\
\text { CONC. }\end{array}$ \\
\hline \multicolumn{7}{|l|}{ MINOR ELEMENTS: } \\
\hline ARSENIC (AS), UG $/ L$ & 4 & 1 & 6 & 4 & 0 & 5 \\
\hline CADMIUM $(C D)$, UG $/ L$ & 4 & $<10$ & 10 & 4 & 0 & 0 \\
\hline CHROMIUM (CR), UG/L & 4 & 0 & 20 & 4 & 0 & 10 \\
\hline COBALT $(C O), U G / L$ & 4 & $<50$ & 50 & 4 & 0 & 3 \\
\hline COPPER (CU), UG/L & 4 & $<10$ & $<10$ & 4 & 1 & 2 \\
\hline IRON $(F E), U G / L$ & 4 & 0 & 1800 & 4 & 0 & 70 \\
\hline LEAD $(P B), U G / L$ & 4 & $<100$ & $<100$ & 4 & 0 & 1 \\
\hline MANGANESE (MN), UG/L & 4 & 50 & 70 & 4 & 0 & 0 \\
\hline MERCURY (HG), UG/L & 4 & 0.0 & 0.1 & 4 & 0.0 & 0.1 \\
\hline SELENIUM (SE), UG/L & 4 & 0 & 1 & 4 & 0 & 1 \\
\hline$Z I N C(Z N), U G / L$ & 4 & 6 & 30 & 4 & 0 & 20 \\
\hline \multicolumn{7}{|l|}{ PERIPHYTON: } \\
\hline $\begin{array}{l}\text { BIOMASS, DRY WT, G/SQ M G } \\
\text { BIOMASS, ASH WT, G/SQ M } \\
\text { CHLOROPHYLL A, MG/SO M } \\
\text { CHLOROPHYLL B, MG/SQ M }\end{array}$ & $\begin{array}{l}2 \\
2 \\
2 \\
2\end{array}$ & $\begin{array}{r}6.2 \\
4.59 \\
16.0 \\
1.1\end{array}$ & $\begin{array}{r}34.00 \\
22.00 \\
21.0 \\
4.5\end{array}$ & & & \\
\hline ORGANIC CARBON, MG/L & 12 & 2.7 & 24.0 & & & \\
\hline
\end{tabular}

6.46

1.30

INDICATED PERCENTAGE OF TIME $\quad \begin{array}{llllllllll}2060 & 1840 & 1760 & 1540 & 1450 & 1230 & 949 & 526 & 452 & 352\end{array}$

SUMMARY OF HARMONIC ANALYSIS OF STREAM TEMPERATURE

$\begin{array}{llllll}198 & 22.45 & 7.90 & 2.90 & 89 & 1.99\end{array}$

SUMMARY OF MAXIMUM AND MINIMUM CONCENTRATIONS OF CONSTITUENTS SAMPLED AT A FREQUENCY OF QUARTERLY (1975 WY)

08210000 -- NUECES RIVER NR. THREE RIVERS, TEX. 
Table 14.--Summary of measurement at each station--Continued

LAT 27D15M51S LONG 098D08M08S

DRAINAGE AREA: 480 SQ MI 11243 SQ KMI

PERIOD OF RECORD: $10 / 01 / 74-09 / 30 / 75$

STATISTICAL SUMMARY OF SELECTED DISSOLVED CHEMICAL CONSTITUENTS AND

REGRESSION RELATIONSHIPS OF CONSTITUENT CONCENTRATIONS TO SPECIFIC CONDUCTANCE

CONSILIUENI

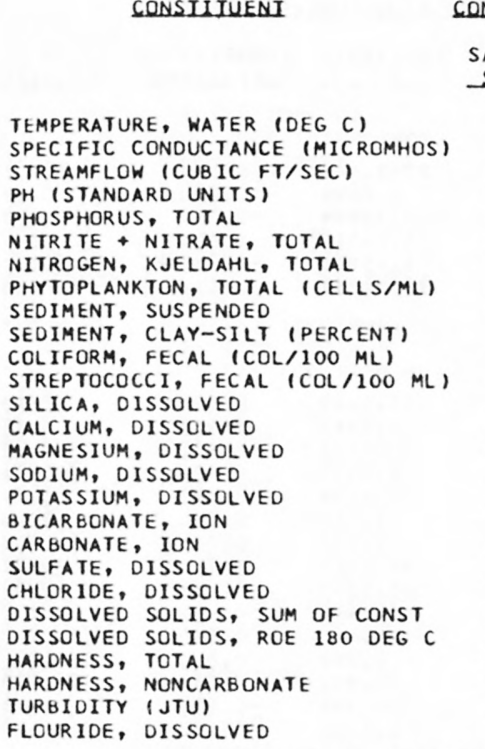

CONSIUUUENI IMG/L OR UNII SHOWN

SAMPLE

SIZE

AN

STANDARD

24.05

4106.0

0.5
7.98

7.98
1.345

0.041

1.830

60093.0

23.1

23.1
96.3

1740.0

2208.0

42.88

185.00

58.90 660.00

44.80

146.4

$$
1.4
$$

1013.00

708.00
2790.2

2790.2
2894.3

2894.3

711.0

588.0
13.0

1.81

6.38
1642.3
1.6
0.55

$0.386 \quad 0.75$

$0.031 \quad 0.01$

$0.568 \quad 1.20$

83175.2

175.2
12.9

4.2

1189.7

1603.3

75.90

25.54

275.08

18.97

33.0

4.4
451.07

451.07
307.06

1152.7

1223.2

301.8
279.2

7.4

BANGE

BE

ON SUMMABY

SAMPLE COEFICIENT.

CONSTANT,
CORRELATION COEEICIENI STANDARD ESIIMAIE

10.5
1180
0

180
0
6.99

$2.80 \quad 10$

$230000 \quad 10$

$\mathrm{B}-\mathrm{B}$

\begin{tabular}{|c|c|c|c|}
\hline \multicolumn{4}{|l|}{$\begin{array}{l}30.5 \\
6910\end{array}$} \\
\hline 5 & 10 & -0.000 & 1.097 \\
\hline 8.8 & 10 & 0.0003 & 6.8944 \\
\hline 2.10 & 10 & -0.00004 & 1.51316 \\
\hline 0.11 & 10 & -0.00001 & 0.07633 \\
\hline 2.80 & 10 & 0.00020 & 1.02063 \\
\hline & & 1.437 & 107051.875 \\
\hline
\end{tabular}

$-0.151$

0.788

$-0.174 *$

$-0.455$

-0.226 *

$-11.437$

107051.875

1.7

0.403

0.029

0.495

85941.7

*Not significant at the 95 percent confidence level.

\section{DURALION IABLE OF DAULY SPECIEIC CONDUCIANCE}

DAILY SPECIFIC CONDUCTANCE IN

MICROMHOS AT 25 DEG C, THAT WAS

EQUALLED OR EXCEEDED FOR THE

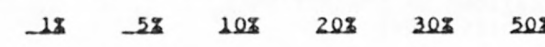

100
3300

4400

66.0
310.0

17.0

100.0

170.0

1100.0

$10-0.0025$

0.0459

0.0149

52.9871

$-3.4246$

$-2.2697$

0.1669

-25.1384
-1.8211

0.0114

0.015

85.259

0.2705

-4.4482
-97.5178

0.1851

$-52.1433$

0.701

0.743

0.182
0.167

$-0.001$

0.0004

$-89.007$

$-157.646$

$-35.699$

$-98.685$

0.0176

$-0.251 *$
0.993
0.958
0.996
0.983
0.740
$0.531 *$
0.985
0.990
0.999
0.998
0.990
0.984
$-0.210 \star$
0.987

16.55

9.54

25.24

25.24

3.71

4.0

83.27

45.50

53.7

82.9

45.9
52.9

42.9
7.7

0.14

INDICATED PERCENTAGE OF TIME

70206900

$6790 \quad 5460$

4670

4060

709

SAMPLE SIZE $=301$

$20 \% \quad 252 \quad 298$

440

20101030

220

SUMMARY OF HARMONIC ANALYSIS OF STREAM TEMPERATURE

\begin{tabular}{|c|c|c|c|c|c|}
\hline & & & & & STANDARD \\
\hline & HARMONIC & AMPLITUDE & PHASE & VARIATION & ERROR OF \\
\hline $\begin{array}{l}\text { SAMPLE } \\
\text { SIZE }\end{array}$ & $\begin{array}{l}\text { MEAN }-M \\
\text { LEEG }\end{array}$ & (DEGA) & $\begin{array}{l}\text { ANGLE - C } \\
\text { (RADLANS) }\end{array}$ & $\begin{array}{c}\text { EXPLAINED } \\
\text { (I) }\end{array}$ & $\begin{array}{l}\text { ESTIMATE } \\
\text { (DEG C }\end{array}$ \\
\hline 218 & 21.75 & 6.93 & 2.89 & 76 & 2.85 \\
\hline
\end{tabular}

SUMMARY OF MAXIMUM AND MINIMUM CONCENTRATIONS OF CONSTITUENTS SAMPLED AT A FREQUENCY OF QUARTERLY (1975 WY)

08212400 -- LOS OLMOS CREEK NEAR FALFURRIAS, TEX.

\begin{tabular}{|c|c|c|c|c|c|c|}
\hline \multirow{2}{*}{ CONSTITUENT } & \multicolumn{3}{|c|}{ TOTAL } & \multicolumn{3}{|c|}{ DISSOLVED } \\
\hline & $\begin{array}{l}\text { NO. } \\
\text { SAMPLES }\end{array}$ & $\begin{array}{l}\text { MINIMUM } \\
\text { CONC. }\end{array}$ & $\begin{array}{l}\text { MAXIMUM } \\
\text { CONC. }\end{array}$ & $\begin{array}{l}\text { NO. } \\
\text { SAMPLES }\end{array}$ & $\begin{array}{l}\text { MINIMUM } \\
\text { CONC. }\end{array}$ & $\begin{array}{l}\text { MAXIMUM } \\
\text { CONC. }\end{array}$ \\
\hline \multicolumn{7}{|l|}{ MINOR ELEMENTS: } \\
\hline ARSENIC (AS), UG/L & 3 & 8 & 18 & 3 & 5 & 17 \\
\hline CADMIUM $(C D), U G / L$ & 3 & $<10$ & $<10$ & 3 & 0 & 0 \\
\hline CHROMIUM (CR), UGIL & 3 & 0 & 20 & 3 & 0 & 20 \\
\hline COBALT $(C O), U G / L$ & 3 & $<50$ & 50 & 3 & 0 & 0 \\
\hline COPPER (CU), UG/L & 3 & $<10$ & 20 & 3 & 1 & 5 \\
\hline IRON (FE), UG/L & 3 & 510 & 800 & 3 & 0 & 50 \\
\hline LEAD $(P B), U G / L$ & 3 & $<100$ & 200 & 3 & 0 & 1 \\
\hline MANGANESE (MN), UG/L & 3 & 60 & 200 & 3 & 10 & 10 \\
\hline MERCURY $(H G), U G / L$ & 3 & 0.0 & 0.0 & 3 & 0.0 & 0.0 \\
\hline SELENIUM (SE), UG/L & 3 & 3 & 8 & 3 & 3 & 6 \\
\hline ZINC $(Z N), U G / L$ & 3 & 10 & 40 & 3 & 0 & 10 \\
\hline \multicolumn{7}{|l|}{ PERIPHYTON: } \\
\hline BIOMASS, DRY WT., GISQ M & 3 & 7.7 & 55.00 & & & \\
\hline BIOMASS, ASH WT., G/SO M & 3 & 4.59 & 43.00 & & & \\
\hline CHLOROPHYLL A, MG/SQ M & 3 & 8.5 & 40.0 & & & \\
\hline CHLOROPHYLL B, MG/SQ M & 3 & 3.3 & 6.7 & & & \\
\hline ORGANIC CARBON, MG/L & 3 & 9.3 & 19.0 & & & \\
\hline
\end{tabular}


LAT 37D04M42S LONG 105D45M22S

DRAINAGE AREA: 7700 SQ MI $(19943$ SQ KM

PERIOD OF RECORD: 10/01/74 - 09/30/75

STATISTICAL SUMMARY OF SELECTED DISSOLVED CHEMICAL CONSTITUENTS AND

REGRESSION RELATIONSHIPS OF CONSTITUENT CONCENTRATIONS TO SPECIFIC CONDUCTANCE

CONSIIIUENI

CONSIUUUENT IMG/LOR UNII SHOWN

SAMPLE

SAMPLE STANDARD

MEAN DEVIALION

TEMPERATURE, WATER (DEG C) SPECIFIC CONDUCTANCE (MICROMHOS) STREAMFLOW (CUBIC FT/SEC)

PH (STANDARD UNITS)

PHOSPHORUS, TOTAL

NITRITE + NITRATE, TOTAL

NITROGEN, KJELDAHL, TOTAL

PHYTOPLANKTON, TOTAL (CELLS/ML)

SEDIMENT, SUSPENDED

SEDIMENT, CLAY-SILT IPERCENT

COLIFORM, FECAL (COL/100 ML)

STREPTOCOCCI, FECAL ( COL/100 ML)

SILICA, DISSOLVED

CALCIUM, DISSOLVED

MAGNESIUM, DISSOL VED

SODIUM, DISSOLVED

POTASSIUM, DISSOLVED

BICAREONATE, ION

CARBONATE, ION

SULFATE, DISSOLVED

CHLORIDE, DISSOLVED

DISSOLVED SOLIOS, SUM OF CONST

DISSOLVED SOLIDS, ROE 180 DEG

HARLNESS, TCTAL

HARONESS, NONCARBONATE

TURUIDITY (JTU)

FLOURIDE, UISSOLVED

$\begin{array}{rr}14.86 & 4.85 \\ 231.0 & 41.4 \\ 797.7 & 575.1 \\ 8.45 & 0.36 \\ 0.130 & 0.046 \\ 0.028 & 0.036 \\ 0.473 & 0.199 \\ 6266.7 & 2526.4 \\ 205.8 & 329.7 \\ 22.2 & 30.3 \\ 63.3 & 81.9 \\ 21.29 & 2.29 \\ 22.43 & 3.99 \\ 4.27 & 0.86 \\ 14.57 & 2.64 \\ 3.17 & 0.29 \\ 78.7 & 15.6 \\ 0.5 & 1.2 \\ 36.29 & 9.34 \\ 3.79 & 1.04 \\ 145.4 & 23.7 \\ 152.7 & 24.1 \\ 73.9 & 13.4 \\ 8.6 & 7.0 \\ 13.6 & 8.0 \\ 0.26 & 0.05\end{array}$

*Not significant at the 95 percent confidence level. 0.05
REGRESSION SUMMARY

REGRESSION
SAMPLE COEFICIENT, CONSTANT,

STANDARD SAMPLE COEFICIENT, B

CORRELATIUN BANGE $\begin{array}{rr}6.5 & 20.0 \\ 150 & 285\end{array}$ $\begin{array}{rr}286 & 1680 \\ 8.2 & 9.0\end{array}$

8.2
0.07

0.07

0.00

0.20

3300
8

0.19

0.10 0.82
9600 9600
861

7
6
6
6
6
6

-8.423
0.0017
-0.00078
-0.00007
-0.00425
-7.642
2743.448
8.0696
0.30984
0.04512
1.45871
7963.211

-0.606 *

$-0.762 *$

$-0.091 *$

$-0.963$

-0.112 *

$\begin{array}{rr}3 & 83 \\ 8 & 200 \\ 18.0 & 24.0\end{array}$

$\begin{array}{ll}18.0 & 24.0\end{array}$

$2.7 \quad 5.5$

$10.0 \quad 17.0$

$\begin{array}{rr}2.8 & 3.6 \\ 55 & 100 \\ 0 & 3\end{array}$

$\begin{array}{rr}0 & 3 \\ 23.0 & 53.0\end{array}$

2.3

102

113

49
1

0.2
53.0
172

172
186
93

22

28
0.3

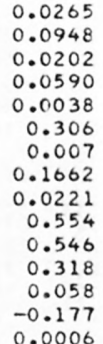

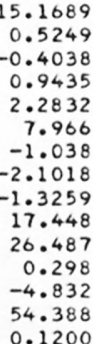

0.5249

$-0.4038$

0.9435

7.966

$-1.038$

$-2.1018$

17.448

26.487

54.388
0.1200

$\begin{array}{rr}0.479 * & 2.20 \\ 0.982 & 0.82 \\ 0.972 & 0.22 \\ 0.926 & 1.09 \\ 0.543 * & 0.27 \\ 0.810 & 10.0 \\ 0.245 * & 1.3 \\ 0.7360^{*} & 6.92 \\ 0.879 & 0.54 \\ 0.966 & 6.7 \\ 0.940 & 9.0 \\ 0.986 & 2.4 \\ 0.341 * & 7.3 \\ -0.917 & 3.5 \\ 0.460 * & 0.05\end{array}$

SUMMARY OF MAXIMUM AND MINIMUM CONCENTRATIONS OF CONSTITUENTS SAMPLED AT A FREQUENCY OF QUARTERLY (1975 WY)

08251500 -- RIO GRANDE NEAR LOBATOS, CO.

\begin{tabular}{|c|c|c|c|c|c|c|}
\hline \multirow{2}{*}{ CONSTITUENT } & \multicolumn{3}{|c|}{ TOTAL } & \multicolumn{3}{|c|}{ DISSOLVED } \\
\hline & $\begin{array}{l}\text { NO. } \\
\text { SAMPLES }\end{array}$ & $\begin{array}{l}\text { MIN IMUM } \\
\text { CONC. }\end{array}$ & $\begin{array}{l}\text { MAXIMUM } \\
\text { CONC. }\end{array}$ & $\begin{array}{l}\text { NO. } \\
\text { SAMPLES }\end{array}$ & $\begin{array}{l}\text { MINIMUM } \\
\text { CONC. }\end{array}$ & $\begin{array}{l}\text { MAXIMUM } \\
\text { CONC. }\end{array}$ \\
\hline \multicolumn{7}{|l|}{ MINOR ELEMENTS: } \\
\hline ARSENIC (AS), UG/L & 3 & 2 & 7 & 3 & 2 & 4 \\
\hline CADMIUM $(C D), U G / L$ & 3 & 0 & $<10$ & 3 & 0 & 0 \\
\hline CHROMIUM (CR), UG/L & 3 & 0 & 25 & 3 & 0 & 10 \\
\hline COBALT (CO), UG/L & 3 & $<50$ & $<50$ & 3 & 0 & 1 \\
\hline COPPER (CU), UG/L & 3 & $<10$ & 10 & 3 & 0 & 2 \\
\hline IRON (FE), UG/L & 3 & 490 & 1300 & 3 & 20 & 100 \\
\hline LEAD $(P B), U G / L$ & 3 & $<100$ & $<100$ & 3 & 0 & 3 \\
\hline MANG ANESE (MN), UG/L & 3 & 90 & 190 & 3 & 0 & 40 \\
\hline MERCURY (HG), UG/L & 3 & 0.0 & 1.7 & 3 & 0.0 & 1.0 \\
\hline SELENIUM (SE), UG/L & 3 & 0 & 1 & 3 & 0 & 0 \\
\hline$Z I N C(Z N), U G / L$ & 3 & 10 & 50 & 3 & 0 & 20 \\
\hline \multicolumn{7}{|l|}{ PERIPHYTON: } \\
\hline GIOMASS, DRY WT., G/SO M & 3 & 2.19 & 42.00 & & & \\
\hline BIOMASS, ASH WT., G/SO M & 3 & 2.09 & 34.00 & & & \\
\hline CHLOROPHYLL A, MG/SQ M & 3 & 1.0 & 59.0 & & & \\
\hline CHLOROPHYLL B, MG/SO M & 3 & .5 & 1.2 & & & \\
\hline ORGANIC CARBON, MG/L & 3 & 2.7 & 7.0 & & & \\
\hline
\end{tabular}


Table 14.--Summary of measurement at each station--Continued

LAT 35052M29S LONG 106DOBM3OS

DRAINAGE AREA: 14300 SQ MI ( 37037 SQ KM)

PERIOD OF RECORD: $10 / 01 / 74-09 / 30 / 75$

STATISTICAL SUMMARY OF SELECTED DISSOLVED CHEMICAL CONSTITUENTS AND

REGRESSION RELATIONSHIPS OF CONSTITUENT CONCENTRATIONS TO SPECIFIC CONDUCTANCE

CONSIITUENT

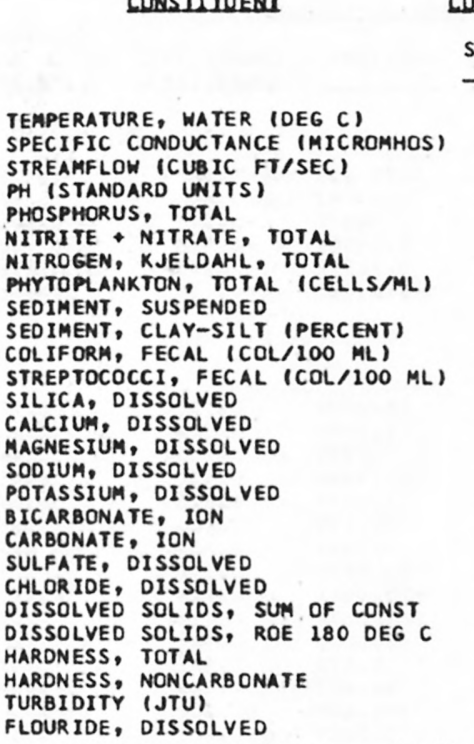

CONSTUUENT LAGLL OR UNUI SHOYNI

\begin{tabular}{|c|c|c|}
\hline $\begin{array}{l}\text { SAMPLE } \\
\text { SUZE }\end{array}$ & MEAN & $\begin{array}{l}\text { STANDARD } \\
\text { DEYUAIUN }\end{array}$ \\
\hline 15 & 11.47 & 7.54 \\
\hline 39 & 343.7 & 75.7 \\
\hline 15 & 1453.2 & 1153.7 \\
\hline 27 & 8.18 & 0.23 \\
\hline 12 & 0.130 & 0.075 \\
\hline 12 & 0.132 & 0.189 \\
\hline 12 & 0.534 & 0.251 \\
\hline 12 & 8525.0 & 5424.7 \\
\hline 11 & 3336.3 & 6335.4 \\
\hline 6 & 41.3 & 25.7 \\
\hline 12 & $600 \cdot 3$ & 638.9 \\
\hline 12 & 535.7 & 718.7 \\
\hline 39 & 19.18 & 3.60 \\
\hline 39 & 40.15 & 8.46 \\
\hline 39 & 7.14 & 1.59 \\
\hline 39 & 20.19 & 6.90 \\
\hline 39 & 2.99 & 0.57 \\
\hline 39 & 126.2 & 28.7 \\
\hline 27 & 0.1 & 0.6 \\
\hline 39 & 61.44 & 19.31 \\
\hline 39 & 6.07 & 2.60 \\
\hline 39 & 220.6 & 48.9 \\
\hline 12 & 235.3 & 53.4 \\
\hline 39 & 129.9 & 27.2 \\
\hline 39 & 26.2 & 15.5 \\
\hline 12 & 47.9 & 54.1 \\
\hline 39 & 0.36 & 0.15 \\
\hline
\end{tabular}

BEGRESSION SUMMABY REGRESSION STANDARD SAMPLE COEFICIENT, CONSTANT, CORRELATION ERROR OF \begin{tabular}{rrr} 
& & \\
\cline { 3 - 3 } 0.0 & 21.0 & \\
209 & & \\
349 & & \\
7.8 & 3680 & 12 \\
7.8 & 8.7 & 27 \\
0.04 & 0.27 & 12 \\
0.00 & 0.70 & 12 \\
0.09 & 0.88 & 12 \\
3900 & 22000 & 12 \\
86 & 18000 & \\
15 & 89 & \\
60 & 2300 & \\
48 & 2500 & \\
15.0 & 27.0 & 39 \\
26.0 & 56.0 & 39 \\
4.4 & 11.0 & 39 \\
9.7 & 34.0 & 39 \\
1.7 & 4.5 & 39 \\
85 & 180 & 39 \\
0 & 3 & 27 \\
28.0 & 120.0 & 39 \\
2.6 & 11.0 & 39 \\
131 & 312 & 39 \\
152 & 307 & 12 \\
83 & 180 & 39 \\
0 & 66 & 39 \\
7 & 200 & 12 \\
0.2 & 0.7 & 39
\end{tabular}

*Not significant at the 95 percent confidence level.

DAILY SPECIFIC CONDUCTANCE IN

DURAIION IABLE OE DAUL SPECIEIC CONDUCTANCE

MICROMHOS AT 25 DEG C, THAT WAS

EQUALLED OR EXCEEDED FOR THE

$\begin{array}{llllll}18 & 58 & 108 & 208 & 308 & 508 \\ 527 & 477 & 469 & 427 & 393 & 357\end{array}$

INDICATED PERCENTAGE OF TIME

\begin{tabular}{llll}
\multicolumn{4}{c}{ SAMPLE SIZE $=365$} \\
702 & $20 \%$ & $25 \%$ & 292 \\
316 & 253 & 217 & 198
\end{tabular}

\begin{tabular}{|c|c|c|c|c|c|}
\hline $\begin{array}{l}\text { SAMPLE } \\
\text { SUZE }\end{array}$ & $\begin{array}{l}\text { HARMONIC } \\
\text { MEAN - M } \\
\text { LDEG_CI }\end{array}$ & $\begin{array}{c}\text { AMP LITUDE } \\
-A \\
\text { IDEG CLL }\end{array}$ & $\begin{array}{l}\text { PHASE } \\
\text { ANGLE - C } \\
\text { IRADIANSL }\end{array}$ & $\begin{array}{l}\text { VAR IATION } \\
\text { EXPLAINED } \\
(\mathbf{X}) \\
\end{array}$ & $\begin{array}{l}\text { STANDARD } \\
\text { ERROR OF } \\
\text { ESTIMATE } \\
\text { LDEG_C) }\end{array}$ \\
\hline 365 & 11.27 & 9.97 & 2.72 & 91 & 2.06 \\
\hline
\end{tabular}

SUMMARY OF MAXIMUM AND MINIMUM CONCENTRATIONS OF CONSTITUENTS SAMPLED AT A FREQUENCY OF QUARTERLY (1975 WY)

08313000 -- RIO GRANDE AT OTOWI BRIDGE,NM

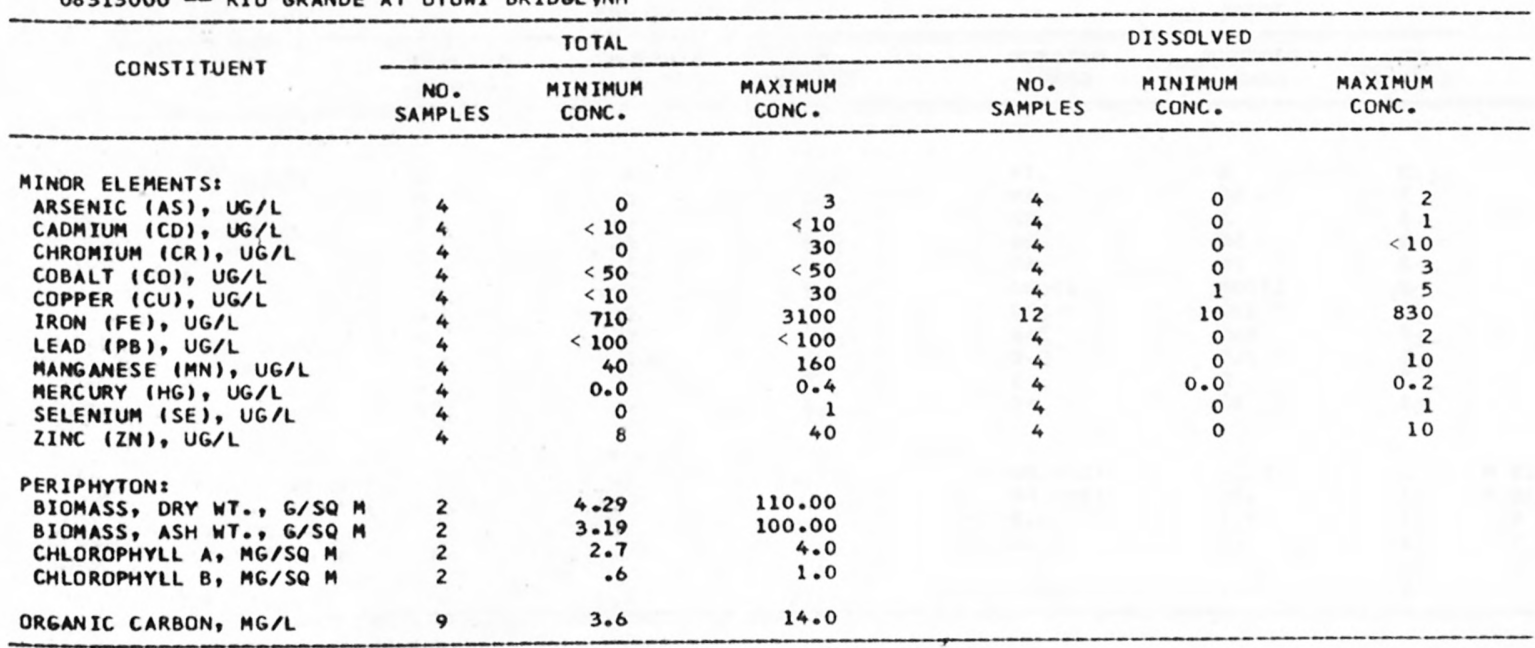


LAT 33041MO7S LONG 106059M40S DRAINAGE AREA: 0 SQ MI PERIOD OF RECORD: $10 / 01 / 74-09 / 30 / 75$ O SO KM)

STATISTICAL SUMMARY OF SELECTED DISSOLVED CHEMICAL CONSTITUENTS AND REGRESSION RELATIONSHIPS OF CONSTITUENT CONCENTRATIONS TO SPECIFIC CONDUCTANCE

CONSILTUENI

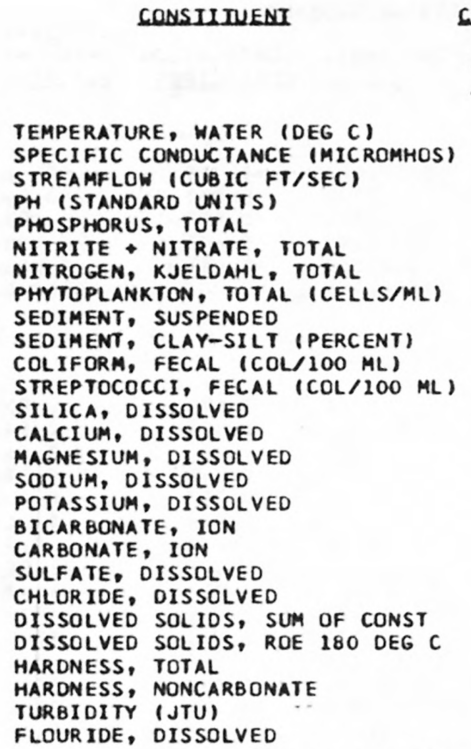

CONSIUTUENI IHG $\angle L$ OR UNII SHOHN

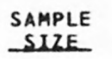

SAMPLE

STANDARD

HEAN DEYIATION
$18.38 \quad 5.25$

$753.1 \quad 112.0$

$531.8 \quad 374.7$

$8.10 \quad 0.18$

0.4910 .401

$0.186 \quad 0.209$

$1.735 \quad 3.190$

1993.9

2865.4

$\begin{array}{r}78.6 \\ \hline\end{array}$

78.6
2794.3

2794.3
1712.9

1712.9
22.11

63.78

11.90

67.78

5.46

181.3

40.1

142.00

43.00
448.2

448.2
459.2

208.9

59.3

1350.5
0.49

2046.3

4104.2

20.7

$3454 \cdot 8$

2529.5

1.62
10.71

2.19

17.18

0.91

23.1

0.4
36.28

36.28
12.96

12.96
89.5

81.8

35.2

18.5
3617.5

3617.5
0.12

$\begin{array}{rrr} & & \\ \text { BANGE } & & \text { SAMPL } \\ & & \text { SIZE } \\ 6.5 & 26.0 & \\ 551 & 879 & \\ 67 & 1480 & 19 \\ 7.9 & 8.4 & 7 \\ 0.13 & 1.50 & 17 \\ 0.02 & 0.65 & 15 \\ 0.30 & 13.00 & 15 \\ 27 & 5800 & 7 \\ 390 & 17200 & \\ 55 & 95 & \\ 200 & 9700 & \\ 330 & 7400 & \\ 20.0 & 25.0 & 9 \\ 52.0 & 82.0 & 9 \\ 9.1 & 16.0 & 9 \\ 44.0 & 100.0 & 9 \\ 4.5 & 7.4 & 9 \\ 154 & 217 & 9 \\ 0 & 1 & 7 \\ 98.0 & 210.0 & 9 \\ 26.0 & 66.0 & 9 \\ 337 & 615 & 9 \\ 356 & 605 & 9 \\ 170 & 270 & 9 \\ 36 & 91 & 9 \\ 6 & 14000 & 15 \\ 0.4 & 0.7 & 9\end{array}$

*Not significant at the 95 percent confidence level.
REGRESSION_SUMHABY

COEFICIENT, CONSTANT, CORRELATION ERROR OARD

- $B$ COEEICIENI ESIIGAIE

DURAIION IABLE OE DAUYY SPECIEIC CONDUCIANCE

CONDUCTANCE IN

MICROMHOS AT 25 DEG C, THAT WAS
EQUALLED OR EXCEEDED FOR THE

EQUALLED OR EXCEEDED FOR THE

626

$\begin{array}{rr}-2.965 & 2695.435 \\ 0.0015 & 6.9943 \\ -0.00139 & 1.54875 \\ -0.00122 & 1.14552 \\ -0.00951 & 9.21222 \\ -3.295 & 4378.063\end{array}$

$-0.883$

0.934
$-0.392 *$

$-0.558$

-0.285 .

-0.180 *

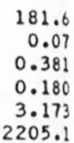

$$
\begin{array}{r}
0.0102 \\
0.0904 \\
0.0180 \\
0.1382 \\
0.0064 \\
0.178 \\
0.002 \\
0.2988 \\
0.1033 \\
0.750 \\
0.687 \\
0.299 \\
0.151 \\
-7.648 \\
0.0004
\end{array}
$$

15.0434

1.2690

-0.5779
-27.7640

27.7640
1.0478

58.199

$-1.362$

$-64.6630$

$-28.4441$

$-70.212$

$-16.204$

1.872

-44.987
7362.668

0.2059

0.737

0.984

0.961

0.937

0.820

\begin{tabular}{|c|c|c|c|c|c|}
\hline $\begin{array}{l}\text { SAMPLE } \\
\text { SIZE }\end{array}$ & $\begin{array}{l}\text { HARMONIC } \\
\text { MEAN - M } \\
\text { LDEG C) }\end{array}$ & $\begin{array}{c}\text { AMPLITUDE } \\
-A \\
\text { (DEG }\end{array}$ & $\begin{array}{l}\text { PHASE } \\
\text { ANGLE - C } \\
\text { IRADLANSS }\end{array}$ & $\begin{array}{c}\text { VARIATION } \\
\text { EXPLAINED } \\
\quad 181 \\
\end{array}$ & $\begin{array}{l}\text { STANDARD } \\
\text { ERROR OF } \\
\text { ESTIMATE } \\
\text { LOEG SI }\end{array}$ \\
\hline 196 & 16.76 & 7.46 & 2.57 & 72 & 2.57 \\
\hline
\end{tabular}

0.900

0.614 *

0.960

0.929

\begin{tabular}{|c|c|c|c|c|c|c|}
\hline \multirow{2}{*}{ CONSTITUENT } & \multicolumn{3}{|c|}{ TOTAL } & \multicolumn{3}{|c|}{ DISSOLVED } \\
\hline & $\begin{array}{l}\text { NO. } \\
\text { SAMPLES }\end{array}$ & $\begin{array}{l}\text { MIN IMUM } \\
\text { CONC. }\end{array}$ & $\begin{array}{l}\text { MAXIMUM } \\
\text { CONC. }\end{array}$ & $\begin{array}{l}\text { NO. } \\
\text { SAMPLES }\end{array}$ & $\begin{array}{l}\text { MINIMUM } \\
\text { CONC. }\end{array}$ & $\begin{array}{l}\text { MAXIMUM } \\
\text { CONC. }\end{array}$ \\
\hline \multicolumn{7}{|l|}{ MINOR ELEMENTS: } \\
\hline ARSENIC (AS), UG/L & 3 & 6 & 14 & 3 & 4 & 6 \\
\hline CADMIUM (CD), UG/L & 3 & $<10$ & 20 & 3 & 0 & 0 \\
\hline CHROMIUM (CR), UG/L & 3 & 2 & 20 & 3 & 0 & 0 \\
\hline COBALT $(C O)$, UG/L & 3 & $<50$ & 50 & 3 & 0 & 1 \\
\hline COPPER (CU), UG/L & 3 & 20 & 40 & 3 & 1 & 2 \\
\hline IRON $(F E), U G / L$ & 3 & 17000 & 25000 & 9 & 0 & 40 \\
\hline LEAD $(P B), U G / L$ & 3 & $<100$ & $<100$ & 3 & 0 & 0 \\
\hline MANGANESE (MN), UG/L & 2 & 560 & 740 & 3 & 0 & 0 \\
\hline MERCURY (HG), UGIL & 3 & 0.0 & 0.0 & 3 & 0.0 & 0.0 \\
\hline SELENIUM (SE), UG/L & 3 & 0 & 1 & 3 & 0 & 0 \\
\hline$Z I N C(Z N), U G / L$ & 3 & 80 & 90 & 3 & 0 & 20 \\
\hline \multicolumn{7}{|l|}{ PER IPHYTON: } \\
\hline BIOMASS, DRY WT., G/SQ M & 3 & 1.09 & 1200.00 & & & \\
\hline BIOMASS, ASH WT., G/SO M & 3 & .79 & 1100.00 & & & \\
\hline CHLOROPHYLL A, MG/SO M & 3 & 1.3 & 6.3 & & & \\
\hline CHLOROPHYLL B, MG/SQ M & 3 & $\cdot 1$ & 1.0 & & & \\
\hline ORGANIC CARBON, MG/L & 4 & 7.8 & 20.0 & & & \\
\hline
\end{tabular}

0.976

0.980

0.992

0.949

-0.202 *

$1230 \quad 987 \quad 885$

SUMMARY OF HARMONIC ANALYSIS OF STREAM TEMPERATURE

SUMMARY OF MAXIMUM AND MINIMUM CONCENTRATIONS OF CONSTITUENTS SAMPLED AT A FREQUENCY OF QUARTERLY (1975 WY)

08358300 - RIO GRANDE CV CH AT SAN MARC NM 
LAT 31D05M05S LONG 105036M25S

DRAINAGE AREA: 32035 SQ MI I 82971 SQ KMI

PERIOD OF RECORD: $10 / 01 / 74$ - 09/30/75

STATISTICAL SUMMARY OF SELECTED DISSOLVED CHEMICAL CONSTITUENTS AND REGRESSION RELATIONSHIPS OF CONSTITUENT CONCENTRATIONS TO SPECIFIC CONDUCTANCE

\section{CONSIUIUENI}

TEMPERTURE, WATER (DEG C)
SPECIFIC CONDUCTANCE (MICROMHOS)
STREAMFLOW (CUBIC, FT/SEC)
PH (STANDARD UNITS)
PHOSPHORUS, TOTAL
NITRITE + NITRATE, TOTAL
NITROGEN, KJELDAHL, TOTAL
PHYTOPLANKTON, TOTAL (CELLS/ML)
SEDIMENT, SUSPENDED
SEDIMENT, CLAY-SILT (PERCENT)
COLIFORM, FECAL (COL/IOO ML)
STREPTOCOCCI, FECAL (COL/IOO ML)
SILICA, DISSOLVED
CALCIUM, DISSOLVED
MAGNESIUM, DISSOLVED
SODIUM, DISSOLVED
POTASSIUM, DISSOLVED
BICARBONATE, ION
CARBONATE, ION
SULFATE, DISSOLVED
CHLORIDE, DISSOLVED
DISSOLVED SOLIDS, SUM OF CONST
DISSOLVED SOLIDS, ROE 18O DEG C
HARDNESS, TOTAL
HARDNESS, NONCARBONATE
IURBIDITY (JTU)
FLOURIDE, DISSOLVED

CONSIUIUENI HG H OB UNII SHOWN

SAMPLE
SIZE

STANDARD

$12 \quad 14.72$

$\begin{array}{rr}24 & 5640.0 \\ 12 & 175.6\end{array}$

$24 \quad 7.98$

$12 \quad 0.332$

$12 \quad 2.606$

$12 \quad 28866.7$

28866.7
623.5

623.5
65.1

65.1
3094.5

3094.5

1255.3
25.29

280.83

77.54

875.00

15.13

311.0

311.0
0.0

900.00

1237.92

3571.3

3935.0

1020.8
762.9

229.6
DEVIAIUN

6.04
1955.5
175.1

0.21
0.762

0.340

1.420

36447.0

951.2
16.3

16.3
7694.9

7694.9
1700.5

2.73

73.42

30.67

334.39

2.33

46.5

274.53

516.24

1220.2

1488.8
310.7

310.7
305.6

397.2
BEG

REGRESSION

SAMPLE

BANGE

4.0
2880

$\begin{array}{rr}2880 & 9230 \\ 31 & 504\end{array}$

7.5
0.07

0.01

0.93

1900

1900
20

42
19

19
25
18.0

18.0
170.0

19.0

400.0

12.0

228

480.0

520.0
1790

1790
2070

2070
530

290

10
0.7

COEFICIENT, SIZE

$10000 \quad 12$

7.968

95
26000

4400

$\begin{array}{lll}340.0 & 24 & -0.0001\end{array}$

420.0

130.0

1500.0

19.0

24
24
24

0.0361

0.0153

0.1701

0.0010

$-0.001$

0.1388

0.2625

0.623

0.667
0.156

0.156
0.152

$-0.036$

0.0000

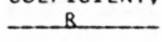

CONSTANT, CORRELATION
COEEICIENI

STANDARD ERROR OF ESIUMAIE

$\begin{array}{rrrr}9230 & & & \\ 504 & 12 & -0.009 & 581.743 \\ 8.3 & 24 & -0.0001 & 8.2958 \\ 2.30 & 12 & -0.00027 & 2.51112 \\ 1.00 & 12 & -0.00013 & 1.08381 \\ 5.10 & 12 & -0.00043 & 5.17698 \\ 110000 & 12 & 7.968 & -18258.953\end{array}$

$-0.874$

-0.532
-0.804

$-0.804$

$-0.682$

$0.487 *$

$-18258.953$

0.18
0.475

0.198

1.089

33383.9
$-0.058$

0.963

0.976

0.995

0.834

-0.023 *

0.000

0.989

0.994

0.998
0.999

0.981

0.975

$-0.204^{*}$
0.509
2.78

6.76

34.98

1.31

47.5

41.96

41.96

56.99

75.9

61.9

69.3

407.8

DURAIION IABLE OE DAUL SPECIEIC CONDUCIANCE

DAILY SPECIFIC CONDUCTANCE IN

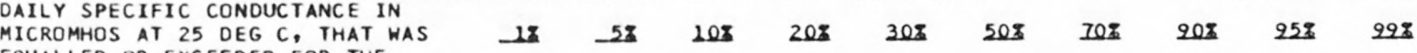

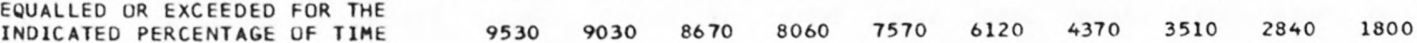

SUMMARY OF HARMONIC ANALYSIS OF STREAM TEMPERATURE

FORM OF EOUATORO T. ADALYSIS OF STREAM TEMPERATURE

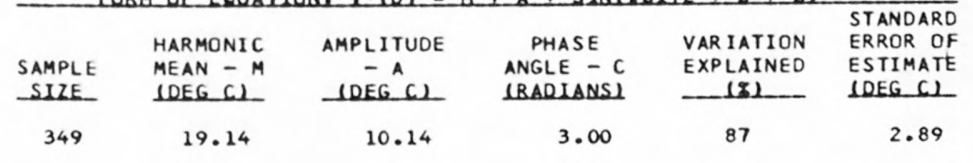

SUMMARY OF MAXIMUM AND MINIMUM CONCENTRATIONS OF CONSTITUENTS

SAMPLED AT A FREQUENCY OF QUARTERLY (1975 WY)

08370500 - RIO GRANDE AT FORT QUITMAN, TEXAS

\begin{tabular}{|c|c|c|c|c|c|c|}
\hline \multirow{2}{*}{ CONSTI TUENT } & \multicolumn{3}{|c|}{ TOTAL } & \multicolumn{3}{|c|}{ DISSOLVED } \\
\hline & $\begin{array}{l}\text { NO. } \\
\text { SAMPLES }\end{array}$ & $\begin{array}{l}\text { MIN IMUM } \\
\text { CONC. }\end{array}$ & $\begin{array}{c}\text { MAXIMUM } \\
\text { CONC. }\end{array}$ & $\begin{array}{c}\text { NO. } \\
\text { SAMPLES }\end{array}$ & $\begin{array}{l}\text { MINIMUM } \\
\text { CONC. }\end{array}$ & $\begin{array}{l}\text { MAXIMUM } \\
\text { CONC. }\end{array}$ \\
\hline \multicolumn{7}{|l|}{ MINOR ELEMENTS: } \\
\hline ARSENIC (AS), UG/L & 4 & 5 & 36 & 4 & 5 & 13 \\
\hline CADMIUM $(C D), U G / L$ & 4 & $<10$ & 10 & 4 & 0 & 0 \\
\hline CHROMIUM (CR), UG/L & 4 & 10 & 20 & 4 & 0 & 0 \\
\hline COBALT $(C O)$, UG/L & 4 & $<50$ & 100 & 4 & 0 & 2 \\
\hline COPPER (CU), UG/L & 4 & 10 & 70 & 4 & 1 & 4 \\
\hline IRON (FE), UG/L & 4 & 410 & 16000 & 4 & 10 & 1900 \\
\hline LEAD $(P B), U G / L$ & 4 & $<100$ & 200 & 4 & 0 & 13 \\
\hline MANGANESE (MN), UG/L & 4 & 750 & 1100 & 4 & 30 & 730 \\
\hline MERCURY (HG), UG/L & 4 & 0.0 & 0.5 & 4 & 0.0 & 0.5 \\
\hline SELENIUM $(S E), U G / L$ & 4 & 0 & 1 & 4 & 0 & 0 \\
\hline ZINC $(Z N), U G / L$ & 4 & 20 & 180 & 4 & 10 & 30 \\
\hline \multicolumn{7}{|l|}{ PERIPHYTON: } \\
\hline BIOMASS, DRY WT., G/SO M & 3 & 39.00 & 53.00 & & & \\
\hline BIOMASS, ASH WT., G/SQ M & 3 & 35.00 & 47.00 & & & \\
\hline CHLOROPHYLL A, MG/SQ M & 3 & 6.1 & 77.0 & & & \\
\hline CHLOROPHYLL B, MG/SO M & 3 & .5 & 5.5 & & & \\
\hline ORGANIC CARBON, MG/L & 4 & 7.7 & 22.0 & & & \\
\hline
\end{tabular}


Table 14,--Summary of measurement at each station--Continued

LAT $29046 M 50 S$ LONG $101045 M 20 S$

DRAINAGE AREA: 84120 SQ MI ( 217871 SQ KM)

PERIOD OF RECORD: $10 / 01 / 74$ - 09/30/75

STATISTICAL SUMMARY OF SELECTED DISSOLVED CHEMICAL CONSTITUENTS AND

REGRESSION RELATIONSHIPS OF CONSTITUENT CONCENTRATIONS TO SPECIFIC CONDUCTANCE

CONSIIIUENI

CONSIUUUENI IMG/L OR UNII SHOWNI

SAMPLE

SIZE

TEMPERATURE, WATER (DEG C)

SPECIFIC CONDUCTANCE (MICROMHOS) STREAMFLOW (CUBIC FT/SEC)

PH (STANDARD UNITS)

PHOSPHORUS, TOTAL

NITRITE + NITRATE, TOTAL

NITROGEN, KJELDAHL, TOTAL

PHYTOPLANKTON, TOTAL (CELLS/ML)

SEDIMENT, SUSPENDED

SEDIMENT, CLAY-SILT (PERCENT)

COLIFORM, FECAL (COL/100 ML)

STREPTOCUCCI, FECAL (CUL/100 ML)

SILICA, DISSOLVED

CALCIUM, DISSOLVED

MAGNESIUM, DISSULVED

SODIUM, DISSOLVED

POTASSIUM, DISSOLVEO

BICARBONATE, ION

CARBONATE, ION

SULFATE, DISSOLVED

CHLORIDE, DISSOLVEO

DISSOLVED SOLIDS, SUM OF CONST

DISSOLVED SOLIDS, ROE 180 DEG

HARDNESS, TOTAL

HARDNESS, NONCARBONATE

TURBIDITY (JTU)

FLOURIDE, DISSOLVED

\section{STANDARD}

MEAN

20.83

$1178 \cdot 4$
$2055 \cdot 0$

2055.0
7.83

0.701

0.812

1.194

6405.2

2240.8

2240.8
93.3

673.2

2213.2

22.42

93.00

16.54

131.21

6.58
191.5

191.5

287.08

287.08
97.24

97.24
763.2

778.6

310.9

153.0

1135.9

1.21

\section{Nov}

LAIION

5.96
309.6

1512.1

1512.1
0.22

0.884

0.302
1.032

6912.7

4335.0

7.3

921.6

4976.0

3.73
22.49

22.49
5.48

5.48
44.02

1.14

25.4
0.0

56.68

62.31

182.4

213.1

55.3

2178.7

0.27
BANGE

11.0
779

$\begin{array}{ll}779 & 27.0 \\ 71780\end{array}$

$\begin{array}{lr}710 & 5640 \\ 7.2 & 8.1\end{array}$

0.01

0.13

0.28

7
42

42
76
4

4
23
15.0

29.0

$\begin{array}{rr}11.0 & 130.0 \\ 8.0 & 27.0\end{array}$

$71.0 \quad 220.0$

$\begin{array}{ll}5.2 & 9.8 \\ 116 & 228\end{array}$

$\begin{array}{rr}116 & 228 \\ 0 & 0 \\ 200.0 & 390.0\end{array}$

$\begin{array}{rr}200.0 & 390.0 \\ 23.0 & 220.0\end{array}$

$502 \quad 1130$

$525 \quad 1140$

220

$15 \quad 250$

$\begin{array}{ll}15 & 1.5\end{array}$

BEGRESSION SUMMARY

REGRESSION

SAMPLE COEFICIENT, CONSTANT, CORRELATION ERROR OF

SIZE - B - B B COEEICIENI ESIUMAIE

DUYY DUBAIION IABLE_OE DALY SPECIEIC CONDUCIANCE

DAILY SPECIFIC CONDUCTANCE IN

MICROMHOS AT 25 DEG C, THAT WAS
EQUALLED OR EXCEEDED FOR THE

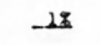

$5 \mathrm{~T}-10 \mathrm{cos}$

$20 \% \quad 30 \% \quad 50 \%$

INUICATED PERCENTAGE OF TIME

1810

1710

1650

1590

1290

1090

$70 \%$

970

$\begin{array}{rrr}12 & -3.592 & 6948.969 \\ 25 & 0.0003 & 7.5243 \\ 12 & -0.00190 & 2.93723 \\ 12 & -0.00051 & 1.40636 \\ 12 & -0.00145 & 2.89192 \\ 11 & -2.422 & 9146.473\end{array}$

$-0.392^{\star}$
$0.357^{*}$
-0.718
$-0.559^{\star}$
$-0.467^{*}$
$-0.101^{\star}$

2709.9

0.21
0.645

0.262

0.262
0.957

7218.6

$\begin{array}{lr}24 & 0.0017 \\ 24 & 0.0459 \\ 24 & 0.0170 \\ 24 & 0.1403 \\ 24 & 0.0021 \\ 24 & 0.035 \\ 24 & 0.000 \\ 24 & 0.1654 \\ 25 & 0.1996 \\ 23 & 0.578 \\ 11 & 0.608 \\ 23 & 0.166 \\ 23 & 0.135 \\ 11 & -3.842 \\ 10 & 0.0003\end{array}$

$$
\begin{array}{r}
20.4176 \\
38.8551 \\
-3.4928 \\
-34.1178 \\
4.1242 \\
149.954 \\
0.000 \\
92.1150 \\
-136.2238 \\
76.095 \\
62.740 \\
113.529 \\
-6.877 \\
5486.359
\end{array}
$$

0.9077

$-0.101^{\star}$

$0.141^{*}$

0.632

0.987

0.569

$0.430^{\circ}$

$0.000^{*}$

0.904

\begin{tabular}{|c|c|c|c|c|c|}
\hline \multirow{4}{*}{$\begin{array}{l}\text { SAMPLE } \\
\text { SIZE }\end{array}$} & \multirow{4}{*}{$\begin{array}{l}\text { HARMONIC } \\
\text { MEAN - M } \\
\text { (DEG C) }\end{array}$} & \multirow{4}{*}{$\begin{array}{c}\text { AMPLITUDE } \\
-{ }^{A} \\
\triangle D E G_{2}(1)\end{array}$} & \multirow{4}{*}{$\begin{array}{c}\text { PHASE } \\
\text { ANGLE - C } \\
\text { (BADIANS) }\end{array}$} & \multirow{4}{*}{$\begin{array}{l}\text { VAR IATION } \\
\text { EXPLAINED } \\
\end{array}$} & \multirow{4}{*}{$\begin{array}{l}\text { STANDARD } \\
\text { ERROR OF } \\
\text { ESTIMATE } \\
\text { LDEG C) }\end{array}$} \\
\hline & & & & & \\
\hline & & & & & \\
\hline & & & & & \\
\hline 334 & 22.20 & 7.33 & 2.98 & 89 & 1.95 \\
\hline
\end{tabular}

0.982

0.992
0.998

0.940

0.858

\begin{tabular}{|c|c|c|c|c|c|c|}
\hline \multirow{2}{*}{ CONSTI TUENT } & \multicolumn{3}{|c|}{ TOTAL } & \multicolumn{3}{|c|}{ DISSOLVEO } \\
\hline & $\begin{array}{l}\text { NO. } \\
\text { SAMPLES }\end{array}$ & $\begin{array}{l}\text { MINIMUM } \\
\text { CONC. }\end{array}$ & $\begin{array}{l}\text { MAXIMUM } \\
\text { CONC. }\end{array}$ & $\begin{array}{l}\text { NO. } \\
\text { SAMPLES }\end{array}$ & $\begin{array}{l}\text { MINIMUM } \\
\text { CONC. }\end{array}$ & $\begin{array}{l}\text { MAXIMUM } \\
\text { CONC. }\end{array}$ \\
\hline \multicolumn{7}{|l|}{ MINOR ELEMENTS: } \\
\hline ARSENIC (AS), UG/L & 4 & 8 & 140 & 4 & 1 & 11 \\
\hline CADMIUM $(C D), U G / L$ & 4 & $<10$ & 20 & 4 & 0 & 1 \\
\hline CHROMIUM (CR), UG/L & 4 & 0 & 150 & 4 & 0 & 10 \\
\hline COBALT $(C O)$, UG/L & 4 & 0 & 250 & 4 & 0 & 1 \\
\hline COPPER $(C U), U G / L$ & 4 & $<10$ & 210 & 4 & 1 & 3 \\
\hline IRON (FE), UG/L & 4 & 260 & 200000 & 4 & 10 & 3400 \\
\hline LEAD $(P B), U G / L$ & 4 & $<100$ & 500 & 4 & 1 & 20 \\
\hline MANG ANESE (MN), UG/L & 4 & 40 & 5600 & 4 & 0 & 50 \\
\hline MERCURY $(H G), U G / L$ & 4 & 0.0 & 0.4 & 4 & 0.0 & 0.4 \\
\hline SELENIUM (SE), UG/L & 4 & 1 & 7 & 4 & 1 & 2 \\
\hline ZINC $(Z N), U G / L$ & 4 & 30 & 920 & 4 & 0 & 20 \\
\hline \multicolumn{7}{|l|}{ PERIPHYTON: } \\
\hline BIOMASS, ORY WT., G/SO M & 1 & 3.80 & & & & \\
\hline B1OMASS, ASH WT, G/SQ M & 1 & 3.09 & & & & \\
\hline CHLOROPHYLL A, MG/SO M & 1 & .6 & & & & \\
\hline CHLOROPHYLL B, MG/SQ M & 1 & .0 & & & & \\
\hline ORGANIC CARBON, MG/L & 4 & 3.2 & 22.0 & & & \\
\hline
\end{tabular}

$-0.554^{*}$

$0.354^{*}$

3.77
17.82
1.55
7.33
0.95
23.4
0.0
$24.8 ?$
12.17
24.2
14.4
19.3
25.8
912.1
0.27

SAMPLE SLZE $=365$

$20 \% 25 \% 29 \%$

$837 \quad 725 \quad 571$

SUMMARY OF HARMONIC ANALYSIS OF STREAM TEMPERATURE

SUMMARY OF MAXIMUM AND MINIMUM CONCENTRATIONS OF CONSTITUENTS

SAMPLED AT A FREQUENCY OF QUARTERLY (1975 WY)

08377200 -- RIO GRANDE AT FOSTER RANCH NR LANGTRY, TEXAS 
Table 14.--Summary of measurement at each station--Continued

LAT 32D04M3OS LONG 104002M21S

DRAINAGE AREA: 19540 SQ MI ( 50609 SQ KM)

PERIOD OF RECORD: $10 / 01 / 74-09 / 30 / 75$

STATISTICAL SUMMARY OF SELECTED DISSOLVED CHEMICAL CONSTITUENTS AND

REGRESSION RELATIONSHIPS OF CONSTITUENT CONCENTRATIONS TO SPECIFIC CONDUCTANCE

CONSIITUENI

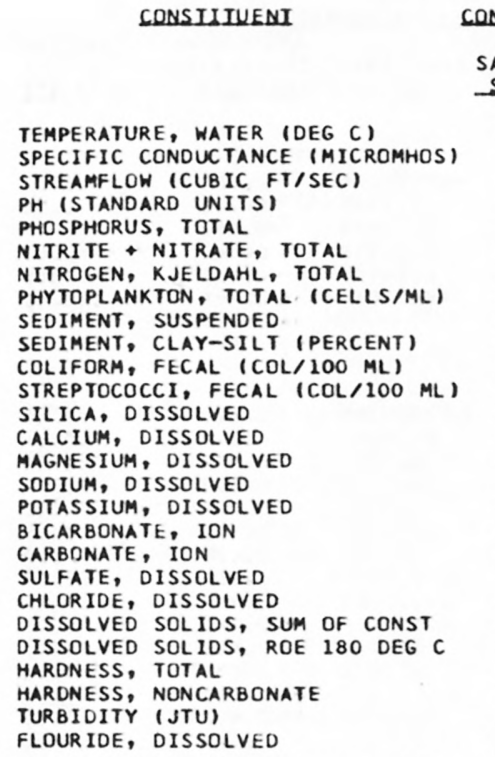

CONSIUTEENI_MG/L OR UNII_SHOWN

SIZE HEAN DEYIAIION

$\begin{array}{ll}12 & \\ 12 & 11\end{array}$

$\begin{array}{rr}11520.8 & 7.26 \\ & 2705.7\end{array}$

128.28

$\begin{array}{ll}12 & 0.073 \\ 12 & 0.383\end{array}$

$12 \quad 1.181$

77708.3

$32 \cdot 1$
73.0

73.0

13.5
20.2

20.2
7.67

467.50

467.50
213.33

213.33
2075.00

2075.00
72.83

72.83
129.5

0.0

1725.00

3425.00

8058.3

8280.8

8280.8
2041.7

1941.7

6.7
0.71

0.27

0.031

0.490
0.366

0.366
73783.6

19.3

26.0

14.6

16.5

3.82
72.25

72.25
61.55

629.75
33.45

33.45
39.3

0.0

349.35

2077.8

2077.8
2113.9

2113.9
405.5

405.5
437.9
5.7

0.12
BEGRESSION SUMHABY

REGRESSION

\begin{tabular}{l} 
SAMPLE COEFICIENT, CONSTANT, C \\
SIZE \\
\hline
\end{tabular}

CORRELATION

STANDARD

ERROR OF

BANGE

$\begin{array}{rrr}7.5 & 6.5 & 27.0 \\ 5105 & 7800 & 16200\end{array}$

$\begin{array}{lrr}51.4 & 25 & 178\end{array}$

8.0

0.03

0.00
0.61

0.61
7500

178
8.8
0.14
1.30
1.80

1.30
1.80
30000

$12-0.016$

12
12
12
12

-0.016
-0.0001
-0.00001

0.00003
-3.730

261.623
9.0562
0.16060
1.77617
0.81678
20683.938

$-0.820$

$-0.674$

$-0.652$

$-0.668$

$0.234 *$
$-0.137 *$

30.9

0.025

0.383

0.373
76656.6

98
40

$\begin{array}{rrr}0 & 56 \\ 0.7 & 11.0 & 12\end{array}$

$310.0 \quad 550.0$

130.0

290.0

12
12
12
12

26.0

2900.0

$\begin{array}{rr}120.0 & 12 \\ 186 & 12\end{array}$

$\begin{array}{rrr}0 & 0 & 12 \\ 1100.0 & 2100.0 & 12 \\ 2000.0 & 4900.0 & 12\end{array}$

$\begin{array}{lrl}5350 & 10900 & 12\end{array}$

$5600 \quad 11300 \quad 12$

1400

2500

2500

1200

0.5

21
0.9

12
12
12

$$
\begin{array}{r}
0.0004 \\
0.0109 \\
0.0168 \\
0.2182 \\
0.0114 \\
-0.007 \\
0.000 \\
0.0805 \\
0.3567 \\
0.094 \\
0.728 \\
0.096 \\
0.104 \\
0.000
\end{array}
$$

0.0000

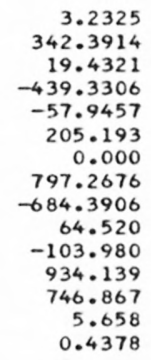

0.273
0.407
0.740
0.938
0.918
-0.452
0.000
0.624
0.919
0.904
0.932
0.641
0.641
0.042
0.546

3.85

69.23

43.42

229.54

13.90

36.8
0.0

286.41

435.51

933.9

806.1

326.3

352.6

352.6

0.16

\begin{tabular}{|c|c|c|c|c|c|}
\hline & & & & & STANDARD \\
\hline $\begin{array}{l}\text { SAMPLE } \\
\text { SIZE } \\
\end{array}$ & $\begin{array}{l}\text { HARMONIC } \\
\text { MEAN - M } \\
\text { IDEG CI }\end{array}$ & $\begin{array}{c}\text { AMPLITUDE } \\
-A \\
\text { (DEG C) }\end{array}$ & $\begin{array}{l}\text { PHASE } \\
\text { ANGLE - C } \\
\text { (RADIANS) }\end{array}$ & $\begin{array}{l}\text { VAR IATION } \\
\text { EXPLAINED } \\
\text { (X) }\end{array}$ & $\begin{array}{l}\text { ERROR OF } \\
\text { ESTIMATE } \\
\text { LEG E) }\end{array}$ \\
\hline 365 & 18.95 & 10.91 & 2.91 & 95 & 1.74 \\
\hline
\end{tabular}

* Not significant at the 95 percent confidence level.

DAILY SPECIFIC CONDUCTANCE IN

MICROMHOS AT 25 DEG C, THAT WAS

EQUALLED OR EXCEEDED FOR THE

\begin{tabular}{|c|c|c|c|c|c|c|}
\hline \multirow{2}{*}{ CONSTITUENT } & \multicolumn{3}{|c|}{ TOTAL } & \multicolumn{3}{|c|}{ DISSOLVED } \\
\hline & $\begin{array}{l}\text { NO. } \\
\text { SAMPLES }\end{array}$ & $\begin{array}{l}\text { MIN IMUM } \\
\text { CONC. }\end{array}$ & $\begin{array}{l}\text { MAXIMUM } \\
\text { CONC. }\end{array}$ & $\begin{array}{l}\text { NO. } \\
\text { SAMPLES }\end{array}$ & $\begin{array}{l}\text { MINIMUM } \\
\text { CONC. }\end{array}$ & $\begin{array}{l}\text { MAXIMUM } \\
\text { CONC. }\end{array}$ \\
\hline \multicolumn{7}{|l|}{ MINOR ELEMENTS: } \\
\hline ARSENIC (AS), UG/L & 4 & 1 & 2 & 4 & $\begin{array}{l}0 \\
0\end{array}$ & 2 \\
\hline CADMIUM $(C D), U G / L$ & 4 & $<10$ & 30 & 4 & $\begin{array}{r}0 \\
10\end{array}$ & 1 \\
\hline CHROMIUM (CR), UGIL & 4 & 10 & 30 & 4 & $<10$ & 20 \\
\hline COBALT $(C O), U G / L$ & 4 & $<50$ & 300 & 4 & 0 & 2 \\
\hline COPPER $(C U), U G / L$ & 4 & 10 & 40 & 4 & 1 & 12 \\
\hline IRON (FE), UG/L & 4 & 120 & 490 & 12 & 10 & 20 \\
\hline LEAD $(P B), U G / L$ & 4 & 100 & 200 & 4 & 0 & 1 \\
\hline MANGANESE (MN), UGIL & 4 & 80 & 170 & 4 & 30 & 90 \\
\hline MERCURY (HG), UG/L & 4 & 0.0 & $<0.1$ & 4 & 0.0 & $<0.1$ \\
\hline SELENIUM (SE), UG/L & 4 & 1 & 2 & 4 & 1 & 2 \\
\hline ZINC $(Z N), U G / L$ & 4 & 20 & 60 & 4 & 10 & 40 \\
\hline \multicolumn{7}{|l|}{ PERIPHYTON: } \\
\hline BIOMASS, DRY WT., G/SO M & 1 & 13.00 & & & & \\
\hline CHLOROPHYLL B, MG/SQ M & 1 & .6 & & & & \\
\hline ORGANIC CARBON, MG/L & 9 & 6.5 & 14.0 & & & \\
\hline
\end{tabular}

$18 \quad 5 \% \quad 20 \% \quad 20 \% \quad 30 \% \quad 50 \%$

INDICATED PERCENTAGE OF TIME

$\begin{array}{llllll}19500 & 17600 & 16700 & 15700 & 14900 & 12500\end{array}$

$70 \%$

SAMPLE SIZE $=365$

SUMMARY OF HARMONIC ANALYSIS OF STREAM TEMPERATURE

EORM OF EQUALON: I. $(0)=M+A+S I N C .0272+D+C)$

SUMMARY OF MAXIMUM AND MINIMUM CONCENTRATIONS OF CONSTITUENTS

SAMPLED AT A FREQUENCY OF QUARTERLY (1975 WY)

08407500 -- PECOS R AT RED BLUFF, NM 
LAT 29D48MIOS LONG 101026M45S

DRAINAGE AREA: 35179 SQ MI I 91114 SO KM

PERIOD OF RECORD: $10 / 01 / 74-09 / 30 / 75$

STATISIICAL SUMMARY OF SELECTED DISSOLVED CHEMICAL CONSTITUENTS AND

REGRESSION RELATIONSHIPS OF CONSTITUENT CONCENTRATIONS TO SPECIFIC CONDUCTANCE

CONSIIIUENI

CONSTIUUENI IMG LL OR UNLI SHOHN

SA

\begin{tabular}{rr} 
& \multicolumn{1}{r}{ STANDARD } \\
MEAN & DEYIAIION \\
20.13 & 6.83 \\
3858.3 & 1224.5 \\
627.5 & 769.1 \\
7.92 & 0.16 \\
0.045 & 0.100 \\
1.837 & 0.723 \\
0.404 & 0.185 \\
4813.3 & 5704.4 \\
74.5 & 190.2 \\
78.3 & 22.7 \\
223.8 & 748.3 \\
591.3 & 1923.9 \\
15.06 & 3.07 \\
176.21 & 49.92 \\
80.08 & 27.58 \\
533.33 & 194.68 \\
9.83 & 2.75 \\
194.8 & 24.4 \\
0.0 & 0.0 \\
513.75 & 180.65 \\
882.08 & 333.28 \\
2312.1 & 785.0 \\
2334.5 & 856.8 \\
767.5 & 227.6 \\
610.8 & 217.8 \\
25.9 & 73.8 \\
0.83 & 0.14 \\
189 &
\end{tabular}

BANGE
8.5
2050
270
7.5
0.00
0.95
0.17
760
3
32
2
15
9.4
99.0
36.0
260.0
5.4
140
0
230.0
410.0
1170
1320
430
270
1
0.7

TEMPERATURE, WATER (DEG C) SPECIFIC CONDUCTANCE (MICROMHOSI STREAMFLOW (CUBIC FT/SEC) PH (STANDARD UNITS) PHOSPHORUS, TOTAL

NITRITE + NITRATE, TOTAL NITROGEN, KJELDAHL, TOTAL PHYTOPLANKTON, TOTAL COLIFORM, CLAY-SILT (PERCENT) STREPTOCOCCI, FECAL (COL/100 ML) SILICA, DISSOLVED CALCIUM, DISSOLVED MAGNE SIUM, DISSOL VED SODIUM, DISSOLVED POTASSIUM, DISSOLVEO BICARBONATE, ION SURBONATE, ION CHLOR IDE, DISSOLVED DISSOLVED SOLIDS, SUM OF CONST DISSOLVED SOLIDS, ROE 180 DEG HARDNESS, TOTAL HARDNESS, NONCARBONATE

FLOUR IDE, DISSOLVED * Not significant at the 95 percent confidence level.

SUMMARY OF HARMONIC ANALYSIS OF STREAM TEMPERATURE EORM OF EOUAIUON: IU(D) $=M+A * S I N C .0172 * 0+C$

\begin{tabular}{|c|c|c|c|c|c|}
\hline & & & & & STANDARD \\
\hline $\begin{array}{l}\text { SAMPLE } \\
\text { SIZE }\end{array}$ & $\begin{array}{l}\text { HARMONIC } \\
\text { MEAN - M } \\
\text { LOEG Cl }\end{array}$ & $\begin{array}{c}\text { AMPLITUDE } \\
-A \\
\text { (DEG } C)\end{array}$ & $\begin{array}{l}\text { PHASE } \\
\text { ANGLE - C } \\
\text { (RADLANS) }\end{array}$ & $\begin{array}{l}\text { VAR IATION } \\
\text { EXPLAINED } \\
\text { (Z) }\end{array}$ & $\begin{array}{l}\text { ERROR OF } \\
\text { ESTIMATE } \\
\text { (DEG C) }\end{array}$ \\
\hline 12 & 20.26 & 8.43 & 2.70 & 86 & 2.83 \\
\hline
\end{tabular}

SUMMARY OF MAXIMUM AND MINIMUM CONCENTRATIONS OF CONSTITUENTS SAMPLED AT A FREQUENCY OF QUARTERLY (1975 WY)

$08447410--$ PECOS R NR LANGTRY, TEXAS

\begin{tabular}{|c|c|c|c|c|c|c|}
\hline \multirow{2}{*}{ CONSTITUENT } & \multicolumn{3}{|c|}{ TOTAL } & \multicolumn{3}{|c|}{ DISSOLVED } \\
\hline & $\begin{array}{l}\text { NO. } \\
\text { SAMPLES }\end{array}$ & $\begin{array}{l}\text { MIN IMUM } \\
\text { CONC. }\end{array}$ & $\begin{array}{l}\text { MAXIMUM } \\
\text { CONC. }\end{array}$ & $\begin{array}{l}\text { NO. } \\
\text { SAMPLES }\end{array}$ & $\begin{array}{l}\text { MINIMUM } \\
\text { CONC. }\end{array}$ & $\begin{array}{l}\text { MAXIMUM } \\
\text { CONC. }\end{array}$ \\
\hline \multicolumn{7}{|l|}{ MINOR ELEMENTS: } \\
\hline ARSENIC (AS), UG/L & 4 & 1 & 12 & 4 & 1 & 4 \\
\hline CADMIUM $(C D), U G / L$ & 4 & $\leqslant 10$ & 20 & 4 & 0 & 1 \\
\hline CHROMIUM (CR), UG/L & 4 & 0 & 10 & 4 & 0 & 10 \\
\hline COBALT $(C O), U G / L$ & 4 & 0 & 50 & 4 & 0 & 1 \\
\hline COPPER $(C U), U G / L$ & 4 & $<10$ & 30 & 4 & 0 & 1 \\
\hline IRON (FE), UG/L & 4 & 140 & 7600 & 4 & 10 & 70 \\
\hline LEAD $(P B), U G / L$ & 4 & $<100$ & $<100$ & 4 & 0 & 3 \\
\hline MANGANESE (MN), UG/L & 4 & 20 & 460 & 4 & 0 & 0 \\
\hline MERCURY (HG), UG/L & 4 & 0.0 & 0.1 & 4 & 0.0 & 0.0 \\
\hline SELENIUH $(S E), U G / L$ & 4 & 0 & 1 & 4 & 0 & 1 \\
\hline$Z I N C(Z N), U G / L$ & 4 & 30 & 110 & 4 & 0 & 60 \\
\hline \multicolumn{7}{|l|}{ PERIPHYTON: } \\
\hline BIOMASS, DRY WT., G/SQ M & 2 & .09 & 3.10 & & & \\
\hline BIOMASS, ASH HT.. G/SO M & 2 & .00 & 1.50 & & & \\
\hline CHLOROPHYLL A, MG/SQ M & 2 & .2 & 1.8 & & & \\
\hline CHLOROPHYLL B, MG/SQ M & 2 & .0 & .1 & & & \\
\hline ORGANIC CARBON, MG/L & 4 & 1.5 & 25.0 & & & \\
\hline
\end{tabular}


Table 14.--Summary of measurement at each station--Continued

LAT 27029M5OS LONG 099D29M40S

DRAINAGE AREA: 135976 SO MI ( 352178 SQ KM)

PERIOD OF RECORD: $10 / 01 / 74-09 / 30 / 75$

STATISTICAL SUMMARY OF SELECTED DISSOLVED CHEMICAL CONSTITUENTS AND

REGRESSION RELATIONSHIPS OF CONSTITUENT CONCENTRATIONS TO SPECIFIC CONDUCTANCE

CONSIITUENI

CONSIIIUENI_IMG/L OR UNII_SHOWNI

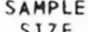

SLZE

MEAN

IEMPERATURE, WATER (DEG C) SPECIFIC CONDUCTANCE (MICROMHOS)

STREAMFLOW (CUBIC FT/SEC)

PH ISTANDARD UNITS

PHOSPHORUS, TOTAL

NITRITE + NITRATE, TOTAL

NITROGEN, KJELDAHL, TOTAL

PHYTOPLANKTON, TOTAL (CELLS/ML)

SEDIMENT, SUSPENDED

SEDIMENT, CLAY-SILT (PERCENT)

COLIFORM, FECAL (COL/100 ML)

STREPTOCOCCI, FECAL ( COL $/ 100 \mathrm{ML}$ )

SILICA, DISSOLVED

CALCIUM, DISSOLVED

MAGNESIUM, DISSOL VED

SODIUM, DISSOLVED

POTASSIUM, DISSOLVED

BICARBONATE, ION

CARBONATE, ION

SULFATE, DISSOLVED

CHLORIDE, DISSOLVED

DISSOLVED SOLIDS, SUM OF CONST

DISSOLVED SOLIDS, RUE 180 DEG C

HARDNESS, TOTAL

HARDNESS, NONCARBONATE

TURBIDITY (JTU)

FLOURIDE, DISSOLVED

*Not significant at the 95 perc
MEAN DEYIAILON

$\begin{array}{rrr}12 & 22.83 & 5.47 \\ 24 & 887.5 & 109.9 \\ 12 & 5381.7 & 4015.7 \\ 24 & 7.82 & 0.17 \\ 12 & 0.101 & 0.095 \\ 12 & 0.549 & 0.132 \\ 12 & 0.517 & 0.175 \\ 12 & 3513.3 & 7215.3 \\ 12 & 302.5 & 676.3 \\ 12 & 82.8 & 17.1 \\ 12 & 1289.5 & 2358.0 \\ 12 & 2013.3 & 3485.8 \\ 14 & 14.57 & 1.55 \\ 24 & 73.04 & 6.58 \\ 24 & 15.23 & 2.23 \\ 24 & 87.04 & 13.60 \\ 14 & 4.73 & 0.54 \\ 24 & 155.9 & 10.6 \\ 24 & 0.0 & 0.0 \\ 14 & 174.29 & 23.11 \\ 24 & 94.38 & 18.89 \\ 14 & 550.4 & 63.8 \\ 12 & 569.8 & 67.6 \\ 24 & 245.4 & 24.5 \\ 24 & 118.1 & 20.9 \\ 11 & 38.2 & 17.9 \\ 10 & 0.61 & 0.07\end{array}$

BANGE

$14.0 \quad 30.0$

$590 \quad 1070$

$1660 \quad 13800$

$\begin{array}{rrr}7.5 & 8.1 & 12\end{array}$

$0.01 \quad 0.38$

$0.30 \quad 0.73$

$0.26 \quad 0.88$

26000

$\begin{array}{rr}9 & 2440 \\ 47 & 100 \\ 84 & 7800\end{array}$

$\begin{array}{rr}84 & 7800 \\ 120 & 11000\end{array}$

$\begin{array}{ll}11.0 & 17.0 \\ 63.0 & 90.0\end{array}$

$\begin{array}{rr}63.0 & 90.0 \\ 9.5 & 19.0\end{array}$

44.0
3.9

134

140.0

51.0

441
468
200
73

73

20
0.5

0.07

5.7

184

220.0

120.0

656

674

290
160

160
70

0.7
BEGRESSION_SUMMABY REGRESSION

SAMPLE COEFICIENT,

CONSTANT

CORRELATION

STANDARD ERROR OF $-\mathrm{B}$ B COEFICIENI

ESIUMAIE
$-21.388$

0.0003

$-0.00045$

$-0.00022$

$-0.00028$

26.265

7.5965

0.50419

0.74417

0.76925

$-20011.273$

$-0.615$

0.164 *

$-0.546$

$-0.191 *$

-0.186 *

$0.421 *$

0.356

9.9693

0.0051

0.0450
0.0188

0.1190

0.0008

0.042

0.000

0.194

0.1637

0.574

0.578
0.195

0.195
0.163

$-0.014$

33.1119
-1.4931

-1.4931
-18.5935

3.9800

119.023

0.000

$-0.9116$

$-50.9537$

31.946

52.268

72.529

$-26.806$

50.770

0.0693

0.751

0.93

0.962

0.167.

0.433 *

0.000 *

0.911

0.953

0.976

0.987
0.874

0.861

$-0.094$

0.669
3319.5

0.17

0.084

0.136

6865.3

SAMPLE SIZE $=365$

$90 \% 252 \quad 99$

$774 \quad 732 \quad 569$

DAILY SPECIFIC CONDUCTANCE IN

MICROMHOS AT 25 DEG C, THAT WAS

EQUALLED OR EXCEEDED FOR THE
INDICATED PERCENTAGE OF TIME

\begin{tabular}{|c|c|c|c|c|}
\hline-28 & $-5 z$ & $10 z$ & 208 & 308 \\
\hline 120 & 1060 & 1030 & 1000 & 972 \\
\hline \multicolumn{5}{|c|}{ 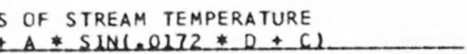 } \\
\hline \multirow{2}{*}{\multicolumn{2}{|c|}{ PHASE }} & \multicolumn{3}{|c|}{ STANDARD } \\
\hline & & VARIATION & \multicolumn{2}{|c|}{ ERROR OF } \\
\hline \multicolumn{2}{|c|}{ ANGLE - C } & EXPLAINED & \multicolumn{2}{|c|}{ ESTIMATE } \\
\hline \multicolumn{2}{|c|}{ (RADIANS) } & 181 & \multicolumn{2}{|c|}{ (DEG C) } \\
\hline \multicolumn{2}{|c|}{4.29} & 28 & & 1.38 \\
\hline
\end{tabular}

SUMMARY OF HARMONIC ANALYSIS OF STREAM TEMPERATURE

EORM OE EOUAIION: I

\begin{tabular}{|c|c|c|c|c|c|}
\hline & & & & & STANDARD \\
\hline & HARMONIC & AMPLITUDE & PHASE & VARIATION & ERROR OF \\
\hline SAMPLE & MEAN - M & - A & ANGLE - C & EXP L A INED & ESTIMATE \\
\hline SIZE - & (DEG_L) & (DEG C) & (BADIANS) & (8) & DEE_ $(1)$ \\
\hline 364 & 24.49 & 1.22 & 4.29 & 28 & 1.38 \\
\hline
\end{tabular}

SUMMARY OF MAXIMUM AND MINIMUM CONCENTRATIONS OF CONSTITUENTS SAMPLED AT A FREQUENCY OF QUARTERLY (1975 WY)

08459000 -- RIO GRANDE AT LAREDO, TEX.

\begin{tabular}{|c|c|c|c|c|c|c|}
\hline \multirow{2}{*}{ CONSTITUENT } & \multicolumn{3}{|c|}{ TOTAL } & \multicolumn{3}{|c|}{ DISSOLVED } \\
\hline & $\begin{array}{l}\text { NO. } \\
\text { SAMPLES }\end{array}$ & $\begin{array}{l}\text { MINIMUM } \\
\text { CONC. }\end{array}$ & $\begin{array}{l}\text { MAXIMUM } \\
\text { CONC. }\end{array}$ & $\begin{array}{l}\text { NO. } \\
\text { SAMPLES }\end{array}$ & $\begin{array}{l}\text { MINIMUM } \\
\text { CONC. }\end{array}$ & $\begin{array}{l}\text { MAXIMUM } \\
\text { CONC. }\end{array}$ \\
\hline CADM IUM $(C D)$, UG/L & 4 & $<10$ & $\begin{array}{r}8 \\
<10\end{array}$ & 4 & $\begin{array}{l}0 \\
0\end{array}$ & $\begin{array}{l}5 \\
0\end{array}$ \\
\hline CHROMIUM (CR), UG/L & 4 & 0 & 10 & 4 & 0 & 10 \\
\hline COBALT $(C O), U G / L$ & 4 & $<50$ & 50 & 4 & 0 & 2 \\
\hline COPPER (CU), UG/L & 4 & $<10$ & 20 & 4 & 1 & 1 \\
\hline IRON (FE), UG/L & 4 & 0 & 2200 & 4 & 0 & 670 \\
\hline LEAD $(P B), U G / L$ & 4 & 400 & $<100$ & 4 & 0 & 0 \\
\hline MANG ANESE (MN), UG/L & 4 & 30 & 80 & 4 & 0 & 5 \\
\hline MERCURY (HG), UG/L & 4 & 0.0 & 0.5 & 4 & 0.0 & 0.2 \\
\hline SELENIUM (SE), UG/L & 4 & 1 & 4 & 4 & 0 & 1 \\
\hline ZINC $(Z N), U G / L$ & 4 & 8 & 50 & 4 & 0 & 10 \\
\hline \multicolumn{7}{|l|}{ PERIPHYTON: } \\
\hline BIOMASS, DRY WT., G/SO M & 0 & & & & & \\
\hline BIOMASS, ASH WT., G/SO M & 0 & & & & & \\
\hline CHLOROPHYLL A, MG/SO M & 0 & & & & & \\
\hline CHLOROPHYLL B, MG/SQ M & 0 & & & & & \\
\hline ORGANIC CARBON, MG/L & 4 & 2.8 & 15.0 & & & \\
\hline
\end{tabular}


Table 14.--Summary of measurement at each station--Continued

LAT 25052M35S LONG 097027M15S

DRAINAGE AREA: 182215 SQ MI ( 471937 SQ KMI

PERIOD OF RECORD: $10 / 01 / 74-09 / 30 / 75$

STATISTICAL SUMMARY OF SELECTED DISSOLVED CMEMICAL CONSTITUENTS AND

REGRESSION RELATIONSHIPS OF CONSTITUENT CONCENTRATIONS TO SPECIFIC CONDUCTANCE

CONSUIUENI

CONSIUIUENI IMG/L OR UNII SHOHNI

SAMPLE

SUZE

TEMPERATURE, WATER (DEG C)

SPECIFIC CONDUCTANCE (MICROMHOS)

PH (STANDARD UNITS)

NITRITE + NITRATE, TOTAL

NITROGEN, KJELDAHL, TOTAL

PHYTOPLANKTON, TOTAL (CELLS/ML)

SEDIMENT, SUSPENDED

SEDIMENT, CLAY-SILT (PERCENT)

COLIFORM, FECAL (COL/100 ML)

STREPTOCOCCI, FECAL ( COL/100 ML)

SILICA, DISSOLVED

CALCIUM, DISSOLVED

MAGNESIUM, DISSOLVED

POTASSIUM, DISSOLVED

CARBONATE, ION

SULFATE, DISSOLVED

CHLOR IDE, DISSOLVED

DISSOLVED SOLIDS, SUM OF CONST

DISSOLVED SOLIDS, ROE 180 DEG

TURBIDITY (JTU)

FLOUR IDE, DISSOLVED

*Not significant at the 95 percent confidence level.

STANDARD

DEYIAIION

2026.88

1160.6

7901.3

7.75

0.234

1.193

67750.0

578.7

578.7
93.9

93.9
2723.3

2553.5

13.33

83.17
22.17

130.00

5.90

159.4

0.0

235.00

147.50

716.9

750.5

300.0

169.2

67.1

0.65

5.16
175.7

175.7
3254.3

3254.3
0.21

0.106

0.412

64766.9

633.7
5.5

5.5
3065.1

3093.1

1.78

15.61

4.49
22.96

22.96
0.79

32.2

0.0

34.25

28.00

106.3

109.8
57.2

31.2

63.8

0.13
STREAMFLOW (CUBIC FT/SEC)

PHOSPHORUS, TOTAL

SODIUM, DISSOLVED

BICARBONATE, ION

HARDNESS, TOTAL

HARDNESS, NONCARBONATE

BANGE

DURAILON IABLE OE_DAILY SPECIEIC CONDUCIANCE

DAILY SPECIFIC CONDUCTANCE IN

MICROMHOS AT 25 DEG C, THAT WAS

EQUALLED OR EXCEEDED FOR THE

INDICATED PERCENTAGE OF TIME

$18 \quad 52 \quad 108$

2150

1590

1500

202

302

509

1370

$\begin{array}{rr}15.0 & 33.0 \\ 945 & 1460\end{array}$

$\begin{array}{rr}945 & 1460 \\ 2220 & 13000\end{array}$

$\begin{array}{ll}7.2 & 8.0\end{array}$

0.07

0.44

10000

0.40
1.50

1.50
2.90

230000

2500

100
7100

7100
8200

8200
17.0

110.0
30.0

110.0

5.0

120

190.0

120.0

586
598

230

130

8
0.4

180.0

200.0

930

942
400

400
220

230

SAMPLE REGRESSION
COEFICIENT, BEGBESSION_SUMMABY

SIZE.

COEFICIENT,

CONSTANT

CORRELATION

STANDARO

ERROR OF

ISILUAIE
0.0003
-0.00009
0.00011
0.00226

$-71.114$

.0052

0.0683

0.0205
0.1121

0.0032

0.128

0.000

0.1714

0.1477

0.593

0.589

0.260

0.152

$-0.231$

0.0004
7.2832

3.8552

$-1.6073$

$-0.0456$

11.162

36.0524

$-23.8804$

28.315
62.761

$-1.193$

$-6.956$

329.327

0.1463
$0.257 *$
$-0.156 *$
$0.047 *$
0.003
$-0.193 *$

0.21

0.432

0.551

06650.9

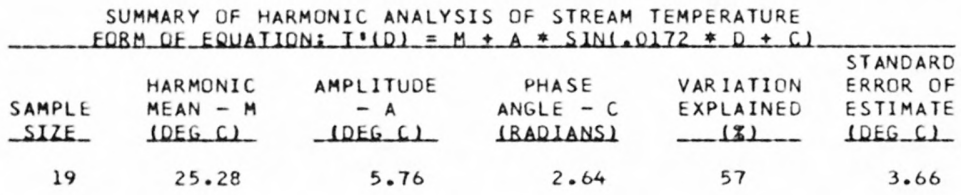

SUMMARY OF MAXIMUM AND MINIMUM CONCENTRATIONS OF CONSTITUENTS

SAMPLED AT A FREQUENCY OF QUARTERLY (1975 WY)

08475000 -- RIO GRANDE NEAR BROWNSVILLE, TEXAS

\begin{tabular}{|c|c|c|c|c|c|c|}
\hline \multirow{2}{*}{ CONSTITUENT } & \multicolumn{3}{|c|}{ TOTAL } & \multicolumn{3}{|c|}{ DISSOLVED } \\
\hline & $\begin{array}{l}\text { NO. } \\
\text { SAMPLES }\end{array}$ & $\begin{array}{l}\text { MINIMUM } \\
\text { CONC. }\end{array}$ & $\begin{array}{l}\text { MAXIMUM } \\
\text { CONC. }\end{array}$ & $\begin{array}{l}\text { NO. } \\
\text { SAMPLES }\end{array}$ & $\begin{array}{l}\text { MINIMUM } \\
\text { CONC. }\end{array}$ & $\begin{array}{l}\text { MAXIMUM } \\
\text { CONC. }\end{array}$ \\
\hline \multicolumn{7}{|l|}{ MINOR ELEMENTS: } \\
\hline ARSENIC (AS), UG/L & 4 & 2 & 0 & 4 & 0 & 4 \\
\hline CADMIUM $(C D)$, UG/L & 4 & $<10$ & 10 & 4 & 0 & 0 \\
\hline CHROMIUM (CR), UG/L & 4 & 0 & 10 & 4 & 0 & 20 \\
\hline COBALT $(C O), U G / L$ & 4 & $<50$ & $<50$ & 4 & 0 & 0 \\
\hline COPPER (CU), UG/L & 4 & $<10$ & 20 & 4 & 1 & 1 \\
\hline IRON (FE), UG/L & 4 & 0 & 6000 & 4 & 0 & 40 \\
\hline LEAD $(P B), U G / L$ & 4 & 400 & 100 & 4 & 0 & 0 \\
\hline MANG ANESE (MN), UG/L & 4 & 100 & 220 & 4 & 0 & 100 \\
\hline MERCURY (HG), UG/L & 4 & 0.0 & 0.5 & 4 & 0.0 & 0.2 \\
\hline SELENIUM (SE), UG/L & 4 & 0 & 1 & 4 & 0 & 1 \\
\hline$Z I N C(Z N), U G / L$ & 4 & 0 & 60 & 4 & 0 & 20 \\
\hline \multicolumn{7}{|l|}{ PERIPHYTON: } \\
\hline BIOMASS, DRY WT., G/SQ M & 0 & & & & & \\
\hline BIOMASS, ASH WT,, G/SO M & 0 & & & & & \\
\hline CHLOROPHYLL A, MG/SO M & 0 & & & & & \\
\hline CHLOROPHYLL B, MG/SO M & 0 & & & & & \\
\hline ORGANIC CARBON, MG/L & 4 & 6.0 & 12.0 & & & \\
\hline
\end{tabular}


Table 14.--Summary of measurement at each station--Continued

LAT 33008M41S LONG 105053M50S

DRAINAGE AREA: $120 \mathrm{SQMI}(11 \mathrm{SQ} \mathrm{KM})$

PERIOD OF RECORD: $10 / 01 / 74-09 / 30 / 75$

STATISTICAL SUMMARY OF SELECTED DISSOLVED CHEMICAL CONSTITUENTS AND

REGRESSION RELATIONSHIPS OF CONSTITUENT CONCENTRATIONS TO SPECIFIC CONDUCTANCE

CONSIUTUENI

CONSIIIUENI IMG $\angle L$ OR UNII SHOWN

\section{SAMPLE} SIZE

TEMPERATURE, WATER (DEG C)

SPECIFIC CONDUCTANCE (MICROMHOS

STREAMFLOH (CUBIC FT/SEC)

PH (STANDARD UNITS)

PHOSPHORUS, TOTAL

NITRITE + NITRATE, TOTAL

NITROGEN, KJELDAHL, TOTAL

PHYTOPLANKTON, TOTAL (CELLS/ML)

SEDIMENT, SUSPENDED

SEDIMENT, CLAY-SILT (PERCENT)

COLIFORM, FECAL (COL/100 ML)

STREPTOCOCCI, FECAL (COL/100 ML)

SILICA, DISSOLVED

CALCIUM, DISSOLVED

MAGNE SIUM, DISSOLVED

SODIUM, DISSOLVED

POTASSIUM, DISSOLVED

BICARBONATE, ION

CARBONATE, ION

SULFATE, DISSOLVED

CHLORIDE, OISSOLVED

DISSOLVED SOLIDS, SUM OF CONST

DISSOLVED SOLIDS, ROE 180 DEG HARDNESS, TOTAL

HARDNESS, NONCARBONATE

TURBIDITY (JTU)

FLOURIDE, DISSOLVED

${ }^{*}$ Not significant at the 95 per

\begin{tabular}{rrr} 
SIZE & \multicolumn{1}{r}{ MEAN } & DEYIAIION \\
19 & 12.42 & 5.75 \\
16 & 1534.3 & 164.8 \\
19 & 11.6 & 1.1 \\
13 & 7.91 & 0.25 \\
8 & 0.154 & 0.220 \\
8 & 0.421 & 0.093 \\
8 & 0.587 & 0.561 \\
8 & 922.5 & 676.4 \\
11 & 347.8 & 385.4 \\
11 & 72.5 & 18.5 \\
8 & 54.4 & 89.4 \\
8 & 235.8 & 434.0 \\
13 & 14.15 & 1.21 \\
13 & 231.54 & 41.60 \\
13 & 61.62 & 4.84 \\
13 & 46.23 & 4.02 \\
13 & 1.91 & 0.62 \\
13 & 240.2 & 19.8 \\
13 & 0.0 & 0.0 \\
13 & 608.46 & 104.15 \\
13 & 63.23 & 5.70 \\
13 & 1150.0 & 150.8 \\
9 & 1222.2 & 161.3 \\
13 & 833.8 & 121.1 \\
13 & 636.2 & 106.0 \\
8 & 69.6 & 71.4 \\
13 & 0.49 & 0.08
\end{tabular}

$\begin{array}{lll}13 & 0.49 & 0.08\end{array}$

NAME: Rio tularosa nEAR BENT, N. MEX.

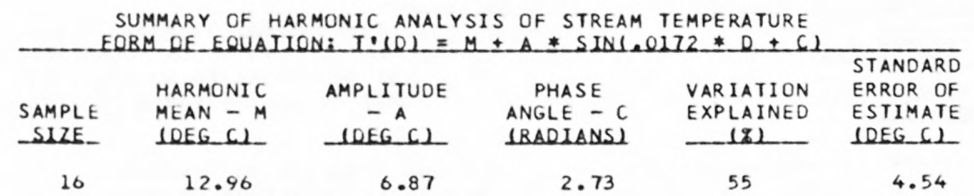

SUMMARY OF MAXIMUM AND MINIMUM CONCENTRATIONS OF CONSTITUENTS SAMPLED AT A FREQUENCY OF QUARTERLY (1975 WY)

$\begin{array}{rr}3.0 & 21.5 \\ 1360 & 2100 \\ 9 & 14 \\ 7.7 & 8.4 \\ 0.01 & 0.66 \\ 0.24 & 0.55 \\ 0.20 & 1.90 \\ 0 & 1700 \\ 38 & 1240 \\ 34 & 90 \\ 0 & 260 \\ 5 & 1300 \\ 12.0 & 16.0 \\ 200.0 & 360.0 \\ 52.0 & 68.0 \\ 38.0 & 52.0 \\ 1.4 & 3.7 \\ 200 & 274 \\ 0 & 0 \\ 530.0 & 920.0 \\ 54.0 & 71.0 \\ 1010 & 1600 \\ 1040 & 1600 \\ 730 & 1200 \\ 550 & 960 \\ 4 & 180 \\ 0.4 & 0.7\end{array}$

SAMPLE
SIZE

REGRESSION

SIZE

COEFICIENT,

CONSTANT
-

CORRELATION

STANDARD

ESIUMAIE

16
13
8
8
8
8



13
13
13
13
13
13
13
13
13
13
9
13
13
8
13

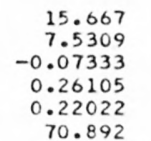

$-0.370$

$0.174 *$

$0.152 *$

0.254 *

$0.097 *$

70.892

$0.186 *$

$-0.122$

0.958

0.417 *

$-0.023$

0.493 .

0.493.

0.000

0.926
0.177

0.177
0.959

0.949

0.958

0.933

0.403 *

0.181 *

$-156.096$

$-207.535$

0.3749
1.2
0.26
0.235
0.097
0.604
717.8

1.26

12.45

4.59
3.98

3.98

18.0

18.0

0.0
40.97

40.97
5.86

44.4

54.6

36.1

08481500 -- RIO TULAROSA NEAR BENT, N. MEX.

\begin{tabular}{|c|c|c|c|c|c|c|}
\hline \multirow{2}{*}{ CONSTITUENT } & \multicolumn{3}{|c|}{ TOTAL } & \multicolumn{3}{|c|}{ DISSOLVED } \\
\hline & $\begin{array}{l}\text { NO. } \\
\text { SAMPLES }\end{array}$ & $\begin{array}{l}\text { MINIMUM } \\
\text { CONC. }\end{array}$ & $\begin{array}{l}\text { MAXIMUM } \\
\text { CONC. }\end{array}$ & $\begin{array}{l}\text { NO. } \\
\text { SAMPLES }\end{array}$ & $\begin{array}{l}\text { MINIMUM } \\
\text { CONC. }\end{array}$ & $\begin{array}{l}\text { MAXIMUM } \\
\text { CONC. }\end{array}$ \\
\hline \multicolumn{7}{|l|}{ MINOR ELEMENTS: } \\
\hline $\begin{array}{l}\text { ARSENIC }(A S), U G / L \\
\text { CADMIUM }(C D), U G / L\end{array}$ & $\begin{array}{l}3 \\
3\end{array}$ & 0 & 19 & 3 & 1 & 2 \\
\hline $\begin{array}{l}\text { CADM IUM (CD), UG/L } \\
\text { CHROMIUM (CR), UG/L }\end{array}$ & $\begin{array}{l}3 \\
3\end{array}$ & $<10$ & 10 & 3 & 0 & 0 \\
\hline $\begin{array}{l}\text { CHROMIUM (CR), UG/L } \\
\text { COBALT (CO), UG/L }\end{array}$ & $\begin{array}{l}3 \\
3\end{array}$ & 10 & 50 & 3 & 0 & 10 \\
\hline COPPER $(C U), U G / L$ & $\begin{array}{l}3 \\
3\end{array}$ & $<50$ & 50 & 3 & 0 & 2 \\
\hline IRON (FE), UG/L & $\begin{array}{l}3 \\
3\end{array}$ & 10 & 50 & 3 & 1 & 2 \\
\hline LEAD $(P B), U G / L$ & $\begin{array}{l}3 \\
3\end{array}$ & $\begin{array}{l}850 \\
100\end{array}$ & $\begin{array}{r}25000 \\
100\end{array}$ & $\begin{array}{l}9 \\
3\end{array}$ & $\begin{array}{l}0 \\
0\end{array}$ & 40 \\
\hline MANGANESE (MN), UG/L & 3 & 40 & 950 & 3 & $\begin{array}{l}0 \\
0\end{array}$ & $\begin{array}{r}1 \\
30\end{array}$ \\
\hline MERCURY (HG), UG/L & 3 & 0.0 & 0.1 & 3 & 0.0 & 0.1 \\
\hline SELENIUM (SE), UG/L & 3 & 1 & 2 & 3 & 1 & 1 \\
\hline ZINC $(Z N), U G / L$ & 3 & 30 & 110 & 3 & 0 & 10 \\
\hline \multicolumn{7}{|l|}{ PERIPHYTON: } \\
\hline BIOMASS, DRY WT., G/SQ M & 3 & 2.00 & 13.00 & & & \\
\hline BIOMASS, ASH WT., G/SQ M & 3 & 1.69 & 13.00 & & & \\
\hline CHLOROPHYLL A, MG/SQ M & 3 & .0 & 1.5 & & & \\
\hline CHLOROPHYLL B, MG/SO M & 3 & .0 & $\cdot 1$ & & & \\
\hline ORGANIC CARBON, MG/L & 5 & 2.0 & 9.5 & & & \\
\hline
\end{tabular}


Table 14.--Summary of measurement at each station--Continued

LAT 38059MOOS LONG 108D27MOOS

DRAINAGE AREA: 7928 SQ MI $(20534$ SQ KM)

PERIOD OF RECORD: $10 / 01 / 74-09 / 30 / 75$

STATISTICAL SUMMARY OF SELECTED OISSOLVED CHEMICAL CONSTITUENTS AND

REGRESSION RELATIONSHIPS OF CONSTITUENT CONCENTRATIONS TO SPECIFIC CONDUCTANCE

CONSIIIUENI

\begin{tabular}{|c|c|c|c|c|}
\hline \multirow[t]{2}{*}{ CONSIIIUENI } & \multicolumn{4}{|c|}{ ONSILIUENI $1 M G / L$ OR UNII SHOWNI } \\
\hline & $\begin{array}{l}\text { SAMPLE } \\
\text { SIZE }\end{array}$ & MEAN & $\begin{array}{l}\text { STANDARD } \\
\text { DEYIAIUON }\end{array}$ & BANG \\
\hline TEMPERATURE, WATER (DEG C) & 9 & 11.44 & 7.67 & 0.5 \\
\hline SPECIFIC CONDUCTANCE (MICROMHOS) & 9 & 1060.8 & 432.3 & 414 \\
\hline STREAMFLOW (CUBIC FT/SEC) & 8 & 2586.3 & 2007.2 & 880 \\
\hline PH (STANDARD UNITS) & 8 & 7.68 & .40 & 7.0 \\
\hline PHOSPHORUS, TOTAL & 4 & 0.167 & 0.069 & 0.09 \\
\hline NITRITE + NITRATE, TOTAL & 4 & 1.137 & 0.579 & 0.35 \\
\hline NITROGEN, KJELDAHL, TOTAL & 4 & 0.685 & 0.367 & 0.38 \\
\hline PHYTOPLANKTON, TOTAL (CELLS/ML) & 4 & $4250 \cdot 0$ & 2000.8 & 1800 \\
\hline $\begin{array}{l}\text { SEDIMENT, SUSPENDED } \\
\text { SEDIMENT, CLAY-SILT (PERCENT) }\end{array}$ & $\begin{array}{l}0 \\
0\end{array}$ & & & \\
\hline COLIFORM, FECAL (COL $100 \mathrm{ML}$ ) & 4 & $170 \cdot 0$ & 66.8 & 70 \\
\hline STREPTOCOCCI, FECAL (COL/100 ML) & 2 & 110.0 & 14.1 & 100 \\
\hline SILICA, DISSOLVED & 9 & 13.87 & 2.88 & 9.8 \\
\hline CALCIUM, DISSOLVED & 9 & 113.78 & 50.98 & 46.0 \\
\hline MAGNESIUM, DISSOLVED & 9 & 40.22 & 17.40 & 14.0 \\
\hline SODIUM, DISSOLVED & 9 & 70.44 & 31.19 & 24.0 \\
\hline POTASSIUM, DISSOLVED & 9 & 3.99 & 1.21 & 2.1 \\
\hline BICARBONATE, ION & 9 & 180.4 & 42.6 & 104 \\
\hline CARBONATE, ION & 4 & 0.0 & 0.0 & 0 \\
\hline SULFATE, DISSOLVED & 9 & 416.67 & 216.91 & 100.0 \\
\hline CHLORIDE, DISSOLVED & 9 & 9.91 & 4.25 & 3.5 \\
\hline DISSOLVED SOLIDS, SUM OF CONST & 9 & 762.2 & 343.3 & 265 \\
\hline DISSOLVED SOLIDS, ROE 180 DEG C & 0 & & & \\
\hline HARDNESS, TOTAL & 9 & 450.0 & 197.4 & 170 \\
\hline $\begin{array}{l}\text { HARDNESS, NCNCARBONATE. } \\
\text { TURBIDITY (JTU) }\end{array}$ & 9 & 303.1 & 163.4 & 68 \\
\hline FLOURIDE, DIS SOLVED & 9 & 0.42 & 0.17 & 0.2 \\
\hline *Not significant at the 9 & ercent & nfiden & level. & \\
\hline \multicolumn{5}{|c|}{ 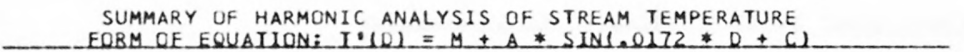 } \\
\hline & & & & STANDARD \\
\hline AMPLITUDE & PHA & ASE & VAR IATION & ERROR OF \\
\hline MEAN - M & ANGLE & $E-C$ & EXPLAINED & ESTIMATE \\
\hline 1DEG $(1)$ & $\angle B A D$ & IANSI & $-(z)$ & $10 E G \quad 6)$ \\
\hline 10.86 & & 2.63 & 88 & 1.91 \\
\hline
\end{tabular}

BEGBESSION SUMMABY

\begin{tabular}{|c|c|c|c|c|}
\hline & REGRESSION & & & STANDARD \\
\hline AMPLE & COEFICIENT, & CONSTANT, & $\begin{array}{l}\text { CORRELATION } \\
\text { COEEIGIENI }\end{array}$ & $\begin{array}{l}\text { ERROR OF } \\
\text { ESIMAIE }\end{array}$ \\
\hline
\end{tabular}

22.0

1600

8.1
0.24

0.24
1.70

1.70
1.20

6700

SIZE

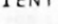

$B$

COEEIGIENI

8
4
4
4
4

$$
\begin{array}{r}
-3.812 \\
0.0005 \\
-0.00000 \\
0.00111 \\
0.00004 \\
1.274
\end{array}
$$

$$
\begin{array}{r}
6392.309 \\
7.2907 \\
0.16841 \\
-0.14826 \\
0.63786 \\
2769.387
\end{array}
$$

$-0.791$

0.747

$-0.000^{*}$

0.946 *

0.055
0.315

1325.9

0.23

.085

0.231

0.449

2325.5

210
120
18.0
180.0
66.0
110.0
5.9
232
0
720.0
15.0
1210
700
520
0.6

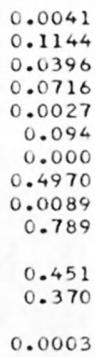

$$
\begin{array}{r}
9.4884 \\
-7.5702 \\
-1.8331 \\
-5.4808 \\
1.1238 \\
80.583 \\
0.000 \\
-110.5310 \\
0.4651 \\
-74.925 \\
-28.311 \\
-89.847 \\
0.0552
\end{array}
$$

0.619

0.970

0.985

0.992

0.963

0.954

\begin{tabular}{|c|c|c|c|c|c|c|}
\hline \multirow{2}{*}{ CONSTI TUENT } & \multicolumn{3}{|c|}{ TOTAL } & \multicolumn{3}{|c|}{ DISSOLVED } \\
\hline & $\begin{array}{l}\text { NO. } \\
\text { SAMPLES }\end{array}$ & $\begin{array}{l}\text { MIN IMUM } \\
\text { CONC. }\end{array}$ & $\begin{array}{l}\text { MAXIMUM } \\
\text { CONC. }\end{array}$ & $\begin{array}{l}\text { NO. } \\
\text { SAMPLES }\end{array}$ & $\begin{array}{l}\text { MINIMUM } \\
\text { CONC. }\end{array}$ & $\begin{array}{l}\text { MAXIMUM } \\
\text { CONC. }\end{array}$ \\
\hline \multicolumn{7}{|l|}{ MINOR ELEMENTS: } \\
\hline ARSENIC (AS), UG/L & 1 & 2 & & 1 & 1 & \\
\hline CADMIUM $(C D), U G / L$ & $i$ & $<10$ & & 1 & 1 & \\
\hline CHROMIUM (CR), UG/L & $i$ & 10 & & 1 & 10 & \\
\hline COBALT $(C O), U G / L$ & $i$ & $<50$ & & 1 & 0 & \\
\hline COPPER (CU), UG/L & 1 & 10 & & 1 & 5 & \\
\hline IRON $(F E), U G / L$ & $i$ & 1000 & & 9 & 10 & 90 \\
\hline LEAD $(P B), U G / L$ & 1 & $<100$ & & 1 & 2 & \\
\hline MANGANESE (MN), UG/L & 1 & 60 & & 9 & 0 & 40 \\
\hline MERCURY (HG), UG/L & i & 0.0 & & 1 & 0.0 & \\
\hline SELENIUM (SE), UG/L & 1 & 21 & & 1 & 16 & \\
\hline$Z I N C(Z N), U G / L$ & 1 & 30 & & 1 & 0 & \\
\hline \multicolumn{7}{|l|}{ PERIPHYTON: } \\
\hline BIOMASS, ORY WT., G/SQ M & 0 & & & & & \\
\hline BIOMASS, ASH WT., G/SO M & 0 & & & & & \\
\hline CHLOROPHYLL A, MG/SO M & 0 & & & & & \\
\hline CHLOROPHYLL B, MG/SO M & 0 & & & & & \\
\hline ORGANIC CARBON, MG/L & 1 & 4.7 & & & & \\
\hline
\end{tabular}

0.000

0.991

0.907

0.994

0.988

0.988
0.980

0.872
2.42

13.24

3.20

4.22

0.35

13.6
0.0

31.87

1.92

1.92

33.0 34.6

0.09

SUMMARY OF MAXIMUM AND MINIMUM CONCENTRATIONS OF CONSTITUENTS

SAMPLED AT A FREQUENCY OF QUARTERLY (1975 WY)

09152500 -- GUNNISON RIVER NEAR GRAND JUNCTION, CO. 
Table 14.--Summary of measurement at each station--Continued

LAT 39D05M18S LONG 109006MOIS

DRAINAGE AREA: 17900 SQ MI 146361 SQ KMI

PERIOD OF RECORD: $10 / Q 1 / 74-09 / 30 / 75$

STATISTICAL SUMMARY OF SELECTED DISSOLVED CHEMICAL CONSTITUENTS AND

REGRESSION RELATIONSHIPS OF CONSTITUENT CONCENTRATIONS TO SPECIFIC CONDUCTANCE

CONSILIUENI

CONSIUIUENI IMG $\angle \perp$ OB UNII SHOHN

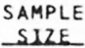

TEMPERATURE, WATER (DEG C)

SPECIFIC CONDUCTANCE (MICROMHOS)

STREAMFLOW (CUBIC FT/SEC)

PH (STANDARD UNITS)

PHOSPHORUS, TOTAL

NITRITE + NITRATE, TOTAL

NITROGEN, KJELDAHL, TOIAL

PHYTOPLANKTON, TOTAL (CELLS/ML)

SEDIMENT, SUSPENDED

SEDIMENT, CLAY-SILT (PERCENT)

COLIFORM, FECAL ( $C O L / 100 \mathrm{ML}$ )

STREPTOCOCCI, FECAL (COL/100 ML)

SILICA, DISSOLVED

CALCIUM, DISSOLVED

MAGNE SIUM, DISSOLVED

SODIUM, DISSOLVED

POTASSIUM, DISSOLVED

BICARBONATE, ION

CARBONATE, ION

SULFATE, DISSOLVED

CHLORIDE, DISSOLVED

DISSOLVED SOLIDS, SUM OF CONST

DISSOLVED SOLIDS, ROE 180 DEG C

HARDNESS, TOTAL

HARDNESS, NONCARBONATE

TURBIDITY (JTU)

FLOUR IDE, DISSOLVED

* Not significant at the 95

ercent confidence level.

\section{QURAIION IABLE OF DALL SPECIEIC CONOUCIANCE}

DAILY SPECIFIC CONDUCTANCE IN

MICROMHOS AT 25 DEG C, THAT WAS

EQUALLED OR EXCEEDED FOR THE
INDICATED PERCENTAGE OF TIME

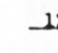

2280
STANDARD

DEYIAIION

13.29

$1008 \cdot 4$

7928.6

8.10

0.175

0.660

2450.0

7.83

381.2
6990.6

0.16

0.070

0.375

0.289

0.0
420
2500
7.9
0.11
0.27
0.43
1000

BANGE

184.5
150.0

150.0
10.39

96.43

32.29

85.57

3.81

172.3
0.0

303.29

68.29

688.9

374.3

233.3

$$
\begin{aligned}
& 76.9 \\
& 70.7
\end{aligned}
$$

1.46

39.11

13.34
38.39

1.23

35.4

159.93

30.69

294.1

78
100

1.5
44.0

14.0

26.0

1. 8

115
0
93.0

93.0
19.0

265

$\begin{array}{rr}151.1 & 170 \\ 129.1 & 73\end{array}$

0.110 .2

250
200

13.0

150.0
47.0

120.0

5.

223

500.0

98.0
1040

570
400

0.5

\section{BEGRESSION SUMMABY}

$\begin{array}{llll}\text { SAMPLE } & \begin{array}{l}\text { REGRESSION } \\ \text { COEFICIENT, CONSTANT, CORRELATION }\end{array} \\ \text { SIZE } & \text { B }\end{array}$

STANDARD
ERROR OF

ESIIMAIE

-15.036
0.0003
0.00006
0.00079
0.00033
0.884

23091.449

$-0.820$

4382.8

$0.742 * 0.13$

$0.374 * 20.079$

0.538 *

$0.288^{*} \quad 0.298$

1684.7

SUMMARY OF HARMONIC ANALYSIS OF STREAM IEMPERATURE

EORM OE EQUALION: I. (D) $=M+A * S I N C .0172 * D+C$

\begin{tabular}{|c|c|c|c|c|c|}
\hline & & & & & STANDARD \\
\hline & HARMONIC & AMPLITUDE & PHASE & VAR IATION & ERROR OF \\
\hline SAMPLE & MEAN - $M$ & $-A$ & ANGLE - C & EXPLAINED & ESTIMATE \\
\hline SIZE_- & 1DEG Cl & DOEG (1) & (BADIANS) & $-1 \% 1$ & (DEG C) \\
\hline 274 & 12.33 & 7.98 & 2.57 & 83 & 2.06 \\
\hline
\end{tabular}

SUMMARY OF MAXIMUM AND MINIMUM CONCENTRATIONS OF CONSTITUENTS

SAMPLED AT A FREQUENCY OF QUARTERLY (1975 WY)

09163530 -- COLORADO RIVER BELOW COLORADO-UTAH STATE LINE

\begin{tabular}{|c|c|c|c|c|c|c|}
\hline \multirow{2}{*}{ CONSTITUENT } & \multicolumn{3}{|c|}{ TOTAL } & \multicolumn{3}{|c|}{ DISSOLVED } \\
\hline & $\begin{array}{l}\text { NO. } \\
\text { SAMPLES }\end{array}$ & $\begin{array}{l}\text { MINIMUM } \\
\text { CONC. }\end{array}$ & $\begin{array}{l}\text { MAXIMUM } \\
\text { CONC. }\end{array}$ & $\begin{array}{l}\text { NO. } \\
\text { SAMPLES }\end{array}$ & $\begin{array}{l}\text { MINIMUM } \\
\text { CONC. }\end{array}$ & $\begin{array}{l}\text { MAXIMUM } \\
\text { CONC. }\end{array}$ \\
\hline \multicolumn{7}{|l|}{ MINOR ELEMENTS: } \\
\hline ARSENIC (AS), UG/L & 1 & 3 & & 1 & 1 & \\
\hline CADMIUM $(C D), U G / L$ & 1 & $<10$ & & 1 & 2 & \\
\hline CHROMIUM (CR), UG/L & 1 & 10 & & 1 & 10 & \\
\hline COBALT $(C O), U G / L$ & 1 & $<50$ & & 1 & 0 & \\
\hline COPPER (CU), UG/L & 1 & $<10$ & & 1 & $\begin{array}{l}5 \\
0\end{array}$ & 50 \\
\hline $\begin{array}{l}\text { IRON }(F E), U G / L \\
\text { LEAD }(P B), U G / L\end{array}$ & $\begin{array}{l}1 \\
1\end{array}$ & $\begin{array}{r}1700 \\
<100\end{array}$ & & $\begin{array}{l}7 \\
1\end{array}$ & 0 & 30 \\
\hline MANGANESE (MN), UG/L & $\begin{array}{l}1 \\
1\end{array}$ & $\begin{array}{r}100 \\
60\end{array}$ & & 7 & 0 & 50 \\
\hline MERCURY $(H G), U G / L$ & 1 & 0.0 & & 1 & 0.0 & \\
\hline SELENIUM (SE), UG/L & 1 & 16 & & 1 & 15 & \\
\hline$Z I N C(Z N), U G / L$ & 1 & 70 & & 1 & 10 & \\
\hline \multicolumn{7}{|l|}{ PERIPHYTON: } \\
\hline BIOMASS, DRY WT., G/SO M & 0 & & & & & \\
\hline BIOMASS, ASH WT., G/SQ M & 0 & & & & & \\
\hline CHLOROPHYLL A, MG/SQ M & 0 & & & & & \\
\hline CHLOROPHYLL B, MG/SQ M & 0 & & & & & \\
\hline ORGANIC CARBON, MG/L & 1 & 4.7 & & & & \\
\hline
\end{tabular}


Table 14.--Summary of measurement at each station--Continued

LAT 38D48M38S LONG 109D17M34S

DRAINAGE AREA: 24100 SQ MI 102419 SQ KMI

PERIOD OF RECORD: 10/01/74 - 09/30/75

STATISTICAL SUMMARY OF SELECTED DISSOLVED CHEMICAL CONSTITUENTS AND

REGRESSION RELATIONSHIPS OF CONSTITUENT CONCENTRATIONS TO SPECIFIC CONDUCTANCE

CONSIUTUENT

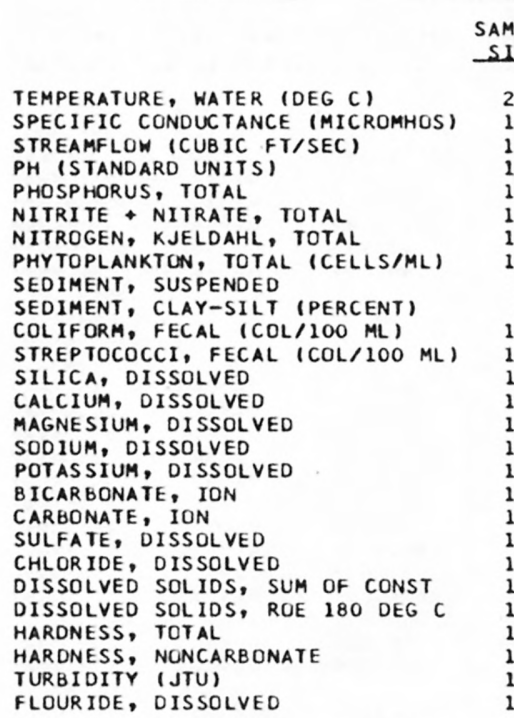

CONSIUUENT IMG/L OR UNII SHOWNI
REGRESSION SUMMABY

REGRESSION

SAMPLE COEFICIENT

BANGE SIZE

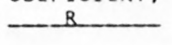

CONSTANT,
$-B$

CORRELATION COEEICIENI STANDARD
ERROR OF

$\begin{array}{rrrr}22 & 11.30 & 6.34 & 0.0 \\ 15 & 1173.3 & 423.2 & 330 \\ 14 & 8155.0 & 8186.9 & 2970 \\ 15 & 8.20 & 0.27 & 7.8 \\ 12 & 0.204 & 0.180 & 0.03 \\ 12 & 0.684 & 0.346 & 0.10 \\ 12 & 1.018 & 0.544 & 0.37 \\ 12 & 4908.3 & 3503.4 & 1400 \\ 8 & 1298.1 & 1673.0 & 138 \\ 2 & 536.5 & 618.7 & 99 \\ 12 & 102.7 & 141.1 & 2 \\ 12 & 153.2 & 140.8 & 11 \\ 13 & 9.68 & 1.47 & 7.2 \\ 13 & 95.23 & 37.05 & 37.0 \\ 13 & 32.42 & 13.49 & 9.5 \\ 13 & 111.85 & 53.13 & 17.0 \\ 13 & 4.94 & 1.63 & 1.6 \\ 13 & 174.2 & 39.8 & 99 \\ 13 & 1.1 & 2.8 & 0 \\ 13 & 302.31 & 155.58 & 59.0 \\ 13 & 117.15 & 61.65 & 13.0 \\ 13 & 761.5 & 324.2 & 198 \\ 12 & 763.2 & 331.5 & 217 \\ 13 & 372.3 & 148.9 & 130 \\ 13 & 228.1 & 114.2 & 45 \\ 12 & 193.8 & 219.9 & 8 \\ 13 & 0.30 & 0.13 & 0.1\end{array}$
21.5 1550
27000 27000
8.5
0.57 0.57 1.30

1.90
12000

12000
5230 5230
974 460
430 430
13.0 $13.0 \quad 13$
$150.0 \quad 13$ 150.0
$49.0 \quad 13$ 160.013 $\begin{array}{ll}6.7 & 13 \\ 222 & 13\end{array}$ $\begin{array}{rr}222 & 13 \\ 10 & 13 \\ 540 & 13\end{array}$ $540.0 \quad 13$ $\begin{array}{rr}200.0 & 13 \\ 1110 & 13\end{array}$ $\begin{array}{ll}1110 & 13 \\ 1170 & 12\end{array}$ *Not significant at the 95 percent confidence level.

\section{DURAILON IABLE OF DALLY SPECIEIC CONDUCIANCE} DAILY SPECIFIC CONDUCTANCE IN MICROMHOS AT 25 DEG C, THAT WAS EQUALLED OR EXCEEDED FOR THE

$\begin{array}{rrrrrr}18 & 58 & 107 & 20 \pi & 308 & 502 \\ 1860 & 1740 & 1650 & 1500 & 1380 & 1230\end{array}$

\begin{tabular}{|c|c|c|}
\hline 703 & 208 & 252 \\
\hline 1010 & 510 & 471 \\
\hline
\end{tabular}

SUMMARY OF HARMONIC ANALYSIS OF STREAM TEMPERATURE

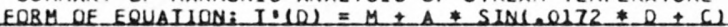

\begin{tabular}{|c|c|c|c|c|c|}
\hline $\begin{array}{l}\text { SAMPLE } \\
\text { SIZE }\end{array}$ & $\begin{array}{l}\text { HARMONIC } \\
\text { MEAN - M } \\
\text { IDEG CI) }\end{array}$ & $\begin{array}{c}\text { AMPLITUDE } \\
-A \\
10 E G(1)\end{array}$ & $\begin{array}{l}\text { PHASE } \\
\text { ANGLE - C } \\
\text { (BADLANS) }\end{array}$ & $\begin{array}{l}\text { VARIATION } \\
\text { EXPLAINED } \\
\text { (Z) }\end{array}$ & $\begin{array}{l}\text { STANDARD } \\
\text { ERROR OF } \\
\text { ESTIMATE } \\
\text { IDEG_C) }\end{array}$ \\
\hline 343 & 11.17 & 9.81 & 2.71 & 90 & 2.31 \\
\hline
\end{tabular}

09180500 -- COLORADO RIVER NEAR CISCO UTAH

\begin{tabular}{|c|c|c|c|c|c|c|}
\hline \multirow{2}{*}{ CONSTITUENT } & \multicolumn{3}{|c|}{ TOTAL } & \multicolumn{3}{|c|}{ DISSOLVED } \\
\hline & $\begin{array}{l}\text { NO. } \\
\text { SAMPLES }\end{array}$ & $\begin{array}{l}\text { MIN IMUM } \\
\text { CONC. }\end{array}$ & $\begin{array}{l}\text { MAXIMUM } \\
\text { CONC. }\end{array}$ & $\begin{array}{l}\text { NO. } \\
\text { SAMPLES }\end{array}$ & $\begin{array}{l}\text { MINIMUM } \\
\text { CONC. }\end{array}$ & $\begin{array}{l}\text { MAXIMUM } \\
\text { CONC. }\end{array}$ \\
\hline \multicolumn{7}{|l|}{ MINOR ELEMENTS: } \\
\hline ARSENIC (AS), UG/L & 4 & 1 & 14 & 4 & 1 & 4 \\
\hline CADMIUM $(C D), U G / L$ & 4 & $<10$ & 20 & 4 & 0 & 0 \\
\hline CHROMIUM (CR), UG/L & 4 & 0 & 10 & 4 & 0 & 0 \\
\hline COBALT $(C O)$, UG/L & 4 & $<50$ & 50 & 4 & 0 & 2 \\
\hline COPPER (CU), UG/L & 4 & $<10$ & 1900 & 4 & 2 & 3 \\
\hline IRON $(F E), U G / L$ & 4 & 410 & 19000 & 4 & 10 & 20 \\
\hline LEAD (PB), UG/L & 4 & $<100$ & 100 & 4 & 1 & 4 \\
\hline MANGANESE (MN), UG/L & 4 & 20 & 500 & 4 & 0 & 20 \\
\hline MERCURY (HG), UG/L & 3 & 0.0 & 0.1 & 4 & 0.0 & 0.0 \\
\hline SELENIUM (SE), UG/L & 4 & 5 & 14 & 4 & 3 & 14 \\
\hline $\operatorname{ZINC}(Z N), U G / L$ & 4 & 40 & 150 & 4 & 10 & 30 \\
\hline \multicolumn{7}{|l|}{ PER IPHYTON : } \\
\hline BIOMASS, DRY WT., G/SO M & 3 & 6.50 & 13.00 & & & \\
\hline BIOMASS, ASH HT., G/SO M & 4 & 3.09 & 12.00 & & & \\
\hline CHLOROPHYLL $A, M G / S Q M$ & 4 & .0 & 6.0 & & & \\
\hline CHLOROPHYLL B, MG/SO M & 4 & .0 & .7 & & & \\
\hline ORGANIC CARBON, MG/L & 4 & 3.6 & 16.0 & & & \\
\hline
\end{tabular}


Table 14.--Summary of measurement at each station--Continued

LAT 40D54M30S LONG 109025M20S

DARAINAGE AREA: 15100 SO MI

39109 SQ KM)

PERIOD OF RECORD: $10 / 01 / 74-09 / 30 / 75$

STATISTICAL SUMMARY OF SELECTED DISSOLVED CHEMICAL CONSTITUENTS AND

REGRESSION RELATIONSHIPS OF CONSTITUENT CONCENTRATIONS TO SPECIFIC CONDUCTANCE

CONSIIUENI

CONSIUIUENI IMG L OR UNII SHOWNI

SAMPLE

SIZE MEAN STANDARD

SIZE MEAN DEVIATION BANGE

TEMPERATURE, WATER (DEG C) SPECIFIC CONDUCTANCE (MICROMHOS) STREAMFLOW (CUBIC FT/SEC)

PH (STANDARD UNITS)

PHOSPHORUS, TOTAL

NITRITE + NITRATE, TOTAL

NITROGEN, KJELDAHL, TOTAL

PHYTOPLANKTON, TOTAL (CELLS/ML)

SEDIMENT, SUSPENDED

SEDIMENT, CLAY-SILT (PERCENT)

COLIFORM, FECAL (COL/100 ML)

STREPTOCOCCI, FECAL (COL/100 ML)

SILICA, DISSOLVED

CALCIUM, DISSOLVED

MAGNESIUM, DI SSOLVED

SODIUM, DISSOLVED

POTASSIUM, DISSOLVED

BICARBONATE, ION

CARBONATE, ION

SULFATE, DISSOLVED

CHLORIDE, OISSOLVED

DISSOLVED SOLIDS, SUM OF CONST

DISSOLVED SOLIDS, ROE 180 DEG C

HARDNESS, TOTAL

HARDNESS, NONCARBONATE

TURBIDITY (JTU)

FLOUR IDE, DISSOLVED

$\begin{array}{rr}5.75 & 1.74 \\ 750.7 & 29.4 \\ 3128.3 & 1233.8 \\ 7.99 & 0.34 \\ 0.016 & 0.021 \\ 0.663 & 0.199 \\ 0.380 & 0.101 \\ 580.2 & 688.5 \\ 2.3 & 2.3 \\ 62.4 & 38.1 \\ 0.0 & 0.0 \\ 1.3 & 2.6 \\ 4.26 & 0.59 \\ 69.08 & 1.75 \\ 26.31 & 1.11 \\ 58.77 & 2.05 \\ 2.98 & 0.82 \\ 185.3 & 4.1 \\ 0.0 & 0.0 \\ 219.23 & 9.54 \\ 18.31 & 0.75 \\ 491.1 & 12.1 \\ 523.1 & 14.2 \\ 281.5 & 8.0 \\ 128.5 & 5.5 \\ 1.7 & 1.2 \\ 0.27 & 0.05\end{array}$

*Not significant at the 95 percent confidence level.
$B E G B$

REGRESSION

SAMPLE SIZE COEFICIENT,

$$
\begin{aligned}
& 3.0 \\
& 710
\end{aligned}
$$

$$
\begin{aligned}
& 710 \\
& 856
\end{aligned}
$$$$
\begin{aligned}
& 856 \\
& 7.6
\end{aligned}
$$$$
0.00
$$$$
0.13
$$$$
0.21
$$$$
\begin{array}{r}
14 \\
14
\end{array}
$$$$
\begin{array}{r}
14 \\
1
\end{array}
$$$$
\begin{array}{r}
10 \\
0
\end{array}
$$$$
3.3
$$$$
\begin{array}{r}
3.3 \\
66.0
\end{array}
$$$$
\begin{aligned}
& 24.0 \\
& 55.0
\end{aligned}
$$$$
55.0
$$$$
\begin{aligned}
& 2.4 \\
& 177
\end{aligned}
$$$$
\begin{array}{rr}
4.1 & 177 \\
0.0 & 0
\end{array}
$$$$
9.54 \quad 210.0
$$$$
.75 \quad 17.0
$$$$
12.1
$$$$
.0 \quad 270
$$$$
.2
$$

0.27

$\begin{array}{rr}8.0 & \\ 820 & \\ 4280 & 14 \\ 8.7 & 15 \\ 0.07 & 11 \\ 0.88 & 11 \\ 0.56 & 11 \\ 2300 & 11 \\ 5 & \\ 97 & \\ 0 & \\ 7 & \\ 5.2 & 13 \\ 72.0 & 13 \\ 28.0 & 13 \\ 62.0 & 13 \\ 5.6 & 13 \\ 190 & 13 \\ 0 & 13 \\ 240.0 & 13 \\ 20.0 & 13 \\ 517 & 13 \\ 545 & 11 \\ 290 & 13 \\ 140 & 13 \\ 5 & 11 \\ 0.3 & 13\end{array}$

0.2

$-0.0000$
GBESSION SUMHABY

CONSTANT, CORRELATION COEEICIENI

STANDARD ERROR OF ESIUMAIE

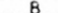

$-B$

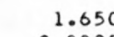

0.0025

0.00005

0.00320

$-0.00161$

$-8.004$

6.1285

$-0.02270$

$-1.73534$

1.59063

6583.246

0.040 *

0.211 *

0.497 *

$-0.494 *$

-0.360 *

1283.1

0.35
0.022

0.182

0.093

677.1
2.3642

74.7673

12.4210

41.0194

$-0.1911$

167.349

0.000

74.1415

15.9584

293.866

347.295

239.273

0.415
0.3005

$\begin{array}{rrr}0.025 & 109.668 & 0.137 \\ -0.006 & 6.415 & -0.163 *\end{array}$

0.131 *

$-0.131 *$

$0.505 *$

0.157 *

0.178 .

$0.178 *$

0.614

0.614.

$0.126 *$

0.510 *

0.213 *

$\begin{array}{rrr}0.025 & 109.668 & 0.137 \\ -0.006 & 6.415 & -0.163 *\end{array}$

$-0.026 *$

DURALION_IABLE_OE_DALYY SPECIEIC CONOUCIANCE

DAILY SPECIFIC CONDUCTANCE IN

MICROMHOS AT 25 DEG C, THAT WAS

EQUALLED OR EXCEEDED FOR THE

$\begin{array}{lllll}28 & 5 \% \quad 208 \quad 308\end{array}$

SAMPLE SIZE $=301$

INDICATED PERCENTAGE OF TIME

$\begin{array}{llllll}832 & 825 & 820 & 818 & 810 & 791\end{array}$

782

$20 \pi \quad 25 \% 29$

$770 \quad 769 \quad 760$

\begin{tabular}{|c|c|c|c|c|c|}
\hline & & & & & STANDARD \\
\hline SAMPLE & MEAN - M & AMPLITE & ANGLE - C & EXPLAINED & ESTIMATE \\
\hline SIZE & WEE C) & IDEG $(1)$ & IRADIANSI & $-(8)$ & IDEG 61 \\
\hline 299 & 6.00 & 2.08 & 1.16 & 84 & 0.62 \\
\hline
\end{tabular}

SUMMARY OF HARMONIC ANALYSIS OF STREAM TEMPERATURE

SUMMARY OF MAXIMUM AND MINIMUM CONCENTRATIONS OF CONSTITUENTS SAMPLED AT A FREQUENCY OF QUARTERLY (1975 WY)

\begin{tabular}{|c|c|c|c|c|c|c|}
\hline \multirow{2}{*}{ CONSTITUENT } & \multicolumn{3}{|c|}{ TOTAL } & \multicolumn{3}{|c|}{ DISSOLVED } \\
\hline & $\begin{array}{l}\text { NO. } \\
\text { SAMPLES }\end{array}$ & $\begin{array}{l}\text { MIN IMUM } \\
\text { CONC. }\end{array}$ & $\begin{array}{l}\text { MAXIMUM } \\
\text { CONC. }\end{array}$ & $\begin{array}{l}\text { NO. } \\
\text { SAMPLES }\end{array}$ & $\begin{array}{l}\text { MINIMUM } \\
\text { CONC. }\end{array}$ & $\begin{array}{l}\text { MAXIMUM } \\
\text { CONC. }\end{array}$ \\
\hline \multicolumn{7}{|l|}{ MINOR ELEMENTS: } \\
\hline ARSENIC (AS), UG/L & 4 & 1 & 3 & 4 & 1 & 2 \\
\hline CADMIUM $(C D), U G / L$ & 4 & $<10$ & $<10$ & 4 & 0 & 1 \\
\hline CHROMIUM (CR), UG/L & 4 & 0 & 0 & 4 & 0 & 10 \\
\hline COBALT $(C O), U G / L$ & 4 & $<50$ & $<50$ & 4 & 0 & 3 \\
\hline COPPER (CU), UGIL & 4 & $<10$ & 10 & 4 & 1 & 3 \\
\hline IRON $(F E), U G / L$ & 4 & 110 & 150 & 4 & 10 & 10 \\
\hline LEAD $(P B), U G / L$ & 4 & $<100$ & $<100$ & 4 & 1 & 4 \\
\hline MANG ANESE (MN), UG/L & 4 & 0 & 20 & 4 & 0 & 10 \\
\hline MERCURY $(H G), U G / L$ & 4 & 0.0 & 0.0 & 4 & 0.0 & 0.0 \\
\hline SELENIUM (SE), UG/L & 4 & 1 & 2 & 4 & 0 & 2 \\
\hline ZINC $(Z N), U G / L$ & 4 & 20 & 60 & 4 & 0 & 10 \\
\hline \multicolumn{7}{|l|}{ PERIPHYTON: } \\
\hline BIOMASS, DRY WT., G/SQ M & 3 & 2.00 & 11.00 & & & \\
\hline BIOMASS, ASH WT., G/SQ M & 4 & 1.50 & 17.00 & & & \\
\hline CHLOROPHYLL A, MG/SQ M & 4 & .2 & 64.0 & & & \\
\hline CHLOROPHYLL $B, M G / S Q M$ & 4 & .0 & 11.0 & & & \\
\hline ORGANIC CARBON, MG/L & 4 & 3.5 & 5.8 & & & \\
\hline
\end{tabular}

09234500 -- GREEN RIVER NEAR GREENDALE, UTAH 
Table 14.--Summary of measurement at each station--Continued

STATION NUMBER: 09251000 NAME: YAMPA RIVER NEAR MAYBELL, CO.

LAT 40D3OMIOS LONG 108D01M45S

DRAINAGE AREA: 3410 SQ MI $1 \quad 8832$ SQ KM)

PERIOD OF RECORD: $10 / 01 / 74-09 / 30 / 75$

STATISTICAL SUMMARY OF SELECTED DISSOLVED CHEMICAL CONSTITUENTS AND

REGRESSION RELATIONSHIPS OF CONSTITUENT CONCENTRATIONS TO SPECIFIC CONDUCTANCE

CONSIIIUENI

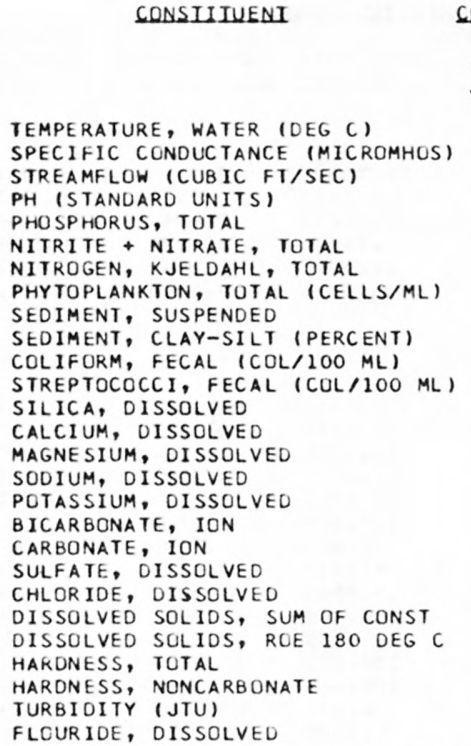

\begin{tabular}{r} 
CONSIII \\
SAMPLE \\
SIZE \\
\hline 16 \\
13 \\
11 \\
10 \\
8 \\
8 \\
8 \\
7 \\
6 \\
3 \\
6 \\
7 \\
7 \\
7 \\
7 \\
7 \\
7 \\
7 \\
6 \\
7 \\
7 \\
7 \\
7 \\
7 \\
7 \\
7 \\
7
\end{tabular}

\section{IMG/L OB UNII SHOWN STANDARD} DEYIAIION

9.31 503.8 1629.3 829.3 8.33
0.107
0.276 0.107
0.276 0.276 0.577
861.4 163.0 74.0

35.3

17.1 42.14 21.63 44.21 4.53 179.7 1.2 114.71 17.73 344.3 348.6

194.3

45.6

31.7
0.19
BANGE

7.37 177.8
3316.5 3316.5 0.61
0.144 0.144
0.254 0.254
0.273 0.273
794.8 794.8
251.8 12.1 66.7 19.3 3.35 14.48 10.85
23.10 23.10
2.10 66.9 2.9 62.09 7.95 144.5 140.0

78.1 36.1 49.4
0.11

$\begin{array}{rr}0.5 & 21.0 \\ 144 & 720 \\ 124 & 11000 \\ 7.3 & 9.1 \\ 0.00 & 0.45 \\ 0.01 & 0.63 \\ 0.25 & 1.20 \\ 190 & 2500 \\ 2 & 588 \\ 63 & 87 \\ 0 & 170 \\ 0 & 55 \\ 4.8 & 14.0 \\ 15.0 & 58.0 \\ 5.4 & 37.0 \\ 6.5 & 67.0 \\ 2.7 & 7.8 \\ 60 & 255 \\ 0 & 7 \\ 18.0 & 210.0 \\ 4.8 & 25.0 \\ 99 & 497 \\ 116 & 508 \\ 60 & 280 \\ 10 & 120 \\ 2 & 130 \\ 0.0 & 0.3\end{array}$

STANDAR BEGRESSION SUMYABY \begin{tabular}{llll} 
SAMPLE COEFICIENT, CONSTANT, CORRELATION ERROR OF \\
SIZE \\
\hline
\end{tabular} SIZE

*Not significant at the 95 percent confidence level. SUMMARY OF HARMONIC ANALYSIS OF STREAM TEMPERATURE

\begin{tabular}{|c|c|c|c|c|c|}
\hline & & & & & STANDARD \\
\hline & HARMONIC & AMPLITUDE & PHASE & VARIATION & ERROR OF \\
\hline SAMPLE & MEAN - M & $-A$ & ANGLE - C & EXP LAINED & ESTIMATE \\
\hline SIZE & $10 E 6 \mathrm{Cl}$ & (DEG $(1)$ & (RADIANSI & $-(8)$ & $10 E G(1)$ \\
\hline 54 & 8.73 & 11.50 & 2.84 & 90 & 1.87 \\
\hline
\end{tabular}

$\begin{array}{rr}9 & -5.008 \\ 9 & 0.0007 \\ 8 & -0.00028 \\ 8 & 0.00048 \\ 8 & -0.00025 \\ 5 & 0.917 \\ & \\ & \\ 7 & \\ 7 & 0.0019 \\ 7 & 0.0661 \\ 7 & 0.0490 \\ 7 & 0.1082 \\ 7 & -0.0046 \\ 7 & 0.288 \\ 6 & 0.006 \\ 7 & 0.2810 \\ 7 & 0.0350 \\ 7 & 0.685 \\ 7 & 0.656 \\ 7 & 0.365 \\ 7 & 0.125 \\ 7 & -0.186 \\ 7 & 0.0001\end{array}$

$\begin{array}{rr}-0.567 * & 1134.9 \\ 0.204 * & 0.67 \\ -0.397 * & 0.143 \\ 0.393 * & 0.252 \\ -0.190 * & 0.289 \\ 0.573 * & 323.5\end{array}$

$$
\begin{array}{r}
8.5831 \\
7.5218 \\
-4.0367 \\
-12.4401 \\
6.9606 \\
29.099 \\
-1.756 \\
-32.3805 \\
-0.6162 \\
-14.006 \\
5.202 \\
3.193 \\
-19.707 \\
129.293 \\
0.1500
\end{array}
$$

$0.120 *$

0.956

0.946

0.981

$-0.402$

0.900

$0.453 *$

0.947

0.923

0.992

0.981

0.979

0.723

-0.790
0.134 *
3.65

4.66

3.86

\begin{tabular}{|c|c|c|c|c|c|c|}
\hline \multirow{2}{*}{ CONSTITUENT } & \multicolumn{3}{|c|}{ TOTAL } & \multicolumn{3}{|c|}{ DISSOLVED } \\
\hline & $\begin{array}{l}\text { NO. } \\
\text { SAMPLES }\end{array}$ & $\begin{array}{l}\text { MIN IMUM } \\
\text { CONC. }\end{array}$ & $\begin{array}{l}\text { MAXIMUM } \\
\text { CONC. }\end{array}$ & $\begin{array}{l}\text { NO. } \\
\text { SAMPLES }\end{array}$ & $\begin{array}{l}\text { MINIMUM } \\
\text { CONC. }\end{array}$ & $\begin{array}{l}\text { MAXIMUM } \\
\text { CONC. }\end{array}$ \\
\hline \multicolumn{7}{|l|}{ MINOR ELEMENTS: } \\
\hline ARSENIC (AS), UG/L & 4 & 1 & 4 & 4 & 0 & 2 \\
\hline CADMIUM $(C D), U G / L$ & 4 & $<10$ & 10 & 5 & 0 & 2 \\
\hline CHROMIUM (CR), UG/L & 3 & 0 & 10 & 4 & 0 & 10 \\
\hline COBALT $(C O), U G / L$ & 4 & $<50$ & $<50$ & 5 & 0 & 20 \\
\hline COPPER (CU), UG/L & 4 & $<10$ & 360 & 5 & 2 & 12 \\
\hline IRON $(F E), U G / L$ & 4 & 110 & 510 & 5 & 10 & 140 \\
\hline LEAD $(P B), U G / L$ & 4 & $<100$ & $<100$ & 5 & 0 & 23 \\
\hline MANGANESE (MN), UG/L & 4 & 20 & 20 & 5 & 0 & 30 \\
\hline MERCURY $(H G), U G / L$ & 4 & 0.0 & $<0.1$ & 5 & 0.0 & $<0.1$ \\
\hline SELENIUM (SE), UG/L & 5 & 0 & 1 & 5 & 0 & 1 \\
\hline ZINC $(Z N), U G / L$ & 4 & 20 & 60 & 5 & 0 & 30 \\
\hline \multicolumn{7}{|l|}{ PERIPHYTON: } \\
\hline BIUMASS, DRY WT., GISO M & 1 & 71.00 & & & & \\
\hline BIOMASS, ASH WT, G/SO M & 1 & 39.00 & & & & \\
\hline CHLOROPHYLL A, MG/SQ M & 0 & & & & & \\
\hline CHLOROPHYLL B, MG/SQ M & 0 & & & & & \\
\hline ORGANIC CARBON, MG/L & 3 & 4.5 & 15.0 & & & \\
\hline
\end{tabular}

2.04

32.0

2.8

21.78

3.34

20.5

29.6

17.5

27.3

33.1
SUMMARY UF MAXIMUM AND MINIMUM CONCENTRATIONS OF CONSTITUENTS SAMPLEO AT A FREQUENCY OF QUARTERLY (1975 WY) 
LAT 4OD32M5OS LONG 108025M25S

DRAINAGE AREA: 3730 SQ MI 19661 SQ KM)

PERIOD OF RECORD: $10 / 01 / 74-09 / 30 / 75$

STATISTICAL SUMMARY OF SELECTED DISSOLVED CHEMICAL CONSTITUENTS AND

REGRESSION RELATIONSHIPS OF CONSTITUENT CONCENTRATIONS TO SPECIFIC CONDUCTANCE

\section{CONSIIIUENI}

CONSIJIUENI
TEMPERATURE, WATER (DEG C)
SPECIFIC CONDUCTANCE (MICROMHOS)
STREAMFLOW (CUBIC FT/SEC)
PH (STANDARD UNITS)
PHOSPHORUS, TOTAL
NITRITE, NITRATE, IOTAL
NITROGEN, KJELDAHL, TOTAL
PHYTOPLANKTON, TOTAL (CELLS/ML)
SEDIMENT, SUSPENDED
SEDIMENT, CLAY-SILT (PERCENT)
COLIFORM, FECAL (COL/IOO ML)
STREPTOCOCI, FECAL (COL/IOO ML)
SILICA, DISSOLVED
CALCIUM, DISSOLVED
MAGNESIUM, DISSOLVED
SODIUM, DISSOLVED
POTASSIUM, DISSOLVED
BICARBONATE, ION
CARBONATE, ION
SULFATE, DISSOLVED
CHLORIDE, DISSOLVED
DISSOLVED SOLIDS, SUM OF CONST
DISSOLVED SOLIDS, ROE I8O DEG C
HARUNESS, TOTAL
HARDNESS, NONCARBONATE
TURBIDITY (JTU)
FLOURIDE, DISSOLVED

CONSILIUENI IMG/L OR UNII SHOWNI

SAMPLE STANDARD

SIZE MEAN DEYIALLON

14
12
8
10
8
8
8
5
5
3
5
5
9
8
8
8
8
9
5
8
8
8
7
8
8
7
8
9.94
671.1
426.3

8.26
0.507

0.114

0.114

1456.0

1456.0
1916.4

1916.4
60.0

82.2

210.6

14.96

47.00

14.01

73.00

3.25

255.3
0.0

0.0
123.00

24.10

401.8

390.6

175.4

18.9
154.11
0.36
BANGE

7.78
355.3

950.3

0.50

0.912

0.127

0.809

1928.9

1869.8

39.5

151.9

408.0

4.40

16.58

5.26

63.58

1.68

167.9
0.0

0.0
76.53

23.07

193.0

189.5

63.6

213.8

213.8
0.19

0.0
175

11
7.5

7.5
0.02

0.01

0.01
0.25

0.25
180

180
25

20
0

0
10

6.6
18.0

18.0
4.5

4.5
10.0

0.7

79
0
18.0

18.0
2.4

2.4
105

115

63
0
15

15
SIZE

$$
\begin{array}{r}
25.5 \\
1330 \\
2770 \\
9.3 \\
2.70 \\
0.40 \\
2.60 \\
4800 \\
4560 \\
99 \\
350 \\
940 \\
21.0 \\
72.0 \\
22.0 \\
220.0 \\
6.2 \\
670 \\
0 \\
280.0 \\
77.0 \\
772 \\
743 \\
270 \\
45 \\
550
\end{array}
$$

* Not significant at the 95 percent confidence level.

SUMMARY OF HARMONIC ANALYSIS OF STREAM TEMPERATURE EORM OE EQUALION: I. $101=M+A+S I N L .0272 * D+C$

\begin{tabular}{|c|c|c|c|c|c|}
\hline & & & & & STANDARD \\
\hline & HARMONIC & AMPLITUDE & PHASE & VARIATION & ERROR OF \\
\hline SAMPLE & MEAN - $M$ & $-A$ & ANGLE - C & EXPLAINED & ESTIMATE \\
\hline SIZE & 1DEG 61 & $\left(0 E G_{C}()\right.$ & (BAD IANSI) & (3) & (DEG () \\
\hline 76 & 11.05 & 10.91 & 1.77 & 51 & 5.10 \\
\hline
\end{tabular}

76

11.05

10.91

1.77

5.10

SUMMARY OF MAXIMUM AND MINIMUM CONCENTRATIONS OF CONSTITUENTS SAMPLED AT A FREQUENCY OF QUARTERLY (1975 WY)

09200000 -- LITTLE SNAKE RIVER NEAR LILY, CO.

\begin{tabular}{|c|c|c|c|c|c|c|}
\hline \multirow{2}{*}{ CONSTITUENT } & \multicolumn{3}{|c|}{ TOTAL } & \multicolumn{3}{|c|}{ DISSOLVED } \\
\hline & $\begin{array}{l}\text { NO. } \\
\text { SAMPLES }\end{array}$ & $\begin{array}{l}\text { MINIMUM } \\
\text { CONC. }\end{array}$ & $\begin{array}{l}\text { MAXIMUM } \\
\text { CONC. }\end{array}$ & $\begin{array}{l}\text { NO. } \\
\text { SAMPLES }\end{array}$ & $\begin{array}{l}\text { MINIMUM } \\
\text { CONC. }\end{array}$ & $\begin{array}{l}\text { MAXIMUM } \\
\text { CONC. }\end{array}$ \\
\hline \multicolumn{7}{|l|}{ MINOR ELEMENTS: } \\
\hline ARSENIC (AS), UG/L & 3 & 0 & 26 & 3 & 1 & 18 \\
\hline CADMIUM $(C D), U G / L$ & 4 & $<10$ & 10 & 4 & 0 & 1 \\
\hline CHROMIUM (CR), UG/L & 3 & 0 & 60 & 3 & 0 & 40 \\
\hline CUBALT $(C O), U G / L$ & 4 & $<50$ & 100 & 4 & 0 & 2 \\
\hline COPPER $(C U), U G / L$ & 4 & $<10$ & 120 & 4 & 2 & 9 \\
\hline IRON $(F E), U G / L$ & 4 & 880 & 63000 & 6 & 10 & 3700 \\
\hline LEAD $(P B), U G / L$ & 4 & $<100$ & 100 & 4 & 0 & 4 \\
\hline MANGANESE (MN), UG/L & 4 & 30 & 340 & 6 & 0 & 150 \\
\hline MERCURY $(H G), U G / L$ & 4 & 0.0 & 0.1 & 4 & 0.0 & 0.1 \\
\hline SELENIUM (SE), UG/L & 4 & 0 & 3 & 4 & 0 & 2 \\
\hline ZINC $(Z N), U G / L$ & 4 & 20 & 130 & 4 & 10 & 70 \\
\hline \multicolumn{7}{|l|}{ PERIPHYTON: } \\
\hline BIOMASS, DRY WT., G/SQ M & 0 & & & & & \\
\hline BIOMASS, ASH WT., G/SQ M & 0 & & & & & \\
\hline CHLOROPHYLL A, MG/SQ M & 0 & & & & & \\
\hline CHLOROPHYLL B, MG/SQ M & 0 & & & & & \\
\hline ORGANIC CARBON, MG/L & 3 & 4.2 & 11.0 & & & \\
\hline
\end{tabular}


AT 38D59M1OS LONG $110009 M 02 S$

IRAINAGE AREA: 40600 SQ MI ( 105154 SQ KM)

'ERIOD OF RECORD: $10 / 01 / 74$ - 09/30/75

STATISTICAL SUMMARY OF SELECTED DISSOLVED CHEMICAL CONSTIIUENIS AND

REGRESSION RELATIONSHIPS OF CONSTITUENT CONCENTRATIONS TO SPECIFIC CONDUCTANCE

CONSIIUENT

CONSIIIUENI IMG/L OR UNII SHOHN

TEMPERATURE, WATER (DEG C)
SPECIFIC CONDUCTANCE (MICROMHOS)
STREAMFLOW (CUBIC FT/SEC)
PH (STANDARD UNITS)
PHOSPHORUS, TOTAL
NITRITE, NITRATE, TOTAL
NITROGEN, KJELDAHL, TOTAL
PHYTOPLANKTON, TOTAL (CELLS/ML)
SEDIMENT, SUSPENDED
SEDIMENT, CLAY-SILT (PERCENT)
COLIFORM, FECAL (COL/IOO ML)
STREPTOCOCCI, FECAL (COL/IOO ML)
SILICA, DISSOLVED
CALCIUM, DISSOLVED
MAGNESIUM, DISSOLVED
SODIUM, DISSOLVED
POTASSIUM, DISSOLVED
BICARBONATE, ION
CARBONATE, ION
SULFATE, DISSOLVED
CHLORIDE, DISSOLVED
DISSOLVED SOLIDS, SUM OF CONST
DISSOLVED SOLIOS, ROE I8O DEG C
HARDNESS, TOTAL
HARDNESS, NONCARBONATE
TURBIDITY (JTU)
FLOURIDE, DISSOLVED

SANSILIJ

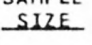

\section{MEAN}

STANDARD QEVIALION

27
14
13
14
12
12
12
12
16
3
9
11
13
13
13
13
13
13
13
13
13
13
12
13
13
12
13$$
\begin{array}{r}
12.30 \\
781 \\
6276 \\
8.26
\end{array}
$$

781.4

8.26

0.342

0.436

0.931

3643.3

2042.0

279.0
55.2

158.6

6.52

66.62

29.31

71.38

71.38
2.94

2.94
188.9

1.5

242.15

24.54

538.5

555.1

286.9

130.8

174.2

7.97
187.3
4776.1
0.30
0.259
0.183
0.516
2940.1
2749.0
383.2
79.9
218.9
1.50
13.67
8.37
21.29
0.62
30.3
2.4
76.31
7.72
140.2
146.6
65.8
44.3
140.9
0.04

7.97

4776.1

0.30

0.259

0.516

940.1

383.2

79.9

18.9

8.37

0.62

0.3

6.31

40.2

46.6

44.3

0.04

\section{N)}

BANGE

SAMPLE REGRESSION

BEGRESSION_SUMMABY

0.0
370
3000
7.7
0.05
0.12
0.46
520
199
41
0
6
4.9
36.0
11.0
25.0
1.7
118
0
78.0
8.0
226
243
140
38
30
0.2

DAILY SPECIFIC CONDUCTANCE IN DUIION_IABLE_OF DAUL SPECIEIC CONDUCIANCE

MICROMHOS AT 25 DEG C. THAT WAS

$\begin{array}{llllll}18 & 52 & 10 z & 20 z \quad 30 z \quad 50 \%\end{array}$

23.0

23.0
1060
19400

$\begin{array}{rrr}19400 & 13 & -22.129\end{array}$

$\begin{array}{rr}8.7 & 14 \\ 0.94 & 12\end{array}$

0.66

2.10

10000
9790

$\begin{array}{lr}14 & 0.0006 \\ 12 & -0.00047\end{array}$

$-0.00047$

0.00041
-0.00092

7.7933
0.09922

0.12378

0.12378

$-4.894$

7386.949

CORRELATION

STANDARO ERROR OF

721

240
740

740
10.0

10.0
79.0

45.0113

95.0

$4.0 \quad 13$

$\begin{array}{rr}219 & 13 \\ 7 & 13\end{array}$

350.0

34.0

$\begin{array}{ll}718 & 13 \\ 716 & 13\end{array}$

-0.0064
0.0670
0.0406
0.1008
0.0020
0.133
0.004
0.3735
0.0356
0.084
0.085
0.329
0.221
-0.195
0.0002

11.4911

$-2.1053$

$-6.5905$

-6.5905
1.3889

86.157

$-1.972$

$-46.8676$

$-3.0157$

8.770
30.907

32.011

$-40.536$

323.264

0.1551 COEEICIENI.

ESIIMAIE

INDICATED PERCENTAGE OF TIME.

$1260 \quad 1075 \quad 1040 \quad 1000$

980

899

TEZ $20 \%$ SAMPLE SIZE $=290$

SUMMARY OF HARMONIC ANALYSIS OF STREAM TEMPERATURE

\begin{tabular}{|c|c|c|c|c|c|}
\hline & & & & & STANDARD \\
\hline & HARMONIC & AMPLITUDE & PHASE & VARIATION & ERROR OF \\
\hline SAMPLE & MEAN - M & $-A$ & ANGLE - C & EXPLA INED & ESTIMATE \\
\hline SIZE & $10 E 6$ C) & (DEG G) & IRADIANSI & -121 & 1DEG CL \\
\hline 284 & 11.43 & 11.33 & 2.75 & 95 & 1.95 \\
\hline
\end{tabular}

SUMMARY OF MAXIMUM AND MINIMUM CONCENTRATIONS OF CONSTITUENTS SAMPLED AT A FREQUENCY OF QUARTERLY (1975 WY)

09315000 -- GREEN RV AT GREEN RV UT

\begin{tabular}{|c|c|c|c|c|c|c|}
\hline \multirow{2}{*}{ CONSTITUENT } & \multicolumn{3}{|c|}{ TOTAL } & \multicolumn{3}{|c|}{ DISSOLVED } \\
\hline & $\begin{array}{l}\text { NO. } \\
\text { SAMPLES }\end{array}$ & $\begin{array}{l}\text { MINIMUM } \\
\text { CONC. }\end{array}$ & $\begin{array}{l}\text { MAXIMUM } \\
\text { CONC. }\end{array}$ & $\begin{array}{l}\text { NO. } \\
\text { SAMPLES }\end{array}$ & $\begin{array}{l}\text { MINIMUM } \\
\text { CONC. }\end{array}$ & $\begin{array}{l}\text { MAXIMUM } \\
\text { CONC. }\end{array}$ \\
\hline \multicolumn{7}{|l|}{ MINOR ELEMENTS: } \\
\hline ARSENIC (AS), UG/L & 4 & 2 & 11 & 4 & 1 & 5 \\
\hline CADMIUM $(C D), U G / L$ & 4 & $<10$ & 20 & 4 & 0 & 1 \\
\hline CHROMIUM (CR), UG/L & 4 & 0 & 20 & 4 & 0 & 10 \\
\hline COBALT $(C O), U G / L$ & 4 & $<50$ & 50 & 4 & 1 & 1 \\
\hline COPPER $(C U), U G / L$ & 4 & 10 & 470 & 4 & 2 & 3 \\
\hline IRON $(F E), U G / L$ & 4 & 1200 & 18000 & 4 & 10 & 30 \\
\hline LEAD $(P B), U G / L$ & 4 & $<100$ & $<100$ & 4 & 0 & 4 \\
\hline MANG ANESE $(M N), U G / L$ & 4 & 40 & 430 & 4 & 0 & 10 \\
\hline MERCURY (HG), UG/L & 4 & 0.0 & 0.2 & 4 & 0.0 & 0.2 \\
\hline SELENIUM $(S E), U G / L$ & 4 & 1 & 3 & 4 & 1 & 3 \\
\hline ZINC $(Z N), U G / L$ & 4 & 40 & 110 & 4 & 10 & 20 \\
\hline \multicolumn{7}{|l|}{ PERIPHYTON: } \\
\hline BIOMASS, DRY WT., G/SO M & 2 & .39 & 4.19 & & & \\
\hline GIOMASS, ASH WT., G/SQ M & 2 & .39 & 3.19 & & & \\
\hline CHLOROPHYLL A, MG/SQ M & 3 & .1 & 1.0 & & & \\
\hline CHLOROPHYLL B, MG/SQ M & 3 & .0 & $\cdot 2$ & & & \\
\hline ORGANIC CARBON, MG/L & 4 & 4.2 & 12.0 & & & \\
\hline
\end{tabular}


Table 14.--Sumary of measurement at each station--Continued

LAT $36047 M 32 S$ LONG $108043 M 54 S$

DRAINAGE AREA: $12900 \mathrm{SQ} M I(133411$ SQ KMI

PERIOD OF RECORD: $10 / 01 / 74-09 / 30 / 75$

STATISTICAL SUMMARY OF SELECTED DISSOLVED CHEMICAL CONSTITUENTS AND

REGRESSION RELATIONSHIPS OF CONSTITUENT CONCENTRATIONS TO SPECIFIC CONDUCTANCE

CONSIIIUENI

CONSIUIUENI_IMG/L_OR UNII SHOWNI

TEMPERATURE, WATER (DEG C)

SPECIFIC CONDUCTANCE (MICROMHOS)

STREAMFLOW (CUBIC FT/SEC)

PH (STANDARD UNITS)

PHOSPHORUS, TOTAL

NITRITE + NITRATE, TOTAL

NITROGEN, KJELDAHL, TOTAL

PHYTOPLANKTON, TOTAL (CELLS/ML)

SEDIMENT, SUSPENDED

SEDIMENT, CLAY-SILT (PERCENT)

COLIFORM, FECAL (COL/100 ML)

STREPTOCOCCI, FECAL (COL/100 ML)

SILICA, DISSOLVED

CALCIUM, DISSOLVED

MAGNESIUM, PISSOLVED

SODIUM, DISSOLVED

POTASSIUM, DISSOLVED

BICARBONATE, ION

CARBONATE, ION

SULFATE, DISSOL VED

CHLORIDE, DISSOLVED

DISSOLVED SOLIDS, SUM OF CONST

DISSOLVED SOLIDS, RUE 180 DEG

HARDNESS, TOTAL

HARDNESS, NONCARBONATE

TUREIDITY (JTU)

FLOURIDE, DISSOLVED
SAMPLE
SIZE

STANDARD

44

${ }^{\star}$ Not significant at the 95 percent confidence level.

\section{DURAIION IABLE OE RALLY SPECIEIC CONOUCIANCE}

DAILY SPECIFIC CONDUCTANCE IN

MICROMHOS AT 25 DEG C, THAT WAS

EQUALLED OR EXCEEDED FOR THE

$\begin{array}{llllll}28 & 50 \% \quad 20 \% \quad 30 \% \quad 58\end{array}$

502703

1200

955

877

805

776

689

471 REGRESSION

REGRESSION SUMMABY

STANDARD SAMPLE COEFICIENT, CONSTANT, CORRELATION ERROR OF
SIZE B B B B BEICIENI ESIUMAIE

SUMMARY OF HARMONIC ANALYSIS OF STREAM TEMPERATURE

\begin{tabular}{|c|c|c|c|c|c|}
\hline & & & & & STANDARD \\
\hline & $\begin{array}{l}\text { HARMONIC } \\
\text { MEAN - M }\end{array}$ & AMPLITUDE & PHASE & VARIATION & $\begin{array}{l}\text { ERROR OF } \\
\text { ESTIMATE }\end{array}$ \\
\hline $\begin{array}{l}\text { SAMPLE } \\
\text { SIZE }\end{array}$ & $\begin{array}{l}\text { MEAN }-M \\
10 E G \quad C I_{-}\end{array}$ & DEEG ${ }^{A}(1)$ & $\begin{array}{l}\text { ANGLE - C } \\
\text { IBADIANSI }\end{array}$ & $\begin{array}{c}\text { EXPLA INED } \\
\text { (I) }\end{array}$ & $\begin{array}{l}\text { ESTIMATE } \\
\text { LEE_CL }\end{array}$ \\
\hline 363 & 10.48 & 8.70 & 2.66 & 91 & 1.97 \\
\hline
\end{tabular}

SUMMARY OF MAXIMUM AND MINIMUM CONCENTRATIONS OF CONSTITUENTS SAMPLED AT A FREQUENCY OF QUARTERLY (1975 WY)

09368000 -- SAN JUAN R AT SHIPROCK, NM

\begin{tabular}{|c|c|c|c|c|c|c|}
\hline \multirow{2}{*}{ CONSTI TUENT } & \multicolumn{3}{|c|}{ TOTAL } & \multicolumn{3}{|c|}{ DISSOLVED } \\
\hline & $\begin{array}{l}\text { NO. } \\
\text { SAMPLES }\end{array}$ & $\begin{array}{l}\text { MIN IMUM } \\
\text { CONC. }\end{array}$ & $\begin{array}{l}\text { MAXIMUM } \\
\text { CONC. }\end{array}$ & $\begin{array}{l}\text { NO. } \\
\text { SAMPLES }\end{array}$ & $\begin{array}{l}\text { MINIMUM } \\
\text { CONC. }\end{array}$ & $\begin{array}{l}\text { MAXIMUM } \\
\text { CONC. }\end{array}$ \\
\hline \multicolumn{7}{|l|}{ MINOR ELEMENTS: } \\
\hline ARSENIC (AS), UG/L & 4 & 2 & 56 & 4 & 0 & 1 \\
\hline CADMIUM $(C D)$, UG $/ L$ & 4 & $<10$ & $<10$ & 4 & 0 & 0 \\
\hline CHROMIUM (CR), UG/L & 4 & 0 & 140 & 4 & 0 & 10 \\
\hline COBALT $(C O), U G / L$ & 4 & $<50$ & 50 & 4 & 0 & 1 \\
\hline COPPER (CU), UG/L & 4 & 20 & 170 & 4 & 2 & 15 \\
\hline IRON (FE), UG/L & 4 & 3100 & 130000 & 16 & 0 & 40 \\
\hline LEAD $(P B), U G / L$ & 4 & $<100$ & 200 & 4 & 0 & 0 \\
\hline MANGANESE (MN), UG/L & 4 & 130 & 3600 & 4 & 0 & 10 \\
\hline MERCURY $(H G), U G / L$ & 4 & 0.0 & 0.1 & 4 & 0.0 & 0.1 \\
\hline SELENIUM (SE), UG/L & 4 & 1 & 3 & 4 & 1 & 3 \\
\hline$Z I N C(Z N), U G / L$ & 4 & 30 & 690 & 4 & 0 & 30 \\
\hline \multicolumn{7}{|l|}{ PERIPHYTON: } \\
\hline BIOMASS, DRY WT., G/SO M & 4 & .59 & 8.79 & & & \\
\hline BIOMASS, ASH WT., G/SO M & 4 & .19 & 6.89 & & & \\
\hline CHLOROPHYLL A, MG/SQ M & 3 & .0 & 21.0 & & & \\
\hline CHLOROPHYLL B, MG/SQ M & 3 & .0 & $2 \cdot 1$ & & & \\
\hline ORGANIC CARBON, MG/L & 9 & 5.6 & 110.0 & & & \\
\hline
\end{tabular}


LAT 37D08M49S LONG 109051 M51S

DRAINAGE AREA: 23000 SQ MI ( 59570 SQ KM)

PERIOD OF RECORD: $10 / 01 / 74-09 / 30 / 75$

STATISTICAL SUMMARY OF SELECTED DISSOLVED CHEMICAL CONSTITUENTS ANO

REGRESSION RELATIONSHIPS OF CONSTITUENT CONCENTRATIONS TO SPECIFIC CONDUCTANCE

\section{CONSIIIUENI}

\section{SAMPLE

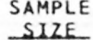

TEMPERATURE, WATER (DEG C) SPECIFIC CONDUCTANCE (MICROMHOS) STREAMFLOW (CUBIC FT/SEC)

PH (STANDARD UNITS)

PHOSPHORUS, TOTAL

NITROGEN, KJELDAHL, TOTAL

PHYTOPLANKTON, TOTAL (CELLS/ML)

SEDIMENT, SUSPENDED

SEDIMENT, CLAY-SILT (PERCENT)

COLIFURM, FECAL ( $C O L / 100 \mathrm{ML}$ )

STREPTOCOCCI, FECAL (COL/100 ML)

CALCIUM, DISSOLVED

MAGNESIUM, DISSOLVED

SODIUM, DISSOLVED

POTASSIUM, DISSOL VED

BICARBONATE, ION

CARBONATE, ION

SULFATE, DISSOLVED

CHLORIDE, DISSOLVED

CHLURIDE, DISSOLVED

DISSOLVED SOLIDS, SUM OF CONST

HARDNESS, TOTAL

HARDNESS, TOTAL
HARDNESS, NONCARBONATE

TURBIDITY ( JTU)

FLOURIDE, DISSOLVED
NITRITE + NITRATE, TOTAL

SILICA, DISSOLVED

$\begin{array}{rrr}27 & 11.35 & 6.58 \\ 14 & 789.3 & 301.9 \\ 26 & 2823.8 & 2379.2 \\ 13 & 8.18 & 0.20 \\ 11 & 0.512 & 0.586 \\ 11 & 0.855 & 0.508 \\ 11 & 1.104 & 0.862 \\ 11 & 3262.7 & 3318.2 \\ 16 & 6969.7 & 10948.1 \\ 2 & 56.0 & 58.0 \\ 9 & 657.1 & 1266.6 \\ 9 & 485.4 & 571.1 \\ 11 & 9.00 & 1.36 \\ 11 & 77.82 & 26.02 \\ 11 & 22.15 & 10.82 \\ 11 & 64.09 & 38.73 \\ 11 & 2.95 & 0.82 \\ 11 & 156.5 & 36.2 \\ 10 & 0.7 & 2.2 \\ 11 & 257.36 & 129.05 \\ 11 & 18.03 & 9.84 \\ 11 & 530.1 & 229.9 \\ 11 & 555.4 & 243.9 \\ 11 & 287.3 & 107.4 \\ 11 & 157.7 & 81.0 \\ 11 & 387.6 & 441.9 \\ 11 & 0.33 & 0.08\end{array}$

$\begin{array}{rr}\text { BANGE } & \\ & \\ 0.0 & \\ 300 & 22.0 \\ 850 & 1150 \\ 7.9 & 8760 \\ 0.06 & 8.4 \\ 0.14 & 2.00 \\ 0.20 & 1.40 \\ 370 & 11000 \\ 41 & 40200 \\ 15 & 97 \\ 42 & 4000 \\ 45 & 1800 \\ 5.8 & 11.0 \\ 34.0 & 110.0 \\ 7.6 & 41.0 \\ 14.0 & 140.0 \\ 1.6 & 4.3 \\ 91 & 198 \\ 0 & 7 \\ 67.0 & 420.0 \\ 3.9 & 31.0 \\ 179 & 014 \\ 195 & 839 \\ 120 & 420 \\ 42 & 260 \\ 20 & 1300 \\ 0.2 & 0.4 \\ & \\ 0.2 & \end{array}$

SAMPLE
SIZE REGRESSION

BEGRESS ION SUMMABY

COEFICIENT,

CONSTANT,

CORRELATION ERANDARO COEEILIENI ESILMAIE

13

1

11

11
11
11
11
11
11
10
11
11
11
11
11
11
11
11 *Not significant at the 95 percent confidence level.

DURAILON IABLE_OF DALLY SPECIEIC CONDUCIANCE

DAILY SPECIFIC CONDUCTANCE IN

MICROMHOS AT 25 DEG C, THAT WAS

EQUALLED OR EXCEEDED FOR THE

$\begin{array}{rrrrrr}18 & -5 \% & 10 z & 20 z & 30 z & 50 \% \\ 1210 & 1150 & 1120 & 1100 & 1060 & 680\end{array}$

SUMMARY OF HARMONIC ANALYSIS OF STREAM TEMPERATURE FORM OE EQUAIION: I.IDI $=M+A * S I N / .0172 * 0+C$

\begin{tabular}{|c|c|c|c|c|c|}
\hline & & & & & STANDARD \\
\hline & HARMONIC & AMPLITUDE & PHASE & VARIATION & ERROR OF \\
\hline SAMPLE & MEAN - M & $-A$ & ANGLE - C & EXPLAINED & ESTIMATE \\
\hline SIZE_ & $10 E G_{2}(1)$ & $-10 E G(1)$ & (BADIANS) & $\ldots 181$ & $10 E G(C)$ \\
\hline 296 & 12.31 & 10.40 & 2.77 & 93 & 1.96 \\
\hline
\end{tabular}

SUMMARY OF MAXIMUM AND MINIMUM CONCENTRATIONS OF CONSTITUENTS SAMPLED AT A FREQUENCY OF QUARTERLY (1975 WY)

09379500 -- SAN JUAN RIVER NEAR BLUFF, UTAH

\begin{tabular}{|c|c|c|c|c|c|c|}
\hline \multirow{2}{*}{ CONSTI TUENT } & \multicolumn{3}{|c|}{ TOTAL } & \multicolumn{3}{|c|}{ DISSOLVED } \\
\hline & $\begin{array}{l}\text { NO. } \\
\text { SAMPLES }\end{array}$ & $\begin{array}{l}\text { MINIMUM } \\
\text { CONC. }\end{array}$ & $\begin{array}{l}\text { MAXIMUM } \\
\text { CONC. }\end{array}$ & $\begin{array}{l}\text { NO. } \\
\text { SAMPLES }\end{array}$ & $\begin{array}{l}\text { MINIMUM } \\
\text { CONC. }\end{array}$ & $\begin{array}{l}\text { MAXIMUM } \\
\text { CONC. }\end{array}$ \\
\hline \multicolumn{7}{|l|}{ MINOR ELEMENTS: } \\
\hline ARSENIC (AS), UG/L & 3 & 1 & 17 & 3 & 1 & 5 \\
\hline CADMIUM $(C D), U G / L$ & 3 & $<10$ & 20 & 3 & 0 & 1 \\
\hline CHROMIUM (CR), UG/L & 3 & 0 & 0 & 3 & 0 & 0 \\
\hline COBALT $(C O), U G / L$ & 3 & $<50$ & $<50$ & 3 & 0 & 1 \\
\hline COPPER (CU), UG/L & 3 & 30 & 410 & 3 & 2 & 7 \\
\hline IRON (FE), UG/L & 3 & 1300 & 14000 & 3 & 10 & 20 \\
\hline LEAD $(P B), U G / L$ & 3 & $<100$ & $<100$ & 3 & 0 & 5 \\
\hline MANGANESE (MN), UG/L & 3 & 50 & 1200 & 3 & 0 & 10 \\
\hline MERCURY (HG), UG/L & 3 & 0.0 & 0.1 & 3 & 0.0 & 0.0 \\
\hline SELENIUM (SE), UG/L & 3 & 2 & 6 & 3 & 1 & 5 \\
\hline$Z I N C(Z N), U G / L$ & 3 & 30 & 150 & 3 & 10 & 20 \\
\hline \multicolumn{7}{|l|}{ PERIPHYTON: } \\
\hline BIOMASS, DRY WT., G/SO M & 2 & .69 & 13.00 & & & \\
\hline BIOMASS, ASH WT., G/SO M & 3 & .69 & 23.00 & & & \\
\hline CHLOROPHYLL A, MG/SQ M & 3 & .0 & .1 & & & \\
\hline CHLOROPHYLL $B, M G / S Q M$ & 3 & .0 & .2 & & & \\
\hline ORGANIC CARBON, MG/L & 3 & 3.0 & 14.0 & & & \\
\hline
\end{tabular}


LAT 36D51M53S LONG 111035 M15S

DRAINAGE AREA: 107900 SQ MI 1279461 SQ KMI

PERIOD OF RECORD: $10 / 01 / 74-09 / 30 / 75$

STATISTICAL SUMMARY OF SELECTED DISSOLVED CHEMICAL CONSTITUENTS AND

REGRESSION RELATIONSHIPS OF CONSTITUENT CONCENTRATIONS TO SPECIFIC CONDUCTANCE

CONSIIUUENI

CONSILIUENI IMG L OR UNII SHOWNL

\section{TEMPERATURE, WATER (DEG C)}

STANDARD

SIZE SPECIFIC CONDUCTANCE (MICROMHOS) STREAMFLOW (CUBIC FT/SEC)

PH (STANDARD UNITS) PHOSPHORUS, TOTAL

NITRITE + NITRATE, TOTAL

NITROGEN, KJELDAHL, TOTAL

PHYTOPLANKTON, TOTAL (CELLS/ML)

SEDIMENT, SUSPENDED

SEDIMENT, CLAY-SILT (PERCENT)

COLIFURM, FECAL (COL/100 ML)

STREPTOCOCCI, FECAL (COL/100 ML)

SILICA, DISSOLVED

CALCIUM, DISSOLVED

MAGNESIUM, DI SSOL VED

SODIUM, DISSOLVED

POTASSIUM, DISSOLVED

BICARBUNATE, ION

CARBONATE, ION

SULFATE, DISSOLVED

CHLORIDE, DISSOLVED

DISSOLVED SOLIDS, ROE 180 DEG C

HARDNESS, TOTAL

HARDNESS, NONCARBONATE

TURBIDITY (JTU)

FLOURIDE, DISSOLVED
DISSOLVED SOLIDS, SUM OF CONST

$\begin{array}{rrrc} & & & \\ 10 & 8.70 & 0.95 & 7.5 \\ 10 & 832.5 & 59.7 & 750 \\ 11 & 14959.1 & 8764.6 & 1680 \\ 10 & 7.92 & 0.36 & 7.2 \\ 10 & 0.011 & 0.012 & 0.00 \\ 10 & 0.499 & 0.089 & 0.38\end{array}$

$\begin{array}{lll}0.499 & 0.089 & 0.38\end{array}$

$\begin{array}{lll}0.234 & 0.040 & 0.19\end{array}$

$743.3 \quad 563.2$

84.998.

100.0

1.5

6.4

7.56

69.10

25.10

72.90
3.63

3.63
162.2

162.2
0.0

222.00

48.30

535.7

552.8

275.0

141.0

14.0

0.25

0.0
1.5

16.5

10.5
0.77

4.28

4.28
2.42

6.03

0.23
7.2

7.2
0.0

16.87

6.06

43.7

21.2

16.0

31.5
0.07

5.9

5.9
64.0

22.0
64.0

64.0
3.3

200.0

200.0
40.0

491
494

494
250

250
120

0
0.1 $\begin{array}{ll}0.03 \\ 0.19 & 0.01\end{array}$

$\begin{array}{rr}120 & 1400 \\ 2 & 303\end{array}$

$\begin{array}{rr}100 & 100 \\ 1 & 6 \\ 1 & 56\end{array}$

8.7
76.0
28.0
81.0
4.0
173

BEGRESS LON SUMMABY

REGRESSION

SAMPLE COEFICIENT, CONSTANT, CORRELATION - B. COEEICIENI

STANDARD ERROR OF ESIUTAIE

$\begin{array}{rr}10.0 & \\ 930 & \\ 25700 & 10 \\ 8.4 & 10 \\ 0.03 & 10 \\ 0.01 & 10 \\ 0.31 & 10 \\ 1400 & 6 \\ 303 & \\ 100 & \\ 6 & \\ 56 & \\ 8.7 & 9 \\ 76.0 & 10 \\ 28.0 & 10 \\ 81.0 & 10 \\ 4.0 & 9 \\ 173 & 10 \\ 0 & 7 \\ 240.0 & 10 \\ 57.0 & 10 \\ 579 & 9 \\ 614 & 10 \\ 300 & 10 \\ 160 & 10 \\ 100 & 10 \\ 0.3 & 10\end{array}$

\section{DURAILON IABLE_OF_DAIL SPECIEIC CONDUCIANCE}

DAILY SPECIFIC CONDUCTANCE IN

MICROMHOS AT 25 DEG C, THAT WAS

EQUALLED OR EXCEEDED FOR THE

$\begin{array}{llllll}21 & -5 z & 20 z & 20 z & 30 z & 50 z\end{array}$

808

\begin{tabular}{llll} 
& \multicolumn{3}{l}{ SAMPLE SIZE $=280$} \\
$70 \%$ & $20 \%$ & $25 \%$ & $29 \%$ \\
810 & 790 & 780 & 730
\end{tabular}

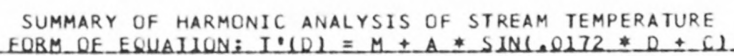

\begin{tabular}{|c|c|c|c|c|c|}
\hline & & & & & STANDARD \\
\hline & HARMONIC & AMPLITUDE & PHASE & VARIATION & ERROR OF \\
\hline SAMPLE & MEAN - M & $-A$ & ANGLE - C & EXPLAINED & ESTIMATE \\
\hline SIZE & $10 E G(1$ & DEE $C 1$ & IBADIANSI & $\ldots(z) \ldots$ & LEEG $C 1$ \\
\hline 279 & 8.66 & 1.05 & 2.63 & 64 & 0.56 \\
\hline
\end{tabular}

SUMMARY OF MAXIMUM AND MINIMUM CONCENTRATIONS OF CONSTITUENTS

SAMPLED AT A FREQUENCY OF QUARTERLY (1975 WY)

09380000 -- COLORADO R AT LEES FERRY, AZ.

CONSTITUENT
SAMPLES


LAT $35052 M 40 S$ LONG $111024 M 40 S$

DRAINAGE AREA: 0 SO MI

PERIOD OF RECORD: $10 / 01 / 74-09 / 30 / 75$ SQ KMI

STATISTICAL SUMMARY OF SELECTED DISSOLVED CHEMICAL CONSTITUENTS AND

REGRESSION RELATIONSHIPS OF CONSTITUENT CONCENTRATIONS TO SPECIFIC CONDUCTANCE

CONSIUTUENI

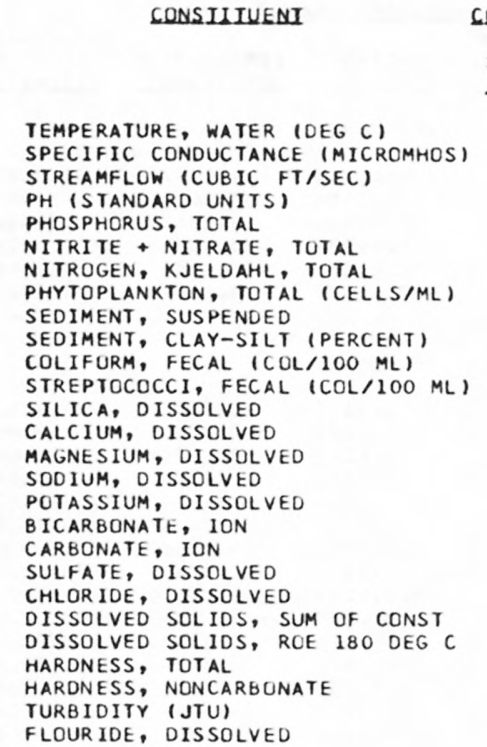

CONSIITUENI IMGLL OR UNII SHOWN SIZE MEA

STANDARD

DEYIATION

6
6
6
4
6
6
6
4
0
0
5
6
6
6
6
6
6
6
4
6
6
6
6
6
6
6
6

$\begin{array}{rrrr}14.50 & 8.12 & 7.0 & 27.0 \\ 727.3 & 429.6 & 275 & 1300 \\ 226.7 & 201.2 & 1 & 520 \\ 8.30 & 0.90 & 7.2 & 9.4 \\ 2.780 & 3.557 & 0.09 & 9.80 \\ 0.690 & 0.802 & 0.04 & 2.10 \\ 5.628 & 9.115 & 0.27 & 24.00 \\ 375.0 & 750.0 & 0 & 1500 \\ & & & \\ 8926.0 & 11334.9 & 260 & 28000 \\ 5794.0 & 87074.1 & 4 & 220000 \\ 9.67 & 4.05 & 5.3 & 16.0 \\ 24.30 & 14.86 & 5.8 & 44.0 \\ 4.42 & 3.01 & 1.2 & 8.7 \\ 126.50 & 72.74 & 37.0 & 210.0 \\ 3.23 & 1.59 & 1.3 & 5.6 \\ 155.5 & 45.6 & 95 & 193 \\ 1.3 & 2.5 & 0 & 5 \\ 97.33 & 80.50 & 16.0 & 210.0 \\ 85.17 & 63.82 & 23.0 & 190.0 \\ 432.5 & 237.6 & 149 & 710 \\ 455.3 & 254.4 & 144 & 750 \\ 79.8 & 51.0 & 19 & 150 \\ 1.7 & 4.1 & 0 & 10 \\ 3035.0 & 144118.4 & 10 & 340000 \\ 0.62 & 0.26 & 0.2 & 0.8\end{array}$

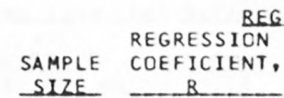

BEG

\begin{tabular}{l} 
SAMPLE \\
SIZE \\
\hline
\end{tabular} B.

6
4
6
6
6

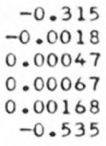

$-0.535$

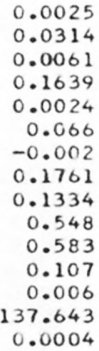

GBESSION SUMMABY

CONSTANT, CORRELATION COEEICIENI ESILMAI

*Not significant at the 95 percent confidence level.

SUMMARY OF MAXIMUM AND MINIMUM CONCENTRATIONS OF CONSTITUENTS SAMPLED AT A FREQUENCY OF QUARTERLY (1975 WY)

09401200 -- LITTLE COLORADO R AT CAMERON ARIZ.

\begin{tabular}{|c|c|c|c|c|c|c|}
\hline \multirow{2}{*}{ CONSTITUENT } & \multicolumn{3}{|c|}{ TOTAL } & \multicolumn{3}{|c|}{ DISSOLVEO } \\
\hline & $\begin{array}{l}\text { NO. } \\
\text { SAMPLES }\end{array}$ & $\begin{array}{l}\text { MINIMUM } \\
\text { CONC. }\end{array}$ & $\begin{array}{l}\text { MAXIMUM } \\
\text { CONC. }\end{array}$ & $\begin{array}{l}\text { NO. } \\
\text { SAMPLES }\end{array}$ & $\begin{array}{l}\text { MINIMUM } \\
\text { CONC. }\end{array}$ & $\begin{array}{l}\text { MAXIMUM } \\
\text { CONC. }\end{array}$ \\
\hline \multicolumn{7}{|l|}{ MINUR ELEMENTS: } \\
\hline ARSENIC (AS), UG/L & 1 & 110 & & 1 & 0 & \\
\hline CADMIUM $(C D), U G / L$ & 1 & 10 & & 1 & 1 & \\
\hline CHROMIUM (CR), UG/L & 1 & 50 & & 1 & 10 & \\
\hline COBALT $(C O), U G / L$ & 1 & 90 & & 1 & 0 & \\
\hline COPPER (CU), UG/L & 1 & 100 & & 1 & 35 & \\
\hline IRON (FE), UG/L & 1 & 60000 & & 1 & 60 & \\
\hline LEAD $(P B), U G / L$ & 1 & 200 & & 1 & 3 & \\
\hline MANG ANESE (MN), UG/L & 1 & 5000 & & 1 & 10 & \\
\hline MERCURY $(H G), U G / L$ & 1 & 0.3 & & 1 & 0.1 & \\
\hline SELENIUM (SE), UG/L & 1 & 3 & & 1 & 1 & \\
\hline$Z I N C(Z N), U G / L$ & 1 & 280 & & 1 & 10 & \\
\hline \multicolumn{7}{|l|}{ PERIPHYTON: } \\
\hline BIOMASS, DRY WT., G/SQ M & 1 & .69 & & & & \\
\hline BIOMASS, ASH WT., G/SO M & 1 & .39 & & & & \\
\hline CHLOROPHYLL A, MG/SQ M & 1 & .0 & & & & \\
\hline CHLOROPHYLL $B, M G / S O M$ & 1 & .0 & & & & \\
\hline ORGANIC CARBON, MG/L & 1 & 50.0 & & & & \\
\hline
\end{tabular}


AT 36DOOM55S LONG $114044 M 16 \mathrm{~S}$

IRAINAGE AREA: 167800 SQ MI ( 434602 SQ KM)

'ERIOD OF RECORD: $10 / 01 / 74-09 / 30 / 75$

STATISTICAL SUMMARY OF SELECTED DISSOLVED CHEMICAL CONSTITUENTS AND REGRESSION RELATIONSHIPS OF CONSTITUENT CONCENTRATIONS TO SPECIFIC CONDUCTANCE

CONSIIIUENI

CONSIUUVENI IHGLL OR UNII SHOWN

$\begin{array}{ll}\text { SAMPLE } & \text { STANDARD } \\ \text { SIZE MEAN DEYIAUION }\end{array}$

AN REYLALION BANGE

TEMPERATURE, WATER (DEG C) SPECIFIC CONDUCTANCE (MICROMHOS) STREAMFLOW (CUBIC FT/SEC)

PH (STANDARD UNITS)

PHOSPHORUS, TOTAL

NITRITE + NITRATE, TOTAL

NITROGEN, KJELOAHL, TOTAL

PHYTOPLANKTON, TOTAL (CELLS/ML)

SEDIMENT, SUSPENDED

SEDIMENT, CLAY-SILT (PERCENT)

COLIFORM, FECAL (COLA100 ML)

STREPTOCOCCI, FECAL (COL/100 ML)

SILICA, DISSOLVED

CALCIUM, DISSOLVED

MAGNESIUM, DISSOL VED

SODIUM, DISSOLVED

POTASSIUM, DISSOLVED

BICARBONATE, ION

CARBONATE, ION

SULFATE, DISSOLVED

CHLORIDE, DIS SOLVED

DISSOLVED SOLIDS, SUM OF CONST

DISSOLVED SOLIDS, ROE 180 DEG

HARDNESS, TOTAL

HARDNESS, NONCARBONATE

TURBIDITY (JTU)

FLOUR IDE, DIS SOLVED

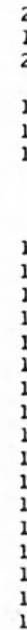

0.385

1146.4

4.0

64.8

1.1
4.9

4.9
8.89

85.27

29.09

99.36

5.13

161.6

287.27

287.27
84.36

84.36
681.4

681.4
713.0

713.0
332.7

200.9

1.5

5257.3

0.08

0.038

0.086

3.2
25.8

0.3

3.9
0.58
2.24

1.14

1.50

1.9

0.0

12.72

2.34
15.2

15.2
9.1

6.5
8.3

8.3

1.3
0.07
2320
7.9

0.00

0.33

0.14

64

1
33

1
1
7.9

7.9
81.0

27.0
95.0

4.2

160

270.0

80.0

655
689

689
320

180

0.3

*Not significant at the 95 percent confidence level.

BEGRESSION_SUMMARY

REGRESSION

SAMPLE COEFICIENT,

CONSTANT,

CORRELATION

STANDARD SIZE B

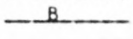
COEEICIENI

ERROR OF

$9.0 \quad 16.5$

$\begin{array}{rr}1060 & 1110 \\ 2320 & 22820\end{array}$

820
8.1
.05
.46
.40
800
8
100
2
12
9.8
9.0
1.0
0.0
6.4
165
0
0.0
8.0
705
722
340
210
5
0.5

$\begin{array}{rr}11 & 24.175 \\ 5 & 0.0017 \\ 11 & -0.00017 \\ 11 & -0.00072 \\ 11 & 0.00180 \\ 7 & -45.422\end{array}$

-12130.625
6.2000
0.21113
1.16602
-1.73050

0.078

$0.218 *$

-0.183 *

$-0.282 *$

$0.314 *$

$50526.621-0.475$.

4903.4
0.09
0.015
0.039
0.086

1271.0

$\begin{array}{lr}11 & -0.0047 \\ 11 & -0.0306 \\ 11 & 0.0415 \\ 11 & 0.0419 \\ 11 & -0.0093 \\ 11 & -0.019 \\ 11 & 0.000 \\ 11 & -0.0045 \\ 11 & 0.0863 \\ 11 & 0.117 \\ 11 & 0.253 \\ 11 & 0.181 \\ 11 & 0.150 \\ 11 & 0.001 \\ 11 & -0.0002\end{array}$

13.972

118.5645

$-16.0282$

53.8065
15.1860

182.663

0.000

292.1787

-9.3790
553.803

553.803

438.255

135.780

38.305

0.669
0.5825

0.5825
-0.121 .

-0.205 .

0.549

-0.244 *

-0.156 *

0.000

$-0.005$.

0.555 .

0.116 *

0.416 *

0.421 .

0.270

0.009

SUMMARY OF HARMONIC ANALYSIS OF STREAM TEMPERATURE

\begin{tabular}{|c|c|c|c|c|c|}
\hline & & & & & STANDARD \\
\hline & HARMONIC & AMPLITUDE & PHASE & VARIATION & ERROR OF \\
\hline SAMPLE & MEAN - M & $-A$ & ANGLE - C & EXPLAINED & ESTIMATE \\
\hline SUZE_ & $10 E G(1$ & DEE $(1)$ & (RADIANS) & $(x)$ & (0EG C) \\
\hline 47 & 11.59 & 0.88 & 0.44 & 0 & 19.14 \\
\hline
\end{tabular}

SUMMARY OF MAXIMUM AND MINIMUM CONCENTRATIONS OF CONSTITUENTS SAMPLED AT A FREQUENCY OF QUARTERLY (1975 WY)

09421500 - - COLORADO RIVER BLW, HOOVER DAM, AR1Z -NEV

\begin{tabular}{l} 
CONSTI TUENT \\
\cline { 2 - 2 }
\end{tabular}


Table 14.--Summary of measurement at each station--Continued

LAT 33049M18S LONG 116058MOIS

DRAINAGE AREA: 0 SO MI

PERIOD OF RECORD:

$10 / 01 / 74-09 / 30 / 75$

O SQ KMI

STATISTICAL SUMMARY OF SELECTED DISSOLVED CHEMICAL CONSTITUENTS AND

REGRESSION RELATIONSHIPS OF CONSTITUENT CONCENTRATIONS TO SPECIFIC CONDUCTANCE

CONSIUIUENI

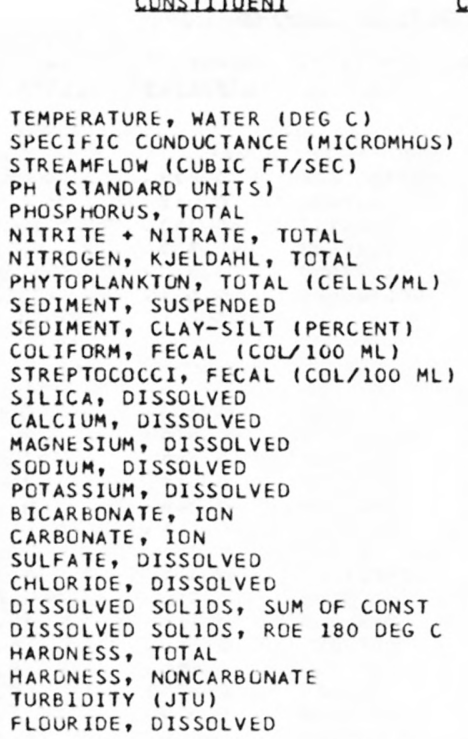

CONSILUUENI IMG/L OR UNDI SHOWNI

\begin{tabular}{|c|c|c|c|c|c|}
\hline $\begin{array}{l}\text { SAMPLE } \\
\text { SIZE }\end{array}$ & MEAN & $\begin{array}{l}\text { STANDARD } \\
\text { REYIAULN }\end{array}$ & \multicolumn{2}{|c|}{ BANGE } & $\begin{array}{l}\text { SAMPL } \\
\text { SIZE }\end{array}$ \\
\hline 167 & 18.75 & 5.96 & 10.0 & 27.8 & \\
\hline 167 & 1088.7 & 64.6 & 338 & 1140 & \\
\hline 167 & 1210.4 & 185.5 & 7 & 1760 & 167 \\
\hline 13 & 8.34 & 0.19 & 7.9 & 8.5 & 13 \\
\hline 12 & 0.022 & 0.016 & 0.00 & 0.05 & 12 \\
\hline 12 & 0.165 & 0.045 & 0.11 & 0.24 & 12 \\
\hline 12 & 0.340 & 0.121 & 0.16 & 0.59 & 12 \\
\hline 12 & 1602.8 & 880.3 & 24 & 2900 & ${ }^{*}$ \\
\hline 12 & 9.4 & 5.0 & 1 & 16 & \\
\hline 12 & 55.4 & 18.5 & 12 & 79 & \\
\hline 14 & 628589.4 & 2351888.0 & 0 & 8799983 & \\
\hline 14 & 26433.6 & 98884.9 & 0 & 369999 & \\
\hline 12 & 9.45 & 4.99 & 6.3 & 25.0 & 12 \\
\hline 12 & 79.58 & 15.18 & 32.0 & 88.0 & 1 \\
\hline 12 & 28.18 & 7.69 & 4.2 & 33.0 & 12 \\
\hline 12 & 96.67 & 21.17 & 31.0 & 110.0 & \\
\hline 12 & 5.20 & 0.73 & 4.1 & 0.7 & 1 \\
\hline 12 & 155.8 & 6.0 & 146 & 164 & 12 \\
\hline 8 & 0.0 & 0.0 & 0 & 0 & \\
\hline 12 & 271.50 & 77.31 & 28.0 & 310.0 & 12 \\
\hline 12 & 83.83 & 21.14 & 17.0 & 93.0 & 12 \\
\hline 12 & 651.7 & 138.4 & 214 & 710 & 12 \\
\hline 12 & 690.6 & 152.3 & 211 & 788 & 12 \\
\hline 12 & 314.8 & 69.1 & 97 & 350 & 12 \\
\hline 12 & 188.3 & 59.7 & 0 & 220 & 1 \\
\hline 12 & 1.6 & 1.0 & 0 & 4 & 1 \\
\hline 12 & 0.34 & 0.07 & 0.3 & 0.5 & 12 \\
\hline
\end{tabular}

BEGBESSION SUMMABY

COEFICIENT, CONSTANT, CORRELATION STANDARO R COEEICIENT ESIMII

${ }^{\star}$ Not significant at the 95 percent confidence level.

DAILY SPECIFIC CONDUCTANCE DURAILON IABLE OF DAILY SPECIEIC CONDUCIANCE

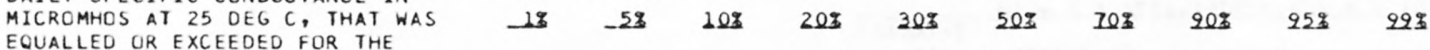

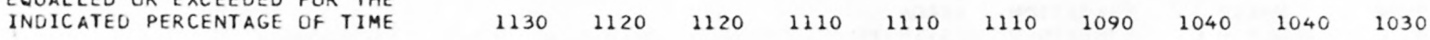

\begin{tabular}{|c|c|c|c|c|c|}
\hline & & & & & STANDARD \\
\hline & HARMONIC & AMPLI TUDE & PHASE & VAR I ATION & ERROR OF \\
\hline SAMPLE & MEAN - M & $-A^{A}$ & ANGLE - C & EXPLAINED & ESTIMATE \\
\hline SIZE_- & 1DEG_Cl & $10=G(1)$ & (BADIANSI & -182 & $10 E 6$ C \\
\hline 162 & 18.88 & 7.64 & 2.57 & 97 & 1.12 \\
\hline
\end{tabular}

SUMMARY OF MAXIMUM AND MINIMUM CONCENTRATIONS OF CONSTITUENTS SAMPLED AT A FREQUENCY OF QUARTERLY (1975 WY)

$09424190-$ COLORADO R AQV NR SAN JACINTO CA.

\begin{tabular}{|c|c|c|c|c|c|c|}
\hline \multirow{2}{*}{ CONSTI TUENT } & \multicolumn{3}{|c|}{ TOTAL } & \multicolumn{3}{|c|}{ DISSOLVEO } \\
\hline & $\begin{array}{l}\text { NO. } \\
\text { SAMPLES }\end{array}$ & $\begin{array}{l}\text { MINIMUM } \\
\text { CONC. }\end{array}$ & $\begin{array}{l}\text { MAXIMUM } \\
\text { CONC. }\end{array}$ & $\begin{array}{l}\text { NO. } \\
\text { SAMPLES }\end{array}$ & $\begin{array}{l}\text { MINIMUM } \\
\text { CONC. }\end{array}$ & $\begin{array}{l}\text { MAXIMUM } \\
\text { CONC. }\end{array}$ \\
\hline \multicolumn{7}{|l|}{ MINOR ELEMENTS: } \\
\hline ARSENIC (AS), UG/L & 4 & 1 & 6 & 4 & 2 & 6 \\
\hline CADMIUM $(C D), U G / L$ & 4 & 0 & $<10$ & 4 & 0 & 1 \\
\hline CHROMIUM (CR), UG/L & 4 & 0 & 20 & 4 & 0 & 0 \\
\hline COBALT (CO), UG/L & 4 & 0 & $<50$ & 4 & 0 & 0 \\
\hline COPPER (CU), UG/L & 4 & 0 & 130 & 4 & 2 & 5 \\
\hline IRON (FE), UG/L & 4 & 80 & 710 & 4 & 10 & 60 \\
\hline LEAD $(P B), U G / L$ & 4 & $<100$ & $<100$ & 4 & 0 & 4 \\
\hline MANG ANESE $(M N), U G / L$ & 3 & 10 & 40 & 4 & 0 & 10 \\
\hline MERCURY (HG), UG/L & 4 & 0.0 & 0.1 & 4 & 0.0 & 0.2 \\
\hline SELENIUM (SE), UG/L & 4 & 0 & 4 & 4 & 0 & 4 \\
\hline$Z I N C(Z N), U G / L$ & 4 & 8 & 90 & 4 & 0 & 20 \\
\hline \multicolumn{7}{|l|}{ PERIPHYTON: } \\
\hline BIOMASS, DRY WT., G/SO M & 2 & 3.19 & 10.00 & & & \\
\hline BIOMASS, ASH WT., G/SQ M & 2 & 3.00 & 8.79 & & & \\
\hline CHLOROPHYLL A, MG/SQ M & 2 & .6 & 3.3 & & & \\
\hline CHLOROPHYLL B, MG/SQ M & 2 & .0 & .2 & & & \\
\hline ORGANIC CARBON, MG/L & 4 & 1.2 & 5.1 & & & \\
\hline
\end{tabular}


Table 14.--Summary of measurement at each station--Continued

LAT 34D15M43S LONG 114001M40S DR AINAGE AREA: LONG $114001 M 40 S$ 0 SQ KM)

PERIOD OF RECORD: $10 / 01 / 74-09 / 30 / 750$ SO KMI

STATISTICAL SUMMARY OF SELECTED DISSOLVED CHEMICAL CONSTITUENTS AND

REGRESSION RELATIONSHIPS OF CONSTITUENT CONCENTRATIONS TO SPECIFIC CONDUCTANCE

CONSIIIUENI

$$
\text { CONSIUIUENI IMG } \angle 1 \text { OB UNDI SHOHNI }
$$

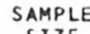

\section{SAMPLE \\ STANDARD}

HEAN

TEMPERATURE, WATER (DEG C)

SPECIFIC CONDUCTANCE (MICROMHOSI

STREAMFLOW (CUBIC FT/SEC)

PH (STANDARD UNITS)

PHOSPHORUS, TOTAL

NITRITE + NITRATE, TOTAL

NITROGEN, KJELOAHL, TOTAL

PHYTOPLANKTON, TOTAL (CELLS/ML)

SEDIMENT, SUSPENDED

SEDIMENT, CLAY-SILT (PERCENT)

COLIFORM, FECAL (COL/100 ML)

STREPTOCOCCI, FECAL ( COL/100 ML)

SILICA, DISSOLVED

CALCIUM, DISSOLVED

MAGNESIUM, DISSOLVED

SODIUM, DISSOLVED

POTASSIUM, DISSOLVED

BICARBONATE, ION

CARBONATE, ION

SULFATE, DISSOLVED

CHLORIDE, DISSOLVED

DISSOLVED SOLIDS, SUM OF CONST

DISSOLVED SOLIDS, ROE 180 DEG C

HARDNESS, TOTAL

HARDNESS, NONCARBONATE

TURBIDITY (JTU)

FLOURIDE, DISSOLVED DISSOLVED

*Not significant
22.06

938.9
1.5

1.5
8.19

8.19
0.036

0.551

0.182

1266.3

52.0

72.8

104.3

251.1

29.63

56.13

18.75

115.00

7.20

261.3

0.0

85.50

13.75

$558 \cdot 3$
556.1

556.1
218.8

5.6

3.5
1.50

5.59
18.3
1.8
0.17
0.023
0.245
0.125
594.3
82.9
5.5
117.1
239.0
5.40
4.82
1.16
5.35
0.65
22.4
0.0
3.42
7.44
14.6
15.1
12.5
7.4
3.1
0.25

5.59

18.3
1.8

0.17

$0.01 \quad 0.37$

$510 \quad 2400$

200

82.9

117.1

239.0
5.40

4.82

1.16

0.65

22.4

0.0

3.42
7.44

14.6
15.1

15.1
12.5
7.4

7.4
3.1
0.25

9
66
11
22
17.0
46.0
17.0
110.0
6.2
223
0
78.0
100.0
536
537
200
0
1
0.9

33
70

700
33.0
61.0

61.0
20.0

120.0

8.0

282

89.0

89.0
120.0

120.0
586
582

230
17

17
10

1.7

DAILY SPECIFIC CONDUCTANCE IN DURAION IABLE OE_DALY SPECIEIC CONDUCIANCE

MICROMHOS AT 25 DEG C, THAT WAS

EQUALLED OR EXCEEDED FOR THE

$\begin{array}{lllllllll}18 & -58 & 10 z & 20 z & 30 z & 50\end{array}$

Q2 702

$975 \quad 971 \quad 965 \quad 960$

956

946

SAMPLE RE REGRESSION

BEGBESSION SUMMABY

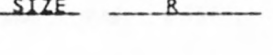

CONSTANT,

$8 \quad 0.052$

-0.0014
-0.00052

$-0.00338$

$-0.00229$

11.041

0.2285

0.0114

$-0.1089$

$-0.0156$

1.187

0.000

0.0109

0.0795

0.504
0.736

0.636

$-0.313$

$-0.097$

$-0.0050$

$-158.3991$

8.0263

217.2259

21.8668

$-852.912$

0.000

75.2774

188.4150

85.205

$-135.002$

$-378.069$

299.625

94.702
6.1947

6.194

SAMPLE SIZE $=154$

$20825 \% 99$

$888 \quad 876 \quad 866$

SUMMARY OF HARMONIC ANALYSIS OF STREAM TEMPERATURE

SORM OF EOUATARM IC ANALYSIS OF STREAM TEMPERATURE

\begin{tabular}{|c|c|c|c|c|c|}
\hline & & & & & STANDARD \\
\hline & HARMONIC & AMPLITUDE & PHASE & VAR IATION & ERROR OF \\
\hline SAMPLE & MEAN - M & $-A$ & ANGLE - C & EXP LAINED & ESTIMATE \\
\hline SLZE_ & $10 E 6 \mathrm{Cl}$ & CDEG $C 1$ & (BADIANS) & $-(z)$ & $10 E G_{C}(1$ \\
\hline 155 & 22.27 & 4.53 & 2.69 & 23 & 2.77 \\
\hline
\end{tabular}

SUMMARY OF MAXIMUM AND MINIMUM CONCENTRATIONS OF CONSTITUENTS SAMPLED AT A FREQUENCY OF QUARTERLY (1975 WY)

09426600 -- BILL WILLIAMS R NR PLANET, ARIZ.

\begin{tabular}{|c|c|c|c|c|c|c|}
\hline \multirow{2}{*}{ CONSTITUENT } & \multicolumn{3}{|c|}{ TOTAL } & \multicolumn{3}{|c|}{ DISSOLVED } \\
\hline & $\begin{array}{l}\text { NO. } \\
\text { SAMPLES }\end{array}$ & $\begin{array}{l}\text { MIN IMUM } \\
\text { CONC. }\end{array}$ & $\begin{array}{l}\text { MAXIMUM } \\
\text { CONC. }\end{array}$ & $\begin{array}{c}\text { NO. } \\
\text { SAMPLES }\end{array}$ & $\begin{array}{l}\text { MINIMUM } \\
\text { CONC. }\end{array}$ & $\begin{array}{l}\text { MAXIMUM } \\
\text { CONC. }\end{array}$ \\
\hline \multicolumn{7}{|l|}{ MINOR ELEMENTS: } \\
\hline ARSENIC (AS), UG/L & 3 & 4 & 11 & 3 & 5 & 8 \\
\hline CADMIUM $(C D), U G / L$ & 3 & $<10$ & 10 & 3 & 0 & 3 \\
\hline CHROMIUM $(C R), U G / L$ & 3 & 0 & 0 & 3 & 0 & 20 \\
\hline COBALT $(C O), U G / L$ & 3 & $<50$ & 50 & 3 & 0 & 0 \\
\hline COPPER $(C U), U G / L$ & 3 & $<10$ & 190 & 3 & 1 & 3 \\
\hline IRON (FE), UG/L & 3 & 0 & 650 & 6 & 10 & 80 \\
\hline$L E A D(P B), U G / L$ & 3 & $<100$ & $<100$ & 3 & 1 & 12 \\
\hline MANGANESE (MN), UG/L & 3 & 10 & 50 & 3 & 0 & 5 \\
\hline MERCURY (HG), UG/L & 3 & 0.0 & 0.1 & 3 & 0.0 & 0.0 \\
\hline SELENIUM (SE), UG/L & 3 & 0 & 1 & 3 & 0 & 0 \\
\hline ZINC $(Z N), U G / L$ & 3 & 20 & 70 & 3 & 6 & 50 \\
\hline \multicolumn{7}{|l|}{ PERIPHYTON: } \\
\hline BIOMASS, DRY WT., G/SO M & 1 & 3.39 & & & & \\
\hline BIOMASS, ASH WT., G/SQ M & 2 & 2.50 & 14.00 & & & \\
\hline CHLOROPHYLL A, MG/SQ M & 3 & 1.6 & 10.0 & & & \\
\hline CHLOROPHYLL B, MG/SQ M & 3 & $\cdot 2$ & $2 \cdot 0$ & & & \\
\hline ORGANIC CARBON, MG/L & 3 & 1.6 & 5.3 & & & \\
\hline
\end{tabular}


LAT $32052 M 59 S$ LONG 114027M55S

DRAINAGE AREA: 184600 SQ MI ( 478114 SQ KM)

PERIOD OF RECORO: 10/01/74 - 09/30/75

STATISTICAL SUMMARY OF SELECTED DISSOLVED CHEMICAL CONSTITUENTS AND REGRESSION RELATIONSHIPS OF CONSTITUENT CONCENTRATIONS TO SPECIFIC CONDUCTANCE

CONSIUIUENI

\begin{tabular}{r} 
CONS \\
SAM \\
SII \\
\hline 2 \\
6 \\
2 \\
6 \\
2 \\
2 \\
2 \\
5 \\
\\
1 \\
1 \\
53 \\
53 \\
53 \\
5 \\
53 \\
53 \\
53 \\
53 \\
53 \\
53 \\
53 \\
53 \\
54 \\
19 \\
53 \\
\end{tabular}

\begin{tabular}{ll} 
NSIUTUE \\
SAMPLE \\
SIZE \\
\cline { 1 - 2 } 23 & \\
23 & \\
65 & 1 \\
23 & 8 \\
65 & \\
23 & \\
23 & \\
23 & \\
9 & 3 \\
0 & \\
0 & \\
11 & \\
11 & \\
53 & \\
53 & \\
53 & \\
53 & 1 \\
53 & \\
53 & \\
53 & \\
53 & 3 \\
53 & 1 \\
53 & \\
53 & \\
53 & \\
54 & \\
19 & \\
53 & \\
&
\end{tabular}

I I $M G / \perp$ OR UNII SHOWNI)

STANDARD

19.96 1321.4 8803.8 8.02 0.023

0.150

0.343

3462.2

STANDARD

GIAION

6.89
73.2

2586.4

0.047

0.156

3473.1

34.1
56.2

56.2
8.30

8.30
95.30

32.38

139.62

5.92

179.2

349.72

120.06

840.4

845.9

370.5

1.2

0.50
0.11

0.013

BANGE
BAN
9.0
1220
4350
7.7
0.00
0.07
0.08
180

42.2

49.8
1.10

1.10
3.88

1.30

12.78

0.42

8.1

0.0
16.12

16.12
12.07

48.9

49.3

11.6
5.9

5.9
0.4

0.06

BEGRESSION SUMMARY

REGRESSION

SAMPLE COEFICIENT, CONSTANT, CORRELATION - B_ COEEICIENI

STANDARD SIZE

B
-38.319
-0.0002
-0.00011
0.00035
-0.00041
-29.813

$$
\begin{array}{r}
59580.559 \\
8.3231 \\
0.16367 \\
-0.30741 \\
0.84291 \\
43775.961
\end{array}
$$

$-0.808$

$-0.149$

$-0.440 *$

$-0.160$

$-0.506 *$

1706.7

0.011

0.15

3203.3

$\begin{array}{rrr}5 & 130 & \\ 5 & 180 & \\ 6.0 & 11.0 & 53 \\ 89.0 & 106.0 & 53 \\ 29.0 & 35.0 & 53 \\ 125.0 & 175.0 & 53 \\ 5.0 & 6.8 & 53 \\ 166 & 206 & 53 \\ 0 & 0 & 53 \\ 330.0 & 390.0 & 53 \\ 104.0 & 155.0 & 53 \\ 780 & 977 & 53 \\ 782 & 982 & 53 \\ 355 & 405 & 53 \\ 214 & 238 & 53 \\ 1 & 2 & 19 \\ 0.4 & 0.7 & 53\end{array}$

$$
\begin{array}{r}
0.0069 \\
0.0428 \\
0.0092 \\
0.1661 \\
0.0037 \\
0.091 \\
0.000 \\
0.2089 \\
0.1563 \\
0.640 \\
0.639 \\
0.145 \\
0.071 \\
-0.000 \\
0.0002
\end{array}
$$

$-0.8431$

38.8859

20.3123

$-79.2132$

1.0955

59.737

0.000

74.4229
-85.9660

$-3.506$

3.794

179.623

130.165

1.624

0.2095
0.480

0.842

0.535

\begin{tabular}{|c|c|c|c|c|c|}
\hline & & & & & STANDARD \\
\hline & HARMONIC & AMPLITUDE & PHASE & VAR IATION & ERROR OF \\
\hline SAMPLE & MEAN - M & $-A$ & ANGLE - C & EXPLA INED & ESTIMATE \\
\hline SIZE_ & LEE $C 1$ & DEEG (1) & (BADIANS) & -132 & LEEG $\quad$ C) \\
\hline 365 & 20.63 & 9.13 & 2.63 & 92 & 1.87 \\
\hline
\end{tabular}

0.663

0.663

0.854

0.000

\begin{tabular}{|c|c|c|c|c|c|c|}
\hline \multirow{2}{*}{ CONSTITUENT } & \multicolumn{3}{|c|}{ TOTAL } & \multicolumn{3}{|c|}{ DISSOLVED } \\
\hline & $\begin{array}{l}\text { NO. } \\
\text { SAMPLES }\end{array}$ & $\begin{array}{l}\text { MINIMUM } \\
\text { CONC. }\end{array}$ & $\begin{array}{l}\text { MAXIMUM } \\
\text { CONC. }\end{array}$ & $\begin{array}{l}\text { NO. } \\
\text { SAMPLES }\end{array}$ & $\begin{array}{l}\text { MINIMUM } \\
\text { CONC. }\end{array}$ & $\begin{array}{l}\text { MAXIMUM } \\
\text { CONC. }\end{array}$ \\
\hline \multicolumn{7}{|l|}{ MINOR ELEMENTS: } \\
\hline ARSENIC (AS), UG/L & 4 & 1 & 4 & 4 & 1 & 4 \\
\hline CADMIUM $(C O)$, UG/L & 4 & $<10$ & 10 & 4 & 0 & $<1$ \\
\hline CHROMIUM (CR), UG/L & 4 & 0 & 6 & 4 & 0 & 5 \\
\hline COBALT $(C O), U G / L$ & 4 & 0 & $<50$ & 4 & 0 & 3 \\
\hline COPPER (CU), UG/L & 4 & $<10$ & 480 & 4 & 0 & 1 \\
\hline IRON (FE), UG/L & 23 & 0 & 950 & 4 & 10 & 100 \\
\hline LEAD $(P B), U G / L$ & 4 & $<100$ & $<100$ & 4 & 0 & 11 \\
\hline MANGANESE $(M N), U G / L$ & 4 & 40 & 70 & 4 & 0 & 10 \\
\hline MERCURY (HG), UG/L & 4 & 0.0 & 0.1 & 4 & 0.0 & 0.0 \\
\hline SELENIUM (SE), UG/L & 4 & 3 & 4 & 4 & 2 & 4 \\
\hline ZINC $(Z N), U G / L$ & 4 & 8 & 90 & 4 & 0 & 30 \\
\hline \multicolumn{7}{|l|}{ PERIPHYTON: } \\
\hline BIOMASS, ORY WT., G/SO M & 3 & .29 & 26.00 & & & \\
\hline BIOMASS, ASH WT., G/SO M & 4 & .19 & 23.00 & & & \\
\hline CHLOROPHYLL A, MG/SO M & 4 & .3 & 22.0 & & & \\
\hline CHLOROPHYLL B, MG/SQ M & 4 & .2 & 3.6 & & & \\
\hline ORGANIC CARBON, MG/L & 23 & 3.0 & 11.0 & & & \\
\hline
\end{tabular}

0.988
0.988

0.998

0.989

0.954

0.908

-0.049 *

0.308

95 percent confidence level. DAILY SPECIFIC CONDUCTANCE IN

MICROMHOS AT 25 DEG C, THAT WAS

EQUALLED OR EXCEEDED FOR THE

$\begin{array}{rrrrrr}18 & 58 & 10 \% & 20 \% & 30 \% & 50 \% \\ 1530 & 1460 & 1420 & 1370 & 1340 & 1300\end{array}$

\begin{tabular}{rrrr}
\multicolumn{4}{c}{ SAMPLE SIZE $=365$} \\
$70 \%$ & $20 \%$ & $25 \%$ & $92 \%$ \\
1280 & 1250 & 1240 & 1230
\end{tabular}

SUMMARY OF HARMONIC ANALYSIS OF STREAM TEMPERATURE

SUMMARY OF MAXIMUM AND MINIMUM CONCENTRATIONS OF CONSTITUENTS SAMPLED AT A FREQUENCY OF QUARTERLY (1975 WY)

09429490 -- COLORADO R AB IMPERIAL D ARIZ-CALIF 
Table 14.--Summary of measurement at each station--Continued

LAT 33D11MO6S LONG $110013 \mathrm{M} 12 \mathrm{~S}$ DRAINAGE AREA: 11470 SQ MI $(29707$ SQ KM)

PERIOD OF RECORD: 10/01/74 - 09/30/75

STATISTICAL SUMMARY OF SELECTED DISSOLVED CHEMICAL CONSTITUENTS AND

REGRESSION RELATIONSHIPS OF CONSTITUENT CONCENTRATIONS TO SPECIFIC CONDUCTANCE

CONSIIIUENI

CONSIIUUENI IMG/L OR UNII SHOHNI

\begin{tabular}{|c|c|c|c|}
\hline & $\begin{array}{l}\text { SAMPLE } \\
\text { SIZE }\end{array}$ & MEAN & $\begin{array}{l}\text { STANDARD } \\
\text { DEYIALION }\end{array}$ \\
\hline MPERATURE, WATER (DEG C) & 12 & 17.54 & 9.72 \\
\hline PECIFIC CONDUCTANCE (MICROMHOS) & 10 & 3727.0 & 2287.1 \\
\hline TREAMFLOW (CUBIC FT/SEC) & 11 & 382.7 & 711.4 \\
\hline (STANDARD UNITS) & 12 & 8.01 & 0.19 \\
\hline HOSPHORUS, TOTAL & 12 & 0.587 & 0.656 \\
\hline ITRITE + NITRATE, TOTAL & 12 & 0.720 & 0.455 \\
\hline ITROGEN, KJELDAHL, TOTAL & 12 & 1.727 & 2.013 \\
\hline HYTOPLANKTON, TOTAL (CELLS/ML) & 8 & 10237.5 & 15424.3 \\
\hline EDIMENT, SUSPENDED & 4 & 2474.5 & 4180.4 \\
\hline EDIMENT, CLAY-SILT (PERCENT) & 4 & 71.8 & 21.9 \\
\hline COLIFORM, FECAL (COL/100 ML) & 3 & 1663.3 & 1027.1 \\
\hline STREPTOCOCCI, FECAL $(\mathrm{COL} / 100 \mathrm{ML})$ & 3 & 6646.7 & 5518.6 \\
\hline SILICA, DISSOLVED & 12 & 32.51 & 8.38 \\
\hline CALCIUM, DISSOLVED & 12 & 163.42 & 105.02 \\
\hline AGNESIUM, DISSOLVED & 12 & 44.18 & 30.68 \\
\hline SODIUM, DISSOLVED & 12 & 564.42 & 399.64 \\
\hline POTASSIUM, DISSOLVED & 12 & 11.18 & 6.12 \\
\hline BICARBONATE, ION & 12 & 257 & 70.0 \\
\hline CARBONATE, ION & 8 & 0.0 & 0.0 \\
\hline SULFATE, DISSULVED & 12 & 378.83 & 286.92 \\
\hline CHLORIDE, DISSOLVED & 12 & 873.83 & 670.75 \\
\hline DISSOLVED SOLIDS, SUM OF CONST & 12 & 2198.6 & 1510.0 \\
\hline DISSOLVED SOLIDS, RUE 180 DEG C & 12 & 2244.3 & 1537.3 \\
\hline ARDNESS, TOTAL & 12 & 594.2 & 394.4 \\
\hline HARDNESS, NONCARBONATE & 12 & 378.8 & 358.3 \\
\hline TURBIDITY (JTU) & 12 & 379.7 & 909.3 \\
\hline FLOURIDE, DISSOLVED & 12 & 1.36 & 0.45 \\
\hline
\end{tabular}

\begin{tabular}{|c|c|c|c|}
\hline & $\begin{array}{l}\text { SAMPLE } \\
\text { SIZE }\end{array}$ & MEAN & $\begin{array}{l}\text { STANDARD } \\
\text { DEYIALION }\end{array}$ \\
\hline MPERATURE, WATER (DEG C) & 12 & 17.54 & 9.72 \\
\hline PECIFIC CONDUCTANCE (MICROMHOS) & 10 & 3727.0 & 2287.1 \\
\hline TREAMFLOW (CUBIC FT/SEC) & 11 & 382.7 & 711.4 \\
\hline H (STANDARD UNITS) & 12 & 8.01 & 0.19 \\
\hline HOSPHORUS, TOTAL & 12 & 0.587 & 0.656 \\
\hline ITRITE + NITRATE, TOTAL & 12 & 0.720 & 0.455 \\
\hline ITROGEN, KJELDAHL, TOTAL & 12 & 1.727 & 2.013 \\
\hline HYTOPLANKTON, TOTAL (CELLS/ML) & 8 & 10237.5 & 15424.3 \\
\hline EDIMENT, SUSPENDED & 4 & 2474.5 & 4180.4 \\
\hline EDIMENT, CLAY-SILT (PERCENT) & 4 & 71.8 & 21.9 \\
\hline COLIFORM, FECAL (COL/100 ML) & 3 & 1663.3 & 1027.1 \\
\hline STREPTOCOCCI, FECAL $(\mathrm{COL} / 100 \mathrm{ML})$ & 3 & 6646.7 & 5518.6 \\
\hline SILICA, DISSOLVED & 12 & 32.51 & 8.38 \\
\hline CALCIUM, DISSOLVED & 12 & 163.42 & 105.02 \\
\hline AGNESIUM, DISSOLVED & 12 & 44.18 & 30.68 \\
\hline SODIUM, DISSOLVED & 12 & 564.42 & 399.64 \\
\hline POTASSIUM, DISSOLVED & 12 & 11.18 & 6.12 \\
\hline BICARBONATE, ION & 12 & 257.3 & 70.0 \\
\hline CARBONATE, ION & 8 & 0.0 & 0.0 \\
\hline SULFATE, DISSULVED & 12 & 378.83 & 286.92 \\
\hline CHLORIDE, DISSOLVED & 12 & 873.83 & 670.75 \\
\hline DISSOLVED SOLIDS, SUM OF CONST & 12 & 2198.6 & 1510.0 \\
\hline DISSOLVED SOLIDS, RUE 180 DEG C & 12 & 2244.3 & 1537.3 \\
\hline ARDNESS, TOTAL & 12 & 594.2 & 394.4 \\
\hline HARDNESS, NONCARBONATE & 12 & 378.8 & 358.3 \\
\hline TURBIDITY (JTU) & 12 & 379.7 & 909.3 \\
\hline LOUR IDE, DISSOLVED & 12 & 1.36 & 0.45 \\
\hline
\end{tabular}

\begin{tabular}{|c|c|c|c|}
\hline & $\begin{array}{l}\text { SAMPLE } \\
\text { SIZE }\end{array}$ & MEAN & $\begin{array}{l}\text { STANDARD } \\
\text { DEYIAILON }\end{array}$ \\
\hline EMPERATURE, WATER (DEG C) & 12 & 17.54 & 9.72 \\
\hline SPECIFIC CONDUCTANCE (MICROMHOS) & 10 & 3727.0 & 2287.1 \\
\hline STREAMFLOW (CUBIC FT/SEC) & 11 & 382.7 & 711.4 \\
\hline PH (STANDARD UNITS) & 12 & 8.01 & 0.19 \\
\hline PHOSPHORUS, TOTAL & 12 & 0.587 & 0.656 \\
\hline NITRITE + NITRATE, TOTAL & 12 & 0.720 & 0.455 \\
\hline NITROGEN, KJELDAHL, TOTAL & 12 & 1.727 & 2.013 \\
\hline PHYTOPLANKTON, TOTAL (CELLS/ML) & 8 & 10237.5 & 15424.3 \\
\hline SEDIMENT, SUSPENDED & 4 & 2474.5 & 4180.4 \\
\hline SEDIMENT, CLAY-SILT (PERCENT) & 4 & 71.8 & 21.9 \\
\hline COLIFORM, FECAL (COL/100 ML) & 3 & 1663.3 & 1027.1 \\
\hline STREPTOCOCCI, FECAL $(\mathrm{COL} / 100 \mathrm{ML})$ & 3 & 6646.7 & 5518.0 \\
\hline SILICA, DISSOLVED & 12 & 32.51 & 8.38 \\
\hline CALCIUM, DISSOLVED & 12 & 163.42 & 105.02 \\
\hline MAGNESIUM, DISSOLVED & 12 & 44.18 & 30.68 \\
\hline SODIUM, DISSOLVED & 12 & 564.42 & 399.64 \\
\hline POTASSIUM, DISSOLVED & 12 & 11.18 & 6.12 \\
\hline BICARBONATE, ION & 12 & 257.3 & 70.0 \\
\hline CARBONATE, ION & 8 & 0.0 & 0.0 \\
\hline SULFATE, DISSULVED & 12 & 378.83 & 286.92 \\
\hline CHLOR IDE, DISSOLVED & 12 & 873.83 & 670.75 \\
\hline DISSOLVED SOLIDS, SUM OF CONST & 12 & 2198.6 & 1510.0 \\
\hline DISSOLVED SOLIDS, ROE 180 DEG C & 12 & 2244.3 & 1537.3 \\
\hline HARDNESS, TOTAL & 12 & 594.2 & 394.4 \\
\hline HARDNESS, NONCARBONATE & 12 & 378.8 & $358 \cdot 3$ \\
\hline TURBIDITY (JTU) & 12 & 379.7 & 909.3 \\
\hline FLOUR IDE, DISSOLVED & 12 & 1.36 & 0.45 \\
\hline
\end{tabular}

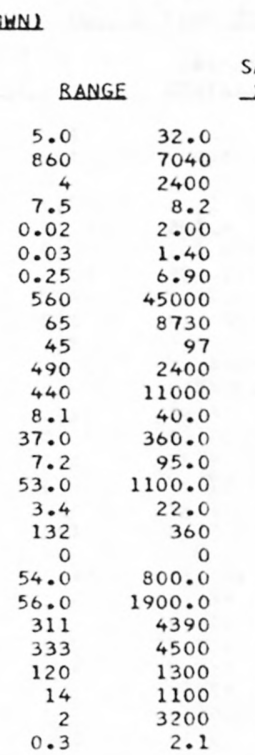

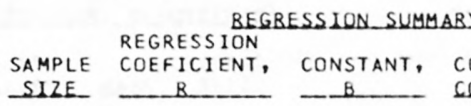

B

SIZE.

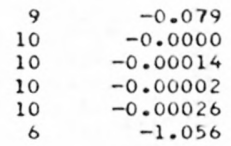
SUMMARY OF HARMONIC ANALYSIS OF STREAM TEMPERATURE

\begin{tabular}{|c|c|c|c|c|c|}
\hline & & & & & STANDARD \\
\hline & HARMONIC & AMPLITUDE & PHASE & VAR IATION & ERROR OF \\
\hline SAMPLE & MEAN - $M$ & $-A$ & ANGLE - C & EXPLAINED & ESTIMATE \\
\hline SIZE & $10 E 6 \quad \mathrm{Cl}$ & UEG 61 & (RADIANS) & $-(8)$ & IDEG $C 1$ \\
\hline 12 & 17.80 & 12.68 & 3.03 & 91 & 3.14 \\
\hline
\end{tabular}

10
10
10
10
10
10
6
10
10
10
10
10
10
10
10

-0.0017
0.0434
0.0126
0.1596
0.0024
0.018
0.000
0.1139
0.2742
0.613
0.627
0.164
0.145
-0.060
-0.0000

$$
\begin{array}{r}
38.8199 \\
3.7673 \\
-2.5347 \\
-32.8677 \\
2.6467 \\
204.960 \\
0.000 \\
-55.2129 \\
-148.9722 \\
-88.268 \\
-92.823 \\
-10.927 \\
-168.674 \\
608.809 \\
1.5005
\end{array}
$$

SUMMARY OF MAXIMUM AND MINIMUM CONCENTRATIONS OF CONSTITUENTS SAMPLED AT A FREQUENCY OF QUARTERLY (1975 WY)

\section{0}

0.971

0.983

0.996

0.900

0.635
0.000

0.991

0.992

0.996

0.996

0.980

0.950

-0.138 .

$-0.144$.
194.5

0.08

0.56

0.414

2.022
8628.2

\begin{tabular}{|c|c|c|c|c|c|c|}
\hline CONSTITUENT & $\begin{array}{l}\text { NO. } \\
\text { SAMPLES }\end{array}$ & $\begin{array}{l}\text { MIN IMUM } \\
\text { CONC. }\end{array}$ & $\begin{array}{l}\text { MAXIMUM } \\
\text { CONC. }\end{array}$ & $\begin{array}{l}\text { NO. } \\
\text { SAMPLES }\end{array}$ & $\begin{array}{l}\text { MINIMUM } \\
\text { CONC. }\end{array}$ & $\begin{array}{l}\text { MAXIMUM } \\
\text { CONC. }\end{array}$ \\
\hline \multicolumn{7}{|l|}{ MINOR ELEMENTS: } \\
\hline CADMIUM $(C D)$, UG/L & 4 & $<10$ & 10 & 4 & 0 & 1 \\
\hline CHROMIUM (CRI, UG L & 4 & 0 & 20 & 4 & 0 & 10 \\
\hline COBALT $(C O), U G / L$ & 4 & $<50$ & $<50$ & 4 & 0 & 1 \\
\hline COPPER (CU), UG/L & 4 & 20 & 70 & 4 & 4 & 24 \\
\hline IRON (FE), UG/L & 4 & 320 & 13000 & 4 & 20 & 50 \\
\hline LEAD $(P B), U G / L$ & 4 & $<100$ & 100 & 4 & 0 & 12 \\
\hline MANG ANESE (MN), UG/L & 4 & 60 & 510 & 4 & 0 & 250 \\
\hline MERCURY $(H G), U G / L$ & 3 & 0.0 & 0.4 & 4 & 0.0 & 0.3 \\
\hline SELENIUM (SE), UG/L & 4 & 0 & 1 & 4 & 0 & 1 \\
\hline ZINC $(2 N), U G / L$ & 4 & 10 & 70 & 4 & 0 & 20 \\
\hline \multicolumn{7}{|l|}{ PERIPHYTON: } \\
\hline BIOMASS, DRY WT., G/SO & M & 1.19 & 33.00 & & & \\
\hline BIOMASS, ASH WT.., G/SQ & M & .00 & 18.00 & & & \\
\hline CHLOROPHYLL A, MG/SO M & 2 & .2 & 1.8 & & & \\
\hline CHLOROPHYLL $B, M G / S Q M$ & 2 & .0 & $\cdot 3$ & & & \\
\hline ORGANIC CARBON, MG/L & 4 & 5.3 & 12.0 & & & \\
\hline
\end{tabular}

8.92

25.98

5.76
33.59

33.59

2.79
52.1

0.0

37.53

85.02

139.1

134.5

80.5

115.3

115.3

1041.6
0.49 
LAT $32058 M 385$ LONG $110046 M 11 S$

DRAINAGE AREA: 4471 SQ MI ( 11580 SQ $\mathrm{KM})$

PERIOD OF RECORD: $10 / 01 / 74-09 / 30 / 75$

STATISTICAL SUMMARY OF SELECTED DISSOLVED CHEMICAL CONSTITUENTS AND

REGRESSION RELATIONSHIPS OF CONSTITUENT CONCENTRATIONS TO SPECIFIC CONDUCTANCE

CONSIIUUENI

CONSIIIUENI IMG/L OR UNII SHOWNI

SAMPLE
SLZE

TEMPERATURE, WATER (DEG C)

SPECIFIC CONDUCTANCE (MICROMHOS)

STREAMFLOW (CUBIC FT/SEC)

PH (STANDARD UNITS)

PHOSPHORUS, TOTAL

NITRIIE + NITRATE, TOTAL

NITROGEN, KJELDAHL, TOTAL

PHYTOPLANKTON, TOTAL (CELLS/ML)

SEDIMENT, SUSPENDED

SEDIMENT, CLAY-SILT (PERCENT)

COLIFORM, FECAL (COL/1OO ML)

STREPTOCOCCI, FECAL (COL/100 ML)

SILICA, DISSOLVED

CALCIUM, DISSOLVED

MAGNESIUM, DISSOL VED

SODIUM, DISSOLVED

POTASSIUM, DISSULVED

BICARBONATE, ION

CARBONATE, ION

SULFATE, DISSOLVED

CHLORIDE, DISSOLVED

DISSOLVED SOLIDS, SUM OF CONST

DISSOLVED SOLIDS, ROE 180 DEG C

HARDNESS, TOTAL

HARDNESS, NONCARBONATE

TURBIDITY (JTU)

FLCURIDE, DISSOLVED

*Not significant at the 95 percent confidence level.

SUMMARY OF HARMONIC ANALYSIS OF STREAM TEMPERATURE

\begin{tabular}{|c|c|c|c|c|c|}
\hline & & & & & STANDARD \\
\hline & HARMONIC & AMPL ITUDE & PHASE & VARIATION & ERROR OF \\
\hline SAMPLE & MEAN - M & $-A$ & ANGLE - C & EXPLAINED & ESTIMATE \\
\hline$S I Z E$ & $10 E G(1$ & IDEG $\mathrm{Cl}$ & (RADLANS) & $(z)$ & $10 E G(C)$ \\
\hline 13 & 20.20 & 7.93 & 2.94 & 83 & 3.10 \\
\hline
\end{tabular}

256.7

53.6

5.2

$375.90 \quad 150.14$

$104.11 \quad 56.25$

59.0

6.1
232

232
237

339.7
137.7

$\begin{array}{ll}413.0 & 137.7 \\ 204.0 & 121.2\end{array}$

204.0

3601.8

110
0

2
0.9
BEGRESSIGN SUMMARY

REGRESSICN

SAMPLE COEFICIENT, CONSTANT, CORRELATION

-

STANDARO

SIZE

R

$\begin{array}{rrrrr}13 & 26.88 & 6.84 & 12.5 & 36.0 \\ 8 & 1362.1 & 548.6 & 181 & 1760\end{array}$

$\begin{array}{rrrr}7.5 & 9.8 & 0 & 1760\end{array}$

$\begin{array}{llll}7.97 & 0.15 & 7.7 & 8.2\end{array}$

$\begin{array}{llll}1.738 & 4.359 & 0.02 & 14.00 \\ 0.656 & 0.362 & 0.18 & 1.30\end{array}$

$\begin{array}{llll}5.333 & 11.048 & 0.13 & 35.00\end{array}$

$\begin{array}{llll}11571.3 & 19310.7 & 970 & 55000\end{array}$

$62028.9 \quad 878 \quad 150000$

$8 \quad 0.002$

0.0000

$-0.00017$

$-0.00018$

$-0.00058$

$-4.370$

1.730

7.9745

0.38879

0.82755

1.57527

0.461 *

$0.123 *$

$-0.306 *$

-0.278 *

-0.296 *

$$
\begin{array}{r}
2.6 \\
0.13 \\
0.310 \\
0.387 \\
1.176 \\
10043.7
\end{array}
$$
$\begin{array}{rrrr}100.0 & 0.0 & 100 & \\ 42666.7 & 33246.5 & 12000 & 78000\end{array}$ $\begin{array}{rrrr}42666.7 & 33246.5 & 12000 & 78000 \\ 98666.6 & 47595.5 & 56000 & 150000\end{array}$

$\begin{array}{rrrr}33.00 & 6.96 & 18.0 & 39.0\end{array}$

$\begin{array}{llll}121.10 & 39.05 & 33.0 & 160.0\end{array}$

$\begin{array}{rrrr}26.86 & 9.89 & 5.6 & 38.0\end{array}$

$\begin{array}{rrrr}8.02 & 57.80 & 34.0 & 200.0\end{array}$

136
0

$953.3 \quad 326.2$

1626.246

490.0

170.0

1230
1300

1300
560
350

350

2.3

$\begin{array}{lr}8 & -0.0009 \\ 8 & -0.0033 \\ 8 & -0.0015 \\ 8 & -0.0068 \\ 8 & -0.0009 \\ 8 & 0.011 \\ 4 & 0.000 \\ 8 & -0.0089 \\ 8 & -0.0088 \\ 8 & -0.026 \\ 8 & -0.054 \\ 8 & -0.016 \\ 8 & -0.025 \\ 8 & -0.256 \\ 8 & -0.0000\end{array}$

37.3020

142.0379

32.7939

190.5368

9.8167

247.982

0.000

457.0754

139.8937

439.8937
1135.219

1208.159

491.669

289.314

504.297

2.0500

-0.219 *

-0.109 *

-0.150 *

-0.332 *

-0.580 *

0.210 *

0.000 *

-0.139 *

-0.167 *

-0.152 *

-0.301 *

-0.135 *

-0.218 .

$-0.333 *$

-0.084 *
2.28

17.92

5.84
11.47

0.76

29.1

37.49

37.49

30.85
100.2

100.8

69.4

66.9

429.9

\begin{tabular}{|c|c|c|c|c|c|c|}
\hline \multirow{2}{*}{ CONSTI TUENT } & \multicolumn{3}{|c|}{ TOTAL } & \multicolumn{3}{|c|}{ DISSOLVED } \\
\hline & $\begin{array}{l}\text { NO. } \\
\text { SAMPLES }\end{array}$ & $\begin{array}{l}\text { MINIMUM } \\
\text { CONC. }\end{array}$ & $\begin{array}{l}\text { MAXIMUM } \\
\text { CONC. }\end{array}$ & $\begin{array}{l}\text { NO. } \\
\text { SAMPLES }\end{array}$ & $\begin{array}{l}\text { MINIMUM } \\
\text { CONC. }\end{array}$ & $\begin{array}{l}\text { MAXIMUM } \\
\text { CONC. }\end{array}$ \\
\hline \multicolumn{7}{|l|}{ MINOR ELEMENTS: } \\
\hline ARSENIC (AS), UG/L & 3 & 3 & 53 & 3 & 5 & 13 \\
\hline CADMIUM $(C D), U G / L$ & 3 & $<10$ & 10 & 3 & 0 & 2 \\
\hline CHROMIUM (CR), UG/L & 3 & 0 & 90 & 3 & 0 & 10 \\
\hline COBALT $(C O), U G / L$ & 3 & $<50$ & 100 & 3 & 0 & 1 \\
\hline COPPER (CU), UG/L & 3 & $<10$ & 280 & 3 & 3 & 8 \\
\hline IRON (FE), UG/L & 3 & 120 & 88000 & 3 & 10 & 40 \\
\hline LEAD $(P B), U G / L$ & 3 & $<100$ & 300 & 3 & 0 & 1 \\
\hline MANG ANESE (MN), UG/L & 3 & 10 & 4300 & 3 & 0 & 20 \\
\hline MERCURY (HG), UG/L & 3 & 0.0 & 0.4 & 3 & 0.0 & 0.3 \\
\hline SELENIUM (SE), UG/L & 3 & 1 & 1 & 3 & 0 & 1 \\
\hline$Z I N C(Z N), U G / L$ & 3 & $<10$ & 470 & 3 & 7 & 30 \\
\hline \multicolumn{7}{|l|}{ PERIPHYTON: } \\
\hline BIOMASS, DRY WT., G/SO M & 1 & 26.00 & & & & \\
\hline BIOMASS, ASH WT., G/SO M & 1 & 24.00 & & & & \\
\hline CHLOROPHYLL A, MG/SO M & 1 & 13.0 & & & & \\
\hline CHLOROPHYLL B, MG/SO M & 1 & 4.5 & & & & \\
\hline ORGANIC CARBON, MG/L & 3 & 3.5 & 32.0 & & & \\
\hline
\end{tabular}

0.26

SUMMARY OF MAXIMUM AND MINIMUM CONCENTRATIONS OF CONSTITUENTS SAMPLED AT A FREQUENCY OF QUARTERLY (1975 WY)

09473500 -- SAN PEDRO R AT WINKELMAN, ARIZ. 
Table 14.--Summary of measurement at each station--Continued

LAT 33DO6MIOS LONG 110058 M33S

DRAINAGE AREA: 18011 SQ MI 146648 SQ KM

PERIOD OF RECORD: $10 / 01 / 74-09 / 30 / 75$

STATISTICAL SUMMARY OF SELECTED DISSOLVED CHEMICAL CONSTITUENTS AND

REGRESSION RELATIONSHIPS OF CONSTITUENT CONCENTRATIONS TO SPECIFIC CONDUCTANCE

CONSIUIUENI

\section{CONSIUIUENI IMG/L_OR_UNII_SHOWN}

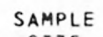

SIZE TEMPERATURE, WATER (DEG C)
SPECIFIC CONDUCTANCE (MICROMHOS) STREAMFLOH (CUBIC FT/SEC) STREAMFLOH (CUBIC FT PH ISTANDARD UNITS

PHOSPHORUS, TOTAL, TOTAL NITROGEN, KJELDAHL, TOTAL PHYTOPLANKTON, TOTAL (CELLS/ML) SEDIMENT, SUSPENDED

SEDIMENT, CLAY-SILT (PERCENT) COLIFORM, FECAL (COL/100 ML) STREPTOCOCCI, FECAL $(\mathrm{COL} / 100 \mathrm{ML})$ SIREP TOCOCCI, FECAL SILICA, DISSOLVED
CALCIUM, DISSOLVED MAGNESIUM, DISSOLVED SODIUM, DISSOLVED POTASSIUM, DISSOLVED BICARBONATE, ION CARBONATE, ION SULFATE, DISSOLVED CHLORIDE, DISSOLVED DISSOLVED SOLIDS, SUM OF CONST DISSOLVED SOLIDS, ROE 180 DEG HARDNESS, TOTAL HARDNESS, TOTAL
HARDNESS, NONCARBONATE HARDNESS, NONCARB

TURBIDITY (JTU)
FLOUR IDE, DISSOLVED * Not significant at the 95 percent confidence level.

STANDARD

1319.23

$9 \quad 1383.8$

$\begin{array}{ll}12 & 463.5 \\ 12 & 7.98\end{array}$

7.98
0.806

0.169

2.330

4141.0

50644.3

95.0

7565.8

42750.0

25.42

80.42
23.49

23.49
162.50

6.45

214.0

0.0

161.25

219.17

786.3

809.3

297.5

122.7

1278.9

EYIAUION

6.44

216.7
223.5

223.5
0.11

1.926

0.172

4.077

6554.3
74292.9

7.1
8738.5

42375.8

2375.8
2.71

2.71
29.08

10.09

25.98

0.83
35.0

0.0

92.74

40.55

185 .

182.

111.1
85.3

2975.5

0.09

BANGE

$\begin{array}{rr}10.5 & 28.0 \\ 1192 & 1940 \\ 37 & 765 \\ 7.8 & 8.2 \\ 0.02 & 6.80 \\ 0.01 & 0.62 \\ 0.37 & 13.00 \\ 730 & 22000 \\ 533 & 136000 \\ 90 & 100 \\ 63 & 17000 \\ 5300 & 87000 \\ 22.0 & 32.0 \\ 54.0 & 170.0 \\ 5.9 & 51.0 \\ 110.0 & 210.0 \\ 5.7 & 8.3 \\ 164 & 311 \\ 0 & 0 \\ 95.0 & 450.0 \\ 120.0 & 290.0 \\ 496 & 1300 \\ 537 & 1320 \\ 160 & 630 \\ 25 & 380 \\ 9 & 9000 \\ 0.8 & 1.1\end{array}$

DURAIION IABLE OF DAILY SPECIEIC CONOUGIANCE

DAILY SPECIFIC CONDUCTANCE IN MICRCMHOS AT 25 DEG C, THAT WAS

EQUALLED OR EXCEEDED FOR THE

INDICATED PERCENTAGE OF TIME

$\begin{array}{rrrrr}-12 & -5 \pi & 10 \% & 20 \% & 30 \% \\ 1600 & 1600 & 1440 & 1360 & 1300\end{array}$

502

1200

1150

SAMPLE REGRESSION

BEGRESSION SUMMABY

SIZE

COEFICIENT,

CONSTANT,

CORRELATION COEEICIENI

ESILMAIE

$$
\begin{aligned}
& 9 \\
& 9 \\
& 9 \\
& 9 \\
& 9 \\
& 8
\end{aligned}
$$

-0.675
0.0004
-0.00047
-0.00002
-0.00221
-19.481

7.4965

0.95002

0.15630

4.50245

29541.035

$-0.646$

0.788
-0.236.

$-0.033$.

$-0.178$

$-0.167 *$

184.5

0.0

0.453

0.111

2.825

7783.8

9
9
9
9
9
9
6
9
9
9
9
9
9
9
9

0.1440

0.0448

0.0552

0.0033

0.151

0.000

0.4714

0.0442

0.85

0.850

0.538
0.421

0.421
-2.305

$-0.0001$

12.3068

$-114.3072$

$-36.4862$

89.2294

1.8157

11.898

$-482.2974$

163.2328

163.2328

-365.170
-342.299

-342.299
-427.222

$-427.222$

-446.753
4221.039

1.1438

0.685

0.973

0.987

0.792

0.816

0.945

0.000

0.966

0.529

0.994

0.993
0.981

0.988

-0.167 .

-0.392 *

SAMPLE SIZE $=357$

$20 \% \quad 25929$

$1000 \quad 1000 \quad 882$

\begin{tabular}{|c|c|c|c|c|c|}
\hline & & & & & STANDARD \\
\hline & HARMONIC & AMPLITUDE & PHASE & VARIATION & ERROR OF \\
\hline SAMPLE & MEAN - M & $-A$ & ANGLE - C & EXPLAINED & ESTIMATE \\
\hline SLZE_ & CDEG 61 & (DEG $C)$ & (BADIANS) & - (8) & LEE (1) \\
\hline 355 & 17.44 & 7.98 & 2.58 & 93 & 1.54 \\
\hline
\end{tabular}

SUMMARY UF MAXIMUM AND MINIMUM CONCENTRATIONS OF CONSTITUENTS

SAMPLED AT A FREQUENCY OF QUARTERLY (1975 WY)

$09474000-$ GILA R AT KELVIN ARIZ

\begin{tabular}{|c|c|c|c|c|c|c|}
\hline \multirow{2}{*}{ CONSTITUENT } & \multicolumn{3}{|c|}{ TOTAL } & \multicolumn{3}{|c|}{ DISSOLVED } \\
\hline & $\begin{array}{l}\text { NO. } \\
\text { SAMPLES }\end{array}$ & $\begin{array}{l}\text { MINIMUM } \\
\text { CONC. }\end{array}$ & $\begin{array}{l}\text { MAXIMUM } \\
\text { CONC. }\end{array}$ & $\begin{array}{l}\text { NO. } \\
\text { SAMPLES }\end{array}$ & $\begin{array}{l}\text { MINIMUM } \\
\text { CONC. }\end{array}$ & $\begin{array}{l}\text { MAXIMUM } \\
\text { CONC. }\end{array}$ \\
\hline \multicolumn{7}{|l|}{ MINOR ELEMENTS: } \\
\hline ARSENIC (AS), UG/L & 4 & 2 & 10 & 4 & 2 & 7 \\
\hline CADMIUM $(C D), U G / L$ & 4 & $<10$ & $<10$ & 4 & 0 & 0 \\
\hline CHROMIUM (CR), UG/L & 4 & 0 & 10 & 4 & 0 & 10 \\
\hline COBALT $(C O), U G / L$ & 4 & $<50$ & $<50$ & 4 & 0 & 0 \\
\hline COPPER $(C U)$, UG/L & 4 & $<10$ & 30 & 4 & 1 & 9 \\
\hline IRON $(F E), U G / L$ & 4 & 1400 & 4400 & 4 & 0 & 20 \\
\hline LEAD $(P B), U G / L$ & 4 & $<100$ & $<100$ & 4 & 0 & 5 \\
\hline MANGANESE $(M N), U G / L$ & 3 & 160 & 360 & 4 & 0 & 10 \\
\hline MERCURY $(H G), U G / L$ & 4 & 0.1 & 0.8 & 4 & $<0.1$ & 0.4 \\
\hline SELENIUM (SE), UG/L & 4 & 0 & 2 & 4 & 0 & 1 \\
\hline ZINC $(Z N), U G / L$ & 4 & $<10$ & 60 & 4 & 0 & 70 \\
\hline \multicolumn{7}{|l|}{ PERIPHYTON : } \\
\hline BIOMASS, DRY WT., G/SQ M & 1 & 4.79 & & & & \\
\hline BIOMASS, ASH WT., G/SO M & 1 & 1.89 & & & & \\
\hline CHLOROPHYLL A, MG/SO M & 2 & 3.1 & 15.0 & & & \\
\hline CHLOROPHYLL B, MG/SQ M & 2 & .6 & $3 \cdot 1$ & & & \\
\hline ORGANIC CARBON, MG/L & 4 & 3.1 & 40.0 & & & \\
\hline
\end{tabular}


Table 14.--Summary of measurement at each station--Continued

STATION NUMBER: 09489000

NAME: SANTA CRUZ RIVER NEAR LAVEEN, ARIZ.

LAT 33013MS6S LONG 112010M08S DRAINAGE AREA: 8581 SQ MI ( 22225 SQ KMI

PERIOD OF RECORD: $10 / 01 / 74-09 / 30 / 75$

STATISIICAL SUMMARY OF SELECTED DISSOLVED CHEMICAL CONSTITUENTS AND REGRESSION RELATIONSHIPS OF CONSTITUENT CONCENTRATIONS TO SPECIFIC CONDUCTANCE

CONSIIIUENI

CONSIUIUENI IMG/L_OB UNWI SHOWNI

SIZE

STANDARD

SEYIAUION

BANGE REGRESSION BEGRESSLON_SUMMABY

TEMPERATURE, WATER (DEG C) SPECIFIC CONDUCTANCE (MICROMHOS) STREAMFLOW (CUBIC FT/SEC)

PH (STANDARD UNITS)

PHOSPHORUS, TOTAL

NITRITE + NITRATE, TOTAL

NITROGEN, KJELDAHL, TOTAL

PHYTOPLANKTON, TOTAL (CELLS/ML)

SEDIMENT, SUSPENDED

SEDIMENT, CLAY-SILT (PERCENT)

COLIFURM, FECAL (COL/100 ML)

STREPTOCOCCI, FECAL (COL/100 ML

SILICA, DISSOLVED

CALCIUM, DISSOLVED

MAGNESIUM, DISSOLVEO

SOUIUM, DISSOLVED

POTASSIUM, DISSOL VED

BICARBONATE, ION

CARBONATE, ION

SULFATE, DISSOLVED

CHLORIDE, DISSOLVED

DISSOLVEO SOLIDS, SUM OF CONST

DISSOLVED SOLIDS, ROE 180 DEG

HARDNESS, TOTAL

HARDNESS, NONCARBONAT

TURBIDITY I JTUI

FLOURIDE, OISSOLVED

0
0
10
0
0
0
0
0
0
0
0
0
0
0
0
0
0
0
0
0
0
0
0
0
0
0
0

SUMMARY OF MAXIMUM AND MINIMUM CONCENTRATIONS OF CONSTITUENTS SAMPLED AT A FREQUENCY OF QUARTERLY (1975 WY)

09489000 -- SANTA CRUZ RIVER NEAR LAVEEN, ARIZ.

CONSTITUENT
SAMPLES


LAT 33033M59S LONG 111032 M08S

DRAINAGE AREA: 6232 SQ MI ( 16141 SQ KM)

PERIOD OF RECORD: $10 / 01 / 74-09 / 30 / 75$

STATISTICAL SUMMARY OF SELECTED DISSOLVED CHEMICAL CONSTITUENTS AND

REGRESSION RELATIONSHIPS OF CONSTITUENT CONCENTRATIONS TO SPECIFIC CONDUCTANCE

CONSIITUENI

\begin{tabular}{|c|}
\hline $\begin{array}{l}\text { MPERATURE, WATER (DEG C) } \\
\text { ECIFIC CONOUCTANCE (MICROMHOS) } \\
\text { REAMFLOW (CUBIC FT/SEC) } \\
\text { (STANDARD UNITS) } \\
\text { OSPHORUS, TOTAL } \\
\text { TRITE \& NITRATE, TOTAL } \\
\text { TROGEN, KJELDAHL, TOTAL } \\
\text { YTOPLANKTON, TOTAL (CELLS/ML) } \\
\text { DIMENT, SUSPENDED } \\
\text { DIMENT, CLAY-SILT (PERCENT) } \\
\text { LIFURM, FECAL (COL/ IOO ML) } \\
\text { REPTOCOCCI, FECAL (COL/IOO } 4 \text { ) } \\
\text { LICA, DISSOLVED } \\
\text { LCIUM, DISSOLVED } \\
\text { GNESIUM, DISSOLVED } \\
\text { DIUM, DISSOLVEO } \\
\text { TASSIUM, DISSOLVED } \\
\text { CARBONATE, ION } \\
\text { RBONATE, ION } \\
\text { LFATE, DISSOLVED } \\
\text { LORIDE, DISSOLVED } \\
\text { SSOLVED SOLIDS, SUM OF CONST } \\
\text { SSOLVED SOLIOS, ROE I8O DEG C } \\
\text { RDNESS, TOTAL } \\
\text { RDNESS, NONCARBONATE } \\
\text { RBIDITY (JTU) } \\
\text { OURIDE, DISSOLVED }\end{array}$ \\
\hline
\end{tabular}

CONSILIUENI IHG LI OR UNII SHOHNI

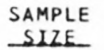

STANDARD

DEYLALION
15.67

975.8
779.6

779.6
7.68

7.68
0.023

0.040

0.217

3.27
161.4

718.5
0.48

0.48
0.015

0.031

0.143
BANGE

$$
\begin{array}{r}
3.8 \\
10.0 \\
15.83
\end{array}
$$

15.83
49.50

49.50
13.00

123.33

4.75

155.0

0.0

51.17

185.00

$519 \cdot 5$

530.3
176.7

176.7
50.0

2.8
0.33

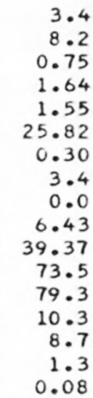

7.1

\section{BEGRESSION SUMMARY}

SAMPLE REGRESSION

SIZE COEFICIENT,

CONSTANT

CORRELATION

STANDARD ERROR OF $11.0 \quad 19.0$ 1200 $\begin{array}{rrrr}0 & 1630 & 6 & 0.502 \\ 7.1 & 8 & 6\end{array}$

$0.01 \quad 0.04$

$\begin{array}{ll}0.04 & 0.47 \\ 370 & 1700\end{array}$

6
6
6
6
6
6
$-0.0027$ 0.00008 $-0.00003$ 0.00048

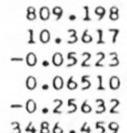

0.235

$-0.924$

0.830

-0.134 *

0.548

3486.459

374.7

0.20

0.009

0.034

0.134
$0.01 \quad 0.09$

$\begin{array}{rr}1 & 8 \\ 1 & 24 \\ 15.0 & 17.0 \\ 47.0 & 52.0 \\ 12.0 & 15.0 \\ 100.0 & 160.0 \\ 4.4 & 5.1 \\ 149 & 159 \\ 0 & 0 \\ 43.0 & 62.0 \\ 150.0 & 240.0 \\ 452 & 616 \\ 463 & 649 \\ 170 & 190 \\ 43 & 65 \\ 2 & 5 \\ 0.3 & 0.5\end{array}$

$\begin{array}{ll}8 & \\ 4 & \\ 0 & 6 \\ 0 & 6 \\ 0 & 6 \\ 0 & 6 \\ 1 & 6 \\ 9 & 6 \\ 0 & 6 \\ 0 & 6 \\ 0 & 6 \\ 6 & 6 \\ 9 & 6 \\ 0 & 6 \\ 5 & 6 \\ 5 & 6 \\ 5 & 6\end{array}$

*Not significant at the 95 percent confidence level.

DURAILON_IABLE_OE_DALY SPECIEIC CONDUCIANCE

DAILY SPECIFIC CONDUCTANCE IN

MICROMHOS AT 25 DEG C, THAT WAS

EQUALLED OR EXCEEDED FOR THE

$\begin{array}{rrrrrr}12 & -5 \pi & 102 & 20 \pi & 30 \% & 50 \% \\ 1200 & 1180 & 1180 & 1160 & 1150 & 1030\end{array}$

INDICATED PERCENTAGE OF TIME

OF STREAM

\begin{tabular}{|c|c|c|c|c|c|}
\hline & & & & & STANDARD \\
\hline & HARMONIC & AMPLITUDE & PHASE & VARIATION & ERROR OF \\
\hline $\begin{array}{l}\text { SAMPLE } \\
\text { SIZE. }\end{array}$ & $\begin{array}{l}\text { MEAN - M } \\
\text { (DEG C) }\end{array}$ & $\mathbb{D E G}_{(1)}^{-A}$ & $\begin{array}{l}\text { ANGLE }-C \\
\text { (RADIANSI }\end{array}$ & $\begin{array}{c}\text { EXPLA INED } \\
(\xi 1\end{array}$ & $\begin{array}{l}\text { ESTIMATE } \\
\text { (DEG C) }\end{array}$ \\
\hline 177 & 16.11 & 3.60 & 2.09 & 86 & 1.01 \\
\hline
\end{tabular}

SUMMARY OF HARMONIC ANALYSIS OF STREAM TEMPERATURE

SUMMARY OF MAXIMUM AND MINIMUM CONCENTRATIONS OF CONSTITUENTS

SAMPLED AT A FREQUENCY OF QUARTERLY (1975 WY)

\begin{tabular}{|c|c|c|c|c|c|c|}
\hline \multirow{2}{*}{ CONST ITUENT } & \multicolumn{3}{|c|}{ TOTAL } & \multicolumn{3}{|c|}{ DISSOLVED } \\
\hline & $\begin{array}{l}\text { NO. } \\
\text { SAMPLES }\end{array}$ & $\begin{array}{l}\text { MIN IMUM } \\
\text { CONC. }\end{array}$ & $\begin{array}{l}\text { MAXIMUM } \\
\text { CONC. }\end{array}$ & $\begin{array}{l}\text { NO. } \\
\text { SAMPLES }\end{array}$ & $\begin{array}{l}\text { MINIMUM } \\
\text { CONC. }\end{array}$ & $\begin{array}{l}\text { MAXIMUM } \\
\text { CONC. }\end{array}$ \\
\hline \multicolumn{7}{|l|}{ MINOR ELEMENTS: } \\
\hline CADMIUM $(C D)$, UG/L & 2 & $<10$ & $<10$ & $\begin{array}{l}2 \\
2\end{array}$ & $\begin{array}{l}2 \\
0\end{array}$ & $\begin{array}{l}4 \\
1\end{array}$ \\
\hline CHROMIUM (CR), UG/L & 2 & 0 & 0 & 2 & 0 & 0 \\
\hline COBALT $(C O), U G / L$ & 2 & $<50$ & $<50$ & 2 & 0 & 2 \\
\hline COPPER $(C U), U G / L$ & 2 & 10 & 10 & 2 & 1 & 2 \\
\hline IRON (FE), UG/L & 2 & 150 & 230 & 2 & 10 & 10 \\
\hline LEAD $(P B), U G / L$ & 2 & $<100$ & $<100$ & 2 & 0 & 1 \\
\hline MANGANESE (MN), UG/L & 2 & 20 & 30 & 2 & 0 & 10 \\
\hline MERCURY (HG), UG/L & 2 & 0.0 & 0.1 & 2 & 0.0 & 0.1 \\
\hline SELENIUM (SE), UG & 2 & 0 & 0 & 2 & 0 & 0 \\
\hline ZINC $(Z N), U G / L$ & 2 & 20 & 90 & 2 & 0 & 7 \\
\hline \multicolumn{7}{|l|}{ PERIPHYTON: } \\
\hline BIOMASS, DRY WT., G/SQ M & 0 & & & & & \\
\hline BIOMASS, ASH WT., G/SO M & 0 & & & & & \\
\hline CHLOROPHYLL A, MG/SO M & 0 & & & & & \\
\hline CHLOROPHYLL B, MG/SQ M & 0 & & & & & \\
\hline ORGANIC CARBON, MG/L & 2 & 3.1 & 4.3 & & & \\
\hline
\end{tabular}

09502000 -- SALT R BL STEWART MOUNTAIN D ARIZ 
LAT 33049M05S LONG 111037M53S

DRAINAGE AREA: 6188 SQ MI 116027 SQ KMI

PERIOD OF RECORD: $10 / 01 / 74-09 / 30 / 75$

STATISTICAL SUMMARY OF SELECTED DISSOLVED CHEMICAL CONSTITUENTS AND REGRESSION RELATIONSHIPS OF CONSTITUENT CONCENTRATIONS TO SPECIFIC CONOUCTANCE

CONSIIIUENI

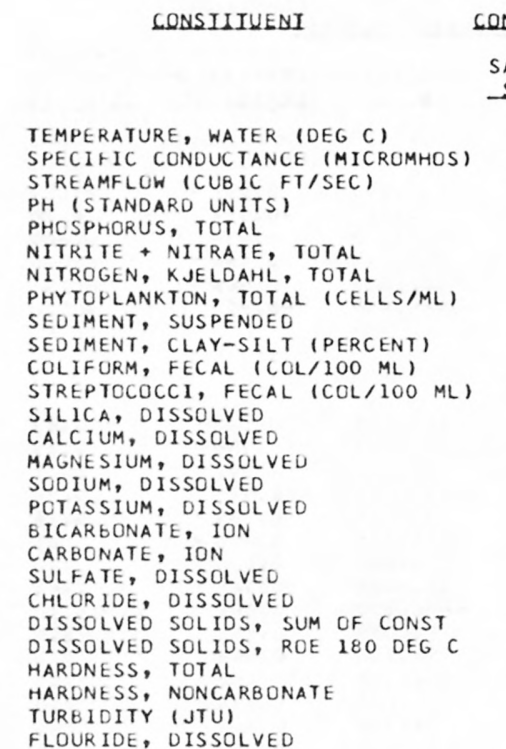

\begin{tabular}{c} 
CONSILI \\
SAMPLE \\
SIZE \\
\hline 12 \\
12 \\
12 \\
12 \\
9 \\
9 \\
9 \\
9 \\
7 \\
7 \\
10 \\
11 \\
9 \\
9 \\
9 \\
9 \\
9 \\
9 \\
8 \\
9 \\
9 \\
9 \\
9 \\
9 \\
9 \\
9 \\
9
\end{tabular}

*Not significant at the 95 percent confidence level.

1 OR UNII SHOWN

\section{STANDARD}

DEVIAIION

15.17

500.9

220.7

8.31

0.038

0.120
0.274

1948.9

20.1

75.7
7.5

7.5

88.9

17.22

42.22
27.67

30.56

2.97
247.3

0.0

56.00

19.79

319.1

311.8

220.0

16.4
9.9

9.9
0.29
5.67

215.0

225.3

225.3
0.30

0.018

0.080

0.140

1850.3

9.8

12.1

6.2

249.7

2.73

6.32

10.51

12.17

0.76

58.3
0.0

23.09

8.34

88.5

82.6

55.9

8.7

4.0
0.11

DURAIION IABLE OF DAILY SPECIEIC CONDUCIANCE

DAILY SPECIFIC CONDUCTANCE IN

MICROMHOS AT 25 DEG C, THAT WAS

EQUALLEO OR EXCEEDED FOR THE

$12 \quad 52 \quad 108$

$20 \%$

$30 \% \quad 50 \%$

$\begin{array}{lr}\text { BANGE } & \\ 9.0 & 23.0 \\ 6 & 795\end{array}$

6
32
7.7
0.01
0.03
0.13
240
7
60
1
1

INDICATED PERCENTAGE OF TIME

690

670

$650 \quad 615$

30.0

10.0

14.0
1.9

168
0

24.0
8.5

8.5
199

191

140
3
5

5
0.2

751
8.7
0.06
0.29
0.60
5400
31
91
16
840
21.0
49.0
36.0
42.0
4.0
297
0
80.0
30.0
387
378
270
27
16
0.5 \begin{tabular}{lc} 
& \multicolumn{2}{c}{ REGRESSION_SUMMARY } \\
REGRESSION & \\
SAMPLE & COEFICIENT, CONSTANT, CORP \\
SIZE & $-B$
\end{tabular}

$\begin{array}{rr}12 & 0.426 \\ 12 & 0.0011 \\ 9 & -0.00008 \\ 9 & 0.00017 \\ 9 & 0.00029 \\ 9 & 3.641\end{array}$

7.249
7.7427
0.08127
0.02469
0.11210
168.263

0.407

0.802

$-0.689$

0.336 *

0.329 *
0.470 *

9
9
9
9
9
9
8
9
9
9
9
9
9
9
9

0.0001
0.0337
0.0585
0.0713
0.0041
0.344
0.000
0.1346
0.0473
0.520
0.492
0.322
0.044
-0.013
0.0001

$0.007^{*}$

0.844

0.879

0.927

0.859

0.932

0.000 *

0.922

0.896

0.896
0.929

0.942

0.911

0.795

-0.501 *
0.175 *
STANDARD ERROR O ESIUMAIE

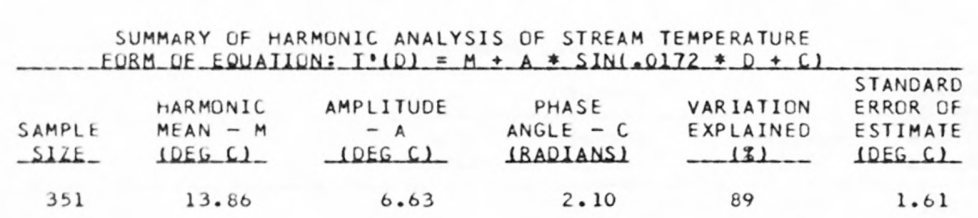

SUMMARY OF MAXIMUM AND MINIMUM CONCENTRATIONS OF CONSTITUENTS SAMPLED AT A FREQUENCY OF QUARTERLY (1975 WY)

09510000 -- VERDE R BL BARTLETT D ARIZ

\begin{tabular}{|c|c|c|c|c|c|c|}
\hline \multirow{2}{*}{ CONSTITUENT } & \multicolumn{3}{|c|}{ TOTAL } & \multicolumn{3}{|c|}{ DISSOLVED } \\
\hline & $\begin{array}{l}\text { NO. } \\
\text { SAMPLES }\end{array}$ & $\begin{array}{l}\text { MINIMUM } \\
\text { CONC. }\end{array}$ & $\begin{array}{l}\text { MAXIMUM } \\
\text { CONC. }\end{array}$ & $\begin{array}{c}\text { NO. } \\
\text { SAMPLES }\end{array}$ & $\begin{array}{l}\text { MINIMUM } \\
\text { CONC. }\end{array}$ & $\begin{array}{l}\text { MAXIMUM } \\
\text { CONC. }\end{array}$ \\
\hline \multicolumn{7}{|l|}{ MINOR ELEMENTS: } \\
\hline ARSENIC (AS), UG/L & 3 & 9 & 18 & 3 & 12 & 18 \\
\hline CAUMIUM $(C D), U G / L$ & 3 & $<10$ & $<10$ & 3 & 0 & 1 \\
\hline CHROMIUM (CR), UG/L & 3 & 0 & 0 & 3 & 0 & $<10$ \\
\hline COBALT $(C O), U G / L$ & 3 & $<50$ & $<50$ & 3 & 0 & 4 \\
\hline COPPER (CU), UG/L & 3 & $<10$ & 20 & 3 & 2 & 5 \\
\hline IRON (FE), UG/L & 3 & 360 & 710 & 3 & 10 & 190 \\
\hline LEAD $(P B), U G / L$ & 3 & $<100$ & 100 & 3 & 1 & 3 \\
\hline MANG ANESE (MN), UG/L & 3 & 50 & 70 & 3 & 0 & 60 \\
\hline MERCURY (HG), UG/L & 3 & 0.0 & 0.2 & 3 & 0.0 & 0.1 \\
\hline SELENIUM (SE), UG/L & 3 & 1 & 1 & 3 & 1 & 1 \\
\hline ZINC $(Z N), U G / L$ & 3 & 20 & 50 & 3 & 0 & 10 \\
\hline \multicolumn{7}{|l|}{ PERIPHYTON: } \\
\hline BIOMASS, DRY WT., G/SQ M & 1 & 8.50 & & & & \\
\hline BIOMASS, ASH WT., G/SQ M & 2 & 4.50 & 7.69 & & & \\
\hline CHLOROPHYLL $A, M G / S Q M$ & 2 & 3.1 & 9.5 & & & \\
\hline CHLOROPHYLL $B, M G / S Q M$ & 2 & .8 & 2.6 & & & \\
\hline ORGANIC CARBON, MG/L & 3 & 2.5 & 4.7 & & & \\
\hline
\end{tabular}


Table 14.--Summary of measurement at each station--Continued

LAT 33013M36S LONG 112D46M17S

DRAINAGE AREA: 49650 SQ MI ( 128594 SQ KM)

PERIOD OF RECORD: $10 / 01 / 74-09 / 30 / 75$

STATISTICAL SUMMARY OF SELECTED DISSOLVED CHEMICAL CONSTITUENTS AND

REGRESSION RELATIONSHIPS OF CONSTITUENT CONCENTRATIONS TO SPECIFIC CONDUCTANCE

CONSIUIUENI

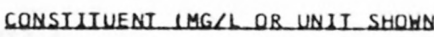

TEMPERATURE, WATER (DEG C)
SPECIFIC CONDUCTANCE (MICROMHOS)
STREAMFLOW (CUBIC FT/SEC)
PH (STANDARD UNITS)
PHOSPHORUS, TOTAL
NITRITE, NITRATE, TOTAL
NITROGEN, KJELDAHL, TOTAL
PHYTOPLANKTON, TOTAL (CELLS/ML)
SEDIMENT, SUSPENDED
SEDIMENT, CLAY-SILT (PERCENT)
COLIFORM, FECAL (COL/IOO ML)
STREPTOCOCI, FECAL (COL/IOO ML)
SILICA, DISSOLVED
CALCIUM, DISSOLVED
MAGNESIUM, DISSOLVED
SODIUM, DISSOLVED
POTASSIUM, DISSOLVED
BICARBONATE, ION
CARBONATE, ION
SULFATE, DISSOLVED
CHLORIDE, DISSOLVED
DISSOLVED SOLIDS, SUM OF CONST
DISSOLVED SOLIDS, ROE I8O DEG C
HARDNESS, TOTAL
HARDNESS, NONCARBONATE
TURBIDITY (JTU)
FLOURIDE, DISSOLVED

SA

*Not significant at the 95 percent confidence level.

SHOHND

AMPLE STANDARD

MEAN

17.55

$5798 \cdot 2$

48.5
8.12

8.12
1.490

9.530

3.690

23255.6

174.0

77.7

3338.9
1473.0

1473.0
18.28

$18 \cdot 28$
226.30

102.20

817.00

11.61

295.6

887.00

1195.00

195.00

3338.4

3499.8

1006.0

745.0

119.5

VIALION

8.09

1577.7
27.0

27.0
0.21

0.857

3.732

1.784

7143.5

119.0

7.6
5463.8

5463.8
1586.5

7.30

63.47

34.84

248.51
1.24

86.1

0.0
251.35

354.69

354.69
976.5

976.5
1019.0

310.2

251.0

274.9
0.80

DAILY SPECIFIC CONDUCTANCE IN

MICROMHOS AT 25 DEG C, THAT WAS

EQUALLED OR EXCEEDED FOR THE
INDICATED PERCENTAGE OF TIME

$\begin{array}{rrrrrr}18 & 5 \% & 10 z & 20 z & 30 \% & 50 \% \\ 7300 & 7100 & 6900 & 6700 & 6500 & 6200\end{array}$

$170.0 \quad 1100.0$

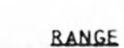

\section{BANGE}

BEGRES

REGRESSION

SAMPLE COEFICIENT,

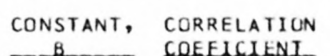

STANDARD ERROR OF ESIUMAIE

$\begin{array}{rrr}9.0 & 30.0 & \\ 1390 & 7000 & \\ 5 & 85 & 11 \\ 7.8 & 8.4 & 11 \\ 0.50 & 2.80 & 10 \\ 2.40 & 13.00 & 10 \\ 1.40 & 6.60 & 10 \\ 1400 & 71000 & 9\end{array}$

$\begin{array}{rr}-0.009 & 101.331 \\ 0.0001 & 7.0686 \\ -0.00017 & 2.48003 \\ 0.00144 & 1.14242 \\ -0.00007 & 4.09694 \\ 25.051 & -140782.750\end{array}$

$-0.534$

$0.573 *$

-0.329 *

0.640

-0.065 *

0.577 .

$\begin{array}{rr}1400 & 329\end{array}$

$25.951-140782.750$

17600

$\begin{array}{rr}190 & 17600 \\ 450 & 5800\end{array}$

$\begin{array}{ll}450 & 5800 \\ 4.8 & 29.0\end{array}$

$\begin{array}{rr}4.8 & 29.0 \\ 63.0 & 300.0\end{array}$

$\begin{array}{rr}21.0 & 150.0 \\ 170.0 & 1000.0\end{array}$

14.0

136

$170.0 \quad 1100.0$

$\begin{array}{rr}784 & 1500.0\end{array}$

848

$240 \quad 1400$

$130 \quad 1100$

$\begin{array}{rr}18 & 900 \\ 0.2 & 2.6\end{array}$

10
10
10
10
10
10
6
10
10
10
10
10
10
10
10

-0.0021
0.0357
0.0178
0.1435
-0.0005
0.030
0.000
0.1419
0.2027
0.562
0.587
0.168
0.139
-0.154
0.0003

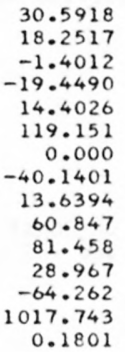

$-0.480$

0.934

0.847

0.959

$-0.640$

0.000

0.937

0.949

0.949

0.956

0.955

0.897

0.918

-0.931
0.537 .
SAMPLE SIZE $=300$

$70 \%$

5700
$202 \quad 252292$

$4800 \quad 4550 \quad 4150$

SUMMARY OF HARMONIC ANALYSIS OF STREAM TEMPERATURE

\begin{tabular}{|c|c|c|c|c|c|}
\hline & & & & & STANDARD \\
\hline & HARMONIC & AMPLITUDE & PHASE & VARIATION & ERROR OF \\
\hline SAMPLE & MEAN - M & $-A$ & ANGLE - C & EXPLA INED & ESTIMATE \\
\hline SIZE & LEE CI & (DEG_S) & (BADLANS) & -181 & IDEG C \\
\hline 301 & 19.20 & 9.32 & 2.73 & 92 & 1.93 \\
\hline
\end{tabular}

SUMMARY OF MAXIMUM AND MINIMUM CONCENTRATIONS OF CONSTITUENTS SAMPLED AT A FREQUENCY OF QUARTERLY (1975 WY)

09518000 - GILA R AB DIVERSIONS AT GILLESPIE DAM AZ .

\begin{tabular}{|c|c|c|c|c|c|c|}
\hline \multirow{2}{*}{ CONSTITUENT } & \multicolumn{3}{|c|}{ TOTAL } & \multicolumn{3}{|c|}{ DISSOLVED } \\
\hline & $\begin{array}{l}\text { NO. } \\
\text { SAMPLES }\end{array}$ & $\begin{array}{l}\text { MINIMUM } \\
\text { CONC. }\end{array}$ & $\begin{array}{l}\text { MAXIMUM } \\
\text { CONC. }\end{array}$ & $\begin{array}{l}\text { NO. } \\
\text { SAMPLES }\end{array}$ & $\begin{array}{l}\text { MINIMUM } \\
\text { CONC. }\end{array}$ & $\begin{array}{l}\text { MAXIMUM } \\
\text { CONC. }\end{array}$ \\
\hline \multicolumn{7}{|l|}{ MINOR ELEMENTS: } \\
\hline ARSENIC (AS), UG/L & 3 & 9 & 11 & 3 & 9 & 11 \\
\hline CADMIUM $(C D), \quad U G / L$ & 3 & $<10$ & 20 & 3 & 0 & 0 \\
\hline CHROMIUM (CR), UG/L & 3 & 0 & 20 & 3 & $<10$ & 10 \\
\hline COBALT $(C O)$, UGIL & 3 & $<50$ & 100 & 3 & 0 & 1 \\
\hline COPPER (CU), UG/L & 3 & 20 & 40 & 3 & 5 & 6 \\
\hline IRON (FE), UG/L & 3 & 1500 & 2300 & 3 & 20 & 220 \\
\hline LEAD $(P B), U G / L$ & 3 & $<100$ & $<100$ & 3 & 0 & 5 \\
\hline MANG ANESE (MN), UG/L & 3 & 130 & 270 & 3 & 40 & 240 \\
\hline MERCURY (HG), UG/L & 3 & $<0.1$ & 0.3 & 3 & $<0.1$ & 0.3 \\
\hline SELENIUM $(S E), U G / L$ & 3 & 9 & 14 & 3 & 8 & 10 \\
\hline ZINC $(Z N), U G / L$ & 3 & 40 & 50 & 3 & 10 & 30 \\
\hline \multicolumn{7}{|l|}{ PERIPHYTON: } \\
\hline BIOMASS, DRY WT., G/SQ M & 1 & 15.00 & & & & \\
\hline BIOMASS, ASH WT., G/SQ M & 2 & 10.00 & 20.00 & & & \\
\hline CHLOROPHYLL A, MG/SQ M & 2 & .6 & 53.0 & & & \\
\hline CHLOROPHYLL B, MG/SQ M & 2 & .2 & 14.0 & & & \\
\hline ORGANIC CARBON, MG/L & 3 & 5.5 & 18.0 & & & \\
\hline
\end{tabular}


LAT $32042 M 45 S$ LONG $114033 M 09 S$

DRAINAGE AREA: 57950 SO MI 1150091 SQ KMI

PERIOD OF RECORD: $10 / 01 / 74-09 / 30 / 75$

STATISTICAL SUMMARY OF SELECTED DISSOLVED CHEMICAL CONSTITUENTS AND

REGRESSION RELATIONSHIPS OF CONSTITUENT CONCENTRATIONS TO SPECIFIC CONDUCTANCE

CONSIIUENI

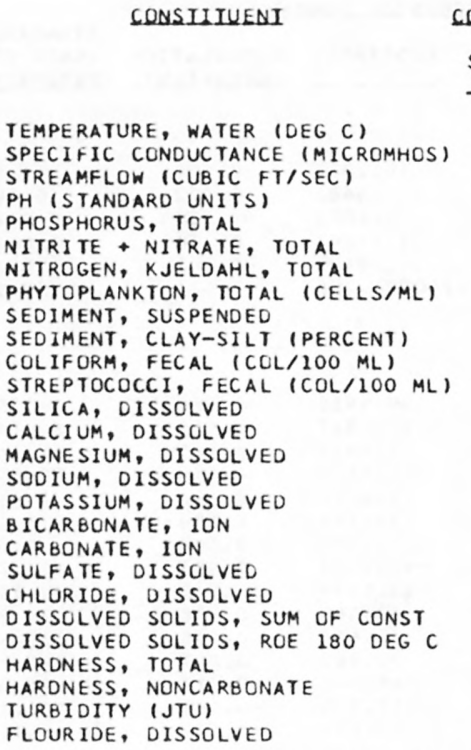

CONSIIIUENT IMG/L OR UNII SHOWN

\begin{tabular}{|c|c|c|}
\hline $\begin{array}{l}\text { SAMPLE } \\
\text { SIZE }\end{array}$ & MEAN & $\begin{array}{l}\text { STANDARD } \\
\text { DEXIAIUON }\end{array}$ \\
\hline 55 & 23.31 & 2.47 \\
\hline 60 & 3316.2 & 316.7 \\
\hline 61 & 86.8 & 29.1 \\
\hline 18 & 7.88 & 0.14 \\
\hline 12 & 0.057 & 0.014 \\
\hline 12 & 0.785 & 0.127 \\
\hline 12 & 0.433 & 0.148 \\
\hline 9 & 1303.3 & 671.6 \\
\hline 9 & 17.1 & 8.1 \\
\hline 9 & 61.3 & 16.6 \\
\hline 11 & 45.0 & 53.5 \\
\hline 11 & 1617.1 & 2937.5 \\
\hline 24 & 24.58 & 0.97 \\
\hline 24 & 154.17 & 18.16 \\
\hline 24 & 61.08 & 7.59 \\
\hline 24 & 487.50 & 46.46 \\
\hline 24 & 7.47 & 1.49 \\
\hline 24 & 306.5 & 13.0 \\
\hline 14 & 0.0 & 0.0 \\
\hline 24 & 476.25 & 42.82 \\
\hline 24 & 672.08 & 94.13 \\
\hline 24 & 2040.4 & 188.4 \\
\hline 24 & 2095.8 & 178.7 \\
\hline 24 & 636.3 & 73.5 \\
\hline 24 & 385.0 & 64.6 \\
\hline 12 & 2.1 & 1.6 \\
\hline 24 & 0.94 & 0.10 \\
\hline
\end{tabular}

BEG REGRESSLION SUMMARY
REGRESSION
SAMPLE COEFICIENT, CONSTANT, CORR , CORE SIZE

R CONSTANT, CORRELATION STANDARD ESIIMAI: $17.0 \quad 27.0$ $2120 \quad 4000$ $\begin{array}{rrrr}2120 & 136 & 60 & 0.044\end{array}$

7.7

0.04

0.60

0.23

500

9
40

10

80

23.0

130.0

46.0

400.0

28

28
410.0

560.0

1810

1870

1870

520
270

1
0.8

$-0.0000$ 0.00000 0.00016

0.000

-0.503
-0.5011

0.671

2200

90
200

200

10000

26.0
190.0

78.0

590.0

13.0

336
0

590.0

860.0

2440

2490

820
7

7
1.2

0.0012
0.0509
0.0218
0.1363
0.0036
0.036
0.000
0.0690
0.2952
0.595
0.559
0.218
0.189
-0.001
0.0000

*Not significant at the 95 percent confidence level. SUMMARY OF HARMONIC ANALYSIS OF STREAM TEMPERATURE

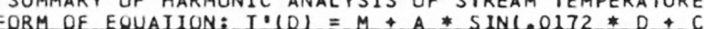

\begin{tabular}{|c|c|c|c|c|c|}
\hline & & & & & STANDARD \\
\hline $\begin{array}{l}\text { SAMPLE } \\
\text { SIZE }\end{array}$ & $\begin{array}{l}\text { HARMONIC } \\
\text { MEAN - M } \\
\text { IDEG CI }\end{array}$ & $\begin{array}{c}\text { AMPLI I UDE } \\
-A \\
\text { IDEG }\end{array}$ & $\begin{array}{c}\text { PHASE } \\
\text { ANGLE - C } \\
\text { (BADIANS) }\end{array}$ & $\begin{array}{l}\text { VARIATION } \\
\text { EXPLAINED } \\
\text { (Z) }\end{array}$ & $\begin{array}{l}\text { ERROR OF } \\
\text { ESTIMATE } \\
\text { (DEG C) }\end{array}$ \\
\hline 54 & 23.37 & 2.82 & 2.90 & 65 & 1.50 \\
\hline
\end{tabular}

SUMMARY OF MAXIMUM AND MINIMUM CONCENTRATIONS OF CONSTITUENTS SAMPLED AT A FREQUENCY OF QUARTERLY (1975 WY)
$-58.359$ 7.9742 0.04265

0.23725

0.80637

2946.750

0.473

$-0.072$

0.128 *

0.502
-0.295
-0.2248

-0.248 *

20.5556

$-16.0356$

$-11.7990$

31.2449

$-4.5798$

187.590

0.000

245.1940

$-315.6921$

48.701

226.471

226.471
-92.838

-92.838
-248.076

-248.076
4.738

4.738
0.8415

0.378 *

0.858

0.879

0.899

0.741
0.838

0.000 *

0.494

0.960

0.967

0.957

0.908

0.897
-0.184

$-0.184 *$
0.087 *
26.1

0.14

0.014
0.115

0.148

695.5

0.92

9.54

3.70
20.83

1.02

7.2
0.0

38.06

26.81

48.8

52.7

31.4

29.2

1.7
0.10
23.37

2.82

2.90

1.50

09520700 -- GILA RIVER NEAR MOUTH, NEAR YUMA, AR12.

\begin{tabular}{|c|c|c|c|c|c|c|}
\hline \multirow{2}{*}{ CONSTI TUENT } & \multicolumn{3}{|c|}{ TOTAL } & \multicolumn{3}{|c|}{ DISSOLVED } \\
\hline & $\begin{array}{l}\text { NO. } \\
\text { SAMPLES }\end{array}$ & $\begin{array}{l}\text { MINIMUM } \\
\text { CONC. }\end{array}$ & $\begin{array}{l}\text { MAXIMUM } \\
\text { CONC. }\end{array}$ & $\begin{array}{l}\text { NO. } \\
\text { SAMPLES }\end{array}$ & $\begin{array}{l}\text { MINIMUM } \\
\text { CONC. }\end{array}$ & $\begin{array}{l}\text { MAXIMUM } \\
\text { CONC. }\end{array}$ \\
\hline \multicolumn{7}{|l|}{ MINOR ELEMENTS: } \\
\hline ARSENIC (AS), UG/L & 4 & 10 & 20 & 4 & 10 & 20 \\
\hline CADMIUM $(C D), U G / L$ & 4 & $<10$ & 20 & 4 & 0 & 1 \\
\hline CHROMIUM $(C R), U G / L$ & 4 & 0 & 5 & 4 & 0 & 10 \\
\hline COBALT $(C O)$, UGIL & 4 & 0 & $<50$ & 4 & 0 & 4 \\
\hline COPPER (CU), UG/L & 4 & $<10$ & 440 & 4 & 0 & 2 \\
\hline IRON (FE), UG/L & 4 & 0 & 260 & 23 & 0 & 150 \\
\hline LEAD $(P B), U G / L$ & 4 & $<100$ & 100 & 4 & 0 & 7 \\
\hline MANG ANESE $(M N), U G / L$ & 4 & 940 & 1200 & 4 & 850 & 1100 \\
\hline MERCURY (HG), UG/L & 4 & 0.0 & 0.0 & 4 & 0.0 & 0.0 \\
\hline SELENIUM (SE), UG/L & 4 & 10 & 13 & 4 & 9 & 13 \\
\hline ZINC $(Z N), U G / L$ & 4 & 10 & 80 & 4 & 10 & 50 \\
\hline \multicolumn{7}{|l|}{ PERIPHYTON: } \\
\hline BIOMASS, DRY WT., G/SQ M & 3 & 11.00 & 17.00 & & & \\
\hline BIOMASS, ASH WT., G/SQ M & 4 & 4.59 & 12.00 & & & \\
\hline CHLOROPHYLL A, MG/SO M & 4 & 12.0 & 60.0 & & & \\
\hline CHLOROPHYLL B, MG/SQ M & 4 & 4.3 & 19.0 & & & \\
\hline ORGANIC CARBON, MG/L & 4 & 2.5 & 13.0 & & & \\
\hline
\end{tabular}


Table 14.--Summary of measurement at each station--Continued

LAT 32D43MOTS LONG 114043M05S

DRAINAGE AREA: 243000 SQ MI 1629370 SQ KMI

PERIOD OF RECORD: $10 / 01 / 74$ - 09/30/75

STATISTICAL SUMMARY OF SELECTED DISSOLVED CHEMICAL CONSTITUENTS AND

REGRESSION RELATIONSHIPS OF CONSTITUENT CONCENTRATIONS TO SPECIFIC CONDUCTANCE

CONSIIIUENI

CONSIUTUENI IMG/L OR UNII SHOWNL

SAMPLE
SLZE

TEMPERATURE, WATER (DEG C) SPECIFIC CONDUCTANCE (MICROMHOS) STREAMFLOW (CUBIC FT/SEC)

STREAMFLOW (CUBIC FT
PH (STANDARD UNITS)

PH ISTANDARD UNITSI

NITRITE + NITRATE, TOTAL

NITROGEN, KJELDAHL, TOTAL

PHYTOPLANKTON, TOTAL (CELLS/ML)

SEDIMENT, SUSPENDED

SEDIMENT, CLAY-SILT (PERCENT)

COLIFURM, FECAL (COL/100 ML)

STREPTOCOCCI, FECAL (COL/100 ML)

SILICA, DISSOLVED

CALCIUM, DISSOLVED

MAGNESIUM, DISSOLVED

SODIUM, DISSOLVED

POTASSIUM, DISSOLVED

BICARBONATE, ION

CARBONATE, ION

SULFATE, DISSOLVED

CHLORIDE, DISSOLVED

DISSOLVED SOLIDS, SUM OF CONST

DISSOLVED SOLIDS, ROE 180 DEG

HARDNESS, TOTAL

HARDNESS, NONCARBONATE

TURBICITY (JTU)

FLOURIDE, DISSOLVED

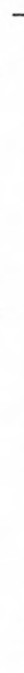

*Not significant at the 95 percer

\begin{tabular}{|c|c|c|c|c|c|}
\hline LZE & MEAN & DEXIALUNN & \multicolumn{2}{|c|}{ BANGE } & SIZE \\
\hline 56 & 19.54 & 5.94 & 10.0 & 29.5 & \\
\hline 65 & 1595.1 & 139.9 & 1430 & 1990 & \\
\hline 76 & 1838.7 & 772.1 & 707 & 3780 & 65 \\
\hline 61 & 8.00 & 0.10 & 7.7 & 8.2 & 61 \\
\hline 24 & 0.081 & 0.035 & 0.04 & 0.18 & 13 \\
\hline 24 & 0.245 & 0.077 & 0.08 & 0.38 & 13 \\
\hline 24 & 0.415 & 0.192 & 0.09 & 0.88 & 13 \\
\hline 8 & 4460.0 & 3822.9 & 500 & 11000 & 8 \\
\hline 0 & & & & & \\
\hline 0 & & & & & \\
\hline 11 & 160.1 & 176.6 & 16 & 540 & \\
\hline 11 & 760.2 & 1940.6 & 48 & 6600 & \\
\hline 52 & 11.06 & 1.38 & 9.0 & 14.0 & 52 \\
\hline 52 & 106.21 & 6.06 & 98.0 & 121.0 & 52 \\
\hline 52 & 35.94 & 2.11 & 32.0 & 41.0 & 52 \\
\hline 52 & 183.65 & 22.39 & 155.0 & 240.0 & 52 \\
\hline 52 & 6.27 & 0.50 & 5.5 & 7.5 & 52 \\
\hline 52 & 205.6 & 14.9 & 184 & 242 & 52 \\
\hline 50 & 0.0 & 0.0 & 0 & 0 & 50 \\
\hline 52 & 379.13 & 21.07 & 355.0 & 430.0 & 52 \\
\hline 52 & 181.33 & 26.59 & 140.0 & 255.0 & 52 \\
\hline 52 & 1006.2 & 85.9 & 903 & 1230 & 52 \\
\hline 52 & 1013.5 & 87.6 & 906 & 1230 & 52 \\
\hline 52 & 413.2 & 21.2 & 390 & 470 & 52 \\
\hline 52 & 244.6 & 9.9 & 230 & 272 & 52 \\
\hline 17 & 1.5 & 0.7 & 1 & 3 & 17 \\
\hline 52 & 0.58 & 0.08 & 0.5 & 0.7 & 52 \\
\hline
\end{tabular}

REGRESSION

BEGRESSION SUMMABY

STANDARD

SAMPLE COEFICIENT, CONSTANT, CORRELATION ERROR CF
SIZE - -1

$\begin{array}{rrrr}-4.365 & 8798.391 & -0.793 & 473.5 \\ -0.0002 & 8.3375 & -0.313 & 0.09 \\ 0.00015 & -0.15057 & 0.583 & 0.034 \\ 0.00022 & -0.11895 & 0.489 * & 0.067 \\ 0.00086 & -0.98603 & 0.650 & 0.170 \\ 18.516 & -26090.828 & 0.864 & 2078.4\end{array}$

DAILY SPECIFIC CONDUCTANCE IN

MICROMHOS AT 25 DEG C, THAT HAS

EQUALLED OR EXCEEDED FCR THE

URALION IABLE_OE DALLY SPECIEIC CONDUCIANCE

INDICATED PERCENTAGE OF TIME

\begin{tabular}{|c|c|c|c|c|}
\hline 18 & -58 & $10 \pi$ & 202 & 302 \\
\hline 1940 & 1870 & 1830 & 1760 & 1610 \\
\hline \multicolumn{5}{|c|}{$\begin{array}{l}\text { IS OF STREAM TEMPERATURE } \\
+\mathrm{A} * \text { SINI.OII } * 0+\mathrm{C})\end{array}$} \\
\hline \multirow{2}{*}{\multicolumn{2}{|c|}{ PHASE }} & & & STANDARD \\
\hline & & \multicolumn{2}{|l|}{ VAR IATION } & ERROR OF \\
\hline \multirow{2}{*}{\multicolumn{2}{|c|}{$\begin{array}{l}\text { ANGLE - C } \\
\text { (RADIANSS) }\end{array}$}} & \multicolumn{2}{|l|}{ EXPLAINED } & ESTIMATE \\
\hline & & $-(x)$ & & $10 E G \mathrm{C})$ \\
\hline & & 93 & & 1.61 \\
\hline
\end{tabular}

SUMMARY OF MAXIMUM AND MINIMUM CONCENTRATIONS OF CONSTITUENTS SAMPLED AT A FREQUENCY OF QUARTERLY (1975 WY)

SUMMARY OF HARMONIC ANALYSIS OF STREAM TEMPERATURE

\begin{tabular}{|c|c|c|c|c|c|}
\hline & & & & & STANDARD \\
\hline SAMPLE & $\begin{array}{l}\text { HARMONIC } \\
\text { MEAN - M }\end{array}$ & AMPLITUDE & $\begin{array}{l}\text { PHASE } \\
\text { ANGLE - }\end{array}$ & $\begin{array}{l}\text { VAR IATION } \\
\text { EXPLANED }\end{array}$ & $\begin{array}{l}\text { ERROR OF } \\
\text { ESTIMATE }\end{array}$ \\
\hline SIZE. & LDEG C) & DEEG $(1)$ & (RADLANS) & 181 & LEE CI \\
\hline 56 & 19.93 & 8.17 & 2.66 & 93 & 1.61 \\
\hline
\end{tabular}

\begin{tabular}{|c|c|c|c|c|c|c|}
\hline \multirow{2}{*}{ CONSTITUENT } & \multicolumn{3}{|c|}{ TOTAL } & \multicolumn{3}{|c|}{ DISSOLVED } \\
\hline & $\begin{array}{l}\text { NO. } \\
\text { SAMPLES }\end{array}$ & $\begin{array}{l}\text { MIN IMUM } \\
\text { CONC. }\end{array}$ & $\begin{array}{c}\text { MAXIMUM } \\
\text { CONC. }\end{array}$ & $\begin{array}{l}\text { NO. } \\
\text { SAMPLES }\end{array}$ & $\begin{array}{l}\text { MINIMUM } \\
\text { CONC. }\end{array}$ & $\begin{array}{l}\text { MAXIMUM } \\
\text { CONC. }\end{array}$ \\
\hline \multicolumn{7}{|l|}{ MINOR ELEMENTS: } \\
\hline ARSENIC (AS), UG/L & 4 & 1 & 6 & 4 & 0 & 6 \\
\hline CADMIUM $(C D), U G / L$ & 4 & $<10$ & 10 & 4 & 0 & 0 \\
\hline CHROMIUM (CR), UGIL & 4 & 0 & 10 & 4 & 0 & 10 \\
\hline COBALT $(C O)$, UG/L & 4 & 0 & 50 & 4 & 0 & 2 \\
\hline COPPER (CU), UG/L & 4 & $<10$ & 280 & 4 & 0 & 1 \\
\hline IRON $(F E), U G / L$ & 24 & 0 & 930 & 4 & 10 & 20 \\
\hline LEAD $(P B), U G / L$ & 4 & $<100$ & $<100$ & 4 & 0 & 9 \\
\hline MANGANESE (MN), UGIL & 4 & 50 & 150 & 4 & 10 & 60 \\
\hline MERCURY $(H G), U G / L$ & 4 & 0.0 & 0.0 & 4 & 0.0 & 0.0 \\
\hline SELENIUM (SE), UG/L & 4 & 3 & 4 & 4 & 2 & 4 \\
\hline ZINC $(Z N), U G / L$ & 4 & 0 & 40 & 4 & 0 & 60 \\
\hline \multicolumn{7}{|l|}{ PERIPHYTON: } \\
\hline BIOMASS, DRY WT., G/SQ & M & 9.69 & 74.00 & & & \\
\hline BIOMASS, ASH WT., G/SQ & $M$ & 3.09 & 64.00 & & & \\
\hline CHLOROPHYLL A, MG/SQ M & 4 & 7.1 & 83.0 & & & \\
\hline CHLOROPHYLL B, MG/SQ M & 4 & 1.1 & 15.0 & & & \\
\hline ORGANIC CARBON, MG/L & 24 & 2.6 & 10.0 & & & \\
\hline
\end{tabular}


LAT $42013 M O O S$ LONG $111020 M 35 S$

DRAINAGE AREA:

0 SO MI

PERIOD UF RECORD: $10 / 01 / 74$ - 09/30/75

O SQ KM)

STATISTICAL SUMMARY OF SELECTED DISSOLVED CHEMICAL CONSTITUENTS AND

REGRESSION RELATIONSHIPS OF CONSTITUENT CONCENTRATIONS TO SPECIFIC CONDUCTANCE

CONSIIUENI

TEMPERATURE, WATER (DEG C)
SPECIFIC CONDUCTANCE (MICROMHOS)
STREAMFLU, (CUBIC FT/SEC)
PH (STANDARD UNITS)
PHOSP MORUS, TOTAL
NITRITE, NITRATE, TOTAL
NITROGEN, KJELDAHL, TOTAL
PHYTOPLANKTON, TOTAL (CELLS/ML)
SEDIMENT, SUSPENDED
SEDIMENT, CLAY SILT (PERCENT)
COLIFORM, FECAL (COL/IOO ML)
STREPTOCOCCI, FECAL (COL/LOO ML)
SILICA, DISSOLVED
CALCIUM, DISSOLVED
MAGNESIUM, DISSOLVED
SODIUM, DISSOLVED
POTASSIUM, DISSOLVED
BICARECNATE, ION
CARBONATE, ION
SULFATE, DISSOLVED
CHLORIDE, DISSOLVED
DISSOLVED SOLIDS, SUM OF CONST
DISSOLVED SOLIDS, ROE I8O DEG C
HARDNESS, TOTAL
HARDNESS, NONCARBONATE
TURBIDITY (JTU)
FLOUR IDE, DISSOLVED

CONSIUUVENI IMG/L OB UNII SHOWNI SAMPLE
SIZE

13
13
13
13
12
12
12
12
5
8
6
9
12
12
12
12
12
12
8
12
12
12
12
12
12
12
12
STANDARD MEAN REYIAUION

8.96
635.0 635.0
350.8 350.8
7.95 0.040 0.041 0.041 0.537 2566.7 35.6
79.1

79.1
12.5

28.8
8.52

8.52
51.92

51.92

35.92

3.17

3.02
290.3

290.3
2.5

2.5
57.92

35.33

369.8

375.3

278.3

36.7
10.4

0.20

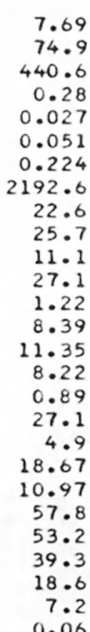

7.69
74.9
440.6
0.28
0.027
0.051
0.224
2192.6
22.6
25.7
11.1
27.1
1.22
8.39
11.35
8.22
0.89
27.1
4.9
18.67
10.97
57.8
53.2
39.3
18.6
7.2
0.06
BANGE

$$
\begin{aligned}
& 0.5 \\
& 530
\end{aligned}
$$

$530 \quad 23.0$

7.4

0.00

0.00

0.17

350

8
35

35
0
1

5.8
32.0

32.0

22.0
14.0

1.4
257

257
0

23.0

12.0

262

268

220
8

1

* Not significant at the 95 percent confidence 1 evel.

SUMMARY OF HARMONIC ANALYSIS OF STREAM TEMPERATURE

\begin{tabular}{|c|c|c|c|c|c|}
\hline & HARMONIC & & PHASE & & STANDARD \\
\hline $\begin{array}{l}\text { SAMPLE } \\
\text { SLZE }\end{array}$ & $\begin{array}{l}\text { MEAN - M } \\
\text { IDEG C) }\end{array}$ & $\begin{array}{l}-A \\
\text { LEE } C 1 \\
\end{array}$ & $\begin{array}{l}\text { ANGLE - C } \\
\text { LRADLANS) }\end{array}$ & $\begin{array}{l}\text { EXP LA INED } \\
\end{array}$ & $\begin{array}{l}\text { ESTIMATE } \\
\text { (OEG C) }\end{array}$ \\
\hline 12 & 9.41 & 10.29 & 2.71 & 93 & 2.27 \\
\hline
\end{tabular}

12

9.41

10.29

$2 \cdot 71$

2.27

SUMMARY OF MAXIMUM AND MINIMUM CONCENTRATIONS OF CONSTITUENTS SAMPLED AT A FREQUENCY OF QUARTERLY (1975 WY)

10059500 -- BEAR LAKE OUTLET CANAL NEAR PARIS IDAHO

\begin{tabular}{|c|c|c|c|c|c|c|}
\hline \multirow{2}{*}{ CONSTI TUENT } & \multicolumn{3}{|c|}{ TOTAL } & \multicolumn{3}{|c|}{ DISSOLVED } \\
\hline & $\begin{array}{c}\text { NO. } \\
\text { SAMPLES }\end{array}$ & $\begin{array}{l}\text { MIN IMUM } \\
\text { CONC. }\end{array}$ & $\begin{array}{l}\text { MAXIMUM } \\
\text { CONC. }\end{array}$ & $\begin{array}{c}\text { NO. } \\
\text { SAMPLES }\end{array}$ & $\begin{array}{l}\text { MINIMUM } \\
\text { CONC. }\end{array}$ & $\begin{array}{l}\text { MAXIMUM } \\
\text { CONC. }\end{array}$ \\
\hline \multicolumn{7}{|l|}{ MINOR ELEMENTS: } \\
\hline ARSENIC (AS), UG/L & 4 & 1 & 4 & 4 & 0 & 3 \\
\hline CADMIUM $(C D), U G / L$ & 4 & $<10$ & 20 & 4 & 0 & 0 \\
\hline CHROMIUM (CR), UG/L & 4 & 0 & 0 & 4 & 0 & 10 \\
\hline COBALT $(C O)$, UG/L & 4 & $<50$ & $<50$ & 4 & 0 & 2 \\
\hline COPPER $(C U), U G / L$ & 4 & $<10$ & 30 & 4 & 0 & 2 \\
\hline IRON $(F E), U G / L$. & 4 & 250 & 830 & 4 & 10 & 150 \\
\hline LEAD $(P B), U G / L$ & 4 & $<100$ & $<100$ & 4 & 2 & 4 \\
\hline MANG ANESE (MN), UG/L & 4 & 40 & 70 & 4 & 0 & 30 \\
\hline MERCURY $(H G), U G / L$ & 4 & 0.0 & 0.1 & 4 & 0.0 & 0.0 \\
\hline SELENIUM (SE), UG/L & 4 & 0 & 0 & 4 & 0 & 0 \\
\hline ZINC $(Z N), U G / L$ & 4 & 20 & 580 & 4 & 10 & 20 \\
\hline \multicolumn{7}{|l|}{ PERIPHYTON: } \\
\hline BIOMASS, ORY WT., G/SQ M & 2 & 4.00 & 91.00 & & & \\
\hline BIOMASS, ASH WT., G/SQ M & 2 & 1.50 & 84.00 & & & \\
\hline CHLOROPHYLL A, MG/SQ M & 2 & $\cdot 1$ & 14.0 & & & \\
\hline CHLOROPHYLL $B, M G / S Q M$ & 2 & $\cdot 0$ & 1.6 & & & \\
\hline ORGANIC CARBON, MG/L & 4 & 3.1 & $8 \cdot 1$ & & & \\
\hline
\end{tabular}


LAT $41034 M 35 S$ LONG 112006MOOS

$\begin{array}{ll}\text { DRAINAGE AREA: } & 7029 \text { SQ MI } 118205 \text { SQ KMI } \\ \text { PERIOD OF RECORD: } & 10 / 01 / 74-09 / 30 / 75\end{array}$

STATISTICAL SUMMARY OF SELECTED DISSOLVED CHEMICAL CONSTITUENTS AND

REGRESSION RELATIONSHIPS OF CONSTITUENT CONCENTRATIONS TO SPECIFIC CONDUCTANCE

CONSIIIUENI

TEMPERATURE, WATER (DEG C)
SPECIFIC CONDUCTANCE (MICROMHOS)
STREAMFLOH (CUBIC FI/SEC)
PH (STANDARD UNITS)
PHOSPHORUS, TOTAL,
NITRITE, NITRATE, TOTAL
NITROGEN, KJELDAHL, TOTAL
PHYTOPLANKTON, TOTAL (CELLS/ML)
SEDIMENT, SUSPENDED
SEDIMENT, CLAY-SILT (PERCENT)
COLIFORM, FECAL (COL/IOO ML)
STREPTOCOCI, FECAL (COL/IOO ML)
SILICA, DISSOLVED
CALCIUM, DISSOLVED
MAGNESIUM, DISSOLVED
SODIUM, DISSOLVED
POTASSIUM, DISSOLVED
BICARBONATE, ION
CARBONATE, ION
SULFATE, DISSOLVED
CHLORIDE, DISSOLVED
DISSOLVED SOLIDS, SUM OF CONST
DISSOLVED SOLIDS, ROE I8O DEG C
HARONESS, TOTAL
HARDNESS, NONCARBONATE
TURBIDITY (JTU)
FLOURIDE, DISSOLVED
FOUR

\section{CONSIUTUENT IMG/L OR UNII SHOWNU \\ SAMPLE \\ STANDARD}

SIZE

DEYIAIION
7.73

346.4

1222.7
0.23

0.176

0.176
0.287

0.287
0.403

12135.0

59.6
36.4

36.4
470.6

389.6

2.19

6.37

10.79

71.01

4.56

51.6

2.5

12.32

111.43

196.1

47.1

47.1
11.5

11.5
21.9
BANGE

$$
\begin{array}{r}
700 \\
1000 \\
7.9 \\
0.07 \\
0.17 \\
0.12 \\
8 \\
510 \\
5 . \\
6.5 \\
7.0 \\
211 \\
23.0 \\
85.0 \\
384 \\
397 \\
200 \\
11 \\
10.1
\end{array}
$$

REGBESS ION SUMMARY REGRESSION

\begin{tabular}{l} 
SAMPLE COEFICIENT, CONSTANT, CORRELATION \\
SIZE \\
\hline
\end{tabular} STANDARD
ERROR OF ESIUMAIE

B

OEEICIENI

${ }^{*}$ Not significant at the 95 percent confidence level.

DURAIION IABLE OE DALY SPECIEIC CONDUCIANCE

DAILY SPECIFIC CONDUCTANCE IN

MICROMHOS AT 25 DEG C, THAT WAS

EQUALLED OR EXCEEDED FOR THE

$\begin{array}{rrrrrr}-17 & 5 \% & 10 \% & 20 \% & 30 \% & 50 \% \\ 7040 & 6430 & 5850 & 5110 & 4470 & 3960\end{array}$

$\begin{array}{rrr}0.0 & 25.5 & \\ 700 & 2030 & \\ 1000 & 4185 & 14 \\ 7.9 & 8.7 & 16 \\ 0.07 & 0.76 & 13 \\ 0.17 & 0.93 & 13 \\ 0.12 & 1.50 & 13 \\ 810 & 43000 & 12 \\ 68 & 235 & \\ 91 & 164 & \\ 2 & 1600 & \\ 25 & 1400 & \\ 8.3 & 16.0 & 13 \\ 51.0 & 69.0 & 13 \\ 6.5 & 44.0 & 13 \\ 59.0 & 300.0 & 13 \\ 7.0 & 22.0 & 13 \\ 211 & 372 & 13 \\ 0 & 8 & 10 \\ 23.0 & 67.0 & 13 \\ 85.0 & 460.0 & 13 \\ 384 & 1040 & 13 \\ 397 & 1140 & 13 \\ 200 & 340 & 13 \\ 11 & 51 & 13 \\ 10 & 76 & 13 \\ 0.1 & 0.4 & 13\end{array}$

$\begin{array}{rr}14 & -2.356 \\ 16 & 0.0003 \\ 13 & 0.00003 \\ 13 & -0.00022 \\ 13 & 0.00061 \\ 12 & 20.383\end{array}$

5030.719
7.9794
0.16861
0.77987
0.03846
-11728.242
$-0.716$
0.500
$0.058 *$
0.285
0.557
0.640

$888 \cdot 5$

.00022

$-11728 \cdot 242$

9.5204

50.4843

40.6431

$-87.2500$

$-0.8174$

343.482

$-4.622$

25.4608

$-147.5156$

54.387

27.496

293.076

19.042

22.572

0.0505
$0.516 *$

$0.530 *$

$-0.227$

0.98

0.935

$-0.169 *$

0.786

0.656

0.977

0.973

0.986

-0.031 .

$0.239 *$

0.242

0.778

SUMMARY OF HARMONIC ANALYSIS OF STREAM TEMPERATURE

\begin{tabular}{|c|c|c|c|c|c|}
\hline & & & & & STANDARD \\
\hline & HARMONIC & AMPLITUDE & PHASE & VARIATION & ERROR OF \\
\hline SAMPLE & MEAN - M & $-A$ & $A N G L E-C$ & EXPLAINED & ESTIMATE \\
\hline SLZE_ & DEEG C & (DE $G$ C) & (BAD LANS) & (8) & $(0 E G \quad C)$ \\
\hline
\end{tabular}

345

10.60

10.73

2.68

1.87

SUMMARY OF MAXIMUM AND MINIMUM CONCENTRATIONS OF CONSTITUENTS SAMPLED AT A FREQUENCY OF QUARTERLY (1975 WY)

10126000 -- BEAR R NR CORINNE

\begin{tabular}{l} 
CONSTITUENT \\
\cline { 2 - 3 }
\end{tabular}


LAT $41016 M 42 S$ LONG 112005M28S

DRAINAGE AREA: 2000 SQ MI ( 5335 SQ KMI

PERIOD OF RECORD: $10 / 01 / 74-09 / 30 / 75$

STATISTICAL SUMMARY OF SELECTED DISSOLVED CHEMICAL CONSTITUENTS AND

REGRESSION RELATIONSHIPS OF CONSTITUENT CONCENTRATIONS TO SPECIFIC CONDUCTANCE

CONSIIIUENI

TEMPERATURE, WATER (DEG C) SPECIFIC CUNDUCTANCE (MICROMHOS) STREAMFLOW (CUBIC FI/SEC)

PHOSPHORUS, TOTAL

NITRITE + NITRATE, TOTAL

NITROGEN, KJELDAHL, TOTAL

PHYTOPLANKTON, TOTAL (CELLS/ML)

SEDIMENT, SUSPENDED

SEDIMENT, CLAY-SILT (PERCENT)

COL IFORM, FECAL (COL/100 ML)

STREPTOCOCCI, FECAL ( $\mathrm{COL} / 100 \mathrm{ML}$ )

SILICA, DISSOLVED

CALCIUM, DISSCLVED

MAGNESIUM, UISSOLVED

SODIUM, DISSOLVED

POTASSIUM, DISSOLVED

BICARGONATE, ION

CARBONATE, ION

SULFATE, DISSOLVED

CHLOR IDE, DISSOLVED

CHLORIOE, DISSOLVED

DISSOLVED SOLIDS, ROE 180 DEG

HARONESS, TOTAL

HARDNESS, NONCARBONATE

TURBIDITY (JTU)

FLOUR IDE, DISSOLVED

\section{SAMPLE \\ SIZE}

PH (STANDARD UNITS)

\begin{tabular}{|c|c|c|c|c|}
\hline \multirow{2}{*}{$\begin{array}{l}\text { SAMPLE } \\
\text { SIZE } \\
16\end{array}$} & \multirow{2}{*}{$\begin{array}{l}\text { MEAN } \\
10.34\end{array}$} & \multirow{2}{*}{$\begin{array}{l}\text { STANDARD } \\
\text { REYIAIIEN } \\
5.36\end{array}$} & \multicolumn{2}{|c|}{ BANGE } \\
\hline & & & 3.0 & 19.5 \\
\hline 17 & 548.5 & 139.0 & 280 & 710 \\
\hline 15 & 810.7 & 894.6 & 112 & 3060 \\
\hline 16 & 7.95 & 0.26 & 7.5 & 8.4 \\
\hline 12 & 0.677 & 0.407 & 0.21 & 1.40 \\
\hline 12 & 1.076 & 0.511 & 0.41 & 1.80 \\
\hline 12 & 0.894 & 0.258 & 0.57 & 1.30 \\
\hline 12 & 3050.0 & 2628.3 & 1000 & 10000 \\
\hline 4 & 84.0 & 71.4 & 14 & 148 \\
\hline 5 & 111.6 & 76.5 & 60 & 247 \\
\hline 9 & 80.8 & 76.2 & 1 & 220 \\
\hline 11 & 31.5 & 35.0 & 2 & 100 \\
\hline 15 & 9.41 & 1.35 & 7.5 & 12.0 \\
\hline 15 & 57.33 & 10.67 & 35.0 & 71.0 \\
\hline 15 & 17.71 & 4.33 & 8.7 & 23.0 \\
\hline 15 & 32.07 & 13.33 & 12.0 & 49.0 \\
\hline 15 & 4.85 & 1.82 & 1.9 & 7.4 \\
\hline 15 & 223.7 & 74.5 & 28 & 303 \\
\hline 9 & 0.0 & 0.0 & 0 & 0 \\
\hline 15 & 28.33 & 7.38 & 15.0 & 41.0 \\
\hline 15 & 43.60 & 17.30 & 16.0 & 64.0 \\
\hline 15 & 307.5 & 76.4 & 163 & 415 \\
\hline 12 & 330.6 & 82.6 & 169 & 458 \\
\hline 15 & 215.3 & 43.6 & 120 & 270 \\
\hline 15 & 32.5 & 52.1 & 8 & 220 \\
\hline 12 & 19.3 & 13.1 & 5 & 40 \\
\hline 15 & 0.19 & 0.06 & 0.1 & 0.3 \\
\hline
\end{tabular}

STANDARD \begin{tabular}{cl}
\multicolumn{2}{c}{ REGBESSION SUMMABY } \\
SAMPLE COEESSION \\
COEFICIENT, CONSTANT, CORR
\end{tabular}

DURAIION IABLE OE DALLY SPECIEIC CONDUCIANCE

DAILY SPECIFIC CONDUCTANCE IN

MICROMHOS AT 25 DEG C, THAT HAS

EQUALLED OR EXCEEDED FOR THE

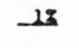

$-57$

202

$30 \% 50 \%$

2580

2310

2160

$688 \quad 546$

SAMPLE SIZE $\equiv 244$
70\% $20 \%$ 25\% $29 \%$

SUMMARY OF HARMONIC ANALYSIS OF STREAM TEMPERATURE

\begin{tabular}{|c|c|c|c|c|c|}
\hline & & & & & STANDARD \\
\hline & HARMONIC & AMPLITUDE & PHASE & VARIATION & ERROR OF \\
\hline $\begin{array}{l}\text { SAMPLE } \\
\text { SIZE_ }\end{array}$ & $\begin{array}{l}\text { MEAN - M } \\
\text { LDEG }(1)\end{array}$ & $\begin{array}{c}-{ }^{A} \\
\text { CEE }\end{array}$ & $\begin{array}{l}\text { ANGLE - C } \\
\text { IBAOIANSII }\end{array}$ & $\begin{array}{l}\text { EXPLAINED } \\
(\Omega)\end{array}$ & $\begin{array}{l}\text { ESTIMATE } \\
\text { COEG C }\end{array}$ \\
\hline 15 & 9.56 & 7.18 & 2.51 & 83 & 2.43 \\
\hline
\end{tabular}

SUMMARY OF MAXIMUM AND MINIMUM CONCENTRATIONS OF CONSTITUENTS

SAMPLED AT A FREQUENCY OF QUARTERLY (1975 WY)

10141000 -- WEGER RIVER NR PLAIN CITY UTAH

\begin{tabular}{|c|c|c|c|c|c|c|}
\hline \multirow{2}{*}{ CONSTITUENT } & \multicolumn{3}{|c|}{ TOTAL } & \multicolumn{3}{|c|}{ DISSOLVED } \\
\hline & $\begin{array}{l}\text { NO. } \\
\text { SAMPLES }\end{array}$ & $\begin{array}{l}\text { MINIMUM } \\
\text { CONC. }\end{array}$ & $\begin{array}{l}\text { MAXIMUM } \\
\text { CONC. }\end{array}$ & $\begin{array}{l}\text { NO. } \\
\text { SAMPLES }\end{array}$ & $\begin{array}{l}\text { MINIMUM } \\
\text { CONC. }\end{array}$ & $\begin{array}{l}\text { MAXIMUM } \\
\text { CONC. }\end{array}$ \\
\hline \multicolumn{7}{|l|}{ MINOR ELEMENTS: } \\
\hline $\begin{array}{ll}\text { ARSENIC } & (A S), U G / L \\
\text { CADMIUM } & (C D), U G / L\end{array}$ & 4 & 1 & 4 & 4 & 0 & 3 \\
\hline $\begin{array}{l}\text { CADMIUM }(C D), U G / L \\
\text { CHROMIUM (CR), UG/L }\end{array}$ & 4 & $<10$ & 10 & 4 & 0 & 1 \\
\hline $\begin{array}{l}\text { CHROMIUM (CR), UG/L } \\
\text { COBALT }(C O), U G / L\end{array}$ & 4 & 0 & 0 & 4 & 0 & 0 \\
\hline $\begin{array}{l}\text { COBALT }(C O), U G / L \\
\text { COPPER }(C U), U G / L\end{array}$ & $\begin{array}{l}4 \\
4\end{array}$ & 0 & $<50$ & 4 & 0 & 3 \\
\hline $\begin{array}{l}\text { COPPER }(C U), U G / L \\
\text { IRUN }(F E), U G / L\end{array}$ & 4 & $<\begin{array}{l}10 \\
10\end{array}$ & 270 & 4 & 2 & 5 \\
\hline & 4 & $\begin{array}{r}10 \\
<100\end{array}$ & 1900 & 7 & 10 & 590 \\
\hline MANG ANESE (MN), UG/L & 4 & $\begin{array}{r}100 \\
60\end{array}$ & $<100$ & 4 & 1 & 5 \\
\hline MERCURY (HG), UG/L & 4 & $\begin{array}{r}60 \\
0.0\end{array}$ & 110 & 7 & 0 & 90 \\
\hline SELENIUM (SE), UG/L & 4 & $\begin{array}{r}0.0 \\
0\end{array}$ & 0.0 & 4 & 0.0 & 0.0 \\
\hline ZINC $(2 N), U G / L$ & 4 & $\begin{array}{r}0 \\
20\end{array}$ & $\begin{array}{r}0 \\
50\end{array}$ & $\begin{array}{l}4 \\
4\end{array}$ & $\begin{array}{l}0 \\
0\end{array}$ & $\begin{array}{r}1 \\
20\end{array}$ \\
\hline \multirow{2}{*}{\multicolumn{7}{|c|}{ PERIPHYTON: }} \\
\hline BIOMASS, DRY WT., G/SO M & 3 & 4.59 & & & & \\
\hline BIOMASS, ASH WT, G/SO M & 4 & 3.09 & 39.00 & & & \\
\hline CHLOROPHYLL A, MG/SQ M & 3 & .1 & 160.0 & & & \\
\hline CHLOROPHYLL B, MG/SQ M & 3 & .0 & 28.0 & & & \\
\hline ORGANIC CARBON, MG/L & 4 & 3.8 & 8.0 & & & \\
\hline
\end{tabular}
REGRESSION

$15-5.835$

16

12

12

$-0.0008$

0.00252

0.00312

0.00136

5.954

8.3588

$-0.67989$

$-0.60069$

0.15974
-153.984

$-0.404$

0.861

0.848

0.315 *

0.0676

0.0297

0.0927

0.0123

0.228

0.0433

0.1206

0.1206

0.473

0.577
0.286

0.103

$-0.074$

0.0003

5.8344
21.3349

1. 8835

$-17.288$

$-1.7132$

102.006

0.000

$-20.6170$

-20.6170
55.690

55.690

19.935
62.987

62.987
-22.293

58.85

0.0291

SAMPLE SIZE $\equiv 244$
0.696

0.885

0.959

0.971

0.947

0.429 *

0.819

0.819

0.974

0.864

0.973

0.917
0.276 *

$-0.783$

0.726
STANDARO ERROR OF ESIIMAIF

$491 \quad 258 \quad 155 \quad 6$


Table 14.--Summary of measurement at each station--Continued

LAT 40D43M39S LONG 111055M26S

DRAINAGE AREA: 3420 SO MI ( 8858 SQ KM)

PERIOD OF RECORD: $10 / 01 / 74-09 / 30 / 75$

STATISTICAL SUMMARY OF SELECTED DISSOLVED CHEMICAL CONSTITUENTS AND

REGRESSION RELATIONSHIPS OF CONSTITUENT CONCENTRATIONS TO SPECIFIC CONDUCTANCE

CONSIIIUENI

CONSIITUENI_LMGL OR UNII SHOWNI

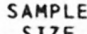

SIZE

TEMPERATURE, WATER (DEG C) SPECIFIC CONDUCTANCE (MICROMHOS) STREAMFLOW (CUBIC FT/SEC)

PH (STANDARD UNITS)

PHOSPHORUS, TOTAL

NITRITE + NITRATE, TOTAL

NITROGEN, KJELDAHL, YOTAL

PHYTOPLANKTON, TOTAL (CELLS/ML)

SEDIMENT, SUSPENDED

SEDIMENT, CLAY-SILT (PERCENT)

COLIFORM, FECAL (COL/100 ML)

STREPTOCOCCI, FECAL (COL/100 ML)

SILICA, DISSOLVED

CALCIUM, DISSOLVED

MAGNESIUM, DISSOLVED

SODIUM, DISSOLVED

POTASSIUM, DISSOLVED

BICARBONATE, ION

CARBONATE, ION

SULFATE, DISSOLVED

CHLORIDE, DISSOLVED

DISSOLVEO SOLIDS, SUM OF CONST

DISSOLVED SOLIDS, ROE 180 DEG C

HARDNESS, TOTAL

HARDNESS, NONCARBONATE

TURBIDITY (JTU)

FLOURIDE, DISSOLVED
MEAN DEYIAIION

$\begin{array}{rrr}13 & 10.38 & 3.89 \\ 14 & 1515.3 & 309.5\end{array}$

$\begin{array}{rr}12 & 112.6 \\ 14 & 7.66\end{array}$

7.66
1.308

2.100

2.283

11155.0

115.6

115.6
96.6

96.6
596.3

219.8

20.83

103.09

51.25

140.08

13.31

278.3

0.0
274.17

274.17
194.00

918.5

918.5
987.0

987.0
464.5

464.5
238.2

28.8
40.6

0.21
0.464

0.464

.062

15672.9

32.2

19.8

1372.7

499.8
4.00

4.00
26.35

10.63

32.90

3.23

50.3

0.0

63.17

48.91

205.6
218.0

97.0

57.4

21.6
BEG

REGRESSION

SAMPLE

COEFICIENT,

SSION SUMMARY

CONSTANT, CORRELATION B COEEICIENI

STANDARD

ERROR OF

$\begin{array}{ll}5.0 & 18.0 \\ 874 & 1800\end{array}$

874
36
7.4
0.63

$160 \quad 12$

160
2.20

2.80

$\begin{array}{rrr}1.30 & 2.80 & 12 \\ 1.40 & 3.30 & 12\end{array}$

$2 \quad 0.039$

$-0.0004$

0.00131

0.00097

20.486

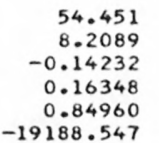

0.312 *

$-0.530 *$

0.681

0.750

0.609

$0.422 *$

ESIIHAIE

$\begin{array}{rr}79 & 156 \\ 83 & 131 \\ 0 & 4200\end{array}$

4200
1600

$\begin{array}{rr}1 & 1600 \\ 12.0 & 26.0 \\ 66.0 & 140.0\end{array}$

$29.0 \quad 64.0$

$69.0 \quad 170.0$

$\begin{array}{rr}6.7 & 17.0 \\ 176 & 328\end{array}$

$\begin{array}{rr}176 & 328 \\ 0 & 0 \\ 50.0 & 350.0\end{array}$

$\begin{array}{rr}50.0 & 350.0 \\ 88.0 & 240.0\end{array}$

88.0

517
558

558
290

130

1130
1190

1190
590

590
320

0.3

66
0.7

*Not significant at the 95 percent confidence level.

DURAIION IABLE OF DAILY SPECIEIC CONDUCIANCE

DAILY SPECIFIC CONDUCTANCE IN

MICROMHOS AT 25 DEG C, THAT WAS

MICROMHOS AT 25 DEG C, THAT HAS
EQUALLED OR EXCEEDED FOR THE

INDICATED PERCENTAGE OF TIME

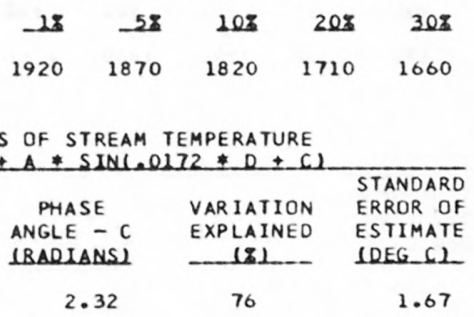

SUMMARY OF HARMONIC ANALYSIS OF STREAM TEMPERATURE

\begin{tabular}{|c|c|c|c|c|c|}
\hline $\begin{array}{l}\text { SAMPLE } \\
\text { SIZE }\end{array}$ & $\begin{array}{l}\text { HARMONIC } \\
\text { MEAN - M } \\
\text { LOEG CI }\end{array}$ & $\begin{array}{c}\text { AMPLITUDE } \\
-A \\
\text { (DEG C) }\end{array}$ & $\begin{array}{c}\text { PHASE } \\
\text { ANGLE - C } \\
\text { (BADIANS) }\end{array}$ & $\begin{array}{l}\text { VARIATION } \\
\text { EXPLAINED } \\
\quad(\boldsymbol{I}) \\
\end{array}$ & $\begin{array}{l}\text { STANDARD } \\
\text { ERROR OF } \\
\text { ESTIMATE } \\
\text { (DEG_C) }\end{array}$ \\
\hline 138 & 11.08 & 7.39 & 2.32 & 76 & 1.67 \\
\hline
\end{tabular}

SUMMARY OF MAXIMUM AND MINIMUM CONCENTRATIONS OF CONSTITUENTS SAMPLED AT A FREQUENCY OF QUARTERLY (1975 HY)

10171000 -- JORDAN R a 2100 SO SALT LAKE CITY UTAH

\begin{tabular}{|c|c|c|c|c|c|c|}
\hline \multirow{2}{*}{ CONSTITUENT } & \multicolumn{3}{|c|}{ TOTAL } & \multicolumn{3}{|c|}{ DISSOLVED } \\
\hline & $\begin{array}{l}\text { NO. } \\
\text { SAMPLES }\end{array}$ & $\begin{array}{l}\text { MIN IMUM } \\
\text { CONC. }\end{array}$ & $\begin{array}{c}\text { MAXIMUM } \\
\text { CONC. }\end{array}$ & $\begin{array}{l}\text { NO. } \\
\text { SAMPLES }\end{array}$ & $\begin{array}{l}\text { MINIMUM } \\
\text { CONC. }\end{array}$ & $\begin{array}{l}\text { MAXIMUM } \\
\text { CONC. }\end{array}$ \\
\hline \multicolumn{7}{|l|}{ MINOR ELEMENTS: } \\
\hline ARSENIC (AS), UG/L & 4 & 9 & 29 & 4 & 8 & 13 \\
\hline CADMIUM $(C D)$, UG/L & 4 & $<10$ & $<10$ & 4 & 0 & 1 \\
\hline CHROMIUM (CR), UG/L & 4 & 0 & 10 & 4 & 0 & 0 \\
\hline COBALT $(C O)$, UG/L & 4 & $<50$ & 50 & 4 & 0 & 1 \\
\hline COPPER $(C U), U G / L$ & 4 & 10 & 60 & 4 & 4 & 10 \\
\hline IRON (FE), UG/L & 4 & 460 & 2300 & 4 & 10 & 60 \\
\hline LEAD $(P B), U G / L$ & 4 & $<100$ & 300 & 4 & 2 & 4 \\
\hline MANG ANESE (MN), UG/L & 4 & 50 & 100 & 4 & 30 & 60 \\
\hline MERCURY (HG), UG/L & 3 & 0.1 & 0.1 & 4 & 0.0 & 0.2 \\
\hline SELENIUM $(S E), U G / L$ & 4 & 2 & 4 & 4 & 2 & 4 \\
\hline ZINC $(Z N), U G / L$ & 4 & 40 & 300 & 4 & 10 & 30 \\
\hline \multicolumn{7}{|l|}{ PERIPHYTON: } \\
\hline BIOMASS, DRY WT.. G/SQ M & 3 & 5.50 & 25.00 & & & \\
\hline BIOMASS, ASH WT., G/SO M & 3 & 4.29 & 20.00 & & & \\
\hline CHLOROPHYLL A, MG/SO M & 3 & $\cdot 1$ & 45.0 & & & \\
\hline CHLOROPHYLL B, MG/SO M & 3 & $\cdot 0$ & $4 \cdot 0$ & & & \\
\hline ORGANIC CARBON, MG/L & 4 & 6.6 & $18 \cdot 0$ & & & \\
\hline
\end{tabular}


Table 14.--Summary of measurement at each station--Continued

LAT 39D28M55S LONG 112D23M35S

DRAINAGE AREA: 6270 SQ MI 116239 SQ KM)

PERIOD OF RECORD: $10 / 01 / 74-09 / 30 / 75$

STATISTICAL SUMMARY OF SELECTED DISSOLVED CHEMICAL CONSTITUENTS AND

REGRESSION RELATIONSHIPS OF CONSTITUENT CONCENTRATIONS TO SPECIFIC CONDUCTANCE

CONSIIIUENI

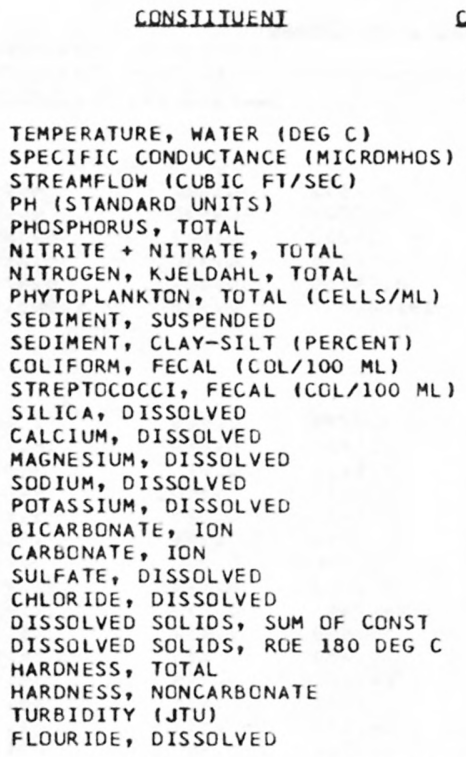

CONSIIIUENI IMG/L OR UNII SHOWN

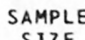

SIZE

STANDARD

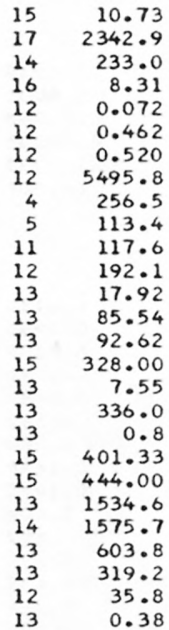

7.88

1010.9

265.8
0.17

0.17
0.063

0.200

0.213

7024.9

139.5

193.3

153.5

153.5

2.33
27.69

37.97

183.97

2.86

50.4
2.0

216.72

239.40

744.5
767.2

767.2

239.2

186.8

0.12
BANGE

0.0
1580
7
8.0
0.01
0.18

$0.21 \quad 0.87$

670

$\begin{array}{ll}83 & 422\end{array}$

42
0

$\begin{array}{rr}14 & 560 \\ 14.0 & 22.0\end{array}$

$\begin{array}{rr}14.0 & 22.0 \\ 58.0 & 140.0\end{array}$

$\begin{array}{ll}58.0 & 140.0 \\ 62.0 & 170.0\end{array}$

$\begin{array}{rr}190.0 & 760.0 \\ 5.0 & 15.0\end{array}$

$275 \quad 445$

$240.0 \quad 900.0$

100.01000 .0

1070

1060

440
170

0.2
BEG REGRESSION SAMPLE COEFICIENT, CONSTANT, CORRELATION ERROR OF SIZE -

* Not significant at the 95 percent confidence level.

DAILY SPECIFIC CONDUCTANCE IN

UUALION IABLE_OE DAILY SPECIEIC CONDUCIANCE MICROMHOS AT 25 DEG C, THAT WAS

EQUALLED OR EXCEEDED FOR THE

$\begin{array}{rrrrrr}21 & 5 z & 10 z & 20 z & 30 z & 50 z \\ 4920 & 4780 & 4500 & 2350 & 2170 & 2060\end{array}$

13
13
13
13
13
13
13
13
13
13
12
13
13
12
13

0.0218

0.0324

0.1631

0.0023

0.040

0.1953

0.1953

0.2130

0.650
0.673

0.203

0.154

$-0.006$

0.0001

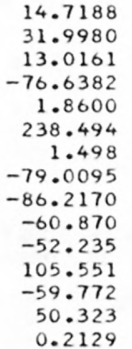

0.639

0.897

0.973

0.989

0.922

0.899

-0.149 *

0.993

0.993

0.994

0.995

0.967

0.942

-0.160 *

0.653

$202 \quad 20 \% \quad 258 \quad 293$

$1990 \quad 1830 \quad 1760 \quad 1700$

INDICATED PERCENTAGE OF TIME

S OF STREAM TEMPERATURE

FORM

\begin{tabular}{|c|c|c|c|c|c|}
\hline & & & & & STANDARD \\
\hline & HARMONIC & AMPLI TUDE & PHASE & VARIATION & ERROR OF \\
\hline $\begin{array}{l}\text { SAMPLE } \\
\text { SIZE }\end{array}$ & MEAN - $M$ & $-A$ & ANGLE - C & EXPLAINED & ESTIMATE \\
\hline SIZE & IDEG C1 & CDEG C) & IRADIANSI & $-(8)$ & LEEG 6$)$ \\
\hline 364 & 11.27 & 9.80 & 2.80 & 86 & 2.85 \\
\hline
\end{tabular}

SUMMARY OF MAXIMUM AND MINIMUM CONCENTRATIONS OF CONSTITUENTS SAMPLED AT A FREQUENCY OF QUARTERLY (1975 WY)

10224000 -- SEVIER RIVER NEAR LYNNDYL, UTAH

\begin{tabular}{|c|c|c|c|c|c|c|}
\hline \multirow{2}{*}{ CONSTITUENT } & \multicolumn{3}{|c|}{ TOTAL } & \multicolumn{3}{|c|}{ DISSOLVED } \\
\hline & $\begin{array}{l}\text { NO. } \\
\text { SAMPLES }\end{array}$ & $\begin{array}{l}\text { MINIMUM } \\
\text { CONC. }\end{array}$ & $\begin{array}{l}\text { MAXIMUM } \\
\text { CONC. }\end{array}$ & $\begin{array}{l}\text { NO. } \\
\text { SAMPLES }\end{array}$ & $\begin{array}{l}\text { MINIMUM } \\
\text { CONC. }\end{array}$ & $\begin{array}{l}\text { MAXIMUM } \\
\text { CONC. }\end{array}$ \\
\hline \multicolumn{7}{|l|}{ MINOR ELEMENTS: } \\
\hline ARSENIC (AS), UG/L & 4 & 4 & 8 & 4 & 4 & 7 \\
\hline CADMIUM $(C D), U G / L$ & 4 & $<10$ & 10 & 4 & 0 & 0 \\
\hline CHROMIUM (CR), UG/L & 4 & 0 & 10 & 4 & 0 & 0 \\
\hline COBALT $(\mathrm{CO}), \mathrm{UG} / \mathrm{L}$ & 4 & $<50$ & 50 & 4 & 0 & 0 \\
\hline COPPER (CU), UG/L & 4 & $<10$ & 50 & 4 & 0 & 2 \\
\hline IRON (FE), UG/L & 4 & 210 & 2800 & 4 & 10 & 40 \\
\hline LEAD $(P B), U G / L$ & 4 & $<100$ & 100 & 4 & 0 & 3 \\
\hline MANGANESE (MN), UG/L & 4 & 30 & 150 & 4 & 0 & 130 \\
\hline MERCURY $(H G), U G / L$ & 4 & 0.0 & 0.5 & 4 & 0.0 & 0.1 \\
\hline SELENIUM (SE), UG/L & 4 & 0 & 1 & 4 & 0 & 1 \\
\hline ZINC $(Z N), U G / L$ & 4 & 10 & 70 & 4 & 0 & 30 \\
\hline \multicolumn{7}{|l|}{ PERIPHYTON: } \\
\hline BIOMASS, DRY WT., G/SQ M & 2 & 41.00 & 57.00 & & & \\
\hline BIOMASS, ASH WT., G/SQ M & 3 & 29.00 & 120.00 & & & \\
\hline CHLOROPHYLL A, MG/SQ M & 3 & 11.0 & 12.0 & & & \\
\hline CHLOROPHYLL $B, M G / S Q M$ & 3 & 1.1 & 2.6 & & & \\
\hline ORGANIC CARBON, MG/L & 4 & 2.0 & 7.7 & & & \\
\hline
\end{tabular}


LAT 38D15M13S LONG 112D46M03S

DRAINAGE AREA: $267 \mathrm{SQ} M I$

PERIOD OF RECORD: $10 / 01 / 74-09 / 30 / 75$ SO KM

STATISTICAL SUMMARY OF SELECTED DISSOLVED CHEMICAL CONSTITUENTS AND

REGRESSION RELATIONSHIPS OF CONSTITUENT CONCENTRATIONS TO SPECIFIC CONDUCTANCE

CONSIUTUENI

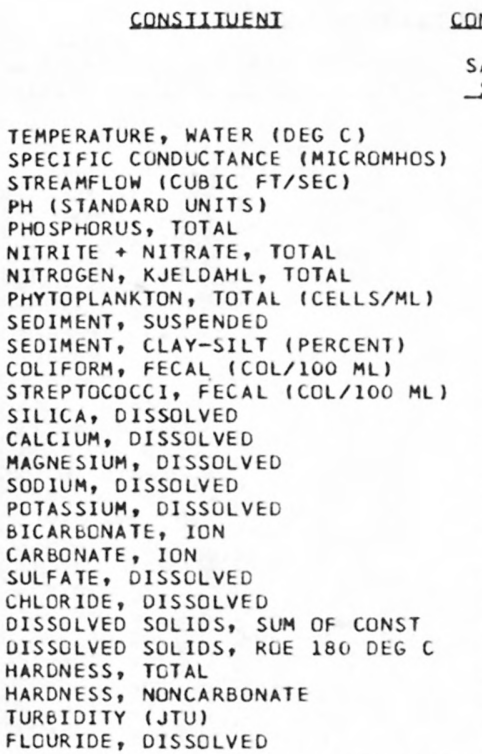

\section{CONSIUTUENT IMG/L OR UNII SHOHNL}

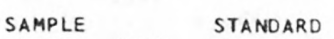

$\begin{array}{ll}\text { SAMPLE } & \text { STANDARD } \\ \text { SIZE MEAN DEYLILION } & \text { BANGE }\end{array}$

$\begin{array}{rrr}18 & 10.75 & 8.29 \\ 17 & 560.0 & 205.4 \\ 17 & 26.9 & 16.0 \\ 10 & 8.09 & 0.50 \\ 10 & 0.311 & 0.230 \\ 10 & 0.136 & 0.169 \\ 10 & 1.142 & 0.518 \\ 10 & 5123.0 & 4297.5 \\ 6 & 89.0 & 68.4 \\ 5 & 96.0 & 17.9 \\ 10 & 2488.3 & 3181.6 \\ 10 & 1070.7 & 1520.6 \\ 10 & 38.40 & 5.21 \\ 10 & 58.00 & 17.03 \\ 10 & 16.03 & 6.00 \\ 10 & 49.00 & 26.99 \\ 10 & 7.85 & 2.21 \\ 10 & 276.5 & 97.0 \\ 8 & 2.9 & 5.9 \\ 10 & 43.50 & 19.96 \\ 10 & 32.80 & 15.65 \\ 10 & 385.3 & 138.6 \\ 10 & 389.5 & 141.3 \\ 10 & 211.0 & 67.1 \\ 10 & 0.0 & 0.0 \\ 10 & 9.8 & 9.2 \\ 10 & 0.98 & 0.44\end{array}$
*Not significant at the 95 percent confidence level.

BANGE SIZE $\begin{array}{rr}0.0 & 25.0 \\ 310 & 975\end{array}$ 310

1.4
0.13

0.00

0.57
760

760
4

4
48

78
43
20

29.0

29.0
37.0

37.0
8.8

8.8
20.0

20.0
4.4

167

24.0

10.0

236

234

130

0
1
0.4

\section{REGRESSION BESSION_SUMMABY}

REGRESSION COEEICIENI

STANDARD ERROR OF ESIIMAIE

DURAIION IABLE OF DALIY SPECIEIC CONOUCIANCE

DAILY SPECIFIC CONDUCTANCE IN

MICROMHOS AT 25 DEG C, THAT WAS

EQUALLED OR EXCEEDED FOR THE

$\begin{array}{rrrrrr}12 & -58 & 20 \% & 20 z & 30 z & 50 \% \\ 1410 & 1320 & 1260 & 975 & 497 & 409\end{array}$

$\begin{array}{rrrrrr}64 & 16 & -0.040 & 50.468 & -0.547 & 13.2 \\ 8.7 & 9 & 0.0021 & 6.9059 & 0.905 & 0.24 \\ 0.74 & 9 & -0.00062 & 0.67296 & -0.598 * & 0.201 \\ 0.44 & 9 & -0.00039 & 0.36059 & -0.499^{*} & 0.162 \\ 2.10 & 9 & -0.00184 & 2.18108 & -0.767 & 0.373 \\ 15000 & 9 & -10.829 & 11581.980 & -0.577^{*} & 3719.3 \\ 197 & & & & & \end{array}$

$-0.547$

0.905

-0.598 *

$-0.499^{*}$
-0.767

-0.767
$-0.577^{*}$

13.2

0.24

0.201

0.162

0.373

INDICATED PERCENTAGE OF TIME

29.9543

17.0654
0.7817

0.7817
-12.5154

12.5154
3.3535

43.069

$-3.054$

4.8437

$-2.4924$

55.787

47.349

47.349

31.583

0.0248

$0.640^{*}$

0.983

0.992

0.992

0.841

0.974

0.322 *

0.925

0.975

0.993

0.994

0.983

0.983 *

0.000 *

-0.931
0.945

SUMMARY UF HARMONIC ANALYSIS OF STREAM TEMPERATURE

\begin{tabular}{|c|c|c|c|c|c|}
\hline & & & & & STANDARD \\
\hline AMPLE & $\begin{array}{l}\text { HARMONIC } \\
\text { MEAN - M }\end{array}$ & $\begin{array}{c}\text { AMPLITUDE } \\
-A^{-}\end{array}$ & $\begin{array}{c}\text { PHASE } \\
\text { ANGLE - C }\end{array}$ & $\begin{array}{l}\text { VARIATION } \\
\text { EXPLAINED }\end{array}$ & $\begin{array}{l}\text { ERROR OF } \\
\text { ESTIMATE }\end{array}$ \\
\hline SLZE & COEG $C)$ & WEEG $(1)$ & (BADIANS) & (8) & LEE (1) \\
\hline
\end{tabular}

18

10.83

10.32

2.62

87

3.19

SUMMARY OF MAXIMUM AND MINIMUM CONCENTRATIONS OF CONSTITUENTS

SAMPLED AT A FREQUENCY OF QUARTERLY (1975 WY)

10237000 -- BEAVER RIV AT ADAMSVILLE UTAH

\begin{tabular}{|c|c|c|c|c|c|c|}
\hline \multirow{2}{*}{ CONSTITUENT } & \multicolumn{3}{|c|}{ TOTAL } & \multicolumn{3}{|c|}{ DISSOLVED } \\
\hline & $\begin{array}{l}\text { NO. } \\
\text { SAMPLES }\end{array}$ & $\begin{array}{l}\text { MINIMUM } \\
\text { CONC. }\end{array}$ & $\begin{array}{l}\text { MAXIMUM } \\
\text { CONC. }\end{array}$ & $\begin{array}{l}\text { NO. } \\
\text { SAMPLES }\end{array}$ & $\begin{array}{l}\text { MINIMUM } \\
\text { CONC. }\end{array}$ & $\begin{array}{l}\text { MAXIMUM } \\
\text { CONC. }\end{array}$ \\
\hline \multicolumn{7}{|l|}{ MINOR ELEMENTS: } \\
\hline ARSENIC (AS), UG/L & 4 & 4 & 7 & 4 & 2 & 4 \\
\hline CAOMIUM $(C D), U G / L$ & 4 & $<10$ & 10 & 4 & 0 & 0 \\
\hline CHROMIUM (CR), UG/L & 4 & 0 & 10 & 4 & 0 & 0 \\
\hline COBALT $(C O), U G / L$ & 4 & 0 & $<50$ & 4 & 0 & 0 \\
\hline COPPER (CU), UG/L & 4 & $<10$ & 60 & 4 & 0 & 2 \\
\hline IRON $(F E), U G / L$ & 4 & 250 & 2600 & 4 & 20 & 80 \\
\hline LEAD $(P B), U G / L$ & 4 & $<100$ & 100 & 4 & 1 & 2 \\
\hline MANG ANESE (MN), UG/L & 4 & 130 & 390 & 4 & 100 & 290 \\
\hline MERCURY $(H G), U G / L$ & 4 & 0.0 & 0.0 & 4 & 0.0 & 0.0 \\
\hline SELENIUM (SE), UG/L & 4 & 0 & 1 & 4 & 0 & 0 \\
\hline ZINC $(Z N), U G / L$ & 4 & 40 & 170 & 4 & 0 & 10 \\
\hline \multicolumn{7}{|l|}{ PERIPHYTON: } \\
\hline BIOMASS, ORY WT., G/SO M & 2 & 1.69 & 9.89 & & & \\
\hline BIOMASS, ASH WT., G/SQ M & 3 & 1.09 & 8.00 & & & \\
\hline CHLOROPHYLL A, MG/SQ M & 3 & .5 & 3.6 & & & \\
\hline CHLOROPHYLL $B, M G / S Q M$ & 3 & .0 & .5 & & & \\
\hline ORGANIC CARBON, MG/L & 4 & 8.1 & 29.0 & & & \\
\hline
\end{tabular}


Table 14.--Summary of measurement at each station--Continued

LAT 3705OMOOS LONG 118012M1OS

JRAINAGE AREA: $\quad 37$ SO MI 1097 SO KMI

PERIOD OF RECORD: $10 / 01 / 74-09 / 30 / 75$

STATISTICAL SUMMARY OF SELECTED DISSOLVED CHEMICAL CONSTITUENTS AND REGRESSION RELATIONSHIPS OF CONSTITUENT CONCENTRATIONS TO SPECIFIC CONDUCTANCE

\section{CONSIUIUENI}

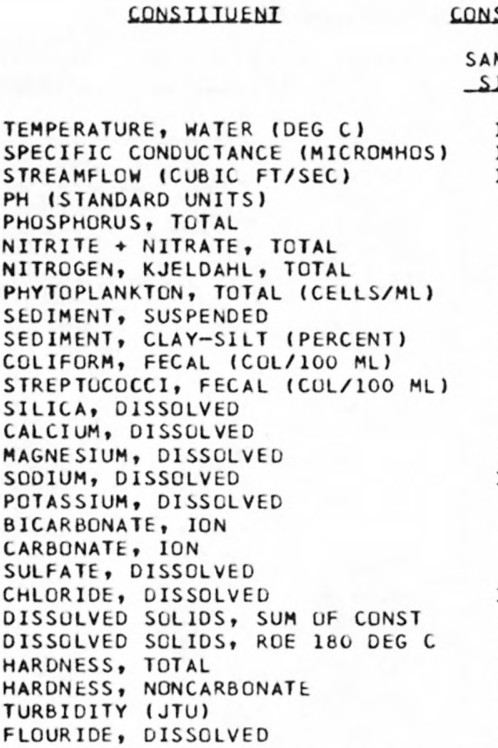

\begin{tabular}{l} 
CONSIUI \\
SAMPLE \\
SIZE \\
\hline 17 \\
11 \\
17 \\
6 \\
9 \\
9 \\
9 \\
8 \\
7 \\
0 \\
9 \\
8 \\
9 \\
8 \\
9 \\
10 \\
9 \\
8 \\
8 \\
9 \\
10 \\
8 \\
8 \\
8 \\
8 \\
9 \\
9
\end{tabular}

\section{NI IMG LI OR UNII SHOWNI}

MPLE

MEAN

6.97
56.4
7.2

7.80

0.047

0.067

0.236

$377 \cdot 5$
44.9

33.0

114.4

16.00
7.54

7.54
0.61

3.40

0.90

31.1

0.0
2.03

2.03
0.66

0.66
46.8

46.9

21.4

12.6
0.20

4.97

3.0

0.9
0.23

0.23
0.059

0.039

0.111

192.9

192.9
59.6

67.6

205.2

0.00
0.87

0.87
0.18

0.30

0.20

1.7
0.0

0.0
0.57

0.57
0.30

0.9

2.0
2.0

0.4

30.9

0.05

*Not significant at the 95 percent confidence level.
BEGRESSION_SUMMABY

REGRESSION

SAMPLE COEFICIENT, CONSTANT, CORRELATION BANGE SIZE $1.5 \quad 15.5$

51
6
7.6
0.01
0.02

$\begin{array}{rr}15.5 & \\ 62 & \\ 9 & 11 \\ 8.2 & 6 \\ 0.20 & 9 \\ 0.13 & 9 \\ 0.39 & 9 \\ 590 & 5\end{array}$
$-1$ COEEICIENI

STANDARO ESIIMAIE

$\begin{array}{rr}-0.024 & 8.604 \\ -0.0524 & 10.7089 \\ -0.01102 & 0.66762 \\ -0.00068 & 0.10511 \\ -0.01053 & 0.82870 \\ -55.833 & 3541.666\end{array}$

$-0.078$

$-0.738 *$

-0.058 *

$-0.313 *$

-0.346 *

1.0 0.050 0.042 0.113 191.4

191.4

0
4
16.0
6.8
0.4
2.9
0.7
29
0
1.5
0.3
46
44
20
0
1
0.1

210
600
16.0
9.6
0.9
3.8
1.3
34
0
3.4
1.3
48
50
26
1
95
0.3

600
16.0
9.6
0.9
3.8
1.3
34
0
3.4
1.3
48
50
26
1
95
0.3

15.8330

0.006

(20)

DAILY SPECIFIC CONDUCTANCE IN

MICROMHOS AT 25 DEG C, THAT WAS

EQUALLED OR EXCEEDED FOR THE

UBALION IABLE OF DALY SPECIEIC CONDUCIANCE

INDICATED PERCENTAGE OF TIME

$\begin{array}{lrr}12 & \frac{58}{10 \%} \\ 64 & 63 & 63\end{array}$

$\begin{array}{rrr}208 & 308 & 50 \% \\ 60 & 59 & 57\end{array}$

9
8
9
10
9
8
8
9
10
8
8
8
8
9
9

0.0000
0.0056
-0.0095
0.0464
0.0023
-0.061
0.000
0.0523
0.0120
0.031
0.152
-0.036
-0.004
-4.587
-0.0000

7.2227

1.1446

0.7834

0.7722

34.573

0.000
-0.9118

-0.9118
-0.0162

44.986

38.294

23.380

270.963

0.2000

0.000 *

0.023 *

-0.171 *

0.488

-0.125 *

0.000 *

0.302 *

$0.124^{*}$

0.125
0.266

-0.063 *

$-0.043$

-0.492 *

-0.000 *

0.00
0.93
0.19
0.28
0.21
1.9
0.0
0.59
0.32
0.9
2.1
2.2
0.4
28.8
0.05

SUMMARY OF HARMONIC ANALYSIS OF STREAM TEMPERATURE

\begin{tabular}{|c|c|c|c|c|c|}
\hline & & & & & STANDARD \\
\hline & HARMONIC & AMPLI IUDE & PHASE & VARIATION & ERROR OF \\
\hline SAMPLE & MEAN - $M$ & $-A$ & ANGLE - C & EXPLAINED & ESTIMATE \\
\hline SIZE & 1DEG_C) & IDEG $C)$ & IBADIANSI & 181 & DEE 61 \\
\hline 179 & 6.88 & 11.07 & 2.98 & 78 & 2.17 \\
\hline
\end{tabular}

SUMMARY OF MAXIMUM AND MINIMUM CONCENTRATIONS CF CONSTITUENTS SAMPLED AT A FREQUENCY OF QUARTERLY (1975 WY)

10249900 -- CHIATOVICH C NR DYER, NV

\begin{tabular}{|c|c|c|c|c|c|c|}
\hline \multirow{2}{*}{ CONSTI TUENT } & \multicolumn{3}{|c|}{ TOTAL } & \multicolumn{3}{|c|}{ DISSOLVED } \\
\hline & $\begin{array}{l}\text { NO. } \\
\text { SAMPLES }\end{array}$ & $\begin{array}{l}\text { MIN IMUM } \\
\text { CONC. }\end{array}$ & $\begin{array}{l}\text { MAXIMUM } \\
\text { CONC. }\end{array}$ & $\begin{array}{l}\text { NO. } \\
\text { SAMPLES }\end{array}$ & $\begin{array}{l}\text { MINIMUM } \\
\text { CONC. }\end{array}$ & $\begin{array}{l}\text { MAXIMUM } \\
\text { CONC. }\end{array}$ \\
\hline \multicolumn{7}{|l|}{ MINOR ELEMENTS: } \\
\hline ARSENIC (AS), UG/L & 3 & 0 & 0 & 3 & 0 & 1 \\
\hline CADMIUM $(C D)$, UG $/ L$ & 3 & 0 & 20 & 3 & 0 & 0 \\
\hline CHROMIUM (CR), UG/L & 3 & 0 & $<10$ & 3 & 0 & 0 \\
\hline COBALT $(C O), U G / L$ & 3 & 0 & 50 & 3 & 0 & 2 \\
\hline COPPER $(C U), U G / L$ & 3 & 0 & 20 & 3 & 0 & 1 \\
\hline IRON (FE), UG/L & 3 & 310 & 560 & 3 & 40 & 90 \\
\hline LEAD (PB), UG/L & 3 & $<100$ & $<100$ & 3 & 2 & 4 \\
\hline MANG ANESE (MN), UG/L & 3 & 10 & 30 & 3 & 0 & 0 \\
\hline MERCURY (HG), UG/L & 3 & 0.0 & 1.6 & 3 & 0.0 & 0.7 \\
\hline SELENIUM (SE), UG/L & 3 & 0 & 0 & 3 & 0 & 0 \\
\hline$Z I N C(Z N), U G / L$ & 3 & 0 & 10 & 3 & 10 & 10 \\
\hline \multicolumn{7}{|l|}{ PERIPHYTON: } \\
\hline BIOMASS, DRY WT., G/SQ M & 2 & 2.50 & 3.89 & & & \\
\hline BIOMASS, ASH WT., G/SO M & 2 & .79 & 1.19 & & & \\
\hline CHLOROPHYLL A, MG/SO M & 2 & .7 & 20.0 & & & \\
\hline CHLOROPHYLL $B, M G / S O M$ & 2 & .0 & 2.0 & & & \\
\hline ORGANIC CARBON, MG/L & 3 & 1.8 & $5 \cdot 3$ & & & \\
\hline
\end{tabular}


Table 14.--Summary of measurement at each station--Continued

LAT 32039M57S LONG 115030M08S

DRAINAGE AREA: 0 SQ MI 1

PERIOD OF RECORD: 10/01/74 - 09/30/75

O SQ KMI

STATISTICAL SUMMARY OF SELECTED DISSOLVED CHEMICAL CONSTITUENTS AND

REGRESSION RELATIONSHIPS OF CONSTITUENT CONCENTRATIONS TO SPECIFIC CONDUCTANCE

CONSIIIUENI

CONSILIUENI
TEMPERATURE, WATER (DEG C)
SPECIFIC CONDUCTANCE (MICROMHOS)
STREAMFLOW (CUBIC FT/SEC)
PH (STANDARD UNITS)
PHOSPHORUS, TOTAL
NITRITE + NITRATE, TOTAL
NITROGEN, KJELDAHL, TOTAL
PHYTOPLANKTON, TOTAL (CELLS/ML)
SEDIMENT, SUSPENDED
SEDIMENT, CLAY SILT (PERCENT)
COLIFORM, FECAL (COL/IOO ML)
STREPTOCOCCI, FECAL (COL/IOO ML)
SILICA, DISSOLVED
CALCIUM, DISSOLVED
MAGNESIUM, DISSOLVED
SODIUM, DISSOLVED
POTASSIUM, DISSOLVED
BICAREONATE, ION
CARBONATE, ION
SULFATE, DISSOLVED
CHLORIDE, DISSOLVED
DISSOLVED SOLIDS, SUM OF CONST
OISSOLVED SOLIDS, ROE I8O DEG C
HARDNESS, TOTAL
HARDNESS, NONCARBONATE
TURBIDITY (JTU)
FLOURIDE, DISSOLVED

CONSTUUENT IMG/L OR UNII SHOWN

SLZE

$\begin{array}{lll}12 \\ 12 & 668 & 0 \\ 12 & 146 & 0\end{array}$

12

127.67

$12 \quad 1.058$

$12 \quad 5.858$

1238933.3

$8 \quad 50.9$

124020821.0
12265166.4

$\begin{array}{lr}12 & 265166.4 \\ 12 & 18.83\end{array}$

$\begin{array}{lr}12 & 18.83 \\ 12 & 247.50\end{array}$

12123.00

$\begin{array}{rr}12 & 993.33 \\ 12 & 50.33\end{array}$

$\begin{array}{ll}12 & 50.33 \\ 12 & 289.6\end{array}$

$\begin{array}{rr}7 & 0.0 \\ 12 & 773.33\end{array}$

$12 \quad 1683.33$

$12 \quad 4035.0$

4275.0

1122.5
880.8

880.8
16.3

0.67

STANDARD

DEXIAIION

6.79
563.9
19.8

0.31
0.280

0.280
1.837

2.166

42865.0

37.4
14.5

3203883.0

140666.9

$100000 \quad 600000$

$\begin{array}{rrr}2.09 & 14.0 & 23.0 \\ 19.60 & 230.0 & 280.0 \\ 17.24 & 96.0 & 150.0\end{array}$

17.24
81.39

$18.14 \quad 12.0$

16.5

75.00

119.34

245.8

335.1

109.1

90.2

7.7
0.10

$\begin{array}{rr}14.0 & 32.0 \\ 5830 & 7800 \\ 123 & 178\end{array}$

7.2

0.97
0.03

0.30

1700

64
32

70000

$860.0 \quad 1100.0$

$12.0 \quad 81.0$

$\begin{array}{rr}258 & 312 \\ 0 & 0 \\ 650.0 & 890.0\end{array}$

$1500.0 \quad 1900.0$

3610

3600

3600

970
730

0.4

4410
4730

$1300 \quad 12$

$\begin{array}{rr}1000 & 12 \\ 30 & 11\end{array}$

*Not significant at the 95 percent confidence level.

DAILY SPECIFIC CONDUCTANCE IN

MICROMHOS AT 25 DEG C, THAT WAS

EQUALLED OR EXCEEDED FOR THE

$\begin{array}{rrrrrr}18 & -5 \pi & 108 & 20 \pi & 307 & 507 \\ 7860 & 7660 & 7540 & 7250 & 7070 & 6770\end{array}$
\begin{tabular}{ll}
\multicolumn{3}{c}{ BEGRESSION SUMMABY } \\
REGRESSION \\
SAMPLE COEFICIENT, CONSTANT, CORRELATION \\
SIZE COB COEICIENI
\end{tabular}

STANDARD

ERROR OF

ESIUMAIE

INDICATED PERCENTAGE OF TIME

SUMMARY OF HARMONIC ANALYSIS OF STREAM TEMPERATURE

EORH OF EOUAIION: I.UDI $=M \pm A+S I N C .0172 * 0+C)$

\begin{tabular}{|c|c|c|c|c|c|}
\hline & & & & & STANDARD \\
\hline & HARMONIC & AMPLITUDE & PHASE & VAR IATION & ERROR OF \\
\hline SAMPLE & MEAN - $M$ & $-A$ & ANGLE - C & EXPLAINED & ESTIMATE \\
\hline SIZE. & LEE 1 . & LEEG C & (BAD LANS) & $-(2)$ & (DEG E) \\
\hline 218 & 22.11 & 8.61 & 2.71 & 93 & 1.61 \\
\hline
\end{tabular}

SUMMARY OF MAXIMUM AND MINIMUM CONCENTRATIONS OF CONSTITUENTS

SAMPLED AT A FREQUENCY OF QUARTERLY (1975 WY

10254970 -- NEW R AT INTERNAT BDY CALEXICO CA

\begin{tabular}{|c|c|c|c|c|c|c|}
\hline \multirow{2}{*}{ CONSTITUENT } & \multicolumn{3}{|c|}{ TOTAL } & \multicolumn{3}{|c|}{ DISSOLVED } \\
\hline & $\begin{array}{l}\text { NO. } \\
\text { SAMPLES }\end{array}$ & $\begin{array}{l}\text { MINIMUM } \\
\text { CONC. }\end{array}$ & $\begin{array}{l}\text { MAXIMUM } \\
\text { CONC. }\end{array}$ & $\begin{array}{l}\text { NO. } \\
\text { SAMPLES }\end{array}$ & $\begin{array}{l}\text { MINIMUM } \\
\text { CONC. }\end{array}$ & $\begin{array}{l}\text { MAXIMUM } \\
\text { CONC. }\end{array}$ \\
\hline \multicolumn{7}{|l|}{ MINOR ELEMENTS: } \\
\hline ARSENIC (AS), UG/L & 4 & 7 & 29 & 4 & 4 & 32 \\
\hline CADMIUM $(C D), U G / L$ & 4 & $<10$ & 10 & 4 & 0 & 3 \\
\hline CHROMIUM (CR), UGIL & 4 & 0 & 30 & 4 & 0 & 20 \\
\hline COBALT $(C O)$, UG/L & 4 & $<50$ & 70 & 4 & 0 & 1 \\
\hline COPPER (CU), UG/L & 4 & 20 & 40 & 4 & 4 & 8 \\
\hline IRON (FE), UG/L & 4 & 700 & 1800 & 5 & 10 & 250 \\
\hline LEAD $(P B), U G / L$ & 4 & $<100$ & 200 & 4 & 3 & 8 \\
\hline MANGANESE (MN), UG/L & 4 & 120 & 230 & 4 & 130 & 140 \\
\hline MERCURY (HG), UG/L & 3 & 0.0 & 0.2 & 4 & 0.0 & 0.1 \\
\hline SELENIUM $(S E), U G / L$ & 4 & 2 & 3 & 4 & 1 & 3 \\
\hline ZINC $(Z N), U G / L$ & 4 & 30 & 490 & 4 & 40 & 80 \\
\hline \multicolumn{7}{|l|}{ PERIPHYTON: } \\
\hline BIOMASS, DRY WT, G/SQ M & 4 & 14.00 & 300.00 & & & \\
\hline BIOMASS, ASH WT., G/SQ M & 4 & 12.00 & 280.00 & & & \\
\hline CHLOROPHYLL $A, M G / S Q M$ & 4 & 1.1 & 34.0 & & & \\
\hline CHLOROPHYLL B, MG/SQ M & 4 & .0 & 15.0 & & & \\
\hline ORGANIC CARBON, MG/L & 4 & 13.0 & 45.0 & & & \\
\hline
\end{tabular}


LAT 34D34M23S LONG 117D19M11S

DRAINAGE AREA: 514 SQ MI 1.1331 SO KMI

PERIOD OF RECORD: $10 / 01 / 74-09 / 30 / 75$

STATISTICAL SUMMARY OF SELECTED DISSOLVED CHEMICAL CONSTITUENTS AND REGRESSION RELATIONSHIPS OF CONSTITUENT CONCENTRATIONS TO SPECIFIC CONDUCTANCE

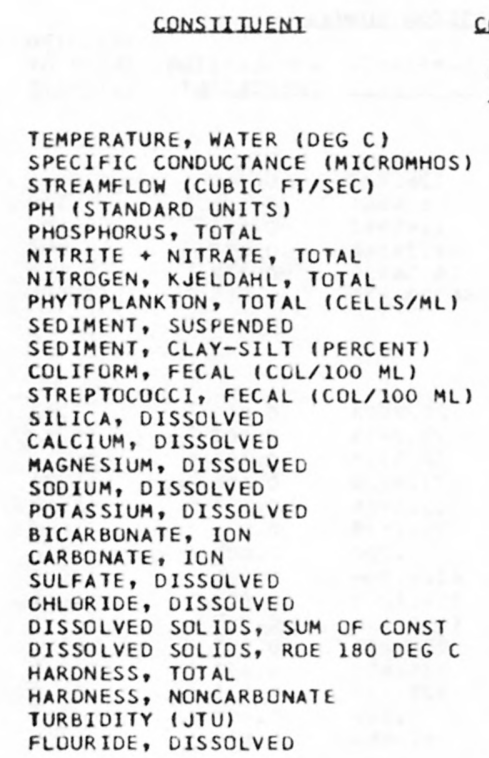

CONSIUUENC IMGCL OR UNIT SHOWNL

STIANDARD
SIZE MEAN DEYIALUON BANGE

$\begin{array}{rrr}15 & 20.25 & 6.14 \\ 14 & 553.9 & 34.7 \\ 15 & 24.7 & 5.8 \\ 14 & 7.97 & 0.18 \\ 9 & 0.500 & 0.176 \\ 9 & 1.230 & 0.367 \\ 9 & 1.258 & 0.808 \\ 10 & 2913.0 & 2146.6 \\ 9 & 35.9 & 26.6 \\ 9 & 44.2 & 17.6 \\ 10 & 22.6 & 28.3 \\ 10 & 150.6 & 204.9 \\ 9 & 24.44 & 1.01 \\ 13 & 49.46 & 2.30 \\ 13 & 9.85 & 1.27 \\ 13 & 55.23 & 4.68 \\ 13 & 8.08 & 1.94 \\ 13 & 216.2 & 7.7 \\ 11 & 0.0 & 0.0 \\ 13 & 55.92 & 2.18 \\ 13 & 35.92 & 2.36 \\ 9 & 347.0 & 10.7 \\ 13 & 351.5 & 15.6 \\ 13 & 163.4 & 6.4 \\ 13 & 0.1 & 0.3 \\ 13 & 3.5 & 2.5 \\ 13 & 0.57 & 0.11\end{array}$

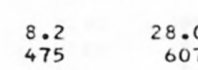

$475 \quad 607$

$\begin{array}{rrrr}15 & 34 & 14 & -0.010 \\ 7.7 & 8.2 & 14 & 0.0013\end{array}$

$\begin{array}{rr}7.7 & 8.2 \\ 0.33 & 0.85\end{array}$

$\begin{array}{ll}0.33 & 0.85 \\ 0.77 & 1.70\end{array}$

$\begin{array}{ll}0.77 & 1.70 \\ 0.28 & 3.20\end{array}$

0.28

630

3.20
6100

6100
92
79

14

0.0013

0.00619

$-0.00876$

-0.00544
-44.821

25
0
18

$\begin{array}{rr}18 & 700\end{array}$

$\begin{array}{ll}23.0 & 26.0 \\ 46.0 & 54.0\end{array}$

6.3

50.0
5.9

5.9
201

53.0

32.0

332

150
0

0
1
0.4

54.0
63.0
12.0

9
13
13
13
13
13
11
13
13
9
13
13
13
13
13

$$
\begin{array}{r}
0.0343 \\
-0.0123 \\
0.0003 \\
0.0700 \\
0.0334 \\
0.061 \\
0.000 \\
0.0014 \\
0.0276 \\
0.395 \\
0.072 \\
-0.076 \\
-0.000 \\
-0.015 \\
0.0009
\end{array}
$$

*Not significant at the 95 percent confidence 1 evel.

\begin{tabular}{|c|c|c|c|c|c|}
\hline & & & & & STANDARD \\
\hline & HARMONIC & AMPLITUDE & PHASE & VARIATION & ERROR OF \\
\hline SAMPLE & MEAN - $M$ & $-A$ & ANGLE - C & EXPLAINED & ESTIMATE \\
\hline SIZE & (DEG C) & (DEG $C)$ & (RADIANS) & $-(2)$ & (DEG C $)$ \\
\hline
\end{tabular}

$$
\text { DURAIION IABLE OE DAILY SPECIEIC CONDUCIANCE }
$$

DAILY SPECIFIC CONDUCTANCE IN

MICROMHOS AT 25 DEG C, THAT WAS

EQUALLED OR EXCEEDED FOR THE

$\begin{array}{llllll}17 & 5 z & 10 \% & 20 z & 30 z & 50 \% \\ 616 & 605 & 600 & 589 & 585 & 574\end{array}$
-. B COEEICIENI

$\begin{array}{rr}31.017 & -0.064 * \\ 7.2670 & 0.243 * \\ -3.02915 & 0.672 \\ 6.22110 & -0.456 * \\ 4.36130 & -0.129 * \\ 28416.242 & -0.382 *\end{array}$

\begin{tabular}{|c|c|c|c|c|c|c|}
\hline \multirow{2}{*}{ CONSTITUENT } & \multicolumn{3}{|c|}{ TOTAL } & \multicolumn{3}{|c|}{ DISSCLVED } \\
\hline & $\begin{array}{l}\text { NO. } \\
\text { SAMPLES }\end{array}$ & $\begin{array}{l}\text { MIN IMUM } \\
\text { CONC. }\end{array}$ & $\begin{array}{l}\text { MAXIMUM } \\
\text { CONC. }\end{array}$ & $\begin{array}{l}\text { NO. } \\
\text { SAMPLES }\end{array}$ & $\begin{array}{l}\text { MINIMUM } \\
\text { CONC. }\end{array}$ & $\begin{array}{l}\text { MAXIMUM } \\
\text { CONC. }\end{array}$ \\
\hline \multicolumn{7}{|l|}{ MINOR ELEMENTS: } \\
\hline ARSENIC (AS), UG/L & 3 & 4 & 5 & 4 & 0 & 7 \\
\hline CADMIUM $(C D), U G / L$ & 3 & $<10$ & 10 & 4 & 0 & 1 \\
\hline CHROMIUM (CR), UG/L & 3 & 0 & 20 & 3 & 0 & 20 \\
\hline COBALT $(C O), U G / L$ & 3 & $<50$ & $<50$ & 3 & 0 & 1 \\
\hline COPPER $(C U), U G / L$ & 3 & $<10$ & 4500 & 4 & 0 & 3 \\
\hline IRON (FE), UG/L & 3 & 260 & 710 & 4 & 30 & 190 \\
\hline LEAD $(P B), U G / L$ & 3 & $<100$ & 100 & 4 & 0 & 5 \\
\hline MANGANESE (MN), UG/L & 3 & 40 & 110 & 3 & 4 & 70 \\
\hline MERCURY $(H G), U G / L$ & 3 & 0.0 & 0.1 & 3 & 0.0 & 0.0 \\
\hline SELENIUM (SE), UG/L & 3 & 0 & 0 & 3 & 0 & 0 \\
\hline$Z I N C(Z N), U G / L$ & 3 & 10 & 110 & 4 & 0 & 30 \\
\hline \multicolumn{7}{|l|}{ PERIPHYTON: } \\
\hline BIOMASS, DRY WT., G/SQ M & 2 & 2.89 & 4.89 & & & \\
\hline BIOMASS, ASH WT., G/SQ M & 2 & 1.09 & 3.69 & & & \\
\hline CHLOROPHYLL A, MG/SO M & 2 & .2 & 7.7 & & & \\
\hline CHLOROPHYLL $B$, MG/SO M & 2 & .1 & 1.5 & & & \\
\hline ORGANIC CARBON, MG/L & 2 & 3.5 & 4.2 & & & \\
\hline
\end{tabular}

SUMMARY OF HARMONIC ANALYSIS OF STREAM TEMPERATURE
84
17.75
4.97
2.77
61
1.73

SUMMARY OF MAXIMUM AND MINIMUM CONCENTRATIONS OF CONSTITUENTS SAMPLED AT A FREQUENCY OF QUARTERLY (1975 WY)

10261500 -- MOJAVE R AT LOWER NARROWS NR VICTORVILLE CALIF 
Table 14.--Summary of measurement at each station--Continued

LAT $37003 M 15 S$ LONG $118013 M 33 S$

DRAINAGE AREA: 1964 SQ MI 1

PERIOD OF RECORD: $10 / 01 / 74-09 / 30 / 75$

STATISTICAL SUMMARY OF SELECTED OISSOLVED CHEMICAL CONSTITUENTS AND

REGRESSION RELATIONSHIPS OF CONSTITUENT CONCENTRATIONS TO SPECIFIC CONDUCTANCE

CONSIUIUENI

CONSILIUENT IMG/L OR UNLI SHOWN

\begin{tabular}{r} 
SAMP \\
S12 \\
\hline 199 \\
198 \\
199 \\
12 \\
12 \\
12 \\
12 \\
12 \\
12 \\
9 \\
12 \\
12 \\
12 \\
12 \\
12 \\
12 \\
12 \\
12 \\
11 \\
12 \\
12 \\
12 \\
12 \\
12 \\
12 \\
12 \\
12
\end{tabular}

STANDARD

DEVIAILON

12.53

276.7

513.

8.38

0.101

0.06

12608.

58.3

77.1

9.7

22.8

26.08

23.17

3.8

28.25

3.67
119.7

0.1

22.67

11.39

178.8

179.3

73.8

0.0
16.9

0.5

\subsection{1}

23.7

188.2
0.39

0.39
0.041

0.057

0.248

10474.7

72.6

$24 \cdot 7$

14.8

24.4

2.87
3.21

3.21
0.69

2.45

0.94

10.6

5.84

1.20

16.8

14.9

9.6

0.0

17.4
0.07

\begin{tabular}{rrr} 
& & \\
BANGE & & SAMPLE \\
0.0 & & SIZE \\
\cline { 3 - 3 } 220 & 24.0 & \\
5 & 323 & \\
7.7 & 775 & 198 \\
0.04 & 8.8 & 12 \\
0.01 & 0.16 & 12 \\
0.14 & 0.18 & 12 \\
1800 & 0.95 & 12 \\
6 & 39000 & 12 \\
30 & 260 & \\
0 & 95 & \\
1 & 54 & \\
21.0 & 31.0 & 12 \\
16.0 & 28.0 & 12 \\
3.0 & 5.2 & 12 \\
25.0 & 33.0 & 12 \\
1.8 & 5.9 & 12 \\
102 & 139 & 12 \\
0 & 1 & 11 \\
14.0 & 32.0 & 12 \\
9.7 & 14.0 & 12 \\
151 & 201 & 12 \\
157 & 200 & 12 \\
52 & 87 & 12 \\
0 & 0 & 12 \\
2 & 64 & 12 \\
0.4 & 0.6 & 12
\end{tabular}

*Not significant at the 95 percent confidence level.
BEGRESSION SUMMARY COEFICIENT

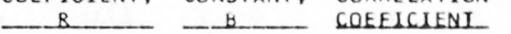

STANDARD

ERROR OF

ESIIMAIE

$\begin{array}{rrrr}-3.581 & 1505.371 & -0.451 & 168.3 \\ -0.0025 & 9.0482 & -0.139 * & 0.41 \\ -0.00001 & 0.10431 & -0.007 * & 0.043 \\ -0.00074 & 0.26405 & -0.288^{*} & 0.057 \\ -0.00194 & 1.02217 & -0.172 * & 0.257 \\ 138.587 & -24600.012 & 0.292^{\star} & 10507.9\end{array}$

DURAIION IABLE OF DALY SPECIEIS CONDUCIANCE

DAILY SPECIFIC CONDUCTANCE IN

MICROMHOS AT 25 DEG C, THAT WAS

EGUALLED OR EXCEEDED FOR THE

$\begin{array}{llllll}28 & -52 & 10 \% & 208 & 308 & 50 \\ 322 & 315 & 308 & 295 & 288 & 26\end{array}$

$50 z$

702

257

0.0613
0.1077
0.0221
0.0941
0.0283
0.388
-0.004
0.1575
0.0436
0.700
0.587
0.358
0.000
0.354
0.0011

$$
\begin{array}{r}
9.5890 \\
-5.8001 \\
-2.0808 \\
2.9491 \\
-3.9379 \\
15.262 \\
1.165 \\
-19.6983 \\
-0.3268 \\
-9.618 \\
21.554 \\
-22.385 \\
0.000 \\
-78.300 \\
0.2013
\end{array}
$$

0.470

0.739

0.707

0.845

0.665

\begin{tabular}{|c|c|c|c|c|c|}
\hline & & & & & STANDARD \\
\hline & HARMONIC & AMPLITUDE & PHASE & VAR IATIICN & ERRCR OF \\
\hline SAMPLE & MEAN - M & $-A$ & ANGLE - C & EXPLAINED & ESTIMATE \\
\hline SUZE & $10 E G \quad C 1$ & DEE $(1)$ & (RADIANSI & $-1 q 1$ & $10 E G(1)$ \\
\hline 267 & 12.61 & 9.04 & 2.74 & 93 & 1.78 \\
\hline
\end{tabular}

0.810
-0.276

$-0.276$

0.595

0.801

\begin{tabular}{|c|c|c|c|c|c|c|}
\hline \multirow{2}{*}{ CONSTITUENT } & \multicolumn{3}{|c|}{ TOTAL } & \multicolumn{3}{|c|}{ DISSOLVED } \\
\hline & $\begin{array}{l}\text { NO. } \\
\text { SAMPLES }\end{array}$ & $\begin{array}{l}\text { MIN IMUM } \\
\text { CONC. }\end{array}$ & $\begin{array}{l}\text { MAXIMUM } \\
\text { CONC. }\end{array}$ & $\begin{array}{l}\text { NO. } \\
\text { SAMPLES }\end{array}$ & $\begin{array}{l}\text { MINIMUM } \\
\text { CONC. }\end{array}$ & $\begin{array}{l}\text { MAXIMUM } \\
\text { CONC. }\end{array}$ \\
\hline \multicolumn{7}{|l|}{ MINOR ELEMENTS: } \\
\hline ARSENIC (AS), UG/L & 4 & 16 & 46 & 4 & 18 & 29 \\
\hline CADMIUM $(C D), U G / L$ & 4 & $<10$ & 10 & 4 & 0 & 3 \\
\hline CHROMIUM (CR), UG/L & 4 & 0 & 10 & 4 & 0 & 0 \\
\hline COBALT $(C O), U G / L$ & 4 & 0 & 50 & 4 & 0 & 1 \\
\hline COPPER (CU), UG/L & 4 & $<10$ & 20 & 4 & 4 & 10 \\
\hline IRON (FE), UG/L & 4 & 290 & 1700 & 4 & 30 & 70 \\
\hline LEAD $(P B), U G / L$ & 4 & $<100$ & 100 & 4 & 2 & 11 \\
\hline MANG ANESE (MN), UG/L & 4 & 10 & 110 & 4 & 0 & 20 \\
\hline MERC URY (HG), UG/L & 3 & 0.0 & 0.0 & 4 & 0.0 & 1.6 \\
\hline SELENIUM (SE), UG/L & 4 & 0 & 0 & 4 & 0 & 0 \\
\hline ZINC $(Z N), U G / L$ & 4 & 40 & 830 & 4 & 10 & 30 \\
\hline \multicolumn{7}{|l|}{ PERIPHYTON: } \\
\hline BIOMASS, DRY WT., G/SQ M & 0 & & & & & \\
\hline BIOMASS, ASH WT., G/SO M & 0 & & & & & \\
\hline CHLOROPHYLL A, MG/SQ M & 0 & & & & & \\
\hline CHLOROPHYLL B, MG/SQ M & 0 & & & & & \\
\hline ORGANIC CARBON, MG/L & 4 & 4.2 & 6.2 & & & \\
\hline
\end{tabular}

0.868

0.822
$0.000^{*}$

$0.000^{*}$
0.448 .

0.377 .
SAMPLE SIZE $=239$

$903 \quad 25 \% 298$

$243 \quad 238$

SUMMARY OF HARMONIC ANALYSIS OF STREAM TEMPERATURE EORM OF EOU HARMONI

SUMMARY OF MAXIMUM AND MINIMUM CONCENTRATIONS OF CONSTITUENTS SAMPLED AT A FREQUENCY OF QUARTERLY (1975 WY)

10277400 -- OWENS R BL TINEMAHA RE NR BIG PINE CA. 
Table 14.--Sumnary of measurement at each station--Continued

STATION NUMBER: 10301500 NAME: WALKER R NR WABUSKA, NV

LAT 39009MIOS LONG 119005M50S

DRAINAGE AREA: 2600 SO MI $1 \quad 6734$ SO KMI

PERIOD OF RECORD: $10 / 01 / 74$ - 09/30/75

STATISIICAL SUMMARY OF SELECTED DISSOLVED CHEMICAL CONSTITUENTS AND

REGRESSION RELATIONSHIPS OF CONSTITUENT CONCENTRATIONS TO SPECIFIC CONDUCTANCE

CONSIIIUENI

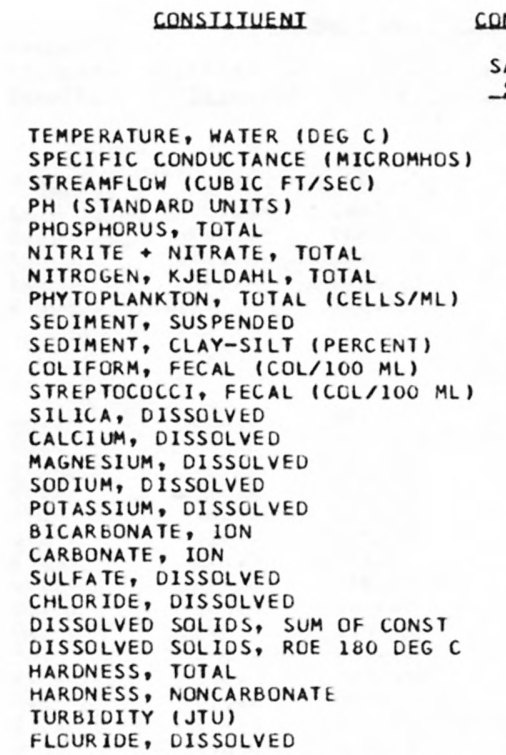

CONSIUIUENI IMG/L OR UNII SHOWN

\begin{tabular}{rrr}
$\begin{array}{rrr}\text { SAMPLE } \\
\text { SIZE }\end{array}$ & MEAN & \multicolumn{1}{r}{ SIANDARD } \\
\cline { 2 - 3 } & REYIAIION \\
22 & 11.30 & 7.72 \\
9 & 467.2 & 158.0 \\
22 & 272.6 & 302.1 \\
7 & 8.11 & 0.17 \\
10 & 0.344 & 0.448 \\
8 & 0.329 & 0.282 \\
10 & 0.881 & 1.117 \\
10 & 15910.0 & 36645.1 \\
11 & 331.8 & 519.6 \\
0 & & \\
11 & 117.7 & 145.2 \\
11 & 225.9 & 179.4 \\
6 & 21.83 & 3.82 \\
6 & 37.83 & 9.81 \\
7 & 8.04 & 2.12 \\
6 & 52.50 & 20.56 \\
6 & 4.87 & 1.09 \\
6 & 200.0 & 56.0 \\
6 & 1.2 & 2.9 \\
6 & 56.00 & 22.57 \\
6 & 15.88 & 6.67 \\
6 & 297.8 & 92.6 \\
6 & 306.8 & 94.4 \\
6 & 128.7 & 33.0 \\
6 & 0.0 & 0.0 \\
8 & 56.0 & 91.7 \\
6 & 0.73 & 0.22
\end{tabular}

BEGRESSION SUMMARY

$\begin{array}{lll} & \text { REGRESSION } & \text { STANDARO } \\ \text { SAMPLE COEFICIENT, CONSTANT, CORRELATION ERROR OF }\end{array}$ SIZE - B - B COEEICIENI ESIUMAI

*Not significant at the 95 percent confidence level.

\section{BANGE}

$0.0 \quad 25.5$

$\begin{array}{rr}0.0 & 25.5 \\ 236 & 644\end{array}$

$\begin{array}{llll}63 & 950 & 9 & -1.827\end{array}$

7.9

0.13

$0.37 \quad 4.00$

1000

25

4.000
120000

$\begin{array}{rr}0 & 470 \\ 20 & 540\end{array}$

17.0

17.0

21.0

4.7
21.0

21.0
3.0

109

18.0
5.3

5.3
144

144
151

151
72
0

0
5
0.4
20000
1720

9
5
9
7
9

$-0.000$

$-0.00094$

0.00156

$-0.00245$

25.0

25.0

11.0
73.0

6.4
251

251
7
79.0

79.0
23.0

379

401

160
0

280
1.0

6
6
6
6
6
6
6
6
6
6
6
6
6
8
6

$$
\begin{array}{r}
0.0079 \\
0.0622 \\
0.0142 \\
0.1322 \\
0.0054 \\
0.359 \\
0.006 \\
0.1446 \\
0.0426 \\
0.596 \\
0.608 \\
0.211 \\
0.000 \\
-0.164 \\
0.0013
\end{array}
$$

DURAILN IABLE OE DALY SPECIEIC CONDUCIANCE

DAILY SPECIFIC CONDUCTANCE IN

MICROMHOS AT 25 DEG C, THAT WAS

EQUALLED OR EXCEEDED FOR THE

$12 \quad-58 \quad 108$

202

302

502

675

628

607

593

$586 \quad 490$

1159.164 8.2026 0.80200 $-0.34965$

\begin{tabular}{|c|c|c|c|c|c|}
\hline & & & & & STANDARD \\
\hline $\begin{array}{l}\text { SAMPLE } \\
\text { SIZE }\end{array}$ & $\begin{array}{l}\text { HARMONIC } \\
\text { MEAN - M } \\
\text { IDEG CI }\end{array}$ & $\begin{array}{c}\text { AMPLITUDE } \\
-A \\
\text { WEEG }\end{array}$ & $\begin{array}{l}\text { PHASE } \\
\text { ANGLE - C } \\
\text { (BADLANS) }\end{array}$ & $\begin{array}{l}\text { VAR IATION } \\
\text { EXPLAINED } \\
\end{array}$ & $\begin{array}{l}\text { ERROR OF } \\
\text { ESTIMATE } \\
\text { IDEG_LI }\end{array}$ \\
\hline 365 & 15.63 & 8.44 & 2.48 & 74 & 3.44 \\
\hline
\end{tabular}
2.07980

$-0.860$ -0.088 * $-0.316$

\begin{tabular}{|c|c|c|c|c|c|c|}
\hline \multirow{2}{*}{ CONSTITUENT } & \multicolumn{3}{|c|}{ TOTAL } & \multicolumn{3}{|c|}{ DISSOLVED } \\
\hline & $\begin{array}{l}\text { NOP } \\
\text { SAMPLES }\end{array}$ & $\begin{array}{l}\text { MIN IMUM } \\
\text { CONC. }\end{array}$ & $\begin{array}{l}\text { MAXIMUM } \\
\text { CONC. }\end{array}$ & $\begin{array}{l}\text { NO. } \\
\text { SAMPLES }\end{array}$ & $\begin{array}{l}\text { MINIMUM } \\
\text { CONC. }\end{array}$ & $\begin{array}{l}\text { MAXIMUM } \\
\text { CONC. }\end{array}$ \\
\hline \multicolumn{7}{|l|}{ MINOR ELEMENTS: } \\
\hline ARSENIC (AS), UG/L & 4 & 11 & 50 & 4 & 4 & 24 \\
\hline CADMIUM $(C D), U G / L$ & 4 & $<10$ & 10 & 4 & 0 & 1 \\
\hline CHROMIUM (CR), UG $/ L$ & 4 & 0 & 20 & 4 & 0 & 20 \\
\hline COBALT $(C O), U G / L$ & 4 & $<50$ & $<50$ & 4 & 0 & 1 \\
\hline COPPER (CU), UG/L & 4 & 10 & 90 & 4 & 2 & 10 \\
\hline IRON $(F E), U G / L$ & 4 & 1600 & 44000 & 4 & 40 & 70 \\
\hline$L E A D(P B), U G / L$ & 4 & $<100$ & $<100$ & 4 & 1 & 4 \\
\hline MANG ANESE (MN), UG/L & 4 & 70 & 2000 & 4 & 10 & 60 \\
\hline MERCURY (HG), UG/L & 4 & 0.0 & 1.6 & 4 & 0.0 & 0.3 \\
\hline SELENIUM (SE), UG/L & 4 & 0 & 1 & 4 & 0 & 1 \\
\hline$Z I N C(Z N), U G / L$ & 4 & 0 & 120 & 4 & 0 & 40 \\
\hline \multicolumn{7}{|l|}{ PERIPHYTON: } \\
\hline BIOMASS, DRY WT., G/SO M & 0 & & & & & \\
\hline BIOMASS, ASH WT., G/SO M & 0 & & & & & \\
\hline CHLOROPHYLL A, MG/SO M & 0 & & & & & \\
\hline CHLOROPHYLL B, MG/SQ M & 0 & & & & & \\
\hline ORGANIC CARBON, MG/L & 4 & 2.5 & 27.0 & & & \\
\hline
\end{tabular}
0.834
-0.330

183.4

0.1 0.47 0.184
1.181

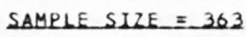

$90 \% 95 \% 99$

$284 \quad 240 \quad 202$

SUMMARY OF HARMONIC ANALYSIS OF STREAM TEMPERATURE

SUMMARY OF MAXIMUM AND MINIMUM CONCENTRATIONS OF CONSTITUENTS SAMPLED AT A FREQUENCY OF QUARTERLY (1975 WY)

10301500 -- WALKER R NR HABUSKA, NV 
LAT 39017M30S LONG 119D18M40S DRAINAGE AREA: 1450 SQ MI 13756 SQ KMI

PERIOD DF RECORD: $10 / 01 / 74-09 / 30 / 75$

STATISTICAL SUMMARY OF SELECTED DISSOLVED CHEMICAL CONSTITUENTS AND REGRESSION RELATIONSHIPS OF CONSTITUENT CONCENTRATIONS TO SPECIFIC CONDUCTANCE

CONSIIIUENI

CONSIUUENI IMG $\angle L$ OR UNII SHOWNI

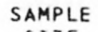

SAMPLE

TEMPERATURE, WATER (DEG C)

STREAMFLOW (CUBIC FT/SEC

PH ISTANDARD UNITS

PHOSPHORUS, TOTAL

NITROGEN, KJELDAHL, TOTAL

PHYTOPLANKTON, TOTAL (CELLS/ML)

SEDIMENT, SUSPENDED

SEDIMENT, CLAY-SILT (PERCENT)

COLIFORM, FECAL (COL/100 ML)

STREPTOCOCCI, FECAL (COL/100 ML)

SILICA, DISSOLVED

CALCIUM, DISSOLVED

MAGNE SIUM, DISSOL VED

SODIUM, DISSOLVED

POTASSIUM, DISSOL VED

BICARBONATE, ION

CARBONATE, ION

SULFATE, DISSOLVED

CHLORIDE, DISSOLVED

DISSOLVED SOLIDS, SUM OF CONST

DISSOLVED SOLIDS, ROE 180 DEG

HARDNESS, TOTAL

HARONESS, NONCARBONATE

TURBIDITY (JTU)

FLOURIDE, DISSOLVED
MEAN DEYIAILON

列

$370.9 \quad 6.94$

376.9

7.97
0.293

0.283

0.533

3048.9

122.1

81.8
104.8
25.80

25.80
42.40

42.40
9.76

39.40

4.42

152.2

0.0

88.20

11.40

297.4

314.5
148.0

148.0
21.2

21.2
20.8
0.45

139.8

717.3
0.29

0.29
0.081

0.081
0.241

0.130

2621.8

212.2

189.5

170.4

4.92
10.60

10.60

9.91

0.97

25.3

0.0
34.55

34.55
1.52

1.52
75.9

75.9
54.4

39.6

18.7
21.2

0.07
SPECIFIC CONDUCTANCE (MICROMHOS)

NITRITE + NITRATE, TOTAL

*Not significant at the 95 perc
BANGE

$0.0 \quad 22.5$

$\begin{array}{rr}166 & 616 \\ 7 & 3160\end{array}$

$\begin{array}{rr}7.6 & 8.4 \\ 0.18 & 0.40\end{array}$

$0.05 \quad 0.66$

$0.30 \quad 0.71$

$810 \quad 7900$

$\begin{array}{ll}1 & 550 \\ 4 & 520\end{array}$

$\begin{array}{rr}4 & 520 \\ 20.0 & 30.0 \\ 32.0 & 56.0\end{array}$

32.0

7.2
31.0

2.9

$55.0 \quad 130.0$

55.0

10.0

225
276

276
110

110
4
3

0.4

14.0
398

353
200

42
60
0.5
$129 \quad 5.4$

BEGRESSION SUMMARY REGRESSION

SAMPLE COEFICIENT, CONSTANT, CORRELATION ERROR OF SIZE - B - B COEEICIENI ESIUMAIE
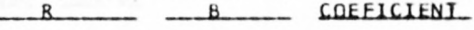

$\begin{array}{rrrrr}9 & -1.378 & 750.039 & -0.915 & 90.7 \\ 4 & 0.0025 & 7.0275 & 0.949 * & 0.11 \\ 6 & -0.00008 & 0.32594 & -0.149 * & 0.081 \\ 6 & 0.00026 & 0.22420 & 0.151 * & 0.250 \\ 6 & -0.00025 & 0.62975 & -0.215 * & 0.167 \\ 3 & -5.637 & 4496.316 & -0.377 * & 3701.8\end{array}$

DAILY SPECIFIC CONDUCTANCE IN

DAILY SPECIFIC CONDUCTANCE IN

作

EQUALLED OR EXCEEDED FOR THE

$18 \quad 52 \quad 108$

202

$30 \%$

$50 \pi$

619

$600 \quad 558$

491

399

5
5
5
5
5
5
5
5
5
5
5
5
4

0.0406
0.0982
0.0283
0.0918
0.0072
0.237
0.000
0.3161
0.0119
0.707
0.366
0.164
-0.067

6.9880

$-3.1430$

$-3.3474$

$-3.1427$

1.0674

42.513

$-58.3356$

5.8996

5.8996

$-21.507$

$-54.994$

36.044

0.881

0.990 *

0.985 *
0.988 *

0.798

0.997 .

0.997
0.000

$0.977^{*}$

0.835 *

$0.994^{*}$

0.985 *

0.940 *

-0.970 *

2.69

1.76

0.61

1.77

2.67

0.0

0.0
8.58

0.96

7.9
7.4
3.4

SAMPLE SIZE $=361$

208252929

SUMMARY OF HARMONIC ANALYSIS OF STREAM TEMPERATURE

\begin{tabular}{|c|c|c|c|c|c|}
\hline & & & & & STANDARD \\
\hline & HARMONIC & AMPLITUDE & PHASE & VARIATION & ERROR OF \\
\hline $\begin{array}{l}\text { SAMPLE } \\
\text { SIZE. }\end{array}$ & MEAN - M & ${ }_{(D E G}{ }^{A}()$ & $\begin{array}{l}\text { ANGLE }-C \\
\text { (RADIANS) }\end{array}$ & $\begin{array}{c}\text { EXPLAINED } \\
(\Omega)\end{array}$ & $\begin{array}{l}\text { ESTIMATE } \\
10 E G \mathrm{Cl}\end{array}$ \\
\hline 362 & 10.15 & 8.93 & 2.73 & 90 & 2.10 \\
\hline
\end{tabular}

SUMMARY OF MAXIMUM AND MINIMUM CONCENTRATIONS OF CONSTITUENTS

SAMPLED AT A FREQUENCY OF QUARTERLY (1975 WY)

10312000 -- CARSON R NR FORT CHURCHILL, NV

\begin{tabular}{|c|c|c|c|c|c|c|}
\hline \multirow{2}{*}{ CONSTITUENT } & \multicolumn{3}{|c|}{ TOTAL } & \multicolumn{3}{|c|}{ DISSOLVED } \\
\hline & $\begin{array}{l}\text { NO. } \\
\text { SAMPLES }\end{array}$ & $\begin{array}{l}\text { MIN IMUM } \\
\text { CONC. }\end{array}$ & $\begin{array}{l}\text { MAXIMUM } \\
\text { CONC. }\end{array}$ & $\begin{array}{l}\text { NOP } \\
\text { SAMPLES }\end{array}$ & $\begin{array}{l}\text { MINIMUM } \\
\text { CONC. }\end{array}$ & $\begin{array}{l}\text { MAXIMUM } \\
\text { CONC. }\end{array}$ \\
\hline \multicolumn{7}{|l|}{ MINOR ELEMENTS: } \\
\hline ARSENIC (AS), UG/L & 2 & 6 & 8 & 2 & 4 & 8 \\
\hline CADMIUM $(C D), U G / L$ & 2 & $<10$ & $<10$ & 2 & 0 & 0 \\
\hline CHROMIUM (CR), UG/L & 2 & 0 & 10 & 2 & 0 & 0 \\
\hline COBALT $(C D), U G / L$ & 2 & 0 & 0 & 2 & 0 & 0 \\
\hline COPPER (CUI, UGIL & 2 & $<10$ & $<10$ & 2 & 1 & 2 \\
\hline IRON (FE), UG/L & 2 & 350 & 360 & 2 & 10 & 40 \\
\hline LEAD $(P B), U G / L$ & 2 & $<100$ & $<100$ & 2 & 2 & 3 \\
\hline MANG ANESE (MN), UG/L & 2 & 30 & 40 & 2 & 30 & 50 \\
\hline MERCURY (HG), UG/L & 2 & 0.3 & 2.6 & 2 & 0.0 & 1.3 \\
\hline SELENIUM (SE), UG/L & 2 & 0 & 0 & 2 & 0 & 0 \\
\hline ZINC $(Z N), U G / L$ & 2 & 10 & 10 & 2 & 0 & 0 \\
\hline \multicolumn{7}{|l|}{ PERIPHYTON: } \\
\hline BIOMASS, ORY WT., G/SO M & 1 & 10.00 & & & & \\
\hline BIOMASS, ASH WT., G/SQ M & 1 & 7.09 & & & & \\
\hline CHLOROPHYLL A, MG/SO M & $i$ & 7.5 & & & & \\
\hline CHLOROPHYLL $B, M G / S O M$ & 1 & 1.3 & & & & \\
\hline ORGANIC CARBON, MG/L & 3 & 3.7 & 6.0 & & & \\
\hline
\end{tabular}


LAT 4OD28MOOS LONG $118018 M 20 S$

DRAINAGE AREA: 16100 SQ MI

STATISTICAL SUMMARY OF SELECTED DISSOLVED CHEMICAL CONSTITUENTS AND

REGRESSION RELATIONSHIPS OF CONSTITUENT CONCENTRATIONS TO SPECIFIC CONDUCTANCE

CONSIITUENI

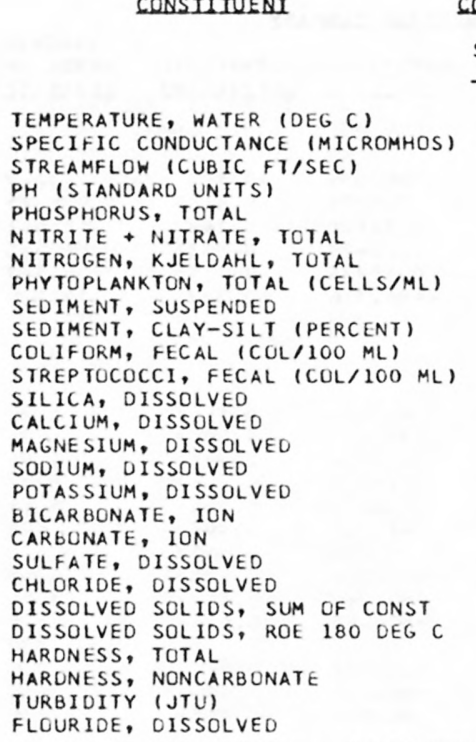

CONSIUTUENI IMG/L OR UNII SHOWNI

$$
\begin{aligned}
& \text { SAMPLE } \\
& \text { SIZE } \\
& \hline
\end{aligned}
$$

MEAN

STANDARD

DEYIAIION

$\begin{array}{rr}24 & 12.04 \\ 11 & 1007.9 \\ 27 & 476.1 \\ 8 & 8.45 \\ 12 & 0.104 \\ 10 & 0.051 \\ 12 & 0.584 \\ 12 & 1460.0 \\ 13 & 26.5 \\ 0 & \\ 11 & 1.4 \\ 12 & 29.0 \\ 6 & 32.00 \\ 6 & 37.33 \\ 6 & 16.00 \\ 6 & 165.00 \\ 6 & 17.50 \\ 6 & 281.8 \\ 6 & 7.2 \\ 6 & 78.17 \\ 6 & 152.17 \\ 6 & 645.2 \\ 6 & 649.8 \\ 6 & 156.7 \\ 6 & 0.0 \\ 10 & 15.7 \\ 6 & 0.82\end{array}$

15.7

6.83
167.7
521.3
0.59
0.028
0.032
0.196
1000.4
10.4
1.3
29.0
3.79
3.98
0.89
27.39
1.76
14.5
6.5
5.74
44.14
65.5
63.4
8.2
0.0
4.1
0.04

0.04
BANGE

$\begin{array}{rr}4.0 & 25 . \\ 783 & 118 \\ 15 & 146 \\ 7.7 & 9.6 \\ 0.06 & 0.15 \\ 0.00 & 0.10 \\ 0.33 & 0.9 \\ 360 & 29 \\ 9 & \end{array}$

SAMPLE SIZE REGRESSION

REGRESSION_SUMMABY

\begin{tabular}{lll} 
COEFICIENT, CONSTANT, CORRELATION \\
\hline \\
\hline
\end{tabular}
STANDARD
ERROR OF ESIIMAIE 5.0 $\begin{array}{llll}460 & 11 & -1.625 & 2093.642\end{array}$ 9.67 0.15 0.10 0.92 900

$-0.00051$

$-29.224$

10.0368

0.18894

$-0.09492$

25281.398

-0.557 *

-0.477 *

-0.517 .

0.808

-0.421 .

-0.550 *

0
27.0
34.0

4
82
37.0

$34.0 \quad 45.0$

$110.0 \quad 180.0$

$\begin{array}{rr}15.0 & 180.0 \\ 15.0 & 20.0\end{array}$

15.0
259

259

68.0
63.0

63.0
514

514
521

150

297
14

14
84.0

180.0

693

684

170
0

9
0
0.8

20
0.9

6
6
6
6
6
6
6
6
6
6
6
6
6
10
6

$-0.0167$

$-0.0272$

0.0037

0.1956

0.0054

$-0.037$

$-0.025$

0.0370

0.3186

0.472

0.459

$-0.046$

$-0.006$

-0.006
0.0001
50.2219

66.9981

12.0107

$-48.6622$

11.6310

322.552

35.002

37.7239

$-195.841$

129.725

148.648

1480.408
0.000

21.981

21.981
0.7502
-0.606 *

$-0.940$

0.563 .

0.985

0.421 .

$-0.354^{*}$

0.889

0.995

0.993

0.997

$-0.769$

0.000 *

-0.259 *

428.6
0.62
0.023
0.020
0.194
1347.7

3.37

. .52
0.83

0.83

1.79

15.2

6.1

2.94
4.88

8.6

5.6

5.8

5.0
4.2

4.2
0.04

DAILY SPECIFIC CONDUCTANCE IN

MICROMHOS AT 25 DEG C, THAT WAS

EQUALLED OR EXCEEDED FOR THE

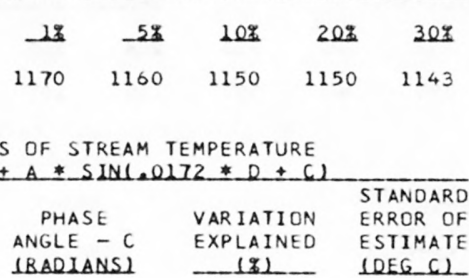

SUMMARY OF HARMONIC ANALYSIS OF STREAM TEMPERATURE

\begin{tabular}{|c|c|c|c|c|c|}
\hline & & & & & STANDARD \\
\hline & HARMONIC & AMPLITUDE & PHASE & VAR IATION & ERROR OF \\
\hline SAMPLE & MEAN - M & $-A$ & ANGLE $-C$ & EXPLAINED & ESTIMATE \\
\hline SIZE & 10EG C1_ & $1 D E E_{2}(1)$ & (BADIANS) & (8) & $10 E E_{2}(1)$ \\
\hline 365 & 11.38 & 9.01 & 2.50 & 95 & 1.42 \\
\hline
\end{tabular}

EORM OE EQUAUION: I'ID) $=M+A *$ SINL.0172*D+CI

SUMMARY OF MAXIMUM AND MINIMUM CONCENTRATIONS CF CONSTITUENTS SAMPLED AT A FREQUENCY OF QUARTERLY (1975 WY)

\begin{tabular}{|c|c|c|c|c|c|c|}
\hline \multirow{2}{*}{ CONSTITUENT } & \multicolumn{3}{|c|}{ TOTAL } & \multicolumn{3}{|c|}{ DISSOLVED } \\
\hline & $\begin{array}{l}\text { NO. } \\
\text { SAMPLES }\end{array}$ & $\begin{array}{l}\text { MINIMUM } \\
\text { CONC. }\end{array}$ & $\begin{array}{l}\text { MAXIMUM } \\
\text { CONC. }\end{array}$ & $\begin{array}{l}\text { NO. } \\
\text { SAMPLES }\end{array}$ & $\begin{array}{l}\text { MINIMUM } \\
\text { CONC. }\end{array}$ & $\begin{array}{l}\text { MAXIMUM } \\
\text { CONC. }\end{array}$ \\
\hline \multicolumn{7}{|l|}{ MINOR ELEMENTS: } \\
\hline ARSENIC (AS), UG/L & 3 & 26 & 44 & 3 & 26 & 48 \\
\hline CADMIUM $(C D), U G / L$ & 3 & $<10$ & 10 & 3 & 0 & 1 \\
\hline CHROMIUM (CR), UG/L & 3 & 0 & 10 & 3 & 0 & 0 \\
\hline COBALT $(C O), U G / L$ & 3 & $<50$ & 50 & 3 & 0 & 0 \\
\hline COPPER (CU), UG/L & 3 & $<10$ & 40 & 3 & 4 & 5 \\
\hline IRON $(F E), U G / L$ & 3 & 660 & 820 & 3 & 20 & 70 \\
\hline LEAD $(P B), U G / L$ & 3 & $<100$ & $<100$ & 3 & 0 & 3 \\
\hline MANG ANESE (MN), UG/L & 3 & 10 & 20 & 3 & 0 & 10 \\
\hline MERCURY (HG), UG/L & 3 & 0.0 & 2.6 & 3 & 0.0 & 1.8 \\
\hline SELENIUM (SE), UG/L & 3 & 1 & 1 & 3 & 0 & 1 \\
\hline$Z I N C(Z N), U G / L$ & 3 & 20 & 50 & 4 & 0 & 10 \\
\hline \multicolumn{7}{|l|}{ PERIPHYTON: } \\
\hline BIOMASS, DRY WT., GISQ M & 1 & 54.00 & & & & \\
\hline BIOMASS, ASH WT., G/SO M & $i$ & 47.00 & & & & \\
\hline CHLOROPHYLL A, MG/SQ M & 2 & 24.0 & 24.0 & & & \\
\hline CHLOROPHYLL B, MG/SO M & $i$ & 3.2 & & & & \\
\hline ORGANIC CARBON, MG/L & 3 & 5.3 & 18.0 & & & \\
\hline
\end{tabular}

10335000 -- HUMBOLOT R NR RYE PATCH, NV 
Table 14.--Summary of measurement at each station--Continued

LAT 39D25M41S LONG 120001M59S

DRAINAGE AREA: $\quad 932$ SQ MI 122414 SQ KM)

PERIOD OF RECORD: $10 / 01 / 74-09 / 30 / 75$

STATISTICAL SUMMARY OF SELECTED DISSOLYED CHEMICAL CONSTIIUENTS AND

REGRESSION RELATIONSHIPS OF CONSTITUENT CONCENTRATIONS TO SPECIFIC CONDUCTANCE

CONSIIIUENI

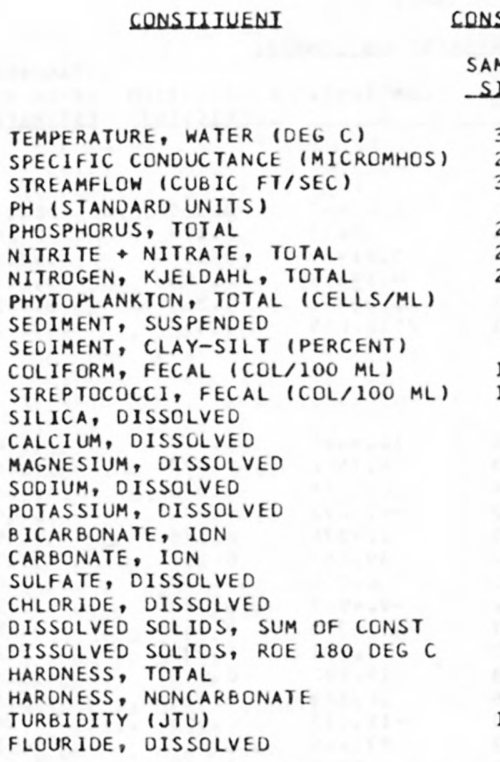

CONSIUTUENI LMG/L OR UNII SHOHNI
STANDARD

DEYIALION

8.05

90.7
927.2

927.2
7.89

0.013

0.056

0.200

871.1
14.9

4.61

13.3

670.1

0.36

0.012

0.031

0.083
370.1

12.9

$\begin{array}{rr}2.3 & 3.5 \\ 9.8 & 20.5\end{array}$

9.8

9.8
14.20

14.20
8.83

2.67

4.88
1.52

1.52
49.5

0.0
2.22

2.22

61.3

61.3
63.0

33.0

0.0

2.2
0.03
2.64

2.64
0.84

0.27

0.83

0.20
3.5

3.5
0.0

0.37

1.70

4.6

3.2

3.0

0.0

1.0
0.06

*Not significant at the 95 percent confidence level.

URAIION IABLE OF DALY SPECDEIC CONDUCIANCE

DAILY SPECIFIC CONDUCTANCE IN

MICROMHOS AT 25 DEG C, THAT WAS

EQUALLED OR EXCEEDED FOR THE

INDICATED PERCENTAGE OF TIME

$\begin{array}{rrrrrr}18 & 58 & 10 z & 208 & 308 & 508 \\ 114 & 110 & 108 & 100 & 96 & 92\end{array}$

BANGE

1.0
67
424
7.2
0.00

0.00

0.08

360
4

0

0
9.2
7.8

7.8
2.3

3.5
1.3

1.3
45

1.9

1.3

60

29
0

0.0
BEGRESSION SUMMARY

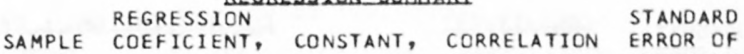

SIZE - B - - B COEEICIENI

ERROR OF

ESIIMAIE

16.0

$\begin{array}{llllll}111 & 23 & -26.151 & 3257.830 & -0.565 & 519.1\end{array}$

$\begin{array}{lll}3100 & 23 & -26.151\end{array}$

$\begin{array}{rrr}8.3 & 8 & -0.0015 \\ 0.03 & 22 & 0.00001\end{array}$

0.00001

0.00067
-0.00263

$-25.166$

8.0297
0.01268

0.01268
-0.00507

-0.00507
0.43884

2682.582

$-0.565$

$-0.063$

0.006 *

0.295

$-0.432$

-0.647 .

0.39
0.012

0.030

0.076

1500
42

10
65

$\begin{array}{rr}65 & \\ 17.0 & 6 \\ 9.9 & 6 \\ 3.0 & 6 \\ 5.5 & 6 \\ 1.9 & 6 \\ 54 & 6 \\ 0 & 6 \\ 2.9 & 6 \\ 5.7 & 6 \\ 68 & 6 \\ 67 & 4 \\ 36 & 6 \\ 0 & 6 \\ 4 & 15 \\ 0.1 & 3\end{array}$

$$
\begin{array}{r}
-0.1184 \\
0.0906 \\
0.0119 \\
0.0947 \\
0.0195 \\
0.352 \\
0.000 \\
0.0324 \\
0.1461 \\
0.432 \\
0.278 \\
0.275 \\
0.000 \\
-0.020 \\
0.0041
\end{array}
$$

-0.371 .

0.896

0.360 *

\begin{tabular}{|c|c|c|c|c|c|}
\hline & & & & & STANDARD \\
\hline & HARMONIC & AMPLITUDE & PHASE & VARIATION & ERROR OF \\
\hline $\begin{array}{l}\text { SAMPLE } \\
\text { SUZE }\end{array}$ & $\begin{array}{l}\text { MEAN }-M \\
(D E G(C)\end{array}$ & $-A^{A}$ & ANGLE - C & $\begin{array}{c}\text { EXPLAINED } \\
(\pi)\end{array}$ & $\begin{array}{l}\text { ESTIMATE } \\
\text { (DEG C) }\end{array}$ \\
\hline 337 & 7.74 & 5.98 & 2.26 & 88 & 1.57 \\
\hline
\end{tabular}

0.940

0.790 *

0.828

0.000 .

\begin{tabular}{|c|c|c|c|c|c|c|}
\hline \multirow{2}{*}{ CONSTITUENT } & \multicolumn{3}{|c|}{ TOTAL } & \multicolumn{3}{|c|}{ DISSOLVED } \\
\hline & $\begin{array}{l}\text { NO. } \\
\text { SAMPLES }\end{array}$ & $\begin{array}{l}\text { MINIMUM } \\
\text { CONC. }\end{array}$ & $\begin{array}{l}\text { MAXIMUM } \\
\text { CONC. }\end{array}$ & $\begin{array}{l}\text { NO: } \\
\text { SAMPLES }\end{array}$ & $\begin{array}{l}\text { MINIMUM } \\
\text { CONC. }\end{array}$ & $\begin{array}{l}\text { MAXIMUM } \\
\text { CONC. }\end{array}$ \\
\hline \multicolumn{7}{|l|}{ MINOR ELEMENTS: } \\
\hline ARSENIC (AS), UG/L & 4 & 1 & 3 & 2 & 0 & 3 \\
\hline CADMIUM (CD), UG/L & 4 & $<10$ & 10 & 2 & 0 & 0 \\
\hline CHROMIUM (CR), UG/L & 4 & 0 & 10 & 2 & 0 & 0 \\
\hline COBALT $(C O), U G / L$ & 2 & 50 & $<50$ & 2 & 0 & 4 \\
\hline COPPER $(C U), U G / L$ & 3 & 10 & 20 & 2 & 0 & 0 \\
\hline IRLN (FE), UG/L & 21 & 90 & 870 & 2 & 10 & 30 \\
\hline LEAD $(P B), U G / L$ & 4 & $<100$ & $<100$ & 2 & 0 & 0 \\
\hline MANGANESE $(M N), U G / L$ & 4 & 10 & 30 & 2 & 0 & 10 \\
\hline MERCURY $(H G), U G / L$ & 4 & 0.0 & 1.0 & 2 & 0.0 & 0.1 \\
\hline SELENIUM $(S E), U G / L$ & 4 & 0 & 0 & 2 & 0 & 0 \\
\hline ZINC $(2 N), U G / L$ & 4 & 0 & 40 & 2 & 0 & 20 \\
\hline \multicolumn{7}{|l|}{ PERIPHYTON: } \\
\hline BIOMASS, DRY WT., G/SQ M & 1 & 9.29 & & & & \\
\hline BIOMASS, ASH WT., G/SO M & 1 & 2.79 & & & & \\
\hline CHLOROPHYLL A, MG/SO M & 1 & 7.7 & & & & \\
\hline CHLOROPHYLL B, MG/SO M & 1 & .5 & & & & \\
\hline ORGANIC CARBON, MG/L & 23 & 1.0 & 5.5 & & & \\
\hline
\end{tabular}

0.733 .

0.709 *

0.777 *

0.680 *

0.750 .

0.750 *

$0.000 *$
$-0.243 *$

-0.243
0.672 .

SUMMARY OF HARMONIC ANALYSIS OF STREAM TEMPERATURE

SUMMARY OF MAXIMUM AND MINIMUM CONCENTRATIONS OF CONSTITUENTS SAMPLED AT A FREQUENCY OF QUARTERLY (1975 WY)

10346000 - TRUCKEE R AT FARAD, CA 
Table 14.--Summary of measurement at each station--Continued

LAT 39046M4OS LONG $119020 M 10 S$

1815 SQ MI (
PERINAGE AREA:
$10 / 01 / 74-09 / 30 / 75$ SQ KM)

STATISTICAL SUMMARY OF SELECTED DISSOLVED CHEMICAL CONSTITUENTS AND

REGRESSION RELATIONSHIPS OF CONSTITUENT CONCENTRATIONS TO SPECIFIC CONDUCTANCE

CONSIIIUENI

CONSIUIUENI IMG $\angle 1$ OB UNII_SHOWNI

\begin{tabular}{r} 
SAMP \\
S12 \\
\hline 25 \\
12 \\
25 \\
9 \\
12 \\
10 \\
12 \\
11 \\
14 \\
0 \\
12 \\
12 \\
12 \\
12 \\
12 \\
11 \\
12 \\
12 \\
12 \\
12 \\
12 \\
11 \\
12 \\
12 \\
12 \\
12 \\
12
\end{tabular}

STANDARD

EYIAIUON

10.92

10.92

255.3

1024.8
7.82

0.307

0.396

0.699

0.699
4943.6

4943.6
134.2

93.3

139.9

19.17

17.60
6.72

21.99

21.99
3.37

83.2

0.0

21.43
21.85

21.85
152.2

157.1

71.4
5.4

29.5

0.12

5.46
108.9
1029.9
0.22
0.253
0.208
0.479
3686.8
184.1
144.6
213.7
1.99
5.60
2.51
12.07
0.99
20.1
0.0
13.35
16.34
62.4
60.3
24.0
8.5
63.7
0.05

BANGE

4.0 21.0

$111 \quad 424$
$109 \quad 3270$

7.4

0.16

0.19

0.31

980

$\begin{array}{ll}0 & 480 \\ 2 & 720\end{array}$

$\begin{array}{rr}16.0 & 22.0 \\ 9.2 & 27.0\end{array}$

3.010 .0

$6.8 \quad 41.0$

1.8

50
0
4.5

4.5
3.9

3.9
71

72
35

0
1
0.1

000$$
\begin{array}{r}
4.9 \\
107 \\
44.0 \\
51.0 \\
244 \\
256 \\
110 \\
21 \\
230
\end{array}
$$

\section{BES}

SAMPLE SIZE

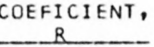

$-$

$\underset{B}{\text { CONSTANT }}$

CORELATIUN

STANDARD STANDARD
ERROR OF $3270 \quad 12$ $1.10 \quad 12$ 0.8910

2
9
12
10
12
3

-6.851
0.0002
0.00036
0.00079
-0.00151
-8.121

2606.448 7.7621 0.21424

1.08451

7518.055

$-0.800$

$0.117 *$

0.156 *

-0.343 *

$-0.372 *$ LIMAIF

${ }^{\star}$ Not significant at the 95 percent confidence level.

\begin{tabular}{|c|c|c|c|c|c|}
\hline & & & & & $\overline{\text { STANDARD }}$ \\
\hline & HARMONIC & AMPLITUDE & PHASE & VARIATION & ERROR OF \\
\hline $\begin{array}{l}\text { SAMPLE } \\
\text { SIZE. }\end{array}$ & $\begin{array}{l}\text { MEAN - M } \\
\text { IDEE GI) }\end{array}$ & DEE ${ }^{A}(1)$ & $\begin{array}{l}\text { ANGLE - C } \\
\text { (RADIANSI) }\end{array}$ & EXPLAINED & ESTIMATE \\
\hline
\end{tabular}
14
$10 \cdot 10$
7.08
2.58
87
2.08

SUMMARY OF MAXIMUM AND MINIMUM CONCENTRATIONS OF CONSTITUENTS SAMPLED AT A FREQUENCY OF QUARTERLY (1975 WY)

10351700 -- TRUCKEE R NR NIXON, NV

CONSTITUENT
SAMPLES


LAT 41058MOOS LONG 117D5OMOIS

DRAINAGE AREA: 225 SQ MI $1 \quad 583$ SQ KM)

PERIOD OF RECORD: $10 / 01 / 74-09 / 30 / 75$

STATISTICAL SUMMARY OF SELECTED DISSOLVED CHEMICAL CONSTITUENTS AND REGRESSION RELATIONSHIPS OF CONSTITUENT CONCENTRATIONS TO SPECIFIC CONDUCTANCE

CONSIUIUENI

TEMPERATURE, WATER (DEG C)
SPECIFIC CONDUCTANCE (MICROMHOS)
STREAMFLOH (CUBIC FT/SEC)
PH (STANDARD UNITS)
PHOSPHORUS, TOTAL
NITRITE, NITRATE, TOTAL
NITROGEN, KJELDAHL, TOTAL
PHYTOPLANKTON, TOTAL (CELLS/ML)
SEDIMENT, SUSPENDED
SEOIMENT, CLAY SILT (PERCENT)
COLIFORM, FECAL (COL/IOO ML)
STREPTOCOCCI, FECAL (COL/IOO ML)
SILICA, DISSOLVED
CALCIUM, DISSOLVED
MAGNESIUM, DISSOLVED
SODIUM, DISSOLVED
POTASSIUM, DISSOLVED
BICAREONATE, ION
CARBONATE, ION
SULFATE, DISSOLVED
CHLORIDE, DISSOLVED
DISSOLVED SOLIDS, SUM OF CONST
DISSOLVED SOLIDS, ROE I8O DEG C
HARDNESS, TOTAL
HARDNESS, NONCARBONATE
TURBIDITY (JTU)
FLOURIDE, DISSOLVED

CONSIIIUENI IMG/L OR UNLI SHOWNI)

\begin{tabular}{r} 
SAMPLE \\
SIZE \\
\hline 19 \\
12 \\
19 \\
8 \\
9 \\
9 \\
9 \\
9 \\
9 \\
0 \\
9 \\
9 \\
9 \\
9 \\
9 \\
12 \\
9 \\
9 \\
9 \\
9 \\
12 \\
9 \\
9 \\
9 \\
9 \\
9 \\
9
\end{tabular}

STANDARD

MEAN DEYIAIION

9.79

251.1

73.2

8.49

0.122

0.136

033.3

$\begin{array}{r}95.1 \\ \hline\end{array}$

8.52

32.1
87.0

87.0
0.67

0.068

0.145

0.106

0.106
1932.0

1932.0
110.8

26.0
75.9

75.9
29.78

29.78
19.67

6.51

21.50

3.28

100.6
3.2

17.89

17.89
10.27

10.27
160.7

162.7

76.0

12.3

0.66

\section{9}

99.0

2.11
2.65

2.05
0.56

3.87

0.53

8.7

7.4

3.33

1.81
15.9

16.6

8.5
0.0

11.9

0.17

SAMPLE

REGRESSION

BEGRESSLON SUMMABY SIZE

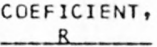

CONSTANT, $\underset{-1}{-B}$

CORRELATION

STANDARD $0.0 \quad 28.0$ 209

4
7.7

297
232

$\begin{array}{ll}7.7 & 9.4\end{array}$

$0.00 \quad 0.40$

0.30

0.30

0.62

8.62

8000
325

$0 \quad 170$

$\begin{array}{rr}4 & 300 \\ 26.0 & 33.0 \\ 16.0 & 25.0\end{array}$

$5.8 \quad 7.5$

$16.0 \quad 27.0$

2.4

90

12.0

7.2

143

143

0

0.4

$$
\begin{array}{r}
4.1 \\
113 \\
22 \\
23.0 \\
13.0 \\
196 \\
196 \\
93 \\
0
\end{array}
$$$$
\begin{aligned}
& 23.0 \\
& 13.0
\end{aligned}
$$$$
\begin{array}{r}
196 \\
196 \\
93
\end{array}
$$

0
38
0.9

12
8
9
9
9
4



9
9
9
12
9
9
9
9
12
9
9
9
9
9
9

-1.920
0.0136
-0.00096
0.00090
-0.00068
1.565

541.703
5.1889
0.35263
-0.07839
0.59443
1815.806

$-0.740$

-0.385 *

0.167 *

$-0.175 *$

$0.442 *$

ERROR OF

\begin{tabular}{|c|c|c|c|c|c|}
\hline & & & & & STANDARD \\
\hline & HARMONIC & AMPLITUDE & PHASE & VARIATION & ERROR OF \\
\hline $\begin{array}{l}\text { SAMPLE } \\
\text { SIZE. }\end{array}$ & $\begin{array}{l}\text { MEAN }-M \\
(D E G())\end{array}$ & (DEG $\bar{A}(1$ & $\begin{array}{l}\text { ANGLE - C } \\
\text { (BADIANS) }\end{array}$ & $\begin{array}{c}\text { EXPLAINED } \\
(z)\end{array}$ & $\begin{array}{l}\text { ESTIMATE } \\
\text { (DEG } C)\end{array}$ \\
\hline & & & & & \\
\hline
\end{tabular}

*Not significant at the 95 percent confidence level.

SUMMARY OF HARMONIC ANALYSIS OF STREAM TEMPERATURE

39

10.93

13.55

2.39

88

2.91

SUMMARY OF MAXIMUM AND MINIMUM CONCENTRATIONS OF CONSTITUENTS

\begin{tabular}{|c|c|c|c|c|c|c|}
\hline \multirow{2}{*}{ CONSTITUENT } & \multicolumn{3}{|c|}{ TOTAL } & \multicolumn{3}{|c|}{ DISSOLVEO } \\
\hline & $\begin{array}{l}\text { NO. } \\
\text { SAMPLES }\end{array}$ & $\begin{array}{l}\text { MINIMUM } \\
\text { CONC. }\end{array}$ & $\begin{array}{l}\text { MAXIMUM } \\
\text { CONC. }\end{array}$ & $\begin{array}{l}\text { NO. } \\
\text { SAMPLES }\end{array}$ & $\begin{array}{l}\text { MINIMUM } \\
\text { CONC. }\end{array}$ & $\begin{array}{l}\text { MAXIMUM } \\
\text { CONC. }\end{array}$ \\
\hline \multicolumn{7}{|l|}{ MINOR ELEMENTS: } \\
\hline ARSENIC (AS), UG/L & 3 & 11 & 19 & 3 & 9 & 14 \\
\hline CADMIUM $(C D), U G / L$ & 3 & $<10$ & 10 & 3 & 0 & 0 \\
\hline CHROMIUM (CR), UGIL & 3 & 0 & 10 & 3 & 0 & 0 \\
\hline COBALT $(C O), U G / L$ & 3 & $<50$ & $<50$ & 3 & 0 & 1 \\
\hline COPPER (CU), UG/L & 3 & $<10$ & 20 & 3 & 1 & 4 \\
\hline IRON $(F E), U G / L$ & 3 & 240 & 8300 & 3 & 40 & 130 \\
\hline LEAD (PB), UG/L & 3 & $<100$ & $<100$ & 3 & 1 & 4 \\
\hline MANGANESE $(M N), U G / L$ & 3 & 0 & 210 & 3 & $\hat{0}$ & 10 \\
\hline MERCURY $(H G), U G / L$ & 3 & 0.0 & 1.4 & 3 & 0.0 & 0.8 \\
\hline SELENIUM (SE), UG/L & 3 & 0 & 0 & 3 & 0 & 0 \\
\hline ZINC $(Z N), U G / L$ & 3 & 10 & 50 & 3 & 10 & 30 \\
\hline \multicolumn{7}{|l|}{ PERIPHYTON: } \\
\hline BIOMASS, DRY WT., G/SO M & 1 & 23.00 & & & & \\
\hline BIOMASS, ASH WT., G/SO M & $i$ & 11.00 & & & & \\
\hline CHLOROPHYLL A, MG/SO M & $i$ & 87.0 & & & & \\
\hline CHLOROPHYLL $B, M G / S O M$ & 1 & 8.3 & & & & \\
\hline ORGANIC CARBON, MG/L & 3 & 3.0 & 6.3 & & & \\
\hline
\end{tabular}
SAMPLED AT A FREQUENCY OF QUARTERLY (1975 WY)

10352500 -- MC DERMITT C NR MC DERMITT, NV 
LAT 42D47M28S LONG $118052 M 00 S$

$\begin{array}{ll}\text { DRAINAGE AREA: } & 200 \text { SQ MI } 1 \\ \text { PERIOD OF RECORD: } & 10 / 01 / 74-09 / 30 / 75\end{array}$

$118052 M O O S$
200 SO MI

STATISTICAL SUMMARY OF SELECTED DISSOLVED CHEMICAL CONSTITUENTS AND

REGRESSION RELATIONSHIPS OF CONSTITUENT CONCENTRATIONS TO SPECIFIC CONDUCTANCE

CONSILIUENI

TEMPERATURE, WATER (DEG C)
SPECIFIC CONDUCTANCE (MICROMHOS)
STREAMFLOH (CUBIC FT/SEC)
PH (STANDARD UNITS)
PHOSPHORUS, TOTAL
NITRITE + NITRATE, TOTAL
NITROGEN, KJELDAHL, TOTAL
PHYTOPLANKTON, TOTAL (CELLS/ML)
SEDIMENT, SUSPENDED
SEDIMENT, CLAY-SILY (PERCENT)
COLIFORM, FECAL (COL/IOO ML)
STREPTOCOCCI, FECAL (COL/IOO ML)
SILICA, DISSOLVED
CALCIUM, DISSOLVED
MAGNESIUM, DISSOLVED
SODIUM, DISSOLVED
POTASSIUM, DISSOLVED
BICAREONATE, ION
CARBONATE, ION
SULFATE, DISSOLVED
CHLORIDE, DISSOLVED
DISSOLVED SOLIDS, SUM OF CONST
DISSOLVED SOLIDS, ROE I8O DEG C
HARDNESS, TOTAL
HARONESS, NONCARBONATE
TURBIDITY IJTU)
FLOURIDE, DISSOLVED

\section{CONSIUIUENI IMG LL OR UNDI SHOWN}

SAMPLE
SIZE

6
6
6
6
6
6
6
6
5
0
6
6
6
6
6
6
6
6
6
6
6
6
6
6
6
6
6
STANDARD

MEAN DEYIAIION

11.35

60.3

288.5

8.12

0.077

0.088

0.385

1238.3

238.3
79.4

9.5

18.3
21.50

21.50
7.27

2.55

4.00

1.13

38.3

38.3
0.5

.97

1.20
59.2
63.5

28.5

0.0
13.7
0.13
5.51

10.7
281.7

281.7

0.53

0.047

0.123

0.123
871.7

149.5

6.6
19.7

19.7
3.15

2.45

0.47

0.88

0.35

6.2

1.2
0.80

0.57

10.6

12.8

7.1

10.6
0.08

*Not significant at the 95 percent confidence level.

SUMMARY OF MAXIMUM AND MINIMUM CONCENTRATIONS OF CONSTITUENTS SAMPLED AT A FREQUENCY OF OUARTERLY (1975 WY)

10390000 - DONNER UND BLITZEN RIVER NR FRENCHGLEN, OREG.

\begin{tabular}{|c|c|c|c|c|c|c|}
\hline \multirow{2}{*}{ CONSTITUENT } & \multicolumn{3}{|c|}{ TOTAL } & \multicolumn{3}{|c|}{ DI SSOLVED } \\
\hline & $\begin{array}{l}\text { NO. } \\
\text { SAMPLES }\end{array}$ & $\begin{array}{l}\text { MIN IMUM } \\
\text { CONC. }\end{array}$ & $\begin{array}{l}\text { MAXIMUM } \\
\text { CONC. }\end{array}$ & $\begin{array}{l}\text { NO. } \\
\text { SAMPLES }\end{array}$ & $\begin{array}{l}\text { MINIMUM } \\
\text { CONC. }\end{array}$ & $\begin{array}{l}\text { MAXIMUM } \\
\text { CONC. }\end{array}$ \\
\hline \multicolumn{7}{|l|}{ MINOR ELEMENTS: } \\
\hline ARSENIC (AS), UG/L & 2 & 0 & 0 & 2 & 0 & 1 \\
\hline CADMIUM $(C D), U G / L$ & 2 & $<10$ & $<10$ & 2 & 0 & 1 \\
\hline CHROMIUM (CR), UG/L & 2 & 0 & 10 & 2 & 0 & $\mathrm{c}$ \\
\hline COBALT $(C O), U G / L$ & 2 & $<50$ & $<50$ & 2 & 0 & 1 \\
\hline COPPER $(C U), U G / L$ & 2 & 20 & 40 & 2 & 1 & 7 \\
\hline IRON $(F E), U G / L$ & 2 & 1400 & 2000 & 2 & 120 & 380 \\
\hline LEAD $(P B), U G / L$ & 2 & $<100$ & $<100$ & 2 & 2 & 2 \\
\hline MANG ANESE $(M N), U G / L$ & 2 & 50 & 70 & 2 & 0 & 20 \\
\hline MERCURY $(H G), U G / L$ & 2 & 0.0 & 0.0 & 2 & 0.0 & 0.0 \\
\hline SELENIUM (SE), UG/L & 2 & 0 & 0 & 2 & 0 & 0 \\
\hline$Z I N C(Z N), U G / L$ & 2 & 30 & 70 & 2 & 0 & 20 \\
\hline \multicolumn{7}{|l|}{ PERIPHYTON: } \\
\hline BIOMASS, ORY WT., G/SQ M & 1 & 46.00 & & & & \\
\hline BIOMASS, ASH WT., G/SO M & 1 & 44.00 & & & & \\
\hline CHLOROPHYLL A, MG/SO M & 1 & 9.5 & & & & \\
\hline CHLOROPHYLL $B, M G / S O M$ & 1 & 1.5 & & & & \\
\hline ORGANIC CARGON, MG/L & 2 & .8 & 6.0 & & & \\
\hline
\end{tabular}


Table 14.--Summary of measurement at each station--Continued

LAT 33D53MOOS LONG 117038M4OS

DRAINAGE AREA: 1490 SQ MI 13859 SQ KMI

PERIOD OF RECORD: $10 / 01 / 74-09 / 30 / 75$

STATISTICAL SUMMARY OF SELECTED DISSOLVED CHEMICAL CONSTITUENTS AND

REGRESSION RELATIONSHIPS OF CONSTITUENT CONCENTRATIONS TO SPECIFIC CONDUCTANCE

CONSIIIUENI

CONSIUUUENI IMG L OR UNII_SHOWN

$$
\text { SAMPLE }
$$

SIZE

TEMPERATURE, WATER (DEG C) SPECIFIC CUNDUCTANCE (MICROMHOS) STREAMFLOW (CUBIC FT/SEC)

PH (STANDARD UNITS)

PHOSPHORUS, TOTAL

NITRITE + NITRATE, TOTAL

NITROGEN, KJELDAHL, TOTAL

PHYTOPLANKTON, TOTAL (CELLS/ML)

SEDIMENT, SUSPENDED

SEDIMENT, CLAY-SILT (PERCENT)

COLIFURM, FECAL ( $\mathrm{COL} / 100 \mathrm{ML}$ )

STREPTOCOCCI, FECAL ( COL/100 ML)

SILICA, DISSOLVED

CALCIUM, DISSOLVED

MAGNESIUM, DISSOLVED

SODIUM, DISSOLVED

POTASSIUM, DISSOLVED

BICARBONATE, ION

CARBONATE, ION

SULFATE, DISSOLVED

CHLR IDE, DISSOLVED

CHLORIOE, DISSOLVED

DISSOLVED SOLIDS, ROE 180 DEG DISSOLVED SOLIDS,
HARDNESS, TOTAL

HARDNESS, TOTAL
HARDNESS, NONCARBONATE

TUREIDITY (JTU)

FLOURIDE, DISSOLVED

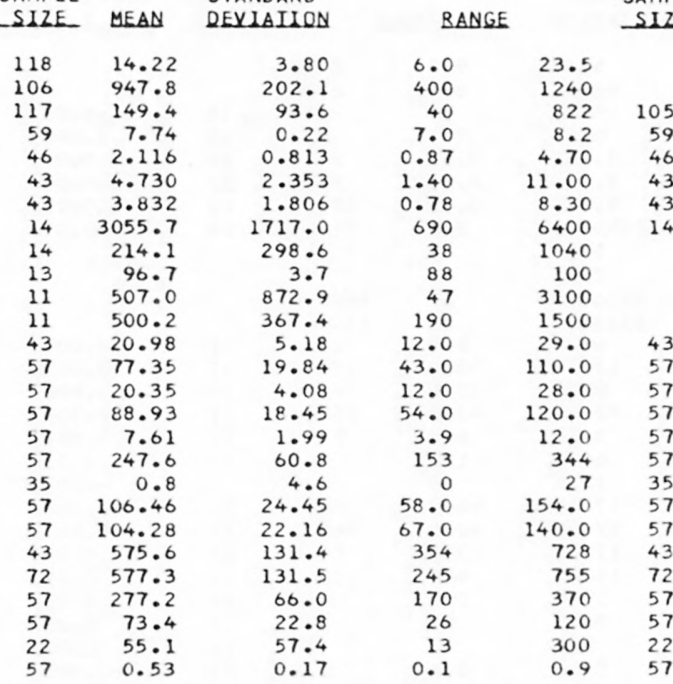

*Not significant at the 95 percent confidence level.
BEGRESSION SUMMABY REGRESSION

SAMPLE COEFICIENT,

CONSTANT, CORRELATION

$\begin{array}{rr}-0.167 & 300.672 \\ -0.0001 & 7.8430 \\ 0.00289 & -0.67530 \\ 0.00722 & -2.21377 \\ 0.00641 & -2.35273 \\ 1.862 & 1375.817\end{array}$

$-0.370$

$-0.099$

0.723
0.626

0.626
0.714

0.222

85.1

0.22

0.568

1.857

1.279
1742.4

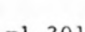

-14.0595
2.3669

2.3669
4.7072

0.7728

$-21.310$

$-2.692$

2.1942

3.7882

$-39.423$

$-10.909$

-10.909
-26.211

$-5.538$

$-31.530$

0.1239

0.907

0.976

0.934

0.967

0.728
0.937

0.937
0.158

0.158
0.903

0.960

0.960
0.993

0.993

0.977

0.974

0.733
0.328

0.495

DAILY SPECIFIC CONDUCTANCE IN

MATLY SPECIFIC CONOUCTANCE TN

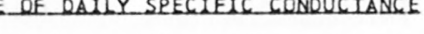

EQUALLED CR EXCEEDED FOR THE

\begin{tabular}{|c|c|c|c|c|}
\hline 18 & 58 & $10 \%$ & $20 z$ & 308 \\
\hline 1 & 1200 & 1180 & 1150 & 1120 \\
\hline \multicolumn{5}{|c|}{5 OF STREAM TEMPERATURE } \\
\hline & \multirow{2}{*}{\multicolumn{2}{|c|}{ VAR IATION }} & \\
\hline & & & & ROR OF \\
\hline \multicolumn{2}{|c|}{ ANGLE - C } & \multicolumn{2}{|c|}{ EXPLAINED } & ESTIMATE \\
\hline \multicolumn{2}{|c|}{ (RADIANS) } & \multicolumn{2}{|c|}{$\ldots(8)$} & (DEG_C) \\
\hline \multicolumn{2}{|c|}{2.70} & 87 & & 1.54 \\
\hline
\end{tabular}

SUMMARY OF HARMONIC ANALYSIS OF STREAM TEMPERATURE

\begin{tabular}{|c|c|c|c|c|c|}
\hline & & & & & STANDARD \\
\hline & HARMONIC & AMPLITUDE & PHASE & VARIATION & ERROR OF \\
\hline SAMPLE & MEAN - M & $-A$ & ANGLE $-C$ & EXPLAINED & ESTIMATE \\
\hline SIZE & 10EG 61 & WEG $(1)$ & (RAD IANS) & $-(8)$ & (DEG_C) \\
\hline 302 & 16.29 & 5.65 & 2.70 & 87 & 1.54 \\
\hline
\end{tabular}

SUMMARY OF MAXIMUM AND MINIMUM CONCENTRATIONS OF CONSTITUENTS SAMPLED AT A FREQUENCY OF QUARTERLY (1975 WY

11074000 -- SANTA ANA RIVER BELOW PRADO DAM, CALIF.

\begin{tabular}{|c|c|c|c|c|c|c|}
\hline \multirow{2}{*}{ CONSTITUENT } & \multicolumn{3}{|c|}{ TOTAL } & \multicolumn{3}{|c|}{ DISSOLVED } \\
\hline & $\begin{array}{l}\text { NO. } \\
\text { SAMPLES }\end{array}$ & $\begin{array}{l}\text { MINIMUM } \\
\text { CONC. }\end{array}$ & $\begin{array}{l}\text { MAXIMUM } \\
\text { CONC. }\end{array}$ & $\begin{array}{l}\text { NO. } \\
\text { SAMPLES }\end{array}$ & $\begin{array}{l}\text { MINIMUM } \\
\text { CONC. }\end{array}$ & $\begin{array}{l}\text { MAXIMUM } \\
\text { CONC. }\end{array}$ \\
\hline \multicolumn{7}{|l|}{ MINOR ELEMENTS: } \\
\hline ARSENIC (AS), UG/L & 12 & 3 & 10 & 9 & 0 & 7 \\
\hline CADMIUM $(C D), U G / L$ & 12 & $<10$ & 20 & 9 & 0 & 3 \\
\hline CHROMIUM (CR), UG/L & 12 & 0 & 50 & 4 & 0 & 10 \\
\hline COBALT $(C O), U G / L$ & 12 & 0 & 50 & 8 & 0 & 0 \\
\hline COPPER (CU), UG/L & 12 & $<10$ & 60 & 9 & 0 & 10 \\
\hline IRON (FE), UG/L & 4 & 2300 & 6500 & 45 & 10 & 1100 \\
\hline LEAD $(P B), U G / L$ & 12 & $<100$ & 100 & 9 & 0 & 10 \\
\hline MANG ANESE (MN), UG/L & 8 & 110 & 1100 & 4 & 50 & 200 \\
\hline MERCURY (HG), UG/L & 11 & 0.0 & 0.1 & 8 & 0.0 & 0.1 \\
\hline SELENIUM (SE), UG/L & 8 & 0 & 1 & 4 & 0 & 1 \\
\hline ZINC $(Z N), U G / L$ & 12 & 40 & 210 & 9 & 20 & 110 \\
\hline \multicolumn{7}{|l|}{ PERIPHYTON: } \\
\hline BIOMASS, DRY WT, G/SQ M & 1 & 19.00 & & & & \\
\hline BIOMASS, ASH WT., G/SO M & 1 & 17.00 & & & & \\
\hline CHLOROPHYLL A, MG/SQ M & 1 & .6 & & & & \\
\hline CHLOROPHYLL B, MG/SQ M & 1 & .0 & & & & \\
\hline ORGANIC CARBON, MG/L & 41 & 5.7 & 26.0 & & & \\
\hline
\end{tabular}


Table 14.--Sumnary of measurement at each station--Continued

LAT $33048 M 16 S$ LONG $118012 M 15 S$

STATISTICAL SUMMARY OF SELECTED DISSOLVED CHEMICAL CONSTITUENTS AND

REGRESSION RELATIONSHIPS OF CONSTITUENT CONCENTRATIONS TO SPECIFIC CONDUCTANCE

CONSIUIUENI

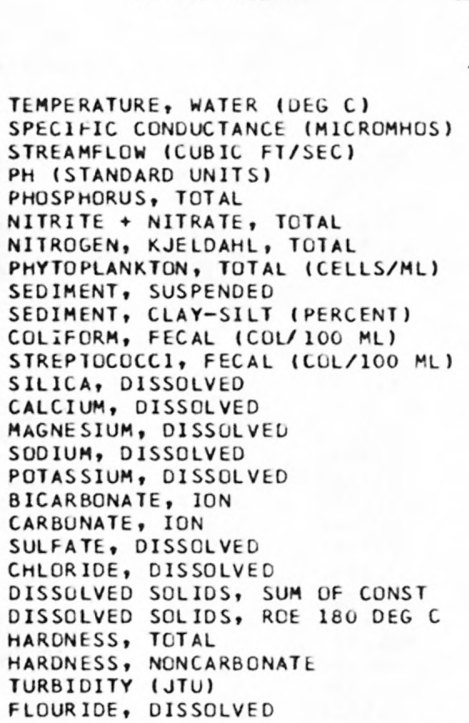

CONSLIUUENI IMG/L OR UNII SHOKNU

\begin{tabular}{rrr}
$\begin{array}{rrr}\text { SAMPLE } \\
\text { SIZE. }\end{array}$ & MEAN & \multicolumn{1}{r}{ STANDARD } \\
DEYIALION \\
12 & 17.79 & 4.85 \\
12 & 1302.1 & 486.1 \\
12 & 44.9 & 50.4 \\
15 & 8.65 & 0.56 \\
12 & 1.160 & 0.532 \\
12 & 2.302 & 2.480 \\
12 & 3.637 & 3.715 \\
14 & 28016.4 & 23934.4 \\
11 & 19.5 & 17.7 \\
10 & 72.8 & 21.7 \\
12 & 19071.7 & 54000.0 \\
12 & 11454.7 & 33189.7 \\
12 & 18.77 & 6.01 \\
12 & 90.58 & 12.57 \\
12 & 32.25 & 8.30 \\
12 & 128.25 & 52.65 \\
12 & 9.48 & 3.15 \\
12 & 226.6 & 44.8 \\
9 & 14.6 & 13.8 \\
12 & 228.00 & 47.30 \\
12 & 138.75 & 72.92 \\
12 & 769.4 & 177.7 \\
12 & 822.9 & 162.9 \\
12 & 357.5 & 57.4 \\
12 & 154.4 & 26.1 \\
12 & 6.3 & 5.2 \\
12 & 0.62 & 0.18
\end{tabular}

BEGRESSLON SUMMABY REGRESSION STANDARO SAMPLE COEFICIENT, CONSTANT, CORRELATION ERROR OF SIZE - B _ - B _ COEEICIENI ESIIMAIE

*Not significant at the 95 percent confidence level.

$\begin{array}{rrr}9.2 & 27.5 & \\ 635 & 2700 & \\ 19 & 200 & 12 \\ 7.3 & 9.2 & 15 \\ 0.54 & 2.20 & 12 \\ 0.01 & 8.80 & 12 \\ 0.72 & 12.00 & 12 \\ 260 & 71000 & 14 \\ 5 & 67 & \\ 38 & 95 & \\ 80 & 190000 & \\ 20 & 116000 & \\ 6.3 & 25.0 & 12 \\ 58.0 & 110.0 & 12 \\ 12.0 & 45.0 & 12 \\ 43.0 & 250.0 & 12 \\ 6.8 & 19.0 & 12 \\ 123 & 282 & 12 \\ 0 & 30 & 9 \\ 96.0 & 300.0 & 12 \\ 42.0 & 340.0 & 12 \\ 335 & 1080 & 12 \\ 448 & 1160 & 12 \\ 190 & 410 & 12 \\ 93 & 190 & 12 \\ 1 & 20 & 12 \\ 0.4 & 1.1 & 12\end{array}$

\section{DURAIJON IABLE_OF_DALIY SPECIEIC_CONDUCIANCE}

DAILY SPECIFIC CONDUCTANCE IN MICROMHOS AT 25 DEG C, THAT WAS

EQUALLED OR EXCEEDED FOR THE

$20 z$

$30 \%$

$50 \%$

19301620

15001380

$1300 \quad 1200$

$\begin{array}{rr}-0.037 & 93.020 \\ 0.0001 & 8.4606 \\ -0.00012 & 1.31674 \\ -0.00024 & 2.61883 \\ -0.00132 & 5.35496 \\ -9.079 & 39718.082\end{array}$

$-0.357^{*}$

$0.113 *$

$-0.110 *$

-0.048 *

$-0.173 *$

$-0.170^{*}$

$-0.0051$

0.0075

0.0087

0.1002

$-0.0011$

0.035

$-0.010$

0.0353

0.1473

0.305

0.302

0.053

0.033

-0.0002
-0.0000
25.3691

20.9677

$-2.2151$

10.8595

181.136
27.960

182.0870

$-53.0873$

371.938

430.163

430.163

288.569

10.941
9.473

0.6296
$-0.410^{*}$
$0.288^{*}$
$0.507 *$
$0.925^{*}$
$-0.1633^{*}$
$0.379 *$
$-0.357^{*}$
$0.362^{*}$
0.982
0.835
0.900
$0.448 *$
0.621
$-0.226^{*}$
$-0.010^{*}$
49.3

0.57
0.555

2.598

3.837

24548.0
SAMPLE SIZE $\equiv 207$

$20 \% \quad 25 \% 29 \%$

$893-594 \quad 312$

SUMMARY OF HARMONIC ANALYSIS OF STREAM TEMPERATURE

\begin{tabular}{|c|c|c|c|c|c|}
\hline & & & & & STANDARD \\
\hline & HARMONIC & AMPLITUDE & PHASE & VARIATION & ERROR OF \\
\hline $\begin{array}{l}\text { SAMPLE } \\
\text { SILE_ }\end{array}$ & $\begin{array}{l}\text { MEAN - M } \\
\text { LOEG SI. }\end{array}$ & IDEG ${ }^{A}(1)$ & $\begin{array}{l}\text { ANGLE - C } \\
\text { (BADIANSI) }\end{array}$ & $\begin{array}{c}\text { EXPLAINED } \\
-(Z)\end{array}$ & $\begin{array}{l}\text { ESTIMATE } \\
\text { LDEG CI }\end{array}$ \\
\hline
\end{tabular}

311

18.51

7.35

2.72

89

1.90

SUMMARY OF MAXIMUM AND MINIMUM CONCENTRATIONS OF CONSTITUENTS SAMPLED AT A FREQUENCY OF QUARTERLY (1975 WY)

11103010 -- LOS ANGELES R. A. HILLO ST BR A LB

\begin{tabular}{|c|c|c|c|c|c|c|}
\hline \multirow{2}{*}{ CONSTITUENT } & \multicolumn{3}{|c|}{ TOTAL } & \multicolumn{3}{|c|}{ DISSOLVED } \\
\hline & $\begin{array}{l}\text { NO. } \\
\text { SAMPLES }\end{array}$ & $\begin{array}{l}\text { MINIMUM } \\
\text { CONC. }\end{array}$ & $\begin{array}{l}\text { MAXIMUM } \\
\text { CONC. }\end{array}$ & $\begin{array}{l}\text { NC. } \\
\text { SAMPLES }\end{array}$ & $\begin{array}{l}\text { MINIMUM } \\
\text { CONC. }\end{array}$ & $\begin{array}{l}\text { MAXIMUM } \\
\text { CONC. }\end{array}$ \\
\hline \multicolumn{7}{|l|}{ MINOR ELEMENTS: } \\
\hline ARSENIC (AS), UG/L & 4 & 2 & 26 & 4 & 5 & 16 \\
\hline CADMIUM $(C D), U G / L$ & 4 & $<10$ & 30 & 3 & 1 & 2 \\
\hline CHROMIUM (CR), UG/L & 4 & 0 & 50 & 4 & 0 & 40 \\
\hline COBALT $(C O), U G / L$ & 4 & $<50$ & $<50$ & 4 & 0 & 1 \\
\hline COPPER $(C U), U G / L$ & 4 & 20 & 50 & 4 & 5 & 35 \\
\hline IRON $(F E), U G / L$ & 4 & 180 & 2300 & 4 & 30 & 390 \\
\hline LEAD $(P B), U G / L$ & 4 & $<100$ & 200 & 4 & 5 & 48 \\
\hline MANGANESE (MN), UG/L & 4 & 30 & 320 & 4 & 0 & 280 \\
\hline MERCURY (HG), UG/L & 4 & 0.0 & 0.2 & 4 & 0.1 & 0.4 \\
\hline SELENIUM (SE), UG/L & 4 & 1 & 3 & 4 & 2 & 3 \\
\hline$Z I N C(Z N), U G / L$ & 4 & 50 & 240 & 4 & 30 & 150 \\
\hline \multicolumn{7}{|l|}{ PERIPHYTON : } \\
\hline BIOMASS, DRY WT., G/SO M & 0 & & & & & \\
\hline BIOMASS, ASH WT., G/SQ M & 0 & & & & & \\
\hline CHLOROPHYLL A, MG/SO M & 0 & & & & & \\
\hline CHLOROPHYLL B, MG/SO M & 0 & & & & & \\
\hline ORGANIC CARBON, MG/L & 3 & 2.5 & 21.0 & & & \\
\hline
\end{tabular}


Table 14.--Summary of measurement at each station--Continued

LAT 36037M52S LONG 121040M17S

DRAINAGE AREA: 4156 SQ MI , 10764 SO KM

PERIOD OF RECORD: $10 / 01 / 74-09 / 30 / 75$

STATISTICAL SUMMARY OF SELECTED DISSOLVED CHEMICAL CONSTITUENTS AND REGRESSION RELATIONSHIPS OF CONSTITUENT CONCENTRATIONS TO SPECIFIC CONDUCTANCE

CONSIUIUENI

CONSILUUENI IMGLL OR UNII SHOWNI

\begin{tabular}{l} 
SAMPLE \\
SIZE \\
\hline
\end{tabular}

TEMPERATURE, WATER (DEG C)

SPECIFIC CONDUCTANCE (MICROMHOS)

STREAMFLOW (CUBIC FT/SEC)

PH ISTANDARD UNITS

PHOSPHORUS, TOTAL

NITRITE + NITRATE, TOTAL

NITROGEN, KJELDAHL, TOTAL

PHYTOPLANKTON, TOTAL (CELLS/ML)

SEDIMENT, SUSPENDED

SEDIMENT, CLAY-SILT (PERCENT)

COLIFORM, FECAL (COL/100 ML)

STREPIOCOCCI, FECAL (COL/100 ML)

SILICA, DISSOLVED

CALCIUM, DISSOLVED

MAGNESIUM, DISSOLVED

SODIUM, DISSOLVED

POTASSIUM, DISSOLVED

BICARBONATE, ION

CARBONATE, ION

SULFATE, DISSOLVED

CHLORIDE, DISSOLVED

DISSOLVED SOLIDS, SUM OF CONST

DISSOLVED SOLIDS, ROE 180 DEG

HARDNESS, TOTAL

HARDNESS, NONCARBQNATE

TURBIDITY (JTU)

FLOURIDE, DISSOLVED

*Not significant at the 95 percent confidence level.

DURAIION IABLE_OF DALY SPECIEIC CONDUCIANCE

DAILY SPECIFIC CONDUCTANCE IN

MICROMHOS AT 25 DEG C, THAT WAS

EQUALLED OR EXCEEDED FOR THE

INDICATED PERCENTAGE OF TIME

$\begin{array}{llll}18 & 58 & 20 \%\end{array}$

$30 \%$

1280

$1130 \quad 1100 \quad 970$

825

BANGE

REGRESSION

BEGRESSLON SUMMARY

SAMPLE COEFICIENT,

CONSTANT,

correlation

STANDARD SIZE
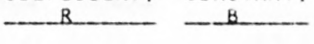
COEEICIENI ESIUMAIE

14

612.6

3.93
356.6

1550.3

0.28

2.299

2.928

7181.8

5.428

4.002

7229.

1055.5
26.4

203.1

120.9
10.91

20.67

12.27

4.15
5.07

83.7

52.56

55.65

211.0

99.2

38.2

11.5
0.12

$\begin{array}{rr}7.0 & 27.5 \\ 181 & 1270 \\ 2 & 6290 \\ 7.4 & 8.5 \\ 0.20 & 14.00 \\ 0.20 & 19.00 \\ 0.21 & 12.00 \\ 1500 & 25000 \\ 107 & 3520 \\ 26 & 99 \\ 8 & 550 \\ 0 & 400 \\ 12.0 & 41.0 \\ 34.0 & 80.0 \\ 15.0 & 44.0 \\ 18.0 & 130.0 \\ 2.1 & 13.0 \\ 95 & 337 \\ 0 & 0 \\ 46.0 & 170.0 \\ 12.0 & 160.0 \\ 215 & 719 \\ 229 & 802 \\ 150 & 380 \\ 37 & 130 \\ 0 & 30 \\ 0.1 & 0.4\end{array}$

1270

$\begin{array}{lll}6290 & 14 & -1.590\end{array}$

0.0000

0.00632

0.01034

8.0826

$-1.63733$

.28319

1.13423
3583.480

-0.448 *

$0.019 *$

.568

0.077

-0.415 .

1178.2

0.29
3.578

4.211

4.087

$-8.618$

(1)

0.0199
0.0432
0.0253
0.0882
0.0100
0.177
0.000
0.0692
0.1189
0.443
0.508
0.212
0.068
0.006
0.0001

6.8399

26.0867

10.3914

$-1.0080$

0.837

0.908
0.945

0.910

0.906

$87.463 \quad 0.919$

0.000

68.1485

$-22.8754$

22.8754
153.439

122.012

104.598

33.059

8.452

0.000 *

$0.572 *$

0.929

0.962

0.955
0.929

0.771

$0.230 *$
$0.195 *$

SAMPLE SIZE $=157$

$20 \% 25 \% \quad 991$

$320 \quad 283 \quad 21$

SUMMARY OF HARMONIC ANALYSIS OF STREAM TEMPERATURE

\begin{tabular}{|c|c|c|c|c|c|}
\hline & & & & & STANDARD \\
\hline & HARMONIC & AMPLITUDE & & VAR IATION & $\begin{array}{l}\text { ERROR OF } \\
\text { ESTIMATE }\end{array}$ \\
\hline $\begin{array}{l}\text { SAMPLE } \\
\text { SUZE_- }\end{array}$ & $\begin{array}{l}\text { MEAN - M } \\
\text { (DEG C) }\end{array}$ & DEEG & $\begin{array}{l}\text { ANGLE }-C \\
\text { (RAD LANS) }\end{array}$ & $\begin{array}{c}\text { EXPLA INED } \\
(\Omega)\end{array}$ & $\begin{array}{l}\text { ESTIMATE } \\
\text { LDEG CL }\end{array}$ \\
\hline 166 & 15.72 & 0.17 & 2.84 & 70 & 2.66 \\
\hline
\end{tabular}

SUMMARY OF MAXIMUM AND MINIMUM CONCENTRATIONS OF CONSTITUENTS SAMPLED AT A FREQUENCY OF QUARTERLY (1975 WY)

11152500 -- SALINAS RIVER NR SPRECKELS CALIF

\begin{tabular}{|c|c|c|c|c|c|c|}
\hline \multirow{2}{*}{ CONSTI TUENT } & \multicolumn{3}{|c|}{ TOTAL } & \multicolumn{3}{|c|}{ DISSOLVED } \\
\hline & $\begin{array}{l}\text { NO. } \\
\text { SAMPLES }\end{array}$ & $\begin{array}{l}\text { MIN IMUM } \\
\text { CONC. }\end{array}$ & $\begin{array}{l}\text { MAXIMUM } \\
\text { CONC. }\end{array}$ & $\begin{array}{l}\text { NO. } \\
\text { SAMPLES }\end{array}$ & $\begin{array}{l}\text { MINIMUM } \\
\text { CONC. }\end{array}$ & $\begin{array}{l}\text { MAXIMUM } \\
\text { CONC. }\end{array}$ \\
\hline \multicolumn{7}{|l|}{ MINOR ELEMENTS: } \\
\hline $\begin{array}{l}\text { ARSENIC (AS), UG/L } \\
\text { CADMIUM (CD): UG }\end{array}$ & 4 & 2 & $\begin{array}{r}220 \\
20\end{array}$ & 4 & 2 & 3 \\
\hline $\begin{array}{l}\text { CADMIUM (CD), UG/L } \\
\text { CHROMIUM (CR), UG/L }\end{array}$ & $\begin{array}{l}3 \\
4\end{array}$ & $<\begin{array}{r}10 \\
0\end{array}$ & $\begin{array}{r}20 \\
1100\end{array}$ & $\begin{array}{l}4 \\
3\end{array}$ & $\begin{array}{l}0 \\
0\end{array}$ & $\begin{array}{l}1 \\
0\end{array}$ \\
\hline COBALT $(C O), U G / L$ & 4 & $<50$ & 450 & 4 & 0 & 0 \\
\hline COPPER (CU), UG/L & 4 & $<10$ & 820 & 4 & 2 & 80 \\
\hline IRON $(F E), U G / L$ & 3 & 440 & 2600 & 3 & 20 & 40 \\
\hline LEAD $(P B), U G / L$ & 4 & $<100$ & 300 & 4 & 0 & 2 \\
\hline MANGANESE (MN), UG/L & 3 & 30 & 240 & 3 & 0 & 170 \\
\hline MERCURY (HG), UG/L & 4 & 0.0 & 1.0 & 4 & 0.0 & 0.1 \\
\hline SELENIUM (SE), UG/L & 3 & 0 & 2 & 3 & 0 & 2 \\
\hline ZINC $(Z N), U G / L$ & 4 & 30 & 1600 & 4 & 0 & 40 \\
\hline \multicolumn{7}{|l|}{ PERIPHYTON: } \\
\hline BIOMASS, DRY WT., G/SQ M & 2 & 5.39 & 10.00 & & & \\
\hline BIOMASS, ASH WT., G/SQ M & 2 & 4.59 & 5.50 & & & \\
\hline CHLOROPHYLL A, MG/SQ M & 2 & 25.0 & 79.0 & & & \\
\hline CHLOROPHYLL B, MG/SQ M & 2 & 3.1 & 31.0 & & & \\
\hline ORGANIC CARBON, MG/L & 3 & 6.5 & 320.0 & & & \\
\hline
\end{tabular}


Table 14.--Summary of measurement at each station--Continued

LAT 36D59M53S LONG $119042 M 11 S$

DRAINAGE AREA:

PERIOD OF RECORD:

$10 / 01 / 74-09 / 30 / 75$

SO KM)

STATISTICAL SUMMARY OF SELECTED DISSOLVED CHEMICAL CONSTITUENTS AND

REGRESSION RELATIONSHIPS OF CONSTITUENT CONCENTRATIONS TO SPECIFIC CONDUCTANCE

CONSIIUENI

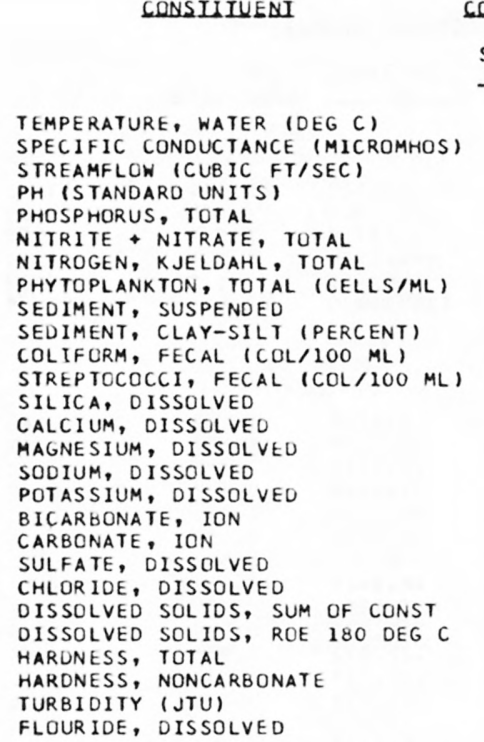

GONSILUENII IMG $\angle L$ OR UNII_SHOWNI

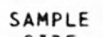

SIZE

MEAN

STANDARD

EEYIAIION

11
11
12
11
11
11
11
11
8
8
9
10
4
4
4
4
4
4
4
4
4
4
4
4
4
4
4

15.27

29.6

2601.7

7.02
0.020

0.020
0.022

0.022
0.216

0.216
9058.1

9058.1

2.9
79.5

79.5
4.3

4.3
2.6

8.62

3.45

0.62
2.75

2.75
0.62

0.62
15.3

0.0

1.37
2.52

2.52

27.5

27.0

27.0
11.3

1.0

2.0
0.07

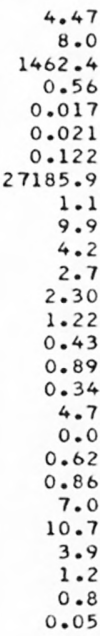

$\begin{array}{rrr}10.0 & 23.0 & \\ 22 & 45 & \\ 260 & 4450 & 11 \\ 5.6 & 7.6 & 11 \\ 0.00 & 0.06 & 11 \\ 0.00 & 0.06 & 11 \\ 0.11 & 0.44 & 11 \\ 29 & 91000 & 11\end{array}$
SAMPLE COEFICIENT, CONSTANT, BEG

*Not significant at the 95 percent confidence level.
BANGE CORRELATION SIZE

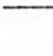

$\begin{array}{rrrr}34.631 & 1414.565 & 0.195 * & 1466.2 \\ 0.0039 & 6.9034 & 0.055 * & 0.59 \\ 0.00067 & 0.00004 & 0.322 * & 0.017 \\ 0.00153 & -0.02354 & 0.585 * & 0.018 \\ 0.00283 & 0.13257 & 0.185 * & 0.127 \\ -815.121 & 33215.289 & -0.240 * & 27821.4\end{array}$

2.1188

0.2169

0.0945

0.0064

0.0819
0.0227

0.000

$-0.0340$

0.0285

0.641

0.975

0.270

$-0.055$

0.049
0.0003

0.0658

0.49

0.88

0.52

0.30

0.30
0.985 .

0.809 *
0.157 *

0.961 *

0.695 .

0.976

0.000

$-0.574$

0.347 *

0.961

$0.950 *$

0.729

$-0.498 *$

0.627 *

0.004 .
STANDARD
ERROR OF ESIIMAIE

0.0

0.1

SUMMARY OF MAXIMUM AND MINIMUM CONCENTRATIONS OF CONSTITUENTS SAMPLED AT A FREQUENCY OF QUARTERLY (1975 WY)

$11250000-$ FRIANT-KERN CANAL AT FRIANT CALIF

\begin{tabular}{|c|c|c|c|c|c|c|}
\hline \multirow{2}{*}{ CONSTI TUENT } & \multicolumn{3}{|c|}{ TOTAL } & \multicolumn{3}{|c|}{ DISSOLVEO } \\
\hline & $\begin{array}{l}\text { NO. } \\
\text { SAMPLES }\end{array}$ & $\begin{array}{l}\text { MIN IMUM } \\
\text { CONC. }\end{array}$ & $\begin{array}{l}\text { MAXIMUM } \\
\text { CONC. }\end{array}$ & $\begin{array}{l}\text { NO. } \\
\text { SAMPLES }\end{array}$ & $\begin{array}{l}\text { MINIMUM } \\
\text { CONC. }\end{array}$ & $\begin{array}{l}\text { MAXIMUM } \\
\text { CONC. }\end{array}$ \\
\hline \multicolumn{7}{|l|}{ MINOR ELEMENTS: } \\
\hline ARSENIC (AS), UG/L & 4 & 1 & 7 & 4 & 1 & 4 \\
\hline CADMIUM $(C D), U G / L$ & 4 & $<10$ & $<10$ & 4 & 0 & 1 \\
\hline CHROMIUM (CR), UG/L & 4 & 0 & 0 & 4 & 0 & 0 \\
\hline COBALT $(C O), U G / L$ & 4 & $<50$ & $<50$ & 4 & 0 & 2 \\
\hline COPPER (CU), UG/L & 4 & $<10$ & 1600 & 4 & 2 & 4 \\
\hline IRON $(F E), U G / L$ & 4 & 80 & 250 & 4 & 10 & 80 \\
\hline LEAD $(P B), U G / L$ & 4 & $<100$ & $<100$ & 4 & 1 & 7 \\
\hline MANGANESE (MN), UG/L & 4 & 0 & 10 & 4 & 0 & 5 \\
\hline MERCURY (HG), UG/L & 4 & 0.0 & 1.1 & 4 & 0.0 & 0.2 \\
\hline SELENIUM (SE), UG/L & 3 & 0 & 1 & 4 & 0 & 1 \\
\hline ZINC $(Z N), U G / L$ & 4 & 30 & 60 & 4 & 0 & 20 \\
\hline \multicolumn{7}{|l|}{ PERIPHYTON: } \\
\hline BIOMASS, DRY WT., G/SQ M & 1 & 19.00 & & & & \\
\hline BIOMASS, ASH WT., G/SO M & 1 & 6.19 & & & & \\
\hline CHLOROPHYLL $A, M G / S O M$ & 1 & 9.0 & & & & \\
\hline CHLOROPHYLL B, MG/SQ M & 1 & .2 & & & & \\
\hline ORGANIC CARBON, MG/L & 3 & 1.7 & 6.3 & & & \\
\hline
\end{tabular}


Table 14.--Sumnary of measurement at each station--Continued

LAT $37040 M 34 S$ LONG $121015 M 515$ DRAINAGE AREA: 13536 SO MI ( 35058 SO KM)

PERIOD OF RECORD: $10 / 01 / 74-09 / 30 / 75$

STATISTICAL SUMMARY OF SELECTED DISSOLVED CHEMICAL CONSTITUENTS AND REGRESSION RELATIONSHIPS OF CONSTITUENT CONCENTRATIONS TO SPECIFIC CONDUCTANCE

CONSIULENI

CONSIUIUENT IMGLL OB UNII SHOWNI

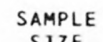

SLEE

TEMPERATURE, WATER (DEG C) SPECIFIC CONDUCTANCE (MICROMHOS) STREAMFLOW (CUBIC FT/SEC)

PH (STANDARD UNITS)

PHOSPHORUS, TOTAL

NITRITE + NITRATE, TOTAL

NITROGEN, KJELDAHL, TOTAL

PHYTOPLANKTON, TOTAL (CELLS/ML)

SEDIMENT, SUSPENDED

SEDIMENT, CLAY-SILT (PERCENT)

COLIFURM, FECAL ( $\mathrm{COL} / 100 \mathrm{ML}$ )

STREPTOCOCCI, FECAL (COL/100 ML)

SILICA, DISSOLVED

CALCIUM, DISSOLVED

MAGNESIUM, DI SSOL VED

SODIUM, DISSOLVED

POTAS SIUM, DISSOLVED

BICARBONATE, ION

CARBONATE, ION

SULFATE, DISSOLVED

CHLORIDE, DISSOLVED

DISSOLVED SOLIDS, SUM OF CONST

DISSOLVED SOLIDS, ROE 180 DEG

HARDNESS, TOTAL

HARDNESS, NONCARBONATE

TURBIDITY (JTU)

FLOURIDE, DISSOLVED

$\begin{array}{rrrr}381 & 15.47 & 4.97 & 7.5 \\ 13 & 517.4 & 221.6 & 187 \\ 381 & 3884.9 & 1709.6 & 1340 \\ 13 & 7.87 & 0.27 & 7.4 \\ 12 & 0.224 & 0.087 & 0.12 \\ 12 & 0.812 & 0.277 & 0.14 \\ 12 & 0.793 & 0.379 & 0.42 \\ 13 & 22484.6 & 33723.6 & 2300 \\ 377 & 102.4 & 43.0 & 28 \\ 26 & 74.5 & 15.3 & 51 \\ 12 & 1691.5 & 3898.0 & 48 \\ 12 & 1542.6 & 3933.4 & 21 \\ 4 & 15.75 & 2.63 & 12.0 \\ 4 & 33.50 & 6.61 & 20.0 \\ 4 & 15.00 & 4.69 & 10.0 \\ 4 & 70.25 & 19.65 & 45.0 \\ 4 & 3.10 & 1.11 & 1.8 \\ 4 & 124.0 & 31.9 & 95 \\ 4 & 0.0 & 0.0 & 0 \\ 4 & 64.75 & 18.01 & 39.0 \\ 4 & 94.75 & 34.79 & 56.0 \\ 4 & 358.3 & 93.7 & 241 \\ 4 & 367.0 & 95.9 & 245 \\ 4 & 145.0 & 34.2 & 110 \\ 4 & 43.8 & 9.4 & 32 \\ 374 & 21.7 & 13.3 & 7 \\ 4 & 0.10 & 0.00 & 0.1\end{array}$

STANDARD

0.00

*Not significant at the 95 percent confidence level.

\section{DURAIION IABLE OF DALY SPECIEIC CONDUCIANCE}

DAILY SPECIFIC CONDUCTANCE IN

MICROMHOS AT 25 DEG C, THAT WAS

EQUALLED OR EXCEEDED FOR THE

$\begin{array}{lllll}18 & 5 z & 10 z & 208 & 30 z \\ 834 & 791 & 751 & 653 & 571\end{array}$

$50 \%$ 708

INDICATED PERCENTAGE OF TIME

834

\begin{tabular}{|c|c|c|c|c|c|}
\hline & & & & & STANDARD \\
\hline & HARMONIC & AMPLITUDE & PHASE & VAR IATION & ERROR OF \\
\hline SAMPLE & MEAN - $M$ & $-A$ & ANGLE - C & EXPLAINED & ESTIMATE \\
\hline SIZE & (DEG C) & LEE C) & (RADIANS) & $-(x)$ & DEE C) \\
\hline 364 & 15.46 & 6.82 & 2.67 & 94 & 1.19 \\
\hline
\end{tabular}

SUMMARY OF MAXIMUM AND MINIMUM CONCENTRATIONS OF CONSTITUENTS

SAMPLED AT A FREQUENCY OF QUARTERLY (1975 WY

11303500 - SAN JOAQUIN RIVER NEAR VERNALIS CALIF

\begin{tabular}{|c|c|c|c|c|c|c|}
\hline \multirow{2}{*}{ CONSTITUENT } & \multicolumn{3}{|c|}{ TOTAL } & \multicolumn{3}{|c|}{ DISSOLVED } \\
\hline & $\begin{array}{l}\text { NO. } \\
\text { SAMPLES }\end{array}$ & $\begin{array}{l}\text { MIN IMUM } \\
\text { CONC. }\end{array}$ & $\begin{array}{l}\text { MAXIMUM } \\
\text { CONC. }\end{array}$ & $\begin{array}{c}\text { NO. } \\
\text { SAMPLES }\end{array}$ & $\begin{array}{c}\text { MINIMUM } \\
\text { CONC. }\end{array}$ & $\begin{array}{l}\text { MAXIMUM } \\
\text { CONC. }\end{array}$ \\
\hline \multicolumn{7}{|l|}{ MINOR ELEMENTS: } \\
\hline ARSENIC (AS), UG/L & 4 & 2 & 8 & 4 & 1 & 4 \\
\hline CADM IUM $(C D), U G / L$ & 4 & $<10$ & $<10$ & 4 & 0 & 1 \\
\hline CHROMIUM (CR), UG/L & 4 & 0 & 20 & 4 & 0 & 0 \\
\hline COBALT $(C O), U G / L$ & 4 & $<50$ & 50 & 4 & 0 & 1 \\
\hline COPPER $(C U), U G / L$ & 4 & $<10$ & 2300 & 4 & 5 & $<10$ \\
\hline IRON (FE), UG/L & 4 & 1800 & 6100 & 4 & 10 & 50 \\
\hline$L E A D(P B), U G / L$ & 4 & $<100$ & 100 & 4 & 1 & 6 \\
\hline MANGANESE $(M N), U G / L$ & 4 & 110 & 390 & 4 & 10 & 40 \\
\hline MERCURY (HG), UG/L & 4 & 0.1 & 0.1 & 4 & 0.0 & 0.1 \\
\hline SELENIUM (SE), UG/L & 4 & 0 & 1 & 4 & 0 & 1 \\
\hline$Z I N C(Z N), U G / L$ & 4 & 40 & 70 & 4 & 10 & 50 \\
\hline \multicolumn{7}{|l|}{ PERIPHYTON: } \\
\hline BIOMASS, DRY WT., G/SQ M & 3 & 15.00 & 110.00 & & & \\
\hline BIOMASS, ASH WT., G/SO M & 3 & 12.00 & 95.00 & & & \\
\hline CHLOROPHYLL A, MG/SG M & 2 & 13.0 & 30.0 & & & \\
\hline CHLOROPHYLL B, MG/SQ M & 2 & .5 & 1.0 & & & \\
\hline ORGANIC CARBON, MG/L & 3 & 4.0 & 11.0 & & & \\
\hline
\end{tabular}


Table 14.--Sumary of measurement at each station--Continued

LAT $38009 M 31 S$ LONG $121018 M 09 S$

DRAINAGE AREA: 661 SQ MI ( 1712 SQ KM)

PERIOD OF RECORD: $10 / 01 / 74-09 / 30 / 75$

STATISTICAL SUMMARY OF SELECTED DISSOLVED CHEMICAL CONSTITUENTS AND

REGRESSION RELATIONSHIPS OF CONSTITUENT CONCENTRATIONS TO SPECIFIC CONDUCTANCE

CONSIIUENI

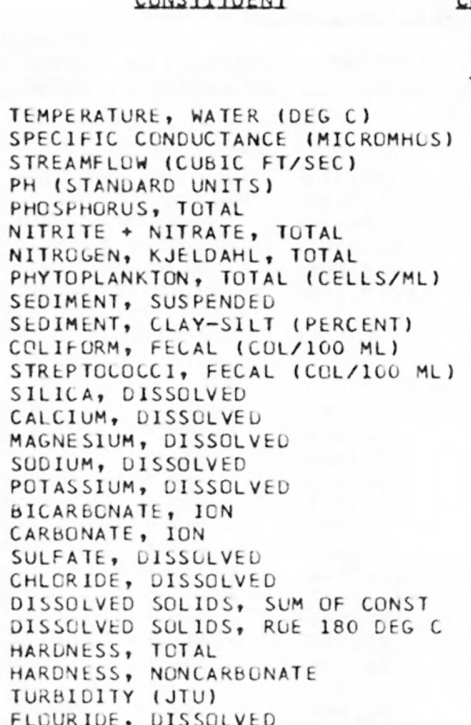

CONSILUUENI IMG/L_OB UNII SHOWNI

\begin{tabular}{c} 
SAMPLE \\
S1ZE \\
\hline 24 \\
22 \\
24 \\
24 \\
12 \\
12 \\
12 \\
12 \\
11 \\
8 \\
12 \\
12 \\
4 \\
6 \\
4 \\
6 \\
4 \\
6 \\
4 \\
4 \\
6 \\
4 \\
6 \\
6 \\
6 \\
6 \\
4
\end{tabular}

STEANDARO
DEYIAIION

14.13

45.3

47.2
7.08

0.022

0.051

0.259

982.5

9.4
43.5

43.5

237.7

725.1
10.30

4.57

1.25

2.42

0.77

22.8

0.0

2.57
2.05

2.05
36.0

36.0
31.8

16.7

0.0

0.02

3.38
4.6
301.3
0.20
0.017
0.105
0.246
1060.9
8.6
46.7
435.5
1718.1
1.16
0.27
0.24
0.12
0.10
3.0
0.0
0.40
0.36
1.8
4.0
1.4
0.0
1.7
0.05

DURAIION IABLE OE DAILY SPECIEIC CONDUCIANCE DAILY SPECIFIC CONDUCTANCE IN MICROMHOS AT 25 DEL COTHAT IN

MICROMHOS AT 25 DEG C, THAT WAS

INDICATED PERCENTAGE OF TIME

$\begin{array}{rr}-16 & -5 \\ 71 & 4\end{array}$

SUMMARY OF HARMUNIC ANALYSIS OF STREAM TEMPERATURE

\begin{tabular}{|c|c|c|c|c|c|}
\hline & & & & & STANDARD \\
\hline & HARMONIC & AMPLITUDE & PHASE & VARIATION & ERROR OF \\
\hline SAMPLE & MEAN - M & $-A$ & ANGLE - C & EXPLAINED & ESTIMATE \\
\hline SIZE_ & 10EG 61 & SDEG CL & IBAQIADSI & $-(\approx)$ & $10 E 6$ (1) \\
\hline 24 & 14.13 & 4.48 & 2.56 & 87 & 1.28 \\
\hline
\end{tabular}

BANGE

8.5
38

BEGRESS ION SUMMABY

REGRESSION SAMPLE COEFICIENT, CONSTANT, CORRELATION SIZE R. COEEICIENI

$22-7.445$ 0.0003 0.00099 0.01101 0.02403 $\begin{array}{r}17.901 \\ \hline\end{array}$

$$
\begin{array}{r}
823.592 \\
7.0831 \\
-0.02355 \\
-0.44740 \\
-0.82312
\end{array}
$$
$-120.645$

-0.115 * 0.006 0.342 * $0.620 *$ 0.586 * 0.334 *

305.5 0.011 0.095 0.22 345.3

0
12
16
9.4
4.1
0.9
2.3
0.7
19
0
2.1
1.7
34
25
15
0
0
0.0

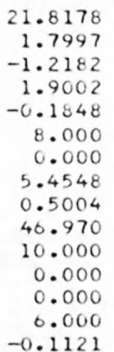

-0.030 .

0.695 .

0.658 *

0.036 *

0.331 .

0.331.

$-0.453^{\circ}$

0.290 .

$-0.381 *$

$0.367 *$

0.815

$0.000 *$

$-0.102 *$

$0.174 *$

\begin{tabular}{|c|c|c|c|c|c|c|}
\hline \multirow{2}{*}{ CONSTITUENT } & \multicolumn{3}{|c|}{ TOTAL } & \multicolumn{3}{|c|}{ DISSOLVED } \\
\hline & $\begin{array}{l}\text { NO. } \\
\text { SAMPLES }\end{array}$ & $\begin{array}{l}\text { MINIMUM } \\
\text { CONC. }\end{array}$ & $\begin{array}{l}\text { MAXIMUM } \\
\text { CONC. }\end{array}$ & $\begin{array}{l}\text { NO. } \\
\text { SAMPLES }\end{array}$ & $\begin{array}{l}\text { MINIMUM } \\
\text { CONC. }\end{array}$ & $\begin{array}{l}\text { MAXIMUM } \\
\text { CONC. }\end{array}$ \\
\hline \multicolumn{7}{|l|}{ MINOR ELEMENTS: } \\
\hline ARSENIC (AS), UG/L & 4 & 0 & 1 & 4 & 0 & 1 \\
\hline CADMIUM $(C D), U G / L$ & 4 & $<10$ & 30 & 4 & 0 & 1 \\
\hline CHROMIUM (CR), UG/L & 4 & 0 & 20 & 4 & 0 & 10 \\
\hline COBALT $(C O), U G / L$ & 4 & $<50$ & $<50$ & 4 & 0 & 0 \\
\hline COPPER $(C U), U G / L$ & 4 & 0 & 40 & 4 & 1 & 6 \\
\hline IRON $(F E), U G / L$ & 4 & 190 & 320 & 4 & 10 & 50 \\
\hline LEAD $(P B), U G / L$ & 4 & $<100$ & 100 & 4 & 3 & 23 \\
\hline MANG ANESE (MN), UG/L & 4 & 10 & 280 & 4 & 0 & 0 \\
\hline MERCURY $(H G), U G / L$ & 3 & 0.0 & 0.3 & 4 & 0.0 & 0.1 \\
\hline SELENIUM (SE), UG/L & 4 & 0 & 0 & 4 & 0 & 0 \\
\hline ZINC $(Z N), U G / L$ & 4 & 30 & 100 & 4 & 10 & 40 \\
\hline \multicolumn{7}{|l|}{ PERIPHYTON: } \\
\hline BIOMASS, ORY WT., G/SQ M & 3 & 5.79 & 27.00 & & & \\
\hline BIOMASS, ASH WT., G/SOM & 3 & 3.39 & 10.00 & & & \\
\hline CHLGROPHYLL A, MG/SQ M & 3 & 1.7 & 6.0 & & & \\
\hline CHLOROPHYLL B, MG/SO M & 3 & .2 & 1.0 & & & \\
\hline ORGANIC CARBON, MG/L & 4 & 1.6 & 3.0 & & & \\
\hline
\end{tabular}

11325500 -- MOKELUMNE RIVER AT WOODBRIDGE CALIF 
Table 14.--Sumary of measurement at each station--Continued

LAT 38D27M2OS LONG 121030 MOTS

DRAINAGE AREA: 0 SQ MI

PERIOD OF RECORD: $10 / 01 / 74-09 / 30 / 75$ O SO KM)

STATISTICAL SUMMARY OF SELECTED DISSOLVED CHEMICAL CONSTITUENTS AND

REGRESSION RELATIONSHIPS OF CONSTITUENT CONCENTRATIONS TO SPECIFIC CONDUCTANCE

CUNSILIUENI

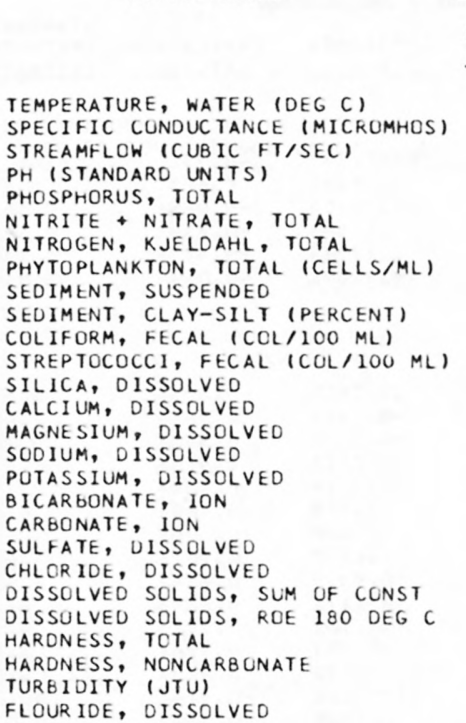

CONSIUIUENI IMGLL OB_UNII_SHOWNI

\begin{tabular}{rrr}
$\begin{array}{rrr}\text { SAMPLE } \\
\text { SIZE }\end{array}$ & MEAN & \multicolumn{1}{r}{ STANDARD } \\
\cline { 1 - 1 } & & \\
15 & 15.63 & 4.52 \\
15 & 118.9 & 31.0 \\
15 & 11.9 \\
14 & 28842.9 & 11591.0 \\
15 & 7.01 & 0.42 \\
12 & 0.120 & 0.068 \\
12 & 0.082 & 0.053 \\
11 & 0.335 & 0.180 \\
12 & 1845.0 & 993.2 \\
12 & 100.8 & 129.4 \\
11 & 83.5 & 3.8 \\
11 & 193.4 & 353.0 \\
11 & 94.3 & 126.0 \\
4 & 16.75 & 1.50 \\
4 & 10.42 & 0.68 \\
4 & 5.17 & 1.03 \\
4 & 7.72 & 2.24 \\
4 & 1.22 & 0.29 \\
4 & 59.5 & 8.0 \\
2 & 0.0 & 0.0 \\
4 & 6.72 & 1.38 \\
4 & 4.42 & 1.33 \\
4 & 81.8 & 10.2 \\
4 & 82.0 & 12.8 \\
4 & 47.3 & 5.9 \\
4 & 1.3 & 2.5 \\
4 & 12.0 & 7.1 \\
4 & 0.10 & 0.00
\end{tabular}

BEGBESSION_SUMMABY

REGRESSION

SAMPLE COEFICIENT, CONSTANT, CORRELATION ERTANDARD SIZE - B

$\begin{array}{rrr}8.0 & 20.5 & \\ 43 & 169 & \\ 18900 & 54200 & 14 \\ 6.5 & 7.8 & 15 \\ 0.06 & 0.32 & 12 \\ 0.00 & 0.21 & 12 \\ 0.16 & 0.81 & 11 \\ 500 & 3300 & 12 \\ 20 & 381 & \\ 78 & 90 & \\ 20 & 1250 & \\ 9 & 450 & \\ 15.0 & 18.0 & 4 \\ 9.7 & 11.0 & 4 \\ 4.1 & 0.5 & 4 \\ 6.0 & 11.0 & 4 \\ 1.0 & 1.6 & 4 \\ 54 & 71 & 4 \\ 0 & 0 & \\ 5.4 & 8.4 & 4 \\ 3.5 & 6.4 & 4 \\ 75 & 97 & 4 \\ 74 & 101 & 4 \\ 41 & 54 & 4 \\ 0 & 5 & 4 \\ 3 & 19 & 4 \\ 0.1 & 0.1 & 4 \\ & & \end{array}$
DURALION IABLE OE DAILY SPECIELC CONDUCIANCE DAILY SPECIFIC CONDUCTANCE IN MICROMHOS AT 25 DEG C, THAT WAS EQUALLED UR EXCEEDED FOR THE

\begin{tabular}{|c|c|c|c|c|}
\hline 18 & $5 \pi$ & $20 \Omega$ & $20 \%$ & $30 z$ \\
\hline 199 & 192 & 186 & 166 & 145 \\
\hline \multicolumn{5}{|c|}{ 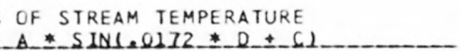 } \\
\hline \multirow{2}{*}{\multicolumn{2}{|c|}{ PHASE }} & \multicolumn{3}{|c|}{ STAND ARD } \\
\hline & & VARIATION & & \\
\hline \multirow{2}{*}{\multicolumn{2}{|c|}{$\begin{array}{l}\text { ANGLE }-C \\
\text { (RADIANSI }\end{array}$}} & EXPLAINED & \multirow{2}{*}{\multicolumn{2}{|c|}{$\begin{array}{l}\text { ESTIMATE } \\
\text { IDEG CI }\end{array}$}} \\
\hline & & . (8) & & \\
\hline
\end{tabular}
SUMMARY OF HARMONIC ANALYSIS OF STREAM TEMPERATURE

\begin{tabular}{|c|c|c|c|c|c|}
\hline & & & & & STANDA \\
\hline & HARMONIC & AMPLI TUDE & PHASE & VARIATION & $\begin{array}{l}\text { ERROR OF } \\
\text { ESIMAIE }\end{array}$ \\
\hline SAMPLE & $M E A N-M$ & $-A$ & ANGLE $-C$ & EXPLAINED & $\begin{array}{l}\text { ESTIMATE } \\
\text { IDEG CI }\end{array}$ \\
\hline SIZE_ & INEG $61_{-}$ & - $D E E G$. & (BAD $\perp A N S)$ & $-(8)$ & \\
\hline
\end{tabular}
13
14.80
6.18
2.64
97
0.88

SUMMARY OF MAXIMUM AND MINIMUM CONCENTRATIONS OF CONSTITUENTS SAMPLED AT A FREQUENCY OF QUARTERLY (1975 WY)

11447650 -- SACRAMENTO RIVER AT FREEPORT CALIF

CONSTI TUENT


LAT 38030M31S LONG 122055M36S

1338 SQ MI 1 3465 SQ KMI
PERIOD OF RECORD: $10 / 01 / 74-09 / 30 / 75$

STATISTICAL SUMMARY OF SELECTED DISSOLVED CHEMICAL CONSTITUENTS ANO

REGRESSION RELATIONSHIPS OF CONSTITUENT CONCENTRATIONS TO SPECIFIC CONDUCTANCE

CONSIIIUENI

\begin{tabular}{|c|}
\hline $\begin{array}{l}\text { TEMPERATURE, WATER (DEG C) } \\
\text { SPECIFIC CONDUCTANCE (MICROMHCS) } \\
\text { STREAMFLOW (CUBIC FT/SEC) } \\
\text { PH (STANDARD UNITS) } \\
\text { PHUSPHORUS, TOTAL } \\
\text { NITRIIE, NITRATE, TUTAL } \\
\text { NITROGEN, KJELDAHL, TOTAL } \\
\text { PHYTOPLANKTON, TOTAL (CELLS/ML) } \\
\text { SEDIMENT, SUSPENDED } \\
\text { SEDIMENT, CLAY-SILY (PERCENT) } \\
\text { COLIFORM, FECAL (COL/IOO ML) } \\
\text { STREPTOCOCCI, FECAL (COL/IOO ML) } \\
\text { SILICA, DISSOLVED } \\
\text { CALCIUM, DISSOLVED } \\
\text { MAGNESIUM, DISSOLVEU } \\
\text { SODIUM, OISSOLVE } \\
\text { POTASSIUM, DISSOLVED } \\
\text { BICARBONATE, ION } \\
\text { CAREONATE, ION } \\
\text { SULFATE, DISSOLVED } \\
\text { CHLCRIDE, DISSOLVED } \\
\text { DISSOLVED SOLIDS, SUM OF CONST } \\
\text { DISSOLVED SOLIDS, ROE I8O DEG C } \\
\text { HARONESS, TOTAL } \\
\text { HARDNESS, NONCARBONATE } \\
\text { TURBIDITY (JTU) } \\
\text { FLUURIDE, DISSOLVED }\end{array}$ \\
\hline
\end{tabular}

CONSIIIUENI IMG/L OR UNII SHOWNI

SAMPLE SIZE

STANDARD
MEAN DEVIAIUON
15.22
222.5
8934.9

7.69
7.636

7.69
0.236

0.266

0.559

4165.0

211.8

80.1

121.3

224.8

14.00

21.00

10.88

9.36

1.67
120.4

120.4
0.0

10.67

6.24

136.3

142.6

4.6
69.2
5.31 58.3

13865.2

0.30

0.132

0.184

0.333

3214.9

365.2

8.1
240.3

565.1

0.82

6.07

3.38

2.68

0.39

32.6

0.0
2.67

2.51

27.1

31.7
28.5

3.2

121.9

0.00

8.5
103
152

0.23

490
5

65
3

13.0

10.0

5.8

4.6
1.3

1.3
56

6.9

.4
96

96
83

49
2

0.1
BEGRESSION SUMMARY SAMPLE COEFICIENT, CONSTANT, SIZE B CONSTANT,

ORRELATION 25.0 280
6800
8.2
0.52
0.64
1.40
9400
1920
98
840
2000
15.0
28.0
14.0
13.0
2.2
15

14.0
9.
15
19
13
11
60
0.1

* Not significant at the 95 percent confidence level.

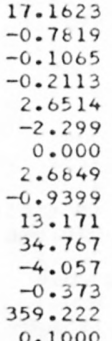

$-0.835 *$

$0.985 *$

$0.983 *$

-0.808 .

$0.988 *$

$0.000 *$

0.907 *

0.874 *

$0.979 *$

0.992 *

$0.996 *$

$-0.914$

$\begin{array}{rrrrr}16 & -109.640 & 28485.352 & -0.732 & 6146.3 \\ 16 & 0.0032 & 0.9891 & 0.608 & 0.25 \\ 12 & -0.00067 & 0.25059 & -0.028 * & 0.138 \\ 12 & -0.00079 & 0.44486 & -0.239 * & 0.188 \\ 12 & -0.00284 & 1.19945 & -0.473 * & 0.308 \\ 12 & -3.419 & 4936.891 & -0.059 * & 3365.9\end{array}$

STANDARD ESIUMAIE

DURAIION IABLE OE OAIYY SPECIEIC CONOUCIANCE

DAILY SPECIFIC CONDUCTANCE IN

MICROMHOS AT 25 DEG C, THAT WAS

EQUALLED OR EXCEEDED FOR THE

$\begin{array}{llllll}2 & 5 \% & 20 \% & 20 \% & 30 \%\end{array}$

502709

SAMPLE_SIZE_E_-280

INUICATED PERCENTAGE OF TIME

320

305

$290 \quad 280$

275

260

240

SUMMARY OF TARMONIC ANALYSIS OF STREAM TEMPERATURE

\begin{tabular}{|c|c|c|c|c|c|}
\hline & & & & & STANDARD \\
\hline & HARMONIC & AMPLITUDE & PHASE & VARIATION & ERROR OF \\
\hline SAMPLE & MEAN - M & $-A$ & ANGLE - C & EXPLAINED & ESTIMATE \\
\hline SIZE & LEE 61 & NOEG $(1)$ & (BADIANS) & $-(3)$ & $10 E G_{C}(1)$ \\
\hline 64 & 16.42 & 7.46 & 2.64 & 92 & 1.68 \\
\hline
\end{tabular}

SUMMARY OF MAXIMUM AND MINIMUM CONCENTRATIONS CF CONSTITUENTS SAMPLED AT A FREQUENCY OF QUARTERLY (1975 WY)

$11467000--$ RUSSIAN RIVER NR GUERNEVILLE CALIF

CONSTI TUENT
SAMPLES


Table 14.--Sumnary of measurement at each station--Continued

LAT $41030 M 45 S$ LONG $123058 M 30 S$

DRAINAGE AREA: 12100 SQ MI 131339 SO KMI

PERIOD OF RECORD: $10 / 01 / 74-09 / 30 / 75$

STATISTICAL SUMMARY OF SELECTED DISSOLVEO CHEMICAL CONSTITUENTS AND

REGRESSION RELATIONSHIPS OF CONSTITUENT CONCENTRATIONS TO SPECIFIC CONDUCTANCE

CONSILIUENI

CONSIUUUENI IMG/L OB UNII SHOWN

SAMPLE

SIZE

TEMPERATURE, WATER (DEG C) SPECIFIC CONDUCTANCE (MICROMHOS) STREAMFLOW (CUBIC FT/SEC)

PH ISTANDARD UNITSI

PHOSPHORUS, TOTAL

NITRITE + NITRATE, TOTAL

NITROGEN, KJELDAHL, TOTAL

PHYTOPLANKTON, TOTAL (CELLS/ML)

SEDIMENT, SUSPENDED

SEUIMENT, CLAY-SILT (PERCENT)

COLIFORM, FECAL ( $\mathrm{CCL} / 100 \mathrm{ML}$ )

STREPTOCOCC 1 , FECAL (COL/100 ML)

SILICA, DISSOLVED

CALCIUM, DISSOLVED

MAGNESIUM, DISSOLVED

SODIUM, DISSOLVED

BICARBONATE, ION

CARBONATE, ION

SULFATE, DISSOLVED

CHLOR IDE, DISSOLVED

DISSOLVED SOLIDS, SUM OF CONST

DISSOLVED SOLIDS, ROE 180 DEG C

HARDNESS, TOTAL

TURBIDITY (JTU)

FLOUR IDE, DISSOLVED
POTASSIUM, DISSOLVED

HARONESS, NONCARBONATE
STANDARD

DEXIAILON

5.46

12.17

12.17
168.2

16475.6

$0.081 \quad 0.032$

0.137

0.411

1993.6

86.3

86.3
43.0

43.0
4.7

4.7
7.4

18.00

18.00

7.46
7.60

7.66
1.26

1.26

0.0
8.8

8.82

4.16

110.8

107.2

75.6

3.6
24.1

24.1
0.08

BANGE
4.0
110
2850
7.1
0.02
0.00
0.19
490
8
43
1
1
14.0
15.0
6.3
3.9
0.9
72
0
5.7
1.8
84
83
63
0
1
0.0

BEGRESSION SUMMARY

REGRESSION

SAMPLE COEFICIENT,

CONSTANT,

CORRELATION

STANDARD

ERROR UF

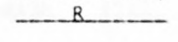

COEEICIENI

ESIIMAIE

*Not significant at the 95 percent confidence level.

DAILY SPECIFIC CONDUCTANG DURALION IABLE OF DAILY SPECIEIC CONOUCIANCE

MAILYOMHOS AT 25 DEG C. THAT IN

MICROMHES AT 25 UEG C, THAT. HAS

EQUALLEO OR EXCEEDED FOR THE
INDICATED PERCENTAGE OF TIME

$\begin{array}{llllll}12 & -58 & 10 z & 20 \% & 30 \% & 50 \% \\ 219 & 215 & 202 & 161 & 149 & 136\end{array}$

23.0
224
43900
8.3
0.12
0.48
0.83
7000
375

20
14
24.0
20.0
9.2
12.0
1.9
114
0
11.0
6.9
139
137
88
14
75
0.1
$-290.927$

0.0052

0.00036

0.00110

0.00413

3.334

6.9363

0.02294

$-0.03693$

$-0.24594$

1463.769

$-0.745$

0.552

0.346 *

$0.192 *$

0.585

$0.058 *$

0.884 *

0.1139

0.0503

0.0364

0.1026

0.0071

0.522

0.000
0.0579

0.0579

0.0234

0.652
0.677

0.280

$-0.079$

$-0.635$

0.0003

$-1.1046$

9.5653

1.3464

$-9.5577$

0.0682

4.172

$-0.8976$

0.2268

1.410

$-6.382$

28.593

16.859

134.410

0.0260

0.793 .

0.875 .

0.809 *

$0.524^{*}$

0.859 *

0.000 .

$0.802 *$

0.371 *

$0.884^{*}$

0.858.

0.887.

$-0.411 *$

-0.771
0.227 *
65187.984
10144.5

0.29

0.032

0.181

952.3

SAMPLE SIZE $=258$

$20 \% \quad 25292 \%$

702

$85-80=00$

SUMMARY OF HARMUNIC ANALYSIS OF STREAM TEMPERATURE

EORM OF EOUAIUON: I.10) = M + A* SINL.0172* D*

\begin{tabular}{|c|c|c|c|c|c|}
\hline & & & & & STANDARD \\
\hline & HARMONIC & AMPLITUDE & PHASE & VARIATION & ERROR OF \\
\hline SAMPLE & MEAN - M & $-A$ & ANGLE - C & EXPLAINED & ESTIMATE \\
\hline SIZE - & COEG 61 & (DEG $C)$ & (BADIANS) & $-(\%)$ & $10 E G(1)$ \\
\hline 21 & 12.83 & 7.29 & 2.54 & 93 & 1.47 \\
\hline
\end{tabular}

SUMMARY UF MAXIMUM AND MINIMUM CONCENTRATIONS OF CONSTITUENTS

SAMPLED AT A FREQUENCY OF QUARTERLY (1975 WY)

11530500 -- KLAMATH RIVER NEAR KLAMATH CALIF

\begin{tabular}{|c|c|c|c|c|c|c|}
\hline \multirow{2}{*}{ CONSTITUENT } & \multicolumn{3}{|c|}{ TOTAL } & \multicolumn{3}{|c|}{ DISSOLVED } \\
\hline & $\begin{array}{l}\text { NO. } \\
\text { SAMPLES }\end{array}$ & $\begin{array}{l}\text { MIN IMUM } \\
\text { CONC. }\end{array}$ & $\begin{array}{l}\text { MAXIMUM } \\
\text { CONC. }\end{array}$ & $\begin{array}{l}\text { NO. } \\
\text { SAMPLES }\end{array}$ & $\begin{array}{l}\text { MINIMUM } \\
\text { CONC. }\end{array}$ & $\begin{array}{l}\text { MAXIMUM } \\
\text { CONC. }\end{array}$ \\
\hline \multicolumn{7}{|l|}{ MINOR ELEMENTS: } \\
\hline ARSENIC (AS), UG/L & 5 & 1 & 4 & 5 & 0 & 4 \\
\hline CADMIUM $(C D), U G / L$ & 5 & $<10$ & 10 & 4 & 0 & 1 \\
\hline CHROMIUM (CR), UG/L & 5 & 0 & 220 & 5 & 0 & 10 \\
\hline COBALT $(C O), U G / L$ & 5 & 0 & $<50$ & 4 & 0 & 2 \\
\hline COPPER $(C U), U G / L$ & 5 & $<10$ & 70 & 4 & 1 & 7 \\
\hline IRUN $(F E), U G / L$ & 5 & 110 & 6900 & 4 & 10 & 90 \\
\hline LEAD $(P B), U G / L$ & 5 & $<100$ & 100 & 4 & 0 & 7 \\
\hline MANGANESE (MN), UG/L & 5 & 30 & 120 & 4 & 0 & 20 \\
\hline MERCURY $(H G), U G / L$ & 5 & 0.0 & 0.2 & 4 & 0.0 & 0.2 \\
\hline SELENIUM $(S E), U G / L$ & 5 & 0 & 1 & 5 & 0 & 0 \\
\hline ZINC $(Z N), U G / L$ & 5 & 20 & 100 & 4 & 0 & 50 \\
\hline \multicolumn{7}{|l|}{ PERIPHYTON: } \\
\hline BIOMASS, ORY WT., G/SQ M & 3 & 1.89 & 8.50 & & & \\
\hline BIOMASS, ASH WT., G/SO M & 3 & 1.39 & 6.19 & & & \\
\hline CHLOROPHYLL A, MG/SQ M & 3 & .0 & 15.0 & & & \\
\hline CHLOROPHYLL $B, M G / S Q M$ & 3 & .0 & 2.8 & & & \\
\hline ORGANIC CARBON, MG/L & 4 & 2.7 & 4.8 & & & \\
\hline
\end{tabular}


Table 14.--Summary of measurement at each station--Continued

STATION NUMBER: 12031000 NAME: CHEHALIS RIVER AT PORTER, WASH.

LAT $46056 M 17 S$ LONG 123018M45S

DRAINAGE AREA: 1294 SQ MI 13351 SO KMI

PERIOD OF RECORD: $10 / 01 / 74-09 / 30 / 75$

STATISTICAL SUMMARY OF SELECTED DISSOLVED CHEMICAL CONSTITUENTS ANU

REGRESSION RELATIONSHIPS OF CONSTITUENT CONCENTRATIONS TO SPECIFIC CONDUCTANCE

CONSLIUENI

CONSILUUENI IMG/L OR UNDI SHOWNL
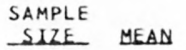

11.50

11.50
83.3

83.3
3121.9

3121.9
7.13

7.13
0.062

0.062
0.411

0.253

1254.8

13.8

13.8
85.8

37.6

44.3

44.3
15.92

7.75

2.24

5.34

0.75

32.8

0.0

3.94
4.97

4.97

$58 \cdot 3$

63.

28.6
2.5
5.1

0.04
DEYIAILON

4.65

16.7
3526.4

3526.4
0.27

0.082

0.193

0.065

1814.7

14.8

9.0

44.8

42.7

1.16
1.88

0.58

1.28

0.23

10.3

0.0

1.04

1.14

10.1
9.8

6.7

2.7

4.5
0.05

TUREIDITY (JTUI

FLOURIDE, DISSOLVEO

*Not significant at the 95 percent confidence 1 evel.

BANGE

$\begin{array}{rr}59 & 11 \\ 314 & 13500\end{array}$

$6.5 \quad 7.6 \quad 35$

0.03

0.06

0.16
58

70

70
1
1

14.0

4.3
1.3

1.3
3.4

0.3

18
0

2.4
3.2

48

17
0

0.0

45
99

99
260
126

$18.0 \quad 12$

$7.9 \quad 30$

$\begin{array}{rr}1.5 & 36 \\ 52 & 36\end{array}$

05

8.2
73
83

$\begin{array}{ll}38 & 36 \\ 12 & 36\end{array}$

$\begin{array}{rr}20 & 36 \\ 0.1 & 12\end{array}$

SUMMARY OF HARMONIC ANALYSIS OF STREAM TEMPERATURE

\begin{tabular}{|c|c|c|c|c|c|}
\hline & & & & & STANDARD \\
\hline & HARMONIC & AMPLITUDE & PHASE & VARIATION & ERROR OF \\
\hline SAMPLE & $M E A N-M$ & $-A$ & ANGLE - C & EXPLAINED & ESTIMATE \\
\hline SILE- & $10 E 6 \mathrm{Cl}_{-}$ & DOEG $C_{1}$ & IBAD IANSI & - $1 \% 1$ & LDEG_CL \\
\hline 35 & 11.57 & 6.26 & 2.63 & 93 & 1.28 \\
\hline
\end{tabular}

BEGRESSION SUMMABY

$\begin{array}{lll} & \text { REGRESSION } & \text { STANDARO } \\ \text { SAMPLE COEFICIENT, CONSTANT, CORRELATION ERROR OF } & \text { CONA } & \text { COEEICIENI ESIIMAII }\end{array}$

0.0054

$-0.00055$

$-0.00296$

$\begin{array}{rrrrrr}0.48 & 35 & 0.00037 & 0.22242 & 0.093^{*} & 0.066 \\ 6400 & 12 & 79.358 & -5140.082 & 0.064 & 1423.3\end{array}$

15868.930

6.6888

0.10797

0.64915

0.22242

$\begin{array}{llllll}6400 & 12 & 79.358 & -5140.082 & 0.064 & 1423.3\end{array}$

$-0.723$

$0.337 *$
$-0.111 *$

-0.233 .

$0.093^{*}$

$\begin{array}{llllll}6400 & 12 & 79.358 & -5140.082 & 0.064 & 1423.3\end{array}$

2470.8

0.25
0.083

0.196

$\begin{array}{rrrrrr}0.48 & 35 & 0.00037 & 0.22242 & 0.093^{*} & 0.066 \\ 6400 & 12 & 79.358 & -5140.082 & 0.064 & 1423.3\end{array}$

11.036

$3.5 \quad 36$

$\begin{array}{ll}7.6 & 36 \\ 8.2 & 36\end{array}$

$83 \quad 11$

0.0626
0.0749
0.0199
0.0585
0.0059
0.444
0.000
0.0207
0.0411
0.413
0.362
0.277
-0.058
-0.139
-0.0000

1.5048

0.580

0.4718

0.2558

$-4.148$

1.545

1.5451

34.365

34.365
5.471

5.471
7.291

16.646

0.0446

0.816

0.665

0.573

0.761

0.428

0.722

0.000 *

0.333

0.604

0.618

0.690

$-0.353$

-0.516
-0.011.

SUMMARY OF MAXIMUM AND MINIMUM CONCENTRATIONS OF CONSTITUENTS SAMPLED AT A FREQUENCY OF QUARTERLY (1975 WY)

12031000 -- CHEHALIS RIVER AT PORTER, WASH.

CONSTITUENT
SAMPLES


Table 14.--Summary of measurement at each station--Continued

LAT 48 DO3MI8S LONG $123034 \mathrm{M} 55 \mathrm{~S}$
DRAINAGE AREA: $269 \mathrm{SQ} \mathrm{MI} \mathrm{(} 697$ SO KM)

PERIOD OF RECORD: $10 / 01 / 74-09 / 30 / 75$

STATISTICAL. SUMMARY OF SELECTED DISSOLVED CHEMICAL CONSTITUENTS AND

REGRESSION RELATIONSHIPS OF CONSTITUENT CONCENTRATIONS TO SPECIFIC CONDUCTANCE

CONSIIIUENI

CONSIUTUENI IMGLL OR UNII SHOWNI

SAMPLE

SIZE

TEMPERATURE, WATER (DEG C)

SPECIFIC CONDUCTANCE (MICROMHOS)

STREAMFLOW (CUBIC FT/SEC)

PH (STANDARD UNITS

PHOSPHORUS, TOTAL

NITRITE + NITRATE, TOTAL

NITROGEN, KJELDAHL, TOTAL

PHYTOPLANKTON, TOTAL (CELLS/ML)

SEDIMENT, SUSPENDED

SEDIMENT, CLAY-SILT (PERCENT)

COLIFORM, FECAL (COL/100 ML)

STREPTOCOCCI, FECAL (COL/100 ML)

SILICA, DISSOLVED

CALCIUM, DISSOLVED

MAGNESIUM, DISSOL VED

SODIUM, DISSOLVED

POTASSIUM, DISSOL VED

BICARBONATE, ION

CARBONATE, ION

SULFATE, DISSOLVED

CHLORIDE, DISSOLVED

DISSOLVED SOLIDS, SUM OF CONST

DISSOLVED SOLIDS, ROE 180 DEG C

HARDNESS, TOTAL

HARDNESS, NONCARBONATE

TURBIDITY (JTU)

FLOURIDE, DISSOLVED

\section{STANDARD}

MEAN DEYIAIION

$\begin{array}{ll}7.26 & 3.31 \\ 86.6 & 16.1\end{array}$

86.6
1505.3

7.20

0.022

0.017

0.107

163.1

6.4

6.4
87.6

87.6
2.3

3.1

5.48

13.83

1.07
2.25

0.27

40.3

40.3
0.0
7.49

7.49
1.02

1.02
51.3

52.2

39.0

6.0

0.05

16.1
729.8

0.30

0.021

0.015

229.2

7.0
7.2

7.2

2.8

5.1
0.72

2.08

0.48

0.36

0.22

7.4

0.0
1.48

1.48
0.51

0.51
8.0

8.9

6.5

2.2
5.6

0.05

3.5
44
6.0
0.00
0.00
0.05
1
7
4.0
11.0
0.0
1.7
0.
2
5.6
0.2
39
35
3
BANGE

$3.5 \quad 14$.

$60 \quad 112$

444
6.8

$\begin{array}{ll}0.00 & 0.08 \\ 0.00 & 0.05\end{array}$

$0.05 \quad 0.20$

850

850
27

96
10
19

19
$6.4 \quad 1$

4.2
11.0

0.3

1.7
0.1
29

29

5.6
0.2

0.2
39

35

2
1
0.0

*Not significant at the 95 percent confidence level.

SUMMARY OF HARMONIC ANALYSIS OF STREAM TEMPERATURE

\begin{tabular}{|c|c|c|c|c|c|}
\hline \multirow{4}{*}{$\begin{array}{l}\text { SAMPLE } \\
\text { SUZE }\end{array}$} & & & & & STANDARD \\
\hline & HARMONIC & AMPLITUDE & PHASE & VARIATION & ERROR OF \\
\hline & MEAN - $M$ & $-A$ & ANGLE - C & EXPLAINED & ESTIMATE \\
\hline & DEEG C) & DEG (1) & IRADLANSI) & -121 & 10EG_C1 \\
\hline 12. & 7.40 & 4.15 & 2.23 & 86 & 1.38 \\
\hline
\end{tabular}

BEGRESSION SUMMABY

$\begin{array}{ll} & \text { REGRESSION } \\ \text { SAMPLE COEFICIENT, CONSTANT, CORRELATION ERROR OFD }\end{array}$

SIZE -B B - B COEEISIENI ESIUMAIE

$17.0 \quad 12 \quad 0.0343$

$1.7 \quad 12 \quad 0.0976$

$3.0 \quad 12 \quad 0.0112$

$\begin{array}{lll}0.8 & 12 & 0.0079\end{array}$

0.0079

0.000

0.000
0.0649

0.0649
0.0043

0.405

0.481

0.321

0.049

0.075
0.0006

$\begin{array}{rrr}2586.489 & -0.276 * & 735.7 \\ 7.1819 & 0.011 * & 0.31 \\ 0.01113 & 0.092 * & 0.022 \\ -0.00875 & 0.329 * & 0.015 \\ 0.02859 & 0.361 * & 0.040 \\ 293.358 & -0.106 * & 239.0\end{array}$

35.7

.022

.040

239.0
0.766

0.756

0.668
0.503.

0.586

0.744

0.000 .

0.707

0.138 .

0.816

0.876

0.796

0.356 .

0.217 .

0.178 .

SUMMARY OF MAXIMUM AND MINIMUM CONCENTRATIONS OF CONSTITUENTS

SAMPLED AT A FREQUENCY OF QUARTERLY (1975 HY)

12045500 - ELWHA RIVER AT MCOONALD BR., NR PORT ANGELES,WA

\begin{tabular}{|c|c|c|c|c|c|c|}
\hline \multirow{2}{*}{ CONSTITUENT } & \multicolumn{3}{|c|}{ TOTAL } & \multicolumn{3}{|c|}{ DISSOLVED } \\
\hline & $\begin{array}{l}\text { NO. } \\
\text { SAMPLES }\end{array}$ & $\begin{array}{l}\text { MIN IMUM } \\
\text { CONC. }\end{array}$ & $\begin{array}{l}\text { MAXIMUM } \\
\text { CONC. }\end{array}$ & $\begin{array}{c}\text { NO. } \\
\text { SAMPLES }\end{array}$ & $\begin{array}{l}\text { MINIMUM } \\
\text { CONC. }\end{array}$ & $\begin{array}{l}\text { MAXIMUM } \\
\text { CONC. }\end{array}$ \\
\hline \multicolumn{7}{|l|}{ MINOR ELEMENTS: } \\
\hline $\begin{array}{l}\text { ARSENIC (AS), UG/L } \\
\text { CADMIUM (CD), UG/L }\end{array}$ & 4 & 0 & 0 & 4 & 0 & 0 \\
\hline $\begin{array}{l}\text { CADM IUM }(C D), U G / L \\
\text { CHROMIUM (CR), UG/L }\end{array}$ & 4 & $<10$ & 20 & 4 & 0 & 1 \\
\hline $\begin{array}{l}\text { CHROMIUM (CR), UG/L } \\
\text { COBALT }(C O), U G / L\end{array}$ & 4 & 0 & 0 & 4 & 0 & 0 \\
\hline $\begin{array}{l}\text { COBALT }(C O), U G / L \\
\text { COPPER }(C U), U G / L\end{array}$ & 4 & $<50$ & $\begin{array}{r}<50 \\
30\end{array}$ & 4 & 0 & 1 \\
\hline IRON (FE), UG/L & $\begin{array}{l}4 \\
4\end{array}$ & $\begin{array}{r}<10 \\
50\end{array}$ & $\begin{array}{r}30 \\
840\end{array}$ & $\begin{array}{l}4 \\
4\end{array}$ & $\begin{array}{r}1 \\
10\end{array}$ & ${ }^{7}$ \\
\hline LEAD $(P B), U G / L$ & 4 & $<100$ & $\begin{array}{l}840 \\
100\end{array}$ & 4 & $\begin{array}{r}10 \\
3\end{array}$ & $\begin{array}{r}30 \\
9\end{array}$ \\
\hline MANGANESE (MN), UG/L & 4 & 10 & 210 & 4 & $\begin{array}{l}3 \\
0\end{array}$ & 20 \\
\hline MERCURY $(H G), U G / L$ & 4 & 0.0 & 0.1 & 4 & 0.0 & 0.1 \\
\hline SELENIUM (SE), UG/L & 4 & 0 & 1 & 3 & 0 & 0 \\
\hline ZINC $(Z N), U G / L$ & 4 & 30 & 50 & 4 & 6 & 120 \\
\hline \multicolumn{7}{|l|}{ PERIPHYTON: } \\
\hline BIOMASS, DRY WT., G/SQ M & 3 & .29 & 3.09 & & & \\
\hline BIOMASS, ASH WT., G/SO M & 3 & .19 & 1.50 & & & \\
\hline CHLOROPHYLL A, MG/SQ M & 3 & .0 & .6 & & & \\
\hline CHLOROPHYLL B, MG/SQ M & 3 & .0 & $\bullet 1$ & & & \\
\hline ORGANIC CARBON, MG/L & 4 & .3 & 2.6 & & & \\
\hline
\end{tabular}


Table 14.--Summary of measurement at each station--Continued

LAT $48 D 30 M 45 S$ LONG 122D20M25S

DRAINAGE AREA: 3093 SQ MI 18011 SQ KMI

PERIOD OF RECORD: $10 / 01 / 74-09 / 30 / 75$

STATISTICAL SUMMARY OF SELECTED DISSOLVED CHEMICAL CONSTITUENTS AND

REGRESSION RELATIONSHIPS OF CONSTITUENT CONCENTRATIONS TO SPECIFIC CONDUCTANCE

CONSILIUENI

\begin{tabular}{r} 
CONSII \\
SAMPL \\
SIZE \\
\hline 12 \\
12 \\
12 \\
12 \\
12 \\
12 \\
12 \\
12 \\
12 \\
12 \\
11 \\
11 \\
12 \\
12 \\
12 \\
12 \\
12 \\
12 \\
6 \\
12 \\
12 \\
12 \\
12 \\
12 \\
12 \\
12 \\
12
\end{tabular}

UENI_IMG L D OB UNII_SHOWNI

E

STANDARD MEAN DEYIALION

7.95 16240.8 6240.8
7.11 0.020

0.113

0.132

0.132
229.6

229.6
36.5

36.5
30.3

31.1

31.2

6.19

6.85

1.07

1.43

0.56

23.6

0.0

4.15

0.99
32.8

32.8
34.4

34.4
21.4

2.4
3.8

0.04
3.38

10.9
6824.6

6824.6
0.31

0.013

0.065

0.059

162.7

13.2
9.5

9.5
36.5

40.3

0.70

1.69

0.59

0.21

0.19

5.8

0.0
0.83

0.83
0.35

0.35
6.0

10.8

5.5
2.0

1.7

1.7
0.07
3.513 .0

$\begin{array}{rr}34 & 66 \\ 5870 & 29500 \\ 6.6 & 7.8 \\ 0.01 & 0.05\end{array}$

0.01

0.04

0.05

36

13
19

4
1
5.0

4.4

0.3

0.3

17

3.1

0.1

25
12

15
0
1

0.0 BEGRESSION SUMMABY

SAMPLE COEFICIENT, CONSTANT, CORRELAIION STANDARO SLZE - B - B COEEICIENI COEEICIENI ESIIMAI:

*Not significant at the 95 percent confidence level.

QURAILON IABLE OE DALLY SPECIEIC CONDUCIANCE DAILY SPECIFIC CONDUCTANCE IN

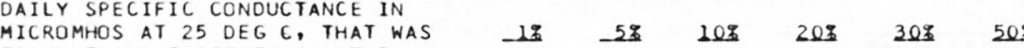

EQUALLED OR EXCEEDED FOR THE

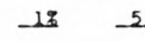

202

$303 \quad 503$

\begin{tabular}{rrrr}
\multicolumn{2}{c}{ SAMPLE SIZE $=$} & 365 \\
$70 \%$ & $20 \%$ & 258 & 293 \\
45 & 35 & 33 & 30
\end{tabular}

SUMMARY OF HARMONIC ANALYSIS OF STREAM TEMPERATURE

\begin{tabular}{|c|c|c|c|c|c|}
\hline & & & & & STANDARD \\
\hline & HARMONIC & AMPLITUDE & PHASE & VARIATION & ERROR OF \\
\hline SAMPLE & MEAN - M & $-A$ & ANGLE - C & EXPLAINED & ESTIMATE \\
\hline SIZE_- & $10 E G C 1$ & DEE $C 1$ & (RADIANS) & $-(\pi)$ & $10 E G \quad C)$ \\
\hline 365 & 8.39 & 4.71 & 2.44 & 90 & 1.05 \\
\hline
\end{tabular}

SUMMARY OF MAXIMUM AND MINIMUM CONCENTRATIONS OF CONSTITUENTS SAMPLED AT A FREQUENCY OF QUARTERLY (1975 WY)

12200500 -- SKAGIT RIVER NEAR MOUNT VERNON, HASH.

\begin{tabular}{|c|c|c|c|c|c|c|}
\hline \multirow{2}{*}{ CONSTITUENT } & \multicolumn{3}{|c|}{ TOTAL } & \multicolumn{3}{|c|}{ DISSOLVED } \\
\hline & $\begin{array}{l}\text { NO. } \\
\text { SAMPLES }\end{array}$ & $\begin{array}{l}\text { MINIMUM } \\
\text { CONC. }\end{array}$ & $\begin{array}{l}\text { MAXIMUM } \\
\text { CONC. }\end{array}$ & $\begin{array}{l}\text { NO. } \\
\text { SAMPLES }\end{array}$ & $\begin{array}{l}\text { MINIMUM } \\
\text { CONC. }\end{array}$ & $\begin{array}{l}\text { MAXIMUM } \\
\text { CONC. }\end{array}$ \\
\hline \multicolumn{7}{|l|}{ MINUR ELEMENTS: } \\
\hline ARSENIC (AS), UG/L & 4 & 0 & 1 & 4 & 0 & 1 \\
\hline CADMIUM $(C D), U G / L$ & 4 & $<10$ & 10 & 4 & 0 & $<10$ \\
\hline CHROMIUM (CR), UG/L & 4 & 0 & 0 & 4 & 0 & 10 \\
\hline COBALT $(C O)$, UG/L & 4 & $<50$ & $<50$ & 4 & 0 & 0 \\
\hline COPPER (CU), UG/L & 4 & $<10$ & 20 & 4 & 0 & 6 \\
\hline IRON (FE), UG/L & 4 & 190 & 630 & 4 & 40 & 100 \\
\hline$L E A D(P B), U G / L$ & 4 & $<100$ & 100 & 4 & 3 & 8 \\
\hline MANGANESE (MN), UG/L & 4 & 10 & 30 & 4 & 0 & 20 \\
\hline MERCURY (HG), UG/L & 3 & 0.0 & 0.0 & 4 & 0.0 & 0.0 \\
\hline SELENIUM (SE), UG/L & 4 & 0 & 0 & 4 & 0 & 0 \\
\hline ZINC $(Z N), U G / L$ & 4 & 10 & 60 & 4 & 0 & 50 \\
\hline \multicolumn{7}{|l|}{ PERIPHYTON: } \\
\hline BIOMASS, DRY WT., G/SO M & 3 & 2.29 & 22.00 & & & \\
\hline BIOMASS, ASH WT., G/SO M & 3 & .79 & 22.00 & & & \\
\hline CHLOROPHYLL A, MG/SO M & 3 & .3 & 4.0 & & & \\
\hline CHLOROPHYLL B, MG/SO M & 3 & .0 & .6 & & & \\
\hline ORGANIC CARBON, MG/L & 4 & .5 & 4.2 & & & \\
\hline
\end{tabular}


Table 14.--Sumary of measurement at each station--Continued

STATION NUMBER: 12318500 NAME: KOOTENAI RIVER NR COPELAND, ID

LAT $48059 M 45 S$ LONG $116025 M 00 S$

DRAINAGE AREA: 13400 SQ MI ( 34706 SO KM)

PERIOD OF RECORD: $10 / 01 / 74-09 / 30 / 75$

STATISTICAL SUMMARY OF SELECTED DISSOLVED CHEMICAL CONSTITUENTS AND

REGRESSION RELATIONSHIPS OF CONSTITUENT CONCENTRATIONS TO SPECIFIC CONDUCTANCE

GONSILIUENI

\begin{tabular}{c} 
CONS \\
SAM \\
SI \\
\hline \\
1 \\
1 \\
1 \\
1 \\
1 \\
1 \\
1 \\
1 \\
\\
1 \\
1 \\
1 \\
1 \\
1 \\
1 \\
1 \\
1 \\
1 \\
1 \\
1 \\
12 \\
1 \\
12 \\
12 \\
12 \\
12 \\
1 \\
12 \\
\end{tabular}

\begin{tabular}{|c|c|c|}
\hline $\begin{array}{l}\text { MPLE } \\
\text { LZEE MEAN }\end{array}$ & $\begin{array}{l}\text { STANDARD } \\
\text { DEYIAIUON }\end{array}$ & BANGE \\
\hline $\begin{array}{r}9.89 \\
156.9\end{array}$ & $\begin{array}{l}6.34 \\
50.2\end{array}$ & $\begin{array}{r}2.0 \\
90\end{array}$ \\
\hline 14242.7 & 7063.5 & 4150 \\
\hline 7.60 & 0.29 & 7.1 \\
\hline 0.026 & 0.025 & 0.01 \\
\hline 0.061 & 0.052 & 0.01 \\
\hline 0.183 & 0.128 & 0.01 \\
\hline 1166.7 & 1833.5 & 120 \\
\hline 8.9 & 5.4 & 2 \\
\hline 89.6 & 8.9 & 70 \\
\hline 9.3 & 8.7 & 1 \\
\hline 19.8 & 28.1 & $\frac{1}{7}$ \\
\hline $\begin{array}{r}3.09 \\
27.08\end{array}$ & $\begin{array}{l}7.24 \\
7.69\end{array}$ & 11.0 \\
\hline 6.99 & 2.25 & 3.2 \\
\hline 2.11 & 0.44 & 1.4 \\
\hline 0.75 & 0.17 & 0.5 \\
\hline 97.6 & 28.2 & 42 \\
\hline 0.0 & 0.0 & \\
\hline 13.08 & 5.32 & 5.8 \\
\hline 1.82 & 0.78 & 0.7 \\
\hline 105.9 & 28.6 & 50 \\
\hline 110.3 & 28.6 & 58 \\
\hline 97.0 & 28.4 & 41 \\
\hline 17.2 & 9.1 & 6 \\
\hline 2.5 & 1.8 & 1 \\
\hline 0.24 & 0.12 & 0.1 \\
\hline
\end{tabular}

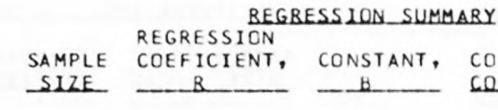

CORELATION OEEICIENI

STANDARD STANDARD
ERROR CF

TEMPERATURE, WATER (DEG C) SPECIFIC CONDUCTANCE (MICROMHOSI) STREAMFLOH (CUBIC FT/SEC)

PH (STANDARD UNITS)

NITRITE + NITRATE, TOTAL

NITROGEN, KJELDAHL, TOTAL

PHYTOPLANKTON, TOTAL (CELLS/ML)

SEDIMENT, SUSPENDED

COLIMENT, CLAY-SILY IPERC

COLIFORA, FECAL ( COL/100 ML)

CALCIUM, DISSOLVED

MAGNESIUM, DISSOLVED

SODIUM, DISSOLVED

POTASSIUM, DISSOLVED

BICARBONATE, ION

SULFATE, DISSOLVED

CHLORIDE, DISSOLVED

OISSOLVEO SOLIDS, SUM OF COI

HARDNESS, TOTAL

HARDNESS, NONCARECNATE

FLOURIDE, DISSOLVED

QURAUION IABLE OE DALLY SPECIEIC CONOUCIANCE

DAILY SPECIFIC CONDUCTANCE IN

MICROMHOS AT 25 DEG C, THAT WAS

EQUALLED OR EXCEEDEU FOR THE

$\begin{array}{lllllll}18 & -5 \% & 10 \% & 20 \% & 30 \% & 50 z\end{array}$

$50270 z$

11

$-30.129$

0.0057

0.00021

0.00109

$-0.00082$

$-1.785$

6.7188

$-0.00622$

$-0.10427$

0.30746

1545.589

$\begin{array}{rr}-0.213 * & 7219.3 \\ 0.771 & 0.19 \\ 0.320 * & 0.025 \\ 0.804 & 0.033 \\ -0.247 * & 0.130 \\ -0.038 * & 2085.2\end{array}$

$-0.0126$

0.1876

0.0558

0.0048

0.0037
0.673

0.673

0.000

0.1308

0.0109

0.715
0.700

0.702

0.146

$-0.021$

0.0014
-0.389 *

0.940

0.956
0.429

0.841
0.922

0.000 *

0.949

0.539 *

0.964

0.945

0.952

0.618
-0.456.

0.422 *

263

261

$234 \quad 222$

214

200

SAMPLE SIZE $=109$

$20 \% 25 \% 297$

$157 \quad 154 \quad 98$

SUMMARY OF HARMONIC ANALYSIS OF STREAM TEMPERATURE

\begin{tabular}{|c|c|c|c|c|c|}
\hline & & & & & STANDARD \\
\hline SAMPLE & $\begin{array}{l}\text { HARMONIC } \\
\text { MEAN - M }\end{array}$ & AMPLITUDE & $\begin{array}{c}\text { PHASE } \\
\text { ANGLE - }\end{array}$ & $\begin{array}{l}\text { VAR IATION } \\
\text { EXPLA INED }\end{array}$ & $\begin{array}{l}\text { ERROR OF } \\
\text { ESTIMATE }\end{array}$ \\
\hline SLZE & (DEG C) & (DEGC) & (RADIANS) & $\frac{181}{-}$ & IDEG $(1)$ \\
\hline 363 & 9.70 & 6.22 & 2.37 & 75 & 2.55 \\
\hline
\end{tabular}

SUMMARY OF MAXIMUM AND MINIMUM CONCENTRATIONS OF CONSTITUENTS

SAMPLED AT A FREOUENCY OF QUARTERLY (1975 WY)

12318500 -- KOOTENAI RIVER NR COPELAND, ID

\begin{tabular}{|c|c|c|c|c|c|c|}
\hline \multirow{2}{*}{ CONSTI TUENT } & \multicolumn{3}{|c|}{ TOTAL } & \multicolumn{3}{|c|}{ DISSOLVED } \\
\hline & $\begin{array}{l}\text { NO. } \\
\text { SAMPLES }\end{array}$ & $\begin{array}{l}\text { MINIMUM } \\
\text { CONC. }\end{array}$ & $\begin{array}{l}\text { MAXIMUM } \\
\text { CONC. }\end{array}$ & $\begin{array}{l}\text { NO. } \\
\text { SAMPLES }\end{array}$ & $\begin{array}{l}\text { MINIMUM } \\
\text { CONC. }\end{array}$ & $\begin{array}{l}\text { MAXIMUM } \\
\text { CONC. }\end{array}$ \\
\hline \multicolumn{7}{|l|}{ MINOR ELEMENTS: } \\
\hline ARSENIC (AS), UG/L & 4 & 1 & 2 & 4 & 1 & 2 \\
\hline CADMIUM $(C D), U G / L$ & 4 & $<10$ & $<10$ & 4 & 0 & 2 \\
\hline CHROMIUM (CR), UG/L & 4 & 0 & 35 & 4 & 0 & 20 \\
\hline COBALT $(C O), U G / L$ & 4 & $<50$ & $<50$ & 4 & 0 & 2 \\
\hline COPPER (CU), UG/L & 4 & $<10$ & 10 & 4 & 1 & 13 \\
\hline IRON $(F E), U G / L$ & 4 & 170 & 920 & 4 & 30 & 40 \\
\hline LEAD $(P B), U G / L$ & 4 & $<100$ & $<100$ & 4 & 1 & 4 \\
\hline MANG ANESE (MN), UG/L & 4 & 10 & 30 & 4 & 0 & 50 \\
\hline MERCURY (HG), UG/L & 4 & 0.0 & 0.2 & 4 & 0.0 & 0.1 \\
\hline SELENIUM $(S E), U G / L$ & 4 & 0 & 1 & 4 & 0 & 0 \\
\hline$Z I N C(Z N), U G / L$ & 4 & 10 & 70 & 4 & 10 & 30 \\
\hline \multicolumn{7}{|l|}{ PERIPHYTON: } \\
\hline BICMASS, DRY WT., G/SQ M & 2 & 14.00 & 23.00 & & & \\
\hline BIOMASS, ASH WT., G/SQ M & 2 & 9.19 & 17.00 & & & \\
\hline CHLOROPHYLL A, MG/SO M & 3 & 3.5 & 38.0 & & & \\
\hline CHLOROPHYLL B, MG/SO M & 3 & $\cdot 8$ & 26.0 & & & \\
\hline ORGANIC CARBON, MG/L & 4 & 2.9 & 5.6 & & & \\
\hline
\end{tabular}


Table 14.--Sumnary of measurement at each station--Continued

LAT 49DOOMO5S LONG 114028 M3OS

DRAINAGE AREA: 450 SQ MI 11166 SQ KM)

PERIOD OF RECORD: $10 / 01 / 74-09 / 30 / 75$

STATISTICAL SUMMARY OF SELECTED DISSOLVED CHEMICAL CONSTITUENTS AND

REGRESSION RELATIONSHIPS OF CONSTITUENT CONCENTRATIONS TO SPECIFIC CONDUCTANCE

GONSIIIUENI

GONSILUUENI IMGCL OR UNII_SHOHNI

SAMPLE
SIZE

TEMPERATURE, WATER (DEG C)

SPECIFIC CONDUCTANCE (MICROMHOS)

SIREAMFLOW (CUBIC FT/SEC)

PH (STANDARD UNITS)

PHOSPHORUS, TOTAL

NITRITE + NITRATE, TOTAL

NITROGEN, KJELDAHL, TOTAL

SEDIMENT, SUSPENDED

SEDIMENT, CLAY-SILT (PERCENT)

COLIFORM, FECAL (COL/100 ML)

SILICA, DISSOLVED

CALCIUM, DISSOLVED

MAGNESIUM, DISSOLVED

SODIUM, DISSOLVED

POTASSIUM, DISSOLVEO

BICARBONATE, ION

CARBONATE, ION

SULFATE, DISSOLVED

CHLORIDE, DISSOLVED

DISSOLVED SOLIDS, SUM OF CONST

DISSOLVED SOLIDS, ROE 180 DEG C

HARONESS, TOTAL

HARONESS, NONCARBONATE

TURBIUITY (JTU)

FLOURIDE, DISSOLVED

SAM
SI
1
1
1
1
1

1
10
10
10
10
1
10
10
10
10
10

PHYTOPLANKTON, TOTAL (CELLS/ML)

STREP TOCOCCI, FECAL (COL/100 ML)
STANDARD

MEAN DEYIALION

4.53

228.5

2202.1

8.07

0.042

0.028

0.125

190.7

111.4
62.5

62.5
5.2

5.2
6.7

6.7
4.18

38.90

8.17

0.78

0.40

153.6

153.0
0.0

5.23

0.56

133.9

133.4

130.8
5.1

5.1
12.5

12.5

4.42
48.9
3506.9

0.28

0.078

0.019

0.098

136.6

148.8

13.6

8.2
8.1

0.52

7.36

1.28

0.24

26.17

26.9

0.0
1.67

1.67
0.33

22.9

23.4

22.8
5.6

25.2

0.05

$\begin{array}{rr}0.0 & 12.5 \\ 133 & 274\end{array}$

$\begin{array}{lr}133 & 274 \\ 117 & 11100\end{array}$

7.4

0.00

$0.01 \quad 0.25$

$0.02 \quad 0.35$

1
48

48
0

0
3.3
25.0

25.0
5.7

0.4

0.1

2.9

2.9
0.1

88

90

86
0
0

0.0

80
24
25

25
4.8
46.0

46.0
9.0

1.1
0.0

173

8.5

151

157

150
16
75
BEG

REGRESSION

SAMPLE COEFICIENT,

SSION_SUMMABY

SIZE

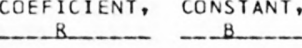

CORRELATION COEEICIENI.

STANDARD ERROR OF ESIIMAIE

*Not significant at the 95 percent confidence level.

DURAIION IABLE OE DAILY SPECIEIC CONDUCIANCE

DAILY SPECIFIC CONDUCTANCE IN

MICROMHOS AT 25 DEG C, THAT WAS

EUUALLED OR EXCEEDED FOR THE

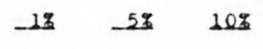

202

$30 z$

$50 \%$

290

$274 \quad 269$

264
7.5713

0.28629

0.04756

5.40591

$\begin{array}{rrr}0.35 & 10 & -0.00123 \\ 470 & 9 & -1.477\end{array}$

520.645

$-0.861$

0.395 *

$-0.672$

-0.614 *

$-0.530$

0.2
9809.785

SUMMARY OF HARMONIC ANALYSIS OF STREAM TEMPERATURE

SORM OF EOUAION: II(D) = M + A SIN 0172 \# + CI

\begin{tabular}{|c|c|c|c|c|c|}
\hline & & & & & STANDARD \\
\hline & HARMONIC & AMPL I TUDE & PHASE & VAR IATION & ERROR OF \\
\hline SAMPLE & MEAN - M & $-A$ & ANGLE - C & EXPLAINED & ESTIMATE \\
\hline SIZE_ & $10 E 6 \quad C 1$ & (DEE $(1)$ & (BADIANS) & $\ldots 181 \ldots$ & 1DEG_C1 \\
\hline 332 & 3.80 & 4.92 & 2.47 & 89 & 1.23 \\
\hline
\end{tabular}

SUMMARY OF MAXIMUM AND MINIMUM CONCENTRATIONS OF CONSTITUENTS SAMPLED AT A FREQUENCY OF QUARTERLY (1975 WY)

12355000 -- FLATHEAD RIVER AT FLATHEAD, BRITISH COLUMBIA

\begin{tabular}{|c|c|c|c|c|c|c|}
\hline \multirow{2}{*}{ CONSTI TUENT } & \multicolumn{3}{|c|}{ TOTAL } & \multicolumn{3}{|c|}{ DISSOLVED } \\
\hline & $\begin{array}{l}\text { NO. } \\
\text { SAMPLES }\end{array}$ & $\begin{array}{l}\text { MIN IMUM } \\
\text { CONC. }\end{array}$ & $\begin{array}{l}\text { MAXIMUM } \\
\text { CONC. }\end{array}$ & $\begin{array}{l}\text { NOP } \\
\text { SAMPLES }\end{array}$ & $\begin{array}{l}\text { MINIMUM } \\
\text { CONC. }\end{array}$ & $\begin{array}{l}\text { MAXIMUM } \\
\text { CONC. }\end{array}$ \\
\hline \multicolumn{7}{|l|}{ MINOR ELEMENTS: } \\
\hline ARSENIC (AS), UG/L & 3 & 0 & 3 & 3 & 0 & 2 \\
\hline (ADMIUM $(C D), U G / L$ & 3 & $<10$ & $<10$ & 3 & 0 & 1 \\
\hline CHRUMIUM (CR), UG/L & 3 & 0 & $<10$ & 3 & 0 & $<10$ \\
\hline COBALT $(C O), U G / L$ & 3 & $<50$ & $<50$ & 3 & 0 & 1 \\
\hline COPPER $(C U), U G / L$ & 3 & $<10$ & 45 & 3 & 0 & 1 \\
\hline IRON (FE), UG/L & 3 & 0 & 2800 & 3 & 10 & 170 \\
\hline LEAD $(P B), U G / L$ & 3 & $<100$ & $<100$ & 3 & 0 & 2 \\
\hline MANGANESE $(M N), U G / L$ & 2 & 0 & 30 & 3 & 0 & 20 \\
\hline MERCURY (HG), UG/L & 3 & 0.0 & $<0.1$ & 3 & 0.0 & $<0.1$ \\
\hline SELENIUM (SE), UG/L & 3 & 0 & 0 & 3 & 0 & 0 \\
\hline$Z I N C(Z N), U G / L$ & 3 & $<10$ & 50 & 3 & 0 & $<10$ \\
\hline \multicolumn{7}{|l|}{ PERIPHYTON: } \\
\hline GIOMASS, DRY WT., G/SO M & 1 & 4.79 & & & & \\
\hline BIOMASS, ASH WT., G/SQ M & 3 & .50 & 4.19 & & & \\
\hline CHLOROPHYLL A, MG/SQ M & 2 & .5 & 1.7 & & & \\
\hline CHLOROPHYLL E, MG/SO M & 2 & .0 & 1.0 & & & \\
\hline URGANIC CARBON, MG/L & 3 & 5.5 & $8 \cdot 2$ & & & \\
\hline
\end{tabular}


LAT 48D59M56S LUNG 117021MO9S

DRAINAGE AREA: 25200 SQ MI 165268 SQ $\mathrm{kM}$

PERIOD DF RECORD: $10 / 01 / 74-09 / 30 / 75$

STATISTICAL SUMMARY OF SELECTED DISSOLVED CHEMICAL CONSTITUENTS AND

REGRESSION RELATIONSHIPS OF CONSTITUENT CONCENTRATIONS TO SPECIFIC CONDUCTANCE

\section{GONSIIIUENI}

CONSIIIUENI IMG LL_OR UNII SHOWN

TEMPERATURE, WATER (DEG C)

SPECIFIC CONDUCTANCE (MICROMHOS)

STREAMFLOW (CUBIC FT/SEC)

PH (STANDARD UNITS)

PHLSPHORUS, TOTAL

NITRITE + NITRATE, TOTAL

NITROGEN, KJELDAHL, TOTAL

NITROGEN, KJELDAHL, TOTAL

PHYTOPLANKTON, TOTAL

SEDIMENT, SUSPENDED

COLIFORM, FECAL (COL/10O ML)

STREPTOCOCCI, FECAL (COL/100 ML)

SILICA, DISSOLVED

CALCIUM, DISSOLVED

MAGNE SIUM, DISSOLVED

SODIUM, DISSOLVED

PCTASSIUM, DISSOLVEU

BICARBONATE, ION

CARBONATE, ION

SULFATE, DISSCLVED

CHLURIDE, DISSOLVED

DISSOLVED SOLIDS, SUM OF CONST
DISSOLVED SOLIDS, RCE 180 DEG

HARDNESS, TOTAL

HARDNESS, NUNCARBUNATE

TURBIDITY (JTU)

FLOURIDE, DISSOLVED

*Not significant at the 95 percent confidence level.
SAMPLE SIZE

\section{STANDARD \\ MEAN \\ EVIALION}

9.47

162.0

34575.0

7.88

0.014

0.01

0.256

475.0
5.3

5.3
91.3

2.2

15.4
6.42

6.42

21.75
5.58

2.59

2.59
0.87

89.5

0.0

8.72
1.68

1.68
91.9

92.3

77.4

3.8

3.8
3.1
0.12

7.21
21.1
19238.3
0.07

0.67

0.007

0.013

3702.0

4.2
9.7

9.7

2.6

25.8
0.99

1.42

0.73

0.27

0.20

6.3

0.0
1.19
1.08

5.3

8.5

6.2
2.0

3.8

0.09 DURATL SPECIFIC CONDUCTANCE IN
MAILROMHOS AT 25 DEG C, THAT HAS

MICROMHOS AT 25 DEG C. THAT WAS

AIION IABLE_OF_DAILY SPECIEIC CONDUCIANCE

EQUALLEO OR EXCEEDED FOR THE

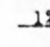

204
BANGE

$\begin{array}{rr}0.4 & 21.4 \\ 131 & 204 \\ 13600 & 7380 \\ 6.4 & 8\end{array}$

0.01

0.00

0.14

2100

2
63
1

1

5.4
19.0

4.3

2.2

78

7.0
7.0
0.7

0.7
84

80

67

c. 1
BEGRESSION SUMMABY SAMPLE CDEFICIENT, CONSTANT,

STANDARD SIZE BOE GICIENI ESILMAIE

204

$\begin{array}{llllll}3800 & 12 & -411.194 & 101188.375 & -0.451^{*} & 18009.3\end{array}$

$\begin{array}{llll}8.6 & 12 & 0.0062 & 6.8778\end{array}$

$-0.00019$

0.00035

0.0017

0.04527

$-0.03842$

$-0.02178$

$-19.833$

8087.863

0.195

$-0.606$

0.565 .

0.343

$-0.113$

8.69
0.006

0.006

0.011

3858.4

14000
16

100

9
81

8.6
23.0

6.7

2.9

12

$90 \quad 12$

$\begin{array}{rr}11.0 & 12 \\ 4.8 & 12\end{array}$

$\begin{array}{ll}4.8 & 12 \\ 101 & 12\end{array}$

101
109

83
7

14
0.4

12
12
12
12
12

12

12
12
12
12
12
12
8
2
2
12
12
12
12
12
12

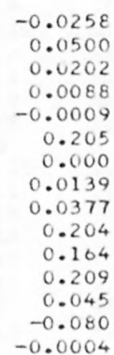

13.6434

2.3176

1.1022

1.0090

20.313

50.313

0.000
6.4781

$-4.4182$

58.795

65.647

43.567

$-3.446$

0.1861

$-0.550$

0.742

0.58

0.686
-0.092.

0.680

0.686

0.000

0.240

0.736

0.817

0.406 ,

0.714

0.476

$-0.452$.

$-0.097$

SUMMARY OF HARMONIC ANALYSIS OF STREAM TEMPERATURE

\begin{tabular}{|c|c|c|c|c|c|}
\hline & & & & & STANDARD \\
\hline & HARMONIC & AMPLITUDE & PHASE & VARIATION & ERROR OF \\
\hline SAMPLE & MEAN - $M$ & $-A$ & ANGLE - C & EXPLAINED & ESTIMATE \\
\hline SIZE_ & $10 E 6 C_{1}$ & DEE 61 & (BADIANS) & $\ldots 181 \ldots$ & 1DEG_L \\
\hline 344 & 9.29 & 9.03 & 2.46 & 97 & 1.21 \\
\hline
\end{tabular}

SUMMARY OF MAXIMUM AND MINIMUM CONCENTRATIONS OF CONSTITUENTS SAMPLED AT A FREQUENCY OF QUARTERLY (1975 WY)

12398600 -- PEND OREILLE RIVER AT INT BOUNDARY

\begin{tabular}{|c|c|c|c|c|c|c|}
\hline \multirow{2}{*}{ CONSTITUENT } & \multicolumn{3}{|c|}{ TOTAL } & \multicolumn{3}{|c|}{ DISSOLVED } \\
\hline & $\begin{array}{l}\text { NO. } \\
\text { SAMPLES }\end{array}$ & $\begin{array}{l}\text { MIN IMUM } \\
\text { CONC. }\end{array}$ & $\begin{array}{l}\text { MAXIMUM } \\
\text { CONC. }\end{array}$ & $\begin{array}{l}\text { NO. } \\
\text { SAMPLES }\end{array}$ & $\begin{array}{l}\text { MINIMUM } \\
\text { CONC. }\end{array}$ & $\begin{array}{l}\text { MAXIMUM } \\
\text { CONC. }\end{array}$ \\
\hline \multicolumn{7}{|l|}{ MINOR ELEMENTS: } \\
\hline ARSENIC (AS), UG/L & 4 & 0 & 2 & 4 & 0 & 2 \\
\hline CADMIUM $(C D), U G / L$ & 4 & $<10$ & $<10$ & 4 & 0 & 0 \\
\hline CHROMIUM (CR), UG/L & 4 & 0 & 0 & 4 & 0 & 0 \\
\hline COBALT $(C O), U G / L$ & 4 & 0 & $<50$ & 4 & 0 & 1 \\
\hline COPPER (CU), UGIL & 4 & 0 & 20 & 4 & 2 & 8 \\
\hline IRON (FE), UG/L & 4 & 100 & 190 & 4 & 10 & 70 \\
\hline LEAD $(P B), U G / L$ & 4 & $<100$ & $<100$ & 4 & 2 & 9 \\
\hline MANGANESE (MN), UG/L & 4 & 0 & 20 & 4 & 0 & 0 \\
\hline MERCURY $(H G), U G / L$ & 4 & 0.0 & 0.2 & 4 & 0.0 & 0.2 \\
\hline SELENIUM (SE), UG/L & 4 & 0 & 0 & 4 & 0 & 0 \\
\hline$\angle I N C(Z N), U G / L$ & 4 & 10 & 40 & 4 & 0 & 10 \\
\hline \multicolumn{7}{|l|}{ PERIPHYTON: } \\
\hline BIOMASS, DRY WT., G/SO M & 1 & .39 & & & & \\
\hline BIOMASS, ASH WT., G/SQ M & 1 & .29 & & & & \\
\hline CHLOROPHYLL A, MG/SQ M & 2 & .0 & .1 & & & \\
\hline CHLOROPHYLL $B, M G / S O M$ & 2 & .0 & $\cdot 1$ & & & \\
\hline ORGANIC CARBON, MG/L & 4 & 1.3 & 3.2 & & & \\
\hline
\end{tabular}


Table 14,--Summary of measurement at each station--Continued

LAT 48055M21S LONG $117046 \mathrm{M} 32 \mathrm{~S}$

DRAINAGE AREA: 60200 SQ MI ( 155918 SQ KM)

PERIOD OF RECORD: $10 / 01 / 74-09 / 30 / 75$

STATISTICAL SUMMARY OF SELECTED DISSOLVED CHEMICAL CONSIITUENTS AND

REGRESSION RELATIONSHIPS OF CONSTITUENT CONCENTRATIONS TO SPECIFIC CONDUCTANCE

CONSIIIUENI

CONSILIUENT IMGLL OR UNDI SHOWN

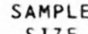

SIZE

TEMPERATURE, WATER (UEG C) SPECIFIC CONDUCTANCE (MICROMHOS)

STREAMFLOW (CUBIC FI/SEC)

PH (STANDARD UNITSI)

PHOSPHORUS, TOTAL

NITRITE + NITRATE, TCTAL

NITROGEN, KJELDAHL, TOTAL

PHYTOPLANKTON, TOTAL (CELLS/ML)

SEDIMENT, SUSPENDED

SEOIMENT, CLAY-SILT (PERCENT)

COLIFCRM, FECAL ( $C O L / 100 \mathrm{ML})$

STREPTOCOCCI, FECAL (COL/100 ML)

SILICA, DISSOLVED

CALCIUM, DISSOLVED

MAGNESIUM, DISSOLVEO

SODIUM, DISSOLVED

POTASSIUM, DISSOLVED

BICARBONATE, ION

CAREONATE, ION

SULFATE, DISSOLVED

CHLORIDE, OISSOLVED

DISSOLVED SOLIDS, SUM OF CONST

DISSOLVED SOLIDS, ROE 180 DEG

HARDNESS, TOTAL

HARDNESS, NONCARBONATE

TURBIDITY (JTU)

FLOURIDE, DISSOLVED

(1)

7.4

86.3

15.9

4.64

21.25

1.64

0.72

73.0

0.0
1.60

81.8

82.7

71.3

11.3

1.8
BEGRESSION_SUMMARY

REGRESSION STANOAR: SAMPLE COEFICIENT, CONSTANT, CORRELATION ERROR OF SIZE

$B$ $-B$ COEEICIENI

ESILMAI:

*Not significant at the 95 percent confidence level.

DAILY SPECIFIC CONDUCTANCE IN

DUBAIION_IABLE_OF_RAIY SPECIEIC CONDUCIANCE

MICROMHOS AT 25 DEG C, THAT WAS

EQUALLED OR EXCEEDED FOR THE

$\begin{array}{llllll}12 & 52 & 208 & 20 z & 30 \% & 50 \% \\ 170 & 164 & 161 & 157 & 155 & 144\end{array}$

$\begin{array}{rrr}6.05 & 2.0 & 18.5 \\ 36.6 & 88 & 220 \\ 30892.3 & 70600 & 177000 \\ 0.40 & 7.1 & 8.3 \\ 0.017 & 0.01 & 0.07 \\ 0.044 & 0.02 & 0.15 \\ 0.227 & 0.14 & 0.97 \\ 2842.8 & 210 & 8700 \\ 7.5 & 2 & 26 \\ 6.9 & 71 & 97 \\ 20.0 & 1 & 58 \\ 8.2 & 1 & 30 \\ 0.93 & 3.5 & 7.1 \\ 2.38 & 18.0 & 25.0 \\ 0.56 & 3.6 & 5.2 \\ 0.23 & 1.2 & 2.1 \\ 0.13 & 0.5 & 1.0 \\ 5.7 & 63 & 81 \\ 0.0 & 0 & 0 \\ 2.86 & 7.7 & 16.0 \\ 0.41 & 0.5 & 1.9 \\ 7.9 & 71 & 92 \\ 13.5 & 61 & 103 \\ 7.7 & 61 & 81 \\ 5.5 & 4 & 23 \\ 1.0 & 1 & 4 \\ 0.14 & 0.1 & 0.6\end{array}$

0.14

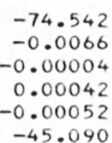

8.6887

0.03942

0.02970

0.34196

10125.238

-0.088 .

$-0.596$.

-0.076 .

0.340 .

-0.085 .

$-0.580$

32273.6

0.3

0.018

0.043

0.231

12
12
12
12
12
12
6
12
12
12
12
12
12
12
12
4.9289

18.3997

3.3113

1.7481

0.7417

62.243

0.000
9.2158

1.3118

1.3118

71.734

02.084

62.548

10.821

0.4911
$-0.077^{*}$

0.194 *

0.487 *

$-0.116 *$

-0.032 *

$0.467 *$

0.000 *

$-0.130$.

$-0.130^{*}$

$0.380 *$

0.280

0.023 *

-0.044 *

-0.546 *
2428.8
INDICATED PERCENTAGE OF THE

SUMMARY OF HARMONIC ANALYSIS OF STREAM TEMPERATURE

\begin{tabular}{|c|c|c|c|c|c|}
\hline & & & & & STANDARD \\
\hline & HARMONIC & AMPLI TUDE & PHASE & VARIATION & ERROR OF \\
\hline SAMPLE & MEAN - M & $-A$ & ANGLE - C & EXPLAINED & ESTIMATE \\
\hline SIZE_ & $10 E G_{C} C L_{2}$ & $-1 D E G_{2}(1)$ & (BADIANS) & $-(2)$ & $\left(D E G_{C}(1)\right.$ \\
\hline
\end{tabular}

365

9.43

8.33

2.42

97

0.93

SUMMARY OF MAXIMUM AND MINIMUM CONCENTRATIONS OF CONSTITUENTS

SAMPLED AT A FREQUENCY OF QUARTERLY (1975 WY)

12400520 -- COLUMBIA RIVER AT NORTHPORT, WASH.

\begin{tabular}{|c|c|c|c|c|c|c|}
\hline \multirow{2}{*}{ CONSTITUENT } & \multicolumn{3}{|c|}{ TOTAL } & \multicolumn{3}{|c|}{ DISSOLVED } \\
\hline & $\begin{array}{l}\text { NO. } \\
\text { SAMPLES }\end{array}$ & $\begin{array}{l}\text { MIN IMUM } \\
\text { CONC. }\end{array}$ & $\begin{array}{l}\text { MAXIMUM } \\
\text { CONC. }\end{array}$ & $\begin{array}{c}\text { NC. } \\
\text { SAMPLES }\end{array}$ & $\begin{array}{l}\text { MINIMUM } \\
\text { CONC. }\end{array}$ & $\begin{array}{l}\text { MAXIMUM } \\
\text { CONC. }\end{array}$ \\
\hline \multicolumn{7}{|l|}{ MINOR ELEMENTS: } \\
\hline ARSENIC (AS), UG/L & 4 & 0 & 1 & 4 & 0 & 1 \\
\hline CALMIUM $(C D)$, UG/L & 4 & 0 & 10 & 4 & 0 & 1 \\
\hline CHROMIUM (CR), UG/L & 4 & 0 & 10 & 4 & 0 & 0 \\
\hline COBALT $(C O), U G / L$ & 4 & $<50$ & $<50$ & 4 & 0 & 2 \\
\hline COPPER (CU), UG/L & 4 & 0 & 20 & 4 & 1 & 7 \\
\hline IRUN $(F E), U G / L$ & 4 & 60 & 170 & 4 & 10 & 30 \\
\hline LEAD $(P B), U G / L$ & 4 & $<100$ & $<100$ & 4 & 2 & 7 \\
\hline MANG ANESE $(M N), U G / L$ & 4 & 0 & 30 & 4 & 0 & 10 \\
\hline MERC URY $(H G), U G / L$ & 4 & 0.0 & 0.2 & 4 & 0.0 & 0.1 \\
\hline SELENIUM (SE), UG/L & 4 & 0 & 0 & 4 & 0 & 0 \\
\hline ZINC $(Z N), U G / L$ & 4 & 30 & 90 & 4 & 10 & 60 \\
\hline \multicolumn{7}{|l|}{ PERIPHYTON: } \\
\hline BIOMASS, DRY WT., G/SQ M & 3 & 1.50 & 4.59 & & & \\
\hline BIOMASS, ASH WT., G/SO M & 3 & .79 & 2.29 & & & \\
\hline CHLOROPHYLL A, MG/SQ M & 3 & .0 & 4.0 & & & \\
\hline CHLOROPHYLL B, MG/SQ M & 3 & .1 & .6 & & & \\
\hline ORGANIC $\mathcal{L} A R B O N, M G / L$ & 4 & 1.3 & 4.2 & & & \\
\hline
\end{tabular}


Table 14.--Sumary of measurement at each station--Continued

LAT 47050M18S LONG $117051 M 05 S$

DRAINAGE AREA: 6020 SQ MI I 15592 SQ KM I

PERIOD OF RECORD: $10 / 01 / 74-09 / 30 / 75$

STATISTICAL SUMMARY OF SELECTED DISSOLVED CHEMICAL CONSTITUENTS AND

REGRESSION RELATIONSHIPS OF CONSTITUENT CONCENTRATIONS TO SPECIFIC CONOUCTANCE

CONSIIUENI

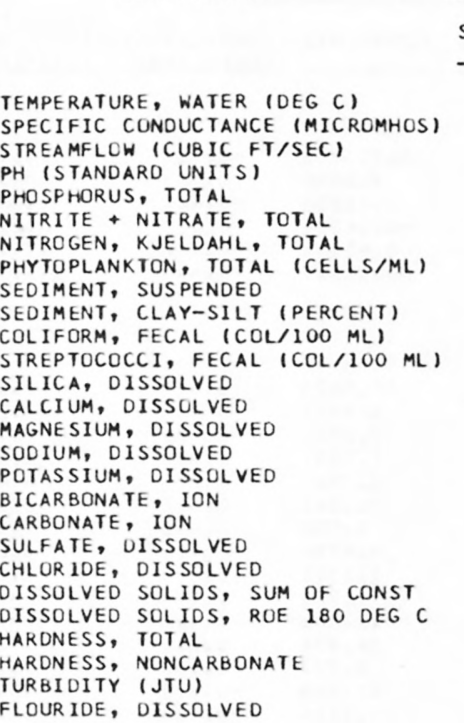

CONSIUIUENI IMGLL OR UNIL SHOHNU

$S A M P$
$S 12$
12
12
12
12
12
12
12
11
12
12
12
12
12
12
12
12
12
12
8
12
12
12
12
12
12
12
12

STANDARD

IAIION

5.55
40.5

7516.0

0.38

0.025
0.303

0.303

7677.6

7.6
7.4
5.9

13.9

13.0

1.64

5.17

7.31
0.78

0.31

25.3

.33

1.83
20.5
20.2

20.2

21.0

5.4

0.03

*Not significant at the 95 percent confidence level.

DAIY SPECIFIC CONDUCTANCE IN INAJUN IABLE OE DALY SPECIEIC CONDUGTANCE

MICROMHOS AT 25 DEG C, THAT WAS

EQUALLED OR EXCEEDED FOR THE

$\begin{array}{llllll}12 & -58 & 102 & 20 \% & 30 \% & 502 \\ 203 & 196 & 191 & 173 & 166 & 132\end{array}$

BANGE

10.47

136.3

8851.7

0.064

0.517

0.544

7169.1

7.6

93.6

6.6

7.7

9.13
16.86

7.65

3.37

1.45

67.7

9.92

3.02

83.1

87.0

65.8

10.2

5.0
0.09
SIZE BEG

EGRESSION SUMMABY

$\begin{array}{rrr}3.3 & 19.0 & \\ 66 & 198 & \\ 2590 & 29500 & 12 \\ 7.2 & 8.2 & 12 \\ 0.03 & 0.11 & 12 \\ 0.04 & 1.10 & 12 \\ 0.18 & 1.60 & 12 \\ 560 & 26000 & 11 \\ 1 & 27 & \\ 78 & 100 & \\ 1 & 47 & \\ 1 & 36 & \\ 7.1 & 12.0 & 12 \\ 7.9 & 23.0 & 12 \\ 2.0 & 30.0 & 12 \\ 1.9 & 4.2 & 12 \\ 0.7 & 1.8 & 12 \\ 21 & 93 & 12 \\ 0 & 0 & 8 \\ 6.8 & 12.0 & 12 \\ 1.4 & 7.8 & 12 \\ 44 & 101 & 12 \\ 46 & 109 & 12 \\ 29 & 91 & 12 \\ 2 & 19 & 12 \\ 1 & 16 & 12 \\ 0.0 & 0.1 & 12\end{array}$

$\begin{array}{rr}-0.0068 & 10.0639 \\ 0.1055 & 2.4697 \\ 0.0771 & -2.8610 \\ 0.0155 & 1.2481 \\ 0.0041 & 0.8906 \\ 0.539 & -5.860 \\ 0.000 & 0.000 \\ 0.0098 & 8.5929 \\ 0.0064 & 2.1581 \\ 0.445 & 22.475 \\ 0.442 & 26.699 \\ 0.435 & 6.451 \\ -0.009 & 11.431 \\ -0.061 & 13.360 \\ 0.0001 & 0.0824\end{array}$
REGRESSION
COEFICIENT, CONSTANT, CORRELATION
R

$\begin{array}{rrrr}-136.535 & 27465.988 & -0.737 & 5331.5 \\ 0.0044 & 6.9541 & 0.467 * & 0.36 \\ 0.00037 & 0.01393 & 0.597 & 0.021 \\ 0.00229 & 0.20510 & 0.307 * & 0.302 \\ 0.00378 & 0.02881 & 0.411 * & 0.356 \\ -56.530 & 14918.879 & -0.312 * & 7087.5\end{array}$

$-0.169$

0.827

0.427 *

0.812

0.544

0.865

0.000

0.298

0.141

0.880

0.889

0.840

$-0.069$

-0.506
0.096

\section{SAMPLE SIZE $=321$ \\ $202 \quad 25 \% 29 \%$ \\ $69 \quad 6506$}

\begin{tabular}{|c|c|c|c|c|c|}
\hline & & & & & STANDARD \\
\hline & HARMONIC & AMPLITUDE & PHASE & VARIATION & ERROR OF \\
\hline $\begin{array}{l}\text { SAMPLE } \\
\text { SUZE }\end{array}$ & MEAN - M & $-A^{A}$ & ANGLE $-\mathrm{C}$ & EXPLAINED & ESTIMATE \\
\hline & $1026 \mathrm{c}$ & 10E- & & & \\
\hline 320 & 10.36 & 7.91 & 2.43 & 98 & 0.86 \\
\hline
\end{tabular}

SUMMARY OF MAXIMUM AND MINIMUM CONCENTRATIONS OF CONSTITUENTS SAMPLED AT A FREQUENCY OF QUARTERLY (1975 WY)

12433000 -- SPOKANE RIVER AT LONG LAKE, WASH

\begin{tabular}{|c|c|c|c|c|c|c|}
\hline \multirow{2}{*}{ CONSTI TUENT } & \multicolumn{3}{|c|}{ TOTAL } & \multicolumn{3}{|c|}{ DISSOLVED } \\
\hline & $\begin{array}{l}\text { NO. } \\
\text { SAMPLES }\end{array}$ & $\begin{array}{l}\text { MINIMUM } \\
\text { CONC. }\end{array}$ & $\begin{array}{l}\text { MAXIMUM } \\
\text { CONC. }\end{array}$ & $\begin{array}{l}\text { NO. } \\
\text { SAMPLES }\end{array}$ & $\begin{array}{l}\text { MINIMUM } \\
\text { CONC. }\end{array}$ & $\begin{array}{l}\text { MAXIMUM } \\
\text { CONC. }\end{array}$ \\
\hline \multicolumn{7}{|l|}{ MINOR ELEMENTS: } \\
\hline ARSENIC (AS), UG/L & 4 & 1 & 3 & 4 & 2 & 2 \\
\hline CADMIUM $(C D), U G / L$ & 4 & $<10$ & 20 & 4 & 0 & 1 \\
\hline CHROMIUM (CR), UG/L & 4 & 0 & 20 & 4 & 0 & 10 \\
\hline COBALT $(C O), U G / L$ & 4 & $<50$ & $<50$ & 4 & 0 & 2 \\
\hline COPPER (CU), UG/L & 4 & $<10$ & 170 & 4 & 3 & 9 \\
\hline IRON (FE), UG/L & 4 & 40 & 420 & 4 & 10 & 50 \\
\hline LEAD $(P B), U G / L$ & 4 & $<100$ & 100 & 4 & 1 & 3 \\
\hline MANG ANESE (MN), UG/L & 4 & 30 & 150 & 4 & 30 & 60 \\
\hline MERCURY $(H G), U G / L$ & 4 & 0.0 & 0.2 & 4 & 0.0 & 0.0 \\
\hline SELENIUM $(S E), U G / L$ & 4 & 0 & 0 & 4 & 0 & 0 \\
\hline ZINC $(Z N), U G / L$ & 4 & 60 & 160 & 4 & 20 & 80 \\
\hline \multicolumn{7}{|l|}{ PERIPHYTON: } \\
\hline BIOMASS, DRY WT., G/SQ M & 4 & 2.09 & 11.00 & & & \\
\hline BIOMASS, ASH WT., G/SQ M & 4 & .79 & 6.69 & & & \\
\hline CHLOROPHYLL A, MG/SO M & 3 & .0 & 43.0 & & & \\
\hline CHLOROPHYLL B, MG/SO M & 3 & .0 & 5.1 & & & \\
\hline ORGANIC CARBON, MG:LL & 4 & 2.0 & 17.0 & & & \\
\hline
\end{tabular}


LAT 46D15M13S LONG $119028 M 37 S$

DRAINAGE AREA: 5015 SQ MI ( 14543 SQ KM)

PERIOD OF RECORD: $10 / 01 / 74-09 / 30 / 75$

STATISTICAL SUMMARY OF SELECTED DISSOLVED CHEMICAL CONSTITUENTS AND

REGRESSION RELATIONSHIPS OF CONSTITUENT CONCENTRATIONS TO SPECIFIC CONDUCTANCE

CONSIIIUENI

CONSILUENI IMGLL OR UNLI SHOWNI

$S A M$
$S I$
36
36
36
35
36
12
36
1
1
12
34
12
12
36
36
36
36
36
36
36
12
12
36
36

6.53

2963.2

7.84

0.39

0.146

0.730

0.402

4641.7

88.8

83.9
212.2

11789.9

21.58

22.36

7.64
13.20

13.20

114.0

0.0

12.14

5.06

136.3

139.0

87.2

12.7

0.070

0.357

0.172

3638.8

131.9

10.7
261.8

201.8
25250.6

4.54
7.63

7.63

2.69

5.37

0.80
39.2

39.2
0.0

5.39

1.94

49.1

47.9

29.4

13.2

0.05
BEGRESSION SUMMARY

REGRESSION SAMPLE
SIZE COEFICIENT.

CONSTANT,

CORRELATION

STANDAR:
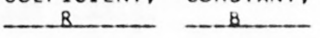
COEELCIENI ESIIMAI:

TEMPERATURE, WATER (DEG C) STREAMFLOW (CUBIC FT/SEC)

PH (STANDARD UNITS)

NITRITE + NITRATE, TOTAL

NITROGEN, KJELDAHL, TOTAL

PHYTOPLANKTON, TOTAL (CELLS/ML)

SEDIMENT, SUSPENDED

SEDIMENT, CLAY-SILT (PERCENT)

COLIFORM, FECAL (COL/1OO ML)
SIREPTOCOCCI, FECAL ICOL/1O0 ML

SILICA, DISSOLVED

CALCIUM, DISSOLVED

MAGNESIUM, DISSOLVED

POTASSIUM, DISSOLVED

BICAREONATE, ION

CARBONATE, ION

SULFATE, DISSOLVED

CHLORIDE, DISSOLVED

DISSOLVED SOLIDS, SUM OF CONST

DISSOLVED SOLIDS,
HARDNESS, TOTAL

HARDNESS, NONCARBONATE

FLOURIDE, DISSOLVED

1.7

23.5
490
1600
8.5

$\begin{array}{rrr}1700 & 11600 & 36 \\ 6.8 & 8.5 & 35\end{array}$

$0.09 \quad 0.40 \quad 36$

$\begin{array}{lll}0.37 & 1.40 & 12 \\ 0.12 & 0.97 & 36\end{array}$

-25.027
0.0022
-0.00030

$-0.00030$

0.00425

$-0.00007$

$-18.407$

10671.695
7.3080
0.21866
-0.16321
0.41981
8511.637

$-0.78$

0.525

$-0.401$

0.953

$-0.040^{*}$

1600
7

14000

1855.

0.06

0.11

0.174

3489

25
99
15.0
11.0
3.8
5.6
1.2
57
0
4.3
1.5
76
78
44
0
0
0.1

95
1500
5000

85000

$29.0 \quad 12$

0.0524

0.0666

0.5623
6.2697

0.924

0.813

0.0226

2.1782

1.8131

0.7762

30.068

0.0071

0.347

0.000

0.0462

0.9750

1.1707

7.781

13.886

0.61

0.595

24.976

0.777

$-0.002$

$-0.083$

32.828

0.1214

0.782

0.817

0.823

0.826

.000

0.798

0.773

0.997

0.996

0.817

-0.156 *

$-0.591$

0.451 *

DAILY SPECIFIC CONDUCTANCE IN

MICROMHOS AT 25 DEG C, THAT WAS

EQUALLED OR EXCEEDED FOR THE

SAMPLE SIZE $=247$

INDICATEO PERCENTAGE OF TIME

$\begin{array}{lll}-16 & 52 & 108 \\ 355 & 340 & 333\end{array}$

202

$30 \%$

*Not significant at the 95 percent confidence level.

SUMMARY OF HARMUNIC ANALYSIS OF STREAM TEMPERATURE

\begin{tabular}{|c|c|c|c|c|c|}
\hline & & & & & STANDARD \\
\hline & HARMONIC & AMPLITUDE & PHASE & VAR IATION & ERROR OF \\
\hline SAMPLE & MEAN - M & $-A$ & ANGLE - C & EXPLAINED & ESTIMATE \\
\hline SIZE_ & $\left.10 E G_{C} C\right)_{2}$ & $1 D E G(1)$ & (RADLANS) & -181 & IDEG_C \\
\hline 248 & 11.02 & 8.12 & 2.64 & 94 & 1.45 \\
\hline
\end{tabular}

SUMMARY OF MAXIMUM AND MINIMUM CONCENTRATIONS OF CONSTITUENTS SAMPLED AT A FREQUENCY OF QUARTERLY (1975 WY)

12510500 -- YAKIMA RIVER AT KIONA, WASH

\begin{tabular}{|c|c|c|c|c|c|c|}
\hline \multirow{2}{*}{ CONSTITUENT } & \multicolumn{3}{|c|}{ TOTAL } & \multicolumn{3}{|c|}{ DISSOLVED } \\
\hline & $\begin{array}{l}\text { NO. } \\
\text { SAMPLES }\end{array}$ & $\begin{array}{l}\text { MINIMUM } \\
\text { CONC. }\end{array}$ & $\begin{array}{l}\text { MAXIMUM } \\
\text { CONC. }\end{array}$ & $\begin{array}{l}\text { NO. } \\
\text { SAMPLES }\end{array}$ & $\begin{array}{l}\text { MINIMUM } \\
\text { CONC. }\end{array}$ & $\begin{array}{l}\text { MAXIMUM } \\
\text { CONC. }\end{array}$ \\
\hline \multicolumn{7}{|l|}{ MINOR ELEMENTS: } \\
\hline ARSENIC (AS), UG/L & 4 & 0 & 3 & 4 & 0 & 2 \\
\hline CAOMIUM $(C D)$, UG/L & 4 & $<10$ & 10 & 4 & 0 & 1 \\
\hline CHROMIUM (CR), UG/L & 4 & 0 & 0 & 28 & 0 & $<10$ \\
\hline COBALT $(C O), U G / L$ & 4 & $<50$ & $<50$ & 4 & 0 & 1 \\
\hline COPPER $(C U), U G / L$ & 4 & $<10$ & 70 & 28 & 0 & 30 \\
\hline IRON (FE), UG/L & 4 & 190 & 11000 & 4 & 10 & 170 \\
\hline$L E A D(P B), U G / L$ & 4 & $<100$ & $<100$ & 28 & 0 & 38 \\
\hline MANGANESE $(M N), U G / L$ & 4 & 10 & 330 & 4 & 0 & 50 \\
\hline MERCURY (HG), UG/L & 27 & 0.0 & 0.4 & 4 & 0.0 & 0.1 \\
\hline SELENIUM (SE), UG/L & 4 & 0 & 0 & 4 & 0 & 0 \\
\hline ZINC $(Z N), U G / L$ & 4 & 20 & 160 & 28 & 0 & 300 \\
\hline \multicolumn{7}{|l|}{ PERIPHYTON: } \\
\hline BIOMASS, DRY WT., G/SQ M & 3 & 1.50 & 3.09 & & & \\
\hline BIOMASS, ASH WT., G/SQ M & 3 & .59 & 1.50 & & & \\
\hline CHLOROPHYLL A, MG/SQ M & 3 & .0 & 3.3 & & & \\
\hline CHLOROPHYLL $B$, MG/SO M & 3 & .0 & $\cdot 1$ & & & \\
\hline ORGANIC CARBON, MG/L & 3 & 2.6 & 15.0 & & & \\
\hline
\end{tabular}


LAT $43018 M 06 S$ LONG $110046 M 335$

DRAINAGE AREA:

3465 SQ $M I$

PERIOL OF RECORO: $10 / 01 / 74-09 / 30 / 75$

STATISTICAL SUMMARY OF SELECTED DISSOLVED CHEMICAL CONSTITUENTS AND

REGRESSION RELATIONSHIPS OF CONSTITUENT CONCENTRATIONS TO SPECIFIC CONDUCTANCE

CONSIHIUENI

CONSIUUENI IMG/L OB UNII SHOWNU

\begin{tabular}{r} 
SAMP \\
S12 \\
\hline 17 \\
17 \\
17 \\
12 \\
12 \\
9 \\
10 \\
12 \\
12 \\
12 \\
12 \\
12 \\
12 \\
12 \\
12 \\
12 \\
12 \\
12 \\
12 \\
12 \\
12 \\
12 \\
12 \\
11 \\
12
\end{tabular}

STANDARD

DEXIAIION

5.68

330.2

5077.1

8.15

8.15
0.012

0.014

0.014
0.198

1921.4

56.0

5.02
06.4

4741.3

0.22

0.013

0.024

0.149

2006.3
112.9

$30.3 \quad 47.0$

38.1

11.59

40.50

9.27

9.03

2.22

133.3

0.0
39.75

39.75
7.02

183.7

47.0
68.7

1.42

8.93

2.62

.07

23.1
0.0

0.0
11.11

3.24
34.3

140.8

140.8
31.5
6.7

31.9

31.9

14.0

11.6 $\begin{array}{rr}0.0 & 15.5 \\ 245 & 480\end{array}$

$1450 \quad 16000$

$\begin{array}{rr}7.8 & 8.6 \\ 0.00 & 0.05\end{array}$

0.00

0.00

$320 \quad 6100$

6100
380

$\begin{array}{ll}1 & 160 \\ 2 & 240\end{array}$

$8.1 \quad 13.0$

$29.0 \quad 56.0$

$6.3 \quad 13.0$

$\begin{array}{rr}3.7 & 15.0 \\ 1.2 & 3.7\end{array}$

1.2

$\begin{array}{rr}0 & 160 \\ 21.0 & 54.0\end{array}$

$3.6 \quad 13.0$

124

$\begin{array}{rr}99 & 170 \\ 10 & 47\end{array}$

$\begin{array}{rr}0 & 30 \\ 0.2 & 0.6\end{array}$

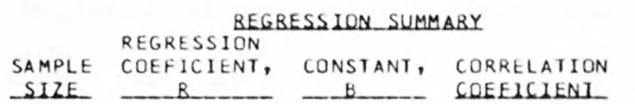

BES

SIZE B B COEEICIENI.

STANDARD ERROR OF ESIIMAIE

$\begin{array}{rr}17 & -39.498 \\ 12 & -0.0012 \\ 12 & -0.00007 \\ 9 & 0.00011 \\ 10 & 0.00058 \\ 7 & 3.480\end{array}$
18118.270
8.5452
0.03696
-0.02271
-0.00527
803.493

$-0.553$

-0.376 .

-0.395 .

0.348 *

0.263 *
0.155 *

4080.7

0.21

0.013

0.024

0.152
2171.2

12
12
12
12
12
12
12
12
12
12
12
12
11
12

$$
\begin{array}{r}
0.0088 \\
0.0041 \\
0.0185 \\
0.0189 \\
0.0043 \\
0.201 \\
0.000 \\
0.0918 \\
0.0233 \\
0.279 \\
0.265 \\
0.101 \\
-0.076 \\
0.0007
\end{array}
$$

$$
\begin{array}{r}
8.6134 \\
18.8108 \\
3.0170 \\
2.6378 \\
0.7477 \\
65.256 \\
0.000 \\
8.7071 \\
-0.8542 \\
89.190 \\
50.951 \\
-2.690 \\
32.123 \\
0.1835
\end{array}
$$

0.438 *

0.507 .

0.499 *

0.463 *

0.459

0.616

0.000

c. 583

0.508 .

0.576

0.588

0.511 *

-0.476 *
1.34

8.07

2.38

\begin{tabular}{|c|c|c|c|c|c|}
\hline & & & & & STANDARD \\
\hline & HARMONIC & AMPLITUDE & PHASE & VARIATION & ERROR OF \\
\hline SAMPLE & MEAN - M & $-A$ & ANGLE $-C$ & EXPLAINED & ESTIMATE \\
\hline SLZE_ & WES Cl & - $D E G(1)$ & IBADIANSI & (z) & 10EG_61 \\
\hline
\end{tabular}

2.68

0.62

19.1

0.0

9.46

2.93
29.4

27.0

27.0

12.6

10.8
0.08

\begin{tabular}{|c|c|c|c|c|c|c|}
\hline \multirow{2}{*}{ CONSTITUENT } & \multicolumn{3}{|c|}{ TOTAL } & \multicolumn{3}{|c|}{ DISSOLVED } \\
\hline & $\begin{array}{l}\text { NO. } \\
\text { SAMPLES }\end{array}$ & $\begin{array}{l}\text { MINIMUM } \\
\text { CONC. }\end{array}$ & $\begin{array}{l}\text { MAXIMUM } \\
\text { CONC. }\end{array}$ & $\begin{array}{c}\text { NO. } \\
\text { SAMPLES }\end{array}$ & $\begin{array}{l}\text { MINIMUM } \\
\text { CONC. }\end{array}$ & $\begin{array}{l}\text { MAXIMUM } \\
\text { CONC. }\end{array}$ \\
\hline \multicolumn{7}{|l|}{ MINOR ELEMENTS: } \\
\hline ARSENIC (AS), UG/L & 4 & 3 & 5 & 4 & 2 & 5 \\
\hline CADMIUM $(C D), U G / L$ & 3 & $<10$ & 10 & 4 & 0 & 1 \\
\hline CHROMIUM (CR), UG/L & 3 & 0 & 0 & 3 & 0 & 0 \\
\hline COBALT $(C C), U G / L$ & 3 & 0 & $<50$ & 3 & 0 & 0 \\
\hline COPPER (CU), UG/L & 3 & $<10$ & 35 & 3 & 0 & 1 \\
\hline IRON $(F E), U G / L$ & 4 & 80 & 2200 & 3 & 0 & 10 \\
\hline LEAD $(P B), U G / L$ & 3 & $<100$ & 100 & 3 & 2 & 2 \\
\hline MANGANESE (MN), UG/L & 4 & 0 & 100 & 4 & 0 & 0 \\
\hline MERCURY $(H G)$, UG/L & 3 & 0.0 & 1.5 & 3 & 0.0 & 0.2 \\
\hline SELENIUM (SE), UG/L & 4 & 0 & 0 & 4 & 0 & 0 \\
\hline$Z I N C(Z N), U G / L$ & 3 & 10 & 40 & 4 & 0 & 10 \\
\hline \multicolumn{7}{|l|}{ PERIPHYTON: } \\
\hline BIOMASS, DRY WT., G/SQ M & 2 & .89 & 15.00 & & & \\
\hline BIOMASS, ASH WT., G/SO M & 3 & .79 & 14.00 & & & \\
\hline CHLOROPHYLL A, MG/SO M & 3 & 1.0 & 53.0 & & & \\
\hline CHLOROPHYLL B, MG/SQ M & 3 & $\cdot 1$ & 9.0 & & & \\
\hline ORGANIC CARBON, MG/L & 4 & 1.1 & 7.0 & & & \\
\hline
\end{tabular}

*Not significant at the 95 percent confidence level.

DAILY SPECIFIC CONDUCTANCE IN

UUBAILON IABLE OE DAILY SPECIEIC CONDUCIANCE

MICROMHOS AT 25 DEG C, THAT WAS

EQUALLED UR EXCEEDED FOR THE

$\begin{array}{lllllll}18 & -53 & 10 \% & 208 & 30 \% & 50 \%\end{array}$

SAMPLE SIZE $=362$

INDICATED PERCENTAGE OF TIME

388

$373 \quad 368$

363

$359 \quad 340$

$70 \%$

$202 \quad 252 \quad 298$

$222 \quad 211 \quad 200$

SUMMARY UF HARMONIC ANALYSIS OF STREAM TEMPERATURE

365

6.06

6.00

2.54

88

1.49

SUMMARY OF MAXIMUM AND MINIMUM CONCENTRATIONS OF CONSTITUENTS SAMPLED AT A FREQUENCY OF QUARTERLY (1975 KY)

13022500 -- SNAKE R AG RESERVOIR NR ALPINE, WYO 
LAT 43DOOMOBS LUNG 115012M06S DRAINAGE AREA: 35800 SO MI 192722 SO KM)

PERIOD OF RECORD: $10 / 01 / 74-09 / 30 / 75$

STATISTICAL SUMMARY OF SELECTED DISSOLVED CHEMICAL CONSTITUENTS AND

REGRESSION RELATIONSHIPS OF CONSTITUENT CONCENTRATIONS TO SPECIFIC CONDUCTANCE

CONSIIIUENI

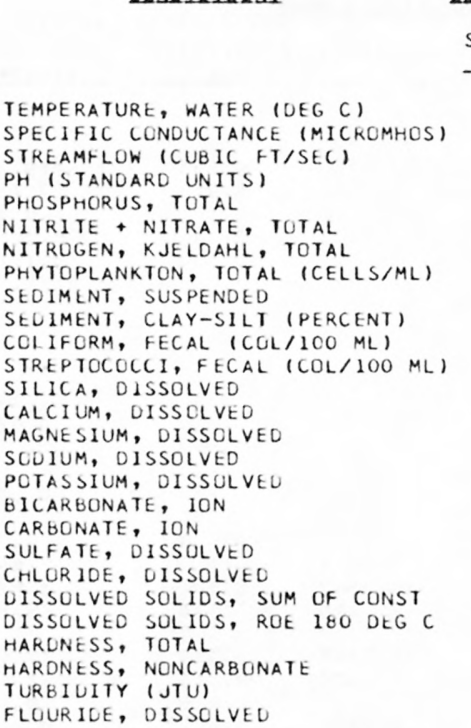

CONSILIUENI_MGLL_OB_UNII_SHOWN)

\begin{tabular}{rrr} 
SAMPLE & & \multicolumn{1}{r}{ STANDARD } \\
SIZE & MEAN. & REYIAIUON \\
12 & 12.96 & 5.11 \\
12 & 433.6 & 47.3 \\
12 & 13797.5 & 5582.8 \\
12 & 8.47 & 0.17 \\
12 & 0.071 & 0.016 \\
12 & 0.783 & 0.319 \\
12 & 0.797 & 1.037 \\
12 & 5775.0 & 5414.1 \\
12 & 27.2 & 20.6 \\
12 & 88.4 & 7.8 \\
12 & 43.9 & 34.4 \\
12 & 203.1 & 163.1 \\
12 & 26.00 & 4.03 \\
12 & 47.08 & 2.27 \\
12 & 18.42 & 1.78 \\
12 & 27.33 & 4.16 \\
12 & 4.45 & 0.48 \\
12 & 187.0 & 39.0 \\
12 & 21.8 & 18.8 \\
12 & 45.17 & 3.04 \\
12 & 22.83 & 2.59 \\
12 & 306.0 & 20.7 \\
12 & 286.9 & 46.7 \\
12 & 193.3 & 12.3 \\
12 & 7.9 & 11.0 \\
12 & 7.9 & 8.4 \\
12 & 0.70 & 0.35
\end{tabular}
BEGRESSION_SUMMABY REGRESSION SAMPLE COEFICIENT, CONSTANT CURRELATION STANDARD
ERRCR UF

ESIIMAIE

\begin{tabular}{rrr} 
BANGE & & SIZ \\
\cline { 3 - 3 } 6.0 & 20.0 & \\
346 & 506 & \\
0870 & 26000 & 12 \\
8.2 & 8.7 & 12 \\
0.05 & 0.10 & 12 \\
0.24 & 1.20 & 12 \\
0.28 & 4.00 & 12 \\
2100 & 21000 & 12 \\
8 & 80 & \\
70 & 96 & \\
10 & 115 & \\
44 & 568 & \\
17.0 & 31.0 & 12 \\
42.0 & 50.0 & 12 \\
16.0 & 22.0 & 12 \\
21.0 & 33.0 & 12 \\
3.4 & 5.0 & 12 \\
120 & 254 & 12 \\
0 & 53 & 12 \\
40.0 & 50.0 & 12 \\
18.0 & 26.0 & 12 \\
271 & 331 & 12 \\
163 & 329 & 12 \\
170 & 210 & 12 \\
0 & 29 & 12 \\
1 & 30 & 12 \\
0.5 & 1.8 & 12 \\
& &
\end{tabular}

-

-30.436
-0.0006
0.00006
0.00494
0.00030
-39.719


0.0583
0.0366
0.0207
0.0623
0.0059
0.080
0.051
0.0544
0.0458
0.375
0.466
0.192
0.031
-0.052

COEELCIENI.
29595.406

8.7243

0.04447

$-1.35881$

0.66803

22996.523

$-0.308 *-5569.8$

$-0.164 *$

$0.732-0.228$

$-0.347 * \quad 5326.1$
$0.014 * \quad 1.087$

*Not significant at the 95 percent confidence level.

DAILY SPECIFIC CONDUCTANCE IN

MICROMHOS AT 25 DEG C, THAT WAS

$\begin{array}{llllll}-12 & -5 \% & 10 \% & 20 z & 30 \% & 50 \%\end{array}$

EQUALLEO UR EXCEEDEL FOR THE

521

518

512

488

$461 \quad 444$

SUMMARY OF HARMONIC ANALYSIS OF STREAM TEMPERATURE

\begin{tabular}{|c|c|c|c|c|c|}
\hline & & & & & STANDARD \\
\hline & HARMONIC & AMPLITUDE & PHASE & VAR IATION & ERROR OF \\
\hline SAMPLE & $M E A N-M$ & $-A$ & ANGLE $-C$ & EXPLAINED & ESTIMATE \\
\hline S12E- & $1056 C 1$ & $10 E G(1$ & (BAD IANSI & $-1 \% 1$ & 10EG $(1)$ \\
\hline
\end{tabular}

SUMMARY OF MAXIMUM AND MINIMUM CONCENTRATIONS OF CONSTITUENTS

SAMPLED AT A FREQUENCY OF QUARTERLY (1975 WY)

13154500 -- SNAKE RIVER AT KING HILL IDAHO

\begin{tabular}{|c|c|c|c|c|c|c|}
\hline \multirow{2}{*}{ CONSTITUENT } & \multicolumn{3}{|c|}{ TOTAL } & \multicolumn{3}{|c|}{ DISSOLVED } \\
\hline & $\begin{array}{l}\text { NO. } \\
\text { SAMPLES }\end{array}$ & $\begin{array}{l}\text { MIN IMUM } \\
\text { CONC. }\end{array}$ & $\begin{array}{l}\text { MAXIMUM } \\
\text { CONC. }\end{array}$ & $\begin{array}{l}\text { NO. } \\
\text { SAMPLES }\end{array}$ & $\begin{array}{l}\text { MINIMUM } \\
\text { CONC. }\end{array}$ & $\begin{array}{l}\text { MAXIMUM } \\
\text { CONC. }\end{array}$ \\
\hline \multicolumn{7}{|l|}{ MINOR ELEMENTS: } \\
\hline ARSENIC (AS), UG/L & 4 & 2 & 5 & 4 & 2 & 5 \\
\hline CADMIUM $(C D), U G / L$ & 4 & $<10$ & 40 & 4 & 0 & 1 \\
\hline CHROMIUM $(C R), U G / L$ & 4 & 0 & 20 & 4 & 0 & 10 \\
\hline COBALT $(C O), U G / L$ & 4 & 50 & $<50$ & 4 & 0 & 2 \\
\hline COPPER (CU), UG/L & 4 & 10 & 45 & 4 & 2 & 7 \\
\hline IRON $(F E), U G / L$ & 4 & 300 & 1300 & 4 & 10 & 10 \\
\hline LEAD (PB), UG/L & 4 & $<100$ & $<100$ & 4 & 0 & 4 \\
\hline MANGANESE (MN), UG/L & 4 & 10 & 90 & 4 & 0 & 10 \\
\hline MERCURY $(H G), U G / L$ & 3 & 0.0 & 0.3 & 4 & 0.0 & 0.3 \\
\hline SELENIUM (SE), UG/L & 4 & 0 & 1 & 4 & 0 & 1 \\
\hline$Z I N C(Z N), U G / L$ & 4 & 10 & 110 & 4 & 10 & 20 \\
\hline \multicolumn{7}{|l|}{ PERIPHYTON: } \\
\hline BLOMASS, DRY WT., G/SQ M & 4 & 27.00 & 52.00 & & & \\
\hline BIOMASS, ASH WT., G/SO M & 4 & 17.00 & 50.00 & & & \\
\hline CHLOROPHYLL A, MG/SO M & 4 & 3.9 & 62.0 & & & \\
\hline CHLOROPHYLL B, MG/SO M & 4 & $\cdot 9$ & $6 \cdot \mathbb{1}$ & & & \\
\hline ORGANIC CARBON, MG/L & 4 & 3.0 & 8.0 & & & \\
\hline
\end{tabular}


LAT $43046 M 54 S$ LONG $116058 M 175$

DRAINAGE AREA: 3970 SO MI ( 10282 SQ KMI

PERICD CF RECORD: 10/01/74-09/30/75

STATISTICAL SUMMARY OF SELECTED DISSOLVED CHEMICAL CONSTITUENTS AND

REGRESSION RELATIONSHIPS OF CONSTITUENT CONCENTRATIONS TO SPECIFIC CONDUCTANCE

CONSIIUUENI

TEMPERATURE, WATER (DEG C)
SPECIFIC CONDUCTANCE (MICROMHOS)
STREAMFLCW (CUBIC FT/SEC)
PH (STANDARD UNITS)
PHOSPHORU, TOTAL
NITRITE + NITRATE, TOTAL
NITROGEN, KJELDAHL, TOTAL
PHYTOPLANKTON, TOTAL (CELLS/ML)
SEDIMENT, SUSPENDED
SEDIMENT, CLAY-SILT (PERCENT)
COLIFORM, FECAL (COL/IOO ML)
STREPTOCOCCI, FECAL (COL/IOO ML)
SILICA, DISSOLVED
CALCIUM, DISSOLVED
MAGNESIUM, DISSOLVED
SOUIUM, DISSOLVE
POTASSIUM, DISSOLVED
BICARBONATE, ION
CARBONATE, ION
SULFATE, DISSOLVED
CHLORIDE, DISSOLVED
DISSOLVED SCLIDS, SUM OF CONST
DISSOLVED SOLIDS, ROE I8O DEG C
HARDNESS, TOTAL
HARDNESS, NONCARBONATE
TUREIDITY (JTU)
FLOURIOE, OISSOLVED

CONSIUUENI IMG $/ L$ OR UNII SHOWNI

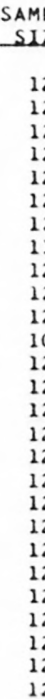

STANDARO

$\begin{array}{ll}\text { SAMPLE } & \text { STANDARO } \\ \text { SIZE } & \text { MEAN } \\ & \text { DEXIALIION }\end{array}$

12
12
12
12
12
12
12
11
12
12
12
10
12
12
12
12
12
12
12
12
12
12
12
12
12
12
12

$\begin{array}{rrr}11.46 & 5.45 & 5.0 \\ 397.1 & 161.9 & 124 \\ 2106.4 & 2204.1 & 92 \\ 7.97 & 0.37 & 7 \\ 0.308 & 0.161 & 0.0 \\ 1.609 & 0.871 & 0.3 \\ 0.987 & 0.833 & 0.34 \\ 4227.3 & 1982.0 & 210 \\ 136.0 & 209.4 & 18 \\ 64.8 & 28.2 & \\ 545.7 & 427.7 & 149 \\ 2454.2 & 3537.4 & 186 \\ 25.42 & 6.68 & 15.0 \\ 35.25 & 11.79 & 14.0 \\ 9.43 & 3.99 & 2.3 \\ 44.00 & 19.20 & 10.0 \\ 4.14 & 1.64 & 1.2 \\ 182.4 & 64.2 & 73 \\ 3.8 & 9.0 & \\ 42.81 & 19.16 & 7.7 \\ 14.12 & 6.66 & 3.1 \\ 269.3 & 98.7 & 90 \\ 262.4 & 101.2 & 88 \\ 128.1 & 46.8 & 45 \\ 0.0 & 0.0 & \\ 11.3 & 7.7 & \\ 0.45 & 0.11 & 0.3\end{array}$

BANGE

5.0
124
920
7.4
0.07
0.30
0.34
2100
18
5
149
186
15.0
14.0
2.3
10.0
1.2
73
0
7.7
3.1
90
88
45
0
2
0.3

BEGBESSION SUMMABY

REGRESSION SAMPLE COEFICIENT, CONSTANT,

CORRELATION SIZE

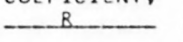
- B COEEICIENI ESIIMAIE

$\begin{array}{rr}20.0 & \\ 561 & \\ 7500 & 12 \\ 8.5 & 12 \\ 0.65 & 12 \\ 2.70 & 12 \\ 3.40 & 12 \\ 8600 & 11 \\ 664 & \\ 94 & \\ 1570 & \\ 12100 & \\ 34.0 & 12 \\ 50.0 & 12 \\ 14.0 & 12 \\ 61.0 & 12 \\ 6.1 & 12 \\ 268 & 12 \\ 24 & 12 \\ 66.0 & 12 \\ 23.0 & 12 \\ 359 & 12 \\ 368 & 12 \\ 180 & 12 \\ 0 & 12 \\ 29 & 12 \\ 0.7 & 12\end{array}$

6489.289
7.2403
0.04701
-0.33636
1.06271
4840.992

4840.992

11.4877

0.2540

$-2.1562$

$-2.1562$

48.271

48.271

$-2.0911$

-2.0911
-1.4959

33.562

37.385

16.258

0.000

23.634

0.2706
$-0.811$

0.806

0.063

$-0.330^{\circ}$

$-0.330^{*}$.

1353.0

0.23

0.126

0.376

0.825
2070.9

0.850

0.979

0.938

0.986
0.953

0.852
0.342

0.342
0.955

0.956

0.974

0.907

0.975

0.000 *

$-0.649$

0.073
0.852 *

*Not significant at the 95 percent confidence level.

DURALION IABLE_CE DALIY SPECIEIC CONDUCIANCE
DAILY SPECIFIC CONDUCTANCE IN
MICROMHOS AT 25 DEG C, THAT WAS

SUMMARY OF HARMONIC ANALYSIS OF STREAM TEMPERATURE

\begin{tabular}{|c|c|c|c|c|c|}
\hline & & & & & STANDARD \\
\hline & HARMONIC & AMPLITUDE & PHASE & VARIATION & ERROR OF \\
\hline SAMPLE & MEAN - M & $-A$ & ANGLE - C & EXPLAINED & ESTIMATE \\
\hline SLIE & INEG EL & $10 E 6(1)$ & LRADIANSI & (\%) & LEE_ $C 1$ \\
\hline 191 & 13.15 & 9.25 & 3.02 & 82 & 2.17 \\
\hline
\end{tabular}

SUMMARY UF MAXIMUM AND MINIMUM CONCENTRATIONS OF CONSTITUENTS SAMPLED AT A FREQUENCY OF QUARTERLY (1975 WY)

13213000 -- BOISE RIVER NR PARMA IDA

\begin{tabular}{|c|c|c|c|c|c|c|}
\hline \multirow{2}{*}{ CONSTI IUENT } & \multicolumn{3}{|c|}{ TOTAL } & \multicolumn{3}{|c|}{ DISSOLVED } \\
\hline & $\begin{array}{l}\text { NO. } \\
\text { SAMPLES }\end{array}$ & $\begin{array}{l}\text { MIN IMUM } \\
\text { CONC. }\end{array}$ & $\begin{array}{l}\text { MAXIMUM } \\
\text { CONC. }\end{array}$ & $\begin{array}{c}\text { NO. } \\
\text { SAMPLES }\end{array}$ & $\begin{array}{l}\text { MINIMUM } \\
\text { CONC. }\end{array}$ & $\begin{array}{c}\text { MAXIMUM } \\
\text { CONC. }\end{array}$ \\
\hline \multicolumn{7}{|l|}{ MINOR ELEMENTS: } \\
\hline ARSENIC (AS), UG/L & 4 & 8 & 20 & 4 & 6 & 11 \\
\hline CADMIUM $(C D), U G / L$ & 4 & $<10$ & $<10$ & 4 & 0 & 2 \\
\hline CHROMIUM (CR), UG/L & 4 & 0 & 10 & 4 & 0 & 10 \\
\hline COBALT $(C O), U G / L$ & 4 & $<50$ & $<50$ & 4 & 0 & 0 \\
\hline COPPER $(C U), U G / L$ & 4 & 10 & 50 & 4 & 5 & 13 \\
\hline IRON (FE), UG/L & 4 & 670 & 2400 & 4 & 10 & 60 \\
\hline$L E A D(P B), U G / L$ & 4 & $<100$ & $<100$ & 4 & 5 & 7 \\
\hline MANG ANESE (MN), UG/L & 4 & 60 & 120 & 4 & 0 & 50 \\
\hline MERCURY $(H G), U G / L$ & 3 & 0.1 & 0.3 & 4 & 0.0 & 90.0 \\
\hline SELENIUM (SE), UG/L & 4 & 0 & 1 & 4 & 0 & 1 \\
\hline$Z I N C(Z N), U G / L$ & 4 & 20 & 40 & 4 & 0 & 30 \\
\hline \multicolumn{7}{|l|}{ PERIPHYTON: } \\
\hline BIOMASS, DRY WT.. G/SQ M & 3 & 19.00 & 91.00 & & & \\
\hline EIOMASS, ASH WT., G/SQ M & 4 & 11.00 & 84.00 & & & \\
\hline CHLOROPHYLL A, MG/SQ M & 4 & 12.0 & 46.0 & & & \\
\hline CHLOROPHYLL B, MG/SU M & 4 & 1.4 & $8 \cdot 8$ & & & \\
\hline ORGANIC CARBON, MG/L & 4 & 4.3 & 9.4 & & & \\
\hline
\end{tabular}


LAT 43052M34S LONG $116059 M 02 S$

DRAINAGE AREA: 58700 SO MI I 152033 SQ KM

PERIOD OF RECURD: $10 / 01 / 74$ - 09/30/75

STATISTICAL SUMMARY OF SELECTEO DISSOLVED CHEMICAL CONSTITUENTS AND

REGRESSION RELATIONSHIPS OF CONSTITUENT CONCENTRATIONS TO SPECIFIC CONDUCTANCE

CONSIUIUENI

CONSIUUENI IMG L OR UNII_SHOWN

\begin{tabular}{rrr}
$\begin{array}{rrr}\text { SAMPLE } \\
\text { SIZE }\end{array}$ & MEAN & \multicolumn{1}{r}{ STANDARO } \\
QEYIAIION \\
12 & 11.92 & 7.07 \\
12 & 457.0 & 97.3 \\
12 & 17627.5 & 9577.0 \\
12 & 8.67 & 0.11 \\
12 & 0.082 & 0.052 \\
12 & 0.689 & 0.363 \\
12 & 0.689 \\
12 & 0.944 & 0.987 \\
11 & 11590.9 & 7071.4 \\
12 & 47.6 & 48.1 \\
12 & 67.1 & 21.4 \\
12 & 702.4 & 1569.7 \\
12 & 3025.2 & 7949.2 \\
12 & 24.17 & 4.78 \\
12 & 44.58 & 5.11 \\
12 & 16.67 & 3.60 \\
12 & 34.17 & 8.93 \\
12 & 4.92 & 1.36 \\
12 & 159.1 & 37.9 \\
12 & 29.6 & 21.2 \\
12 & 55.00 & 11.86 \\
12 & 22.33 & 5.60 \\
12 & 310.3 & 52.1 \\
12 & 305.7 & 58.9 \\
12 & 180.0 & 25.6 \\
12 & 8.6 & 12.1 \\
12 & 11.3 & 9.7 \\
12 & 0.62 & 0.11
\end{tabular}

0.62

2.1

0.11

BEGRESSION_SUMMABY

REGRESSION REGRESSION,
COEFICIENT, CONSTANT, SAMPLE COEFICIENT, CORRELATIUN COEEICIENI.

STANDARD ERROR OF ESIIMAIE

TEMPERATURE, WATER (DEG C) SPECIFIC CONDUCTANCE (MICROMHOS) STREAMFLOW (CUBIC FT/SEC)

PH (STANDARD UNITS )

PHOSPHORUS, TOTAL

NITRITE + NITRATE, TOTAL

NITROGEN, KJELDAHL, TOTAL

PHYTOPLANKTON, TOTAL ICELLS/ML

SEDIMENT, SUSPENDED

SEDIMENT, CLAY-SILT IPERCENT

COLIFORM, FECAL (COL/100 ML)

STREPTOCOCCI, FECAL $(\mathrm{COL} / 100 \mathrm{ML})$

SILICA, DISSOLVED

CALCIUM, DISSOLVED

MAGNE SIUM, DI SSOLVED

SODIUM, DISSOLVED

POTASSIUM, DISSOLVED

GICAR BONATE, ION

CARBONATE, ION

SULFATE, DISSOLVED

CHLORIDE, DISSOLVED

DISSOLVED SOLIDS, SUM OF CONST

OISSOLVED SOLIDS, ROE 180 DEG

HARONESS, TUTAL

HARUNESS, NONCARBONATE

TURBIDITY (JTU)

FLOURIDE, DISSOLVED

24.0

$\begin{array}{rr}3.5 & 2400 \\ 302 & 508 \\ 8790 & 39200\end{array}$

$\begin{array}{lll}8790 & 39200 & 12\end{array}$

$8.8 \quad 12$

0.02

0.06

0.06

4.00

28000

$\begin{array}{rr}4500 & 28000 \\ 5 & 179 \\ 9 & 87 \\ 25 & 5530\end{array}$

5530
28100

$\begin{array}{rrr}75 & 28100 & 30.0\end{array}$

$\begin{array}{lll}14.0 & 51.0 & 12\end{array}$

21.0

47.0

21.0

$\begin{array}{rrr}3.0 & 8.1 & 12 \\ 88 & 232 & 12\end{array}$

$\begin{array}{rrr}0 & 77 & 12 \\ 34.0 & 72.0 & 12\end{array}$

$14.0 \quad 32.0$

367
376
210

210

140

0
1
0.5

210
41
31

41
31
0.9

*Not significant at the 95 percent confidence level.

DAILY SPECIFIC CONDUCTANCE IN

WURAILON IABLE OF PAJLY SPECIEIC CONOUCIANCE

MICROMHOS AT 25 DEG C, THAT WAS

EQUALLED OR EXCEEDED FOR THE

$\begin{array}{llllll}-1 \% & -5 \% & 10 \% & 20 \% & 30 \% & 50 \%\end{array}$

502

575

$570 \quad 565$

553

480

428

702

$$
\begin{array}{r}
-71.846 \\
0.0002 \\
-0.00015 \\
0.00272 \\
-0.00487
\end{array}
$$

$-27.465$

8.5723

0.15130

$-0.55500$

3.16960

23922.621

$-0.730$

$0.187 *$
$-0.282 *$

$-0.282$

0.729
-0.480

$-0.480 *$

0.11

0.052

0.261

6894.3

\begin{tabular}{|c|c|c|c|c|c|}
\hline $\begin{array}{l}\text { SAMPLE } \\
\text { SIZE- }\end{array}$ & $\begin{array}{l}\text { HARMONIC } \\
\text { MEAN - M } \\
\text { IDEG_CI }\end{array}$ & $\begin{array}{c}\text { AMPLITUDE } \\
-A \\
\text { - } \\
\end{array}$ & $\begin{array}{l}\text { PHASE } \\
\text { ANGLE - C } \\
\text { IBAOIANSI) }\end{array}$ & $\begin{array}{l}\text { VARIATION } \\
\text { EXPLAINED } \\
(18)\end{array}$ & $\begin{array}{l}\text { STANDARD } \\
\text { ERROR OF } \\
\text { ESTIMATE } \\
\text { JOEG EL }\end{array}$ \\
\hline 97 & 14.37 & 10.67 & 2.99 & 88 & 2.27 \\
\hline
\end{tabular}

=

SUMMARY OF HARMONIC ANALYSIS OF STREAM TEMPERATURE

SUMMARY OF MAXIMUM AND MINIMUM CONCENTRATIONS OF CONSTITUENTS

SAMPLED AT A FREQUENCY OF QUARTERLY (1975 WY)

13213100 -- SNAKE R AT NYSSA OR

\begin{tabular}{l} 
CONSIITUENT \\
\hline SAMPLES
\end{tabular}


Table 14.--Sumnary of measurement at each station--Continued

LAT 45D15MO5S LONG 116D41M50S

DRAINAGE AREA: 73300 SQ MI 1189847 SQ KMI

PERIOD OF RECORD: $10 / 01 / 74-09 / 30 / 75$

STATISTICAL SUMMARY OF SELECTED DISSOLVED CHEMICAL CONSTITUENTS AND

REGRESSION RELATIONSHIPS OF CONSTITUENT CONCENTRATIONS TO SPECIFIC CONDUCTANCE

CONSILIUENI

CONSILIUENI IHG L OR UNII SHOWN

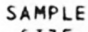

STANDARD

SHZE

MEAN

DEYIAIION

TEMPERATURE, WATER (DEG C) SPECIFIC CONDUCTANCE (MICROMHOS) STREAMFLOW (CUBIC FT/SEC)

PH ISTANDARD UNITS

PHCSPHORUS, TOTAL

NITRITE + NITRATE, TOTAL

NITROGEN, KJELDAHL, TOTAL

PHYTOPLANKTON, TOTAL (CELLS/ML)

SEDIMENT, SUSPENDED

SEDIMENT, CLAY-SILT (PERCENT)

COLIFORM, FECAL (COL $100 \mathrm{ML}$ )

STREPTOCOCCI, FECAL (COL/100 ML)

SILICA, DISSOLVED

CALCIUM, DISSOLVED

MAGNESIUM, DISSOLVED

SODIUM, UISSOLVED

POTASSIUM, DISSOLVED

BICARBONATE, ION

CARBONATE, ION

SULFATE, DISSOLVED

CHLORIDE, OISSOLVED

DISSOLVED SOLIDS, SUM UF CONST

DISSOLVED SOLIOS, RUE 180 DEG

HARDNESS, TOTAL

HARDNESS, NONCARBONATE

TURBIDITY (JTU)

FLOURIDE, DISSOLVED

*Not significant at the 95 percent confidence level.

SUMMARY OF HARMONIC ANALYSIS OF STREAM TEMPERATURE

\begin{tabular}{|c|c|c|c|c|c|}
\hline & & & & & STANDARD \\
\hline & HARMONIC & AMPLITUDE & PHASE & VARIATION & ERROR OF \\
\hline SAMPLE & MEAN - $M$ & $-A$ & ANGLE - C & EXPLAINED & ESTIMATE \\
\hline SLZE_ & $10 E 6$ (1) & LEE_L & (BADLANS) & -181 & LEEG C \\
\hline 12 & 12.60 & 9.59 & 2.47 & 97 & 1.24 \\
\hline
\end{tabular}

BEGRESSION SUMMARY REGRESSION

SAMPLE COEFICIENT, CONSTANT, CORRELATION -B COEEICIENI

STANDARD ERROR OF ESIUMAIE

$\begin{array}{rrrrrr}12 & 12.54 & 0.97 & 1.5 & 24.0 & \\ 12 & 349.3 & 91.9 & 229 & 535 & \\ 12 & 28333.3 & 16122.4 & 10400 & 60100 & 12 \\ 12 & 8.39 & 0.23 & 8.1 & 8.8 & 12 \\ 12 & 0.072 & 0.032 & 0.03 & 0.15 & 12 \\ 12 & 0.548 & 0.387 & 0.02 & 1.10 & 12 \\ 12 & 0.747 & 0.907 & 0.22 & 3.50 & 12 \\ 12 & 4742.5 & 5001.9 & 320 & 16000 & 12 \\ 0 & & & & & \\ 0 & & & & & \\ 12 & 1.8 & 1.1 & 1 & 4 & \\ 12 & 67.7 & 110.4 & 3 & 350 & \\ 12 & 19.75 & 4.92 & 12.0 & 26.0 & 12 \\ 12 & 34.75 & 6.72 & 25.0 & 43.0 & 12 \\ 12 & 12.99 & 4.07 & 7.7 & 19.0 & 12 \\ 12 & 28.92 & 9.30 & 17.0 & 41.0 & 12 \\ 12 & 4.01 & 0.93 & 2.7 & 5.0 & 12 \\ 12 & 144.8 & 43.2 & 37 & 210 & 12 \\ 12 & 15.8 & 17.7 & 0 & 48 & 12 \\ 12 & 41.75 & 11.50 & 28.0 & 59.0 & 12 \\ 12 & 15.98 & 4.71 & 9.8 & 23.0 & 12 \\ 12 & 245.8 & 57.0 & 170 & 320 & 12 \\ 12 & 242.4 & 62.3 & 156 & 333 & 12 \\ 12 & 141.3 & 33.7 & 97 & 190 & 12 \\ 12 & 3.9 & 5.6 & 0 & 18 & 12 \\ 12 & 4.1 & 4.1 & 1 & 13 & 12 \\ 12 & 0.51 & 0.08 & 0.4 & 0.7 & 12\end{array}$

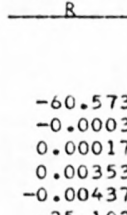

49488.566
8.5005
0.01058
-0.68522
2.27318

$-0.345$

$-0.126$

$-0.443$.

$-0.401 *$

15868.9

0.24

0.029

0.22

0.853

4654.5

0.0447
0.0593
0.0351
0.0876
0.0087
0.281
0.015
0.1125
0.0432
0.546
0.604
0.290
0.017
-0.021
0.0005

4.1519

14.0223

0.7423

$-1.6887$

0.9799

46.497

10.34

2.4432

0.9004

55.206
31.524

31.524
40.137

$-1.999$

11.266

0.3442

0.834

0.812

0.793

0.866

0.861

0.599

0.080 *

0.900

0.842

0.879

0.891

0.790

0.276 *

$0.456 *$
$0.545 *$
2.84

4.12

2.00

4.87

0.49

36.3

18.5

5.26

2.67

28.5

29.7

21.7

3.9

0.07

SUMMARY OF MAXIMUM AND MINIMUM CONCENTRATIONS OF CONSTITUENTS

SAMPLED AT A FREQUENCY OF OUARTERLY (1975 WY)

13290450 -- SNAKE RIVER AT HELLS CANYON DAM ID OR LINE

CONSTITUENT
SAMPLES


LAT 45045MOIS LONG $116019 M 23 S$ DRAINAGE AREA: 13550 SQ MI 135095 SO KM) PERIOD GF RECORD: $10 / 01 / 74-09 / 30 / 75$

STATISTICAL SUMMARY OF SELECTED DISSOLVED CHEMICAL CONSTITUENTS AND

REGRESSION RELATIONSHIPS OF CONSTITUENT CONCENTRATIONS TO SPECIFIC CONDUCTANCE

CONSIIIUENI

CONSIUIUENI IMG L OR UNII SHOWN

SAMP
$S 12$

12
12
12
12
12
12
12
12
11
1
12
1
12
12
12
12
12
12
12
1
1
12
1
1
12
12

STANDARD

MEAN DEYIALION

8.33

142.5

13002.5

7.65

0.032

0.059

0.529

1653.3

18.3

66.1

14.17

19.13

3.77

6.60

1.33

81.4

0.0
9.18

97.3

96.8

63.5

63.5

3.0
5.2

5.2
0.33
6.44
44.7

16999.1

0.39

0.019

0.052

1.033

1590.9
20.9

20.9
25.0

33.6

199.5

1.27

6.50

6.50
1.46

1.46
1.90

1.90
0.28

26.7

0.0
3.23

0.53

25.5

23.8

22.0

6.6

0.08

TURBIDITY (JTU)

FLOUR IDE, DISSOLVED

*Not significant at the 95 percent confidence leve1.

SUMMARY OF HARMONIC ANALYSIS OF STREAM TEMPERATURE

\begin{tabular}{|c|c|c|c|c|c|}
\hline & & & & & STANDARD \\
\hline & HARMONIC & AMPLITUDE & PHASE & VARIATION & ERROR OF \\
\hline SAMPLE & MEAN - M & $-A$ & ANGLE - C & EXPLAINED & ESTIMATE \\
\hline SIZE_ & DEEG & IDEG $C 1$ & IBADLANSI & $-1 \% 1$ & (DEG $C)_{2}$ \\
\hline 12 & & 8.32 & 50 & 86 & 2.63 \\
\hline
\end{tabular}

BANGE REGRESSION

BEGBESS ION SUMMABY SAMPLE COEFICIENT, CONSTANT, CORRELATION ERROR UF
SIZE SAMPLE COEFICIENT, CONSTANT, CORRELATION ERROR UF
SIZE - B - B

CORRELATION STANOARU $\begin{array}{rr}0.5 & 20.0 \\ 52 & 202\end{array}$ $2740 \quad 61200 \quad 12$

7.18 .2 $0.01 \quad 0.07$ 0.00 0.06 230 3
25

1
7
11.0

11.0
7.0

7.6
0.9
2.8

2.8
0.7

0.7
20

0
2.9

1.0
43
47

23
0

1
0.2
SIZE

$-1-1$

$\begin{array}{rr}-329.832 & 60003.563 \\ 0.0071 & 6.6371 \\ -0.00028 & 0.07256 \\ -0.00012 & 0.07623 \\ -0.00998 & 1.95090 \\ 7.889 & 529.129\end{array}$

-0.868
0.816
-0.657
$-0.104^{*}$
$-0.432 *$
$0.222 *$

8861.0

0.24

0.015

0.054

1627.0

29.129
$5900 \quad 1$

0.0150
0.1167
0.0301
0.0408
0.0046
0.551
0.000
0.0693
0.0089
0.536
0.498
0.417
0.005
-0.140
0.0015

12.0357
2.5056
-0.5079
0.7888
0.0831
2.919
0.000
-0.0856
0.7285
20.838
25.779
4.145
2.262
25.077
0.1125

0.528 *

1.13

4.06

0.60
0.57

0.57

0.20

0.958

0.730

0.922

0.000 *

0.959

0.752

0.941

0.936

0.846

0.035 *

$-0.878$

$0.1125 \quad 0.890$

13317000 - SALMON RIVER AT WHITEBIRD, IDAHO

\begin{tabular}{|c|c|c|c|c|c|c|}
\hline \multirow{2}{*}{ CONSTITUENT } & \multicolumn{3}{|c|}{ TOTAL } & \multicolumn{3}{|c|}{ DISSOLVED } \\
\hline & $\begin{array}{l}\text { NO. } \\
\text { SAMPLES }\end{array}$ & $\begin{array}{l}\text { MINIMUM } \\
\text { CONC. }\end{array}$ & $\begin{array}{l}\text { MAXIMUM } \\
\text { CONC. }\end{array}$ & $\begin{array}{l}\text { NO. } \\
\text { SAMPLES }\end{array}$ & $\begin{array}{l}\text { MINIMUM } \\
\text { CONC. }\end{array}$ & $\begin{array}{l}\text { MAXIMUM } \\
\text { CONC. }\end{array}$ \\
\hline \multicolumn{7}{|l|}{ MINOR ELEMENTS: } \\
\hline ARSENIC (AS), UG/L & 4 & 1 & 3 & 4 & 1 & 2 \\
\hline CADMIUM $(C D), U G / L$ & 4 & $<10$ & $<10$ & 4 & 0 & 1 \\
\hline CHROMIUM (CR), UG/L & 4 & 0 & 50 & 4 & 0 & 10 \\
\hline COBALT $(C O), U G / L$ & 4 & 0 & $<50$ & 4 & 0 & 0 \\
\hline COPPER $(C U), U G / L$ & 4 & 20 & 170 & 4 & 1 & 8 \\
\hline IRON (FE), UG/L & 4 & 120 & 3000 & 4 & 30 & 50 \\
\hline$L E A D(P B), U G / L$ & 4 & $<100$ & $<100$ & 4 & 2 & 9 \\
\hline MANGANESE (MN), UG/L & 4 & 10 & 60 & 4 & 0 & 10 \\
\hline MERCURY (HG), UG/L & 3 & 0.0 & 0.1 & 4 & 0.0 & 0.0 \\
\hline SELENIUM (SE), UG/L & 4 & 0 & 2 & 4 & 0 & 0 \\
\hline ZINC $(Z N), U G / L$ & 4 & 10 & 40 & 4 & 0 & 10 \\
\hline \multicolumn{7}{|l|}{ PERIPHYTON: } \\
\hline BIOMASS, DRY WT. , G/SQ M & 0 & & & & & \\
\hline BIOMASS, ASH WT., G/SO M & 1 & 5.39 & & & & \\
\hline CHLOROPHYLL A, MG/SO M & 1 & $\cdot 2$ & & & & \\
\hline CHLOROPHYLL B, MG/SQ M & 1 & $\cdot 4$ & & & & \\
\hline ORGANIC CARBON, MG/L & 4 & .0 & 4.9 & & & \\
\hline
\end{tabular}


LAT 46D12M59S LONG $119001 M 22 S$

DRAINAGE AREA: 0 SQ MI I

PERIOD OF RECORD: $10 / 01 / 74-09 / 30 / 75$

SQ KMI

STATISTICAL SUMMARY OF SELECTED DISSOLVED CMEMICAL CONSTITUENTS AND

REGRESSION RELATIONSHIPS OF CONSTITUENT CONCENTRATIONS TO SPECIFIC CONDUCTANCE

CONSILIUENI

TEMPERATURE, WATER (DEG C)
SPECIFIC CUNDUCTANCE (MICROMHOS)
STREAMFLOW (CUBIC FT/SEC)
PH (STANDARD UNITS)
PHOSPHORUS, TOTAL
NITRITE, NITRATE, TOTAL
NITROGEN, KJELDAHL, TOTAL
PHYTOPLANK TON, TOTAL (CELLS/ML)
SEDIMENT, SUSPENDED
SEDIMENT, CLAY-SILT (PERCENT)
COLIFORM, FECAL (COL/IOO ML)
STREPTOCOCCI, FECAL (COL/IOO ML)
SILICA, DISSOLVED
CALCIUM, DISSOLVED
MAGNESIUM, DISSOLVED
SODIUM, DISSOLVED
POTASSIUM, DISSOLVED
BICARBONATE, ION
CARBONATE, ION
SULFATE, DISSOLVED
CHLORIDE, DISSOLVED
DISSOLVED SOLIDS, SUM OF CONST
DISSOLVED SOLIDS, ROE I8O DEG C
HARDNESS, TOTAL
HARDNESS, NONCARBONATE
IURBIDITY (JTU)
FLOURIDE, DISSOLVED

\begin{tabular}{r} 
SONSI \\
SAMP \\
SI2 \\
\hline 12 \\
12 \\
12 \\
12 \\
12 \\
12 \\
12 \\
12 \\
12 \\
10 \\
11 \\
11 \\
12 \\
12 \\
12 \\
12 \\
12 \\
12 \\
5 \\
12 \\
12 \\
12 \\
12 \\
12 \\
12 \\
12 \\
12 \\
\end{tabular}

BEGRESSION SUMMABY

REGRESSION SAMPLE COEFICIENT, CONSTANT, COR

STANDARD SIZE - B - B B - B COEEICIENI ESIIMAIE

STEANDARD
MEYIAIION

BANGE

11.48
235.3

62475.0

7.94

6.38
101.1
48347.0

101.0
0.33

2.
74
27300
7

0.122

0.190

0.328

0.117

0.302

3091.7

18.3

95.8
6.2
12.9

12.9
16.08

22.53

7.23

16.67

2.53

104.5

104.5
0.0

24.02
9.02

9.02
150.1

150.1
156.1

156.1
86.2

86.2
2.5

9.8

3036.1

15.4
5.9

5.9
8.0

13.1

3.15

7.81

3.60

8.50

41.4

41.4
0.0

12.02

4.79
60.3

61.4

34.4
3.9

3.9

0.25
21.2
381

$300 \quad 166000$

$\begin{array}{ll}0.57 & 12 \\ 9100 & 12\end{array}$

460

4

11. 1

46
100

100
22

22
39
19.0

19.0
34.0

13.0

29.0

3.9
162

162
0

41.0
16.0

16.0
236

241
140

140
13

24 $\begin{array}{ll}7.4 & 8.6 \\ 0.04 & 0.72\end{array}$

$\begin{array}{lll}0.08 & 1.00 & 12 \\ 0.17 & 0.57 & 12\end{array}$

12
12
12
12
12
12


12
12
12
12
12
12
5
12
12
12
12
12
12
12
12

133048.250
7.4151
0.31322
-0.18262
0.21536

$-0.027$

0.694.
-0.433.

$-0.433$

0.776

0.321
$-0.188^{*}$

$-5.630$

4416.598

9.7919

$-0.9382$

$-2.7528$

0.4739
8.337

0.000

$-3.3237$

$-1.9957$

10.365

13.967

7.735
2.960

19.905

$-0.0042$
39484.8

0.25

0.180

0.217

3127.8 $\begin{array}{lll}0.72 & 12\end{array}$

*Not significant at the 95 percent confidence level.

\section{DURAILON IABLE_OE DAILY SPECIEIC_CONDUCIANCE}

DAILY SPECIFIC CONDUCTANCE IN

MICROMHOS AT 25 DEG C. THAT WAS

EQUALLED OR EXCEEDED FOR THE

$\begin{array}{lllllll}17 & -5 \pi & 10 z & 20 z & 30 z & 50 z\end{array}$

Q2.

$70 z$

SAMPLE SIZE $=319$

$20 \% 25 \% \quad 993$

INDICATED PERCENTAGE OF TIME

377

146

$88 \quad 80 \quad 76$

SUMMARY OF HARMONIC ANALYSIS OF STREAM TEMPERATURE

\begin{tabular}{|c|c|c|c|c|c|}
\hline & & & & & STANDARD \\
\hline $\begin{array}{l}\text { SAMPLE } \\
\text { SIZE }\end{array}$ & $\begin{array}{l}\text { HARMONIC } \\
\text { MEAN - M } \\
\text { (DEG C) }\end{array}$ & $\begin{array}{c}\text { AMPLI TUDE } \\
-A \\
(D E G C)\end{array}$ & $\begin{array}{c}\text { PHASE } \\
\text { ANGLE - C } \\
\text { (BADIANS) }\end{array}$ & $\begin{array}{l}\text { VAR IATION } \\
\text { EXPLAINED } \\
\end{array}$ & $\begin{array}{l}\text { ERROR OF } \\
\text { ESTIMATE } \\
\text { LDEG_C }\end{array}$ \\
\hline 319 & 11.19 & 8.74 & 2.34 & 95 & 1.38 \\
\hline
\end{tabular}

SUMMARY OF MAXIMUM AND MINIMUM CONCENTRATIONS OF CONSTITUENTS SAMPLED AT A FREQUENCY OF QUARTERLY (1975 WY)

13353200 -- SNAKE RIVER AT BURBANK, WASH.

\begin{tabular}{|c|c|c|c|c|c|c|}
\hline \multirow{2}{*}{ CONSTI TUENT } & \multicolumn{3}{|c|}{ TOTAL } & \multicolumn{3}{|c|}{ DISSOLVED } \\
\hline & $\begin{array}{l}\text { NO. } \\
\text { SAMPLES }\end{array}$ & $\begin{array}{l}\text { MIN IMUM } \\
\text { CONC. }\end{array}$ & $\begin{array}{l}\text { MAXIMUM } \\
\text { CONC. }\end{array}$ & $\begin{array}{l}\text { NO. } \\
\text { SAMPLES }\end{array}$ & $\begin{array}{l}\text { MINIMUM } \\
\text { CONC. }\end{array}$ & $\begin{array}{l}\text { MAXIMUM } \\
\text { CONC. }\end{array}$ \\
\hline \multicolumn{7}{|l|}{ MINOR ELEMENTS: } \\
\hline ARSENIC (AS), UG/L & 4 & 2 & 4 & 4 & 3 & 5 \\
\hline CADMIUM $(C D), U G / L$ & 4 & 40 & 20 & 4 & 0 & 1 \\
\hline CHROMIUM (CR), UG/L & 4 & 0 & 10 & 4 & 0 & 10 \\
\hline COBALT $(C O), U G / L$ & 4 & 50 & $<.50$ & 4 & 0 & 1 \\
\hline COPPER $(C U), U G / L$ & 4 & $<10$ & 10 & 4 & 2 & 3 \\
\hline IRON (FE), UG/L & 4 & 110 & 1100 & 4 & 20 & 300 \\
\hline LEAD $(P B), U G / L$ & 4 & $<100$ & 100 & 4 & 0 & 4 \\
\hline MANGANESE (MN), UG/L & 3 & 0 & 40 & 4 & 0 & 10 \\
\hline MERCURY (HG), UG/L & 4 & 0.0 & 0.4 & 4 & 0.0 & 0.1 \\
\hline SELENIUM $(S E), U G / L$ & 4 & 0 & 0 & 4 & 0 & 0 \\
\hline ZINC $(Z N), U G / L$ & 4 & 20 & 190 & 4 & 0 & 80 \\
\hline \multicolumn{7}{|l|}{ PERIPHYTON: } \\
\hline BIOMASS, DRY WT., G/SO M & 4 & 1.50 & 23.00 & & & \\
\hline BIOMASS, ASH WT., G/SO M & 4 & .79 & 19.00 & & & \\
\hline CHLOROPHYLL A, MG/SQ M & 4 & .0 & 54.0 & & & \\
\hline CHLOROPHYLL $B$, MG/SQ M & 4 & .0 & 7.2 & & & \\
\hline ORGANIC CARBON, MG/L & 4 & 1.8 & 17.0 & & & \\
\hline
\end{tabular}


LAT 45035M16S LONG 120024M30S

JRAINAGE AREA: 7580 SQ MI ( 19632 SQ KMI

PERIOD OF RECORD: $10 / 01 / 74-09 / 30 / 75$

STATISTICAL SUMMARY OF SELECTED DISSOLVED CHEMICAL CONSTITUENTS AND

REGRESSION RELATIONSHIPS OF CONSTITUENT CONCENTRATIONS TO SPECIFIC CONDUCTANCE

CONSIUIUENI

CONSILUENI IHGLL OR UNII SHOWNI

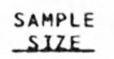

TEMPERATURE, WATER (DEG C)

SPECIFIC CONDUCTANCE (MICROMHOS)

STREAMFLOW (CUBIC FT/SEC)

PH (STANDARD UNITS)

PHOSPHORUS, TOTAL

NITRITE + NITRATE, TOTAL

NITROGEN, KJELOAHL, TOTAL

PHYTOPLANKTON, TOTAL (CELLS/ML)

SEDIMENT, SUSPENDED

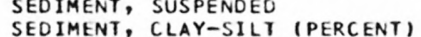

SEDIMENT, CLAY-SILT (PERCENT)
COLIFORM, FECAL (COL/100 ML)

COLIFORM, FECAL (COL/100 ML)
STREPTOCCCCI, FECAL (COL/100 ML)

SILICA, DISSOLVED

CALCIUM, DISSOLVED

MAGNE SIUM, DISSOLVED

SODIUM, DISSOLVED

POTASSIUM, DISSOLVED

BICARBONATE, ION

CARBONATE, ION

SULFATE, DISSOLVED

SULFATE, DISSOLVED
CHLORIDE, DISSOLVED

CHLORIDE, DISSOLVED

DISSOLVED SOLIDS, ROE 180 DEG C

HARDNESS, TOTAL

HARDNESS, NONCARBONATE

TURBIDITY (JTU)

FLOURIDE, DISSOLVED

${ }^{\star}$ Not significant at the 95 percent confidence level.
STANDARO

MEAN DEYIALION

12.03

220.6

2572.6

7.84

0.112

0.069

0.561

5700.0
164.1

164.1
85.0

85.0
25.9

24.9

23.82

20.33

8.85
12.12

12.12

124.5

124.5
0.0

0.0
7.09

2.45

139.3

141.8

88.4

0.0

31.6
7.51
85.7
2678.9

2678.9
0.39

0.221

0.095

0.816

7928.4

383.7

5.5

25.3
24.1
5.08

6.92

3.51

6.54

0.64

51.0
0.0

0.0

3.74

0.83
47.6

47.6

32.8

0.0

0.06
BANGE

$\begin{array}{ll}2.2 & 26.2 \\ 105 & 355\end{array}$

140

6.8

0.00

0.00
0.14

1000

1
79

7
1
11.0

11.0
11.0

4.3

4.3
4.8
1.0

1.0

62
0
2.7

2.7
1.3

1.3
79

82

46
0

0.1

SUMMARY OF HARMONIC ANALYSIS OF STREAM TEMPERATURE

\begin{tabular}{|c|c|c|c|c|c|}
\hline \multirow{4}{*}{$\begin{array}{l}\text { SAMPLE } \\
\text { SLZE }\end{array}$} & & & & & STANDARD \\
\hline & HARMONIC & AMPLITUDE & PHASE & VARIATION & ERROR OF \\
\hline & MEAN - M & - A & ANGLE - C & EXPLAINED & ESTIMATE \\
\hline & 10EG C1 & DEEG (1) & (RADIANS) & -181 & (DEG_C) \\
\hline 12 & 11.93 & 9.49 & 2.72 & 84 & 3.29 \\
\hline
\end{tabular}

SUMMARY OF MAXIMUM AND MINIMUM CONCENTRATIONS OF CONSTITUENTS SAMPLED AT A FREQUENCY OF QUARTERLY (1975 HY)

14048000 -- JOHN DAY R AT MCDONALD FERRY, OREG.

\begin{tabular}{|c|c|c|c|c|c|c|}
\hline \multirow{2}{*}{ CONSTITUENT } & \multicolumn{3}{|c|}{ TOTAL } & \multicolumn{3}{|c|}{ DISSOLVED } \\
\hline & $\begin{array}{l}\text { NO. } \\
\text { SAMPLES }\end{array}$ & $\begin{array}{l}\text { MIN IMUM } \\
\text { CONC. }\end{array}$ & $\begin{array}{l}\text { MAXIMUM } \\
\text { CONC. }\end{array}$ & $\begin{array}{l}\text { NO. } \\
\text { SAMPLES }\end{array}$ & $\begin{array}{l}\text { MINIMUM } \\
\text { CONC. }\end{array}$ & $\begin{array}{l}\text { MAXIMUM } \\
\text { CONC. }\end{array}$ \\
\hline \multicolumn{7}{|l|}{ MINOR ELEMENTS: } \\
\hline ARSENIC (AS), UG/L & 4 & 1 & 2 & 4 & 0 & 2 \\
\hline CADMIUM $(C D), U G / L$ & 4 & $<10$ & $<10$ & 4 & 0 & 3 \\
\hline CHROMIUM (CR), UG/L & 4 & 0 & 60 & 4 & 0 & 0 \\
\hline COBALT $(C O), U G / L$ & 4 & $<50$ & 50 & 4 & 0 & 2 \\
\hline COPPER (CU), UG/L & 4 & $<10$ & 120 & 4 & 2 & 10 \\
\hline IRON (FE), UG/L & 4 & 70 & 8800 & 4 & 20 & 170 \\
\hline LEAD $(P B), U G / L$ & 4 & $<100$ & 100 & 4 & 0 & 3 \\
\hline MANGANESE (MN), UG/L & 4 & 20 & 1600 & 4 & 0 & 30 \\
\hline MERCURY (HG), UG/L & 3 & 0.0 & 0.1 & 4 & 0.0 & 0.1 \\
\hline SELENIUM (SE), UG/L & 4 & 0 & 0 & 4 & 0 & 0 \\
\hline$Z I N C(Z N), U G / L$ & 4 & 20 & 300 & 4 & 0 & 90 \\
\hline \multicolumn{7}{|l|}{ PERIPHYTON: } \\
\hline BIOMASS, DRY WT., G/SQ M & 2 & .19 & 1.50 & & & \\
\hline BIOMASS, ASH WT.. G/SQ M & 2 & .09 & .79 & & & \\
\hline CHLOROPHYLL A, MG/SO M & 2 & .2 & .5 & & & \\
\hline CHLOROPHYLL B, MG/SO M & 2 & .0 & .1 & & & \\
\hline ORGANIC CARBON, MG/L & 3 & 2.7 & 28.0 & & & \\
\hline
\end{tabular}


Table 14.--Summary of measurement at each station--Continued

LAT 45D37M2OS LONG 120054M05S

DRAINAGE AREA: 10500 SQ MI I 27195 SQ KMI

PERIOD OF RECORD: $10 / 01 / 74-09 / 30 / 75$

STATISTICAL SUMMARY OF SELECTED DISSOLVED CHEMICAL CONSTITUENTS AND

REGRESSION RELATIONSHIPS OF CONSTITUENT CONCENTRATIONS TO SPECIFIC CONDUCTANCE

CONSIUIUENI

CONSIUIUENI IMG/L OR UNII SHOHN

SAMPLE
SIZE

STANDARD

MEAN DEYIAIION

TEMPERATURE, WATER (DEG C)

SPECIFIC CONDUCTANCE (MICROMHOS

STREAMFLOH (CUBIC FT/SEC)

PH (STANDARD UNITS)

PHOSPHORUS, TOTAL

NITRITE + NITRATE, TOTAL

NITROGEN, KJELDAHL, TOTAL

PHYTOPLANKTON, TOTAL (CELLS/ML)

SEDIMENT, SUSPENDED

SEDIMENT, CLAY-SILT (PERCENT)

COLIFORM, FECAL (COL/100 ML)

STREPIOCOCCI, FECAL ( $\mathrm{COL} / 100 \mathrm{ML})$

SILICA, DISSOLVED

CALCIUM, DISSOLVED

MAGNESIUM, DISSOLVED

SODIUM, DISSOLVED

POTASSIUM, DISSOL VED

BICARBONATE, ION

CARBONATE, ION

SULFATE, DISSOLVED

CHLORIDE, DISSOLVED

DISSOLVED SOLIDS, SUM OF CONST

DISSOLVED SOLIDS, ROE 180 DEG C

HARDNESS, TOTAL

HARDNESS, NONCARBONATE

TURBIDITY (JTU)

FLOURIDE, DISSOLVED

$\begin{array}{rrr}12 & 11.51 & 4.70 \\ 12 & 127.1 & 10.3 \\ 12 & 6474.8 & 1493.5 \\ 12 & 7.93 & 0.66 \\ 12 & 0.074 & 0.020 \\ 12 & 0.074 & 0.066 \\ 11 & 0.225 & 0.113 \\ 12 & 3156.7 & 3069.9 \\ 11 & 23.0 & 22.7 \\ 8 & 53.3 & 19.7 \\ 10 & 21.7 & 46.0 \\ 12 & 18.0 & 17.1 \\ 12 & 27.92 & 1.83 \\ 12 & 8.21 & 2.11 \\ 12 & 4.80 & 0.52 \\ 12 & 10.01 & 0.94 \\ 12 & 1.89 & 0.15 \\ 12 & 69.3 & 5.3 \\ 9 & 0.0 & 0.0 \\ 12 & 2.48 & 0.58 \\ 12 & 2.41 & 0.58 \\ 12 & 92.6 & 5.6 \\ 12 & 90.3 & 4.8 \\ 12 & 41.5 & 2.7 \\ 12 & 0.0 & 0.0 \\ 12 & 5.7 & 7.2 \\ 12 & 0.11 & 0.03\end{array}$

\section{BANGE}

\section{$\begin{array}{ll}5.5 & 20.5\end{array}$}

$108 \quad 148$

$\begin{array}{rr}4480 & 9170 \\ 6.4 & 8.8\end{array}$

6.4

0.04

0.10

560

8

25
1

1
26.0

26.0
1.9

1.9
4.1

8.7

1. 7

61

0
1.6
1.8
85

85
79

37

0
1

0.1

8.8
0.10

0.22

0.46

10000
85

150
56

56
32.0

32.0
9.9

6.0
11.0

2.3

0
3.8

3.8
3.9

103
95

95
45
0
23

23
0.2
BEGRESSION SUMMARY

REGRESSION

SAMPLE COEFICIENT, CONSTANT, CORRELATION

- B COEEICIENI

STANDARD

ERROR OF

SIZE

B

COEFICIENI ESILIMAIE

$\begin{array}{lr}12 & 19.638 \\ 12 & 0.0048\end{array}$

0.0048

0.00190

$-0.00445$

$-98.655$

7.3234

0.13834

$-0.16703$

0.79052

$0.135 *$

$0.074 *$

$-0.262$

$0.294^{*}$

-0.330 .

1552.

0.69

0.020

0.066

0.107

3039.8

12
12
12
12
12
12
9
12
12
12
12
12
12
12
12

0.0796
0.0181
0.0290
0.0189
-0.0031
0.071
0.000
0.0101
0.0255
0.213
0.105
0.145
0.000
-0.072
-0.0016

17.8016

5.9038

1.1201

7.6043

2.2859

60.363

0.000

1.1961

$-0.8315$

65.515
76.876

76.876
23.101

0.000

14.857

0.3180

0.446 *

0.088 *

0.572

0.206

$-0.211 *$

$0.136 *$

$0.000^{\circ}$

0.451.

0.451 *

0.397

0.227 *

0.547

0.000

-0.103.
-0.586

1.72

2.21

0.45

0.97

0.15
5.5

5.5
0.0
0.59

0.59

0.54

5.4
4.9

2.4

0.0

7.5
0.02

SUMMARY OF HARMONIC ANALYSIS OF STREAM TEMPERATURE

\begin{tabular}{|c|c|c|c|c|c|}
\hline & & & & & $\overline{\text { STANDARD }}$ \\
\hline & HARMONIC & AMPLITUDE & $\begin{array}{c}\text { PHASE } \\
\text { ANGLE }\end{array}$ & $\begin{array}{l}\text { VAR IATION } \\
\text { EXPIAINED }\end{array}$ & $\begin{array}{l}\text { ERROR OF } \\
\text { ESTIMATE }\end{array}$ \\
\hline $\begin{array}{l}\text { SAMPLE } \\
\text { SIZE }\end{array}$ & $\begin{array}{l}\text { MEAN }-M \\
\text { IOEG CI_ }\end{array}$ & ${ }_{D E G}{ }^{A}()$ & (BADIANSI) & $\begin{array}{l}\text { EXPLA } \\
-(8) \\
\end{array}$ & (DEG_C) \\
\hline 12 & 11.47 & 6.28 & 2.65 & 92 & 1.44 \\
\hline
\end{tabular}

SUMMARY OF MAXIMUM AND MINIMUM CONCENTRATIONS OF CONSTITUENTS SAMPLED AT A FREQUENCY OF QUARTERLY (1975 WY

14103000 -- DESCHUTES RIVER AT MOODY, NEAR BIGGS OREG

CONSTI TUENT


LAT $45045 M 24 S$ LONG $121012 M 32 \mathrm{~S}$
DRAINAGE AREA: 1297 SQ MI I

PERIOD OF RECORD: $10 / 01 / 74-09 / 30 / 3359$ SQ KM)

STATISTICAL SUMMARY OF SELECTED DISSOLVED CHEMICAL CONSTITUENTS AND

REGRESSION RELATIONSHIPS OF CONSTITUENT CONCENTRATIONS TO SPECIFIC CONDUCTANCE

CONSIIIUENI

TEMPERATURE, WATER (DEG C)
SPECIFIC CONDUCTANCE (MICROMHOS)
STREAMFLOW (CUBIC FT/SEC)
PH (STANDARD UNITS)
PHOSPHORUS, TOTAL
NITRITE, NITRATE, TOTAL
NITROGEN, KJELDAHL, TOTAL
PHYTOPLANKTON, TOTAL (CELLS/ML)
SEDIMENT, SUSPENDED
SEDIMENT, CLAY SILT (PERCENT)
COLIFORM, FECAL (COL/IOO ML)
STREPTOCOCCI, FECAL (COL/IOO ML)
SILICA, DISSOLVED
CALCIUM, DISSOLVED
MAGNESIUM, DISSOLVED
SOUIUM, DISSOLVED
POTASSIUM, DISSOLVED
BICARBONATE, ION
CARBONATE, ION
SULFATE, DISSOLVED
CHLORIDE, DISSOLVED
DISSOLVED SOLIOS, SUM OF CONST
DISSOLVED SOLIDS, ROE I8O DEG C
HARONESS, TOTAL
HARDNESS, NONCARBONATE
TUREIDITY (JTU)
FLOURIDE, DISSOLVED

CONSILIUENI IMG/L OR UNLI SHOWNI

\begin{tabular}{r} 
SAMPLE \\
S1ZE \\
\hline 12 \\
12 \\
12 \\
12 \\
12 \\
12 \\
12 \\
11 \\
12 \\
10 \\
12 \\
12 \\
12 \\
12 \\
12 \\
12 \\
12 \\
12 \\
5 \\
12 \\
12 \\
12 \\
12 \\
12 \\
12 \\
12 \\
12
\end{tabular}

MEAN

9.44

70.6

1935.2

7.69

0.112

0.153

0.169

913.6

49.2

64.0

30.1

46.3
27.00

7.00

3.05

4.59

1.35

41.1

0.0

2.31

1.47

67.2

70.9

30.3

0.4
7.6

0.10
STANDARD

4.16

12.5

1022.3

0.31
0.183

0.183
0.226

0.160

1456.3

110.4
210.4

21.7

52.0
109.7

109.7
3.28

1.56

0.49

3.31
0.22

6.2

0.0
0.65

0.65
0.96

9.7

15.3

4.9

1.4
9.3

9.3
0.07

BEGRESSION SUMMARY

REGRESSION \begin{tabular}{l} 
SAMPLE COEFICIENT, CONSTANT, CORRELATION \\
SIZE \\
\hline
\end{tabular}

STANDARD ERROR OF $-1$

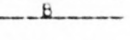

ESIIMAIE

*Not significant at the 95 percent confidence level.

4.0
48
904
7.0
0.03
0.00
0.08
150
5
35
1
2
22.0
5.3
1.9
2.7
1.0
27
0
1.4
0.2
49
51
22
0
1
0.0

$\begin{array}{rr}17.6 & \\ 91 & \\ 3060 & 12 \\ 8.1 & 12 \\ 0.68 & 12 \\ 0.73 & 12 \\ 0.63 & 12 \\ 5200 & 11 \\ 386 & \\ 94 & \\ 160 & \\ 390 & \\ 33.0 & 12 \\ 11.0 & 12 \\ 3.6 & 12 \\ 15.0 & 12 \\ 1.7 & 12 \\ 48 & 12 \\ 0 & 5 \\ 3.4 & 12 \\ 4.1 & 12 \\ 87 & 12 \\ 104 & 12 \\ 40 & 12 \\ 5 & 12 \\ 30 & 12 \\ 0.3 & 12\end{array}$

$-15.615$ 0.0007 0.00381 0.00849 0.00268

17.488 3037.344
7.6444 $-0.15657$ $-0.44564$ $-0.01997$

$-318.459$

-0.191 * 0.027 * $0.260^{*}$ 0.469 * $0.209^{*}$ 0.157

1052.4 0.33
0.186 0.210 0.165 1516.0

0.1827
0.0342
0.0238
0.0946
0.0077
0.405
0.000
0.0190
0.0194
0.593
0.910
0.172
-0.016
0.108
-0.0008

0.697

0.273 *

0.611 .

0.436 *

0.810

0.810 *

0.000

0.367
0.252 *
0.761

0.252
0.761

0.746

0.440 *

-0.141 *

$0.144^{*}$
2.46
1.58
0.40
3.24
0.21
3.8
0.0
0.63
0.98
6.6
10.7
4.6
1.5
9.7
0.08
0.1575

SUMMARY OF HARMONIC ANALYSIS OF STREAM TEMPERATURE

\begin{tabular}{|c|c|c|c|c|c|}
\hline & & & & & STANDARD \\
\hline & HARMONIC & AMPLITUDE & PHASE & VAR IATION & ERROR OF \\
\hline $\begin{array}{l}\text { SAMPLE } \\
\text { SIZE }\end{array}$ & MEAN - M & $-A$ & ANGLE - C & EXPLAINED & ESTIMATE \\
\hline & $10 E 6$ al & & IRADIANSI & -131 & (DEG C) \\
\hline
\end{tabular}

SUMMARY OF MAXIMUM AND MINIMUM CONCENTRATIONS OF CONSTITUENTS

SAMPLED AT A FREQUENCY OF QUARTERLY (1975 WY)

$14113000--$ KLICKITAT R NR PITT

CONSTITUENT
SAMPLES


Table 14,--Summary of measurement at each station--Continued

AT $45036 M 45 S$ LONG 122001 M35S

RAINAGE AREA: 240400 SO MI 1622636 SQ KMI

ERIOD OF RECORD: $10 / 01 / 74-09 / 30 / 75$

STATISTICAL SUMMARY OF SELECTED DISSOLVED CHEMICAL CONSTITUENTS AND

REGRESSION RELATIONSHIPS OF CONSTITUENT CONCENTRATIONS TO SPECIFIC CONDUCTANCE

CONSIIIUENI

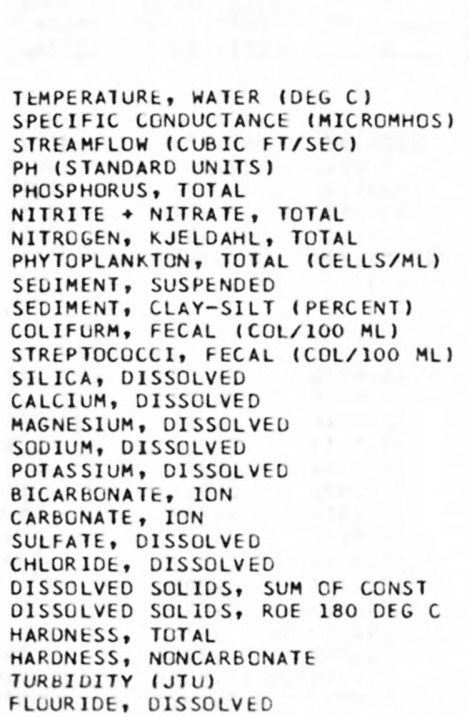

CONSIUUVENI IMG $/ 1$ OR UNII SHOWNI

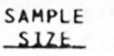

$\begin{array}{rrr}22 & 10.18 & 5.36 \\ 22 & 188.4 & 37.5 \\ 22 & 215500.0 & 72851.1 \\ 22 & 7.64 & 0.36 \\ 21 & 0.045 & 0.026 \\ 21 & 0.373 & 1.022 \\ 22 & 0.280 & 0.214 \\ 7 & 5957.1 & 3713.0 \\ 20 & 22.5 & 16.3 \\ 10 & 83.5 & 7.6 \\ 21 & 13.4 & 19.4 \\ 22 & 3.7 & 2.5 \\ 22 & 9.53 & 1.59 \\ 12 & 18.25 & 3.62 \\ 12 & 5.67 & 1.44 \\ 12 & 6.36 & 1.57 \\ 12 & 1.45 & 0.38 \\ 14 & 76.8 & 16.4 \\ 12 & 0.0 & 0.0 \\ 14 & 12.64 & 3.10 \\ 14 & 3.37 & 0.94 \\ 11 & 94.9 & 19.4 \\ 21 & 106.4 & 19.6 \\ 12 & 69.0 & 11.8 \\ 11 & 6.8 & 5.8 \\ 12 & 5.8 & 4.1 \\ 12 & 0.21 & 0.03\end{array}$

REGRESSION SUMMABY

REGRESSION

SAMPLE COEFICIENT, CONSTANT,

CORRELATION SIZE COEFICIENT, CONSTANT, COEEICIENI ESIUMAIE

$\begin{array}{rr}\text { BANGE } & \\ 3.0 & 20.3 \\ 107 & 230 \\ 114000 & 351500 \\ 6.9 & 8.3 \\ 0.02 & 0.12 \\ 0.01 & 4.80 \\ 0.07 & 1.00 \\ 1400 & 12000 \\ 1 & 48 \\ 67 & 94 \\ 1 & 84 \\ 1 & 12 \\ 5.8 & 12.0 \\ 12.0 & 23.0 \\ 3.6 & 8.8 \\ 3.9 & 8.3 \\ 1.0 & 2.1 \\ 48 & 103 \\ 0 & 0 \\ 7.7 & 18.0 \\ 1.5 & 5.1 \\ 64 & 127 \\ 57 & 146 \\ 45 & 94 \\ 0 & 16 \\ 2 & 13 \\ 0.2 & 0.3\end{array}$

-28836.375
7.7501
-0.00784
0.21046
0.00595
12438.600

0.667 $-0.063^{\circ}$ $0.394^{*}$ $0.031^{*}$

$0.255^{\circ}$

$-0.513^{*}$
55618.1 0.36
0.025 1.048 0.212 3491.0 *Not significant at the 95 percent confidence level. SUMMARY OF HARMGNIC ANALYSIS OF STREAM TEMPERATURE

\begin{tabular}{|c|c|c|c|c|c|}
\hline & & & & & STANDARD \\
\hline & HARMONIC & AMPLITUDE & PHASE & VARIATION & ERROR OF \\
\hline SAMPLE & MEAN - M & $-A$ & ANGLE - C & EXPLAINED & ESTIMATE \\
\hline SIZE. & IDEG 01 & (DEG $(1)$ & (BADLANS) & $(3)$ & CDEG C \\
\hline 22 & 11.50 & 7.85 & 2.23 & 95 & 1.28 \\
\hline
\end{tabular}

SUMMARY OF MAXIMUM AND MINIMUM CONCENTRATIONS OF CONSTITUENTS SAMPLED AT A FREQUENCY OF QUARTERLY (1975 WY)

14128910 -- COLUMBIA RIVER AT WARRENDALE, OREG.

\begin{tabular}{|c|c|c|c|c|c|c|}
\hline \multirow{2}{*}{ CONSTITUENT } & \multicolumn{3}{|c|}{ TOTAL } & \multicolumn{3}{|c|}{ DISSOLVED } \\
\hline & $\begin{array}{l}\text { NO. } \\
\text { SAMPLES }\end{array}$ & $\begin{array}{l}\text { MIN IMUM } \\
\text { CONC. }\end{array}$ & $\begin{array}{l}\text { MAXIMUM } \\
\text { CONC. }\end{array}$ & $\begin{array}{l}\text { NO. } \\
\text { SAMPLES }\end{array}$ & $\begin{array}{l}\text { MINIMUM } \\
\text { CONC. }\end{array}$ & $\begin{array}{l}\text { MAXIMUM } \\
\text { CONC. }\end{array}$ \\
\hline \multicolumn{7}{|l|}{ MINOR ELEMENTS: } \\
\hline ARSENIC (AS), UG/L & 20 & 0 & 4 & 3 & 0 & 1 \\
\hline CADMIUM $(C D)$, UG $/ L$ & 20 & 0 & 10 & 3 & 0 & 0 \\
\hline CHROMIUM (CR), UG/L & 20 & 0 & 20 & 3 & 0 & 10 \\
\hline COBALT $(C O), U G / L$ & 3 & $<50$ & 50 & 3 & 0 & 1 \\
\hline COPPER (CU), UG/L & 20 & $<10$ & 230 & 3 & 4 & 18 \\
\hline IRON (FE), UG/L & 20 & 170 & 1400 & 3 & 10 & 120 \\
\hline LEAD $(P B), U G / L$ & 20 & $<100$ & $<100$ & 3 & 0 & 2 \\
\hline MANGANESE (MN), UG/L & 3 & 10 & 30 & 3 & 0 & 0 \\
\hline MERCURY (HG), UG/L & 19 & 0.0 & 0.5 & 3 & 0.0 & 0.2 \\
\hline SELENIUM (SE), UG/L & 20 & 0 & 1 & 3 & 0 & 1 \\
\hline$Z I N C(Z N), U G / L$ & 20 & 20 & 100 & 3 & 0 & 10 \\
\hline \multicolumn{7}{|l|}{ PERIPHYYON: } \\
\hline BIOMASS, DRY WT., G/SO M & 3 & .19 & 10.00 & & & \\
\hline BIOMASS, ASH WT., G/SO M & 3 & .09 & 10.00 & & & \\
\hline CHLOROPHYLL A, MG/SO M & 3 & .0 & 7.1 & & & \\
\hline CHLOROPHYLL B, MG/SO M & 3 & .0 & $1 \cdot 5$ & & & \\
\hline ORGANIC CARBON, MG/L & 20 & 1.5 & 11.0 & & & \\
\hline
\end{tabular}


Table 14,--Sumary of measurement at each station--Continued

STATION NUMBER: 14207500

NAME: TUALATIN RIVER AT WEST LINN,OREG.

LAT 45D21M03S LONG $122040 M 30 S$ DRAINAGE AREA: 0 SO MI

10 SO KMI

PERIOD OF RECORD: $10 / 01 / 74$ - 09/30/75

STATISTICAL SUMMARY OF SELECTED DISSOLVED CHEMICAL CONSTITUENTS AND

REGRESSION RELATIONSHIPS OF CONSTITUENT CONCENTRATIONS TO SPECIFIC CONDUCTANCE

CONSIIIUENI

CONSIUUENI IMG/L OR UNII SHOWNI

SAMPLE

SIZE

TEMPERATURE, WATER (DEG C)

SPECIFIC CONDUCTANCE (MICROMHOS)

STREAMFLOW (CUBIC FT/SEC)

PH (STANDARO UNITS

PHOSPHORUS, TOTAL

NITRITE + NITRATE, TOTAL

NITROGEN, KJELOAHL, TOTAL

PHYTOPLANKTON, TOTAL (CELLS/ML)

SEDIMENT, SUSPENDED

SEDIMENT, CLAY-SILT (PERCENT)

COLIFORM, FECAL (COL/100 ML)

STREPTOCOCCI, FECAL (COL/100 ML)

SILICA, DISSOLVED

CALCIUM, DISSULVED

MAGNESIUM, DISSOLVED

SODIUM, DISSOLVED

PUTASSIUM, DISSOLVED

BICAREONATE, ION

CARBONATE, ION

SULFATE, DISSULVED

CHLORIDE, DISSOLVED

DISSOLVED SOLIDS, SUM OF CONST

UISSOLVED SOLIOS, RGE 180 DEG C

HARUNESS, TOTAL

HARDNESS, NONCARBUNATE

TURBILITY I JTU

FLOURIDE, DIS SOLVED

STANOARD

MEAN DEYIAIION

11.95
117.5

1768.3

7.61

0.271

1.038

0.629
19703.3

19703.3

25.3
84.7

84.7
86.4

86.4
98.9

98.9
18.50

18.50
9.67

9.67
3.42

7.46

1.52

40.0

1.8

5.39

8.24

75.3
85.6

85.6
38.1

4.0

12.4
0.10

YIAILON

RANGE

56.9

2027.4

0.52
0.135

0.135

0.592

25848.6

14.7
7.7

7.7

19.2

96.7
1.62

1.62
3.81

1.25

4.48

0.56

14.6
4.9

4.9
2.63

7.02

27.0

28.8

14.2

4.7

10.6
0.13

5.0

70
58

58
6.9
0.14

0.14
0.16

0.16
0.31

530

11

16
3

16.0

6.0
2.3

4.2

1.1

0
3.3

3.3
4.0
54
59

25
0

0.1

SUMMARY OF HARMONIC ANALYSIS OF STREAM TEMPERATURE

\begin{tabular}{|c|c|c|c|c|c|}
\hline & HARMONIC & $\triangle M P I T T U F$ & PHASE & YAR IATION & STANDARD \\
\hline $\begin{array}{l}\text { SAMPLE } \\
\text { SUZE }\end{array}$ & $\begin{array}{l}\text { MEAN - M } \\
\text { IOEG CI) }\end{array}$ & $\begin{array}{l}-A \\
\text { DEG }\end{array}$ & $\begin{array}{l}\text { ANGLE - C } \\
\text { IBADIANSI) }\end{array}$ & $\begin{array}{l}\text { EXP LA INED } \\
(\xi)\end{array}$ & $\begin{array}{l}\text { ESTIMATE } \\
\text { (DEG C) }\end{array}$ \\
\hline & 12.00 & 6.81 & 2.82 & 94 & 1.50 \\
\hline
\end{tabular}

\section{BEGRESSION SUMMABY}

REGRESSION

SAMPLE COEFICIENT,

CONSTANT,

CORRELATION

STANDARL

ESIUMAI

$$
\begin{array}{r}
20.4 \\
282
\end{array}
$$

$\begin{array}{rrr}282 & \\ 6250 & 12 \quad-19.867\end{array}$

$\begin{array}{rrr}6250 & 12 & -19.867 \\ 8.7 & 12 & -0.0017\end{array}$

$\begin{array}{lll}0.60 & 12 & -0.0017 \\ 2.60 & 12 & 0.00221\end{array}$

$\begin{array}{lll}2.10 & 12 & 0.0042\end{array}$

$\begin{array}{lll}1.10 \quad 12 & 0.00271\end{array}$

302.101

4102.064

7.8061
0.01105

0.01105

$-17555.738$

$-0.558^{*}$

$-0.183^{*}$
0.931

$0.411^{\star}$

0.083

0.742

1764.9

0.54
0.052

0.566

0.173

50

95
350

350
230

$21.0 \quad 12$

21.

6.8

21.0

3.2
79

14
13.0

13.0

155
168

155
168

12
12
12
12
12
8
12
12
12
12
12
12
12
12

$\begin{array}{ll}80 & 12 \\ 16 & 12 \\ 30 & 12\end{array}$

$\begin{array}{rr}30 & 12 \\ 0.5 & 12\end{array}$

0.0173
0.0653
0.0202
0.0766
0.0096
0.212
0.080
0.0436
0.1190
0.459
0.481
0.244
0.065
-0.088
0.0002

16.4716

2.0078

1.0410

$-1.5411$

0.3991

15.072

$-6.618$

$-5.7391$

21. 367

29.060

9.380

$-3.665$

22.699

0.0743

0.005

0.974

0.922

0.972

0.975

0.828

0.397

0.942

0.964

0.969

0.952

0.976

0.788

0.469 .
0.092 *

SUMMARY OF MAXIMUM AND MINIMUM CONCENTRATIONS OF CONSTITUENTS SAMPLED AT A FREQUENCY OF QUARTERLY (1975 WY)

14207500 - - TUALATIN RIVER AT WEST LINN, OREG

CONSTITUENT
SAMPLES


LAT 45D3LMO3S LONG 122040M03S

DRAINAGE AREA: 11100 SQ MI ( 28749 SQ KM)

PERIOD OF RECORD: $10 / 01 / 74-09 / 30 / 75$

STATISTICAL SUMMARY OF SELECTED DISSOLVED CHEMICAL CONSTITUENTS AND

REGRESSION RELATIONSHIPS OF CONSTITUENT CONCENTRATIONS TO SPECIFIC CONDUCTANCE

CONSIUTUENI

CONSIUIUENI
IEMPERATURE, WATER (DEG C)
SPECIFIC CONDUCTANCE (MICROMHOS)
STREAMFLOW (CUBIC FT/SEC)
PH (STANDARD UNITS)
PHOSPHORUS, TOTAL
NITRITE, NITRATE, TOTAL
NITROGEN, KJELDAHL, TOTAL
PHYTOPLANKTON, TOTAL (CELLS/ML)
SEDIMENT, SUSPENDED
SEDIMENT, CLAY-SILT (PERCENT)
COLIFORM, FECAL (COL/IOO ML)
STREPTOCOCCI, FECAL (COL/1OO ML)
SILICA, DISSOLVED
CALCIUM, DISSOLVED
MAGNESIUM, DISSOLVED
SODIUM, DISSOLVED
POTASSIUM, DISSOLVED
BICARBONATE, ION
CARBONATE, ION
SULFATE, DISSOLVED
CHLORIOE, OISSOLVED
DISSOLVED SOLIDS, SUM OF CONST
DISSOLVED SOLIDS, ROE 18O DEG C
HARDNESS, TOTAL
HARDNESS, NONCARBONATE
TURBIOITY (JTU)
FLOURIDE, DISSOLVED

\section{CONSIUUENI IHG/L OR UNUI_SHOHNI}

\begin{tabular}{rrr}
$\begin{array}{rrr}\text { SAMPLE } \\
\text { SIZE }\end{array}$ & MEAN & \multicolumn{1}{r}{ STANDARD } \\
\cline { 1 - 1 } & & REYIAILON \\
12 & 11.72 & 4.70 \\
12 & 67.8 & 11.5 \\
12 & 33975.0 & 26163.5 \\
12 & 7.87 & 0.44 \\
12 & 0.067 & 0.021 \\
12 & 0.682 & 1.023 \\
12 & 0.338 & 0.152 \\
12 & 2605.0 & 1882.3 \\
11 & 11.7 & 6.8 \\
8 & 85.1 & 7.0 \\
11 & 96.9 & 112.9 \\
11 & 27.0 & 27.2 \\
12 & 15.00 & 1.28 \\
12 & 6.45 & 1.15 \\
11 & 1.85 & 0.37 \\
12 & 3.99 & 0.74 \\
12 & 0.82 & 0.26 \\
11 & 27.3 & 3.1 \\
5 & 0.0 & 0.0 \\
12 & 3.61 & 1.15 \\
12 & 3.76 & 1.20 \\
11 & 49.7 & 5.5 \\
12 & 56.1 & 5.8 \\
11 & 24.0 & 3.4 \\
11 & 2.1 & 2.7 \\
12 & 7.8 & 6.0 \\
12 & 0.06 & 0.05
\end{tabular}

BEGRESSION_SUMMABY

$\begin{array}{ll} & \text { REGRESSION } \\ \text { SAMPLE COEFICIENT, CONSTANT, CORRELATION ERTORD } & \text { OF }\end{array}$ SIZE -

*Not significant at the 95 percent confidence level.

SUMMARY OF HARMONIC ANALYSIS OF STREAM TEMPERATURE

\begin{tabular}{|c|c|c|c|c|c|}
\hline & & & & & STANDARD \\
\hline & HARMONIC & AMPLI TUDE & PHASE & VARIATION & ERROR OF \\
\hline $\begin{array}{l}\text { SAMPLE } \\
\text { SIZE }\end{array}$ & $\begin{array}{l}\text { MEAN }-{ }^{M} \\
\text { IDEG } C 1\end{array}$ & ${ }_{(D E G} A()$ & $\begin{array}{l}\text { ANGLE - C } \\
\text { (RADIANS) }\end{array}$ & $\begin{array}{c}\text { EXPLA INED } \\
(8)\end{array}$ & $\begin{array}{l}\text { ESTIMATE } \\
\text { LOEG } 61\end{array}$ \\
\hline 12 & 12.03 & 6.37 & 2.56 & 92 & 1.43 \\
\hline
\end{tabular}

SUMMARY OF MAXIMUM AND MINIMUM CONCENTRATIONS OF CONSTITUENTS SAMPLED AT A FREQUENCY OF QUARTERLY (1975 WY)

14211720 -- WILLAMETTE RIVER AT PORTLAND, OREG.

\begin{tabular}{|c|c|c|c|c|c|c|}
\hline \multirow{2}{*}{ CONSTITUENT } & \multicolumn{3}{|c|}{ TOTAL } & \multicolumn{3}{|c|}{ DISSOLVED } \\
\hline & $\begin{array}{l}\text { NO. } \\
\text { SAMPLES }\end{array}$ & $\begin{array}{l}\text { MIN IMUM } \\
\text { CONC. }\end{array}$ & $\begin{array}{l}\text { MAXIMUM } \\
\text { CONC. }\end{array}$ & $\begin{array}{l}\text { NO. } \\
\text { SAMPLES }\end{array}$ & $\begin{array}{l}\text { MINIMUM } \\
\text { CONC. }\end{array}$ & $\begin{array}{l}\text { MAXIMUM } \\
\text { CONC. }\end{array}$ \\
\hline \multicolumn{7}{|l|}{ MINOR ELEMENTS: } \\
\hline ARSENIC (AS), UG/L & 4 & 0 & 1 & 4 & 0 & 1 \\
\hline CADMIUM $(C D), U G / L$ & 4 & $<10$ & $<10$ & 4 & 0 & 0 \\
\hline CHROMIUM (CR), UG/L & 4 & 0 & 10 & 4 & 0 & 10 \\
\hline COBALT $(C O)$, UG/L & 4 & $<50$ & 50 & 4 & 0 & 3 \\
\hline COPPER (CU), UG/L & 4 & $<10$ & 180 & 4 & 2 & 20 \\
\hline IRON (FE), UG/L & 4 & 270 & 1700 & 4 & 60 & 210 \\
\hline LEAD $(P B), U G / L$ & 4 & $<100$ & $<100$ & 4 & 1 & 2 \\
\hline MANGANESE $(M N), U G / L$ & 4 & 20 & 80 & 4 & $a$ & 58 \\
\hline MERCURY $(H G), U G / L$ & 4 & 0.0 & 0.0 & 4 & 0.0 & 0.0 \\
\hline SELENIUM (SE), UG/L & 4 & 0 & 0 & 4 & 0 & 0 \\
\hline ZINC $(Z N), U G / L$ & 4 & 20 & 230 & 4 & 0 & 30 \\
\hline \multicolumn{7}{|l|}{ PER IPHYTON: } \\
\hline BIOMASS, DRY WT., G/SQ M & 1 & 4.50 & & & & \\
\hline BIOMASS, ASH WT., G/SQ M & 1 & .50 & & & & \\
\hline CHLOROPHYLL A, MG/SQ M & $i$ & 2.5 & & & & \\
\hline CHLOROPHYLL B, MG/SQ M & 1 & $\cdot 3$ & & & & \\
\hline ORGANIC CARBON, MG/L & 4 & 2.0 & 3.1 & & & \\
\hline
\end{tabular}


LAT 45D42M15S LONG 123045M15S

$\begin{array}{lll}\text { DRAINAGE AREA: } & 667 \text { SQ MI } 1 & 17 \\ \text { PERIOD OF RECORD: } & 10 / 01 / 74-09 / 30 / 75\end{array}$

667 SQ MI

STATISTICAL SUMMARY OF SELECTED DISSOLVED CHEMICAL CONSTITUENTS AND

REGRESSION RELATIONSHIPS OF CONSTITUENT CONCENTRATIONS TO SPECIFIC CONDUCTANCE

CONSIUIUENI

\section{CONSIUUENI IMGLL OR UNUI SHOHNL}

TEMPERATURE, WATER (DEG C)
SPECIFIC CONDUCTANCE (MICROMHOS)
STREAMFLOW (CUBIC FT/SEC)
PH (STANDARD UNITS)
PHOSPHORUS, TOTAL
NITRITE, NITRATE, TOTAL
NITROGEN, KJELDAHL, TOTAL
PHYTOPLANKTON, TOTAL (CELLS/ML)
SEDIMENT, SUSPENDED
SEDIMENT, CLAY-SILT (PERCENT)
COLIFORM, FECAL (COL/ IOO ML)
STREPTOCOCCI, FECAL (COL/IOO ML)
SILICA, DISSOLVED
CALCIUM, DISSOLVED
MAGNESIUM, DISSOLVED
SODIUM, DISSOLVE
POTASSIUM, DISSOLVED
BICARBONATE, ION
CARBONATE, ION
SULFATE, DISSOLVED
CHLORIDE, DISSOLVED
DISSOLVED SOLIDS, SUM OF CONST
DISSOLVED SOLIDS, ROE 18O DEG C
HARDNESS, TOTAL
HARDNESS, NONCARBONATE
TURBIDITY (JTU)
FLOURIDE, DISSOLVED

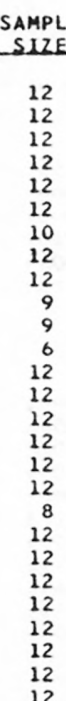

STANDARD

DEYIAIION

10.62

65.9

2641.0

7.57

0.017

0.203

0.360

2798 . 9

11.9
81.3

81.3
29.0

38.7

13.50

5.64

1.18

5.20

0.68
21.4

21.4
0.0

3.62

5.01

45.5
50.9

50.9

18.9

2.0
4.3
0.04

3000

4.39
18.5

3000.2

0.014

0.179

0.386

5195.3

13.4

11.1

47.5

44.7

0.90

2.04

0.50

1.15

8.3

0.0

1.31

1.12

9.4

6.5

2.6

3.7

3.7
0.05

nfidence level. SUMMARY OF HARMONIC ANALYSIS OF STREAM TEMPERATURE

\begin{tabular}{|c|c|c|c|c|c|}
\hline & & & & & $\begin{array}{l}\text { STANDARD } \\
\text { ERROR }\end{array}$ \\
\hline $\begin{array}{l}\text { AMPLE } \\
\text { SIZE }\end{array}$ & $\begin{array}{l}\text { HARMONIC } \\
\text { MEAN - M } \\
\text { LOEG CI }\end{array}$ & $\begin{array}{c}\text { AMPLITUDE } \\
-A \\
\text { WDEG }\end{array}$ & $\begin{array}{c}\text { PHASE } \\
\text { ANGLE - C } \\
\text { (RADIANS) }\end{array}$ & $\begin{array}{l}\text { VAR IATION } \\
\text { EXP LAINED } \\
\text { (Z) }\end{array}$ & $\begin{array}{l}\text { ERROR OF } \\
\text { ESTIMATE } \\
\text { (DEG_C) }\end{array}$ \\
\hline
\end{tabular}

12

10.67

5.76

2.57

94

1.17
BEGRESSION SUMMARY

REGRESSION

SAMPLE COEFICIENT, CONSTANT, CORRELATION

BANGE SIZE

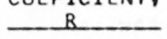
B COEEICIENI.

STANDARD ESIUMAIE

$\begin{array}{rrrr}4.9 & 17.3 & & \\ 45 & 91 & & \\ 62 & 7510 & 12 & -133.407 \\ 6.9 & 8.2 & 12 & -0.0027 \\ 0.00 & 0.04 & 12 & -0.00023 \\ 0.03 & 0.61 & 12 & -0.00691 \\ 0.08 & 1.20 & 10 & 0.00194 \\ 45 & 18000 & 12 & 143.634\end{array}$

$$
\begin{array}{r}
11434.727 \\
7.7467 \\
0.03253 \\
0.65876 \\
0.22625 \\
-6668.984
\end{array}
$$

7.7467

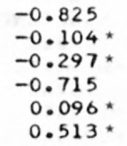

1780.1

0.51

0.014

0.131
0.408

0.408
4678.2

0.513 *

44
94
144

144

116
15.0

15.0
9.2

12
12
12
12
12
12
8
12
12
12
12
12
12
12
12

0.0033
0.0962
0.0153
0.0587
0.0030
0.359
0.000
0.0435
0.0554
0.458
0.401
0.301
0.030
-0.093
0.0025

13.2822

$-0.6965$

0.1730

1.3334

0.4850

$-2.271$

0.000
0.7517

0.7517
1.3542

15.329

24.467

$-0.929$

0.014

\begin{tabular}{|c|c|c|c|c|c|c|}
\hline \multirow{2}{*}{ CONSTITUENT } & \multicolumn{3}{|c|}{ TOTAL } & \multicolumn{3}{|c|}{ DISSOLVED } \\
\hline & $\begin{array}{l}\text { NO. } \\
\text { SAMPLES }\end{array}$ & $\begin{array}{l}\text { MINIMUM } \\
\text { CONC. }\end{array}$ & $\begin{array}{l}\text { MAXIMUM } \\
\text { CONC. }\end{array}$ & $\begin{array}{l}\text { NC. } \\
\text { SAMPLES }\end{array}$ & $\begin{array}{l}\text { MINIMUM } \\
\text { CONC. }\end{array}$ & $\begin{array}{l}\text { MAXIMUM } \\
\text { CONC. }\end{array}$ \\
\hline \multicolumn{7}{|l|}{ MINOR ELEMENTS: } \\
\hline ARSENIC (AS), UG/L & 4 & 0 & 1 & 4 & 0 & 2 \\
\hline CADMIUM (CD), UG/L & 4 & $<10$ & 10 & 4 & 0 & 1 \\
\hline CHROMIUM (CR), UG/L & 4 & 0 & 10 & 4 & 0 & 10 \\
\hline COBALT $(C O)$, UG/L & 4 & $<50$ & $<50$ & 4 & 0 & 0 \\
\hline COPPER $(C U), U G / L$ & 4 & $<10$ & 100 & 4 & 1 & 11 \\
\hline IRON $(F E), U G / L$ & 4 & 190 & 490 & 4 & 60 & 170 \\
\hline LEAD (PB), UG/L & 4 & 100 & $<100$ & 4 & 0 & 3 \\
\hline MANGANESE (MN), UG/L & 4 & 0 & 40 & 4 & 0 & 20 \\
\hline MERCURY (HG), UG/L & 4 & 0.0 & 0.1 & 4 & 0.0 & 0.0 \\
\hline SELENIUM (SE), UG/L & 4 & 0 & 0 & 4 & 0 & 0 \\
\hline$Z I N C(Z N), U G / L$ & 4 & 20 & 60 & 4 & 0 & 30 \\
\hline \multicolumn{7}{|l|}{ PERIPHYTON: } \\
\hline BIOMASS, DRY WT., G/SQ M & 2 & .29 & .29 & & & \\
\hline BIOMASS, ASH WT, G/SO M & 2 & .19 & .19 & & & \\
\hline CHLOROPHYLL A, MG/SQ M & 2 & .0 & 2.1 & & & \\
\hline CHLOROPHYLL $B, M G / S Q M$ & 2 & .0 & .3 & & & \\
\hline ORGANIC CARBON, MG/L & 3 & 1.0 & 2.5 & & & \\
\hline
\end{tabular}

10.379

SUMMARY OF MAXIMUM AND MINIMUM CONCENTRATIONS OF CONSTITUENTS

SAMPLED AT A FREQUENCY OF QUARTERLY (1975 WY)

14301000 - NEHALEM RIVER NEAR FOSS, OREG. 
Table 14.--Summary of measurement at each station--Continued

LAT 43035MIOS LONG 123033MOS

DRAINAGE AREA: 3683 SQ MI ( 9539 SQ KM)

PERIOD OF RECORD: $10 / 01 / 74$ - 09/30/75

STATISTICAL SUMMARY OF SELECTED DISSOLVED CHEMICAL CONSTITUENTS AND

REGRESSION RELATIONSHIPS OF CONSTITUENT CONCENTRATIONS TO SPECIFIC CONDUCTANCE

CONSIITUENI

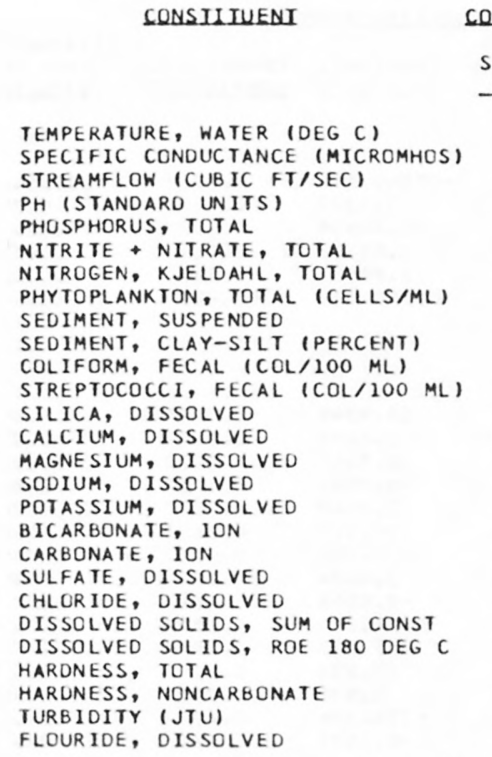

CONSIUIUENI IMG LL OR UNII SHOWNI
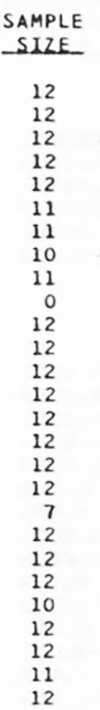

STANDARD

DEYIALION

12.58

6263.204287 .0

7.20

0.062
0.130

0.130
0.285

4890.0

11.5

4287.0

0.41
0.042

0.194

0.236

11092.2

8.3

$273.0 \quad 695.5$

$56.4 \quad 110.6$

17.25

17.25

7.60
2.27

2.27
5.35

0.98

34.8

0.0

2.98

3.02

59.8

59.8

28.3

1.1
12.7

12.7
0.06

2.56

2.56
1.81

0.71

2.10
0.35

4.8

0.0

0.96
1.39

8.0

10.2

4.3
1.4

29.1
0.07

*Not significant at the 95 percent confidence level. SUMMARY OF HARMONIC ANALYSIS OF STREAM TEMPERATURE

\begin{tabular}{|c|c|c|c|c|c|}
\hline & & & & & STANOARD \\
\hline & HARMONIC & AMPLITUDE & PHASE & VARIATION & ERROR OF \\
\hline SAMPLE & MEAN - M & $-A$ & ANGLE - C & EXPLAINED & ESTIMATE \\
\hline SIZE & 1DEG C1 & DEEG_(1) & (RADIANS) & $(8)$ & IDEG C L \\
\hline 22 & 12.33 & 7.48 & 2.66 & 89 & 1.55 \\
\hline
\end{tabular}

SUMMARY OF MAXIMUM AND MINIMUM CONCENTRATIONS OF CONSTITUENTS

SAMPLED AT A FREQUENCY OF QUARTERLY (1975 WY)

14321000 -- UMPQUA RIVER NEAR ELKTON, OREG.

\begin{tabular}{|c|c|c|c|c|c|c|}
\hline \multirow{2}{*}{ CONSTI TUENT } & \multicolumn{3}{|c|}{ TOTAL } & \multicolumn{3}{|c|}{ DISSOLVED } \\
\hline & $\begin{array}{l}\text { NO. } \\
\text { SAMPLES }\end{array}$ & $\begin{array}{l}\text { MIN IMUM } \\
\text { CONC. }\end{array}$ & $\begin{array}{l}\text { MAXIMUM } \\
\text { CONC. }\end{array}$ & $\begin{array}{l}\text { NO. } \\
\text { SAMPLES }\end{array}$ & $\begin{array}{l}\text { MINIMUM } \\
\text { CONC. }\end{array}$ & $\begin{array}{l}\text { MAXIMUM } \\
\text { CONC. }\end{array}$ \\
\hline \multicolumn{7}{|l|}{ MINOR ELEMENTS: } \\
\hline $\begin{array}{l}\text { ARSENIC }(A S), U G / L \\
\text { CADMIUM }(C D), U G / L\end{array}$ & 3 & 1 & $<\begin{array}{r}1 \\
0\end{array}$ & $\begin{array}{l}3 \\
2\end{array}$ & $\begin{array}{l}0 \\
0\end{array}$ & 1 \\
\hline $\begin{array}{l}\text { CADMIUM (CD), UG/L } \\
\text { CHROMIUM (CR), UG/L }\end{array}$ & $\begin{array}{l}3 \\
3\end{array}$ & $<\begin{array}{r}10 \\
0\end{array}$ & $\begin{aligned} &< 10 \\
& 10\end{aligned}$ & 3 & $\begin{array}{l}0 \\
0\end{array}$ & $\begin{array}{l}2 \\
0\end{array}$ \\
\hline COBALT $(C O), U G / L$ & 3 & $\begin{array}{r}0 \\
<50\end{array}$ & $\begin{array}{r}10 \\
<50\end{array}$ & 3 & 0 & 1 \\
\hline COPPER (CU), UG/L & 3 & 10 & 1500 & 2 & 3 & 12 \\
\hline IRON (FE), UG/L & 3 & 60 & 1300 & 4 & 10 & 190 \\
\hline LEAD $(P B), U G / L$ & 3 & $<100$ & 100 & 3 & 1 & 9 \\
\hline MANG ANESE (MN), UG/L & 3 & 20 & 40 & 3 & 0 & 20 \\
\hline MERCURY (HG), UG/L & 2 & 0.0 & 0.3 & 3 & 0.0 & 0.3 \\
\hline SELENIUM (SE), UG/L & 3 & 0 & 0 & 3 & 0 & 0 \\
\hline$Z I N C(Z N), U G / L$ & 3 & 30 & 360 & 3 & 8 & 40 \\
\hline \multicolumn{7}{|l|}{ PERIPHYTON: } \\
\hline BIOMASS, DRY WT., G/SQ M & 3 & .59 & 20.00 & & & \\
\hline BIOMASS, ASH WT., G/SO M & 3 & .59 & 17.00 & & & \\
\hline CHLOROPHYLL A, MG/SO M & 2 & $\cdot 3$ & 2.7 & & & \\
\hline CHLOROPHYLL B, MG/SQ M & 2 & .0 & .5 & & & \\
\hline ORGANIC CARBON, MG/L & 3 & 1.8 & 8.0 & & & \\
\hline
\end{tabular}


Table 14.-- Sumnary of measurement at each station--Continued

LAT 42D34M5OS LONG 124D03M30S

DRAINAGE AREA: 3939 SO MI 110202 SQ KM)

PERIOD OF RECORD: $10 / 01 / 74-09 / 30 / 75$

STATISTICAL SUMMARY OF SELECTED DISSOLVED CHEMICAL CONSTITUENTS AND

REGRESSION RELATIONSHIPS OF CONSTITUENT CONCENTRATIONS TO SPECIFIC CONDUCTANCE

CONSIUIUENI

CONSILIUENI
TEMPERATURE, WATER (DEG C)
SPECIFIC CONDUCTANCE (MICROMHOS)
STREAMFLOW (CUBIC FT/ SEC)
PH (STANDARD UNITS)
PHOSPHORUS, TOTAL
NITRITE, NITRATE, TOTAL
NITROGEN, KJELDAHL, TOTAL
PHYTOPLANKTON, TOTAL (CELLS/ML)
SEDIMENT, SUSPENDED
SEDIMENT, CLAY-SILT (PERCENT)
COLIFORM, FECAL (COL/IOO ML)
STREPTOCOCCI, FECAL (COL/IOO ML)
SILICA, DISSOLVED
CALCIUM, DISSOLVED
MAGNESIUM, DISSOLVED
SODIUM, DISSOLVED
POTASSIUM, DISSOLVED
BICARBONATE, ION
CARBONATE, ION
SULFATE, DISSOLVED
CHLORIDE, DISSOLVED
DISSOLVED SOLIDS, SUM OF CONST
DISSOLVED SOLIDS, ROE I8O DEG C
HARDNESS, TOTAL
HARDNESS, NONCARBONATE
TURBIDITY (ITU)
FLOURIDE, DISSOLVED

CONSIJUENI IHG/L OR UNII SHOWNI

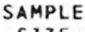

SIZE

12
12
12
12
12
11
11
11
12
0
11
11
12
12
12
12
12
12
7
12
12
12
11
12
12
11
12
STANDARD

DEYLALION

11.67

112.7

12373.3

7.27
0.175

0.175
0.068

0.718

1393.6

237.4

124.2

164.5

21.75
9.70

9.70
3.22

5.78
1.19

1.19

50.1

3.15

2.81

72.5

77.2

37.5

0.4

45.4
0.08
5.66
29.0

25079.0

0.27
0.293

0.293
0.051

1.160

1149.8

344.2
413.1

413.1
4.69

1.36

0.93

3.24
0.28

7.6

0.0

0.85

1.56

9.9

19.2

5.1

0.8

118.8
0.08

$\begin{array}{rr} & \\ \text { BANGE } & \\ 4.5 & 22 . \\ 69 & 17 \\ 1400 & 9090 \\ 6.6 & 7 . \\ 0.05 & 1.1 \\ 0.01 & 0.1 \\ 0.02 & 4.0 \\ 120 & 370 \\ 4 & 260 \\ & \\ 3 & 116 \\ 2 & 140 \\ 14.0 & 29 . \\ 7.4 & 12 . \\ 0.8 & 4.0 \\ 2.2 & 15.0 \\ 0.8 & 1.6 \\ 38 & 6 \\ 0 & \\ 2.3 & 4 . \\ 0.8 & 5.8 \\ 56 & 8 \\ 55 & 11 \\ 30 & 4 \\ 0 & \\ 1 & 40 \\ 0.0 & 0.3 \\ & \end{array}$

BEGRESSION SUMMARY REGRESSION SAMPLE COEFICIENT, CONSTANT, CORRELATION STANDARD SIZE —B _ - B - - COEEICIENI ESIUMAIF

$\begin{array}{rr}22.0 & \\ 173 & \\ 90900 & 12 \\ 7.7 & 12 \\ 1.10 & 12 \\ 0.15 & 11 \\ 4.00 & 11 \\ 3700 & 11 \\ 2600 & \\ 1160 & \\ 1400 & \\ 29.0 & 12 \\ 12.0 & 12 \\ 4.3 & 12 \\ 15.0 & 12 \\ 1.6 & 12 \\ 62 & 12 \\ 0 & 17 \\ 4.8 & 12 \\ 5.8 & 12 \\ 88 & 12 \\ 118 & 11 \\ 45 & 12 \\ 2 & 12 \\ 400 & 1 \\ 0.3 & 12\end{array}$

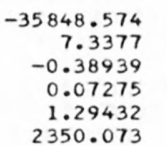

$0.495^{*}$

$-0.067^{*}$

0.495 *

$-0.024$

$-0.134 *$

$-0.225^{*}$

22855.6

0.29

0.267

0.053

1.212

1180.9

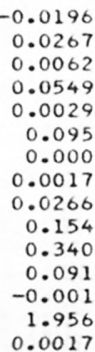

$-0.121$

0.571 *

$0.195^{*}$

0.491 *

0.301 *

$0.362^{*}$

0.000 *

$0.057^{*}$

$0.494^{*}$ *

0.447 *
0.534 *

$0.519^{*}$

-0.053 *

0.498

0.587
4.89

1.17

0.95

2.96

0.28

7.4
0.0

0.0
0.89

0.89

1.42

17.1

4.6

0.8

108.6
0.07

Not significant at the 95 percent confidence level. SUMMARY OF HARMONIC ANALYSIS OF STREAM TEMPERATURE

\begin{tabular}{|c|c|c|c|c|c|}
\hline & & & & & STANDARD \\
\hline & HARMONIC & AMPLITUDE & PHASE & VAR IATION & ERROR OF \\
\hline $\begin{array}{l}\text { SAMPLE } \\
\text { SIZE }\end{array}$ & $\begin{array}{l}\text { MEAN }-M \\
\text { JDEG } C)^{2}\end{array}$ & $\begin{array}{c}-A \\
\text { (DEG }\end{array}$ & $\begin{array}{l}\text { ANGLE - C } \\
\text { (BADIANSI) }\end{array}$ & $\begin{array}{l}\text { EXP LAINEO } \\
-(Z)\end{array}$ & $\begin{array}{l}\text { ESTIMATE } \\
\text { (DEG Gl) }\end{array}$ \\
\hline 12 & 11.72 & 7.49 & 2.57 & 95 & 1.43 \\
\hline
\end{tabular}

SUMMARY OF MAXIMUM AND MINIMUM CONCENTRATIONS OF CONSTITUENTS SAMPLED AT A FREQUENCY OF QUARTERLY $(1975$ WY $)$

14372300 -- ROGUE RIVER NR AGNESS

\begin{tabular}{|c|c|c|c|c|c|c|}
\hline \multirow{2}{*}{ CONSTI TUENT } & \multicolumn{3}{|c|}{ TOTAL } & \multicolumn{3}{|c|}{ DISSOLVED } \\
\hline & $\begin{array}{l}\text { NO. } \\
\text { SAMPLES }\end{array}$ & $\begin{array}{l}\text { MIN IMUM } \\
\text { CONC. }\end{array}$ & $\begin{array}{l}\text { MAXIMUM } \\
\text { CONC. }\end{array}$ & $\begin{array}{c}\text { NO. } \\
\text { SAMPLES }\end{array}$ & $\begin{array}{l}\text { MINIMUM } \\
\text { CONC. }\end{array}$ & $\begin{array}{l}\text { MAXIMUM } \\
\text { CONC. }\end{array}$ \\
\hline \multicolumn{7}{|l|}{ MINOR ELEMENTS: } \\
\hline ARSENIC (AS), UG/L & 3 & 1 & 1 & 3 & 1 & 4 \\
\hline CADMIUM $(C D), U G / L$ & 3 & $<10$ & 10 & 2 & 1 & 1 \\
\hline CHROMIUM (CR), UG/L & 3 & 0 & 10 & 3 & 0 & 0 \\
\hline COBALT $(C O)$, UG/L & 3 & $<50$ & $<50$ & 3 & 0 & 1 \\
\hline COPPER (CU), UG/L & 3 & $<10$ & 2300 & 2 & 3 & 4 \\
\hline IRON (FE), UG/L & 3 & 150 & 1200 & 4 & 20 & 330 \\
\hline LEAD $(P B), U G / L$ & 3 & $<100$ & 100 & 3 & 1 & 4 \\
\hline MANG ANESE $(M N), U G / L$ & 3 & 20 & 40 & 3 & 0 & 0 \\
\hline MERCURY $(H G), U G / L$ & 3 & 0.1 & 0.3 & 3 & 0.0 & 0.1 \\
\hline SELENIUM $(S E), U G / L$ & 3 & 0 & 0 & 3 & 0 & 0 \\
\hline ZINC $(Z N), U G / L$ & 3 & 40 & 140 & 3 & 8 & 20 \\
\hline \multicolumn{7}{|l|}{ PERIPHYTON: } \\
\hline BIOMASS, DRY WT., G/SO M & 2 & 14.00 & 25.00 & & & \\
\hline BIOMASS, ASH WT., G/SQ M & 2 & 6.09 & 23.00 & & & \\
\hline CHLOROPHYLL A, MG/SQ M & 2 & 16.0 & 24.0 & & & \\
\hline CHLOROPHYLL B, MG/SO M & 2 & 2.3 & 3.0 & & & \\
\hline ORGANIC CARBON, MG/L & 3 & 2.7 & 5.6 & & & \\
\hline
\end{tabular}


Table 14.--Summary of measurement at each station--Continued

IT 56D42M07S LONG $132008 \mathrm{M} 28 \mathrm{~S}$ IAINAGE AREA: ERIOD OF RECORD:

0 SO MI 1 $10 / 01 / 74-09 / 30 / 75$
O SQ KM)

STATISTICAL SUMMARY OF SELECTED DISSOLVED CHEMICAL CONSTITUENTS AND REGRESSION RELATIONSHIPS OF CONSTITUENT CONCENTRATIONS TO SPECIFIC CONDUCTANCE

CONSIUIUENI

CONSIUTUENI IMG/L OB UNII SHOHNI

SAMPLE

\section{SIZE}

TEMPERATURE, WATER (DEG C)

SPECIFIC CONDUCTANCE (MICROMHOS)

STREAMFLOW (CUBIC FT/SEC)

PH (STANDARD UNITS)

PHOSPHORUS, TOTAL

NITRITE + NITRATE, TOTAL

NITROGEN, KJELDAHL, TOTAL

PHYTOPLANKTON, TOTAL (CELLS/ML)

SEDIMENT, SUSPENDED

SEDIMENT, CLAY-SILT (PERCENT)

COLIFORM, FECAL (COL/100 ML)

STREPTOCOCCI, FECAL (COL/100 ML)

SILICA, DISSOLVED

CALCIUM, DISSOLVED

MAGNE SIUM, DISSOLVED

SODIUM, DISSOLVED

POTASSIUM, DISSOLVED

BICARBONATE, ION

CARBONATE, ION

SULFATE, DISSOLVED

CHLOR IDE, DISSOLVED

DISSOLVED SOLIDS, SUM OF CONST

DISSOLVED SOLIDS, ROE 180 DEG C

HARDNESS, TOTAL

HARDNESS, NONCARBONATE

TUREIDITY (JTU)

FLOUR IDE, DISSOLVED
STANDARD

DEY IATIOA

6.00

119.5

44366.7

7.50

0.115

0.085

.160

17.0

89.5

56.0
1.0

1.0
1.0

4.30

21.50

2.50

2.85

1.00

64.0

0.0

12.95

2.20

79.5

80.5

64.0

11.5

24.0

0.10
1.73

54.4
991.9

40991.9
0.14

0.092

0.078

0.113

0.0

0.7

5.7
0.0

0.0
0.0

2.26

9.19

0.71

1.77

0.28

26.9

0.0

5.73

1.13
34.6

37.5

25.5

3.5

36.4

0.00
BES

REGRESSION

SAMPLE COEFICIENT, SSION SUMMARY

BANGE SIZE

$\begin{array}{rr}5.0 & 8.0 \\ 81 & 15 \\ 20700 & 91700 \\ 7.4 & 7.6\end{array}$

8.0
158
1700

7.6
0.18

$\begin{array}{ll}0.05 & 0.18 \\ 0.03 & 0.14\end{array}$

$0.08 \quad 0.24$

17

17
89

$\begin{array}{ll}89 & 90 \\ 52 & 60\end{array}$

1
1
2.7

2.7
15.0

15.0
2.0

1.6

0.8

45
0

8.9
1.4

1.4
55

54
46
9

2
0.1

SUMMARY OF MAXIMUM AND MINIMUM CONCENTRATIONS OF CONSTITUENTS SAMPLED AT A FREQUENCY OF QUARTERLY (1975 WY)

15024800 -- STIKINE R NR WRANGELL AK

\begin{tabular}{|c|c|c|c|c|c|c|}
\hline \multirow{2}{*}{ CONSTI TUENT } & \multicolumn{3}{|c|}{ TOTAL } & \multicolumn{3}{|c|}{ DISSOLVED } \\
\hline & $\begin{array}{l}\text { NO. } \\
\text { SAMPLES }\end{array}$ & $\begin{array}{l}\text { MINIMUM } \\
\text { CONC. }\end{array}$ & $\begin{array}{l}\text { MAXIMUM } \\
\text { CONC. }\end{array}$ & $\begin{array}{l}\text { NO. } \\
\text { SAMPLES }\end{array}$ & $\begin{array}{l}\text { MINIMUM } \\
\text { CONC. }\end{array}$ & $\begin{array}{l}\text { MAXIMUM } \\
\text { CONC. }\end{array}$ \\
\hline \multicolumn{7}{|l|}{ MINOR ELEMENTS: } \\
\hline ARSENIC (AS), UG/L & 2 & 0 & 5 & 2 & 0 & 1 \\
\hline CADMIUM $(C D), U G / L$ & 2 & $<10$ & $<10$ & 2 & 0 & 1 \\
\hline CHROMIUM (CR), UG/L & 2 & 10 & 20 & 2 & 0 & 0 \\
\hline COBALT $(C O), U G / L$ & 2 & $<50$ & $<50$ & 2 & 0 & 0 \\
\hline COPPER $(C U), U G / L$ & 2 & 30 & 50 & 2 & 3 & 5 \\
\hline IRON (FE), UG/L & 2 & 1200 & 6900 & 2 & 130 & 500 \\
\hline LEAD $(P B), U G / L$ & 2 & $<100$ & $<100$ & 2 & 3 & 5 \\
\hline MANGANESE (MN), UG/L & 2 & 70 & 190 & 2 & 0 & 60 \\
\hline MERCURY (HG), UG/L & 2 & 1.5 & 2.2 & 2 & 1.7 & 1.8 \\
\hline SELENIUM (SE), UG/L & 2 & 0 & 0 & 2 & 0 & 0 \\
\hline ZINC $(Z N), U G / L$ & 2 & 40 & 50 & 2 & 10 & 80 \\
\hline \multicolumn{7}{|l|}{ PERIPHYTON: } \\
\hline BIOMASS, DRY WT., G/SO M & 0 & & & & & \\
\hline BIOMASS, ASH WT., G/SO M & 0 & & & & & \\
\hline CHLOROPHYLL A, MG/SQ M & 0 & & & & & \\
\hline CHLOROPHYLL B, MG/SQ M & 0 & & & & & \\
\hline ORGANIC CARBON, MG/L & 1 & 1.0 & & & & \\
\hline
\end{tabular}


LAT 61032 M41S LONG 150030 M45S

PRAINAGE AREA: 19400 SQ MI 150246 SQ KM)

STATISTICAL SUMMARY OF SELECTED DISSOLVED CHEMICAL CONSTITUENTS AND

REGRESSION RELATIONSHIPS OF CONSTITUENT CONCENTRATIONS TO SPECIFIC CONDUCTANCE

CONSIIIUENI

CONSILUENI_LGGL OR UNII SHOWN

SAMPLE

SIZE

TEMPERATURE, WATER (DEG C) SPECIFIC CONDUCTANCE (MICROMHOS) STREAMFLOW ICUBIC FT/SEC)

PH (STANDARD UNITS)

PHOSPHORUS, TOTAL

NITRITE + NITRATE, TOTAL

NITROGEN, KJELDAHL, TOTAL

PHYTOPLANKTON, TOTAL (CELLS/ML)

SEDIMENT, SUSPENDED

SEDIMENT, CLAY-SILT (PERCENT

COLIFORM, FECAL (COL/100 ML)

STREPTOCOCCI, FECAL (COL/100 ML)

SILICA, DISSOLVED

CALCIUM, DISSOLVED

MAGNESIUM, DISSOLVED

SODIUA, DISSOLVED

POTASSIUM, DISSOLVED

BICARBONATE, ION

CARBONATE, ION

SULFATE, DISSOLVED

CHLORIDE, DISSOLVED

DISSOLVED SOLIDS, SUM OF CONST

OISSOLVED SOLIDS, ROE 180 DEG

HARDNESS, TOTAL

HARONESS, NONCARBONATE

TURBIDITY (JTU)

FLOURIDE, DISSOLVED

*Not significant at the 95 percent confidence level.

SUMMARY OF HARMONIC ANALYSIS OF STREAM TEMPERATURE SUMMARY OF HARMONIC ANALYSIS OF STREAM TEMPERATURE

\begin{tabular}{|c|c|c|c|c|c|}
\hline \multirow{4}{*}{$\begin{array}{l}\text { SAMPLE } \\
\text { SIZE. }\end{array}$} & \multirow{3}{*}{$\begin{array}{l}\text { HARMONIC } \\
\text { MEAN - M }\end{array}$} & \multirow{4}{*}{$\begin{array}{c}\text { AMPLITUDE } \\
-A \\
\text { IDEG }\end{array}$} & \multirow{4}{*}{$\begin{array}{l}\text { PHASE } \\
\text { ANGLE - C } \\
\text { (RADIANS) }\end{array}$} & \multirow{4}{*}{$\begin{array}{l}\text { VAR IATION } \\
\text { EXPLAINED } \\
\text { II) }\end{array}$} & \multirow{2}{*}{$\begin{array}{l}\text { STANDARD } \\
\text { ERROR OF } \\
\text { ESTIMATE }\end{array}$} \\
\hline & & & & & \\
\hline & & & & & ESTIMATE \\
\hline & & & & & 10EG $C 1$ \\
\hline 126 & 3.16 & 7.48 & 2.75 & 36 & 2.74 \\
\hline
\end{tabular}

REGRESSION SUMMARY SAMPLE COEFICIENT, CONSTANT, CORRELATION $-B$ CORRELATION ERROR OI SIZE

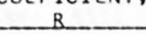
COEEICIENI ESIUMAI:

$\begin{array}{rrrr}6.33 & 4.88 & 0.0 & 10.5 \\ 154.8 & 57.9 & 88 & 225 \\ 71211.8 & 53882.6 & 7080 & 141000 \\ 7.75 & 0.40 & 7.2 & 8.3 \\ 0.250 & 0.229 & 0.01 & 0.57 \\ 0.248 & 0.195 & 0.08 & 0.62 \\ 0.353 & 0.267 & 0.05 & 0.76 \\ 184.2 & 270.9 & 0 & 590 \\ 441.5 & 387.5 & 5 & 994 \\ 56.5 & 20.7 & 26 & 72 \\ 15.8 & 20.5 & 1 & 50 \\ 12.2 & 17.5 & 1 & 42 \\ 6.68 & 2.57 & 4.6 & 10.0 \\ 20.17 & 6.77 & 11.0 & 28.0 \\ 2.97 & 1.03 & 2.0 & 4.3 \\ 4.60 & 2.74 & 2.3 & 8.4 \\ 1.65 & 0.51 & 1.1 & 2.5 \\ 64.0 & 18.0 & 44 & 86 \\ 0.0 & 0.0 & 0 & 0 \\ 12.37 & 4.21 & 5.2 & 17.0 \\ 6.40 & 5.94 & 2.0 & 15.0 \\ 86.5 & 30.5 & 54 & 125 \\ 90.7 & 29.1 & 66 & 130 \\ 62.7 & 20.7 & 36 & 88 \\ 10.0 & 7.9 & 0 & 20 \\ 104.7 & 105.4 & 1 & 240 \\ 0.12 & 0.08 & 0.0 & 0.2\end{array}$

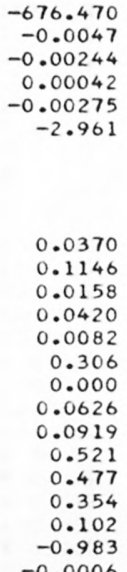

$-0.0006$

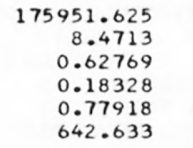

$-0.727^{*}$

$-0.677 \times$

-0.617 .

0.125 *

$-0.597$

$-0.633^{\star}$

41353.1

0.33

0.202

0.216
0.239

234.4

.58

1.44

0.54

0.42
0.22

3.3

0.0

2.38
2.95

4.5

10.2

3.3

5.9

SUMMARY OF MAXIMUM AND MINIMUM CONCENTRATIONS OF CONSTITUENTS SAMPLED AT A FREQUENCY OF QUARTERLY (1975 WY)

15294350 -- SUSITNA R AT SUSITNA STATION AK

\begin{tabular}{|c|c|c|c|c|c|c|}
\hline \multirow{2}{*}{ CONSTI TUENT } & \multicolumn{3}{|c|}{ TOTAL } & \multicolumn{3}{|c|}{ DISSOLVED } \\
\hline & $\begin{array}{l}\text { NO. } \\
\text { SAMPLES }\end{array}$ & $\begin{array}{l}\text { MIN IMUM } \\
\text { CONC. }\end{array}$ & $\begin{array}{l}\text { MAXIMUM } \\
\text { CONC. }\end{array}$ & $\begin{array}{l}\text { NO. } \\
\text { SAMPLES }\end{array}$ & $\begin{array}{l}\text { MINIMUM } \\
\text { CONC. }\end{array}$ & $\begin{array}{l}\text { MAXIMUM } \\
\text { CONC. }\end{array}$ \\
\hline \multicolumn{7}{|l|}{ MINOR ELEMENTS: } \\
\hline ARSENIC (AS), UG/L & 3 & 1 & 11 & 3 & 0 & 2 \\
\hline CADMIUM $(C D), U G / L$ & 3 & $<10$ & 10 & 3 & 0 & 0 \\
\hline CHROMIUM (CR), UG/L & 3 & 0 & 20 & 3 & 0 & 30 \\
\hline COBALT $(C O), U G / L$ & 3 & $<50$ & $<50$ & 3 & 0 & 0 \\
\hline COPPER (CU), UG/L & 3 & 60 & 140 & 3 & 1 & 6 \\
\hline IRON (FE), UG/L & 3 & 360 & 16000 & 3 & 60 & 460 \\
\hline LEAD $(P B), U G / L$ & 3 & $<100$ & $<100$ & 3 & 1 & 3 \\
\hline MANGANESE $(M N), U G / L$ & 3 & 30 & 320 & 3 & 0 & 20 \\
\hline MERCURY $(H G), U G / L$ & 3 & 0.0 & 0.0 & 3 & 0.0 & 0.0 \\
\hline SELENIUM (SE), UG/L & 3 & 0 & 1 & 3 & 0 & 0 \\
\hline ZINC $(Z N), U G / L$ & 3 & 30 & 90 & 3 & 0 & 20 \\
\hline \multicolumn{7}{|l|}{ PERIPHYTON: } \\
\hline BIOMASS, DRY WT., G/SQ M & 1 & .19 & & & & \\
\hline BIOMASS, ASH WT, G/SQ M & 1 & .19 & & & & \\
\hline CHLOROPHYLL A, MG/SQ M & $i$ & .1 & & & & \\
\hline CHLOROPHYLL $B$, MG/SO M & 1 & .0 & & & & \\
\hline ORGANIC CARBON, MG/L & 3 & .8 & 11.0 & & & \\
\hline
\end{tabular}


Table 14.--Summary of measurement at each station--Continued

IT $61052 M 1 O S$ LONG $158006 M 42 S$

[AINAGE AREA: 31100 SQ MI ( 80549 SQ KM)

ERIOD OF RECORD: $10 / 01 / 74-09 / 30 / 75$

STATISTICAL SUMMARY OF SELECTED DISSOLVED CHEMICAL CONSYITUENTS AND

REGRESSION RELATIONSHIPS OF CONSTITUENT CONCENTRATIONS TO SPECIFIC CONDUCTANCE

CONSILIUENI

CONSIUIUENI_HG/L OR UNII SHOHNI
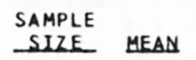

STANDARD TEMPERATURE, WATER (DEG C)
SPECIFIC CONDUCTANCE (MICROMHOS) STREAMFLOW (CUBIC FT/SEC)

STREAMFLOW (CUBIC FT/S
PH (STANDARD UNITS)

PHOSPHORUS, TOTAL

NITRITE + NITRATE, TOTAL

NITROGEN, KJELDAHL, TOTAL

PHYTOPLANKTON, TOTAL (CELLS/ML)

SEDIMENT, SUSPENDED

SEDIMENT, CLAY-SILT (PERCENT)

COLIFORM, FECAL (COL 100 ML)

COLIFORM, FECAL (COL/1OO ML)

SILICA, DISSOLVED

CALCIUM, DISSOLVED

MAGNESIUM, DISSOL VED

SODIUM, DISSOLVED

POTASSIUM, DISSOL VED

BICARBONATE, ION

CARBONATE, ION

SULFATE, DISSOLVED

CHLOR IDE, DISSOLVED

DISSOLVED SOLIDS, SUM OF CONST

DISSOLVED SOLIDS, ROE 180 DEG

HARDNESS, TOTAL

HARDNESS, NONCARBONATE

TURBIDITY (JTU)

FLOURIDE, DISSOLVED

$\begin{array}{rr}5 & 9.90 \\ 5 & 175.8 \\ 5 & 61324.0 \\ 5 & 7.74 \\ 4 & 0.060 \\ 5 & 0.106 \\ 5 & 0.394 \\ 5 & 435.4 \\ 4 & 78.8 \\ 2 & 49.0 \\ 4 & 9.0 \\ 4 & 13.3 \\ 4 & 7.60 \\ 5 & 24.20 \\ 5 & 5.50 \\ 4 & 2.20 \\ 4 & 0.77 \\ 5 & 89.6 \\ 5 & 0.0 \\ 4 & 14.15 \\ 5 & 0.66 \\ 4 & 89.5 \\ 4 & 94.8 \\ 5 & 82.2 \\ 5 & 9.8 \\ 5 & 32.4 \\ 4 & 0.15\end{array}$

6.66
49.5
35706.3
0.40
0.040
0.049
0.270
377.7
51.4
8.5
8.1
11.8
1.04
7.69
2.08
0.61
0.15
29.7
0.0
6.00
0.13
18.1
17.7
26.0
6.6
30.0
0.06
BANGE SAMPLE

REGRESSION

$\mathrm{R}$

\section{EGRESSION SUMMARY}

$\begin{array}{rr}0.0 & 16 . \\ 132 & 25\end{array}$

$\begin{array}{rr}132 & 253 \\ 8920 & 96600\end{array}$

8920
7.2

0.00

0.05

8.2
0.08
0.18

0.18
0.86

1000

116

27

43

1
3
6.3

6.3
16.0

2.7

1.8
0.6

0.6
66

0
7.6
0.5
71

71
74

51
0
2

2
0.1

${ }^{*}$ Not significant at the 95 percent confidence level.

SUMMARY OF MAXIMUM AND MINIMUM CONCENTRATIONS OF CONSTITUENTS

SAMPLED AT A FREQUENCY OF QUARTERLY (1975 WY)

15304000 -- KUSKOKWIM R AT CROOKED C AK

\begin{tabular}{|c|c|c|c|c|c|c|}
\hline \multirow{2}{*}{ CONSTI TUENT } & \multicolumn{3}{|c|}{ TOTAL } & \multicolumn{3}{|c|}{ DISSOLVED } \\
\hline & $\begin{array}{l}\text { NO. } \\
\text { SAMPLES }\end{array}$ & $\begin{array}{l}\text { MIN IMUM } \\
\text { CONC. }\end{array}$ & $\begin{array}{l}\text { MAXIMUM } \\
\text { CONC. }\end{array}$ & $\begin{array}{l}\text { NO. } \\
\text { SAMPLES }\end{array}$ & $\begin{array}{l}\text { MINIMUM } \\
\text { CONC. }\end{array}$ & $\begin{array}{l}\text { MAXIMUM } \\
\text { CONC. }\end{array}$ \\
\hline \multicolumn{7}{|l|}{ MINOR ELEMENTS: } \\
\hline ARSENIC (AS), UG/L & 3 & 1 & 5 & 2 & 0 & 1 \\
\hline CADMIUM $(C D), U G / L$ & 3 & $<10$ & $<10$ & 2 & 0 & 0 \\
\hline CHROMIUM (CR), UG/L & 3 & 0 & 10 & 2 & 0 & 0 \\
\hline COBALT $(C O), U G / L$ & 3 & $<50$ & $<50$ & 2 & 0 & 2 \\
\hline COPPER $(C U), U G / L$ & 3 & 10 & 45 & 2 & 2 & 2 \\
\hline IRON (FE), UG/L & 3 & 680 & 4500 & 2 & 20 & 310 \\
\hline LEAD $(P B), U G / L$ & 3 & $<100$ & $<100$ & 2 & 1 & 2 \\
\hline MANG ANESE (MN), UG/L & 3 & 0 & 130 & 2 & 10 & 40 \\
\hline MERCURY $(H G), U G / L$ & 3 & 0.1 & 0.3 & 2 & 0.0 & 0.1 \\
\hline SELENIUM (SE), UG/L & 3 & 0 & 1 & 2 & 0 & 1 \\
\hline ZINC $(Z N), U G / L$ & 3 & 30 & 50 & 2 & 10 & 20 \\
\hline \multicolumn{7}{|l|}{ PERIPHYTON: } \\
\hline BIOMASS, DRY WT., G/SQ M & 0 & & & & & \\
\hline BIOMASS, ASH WT., G/SQ M & 0 & & & & & \\
\hline CHLOROPHYLL A, MG/SQ M & 0 & & & & & \\
\hline CHLOROPHYLL B, MG/SO M & 0 & & & & & \\
\hline ORGANIC CARBON, MG/L & 3 & 3.0 & 6.7 & & & \\
\hline
\end{tabular}


Table 14.--Sumnary of measurement at each station--Continued

STATION NUMBER: 15565447 NAME: YUKON R AT PILOT STATION AK

LAT 61D56M04S LONG 162052M50S

DRAINAGE AREA: 321000 SQ MI ( 831390 SQ KM)

PERIOD OF RECORD: $10 / 01 / 74-09 / 30 / 75$

STATISTICAL SUMMARY OF SELECTED DISSOLVED CHEMICAL CONSTITUENTS AND

REGRESSION RELATIONSHIPS OF CONSTITUENT CONCENTRATIONS TO SPECIFIC CONDUCTANCE

CONSIIIUENI

TEMPERATURE, WATER (DEG C)

SPECIFIC CONDUCTANCE (MICROMHOS)

STREAMFLOW (CUBIC FI/SEC)

PH (STANDARD UNITS)

PHOSPHORUS, TOTAL

NITRITE + NITRATE, TOTAL

NITROGEN, KJELDAHL, TOTAL

PHYTOPLANKTON, TOTAL (CELLS/ML)

SEDIMENT, SUSPENDED

SEDIMENT, CLAY-SILT (PERCENT)

COLIFORM, FECAL (COL/100 ML)

STREPTOCOCC I, FECAL (COL/100 ML)

SILICA, DISSOLVED

CALCIUM, DISSULVED

MAGNESIUM, DISSOLVED

SODIUM, DISSOLVED

POTASSIUM, DISSOLVED

BICARBCNATE, ION

CARBONATE, ION

SULFATE, DISSOLVED

CHLORIDE, OISSOLVED

DISSOLVED SOLIDS, SUM OF CONST

DISSOLVED SOLIDS, ROE 180 DEG

HARDNESS, TOTAL

HARDNESS, NONCARBONATE

TURBIDITY (JTU)

FLOUR IDE, DISSOLVED

\begin{tabular}{|c|c|c|}
\hline $\begin{array}{l}\text { SAMPL } \\
\text { SIZE }\end{array}$ & MEAN & $\begin{array}{l}\text { STANDARD } \\
\text { DEYIAIION }\end{array}$ \\
\hline $\begin{array}{l}5 \\
5\end{array}$ & $\begin{array}{l}10.70 \\
202.4\end{array}$ & $\begin{array}{l}6.92 \\
67.4\end{array}$ \\
\hline 5 & 385999.2 & 214512.9 \\
\hline 5 & 7.76 & 0.30 \\
\hline 5 & 0.210 & 0.181 \\
\hline 5 & 0.130 & 0.072 \\
\hline 5 & 0.596 & 0.474 \\
\hline 5 & 538.0 & 878.6 \\
\hline 5 & 204.6 & 141.2 \\
\hline 4 & 81.5 & 8.7 \\
\hline 3 & 8.0 & 0.1 \\
\hline 3 & 6.0 & 5.3 \\
\hline 4 & 6.45 & 1.21 \\
\hline 5 & 29.60 & 10.99 \\
\hline 5 & 6.42 & 2.71 \\
\hline & 2.12 & 0.33 \\
\hline 4 & 1.15 & 0.24 \\
\hline 5 & 102.6 & 45.1 \\
\hline 5 & 0.0 & 0.0 \\
\hline 4 & 16.00 & 3.74 \\
\hline 5 & 1.02 & 0.08 \\
\hline 4 & 98.0 & 11.6 \\
\hline 4 & 116.5 & 8.3 \\
\hline 5 & 100.8 & 39.5 \\
\hline 5 & 16.2 & 3.1 \\
\hline 5 & 63.8 & 52.8 \\
\hline 4 & 0.10 & 0.00 \\
\hline
\end{tabular}

BANGE
BNA
0.0
150
43000
7.3
0.00
0.06
0.24
0
4
70
1
2
4.7
23.0
4.3
1.8
1.0
73
0
12.0
0.9
88
109
75
11
4
0.1

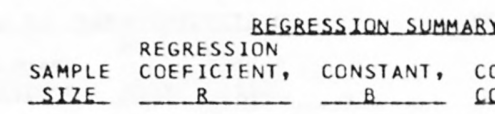

CORRELATIUN ST ANDARD
ERROR OF ESIIMAIE

*Not significant at the 95 percent confidence level.
SUMMARY OF MAXIMUM AND MINIMUM CONCENTRATIONS OF CONSTITUENTS SAMPLED AT A FREQUENCY OF QUARTERLY (1975 WY)
15565447 -- YUKON R AT PILOT STATION AK

CONSTI TUENT


Table 14.--Sumnary of measurement at each station--Continued

STATION NUMBER: 15744500 NAME: KOBUK R NR KIANA AK

LAT 66D58M27S LONG 160007M51S

DRAINAGE AREA: 952 SO MI

PERIOD OF RECORD: $10 / 01 / 74-09 / 30 / 75$

STATISTICAL SUMMARY OF SELECTED DISSOLVED CHEMICAL CONSTITUENTS AND

REGRESSION RELATIONSHIPS OF CONSTITUENT CONCENTRATIONS TO SPECIFIC CONOUCTANCE

CONSILIUENI

CONSIUUENI IMG/L OR UNII SHOWNI

SAMPLE STANDARD

SIZE MEAN DEYIALION
BANGE
REGRESSION SUMMABY

SAMPLE REGRESSION COEFICIENT.
STANDARD ERROR OF ESIUMAIE

TEMPERATURE, WATER (DEG C) SPECIFIC CONDUCTANCE (MICROMHOS) STREAMFLOH (CUBIC FT/SEC)

PH (STANDARD UNITS)

PHOSPHORUS, TOTAL

NITRITE + NITRATE, TOTAL

NITROGEN, KJELDAHL, TOTAL

PHYTOPLANKTON, TOTAL (CELLS/ML)

SEDIMENT, SUSPENDED

SEDIMENT, CLAY-SILT (PERCENT)

COLIFORM, FECAL (COL/100 ML)

STREPTOCOCCI, FECAL (COL/100 ML)

SILICA, DISSOLVEO

CALCIUM, DISSOLVED

MAGNE SIUM, DI SSOLVED

SODIUM, DISSOLVED

POTASSIUM, DISSOLVED

BICARBONATE, ION

CARBONATE, ION

SULFATE, DISSOLVED

CHLOR IDE, DISSOLVED

DISSOLVEO SOLIDS, SUM OF CONST

OISSOLVEO SOLIDS, ROE 180 DEG C

HARDNESS, TOTAL

HARDNESS, NONCARBONATE

TURBIDITY (JTU)

FLOUR IDE, DISSOLVED

0
0
0
0
0
0
0
0
0
0
0
0
0
0
0
0
0
0
0
0
0
0
0
0
0
0
0

SUMMARY OF MAXIMUM AND MINIMUM CONCENTRATIONS OF CONSTITUENTS

SAMPLED AT A FREQUENCY OF QUARTERLY (1975 WY)

15744500 -- KOBUK R NR KIANA AK

\begin{tabular}{|c|c|c|c|c|c|c|}
\hline \multirow{2}{*}{ CONSTITUENT } & \multicolumn{3}{|c|}{ TOTAL } & \multicolumn{3}{|c|}{ DISSOLVED } \\
\hline & $\begin{array}{l}\text { NO. } \\
\text { SAMPLES }\end{array}$ & $\begin{array}{l}\text { MIN IMUM } \\
\text { CONC. }\end{array}$ & $\begin{array}{l}\text { MAXIMUM } \\
\text { CONC. }\end{array}$ & $\begin{array}{l}\text { NO. } \\
\text { SAMPLES }\end{array}$ & $\begin{array}{l}\text { MINIMUM } \\
\text { CONC. }\end{array}$ & $\begin{array}{l}\text { MAXIMUM } \\
\text { CONC. }\end{array}$ \\
\hline \multicolumn{7}{|l|}{ MINOR ELEMENTS: } \\
\hline ARSENIC (AS), UG/L & 0 & & & 0 & & \\
\hline CADMIUM $(C D), U G / L$ & 0 & & & 0 & & \\
\hline CHROMIUM $(C R), U G / L$ & 0 & & & 0 & & \\
\hline COBALT $(C O), U G / L$ & 0 & & & 0 & & \\
\hline COPPER ICUI, UG/L & 0 & & & 0 & & \\
\hline IRON $(F E), U G / L$ & 0 & & & 0 & & \\
\hline LEAD $(P B), U G / L$ & 0 & & & 0 & & \\
\hline MANGANESE (MN), UG/L & 0 & & & 0 & & \\
\hline MERCURY (HG), UG/L & 0 & & & 0 & & \\
\hline SELENIUM (SE), UG/L & 0 & & & 0 & & \\
\hline$Z I N C(Z N), U G / L$ & 0 & & & 0 & & \\
\hline \multicolumn{7}{|l|}{ PERIPHYTON: } \\
\hline BIOMASS, DRY WT., G/SO M & 0 & & & & & \\
\hline BIOMASS, ASH WT., G/SQ M & 0 & & & & & \\
\hline CHLOROPHYLL A, MG/SQ M & 0 & & & & & \\
\hline CHLOROPHYLL B, MG/SQ M & 0 & & & & & \\
\hline ORGANIC CARBON, MG/L & 0 & & & & & \\
\hline
\end{tabular}


Table 14.--Summary of measurement at each station--Continued

STATION NUMBER: 15896000 NAME: KUPARUK R NR DEADHORSE AK

LAT 70D16M54S LONG 148D57M35S

DRAINAGE AREA: 3130 SQ MI 188107 SQ KM

PERIOD OF RECORD: $10 / 01 / 74-09 / 30 / 75$

STATISTICAL SUMMARY OF SELECTED DISSOLVED CHEMICAL CONSTITUENTS AND

REGRESSION RELATIONSHIPS OF CONSTITUENT CONCENTRATIONS TO SPECIFIC CONDUCTANCE

CONSILTUENI

CONSIUIUENI
TEMPERATURE, WATER (DEG C)
SPECIFIC CONDUCTANCE (MICROMHOS)
STREAMFLOW (CUBIC FT/SEC)
PH (STANDARD UNITS)
PHOSPHORUS, TOTAL
NITRITE + NITRATE, TOTAL
NITROGEN, KJELDAHL, TOTAL
PHYTOPLANKTON, TOTAL (CELLS/ML)
SEDIMENT, SUSPENDED
SEOIMENT, CLAY-SILT (PERCENT)
COLIFORM, FECAL (COL/IOO ML)
STREPTOCOCCI, FECAL (COL/IOO ML)
SILICA, DISSOLVED
CALCIUM, DISSOLVED
MAGNESIUM, OISSOLVED
SODIUM, DISSOLVED
POTASSIUM, DISSOLVED
BICARBCNATE, ION
CARBONATE, ION
SULFATE, DISSOLVED
CHLORIDE, DISSOLVED
DISSOLVED SOLIDS, SUM OF CONST
DISSOLVED SOLIDS, ROE I8O OEG C
HARDNESS, TOTAL
HARDNESS, NONCAREONATE
TURBIDITY (JTU)
FLOURIDE, DISSOLVED

CONSIUIUENI IHG/L OR UNII SHOWN

SAMPLE

SIZE

MEAN

STANDARD

EYLALION

5
3

225.3

3605.3
5

0.000

0.060

0.260

71.5

50.5

81.0

1.0

1.0
1.60

1.60
20.67

20.67
1.53

2.40

0.57

135.2

0.0

2.62

1.65

64.3

70.0

58.0

0.0
5.8

0.02

6.42

175.6
6266.7

6266.7
0.43

0.43
0.000

0.057

0.057

96.9

68.6

0.0

0.0

0.0

1.91
4.04

0.98

1.57

0.49

84.6

1.53

1.64

11.2

0.0

11.3

0.0
9.5

0.05

\section{BEGRESSION SUMMARY}

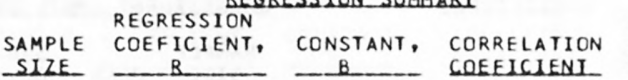

STANDARD ERROR OF

$0.0 \quad 13.5$

$100 \quad 420$

$\begin{array}{rr}0.02 & 0.10 \\ 0.22 & 0.30 \\ 3 & 140 \\ 2 & 99\end{array}$

$\begin{array}{rr}0.02 & 0.10 \\ 0.22 & 0.30 \\ 3 & 140 \\ 2 & 99\end{array}$

81

1
1
0.1

0.1
17.0

0.4

0.9

0.2

67
0

1.2

0.6

56

51

0.1 ESIIMAIE

13000

7.8
0.00

0.00
0.10

SIZE

3

$-0.0010$

7.9200

-0.990 *

0.03

4.4
25.0
2.1

2.1
4.6

4.6
1.3
246

246

4.8
4.17
77

30.0108

0.0033
0.555

$-0.9873$

0.950 *

1.01

3

3

0.0105

0.0103

0.0283

$-0.1184$

9.381

0.993 *

1.000 *

1.000 *

0.3683

$-0.3195$

0.992 *

0.993 *

3.4

0.34

0.30
71
0
20

0.1

3

$-0.0002$

0.0791

$-0.618 *$

0.06

SUMMARY OF MAXIMUM AND MINIMUM CONCENTRATIONS OF CONSTITUENTS

SAMPLED AT A FREQUENCY OF QUARTERLY (1975 WY)

15896000 -- KUPARUK R NR DEADHORSE AK

\begin{tabular}{|c|c|c|c|c|c|c|}
\hline \multirow{2}{*}{ CONSTITUENT } & \multicolumn{3}{|c|}{ TOTAL } & \multicolumn{3}{|c|}{ DISSOLVED } \\
\hline & $\begin{array}{l}\text { NO. } \\
\text { SAMPLES }\end{array}$ & $\begin{array}{l}\text { MIN IMUM } \\
\text { CONC. }\end{array}$ & $\begin{array}{l}\text { MAXIMUM } \\
\text { CONC. }\end{array}$ & $\begin{array}{l}\text { NO. } \\
\text { SAMPLES }\end{array}$ & $\begin{array}{l}\text { MINIMUM } \\
\text { CONC. }\end{array}$ & $\begin{array}{l}\text { MAXIMUM } \\
\text { CONC. }\end{array}$ \\
\hline \multicolumn{7}{|l|}{ MINOR ELEMENTS: } \\
\hline ARSENIC (AS), UG $/ L$ & 3 & 0 & 0 & 3 & 0 & 0 \\
\hline CADMIUM $(C D), U G / L$ & 3 & $<10$ & $<10$ & 3 & 0 & 0 \\
\hline CHROMIUM (CR), UG/L & 3 & 0 & 10 & 3 & 0 & 10 \\
\hline COBALT $(C O), U G / L$ & 3 & $<50$ & $<50$ & 3 & 0 & 0 \\
\hline COPPER (CU), UG/L & 3 & $<10$ & 20 & 3 & 1 & 10 \\
\hline IRON (FE), UG/L & 3 & 0 & 4000 & 3 & 0 & 160 \\
\hline LEAD $(P B), U G / L$ & 3 & $<100$ & $<100$ & 3 & 0 & 3 \\
\hline MANGANESE (MN), UG/L & 2 & 0 & 60 & 3 & 0 & 60 \\
\hline MERC URY $(H G), U G / L$ & 3 & 0.0 & 0.3 & 3 & 0.0 & 0.1 \\
\hline SELENIUM (SE), UG/L & 3 & 0 & 0 & 3 & 0 & 0 \\
\hline ZINC $(Z N), U G / L$ & 3 & 10 & 60 & 3 & 0 & 20 \\
\hline \multicolumn{7}{|l|}{ PERIPHYTON: } \\
\hline BIOMASS, DRY WT., G/SQ M & 1 & 1.79 & & & & \\
\hline BIOMASS, ASH WT., G/SQ M & 1 & 1.29 & & & & \\
\hline CHLOROPHYLL A, MG/SQ M & $\overline{1}$ & .1 & & & & \\
\hline CHLOROPHYLL $B$, MG/SO M & 1 & .0 & & & & \\
\hline ORGANIC CARBON, MG/L & 4 & 3.7 & 18.0 & & & \\
\hline
\end{tabular}


Table 14.--Sumnary of measurement at each station--Continued

LAT 21D59MO2S LONG 159039M46S DRAINAGE AREA: 58 SQ MI 1150 SQ KM)

PERIOD OF RECORD: $10 / 01 / 74-09 / 30 / 75$

STATISTICAL SUMMARY OF SELECTED DISSOLVED CHEMICAL CONSTITUENTS AND

REGRESSION RELATIONSHIPS OF CONSTITUENT CONCENTRATIONS TO SPECIFIC CONDUCTANCE

CONSILIUENI

CONSILIUENI IMG/L OB UNUI SHOWNU

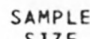

SIZE

TEMPERATURE, WATER (DEG C) SPECIFIC CONDUCTANCE (MICROMHOS ) STREAMFLOW (CUBIC FT/SEC) PH (STANDARO UNITS)

PHOSPHORUS, TOTAL

NITRITE + NITRATE, TOTAL

NITROGEN, KJELDAHL, TOTAL

PHYTOPLANKTON, TOTAL (CELLS/ML)

SEDIMENT, SUSPENDED

SEDIMENT, CLAY-SILT (PERCENT)

COLIFORM, FECAL (COL/100 ML)

STREPTOCOCCI, FECAL (COL/100 ML)

SILICA, DISSOLVED

CALCIUM, DISSOLVED

MAGNESIUM, DISSOL VED

SODIUM, DISSOLVED

POTASSIUM, DISSOLVED

BICARBONATE, ION

CARBONATE, ION

SULFATE, DISSOLVED

CHLORIDE, DISSOLVED

DISSOLVED SOLIDS, SUM OF CONST

DISSOLVED SOLID, ROE 180 DEG

HARDNESS, TOTAL

HARDNESS, NONCARBONATE

TURBIDITY (JTU)

FLOURIDE, DISSOLVED



$\begin{array}{rrr}13 & 22.88 & 2.72 \\ 13 & 160.0 & 63.7 \\ 13 & 52.5 & 137.7 \\ 13 & 7.17 & 0.34 \\ 12 & 0.020 & 0.024 \\ 12 & 0.026 & 0.046 \\ 12 & 0.473 & 0.866 \\ 11 & 793.6 & 473.7 \\ 12 & 6.9 & 10.8 \\ 12 & 93.8 & 13.3 \\ 11 & 156.4 & 71.0 \\ 11 & 359.2 & 364.6 \\ 13 & 21.02 & 5.12 \\ 13 & 8.01 & 2.97 \\ 13 & 9.52 & 4.34 \\ 13 & 8.58 & 2.45 \\ 13 & 0.83 & 0.15 \\ 13 & 71.1 & 30.4 \\ 8 & 0.0 & 0.0 \\ 13 & 2.36 & 0.61 \\ 13 & 12.38 & 3.81 \\ 13 & 98.0 & 33.0 \\ 12 & 98.8 & 31.9 \\ 13 & 59.2 & 24.7 \\ 13 & 2.1 & 3.0 \\ 13 & 3.5 & 5.0 \\ 13 & 0.09 & 0.10\end{array}$

0.10

\section{BEGBESSION SUMMABY}

SAMPLE REGRESSION

SIZE

COEFICIENT,

CONSTANT,

CORRELATION COEEICIENI

STANDARD ERROR OF

17.526 .5

$40 \quad 220$

$3 \quad 504 \quad 13$

$0.00 \quad 0.09$

$0.00 \quad 0.16$

0.09

270

2
63

63
90

$\begin{array}{ll}90 & 320 \\ 56 & 1200\end{array}$

$9.3 \quad 27.0$

$2.4 \quad 13.0$

$2.0 \quad 15.0$

3.4

16

0

1.5

4.7
33

36

14

0.0

3.4

17.0

132
133

90
10
20

0.4

13
12

$-1.433$

$-0.0015$

$-0.00020$

$-0.00052$

0.00331

7.4063

0.05255

0.11080

$-0.06965$

385.938

$-0.663$

$-0.276$

-0.534 .

$-0.736$

0.357 .

107.7

0.34

0.032

0.879

466.5

SUMMARY OF HARMONIC ANALYSIS OF STREAM TEMPERATURE

\begin{tabular}{|c|c|c|c|c|c|}
\hline & & & & & STANDARD \\
\hline & HARMONIC & AMPLITUDE & PHASE & VARIATION & ERROR OF \\
\hline SAMPLE & MEAN - M & $-A$ & ANGLE - C & EXPLAINEO & ESTIMATE \\
\hline SIZE & $10 E G(1)$ & (DEG $C 1$ & (RADIANS) & (z) & $10 E G(1)$ \\
\hline 13 & 22.58 & 2.86 & 3.09 & 71 & 1.61 \\
\hline
\end{tabular}

SUMMARY OF MAXIMUM AND MINIMUM CONCENTRATIONS OF CONSTITUENTS SAMPLED AT A FREQUENCY OF QUARTERLY (1975 WY)

16031000 -- WAIMEA RIVER NR WAIMEA, KAUAI, HI

\begin{tabular}{|c|c|c|c|c|c|c|}
\hline \multirow{2}{*}{ CONSTI TUENT } & \multicolumn{3}{|c|}{ TOTAL } & \multicolumn{3}{|c|}{ DISSOLVED } \\
\hline & $\begin{array}{l}\text { NO. } \\
\text { SAMPLES }\end{array}$ & $\begin{array}{l}\text { MIN IMUM } \\
\text { CONC. }\end{array}$ & $\begin{array}{l}\text { MAXIMUM } \\
\text { CONC. }\end{array}$ & $\begin{array}{l}\text { NO. } \\
\text { SAMPLES }\end{array}$ & $\begin{array}{l}\text { MINIMUM } \\
\text { CONC. }\end{array}$ & $\begin{array}{l}\text { MAXIMUM } \\
\text { CONC. }\end{array}$ \\
\hline \multicolumn{7}{|l|}{ MINOR ELEMENTS: } \\
\hline ARSENIC (AS), UG/L & 4 & 0 & 1 & 4 & 0 & 1 \\
\hline CADMIUM $(C D)$, UG $/ L$ & 4 & $<10$ & 10 & 4 & 0 & 1 \\
\hline CHROMIUM (CR), UG/L & 4 & 0 & 0 & 4 & 0 & 0 \\
\hline COBALT $(C O), U G / L$ & 4 & 0 & 100 & 4 & 0 & 1 \\
\hline COPPER (CU), UG/L & 4 & 10 & 260 & 4 & 1 & 1 \\
\hline IRON $(F E), U G / L$ & 4 & 270 & 650 & 5 & 50 & 260 \\
\hline$L E A D(P B), U G / L$ & 4 & $<100$ & $<100$ & 4 & 1 & 7 \\
\hline MANGANESE (MN), UG/L & 4 & 20 & 70 & 5 & 0 & 30 \\
\hline MERCURY (HG), UG/L & 3 & 0.0 & 0.0 & 4 & 0.0 & 0.0 \\
\hline SELENIUM (SE), UG & 4 & 0 & 0 & 4 & 0 & 0 \\
\hline ZINC $(Z N), U G / L$ & 4 & 20 & 110 & 4 & 0 & 10 \\
\hline \multicolumn{7}{|l|}{ PERIPHYTON: } \\
\hline BIOMASS, DRY WT., G/SQ M & 4 & 1.09 & 13.00 & & & \\
\hline BIOMASS, ASH WT., G/SO M & 4 & 1.00 & 9.79 & & & \\
\hline CHLOROPHYLL A, MG/SQ M & 4 & 7.1 & 24.0 & & & \\
\hline CHLOROPHYLL B, MG/SQ M & 4 & 1.0 & 6.2 & & & \\
\hline ORGANIC CARBON, MG/L & 4 & 3.0 & $5 \cdot 3$ & & & \\
\hline
\end{tabular}


Tab1e 14.--Sumnary of measurement at each station--Continued
STATION NUMBER: 16213000
NAME: WAIKELE STREAM AT WAIPAHU, OAHU, HI

LAT $21023 M 11 S$ LONG 158000M49S

$\begin{array}{lll}\text { DRAINAGE AREA: } & 46 \text { SQ MI } 11118 \text { SQ KM) } \\ \text { PERIOD OF RECORD: } & 10 / 01 / 74-09 / 30 / 75\end{array}$

STATISTICAL SUMMARY OF SELECTED DISSOLVED CHEMICAL CONSTITUENTS AND

REGRESSION RELATIONSHIPS OF CONSTITUENT CONCENTRATIONS TO SPECIFIC CONOUCTANCE

CONSIUIUENI

CONSILIUENI IMG L OB UNII SHOWNI

TEMPERATURE, WATER (DEG C)
SPECIFIC CONDUCTANCE (MICROMHOS)
SIREAMFLOW (CUBIC FT/SEC)
PH (STANDARD UNITS)
PHOSPHORUS, TOTAL
NITRITE, NITRATE, TOTAL
NITROGEN, KJELDAHL, TOTAL
PHYTOPLANKTON, TOTAL (CELLS/ML)
SEDIMENT, SUSPENDED
SEDIMENT, CLAY-SILT (PERCENT)
COLIFORM, FECAL (COL/IOO ML)
STREPTOCOCCI, FECAL (CCL/IOO ML)
SILICA, DISSOLVE
CALCIUM, DISSOLVED
MAGNESIUM, DISSOLVED
SODIUM, DISSOLVED
POTASSIUM, DISSOLVED
BICARBONATE, ION
CAREONATE, ION
SULFATE, DISSOLVED
CHLORIDE, DISSOLVED
DISSOLVED SOLIDS, SUM OF CONST
DISSOLVED SOLIDS, ROE ISO DEG C
HARONESS, TOTAL
HARDNESS, NONCARBONATE
TURBIDITY (JTU)
FLOURIDE, OISSOLVED

SAMPLE
S1ZE
12
13
16
13
12
12
12
12
14
14
12
12
12
12
12
12
12
12
7
12
12
12
12
12
12
12
12

STANDARD

$\begin{array}{ll}22.40 & 0.86 \\ 354.4 & 91.1\end{array}$

$\begin{array}{rr}354.4 & 1377.0\end{array}$

$\begin{array}{rr}424.8 & 1377.0 \\ 6.93 & 0.25\end{array}$

$1.090 \quad 0.346$

1.090

2.119

0.492
742.8

742.8
836.1

93.9

1622.5

1198.3

45.17

7.48
46.83

46.83
3.03

3.03
59.6

0.0

19.07

61.58

223.0

236.4

56.8

7.7
24.8

24.8
0.17

0.346
0.697

0.210

553.7
2366.2

2366.2
8.0

1669.5

1026.4

10.84

2.29

2.06
14.73

14.73

0.72
14.9

14.9
0.0

4.85

17.56

58.9
62.9

13.4

4.0

4.0
28.7

0.08
*Not significant at the 95 percent confidence level.

DURAIION IABLE OF DAILY SPECIEIC CONDUCIANCE

DAILY SPECIFIC CONDUCTANCE IN

MICROMHOS AT 25 DEG C, THAT WAS

EQUALLED OR EXCEEDED FOR THE

$\begin{array}{lll}-18 \quad-58 & 208\end{array}$

208

$30 \%$

BEGBESSION SUMMABY

INUICATED PERCENTAGE UF TIME

$\begin{array}{rr}21.0 & 23.5 \\ 185 & 465 \\ 3 & 5550\end{array}$

$\begin{array}{rrr}0.5 & 7.3 & 13 \\ 0.57 & 1.60 & 12\end{array}$

0.83

0.30

$\begin{array}{lll}94 & 1900 & 12\end{array}$

$\begin{array}{rr}6 & 8660 \\ 79 & 100\end{array}$

360

210
28.0
5.5

3.6

23.0

1.6

33
0
9.9

9.9
33.0

121

119
29

1

0.1

$$
3000
$$$$
\begin{aligned}
& 6600 \\
& 3000
\end{aligned}
$$

$60.0 \quad 12$

$15.0 \quad 12$

$9.8 \quad 12$

64.0

4.6
80

0
27.0
82.0

82.0
294

294
312

76
14

14
100

0.3 $\begin{array}{rrr}3 & 5550 \quad 13 \\ 6.5 & 7.3\end{array}$
REGRESSION \begin{tabular}{l} 
REGRESSION \\
COEFICIENT, CONSTANT, \\
\hline
\end{tabular} SAMPLE SIZE

CORRELATION COEFICIENI

STANDARO

ERROR OF

ESIUMAIE

$\begin{array}{rr}-0.281 & 138.051 \\ -0.0003 & 7.0282 \\ 0.00318 & -0.06154 \\ 0.00623 & -0.13412 \\ -0.00146 & 1.02099 \\ -0.498 & 922.859\end{array}$

$-0.915$

-0.102 *

0.836

0.812

$-0.633$

-0.082 *

11.8

0.26

0.199

0.426

0.170
578.8
4.0527

2.9036

$-0.5018$

$-10.7231$

1.1183

3.128

0.000
0.5831

$-8.032$

$-12.303$

5.906

112.093

$-0.0176$

0.959
0.820
0.979
0.988
0.674
0.959
$0.000 *$
0.964
0.987
0.992
0.999
0.959
$0.348 *$
0.767
0.046

SUMMARY OF HARMONIC ANALYSIS OF STREAM TEMPERATURE

\begin{tabular}{|c|c|c|c|c|c|}
\hline & & & & & STANDARD \\
\hline & HARMONIC & AMPLITUDE & PHASE & VAR IATION & ERROR OF \\
\hline SAMPLE & MEAN - M & $-A$ & ANGLE - C & EXPLAINED & ESTIMATE \\
\hline SIZE & IDES Cl & (DEG $(1)$ & (BADIANS) & $-(z)$ & $10 E G_{2} C L$ \\
\hline 283 & 22.58 & 0.98 & 3.16 & 06 & 0.49 \\
\hline
\end{tabular}

SUMMARY OF MAXIMUM AND MINIMUM CONCENTRATIONS OF CONSTITUENTS SAMPLED AT A FREQUENCY OF QUARTERLY (1975 WY)

16213000 -- WAIKELE STREAM AT HAIPAHU, OAHU, HI

\begin{tabular}{|c|c|c|c|c|c|c|}
\hline \multirow{2}{*}{ CONSTITUENT } & \multicolumn{3}{|c|}{ TOTAL } & \multicolumn{3}{|c|}{ DISSOLVED } \\
\hline & $\begin{array}{l}\text { NO. } \\
\text { SAMPLES }\end{array}$ & $\begin{array}{l}\text { MINIMUM } \\
\text { CONC. }\end{array}$ & $\begin{array}{l}\text { MAXIMUM } \\
\text { CONC. }\end{array}$ & $\begin{array}{l}\text { NO. } \\
\text { SAMPLES }\end{array}$ & $\begin{array}{l}\text { MINIMUM } \\
\text { CONC. }\end{array}$ & $\begin{array}{l}\text { MAXIMUM } \\
\text { CONC. }\end{array}$ \\
\hline \multicolumn{7}{|l|}{ MINOR ELEMENTS: } \\
\hline ARSENIC (AS), UG/L & 4 & 1 & 2 & 4 & 0 & 2 \\
\hline CADMIUM $(C D), U G / L$ & 4 & $<10$ & $<10$ & 4 & 0 & 0 \\
\hline CHROMIUM (CR), UG/L & 4 & 0 & 60 & 4 & 0 & $<10$ \\
\hline COBALT $(C O), U G / L$ & 4 & $<50$ & $<50$ & 4 & 0 & 4 \\
\hline COPPER $(C U), U G / L$ & 4 & $<10$ & 400 & 4 & 1 & 5 \\
\hline IRON $(F E), U G / L$ & 4 & 550 & 8600 & 4 & 0 & 80 \\
\hline LEAD $(P B), U G / L$ & 4 & $<100$ & 100 & 4 & 0 & 9 \\
\hline MANGANESE (MN), UG/L & 4 & 20 & 210 & 4 & 20 & 70 \\
\hline MERCURY $(H G), U G / L$ & 4 & 0.0 & 0.2 & 4 & 0.0 & 0.1 \\
\hline SELENIUM (SE), UG/L & 4 & 1 & 2 & 4 & 1 & 1 \\
\hline ZINC $(Z N), U G / L$ & 4 & 10 & 90 & 4 & 0 & 20 \\
\hline \multicolumn{7}{|l|}{ PERIPHYTON: } \\
\hline BIOMASS, DRY WT., G/SO M & 4 & .79 & 13.00 & & & \\
\hline BIOMASS, ASH WT, G/SO M & 4 & .79 & 8.59 & & & \\
\hline CHLOROPHYLL A, MG/SO M & 4 & .0 & 81.0 & & & \\
\hline CHLOROPHYLL B, MG/SO M & 4 & .0 & 39.0 & & & \\
\hline ORGANIC CARBON, MG/L & 4 & 1.8 & 7.0 & & & \\
\hline
\end{tabular}


LAT $21020 M 29 S$ LONG $157052 M 36 S$ DRAINAGE AREA: 5 SQ MI , PERIOD OF RECORD: $10 / 01 / 74$ - 09/30/75

STATISTICAL SUMMARY OF SELECTED DISSOLVED CHEMICAL CONSTITUENTS AND

REGRESSION RELATIONSHIPS OF CONSTITUENT CONCENTRATIONS TO SPECIFIC CONDUCTANCE

CONSILIUENI

CONSILIUENI
TEMPERATURE, WATER (DEG C)
SPECIFIC CONDUCTANCE (MICROMHOS)
STREAMFLOW (CUBIC FT/SEC)
PH (STANDARD UNITS)
PHOSPHORUS, TOTAL
NITRITE, NITRATE, TOTAL
NITROGEN, KJELDAHL, TOTAL
PHYTOPLANKTON, TOTAL (CELLS/ML)
SEDIMENT, SUSPENDED
SEDIMENT, CLAY SILT (PERCENT)
COLIFORM, FECAL (COL/IOO ML)
STREPTOCOCCI, FECAL (COL/IOO ML)
SILICA, DISSOLVED
CALCIUM, DISSOLVED
MAGNESIUM, DISSOLVED
SODIUM, DISSOLVE
POTASSIUM, DISSOLVED
BICARBONATE, ION
CARBONATE, ION
SULFATE, DISSOLVED
CHLORIDE, DISSOLVED
OISSOLVED SOLIDS, SUM OF CONST
DISSOLVED SOLIDS, ROE I8O DEG C
HARDNESS, TOTAL
HARDNESS, NONCARBONATE
TUREIDIIY (JTU)
FLOURIDE, DISSOLVED

CONSIUTUENI IMG/L OR UNII SHOWN
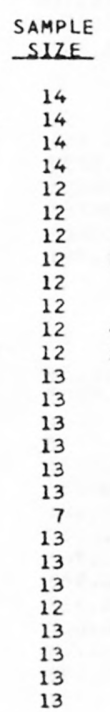

STANDARD

\section{DEYIAILON}

22.76

252.6

7.5
7.74

7.74

0.09

0.182
0.302

0.302
1149.2

1149.2
14.4

98.6

4825.0

5439.2

15.00

15.69

15.69
8.26

8.26
23.08

1.57

83.2

0.0

10.54

31.46

146.9

148.1

73.1

5.2
15.1
0.08

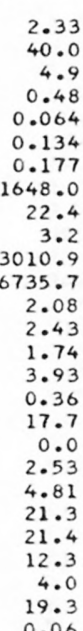

2.33
40.0

4.9

0.48

0.064
0.134

0.177

0.178 .0
22.4

3.2

3010.9

6735.7

2.08
2.43
1.74

1.74

3.93
0.36
17.7

0.36
17.7
0.0

2.53

4.81
21.3

21.3
21.4
12.3

2.3

19.

0.06

*Not significant at the 95 percent confidence level. SUMMARY OF HARMONIC ANALYSIS OF STREAM TEMPERATURE EORM OF EQUAIION: I. $101=M+A *$ SINLCO $72 * D+C$

\begin{tabular}{|c|c|c|c|c|c|}
\hline & & & & & STANDARD \\
\hline & HARMONIC & AMPLITUDE & PHASE & VAR IATION & ERROR OF \\
\hline SAMPLE & MEAN - $M$ & & ANGLE - C & EXPLAINED & ESTIMATE \\
\hline SLZE & WDEG CL & - $D E G(1$ & (RADIANS) & $-(X)$ & (DEG C) \\
\hline 14 & 23.22 & 2.32 & 2.70 & 58 & 1.64 \\
\hline
\end{tabular}

SUMMARY OF MAXIMUM AND MINIMUM CONCENTRATIONS OF CONSTITUENTS SAMPLED AT A FREQUENCY OF QUARTERLY (1975 WY)

16229300 -- KALIHI STREAM AT KALIHI, OAHU, HI

\begin{tabular}{|c|c|c|c|c|c|c|}
\hline \multirow{2}{*}{ CONSTITUENT } & \multicolumn{3}{|c|}{ TOTAL } & \multicolumn{3}{|c|}{ DISSOLVED } \\
\hline & $\begin{array}{l}\text { NO. } \\
\text { SAMPLES }\end{array}$ & $\begin{array}{l}\text { MINIMUM } \\
\text { CONC. }\end{array}$ & $\begin{array}{l}\text { MAXIMUM } \\
\text { CONC. }\end{array}$ & $\begin{array}{l}\text { NO. } \\
\text { SAMPLES }\end{array}$ & $\begin{array}{l}\text { MINIMUM } \\
\text { CONC. }\end{array}$ & $\begin{array}{l}\text { MAXIMUM } \\
\text { CONC. }\end{array}$ \\
\hline \multicolumn{7}{|l|}{ MINOR ELEMENTS: } \\
\hline ARSENIC (AS), UG/L & 4 & 1 & 10 & 4 & 0 & 8 \\
\hline CADM IUM $(C D), U G / L$ & 4 & $<10$ & $<10$ & 4 & 0 & 0 \\
\hline CHROMIUM (CR), UG/L & 4 & 0 & 50 & 4 & 0 & 10 \\
\hline COBALT $(C O), U G / L$ & 4 & $<50$ & $<50$ & 4 & 0 & 3 \\
\hline COPPER $(C U), U G / L$ & 4 & 10 & 1000 & 4 & 1 & 4 \\
\hline IRON $(F E), U G / L$ & 4 & 150 & 1700 & 5 & 60 & 170 \\
\hline LEAD $(P B), U G / L$ & 4 & $<100$ & $<100$ & 4 & 2 & 100 \\
\hline MANG ANESE (MN), UG/L & 4 & 10 & 30 & 5 & 0 & 10 \\
\hline MERCURY $(H G), U G / L$ & 4 & 0.0 & 0.1 & 4 & 0.0 & 0.1 \\
\hline SELENIUM (SE), UG/L & 4 & 0 & 1 & 4 & 0 & 0 \\
\hline$Z I N C(Z N), U G / L$ & 4 & 20 & 60 & 4 & 0 & 20 \\
\hline \multicolumn{7}{|l|}{ PERIPHYTON: } \\
\hline BIOMASS, DRY WT.. G/SQ M & 4 & 2.19 & 6.19 & & & \\
\hline BIOMASS, ASH WT., G/SQ M & 4 & 1.09 & 3.79 & & & \\
\hline CHLOROPHYLL A, MG/SO M & 4 & 2.2 & 36.0 & & & \\
\hline CHLOROPHYLL B, MG/SO M & 4 & .0 & 22.0 & & & \\
\hline ORGANIC CARBON, MG/L & 4 & 3.7 & 5.5 & & & \\
\hline
\end{tabular}


LAT $21009 M 32 S$ LONG 150045M53S LAT $21009 M 32 S$
DRAINAGE AREA:

STATISTICAL SUMMARY OF SELECTED DISSOLVED CHEMICAL CONSTITUENTS AND REGRESSION RELATIONSHIPS OF CONSTITUENT CONCENTRATIONS TO SPECIFIC CONDUCTANCE

\section{CUNSIITUENI}

\section{SONSIIT \\ SAMPLE}

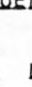
TEMPERATURE, WATER (DEG C)
SPECIFIC CONDUCTANCE (MICROMHOS) STREAMFLOW (CUBIC FT/SEC)

PH (STANDARO UNITS)

PHOSPHORUS, TOTAL

NITRITE + NITRATE, TOTAL

NITROGEN, KJELDAHL, TOTAL

PHYTOPLANKTON, TOTAL (CELLS/ML)

SEDIMENT, SUSPENDED

SEDIMENT, CLAY-SILT (PERCENT)

COLIFORM, FECAL (COL/1OO ML)

STREPTOCOCCI, FECAL (COL/100 ML)

SILICA, DISSOLVED

CALCIUM, DISSOLVED

MAGNESIUM, DI SSULVEO

SODIUM, DISSOLVED

POTASSIUM, DISSOLVEO

BICARBONATE, ION

CARBONATE, ION

SULFATE, DISSOLVED

CHLURIDE, DISSOLVED

DISSOLVED SOLIDS, SUM OF CONST

DISSOLVED SOLIDS, SUM OF CONST
DISSOLVED SOLIDS, ROE 180 DEG C HARUNESS, TOTAL

HARUNESS, TOTAL
HARONESS, NONCARBONATE

HARONESS, NONCA
TURBIDITY (JTU)

FLOURIDE, DISSOLVED

*Not significant at the 95 percent confidence level.

$\begin{array}{rrr}11 & 20.14 & 1.95 \\ 11 & 58.9 & 4.1 \\ 11 & 6.6 & 3.1 \\ 11 & 6.69 & 0.29 \\ 10 & 0.026 & 0.016 \\ 10 & 0.034 & 0.038 \\ 10 & 0.206 & 0.096 \\ 10 & 162.9 & 108.4 \\ 10 & 2.2 & 0.8 \\ 10 & 100.0 & 0.0 \\ 10 & 657.4 & 609.6 \\ 10 & 141.6 & 73.2 \\ 11 & 7.93 & 1.49 \\ 11 & 1.79 & 0.62 \\ 11 & 1.07 & 0.33 \\ 11 & 7.27 & 0.59 \\ 11 & 0.63 & 0.12 \\ 11 & 8.5 & 2.5 \\ 7 & 0.0 & 0.0 \\ 11 & 2.59 & 0.40 \\ 11 & 11.59 & 1.20 \\ 11 & 37.2 & 3.6 \\ 10 & 40.4 & 3.5 \\ 11 & 8.8 & 2.4 \\ 11 & 2.3 & 2.2 \\ 11 & 1.7 & 0.8 \\ 11 & 0.06 & 0.07\end{array}$

0.07
REGRESSION SUMMARY
REGRESSION

SAMPLE COEFICIENT, CONSTANT, CORRELATION ERROR OF

SIZE

- B - - B COEEICIENI

ESIUMAIE

$16.0 \quad 22.5$

52
2
6.2
0.00
0.00
0.08
35
1
100
30
42
5.2
0.9
0.4
6.6
0.5
5
0
2.0
9.5
32
37
6
0
1
0.0

2.5
66
12

12
7.2
0.05
0.13

$\begin{array}{lrrrr}11 & -0.451 & 33.201 & -0.583 & 2.7 \\ 11 & -0.0237 & 8.0872 & -0.330 * & 0.29 \\ 10 & 0.00253 & -0.12459 & 0.560 * & 0.014 \\ 10 & -0.00182 & 0.14218 & -0.170 * & 0.039 \\ 10 & 0.00609 & -0.15672 & 0.224 * & 0.099 \\ 10 & 21.891 & -1141.830 & 0.714 & 80.6\end{array}$

100

1600

1600
260

260
9.6
2.7

2.7
1.6

$1.6 \quad 11$

8.6
0.9

12
0

3.3

13.0
43

43
47
13

13
6
3

$\begin{array}{rr}3 & 11 \\ 0.2 & 11\end{array}$

$\begin{array}{rr}11 & 0.2136 \\ 11 & -0.0007 \\ 11 & 0.0186 \\ 11 & 0.1278 \\ 11 & -0.0071 \\ 11 & 0.179 \\ 7 & 0.000 \\ 11 & -0.0510 \\ 11 & 0.1764 \\ 11 & 0.583 \\ 10 & 0.317 \\ 11 & 0.060 \\ 11 & -0.126 \\ 11 & -0.099 \\ 11 & 0.0052\end{array}$

$-4.6562$

1.8300

$-0.0247$

$-0.2548$

1.0464

0.000

5.5944

1.1990

2.824

2.824
21.523

5.311

9.677

7.540
-0.2448

0.581 *

-0.004 *

0.232 *

0.879

-0.243 *

0.000 *

-0.523 *

0.597 *

0.663

0.323 *

0.099

-0.228 .

-0.510 .

0.315 *

1.28

0.65

0.30

0.12

SUMMARY OF MAXIMUM AND MINIMUM CONCENTRATIONS OF CONSTITUENTS

SAMPLED AT A FREQUENCY OF QUARTERLY (1975 WY)

10400000 -- HALAWA STREAM NR HALAWA, MOLOKAI, HI

\begin{tabular}{|c|c|c|c|c|c|c|}
\hline \multirow{2}{*}{ CONSTITUENT } & \multicolumn{3}{|c|}{ TOTAL } & \multicolumn{3}{|c|}{ DISSOLVED } \\
\hline & $\begin{array}{l}\text { NO. } \\
\text { SAMPLES }\end{array}$ & $\begin{array}{l}\text { MIN IMUM } \\
\text { CONC. }\end{array}$ & $\begin{array}{l}\text { MAXIMUM } \\
\text { CONC. }\end{array}$ & $\begin{array}{l}\text { NO. } \\
\text { SAMPLES }\end{array}$ & $\begin{array}{l}\text { MINIMUM } \\
\text { CONC. }\end{array}$ & $\begin{array}{l}\text { MAXIMUM } \\
\text { CONC. }\end{array}$ \\
\hline \multicolumn{7}{|l|}{ MINOR ELEMENTS: } \\
\hline ARSENIC (AS), UG/L & 4 & 0 & 1 & 4 & 0 & 1 \\
\hline CADMIUM (CD), UG/L & 4 & $<10$ & 10 & 4 & 0 & $i$ \\
\hline CHROMIUM (CR), UG/L & 4 & 0 & 20 & 4 & 0 & 0 \\
\hline CUBALT $(C O), U G / L$ & 4 & 0 & $<50$ & 4 & 0 & 0 \\
\hline COPPER $(C U), U G / L$ & 4 & $<10$ & 50 & 4 & 0 & 1 \\
\hline IRON $(F E), U G / L$ & 4 & 100 & 210 & 5 & 30 & 80 \\
\hline LEAD $(P B), U G / L$ & 4 & $<100$ & $<100$ & 4 & 0 & 10 \\
\hline MANG ANESE (MN), UG/L & 4 & 0 & 10 & 5 & 0 & 0 \\
\hline MERCURY $(H G), U G / L$ & 3 & 0.0 & 0.1 & 4 & 0.0 & 0.1 \\
\hline SELENIUM (SE), UG/L & 4 & 0 & 1 & 4 & 0 & 0 \\
\hline ZINC $(Z N), U G / L$ & 4 & 10 & 20 & 4 & 0 & 6 \\
\hline \multicolumn{7}{|l|}{ PERIPHYTON: } \\
\hline BIOMASS, DRY WT., G/SQ M & 4 & 1.19 & 8.59 & & & \\
\hline BIOMASS, ASH WT., G/SQ M & 5 & .50 & 1.79 & & & \\
\hline CHLOROPHYLL A, MG/SQ M & 5 & 2.5 & 12.0 & & & \\
\hline CHLOROPHYLL B, MG/SQ M & 5 & .6 & 2.7 & & & \\
\hline ORGANIC CARBON, MG/L & 3 & 1.5 & 3.0 & & & \\
\hline
\end{tabular}


Tab1e 14.--Summary of measurement at each station--Continued

STATION NUMBER: 16618000

NAME: KAHAKULOA STREAM NR HONOKOHAU, MAUI, HI

LAT 20D58M54S LONG 156033M26S

DRAINAGE AREA:

PERIOD OF RECORD: $10 / 01 / 74-09 / 30 / 75$

9 SQ KMI

STATISTICAL SUMMARY OF SELECTED DISSOLVED CHEMICAL CONSTITUENTS AND

REGRESSION RELATIONSHIPS OF CONSTITUENT CONCENTRATIONS TO SPECIFIC CONDUCTANCE

CONSIUIUENI

CONSIUIUENI IMG/L OR UNII SHOHN

SA

STANDARD

DEYIAIION

TEMPERATURE, WATER (DEG C) SPECIFIC CONDUC TANCE (MICROMHOS) STREAMFLOW (CUBIC FT/SEC) PH (STANDARD UNITS)

PHOSPHORUS, TOTAL

NITRITE + NITRATE, TOTAL

NITROGEN, KJELDAHL, TOTAL PHYTOPLANKTON, TOTAL (CELLS/ML)

SEDIMENT, SUSPENDED

SEDIMENT, CLAY-SILT (PERCENT)

COLIFORM, FECAL (COL/100 ML)

STREPTOCOCCI, FECAL (COL/100 ML)

SILICA, DISSOLVED

CALCI UM, DISSOLVED

MAGNESIUM, DISSOLVED

SODIUM, DISSOLVED

POTASSIUM, DISSOLVED

BICARBONATE, ION

CARBONATE, ION

SULFATE, DISSOLVED

CHLOR IDE, DISSOLVED

DISSOLVED SOLIDS, SUM OF CONST

DISSOLVED SOLIDS, ROE 180 DEG

HARDNESS, TOTAL

HARDNESS, NONCARBONATE

TURBIDITY (JTU)

FLOURIDE, DISSOLVED

*Not significant at the 95 percent confidence level.

$\begin{array}{rrr}11 & 20.36 & 1.07 \\ 11 & 73.9 & 16.2 \\ 11 & 12.7 & 12.1 \\ 11 & 7.20 & 0.46 \\ 11 & 0.025 & 0.012 \\ 11 & 0.086 & 0.033 \\ 11 & 0.247 & 0.391 \\ 11 & 528.7 & 459.7 \\ 11 & 2.6 & 1.9 \\ 11 & 100.0 & 0.0 \\ 11 & 887.3 & 790.7 \\ 11 & 330.8 & 250.1 \\ 11 & 16.25 & 4.77 \\ 11 & 3.98 & 1.24 \\ 11 & 2.03 & 0.73 \\ 11 & 7.25 & 1.08 \\ 11 & 1.05 & 0.29 \\ 11 & 24.2 & 10.4 \\ 8 & 0.0 & 0.0 \\ 11 & 2.23 & 0.56 \\ 11 & 10.16 & 1.18 \\ 11 & 54.8 & 12.7 \\ 11 & 56.1 & 13.2 \\ 11 & 18.4 & 5.8 \\ 11 & 0.9 & 1.4 \\ 11 & 2.7 & 3.6 \\ 11 & 0.05 & 0.05\end{array}$

1.07
16.2
12.1
0.46
0.012
0.033
0.391
459.7
1.9
0.0
790.7
250.1
4.77
1.24
0.73
1.08
0.29
10.4
0.0
0.56
1.18
12.7
13.2
5.8
1.4
3.6
0.05
BANGE

$18.5 \quad 22.0$

SAMPLE

REGRESSION

BEGRESSION SUMMABY

$\begin{array}{rr}45 & 42 \\ 6.5 & 7.9\end{array}$

$0.00 \quad 0.04$

0.04

0.03

56

100

100
110
89

6.8
1.7

1.7
0.6

0.6
5.5

0.7

9
0

1.2

8.3

32

7
0
0

0.0

$1.40 \quad 11$

COEFICIENT,

CONSTANT,

CORRELATION

STANDARD

ERROR OF

ESIUMAIE

100

2900

2900
740

21.0
0.4

6.4
2.8

8.4
1.6

37

3.3

12.0

69
71
27

27
4
13

0.1

11
11
11
11
11
11



11
11
11
11
11
11
8
11
11
11
11
11
11
11
11

-0.704
0.0213
0.00048
-0.00084
0.00901
15.976

64.770
5.6257
-0.01091
0.14865
-0.41884
-652.014

$-0.942$

0.741

0.639 .

0.373 *

0.562 *

4.3

0.33
0.010

0.032

0.383

400.8

$\begin{array}{rr}11 & 0.2769 \\ 11 & 0.0627 \\ 11 & 0.0394 \\ 11 & 0.0643 \\ 11 & 0.0009 \\ 11 & 0.581 \\ 8 & 0.000 \\ 11 & -0.0107 \\ 11 & 0.0287 \\ 11 & 0.751 \\ 11 & 0.799 \\ 11 & 0.317 \\ 11 & -0.030 \\ 11 & -0.164 \\ 11 & 0.0020\end{array}$

$-4.2104$

$-0.6503$

$-0.8819$

2.4904
0.9880

$-18.785$

0.000

3.0179

8.0424

8.0424

$-2.76$

-2.984
-5.078

3.145

14.860

$-0.1056$

0.938

0.819

0.873

0.966

0.051 .

0.907

0.000 *

-0.310 *

0.393 *

0.959

0.978

0.884

$-0.338$

$-0.741$

0.633

SUMMARY OF MAXIMUM AND MINIMUM CONCENTRATIONS OF CONSTITUENTS SAMPLED AT A FREQUENCY OF QUARTERLY (1975 WY)

16618000 -- KAHAKULOA STREAM NR HONOKOHAU, MAUI, HI

\begin{tabular}{|c|c|c|c|c|c|c|}
\hline \multirow{2}{*}{ CONSTITUENT } & \multicolumn{3}{|c|}{ TOTAL } & \multicolumn{3}{|c|}{ DISSOLVED } \\
\hline & $\begin{array}{l}\text { NO. } \\
\text { SAMPLES }\end{array}$ & $\begin{array}{l}\text { MINIMUM } \\
\text { CONC. }\end{array}$ & $\begin{array}{l}\text { MAXIMUM } \\
\text { CONC. }\end{array}$ & $\begin{array}{l}\text { NO. } \\
\text { SAMPLES }\end{array}$ & $\begin{array}{l}\text { MINIMUM } \\
\text { CONC. }\end{array}$ & $\begin{array}{l}\text { MAXIMUM } \\
\text { CONC. }\end{array}$ \\
\hline \multicolumn{7}{|l|}{ MINOR ELEMENTS: } \\
\hline ARSENIC (AS), UG/L & 4 & 0 & 1 & 4 & 0 & 1 \\
\hline CADMIUM $(C D)$, UG/L & 4 & $<10$ & 10 & 4 & 0 & 1 \\
\hline CHROMIUM (CR), UG/L & 4 & 0 & 10 & 4 & 0 & 0 \\
\hline COBALT $(C O)$, UGIL & 4 & $<50$ & $<50$ & 4 & 0 & 4 \\
\hline COPPER $(C U), U G / L$ & 4 & 0 & 20 & 4 & 0 & 1 \\
\hline IRON $(F E)$, UG/L & 4 & 60 & 300 & 4 & 10 & 50 \\
\hline LEAD $(P B), U G / L$ & 4 & $<100$ & $<100$ & 4 & 2 & 8 \\
\hline MANG ANESE (MN), UG/L & 4 & 0 & 10 & 4 & 0 & 5 \\
\hline MERCURY (HG), UG/L & 4 & 0.0 & 0.1 & 4 & 0.0 & 0.1 \\
\hline SELENIUM (SE), UG/L & 4 & 0 & 0 & 4 & 0 & 0 \\
\hline ZINC $(Z N), U G / L$ & 4 & 20 & 70 & 4 & 0 & 20 \\
\hline \multicolumn{7}{|l|}{ PERIPHYTON: } \\
\hline BIOMASS, DRY WT.. G/SQ M & 4 & .89 & 18.00 & & & \\
\hline BIOMASS, ASH WT,, G/SQ M & 4 & .50 & 14.00 & & & \\
\hline CHLOROPHYLL A, MG/SO M & 4 & 5.1 & 100.0 & & & \\
\hline CHLOROPHYLL B, MG/SO M & 4 & 1.1 & 31.0 & & & \\
\hline ORGANIC CARBON, MG/L & 4 & .7 & 4.1 & & & \\
\hline
\end{tabular}


Table 14.--Summary of measurement at each station--Continued

LAT 19042M58S LONG 155009M13S DRAINAGE AREA: 125 SQ MI 1324 SO KMI

PERIOD OF RECORD: $10 / 01 / 74-09 / 30 / 75$

STATISTICAL SUMMARY OF SELECTED DISSOLVED CHEMICAL CONSTITUENTS AND REGRESSION RELATIONSHIPS OF CONSTITUENT CONCENTRATIONS TO SPECIFIC CONDUCTANCE

CONSIIUUENI

CONSIUTUENI IMG/L OR UNII_SHOWNI
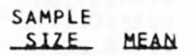

SIZE

TEMPERATURE, WATER (DEG C) SPECIFIC CONDUCTANCE (MICROMHOS) STREAMFLOW (CUBIC FT/SEC)

PH (STANDARO UNITS

PHOSPHORUS, TOTAL

NITRITE + NITRATE, TOTAL

NITROGEN, KJELDAHL, TOTAL

PHYTOPLANKTON, TOTAL (CELLS/ML)

SEDIMENT, SUS'PENDED

SEDIMENT, CLAY-SILT (PERCENT)

COLIFORM, FECAL (CUL/100 ML)

STREPTOCOCCI, FECAL ( COL/100 ML)

SILICA, DISSOLVED

CALCIUM, DISSOLVED

MAGNESIUM, DISSOLVEO

SODIUM, DISSOLVED

POTASSIUM, DISSOLVED

BICARBONATE, ION

CARBONATE, ION

SULFATE, DISSOLVED

CHLORIDE, DISSOLVED

DISSOLVED SCLIDS, SUM OF CONST

DISSOLVED SOLIDS, RUE 180 DEG C HARDNESS, TOTAL

HARDNESS, NONCARBONATE

TURBIDITY (JTU)

FLOURIDE, DISSOLVED
1.80
11.6
136.5
0.53
0.019
0.062
0.258
582.0
3.1
9.3
71.7
463.8
2.81
1.00
0.69
0.42
0.15
6.7
0.0
0.82
0.96
7.6
7.6
4.8
2.3
2.5
0.05

\section{BEGRESSION SUMMARY} REGRESSION

SAMPLE SIZE COEFICIENT,

CONSTANT, CORRELATION STANDARD COEFICUENT ESIIMAIE

$\begin{array}{rrr}16.5 & 23.0 & \\ 26 & 70 & \\ 6 & 500 & 12 \\ 5.8 & 7.9 & 11 \\ 0.00 & 0.05 & 12 \\ 0.05 & 0.26 & 12 \\ 0.08 & 0.91 & 12 \\ 29 & 2100 & 12 \\ 0 & 11 & \\ 73 & 100 & \\ 3 & 230 & \\ 31 & 1700 & \\ 5.8 & 15.0 & 12 \\ 1.9 & 5.2 & 12 \\ 0.8 & 3.1 & 12 \\ 2.2 & 3.8 & 12 \\ 0.3 & 0.8 & 12 \\ 8 & 33 & 12 \\ 0 & 0 & 7 \\ 0.8 & 4.1 & 12 \\ 1.0 & 4.5 & 12 \\ 23 & 50 & 12 \\ 20 & 44 & 12 \\ 9 & 26 & 12 \\ 0 & 8 & 12 \\ 1 & 10 & 12 \\ 0.0 & 0.1 & 12\end{array}$

*Not significant at the 95 percent confidence level.

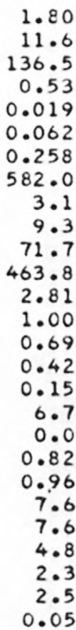

QURAIION IABLE_OF DAILY SPECIEIC CONDUCIANCE DAILY SPECIFIC CONDUCTANCE IN MICROMHOS AT 25 DEG C, THAT WAS

EQUALLED OR EXCEEDED FOR THE

$18 \quad-5 \% \quad 102$

$20 \% \quad 308 \quad 508$

\section{2}

SAMPLE SIZE $=142$

SUMMARY OF HARMONIC ANALYSIS OF STREAM TEMPERATURE

\begin{tabular}{|c|c|c|c|c|c|}
\hline $\begin{array}{l}\text { SAMPLE } \\
\text { SIZE_ }\end{array}$ & $\begin{array}{l}\text { HARMONIC } \\
\text { MEAN - M } \\
\text { LOEG EL }\end{array}$ & $\begin{array}{c}\text { AMPLITUDE } \\
-A \\
\text { IDESCL }\end{array}$ & $\begin{array}{c}\text { PHASE } \\
\text { ANGLE - C } \\
\text { (BADLANS) }\end{array}$ & $\begin{array}{l}\text { VAR IATION } \\
\text { EXPLAINED } \\
\end{array}$ & $\begin{array}{l}\text { STANDARD } \\
\text { ERROR OF } \\
\text { ESTIMATE } \\
\text { LEEG_L }\end{array}$ \\
\hline 141 & 19.40 & 1.84 & 2.06 & 54 & 0.61 \\
\hline
\end{tabular}

SUMMARY OF MAXIMUM AND MINIMUM CONCENTRATIONS OF CONSTITUENTS SAMPLED AT A FREQUENCY OF QUARTERLY (1975 WY)

16704000 -- WAILUKU RIVER AT PIIHONUA HAWAII HI

\begin{tabular}{|c|c|c|c|c|c|c|}
\hline \multirow{2}{*}{ CONSTITUENT } & \multicolumn{3}{|c|}{ TOTAL } & \multicolumn{3}{|c|}{ DISSOLVED } \\
\hline & $\begin{array}{l}\text { NO. } \\
\text { SAMPLES }\end{array}$ & $\begin{array}{l}\text { MINIMUM } \\
\text { CONC. }\end{array}$ & $\begin{array}{l}\text { MAXIMUM } \\
\text { CONC. }\end{array}$ & $\begin{array}{l}\text { NO. } \\
\text { SAMPLES }\end{array}$ & $\begin{array}{l}\text { MINIMUM } \\
\text { CONC. }\end{array}$ & $\begin{array}{l}\text { MAXIMUM } \\
\text { CONC. }\end{array}$ \\
\hline \multicolumn{7}{|l|}{ MINOR ELEMENTS: } \\
\hline ARSEN1C (AS), UG/L & 4 & 1 & 3 & 4 & 0 & 3 \\
\hline CADMIUM $(C D), U G / L$ & 4 & $<10$ & 10 & 4 & 0 & 1 \\
\hline CHROMIUM (CR), UG/L & 4 & 0 & 10 & 4 & 0 & 10 \\
\hline COBALT $(C O)$, UG/L & 4 & $<50$ & $<50$ & 4 & 0 & 1 \\
\hline COPPER (CU), UG/L & 4 & $<10$ & 20 & 4 & 0 & 3 \\
\hline IRON $(F E), U G / L$ & 4 & 160 & 240 & 4 & 40 & 110 \\
\hline LEAD $(P B), U G / L$ & 4 & $<100$ & 200 & 4 & 1 & 13 \\
\hline MANG ANESE (MN), UG/L & 3 & 0 & 10 & 4 & 0 & 5 \\
\hline MERCURY (HG), UG/L & 4 & 0.1 & 0.9 & 4 & 0.0 & 0.2 \\
\hline SELENIUM (SE), UG/L & 4 & 0 & 1 & 4 & 0 & 0 \\
\hline ZINC $(Z N), U G / L$ & 4 & 10 & 40 & 4 & 0 & 0 \\
\hline PERIPHYTON: & & 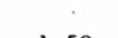 & & & & \\
\hline BIOMASS, DRY WT., G/SQ M & 2 & 1.59 & 4.59 & & & \\
\hline BIOMASS, ASH WT, G/SO M & 2 & .79 & 4.50 & & & \\
\hline CHLOROPHYLL A, MG/SQ M & 2 & .5 & 1.0 & & & \\
\hline CHLOROPHYLL B, MG/SQ M & 2 & .0 & $\cdot 3$ & & & \\
\hline ORGANIC CARBON, MG/L & 4 & 1.3 & $4 \cdot 0$ & & & \\
\hline
\end{tabular}


LAT 18D25M52S LONG 066031M37S

DRAINAGE AREA: 0 SQ MI

PERIOD OF RECORD: $10 / 01 / 74-09 / 30 / 75$ SQ KMI

STATISTICAL SUMMARY OF SELECTED DISSOLVED CHEMICAL CONSTITUENTS AND

REGRESSION RELATIONSHIPS OF CONSTITUENT CONCENTRATIONS TO SPECIFIC CONDUCTANCE

CONSIIUENI

\section{SONSIUT}

\section{UE}

NI IMG $L$

\section{TEMPERATURE, WATER (DEG C)}

SEDIMENT, CLAY-SILT (PERCENT)

SILICA, DISSOLVED

$$
\begin{aligned}
& \text { SAMPLE } \\
& \text { SIZE } \\
& \hline
\end{aligned}
$$

SPECIFIC CONDUCTANCE (MICROMHOS)

STREAMFLOW (CUBIC FT/SEC)

PH (STANDARD UNITS)

PHOSPHORUS, TOTAL

NITRITE + NITRATE, TOTAL

NITROGEN, KJELDAHL, TOTAL

PHYTOPLANKTON, TOTAL (CELLS/ML)

SEDIMENT, SUSPENDED

COLIFORM, FECAL (COL/100 ML)

STREP TOCOCCI, FECAL (COL/100 ML)

CALCIUM, DISSOLVED

MAGNESIUM, DISSOLVED

SODIUM, DISSOLVED

SODIUM, DISSOLVED
POTASSIUM, DISSOLVED

BUTASSIUM, DI SSOL

CARBONATE, ION

SULFATE, DISSOLVED

CHLORIDE, DISSOLVED

DISSOLVED SOLIDS, SUM OF CONST

DISSOLVED SOLIDS, ROE 180 DEG C

HARDNESS, TOTAL

HARONESS, NONCARBONATE

TURBIDITY (JTU)

FLOURIDE, DISSOLVED *Not significant at the 95 percen

25.39 258.5
1443.0

1443.0
7.52

0.183

0.687

0.687
0.561

1623.4

171.7

18116.7

9119.2
19.38

19.38
38.40

7.50

9.30

1.79

135.5
0.0

0.0
8.85

12.50

172.0

170.6

125.6

7.0

19.0

0.29

(1)

1.98
69.0
1707.0
0.31

0.31
0.198

0.363

2885.7

333.3

18409.6

16193.6

1.69

7.06

1.02

3.74

0.24

34.7

0.0
1.90

0.53

19.0

32.1

21.4

4.3

24.0
0.26

SUMMARY OF HARMONIC ANALYSIS OF STREAM TEMPERATURE

\begin{tabular}{|c|c|c|c|c|c|}
\hline & & & & & STANDARD \\
\hline $\begin{array}{l}\text { SAMPLE } \\
\text { SIZE. }\end{array}$ & $\begin{array}{l}\text { HARMONIC } \\
\text { MEAN - M } \\
\text { IDEG CI }\end{array}$ & $\begin{array}{c}\text { AMPLITUDE } \\
-A \\
\text { (DEG_L }\end{array}$ & $\begin{array}{l}\text { PHASE } \\
\text { ANGLE - C } \\
\text { (BADIANSI) }\end{array}$ & $\begin{array}{l}\text { VAR IATION } \\
\text { EXPLAINED } \\
\text { (I) }\end{array}$ & $\begin{array}{l}\text { ERROR OF } \\
\text { ESTIMATE } \\
\text { LEEG CL }\end{array}$ \\
\hline 12 & 25.36 & 2.20 & 2.74 & 69 & 1.21 \\
\hline
\end{tabular}

12
13
2
12 FORM OE EOUAIION: I. (D) = M A SINC.0172*O+C
BANGE

$\begin{array}{rr}22.5 & 28.0 \\ 130 & 335 \\ 236 & 2650 \\ 6.7 & 7.8\end{array}$

$6.7 \quad 7.8$

0.09

0.23

0.19
57

1.30

1.30
10000

10000
1350

3000
$640 \quad 51000$

$\begin{array}{rr}640 & 57000 \\ 17.0 & 22.0\end{array}$

$29.0 \quad 48.0$

$6.2 \quad 8.4$

1.1212 .0

1.5
67

6.9
12.0

12.0
145

145
132

98
1

0.1

2.2
178
0
12.0
13.0
195
219
150
13
50
0.9 \begin{tabular}{ll}
\multicolumn{2}{c}{ REGRESSION SUMMABY } \\
REGRESSION \\
SAMPLE COEFICIENT, CONSTANT, \\
SIZE
\end{tabular}

$B Y$

CORRELATION STANDARD COEEICIENI ESIUMAIE

$\begin{array}{lr}12 & 0.0010 \\ 11 & -0.00201 \\ 11 & -0.00315 \\ 11 & -0.00422 \\ 11 & -20.619\end{array}$

7.2421
0.71299
1.51997
1.67626
7076.023

$0.225 *$
-0.721
-0.617
-0.541.
-0.509.

0.32

0.145

0.301

0.493

\section{传}

$\begin{array}{rrr}7 & 0.0043 & 18.5325 \\ 5 & 0.1586 & -7.2787 \\ 5 & 0.0227 & 0.9493 \\ 7 & -0.0017 & 9.7748 \\ 7 & -0.0019 & 2.3090 \\ 8 & 0.633 & -41.095 \\ 3 & 0.000 & 0.000 \\ 7 & -0.0273 & 16.6123 \\ 7 & 0.0064 & 10.8173 \\ 5 & 0.422 & 50.426 \\ 5 & 0.579 & 3.820 \\ 5 & 0.511 & -21.705 \\ 5 & 0.027 & -0.672 \\ 5 & -0.340 & 116.967 \\ 7 & -0.0004 & 0.4179\end{array}$

$\begin{array}{rr}0.143 * & 1.62 \\ 0.785 * & 5.05 \\ 0.775 * & 0.75 \\ -0.023 * & 4.09 \\ -0.393 * & 0.24 \\ 0.878 * & 17.9 \\ 0.000 * & 0.0 \\ -0.728 * & 1.40 \\ 0.594 * & 0.47 \\ 0.775 * & 13.9 \\ 0.630 * & 28.8 \\ 0.836 * & 13.5 \\ 0.216 * & 4.8 \\ -0.495 * & 24.1 \\ -0.070 * & 0.29\end{array}$

$-0.070 *$

SUMMARY OF MAXIMUM AND MINIMUM CONCENTRATIONS OF CONSTITUENTS

SAMPLED AT A FREQUENCY OF QUARTERLY (1975 WY)

50038100 - RIO GRANDE DE MANATI AT HWY 2 NR MANATI, PR

\begin{tabular}{|c|c|c|c|c|c|c|}
\hline \multirow{2}{*}{ CONSTITUENT } & \multicolumn{3}{|c|}{ TOTAL } & \multicolumn{3}{|c|}{ DISSOLVED } \\
\hline & $\begin{array}{l}\text { NO. } \\
\text { SAMPLES }\end{array}$ & $\begin{array}{l}\text { MINIMUM } \\
\text { CONC. }\end{array}$ & $\begin{array}{l}\text { MAXIMUM } \\
\text { CONC. }\end{array}$ & $\begin{array}{l}\text { NO. } \\
\text { SAMPLES }\end{array}$ & $\begin{array}{l}\text { MINIMUM } \\
\text { CONC. }\end{array}$ & $\begin{array}{l}\text { MAXIMUM } \\
\text { CONC. }\end{array}$ \\
\hline \multicolumn{7}{|l|}{ MINOR ELEMENTS: } \\
\hline ARSENIC (AS), UG/L & 4 & 0 & 2 & 5 & 0 & 0 \\
\hline CADMIUM $(C D), U G / L$ & 5 & 0 & 2 & 5 & 0 & 1 \\
\hline CHROMIUM (CR), UG/L & 5 & $<10$ & 10 & 5 & 0 & 1 \\
\hline COBALT $(C O), U G / L$ & 5 & 0 & 5 & 5 & 0 & 1 \\
\hline COPPER (CU), UG/L & 5 & 4 & 19 & 5 & 1 & 6 \\
\hline IRON (FE), UG/L & 6 & 320 & 6800 & 5 & 0 & 190 \\
\hline LEAD $(P B), U G / L$ & 5 & 1 & 6 & 5 & 0 & 2 \\
\hline MANG ANESE (MN), UG/L & 8 & 20 & 500 & 5 & 0 & 40 \\
\hline MERCURY (HG), UG/L & 5 & 0.1 & 0.3 & 5 & 0.0 & 0.2 \\
\hline SELENIUM (SE), UGIL & 2 & 0 & 0 & 5 & 0 & 0 \\
\hline ZINC $(Z N), U G / L$ & 5 & 30 & 170 & 5 & 0 & 40 \\
\hline \multicolumn{7}{|l|}{ PERIPHYTON: } \\
\hline BIOMASS, DRY WT., G/SQ M & 0 & & & & & \\
\hline BIOMASS, ASH WT, G/SO M & 0 & & & & & \\
\hline CHLOROPHYLL A, MG/SO M & 0 & & & & & \\
\hline CHLOROPHYLL B, MG/SQ M & 0 & & & & & \\
\hline ORGANIC CARBON, MG/L & 6 & 1.5 & 11.0 & & & \\
\hline
\end{tabular}


LAT 18D23M5OS LONG 066D15MI7S

DRAINAGE AREA: 200 SQ MI

PERIOD OF RECORD: $10 / 01 / 74-09 / 30 / 75$ SQ KM)

STATISTICAL SUMMARY OF SELECTED DISSOLVED CHEMICAL CONSTITUENTS AND

REGRESSION RELATIONSHIPS OF CONSTITUENT CONCENTRATIONS TO SPECIFIC CONDUCTANCE

CONSILTUENI

CONSIUTUENT IMG L OR UNII SHOWNI

SAMPLE MEANDARD

MEAN REYIALION

26.46

425.3

1172.0

1172.0
7.37

0.097

0.412

0.476

2273.7
67.0

2.02

2.02
145.8

1595.2

0.38
0.109

0.449

0.122
3626.8

3626.8
114.6

3384.2

904.2

16.43

53.20

53.20
12.80

12.80
20.86

20.86
2.67

191.0

0.0

18.14

32.71

259.6

267.8

184.0

184.0
20.4

3.6

4052.3
944.7

2.04
14.13

4.13
2.59

2.59
5.08

5.08
1.25

1.25
47.8

0.0

5.70

11.54

50.6

62.0

4.4
9.5

$9 \cdot 5$

0.39

0.4 1 .

${ }^{*}$ Not significant at the 95 percent confidence level.

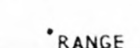

BANGE

$23 \cdot 5$
225

$44 \quad 2300$

6.8

0.02

0.01

0.30

13

0.43
1.60

1.60
0.66

12000
417

$\begin{array}{rr}50 & 14000 \\ 100 & 2700\end{array}$

$\begin{array}{rr}100 & 2700 \\ 13.0 & 19.0\end{array}$

$40.0 \quad 70.0$

$10.0 \quad 17.0$

$13.0 \quad 30.0$

0.2

104

15.0

17.0

210

208

140
10

1
0.1

SUMMARY OF HARMONIC ANALYSIS OF STREAM TEMPERATURE

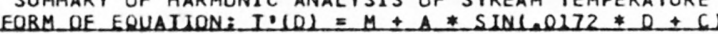

\begin{tabular}{|c|c|c|c|c|c|}
\hline & & & & & STANDARD \\
\hline & HARMONIC & AMPLITUDE & PHASE & VAR IATION & ERROR OF \\
\hline $\begin{array}{l}\text { SAMPLE } \\
\text { SUZE_- }\end{array}$ & $\begin{array}{l}\text { MEAN - M } \\
\text { LEEG CI L }\end{array}$ & $\begin{array}{c}-A \\
-1 D E G_{2}(1)\end{array}$ & $\begin{array}{l}\text { ANGLE - C } \\
\text { (RADIANSI) }\end{array}$ & $\begin{array}{l}\text { EXPLA INED } \\
(8) \\
\end{array}$ & $\begin{array}{l}\text { ESTIMATE } \\
\text { LOEG C) }\end{array}$ \\
\hline 12 & 26.44 & 1.32 & 3.12 & 24 & 1.94 \\
\hline
\end{tabular}

SUMMARY OF MAXIMUM AND MINIMUM CONCENTRATIONS OF CONSTITUENTS

SAMPLED AT A FREQUENCY OF QUARTERLY (1975 WY)

50046000 -- RIO DE LA PLATA AT TOA ALTA, PR

\begin{tabular}{|c|c|c|c|c|c|c|}
\hline \multirow{2}{*}{ CONSTI TUENT } & \multicolumn{3}{|c|}{ TOTAL } & \multicolumn{3}{|c|}{ DISSOLVED } \\
\hline & $\begin{array}{l}\text { NO. } \\
\text { SAMPLES }\end{array}$ & $\begin{array}{l}\text { MIN IMUM } \\
\text { CONC. }\end{array}$ & $\begin{array}{l}\text { MAXIMUM } \\
\text { CONC. }\end{array}$ & $\begin{array}{l}\text { NO. } \\
\text { SAMPLES }\end{array}$ & $\begin{array}{l}\text { MINIMUM } \\
\text { CONC. }\end{array}$ & $\begin{array}{c}\text { MAXIMUM } \\
\text { CONC. }\end{array}$ \\
\hline \multicolumn{7}{|l|}{ MINOR ELEMENTS: } \\
\hline ARSENIC (AS), UG/L & 4 & 1 & 2 & 5 & 0 & 1 \\
\hline CADM IUM $(C D), U G / L$ & 5 & 0 & 20 & 5 & 0 & 5 \\
\hline CHROMIUM (CR), UG/L & 5 & $<10$ & 10 & 5 & 0 & 1 \\
\hline COBALT $(C O)$, UG/L & 5 & 0 & 3 & 5 & 0 & 1 \\
\hline COPPER (CU), UG/L & 5 & 0 & 14 & 5 & 0 & 10 \\
\hline IRON (FE), UG/L & 5 & 220 & 910 & 5 & 0 & 130 \\
\hline LEAD $(P B), U G / L$ & 5 & 0 & 7 & 5 & 1 & 10 \\
\hline MANG ANESE (MN), UG/L & 7 & 60 & 370 & 5 & 0 & 100 \\
\hline MERCURY (HG), UG/L & 5 & 0.1 & 0.3 & 5 & 0.0 & 0.3 \\
\hline SELENIUM (SE), UG/L & 2 & 0 & 0 & 5 & 0 & 0 \\
\hline$Z I N C(Z N), U G / L$ & 5 & 0 & 90 & 5 & 0 & 20 \\
\hline \multicolumn{7}{|l|}{ PERIPHYTON: } \\
\hline BIOMASS, DRY WT., G/SQ M & 1 & .19 & & & & \\
\hline BIOMASS, ASH WT., G/SO M & 1 & .19 & & & & \\
\hline CHLOROPHYLL A, MG/SQ M & 1 & .0 & & & & \\
\hline CHLOROPHYLL B, MG/SQ M & 1 & $\cdot 0$ & & & & \\
\hline ORGANIC CARBON, MG/L & 6 & 3.0 & 11.0 & & & \\
\hline
\end{tabular}


Table 14.--Summary of measurement at each station--Continued

LAT 18D02M04S LONG 066D01M58S

DRAINAGE AREA: 18 SO MI

PERIOD OF RECORD: $10 / 01 / 74-09 / 30 / 75$

7 SQ KMI

STATISTICAL SUMMARY OF SELECTED DISSOLVED CHEMICAL CONSTIIUENTS AND

REGRESSION RELATIONSHIPS OF CONSTITUENT CONCENTRATIONS TO SPECIFIC CONDUCTANCE

CONSIIUENI

CONSIIIUENI IMG/L OR UNII_SHOWN

TEMPERATURE, WATER (DEG C)
SPECIFIC CONDUCTANCE (MICROMHOS)
STREAMFLOH (CUBIC FT/SEC)
PH (STANDARD UNITS)
PHOSPHORUS, TOTAL,
NITRITE, NITRATE, TOTAL
NITROGEN, KJELDAHL, TOTAL
PHYTOPLANKTON, TOTAL (CELLS/ML)
SEDIMENT, SUSPENDED
SEDIMENT, CLAY-SILT (PERCENT)
COLIFORM, FECAL (COL/ IOO ML)
STREPTOCOCCI, FECAL (COL/IOO ML)
SILICA, DISSOLVED
CALCIUM, DISSOLVED
MAGNESIUM, DISSOLVEO
SODIUM, DISSOLVED
POTASSIUM, DISSOLVED
BICARBONATE, ION
CARBONAT, ION
SULFATE, DISSOLVED
CHLORIDE, DISSOLVED
DISSOLVED SOLIDS, SUM OF CONST
DISSOLVED SOLIDS, ROE IBO DEG C
HARDNESS, TOTAL
HARDNESS, NONCARBONATE
TURBIDITY (JTU)
FLOURIDE, DISSOLVED

\begin{tabular}{c} 
SAMPLE \\
SIZE \\
\hline 14 \\
13 \\
13 \\
1 \\
13 \\
11 \\
11 \\
10 \\
11 \\
13 \\
0 \\
12 \\
11 \\
7 \\
6 \\
6 \\
7 \\
7 \\
8 \\
4 \\
7 \\
7 \\
6 \\
6 \\
6 \\
6 \\
6 \\
7
\end{tabular}

STANDARD

DEVIAIION

MEAN

25.16

161.0

11.0
7.67

0.076

0.166

0.148

230.7
7.5

1477.5

1559.1

22.57

11.62

5.12
14.29

14.29
0.56

62.6

62.6
0.5

11.23

11.43

107.3

101.7

50.0

0.7

1.5
0.23
2.85
31.4

0.0

0.54

0.129

0.198

0.117

147.4

1004.9

1800.0

3.15
2.15

1.00

1.98

1.98

ii. 3

11.3
1.0

1.64

16.1

13.0

9.3
1.2

2.3

0.14

MME: RIO GRANDE DE PATILLLAS NR PATILLAS

*Not significant at the 95 percent confidence level.

$N$
BANGE
20.0
110
11
6.5
0.01
0.00
0.00
51
0
290
250
17.0
8.7
3.5
10.0
0.4
40
0
7.6
10.0
77
82
36
0
0
0.1

BEGRESSION SUMMABY

REGRESSION

TONSTANT, CORRELATION ERTANDARD SIZE

COEFICIENT, CONSTANT,

230

0.42

11

$0.36 \quad 10$

$570 \quad 11$ GEEICIENI ESIIMAIE

SUMMARY OF HARMONIC ANALYSIS OF STREAM TEMPERATURE FOBM OF EQUALION: I. $(0)=M+A * S I N C .0172 * 0 \pm C$

\begin{tabular}{|c|c|c|c|c|c|}
\hline & & & & & STANDARD \\
\hline & HARMONIC & AMPLITUDE & PHASE & VARIATION & ERROR OF \\
\hline $\begin{array}{l}\text { SAMPLE } \\
\text { SIZE. }\end{array}$ & $\begin{array}{l}\text { MEAN - M } \\
\text { LOEG CI }\end{array}$ & $\begin{array}{c}-A \\
D E G_{C}(1)\end{array}$ & $\begin{array}{l}\text { ANGLE - C } \\
\text { (BADIANSI) }\end{array}$ & $\begin{array}{l}\text { EXPLA INED } \\
-(Z)\end{array}$ & $\begin{array}{l}\text { ESTIMATE } \\
\text { (DEG C) }\end{array}$ \\
\hline
\end{tabular}
14
25.15
2.97
2.89
68
1.74

SUMMARY OF MAXIMUM AND MINIMUM CONCENTRATIONS OF CONSTITUENTS

SAMPLED AT A FREQUENCY OF QUARTERLY (1975 WY)

50092000 -- RIO GRANDE DE PATILLAS NR PATILLAS

\begin{tabular}{|c|c|c|c|c|c|c|}
\hline \multirow{2}{*}{ CONSTI IUENT } & \multicolumn{3}{|c|}{ TOTAL } & \multicolumn{3}{|c|}{ DISSOLVED } \\
\hline & $\begin{array}{l}\text { NO. } \\
\text { SAMPLES }\end{array}$ & $\begin{array}{l}\text { MIN IMUM } \\
\text { CONC. }\end{array}$ & $\begin{array}{l}\text { MAXIMUM } \\
\text { CONC. }\end{array}$ & $\begin{array}{l}\text { NO. } \\
\text { SAMPLES }\end{array}$ & $\begin{array}{l}\text { MINIMUM } \\
\text { CONC. }\end{array}$ & $\begin{array}{l}\text { MAXIMUM } \\
\text { CONC. }\end{array}$ \\
\hline \multicolumn{7}{|l|}{ MINOR ELEMENTS: } \\
\hline ARSENIC (AS), UG/L & 5 & 0 & 0 & 6 & 0 & 0 \\
\hline CADMIUM $(C D)$, UG/L & 6 & 0 & 1 & 6 & 0 & 4 \\
\hline CHROMIUM (CR), UG/L & 6 & $<10$ & 10 & 6 & 0 & 1 \\
\hline COBALT $(C O)$, UG/L & 6 & 0 & 7 & 6 & 0 & 1 \\
\hline COPPER (CU), UG/L & 6 & 1 & 29 & 6 & 0 & 34 \\
\hline IRON $(F E), U G / L$ & 6 & 50 & 560 & 6 & 0 & 80 \\
\hline LEAD $(P B), U G / L$ & 6 & 0 & 15 & 6 & 0 & 17 \\
\hline MANGANESE (MN), UG/L & 7 & 0 & 20 & 6 & 0 & 10 \\
\hline MERCURY $(H G), U G / L$ & 5 & 0.1 & 0.2 & 6 & 0.0 & 0.3 \\
\hline SELENIUM (SE), UG/L & 2 & 0 & 0 & 6 & 0 & 0 \\
\hline ZINC $(Z N), U G / L$ & 6 & 10 & 40 & 6 & 0 & 40 \\
\hline \multicolumn{7}{|l|}{ PERIPHYTON: } \\
\hline BIOMASS, DRY WT., G/SQ M & 0 & & & & & \\
\hline BIOMASS, ASH WT., G/SQ & 0 & & & & & \\
\hline CHLOROPHYLL A, MG/SQ M & 0 & & & & & \\
\hline CHLOROPHYLL B, MG/SO M & 0 & & & & & \\
\hline ORGANIC CARBON, MG/L & 5 & .8 & 3.1 & & & \\
\hline
\end{tabular}


LAT 18D16MS3S LONG 067D02M56S

DRAINAGE AREA: 94 SO MI 1244 SO KMI

94 SOMINAGE AREA:
PERIOD OF RECORD:
$10 / 01 / 74-09 / 30 / 75$

STATISTICAL SUMMARY OF SELECTED DISSOLVED CHEMICAL CONSTITUENTS AND

REGRESSION RELATIONSHIPS OF CONSTITUENT CONCENTRATIONS TO SPECIFIC CONDUCTANCE

CONSIIUENI

CONSILIUENI IMG/L OR UNLI SHOWNI
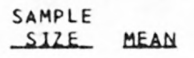

STANDARD

DEYIAIION

IEMPERATURE, WATER (DEG C) SPECIFIC CONDUCTANCE (MICROMHOS) STREAMFLOW (CUBIC FT/SEC)

PH ISTANDARD UNITS

PHOSPHORUS, TOTAL

NITROGEN, KJELDAHL, TOTAL

SEDIMENT, SUSPENDED

SEDIMENT, CLAY-SILT (PERCENT)

COLIFORM, FECAL (COL/100 ML)

STREPTOCOCCI, FECAL (COL/100 ML)

SILICA, DISSOLVED

MAGNESIUM, DISSOLVEO

SODIUM, DISSOLVED

POTASSIUM, DISSOLVEO

BICARBONATE, ION

CARBONATE, ION

SULFATE, DISSOLVED

CMLOR IDE, DISSOLVED

DISSOLVED SOLIDS, SUM OF CONST

DISSOLVED SOLIDS, ROE 180 DEG C

HARDNESS, TOTAL

TURBIDITY (JTU)

FLOURIDE, DISSOLVED

12

23.13
207.3
110.0

7.39

0.062

0.759

0.260

840.7

120.

IAULN

2.33
36.3
0.0

0.0
0.35

0.35
0.033

0.327

0.156

1487.7

164.0

915.8

915.8
1042.8

1042.8
29.17

29.17
26.40

9.60

9.87

1.53

122.1

0.0

10.32

6.02

154.8
153.6

153.6
103.8

3.8
24.4

832.1

832.1
1214.6

$\begin{array}{r}214.56 \\ \hline\end{array}$

2.56
2.97

1.47

0.92

0.18
8.4

8.4
0.0

1.18

0.69

$\begin{array}{r}9.39 \\ \hline .9 .0\end{array}$

14.0

11.5

6.9

42.6
0.08

0.15
NITRITE + NITRATE, TOTAL

PHYTOPLANKTON, TOTAL (CELLS/ML)

CALCIUM, DISSOLVED

HARDNESS, NONCARBONATE

BEG REGRESSION

SAMPLE

SIZE

COEFICIENT,

CONSTANT, CORRELATION

STANDARD

ERROR OF

BANGE

$128 \quad 252$

110

$6.6 \quad 7.7$

0.02

0.19

$0.04 \quad 0.61$

0.13
1.20
0.61
4700

12
11
11
11
11

0.0027

$-0.00016$

$-0.00501$

$-0.00027$

0.09590

1.79538
0.31675

1703.479

0.283
-0.191

$-0.583$

$-0.067^{*}$

$-0.114^{*}$

0.280

0.164

1557.9

Not significant at the 95 percent confidence level.

SUMMARY OF HARMONIC ANALYSIS OF STREAM TEMPERATURE

\begin{tabular}{|c|c|c|c|c|c|}
\hline & & & & & STANDARD \\
\hline & HARMONIC & AMPLITUDE & PHASE & VAR IATION & ERROR OF \\
\hline SAMPLE & MEAN - M & $-A$ & ANGLE - C & EXPLAINED & ESTIMATE \\
\hline SIZE_ & 1DEG C) & DDEG (1) & (RADLANS) & $\ldots(x)$ & (DEG $C 1$ \\
\hline 12 & 23.11 & 2.41 & 3.23 & 60 & 1.62 \\
\hline
\end{tabular}

$\begin{array}{rr}56 & 2400 \\ 4 & 3600 \\ 26.0 & 33.0\end{array}$

26.0
22.0

8.3
9.1

1.3

110

9.1

5.2

144

0
1

0.1

33.0
30.0

12.0

11.0
1.8

132

12.0

6.9
170

178
178

120
16

16
100
0.3

-0.0178
0.0195
0.0103
0.0139
-0.0006
0.016
0.000
0.0134
0.0039
0.075
0.145
0.114
0.067
0.391
0.0006

32.8541

22.3751

7.4824

6.9899

1.6062

118.826

0.000
7.5387

5.2082

5.2082
139.295

139.295

123.779
80.337

80.337
-10.013

$-56.052$

-0.296 *

0.313 *

0.331 *

$0.645^{*}$

$-0.156^{*}$

$0.000^{*}$

0.482 *

0.242 *

$0.386 *$

0.489 *

0.470 *

0.463 *

0.435 *
0.309 *

2.74

2.74
3.25
1.60

0.78

0.19

9.1
0.0

1.16

1.16
0.74

SUMMARY OF MAXIMUM AND MINIMUM CONCENTRATIONS OF CONSTITUENTS

SAMPLED AT A FREQUENCY OF QUARTERLY (1975 WY)

SO144000 -- RIO GRANDE DE ANASCO NR SAN SEBASTIAN, PR

\begin{tabular}{|c|c|c|c|c|c|c|}
\hline \multirow{2}{*}{ CONSTI IUENT } & \multicolumn{3}{|c|}{ TOTAL } & \multicolumn{3}{|c|}{ DISSOLVED } \\
\hline & $\begin{array}{l}\text { NO. } \\
\text { SAMPLES }\end{array}$ & $\begin{array}{l}\text { MINIMUM } \\
\text { CONC. }\end{array}$ & $\begin{array}{l}\text { MAXIMUM } \\
\text { CONC. }\end{array}$ & $\begin{array}{l}\text { NO. } \\
\text { SAMPLES }\end{array}$ & $\begin{array}{l}\text { MINIMUM } \\
\text { CONC. }\end{array}$ & $\begin{array}{l}\text { MAXIMUM } \\
\text { CONC. }\end{array}$ \\
\hline \multicolumn{7}{|l|}{ MINOR ELEMENTS: } \\
\hline ARSENIC (AS), UG/L & 4 & 0 & 2 & 5 & 0 & 0 \\
\hline CADMIUM $(C D)$, UG $/ L$ & 5 & 0 & 1 & 5 & 0 & 1 \\
\hline CHROMIUM (CR), UG/L & 5 & $<10$ & 10 & 5 & 0 & 1 \\
\hline COBALT $(C O), U G / L$ & 5 & 0 & 6 & 5 & 0 & 4 \\
\hline COPPER (CU), UG/L & 5 & 1 & 22 & 5 & 0 & 13 \\
\hline IRON $(F E), U G / L$ & 5 & 70 & 8500 & 5 & 0 & 2400 \\
\hline$L E A D(P B), U G / L$ & 5 & 0 & 8 & 5 & 0 & 2 \\
\hline MANGANESE $(M N), U G / L$ & 6 & 0 & 450 & 5 & 0 & 360 \\
\hline MERCURY (HG), UG/L & 5 & 0.0 & 0.3 & 5 & 0.0 & 0.2 \\
\hline SELENIUM (SE), UG/L & 2 & 0 & 0 & 5 & 0 & 0 \\
\hline ZINC $(2 N), U G / L$ & 5 & 0 & 60 & 5 & 0 & 30 \\
\hline \multicolumn{7}{|l|}{ PERIPHYTON : } \\
\hline BIOMASS, DRY WT., G/SO M & 1 & .59 & & & & \\
\hline BIOMASS, ASH WT., G/SO M & 1 & .50 & & & & \\
\hline CHLOROPHYLL A, MG/SO M & 1 & .7 & & & & \\
\hline CHLOROPHYLL $B, M G / S Q M$ & 1 & .1 & & & & \\
\hline ORGANIC CARBON, MG/L & 5 & 2.0 & 4.5 & & & \\
\hline
\end{tabular}

